DEPARTAMENTO DE INGENIERÍA Y MORFOLOGÍA DEL TERRENO

ESCUELA TÉCNICA SUPERIOR DE INGENIEROS DE CAMINOS, CANALES Y PUERTOS

UNIVERSIDAD POLITÉCNICA DE MADRID
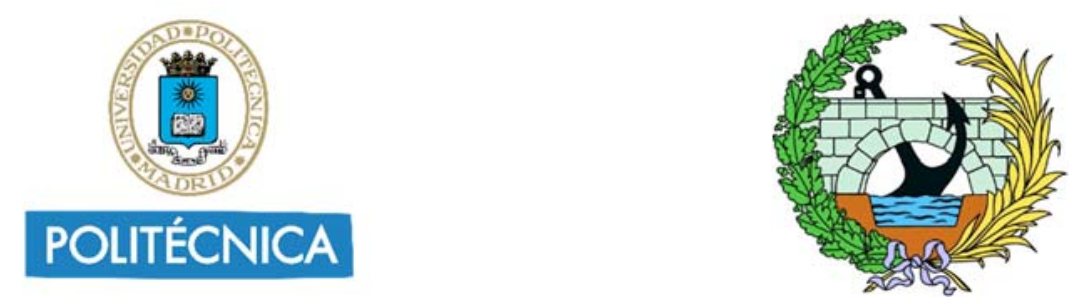

\title{
ANÁLISIS SÍSMICO DE ESTACIONES SUBTERRÁNEAS DE METRO CONSTRUIDAS POR EL MÉTODO DE CUT-AND-COVER
}

\section{TESIS DOCTORAL}

\author{
CARLOS GORDO MONSÓ \\ Ingeniero de Caminos, Canales y Puertos \\ Ingénieur Diplômé de l'Ecole Nationale des Ponts et Chaussées
}

Master of Science in Civil and Environmental Engineering, Stanford University

DIRECTORES DE TESIS:

CLAUDIO OLALLA MARAÑÓN

Dr. Ingeniero de Caminos, Canales y Puertos

JESÚS GONZÁLEZ GALINDO

Dr. Ingeniero de Caminos, Canales y Puertos 



\section{POLITÉCNICA}

Tribunal nombrado por el Magfco. Y Excmo. Sr. Rector de la Universidad Politécnica de Madrid, el día de de

Presidente:

Vocal:

Vocal:

Vocal:

Secretario:

Realizado el acto de defensa y lectura de la tesis el día ....... de de En la E.T.S de Ingenieros de Caminos, Canales y Puertos de la Universidad Politécnica de Madrid, los miembros del Tribunal acuerdan otorgar la calificación de: 

A mi padre 



\section{RESUMEN}

La acción que ejerce el sismo sobre las estaciones subterráneas de metro es un aspecto más que debe tener en cuenta el ingeniero proyectista a la hora de abordar el diseño de las mismas. En las normativas internacionales actuales de diseño sismorresistente conviven diversas técnicas simplificadas para analizar los efectos que la acción sísmica ejerce sobre las estructuras enterradas. En el caso de estructuras rectangulares para estaciones subterráneas de metro, construidas por el método de cutand-cover, cada una de estas metodologías de análisis puede proporcionar resultados dispares, en términos de esfuerzos estructurales tales como momentos flectores o esfuerzos cortantes. Esta falta de homogeneidad en los criterios de análisis redunda en estructuras que presentan márgenes de seguridad diferentes frente a los terremotos en función del método seleccionado.

En esta tesis doctoral se aborda un análisis crítico de las metodologías presentes en la normativa internacional actual y literatura técnica pertinente, y se propone un método simplificado para el análisis de deformaciones y esfuerzos de estructuras enterradas rectangulares sometidas a la acción del sismo. El método propuesto unifica las dos tendencias actuales más relevantes, correspondientes al método propuesto por Wang (Wang 1993) y recogido en la normativa estadounidense (AASHTO 2017, FHWA 2009), y a los métodos preconizados por las normativas sismorresistentes europea (EN 19982:2005, EN 1998-5:2004), y japonesa (JSCE 2018, RTRI 2007) entre otras.

Para evaluar la precisión del método simplificado propuesto se ha desarrollado un conjunto de modelos de elementos finitos bidimensionales en deformación plana, con comportamiento tanto lineal como no lineal del terreno, sobre los que se han realizado múltiples análisis paramétricos para estudiar la influencia de los diversos factores que afectan al comportamiento de las estaciones subterráneas de metro bajo la acción del sismo, tales como la rigidez de la estructura y del terreno, geometría de la estructura, y el comportamiento del terreno bajo grandes deformaciones a cortante.

Asimismo, en esta tesis doctoral se realiza un análisis crítico de los criterios de demanda y desempeño sísmicos presentes en la normativa internacional actual, y se propone un marco conceptual para establecer una matriz de demanda/desempeño teniendo en cuenta tanto la accesibilidad como la reparabilidad de los elementos estructurales susceptibles de sufrir daño durante un sismo. 


\section{ABSTRACT}

Earthquake action on underground subway stations is one more aspect that engineers shall consider when facing its design. In current international earthquakeresistant design codes several distinct simplified techniques coexist in order to analyze the effects that seismic action bears on buried structures. In the case of rectangular structures for underground subway stations, built by the cut-and-cover method, each of these methodologies may provide uneven results, in terms of internal forces like bending moments and shearing forces. This lack of consistency across codes in the analysis criteria results into structures with different safety margins against earthquakes, depending on the particular analysis method selected.

In this Ph.D. dissertation a critical analysis of current international design codes and relevant technical literature is addressed, and a simplified method is proposed for the analysis of strains and internal forces in rectangular underground structures subjected to the earthquake action. The proposed method unifies the current two more relevant tendencies, corresponding to the Wang method (Wang 1993) covered by the US design codes (AASHTO 2017, FHWA 2009), and the methods present in the European (EN 1998-2:2005, EN 1998-5:2004), and Japanese (JSCE 2018, RTRI 2007) earthquakeresistant design codes.

To assess the accuracy of the proposed simplified method, a series of twodimensional finite element models in plane-strain, both with linear and non-linear soil behavior have been developed. Extensive parametric analyses have been carried out to study the influence of the several factors, such as structure geometry, stiffness, soil characteristics, and soil strain level, affecting the behavior of underground subway stations subjected to the earthquake action.

Additionally, in this Ph.D. dissertation, a critical analysis of the seismic demand and performance criteria present in current international design codes is addressed, and a conceptual frame is proposed to establish a demand/performance matrix considering the repairability and accessibility of those elements likely to be damaged during an earthquake. 


\section{AGRADECIMIENTOS}

Como bien saben todos aquellos que se han visto en el trance del doctorado, la redacción de una tesis se parece a un puerto de etapa reina del Tour de Francia, en el que el ciclista pedalea y sufre las pájaras en solitario, pero cuya coronación depende sin duda del director del conjunto, de la ayuda prestada por los otros miembros del equipo cuando flaquean las fuerzas, y del aliento y cariño de los espectadores, tan cercanos en los tramos más pendientes que casi parece que puedan pedalear por uno.

Quisiera agradecer el estímulo de todos aquellos que me han ayudado a presentar esta tesis. En primer lugar, a mis directores Claudio Olalla Marañón y Jesús González Galindo, que además del entusiasmo con el que recibieron el tema de la tesis, y del ánimo constante que me han proporcionado, han sabido marcarme objetivos, metas, y plazos concretos, atendiendo siempre a la intensa actividad profesional en el campo de la ingeniería civil que debía compaginar con el desarrollo de la tesis. También quiero agradecer a mi anterior director de tesis Pablo de la Fuente Martín, quien falleció durante el transcurso de la misma, el interés mostrado por el tema, su cálida acogida y orientación inicial, y su más que reconocida amabilidad.

Sin lugar a dudas, el origen de esta tesis es el proyecto del Nuevo Metro de Quito, en Ecuador, cuando en 2013 en IDEAM nos vimos confrontados al desafío de diseñar quince estaciones subterráneas de una obra emblemática, en una ciudad en la que la amenaza sísmica es muy real, en un tiempo récord. Sin normativa específica al respecto, y con escasas experiencias internacionales recientes, algunas de las preguntas que nos hicimos acerca del comportamiento sísmico y respuesta estructural resistente en el Metro de Quito fueron el germen de los métodos propuestos en esta tesis. En ese sentido, quiero agradecer especialmente a Fernando Ruano Parra y a Luis Matute Rubio todas las ideas, conversaciones, y discusiones técnicas que hemos compartido durante y después del proyecto. Esta tesis también es vuestra.

Puesto que una tesis doctoral de estructuras es una etapa en el aprendizaje de ser ingeniero, no puedo dejar de dar las gracias a todos mis compañeros de IDEAM de los que no dejo de aprender todos los días con su ejemplo y brillantez. Pablo, Pepe, Helder, Jokin, Raúl, Reyes, Rosi, Virginia, Ildefonso, Adrián, Ignacio, Dani, Enrique, Miguel, Paco, y tantos más con los que he trabajado... Gracias a todos. 
La intención de realizar el doctorado, especializarme en ingeniería sísmica, y probar a qué sabe la investigación académica me llevó a estudiar en California. Quiero dar las gracias especialmente al Prof. Eduardo Miranda, de la Universidad de Stanford que, aunque ya se ha convertido en un amigo entrañable, seguirá siendo siempre mi maestro en todos los aspectos de la ingeniería sísmica.

Quiero agradecer también a todos mis compañeros de la Unidad Docente de Expresión Gráfica de la Escuela de Caminos de Madrid, Antonio, Salva, Miguel, Chus, José Luis, y Fernando su aliento y apoyo para realizar la tesis, y de forma especial a Luis Méndez Valentín y a José Manuel Martínez Simón, quienes además me sirven de ejemplo a la hora de intentar ser buen profesor.

Por último, y porque el desenlace de una obra se recuerda más que la introducción y el nudo, gracias a mi familia por su apoyo infatigable y amor incondicional; a mis padres Carlos y Pilar y a mi tío Emilio por haberme ayudado en todas las etapas de mi vida, y a mi mujer Iria por haber compartido ex aequo las penas, alegrías, y tiempo infinito de la génesis de esta tesis.

A todos vosotros, muchas gracias. 


\section{$\underline{\text { ÍNDICE }}$}

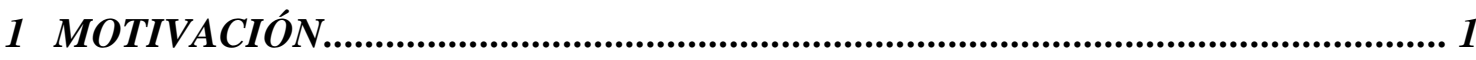

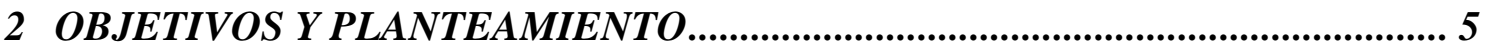

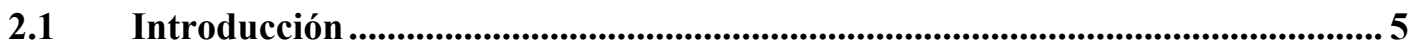

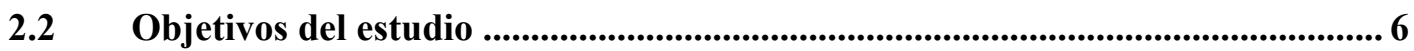

2.2.1 Estudio del estado del conocimiento acerca de los objetivos buscados en esta tesis ............... 7

2.2.2 Marco conceptual para el estudio de la interacción suelo-estructura de una obra subterránea

bajo solicitación sísmica, y métodos simplificados para su análisis

2.2.3 Estudio de la influencia de la plastificación diferencial del terreno circundante a la obra frente a la producida por la deformación de campo libre, y método simplificado para su análisis .....9

2.2.4Criterios de proyecto para el diseño sismorresistente de estaciones de metro. Niveles de

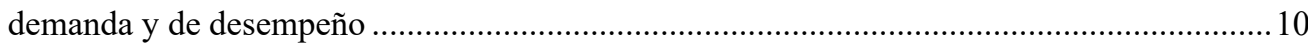

2.3 Planteamiento del estudio ........................................................................ 10

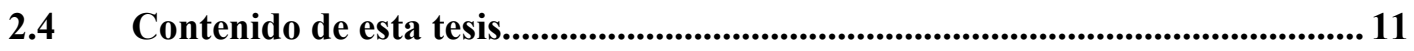

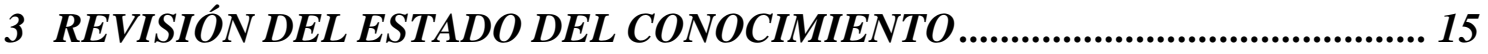

3.1 Metodologías habituales de construcción de estaciones de Metro....................... 15

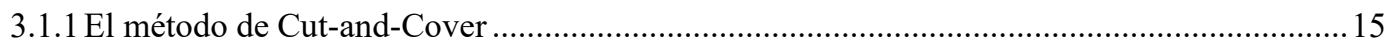

3.1.2 Tipologías habituales de pantallas de contención ........................................................... 18

3.1.3 Especificidades tipológicas y constructivas de estaciones de Metro ....................................21

\section{El proyecto sismorresistente de estructuras en superficie ................................ 24}

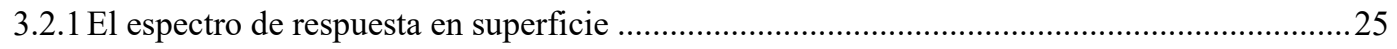

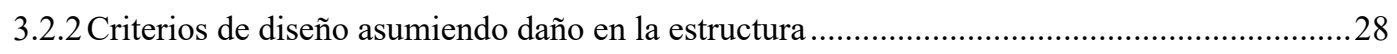

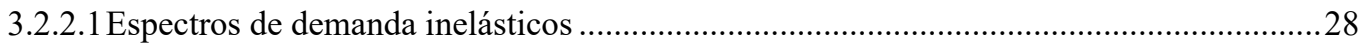

3.2.2.2El marco conceptual del diseño sísmico basado en el desempeño (PBEE, Performance Based Earthquake Engineering)

3.3 Particularidades del proyecto sismorresistente de obras subterráneas con respecto a las obras en superficie ............................................................................... 34

3.4 La acción estática del terreno en estructuras de contención................................35

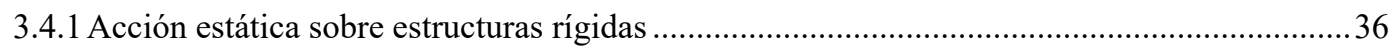

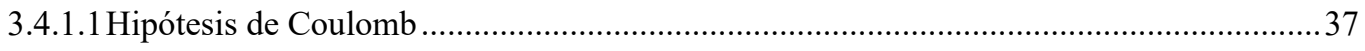

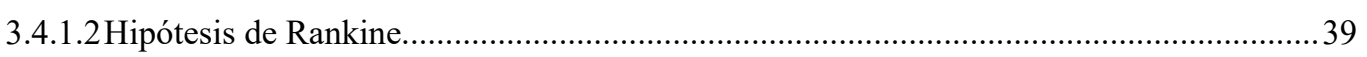

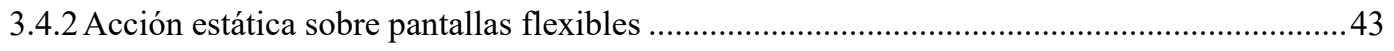

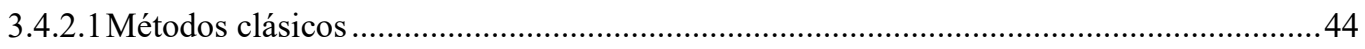


3.4.2.1.1 Método de empuje libre de tierras ................................................................... 44

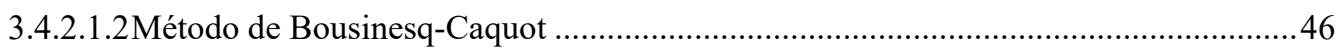

3.4.2.1.3 Método de Blum para pantallas ancladas en cabeza..................................................46

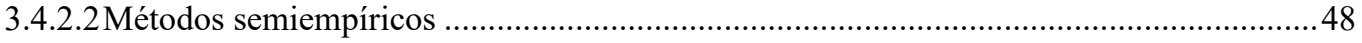

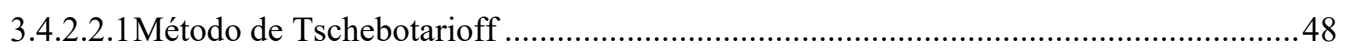

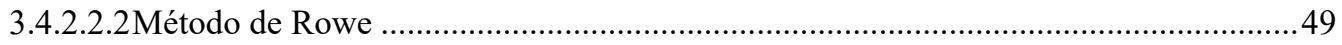

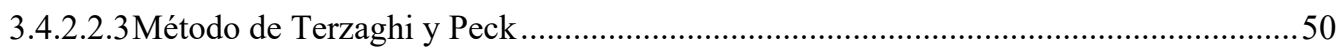

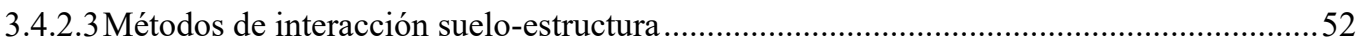

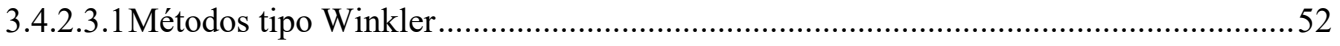

3.4.2.3.2Métodos numéricos de elementos finitos ……......................................................5

3.5 Lacción dinámica del terreno en campo libre .............................................. 56

3.5.1 Estudios probabilistas de peligrosidad sísmica ..............................................................5

3.5.1.1 Marco conceptual de los estudios de peligrosidad sísmica ..........................................57

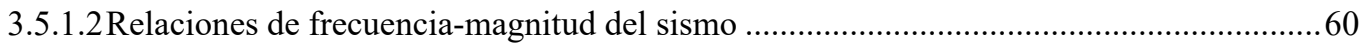

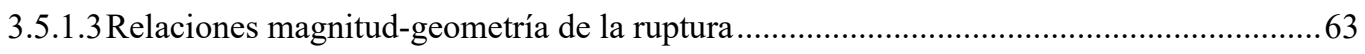

3.5.1.4Relaciones de atenuación para la predicción del movimiento del terreno.........................65

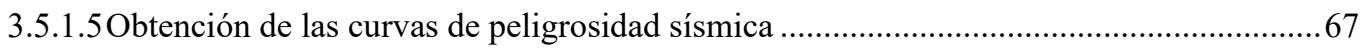

3.5.1.6 Árboles lógicos para tratar la incertidumbre epistémica ..................................................6 68

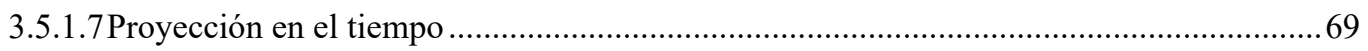

3.5.2 La acción sísmica como respuesta del terreno ............................................................ 70

3.5.3 Propagación de ondas sísmicas a través de un medio elástico .................................................73

3.5.3.1 Propagación de ondas en un medio continuo unidimensional homogéneo de longitud

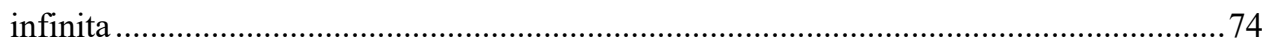

3.5.3.1.1 Planteamiento de las ecuaciones de movimiento de vibración longitudinal................74

3.5.3.1.2Planteamiento de las ecuaciones de movimiento de vibración transversal.................77

3.5.3.1.3 Solución de las ecuaciones de movimiento unidimensional ........................................ 80

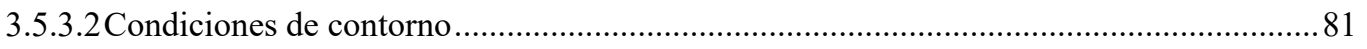

3.5.3.2.1 Propagación de ondas en un medio estratificado .................................................... 81

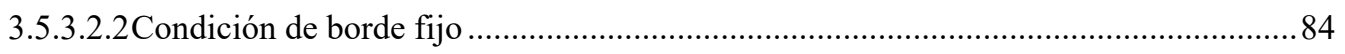

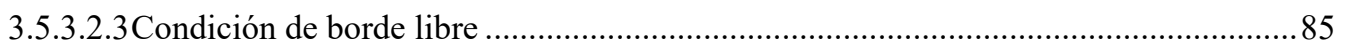

3.5.3.3 Métodos de representación de las condiciones de contorno en el contexto de la modelización mediante elementos finitos. ................................................................... 86

\subsection{Comportamiento del terreno bajo la acción dinámica .......................................... 87}

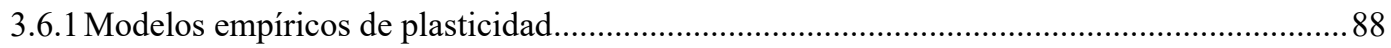

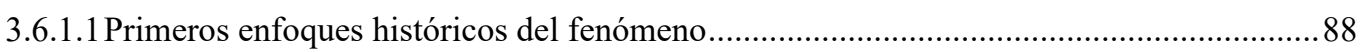

3.6.1.2 Relaciones tensión-deformación tangencial y reglas de Masing ...................................92

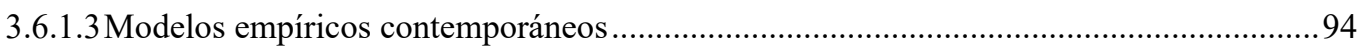

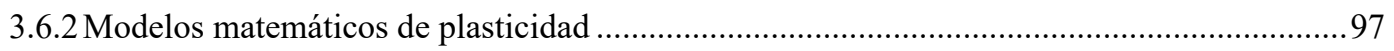

3.6.2.1 Aspectos generales de la formualción de la plasticidad tridimensional .........................97

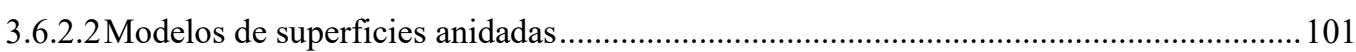


3.6.3 Respuesta dinámica de un suelo frente a la acción sísmica ............................................ 103

3.6.3.1 Respuesta lineal equivalente tipo SHAKE ................................................................. 104

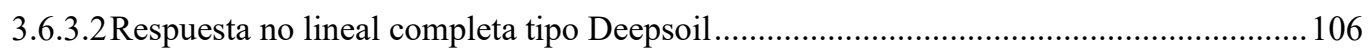

3.7 La acción dinámica del terreno sobre la estructura ...........................................109

3.7.1 Métodos pseudo-estáticos de empuje dinámico ................................................................. 109

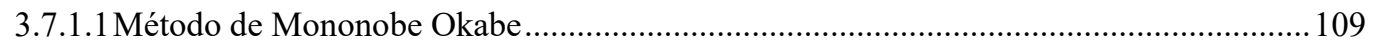

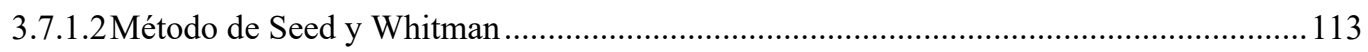

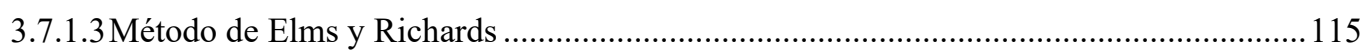

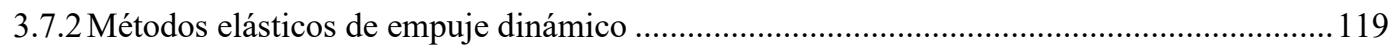

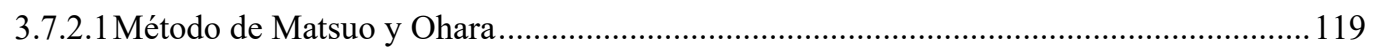

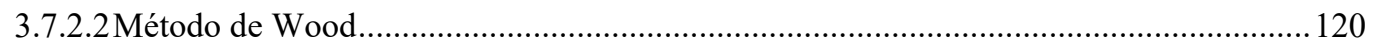

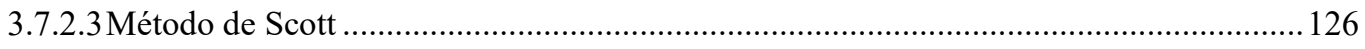

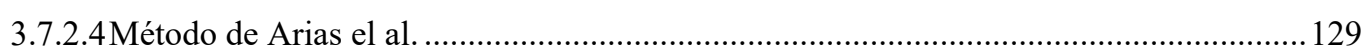

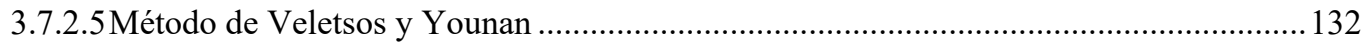

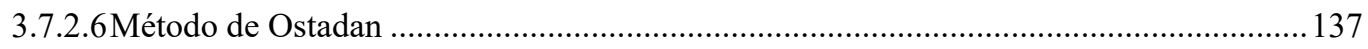

3.7.3 Métodos de deformaciones de campo libre impuestas......................................................... 141

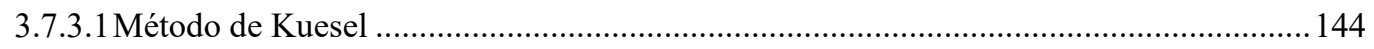

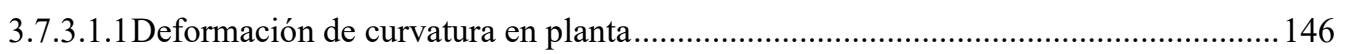

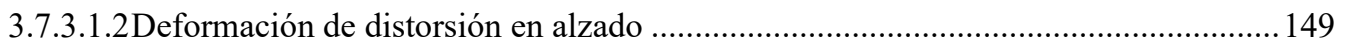

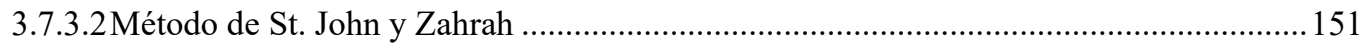

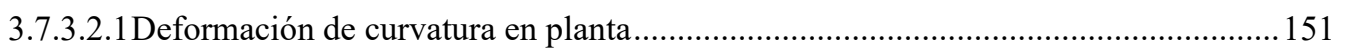

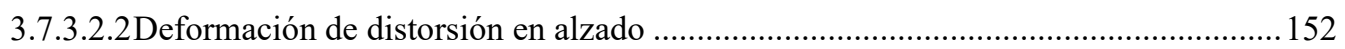

3.7.3.3 Método de Ortigosa y Musante ............................................................................... 155

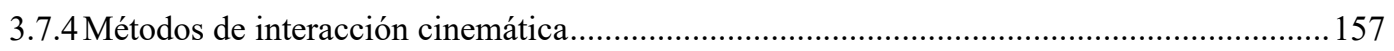

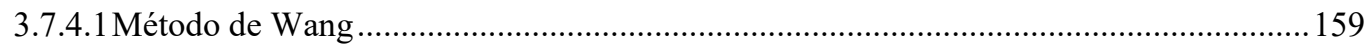

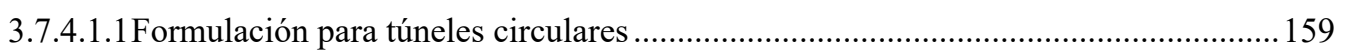

3.7.4.1.2Formulación para túneles rectangulares .............................................................. 163

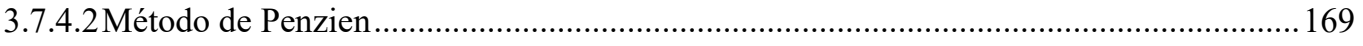

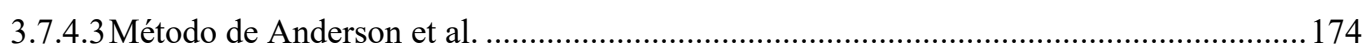

3.7.4.4Método de Huo....................................................................................................... 178

\subsection{Revisión de la normativa internacional de proyecto sismorresistente de obras}

Subterráneas .......................................................................................................... 182

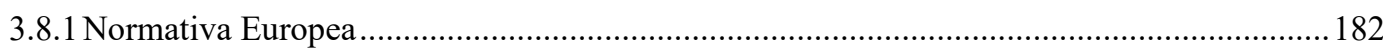

3.8.1.1 Eurocódigo 8. EN 1998-2:2005 Diseño sismorresistente de puentes y EN 1998-5:2004

Diseño sismorresistente de cimentaciones, obras de contención, y aspectos geotécnicos 183

3.8.1.1.1 Niveles de demanda y desempeño ................................................................. 183

3.8.1.1.2Métodos de análisis en EN 1998-2:2005 de puentes ................................................... 185

3.8.1.1.3 Métodos de análisis en EN 1998-5:2004 de aspectos geotécnicos ........................... 188 


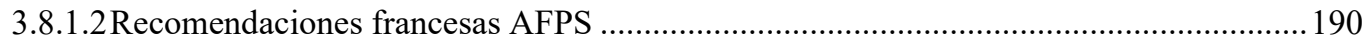

3.8.1.2.1 Niveles de demanda y desempeño ......................................................................... 190

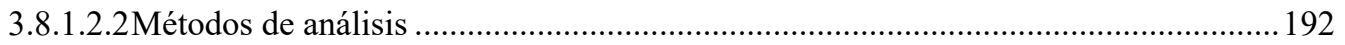

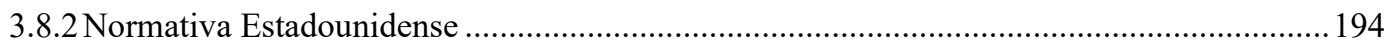

3.8.2.1 AASHTO LRFD Road Tunnel Design and Construction Guide Specifications 2017 .... 194

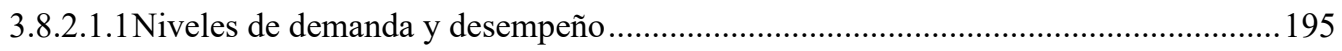

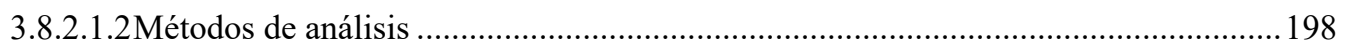

3.8.2.2AASHTO LRFD 2012 y AASHTO Guide Specifications for LRFD Seismic Bridge

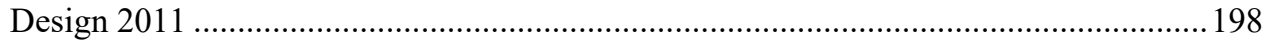

3.8.2.2.1 Niveles de demanda y desempeño ........................................................................... 198

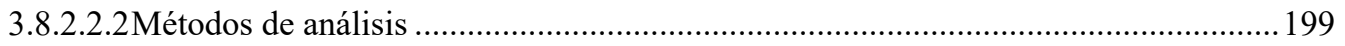

3.8.2.3 FHWA Technical Manual for Design and Construction of Road Tunnels 2009............200

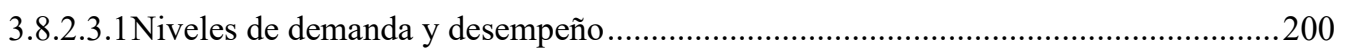

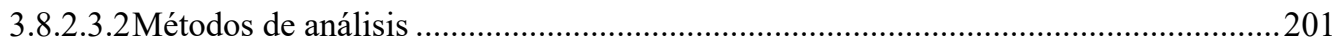

3.8.2.4FHWA Seismic Retrofitting Manual for Highway Structures 2004 ...............................204

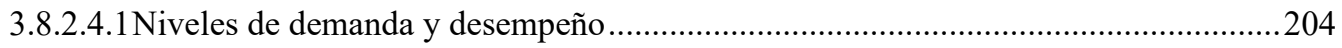

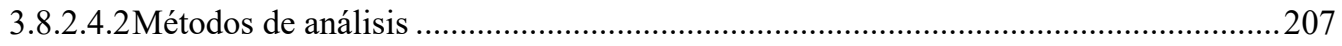

3.8.2.5FHWA Manual for the Seismic Analysis and Design of Transportation Geotechnical

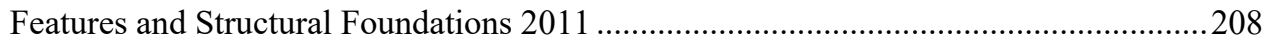

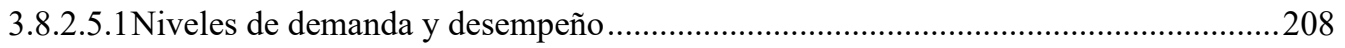

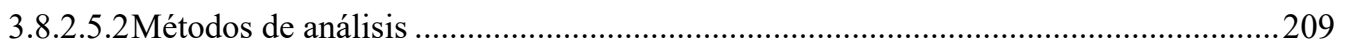

3.8.2.6NCHRP 611 Seismic Analysis and design of retaining walls, buried structures, slopes,

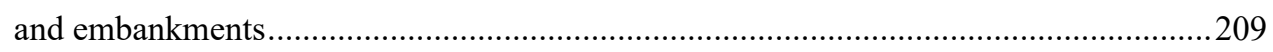

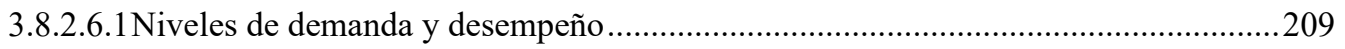

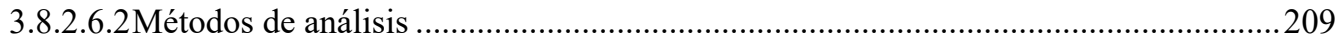

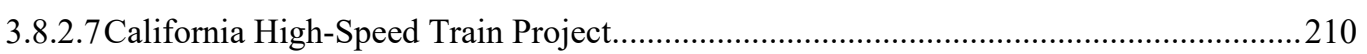

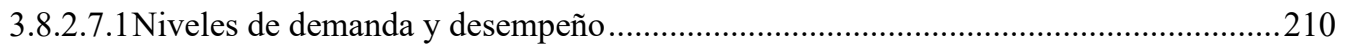

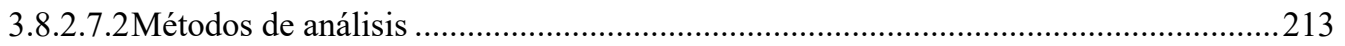

3.8.2.8Los Angeles Metro Design Criteria, 2012 ................................................................... 213

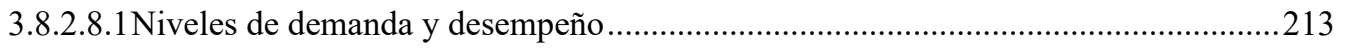

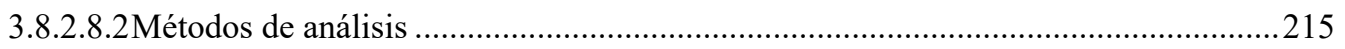

3.8.2.9WSDOT Alaskan Way SR99 Tunnel Design Criteria 2010......................................216

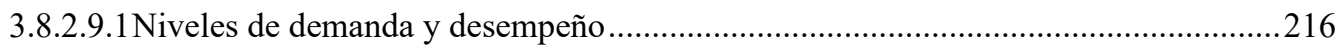

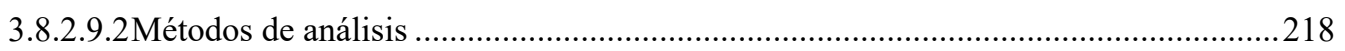

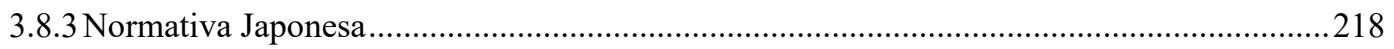

3.8.3.1 RTRI Railway Structures, Cut and Cover Tunnel, Seismic Design, 2007 ...................218

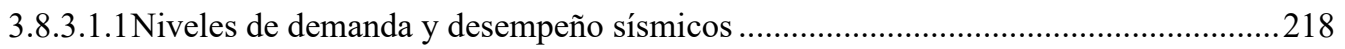

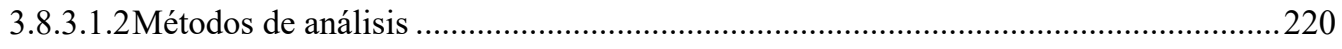

3.8.3.2 JSCE Standard Specification for Tunneling-2016: Cut-and-Cover Tunnels..................222

3.8.3.2.1 Niveles de demanda y desempeño sísmicos .........................................................222 


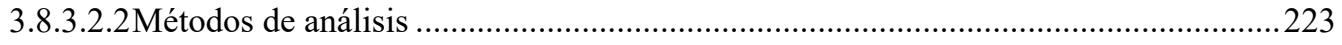

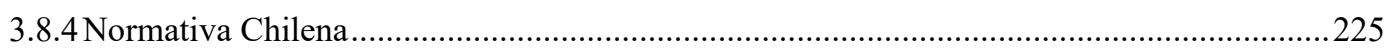

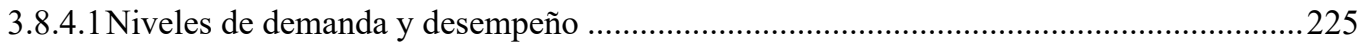

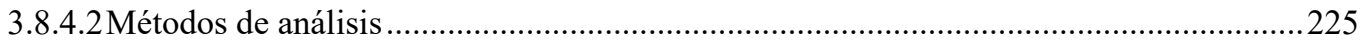

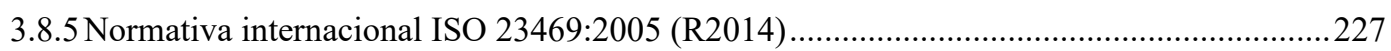

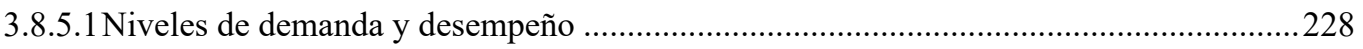

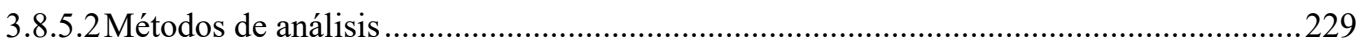

\section{ESTUDIO DE LA DISTORSIÓN EN SISTEMAS SUELO-ESTRUCTURA}

LINEALES EN DEFORMACIÓN PLANA ......................................................... 233

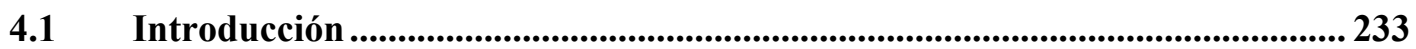

4.2 Propósito de la solución propuesta......................................................................236

4.3 Solución propuesta para el coeficiente de distorsión de Racking .....................237

4.4 Solución propuesta para el perfil de distorsión de Racking............................... 246

4.5 Solución propuesta para el coeficiente de rotación de Rocking ....................... 249

4.6 Modificación de las soluciones propuestas para considerar la influencia del coeficiente de Poisson .......................................................................................... 252

4.7 Evaluación de las soluciones propuestas.............................................................. 255

4.8 Aplicación del método al caso de estructuras infinitamente rígidas ................ 256

5 ESTUDIO DE LOS ESFUERZOS DE DISTORSIÓN EN SISTEMAS LINEALES

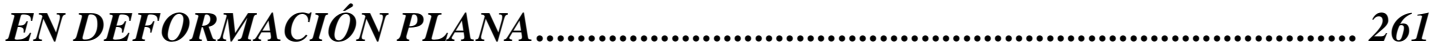

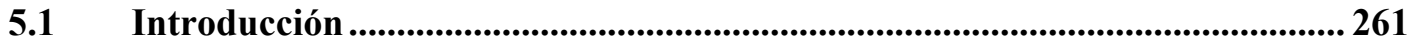

5.2 Modelo propuesto para la obtención de esfuerzos en la estructura ................. 263

$5.3 \quad$ Verificación de momentos flectores ........................................................................ 266

$5.4 \quad$ Verificación de esfuerzos cortantes ................................................................. 273

5.5 Método propuesto para la obtención de esfuerzos en la estructura ................. 278

6 ESTUDIO DE LA DISTORSIÓN EN SISTEMAS SUELO-ESTRUCTURA CON COMPORTAMIENTO NO LINEAL EN DEFORMACIÓN PLANA.................. 281

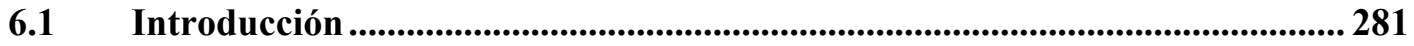

6.2 Propósito de la solución propuesta........................................................................... 283

6.3 Solución propuesta para considerar el comportamiento no lineal del suelo.283

6.4 Verificación de la solución propuesta ............................................................ 286 
6.4.1 Parámetros del modelo de elementos finitos no lineal.................................................286

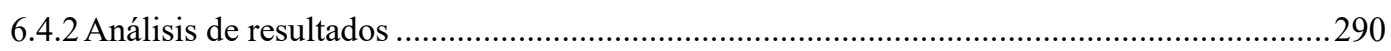

6.4.2.1Comparación del método propuesto frente a los resultados de modelos numéricos .......291

6.4.2.2 Comparación del método propuesto frente a los métodos de otros autores....................295

7 ESTUDIO DE LA INFLUENCIA DE LA PROFUNDIDAD ............................... 301

7.1 Introducción 301

7.2 Variación del coeficiente de racking a diferentes profundidades .................. 302

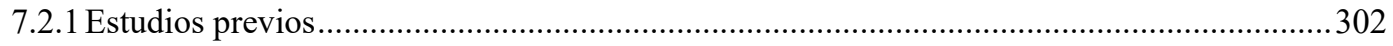

7.2.2 Análisis de la variación del coeficiente de racking con la profundidad ...............................305

7.2.3 Coeficiente de corrección en función de la profundidad. .....................................................309

\subsection{Modelo propuesto para la obtención de esfuerzos en la estructura a diferentes} profundidades .................................................................................. 312

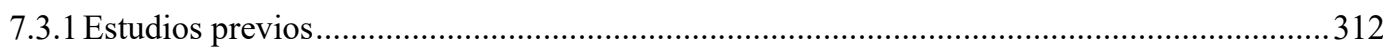

7.3.2 Modelo propuesto para la obtención de esfuerzos en la estructura a diferentes profundidades 316

7.3.3 Verificación de momentos flectores .322

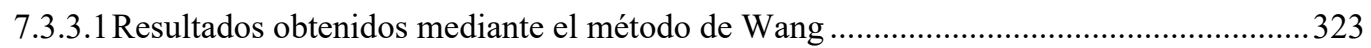

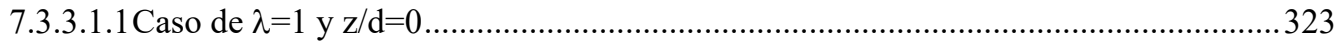

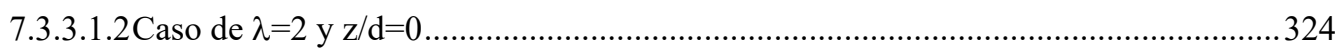

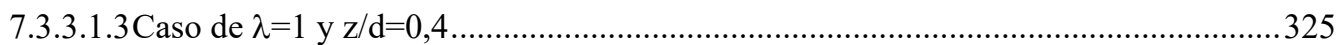

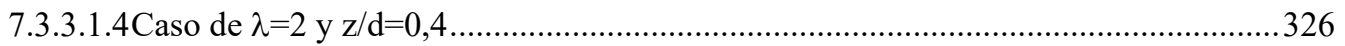

7.3.3.2 Resultados obtenidos mediante el método propuesto................................................327

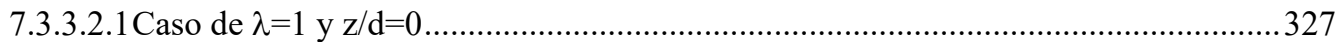

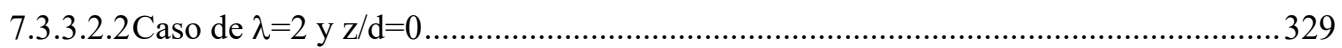

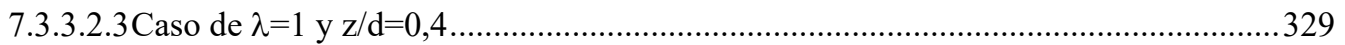

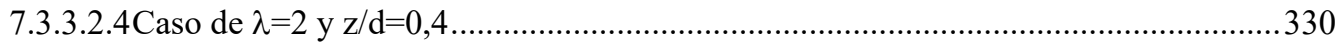

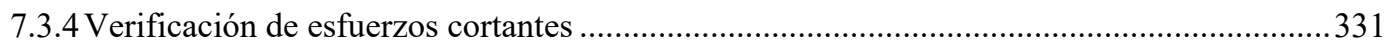

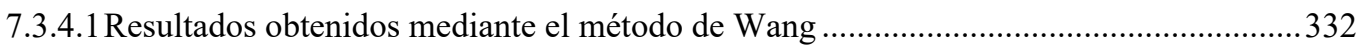

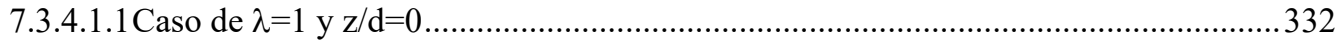

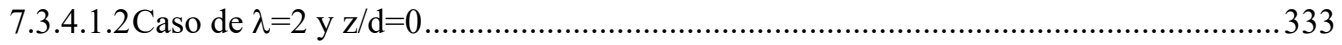

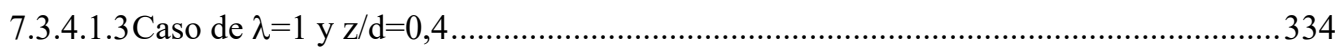

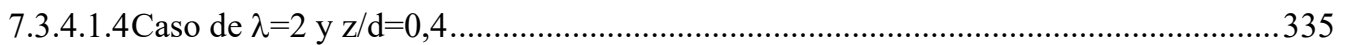

7.3.4.2 Resultados obtenidos mediante el método propuesto................................................336

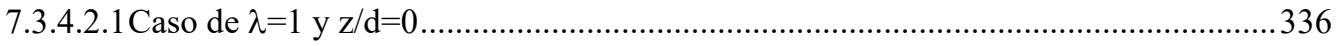

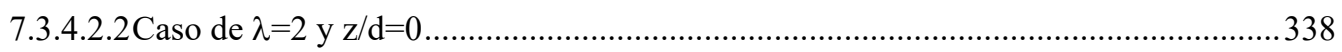

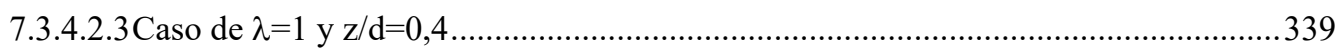

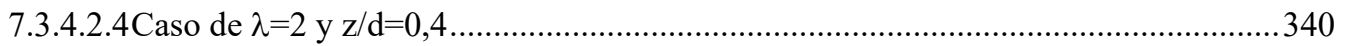




\section{CRITERIOS DE DEMANDA Y DESEMPEÑO PARA EL PROYECTO DE} ESTACIONES SUBTERRÁNEAS DE METRO ................................................. 341

8.1 Niveles de relevancia urbana de la estación ................................................343

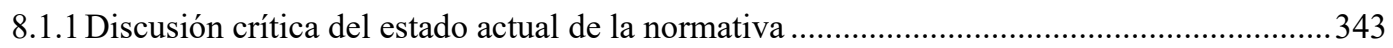

8.1.2 Propuesta de clasificación de la relevancia urbana de la estación ..........................................345

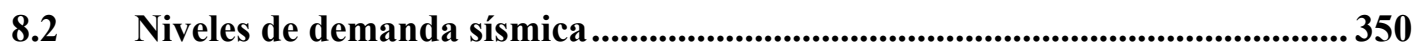

8.2.1 Discusión crítica del estado actual de la normativa ................................................................351

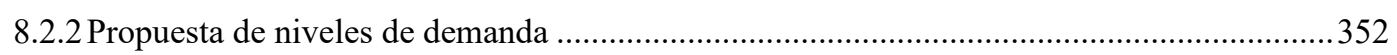

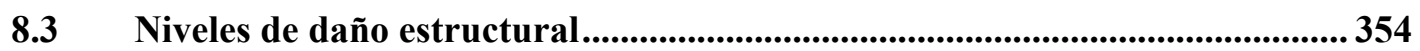

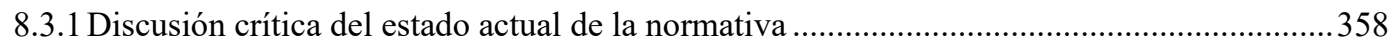

8.3.2 Propuesta de niveles de daño admisibles en función de la reparabilidad................................359

8.4 Niveles de accesibilidad a elementos susceptibles de sufrir daño ....................360

8.4.1 Discusión crítica del estado actual de la normativa ................................................................360

8.4.2 Propuesta de clasificación de la accesibilidad para la reparación.............................................362

8.5 Propuesta de matrices demanda-desempeño en función de la relevancia urbana, accesibilidad, y reparabilidad ...................................................................365

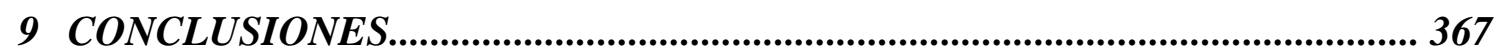

9.1 Conclusiones de esta tesis ..........................................................................................367

$9.2 \quad$ Aportaciones originales de esta tesis ....................................................................... 371

9.3 Publicaciones derivadas de esta tesis .................................................................373

10 FUTURAS LÍNEAS DE INVESTIGACIÓN ................................................ 375

10.1 Estudio de la acción del sismo sobre estructuras tridimensionales...................375

10.2 Ampliación de los métodos simplificados propuestos al caso de comportamiento no lineal de la estructura

10.3 Aplicación de los métodos presentados en la tesis al análisis probabilista de riesgo ...................................................................................................................................... 378

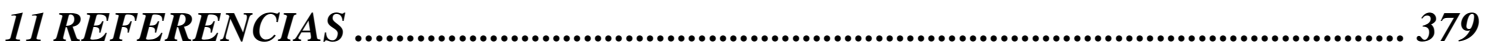




\section{LISTADO DE FIGURAS}

Fig. 1-1.Volumen anual de pasajeros en las 178 redes de metro existentes. (UITP Observatory of Automated Metros 2018).

Fig. 1-2.Daños en la estación de Daikai tras el sismo de Kobe, 1995. (izda.) Colapso de la losa de cubrición. (dcha.) Colapso de la alineación central de pilares. (An et al. 1997)..............................

Fig. 1-3. Vista en planta de la estación de Daikai tras el sismo de Kobe, 1995. (Iwatate et al. 2000)..........4

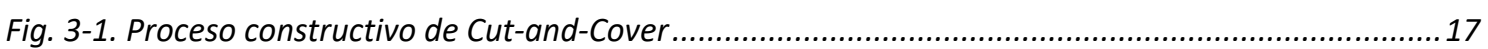

Fig. 3-2. Secciones transversales de tipologías de pantallas de contención 18

Fig. 3-3. (izda.) Inserción de tubo guía. (cent.) Cuchara de pantalladora introduciéndose en la zanja. (dcha.) Cuchara bivalva extrayendo terreno excavado. (Metro de Quito).

Fig. 3-4. Detalle de la cuchara bivalva de excavación de pantallas. (Metro de Quito).

Fig. 3-5. Armadura de pantallas acopiada en posición horizontal, preparada para ser izada e insertada verticalmente en la excavación en la que se hormigonará la pantalla. (Metro de Quito) .....

Fig. 3-6. Pantallas de pilotes. (izda.) Secantes. (cent.) Tangentes. (dcha.) Separados............................20

Fig. 3-7. (izda.) Armadura de pantalla e pilotes. (dcha.) Inserción de la armadura del pilote.

Fig. 3-8. Dimensiones en alzado de una estación típica de metro (sup.) Sección transversal. (inf.) Vista del nivel de contrabóveda durante la construcción. (Metro de Quito)

Fig. 3-9. Dimensiones en planta de una estación típica de metro (sup.) Esquema en Planta de losa de cubrición. (inf.) Vista en planta durante la construcción. (Metro de Quito)...

Fig. 3-10. (izda.) Operación de cale de la tuneladora en la estación, con detalle de la armadura de fibra de vidrio (Metro de Quito). (dcha.) Croquis en planta y alzado del recinto en "corralito" (OteoMazo et al., 2009).

Fig. 3-11. Figura y texto originales de Biot acerca de la posibilidad de generar espectros de respuesta para determinar la (Biot, 1934).

Fig. 3-12. Sismo de Lorca de 2011. (izda.) Acelerogramas registrados en componentes paralela y normal a la falla. (dcha.) Espectros de respuesta de pseudoaceleraciones de los acelerogramas. (GordoMonsó \& Miranda, 2018). 26

Fig. 3-13. Ejemplo de espectros de diseño del Eurocódigo EN 1998-1:2004. 28

Fig. 3-14. (izda.) Esquema de comportamiento elastoplástico. (dcha.) Historia de aceleración y desplazamiento del sistema elasplástico sometido al acelerograma del terremoto de El Centro, 1940. (Veletsos \& Newmark, 1960).

Fig. 3-15. (izda.) Esquema de comportamiento elastoplástico equivalente y definición de la ductilidad de desplazamiento $\mu$. (Newmark \& Hall, 1982). (dcha.) Espectro de aceleraciones del terremoto de El Centro, 1940 para estructuras con ductilidad constante ?. (Veletsos \& Newmark, 1960).......30 
Fig. 3-16. Nivel progresivo de daño en estructura de hormigón armado (izda.) Fisuración correspondiente a la plastificación de la armadura longitudinal (cent.) Spalling del recubrimiento. (dcha.) Pandeo y fractura de armado longitudinal. (Kim, Giacalone, Elgamal, \& Shing, 2016).

Fig. 3-17. (izda.) Curvas de fragilidad de tres medidas de daño (DM, Damage Measure). (dcha.) Umbrales de daño definidos sobre una curva pushover fuerza-desplazamiento. 32

Fig. 3-18. Matriz de objetivos de desempeño y niveles de demanda sísmica. (Poland et al., 1995). .........32

Fig. 3-19. Esquema de equilibrio de la cuña de empuje activo de Coulomb.

Fig. 3-20. Empuje activo de Coulomb para un muro de $\mathrm{H=10} \mathrm{m}$ de altura, densidad del relleno del trasdós $\rho=18 \mathrm{kN} / \mathrm{m}^{3}$, y ángulo de rozamiento interno $\phi$ variable entre $25 \circ$ y 60 . El ángulo de la cuña activa movilizada, para cada ángulo ф, es el correspondiente al máximo del empuje total........39

Fig. 3-21. Estado tensional del terreno de Rankine de empuje activo (izda.) para un suelo con rozamiento y sin cohesión. (dcha.) para un suelo con rozamiento y con cohesión. Las tensiones horizontales $\sigma_{h}$ evolucionan desde el estado 1 al reposo, al estado 4 de rotura activa, manteniendo la tensión vertical $\sigma_{v}$ constante

Fig. 3-22. Estado tensional del terreno de Rankine de empuje pasivo. (izda.) Para un suelo con rozamiento y sin cohesión. (dcha.) Para un suelo con rozamiento y con cohesión. Las tensiones horizontales $\sigma_{h}$ evolucionan desde el estado 1 al reposo al estado 4 de rotura pasiva, manteniendo la tensión vertical $\sigma_{v}$ constante.

Fig. 3-23. (izda) Condición elástica de tensión de empuje al reposo. (dcha) Representación de los empujes límites activo $K_{a}$, pasivo $K_{p}$, y al reposo $K_{0}$ en función del desplazamiento.

Fig. 3-24 Cinemática de una pantalla rígida y del suelo circundante (Delattre, 2001). 45

Fig. 3-25 Superficie de ruptura del terreno trabajando de manera pasiva como combinación de espirales logarítmicas y planos (Delattre, 2001).

Fig. 3-26 (izda) Hipótesis de Blum para el cálculo de pantallas en voladizo. (dcha) Simplificación de Blum, método de la carga idealizada.

Fig. 3-27 Ley que relaciona la profundidad del punto de flector nulo y el ángulo de rozamiento interno del suelo (Blum, 1931). X representa la profundidad del punto de flector nulo medido desde el fondo de la excavación, $H$ la altura de la pantalla entre cabeza y fondo de excavación, y $\phi$ el ángulo de rozamiento interno del terreno (Sanhueza-Plaza, 2008).

Fig. 3-28 Influencia del grado de empotramiento de la pantalla en la distribución de momentos flectores. (izda.) Diagrama que muestra el principio del método de Tschebotarioff. (dcha.) Distribución de la ley de presiones correspondiente (Delattre, 2001).

Fig. 3-29 (izda.) Método de Rowe para el cálculo de pantallas flexibles. (dcha.) Coeficientes de reducción de esfuerzos de Rowe en función de la flexibilidad $\rho$ (Delattre, 2001). 50

Fig. 3-30 Modelo de tablestacas estudiadas por Terzaghi y Peck (Terzaghi et al., 1996). 51

Fig. 3-31 Diagramas de presiones aparentes propuesto por Peck (Terzaghi et al., 1996). (izda.) Arenas. (cent.) Arcillas medias a blandas. (dcha.) Arcillas rígidas y fisuradas. 
Fig. 3-32 Modelo de carga propuesto por Haliburton (1968) y modificaciones de Castillo-Ron (1973), donde $K_{0}$ es el coeficiente de empuje al reposo, $K_{a}$ el coeficiente de empuje activo, y $K_{p}$ el coeficiente de empuje pasivo. (izda) La curva azul indica la presión correspondiente a un punto de la pantalla en función de la deformación que experimenta para carga noval. (cent) Estado de carga para un punto de la pantalla que ha sufrido una deformación cíclica, pasando de un estado activo $K_{a}$ a uno pasivo $K_{p}$ debido al proceso constructivo. (dcha) Estado de carga para un punto de la pantalla que ha sufrido primero una carga elástica de reacción, y una excavación posteriormente.

Fig. 3-33 Modelo conceptual de Haliburton (1968), y fases constructivas con sus correspondientes desplazamientos horizontales en las pantallas a los que corresponden diferentes estados de presión.

Fig. 3-34. Ejemplo de sismograma de un terremoto M 6.2, registrado a una distancia telesísmica de 4200 km. A esta distancia pueden diferenciarse claramente los tiempos de llegada de las fases de ondas $P, S$, y superficiales respectivamente (Havskov, 2010).

Fig. 3-35. Acelerograma del terremoto del 16 de Enero de 1995 de Kobe M 6.9 (PEER Strong Ground Motion Database. Universidad de Kobe a una distancia $R_{j b}=900 \mathrm{~m}$ )

Fig. 3-36. Ubicación de fuentes sismogenéticas principales de Ecuador. (izda.) Zonas de subducción. (dcha.) Fallas activas del Cuaternario. (Parra et al., 2018).

Fig. 3-37. Tres zonificaciones diferentes de Ecuador para sismos corticales. (Parra et al., 2018).

Fig. 3-38. Catálogo sísmico de Ecuador. (izda) Epicentros de eventos $M_{w} \geq 4$. (dcha.) Epicentros y adscripción focal de eventos $M_{w} \geq 6$. (Parra et al., 2018).

Fig. 3-39. Modelos magnitud vs. Número acumulado de terremotos. (izda) Ajuste a ley GuttenbergRichter. (dcha.) Ajuste a ley de terremoto característico. (Schwartz \& Coppersmith, 1984). ......62

Fig. 3-40. (izda.) Geometría de la zona de ruptura de falla. (dcha.) Tipos de falla. (Stein \& Wysession, 2003).

Fig. 3-41. Relaciones de Wells y Coppersmith (izda.) Longitud de falla rota vs. $M_{w}$ (dcha.) Área de falla rota vs. $M_{w}$. (dcha.) Desplazamiento cosísmico vs. $M_{w}$. (Wells \& Coppersmith, 1994).

Fig. 3-42. Esquema geométrico de ubicación de un sismo respecto al sitio de interés (izda.) Para una falla vertical (dcha.) Para una falla inclinada, con diferentes definiciones de distancia $R_{j b}, R_{x}, R_{R U P .} . .65$

Fig. 3-43. (izda.) Probabilidad acumulada $F_{R}(R \leq r / m)$ de la (Ec. 3-24). (dcha.) Densidad de probabilidad $f_{R}(r / m)$ de la (Ec. 3-25).

Fig. 3-44. Relaciones de atenuación GMPE de aceleración espectral para terremotos corticales (Boore \& Atkinson, 2008) para diferentes magnitudes y distancias. (izda.) $S_{a}(T=0 s)$. (cent.) $S_{a}(T=0.2 s)$. (dcha.) $S_{a}(T=1 s)$. (sup.) $M_{w}$ 5. (med.) $M_{w}$ 6. (inf.) $M_{w} 7$.

Fig. 3-45. (izda.) Distribución de probabilidad en las relaciones de atenuación. (dcha.) Probabilidad de exceder un valor de $P G A>1 \cdot g$ para un escenario de magnitud $M=5$, a una distancia de $r=3 \mathrm{~km}$. Figura modificada a partir de (Baker, 2013). 
Fig. 3-46. (izda.) Curvas de peligrosidad para IMs correspondientes a aceleraciones espectrales $S_{a, P G A}$ $S_{a, 0.2 s}, S_{a, 1.0,} S_{a, 2.0 s}$. (dcha.) Gráfico de desagregación de la peligrosidad sísmica por magnitud y distancia.

Fig. 3-47. (izda.) Ejemplo de árbol lógico de un estudio PSHA (Kramer, 1996). (dcha.) Distibución de probabilidad del espectro de probabilidad uniforme UHS debida al tratamiento de la incertidumbre epistémica mediante árboles lógicos.

Fig. 3-48. Proyección en el tiempo del fenómeno poissoniano de probabilidad de rebasar el umbral de aceleración correspondiente a distintos periodos de retorno.

Fig. 3-49. Diagrama conceptual del análisis de respuesta sísmica del terreno (adaptado de Matasovic \&

Hashash 20121

Fig. 3-50. Barra para el estudio de la propagación de ondas unidimensional (Kramer, 1996) ................. 74

Fig. 3-51. Equilibrio dinámico de una rebanada diferencial sometida a tensión axial ...............................75

Fig. 3-52. Esquema de propagación de ondas axiales (NEES, 2011) .................................................... 76

Fig. 3-53. Equilibrio dinámico de una rebanada diferencial sometida a tensión tangencial..................... 78

Fig. 3-54. Esquema de propagación de ondas transversales de cortante (NEES, 2011)..........................79

Fig. 3-55. Onda incidente aproximándose a una interfaz de cambio de propiedades mecánicas del medio (Kramer, 1996)

Fig. 3-56. Desplazamientos de una onda de cortante reflectando en un borde fijo. (a) La onda se aproxima. (b) La onda llega al fondo. (c) La onda intenta propagarse más allá del fondo. (d) EI frente de la onda se refleja y se superpone, cambiando su polaridad, al tramo que aún no ha llegado al fondo, anulándose ambos. (e) La onda se ha reflejado completamente. (f) La onda prosige hacia la superficie.

Fig. 3-57. Desplazamientos de una onda de cortante reflectando en un borde libre. (a) La onda se aproxima. (b) La onda llega a superficie. (c) La onda intenta propagarse más allá de la superficie. (d) El frente de la onda se refleja y se superpone al tramo que aún no ha llegado a superficie, amplificándose. (e) La onda se ha reflejado completamente. (f) La onda prosige hacia la profundidad.

Fig. 3-58. (a) Condición de borde absorbente de Lysmer-Kuhlemeyer (O. Lysmer \& Kuhlemeyer, 1969). (b) Condición de borde fijo.

Fig. 3-59. Reducción del módulo de cortante con la deformación. (izda.) Para arenas limpias. (dcha.) Para una variedad de suelos arcillosos. (Hardin \& Drnevich, 1972).

Fig. 3-60. (izda.) Ciclo de carga e histéresis del modelo de suelo. (dcha) Definición del módulo de cortante secante, y amortiguamiento equivalente. (Hardin \& Drnevich, 1972). 90

Fig. 3-61. (izda.) Curvas de reducción del módulo de cortante $G / G_{\max }$ para arenas. (dcha.) Curvas de amortiguamiento para arenas. (Seed \& Idriss, 1972).

Fig. 3-62. (izda.) Curva típica de reducción del módulo de cortante $G / G_{\max }$ para arcilla. (dcha.) Curvas típicas de amortiguamiento para arcillas. (Seed \& Idriss, 1972). 
Fig. 3-63. (izda.) Modelo de comportamiento bilineal (Thiers \& Seed, 1968). (dcha.) Modelo de comportamiento hiperbólico (Kondner \& Zelasko, 1963) con reglas de descarga de Masing (Masing, 1926).

Fig. 3-64. (izda.) Curvas de reducción del módulo de cortante $G / G_{\max }$ para arcillas en función del índice de plasticidad PI. (dcha.) Curvas de amortiguamiento para arcillas en función del índice de plasticidad PI. (Vucetic \& Dobry, 1990).

Fig. 3-65. Curvas de reducción del módulo de cortante $G / G_{\max }$ y de amortiguamiento equivalente en función del índice de plasticidad para diferentes presiones efectivas de confinamiento $\sigma_{0}^{\prime}$. (izda.) $\sigma_{0}{ }^{\prime}=0.25 \mathrm{~atm}$. (dcha.) $\sigma_{0}{ }^{\prime}=16 \mathrm{~atm}$. (Darendeli, 2001).

Fig. 3-66. Curvas de reducción del módulo de cortante $G / G_{\max }$ y de amortiguamiento. (Menq, 2003). ....96

Fig. 3-67. (izda.) Espacio de tensiones principales y plano de tensiones octaédricas. (dcha.) Punto de tensiones principales $P$ expresado como función de sus invariantes tensoriales. (Olivella \& Agelet de Saracíbar-Bosch, 2000).

Fig. 3-68. Criterios de plastificación (izda.) de von Mises. (dcha.) de Drucker-Prager. (Olivella \& Agelet de Saracíbar-Bosch, 2000). 100

Fig. 3-69. Criterio de endurecimiento isotrópico para carga y descarga uniaxial. ................................101

Fig. 3-70. Criterio de endurecimiento cinemático para carga y descarga uniaxial. 101

Fig. 3-71. Criterio de endurecimiento planteado por Mróz (Mróz, 1967). (sup.) Trayectoria uniaxial tensión-deformación. (inf. izda.) Evolución de las superficies de fluencia durante la carga. (if. Dcha.) Evolución de las superficies de fluencia durante la descarga. 102

Fig. 3-72. Refracción y reflexión de las ondas de cortante desde el sustrato rocoso hasta la superficie del terreno. (Owen \& Scholl, 1981)

Fig. 3-73. (izda.) Modelo de capas de SHAKE con ondas ascendentes y descendentes. (Schnabel et al., 1972). (dcha.) Parámetros de rigidez G y amortiguamiento $\beta$ de la linealización equivalente. (Stewart et al., 2008)

Fig. 3-74. (izda.) Análisis de deconvolución para obtener un acelerograma en superficie rocosa de un sismo registrado en suelo blando. (dcha.) Análisis de convolución para obtener un acelerograma en superficie de un suelo blando conocido el sismo en superficie rocosa. (Schnabel et al., 1972).

Fig. 3-75. (izda.) Modelo discretizado en nudos con masa, y elementos con rigidez a cortante y amortiguamiento. (dcha.) Parámetros de rigidez $G$ y amortiguamiento $\beta$ de la linealización equivalente. (Stewart et al., 2008).

Fig. 3-76. Esquema de cuña de empuje activo de Mononobe (Mononobe \& Matsuo, 1929).

Fig. 3-77. Empuje activo total de Mononobe para un muro de $10 \mathrm{~m}$ de altura, relleno del trasdós con densidad $\rho=18 \mathrm{kN} / \mathrm{m}^{3}$ ángulo de rozamiento interno $\phi=30$, aceleración vertical $k_{v}$ nula, $y$ aceleración máxima horizontal del terreno $k_{h}$ variable entre $0 . g$ y $0.6 \cdot g$.

Fig. 3-78. Geometría del trasdós del muro de gravedad planteada originalmente por Mononobe.

Fig. 3-79. Interpretación conceptual de la distribución de presiones de Okabe. 
Fig. 3-80. (izda.) Mecanismo de fallo de un muro de gravedad durante un sismo. (dcha.) Mecanismo de fallo de una tablestaca durante un sismo (Murphy, 1960). 114

Fig. 3-81. Distribución de presiones de propuesta por Seed y Whitman (Seed \& Whitman, 1970) 115

Fig. 3-82. Respuesta conceptual al desplazamiento de un bloque rígido sometido a un pulso finito de aceleración constante (Newmark, 1965).

Fig. 3-83. (izda.) Método de Newmark para calcular el desplazamiento de un bloque, apoyado en un plano horizontal con rozamiento, sometido a un acelerograma. (dcha.) Ábaco de desplazamiento calculado por Newmark para diferentes ratios de coeficiente de rozamiento frente a la aceleración horizontal máxima $\mu / P G A$ (Newmark, 1965).

Fig. 3-84. Aplicación del método de Newmark al cálculo del desplazamiento de un muro de gravedad (Elms \& Richards, 1979).

Fig. 3-85. Esquema de los dos modelos de muro estudiados (Matsuo \& Ohara, 1960). (izda.) Muro infinitamente rígido. (dcha.) Muro con base infinitamente flexible.

Fig. 3-86. Distribución de presiones ejercidas por el terreno sobre un muro. (Matsuo \& Ohara, 1960). (izda.) Caso de un muro infinitamente rígido. (dcha.) Caso de un muro con base infinitamente flexible.

Fig. 3-87. Esquema de estructura de la estación hidroeléctrica de Castaic (Wood, 1973). 121

Fig. 3-88. Esquema de muro rígido apoyado sobre fondo rígido estudiado por Wood (Wood, 1973).....121

Fig. 3-89. Distribución de presiones dinámicas estudiadas por Wood (Wood, 1973) para diferentes ratios longitud/altura del contenedor de suelo, y coeficientes de Poisson $v$.

Fig. 3-90. (izda.) Resultante total de fuerzas horizontales, (dcha.) y de momentos en la base del muro obtenidas por Wood (Wood, 1973) para diferentes ratios longitud/altura del contenedor de suelo, y coeficientes de Poisson $v$.

Fig. 3-91. (izda.) Modelo de elementos finitos empleado por Wood (Wood, 1973) para su estudio. (dcha.) Distribución equivalente de presiones dinámicas de acuerdo a la formulación de Wood. .124

Fig. 3-92. Resultantes totales de empuje sísmico y estático sobre un muro de altura $h=10 \mathrm{~m}$, relleno del trasdós $\phi=30^{\circ}$ sin cohesión, y diferentes valores de aceleración máxima horizontal PGA, normalizadas a las resultantes de empuje activo estático. (izda.) Ratio de empuje horizontal total $P_{T O T A L}=P_{A}+\Delta P_{A E}$ entre empuje activo estático $P_{A}$. (dcha.) Momento volcador total $M_{\text {TOTAL }}=M_{A}+\Delta M_{A E}$ entre momento activo estático $M_{A}$.

Fig. 3-93. Ratio de resultantes de componentes sísmicas de las resultantes de empujes (resultante horizontal, y momento volcador), entre la hipótesis de Wood (Wood, 1973), y la hipótesis de Mononobe-Okabe modificada según Seed y Whitman (Seed \& Whitman, 1970).

Fig. 3-94. Modelo de Scott para el análisis dinámico conjunto de muro deformable y suelo del trasdós elástico.

Fig. 3-95. (izda.) Geometría de los casos analizados. (dcha.) modelo simplificado (Arias et al., 1981). .. 130

Fig. 3-96. (izda.) Distribución de presiones normalizada a la altura del muro y a la tensión vertical. (dcha.) Resultante de empuje horizontal y de momento volcador. (Arias et al., 1981). 131 
Fig. 3-97. Modelo de muro rígido con cimentación rígida (Veletsos \& Younan, 1994).

Fig. 3-98. Modelo de muro rígido con cimentación flexible (Veletsos \& Younan, 1993). 132

Fig. 3-99. Distribución de presiones sobre el muro para sistemas solicitados estáticamente, con diferentes flexibilidades de muro y base. (izda.) Caso con base infinitamente rígida $d_{\theta}=0$ y alzado flexible. (dcha.) Caso con alzado del muro infinitamente rígido $d w=0$ y base flexible. (Veletsos \& Younan, 1997). 136

Fig. 3-100. Deformaciones en el muro relativas a la base para sistemas solicitados estáticamente, diferentes flexibilidades de muro y base. (izda.) Caso con base infinitamente rígida $d_{\theta}=0$ y alzado flexible. (dcha.) Caso con alzado del muro infinitamente rígido $d_{w}=0$ y base flexible. (Veletsos \& Younan, 1997).

Fig. 3-101. Modelo de interacción suelo-estructura desarrollado por Ostadan en el programa SASSI.

(Ostadan \& White, 1998)......

Fig. 3-102. Función de transferencia de presión máxima ejercida por el suelo. (izda.) En función de diferentes velocidades de propagación de ondas de cortante del suelo contenido. (dcha.) En función de la frecuencia normalizada del primer modo de cortante del suelo contenido.

(Ostadan \& White, 1998).

Fig. 3-103. Distribución de presiones propuesta por Ostadan (Ostadan, 2004), y comparación con las distribuciones de Mononobe-Okabe modificada según Seed y Whitman (Seed \& Whitman, 1970), y la distribución de Wood (Wood, 1973).

Fig. 3-104. Algunos caminos seguidos por las ondas desde la zona de fractura de la falla hasta la obra subterránea (Owen \& Scholl, 1981).

Fig. 3-105. (Izda.) Vista en planta de la deformación longitudinal del túnel durante el paso de ondas $P$ de compresión-tracción propagándose en la dirección longitudinal del túnel. (Dcha.) Vista en sección de la deformación anular del túnel durante el paso de ondas P de compresión tracción propagándose en la dirección perpendicular del túnel (Owen \& Scholl, 1981).

Fig. 3-106. (Izda.) Esquema de deformación del terreno bajo una onda $S_{H}$ que se propaga verticalmente.

(Dcha.) Esquema de deformación del terreno bajo una onda $S_{H}$ que se propaga subverticalmente.

Fig. 3-107. Vista en planta de la deformación transversal en planta del túnel y efectos sobre la curvatura de la estructura por el desfase espacial de ondas $S_{H}$ de cortante propagándose en dirección vertical (Owen \& Scholl, 1981).

Fig. 3-108. Deformaciones de distorsión $\left(y_{s}\right)$, y de curvatura en planta $\left(A_{r}\right.$ y $\left.A_{s}\right)$ de una sección rectangular enterrada de túnel de metro sometida a la acción del sismo (Kuesel, 1969). 146

Fig. 3-109. (izda.) Esquema de deformaciones transversales de un túnel bajo el paso de una onda en dirección longitudinal. (dcha.) Esquema de la pendiente de la deformada longitudinal. (cent.) Composición de deformaciones en la estructura para el paso de un tren de ondas que se propaga oblicuamente al eje. (Kuesel, 1969). 
Fig. 3-110. Deformaciones de curvatura en planta (A) de una sección rectangular enterrada de túnel de metro sometida a la acción del sismo (Kuesel, 1969). 148

Fig. 3-111. Deformación de distorsión en alzado del terreno sometido al sismo (Kuesel, 1969). 150

Fig. 3-112. (izda.) Deformación elástica de 1/4 de marco. (dcha.) Distribución de deformaciones elásticas y plásticas en un elemento tipo losa o muro del túnel. (Kuesel, 1969). 150

Fig. 3-113. Deformación en planta de un túnel frente al paso de un tren de ondas oblícuo (St John \& Zahrah, 1987).

Fig. 3-114. Perfil de deformación transversal del terreno en campo libre frente a ondas que se propagan verticalmente (St John \& Zahrah, 1987).

Fig. 3-115. Vista en Sección de la deformación transversal de distorsión durante el paso de ondas $S_{H}$ propagándose en dirección vertical (St John \& Zahrah, 1987).

Fig. 3-116. Modelo de análisis de interacción cinemática.(Ortigosa \& Musante, 1991).

Fig. 3-117. Curva de reducción del módulo de cortante para gravas arenosas. (Ortigosa \& Musante, 1991).

Fig. 3-118. Resultados del modelo de interacción. (izda.) Comportamiento lineal. (dcha.)

Comportamiento no lineal. (Ortigosa \& Musante, 1991).

Fig. 3-119. (Izda.) Deformación de distorsión (ovaling) en forma de óvalo de una sección circular. (Dcha.) Deformación de distorsión (racking) de una sección rectangular (J. N. Wang, 1993). 159

Fig. 3-120. Esquema de deformación diametral $\triangle D$ para un suelo sometido a cortante puro. (Izda.) Si no se considera el suelo perforado por el túnel circular. (Dcha.) Considerando la perforación del túnel circular. (J. N. Wang, 1993).

Fig. 3-121. Coeficiente de respuesta $K_{1}$ en función del coeficiente de flexibilidad F. (Izda.) Valores de $K_{1}$ para valores $0 \leq F \leq 10$. (Dcha.) Valores de $K_{1}$ para valores $0 \leq F \leq 100$ (Wang 1993)......

Fig. 3-122. Amplificación de la deformación de distorsión $\gamma_{1} / \gamma_{f f}$ de una sección circular en función del coeficiente de flexibilidad F y del coeficiente de Poisson del suelo. (Wang 1993).

Fig. 3-123. (Ida.) Perfil de deformación del terreno en campo libre. (Dcha.) Deformación de distorsión o de la estructura asumiendo que la deformación es la misma que la del campo libre (J. N. Wang, 1993).

Fig. 3-124. Concepto de deformación de coeficiente de racking o distorsión R. (izda.) La estructura y el terreno no deformados en ausencia de acción sísmica. (dcha.) La estructura y el terreno bajo la acción sísmica en el instante de máxima deformación. $\gamma_{f f}$ es la máxima deformación angular del terreno en campo libre, $\gamma_{s}$ es la máxima deformación angular o de racking de la estructura. ..164

Fig. 3-125. Rigidez a la distorsión del suelo que sustituye la estructura ( $K_{\text {suelolo }}$, y rigidez de la propia estructura (Kestructura) frente a un estado de cortante puro.

Fig. 3-126. Rigidez a la distorsión de la propia estructura (Kestructura) frente a una fuerza aplicada en la losa superior. 166

Fig. 3-127. Geometrías analizadas en el estudio numérico de elementos finitos (J. N. Wang, 1993)......167 
Fig. 3-128. Modelo de elementos finitos para el estudio del coeficiente de racking $R$ de una sección rectangular (J. N. Wang, 1993).

Fig. 3-129. Valores de los coeficientes de racking $R$ para diferentes valores del coeficiente de flexibilidad F. (Izda.) Para valores entre $0 \leq F \leq 1$. (Dcha.) Para valores entre $0 \leq F \leq 10$. Los triángulos representan las soluciones obtenidas con los modelos MEF, las curvas sólidas representan la solución analítica obtenida para secciones circulares. (J. N. Wang, 1993).

Fig. 3-130. (izda.) Modelo de elementos finitos para el estudio de la interacción cinemática sueloestructura de estructuras enterradas. (dcha.) Amplificación de la deformación de distorsión del túnel en función de la relación de rigideces. (Penzien, 2000).

Fig. 3-131. Deformación de una cavidad rectangular sometida a un estado de cortante puro. (izda.) Con una distribución de tensiones de cortante igual a la del campo libre aplicada en la superficie interior de la cavidad. (cent.) Sin la distribución de tensiones en la superficie de la cavidad interior. (dcha.) Con una distribución de tensiones de cortante en el interior de la cavidad (Penzien, 2000).

Fig. 3-132. (izda.) Rigidez de la estructura. (dcha.) Rigidez del suelo que es sustituido por el túnel.

(Penzien, 2000).

Fig. 3-133. Coeficiente de racking $R$ en función del coeficiente de flexibilidad F. Las líneas continuas representan la expresión (Ec. 3-193) para valores del coeficiente de Poisson $v=0.4$ y v=0.5. Los puntos triangulares representan los valores de los análisis numéricos referidos por Wang (Penzien, 2000).

Fig. 3-134. Estructuras analizadas por Anderson en su estudio paramétrico. (Anderson et al., 2008)....175

Fig. 3-135. Coeficientes de racking $R$ obtenidos por Anderson en su estudio numérico (Anderson et al., 2008). (sup. izda.) Caso 1. (sup. dcha.) Caso 2. (inf. izda) Caso 3. (inf. dcha.) Caso 4.

Fig. 3-136. Expresión del coeficiente de racking $R$ y resultados numéricos obtenidos por Anderson

(Anderson et al., 2008).

Fig. 3-137. Coeficiente de racking $R$ propuesto por Anderson (Anderson et al., 2008), comparado al obtenido por Wang (J. N. Wang, 1993), y Penzien (Penzien, 2000), para diferentes valores del coeficiente de Poisson.

Fig. 3-138. (Izda.) Esquema de la configuración de bloque de suelo sometido a cortante puro y estructura rectangular embebida. (Dcha.) Distribución de tensiones tangenciales y normales sobre la estructura asumido en el estudio (Bobet, Fernandez, Huo, \& Ramirez, 2008).

Fig. 3-139. Transformación de mapeo conformal entre el problema. (Izda.) En el plano real. (Dcha.) En el plano imaginario. (H. Huo, Bobet, Fernández, \& Ramírez, 2006).

Fig. 3-140. Coeficiente de racking $R$ propuesto por Huo, junto con. la solución analítica de Penzien, y los resultados numéricos de Wang (H. Huo et al., 2006).

Fig. 3-141. Esquema de EC8-2 representado la deformación del terreno que rodea la estructura enterrada $\gamma_{s}$ y la acción que esta ejerce sobre la propia estructura a través de una malla de muelles elásticos tipo Winkler que simulan la interacción suelo-estructura. 
Fig. 3-142. Diagrama momento curvatura de una rótula plástica de la guía AFPS (Wojtkowiak et al., 2001).

Fig. 3-143. Esquema de acción sísmica transversal de la guía AFPS (Wojtkowiak et al., 2001) 192

Fig. 3-144. Esquemas de cuña activa de empuje en situación sísmica. (AASHTO, 2012). 199

Fig. 3-145. Esquemas de diseño grosero con deformación de campo libre. (Hung et al., 2009). 202

Fig. 3-146. Coeficiente de racking. (izda) Flexibilidades $0<F<10$. (dcha) Flexibilidades $0<F<1$. (Hung et al., 2009).

Fig. 3-147. Esquemas de cargas equivalentes que producen el desplazamiento de racking. (Hung et al., 2009).

Fig. 3-148. Esquema de distribución de presiones dinámicas ejercidas por el terreno. (Power et al., 2004).

Fig. 3-149. Esquemas de formación de rótulas y mecanismos plásticos. (sup.) Mecanismos aceptables. (inf) Mecanismos inaceptables. (Hung et al., 2009).

Fig. 3-150. Espectros de diseño de la norma japonesa. (izda.) Nivel L1. (cent.) Nivel L2-I Subducción. (dcha.) Nivel L2-II Falla local. (Design Standards for Railway Structures and Commentary (Seismic Design), 2007).

Fig. 3-151. Niveles de daño en estructuras de hormigón según la normativa japonesa. (Design Standards for Railway Structures and Commentary (Seismic Design), 2007). 219

Fig. 3-152. Esquema de acción sísmica transversal de la normativa Japonesa RTRI. (Design Standards for Railway Structures and Commentary (Seismic Design), 2007).

Fig. 3-153. Esquema de acción sísmica transversal de la normativa Japonesa JSCE Standard Specifications for Tunnelling 2016. Cut-and-Cover Tunnels (Takemura et al., 2018).

Fig. 3-154. Esquema de acción sísmica transversal de la normativa Chilena. (Manual de Carreteras. Instrucciones y Criterios de Diseño, 2015).

Fig. 3-155. Reducción del módulo de cortante de la normativa Chilena. (Manual de Carreteras. Instrucciones y Criterios de Diseño, 2015).

Fig. 3-156. Método de análisis estático simplificado equivalente. (ISO-23469).

Fig. 3-157. Método de análisis estático simplificado equivalente. (ISO-23469).

Fig. 4-1. (a) Diagrama de bloques de una porción arbitraria del sistema suelo-estructura. (b) Distorsión a cortante puro de un bloque individual.

Fig. 4-2. Diagrama de bloques, transferencia de rasante entre capas, y rigidez horizontal a cortante de cada bloque. (a) Horizontales. (b) Verticales.

Fig. 4-3. Perfil de deformación a cortante horizontal para: (a) Una estructura más rígida que el suelo sustituido $\left(F_{R}<1\right)$, con una deformación de la capa intermedia $\gamma_{I N T, H}$ menor que la deformación media $\gamma_{A V G, H \cdot}\left(\right.$ (b) Una estructura más flexible que el suelo sustituido $\left(F_{R}>1\right)$, con una deformación de la capa intermedia $\gamma_{I N T, H}$ mayor que la deformación media $\gamma_{A V G, H}$.

Fig. 4-4. Perfil de deformación a cortante vertical para: (a) Una estructura más rígida que el suelo sustituido $\left(F_{R}<1\right)$, con una deformación de la capa central $\gamma_{C E N T, H}$ menor que la deformación 
media $\gamma_{A V G, H .}(b)$ Una estructura más flexible que el suelo sustituido $\left(F_{R}>1\right)$, con una deformación de la capa central $\gamma_{C E N T, H}$ mayor que la deformación media $\gamma_{A V G, H}$

Fig. 4-5. Serie de perímetros de control sucesivos de 1 a $\mathrm{n}$. Cada coeficiente individual de racking $\boldsymbol{R} \boldsymbol{i}$ mide la relación de distorsión entre los perímetros de control i-1 e i, siendo $\boldsymbol{R i}=\boldsymbol{\gamma} \boldsymbol{A V G}, \boldsymbol{i}-$ $1 \gamma A V G, i$.

Fig. 4-6. Croquis conceptual del modelo de elementos finitos con las dimensiones más relevantes, las condiciones de contorno, y el estado tensional de cortante. El mallado y dimensiones no se muestran a escala.

Fig. 4-7. Comparación de las soluciones analíticas propuestas por Wang (J. N. Wang, 1993), Penzien (Penzien, 2000), y Anderson (Anderson et al., 2008), y las propuestas en esta tesis, superpuestas a los resultados de análisis MEF desarrollados en este estudio, y los descritos por Wang (J. N. Wang, 1993). Para coeficientes de Poisson (a) v=0,5, (b) v=0,4, (c) v=0,3, y para (d) $v=0,2 \ldots 246$

Fig. 4-8. (a) Puntos de control del desplazamiento para un perímetro de control intermedio $j$ de ancho $L_{j}$, y canto $H_{j}$, para calcular el coeficiente de racking intermedio. (b) Perfil de racking. 247

Fig. 4-9. Perfiles de coeficiente de racking calculados con la expresión analítica (líneas macizas), y mediante modelos MEF (líneas a trazos), para diferentes proporciones $\lambda$, valores del coeficiente de flexibilidad $F_{R}$ y coeficientes de Poisson v. Las distancias horizontales abarcan desde adyacentes a la estructura $\left(X_{P E R I M} / b_{S T R U}=0\right)$ hasta una distancia de 2 anchos de la estructura $\left(X_{\text {PERIM }} / b_{\text {STRU }}=2\right)$.

Fig. 4-10. Patrones de desplazamiento resultantes de los análisis FEM, en función de la relación de flexibilidad $F_{R}$ y de la proporción geométrica $\lambda=b / d$.

Fig. 4-11. Patrones conceptuales de rocking en función de la rigidez de la estructura. 250

Fig. 4-12. Comparación de la solución analítica del coeficiente de rocking para tres proporciones geométricas $\lambda=1,2,3$, y resultados de análisis MEF desarrollados para este estudio, junto con los publicados por Tsinidis y Pitilakis (Grigorios Tsinidis \& Pitilakis, 2018) en los casos en los que están disponibles. Para coeficientes de Poisson (a) v=0,5, (b) $v=0,4$, (c) $v=0,3$, (d) $v=0,2$..... 252

Fig. 4-13. Expresiones para el factor de modificación a para diferentes coeficientes de Poisson v.........253

Fig. 4-14. Expresiones para el factor de modificación $\alpha$. .254

Fig. 4-15. (a) Ratio de convergencia del coeficiente de racking en función del número de perímetros empleado en la discretización. (b) Error en el valor de los coeficientes de racking y rocking calculados con las expresiones analíticas propuestas en esta tesis y con los análisis de elementos finitos MEF..

Fig. 4-16. (a) Diagrama de bloques con capas horizontales, y transferencia de rasante entre capas, y rigidez horizontal a cortante de cada bloque. (b) Reparto de rasante entre bloques de la capa intermedia, en el que se ha supuesto que el bloque 5 es más rígido que el suelo. 257

Fig. 4-17. Estado de cortante puro para una estructura infinitamente rígida. 259

Fig. 4-18. Comparación de coeficientes de transferencia de rasante. 259 
Fig. 5-1. Vista esquemática del modelo mejorado con el marco estructural, vigas rígidas rotuladas, y muelles de vinculación de Winkler.

Fig. 5-2. (a) Modelo marco propuesto por Wang (J. N. Wang, 1993) para obtener esfuerzos. (b) Modelo marco mejorado propuesto en esta tesis. (c) Diagrama de momentos flectores consecuente con la hipótesis de comportamiento de Wang (J. N. Wang, 1993). (d) Diagrama de momentos flectores consecuente con la hipótesis de comportamiento mejorado propuesta en esta tesis.265

Fig. 5-3. Croquis conceptual del modelo de elementos finitos con las dimensiones más relevantes, las condiciones de contorno, y el estado tensional de cortante. El mallado y dimensiones no se muestran a escala.

Fig. 5-4. Diagramas de momentos flectores en la losa superior, resultantes de un análisis de elementos finitos, y del método de Wang (J. N. Wang, 1993), para un amplio rango de flexibilidades relativas $F_{R}$ y con (a) Coeficiente de Poisson $v=0,5$ y proporción geométrica $\lambda=1$. (b) Coeficiente de Poisson $v=0,3$ y proporción geométrica $\lambda=1$. (c) Coeficiente de Poisson $v=0,5$ y proporción geométrica $\lambda=2$. (d) Coeficiente de Poisson $v=0,3$ y proporción geométrica $\lambda=2$.

Fig. 5-5. Diagramas de momentos flectores en la losa superior, resultantes de un análisis de elementos finitos, y del método mejorado propuesto en esta tesis, para un amplio rango de flexibilidades relativas $F_{R}$ y con (a) Coeficiente de Poisson $v=0,5$ y proporción geométrica $\lambda=1$. (b) Coeficiente de Poisson $v=0,3$ y proporción geométrica $\lambda=1$. (c) Coeficiente de Poisson $v=0,5$ y proporción geométrica $\lambda=2$. (d) Coeficiente de Poisson $v=0,3$ y proporción geométrica $\lambda=2$.

Fig. 5-6. Diagramas de momentos flectores en el muro izquierdo, resultantes de un análisis de elementos finitos, y del método de Wang (J. N. Wang, 1993), para un amplio rango de flexibilidades relativas $F_{R}$ y con (a) Coeficiente de Poisson $v=0,5$ y proporción geométrica $\lambda=1$. (b) Coeficiente de Poisson $v=0,3$ y proporción geométrica $\lambda=1$. (c) Coeficiente de Poisson v=0,5 y proporción geométrica $\lambda=2$. (d) Coeficiente de Poisson $v=0,3$ y proporción geométrica $\lambda=2$.

Fig. 5-7. Diagramas de momentos flectores en el muro izquierdo, resultantes de un análisis de elementos finitos, y del método mejorado propuesto en esta tesis, para un amplio rango de flexibilidades relativas $F_{R}$ y con (a) Coeficiente de Poisson $v=0,5$ y proporción geométrica $\lambda=1$. (b) Coeficiente de Poisson v=0,3 y proporción geométrica $\lambda=1$. (c) Coeficiente de Poisson $v=0,5$ y proporción geométrica $\lambda=2$. (d) Coeficiente de Poisson $v=0,3$ y proporción geométrica $\lambda=2$.

Fig. 5-8. Máximo error de valor del momento flector en la losa superior, para un amplio rango de flexibilidades relativas $F_{R}$, coeficientes de Poisson $v$, y proporciones (a) $\lambda=1$. (b) $\lambda=2$. (c) $\lambda=3 . .273$

Fig. 5-9. Diagramas de esfuerzos cortantes en la losa superior, resultantes de un análisis de elementos finitos, y del método de Wang (J. N. Wang, 1993), para un amplio rango de flexibilidades relativas $F_{R}$ y con (a) Coeficiente de Poisson $v=0,5$ y proporción geométrica $\lambda=1$. (b) Coeficiente de Poisson $v=0,3$ y proporción geométrica $\lambda=1$. (c) Coeficiente de Poisson $v=0,5$ y proporción geométrica $\lambda=2$. (d) Coeficiente de Poisson $v=0,3$ y proporción geométrica $\lambda=2$.

Fig. 5-10. Diagramas de esfuerzos cortantes en la losa superior, resultantes de un análisis de elementos finitos, y del método mejorado propuesto en esta tesis, para un amplio rango de flexibilidades 
relativas $F_{R}$ y con (a) Coeficiente de Poisson $v=0,5$ y proporción geométrica $\lambda=1$. (b) Coeficiente de Poisson $v=0,3$ y proporción geométrica $\lambda=1$. (c) Coeficiente de Poisson $v=0,5$ y proporción geométrica $\lambda=2$. (d) Coeficiente de Poisson $v=0,3$ y proporción geométrica $\lambda=2$.

Fig. 5-11. Diagramas de esfuerzos cortantes en el muro izquierdo, resultantes de un análisis de elementos finitos, y del método de Wang (J. N. Wang, 1993), para un amplio rango de flexibilidades relativas $F_{R}$ y con (a) Coeficiente de Poisson $v=0,5$ y proporción geométrica $\lambda=1$. (b) Coeficiente de Poisson $v=0,3$ y proporción geométrica $\lambda=1$. (c) Coeficiente de Poisson $v=0,5$ y proporción geométrica $\lambda=2$. (d) Coeficiente de Poisson $v=0,3$ y proporción geométrica $\lambda=2$....276

Fig. 5-12. Diagramas de esfuerzos cortantes en el muro izquierdo, resultantes de un análisis de elementos finitos, y del método mejorado propuesto en esta tesis, para un amplio rango de flexibilidades relativas $F_{R}$ y con (a) Coeficiente de Poisson $v=0,5$ y proporción geométrica $\lambda=1$.

(b) Coeficiente de Poisson $v=0,3$ y proporción geométrica $\lambda=1$. (c) Coeficiente de Poisson $v=0,5$ y proporción geométrica $\lambda=2$. (d) Coeficiente de Poisson $v=0,3$ y proporción geométrica $\lambda=2 \ldots .277$

Fig. 5-13. Máximo error de valor del esfuerzo cortante en la losa superior, para un amplio rango de flexibilidades relativas $F_{R}$, coeficientes de Poisson $v$, y proporciones (a) $\lambda=1$. (b) $\lambda=2$. (c) $\lambda=3$.. 278

Fig. 6-1. Perfil de coeficiente de racking. 284

Fig. 6-2. Diagrama de flujo del procedimiento propuesto para considerar el comportamiento no lineal del terreno. 285

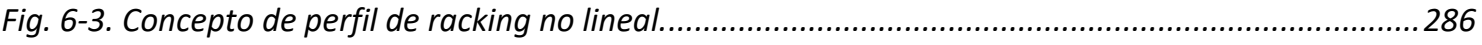

Fig. 6-4. Esquema del modelo de elementos finitos no lineal implementado. 287

Fig. 6-5. Modelo de plastificación con endurecimiento de superficies anidadas (Mróz, 1967). (izda.) Antes de empezar la carga. (cent.) Tras la plastificación total en una dirección. (dcha.) Tras la plastificación total en la dirección opuesta.

Fig. 6-6. Leyes tensión-deformación tangencial del suelo con comportamiento plástico. (izda.) Leyes $\tau-\gamma$ sin normalizar. (dcha.) Leyes $\tau-\gamma$ normalizadas.

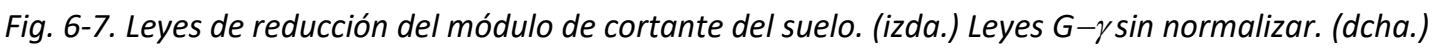
Leyes normalizadas $G / G_{\max }$.

Fig. 6-8. Relación de deformaciones de la estructura enterrada $\gamma_{\text {Tunnel }}$ y de campo libre $\gamma_{F F}$. 291

Fig. 6-9. Evolución del coeficiente de racking no lineal $R_{N L}$ frente al incremento de deformaciones de campo libre $\gamma_{F F}$.

Fig. 6-10. Coeficiente de racking no lineal $R_{N L}$ en función de la ratio de flexibilidad relativa inicial $F_{R, 0}$ para diferentes deformaciones de campo libre $\gamma_{F F}$.

Fig. 6-11. Máximo error del valor del coeficiente de racking no lineal $R_{N L}$ medido como relación entre el obtenido con el método propuesto en esta tesis y con análisis numérico MEF..

Fig. 6-12. Relación de deformaciones de la estructura enterrada $\gamma_{\text {Tunnel }}$ y de campo libre $\gamma_{F F}$ para el método propuesto en esta tesis, los resultados MEF, el método de Hung y Anderson (Anderson et al., 2008; Hung et al., 2009), y el método de Bobet (Bobet et al., 2008). 
Fig. 6-13. Coeficiente de racking no lineal $R_{N L}$ en función de la ratio de flexibilidad relativa inicial $F_{R, 0}$ para diferentes deformaciones de campo libre $\gamma_{F F}$ para el método propuesto en esta tesis, los resultados MEF, el método de Hung y Anderson (Anderson et al., 2008; Hung et al., 2009), y el método de Bobet (Bobet et al., 2008).

Fig. 6-14. Evolución del coeficiente de racking no lineal $R_{N L}$ frente al incremento de deformaciones de campo libre $\gamma_{F F}$ para el método propuesto en esta tesis, los resultados MEF, el método de Hung y Anderson (Anderson et al., 2008; Hung et al., 2009), y el método de Bobet (Bobet et al., 2008).

Fig. 6-15. Máximo error del valor del coeficiente de racking no lineal $R_{N L}$ medido como relación entre el obtenido con el método propuesto en esta tesis, el método de Hung y Anderson (Anderson et al., 2008; Hung et al., 2009), el método de Bobet (Bobet et al., 2008), con respecto al MEF.........299

Fig. 7-1. Resultados de Wang (Wang, 1993) de la influencia de la profundidad en el coeficiente de racking $R$ para estructuras moderadamente rígidas $\left(0,45<F_{R}<0,60\right)$.

Fig. 7-2. Resultados de Bobet (Bobet, 2011) de la influencia de la profundidad en el coeficiente de racking $R$, sin indicar la rigidez relativa de la estructura. 303

Fig. 7-3. Resultados de Anderson et al. (Anderson et al., 2008) de la influencia de la profundidad en el coeficiente de racking $R$. (sup. izda.) $F_{R}=0,97$. (sup. dcha.) $F_{R}=2,40$. (inf. izda.) $F_{R}=2,90$. (inf. dcha.) $F_{R}=7,30$. 304

Fig. 7-4. Resultados de Tsinidis y Pitilakis (Grigorios Tsinidis \& Pitilakis, 2018) de la influencia de la profundidad en el coeficiente de racking $R$.

Fig. 7-5. Esquema del modelo de elementos finitos implementado. 306

Fig. 7-6. Influencia de la profundidad en el coeficiente de racking para $v=0,5$ y $\lambda=b / d=1$. (a) Coeficiente de racking $R$. (b) Ratio entre el coeficiente de racking $R_{z}$ a la profundidad $z$, y el coeficiente de racking a gran profundidad $R_{\text {Deep. }}$

Fig. 7-7. Influencia de la profundidad en el coeficiente de racking para $v=0,3$ y $\lambda=b / d=1$. (a) Coeficiente de racking $R$. (b) Ratio entre el coeficiente de racking $R_{z}$ a la profundidad $z$, y el coeficiente de racking a gran profundidad $R_{\text {Deep. }}$

Fig. 7-8. Primera etapa de ajuste de curvas del factor de corrección $R_{z} / R_{\text {Deep }}$ en función de la ratio de flexibilidad $F_{R}$ y la profundidad normalizada $z / d$.

Fig. 7-9. Segunda etapa de obtención de los parámetros $\alpha_{1}, \alpha_{2}, \beta_{1}, y \beta_{2}$, de la expresión de corrección $R_{z} / R_{\text {Deep }}$ en función de la profundidad normalizada $\mathrm{z} / \mathrm{d}$.

Fig. 7-10. Expresión del coeficiente de corrección $R_{z} / R_{\text {Deep }}$ dependiente de la profundidad frente a los resultados obtenidos mediante análisis numéricos de elementos finitos.

Fig. 7-11. Patrones de carga propuestos por Wang (Wang, 1993). (izda.) Para túneles profundos. (dcha.) Para túneles superficiales.

Fig. 7-12. Comparación de esfuerzos MEF-método simplificado(Wang, 1993) para túneles profundos con fuerza concentrada. Momentos en losa: (izda.) Superior. (dcha.) Inferior. 314 
Fig. 7-13. Comparación de esfuerzos MEF-método simplificado (Wang, 1993) para túneles superficiales con fuerza concentrada. Momentos en losa: (izda.) Superior. (dcha.) Inferior.

Fig. 7-14. Esquema de tensiones normales y tangenciales subyacente en la propuesta de Huo (Huo et al., 2006) para obtener su expresión del coeficiente de racking $R$. 315

Fig. 7-15. (a) Estado tensional de cortante a una profundidad z en equilibrio con una aceleración horizontal de valor constante. (b) Perfil parabólico de deformación del suelo compatible con una solicitación de aceleración uniforme. (c) Estado tensional de cortante puro, (d) Perfil lineal de deformación del suelo compatible con un estado de cortante puro.

Fig. 7-16. (a) Estado tensional de cortante a una profundidad z en equilibrio con una aceleración horizontal de valor constante y estructura embebida. (b) Perfil parabólico de deformación del suelo compatible a una solicitación aceleración uniforme y estructura embebida. (c) Estado tensional de cortante puro y estructura embebida. (d) Perfil lineal de deformación del suelo compatible con un estado de cortante puro y estructura embebida.

Fig. 7-17. Vista esquemática del modelo mejorado con perfil de deformaciones curvas impuestas en los muros laterales, y vinculaciones de Winkler. 320

Fig. 7-18. (a) Modelo marco propuesto por Wang (Wang, 1993) para obtener esfuerzos. (b) Modelo marco mejorado propuesto en esta tesis. (c) Diagrama de momentos flectores consecuente con la hipótesis de comportamiento de Wang (Wang, 1993). (d) Diagrama de momentos flectores consecuente con la hipótesis de comportamiento mejorado propuesta en esta tesis.

Fig. 7-19. Método de Wang. Momentos flectores para profundidad z/d=0 y proporción geométrica $\lambda=b / d=1$. (a) En losa superior. (b) En losa inferior, (c) En muro lateral izquierdo. (d) Ratio de resultados obtenidos mediante el método y los modelos numéricos MEF.

Fig. 7-20. Método de Wang. Momentos flectores para profundidad z/d=0 y proporción geométrica $\lambda=b / d=2$. (a) En losa superior. (b) En losa inferior, (c) En muro lateral izquierdo. (d) Ratio de resultados obtenidos mediante el método y los modelos numéricos MEF.

Fig. 7-21. Método de Wang. Momentos flectores para profundidad z=0,4 y proporción geométrica $\lambda=b / d=1$. (a) En losa superior. (b) En losa inferior, (c) En muro lateral izquierdo. (d) Ratio de resultados obtenidos mediante el método y los modelos numéricos MEF.

Fig. 7-22. Método de Wang. Momentos flectores para profundidad z/d=0,4 y proporción geométrica $\lambda=b / d=2$. (a) En losa superior. (b) En losa inferior, (c) En muro lateral izquierdo. (d) Ratio de resultados obtenidos mediante el método y los modelos numéricos MEF.

Fig. 7-23. Método propuesto. Momentos flectores para profundidad $\mathrm{z} / \mathrm{d}=0$ y proporción geométrica $\lambda=b / d=1$. (a) En losa superior. (b) En losa inferior, (c) En muro lateral izquierdo. (d) Ratio de resultados obtenidos mediante el método y los modelos numéricos MEF.

Fig. 7-24. Método propuesto. Momentos flectores para profundidad z/d=0 y proporción geométrica $\lambda=b / d=2$. (a) En losa superior. (b) En losa inferior, (c) En muro lateral izquierdo. (d) Ratio de resultados obtenidos mediante el método y los modelos numéricos MEF. 
Fig. 7-25. Método propuesto. Momentos flectores para profundidad z/d=0,4 y proporción geométrica $\lambda=b / d=1$. (a) En losa superior. (b) En losa inferior, (c) En muro lateral izquierdo. (d) Ratio de resultados obtenidos mediante el método y los modelos numéricos MEF.

Fig. 7-26. Método propuesto. Momentos flectores para profundidad $z / d=0,4$ y proporción geométrica $\lambda=b / d=2$. (a) En losa superior. (b) En losa inferior, (c) En muro lateral izquierdo. (d) Ratio de resultados obtenidos mediante el método y los modelos numéricos MEF.

Fig. 7-27. Método de Wang. Esfuerzos cortantes para profundidad z/d=0 y proporción geométrica $\lambda=b / d=1$. (a) En losa superior. (b) En losa inferior, (c) En muro lateral izquierdo. (d) Ratio de resultados obtenidos mediante el método y los modelos numéricos MEF.

Fig. 7-28. Método de Wang. Esfuerzos cortantes para profundidad z/d=0 y proporción geométrica $\lambda=b / d=2$. (a) En losa superior. (b) En losa inferior, (c) En muro lateral izquierdo. (d) Ratio de resultados obtenidos mediante el método y los modelos numéricos MEF.

Fig. 7-29. Método de Wang. Momentos flectores para profundidad z=0,4 y proporción geométrica $\lambda=b / d=1$. (a) En losa superior. (b) En losa inferior, (c) En muro lateral izquierdo. (d) Ratio de resultados obtenidos mediante el método y los modelos numéricos MEF.

Fig. 7-30. Método de Wang. Esfuerzos cortantes para profundidad z/d=0,4 y proporción geométrica $\lambda=b / d=2$. (a) En losa superior. (b) En losa inferior, (c) En muro lateral izquierdo. (d) Ratio de resultados obtenidos mediante el método y los modelos numéricos MEF.

Fig. 7-31. Método propuesto. Esfuerzos cortantes para profundidad z/d=0 y proporción geométrica $\lambda=b / d=1$. (a) En losa superior. (b) En losa inferior, (c) En muro lateral izquierdo. (d) Ratio de resultados obtenidos mediante el método y los modelos numéricos MEF.

Fig. 7-32. Método propuesto. Esfuerzos cortantes para profundidad z/d=0 y proporción geométrica $\lambda=b / d=2$. (a) En losa superior. (b) En losa inferior, (c) En muro lateral izquierdo. (d) Ratio de resultados obtenidos mediante el método y los modelos numéricos MEF.

Fig. 7-33. Método propuesto. Esfuerzos cortantes para profundidad $z / d=0,4$ y proporción geométrica $\lambda=b / d=1$. (a) En losa superior. (b) En losa inferior, (c) En muro lateral izquierdo. (d) Ratio de resultados obtenidos mediante el método y los modelos numéricos MEF.

Fig. 7-34. Método propuesto. Esfuerzos cortantes para profundidad $z / d=0,4$ y proporción geométrica $\lambda=b / d=2$. (a) En losa superior. (b) En losa inferior. (c) En muro lateral izquierdo. (d) Ratio de resultados obtenidos mediante el método y los modelos numéricos MEF.

Fig. 8-1 (sup. izda.) Tramo Este del puente de la bahía de San Francisco-Oakland. (sup. dcha.) Puente de Antioch, Sacramento. (inf. izda.) Puente Gerald-Desmond, Long Beach. (inf. dcha.) Puente Vincent Thomas, Los Ángeles.

Fig. 8-2 (izda.) Vista de la Iglesia de San Francisco del s. XVI en Quito, Patrimonio Cultural de la Humanidad, y estación de metro bajo la plaza durante su construcción. (dcha.) Vista de la superficie de la zona de la estación de Fondo de Saco del metro de Quito y de la propia estación en construcción. 
Fig. 8-3 (izda.) Paseo de la Reforma, y estación de Insurgentes en las inmediaciones de este en Ciudad de México. (dcha.) Av. Universidad y de la estación de metro de Coyoacán en Ciudad de México.348

Fig. 8-4 (izda.) Vista del cruce de Shibuya y estación-intercambiador de metro bajo este en Tokio. (dcha.) Vista en superficie y subterránea de la estación de metro de Takebashi en Tokio. 349

Fig. 8-5 (izda.) Metro de Madrid en 1919. (dcha.) Metro de Madrid en 2019. 351

Fig. 8-6 Niveles de daño en rótulas plásticas. (sup. izda.) Nivel l, aparición de fisuras. (sup. dcha.) Nivel II, ensanchamiento de fisuras. (inf. izda.) Nivel IV, propagación del spalling. (Inf. Dcha.) Nivel V, pandeo de barras longitudinales y rotura de zunchos de confinamiento. (Caltrans, 2008). .....

Fig. 8-7 Dispersión de la deformación en el hormigón $\varepsilon_{\text {spall }}$ a la que se produce el spalling del recubrimiento. (izda.) Dispersión respecto al recubrimiento normalizado al diámetro de la columna. (dcha.) Dispersión respecto a la esbeltez de la columna. (Berry \& Eberhard, 2003). . 356

Fig. 8-8 Dispersión de la deformación en el hormigón $\varepsilon_{b b}$ a la que se produce el pandeo de la armadura comprimida. (izda.) Dispersión respecto a la separación entre cercos normalizada al diámetro de la barra. (dcha.) Dispersión respecto al axil en la columna normalizado a la capacidad bruta a compresión. (Berry \& Eberhard, 2003).

Fig. 8-9 Muelle marginal cimentado sobre pilotes (izda.) Curva pushover. (dcha.) Esquema en sección transversal con la posible ubicación de las rótulas plásticas (POLB, 2012).

Fig. 8-10 (izda.) Ubicación admisible de rótulas plásticas en un pilote de muelle portuario (ASCE 61-14). (dcha.) Ubicación admisible de rótulas plásticas (POLB, 2012).

Fig. 8-11 Mapa propuesto de accesibilidad de las diferentes ubicaciones potenciales de rótulas plásticas para una estación subterránea de metro construida mediante el método de cut-and-cover....364

Fig. 10-1. Esquema tridimensional de la deformación de distorsión de un cajón. (izda) Sin mamparos. (dcha.) Con mamparos.

Fig. 10-2. Analogía de la viga sobre fundación elástica para el estudio de problemas de distorsión en secciones cerradas (Pascual Santos, 2004). 


\section{LISTADO DE TABLAS}

Tabla 1-1. Cifras significativas de volumen de pasajeros de transporte suburbano en ciudades con peligrosidad sísmica elevada. (UITP Observatory of Automated Metros 2018).

Tabla 3-1. Clasificación de los tipos de terreno según Eurocódigo 8. (EN-1998-1:2004). ............................ 71

Tabla 3-2. Módulo de cortante para pequeñas deforamciones en arenas. (Hardin \& Black, 1966)............88

Tabla 3-3. Valor del exponente a dependiente del índice de plasticidad IP. (Seed \& Idriss, 1972).............92

Tabla 3-4. Exponente del parámetro de degradación del módulo de cortante por carga cíclica. (Vucetic \& Dobry, 1990). 95

Tabla 3-5. Parámetros típicos de los modelos de Darendeli y Menq para diferentes tipos de suelos.

(Stokoe et al., 2004). .............................................................................................................

Tabla 3-6. Combinaciones de condiciones de contorno y acelerograma solicitante ................................108

Tabla 3-7. Deformaciones y curvaturas correspondientes a paso de ondas volumétricas y superficiales. (St

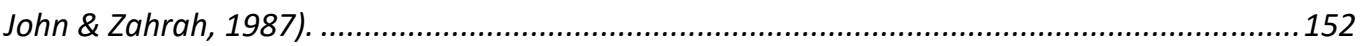

Tabla 3-8. Parámetros del estudio numérico para secciones rectangulares (J. N. Wang, 1993)...............167

Tabla 3-9. Propiedades mecánicas de las estructuras de los casos estudiados por Anderson en su análisis

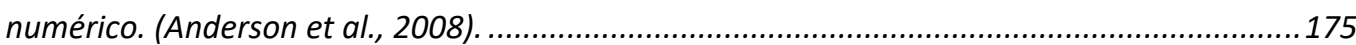

Tabla 3-10. Casos estudiados por Anderson en su análisis numérico. (Anderson et al., 2008). 176

Tabla 3-11. Configuraciones de profundidad de la estructura de los casos estudiados por Anderson en su análisis numérico. (Anderson et al., 2008). ...................................................................... 176

Tabla 3-12. Clases de importancia sísmica para puentes del Eurocódigo. (EN 1998-2:2005)...................183

Tabla 3-13. Clases de consecuencias del Eurocódigo. (EN 1990:2002). ....................................................184

Tabla 3-14. Niveles de Desempeño del Eurocódigo. (EN 1990:2002).....................................................184

Tabla 3-15. Niveles de Demanda y Desempeño del Eurocódigo. (EN 1998-1-1:2004). ............................. 184

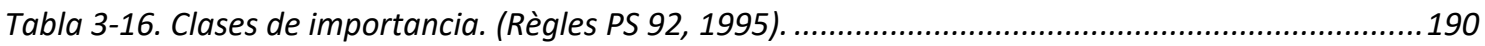

Tabla 3-17. Niveles de demanda sísmica y periodos de retorno correspondientes en la normativa AASHTO de Túneles. (AASHTO Tunnels 2017). 196

Tabla 3-18. Límites de deformación en los materiales correspondientes en la normativa AASHTO de

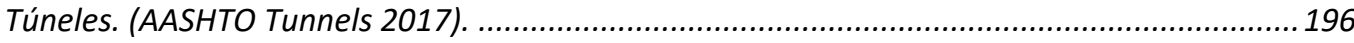

Tabla 3-19. Matriz de Demanda-Desempeño de la normativa AASHTO. (AASHTO Guide Specifications for

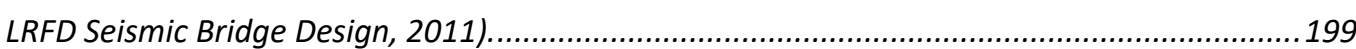

Tabla 3-20. Niveles de demanda sísmica del manual de túneles FHWA. (Hung et al., 2009)...................201

Tabla 3-21. Niveles de demanda sísmica para reacondicionamiento de puentes. (Buckle et al., 2006). . 205

Tabla 3-22. Categorías sísmicas para reacondicionamiento de puentes. (Buckle et al., 2006)................205

Tabla 3-23. Categorías de clasificación de vida remanente para reacondicionamiento de puentes. (Buckle et al., 2006). 206 
Tabla 3-24. Niveles de desempeño sísmico para reacondicionamiento de puentes. (Buckle et al., 2006).

Tabla 3-25. Asignación de objetivos de desempeño para reacondicionamiento de puentes. (Buckle et al., 2006). 207

Tabla 3-26. Niveles de demanda sísmica para obras geotécnicas. (Kavazanjian et al., 2011)..... 208

Tabla 3-27. Asignación de objetivos de desempeño para obras geotécnicas. (Kavazanjian et al., 2011).

Tabla 3-28. Niveles de demanda sísmica para la línea ferroviaria de Alta Velocidad de California.

(Waggoner et al., 2011).

Tabla 3-29. Correspondencia entre demanda y desempeño sísmicos para la línea ferroviaria de Alta

Velocidad de California. (Waggoner et al., 2011).

Tabla 3-30. Niveles de desempeño sísmico para la línea ferroviaria de Alta Velocidad de California.

(Waggoner et al., 2011).

Tabla 3-31. Niveles de demanda sísmica para obras subterráneas. (LA Metro Authority, 2012). ...........214

Tabla 3-32. Niveles de desempeño sísmica para obras subterráneas. (LA Metro Authority, 2012).........214

Tabla 3-33. Niveles de demanda y desempeño sísmicos para obras subterráneas. (LA Metro Authority, 2012).

Tabla 3-34. Niveles de demanda sísmica para obras subterráneas. (WSDOT, 2010)......

Tabla 3-35. Niveles de desempeño sísmica para obras subterráneas. (WSDOT, 2010).

Tabla 3-36. Niveles de demanda y desempeño sísmicos para obras subterráneas. (WSDOT, 2010).......218

Tabla 3-37. Niveles de demanda sísmica de la normativa japonesa. (Design Standards for Railway Structures and Commentary (Seismic Design), 2007).

Tabla 3-38. Niveles de daño en estructuras de hormigón según la normativa japonesa RTRI. (Design Standards for Railway Structures and Commentary (Seismic Design), 2007).

Tabla 3-39. Matriz de Demanda-Desempeño de la normativa japonesa RTRI. (Design Standards for

Railway Structures and Commentary (Seismic Design), 2007).

Tabla 3-40. Niveles de demanda sísmica de la normativa japonesa JSCE Concrete Structures. (Hiroyuki et al., 2007) 222

Tabla 3-41. Niveles de daño sísmico de la normativas japonesas JSCE Cut-and-Cover Tunnels (Takemura et al., 2018), y JSCE Concrete Structures. (Hiroyuki et al., 2007).

Tabla 3-42. Matriz de Demanda-Desempeño de la normativa japonesa JSCE Standard Specifications for Tunnelling 2016. Cut-and-Cover Tunnels (Takemura et al., 2018).

Tabla 3-43. Coeficientes de importancia según la clasificación de la obra de la normativa chilena.

(Manual de Carreteras. Instrucciones y Criterios de Diseño, 2015) ......................................225

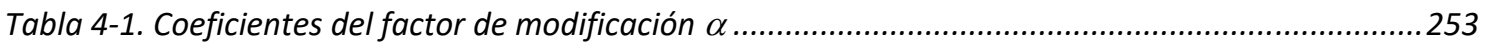

Tabla 4-2. Valores del coeficiente de transferencia de rasante para estructuras rígidas $F_{R}=0$...............258

Tabla 6-1. Parámetros de definición de los materiales. .....................................................................289

Tabla 6-2. Espesores de losa y muro de los modelos estudiados.........................................................290 
Tabla 7-1. Parámetros de los coeficientes $\alpha$ y $\beta$.

Tabla 7-2. Casos estudiados por Wang (Wang, 1993) para validar el método de fuerza concentrada en cabeza y distribución triangular de presiones laterales.

Tabla 7-3. Expresiones para los parámetros del modelo dependientes de la profundidad.

Tabla 8-1. Propuesta de criterios de clasificación de la relevancia urbana de las estaciones de metro, y ejemplos de adscripción a cada categoría. 350

Tabla 8-2. Periodos de retorno de diferentes niveles de demanda sísmica adoptados por las normativas sismorresistentes analizadas.

Tabla 8-3. Niveles de demanda sísmica propuestos para el diseño de estaciones subterráneas de metro construidas por el método de cut-and-cover.

Tabla 8-4. Niveles de daño en rótulas plásticas. (Caltrans, 2008).

Tabla 8-5. Valores de deformación máxima permitida en el hormigón adoptados por las normativas sismorresistentes analizadas.

Tabla 8-6. Valores de deformación máxima permitida en la armadura de acero pasivo adoptados por las normativas sismorresistentes analizadas. 359

Tabla 8-7. Límites de deformación en los materiales en función de la reparabilidad, propuestos para el diseño de estaciones subterráneas de metro construidas por el método de cut-and-cover.

Tabla 8-8. Propuesta de caracterización de la accesibilidad a las zonas de rótula plástica susceptibles de sufrir daño durante un sismo. 364

Tabla 8-9. Matriz de objetivos de desempeño y niveles de demanda sísmica, en función de la accesibilidad, propuestos para el diseño de estaciones subterráneas de metro construidas por el método de cut-and-cover, de relevancia urbana normal.

Tabla 8-10. Matriz de objetivos de desempeño y niveles de demanda sísmica, en función de la accesibilidad, propuestos para el diseño de estaciones subterráneas de metro construidas por el método de cut-and-cover, de relevancia urbana especial. 365 


\section{MOTIVACIÓN}

Los terremotos son fenómenos naturales asociados a los mecanismos de deriva continental de la Tierra, y representan una de las manifestaciones más directas y perceptibles que puede experimentar el ser humano de la estructura a gran escala del planeta. Los procesos geológicos de transformación involucran, por regla general, periodos de tiempo mucho mayores que los comparables con la vida de una persona (incluso mucho mayores que los comparables con la historia de la civilización), y parecen por lo tanto difuminados bajo una cierta perspectiva de constancia e inmutabilidad.

Los sismos, sin embargo, son fenómenos de carácter casi instantáneo, violento, y a menudo con consecuencias trágicas cuando se producen en zonas densamente pobladas, de escaso desarrollo económico y tecnológico, que no están suficientemente preparadas para afrontar tales eventos. Los terremotos de Haití en 2010 (M 7,0), y Maule (Chile) en 2010 (M 8,8) son un claro ejemplo. Siendo ambos eventos catastróficos, el terremoto de Chile liberó una cantidad de energía 800 veces superior al de Haití (Boroschek et al. 2012), y sin embargo las pérdidas humanas y materiales fueron mucho mayores en el país caribeño (último país en grado de desarrollo económico de América) que en el andino (segundo país en renta per cápita de América del Sur). Resulta por lo tanto evidente que la preparación de las construcciones frente a la acción del sismo reviste una gran importancia, tanto para evitar que estas sean causantes de daños personales y económicos (p.ej. destrucción de viviendas e infraestructuras), como para asegurar el adecuado funcionamiento de los servicios inmediatamente después de un sismo.

Las infraestructuras de transporte metropolitano son componentes esenciales del desarrollo económico y de cohesión social de las ciudades contemporáneas, y constituyen una de las principales arterias por las que circula el transporte urbano de pasajeros, con volúmenes de trayectos del orden de decenas de miles de millones al año (Tabla 1-1), (Fig. 1-1). Las disrupciones de estos servicios de transporte pueden ocasionar pérdidas económicas importantes, no tan sólo en forma de coste directo asociado a los daños 
ocasionados por el sismo, o ligados la disminución del número de viajeros, sino también asociadas a los costes indirectos derivados de la necesidad de transporte alternativo (p.ej. incremento de desplazamientos en vehículos privados, aumento en el consumo de carburante, aumento de la congestión del transporte por carretera, aumento de emisiones contaminantes, etc.).

\begin{tabular}{|c|c|c|}
\hline Ciudad & País & $\begin{array}{c}\text { Volumen anual } \\
\text { [mill. pasajeros / año] }\end{array}$ \\
\hline Ciudad de México & México & 1685.0 \\
\hline Santiago & Chile & 666.9 \\
\hline Medellín & Colombia & 165.4 \\
\hline Lima & Perú & 91.0 \\
\hline Los Ángeles & EE.UU. & 51.0 \\
\hline San Francisco & EE.UU. & 117.8 \\
\hline Vancouver & Canadá & 120.4 \\
\hline Atenas & Grecia & 493.8 \\
\hline Estambul & Turquía & 232.2 \\
\hline Ankara & Turquía & 89.4 \\
\hline Teherán & Irán & 633.0 \\
\hline Tokio & Japón & 3289.0 \\
\hline Osaka & Japón & 899.0 \\
\hline Yokohama & Japón & 395.7 \\
\hline Taipei & Taiwán & 679.5 \\
\hline
\end{tabular}

Tabla 1-1. Cifras significativas de volumen de pasajeros de transporte suburbano en ciudades con peligrosidad sísmica elevada. (UITP Observatory of Automated Metros 2018).

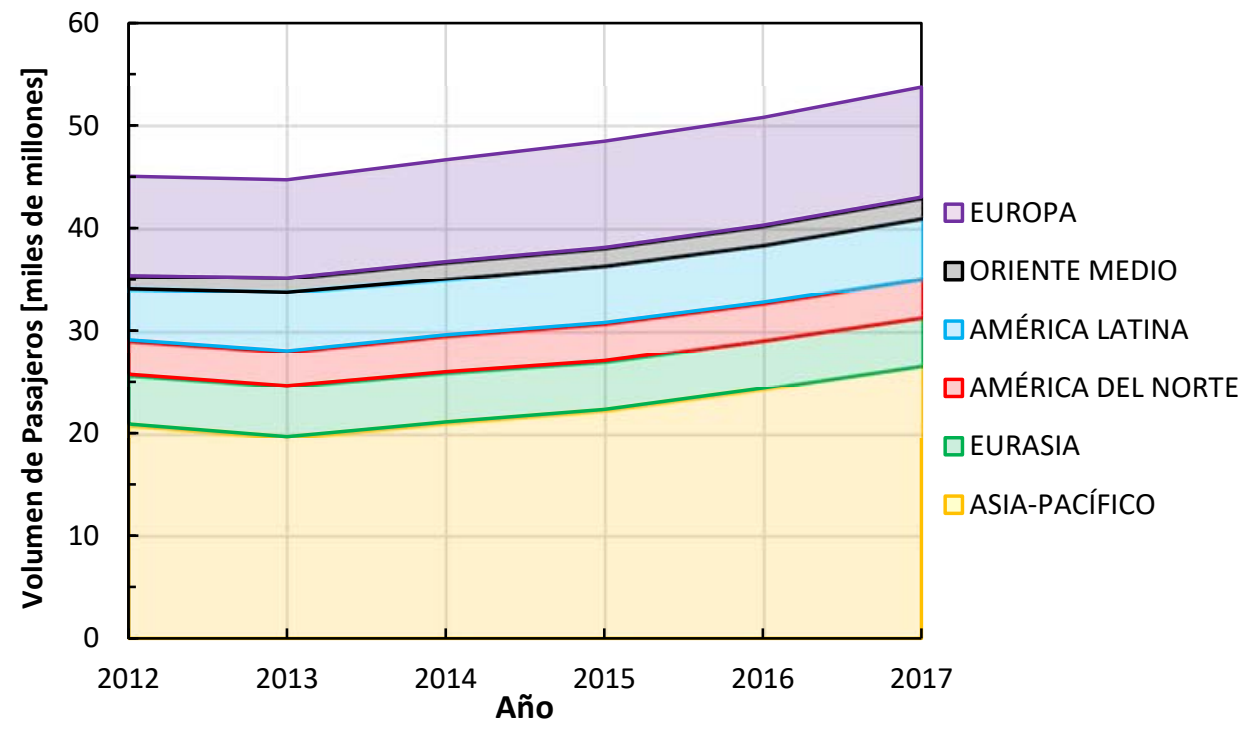

Fig. 1-1.Volumen anual de pasajeros en las 178 redes de metro existentes. (UITP Observatory of Automated Metros 2018).

Una parte fundamental de estos sistemas de transporte masivo de pasajeros son las obras subterráneas, y en especial las estaciones que dan acceso a la red de transporte. 
A lo largo de la reciente historia de la ingeniería sísmica, la percepción que se ha tenido respecto a la susceptibilidad de las estructuras subterráneas frente a los efectos de los terremotos ha sido, por lo general, heterogénea. Tradicionalmente, una línea de pensamiento ha considerado que los efectos de los sismos en estructuras subterráneas son poco significantes comparados con los de estructuras en superficie; esencialmente debido al confinamiento que ejerce el terreno circundante, que impide el colapso de la obra por la deformación lateral excesiva (Huo et al. 2004), (Lanzano et al. 2008). Otra línea más reciente de pensamiento ha entendido que las estructuras subterráneas pueden ser tan susceptibles como cualquier otra a los efectos de los terremotos, y que su concepción debe tener en cuenta dicha acción de manera apropiada (Wang 1993), (Penzien 2001).

El colapso de la estación de Daikai (Kobe, Japón), durante el terremoto de Hyogoken-Nanbu en 1995, supuso un claro ejemplo de cómo las estructuras subterráneas pueden ser muy vulnerables a la acción sísmica (Fig. 1-2, Fig. 1-3). El segmento central de la estación de Daikai, que se ha convertido en epítome de la vulnerabilidad de las estructuras subterráneas a la acción del sismo, colapsó tras el fallo de un gran número de pilares de la alineación central que soportaban la losa de cubrición (An et al. 1997).
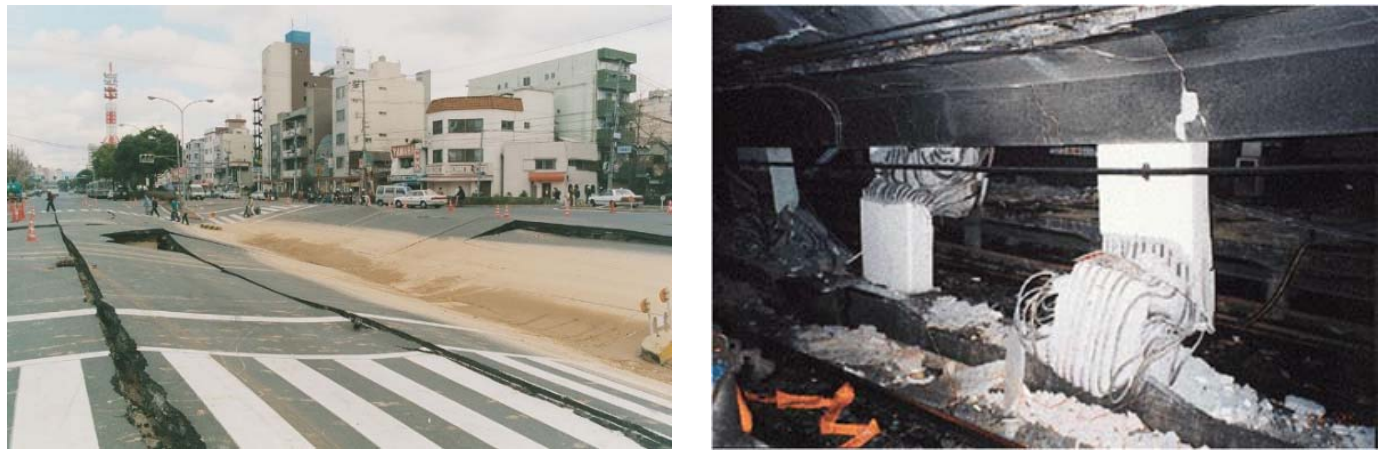

Fig. 1-2.Daños en la estación de Daikai tras el sismo de Kobe, 1995. (izda.) Colapso de la losa de cubrición. (dcha.) Colapso de la alineación central de pilares. (An et al. 1997).

Aunque la causa del colapso de esta estación parece haberse identificado con cierta fiabilidad (exceso de demanda de deformación transversal en los pilares centrales, con el consecuente exceso de solicitación a cortante en una sección poco armada transversalmente (Huo et al. 2004), y a pesar de que actualmente existe consenso acerca de la importancia del diseño sísmico de obras subterráneas, las normativas internacionales actuales siguen proporcionando criterios de diseño dispares en este contexto. 


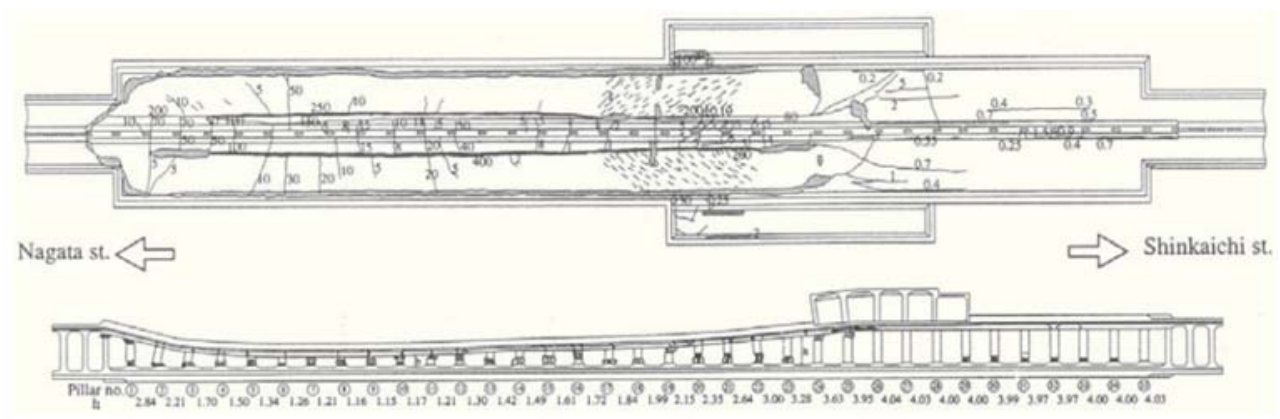

Fig. 1-3. Vista en planta de la estación de Daikai tras el sismo de Kobe, 1995. (Iwatate et al. 2000).

En especial, la falta de homogeneidad de criterios se acentúa más en lo que se refiere a la acción que ejerce el terreno circundante, en el que se encuentra enterrada la obra subterránea, sobre la propia estructura durante un evento sísmico. De hecho, en ciertos casos de proyecto, como pueden ser las estaciones subterráneas de metropolitano, la normativa internacional actual puede tratar la acción sísmica de manera muy diferente, proporcionando estructuras con resistencias dispares en función del método de diseño seleccionado. Algunas preguntas naturales que el ingeniero proyectista se plantea, ante esta situación, a la hora de abordar el diseño de una estación subterránea de metro son ¿de dónde surge esta diferencia de criterios?, ¿qué criterio debería aplicarse en cada caso concreto?, ¿en base a qué parámetros puede hacerse la distinción entre criterios a aplicar?, ¿cuál es la fiabilidad que presentan a día de hoy los métodos de determinación de la acción sísmica en estructuras subterráneas?

En esta tesis doctoral se busca profundizar en el conocimiento de los efectos de la acción sísmica en las obras subterráneas, con especial énfasis en las estaciones suburbanas de metro, para lo que se definen tres objetivos generales:

- Analizar críticamente las metodologías actuales de diseño sismorresistente de obras subterráneas, tanto las propuestas por varios autores, como las recogidas en la normativa internacional al respecto.

- Analizar los efectos de interacción suelo-estructura que se dan en las obras subterráneas durante los terremotos.

- Desarrollar un marco conceptual que, junto con formulaciones simplificadas, permita al proyectista de obras subterráneas determinar, de manera aproximada, pero suficientemente precisa, la influencia que tienen la rigidez de la estructura y las características del terreno en la determinación de la acción sísmica. 


\section{OBJETIVOS Y PLANTEAMIENTO}

\subsection{Introducción}

En la actualidad, no existe un consenso inequívoco con respecto a las metodologías mediante las que se debe abordar el análisis de la acción del sismo en las obras subterráneas. Diversos autores han propuesto diferentes planteamientos simplificados para tratar el problema, que han quedado recogidos en las normativas internacionales de proyecto sismorresistente de estructuras, pero sin formar un cuerpo homogéneo.

Aunque todos estos planteamientos tienen una base racional, y en algunas ocasiones puedan parecer similares a primera vista, la aplicación de estos métodos conduce en último término a resultados dispares, en términos de esfuerzos solicitantes en la estructura, y consecuentemente de la resistencia con la que se debe dotar a la misma.

Recientemente, la Comisión Europea ha elaborado un informe titulado "Standardisation needs for the design of underground structures" (Athanasopoulou et al., 2019), en el que advierte sobre la falta de homogeneidad de criterios de proyecto y construcción de obras subterráneas entre los diferentes estados miembro de la UE, y sobre la necesidad de elaborar un normativa común propia para este tipo de obras. Entre los aspectos que aborda dicho informe destaca la necesidad de plantear, desde el punto de vista normativo y de inclusión en los Eurocódigos, el diseño sismorresistente de túneles.

Por otra parte, y como se verá a lo largo de esta tesis, los métodos simplificados que cuentan con mayor aceptación, producen resultados que no son coherentes con los resultados que se obtienen mediante técnicas numéricas más complejas como modelos de elementos finitos. Esta circunstancia ha motivado que, recientemente, varios autores recomienden el uso extensivo de estas técnicas complejas en detrimento de los métodos simplificados (Debiasi, Gajo, \& Zonta, 2013; Hushmand et al., 2016b, 2016a; Pitilakis \& Tsinidis, 2014; Tsinidis, 2017; Tsinidis, Pitilakis, \& Heron, 2015), ya que los métodos 
más sofisticados pueden tener en cuenta de manera apropiada y detallada diferentes aspectos mecánicos de la interacción suelo-estructura.

Esta recomendación es, a juicio del autor, poco conveniente. En primer lugar, el proceso de diseño de una obra contempla fases de proyecto conceptual, preliminar, y detallado, durante las cuales la planificación funcional y de la arquitectura (p.ej. esquemas de circulación de los pasajeros en estaciones de metro) pueden modificar ampliamente, y con frecuencia, las configuraciones estructurales y geotécnicas previas. Esto convierte a los modelos de elementos finitos en muy poco prácticos hasta que se alcanzan las fases finales del diseño, cuando muchas de las decisiones referentes a la ingeniería del proyecto ya se han tomado, y apenas queda margen para realizar cambios, si no únicamente para la verificación de resultados. En segundo lugar, el confiar únicamente en modelos numéricos complejos para obtener resultados estructurales relevantes (p.ej. momentos flectores, esfuerzos cortantes, desplazamientos, etc.), puede dejar al ingeniero proyectista sin herramientas más prácticas e inmediatas para que pueda guiar sus decisiones hacia un diseño seguro y económico. Por último, los métodos simplificados, precisamente por ser sencillos, permiten al ingeniero proyectista abordar aspectos y cuestiones específicas de cada proyecto que no quedan resueltos en la normativa, ni han sido estudiados en la literatura técnica, desde una perspectiva práctica.

Por otra parte, la mayor parte de las metodologías simplificadas actuales de análisis del fenómeno de interacción suelo-estructura de obras subterráneas, asumen que el terreno se comporta de manera lineal durante el evento sísmico (sin plastificación significativa del terreno), o que por lo menos la interacción suelo-estructura no altera el estado de plastificación del terreno que tendría el suelo bajo las condiciones de campo libre. Este aspecto es relevante a juicio del autor, y requiere de un análisis más detallado para poder ser capaces de extraer conclusiones significativas.

\subsection{Objetivos del estudio}

En base a los planteamientos de partida enunciados anteriormente, y de acuerdo a lo expuesto sucintamente en el Capítulo $§ 1$, en esta tesis se busca profundizar en el conocimiento de los efectos de la acción sísmica en las obras subterráneas, con especial énfasis en las estaciones suburbanas de metro, para lo que se definen los siguientes objetivos generales: 
1. Realizar un estudio del estado del conocimiento del fenómeno de interacción suelo-estructura en obras subterráneas bajo la acción del sismo.

2. Establecer un marco conceptual que proporcione al ingeniero proyectista un medio efectivo para entender intuitivamente la auténtica naturaleza de los efectos de interacción suelo-estructura en obras subterráneas durante un evento sísmico, y proponer un método simplificado que, apoyándose en algunas de las ideas presentes en los métodos actuales, logre una convergencia de resultados hacia los predichos por modelos numéricos más detallados.

3. Realizar un estudio de la influencia de la plastificación diferencial del terreno circundante a la obra frente a la producida por la deformación de campo libre, y enunciar una formulación simplificada para tener en cuenta dicha plastificación diferencial.

4. Proponer una serie de criterios prácticos de demanda y desempeño sísmicos para el proyecto de estaciones subterráneas de Metro construídas por el método de cut-and-cover. Es decir, de acuerdo al reciente enfoque de de proyecto sísmico por desempeño (Performance Based Design en la literatura anglosajona), proponer unos criterios de deformaciones máximas a no rebasar en los materiales, para diversos escenarios de intensidad de la acción sísmica.

Queda explícitamente fuera de los objetivos de esta tesis estudiar los efectos que el agua del nivel freático pudiera ejercer sobre la estructura subterránea durante un sismo.

A continuación, se concreta y delimita el alcance de cada uno de estos objetivos.

\subsubsection{Estudio del estado del conocimiento acerca de los objetivos buscados en esta tesis}

El estudio del estado del conocimiento que se aborda en esta tesis, acerca de los diferentes métodos que existen para abordar el problema de la acción sísmica en obras subterráneas, se centra en 5 líneas fundamentales. 
1. En primer lugar, se aborda un estudio de la evolución histórica, y del estado del arte actual, referente a la determinación de la acción estática del terreno sobre las estructuras de contención.

2. En segundo lugar, se realiza un estudio del estado del arte en cuanto a las metodologías disponibles para determinar la respuesta del terreno en campo libre durante un terremoto, esto es, de las metodologías que permiten determinar las deformaciones que se dan en un terreno en el que no existe ninguna estructura durante el evento sísmico.

3. En tercer lugar, se plantea un estudio del estado del arte un cuanto a los modelos existentes para tratar el comportamiento dinámico no lineal de suelos solicitados por la acción sísmica.

4. En cuarto lugar, se aborda un estudio acerca del estado del arte en cuanto a las metodologías disponibles para determinar la acción sísmica sobre muros en ménsula o estructuras asimilables, así como en túneles y obras subterráneas. El propósito de este estudio es analizar hasta qué punto pudiera emplearse alguna de estas metodologías para determinar la acción del sismo sobre las pantallas laterales de una estación de metro.

5. En quinto lugar, se plantea un estudio de las formas que tienen de tratar el problema de la acción sísmica, en estructuras subterráneas, las normativas internacionales más significativas de diseño sismorresistente. A este respecto, el estudio no se ha limitado únicamente a los códigos estructurales de obligado cumplimiento, sino también a los diferentes criterios que han adoptado al respecto las Propiedades o Autoridades Explotadoras de algunas líneas de metro.

\subsubsection{Marco conceptual para el estudio de la interacción suelo-estructura de una obra subterránea bajo solicitación sísmica, y métodos simplificados para su análisis}

Las metodologías simplificadas actuales presentan ideas interesantes para determinar, en líneas generales, cuales son los parámetros más significativos que influyen en la respuesta sísmica de una estructura enterrada. Sin embargo, algunas de ellas están basadas en formulaciones matemáticas complejas resultado de problemas de elasticidad bidimensional (p.ej. solución con funciones de Airy en los métodos de Wang (Wang, 1993) y Penzien (Penzien, 2000)), o proporcionan resultados contradictorios con otras 
metodologías (p.ej. métodos de las normativas europea EN 1998-2, francesa AFPS 2001 (Wojtkowiak et al., 2001), japonesa (Design Standards for Railway Structures and Commentary (Seismic Design), 2007), o internacional ISO 23469:2005).

Por un lado, se pretende desarrollar un marco conceptual que explique de manera intuitiva, y en términos fácilmente asimilables por un ingeniero proyectista, como se produce el fenómeno de interacción suelo-estructura de obras subterráneas bajo solicitación sísmica, en términos de deformaciones globales.

Por otro lado, y a partir del marco conceptual anterior, se pretende desarrollar métodos simplificados que sean capaces de predecir la respuesta estructural en términos de deformaciones y esfuerzos. Estos métodos deberán presentar ventajas frente a los métodos actuales sin añadir complejidad excesiva, y deberán ser capaces de reproducir con una precisión razonable los resultados obtenidos mediante modelos numéricos de elementos finitos.

\subsubsection{Estudio de la influencia de la plastificación diferencial del terreno circundante a la obra frente a la producida por la deformación de campo libre, y método simplificado para su análisis}

Como se ha indicado, la mayor parte de las metodologías actuales de análisis del fenómeno de interacción suelo-estructura de obras subterráneas, asumen que el terreno se comporta de manera lineal durante el evento sísmico.

Esta asunción puede no ser válida para el caso de estructuras que presenten una rigidez significativamente diferente a la rigidez del suelo al que sustituyen. Resulta razonable pensar que una estructura mucho más rígida que el suelo en el que está excavada se deformará menos que este durante un terremoto, y que por lo tanto obligará a deformarse menos al terreno adyacente de lo que se deformaría si no existiera dicha estructura. De manera recíproca, resulta razonable pensar que una estructura mucho más flexible que el suelo en el que está excavada se deformará más que este durante un terremoto, y que por lo tanto obligará a deformarse más al terreno adyacente de lo que se deformaría si no existiese estructura. De esta manera, parece lógico pensar que la presencia de una estructura enterrada puede alterar ampliamente el estado deformacional del terreno circundante, y por lo tanto afectar de manera significativa en el estado de plastificación del mismo. 
Uno objetivo de esta tesis será el estudio de bajo qué circunstancias puede darse alguno de estos escenarios, y cuál es la acción sísmica resultante en cada uno de ellos.

Adicionalmente, se pretende desarrollar un método simplificado que, integrándose en el marco conceptual indicado en el apartado §2.2.2, sea capaz de reproducir con una precisión razonable los resultados obtenidos mediante modelos numéricos de elementos finitos que consideren el comportamiento no lineal del terreno.

\subsubsection{Criterios de proyecto para el diseño sismorresistente de estaciones de metro. Niveles de demanda y de desempeño}

Como se verá a lo largo de la tesis, los criterios concretos de diseño, en forma de niveles de demanda y de desempeño, que se establecen en las diferentes normativas internacionales no son homogéneos.

Aunque cada autoridad reguladora es competente para fijar tanto los niveles de intensidad sísmica, como los de capacidad resistente, para los que debe diseñarse una estructura, la profusión de criterios hace que estructuras subterráneas similares puedan presentar expectativas de comportamiento diversas para un mismo escenario sísmico, en función de la entidad que promueva su construcción.

Un objetivo de esta tesis será analizar el cuerpo de criterios actualmente existente, y hacer una propuesta unificada de parámetros de diseño para el proyecto sismorresistente de estaciones de metro construidas por el método de cut-and-cover. Estos criterios se concretarán en la definición de niveles de demanda en términos probabilistas, en la definición de niveles de desempeño, y en la definición de umbrales de daño en los materiales estructurales que correspondan a estos niveles de desempeño.

\subsection{Planteamiento del estudio}

Para alcanzar los objetivos enunciados en el apartado §2.2 se empleará la siguiente metodología:

1. Se realizará un estudio detallado de la bibliografía técnica publicada acerca de los diferentes aspectos que se consideren relevantes en el análisis de los fenómenos en estudio. Esencialmente estos son:

- Un estudio de las metodologías actuales de análisis de esfuerzos debidos a la acción sísmica sobre estructuras enterradas. 
- Un estudio de las diversas aproximaciones al fenómeno de la plastificación del terreno bajo la acción sísmica.

2. Se realizará un conjunto de análisis numéricos mediante el código de elementos finitos OpenSEES desarrollado en University of California, Berkeley. Este conjunto de análisis, de complejidad creciente, tendrá los siguientes objetivos:

- Comparar los resultados obtenidos en los modelos aquí desarrollados, bajo las hipótesis descritas en la bibliografía técnica, con los resultados presentados en esta misma bibliografía, con el propósito de reproducir los resultados y ganar un conocimiento más profundo de los mecanismos resistente-deformacionales subyacentes.

- Realizar un estudio paramétrico de un conjunto de modelos, con diferentes geometrías y propiedades mecánicas de la estructura enterrada y del terreno circundante, considerando que el problema es asimilable a un problema bidimensional de deformación plana, tanto en régimen elástico como elasto-plástico del terreno. El objetivo de este análisis es estudiar la respuesta mecánica conjunta de suelo y estructura en términos de deformaciones y esfuerzos, así como la influencia de la eventual plastificación del terreno alrededor de la estructura enterrada.

3. En base a los resultados analíticos de los modelos bidimensionales de deformación plana, se plantearán formulaciones para el análisis del problema lo suficientemente sencillas como para ser abordables desde el punto de vista de la práctica diaria de la ingeniería en la fase de proyecto de la estructura subterránea.

\subsection{Contenido de esta tesis}

Para abordar los objetivos enumerados anteriormente, esta tesis se ha estructurado en 10 capítulos cuyo contenido se describe a continuación.

En el capítulo $§ 1$ se plantea la motivación que lleva al planteamiento del estudio, así como se resumen aspectos generales de la tesis. 
En el capítulo $\S 2$ se especifican los objetivos concretos que se plantea estudiar en esta tesis, describiendo el alcance de los problemas a tratar, estableciendo la metodología para su estudio, y planteando las metas que cabría esperar alcanzar.

En el capítulo $\S 3$ se revisa en detalle el estado del arte en lo que respecta al diseño sismorresistente de estructuras subterráneas asimilables a una estación de metro. Se parte de una descripción de la metodología de construcción cut-and-cover, de los aspectos específicos relativos a la determinación de la acción del sismo en las obras subterráneas, de los métodos probabilistas de obtención de la acción del sismo, y de la filosofía de diseño basada en el desempeño. En particular se hace una revisión histórica de los métodos de análisis de estructuras de contención de tierras, tanto para estados de empuje estáticos como dinámicos, y se presentan los métodos actuales de análisis de la acción sísmica en obras subterráneas. Adicionalmente se hace una revisión crítica de la normativa internacional más avanzada al respecto.

En el capítulo $\S 4$ se estudia el comportamiento deformacional en régimen elástico de estructuras rectangulares subterráneas profundas bajo la acción del sismo, y se propone un método simplificado para analizar dicho comportamiento. Asimismo, se hace una comparación crítica de los resultados obtenidos mediante este método simplificado propuesto, con los resultados de una colección de análisis numéricos mediante elementos finitos, y con los resultados de métodos simplificados propuestos por otros autores.

En el capítulo $§ 5$ se estudia el comportamiento en términos de esfuerzos internos (momentos flectores y esfuerzos cortantes), en régimen elástico, de estructuras rectangulares subterráneas profundas bajo la acción del sismo, y se propone un método simplificado para analizar dichos esfuerzos. Asimismo, se hace una comparación crítica de los resultados obtenidos mediante este método simplificado propuesto, con los resultados de una colección de análisis numéricos mediante elementos finitos, y con los resultados de métodos simplificados propuestos por otros autores.

En el capítulo $§ 6$ se estudia la influencia de la no linealidad del terreno en el comportamiento deformacional estructuras rectangulares subterráneas bajo la acción del sismo, y se propone un método simplificado que, junto con el método descrito en el capítulo $\S 4$, es capaz de abordar de manera sencilla el fenómeno de interacción sueloestructura en régimen no lineal. Asimismo, se hace una comparación crítica de los resultados obtenidos mediante este método simplificado propuesto, con los resultados de 
una colección de análisis numéricos mediante elementos finitos, y con los resultados de métodos propuestos por otros autores.

En el capítulo $§ 7$ se estudia la influencia de la proximidad de la estructura subterránea a la superficie del terreno, y se plantean modificaciones racionales a los métodos simplificados planteados en los capítulos $\S 4$ y $\S 5$, para el análisis deformacional de la estructura subterránea y obtención de los esfuerzos internos respectivamente.

En el capítulo $\S 8$ se proponen, en base a los criterios dispares de la normativa internacional, una base común de criterios para el proyecto sismorresistente de estaciones de metro construidas por el método de cut-and-cover, en términos de definición probabilista de niveles de demanda, y de aspectos concretos de limitación de daño en los materiales para diferentes niveles de desempeño.

En el capítulo $\$ 9$ se resumen las principales conclusiones obtenidas en esta tesis, y se describen sus principales aportaciones.

En el capítulo $§ 10$ se plantean algunas posibles líneas futuras de investigación.

En el capítulo $§ 11$ se incluye la bibliografía técnica considerada en esta tesis.

Para concluir, se incluyen tres apéndices. El apéndice §A complementa al capítulo $\S 5$, y en él se deriva una expresión analítica para la rigidez a la distorsión de un marco elástico con una condición de fundación elástica de Winkler en sus elementos estructurales. El apéndice $\S \mathrm{B}$ complementa al capítulo $\S 6$, y en él se incluyen, en forma de gráficos, todos los resultados de deformaciones de distorsión de los análisis no-lineales desarrollados en este capítulo. El apéndice $§ C$ complementa al capítulo §7, y en él se incluyen, en forma de gráficos, todos los resultados de deformaciones de distorsión, de momentos flectores, y de esfuerzos cortantes de los análisis desarrollados en este capítulo. 


\section{REVISIÓN DEL ESTADO DEL CONOCIMIENTO}

\subsection{Metodologías habituales de construcción de estaciones de Metro}

Una de las metodologías más empleadas para la construcción de obras subterráneas, si el planeamiento de esta está lo suficientemente cerca de la superficie del terreno, es mediante la técnica denominada de Cut-and-Cover (cortar y cubrir). Este procedimiento constructivo presenta las numerosas ventajas frente a otras técnicas de ejecución como puede ser la excavación en mina (López-Jimeno, 2003):

- Facilita el acceso a la superficie de excavación.

- Presenta menor riesgo de derrumbe durante la excavación, ya que se cuenta con una estructura de contención del terreno ejecutada previamente a la fase de excavación del espacio principal.

- Resulta, en muchos casos, más económica, ya que los medios auxiliares son más convencionales que los correspondientes a la excavación en mina.

- Se cuenta desde la fase inicial de excavación con una cubrición de la misma, que hace poco susceptible al fondo de la excavación a las condiciones meteorológicas de la superficie.

\subsubsection{El método de Cut-and-Cover}

El método de construcción de obras subterráneas denominado Cut-and Cover, consiste esencialmente en la excavación del espacio subterráneo de la infraestructura tras la ejecución de una estructura de contención del terreno. Las fases principales de la construcción son las siguientes (López-Jimeno, 2003) (Fig. 3-1):

- FASE 1: Excavación del terreno hasta la cota inferior de la losa superior de cubrición de la obra. La excavación se realiza mediante medios convencionales. 
- FASE 2: Ejecución de las pantallas laterales de contención. Las diferentes tipologías estructurales de pantallas más habituales se detallan en el apartado $\S 3.1 .2$. Estas pantallas se ejecutan desde la superficie mediante pantalladoras o pilotadoras, que excavan el terreno, para después insertar en la oquedad la armadura pasiva, y proceder en última fase al hormigonado de la pantalla, habitualmente mediante el empleo de tubos tremie que permiten el bombeo del hormigón desde la cota inferior de la pantalla.

- FASE 3: Ejecución de la losa de cubrición. Se procede al armado y hormigonado de la losa que cubre superiormente el túnel, empleando como apoyo del encofrado inferior el propio terreno superficial que todavía no se ha excavado.

- FASE 4: Excavación del terreno hasta la cota intermedia de estampidores. Si la cota de fondo de la obra es superior al entorno de los 10-12 m, resulta necesario realizar la excavación de la obra en dos etapas, colocando un nivel intermedio de puntales de arriostramiento denominados estampidores. El empuje lateral de las tierras es elevado a esta profundidad, y no resulta económicamente viable profundizar más la excavación sin colocar un nivel de apoyos intermedios. Este nivel de apoyos puede ser una losa que se emplee en la fase definitiva de la obra, siendo por ejemplo la planta de vestíbulo de una estación de metro.

- FASE 5: Ejecución del estampidor. Este puntal, que resiste esencialmente los esfuerzos axiles debidos al empuje lateral de tierras, se equilibra de uno y otro lado de sus apoyos en las pantallas por los propios empujes simétricos de tierras. Los esfuerzos del estampidor evolucionan desde un axil nulo en el momento de su construcción, hasta un axil máximo en el momento en el que se termina de excavar la obra.

- FASE 6: Excavación hasta el nivel de contrabóveda. Se continúa excavando bajo el nivel de estampidores hasta alcanzar el nivel de mayor de profundidad donde se ejecutará la contrabóveda.

- FASE 7: Ejecución de la contrabóveda. Se arma y hormigona la losa inferior de la obra subterránea, denominada habitualmente de contrabóveda.

- FASE 8: Ejecución del relleno sobre losa de cubrición. 

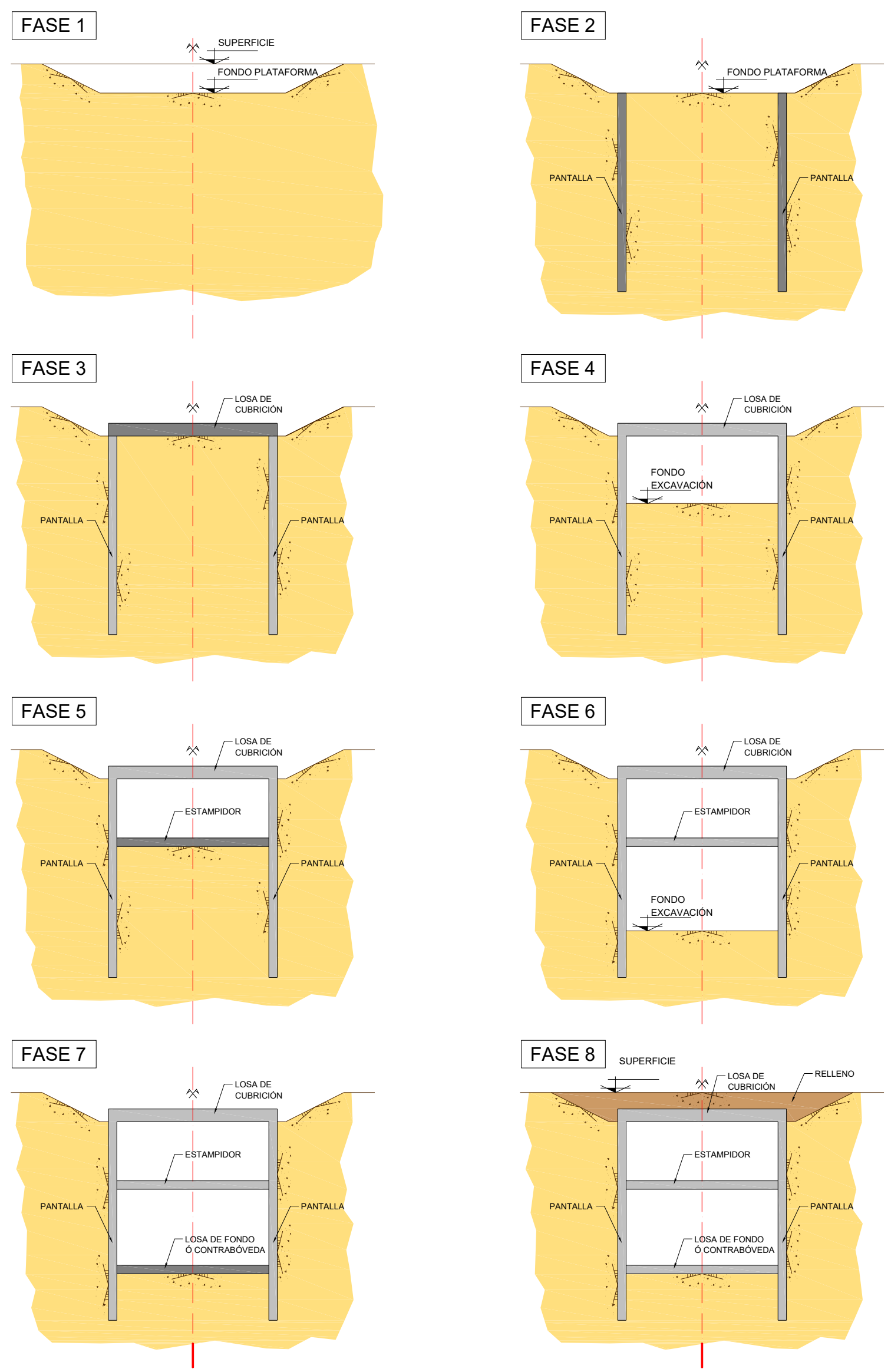

Fig. 3-1. Proceso constructivo de Cut-and-Cover 


\subsubsection{Tipologías habituales de pantallas de contención}

Las pantallas laterales de contención de tierras que delimitan la extensión transversal de las obras construidas por el método de Cut-and-Cover suelen pertenecer a la categoría de pantallas de hormigón ejecutadas in situ, bien sea mediante el uso de pantalladoras o mediante el uso de pilotadoras. En función de esta maquinaria auxiliar de ejecución que se emplee se obtienen pantallas de contención de características mecánicas diferentes (Fig. 3-2):

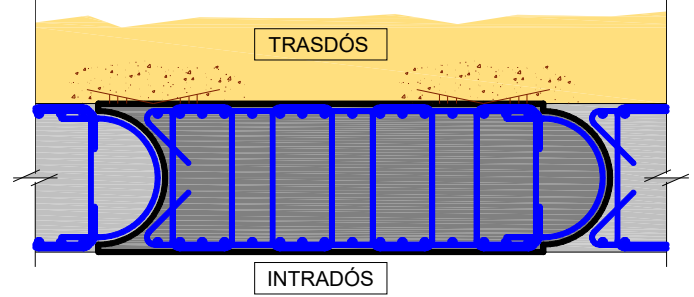

a) Pantalla Continua

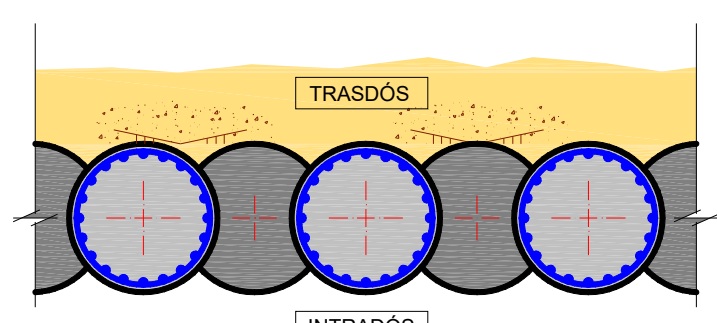

c) Pilotes Secantes

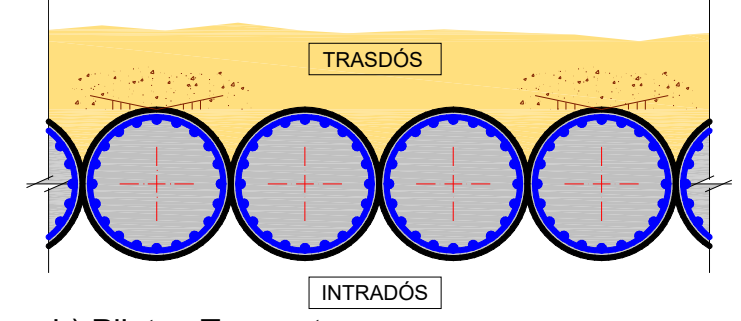

b) Pilotes Tangentes

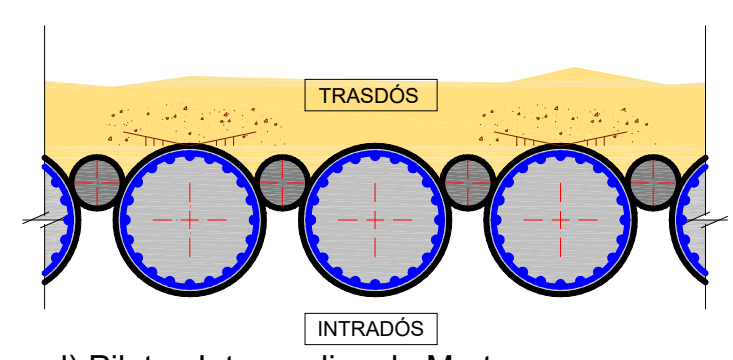

d) Pilotes Intermedios de Mortero

Fig. 3-2. Secciones transversales de tipologías de pantallas de contención

- Pantalla continua: La pantalla continua se ejecuta tras la excavación con una cuchara de sección rectangular, que permite excavar tramos regulares de aproximadamente 3,00 $\mathrm{m}$ de longitud. La contención del terreno durante la ejecución suele realizarse mediante la inundación de la oquedad con lodos bentoníticos (Brown et al., 2010). Tras la excavación se introduce la armadura del tramo de pantalla a ejecutar, y posteriormente se hormigona mediante el uso de tubos tremie desde la cota inferior de pie de pantalla hasta la cota superior de coronación. Puesto que el hormigón es más denso que el lodo empleado para la contención de tierras, a medida que se hormigona la pantalla se expulsan por la parte superior estos lodos bentoníticos. Mecánicamente, la sección transversal de la pantalla queda constituida por una sucesión continua de módulos sin ningún tipo de armadura pasante entre ellos (Fig. 3-2-a) que, sin embargo, cuentan con 
una forma de encofrado tal que permite la vinculación a esfuerzo cortante de los diferentes módulos de la pantalla en sentido perpendicular al plano.
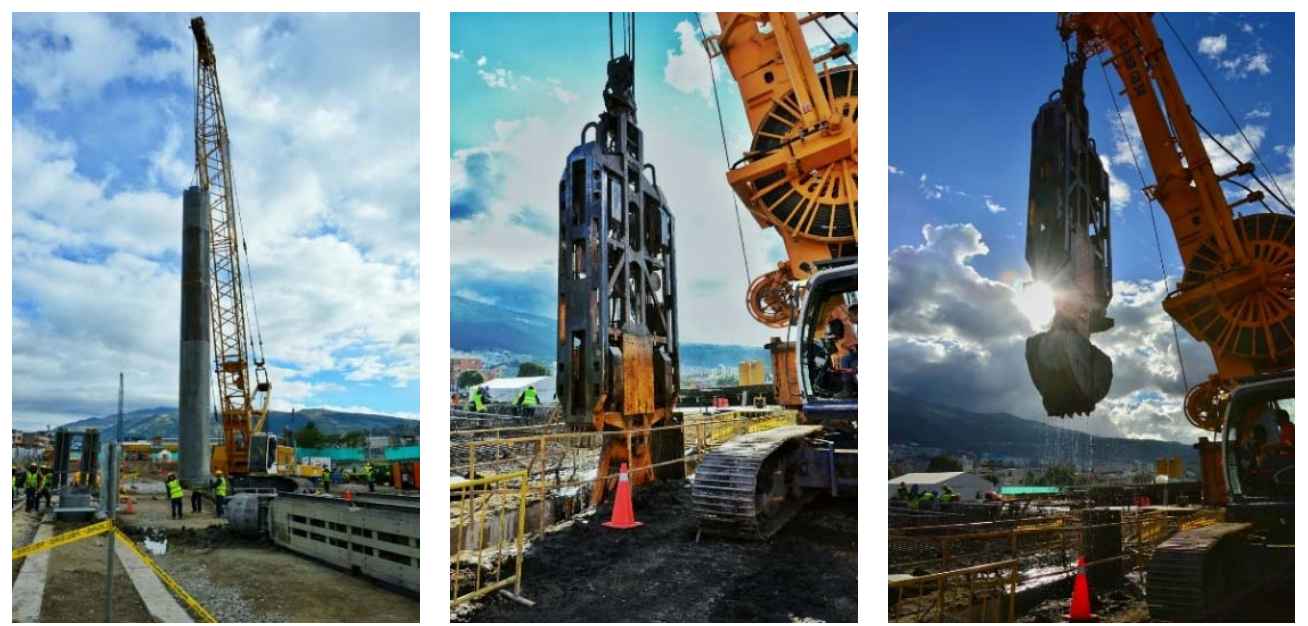

Fig. 3-3. (izda.) Inserción de tubo guía. (cent.) Cuchara de pantalladora introduciéndose en la zanja.

(dcha.) Cuchara bivalva extrayendo terreno excavado. (Metro de Quito)

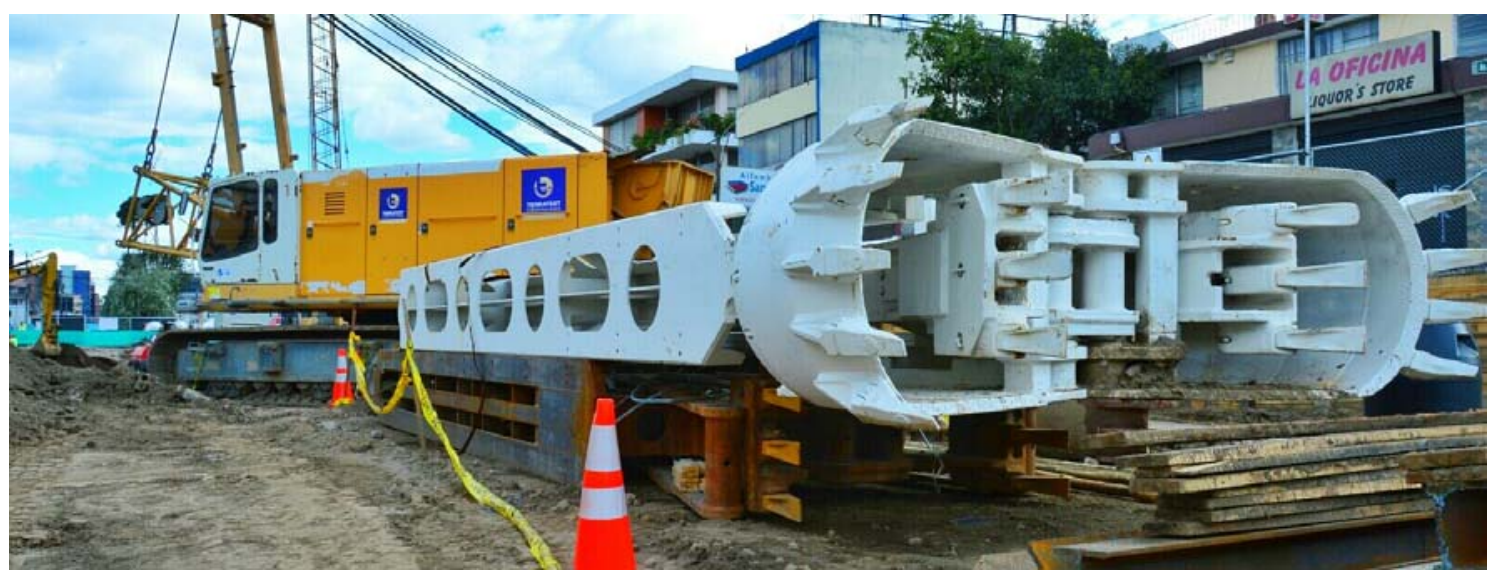

Fig. 3-4. Detalle de la cuchara bivalva de excavación de pantallas. (Metro de Quito)

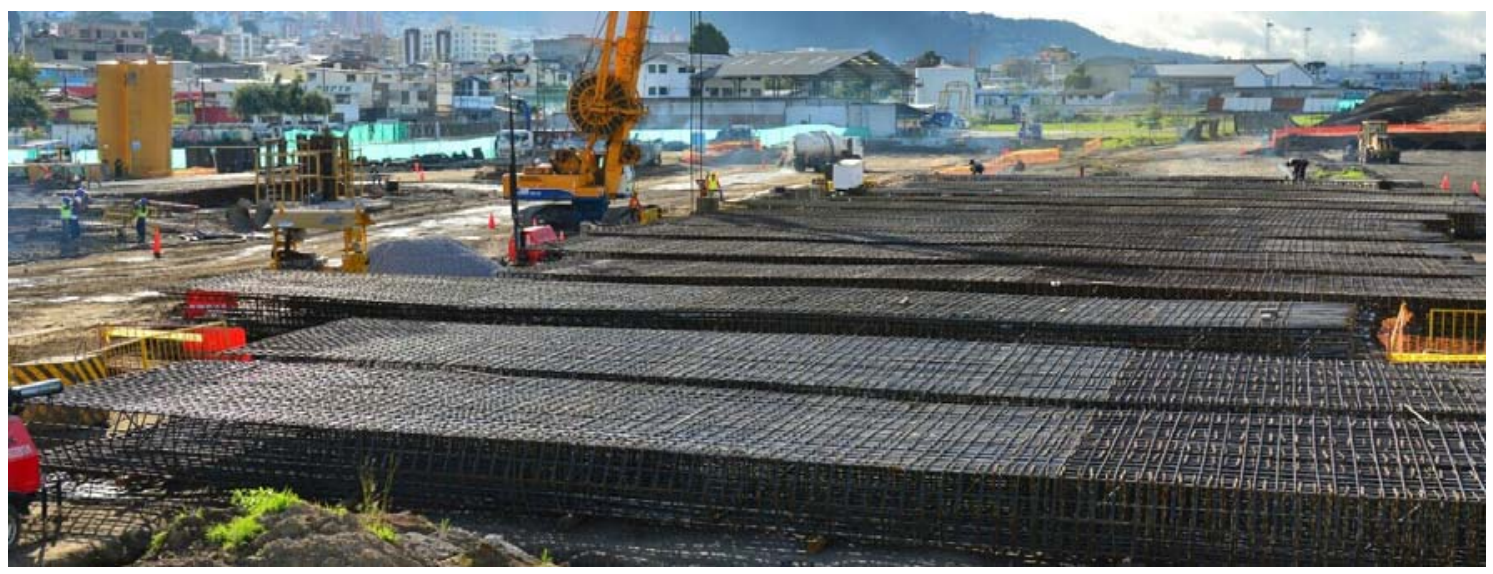

Fig. 3-5. Armadura de pantallas acopiada en posición horizontal, preparada para ser izada e insertada verticalmente en la excavación en la que se hormigonará la pantalla. (Metro de Quito) 
- Pantalla de pilotes: La pantalla de pilotes se ejecuta mediante la construcción consecutiva de pilotes en hilera, bien sean estos tangentes, secantes, o separados (Fig. 3-2 y Fig. 3-6). Los pilotes se ejecutan mediante una pilotadora convencional, y mediante el procedimiento de contención de tierras que resulte más apropiado al terreno que excave y condiciones del nivel freático (con camisa recuperable, con lodos bentoníticos, o con una combinación de ambos). Una vez excavado el terreno, se introduce la jaula de armadura pasiva en la oquedad, y se hormigona mediante el uso de tubos tremie. Mecánicamente la sección transversal de pantalla queda constituida por una sucesión continua de pilotes sin ningún tipo de armadura pasante entre ellos. En ninguno de los tres casos de disposición geométrica de pilotes (secantes, tangentes o separados) hay vinculación mecánica entre las secciones, en el sentido de que no hay armadura horizontal de rasante.
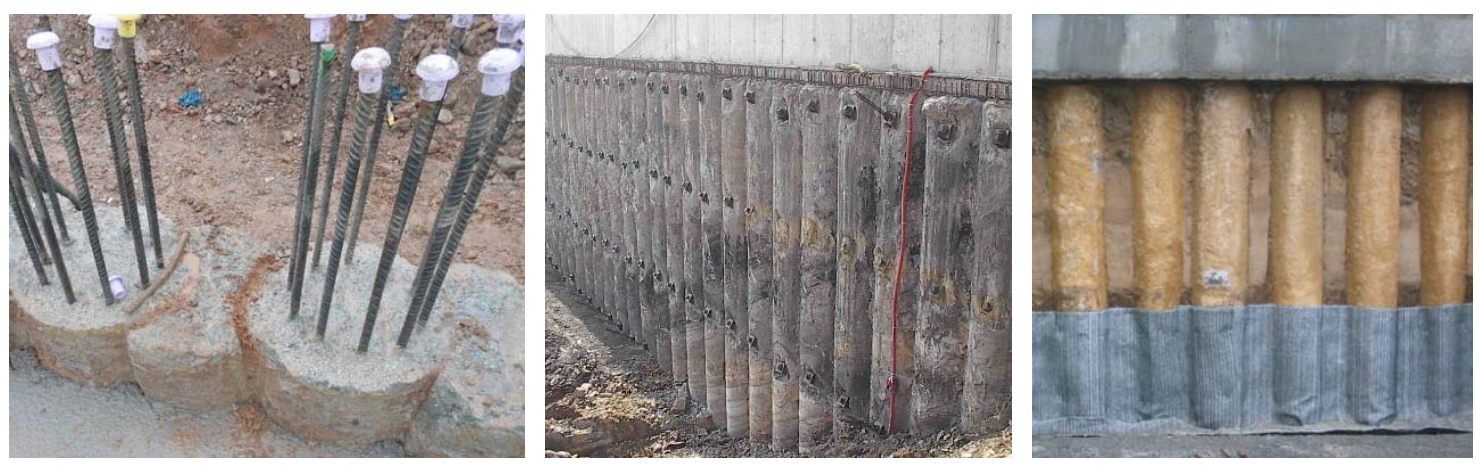

Fig. 3-6. Pantallas de pilotes. (izda.) Secantes. (cent.) Tangentes. (dcha.) Separados.
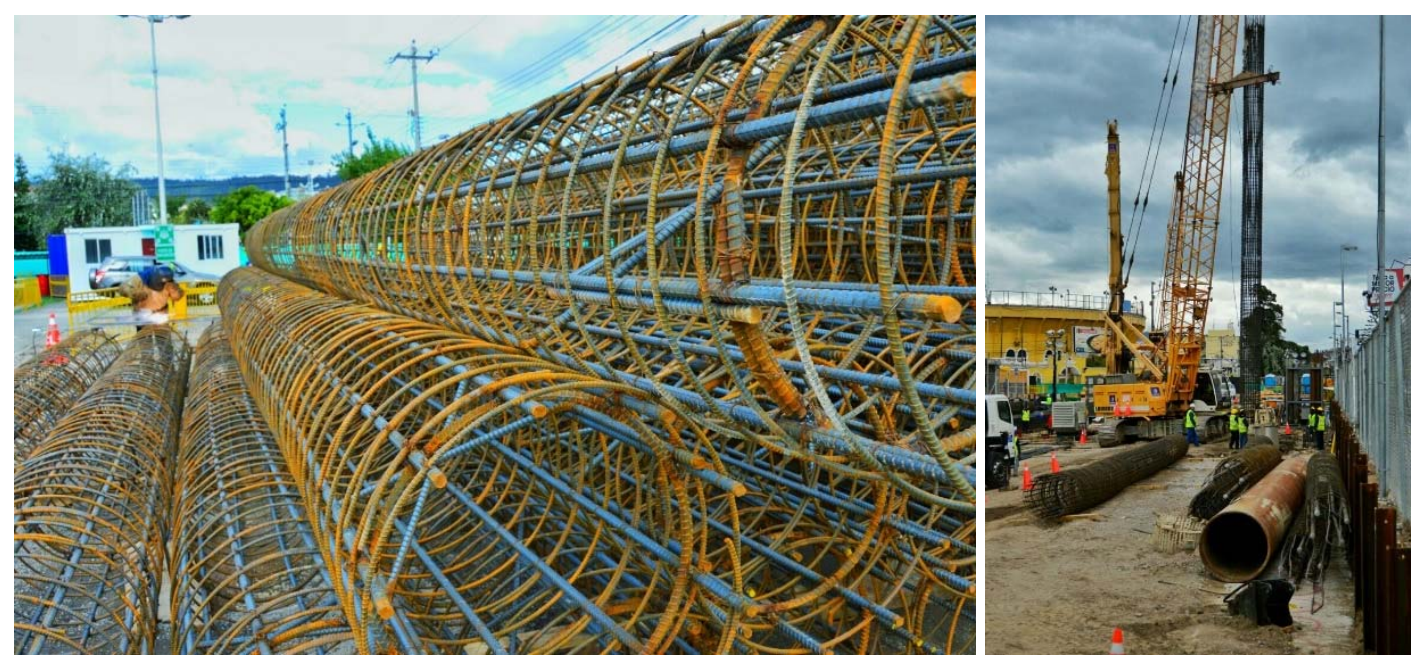

Fig. 3-7. (izda.) Armadura de pantalla e pilotes. (dcha.) Inserción de la armadura del pilote. 


\subsubsection{Especificidades tipológicas y constructivas de estaciones de Metro}

Las estaciones de ferrocarril suburbano suelen albergar espacios diáfanos de forma rectangular en los que la dimensión mayor en planta viene impuesta en muchos casos por la máxima longitud del tren que accede a la estación, mientras que la dimensión transversal está condicionada por aspectos funcionales relacionados con el gálibo horizontal de los trenes, la anchura de los andenes necesaria para albergar un número suficiente de viajeros de manera segura, y la anchura de las escaleras y rellanos de acceso a los andenes. Las figuras (Fig. 3-8) y (Fig. 3-9) muestran dos ejemplos visuales de las dimensiones típicas de estas obras, en alzado y en planta.
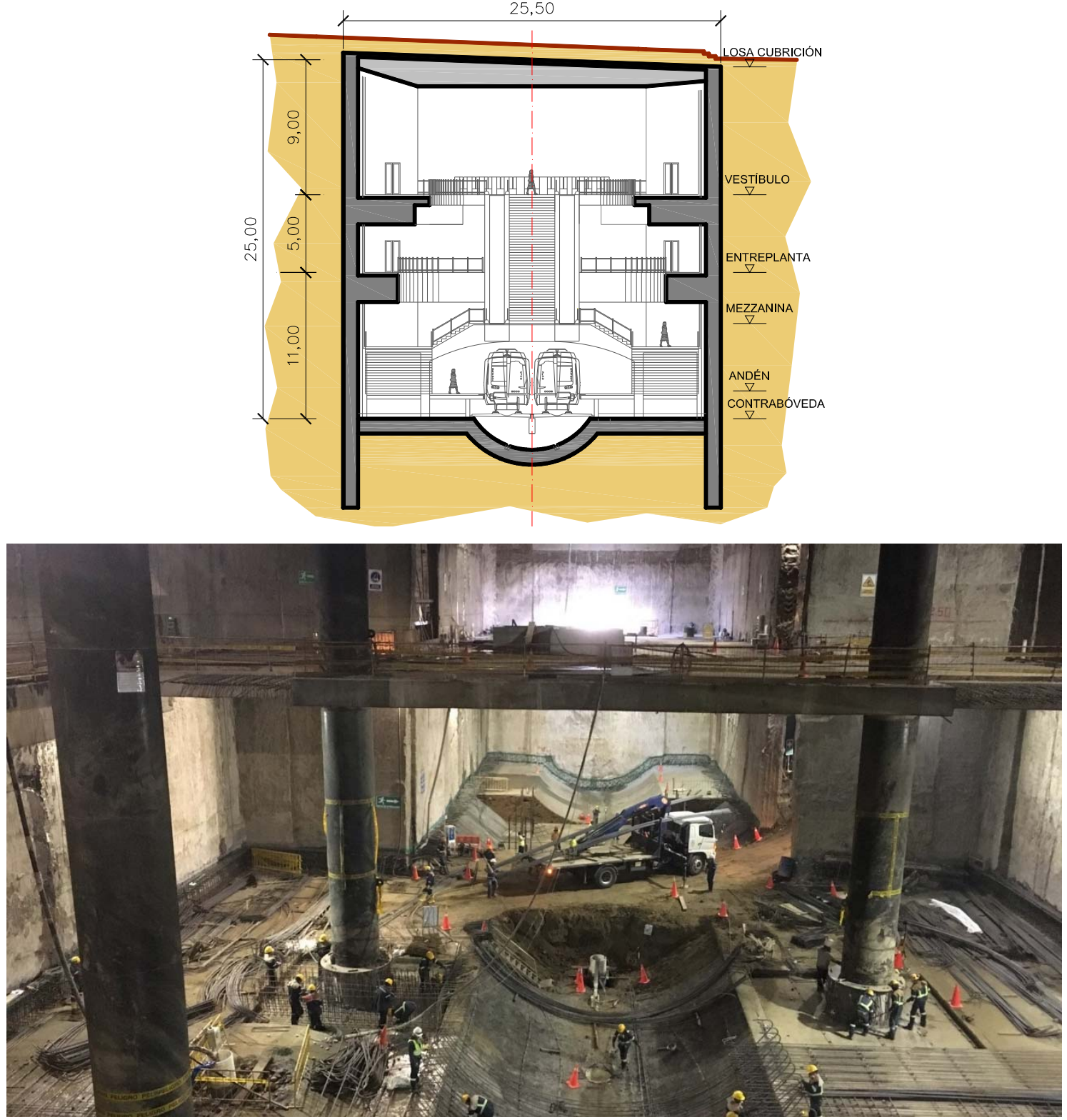

Fig. 3-8. Dimensiones en alzado de una estación típica de metro (sup.) Sección transversal. (inf.) Vista del nivel de contrabóveda durante la construcción. (Metro de Quito) 

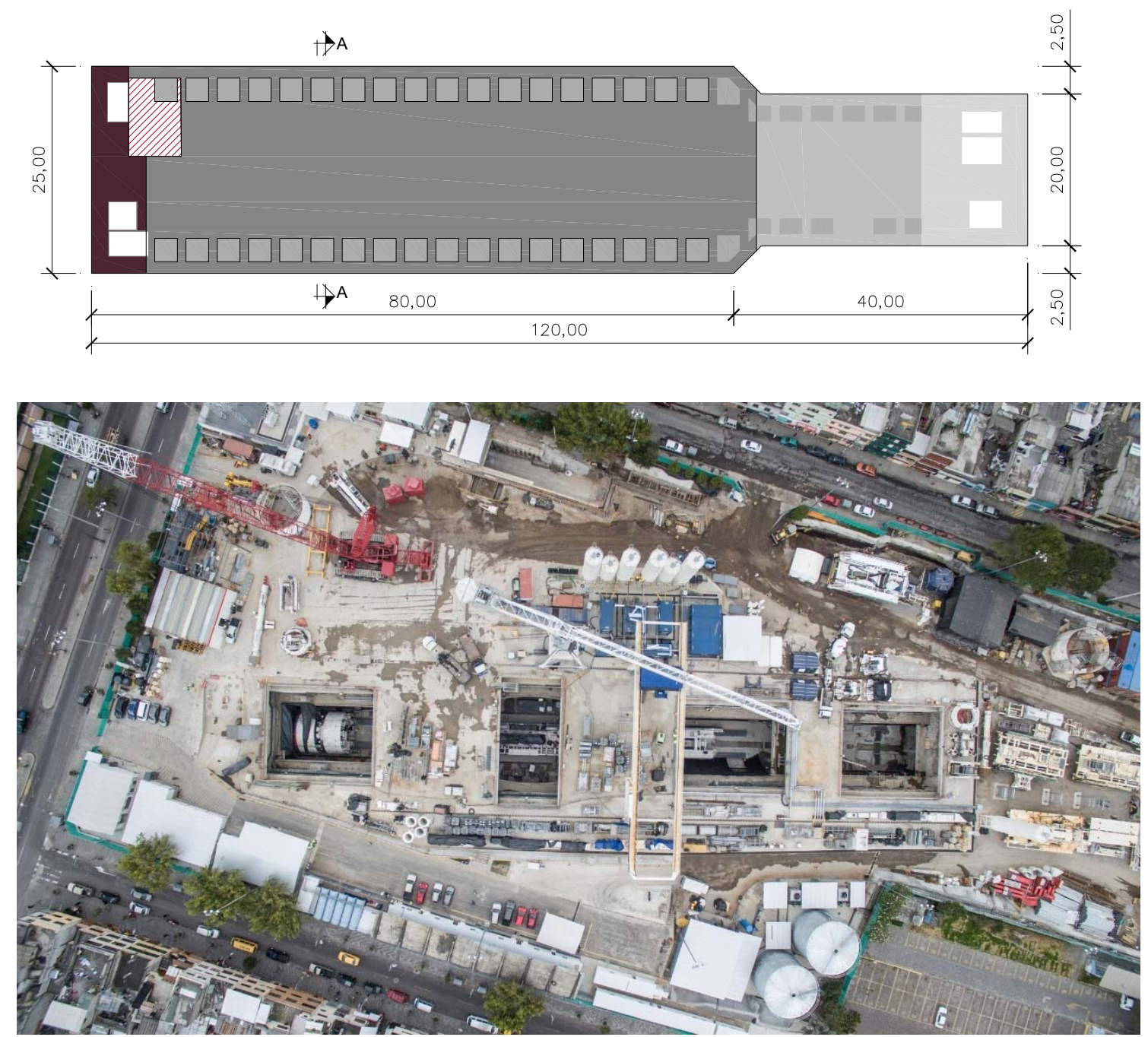

Fig. 3-9. Dimensiones en planta de una estación típica de metro (sup.) Esquema en Planta de losa de cubrición. (inf.) Vista en planta durante la construcción. (Metro de Quito)

En alzado, las estaciones de Metro suelen contar con al menos dos niveles bajo la superficie, y en ocasiones hasta un tercero (Fig. 3-8). El número de niveles está por lo general determinado tan sólo por la profundidad a la que discurra la línea de Metro. El nivel superior es el denominado vestíbulo, al que acceden los viajeros desde la superficie, donde se distribuye la circulación de pasajeros, y donde se ubican los tornos de acceso y otros servicios accesorios. El nivel inferor o de contrabóveda (invert slab, en literatura anglosajona) es sobre el que circula el tráfico ferroviario, y donde se sitúan los andenes de acceso a los convoyes. Los niveles intermedios, en el caso de que existan, se ejecutan para que sirvan de puntos de compensación de empujes entre pantallas de uno y otro lado de la estación, a modo de puntales o estampidores.

Si el túnel se ejecuta mediante tuneladora (TBM, Tunnel Boring Machine), es habitual que se construya el recinto en planta de la estación, de forma más menos 
rectangular, antes de la llegada de la tuneladora, mediante alguna de las tipologías de pantallas descritas en $§ 3.1 .2$, y se proceda a excavar el interior del espacio siguiendo el esquema de la Fig. 3-1. Para que la tuneladora pueda acceder con seguridad al interior de la estación, en la operación denominada de "cale", es necesario tomar dos medidas:

- La zona de pantalla del emboquille por donde entrará la tuneladora a la estación no puede armarse con barras habituales de acero. De hacerse así, este acero dañaría el frente de la tuneladora, y esta no podría atravesar la jaula de metal. Es frecuente que el tramo de pantallas correspondiente al emboquille se arme con barras de fibra de vidrio, un material con resistencia apropiada pero muy frágil, de tal manera que frente a la llegada de la tuneladora se corta y rompe con facilidad, permitiendo el acceso de esta a la estación (Fig. 3-10, izda).

- En caso de que la estación esté por debajo del nivel freático, para evitar que el agua entre en la estación por la oquedad de la tuneladora, es habitual ejecutar una estructura auxiliar denominada "corralito" (Fig. 3-10, dcha.), consistente en una pantalla contínua de mortero, y hormigón sin armadura, que rodea el emboquille, en cuyo interior se ejecutan pilotes de mortero adicionales. De esta manera se obtiene una estructura estanca en la que es posible agotar el agua mediante pozos de drenaje. Adicionalmente, mediante los pilotes de mortero se consigue que el terreno del trasdós del emboquille tenga una "cohesión aparente" que evite los empujes excesivos sobre la pantalla (Oteo-Mazo, Moreno-Jiménez, Arozamena-Cagigal, \& Díez-Fernández, 2009).
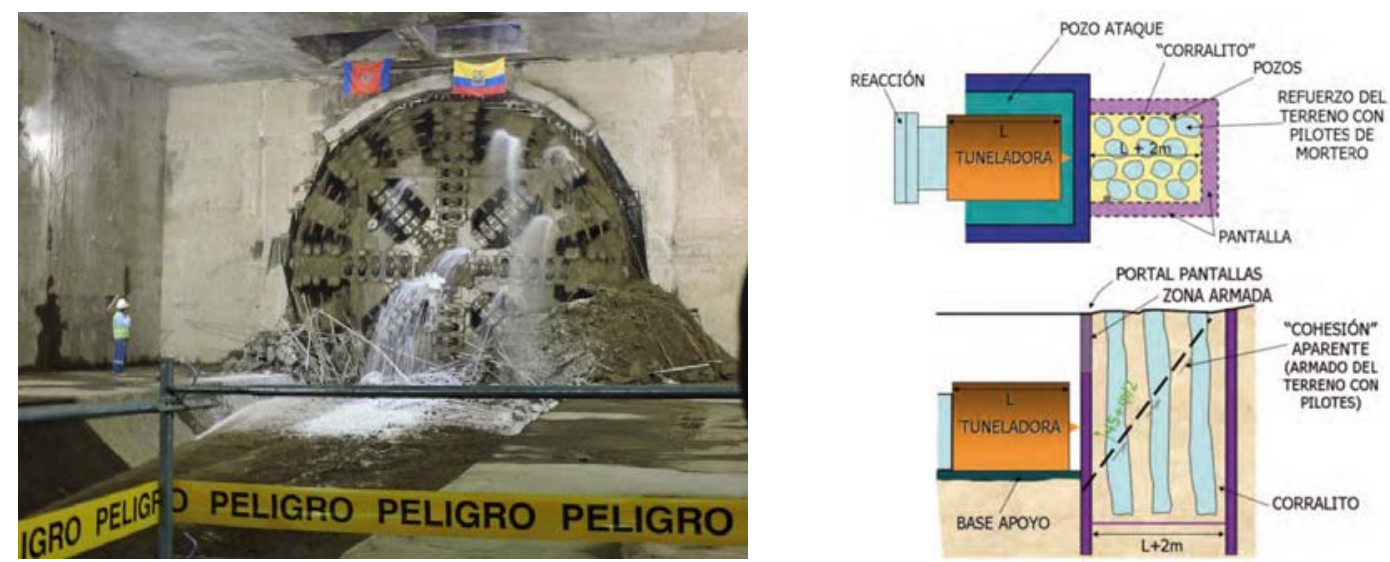

Fig. 3-10. (izda.) Operación de cale de la tuneladora en la estación, con detalle de la armadura de fibra de vidrio (Metro de Quito). (dcha.) Croquis en planta y alzado del recinto en "corralito" (Oteo-Mazo et al., 2009). 


\subsection{El proyecto sismorresistente de estructuras en superficie}

La acción sísmica se caracteriza por el movimiento rápido del terreno, tanto en dirección horizontal como en dirección vertical. Estos movimientos del terreno se transmiten a las obras que se cimientan sobre él, y, a pesar de que como se ha mencionado los movimientos ocurren en todas las direcciones del espacio, son los horizontales los que revisten un carácter más relevante de cara al diseño sismorresistente.

La acción principal que condiciona el diseño de estructuras en superficie es la gravedad, motivo por el cual las estructuras se proyectan y construyen para contar con mecanismos suficientes, y muy a menudo redundantes, para hacer frente a las acciones verticales de su peso propio, cargas muertas y sobrecargas de uso. Si bien la consideración de la acción vertical del sismo debe suponer una revisión de los planteamientos estructurales que se establecen para hacer frente a dichas cargas verticales, normalmente estos mismos mecanismos son suficientes para soportar los efectos verticales de los terremotos.

Sin embargo, no es este el caso para los efectos horizontales de los sismos. Las acciones horizontales (aparte de las sísmicas) que solicitan una estructura son proporcionalmente mucho menores que las verticales (esencialmente viento, y en puentes sobrecargas horizontales de tráfico como frenado de vehículos o fuerza centrífuga). Por esta razón, la consideración del sismo en dirección horizontal suele entrañar el diseño específico de ciertas medidas y disposiciones constructivas que le hagan frente y que no se encuentran en obras sin riesgo de sufrir la acción sísmica (como pueden ser pantallas $\mathrm{y}$ arriostramientos en los edificios o pórticos, pilas resistentes, o amortiguadores mecánicos frente a las acciones horizontales en los puentes).

Por otra parte, la acción sísmica difiere de manera fundamental del resto de acciones a las que se encuentra sometida una estructura en lo que se refiere a su propia naturaleza. Cuando se contemplan las acciones habituales, ya sean pesos, sobrecargas de tráfico, viento, etc. estas se establecen en términos de cargas impuestas conocidas a priori, frente a las cuales el diseño de la estructura deberá aportar una distribución de rigidez y de resistencia suficientes como para alcanzar el equilibrio de las mismas y satisfacer los criterios de aptitud al servicio. Sin embargo, la acción sísmica es radicalmente diferente, ya que se trata de una acción engendrada por la propia estructura y sus características mecánicas, no hay conocimiento a priori de las cargas de sismo, en el sentido de que no 
existe un conjunto de cargas impuestas o de deformaciones impuestas, conocido de antemano, que corresponda a la acción que ejercerá previsiblemente un sismo sobre la estructura.

\title{
3.2.1 El espectro de respuesta en superficie
}

El método más habitual para establecer la acción que un sismo ejerce sobre una determinada estructura en superficie es a través de un espectro de respuesta. El método, concebido originalmente por Biot (Biot, 1934), no fue adoptado de manera extensiva hasta la década de los años 70 del s. XX debido esencialmente a la falta, en la época, de registros sísmicos a partir de los cuales obtener los espectros y a la enorme complejidad de cálculo que suponía en aquel momento obtener un espectro de respuesta (Trifunac, 2006).

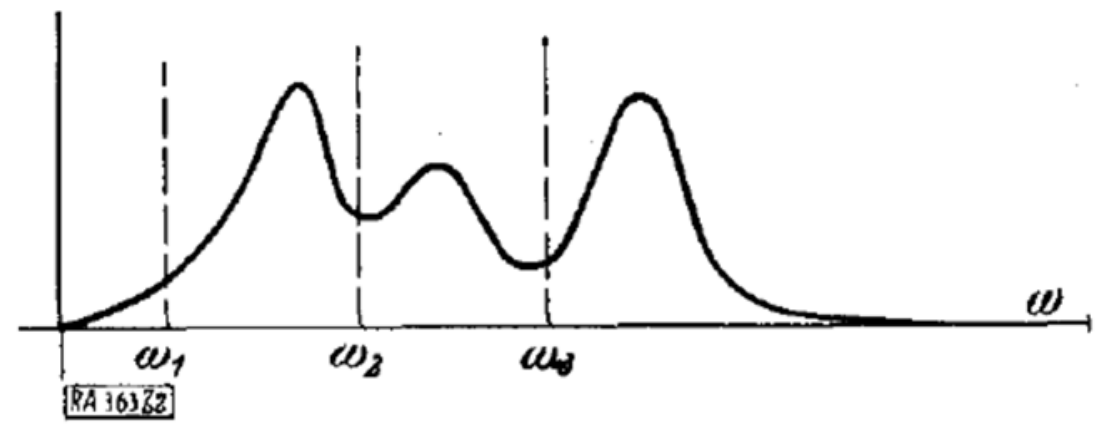

Fig. 2.

\begin{abstract}
According to recent observations ${ }^{3}$ ) there seems to exist characteristic frequencies of the ground at given locations. These frequencies would be given by the peaks in the spectral curve.

If we possessed a great number of seismogram spectra we could use their envelope as a standard spectral curve for the evaluation of the probable maximum effect on buildings. The spectral curves would be of interest as much to seismologists as to civil engineers.

The direct computation of such spectra might be tedious but automatic electrical methods can be easily imagined such as a photographic record passing in front of a photo-electric cell acting upon a tuned circuit.
\end{abstract}

Fig. 3-11. Figura y texto originales de Biot acerca de la posibilidad de generar espectros de respuesta para determinar la (Biot, 1934).

Un espectro de respuesta de un registro sísmico o acelerograma consiste en un gráfico de los máximos de alguna magnitud de respuesta estructural (generalemente pseudo-aceleración) frente al periodo propio de una estructura lineal de un único grado de libertad (SDOF, Single Degree Of Freedom en la literatura anglosajona). El cálculo de esta magnitud de respuesta máxima se realiza numéricamente, partiendo del registro o acelerograma de un evento sísmico $a_{g}(t)$, e integrando la ecuación diferencial del movimiento (Ec. 3-1) mediante alguna técnica numérica (Clough \& Penzien, 1993; 
Chopra, 2007; Humar, 2002). Repitiendo el proceso para diferentes estructuras SDOF caracterizadas por diferentes periodos, se consigue la representación gráfica del espectro de respuesta de dicho acelerograma.

$$
\ddot{x}+\frac{c}{m} \dot{x}+\frac{k}{m} x=-a_{g}(t)
$$

Generalmente se obtiene la respuesta en términos de desplazamiento máximo y, asumiendo un comportamiento dinámico en régimen permanente de la estructura, de amplitud la amplitud máxima calculada (Ec. 3-2), se pasa de desplazamiento a pseudovelocidades, y a pseudo-aceleraciones mediante las expresiones (Ec. 3-3) y (Ec. 3-4). En el resto de la tesis se empleará el término de aceleraciones espectrales como equivalente de pseudo-aceleraciones, como es de uso habitual en este campo.

$$
\begin{array}{cc}
x(t)=A_{\text {max }} \cdot \sin (\omega t) & x_{\text {max }}=A_{\max } \\
\dot{x}(t)=A_{\max } \omega \cos (\omega t)=A_{\max } \frac{2 \pi}{T} \cos (\omega t) & \dot{x}_{\max }=A_{\max } \frac{2 \pi}{T} \\
\ddot{x}(t)=-A_{\max } \omega^{2} \sin (\omega t) & \ddot{x}_{\max } \\
=A_{\max }\left(\frac{2 \pi}{T}\right)^{2} \sin (\omega t) & =A_{\max }\left(\frac{2 \pi}{T}\right)^{2}
\end{array}
$$
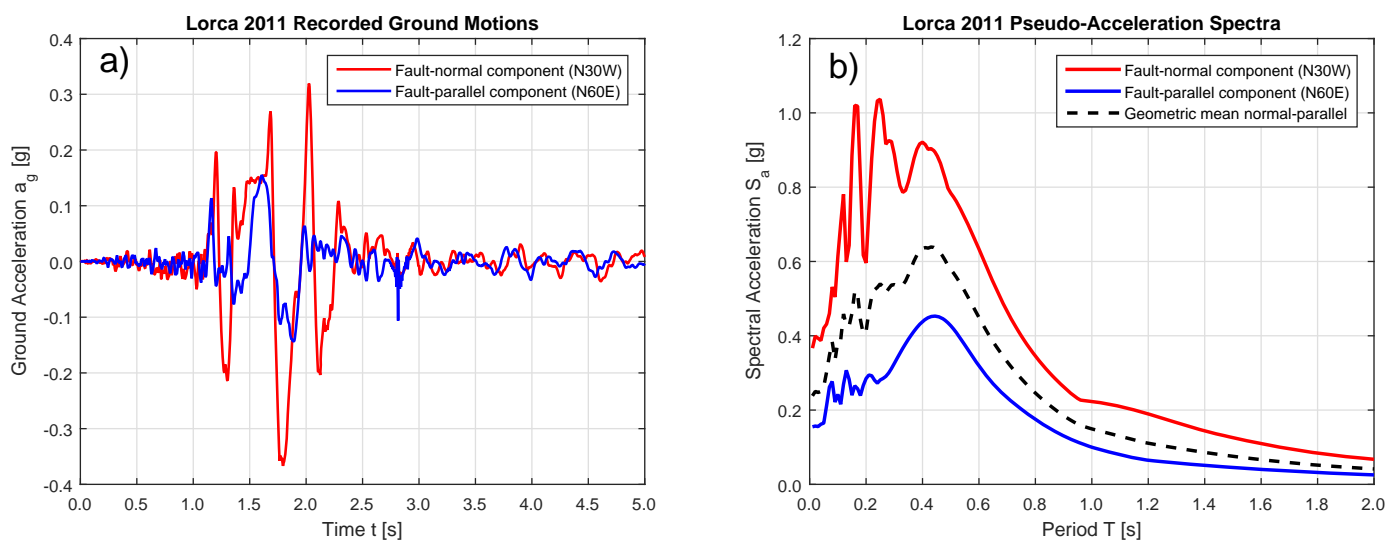

Fig. 3-12. Sismo de Lorca de 2011. (izda.) Acelerogramas registrados en componentes paralela y normal a la falla. (dcha.) Espectros de respuesta de pseudoaceleraciones de los acelerogramas. (Gordo-Monsó \& Miranda, 2018).

Las expresiones de pseudo-velocidad y pseudo-aceleración no proporcionan el valor exacto de la velocidad y aceleración máximas de la estructura, pero son una aproximación precisa de las mismas. La razón que subyace en el empleo de las las pseudo- 
respuestas máximas en lugar de las máximas per-se, es la comodidad y facilidad que representa el pasar de una a otra a través de las expresiones (Ec. 3-3) y (Ec. 3-4), y que la diferencia entre ambas no resulta relevante en la práctica (Chopra, 2007).

Los espectros de respuesta suponen una definición muy eficaz y útil de la acción sísmica, en términos de las pseudo-aceleraciones máximas que experimenta una estructura en superficie sometida al sismo. Conociendo el periodo propio de oscilación $T$ de una determinada estructura, el espectro de respuesta permite deteminar cual será la aceleración fundamental máxima solicitante $S_{a}, \mathrm{y}$ traducir este movimiento a fuerza máxima solicitante $f_{\max }$ multiplicando la aceleración espectral $S_{a}$ correspondiente a dicho periodo por la masa $M$ de la estructura (Ec. 3-5).

$$
F_{\text {max }}=M \cdot S_{a}(T)
$$

Si la masa y rigidez de la estructura se encuentran distribuídas a lo largo de la misma (p.ej. masas de cada planta en un edificio, o masa distribuída a lo largo del tablero de un puente), la estructura contará con más de un modo propio y periodo propio de oscilación. Para estos casos, que en la práctica comprenden la totalidad de las construcciones, el espectro de respuesta sigue siendo una herramiento muy efectiva para determinar la acción sísmica. El movimiento total de la estructura se puede descomponer en la suma de sus varios modos propios de oscilación, y se puede asignar a cada modo la aceleración del especto de respuesta correspondiente a su periodo. El producto de la distribución de masa $[M]$, del patrón de desplazamiento del modo propio $\{\Phi i\}$, de la aceleración espectral $S_{a}(T)$, y de un factor de participación modal $\Gamma$, proporciona la contribución de dicho modo en términos de fuerzas a la respuesta máxima de la estructura (Ec. 3-6). Puesto que resulta improbable que los máximos correspondientes a cada modo y periodo ocurran en el mismo instante de tiempo, se han propuesto diversas reglas de combinación de solicitaciones generadas por cada modo, de entre ellas las más habituales son la regla SRSS (Rosenblueth, 1951) y CQC (Wilson, Der Kiureghian, \& Bayo, 1981), basadas en el análisis estocástico de vibraciones.

$$
\left\{f_{i, \max }\right\}=[M] \cdot\left\{\phi_{i}\right\} \cdot S_{a}(T) \cdot \Gamma_{i}
$$

Este método de análisis es el denominado análisis elástico espectral multimodal, y es el método de análisis habitual en la mayor parte de estructuras de ingeniería civil 
construídas en superficie. El método se describe con detalle en la literatura técnica al uso (Clough \& Penzien, 1993; Chopra, 2007; Humar, 2002) y no se profundizará al respecto.

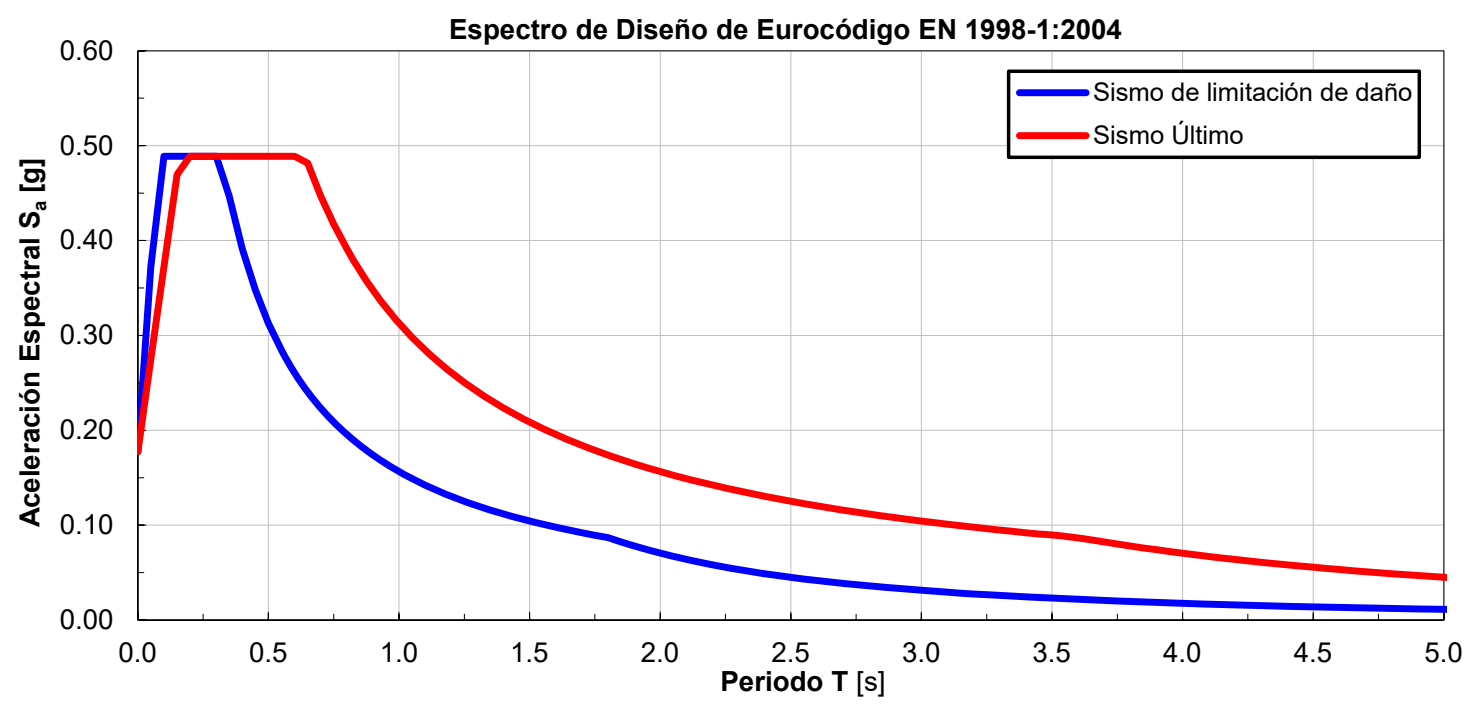

Fig. 3-13. Ejemplo de espectros de diseño del Eurocódigo EN 1998-1:2004.

La práctica totalidad de las normativas de proyecto sismorresistente a nivel mundial establece este método de análisis como la base sobre la que justificar el diseño de una estructura en superficie. Por esta razón, la definición de la acción sísmica en las normativas se realiza a través de espectros de diseño

\subsubsection{Criterios de diseño asumiendo daño en la estructura}

\subsubsection{Espectros de demanda inelásticos}

Casi desde los primeros momentos de la ingeniería sísmica se reconoció que, en aquellas regiones donde los terremotos suponen una amenaza significativa, el diseñar las estructuras para que fueran capaces de resistir elásticamente la acción de un sismo era excesivamente oneroso. Por otra parte, la constatación empírica de que muchas estructuras diseñadas sin criterios sismorresistentes (o con criterios sin base en la dinámica de estructuras, tales como diseñar con una aceleración lateral de $0,1 \cdot \mathrm{g}$ independientemente del periodo de la estructura) sobrevivían a la acción de los terremotos, con daños, pero sin colapsar, llevó al planteamiento de una estrategia de diseño que admitiera el daño en las estructuras (Veletsos \& Newmark, 1960).

A partir de los años 60 del s. XX, con el trabajo pionero de Veletsos y Newmark (Newmark \& Hall, 1982; Veletsos \& Newmark, 1960; Veletsos, Newmark, \& Chelapati, 1965), se plantearon los primeros métodos de análisis sísmico basados en el 
comportamiento inelástico de estructuras, que consideraban como parámetro fundamental de diseño la demanda máxima de desplazamiento plástico de aquellas estructuras incapaces de resistir elásticamente la acción del sismo (Fig. 3-14).

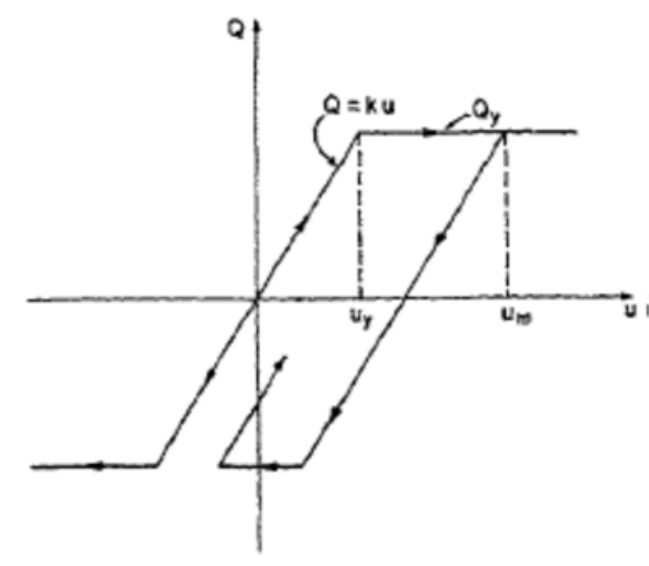

Fig. 2

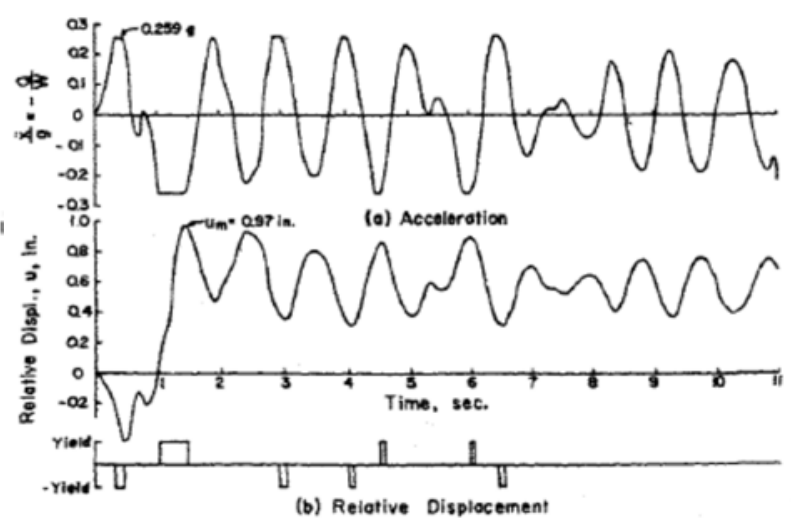

Fig. 3-14. (izda.) Esquema de comportamiento elastoplástico. (dcha.) Historia de aceleración y desplazamiento del sistema elasplástico sometido al acelerograma del terremoto de El Centro, 1940. (Veletsos \& Newmark, 1960).

A partir de este momento, la determinación de la acción sísmica se convierte en la caracterización conjunta de la demanda de deformaciones que corresponde a estructuras dotadas con una fuerza resistente inferior a la correspondiente a la demanda elástica de aceleraciones, y de dicha fuerza resistente.

Basándose en el escaso número de registros existente en la época, que consistían en poco más que el de el terremoto de El Centro, California, de 1940, Veletsos y Newmark (Veletsos \& Newmark, 1960) establecieron los términos en los que todavía hoy se asienta diseño sismorresistente con ductilidad. Denominando ductilidad de desplazamiento $\mu=u_{\max } / u_{y}$ al factor que relaciona la máxima deformación $u_{\max }$ ocurrida en una estructura bajo el sismo, siendo $u_{y}$ la deformación elástica a partir de la cual el sistema deja de comportarse linealmente (Fig. 3-15, izda.), estos autores desarrollaron los primeros espectros de aceleraciones de ductilidad constante (Fig. 3-15). Para elaborarlos calcularon espectros de respuesta para una colección de estructuras de 1 grado de libertad (SDOF en inglés), caracterizadas por diferentes periodos de oscilación, y diferentes valores de la fuerza de plastificación $r_{y}$, para posteriormente ordenar los resultados en función de la ductilidad $\mu$ desarrollada en cada uno de ellos. De esta manera, caracterizando cual es la ductilidad de desplazamiento inelástico de la que es capaz una determinada estructura, se puede conocer cuál es la mínima resistencia con la que hay que 
dotarla; o de manera análoga, caracterizando cual es la resistencia de la estructura, cual es la ductilidad que hay que proporcionar a la misma.

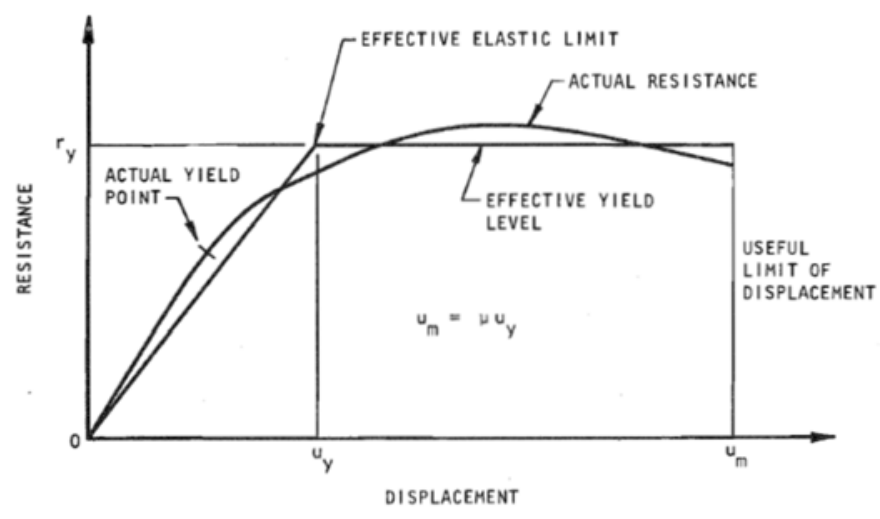

Figure 6. Resistance-Displacement Relationship.

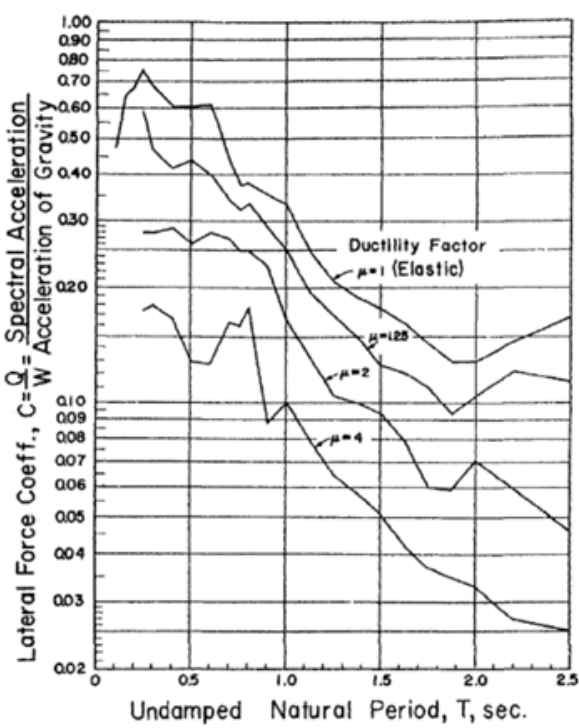

Fig. 3-15. (izda.) Esquema de comportamiento elastoplástico equivalente y definición de la ductilidad de desplazamiento $\mu$. (Newmark \& Hall, 1982). (dcha.) Espectro de aceleraciones del terremoto de El Centro, 1940 para estructuras con ductilidad constante $\square$. (Veletsos \& Newmark, 1960).

El concepto ha sido objeto de diversas revisiones, y numerosos autores han contribuido, con estudios similares y diferentes catálogos de acelerogramas, a llevarlo a su forma actual. Una excelente revisión de las diversas propuestas puede encontrarse en el trabajo de Miranda y Bertero (Miranda \& Bertero, 1994).

La demanda de ductilidad como concepto refleja una medida cuantitativa de la cantidad de comportamiento inelástico que se genera en una estructura. En una estructura con demanda de ductilidad $\mu \approx 1$ el comportamiento será esencialmente elástico, mientras que una estructura con demanda de ductilidad alta $\mu \approx 8$ el comportamiento será muy plástico, y deformará mucho en el rango inelástico los materiales de la misma.

\subsubsection{El marco conceptual del diseño sísmico basado en el desempeño (PBEE, Performance Based Earthquake Enqineering)}

La deformación de los materiales constituye una medida directa del daño que soportan durante el sismo (Fig. 3-16), y por esta razón las normativas sismorresistentes más recientes establecen diferentes umbrales de daño en cada material para diversos escenarios de demanda sísmica. Algunos de estos criterios se exponen en el apartado $§ 3.8$ de esta tesis. 


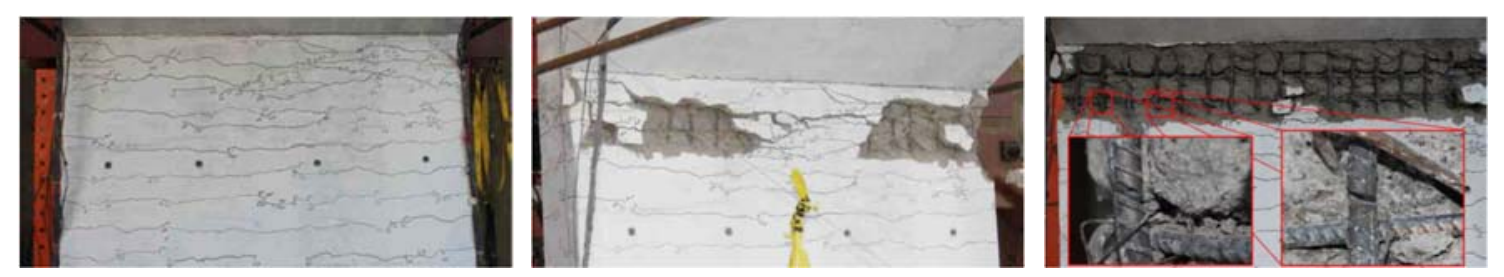

Fig. 3-16. Nivel progresivo de daño en estructura de hormigón armado (izda.) Fisuración correspondiente a la plastificación de la armadura longitudinal (cent.) Spalling del recubrimiento. (dcha.) Pandeo y fractura de armado longitudinal. (Kim, Giacalone, Elgamal, \& Shing, 2016).

Los terremotos frecuentes, y que por lo tanto tienen más probabilidad de ocurrir durante la vida útil, son de menor intensidad que los terremotos raros, que ocurren en periodos de tiempo mucho mayores y que por lo tanto tienen menos probabilidad de ocurrir durante la vida útil de la obra (Cornell, 1968).

Lo incierto de la acción sísmica que puede solicitar una obra durante la vida útil de esta, el diferente rango de intensidades que corresponde a los eventos que pueden solicitarla, y el diverso rango de daños, y consiguientes pérdidas económicas, que pueden corresponder a cada uno de estos eventos, quedó patente a partir de los terremotos de mediados de los años 90 del s. XX (Northridge en Los Ángeles, 1994, y Kobe en Japón, en 1995). Estos terremotos, en países desarrollados, pusieron de manifiesto la gran importancia que tienen las pérdidas económicas debidas a daños estructurales y no estructurales, incluso en estructuras diseñadas de acuerdo a la normativa del momento (Krawinkler \& Miranda, 2004).

Desde ese momento se ha promovido un nuevo paradigma en el diseño sismorresistente de estructuras denominado diseño basado en el desempeño (PBEE, Performance Based Earthquake Engineering en la literatura anglosajona). El concepto del diseño basado en el desempeño considera diferentes escenarios de demanda sísmica, bien sea de manera continua o discreta (terremotos frecuentes y pequeños, infrecuentes y medianos, y excepcionales y grandes), la incertidumbre inherente a la acción que corresponde a estos escenarios, así como diferentes objetivos de comportamiento máximo esperable para estos escenarios (ya sea mediante funciones de probabilidad de daño, o mediante umbrales de daño). El objetivo final es tener una descripción cuantitativa completa del riesgo, en términos económicos y sociales, al que se expone una infraestructura por el hecho de encontrarse en una zona sujeta a la amenaza sísmica, y 
poder actuar en consecuencia en el diseño de la misma para llevar dicho riesgo a niveles aceptables.
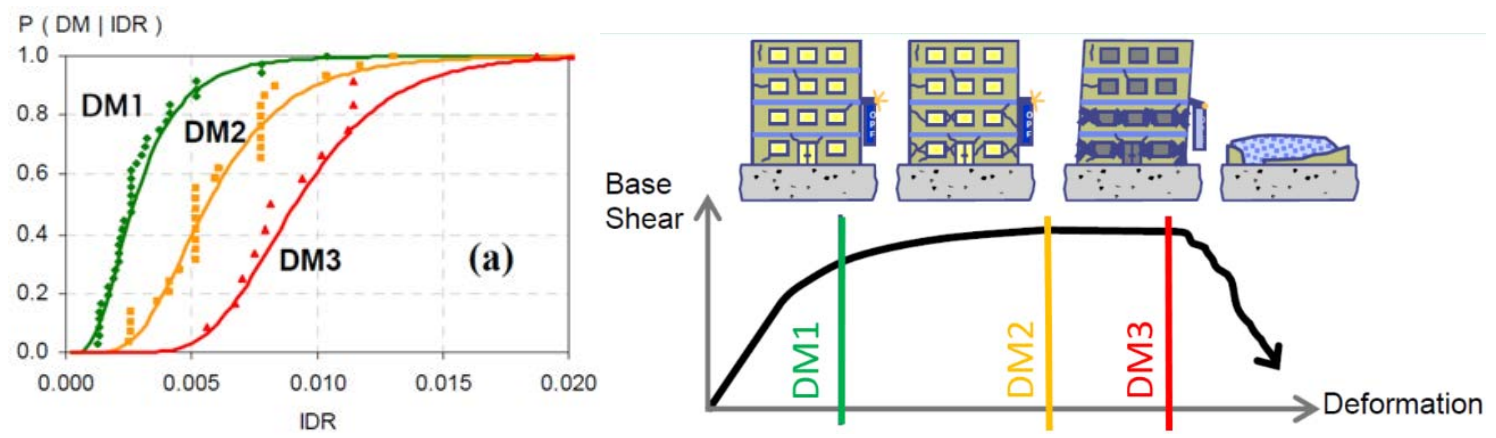

Fig. 3-17. (izda.) Curvas de fragilidad de tres medidas de daño (DM, Damage Measure). (dcha.)

Umbrales de daño definidos sobre una curva pushover fuerza-desplazamiento.

En su versión más elemental, orientada al proyecto de obra nueva y pensada para ser incluida en normativas de diseño, siguiendo el modelo de código desarrollado para edificios por la SEAOC (Structural Engineers Association of California), en el documento comúnmente denominado Vision 2000 (Poland et al., 1995), el diseño basado en el desempeño consiste en un conjunto de objetivos de comportamiento máximo para diferentes niveles de demanda sísmica, tanto para elementos estructurales (pilares, columnas, etc.), como para elementos no estructurales (tabiquerías, cerramientos, sistemas mecánicos y eléctricos), y para diferentes categorías de importancia de los edificios (Fig. 3-18).

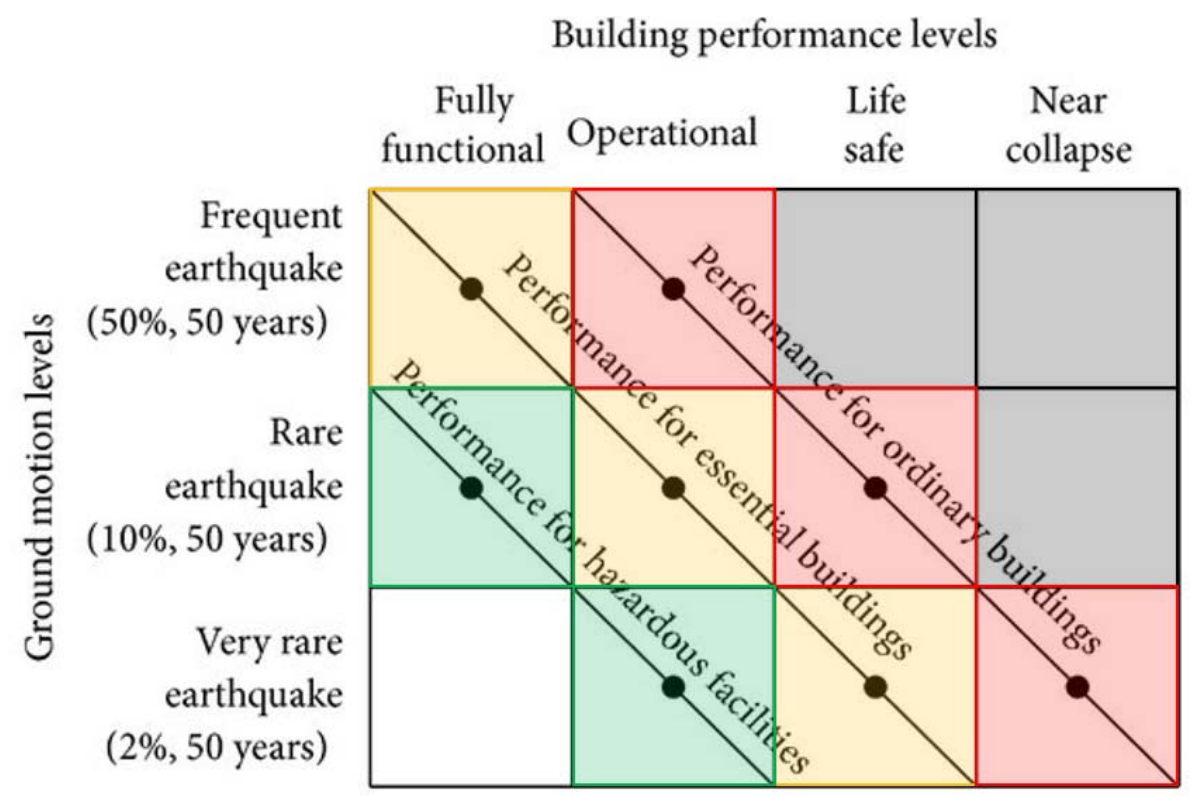

Fig. 3-18. Matriz de objetivos de desempeño y niveles de demanda sísmica. (Poland et al., 1995). 
En su versión más desarrollada, orientada a la evaluación sismorresistente de obra ya construida (p.ej. parque inmobiliario de una población, puentes y obras de paso de una red regional de carreteras, etc.), la ingeniería basada en el desempeño consiste en un marco conceptual, y metodologías de análisis asociadas, para traducir a una variable cuantitativa de riesgo (p.ej. pérdidas económicas) la exposición de la infraestructura existente a la peligrosidad sísmica.

$$
\lambda(D V)=\iiint f(D V \mid D M) \cdot g(D M \mid E D P) \cdot h(E D P \mid I M) \cdot d \lambda(I M)
$$

La (Ec. 3-7) resume la formulación básica para esta evaluación. Condensando en una única variable la medida de la acción sísmica (IM, Intensity Measure), y conociendo las distribuciones probabilistas:

- $\boldsymbol{h}(\boldsymbol{E D P} \mid \boldsymbol{I M}):$ Distribución probabilista de algún tipo de medida física con sentido ingenieril (EDP, Engineering Demand Parameter, p.ej. desplazamiento relativo entre plantas consecutivas de un edificio) condicional a la ocurrencia de un nivel determinado de intensidad sísmica $I M$.

- $\boldsymbol{g}(\boldsymbol{D M} \mid \boldsymbol{E D P}):$ Distribución probabilista de algún tipo de medida física del daño (DM, Damage Measure, p.ej. abertura de fisuras de más de $w_{k}=1 \mathrm{~mm}$ en vigas) condicional a la ocurrencia de un nivel determinado de parámetro ingenieril EDP. Esta distribución suele denominarse curva de fragilidad (Fig. 3-17, izda.).

- $\boldsymbol{f}(\boldsymbol{D V} \mid \boldsymbol{D} \boldsymbol{M}):$ Distribución probabilista de algún tipo de variable para la decisión (DV, Decision Variable, p.ej. pérdidas económicas en $€$ ) condicional a la ocurrencia de una medida del daño DM.

Es posible obtener una medida en forma de probabilidad de pérdidas monetarias para un determinado nivel de intensidad sísmica, o de forma más general una pérdida económica anualizada esperable (p.ej. frecuencia anual esperable de pérdidas económicas equivalente al $1 \%$ del coste de construcción del inmueble). Con medidas de este tipo se pueden tomar decisiones informadas acerca de la conveniencia de invertir en rehabilitación sísmica, establecer primas de riesgo en seguros, etc. (Krawinkler \& Miranda, 2004). 


\subsection{Particularidades del proyecto sismorresistente de obras subterráneas con respecto a las obras en superficie}

Las obras subterráneas presentan diferencias significativas con respecto a las estructuras en superficie, en particular en lo que se refiere a la caracterización de su comportamiento dinámico, y a cuáles son las variables principales que intervienen en la determinación de la solicitación sísmica. Algunas de las más destacables son las siguientes:

- La masa inercial de la estructura en sí (esto es, de los elementos como pantallas y losas dispuestos para soportar cargas diferentes a la solicitación sísmica), a pesar de que pueda ser del mismo orden de magnitud que en otras estructuras en superficie, es despreciable con respecto a la masa inercial del terreno circundante que previsiblemente acompañará en el movimiento a la estructura portante durante un sismo.

- La masa inercial del terreno circundante que oscila de manera conjunta con la estructura, a diferencia de lo que ocurre en una estructura en superficie, está en principio indeterminada. En efecto, en una estructura en superficie es relativamente sencillo establecer cuál es la masa que oscila con la estructura, que es esencialmente la masa de la estructura junto con otras masas eventuales que puedan estar vinculadas a esta (i.e. en el caso de un edificio, la masa del peso propio de los forjados y columnas, junto con la masa de los acabados, instalaciones, etc.). Sin embargo, en una estructura subterránea, no está claro de qué manera se puede establecer, a priori, que masa del terreno se mueve de manera conjunta con la estructura.

- La rigidez de la estructura en sí (esto es, de los elementos como pantallas y losas dispuestos para soportar cargas diferentes a la solicitación sísmica), a pesar de poder establecerse con relativa precisión, parece que pueda jugar un papel secundario cuando se compara con la rigidez que ofrece el terreno circundante frente a la deformación del conjunto suelo-estructura. En efecto, la rigidez elástica de una estructura en superficie, a pesar de que en ciertos casos pueda presentar cierta incertidumbre (i.e. grado de fisuración en una estructura de hormigón) es un parámetro que puede determinarse a priori. Sin embargo, en el caso de una estructura 
subterránea, no está claro de qué manera se puede establecer, a priori, que parte del terreno aportará rigidez en su movimiento conjunto con la estructura.

- De la misma manera, y relacionado con la rigidez, mientras que en una estructura en superficie se puede establecer con cierta fiabilidad a partir de qué momento la estructura dejará de comportarse linealmente para formar mecanismos plásticos (ya que se conoce su rigidez y su resistencia), en una estructura subterránea es más incierto establecer puntos que dividan el comportamiento claramente elástico del manifiestamente inelástico. En efecto, la rigidez aportada por la estructura subterránea puede presentar claros puntos que separen el comportamiento elástico del inelástico (i.e. formación de rótulas plásticas en los nudos de hormigón); sin embargo, la rigidez aportada por el terreno circundante presenta un comportamiento no lineal mucho más continuo, sin claros puntos diferenciadores que dividan ambos rangos de comportamiento.

Estas diferencias ponen de manifiesto un elemento claramente diferenciador de las estructuras subterráneas sometidas a la acción sísmica con respecto a las estructuras en superficie: la gran interdependencia entre el comportamiento del suelo circundante y el de la estructura en sí, es decir, la interacción suelo-estructura.

Las consideraciones anteriores hacen que los métodos de análisis de la acción sísmica en estructuras subterráneas sean muy diferentes a los más habituales correspondientes a las estructuras superficiales (p.ej. espectro de respuesta y análisis modal espectral).

\subsection{La acción estática del terreno en estructuras de contención}

El problema de la contención de tierras es uno de los más antiguos en ingeniería geotécnica, y algunos de los principios más fundamentales de este campo del conocimiento fueron desarrollados con el propósito de establecer metodologías racionales para el diseño de estructuras de contención de tierras.

La acción estática del terreno sobre una estructura se concreta en la presión lateral de tierras que los suelos ejercen sobre estructuras verticales o prácticamente verticales, y que tienden a desestabilizar la estructura de contención. 
La solución a los problemas de empuje lateral de tierras figura entre las primeras aplicaciones del método científico al diseño de estructuras (Atik \& Sitar, 2009). Dos de los pioneros en el empeño de resolver el problema del empuje lateral del terreno sobre estructuras de contención fueron Coulomb (Coulomb, 1776) y Rankine (Rankine, 1856), y a pesar de que muchos otros autores hayan realizado contribuciones significativas al conocimiento que se tiene sobre este fenómeno, el trabajo de estos dos científicos ha sido tan fundamental que todavía constituye la base sobre las que se asienta el análisis de la presión de tierras en la actualidad.

La evolución histórica de las tipologías de estructuras de construcción ha hecho que los métodos desarrollados por Coulomb y Rankine proporcionaran durante un largo periodo resultados satisfactorios a la hora de tratar el problema de estructuras de contención, esencialmente rígidas hasta el $\mathrm{s}$. XX. La cinemática de los mecanismos de fallo de estas estructuras rígidas, relacionada principalmente con el deslizamiento y el vuelco, se adapta especialmente bien a las teorías desarrolladas por estos dos autores (Delattre, 2001).

Sin embargo, el desarrollo de estructuras de contención flexibles (p.ej. pantallas) a partir del s. XX añadió una nueva capa de complejidad al problema de la acción del terreno sobre la estructura: la interacción suelo-estructura. La deformabilidad de la estructura modifica el estado tensional del terreno circundante, que ejerce una acción diferente en función de cuanto se deforme la estructura, pero a su vez la deformación de la estructura es función de la acción del terreno.

A continuación, se hace un resumen de los métodos más representativos que permiten analizar la acción del terreno sobre las estructuras de contención, tanto en estructuras rígidas tales como muros de gravedad, como en estructuras flexibles tales como pantallas.

\subsubsection{Acción estática sobre estructuras ríqidas}

De todos los aspectos que influyen en la acción que ejerce el terreno sobre las estructuras, el más determinante es la propia flexibilidad de la estructura de contención (Delattre, 2001). Los métodos de análisis desarrollados por Coulomb (Coulomb, 1776) y Rankine (Rankine, 1856) fueron propuestos con el objetivo principal de ofrecer una solución al problema que correspondía a la tipología de muros más extendida en la época (esencialmente muros de fábrica de sillares de piedra); es decir, son métodos apropiados 
para estructuras de contención rígidas, cuyo modo de fallo presenta una cinemática de movimiento de sólido rígido, capaz de movilizar los estado límite del terreno.

La magnitud de la presión lateral de tierras está estrechamente relacionada con el movimiento posible de la estructura de contención, y en el caso de estructuras rígidas, con las presiones máximas y mínimas que es capaz de desarrollar el terreno cuando se encuentra en un estado límite de rotura. La presión mínima (activa) y máxima (pasiva) ocurren cuando la estructura de contención puede moverse alejándose del terreno contenido, y acercándose al mismo respectivamente. La presión llamada de reposo corresponde a un estado intermedio entre estos dos estados extremos, y se da en aquellos casos en los que la estructura de contención no puede moverse.

\subsubsection{Hipótesis de Coulomb}

Coulomb (Coulomb, 1776) fue el primero en estudiar el problema de la presión lateral de tierras mediante una estructura de contención. Estableciendo sendos equilibrios de fuerzas, en dirección horizontal y vertical, fue capaz de determinar el empuje total del terreno sobre la estructura de contención para los casos extremos, denominados de “estado límite”, de empuje mínimo (activo) y empuje máximo (pasivo).

Para analizar el equilibrio de fuerzas, Coulomb parte de la premisa de que, en el estado límite de equilibrio, en el terreno en el trasdós de la estructura de contención (p.ej. muro) se desarrolla un plano de rotura por deslizamiento, de tal manera que se forma una cuña de terreno que a efectos de equilibrio de fuerzas puede considerarse como un sólido rígido (Fig. 3-19). Esta cuña de terreno del trasdós recibe el nombre de cuña activa. Estudiando para un determinado plano de deslizamiento cuales son las fuerzas que se desarrollan en la interfaz muro-cuña, y cuña-resto del terreno, y estableciendo las ecuaciones de equilibrio de fuerzas horizontales y verticales, se obtiene cual es la fuerza horizontal mínima que debe ser capaz de resistir el muro para que la cuña de terreno del trasdós se encuentre en equilibrio.

Puesto que el equilibrio de la cuña depende de la propia geometría de la cuña, es decir del plano de deslizamiento estudiado, el problema resulta indeterminado ya que no se puede saber a priori cual será el plano de deslizamiento. Por lo tanto, Coulomb establece que debe estudiarse un conjunto de superficies potenciales de deslizamiento para identificar aquella que proporciona el mayor empuje activo, y que corresponde a la situación crítica. 


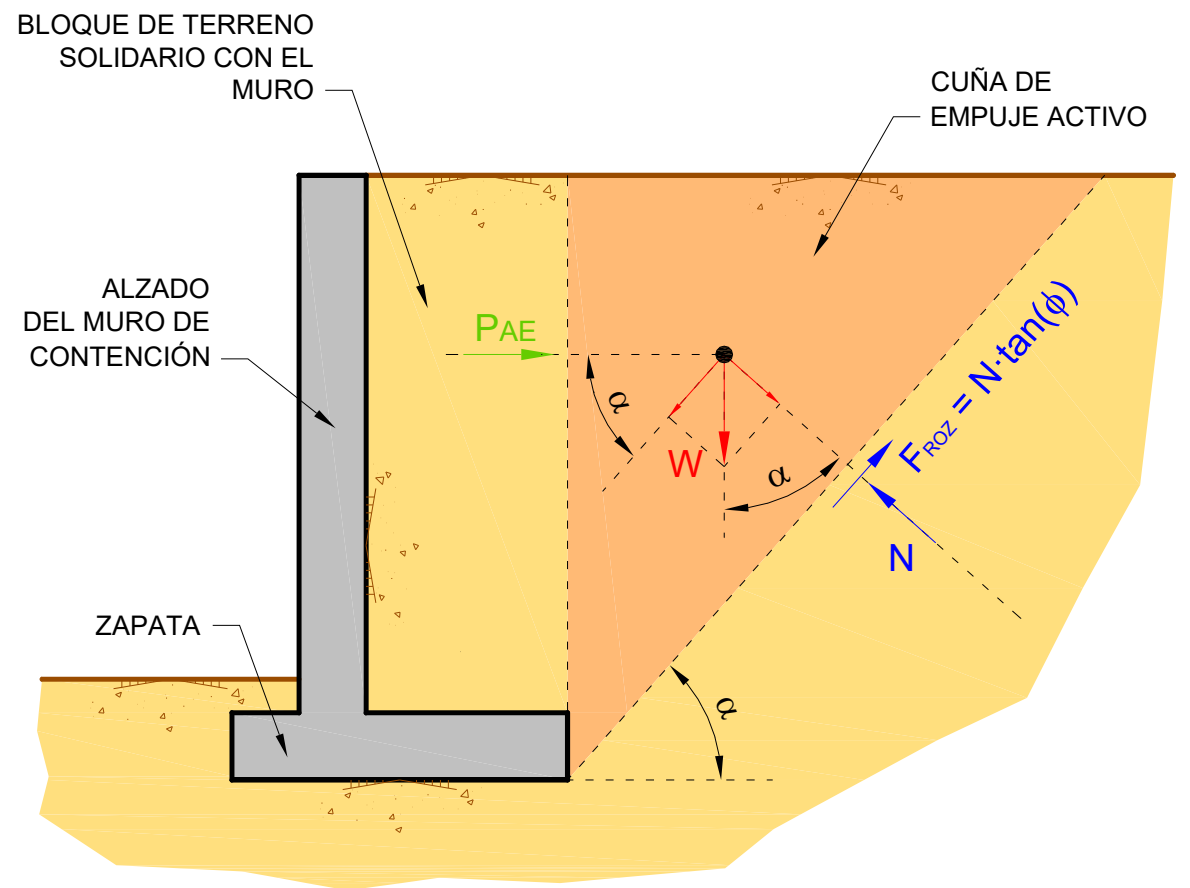

Fig. 3-19. Esquema de equilibrio de la cuña de empuje activo de Coulomb.

Si se establece el equilibrio de la cuña de terreno indicada en la figura (Fig. 3-19), se obtienen los siguientes resultados:

- Equilibrio de fuerzas vertical:

$$
\begin{gathered}
W=N \cdot \cos (\alpha)+N \cdot \tan (\varphi) \cdot \sin (\alpha) \therefore \\
N=\frac{W}{\cos (\alpha)+\tan (\varphi) \cdot \sin (\alpha)}
\end{gathered}
$$

- Equilibrio de fuerzas horizontal:

$$
\begin{gathered}
N \cdot \sin (\alpha)=E_{a}+N \cdot \tan (\varphi) \cdot \cos (\alpha) \therefore \\
E_{a}=N \cdot(\sin (\alpha)-\tan (\varphi) \cdot \cos (\alpha)) \therefore \\
E_{a}=\frac{W \cdot(\sin (\alpha)-\tan (\varphi) \cdot \cos (\alpha))}{\cos (\alpha)+\tan (\varphi) \cdot \sin (\alpha)}
\end{gathered}
$$

Como puede observarse, el empuje activo $E_{a}$ (Ec. 3-9) que debe ser capaz de resistir el muro depende tanto del ángulo geométrico $\alpha$, como del ángulo de rozamiento interno del terreno del trasdós $\phi$, (Fig. 3-20). 


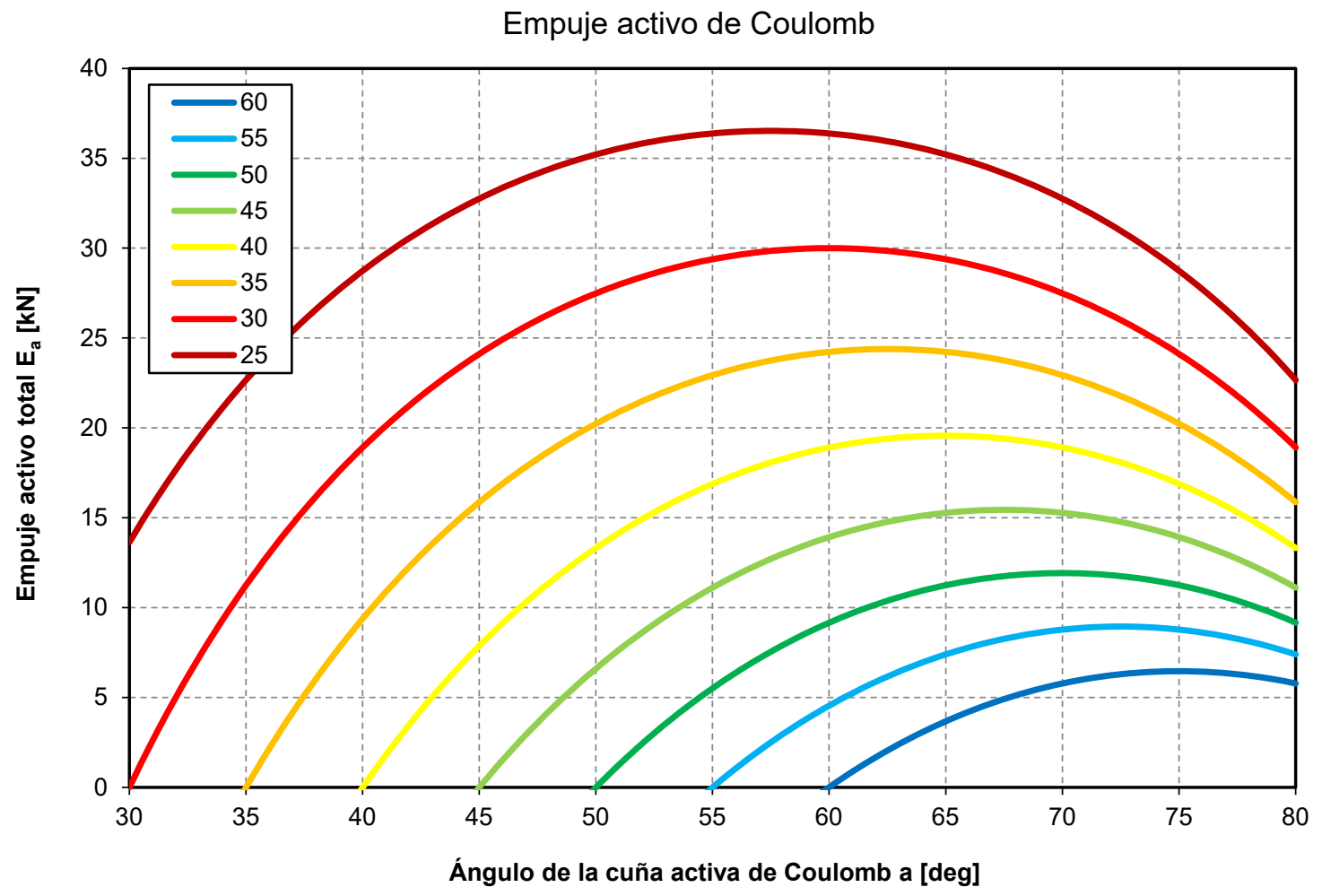

Fig. 3-20. Empuje activo de Coulomb para un muro de $H=10 \mathrm{~m}$ de altura, densidad del relleno del trasdós $\rho=18 \mathrm{kN} / \mathrm{m}^{3}$, y ángulo de rozamiento interno $\phi$ variable entre $25^{\circ}$ y $60^{\circ}$. El ángulo de la cuña activa movilizada, para cada ángulo $\phi$, es el correspondiente al máximo del empuje total.

\subsubsection{Hipótesis de Rankine}

Rankine (Rankine, 1856) desarrolló un procedimiento más simple para calcular la presión mínima (activa) y máxima (pasiva). Estableciendo una hipótesis acerca del estado tensional del terreno, así como de la envolvente de resistencia del suelo en el trasdós de la estructura de contención, Rankine fue capaz de transformar el problema indeterminado de la presión lateral de tierras en un problema determinado, y calcular directamente las presiones que actúan en el trasdós del muro.

La hipótesis fundamental que subyace en el planteamiento de Rankine es que el terreno inmediatamente adyacente a la superficie vertical del muro se encuentra en un estado tensional límite correspondiente al fallo del terreno del trasdós (Magnan, 1999). Este estado límite queda determinado por la tangencia del círculo de Mohr (que representa el tensor de tensiones) con las envolventes de resistencia del terreno representado por la recta $\sigma-\tau$ (Fig. 3-21). 


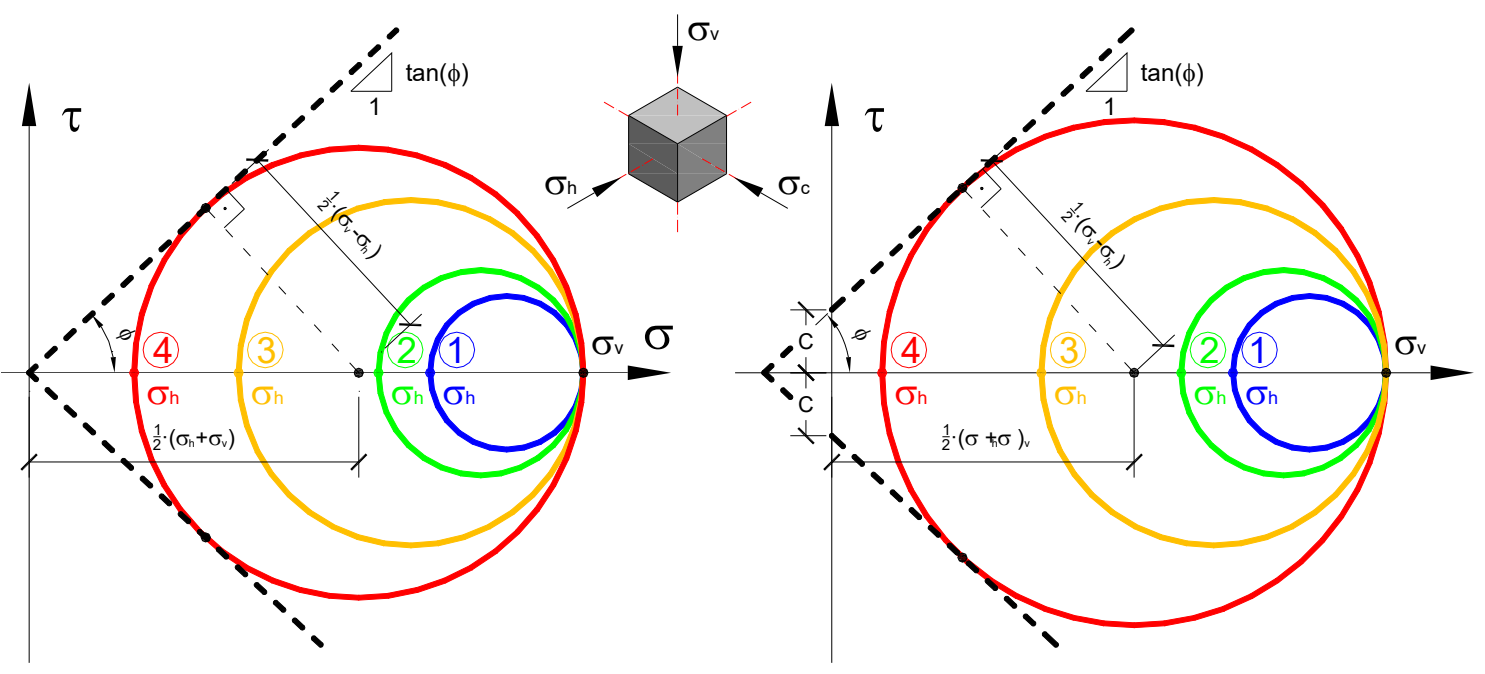

Fig. 3-21. Estado tensional del terreno de Rankine de empuje activo (izda.) para un suelo con rozamiento y sin cohesión. (dcha.) para un suelo con rozamiento y con cohesión. Las tensiones horizontales $\sigma_{h}$ evolucionan desde el estado 1 al reposo, al estado 4 de rotura activa, manteniendo la tensión vertical $\sigma_{v}$ constante

Asumiendo como válida la hipótesis de que la tensión vertical del terreno corresponde tan sólo al peso de la columna de tierras que gravita sobre cada elemento de terreno, y en referencia a lo representado en la (Fig. 3-21), puede observarse como para una determinada tensión vertical ( $\sigma_{v}$ correspondiente a una determinada profundidad del terreno) el estado de menor empuje horizontal que corresponde a un estado de fallo del terreno es el correspondiente al estado numerado como 4. En efecto, con esta representación por fases de la (Fig. 3-21, izda.), puede observarse como se pasa progresivamente de un estado de mayor empuje horizontal $\sigma_{h, 1}$ (estado 1) que podría corresponder a una situación de empuje al reposo, hasta un estado de menor empuje horizontal (estado 4), que corresponde a la situación de empuje activo. Si la estructura no es capaz de proporcionar una tensión horizontal de al menos $\sigma$,4, el terreno del trasdós habrá fallado.

Bajo estos condicionantes, la componente esférica de la tensión del terreno (centro del círculo de Mohr), y el radio del círculo de Mohr correspondiente al estado de fallo del terreno, resultan ser las expresiones siguientes para un terreno puramente friccionante:

$$
\begin{gathered}
\sigma_{e s f}=\frac{1}{2} \cdot\left(\sigma_{h}+\sigma_{v}\right) \\
r_{M o h r}=\frac{1}{2} \cdot\left(\sigma_{v}-\sigma_{h}\right)
\end{gathered}
$$


Relacionando geométricamente ambos valores a través del ángulo de rozamiento interno del terreno, y tras algunas transformaciones trigonométricas, se obtiene la expresión clásica del coeficiente de empuje activo para un terreno no cohesivo:

$$
\begin{gathered}
\frac{1}{2} \cdot\left(\sigma_{h}+\sigma_{v}\right) \cdot \sin (\varphi)=\frac{1}{2} \cdot\left(\sigma_{v}-\sigma_{h}\right) \therefore \\
\sigma_{h}=\frac{1-\sin (\varphi)}{1+\sin (\varphi)} \cdot \sigma_{v} \therefore \\
\sigma_{h}=\tan ^{2}\left(\frac{\pi}{4}-\frac{\varphi}{2}\right) \cdot \sigma_{v}
\end{gathered}
$$

La tensión mínima horizontal del terreno presenta por lo tanto una relación lineal con la tensión vertical, llamándose coeficiente de empuje activo $K_{a}$ al coeficiente de proporcionalidad entre ambos, (Ec. 3-12).

$$
K_{a}=\tan ^{2}\left(\frac{\pi}{4}-\frac{\varphi}{2}\right)
$$

Para el caso en el que el terreno presente cohesión de valor $c$, y razonando sobre la (Fig. 3-21, dcha.) de manera similar al caso puramente friccionante, la presión mínima horizontal que debe ser capaz de resistir el muro es (Ec. 3-13):

$$
\sigma_{h}=K_{a} \cdot \sigma_{v}-2 \cdot c \cdot \sqrt{K_{a}}
$$

Para el caso en el que el empuje de la estructura se realice contra el terreno, el valor máximo de la tensión horizontal que se ejerce sobre el muro es el denominado empuje pasivo, cuyo valor se obtiene de manera similar caso del empuje activo, sobre un diagrama con círculo de Mohr como el de la Fig. 3-22. En este caso la tensión vertical debida al peso de la columna de tierras $\sigma_{v}$ es la tensión de menor valor, y la tensión horizontal $\sigma_{h}$ se incrementa hasta que se produce el fallo al hacerse tangente el círculo de Mohr con la recta. 


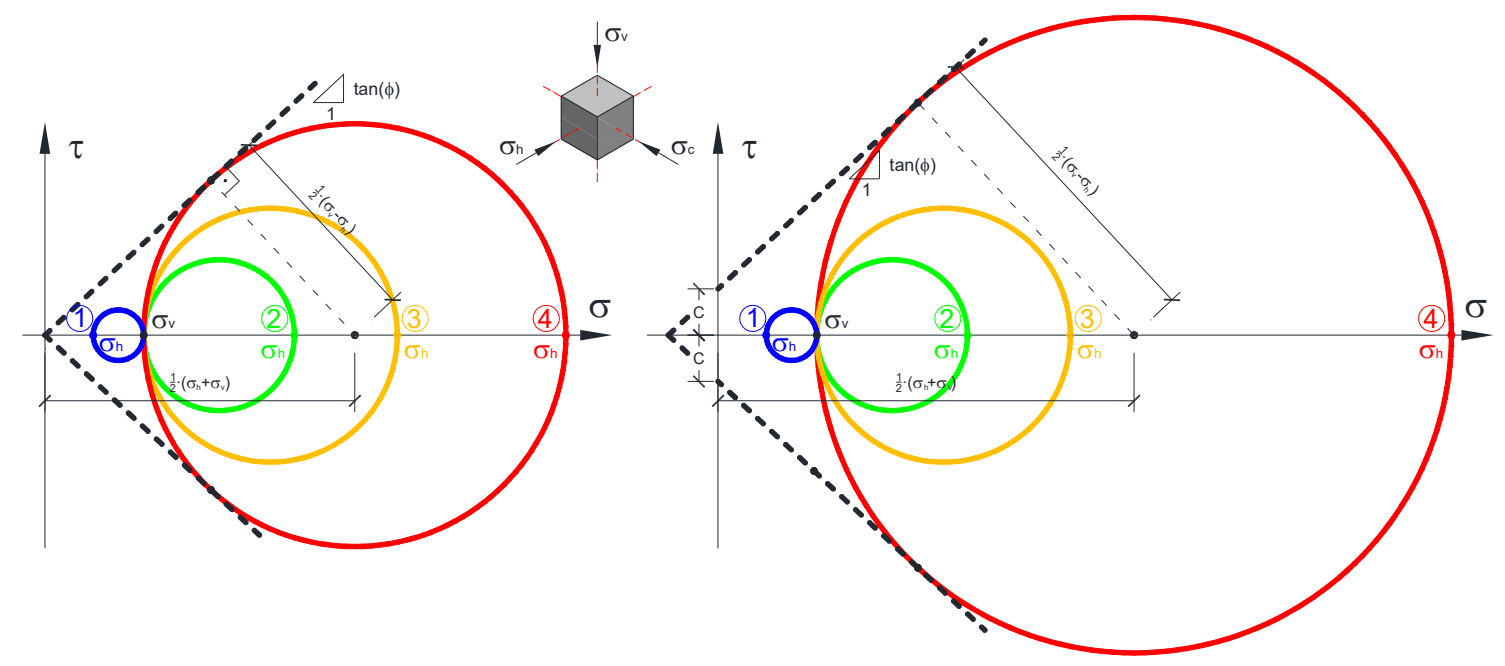

Fig. 3-22. Estado tensional del terreno de Rankine de empuje pasivo. (izda.) Para un suelo con rozamiento y sin cohesión. (dcha.) Para un suelo con rozamiento y con cohesión. Las tensiones horizontales $\sigma_{\mathrm{h}}$ evolucionan desde el estado 1 al reposo al estado 4 de rotura pasiva, manteniendo la tensión vertical $\sigma_{v}$ constante

Para el caso de un suelo puramente friccionante, la tensión horizontal oh para la cual se alcanza la rotura del terreno trabajando en pasivo es (Ec. 3-14):

$$
\sigma_{h}=\tan ^{2}\left(\frac{\pi}{4}+\frac{\varphi}{2}\right) \cdot \sigma_{v}
$$

El coeficiente de proporcionalidad entre tensión vertical y horizontal se denomina coeficiente de empuje pasivo $K_{p}$. (Ec. 3-15).

$$
K_{p}=\tan ^{2}\left(\frac{\pi}{4}+\frac{\varphi}{2}\right)
$$

Para el caso en el que el terreno presente cohesión de valor $c$, y razonando sobre la (Fig. 3-22, dcha.) de manera similar al caso puramente friccionante, la presión máxima horizontal que reacciona contra el movimiento del muro es (Ec. 3-16):

$$
\sigma_{h}=K_{p} \cdot \sigma_{v}+2 \cdot c \cdot \sqrt{K_{p}}
$$

Entre ambos estados límite de tensión horizontal activa y tensión horizontal pasiva existe una tensión intermedia denominada de empuje al reposo, y que corresponde al caso en el que la estructura de contención no ha sufrido ningún desplazamiento. En el caso de que el terreno fuera completamente elástico, y estuviera sometido únicamente a la acción de la gravedad, el valor de dicha tensión se podría obtener mediante las ecuaciones de la 
elasticidad, imponiendo la condición de que el desplazamiento lateral fuera nulo, dada la simetría del problema (Magnan, 1999), como se representa en la (Fig. 3-23, izda.).
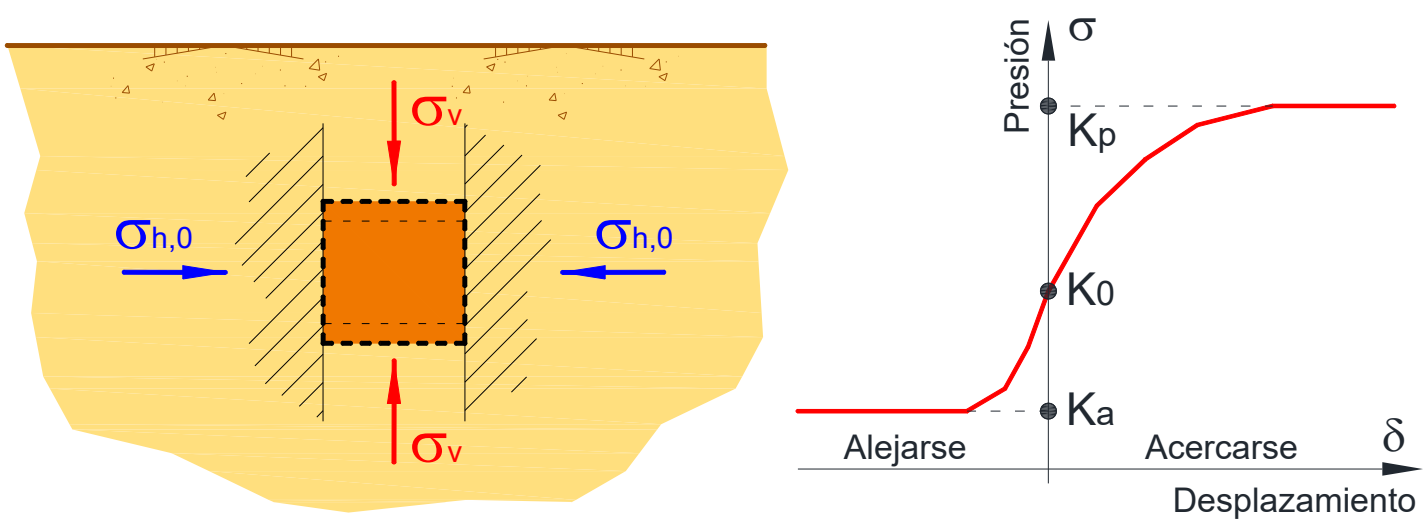

Fig. 3-23. (izda) Condición elástica de tensión de empuje al reposo. (dcha) Representación de los empujes límites activo $K_{a}$, pasivo $K_{p}$, y al reposo $K_{0}$ en función del desplazamiento.

Con este planteamiento del problema, la tensión al reposo horizontal $\sigma_{h, 0}$ resulta proporcional a la tensión vertical $\sigma_{v}$, y el coeficiente que relaciona ambas tensiones es el denominado coeficiente de empuje al reposo $K_{0}$, donde $v$ es el coeficiente de Poisson del terreno (Ec. 3-17).

$$
\sigma_{h}=K_{0} \cdot \sigma_{v}=\frac{v}{1-v} \cdot \sigma_{v}
$$

Dependiendo de los procesos anelásticos de formación y deposición del suelo, el coeficiente de empuje al reposo puede apartarse del valor proporcionado por la elasticidad. Un resumen de las expresiones más relevantes puede encontrarse en la tesis doctoral de Sanhueza Plaza (Sanhueza-Plaza, 2008).

Si se considera, de manera global, el empuje activo cuando el muro se aleja del terreno, el empuje pasivo cuando el muro se acerca al terreno, y el empuje al reposo cuando el muro no presenta ningún desplazamiento con respecto al terreno, se puede elaborar un gráfico conceptual que relacione los movimientos del muro y la tensión solicitante correspondiente, como el de la (Fig. 3-23, dcha.).

\subsubsection{Acción estática sobre pantallas flexibles}

Tal y como se ha comentado anteriormente, de todos los aspectos que influyen en la acción que ejerce el terreno sobre las pantallas de contención, el más determinante es la propia flexibilidad de la estructura de contención (Delattre, 2001). 
El determinar la acción estática que ejerce el terreno circundante sobre las pantallas de contención flexibles es un problema de complejidad considerable, que depende de diversas variables, algunas de ellas de cuantificación incierta, y cuya multiplicidad es inherente a la caracterización de un fenómeno de interacción sueloestructura.

La complejidad del fenómeno ha llevado al desarrollo de numerosos métodos para abordar el problema desde diferentes perspectivas. Una excelente descripción de las metodologías más significativas para abordar el problema puede encontrarse en los trabajos de Delattre (Delattre, 2001, 2004; Delattre \& Marten, 2003), así como en las tesis doctorales de Sanhueza Plaza (Sanhueza-Plaza, 2008), y Caro Perdigón (Caro-Perdigón, 2015). A continuación, se resumen brevemente los aspectos más destacables de las contribuciones históricas más relevantes para el análisis de este problema, que se categorizan en métodos clásicos, métodos empíricos y semi-empíricos, y métodos de interacción suelo-estructura.

\subsubsection{Métodos clásicos}

Los métodos denominados clásicos evolucionan esencialmente en tres etapas. La primera, partiendo de las hipótesis de comportamiento del suelo frente a un muro rígido establecidas por Coulomb (Coulomb, 1776) y Rankine (Rankine, 1856) descritas en el apartado §3.4.1, añadiendo la reacción del terreno en la parte enterrada de la pantalla. En una segunda etapa se intentó tener en cuenta la flexibilidad de la pantalla en su parte enterrada, con el desarrollo de diversos métodos entre las décadas de los años 30 y 60 del s. XX. Finalmente, en una tercera etapa, la aparición de los métodos de cálculo computacionales a partir de los años 50 del s. XX permitió formular un planteamiento más general considerando la flexibilidad relativa y del suelo a través de coeficientes de balasto (subgrade reaction modulus en la literatura anglosajona).

\subsection{Método de empuje libre de tierras}

El primer método desarrollado, denominado de empuje libre de tierras, asume que el muro de contención se comporta de manera perfectamente rígida bajo la acción del empuje lateral de las tierras contenidas, y que moviliza tanto el empuje pasivo en la parte embebida en el terreno, como tensiones activas. Este método permitió el empleo inmediato de los resultados procedentes del empuje activo de tierras y que habían sido 
desarrollados para los muros de contención en los s. XVIII y XIX, pero rápidamente encontró serias limitaciones debidas al escaso conocimiento de la época en lo que se refiere a las presiones de empuje pasivo.

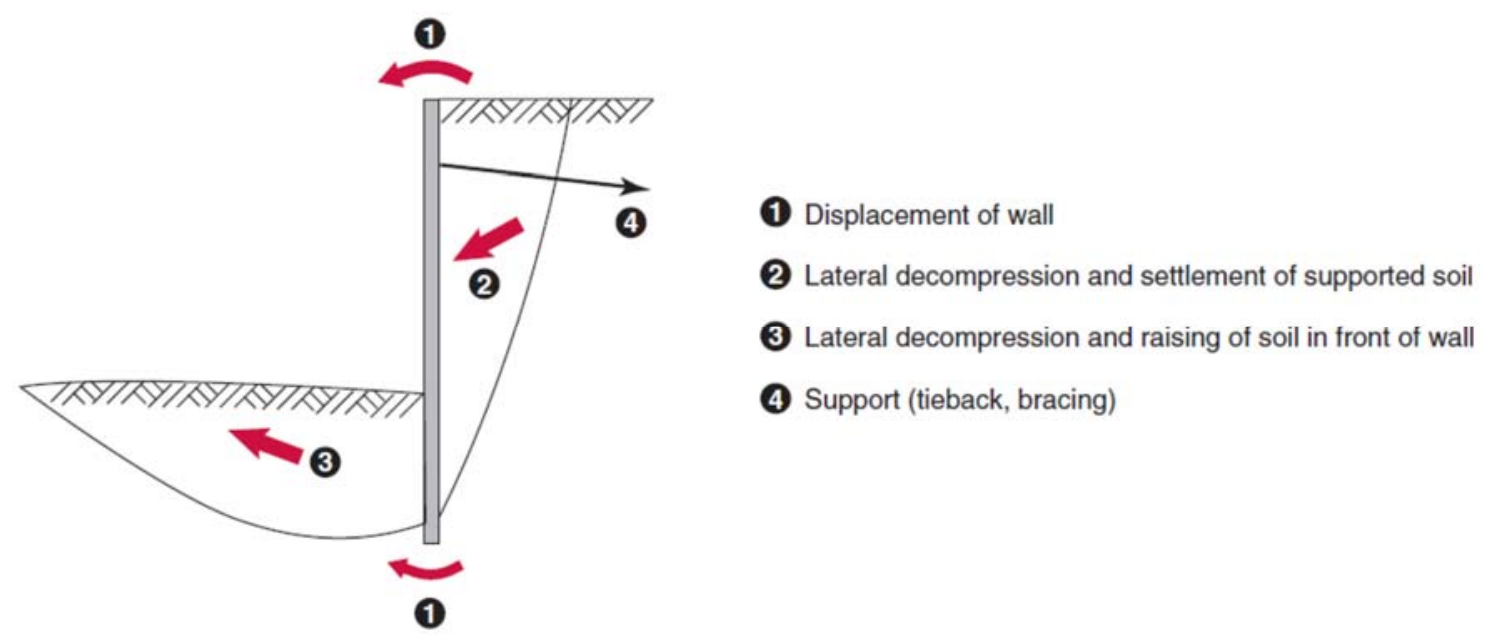

Fig. 3-24 Cinemática de una pantalla rígida y del suelo circundante (Delattre, 2001).

El concepto de empuje pasivo, inicialmente enunciado por Coulomb (Coulomb, 1776), y más tarde empleado por Poncelet (Poncelet, 1840) para evitar el deslizamiento en la base de muros de gravedad construidos en arcillas en el norte de Francia, no había jugado hasta el momento un papel decisivo en la estabilidad de los muros de gravedad, hasta la aparición de la tipología de pantalla de contención. Es en este caso, el de las pantallas de contención, donde el concepto de resistencia pasiva del terreno se torna de máxima importancia. En consecuencia, y a partir de la aparición de esta tipología, la resistencia pasiva del terreno es objeto de varios desarrollos.

Las primeras comprobaciones frente al equilibrio de pantallas de contención embebidas parcialmente en el terreno se abordaron, en lo que se refiere a la resistencia pasiva del terreno, con un enfoque basado en el desarrollo de Coulomb, como una simple extensión del método de empuje activo. Sin embargo, esta estrategia se reveló como un método pobre tanto desde el punto de vista teórico como experimental.

Por una parte, si bien la hipótesis de partida de Coulomb para establecer los mecanismos de ruptura del terreno, en lo que se refiere a las presiones activas, era que el fallo a cortante del terreno se produce a lo largo de planos de rotura, la asunción de esta hipótesis no resultaba tan justificada para el caso de las presiones pasivas del terreno. Durante la primera parte del s. XX surgieron diversas modificaciones a las superficies de 
rotura del terreno, en forma de combinaciones de espirales logarítmicas y planos, que culminaron con el trabajo de Ohde (Ohde, 1938) (Fig. 3-25).

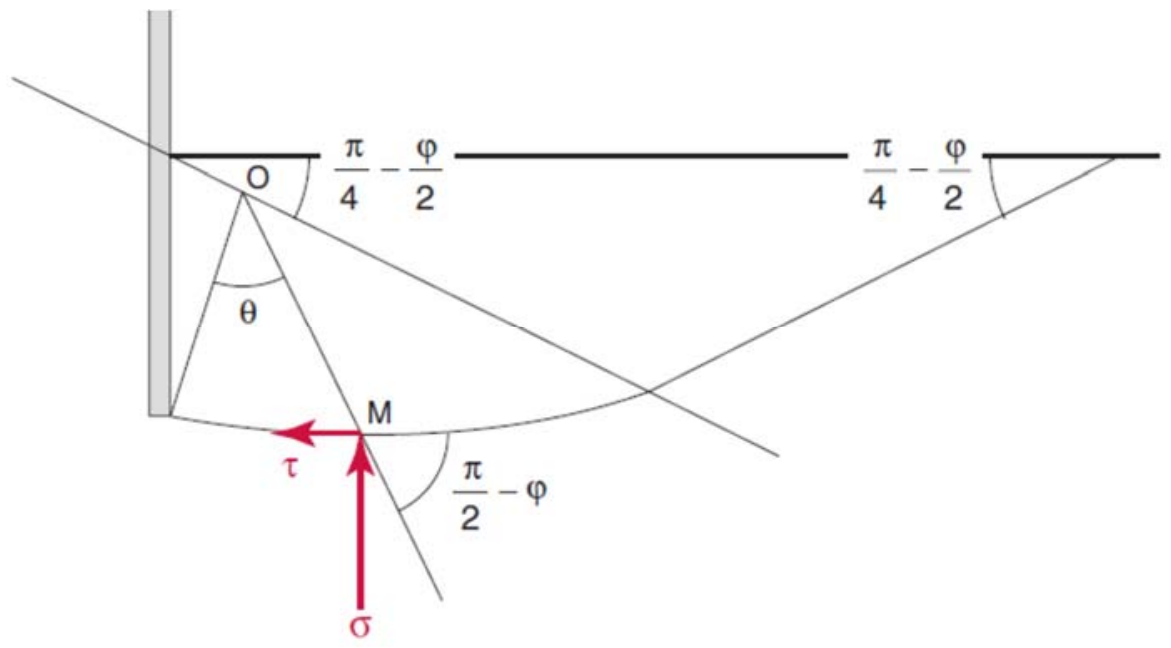

Fig. 3-25 Superficie de ruptura del terreno trabajando de manera pasiva como combinación de espirales logarítmicas y planos (Delattre, 2001).

\subsection{Método de Bousinesq-Caquot}

La aplicación del trabajo de Boussinesq (Boussinesq, 1882) estuvo en origen enfocada al equilibrio y reparto de tensiones en un macizo de terreno retenido por un muro de contención, solicitado esencialmente por la presión activa del terreno. Sin embargo, la dificultad de resolución de las ecuaciones planteadas por Boussinesq impidió su aplicación extensiva, y durante la primera mitad del s. XX no pudieron resolverse para el caso de presiones de empuje pasivo hasta la aparición del trabajo de Caquot (Caquot, 1934). Caquot publicó tablas de coeficientes de empuje pasivo tanto para el caso de terrenos no cohesivos como cohesivos, y durante la década de los años 60 del s. XX este método de análisis se convirtió en el método de referencia.

\subsection{Método de Blum para pantallas ancladas en cabeza}

El método del empuje libre de tierras no tardó mucho en revelarse como inadecuado, cuando se pudo establecer que existía una conexión causal entre la deformación real de la propia estructura de contención y el empuje ejercido por el suelo sobre esta.

Blum (Blum, 1931) analizó el caso de un muro de contención anclado en cabeza, y con diferentes longitudes de muro embebidas en el terreno en el fondo de la excavación. Para esta tipología, estudió la distribución de presiones que actuaban en la estructura, los 
momentos flectores a los que estas daban lugar, y las flechas horizontales resultantes en la pantalla. Su análisis era fundamentalmente cualitativo, y basado en la dependencia mutua de las diferentes distribuciones (la flecha horizontal del muro tiene puntos de inflexión en los que el momento es cero, al igual que la ley de momentos donde la presión es nula y la presión movilizada está relacionada con la flecha horizontal del muro). Estos análisis permitieron a Blum percatarse de que las estructuras con una pequeña porción de la pantalla embebida en el fondo de la excavación se pueden considerar como simplemente apoyadas en su base, mientras que aquellas con una longitud mayor embebida tienden a desarrollar una condición de empotramiento a flexión.

La hipótesis que realizó Blum (Blum, 1931) para desarrollar su método de cálculo, y que denominó "carga aproximada", consiste en asumir que, en el punto $A$ de rotación de la pantalla, el momento flector producido por las presiones del terreno es cero (Fig. 3-26, izda.). Estableciendo el equilibrio de fuerzas horizontales totales $\Sigma F_{H}=0$ y de momentos $\Sigma M_{A}=0$ en este punto $A$, se puede determinar el valor de contrarreacción $R$ del terreno en el pie de la pantalla, y la longitud de empotramiento de la pantalla $t+t$ ' necesaria en la parte embebida en el terreno. Blum apreció que había ligeras diferencias entre el punto de momento nulo y el punto en el que las presiones del terreno resultaban nulas, pero asumió que las diferencias no resultaba significativa en lo que respecta a la estimación tanto del momento máximo en la pantalla, ni en la estimación de la fuerza de contrarreacción $R$ movilizada en la base de la pantalla.
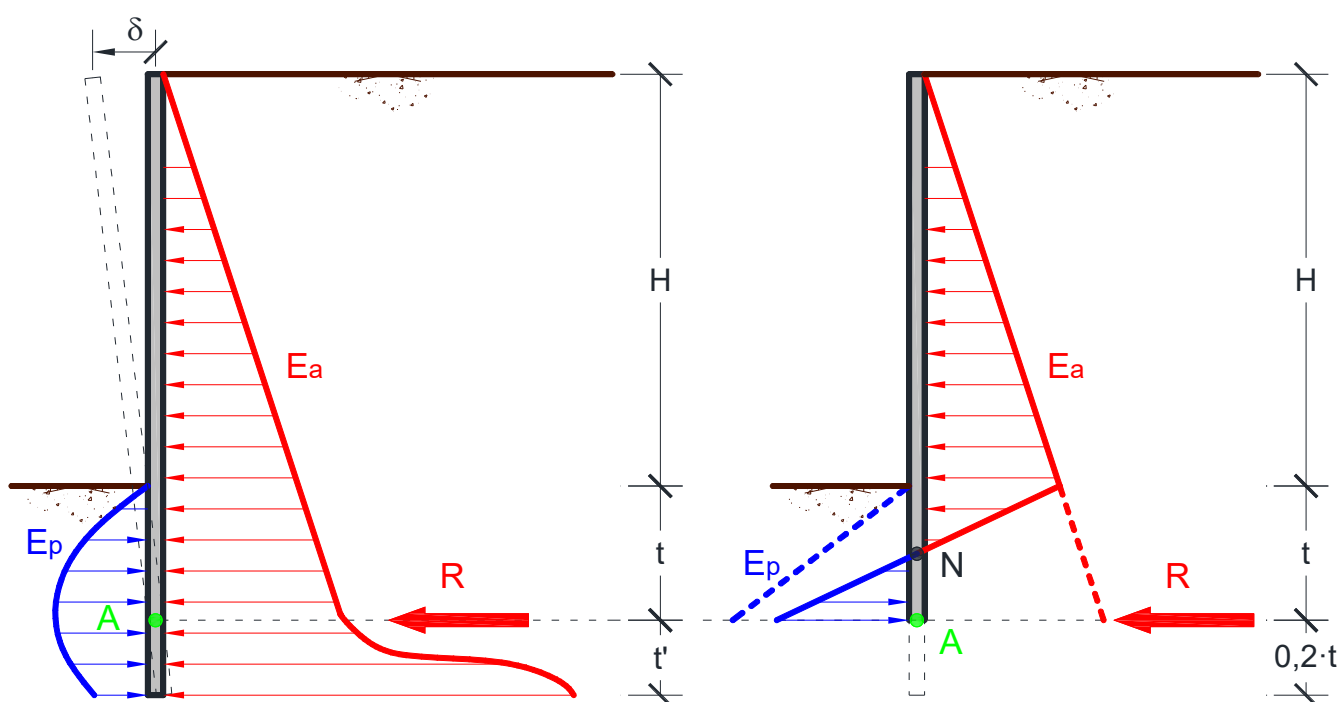

Fig. 3-26 (izda) Hipótesis de Blum para el cálculo de pantallas en voladizo. (dcha) Simplificación de Blum, método de la carga idealizada. 
Con el propósito de simplificar el método de cálculo de la profundidad de empotramiento, Blum propuso que la resultante de la distribución de presiones en la parte embebida de la pantalla debía aplicarse en el centro de rotación de la pantalla, denominando a este método "método de la carga idealizada" (Fig. 3-26, dcha.). Adicionalmente, Blum propuso que, si se adopta esta metodología de cálculo, la profundidad del pie de la pantalla debía incrementarse un $20 \%$. Por otra parte, Blum adoptó la hipótesis correspondiente a suelos no cohesivos que relaciona la profundidad del punto de flector nulo con el ángulo de rozamiento del terreno (Fig. 3-27).

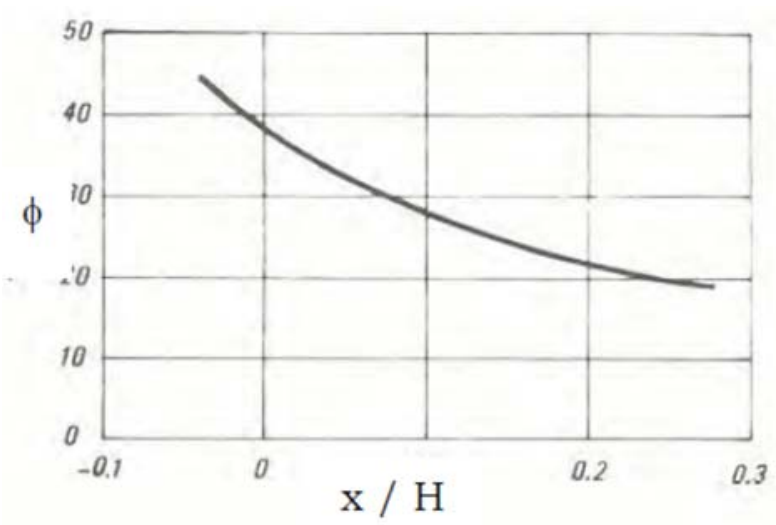

Fig. 3-27 Ley que relaciona la profundidad del punto de flector nulo y el ángulo de rozamiento interno del suelo (Blum, 1931). $X$ representa la profundidad del punto de flector nulo medido desde el fondo de la excavación, $H$ la altura de la pantalla entre cabeza y fondo de excavación, y $\phi$ el ángulo de rozamiento interno del terreno (Sanhueza-Plaza, 2008).

\subsubsection{Métodos semiempíricos}

\subsection{Método de Tschebotarioff}

Tschebotarioff (Tschebotarioff, 1948) desarrolló entre 1941 y 1949 una serie de ensayos a escala reducida de pantallas de contención, que permitieron confirmar de manera cualitativa las hipótesis de Blum. En su trabajo propuso que el empotramiento de la pantalla en el suelo se desarrolla a través de la amplia movilización de la presión pasiva del terreno en la parte superior de la parte de la pantalla embebida en el terreno, así como en el contraempuje en el pie de la propia pantalla, aunque este en menor medida.

El empotramiento resulta en un punto en el que el momento flector es nulo, y que resulta más cercano a la línea de fondo de excavación que del nivel en el que la resultante de presiones es nula, como se postula en la hipótesis de Blum. Este hallazgo llevó a Tschebotarioff a proponer un nuevo método para el diseño de pantallas flexibles de 
contención en suelos arenosos, y ancladas en cabeza, basado en dos hipótesis de base: la porción de pantalla embebida en el terreno bajo el fondo de la excavación es del orden del $30 \%$ de la altura total de la pantalla, y la existencia de una rótula o punto de momento nulo a la cota del fondo de excavación (Fig. 3-28).

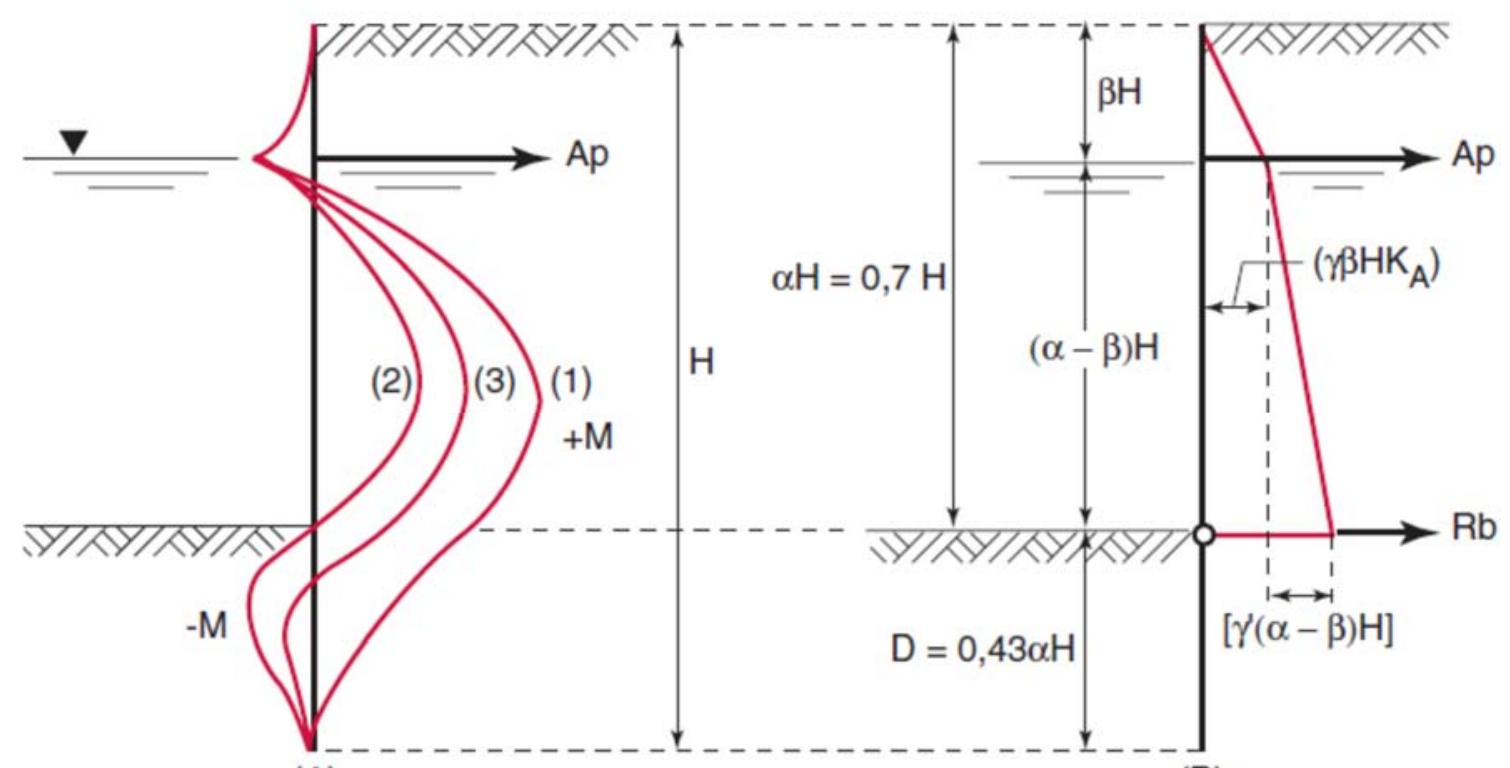

(A)

(B)

Fig. 3-28 Influencia del grado de empotramiento de la pantalla en la distribución de momentos flectores. (izda.) Diagrama que muestra el principio del método de Tschebotarioff. (dcha.) Distribución de la ley de presiones correspondiente (Delattre, 2001).

\subsection{Método de Rowe}

Los resultados experimentales de Tschebotarioff demostraron cualitativamente el fenómeno del empotramiento, en el caso de pantallas flexibles de contención embebidas en arenas de moderadamente densas a densas.

Por su parte Rowe (Rowe, 1952) estudió el fenómeno en mayor detalle mediante una serie de ensayos a escala reducida con materiales geotécnicos de diferentes densidades relativas (gravas, arenas, cenizas, astillas de madera, etc). Sus resultados confirmaron que, debido a la movilización del empotramiento en el suelo, los esfuerzos en las estructuras flexibles de contención (máximo flector, reacción de apoyo) eran menores que en el caso de una estructura rígida. A partir de sus resultados Rowe demostró que para muros con una longitud embebida de aproximadamente el $30 \%$ de la altura total, la reducción de solicitación en el muro depende esencialmente de la flexibilidad de la pantalla (expresada por el parámetro $\rho=H^{4} / E I$, en el que $\mathrm{H}$ es la altura total del muro, $E$ 
el módulo de Young de la pantalla, e I su inercia a flexión), y de la densidad relativa del suelo. Adicionalmente, los esfuerzos en la pantalla no eran apenas afectados por otros factores estudiados, tales como el ángulo de rozamiento interno del terreno, o posición relativa del anclaje en la cabeza del muro.

Rowe demostró que podían producirse reducciones de esfuerzos con respecto a las resultantes del método de Blum o Tschebotarioff, las cuales cuantificó proponiendo un nuevo método de diseño para pantallas flexibles de contención.

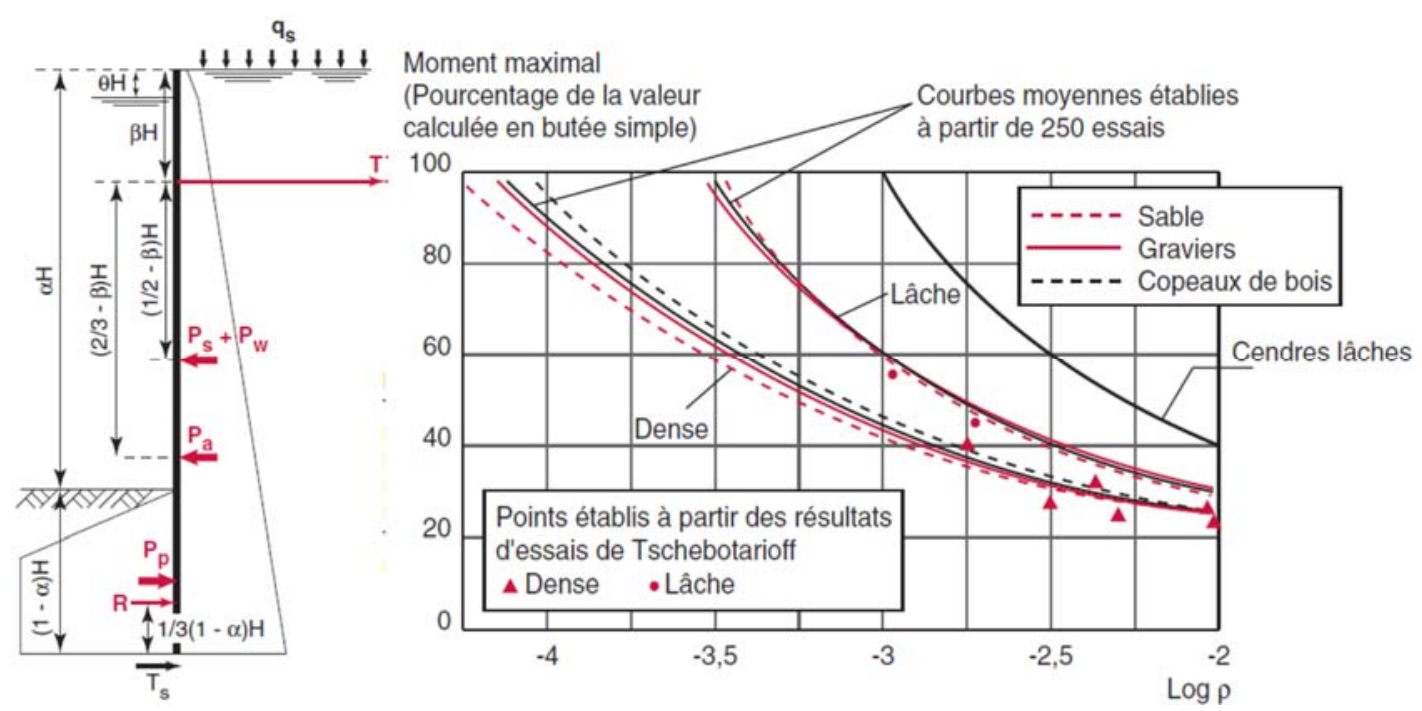

Fig. 3-29 (izda.) Método de Rowe para el cálculo de pantallas flexibles. (dcha.) Coeficientes de reducción de esfuerzos de Rowe en función de la flexibilidad $\rho$ (Delattre, 2001).

El método propuesto por Rowe comienza con un análisis de muro rígido con empuje libre de tierras (Fig. 3-29, izda.), el cual se modifica para considerar la movilización de la fuerza de cortante en la base de la pantalla. Los esfuerzos calculados de esta manera se corrigen y reducen, mediante ábacos obtenidos de ensayos, para tener en cuenta la flexibilidad del muro y densidad del suelo (Fig. 3-29, dcha.).

\subsection{Método de Terzaghi y Peck}

Una manera alternativa de proceder en el dimensionamiento de las estructuras de contención es haciendo uso directamente de una envolvente de presiones en el terreno determinada de manera experimental. Este procedimiento ha sido el adoptado por la denominada "escuela americana", y desarrollado esencialmente por Terzaghi y Peck durante el proyecto y construcción del metro de Chicago.

Terzaghi y Peck (Terzaghi, Peck, \& Mesri, 1996) estudiaron el comportamiento de tablestacas con varios puntos fijos a lo largo de su altura, para suelos de tipo arenoso 
y arcilloso. En base a estos estudios, propusieron unos diagramas de presión del terreno a partir de los cuales se puede determinar los esfuerzos actuantes sobre las pantallas, es decir, momentos flectores, esfuerzos cortantes, y esfuerzos axiles en las retenidas.

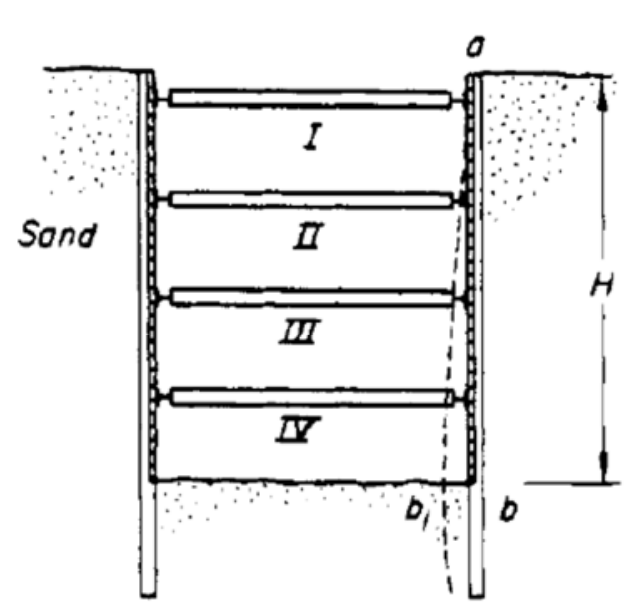

(a)

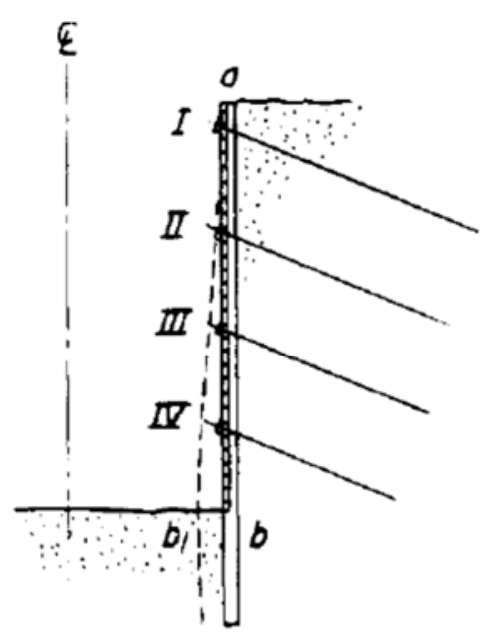

(b)

Fig. 3-30 Modelo de tablestacas estudiadas por Terzaghi y Peck (Terzaghi et al., 1996).

Estos dos autores propusieron que las tensiones ejercidas por el terreno dependen, en gran medida, de las deformaciones desarrolladas en la estructura durante el proceso constructivo de la misma, y que en líneas generales corresponden a la indicada con una línea punteada en la Fig. 3-30, con una deformación mayor en el pie de la tablestaca, ya que los sucesivos puntales que contienen la deformación tan sólo pueden colocarse una vez que se ha alcanzado la cota correspondiente de terreno.

De esta manera, puesto que el primer puntal puede colocarse pronto durante el proceso constructivo, la deformación horizontal en este nivel es pequeña durante toda la obra, y por lo tanto la presión permanece constante e igual al empuje al reposo Ko.

En la parte inferior de la excavación, sin embargo, el movimiento de la tablestaca es notable, y por lo tanto tienden a desarrollarse presiones activas $K_{a}$. De esta manera, las presiones en el terreno no se apartan de la forma clásica. En base a estas consideraciones, Terzaghi y Peck propusieron utilizar diagramas de presión del terreno envolventes de la evolución de tensiones aparentes como los de la (Fig. 3-31). 


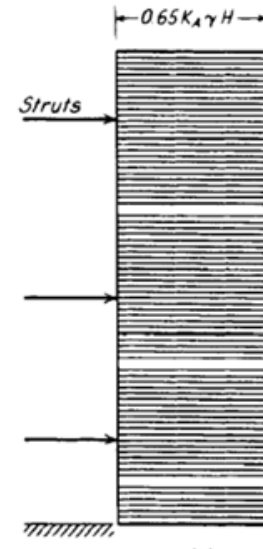

(b)
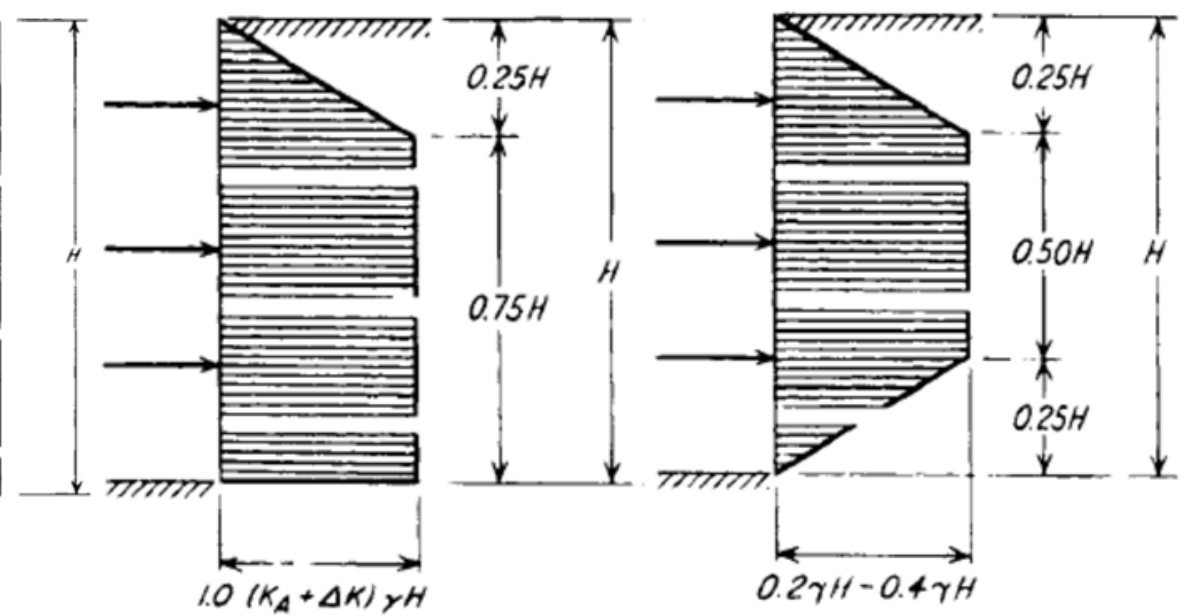

Fig. 3-31 Diagramas de presiones aparentes propuesto por Peck (Terzaghi et al., 1996). (izda.) Arenas. (cent.) Arcillas medias a blandas. (dcha.) Arcillas rígidas y fisuradas.

\subsubsection{Métodos de interacción suelo-estructura}

La resolución del problema de interacción suelo-pantalla conlleva la integración de una ecuación diferencial de $4^{\circ}$ orden. Esto fue por sí mismo un problema que retrasó la aplicación del método de interacción pantalla-estructura durante un largo periodo de tiempo, hasta que su resolución numérica fue viable. A partir del final la década de los años 60 del s. XX, las capacidades de cálculo computacional se habían desarrollado lo suficiente como para permitir abordar el problema desde la perspectiva de la integración numérica directa, y del análisis conjunto del suelo y de la estructura para determinar su interacción mutua.

\subsection{Métodos tipo Winkler}

A partir de los años 50 del s. XX, en base las hipótesis de comportamiento basadas en el modelo de fundación elástica de Winkler (Winkler, 1867), y con los limitados métodos de cálculo disponibles en la época, varios autores propusieron métodos simplificados para reducir las tensiones calculadas mediante el método de terreno libre, para una casuística de pantallas de contención. De entre ellos, Rowe (Rowe, 1955) fue el primero en emplear el módulo de balasto para producir ábacos de cálculo, que dan cuenta de la influencia de la flexibilidad de un muro anclado en cabeza y empotrado en el terreno, en la determinación de las tensiones de reacción en el empotramiento para un terreno no cohesivo, pero considerando que la acción solicitante en la parte libre de la pantalla corresponde a una ley de empuje activo. 
Más adelante, Turabi y Balla (Turabi y Balla, 1968) propusieron una modelización del terreno mediante una fundación elástica de Winkler, asignando un estado de empuje al reposo a aquellos puntos de la pantalla que no sufren desplazamiento horizontal, y variando este empuje linealmente (elásticamente) en función del desplazamiento de la pantalla.

Por su parte, Haliburton (Haliburton, 1968) complementó el método anterior proponiendo un modelo de respuesta del suelo no lineal, en forma de muelle de Winkler con módulo de balasto $K_{h}$, pero asignando umbrales de valores mínimos y máximos de la reacción que este puede asumir, correspondientes a los estados de fallo activo $K_{a}$ y pasivo $K_{p}$ (Fig. 3-32, izda.). En la misma línea, Castillo-Ron (Castillo-Ron, 1973) propone una modificación al concepto expuesto por Haliburton, y plantea una modificación para los casos de recarga con deformación remanente, y excavación.

Una de las ventajas más significativas del método propuesto por Haliburton, y que lo aleja del tratamiento clásico del problema, es su gran generalidad, y con la consiguiente posibilidad de considerar diferentes condiciones de contorno; pudiendo considerar apoyos a diferentes niveles, e incluso reproducir la evolución de las tensiones en el terreno y los esfuerzos en las pantallas a lo largo del proceso constructivo, con los correspondientes cambios de tensión de estado activo a pasivo, reducción de estas tensiones debido a las eventuales excavaciones (Fig. 3-32 y Fig. 3-33), modificaciones en las condiciones de apoyo, etc.
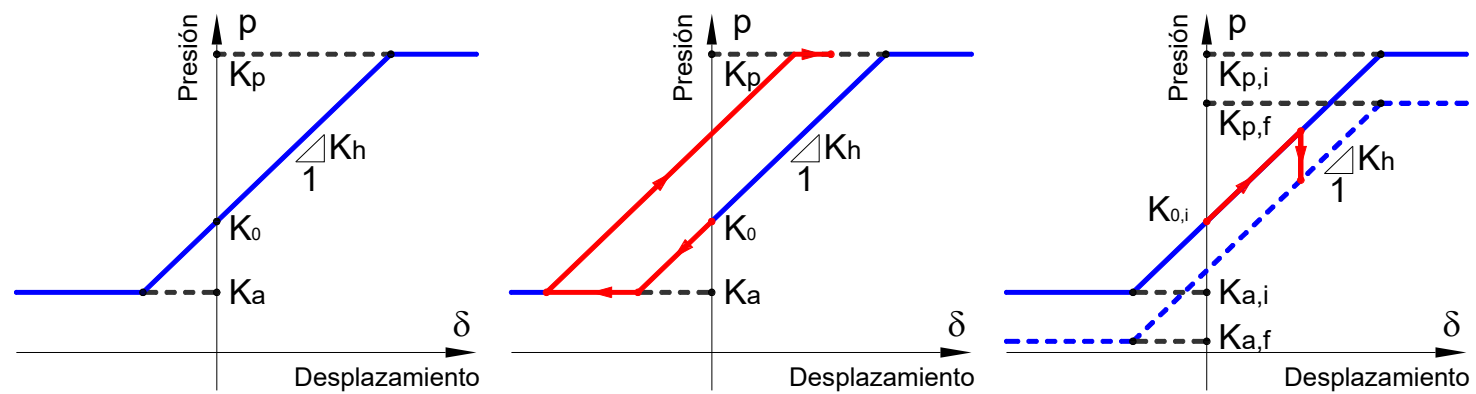

Fig. 3-32 Modelo de carga propuesto por Haliburton (1968) y modificaciones de Castillo-Ron (1973), donde $K_{0}$ es el coeficiente de empuje al reposo, $K_{a}$ el coeficiente de empuje activo, y $K_{p}$ el coeficiente de empuje pasivo. (izda) La curva azul indica la presión correspondiente a un punto de la pantalla en función de la deformación que experimenta para carga noval. (cent) Estado de carga para un punto de la pantalla que ha sufrido una deformación cíclica, pasando de un estado activo $K_{a}$ a uno pasivo $K_{p}$ debido al proceso constructivo. (dcha) Estado de carga para un punto de la pantalla que ha sufrido primero una carga elástica de reacción, y una excavación posteriormente. 
Esta metodología de análisis fue rápidamente puesta en práctica mediante el desarrollo de varios programas de cálculo en la década de los 70 del s. XX, entre otros, por el programa de cálculo RIDO (Fages, R., Bouyat, C. 1971a, 1971b), un programa que se ha convertido en el estándar de facto utilizado en la mayor parte de obras de Metro de Madrid (Caro-Perdigón, 2015; Sanhueza-Plaza, 2008).

Por otra parte, esta metodología difiere de otras aplicaciones de la fundación elástica de Winkler, como puede ser por ejemplo la distribución de tensiones en una zapata, en un aspecto fundamental. En el caso de una zapata la acción ejercida sobre ella es un dato independiente de las características del terreno y del coeficiente de balasto del mismo. La rigidez del terreno jugará un papel en la distribución de tensiones bajo la zapata, pero es independiente de la acción. Sin embargo, en el caso de estructuras de contención, es la propia flexibilidad de la fundación de Winkler comparada con la rigidez de la estructura la que produce tanto la acción como la distribución de tensiones en forma de reacción.

Para implementar el método en la práctica, los problemas de acción y reacción se tratan de manera separada. Por un lado, se aplica una carga correspondiente a un estado de empuje al reposo $K_{0}$ bajo la hipótesis de deformación nula de la estructura, para más tarde, en base a la deformada obtenida para esta carga, establecer la carga correspondiente a los desplazamientos con un modelo como el de la Fig. 3-33. Procediendo iterativamente con sucesivos estados de carga obtenidos a partir de la deformada anterior se alcanza el estado final correspondiente a la fase de construcción en estudio. 


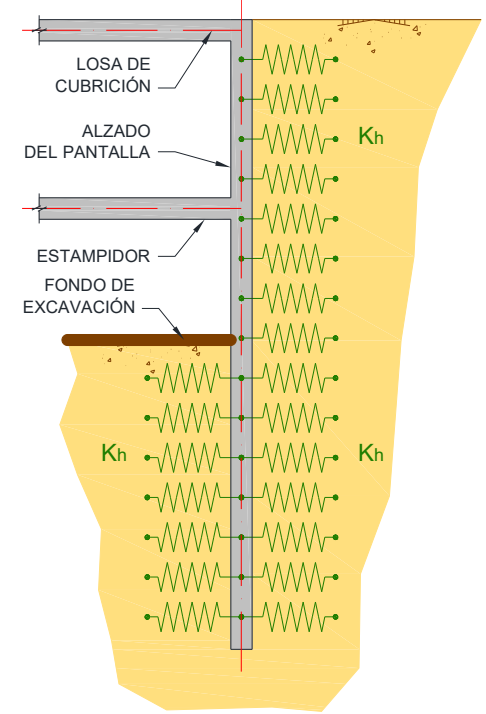

MODELO DE CÁLCULO

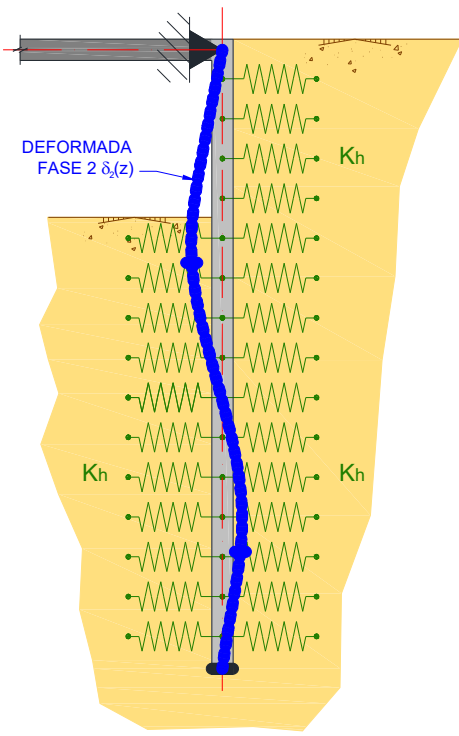

FASE 2: EXCAVACIÓN 1

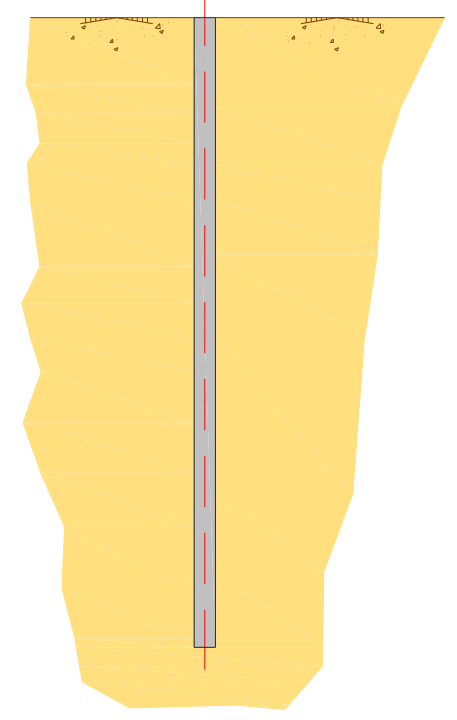

FASE 0: PANTALLA

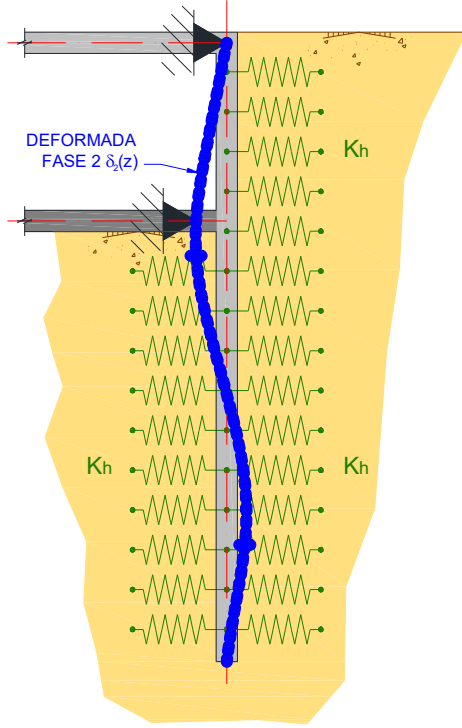

FASE 3: ESTAMPIDOR INTERMEDIO

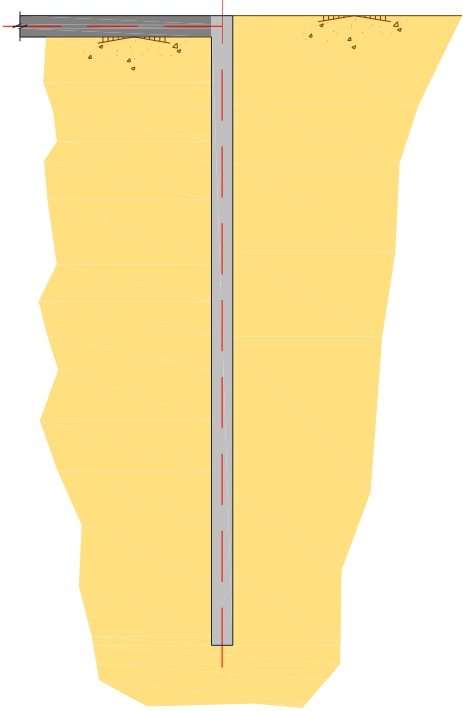

FASE 1: LOSA DE CUBRICIÓN

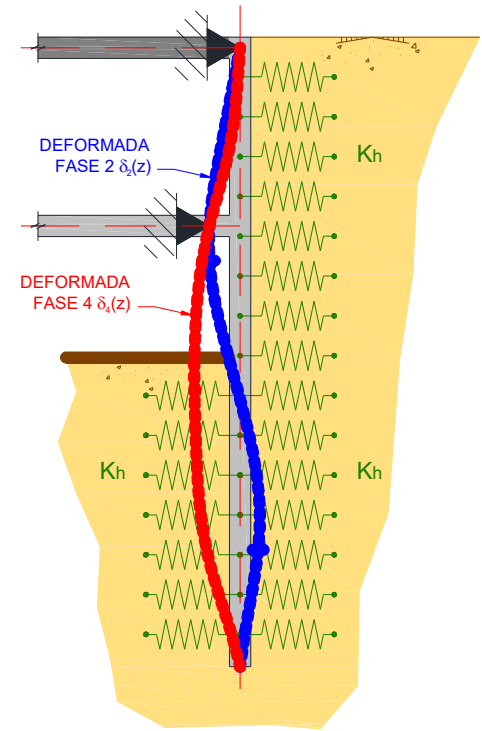

FASE 4: EXCAVACIÓN 2

Fig. 3-33 Modelo conceptual de Haliburton (1968), y fases constructivas con sus correspondientes desplazamientos horizontales en las pantallas a los que corresponden diferentes estados de presión.

\subsection{Métodos numéricos de elementos finitos}

La aplicación del método de los elementos finitos a los problemas geotécnicos comienza con los estudios de Clough sobre presas (Clough y Woodward, 1967), y a los muros de contención (Duncan y Clough, 1971), y en la década de los años 70 del s. XX aparecen los primeros estudios que emplean este método para el análisis de pantallas.

Sin embargo, la aplicación práctica y cotidiana del método de los elementos finitos en el campo de la geotecnia no es tan generalizada como cabría esperar incluso a día de 
hoy, exceptuando el caso de los túneles (Delattre, 2004). Una de las razones posibles que puede aducirse para explicar el por qué este método no se haya extendido puede ser que los métodos tradicionales descritos anteriormente han sido capaces de dar respuesta a las necesidades de análisis y dimensionamiento de las obras, de cara a su resistencia a la ruptura. Otra razón, ligada a la especificidad de los problemas geotécnicos, es la difícil modelización de los materiales naturales geotécnicos (suelos de diverso origen y características), frente a los materiales industriales de construcción (hormigón y acero) (Delattre, 2004).

\subsection{La acción dinámica del terreno en campo libre}

De manera general, la acción sísmica queda representada en la ubicación de interés por un registro de los movimientos que se han desarrollado en la superficie del terreno durante un evento determinado (Samartín, 2008). Este registro de movimientos suele concretarse en un registro de aceleraciones o acelerograma, cuyas características dependen en gran medida del propósito para el cual se lleve a cabo la medida del movimiento: estudios sismológicos, o estudios de ingeniería sísmica.

Los registros orientados a los estudios sismológicos se centran en la obtención mediante sismógrafos de los movimientos originados por un terremoto a distancias lejanas, y muy lejanas (distancias denominadas telesísmicas), del epicentro del evento sísmico. De esta manera se puede resolver con mayor precisión la ubicación del hipocentro y mecanismo focal del mismo, mediante la medida de la diferencia de tiempos de llegada, y polaridad de las diferentes fases de las ondas sísmicas (Stein y Wysession, 2009). Por lo general se trata de registros de gran precisión llevados a cabo con dispositivos de gran sensibilidad que miden aceleraciones del orden de microgals.

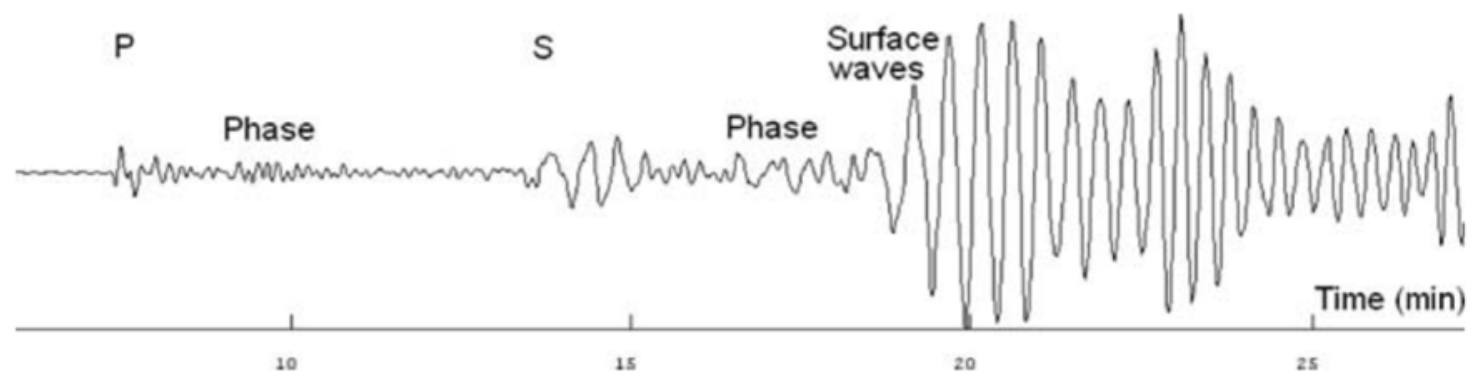

Fig. 3-34. Ejemplo de sismograma de un terremoto $M$ 6.2, registrado a una distancia telesísmica de $4200 \mathrm{~km}$. A esta distancia pueden diferenciarse claramente los tiempos de llegada de las fases de ondas $P, S$, y superficiales respectivamente (Havskov, 2010). 
Los registros orientados a los estudios de ingeniería sísmica, sin embrago, se centran en la obtención de movimientos a distancias cercanas a la fuente del terremoto (inferiores por lo general al orden de magnitud de los $100 \mathrm{~km}$ ), y miden aceleraciones del orden de décimas de la aceleración de la gravedad $g$. En estos registros el interés principal es la medida directa de los movimientos en superficie que eventualmente pueden afectar a las obras públicas. Estos registros de aceleraciones en superficie proporcionan una representación fidedigna del movimiento ocurrido en el área de influencia significativa del sismo, denominado movimiento en campo libre (por oposición al movimiento cercano a las estructuras que puede verse influido por la presencia de estas), y son la base a partir de la cual se desarrolla el tratamiento normativo de la acción sísmica en los códigos de construcción sismorresistente.

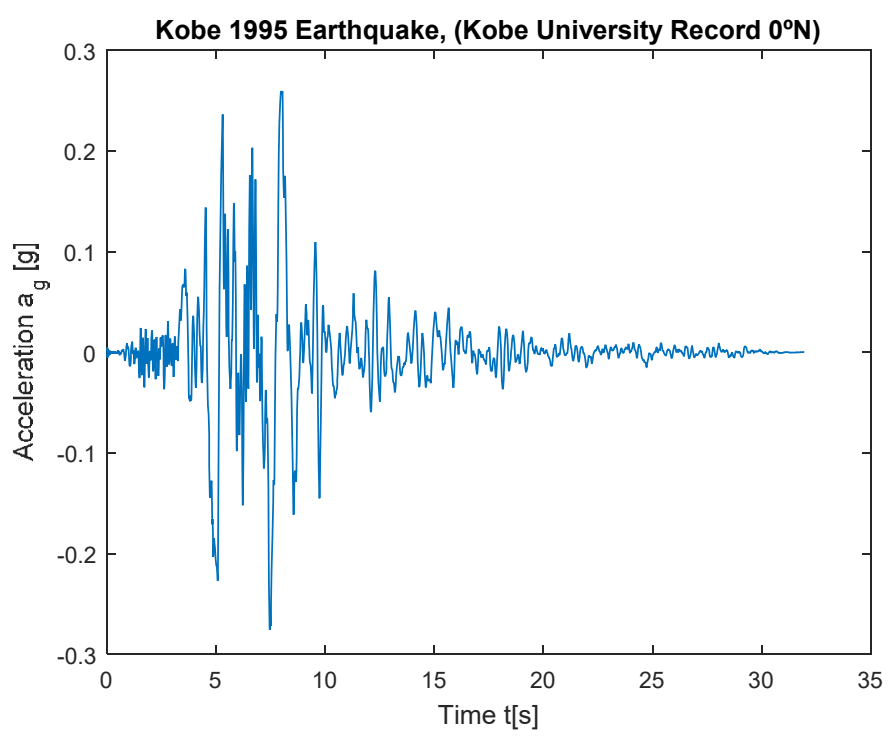

Fig. 3-35. Acelerograma del terremoto del 16 de Enero de 1995 de Kobe M 6.9 (PEER Strong Ground

Motion Database. Universidad de Kobe a una distancia $\boldsymbol{R}_{\boldsymbol{j b}}=\mathbf{9 0 0} \mathrm{m}$ )

En los siguientes apartados, se realiza una breve síntesis del estado del arte en lo que se refiere a la determinación de la acción sísmica en el terreno, mediante los denominados estudios probabilistas de peligrosidad sísmica (PSHA, Probabilistic Seismic Hazard Analysis en la literatura anglosajona).

\subsubsection{Estudios probabilistas de peligrosidad sísmica}

\subsubsection{Marco conceptual de los estudios de peligrosidad sísmica}

El objetivo fundamental de un estudio de peligrosidad sísmica es caracterizar la acción sísmica que puede producirse en una ubicación específica en términos de 
probabilidad de alguna medida del movimiento. Generalmente se concretan en la obtención de espectros (descritos en el apartado §3.2.1 de esta tesis) de peligrosidad uniforme en términos de aceleraciones (UHS, Uniform Hazard Spectra).

La peligrosidad sísmica de un emplazamiento se define como la probabilidad de excedencia de un determinado nivel de movimiento del terreno como resultado de la acción de terremotos en el área de influencia, durante un periodo de tiempo especificado (Benito \& Torres, 2009). Si se denomina de manera genérica IM (Intensity Measure en inglés) al nivel de movimiento (p.ej. aceleración máxima del terreno, PGA) cuya probabilidad de excedencia se quiere determinar en el emplazamiento $E$, y $t$ al periodo de tiempo durante el cual se pretende evaluar la peligrosidad $H$ (de hazard en inglés), dicha peligrosidad se define mediante la expresión (Ec. 3-18), donde el símbolo 'l' indica condicionalidad en el sentido probabilista .

$$
H=P[I M \geq \boldsymbol{x} \mid \text { emplazamiento } \boldsymbol{E} \mid \boldsymbol{t} \text { años }]
$$

Esta expresión (Ec. 3-18) muestra las dependencias fundamentales de la peligrosidad: por un lado, es necesario obtener algún tipo de descripción temporal $\boldsymbol{t}$ de cómo de frecuentes son los terremotos en la zona de estudio, por otro lado, evaluar la distancia a la obra $\boldsymbol{E}$ de dichos terremotos, y finalmente evaluar cual es la relación que hay entre dichos terremotos y la excedencia del umbral de intensidad fijado $I M \geq x$.

Basándose en el teorema de probabilidad total de Bayes, que indica que la probabilidad total de sucesos independientes y mutuamente excluyentes es la suma de las probabilidades individuales de cada suceso, Cornell (Cornell, 1968) estableció que la frecuencia anual de excedencia de una determinada intensidad $\lambda(I M \geq x)$ (probabilidad anual $\lambda$ de que se sobrepase una determinada aceleración), puede calcularse mediante la siguiente expresión (Ec. 3-19), denominada integral de peligrosidad.

$$
\lambda(I M>x)=\int_{0}^{r_{\max }} \int_{m_{\min }}^{m_{\max }} P(I M>x \mid m, r) \cdot f_{R}(r \mid m) \cdot f_{M}(m) \cdot d r \cdot d m
$$

El sentido de esta integral es simplemente el de la suma de una serie de escenarios, o más concretamente, la suma de probabilidades de que se sobrepase un nivel de aceleración $P\left(I M>_{x} \mid m, r\right)$ para cada uno de los escenarios posibles de terremotos. Estos escenarios de terremotos están descritos por la probabilidad temporal de ocurrencia $f_{M}(m)$ 
(probabilidad anual de que se produzca un terremoto de magnitud $m$ ), y por la probabilidad de que dicho terremoto de magnitud $m$ se produzca a una distancia $r$ del sitio de interés $f_{R}(r \mid m)$. Sumando todas las contribuciones individuales de probabilidad de excedencia para cada escenario magnitud-distancia posible (par $m-r$ ), se obtiene la probabilidad total anual de excedencia de esa intensidad $x$.

La evaluación de la integral requiere el conocer los tres elementos que componen el integrando. Para ello, los estudios de peligrosidad sísmica se dividen en 3 partes:

- Obtención del término $f_{M}(m)$. Es decir, obtener una descripción estadística de la frecuencia de los terremotos de cada magnitud $m$. Este paso se realiza mediante las relaciones frecuencia-magnitud, descritas en el §3.5.1.2.

- Obtención del término $f_{R}(r \mid m)$. Es decir, obtener una descripción estadística de la probabilidad de que un terremoto, de magnitud $m$, se produzca a una distancia $r$. Este paso se realiza mediante las relaciones magnitud-geometría, descritas en el apartado §3.5.1.3.

- Obtención del término $P\left(I M>_{x} \mid m, r\right)$. Es decir, obtener una descripción estadística de la probabilidad de que un terremoto de magnitud $m$, a una distancia $r$, supere el valor de aceleración $x$. Este paso se realiza mediante las relaciones de atenuación, descritas en el apartado §3.5.1.4.

Obtenidos estos pasos intermedios, se realiza el cálculo de la integral y se obtienen las denominadas curvas de peligrosidad, que se describen en el apartado §3.5.1.5.

Por otra parte, puesto que la elección de cada uno de los parámetros físicos que intervienen en cada uno de los elementos indicados más arriba viene sancionada por la interpretación, hasta cierto punto subjetiva, del analista que desarrolla el estudio PSHA, $\mathrm{y}$ puesto que diversos criterios de elección pueden tener una justificación racional igualmente válida, es común introducir un esquema de árbol lógico para ponderar estadísticamente cada una de las alternativas. El proceso de árbol lógico se describe en el apartado 33.5 .1 .6 .

Finalmente, puesto que la resolución de la integral de peligrosidad (Ec. 3-19) proporciona tan sólo la probabilidad anual (de cada año individual) de sobrepasar un umbral de aceleración, es necesario realizar una proyección en el tiempo de dicha probabilidad, para conocer cual es la probabilidad de excedencia de dicho umbral en un 
determinado lapso de tiempo, tal como la vida útil de la obra. Este proceso se describe en el apartado $\S 3.5 .1 .7$

\subsubsection{Relaciones de frecuencia-magnitud del sismo}

El primer paso en un estudio PSHA consiste en obtener una descripción geográfica de las zonas en las que puede generase un sismo (llamadas indistintamente zonas sismogenéticas o zonas sismogénicas). Este paso en general requiere de la identificación geométrica de las posibles grandes zonas de subducción de placas, y de la identificación de las fallas corticales activas del cuaternario (Fig. 3-36), en lo que se denomina determinación del ambiente sismotectónico.
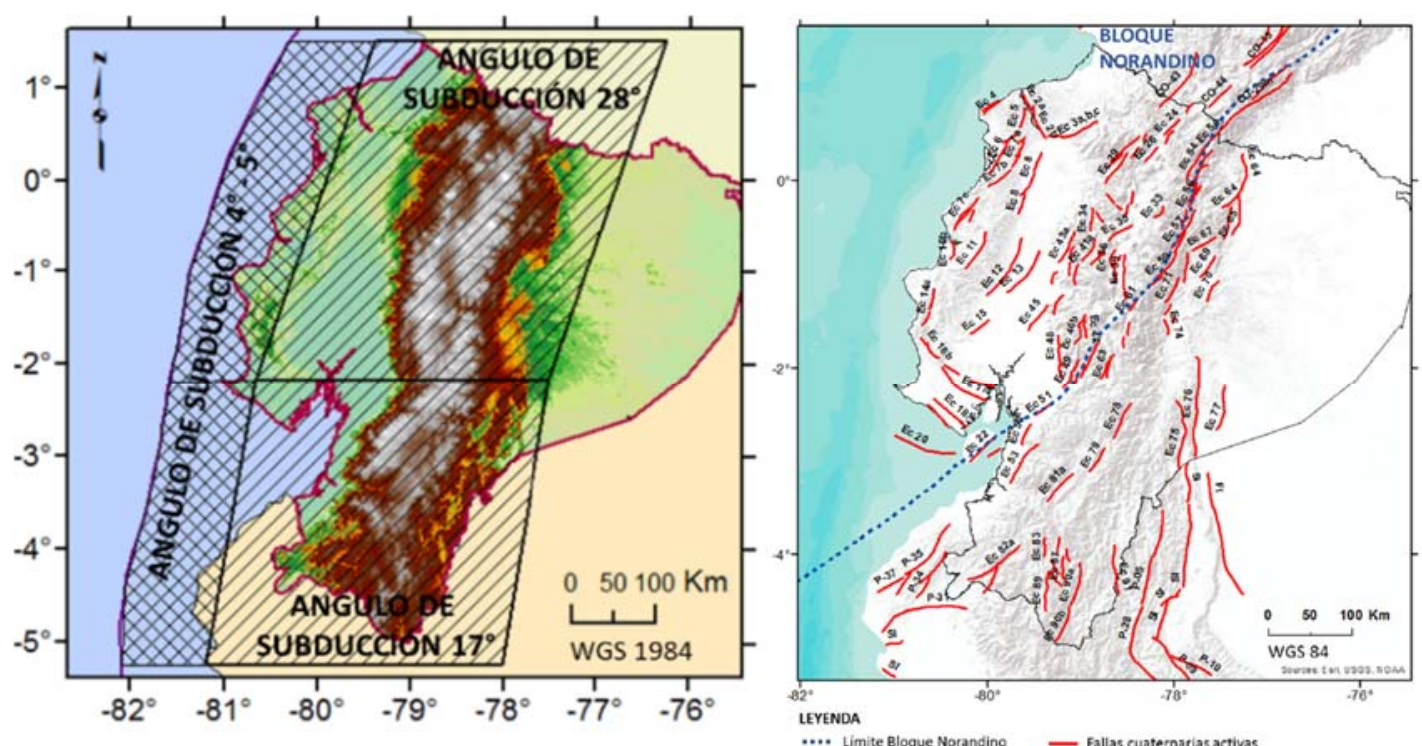

Fig. 3-36. Ubicación de fuentes sismogenéticas principales de Ecuador. (izda.) Zonas de subducción. (dcha.) Fallas activas del Cuaternario. (Parra et al., 2018).

De manera paralela, es necesario obtener un catálogo de los terremotos ocurridos en dichas fuentes sismogenéticas, y en general en toda la zona de estudio. Si la densidad de datos del catálogo es suficiente, puede adscribirse cada terremoto a cada una de las fuentes. Si el catálogo es más escaso, cada sismo se agrupa en las denominadas zonas sismogenéticas, que son delimitaciones geográficas poligonales que contienen una o varias fuentes, y a las que por algún criterio sismotectónico o geológico se les puede suponer un comportamiento más o menos uniforme. Los criterios por los cuales se establecen estas zonificaciones suelen estar sujetos a gran discrecionalidad, y por ello no es infrecuente que diversos analistas propongan diferentes zonificaciones, en base a 
criterios que en principio son igualmente racionales (Fig. 3-37). La zonificación es por lo tanto un elemento importante a integrar en los árboles lógicos descritos en §3.5.1.6.

A.

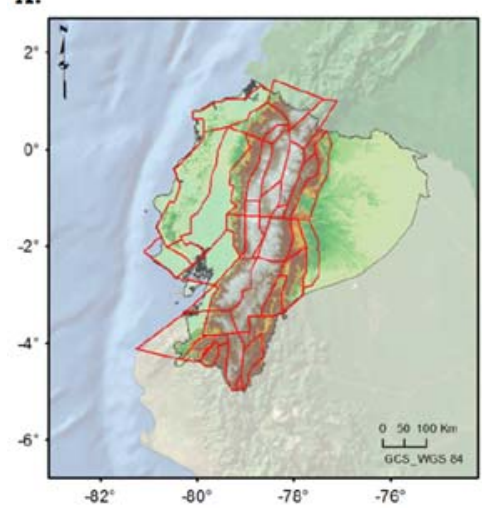

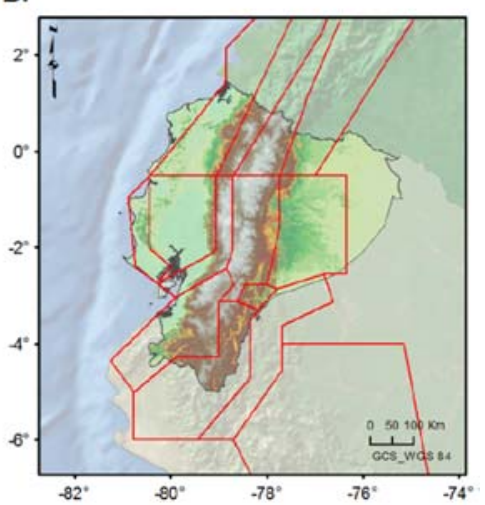

c.

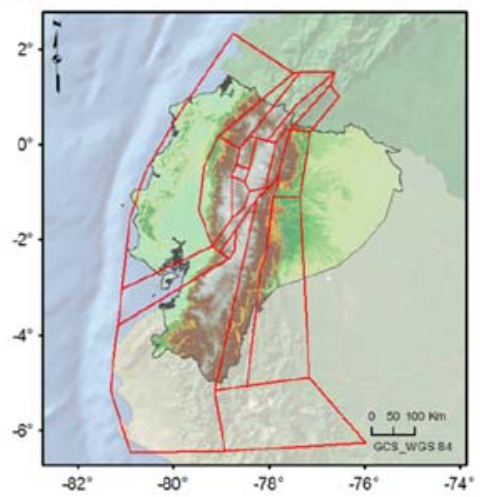

Fig. 3-37. Tres zonificaciones diferentes de Ecuador para sismos corticales. (Parra et al., 2018).

Para confeccionar un catálogo es necesario recopilar datos de eventos estadísticamente independientes (descartando réplicas y premonitorios), ubicándolos en posición y en el tiempo, y caracterizándolos por una escala común de magnitud, habitualmente escala magnitud-momento $M_{w}$ (Hanks \& Kanamori, 1979). Esta etapa puede conllevar pasos intermedios de transformación entre escalas locales, o intensidades macrosísmicas, a escala $M_{w}$, en lo que se denomina homogeneización del catálago.
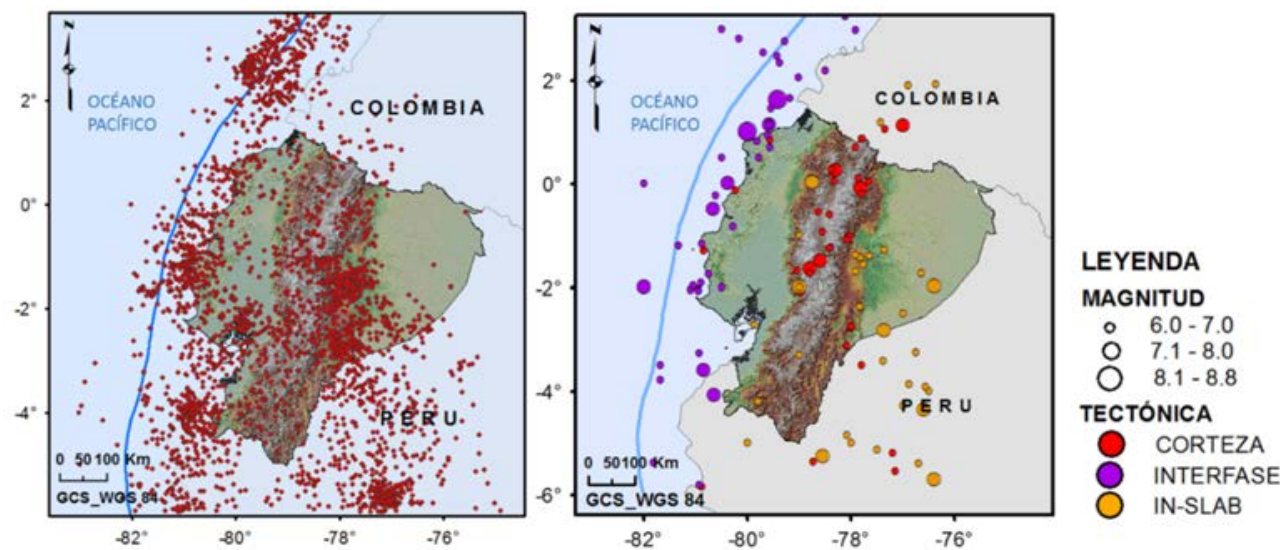

Fig. 3-38. Catálogo sísmico de Ecuador. (izda) Epicentros de eventos $M_{w} \geq 4$. (dcha.) Epicentros y adscripción focal de eventos $M_{w} \geq 6$. (Parra et al., 2018).

Para generar un catálogo fiable es necesario determinar cual es la magnitud más pequeña del catálogo, es decir, cual es la magnitud más pequeña que se asume que puede producir un movimiento significativo, y si el catálogo incorpora sismos históricos obtenidos con datos no instrumentales, determinar cual es la magnitud más pequeña para la cual se supone que el catálogo está completo (es más que probable que los terremotos 
antiguos de los que sólo se tiene una descripción somera en algún relato histórico abarquen sólo terremotos significativos) (Martinez-Solares \& Mezcua-Rodriguez, 2002).

En base a los terremotos del catálogo que se adscriben a cada zona sismogenética, se puede elaborar lo que se denomina una distribución de número acumulado de terremotos y de sus magnitudes. Gutenberg y Richter (Gutenberg \& Richter, 1944) determinaron que la distribución acumulada de número de terremotos de una magnitud $m \geq M$ seguía una ley del tipo (Ec. 3-20) en California. En esta fórmula, denominada ley Gutenberg-Richter (G-R de forma abreviada), a representa un parámetro de sismicidad absoluta (cuantos terremotos hay), y $b$ un parámetro que indica la proporción de tamaños de terremotos (cuantos terremotos grandes hay, relativo al número de terremotos pequeños). También determinaron que el valor de $b$ suele ser $b \approx 1$, estableciendo que los terremotos una magnitud mayor son del orden de 10 veces menos frecuentes (Fig. 3-39, izda). Este modelo ha resultado de aplicación generalizada en todo el mundo, cuando se han examinado catálogos sísmicos de diversas regiones.

$$
\log _{10} N(m \geq M)=a-b \cdot M
$$
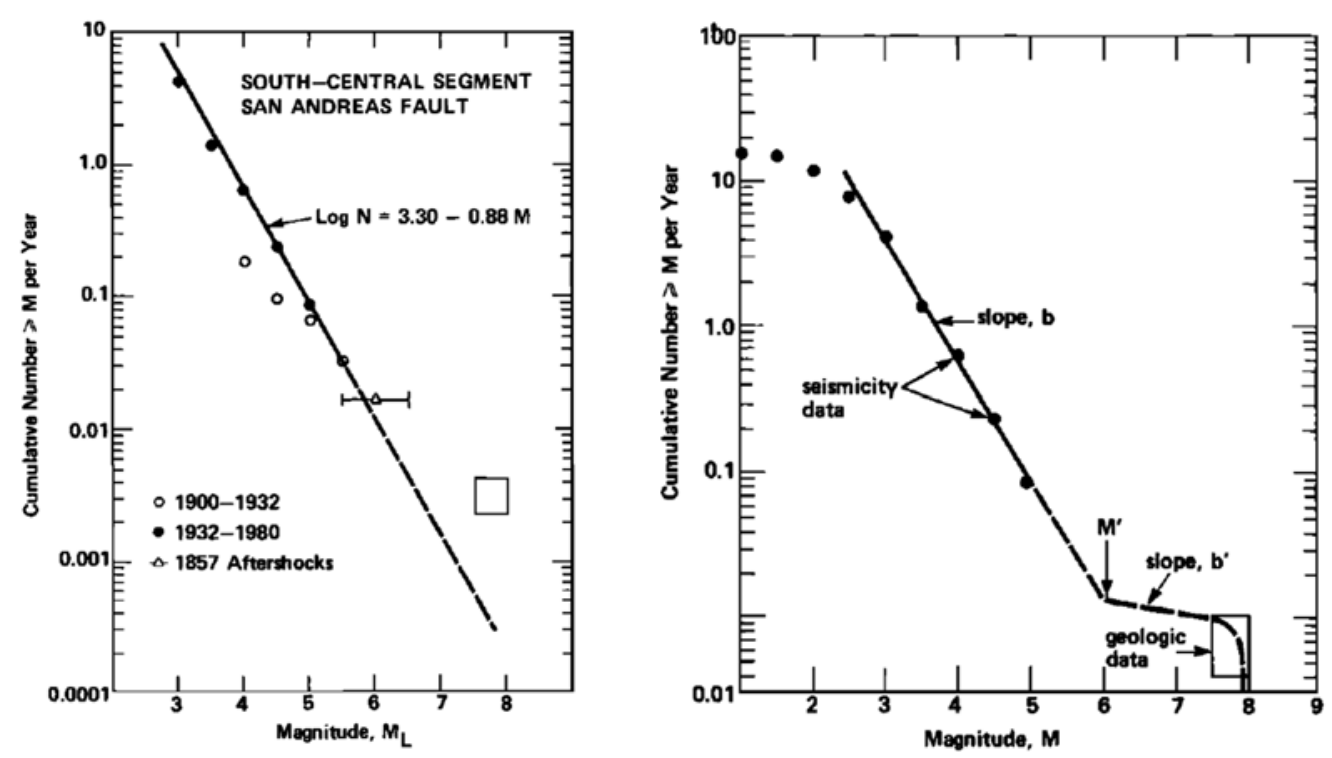

Fig. 3-39. Modelos magnitud vs. Número acumulado de terremotos. (izda) Ajuste a ley Guttenberg-

Richter. (dcha.) Ajuste a ley de terremoto característico. (Schwartz \& Coppersmith, 1984).

En ocasiones, los datos disponibles indican que hay más terremotos de magnitudes grandes que los que se predicen con la expresión de Gutenberg-Richter. Para estos casos, es frecuente emplear el modelo característico desarrollado de Schwartz y Coppersmith (Schwartz \& Coppersmith, 1984), representado en la (Fig. 3-39, dcha.). 
Si se asume una distribución uniforme de los terremotos en el tiempo (para grandes periodos de tiempo, los terremotos de una determinada magnitud ocurren de media cada cierto número de años), dividiendo las distribuciones $N(m \geq M)$ por la duración temporal del catálogo se obtiene $\lambda(m \geq M)$, la frecuencia anual de ocurrencia de terremotos de magnitud igual o mayor que $M$. Adicionalmente, si se quiere saber la frecuencia anual de ocurrencia de terremotos de una determinada magnitud $M$ (p.ej. cuantos terremotos ocurren al año de magnitud $M=5$ ), se puede restar las frecuencias anuales para dos valores de magnitud cercanos a esa magnitud $M$ (p.ej. $M=5+0,25=5,25$ y $M=5-0,25=4,75$ ), según la expresión (Ec. 3-21).

$$
\lambda(m=M)=\lambda(m \geq M+\Delta M)-\lambda(m \geq M-\Delta M)
$$

Con la obtención de esta expresión se ha completado el primer paso del análisis PSHA, es decir, se ha determinado la distribución temporal de terremotos de una determinada magnitud $f_{M}(m)$ de la integral de peligrosidad (Ec. 3-19).

\subsubsection{Relaciones magnitud-geometría de la ruptura}

La magnitud de un evento sísmico está íntimamente relacionada con las dimensiones físicas del área de ruptura de la falla (Fig. 3-40). La definición de momento sísmico Mo mediante la expresión (Ec. 3-22) (Kanamori, 1977) es la descripción física del tamaño de un sismo, en la que $A$ es el área de ruptura de la falla en $\left[\mathrm{cm}^{2}\right], \mu$ es el módulo de cortante de la roca en $\left[\mathrm{dyn} / \mathrm{cm}^{2}\right], y \Delta$ el desplazamiento medio que se produce en el área de ruptura. Esta entidad física, en la escala logarítmica de la expresión (Ec. 3-23) proporciona la denominada magnitud-momento $M_{w}$ o simplemente magnitud $M$.

$$
\begin{gathered}
M_{0}=A \cdot \Delta \cdot \mu \\
M_{W}=\frac{2}{3} \log _{10}\left(M_{0}\right)-10.7
\end{gathered}
$$



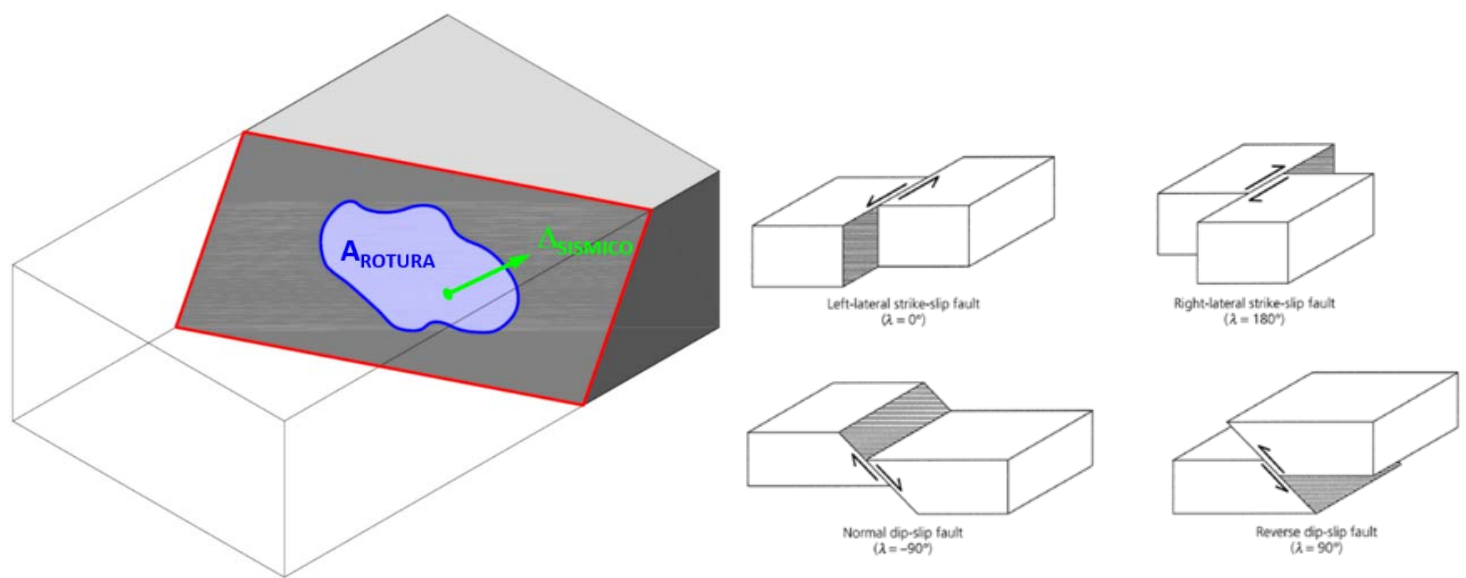

Fig. 3-40. (izda.) Geometría de la zona de ruptura de falla. (dcha.) Tipos de falla. (Stein \& Wysession, 2003).

Por otra parte Wells y Coppersmith (Wells \& Coppersmith, 1994) establecieron varias correlaciones empíricas entre la longitud de ruptura de un segmento de falla y la magnitud, del área de falla rota y de la magnitud, así como del desplazamiento cosísimico y la magnitud (Fig. 3-41).
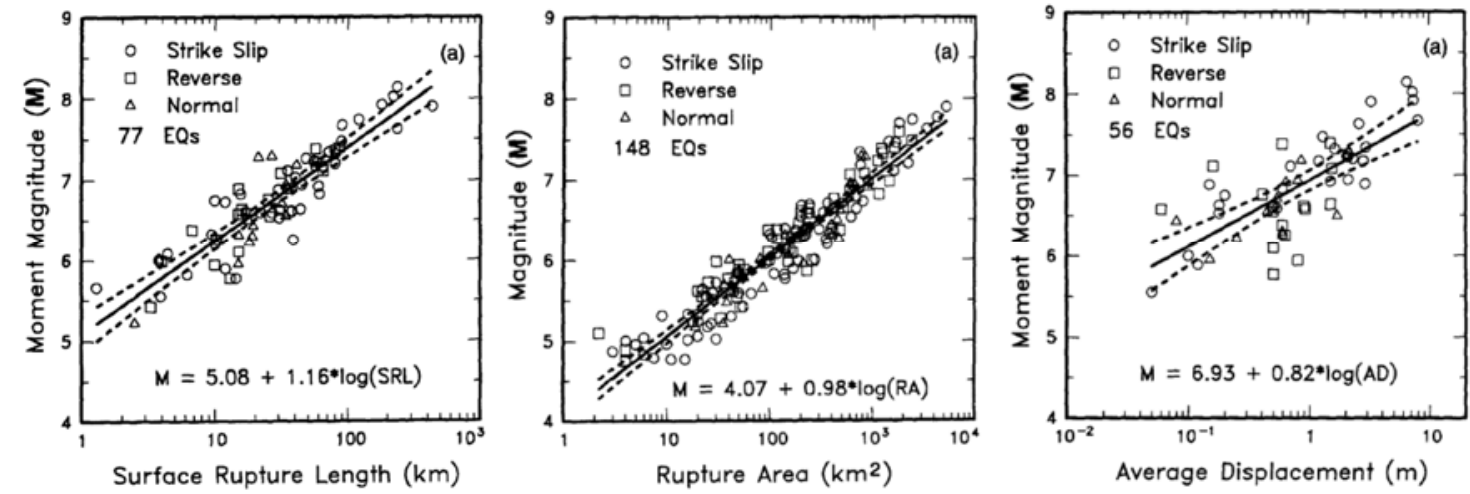

Fig. 3-41. Relaciones de Wells y Coppersmith (izda.) Longitud de falla rota vs. $M_{w}$. (dcha.) Área de falla rota vs. $M_{w}$. (dcha.) Desplazamiento cosísmico vs. $M_{w}$. (Wells \& Coppersmith, 1994).

En base al marco de estudio probabilista planteado por Cornell (Cornell, 1968), y a las relaciones de Wells y Coppersmith de longitud-M y área-M, se puede plantear cual es la probabilidad $F_{R}(R \leq r \mid m)$ de que ocurra un sismo de magnitud $m$ a una determinada distancia $r$ o menor del emplazamiento de interés. Para ello, se estudia el número de posiciones en las que la zona de ruptura está a una distancia menor que $r$ frente al número total de posibles posiciones dentro de la falla. Este análisis proporciona una distribución de probabilidad acumulada $F_{R}(R \leq r \mid m)$, del tipo de la (Ec. 3-24) desarrollada para una falla rectilínea de $L_{F A L L A}=100 \mathrm{~km}$ con un sitio de interés próximo al final de la falla una distancia $d=10 \mathrm{~km}$ de la (Fig. 3-42, izda.). 

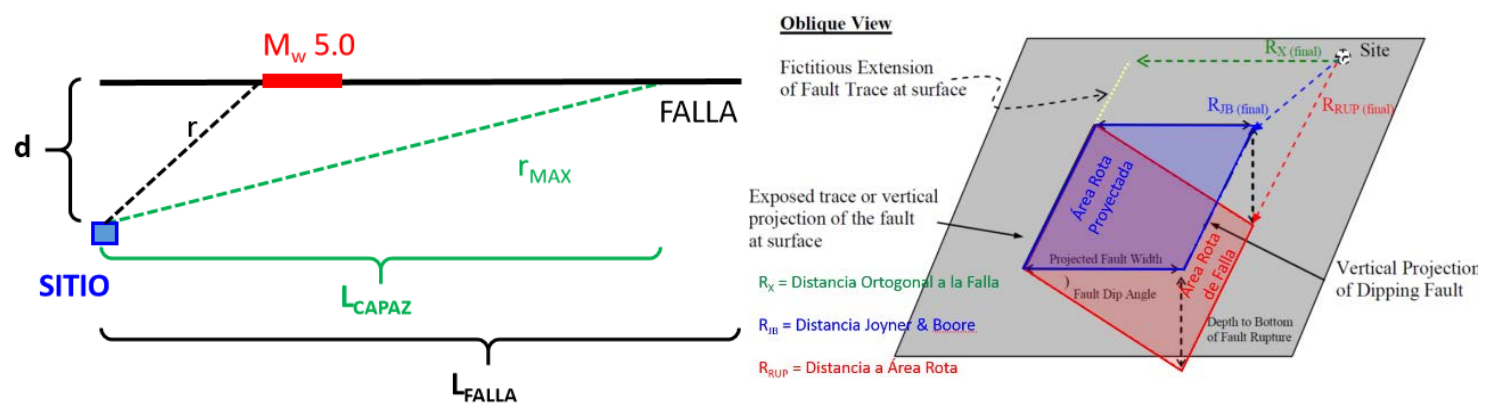

Fig. 3-42. Esquema geométrico de ubicación de un sismo respecto al sitio de interés (izda.) Para una falla vertical (dcha.) Para una falla inclinada, con diferentes definiciones de distancia $R_{j b}, R_{x}$, $\boldsymbol{R}_{\text {RUP. }}$

Geometrías más complejas de falla proporcionarán expresiones de distribuciones más complejas, o que sólo se puedan analizar por métodos numéricos, pero el esquema conceptual subyacente será el mismo descrito anteriormente.

$$
F_{R}(R \leq r \mid m)=\left\{\begin{array}{ccc}
0 & \text { si } r<d \\
\frac{\sqrt{r^{2}-d^{2}}}{L_{\text {capaz }}} & \text { si } d \leq r \leq r_{\max } \\
1 & \text { si } r>r_{\max }
\end{array} \quad f_{R}(r \mid m)=\left\{\begin{array}{cc}
0 & \text { si } r<d \\
\frac{r}{2 L_{\text {capaz }} \sqrt{r^{2}-d^{2}}} & \text { si } d \leq r \leq r_{\text {max }} \\
0 & \text { si } r>r_{\text {max }}
\end{array}\right.\right.
$$

(Ec. 3-24)

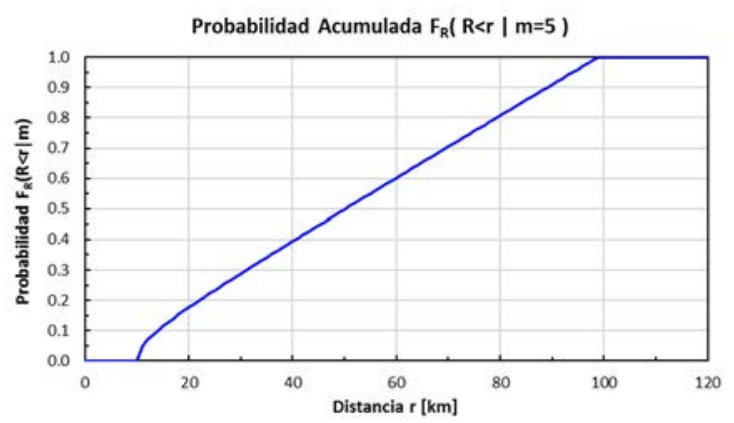

(Ec. 3-25)

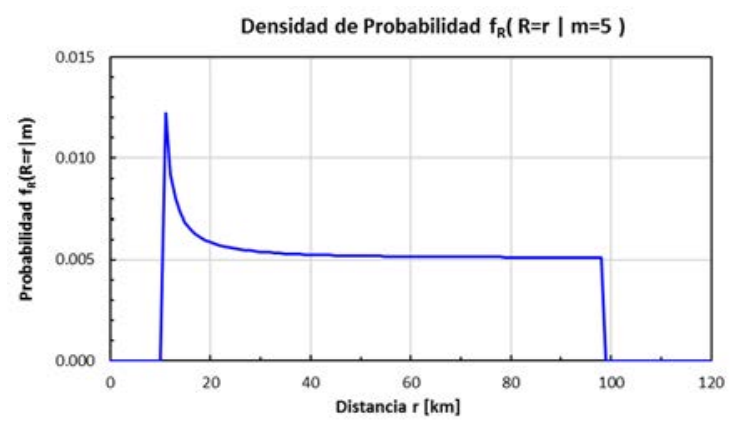

Fig. 3-43. (izda.) Probabilidad acumulada $F_{R}(R \leq r \mid m)$ de la (Ec. 3-24). (dcha.) Densidad de probabilidad $f_{R}(r \mid m)$ de la (Ec. 3-25).

Con la obtención de esta expresión (Ec. 3-25) se ha completado el segundo paso del análisis PSHA, es decir, se ha determinado la distribución espacial de terremotos de una determinada magnitud $f_{R}(r \mid m)$ de la integral de peligrosidad (Ec. 3-19).

\subsubsection{Relaciones de atenuación para la predicción del movimiento del terreno}

Mediante el análisis riguroso de bases de datos, mundiales o regionales, de las aceleraciones máximas correspondientes a diferentes periodos de oscilación, es posible obtener regresiones estadísticas que relacionen esencialmente la aceleración máxima 
(p.ej. la PGA, o la aceleración espectral para $\mathrm{T}=1 \mathrm{~s} S_{a, 1 s}$ ) para diferentes magnitudes de sismo, ocurridos a diferentes distancias. Debido a esta relación aceleración-distancia estas regresiones recibieron en sus orígenes el nombre de relaciones de atenuación; actualmente los modelos estadísticos empleados son tan complejos y detallados que se han pasado a denominar GMPE o GMPM (Ground Motion Prediction Equations ó Models). Las GMPE se desarrollan específicamente para algún tipo de mecanismo focal y región en función de qué tipo de terremotos se emplee para su confección. Así hay relaciones GMPE para terremotos corticales (Abrahamson, Silva, \& Kamai, 2014; Akkar, Sandikkaya, \& Bommer, 2014; Atkinson \& Silva, 1997; Boore, Stewart, Atkinson, \& Eeri, 2014), para zonas de subducción (García-Jiménez, 2006; H. Wang \& Nishimura, 1999), etc. Un ejemplo para terremotos corticales (Boore \& Atkinson, 2008) es el de la (Fig. 3-44).
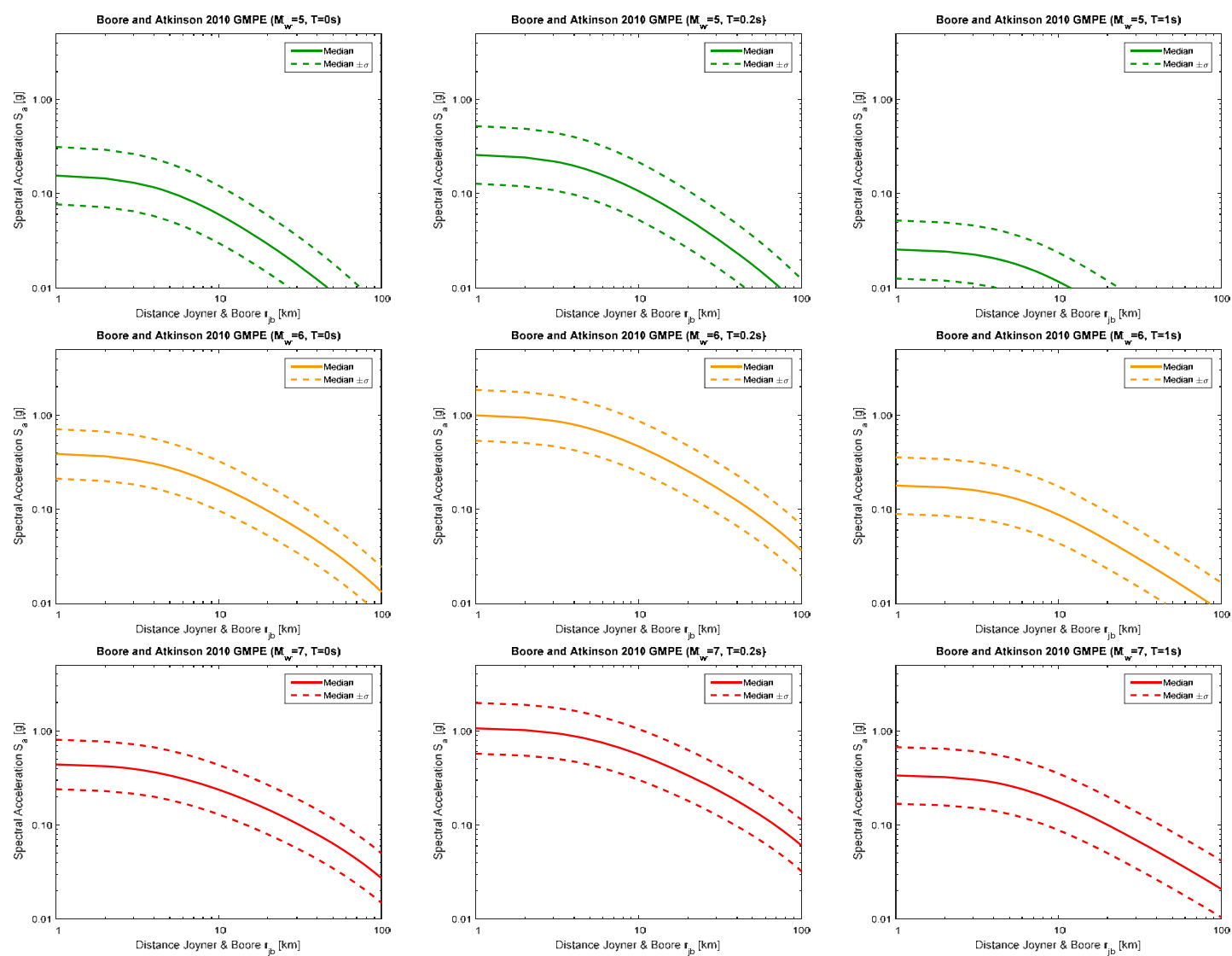

Fig. 3-44. Relaciones de atenuación GMPE de aceleración espectral para terremotos corticales (Boore \& Atkinson, 2008) para diferentes magnitudes y distancias. (izda.) $S_{a}(T=0 \mathrm{~s})$. (cent.) $S_{a}(T=0.2 \mathrm{~s})$. (dcha.) $S_{a}(T=1 \mathrm{~s})$. (sup.) $M_{w}$ 5. (med.) $M_{w}$ 6. (inf.) $M_{w} 7$. 

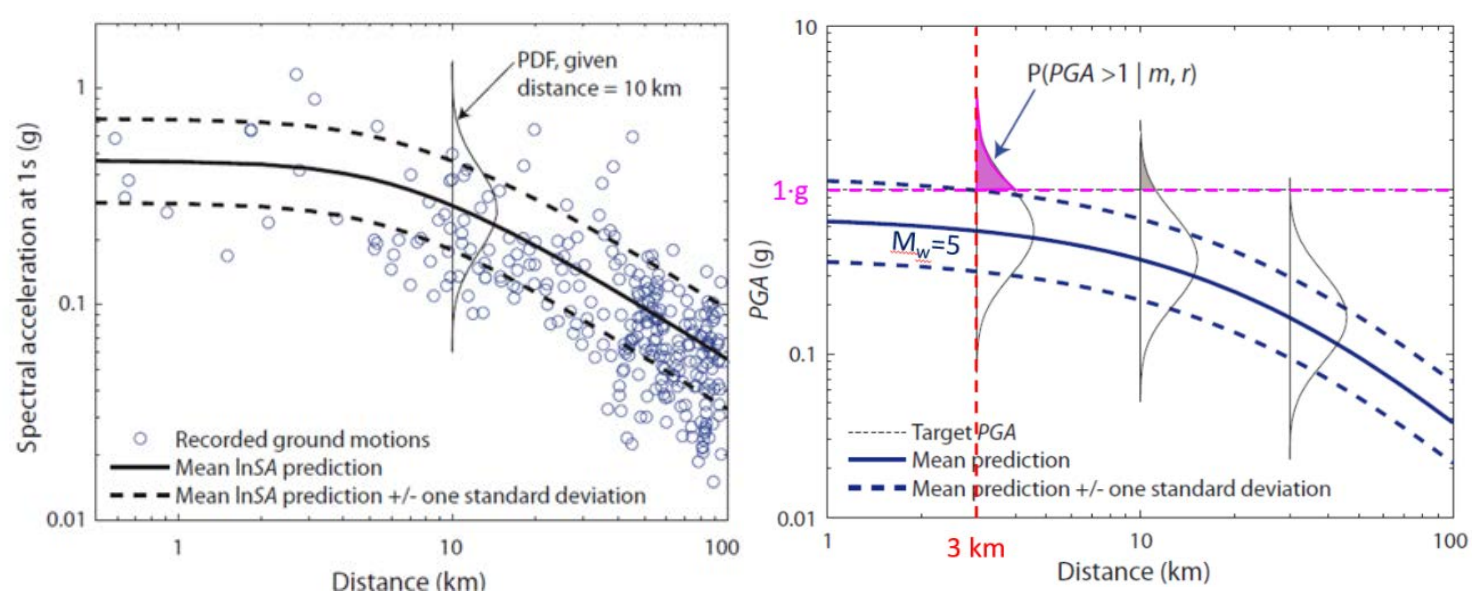

Fig. 3-45. (izda.) Distribución de probabilidad en las relaciones de atenuación. (dcha.) Probabilidad de exceder un valor de $\mathrm{PGA}>1 \cdot \mathrm{g}$ para un escenario de magnitud $M=5$, a una distancia de $r=3$ km. Figura modificada a partir de (Baker, 2013).

Con la elección de la relación GMPE de entre las confeccionadas y publicadas para el ambiente sísmico de interés se ha completado el tercer paso del análisis PSHA, es decir, se ha determinado la probabilidad $\mathrm{P}\left(\operatorname{IM}>_{x} \mid r, m\right)$ de que un determinado escenario de magnitud $m$ a una distancia $r$ sobrepase el valor de aceleración $x$, de la integral de peligrosidad (Ec. 3-19).

\subsubsection{Obtención de las curvas de peligrosidad sísmica}

Una vez que se cuenta con las tres expresiones del integrando de la (Ec. 3-19) se puede proceder a su integración numérica. Si se repite la integral para diversos umbrales de aceleración $x$, se obtiene lo que se denomina una curva de peligrosidad $\lambda(I M>x)$, es decir, la frecuencia anual de que se rebasen diferentes umbrales de aceleración.

Si se repite este proceso para diversas medidas de la intensidad IM (p.ej. aceleración a $T=0 \mathrm{~s}$, aceleración a $T=0,1 \mathrm{~s}$, aceleración a $T=0,2 \mathrm{~s}$, etc.), se obtienen varias curvas de peligrosidad como las de la (Fig. 3-46, izda.). En este gráfico, si se realizara un corte por una línea horizontal correspondiente a una frecuencia anual determinada (p.ej. $\lambda=0,002$, que corresponde a un periodo de retorno de $T_{R}=1 / \lambda=500$ años), la intersección con cada curva de peligrosidad proporcionaría un valor de aceleración del espectro correspondiente a dicha frecuencia anual o periodo de retorno. 

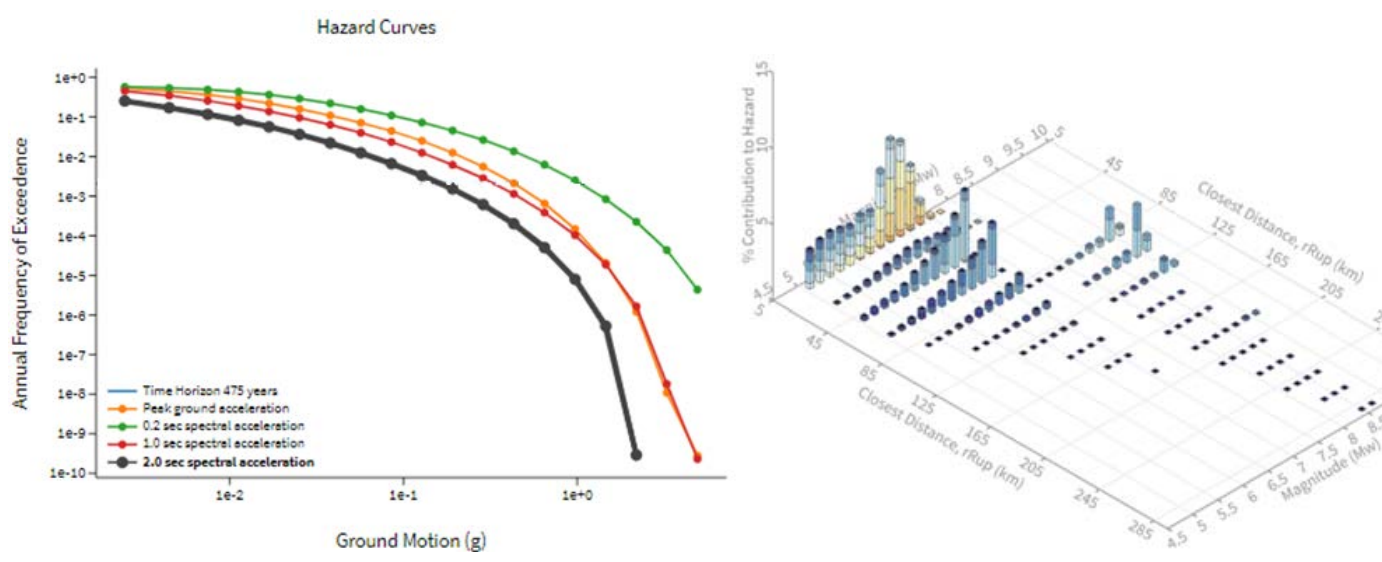

Fig. 3-46. (izda.) Curvas de peligrosidad para IMs correspondientes a aceleraciones espectrales $S_{a, P G A \text {, }}$ $S_{a, 0.2 s}, S_{a, 1.0}, S_{a, 2.0 s .}$ (dcha.) Gráfico de desagregación de la peligrosidad sísmica por magnitud y distancia.

De todos los sumandos que se integran en la integral (Ec. 3-19), es decir de todos los escenarios magnitud-distancia, algunos tienen valores más elevados que otros, $\mathrm{y}$ contribuyen más al valor final de la integral. Si se representa cuanto contribuye cada par $m-r$ en un gráfico como el de la (Fig. 3-46, dcha.), se obtiene lo que se conoce como un estudio de desagregación de la peligrosidad sísmica. Este estudio de desagregación proporciona información acerca de cuales son los escenarios más probables que excedan el valor particular de aceleración $x$.

\subsubsection{6 Árboles lógicos para tratar la incertidumbre epistémica}

En cada uno de los múltiples pasos intermedios involucrados en las tres etapas de un estudio PSHA existe incertidumbre a la hora de elegir los parámetros del análisis (zonificación sísmica, valores $a$ y $b$ en la relación Gutenberg-Richter, relación de atenuación empleada, etc), esta incertidumbre es la denominada incertidumbre epistémica (McGuire, 2004), en el sentido de que refleja la incertidumbre de nuestro conocimiento acerca de la idoneidad de los datos elegidos.

Para tener en cuenta la posible variación de los valores de los datos escogidos, y tener una descripción de cual es la sensibilidad a dichos parámetros, se emplean los denominados árboles lógicos o árboles de decisión. En ellos, se establece un nudo en cada paso del análisis en el que hay que tomar una decisión acerca del valor concreto que se asigna un parámetro, se plantean ramas con cada una de las alternativas posibles que parten de ese nudo, y se asigna un peso de probabilidad a cada rama (Fig. 3-47, izda). Este peso, que refleja la confianza subjetiva del equipo que participa en el estudio PSHA 
en la idoneidad del valor de un parámetro sobre otro, debe estar basado sobre estudios y datos sólidos.

Los pesos que se asignan a cada juego de ramas que parten de un mismo nudo deben sumar 1, ya que representan la probabilidad de que ocurra una rama frente a otra. Finalmente, el producto de pesos de todas las ramas escogidas desde el nudo inicial (izda.) hasta el nudo final (dcha.), para una realización particular del árbol, supone la probabilidad de que ocurra esa combinación específica de ramas.

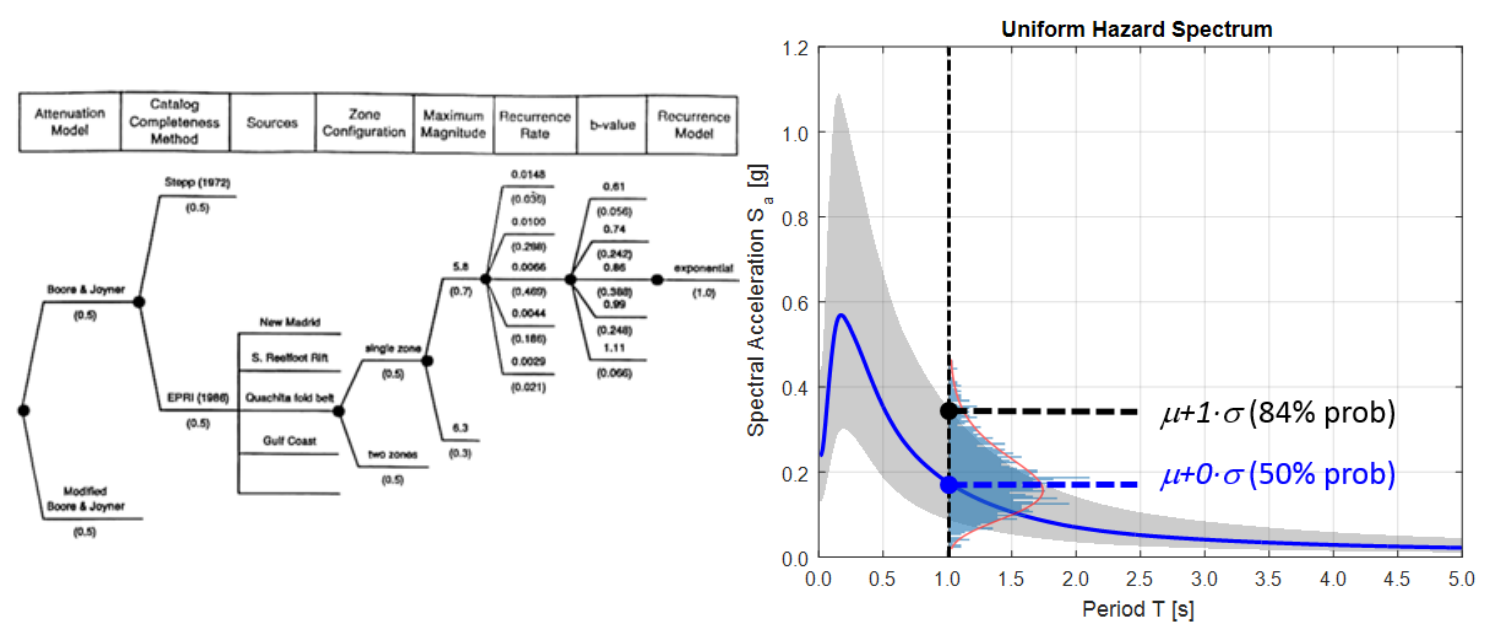

Fig. 3-47. (izda.) Ejemplo de árbol lógico de un estudio PSHA (Kramer, 1996). (dcha.) Distibución de probabilidad del espectro de probabilidad uniforme UHS debida al tratamiento de la incertidumbre epistémica mediante árboles lógicos.

El resultado de incorporar un esquema de árbol lógico para tratar la incertidumbre epistémica en el estudio PSHA es que cada combinación de ramas (recorrer el árbol de izda. a dcha.), para la cual hay que evaluar la integral (Ec. 3-19), proporciona un valor de aceleración diferente. Puesto que cada combinación de ramas tendrá una probabilidad final de que se de esa combinación en particular, el resultado final será una distribución estadística del espectro de peligrosidad uniforme UHS, en lugar de un único espectro concreto. Esta distribución de probabilidad permite establecer intervalos de confianza para el espectro (p.ej. espectro del $50 \%$ de probabilidad, espectro del $84 \%$ de probabilidad), como se representa en la (Fig. 3-47, dcha.).

\subsubsection{Proyección en el tiempo}

Conocida la frecuencia anual de exceder un determinado nivel de aceleración $\lambda(I M \geq x)$, y de manera coherente con la hipótesis de distribución uniforme en el tiempo de los terremotos descrita en el apartado §3.5.1.2, se puede asumir que el suceso de 
exceder dicha aceleración corresponde a un proceso poissoniano. De esta manera, y dado un horizonte de tiempo $t$ (p.ej. la vida útil de la estructura), se puede calcular la probabilidad de ocurrencia del suceso (que la aceleración sobrepase el umbral x), mediante la expresión (Ec. 3-26). En esta expresión, $\lambda$ es la frecuencia anual de sobrepasar el umbral $x$, y $t$ el horizonte de tiempo en el que se proyecta la predicción.

$$
P(I M \geq x)=1-e^{-\lambda \cdot t}
$$

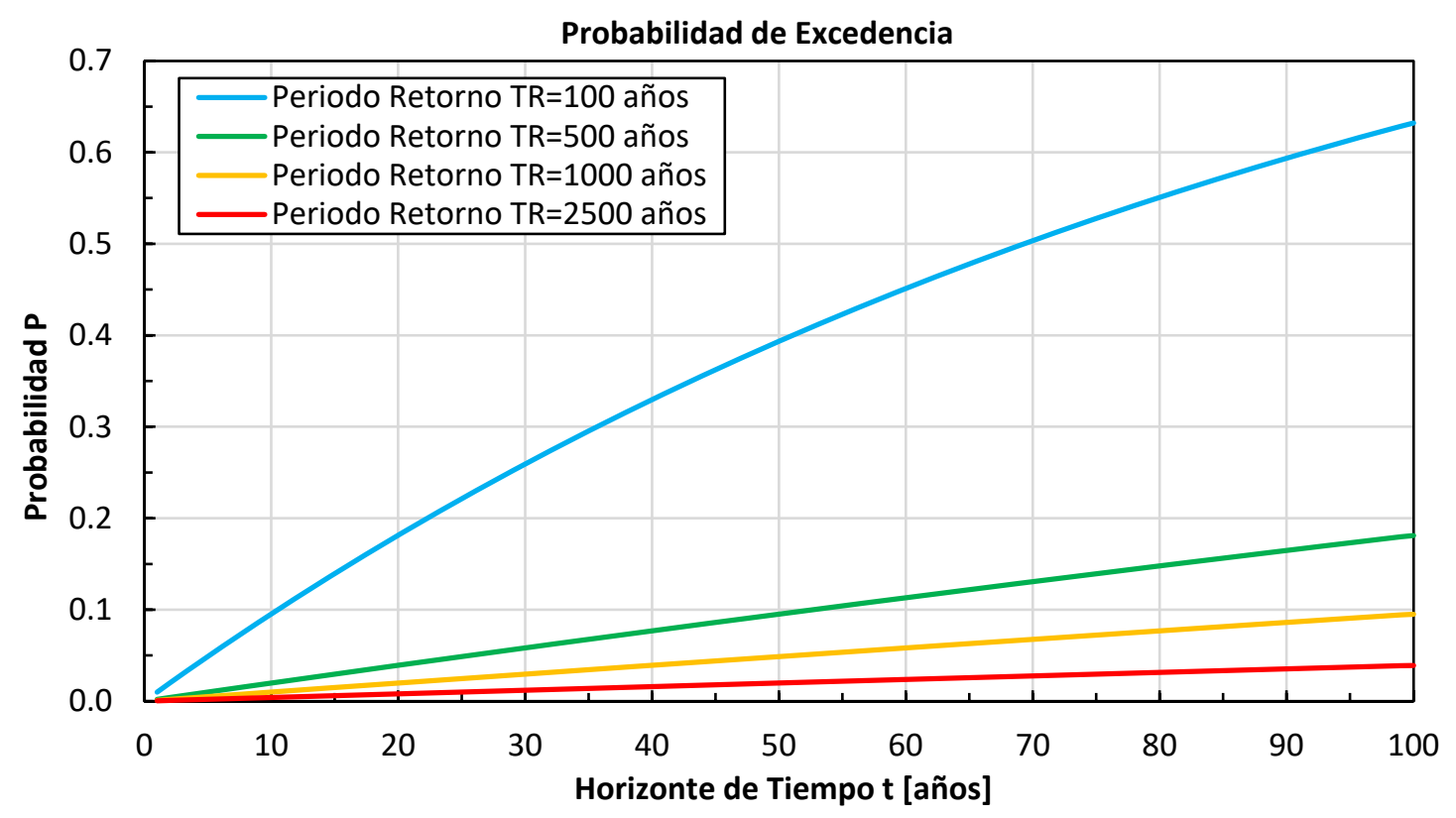

Fig. 3-48. Proyección en el tiempo del fenómeno poissoniano de probabilidad de rebasar el umbral de aceleración correspondiente a distintos periodos de retorno.

\subsubsection{La acción sísmica como respuesta del terreno}

Como es bien sabido, las características de amplitud y frecuencia de los acelerogramas en superficie como el mostrado en la (Fig. 3-35) dependen en muchos aspectos de las condiciones geotécnicas en los que fueron registrados. Un mismo evento sísmico, registrado por dos acelerómetros a distancias similares de la falla que causa el terremoto, puede presentar diferencias muy pronunciadas en cuanto a los parámetros más significativos que definen el movimiento en superficie.

Si bien los registros sísmicos ofrecen información muy útil acerca del movimiento del terreno en superficie durante un terremoto, no son capaces por sí solos de proporcionar una descripción detallada del movimiento que ocurre por debajo de la misma, ni tampoco 
de los procesos mecánicos que se desarrollan en el subsuelo, y que proporcionan como resultado en superficie el movimiento que es capaz de registrar un acelerómetro.

Las relaciones de atenuación semiempíricas, o ecuaciones para la predicción del movimiento del terreno (GMPEs, Ground Motion Prediction Equations) descritas en el apartado §3.5.1.4, incluyen términos para considerar la respuesta del terreno en un determinado emplazamiento, que se basan habitualmente en algún parámetro de medida sencilla (denominado proxy) para caracterizar las condiciones geotécnicas del lugar (Stewart, Afshari, \& Hashash, 2014). Uno de estos parámetros sencillos es, por ejemplo, la media temporal de la velocidad de ondas de cortante en los $30 \mathrm{~m}$ superficiales del terreno, denominada $V_{S 30}$. Puesto que los términos correspondientes a la amplificación debida a las condiciones geotécnicas en las GMPEs se derivan a partir de bases de datos globales de movimientos sísmicos, y puesto que estas bases de datos están recopiladas de acuerdo a información incompleta acerca de las características geotécnicas del emplazamiento (Stewart et al., 2014), sus predicciones representan, tan sólo, niveles medios de la acción sísmica que ha sido observada en emplazamientos con valores similares del parámetro $V_{S 30}$. Estas predicciones reciben por lo tanto el nombre de ergódicas, y en ellas se basan la mayor parte de las normativas sismorresistentes a la hora de establecer los factores de amplificación que rigen para cada tipo de suelo.

En efecto, la mayor parte de las normativas sismorresistentes recogen en su articulado alguna clasificación de suelos basada en el parámetro Vs30 (EN-1998-1:2004, AASHTO 2014, NEHRP-450:2003), como la de la Tabla 3-1 del Eurocódigo 8.

\begin{tabular}{|c|c|c|}
\hline Suelo & Descripción & $V_{S 30}[\mathrm{~m} / \mathrm{s}]$ \\
\hline A & $\begin{array}{l}\text { Roca u otro material asimilable a una formación geológica rocosa, con un máximo } \\
\text { de } 5 \mathrm{~m} \text { de material más débil en superficie. }\end{array}$ & $\geq 800$ \\
\hline B & $\begin{array}{l}\text { Depósitos de arena muy densa, grava, o arcilla muy rígida, de al menos varias } \\
\text { decenas de metros de espesor, caracterizados por un incremento gradual de las } \\
\text { propiedades mecánicas con la profundidad. }\end{array}$ & $800-360$ \\
\hline $\mathrm{C}$ & $\begin{array}{l}\text { Depósitos profundos de arena densa o medianamente densa, grava o arcilla rígida } \\
\text { con espesores comprendidos entre las decenas de metros y las centenas de metros. }\end{array}$ & $360-180$ \\
\hline $\mathrm{D}$ & $\begin{array}{l}\text { Depósitos de suelo no cohesivo de consistencia floja a media (con o sin capas } \\
\text { cohesivas blandas), o predominantemente suelo cohesivo de consistencia blanda } \\
\text { a firme. }\end{array}$ & $<180$ \\
\hline $\mathrm{E}$ & $\begin{array}{l}\text { Perfil de suelo con una capa superficial aluvial con valores de } V_{\mathrm{S} 30} \\
\text { correspondientes al tipo } \mathrm{C} \text { o } \mathrm{D} \text { y espesores variables entre } \operatorname{los} 5 \mathrm{~m} \text { y los } 20 \mathrm{~m} \text {, bajo } \\
\text { los que subyace un material más rígido con valores de } \mathrm{V}_{\mathrm{S} 30}>800 \mathrm{~m} / \mathrm{s} \text {. }\end{array}$ & Ver C y D \\
\hline $\mathrm{S}_{1}$ & $\begin{array}{l}\text { Depósitos con una capa de al menos } 10 \mathrm{~m} \text { de espesor de arcilla o limo blando, con } \\
\text { un índice de plasticidad alto (PI }>40) \text { y con gran contenido de agua. }\end{array}$ & $\begin{array}{l}<100 \\
\text { (indicativo) }\end{array}$ \\
\hline $\mathrm{S}_{2}$ & $\begin{array}{l}\text { Depósitos de suelo licuefactable, de arcillas sensibles, o cualquier otro tipo de } \\
\text { suelo no incluido en los tipos A-E ó } S_{1} \text {. }\end{array}$ & - \\
\hline
\end{tabular}

Tabla 3-1. Clasificación de los tipos de terreno según Eurocódigo 8. (EN-1998-1:2004). 
La acción sísmica real en superficie, o respuesta al sismo del terreno, será probablemente diferente a esta predicción media global. En este contexto, el estudio particular de la respuesta real del terreno para unas condiciones específicas de geotecnia y de intensidad sísmica proporcionará, en principio, resultados más ajustados y más representativos de la acción sísmica que puede esperarse en el emplazamiento en el que se pretende determinar la acción sísmica. De esta manera, si se realiza un estudio específico de la influencia del terreno local en el movimiento registrado en superficie, se puede decir que se rechaza la hipótesis de ergodicidad (correspondiente a considerar las propiedades medias del suelo y compararlas con las análogas de un catálogo global de sismos), pero que se mantienen el resto de consideraciones derivadas de un estudio de peligrosidad sísmica (Fig. 3-49).

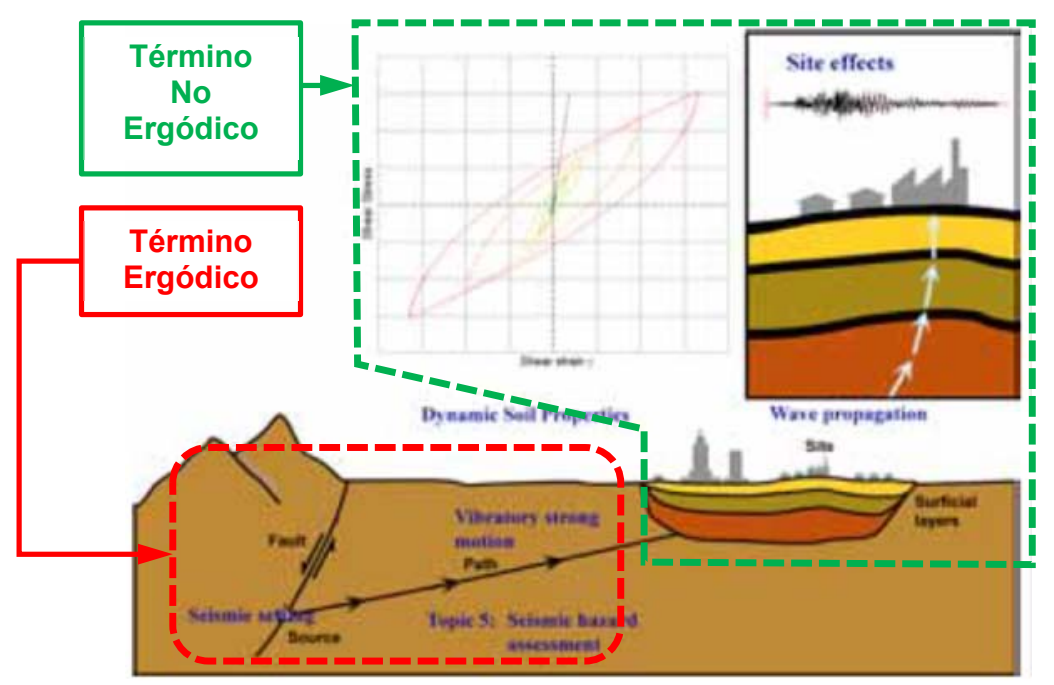

Fig. 3-49. Diagrama conceptual del análisis de respuesta sísmica del terreno (adaptado de Matasovic \& Hashash 2012).

La manera más habitual de estudiar las particularidades de la acción dinámica que ejercen los sismos sobre unas condiciones específicas del terreno es a través de los denominados análisis de respuesta del terreno (GRA, Ground Response Analysis). Un GRA consiste, en términos generales, en la modelización teórica de la propagación de ondas sísmicas desde el sustrato rocoso del emplazamiento hasta la superficie del terreno (Kramer, 1996), (Stewart et al., 2008). Mediante esta técnica se evalúan las tensiones y deformaciones dinámicas producidas en el terreno para, entre otros objetivos, analizar la posibilidad de licuefacción, o determinar las fuerzas inducidas por el sismo que pueden llevar a la inestabilidad de estructuras de tierra o de contención del terreno. 
A pesar de que las ondas sísmicas viajan del orden de decenas a centenas de kilómetros desde el origen en la falla hasta el emplazamiento a través de la roca subyacente, y tan sólo unas pocas decenas de metros desde esta hasta la superficie a través de los depósitos de suelo, es el filtro que supone atravesar estos depósitos el que determina en gran medida las características del movimiento sísmico. Idealmente, un GRA tendría en cuenta todos los parámetros de la geología local susceptibles de influir en la respuesta sísmica en un determinado lugar. Los parámetros generalmente citados en la literatura son (Stewart et al., 2008):

- Comportamiento mecánico de los estratos de suelo bajo el emplazamiento.

- Topografía local del emplazamiento que pueda concentrar la acción sísmica en ciertas zonas, amplificándola (como en el caso de escarpes o acantilados) o atenuándola (como en el caso de vaguadas o depresiones).

- Geometría en profundidad de los diferentes estratos de terreno y del sustrato rocoso, que pueda concentrar la acción sísmica en ciertas zonas produciendo efectos de "lente" amplificándola. Estos efectos reciben por lo general el nombre de efecto cuenca (Bassin effect).

De los tres parámetros citados, el comportamiento mecánico del suelo bajo el emplazamiento es generalmente el más estudiado, y por lo tanto en el que centraremos la descripción que sigue.

\subsubsection{Propagación de ondas sísmicas a través de un medio elástico}

En lo que sigue se resumen sucintamente los principios de la mecánica del medio continuo que sirven para describir el movimiento oscilatorio del terreno al verse sometido a la acción de un sismo. En particular se resumen las ecuaciones que rigen:

- La propagación de una onda a través de un medio continuo homogéneo unidimensional de longitud infinita.

- Los efectos de diferentes condiciones de contorno en el medio continuo, tales como la existencia de diferentes materiales en el medio, la condición de borde infinito, la condición de borde fijo, y la condición de borde libre.

- Las ecuaciones generales de la dinámica en el contexto de la elasticidad de medios continuos tridimensionales. 
- Los métodos de representación de dichas condiciones de contorno en el contexto de la modelización mediante elementos finitos.

\subsubsection{Propagación de ondas en un medio continuo unidimensional homogéneo de $\underline{\text { longitud infinita }}$}

Un medio homogéneo elástico unidimensional ilimitado puede idealizarse como una barra de longitud infinita. En este contexto, pueden darse tres tipos diferentes de vibración en dicha barra:

- Vibración longitudinal, en la que la barra se alarga y se contrae longitudinalmente sin que ocurra ningún tipo de desplazamiento lateral.

- Vibración transversal, en la que las diferentes secciones de la barra se desplazan lateralmente con respecto al eje de la misma, con deformación de cortante pero no de flexión.

- Vibración torsional, en la que las diferentes secciones de la barra rotan con respecto al eje de la misma, pero manteniendo constante dicho eje.

Por su importancia en el estudio de propagación de ondas sísmicas en el subsuelo, se derivan a continuación las expresiones que rigen tanto las vibraciones longitudinales como transversales.

\subsection{Planteamiento de las ecuaciones de movimiento de vibración lonqitudinal}

Consideraremos el movimiento de una barra infinitamente larga, de comportamiento linealmente elástico con módulo de Young E, módulo de Poisson $v$, que se encuentra coaccionada transversalmente de tal manera que no puede desplazarse lateralmente, cuya sección transversal tiene un área $A$, y la densidad del material que la constituye es $\rho$ (Fig. 3-50).

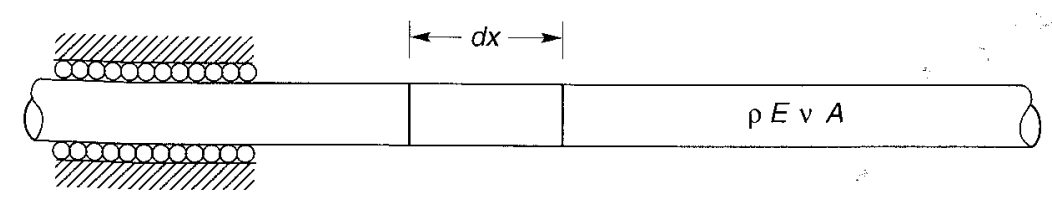

Fig. 3-50. Barra para el estudio de la propagación de ondas unidimensional (Kramer, 1996)

La hipótesis de desplazamiento transversal coaccionado, que en principio puede parecer arbitraria, resulta justificada si se piensa en la aplicación que buscamos obtener en este apartado. Pensando en que el resultado de este análisis pueda extrapolarse al caso 
más general de una onda de tensión axil propagándose en un medio tridimensional de dimensiones infinitas en todas sus direcciones, y pensando en cuáles serán las condiciones de contorno en ese caso, resulta razonable asumir que, debido a la simetría del problema, no es posible la deformación transversal. En efecto, si se supone el medio tridimensional como compuesto por una serie de fibras paralelas, cada una de ellas representada por una barra como la que aquí se estudia, la tendencia a la deformación transversal de cada barra por efecto Poisson se verá impedida por la tendencia a la deformación de la barra adyacente.

En este caso, el desplazamiento de las partículas de la barra causado por una onda longitudinal debe ser paralelo al eje de la propia barra. De esta manera, las secciones transversales permanecerán planas, y las tensiones longitudinales se distribuirán uniformemente en toda la sección de la barra. Si se aisla una rebanada de longitud diferencial $d x$ (Fig. 3-51), y se hace uso del principio de d'Alembert para establecer el equilibrio dinámico de dicha rebanada se obtiene (Kramer, 1996):

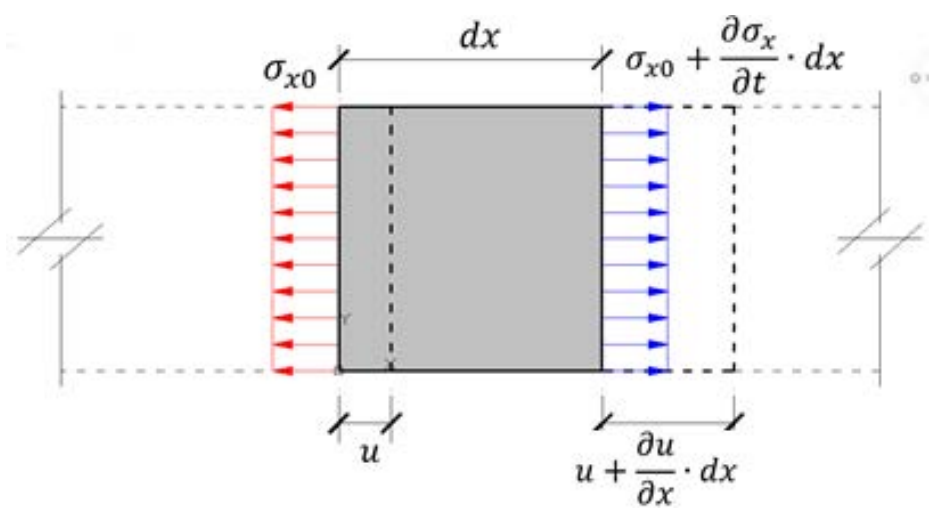

Fig. 3-51. Equilibrio dinámico de una rebanada diferencial sometida a tensión axial

$$
\begin{gathered}
\left(\sigma_{x 0}+\frac{\partial \sigma_{x}}{\partial t} \cdot d x\right) \cdot A-\sigma_{x 0} \cdot A=\rho \cdot A \cdot d x \cdot \frac{\partial^{2} u}{\partial t^{2}} \\
\frac{\partial \sigma_{x}}{\partial t}=\rho \cdot \frac{\partial^{2} u}{\partial t^{2}}
\end{gathered}
$$

Para simplificar esta ecuación dinámica en términos de tensiones y desplazamientos, el término izquierdo puede expresarse en términos de desplazamiento haciendo uso de la relación tenso-deformacional $\sigma_{x}=M \cdot \varepsilon_{x}$, en la que $M$ es el módulo de deformación con efecto Poisson restringido (Ec. 3-29), y $\varepsilon_{x}$ la deformación longitudinal (Ec. 3-30). 


$$
\begin{gathered}
M=\left(\frac{1-v}{(1+v) \cdot(1-2 v)}\right) \cdot E \\
\varepsilon_{x}=\frac{\partial u}{\partial x}
\end{gathered}
$$

Y obteniéndose finalmente:

$$
\begin{gathered}
\frac{\partial^{2} u}{\partial t^{2}}=\frac{M}{\rho} \cdot \frac{\partial^{2} u}{\partial t^{2}} \\
\frac{\partial^{2} u}{\partial t^{2}}=V_{p}^{2} \cdot \frac{\partial^{2} u}{\partial t^{2}} \\
V_{p}=\sqrt{\frac{M}{\rho}}
\end{gathered}
$$

Donde $V_{p}$ se identifica con la velocidad de propagación de la onda elástica de tensiones y desplazamientos que recorre el medio unidimensional. Como puede observarse, la velocidad de propagación $V_{p}$ de la onda depende tan sólo de las propiedades mecánicas del medio (módulo de Young E, módulo de Poisson $v$, y densidad $\rho$ ), y resulta independiente de la amplitud de la perturbación que se propaga. Igualmente, como puede observarse, la velocidad de propagación de la onda aumenta cuando aumenta la rigidez del medio, y disminuye cuando aumenta la densidad del mismo.

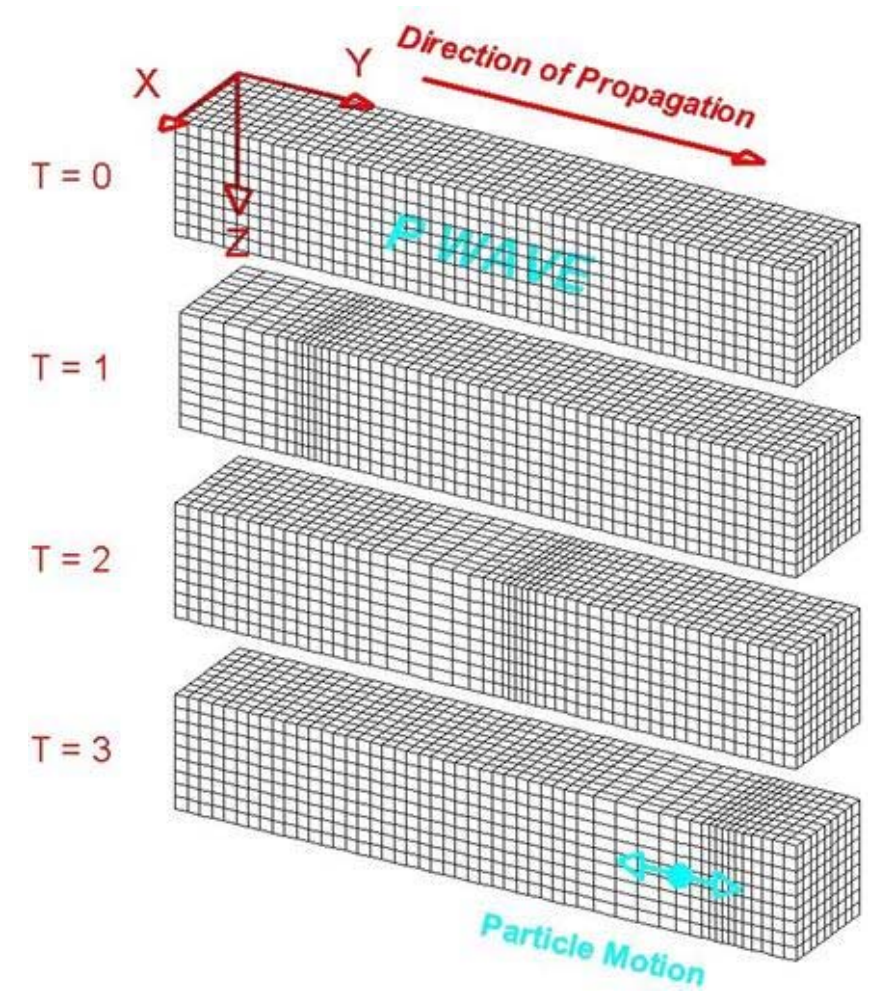

Fig. 3-52. Esquema de propagación de ondas axiales (NEES, 2011) 
La velocidad de propagación de la onda es la velocidad a la cual viaja la perturbación de tensiones en el medio y, sin embargo, no es la velocidad a la cual se desplaza una determinada sección del medio cuando es atravesada por la perturbación. Para conocer la velocidad a la cual se desplazaría dicha sección, se puede establecer en base a las definiciones de velocidad de propagación $V_{p}$ (Ec. 3-34), y deformación longitudinal $\varepsilon_{x}$ definida a partir de la ecuación constitutiva del material elástico (Ec. 3-35).

$$
\begin{gathered}
V_{p}=\frac{\partial x}{\partial t} \\
\varepsilon_{x}=\frac{\sigma_{x}}{M} \\
\dot{u}=\frac{\partial u}{\partial t}=\frac{\varepsilon_{x} \partial x}{\partial t}=\frac{\sigma_{x}}{M} \frac{V_{p} \cdot \partial t}{\partial t}=\frac{\sigma_{x}}{M} V_{p}=\frac{\sigma_{x}}{\rho \cdot V_{p}^{2}} V_{p}=\frac{\sigma_{x}}{\rho \cdot V_{p}}
\end{gathered}
$$

En esta expresión (Ec. 3-36) puede apreciarse como la velocidad de la sección $\dot{u}$ es proporcional a la tensión axial $\sigma_{x}$ en el medio unidimensional. El coeficiente de proporcionalidad $\rho \cdot V_{p}$ recibe el nombre de impedancia específica del material.

\subsection{Planteamiento de las ecuaciones de movimiento de vibración transversal}

De manera similar a como se ha hecho al analizar la propagación de ondas axiales, se puede estudiar la propagación de ondas de movimiento transversal a la dirección de propagación. Consideraremos el movimiento de una barra infinitamente larga, de comportamiento linealmente elástico con módulo de Young E, módulo de Poisson $v$, que se encuentra coaccionada transversalmente de tal manera que no puede producirse flexión pero sí deformación por cortante, cuya sección transversal tiene un área $A$, y la densidad del material que la constituye es $\rho$.

De manera análoga al caso de ondas axiales, la condición de contorno que puede parecer a priori arbitraria, puede justificarse en virtud de su futura aplicación al caso de la propagación en un medio tridimensional, infinito en todas sus direcciones. En efecto, si se supone el medio tridimensional como compuesto por una serie de fibras paralelas, cada una de ellas representada por una barra como la que aquí se estudia, si fuera posible la deformación por flexión de cada una de las barras, se produciría un corrimiento longitudinal relativo entre los puntos adyacentes de barras contiguas. Como, dada la simetría del problema, este corrimiento relativo no es posible (ya que todas las fibras del 
medio se encuentran adheridas entre sí formando un continuo), las condiciones de contorno transforman el problema en uno de cortante puro.

En este caso, el desplazamiento de las partículas de la barra causado por una onda transversal debe ser ortogonal al eje de la propia barra. De esta manera, las secciones transversales permanecerán planas, y las tensiones tangenciales se distribuirán uniformemente en toda la sección de la barra. Si se aísla una rebanada de longitud diferencial $d x$ (Fig. 3-53), y se hace uso del principio de d'Alembert para establecer el equilibrio dinámico de dicha rebanada en dirección perpendicular al eje de la misma, se obtiene las expresiones (Ec. 3-37) y (Ec. 3-38).

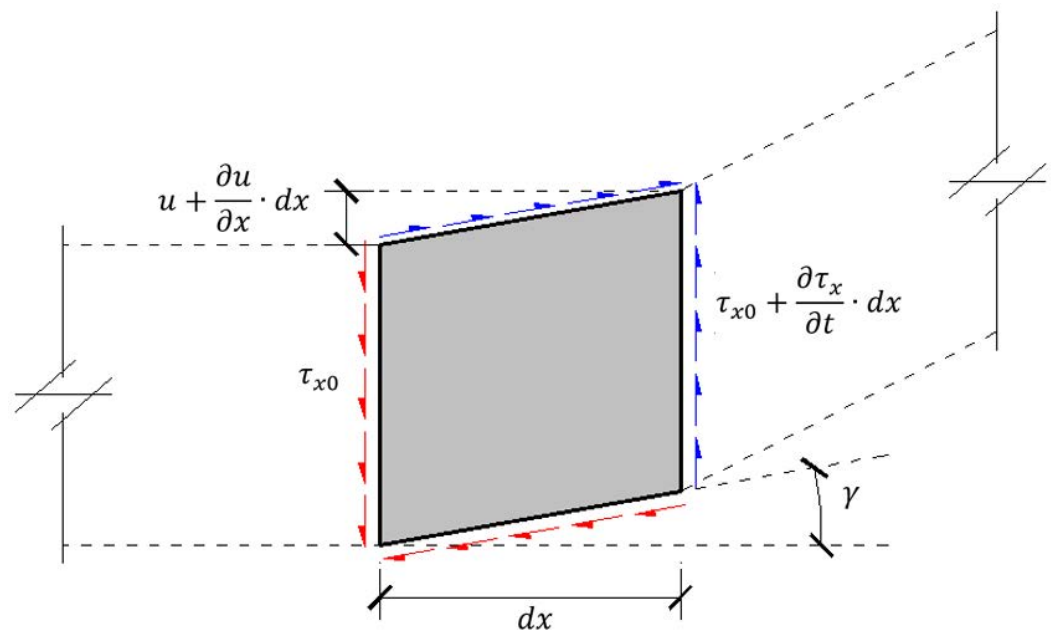

Fig. 3-53. Equilibrio dinámico de una rebanada diferencial sometida a tensión tangencial

$$
\begin{gathered}
\left(\tau_{x 0}+\frac{\partial \tau_{x}}{\partial t} \cdot d x\right) \cdot A-\tau_{x 0} \cdot A=\rho \cdot A \cdot d x \cdot \frac{\partial^{2} u}{\partial t^{2}} \\
\frac{\partial \tau_{x}}{\partial t}=\rho \cdot \frac{\partial^{2} u}{\partial t^{2}}
\end{gathered}
$$

Para simplificar esta ecuación dinámica en términos de tensiones y desplazamientos, el término izquierdo puede expresarse en términos de desplazamiento haciendo uso de la relación tenso-deformacional $\tau=G \cdot \gamma$, en la que $G$ es el módulo de deformación a cortante (Ec. 3-39), y $\gamma$ la deformación transversal de cortante (Ec. 3-40).

$$
\begin{gathered}
G=\frac{1}{2(1+v)} E \\
\gamma=\frac{\partial u}{\partial x}
\end{gathered}
$$

Y obteniéndose finalmente: 


$$
\begin{gathered}
\frac{\partial^{2} u}{\partial t^{2}}=\frac{G}{\rho} \cdot \frac{\partial^{2} u}{\partial t^{2}} \\
\frac{\partial^{2} u}{\partial t^{2}}=V_{s}^{2} \cdot \frac{\partial^{2} u}{\partial t^{2}} \\
V_{s}=\sqrt{\frac{G}{\rho}}
\end{gathered}
$$

Donde $V_{s}$ (Ec. 3-43) se identifica con la velocidad de propagación de la onda elástica de tensiones y desplazamientos que recorre el medio unidimensional. Como en el caso anterior, la velocidad de propagación $V_{s}$ de la onda depende tan sólo de las propiedades mecánicas del medio (módulo de Young E, módulo de Poisson v, y densidad $\rho$ ), y resulta independiente de la amplitud de la perturbación que se propaga. Igualmente, como puede observarse, la velocidad de propagación de la onda aumenta cuando aumenta la rigidez del medio, y disminuye cuando aumenta la densidad del mismo.

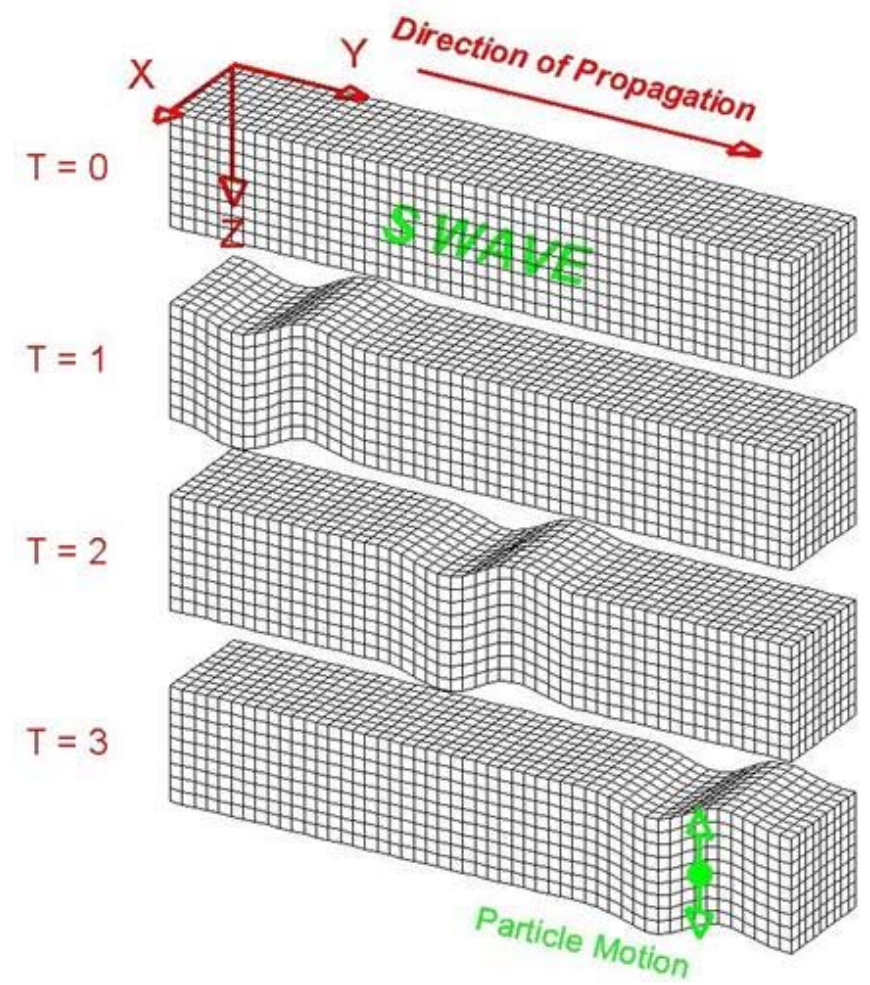

Fig. 3-54. Esquema de propagación de ondas transversales de cortante (NEES, 2011)

De manera análoga a lo indicado en el caso anterior, la velocidad de propagación $V_{s}$ de la onda es la velocidad a la cual viaja la perturbación de tensiones en el medio, y sin embargo no es la velocidad a la cual se desplaza transversalmente una determinada sección del medio cuando es atravesada por la perturbación. Para conocer la velocidad $\dot{u}$ a la cual se desplazaría dicha sección, esta se puede establecer en base a la definición de 
velocidad de propagación $V_{s}$ (Ec. 3-44), y a la deformación de cortante $\gamma$ definida a partir de la ecuación constitutiva del material elástico (Ec. 3-45), obteniéndose la expresión (Ec. 3-46).

$$
\begin{gathered}
V_{s}=\frac{\partial x}{\partial t} \\
\gamma=\frac{\tau}{G} \\
\dot{u}=\frac{\partial u}{\partial t}=\frac{\gamma \partial x}{\partial t}=\frac{\tau}{G} \frac{V_{s} \cdot \partial t}{\partial t}=\frac{\tau}{G} V_{s}=\frac{\tau}{\rho \cdot V_{s}^{2}} V_{s}=\frac{\tau}{\rho \cdot V_{s}}
\end{gathered}
$$

De manera similar a como ocurriera en el caso de ondas de tensión axial longitudinal, en esta expresión puede apreciarse como la velocidad de la sección $\dot{u}$ es proporcional a la tensión tangencial en el medio unidimensional. El coeficiente de proporcionalidad $\rho \cdot V_{s}$ recibe el nombre de impedancia específica del material.

\subsection{Solución de las ecuaciones de movimiento unidimensional}

Como se ha demostrado en los apartados anteriores, la ecuación diferencial que rige el movimiento ondulatorio de una onda unidimensional (ya sea axial o de cortante) es de la forma (Ec. 3-47).

$$
\frac{\partial^{2} u}{\partial t^{2}}=V^{2} \cdot \frac{\partial^{2} u}{\partial t^{2}}
$$

Donde $V$ representa la velocidad de propagación de la onda correspondiente al tipo de la onda de tensión considerada. La solución de esta ecuación puede escribirse de la forma (Ec. 3-48) (Kramer, 1996).

$$
u(x, t)=f(V \cdot t-x)+g(V \cdot t+x)
$$

Donde $f$ y $g$ pueden ser cualquier tipo de funciones arbitrarias de $(V \cdot t-x)$ y $(V \cdot t+x)$ que satisfagan la ecuación diferencial anterior. Puesto que el argumento de $f$ puede permanecer constante si a la vez que aumenta el tiempo $t$ aumenta $x$ (a velocidad $V$ ), y el argumento de $g$ puede permanecer constante si a la vez que aumenta el tiempo $t$ disminuye $x($ a velocidad $V)$, la solución a la ecuación diferencial anterior describe una pareja de ondas de desplazamiento $f(V \cdot t-x)$ y $g(V \cdot t+x)$. Ambas ondas viajan a la misma velocidad $V, f$ en el sentido negativo del eje $x, y$ en el sentido positivo de este eje. Esto implica igualmente que la forma de la onda no varía con el tiempo. 
Si el medio unidimensional se somete a algún tipo de tensión armónica estacionaria del tipo $\sigma(t)=\sigma_{0} \cdot \cos (\omega \cdot t)$ (donde $\sigma_{0}$ es la amplitud de la tensión aplicada, y $\omega$ la frecuencia circular de la carga cíclica aplicada), la solución puede expresarse empleando el concepto de número de onda $k=\omega / V$ de la siguiente manera (Ec. 3-49).

$$
u(x, t)=A \cdot \cos (\omega \cdot t-k \cdot x)+B \cdot \cos (\omega \cdot t+k \cdot x)
$$

Como se ha anticipado en el párrafo anterior, el primer y el segundo término describen ondas armónicas que se propagan en las direcciones positiva y negativa del eje $x$ respectivamente. El número de onda está relacionado con la longitud de onda $\lambda$ del movimiento por (Ec. 3-50).

$$
\lambda=V \cdot T=\frac{V}{f}=\frac{2 \cdot \pi}{\omega} V=\frac{2 \cdot \pi}{k}
$$

Donde $T$ es el periodo de la carga cíclica aplicada, y $f=1 / T$ la frecuencia de la misma. La ecuación (Ec. 3-49) indica que el desplazamiento varía armónicamente tanto con respecto al tiempo, como a la posición.

\subsubsection{Condiciones de contorno}

En este apartado se discuten las variaciones que ejercen, en las ecuaciones del movimiento ondulatorio obtenidas anteriormente, las condiciones de contorno más habituales que pueden encontrarse en la práctica. En particular se estudia:

- La propagación de ondas en un medio estratificado. Es decir, la propagación de ondas unidimensionales a través de un medio que presenta variaciones discretas de sus parámetros mecánicos.

- La propagación de ondas en un medio unidimensional semi-infinito con una condición de borde fijo. Es decir, la perturbación al flujo de ondas que supone que uno de los extremos no admita desplazamientos.

- La propagación de ondas en un medio unidimensional semi-infinito con una condición de borde libre. Es decir, la perturbación al flujo de ondas que supone que uno de los extremos no admita tensiones.

\subsection{Propagación de ondas en un medio estratificado}

Si se considera la propagación de un tren de ondas armónico viajando en la dirección positiva del eje $x$, en las proximidades de un punto en la que el medio 
unidimensional cambia de propiedades mecánicas (de $E_{1}, v_{1}, G_{1}, \mathrm{y} \rho_{1}$ en la zona de donde proviene la perturbación, a $E_{2}, v_{2}, G_{2}, y \rho_{2}$ en la zona hacia donde se va a propagar la onda), la onda de tensión puede describirse (haciendo uso de la notación trigonométrica exponencial y del concepto de número de onda) en el medio 1 como:

$$
\sigma_{1}(x, t)=\sigma_{i} \cdot e^{i\left(\omega \cdot t-k_{1} \cdot x\right)}
$$

La onda que viaja por el medio 1 tendrá una longitud de onda de valor $\lambda_{1}=2 \cdot \pi / k_{1}$. Cuando la onda incidente desde el medio 1 alcance la interfaz, parte de su energía se transmitirá al medio adyacente 2 , para continuar viajando en la dirección positiva del eje $x$. Esta onda transmitida (también denominada refractada) tendrá sin embargo una longitud de onda $\lambda_{2}=2 \cdot \pi / k_{2}$ diferente a la del medio uno. El resto de la energía se verá reflejado por la interfaz, y viajará de nuevo por el medio 1 en dirección contraria.

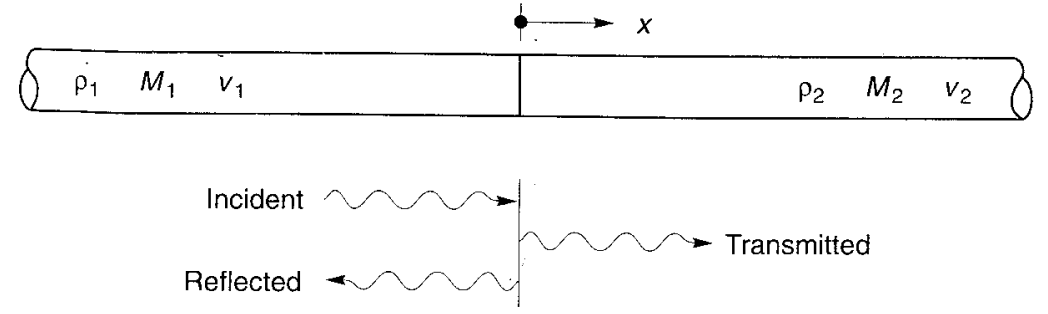

Fig. 3-55. Onda incidente aproximándose a una interfaz de cambio de propiedades mecánicas del medio (Kramer, 1996)

Las ondas transmitidas y reflejadas pueden describirse mediante las siguientes ecuaciones, en las que el subíndice $T$ indica onda transmitida (Ec. 3-52), y el subíndice $R$ indica onda reflejada (Ec. 3-53).

$$
\begin{aligned}
& \sigma_{T}(x, t)=\sigma_{t} \cdot e^{i\left(\omega \cdot t-k_{2} \cdot x\right)} \\
& \sigma_{R}(x, t)=\sigma_{r} \cdot e^{i\left(\omega \cdot t+k_{1} \cdot x\right)}
\end{aligned}
$$

Asumiendo que los desplazamientos asociados con cada una de estas ondas tiene una expresión armónica similar a la de las tensiones que los causan, las relaciones tensodeformacionales, y deformación-desplazamiento, pueden emplearse para relacionar la amplitud (Ec. 3-54), (Ec. 3-55), (Ec. 3-56).

$$
\begin{aligned}
& u_{I}(x, t)=A_{i} \cdot e^{i\left(\omega \cdot t-k_{1} \cdot x\right)} \\
& u_{R}(x, t)=A_{r} \cdot e^{i\left(\omega \cdot t+k_{1} \cdot x\right)}
\end{aligned}
$$




$$
u_{T}(x, t)=A_{t} \cdot e^{i\left(\omega \cdot t-k_{2} \cdot x\right)}
$$

(Ec. 3-56)

Se pueden emplear las relaciones de tensión-deformación y de deformacióndesplazamiento para relacionar las amplitudes de desplazamiento con las amplitudes de tensiones (Ec. 3-57), (Ec. 3-58), (Ec. 3-59).

$$
\begin{aligned}
& \sigma_{I}(x, t)=M_{1} \frac{\partial u_{l}(x, t)}{\partial x}=-i k_{1} M_{1} A_{i} \cdot e^{i\left(\omega \cdot t-k_{1} \cdot x\right)} \\
& \sigma_{R}(x, t)=M_{1} \frac{\partial u_{R}(x, t)}{\partial x}=+i k_{1} M_{1} A_{r} \cdot e^{i\left(\omega \cdot t+k_{1} \cdot x\right)} \\
& \sigma_{T}(x, t)=M_{2} \frac{\partial u_{T}(x, t)}{\partial x}=-i k k_{2} A_{t} \cdot e^{i\left(\omega \cdot t+k_{1} \cdot x\right)}
\end{aligned}
$$

En la interfaz entre materiales, se debe satisfacer la compatibilidad de desplazamientos (Ec. 3-60) y continuidad de tensiones (Ec. 3-61).

$$
\begin{aligned}
& u_{I}(0, t)+u_{R}(0, t)=u_{T}(0, t) \\
& \sigma_{I}(0, t)+\sigma_{R}(0, t)=\sigma_{T}(0, t)
\end{aligned}
$$

Sustituyendo las ecuaciones de desplazamiento (Ec. 3-54), (Ec. 3-55), (Ec. 3-56), y de tensiones (Ec. 3-57), (Ec. 3-58), (Ec. 3-59) en (Ec. 3-73) y (Ec. 3-74) respectivamente, se obtiene que las siguientes igualdades que se cumplen en en la interfaz.

$$
\begin{aligned}
& A_{i}+A_{r}=A_{T} \\
& \sigma_{i}+\sigma_{R}=\sigma_{T}
\end{aligned}
$$

Haciendo uso de la relación $k \cdot M=\omega \cdot \rho \cdot v$ se obtiene las siguientes importantes relaciones entre las amplitudes de las ondas incidente, reflejada, y refractada. En estas expresiones, el término $\alpha_{z}$ recibe el nombre de contraste de impedancia.

$$
\begin{gathered}
A_{r}=\frac{1-\frac{\rho_{2} v_{2}}{\rho_{1} v_{1}}}{1+\frac{\rho_{2} v_{2}}{\rho_{1} v_{1}}} A_{i}=\frac{1-\alpha_{z}}{1+\alpha_{z}} A_{i} \\
A_{t}=\frac{2}{1+\frac{\rho_{2} v_{2}}{\rho_{1} v_{1}}} A_{i}=\frac{2}{1+\alpha_{z}} A_{i} \\
\alpha_{z}=\frac{\rho_{2} v_{2}}{\rho_{1} v_{1}}
\end{gathered}
$$


De manera similar, operando en términos de tensiones, se llega a las relaciones entre las tensiones de las ondas incidente, reflejada y refractada.

$$
\begin{aligned}
& \sigma_{r}=\frac{\alpha_{z}-1}{1+\alpha_{z}} \sigma_{i} \\
& \sigma_{t}=\frac{2 \alpha_{z}}{1+\alpha_{z}} \sigma_{i}
\end{aligned}
$$

La importancia del contraste de impedancia $\alpha_{z}=\rho_{2} \cdot v_{2} / \rho_{1} \cdot v_{1}$ queda patente en estas ecuaciones. En función de cual sea su valor, el mecanismo de la transmisión de energía, amplitudes, y tensiones, resulta muy diferente.

Si el contraste de impedancia es menor que la unidad $\left(\alpha_{z}<1\right)$, la onda incidente se aproxima a un material más blando. En este caso, la onda reflejada tendrá una amplitud de tensiones más pequeña que la onda incidente y su signo cambiará (un pulso de compresión se transformará en un de tracción y viceversa). Si el contraste de impedancia es mayor que la unidad $\left(\alpha_{\mathrm{z}}>1\right)$, la onda incidente se aproxima a un material más rígido. En este caso, la onda transmitida tendrá una amplitud de tensiones menor, pero mantendrá el signo. De hecho, las condiciones de borde fijo y de borde libre pueden tratarse como casos extremos del contraste de impedancia. Dada su importancia las tratamos en detalle en los siguientes apartados.

\subsection{Condición de borde fiio}

Una condición de borde fijo se puede considerar como un contraste de impedancia de valor infinito $\left(\alpha_{z}=\infty\right)$. Es decir un valor de $\alpha_{z}=\infty$ hará que el valor de la amplitud del movimiento transmitido en la (Ec. 3-65) sea $A_{t}=0$. En este caso, la tensión en el borde $\sigma_{t}$ resulta ser el doble de la onda incidente $\left(\sigma_{t}=2 \cdot \sigma_{i}\right)$. Adicionalmente, la amplitud de la onda reflejada sigue siendo la misma que la de la onda incidente, pero con el signo cambiado $(A r=-A i)$ tal y como resulta de la (Ec. 3-64).

Intuitivamente, se puede interpretar este cambio de polaridad (cambio de signo) de tal manera que la suma de amplitudes la onda incidente $(+A)$ y reflejada $(-A)$ proporcione desplazamiento nulo en el borde (Fig. 3-56). 


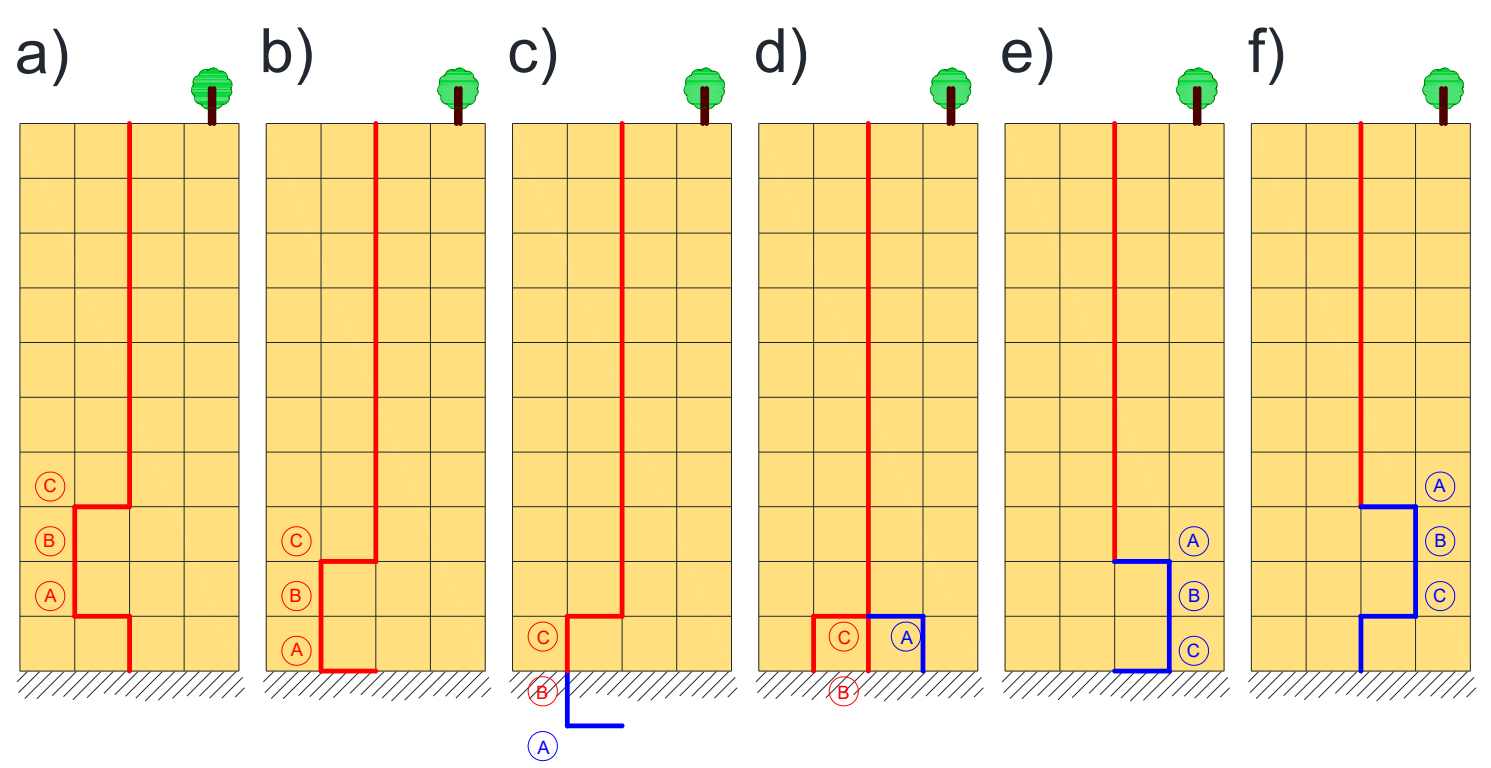

Fig. 3-56. Desplazamientos de una onda de cortante reflectando en un borde fijo. (a) La onda se aproxima. (b) La onda llega al fondo. (c) La onda intenta propagarse más allá del fondo. (d) EI frente de la onda se refleja y se superpone, cambiando su polaridad, al tramo que aún no ha llegado al fondo, anulándose ambos. (e) La onda se ha reflejado completamente. (f) La onda prosige hacia la superficie.

Este aspecto resulta de especial relevancia a la hora de modelizar las condiciones de contorno para analizar la respuesta sísmica del terreno, tal y como se discutirá en el apartado $§ 3.6 .3$ de esta tesis.

\subsection{Condición de borde libre}

Una condición de borde libre se puede considerar como un contraste de impedancia de valor nulo $\left(\alpha_{\mathrm{z}}=0\right)$. Es decir, un valor de $\alpha_{\mathrm{z}}=0$ hará que el valor de la amplitud de tensiones transmitido en la (Ec. 3-68) sea $\sigma_{t}=0$. En este caso, el desplazamiento en el borde $A_{t}$ resulta ser el doble de la onda incidente $\left(A_{t}=2 \cdot A_{i}\right)$. Adicionalmente, la tensión de la onda reflejada sigue siendo la misma que la de la onda incidente, pero con el signo cambiado $\left(\sigma_{r}=-\sigma_{l}\right)$ tal y como resulta de la (Ec. 3-67).

Intuitivamente, se puede interpretar la amplificación $x 2$ de los desplazamientos en el borde libre como una onda que, al intentar evolucionar hacia un medio al que no puede transmitirse, se ve obligada a reflejarse, y se acumula con la parte de onda que todavía no ha llegado al borde (Fig. 3-57). 
a)

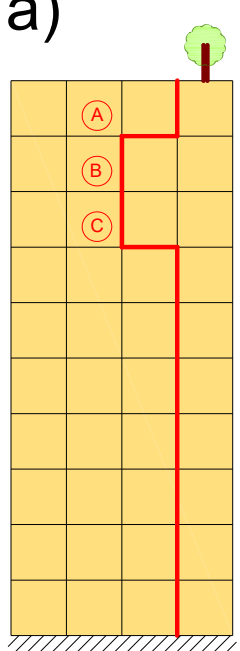

b)

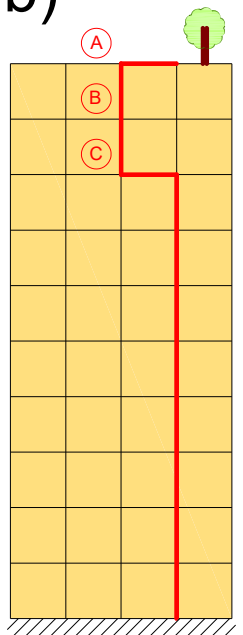

c) ${ }^{A} \cdots(d)$

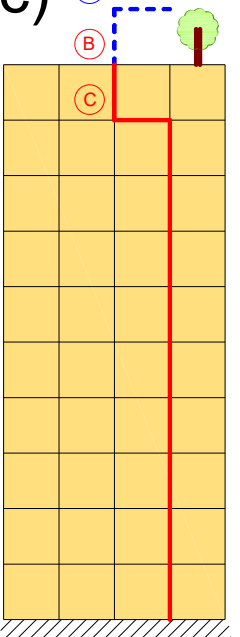

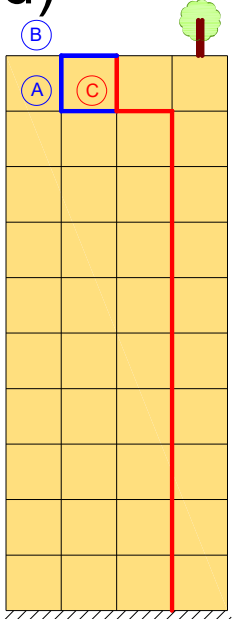

e)

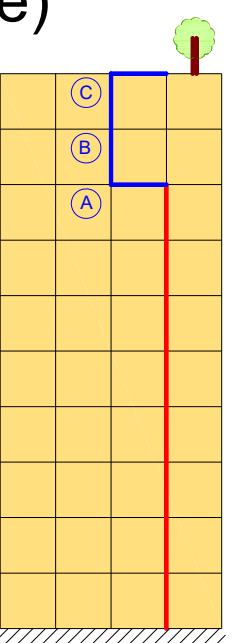

f)

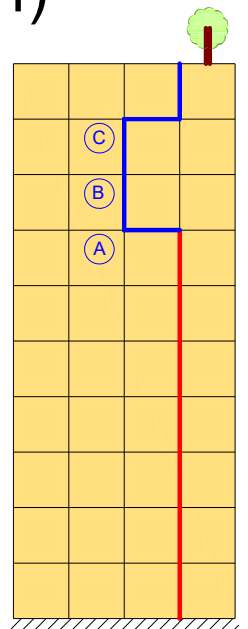

Fig. 3-57. Desplazamientos de una onda de cortante reflectando en un borde libre. (a) La onda se aproxima. (b) La onda llega a superficie. (c) La onda intenta propagarse más allá de la superficie. (d) El frente de la onda se refleja y se superpone al tramo que aún no ha llegado a superficie, amplificándose. (e) La onda se ha reflejado completamente. (f) La onda prosige hacia la profundidad.

\subsubsection{Métodos de representación de las condiciones de contorno en el contexto de la modelización mediante elementos finitos.}

En el momento de modelizar el terreno para estudiar la propagación de las ondas sísmicas, es muy frecuente que no se pueda representar la columna completa del terreno hasta el basamento rocoso si este se encuentra a mucha profundidad.

En esos casos, se suele recurrir a un modelo de condición de borde tal que permita la difusión de las ondas elásticas más allá de los bordes del modelo, sin que se produzca reflexión en este límite ficticio. Esta condición, desarrollada por Lysmer y Kuhlemeyer (O. Lysmer \& Kuhlemeyer, 1969) se modeliza mediante unos amortiguadores viscosos, cuya constante $C$ responde a la sencilla fórmula (Ec. 3-69). En la que $\rho$ es la densidad del medio, y $V$ la velocidad de propagación de las ondas de interés $\left(V_{S}\right.$ si se pretenden realizar un estudio de propagación de ondas de cortante). Esta condición de Lysmer-Kuhlemeyer recibe diversos nombres en función del programa de cálculo que se emplee (silent boundary, compliant boundary, etc.).

$$
C=\rho \cdot V
$$




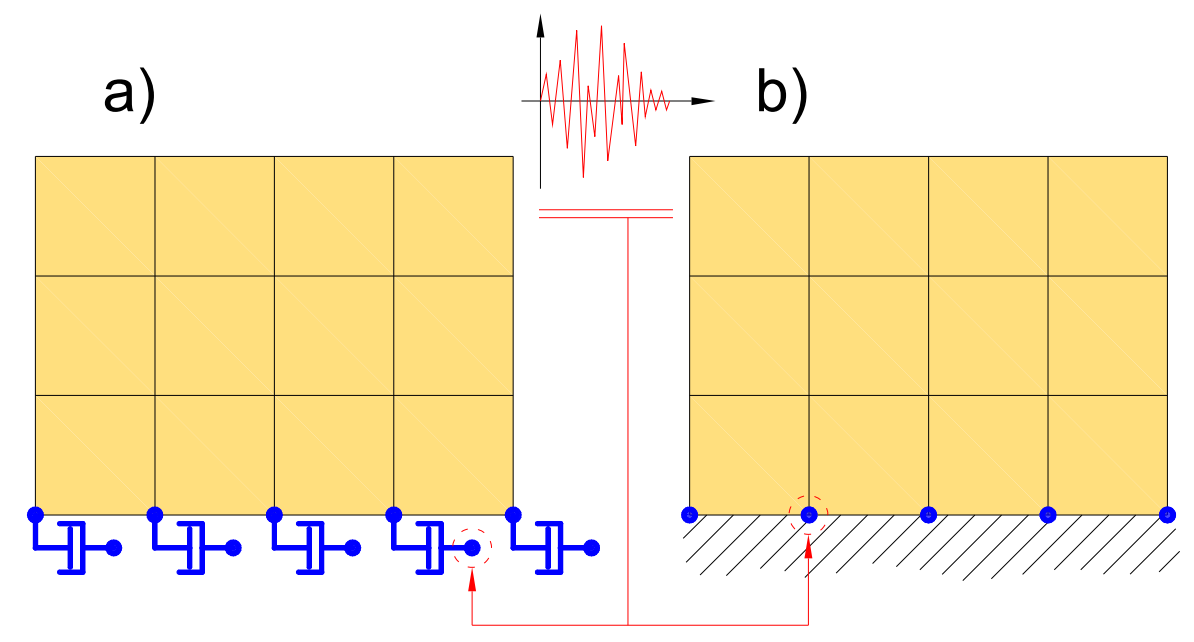

Fig. 3-58. (a) Condición de borde absorbente de Lysmer-Kuhlemeyer (O. Lysmer \& Kuhlemeyer, 1969). (b) Condición de borde fijo.

Es relevante destacar que, en función de cual sea la condición de contorno adoptada (condición de Lysmer-Kuhlemeyer o borde rígido), el input de entrada en forma de registro de aceleraciones o de velocidades debe ser diferente en valor, de manera a evitar fenómenos de captura de ondas (que multiplican ficticiamente los resultados x2), o de transmisión en dos direcciones (que dividen ficticiamente los resultados x1/2). Esta circunstancia se discute en más detalle en el apartado §3.6.3.2 de esta tesis.

\subsection{Comportamiento del terreno bajo la acción dinámica}

Comprender y ser capaz de modelizar el comportamiento del terreno bajo acciones dinámicas y cíclicas es un subcampo completo de la ingeniería geotécnica y sísmica. Por esta razón, la literatura técnica de estudios que se han llevado a cabo, esencialmente desde los años 60 del s. XX, para comprender el fenómeno es muy extensa.

Históricamente, la comprensión del comportamiento del terreno bajo acciones cíclicas ha evolucionado desde una primera aproximación puramente empírica al fenómeno, hasta una descripción matemática fenomenológida detallada. En los siguientes apartados $§ 3.6 .1$ y $§ 3.6 .2$ de esta tesis se hace una revisión de algunos de los estudios más relevantes llevados a cabo en este campo. Esta revisión no tiene ánimo de exhaustividad ni completitud, si no que sirve tan sólo de antecedente teórico para justificar la elección de modelo para el estudio frente al comportamiento cíclico del terreno desarrollado en el capítulo $\S 6$ de esta tesis. Un buen resumen del estado del arte a este respecto puede encontrarse en la tesis de doctoral de Rubén Galindo Aires (Galindo-Aires, 2010). 
Más adelante, en el apartado §3.6.3, se revisan dos de los métodos más habituales a la hora de determinar la acción del sismo en superficie y la deformación del terreno debajo de esta, en lo que se denomina análisis de respuesta del suelo GRA (Ground Response Analysis).

\subsubsection{Modelos empíricos de plasticidad}

\subsubsection{Primeros enfoques históricos del fenómeno}

Hardin y Black (Hardin \& Black, 1968) establecen que relación lineal entre tensiones $\tau$ y deformaciones tangenciales $\gamma$ de arcillas normalmente consolidadadas, a través del módulo de cortante Go para pequeñas deformaciones (menores que $\gamma \leq 1 \cdot 10^{-4}$ ), es en la práctica independiente del nivel de tensiones efectivas.

Por otra parte, para suelos arenosos, Hardin y Black (Hardin \& Black, 1966), establecen que el módulo de cortante Go para deformaciones pequeñas puede establecerse mediante las expresiones de la Tabla 3-2. En estas expresiones, e es el índice de huecos, y $\sigma_{0}$ la tensión efectiva de confinamiento con unidades imperiales [psf] libras por pie cuadrado.

\begin{tabular}{|c|cc|}
\hline Tipo de arena & \multicolumn{3}{|c|}{ Módulo de cortante para pequeñas deformaciones $\mathbf{G}_{0}$} \\
\hline $\begin{array}{c}\text { Granos redondeados } \\
\sigma_{0}>2000 \mathrm{psf}\end{array}$ & $G=\frac{(32.17-14.8 \cdot e)^{2}}{1+e} \sigma_{0}^{\frac{1}{2}}$ & (Ec. 3-70) \\
\hline $\begin{array}{c}\text { Granos redondeados } \\
\sigma_{0}<2000 \mathrm{psf}\end{array}$ & $G=\frac{(22.52-10.6 \cdot e)^{2}}{1+e} \sigma_{0}^{\frac{3}{5}}$ & (Ec. 3-71) \\
\hline Granos angulosos & $G=\frac{(30.09-10.12 \cdot e)^{2}}{1+e} \sigma_{0}^{\frac{1}{2}}$ & (Ec. 3-72) \\
\hline
\end{tabular}

Tabla 3-2. Módulo de cortante para pequeñas deforamciones en arenas. (Hardin \& Black, 1966).

Más tarde, Hardin y Drnevich (Hardin \& Drnevich, 1972) estudian el comportamiento de los suelos bajo cargas cíclicas alternantes de corte simple, indicando que el caso más claro de este comportamiento se da para suelos solicitados sísmicamente. En particular, y en base a ensayos de muestras en dispositivos huecos y de columna resonante, determinan la evolución del módulo de cortante secante $G_{s e c}$, y su reducción para diferentes valores de la deformación tangencial, en suelos arenosos y arcillosos. 

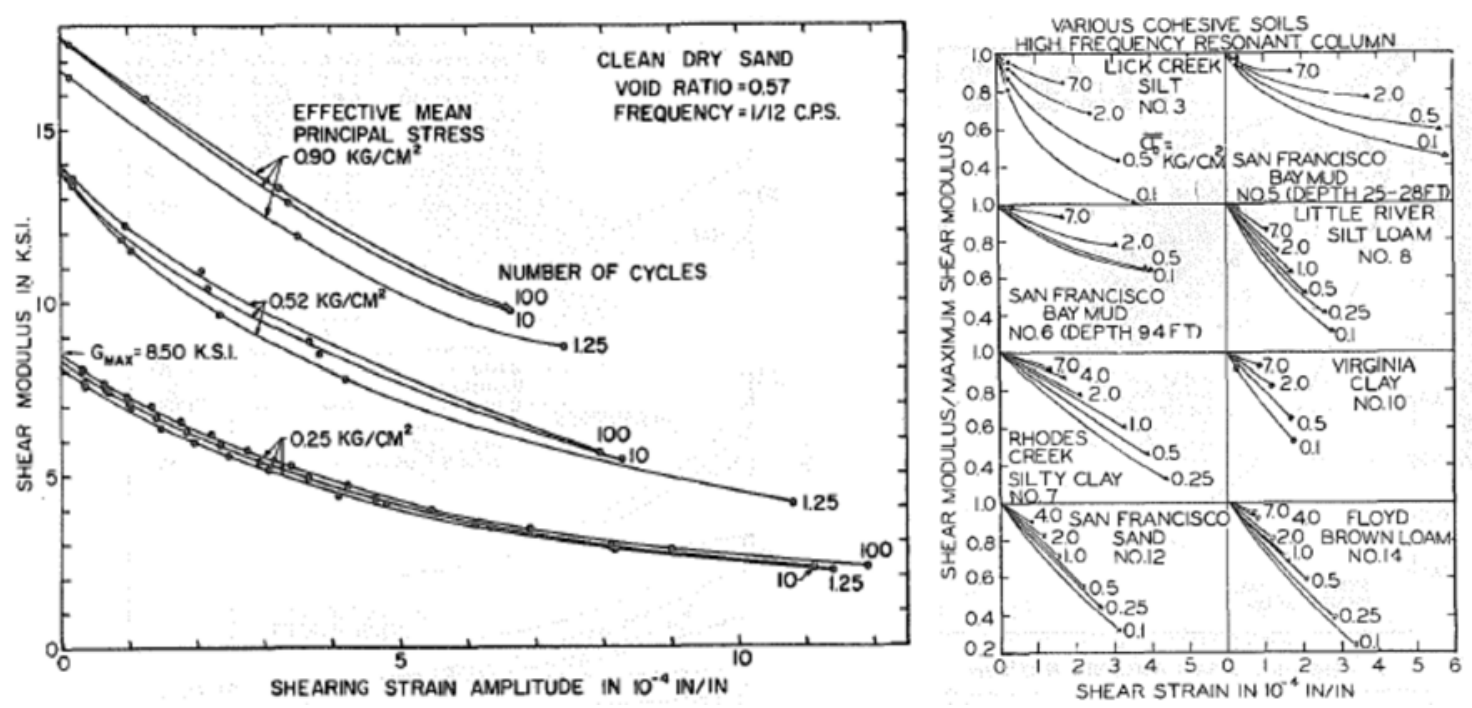

Fig. 3-59. Reducción del módulo de cortante con la deformación. (izda.) Para arenas limpias. (dcha.)

Para una variedad de suelos arcillosos. (Hardin \& Drnevich, 1972).

De manera adicional, estudian el amortiguamiento $\xi$ histerético desarrollado, como una función de la deformación tangencial $\gamma$ (Fig. 3-60). Hardin y Drnevich (Hardin \& Drnevich, 1972) definen el amortiguamiento como la relación (Ec. 3-73), que corresponde al concepto de amortiguamiento equivalente desarrollado por Jacobsen (Jacobsen, 1930) para oscilaciones forzadas en régimen permanente. Es decir, el amortiguamiento desarrollado en forma de histéresis para cada nivel de deformación $\gamma$, se expresa como la fracción del amortiguamiento crítico que correspondería a un sistema de un grado de libertad con la rigidez secante $G_{s e c}$ que corresponde a la deformación $\gamma$ dada, y que tuviera un amortiguamiento puramente viscoso (dependiente de la velocidad). En esta fórmula (Ec. 3-73) Ahistéresis corresponde al área encerrada en el ciclo de histéresis del ensayo cíclico del suelo: es decir, la energía disipada en el ciclo, y $A_{T}$ al área de la (Fig. 3-60, dcha.), es decir la energía elástica almacenada en el punto de máxima deformación.

$$
\xi=\frac{A_{\text {histeresis }}}{4 \pi \cdot A_{T}}=\frac{A_{\text {histeresis }}}{4 \pi \cdot \frac{1}{2}(\tau \cdot \gamma)}=\frac{A_{\text {histeresis }}}{2 \pi \cdot G \cdot \gamma^{2}}
$$



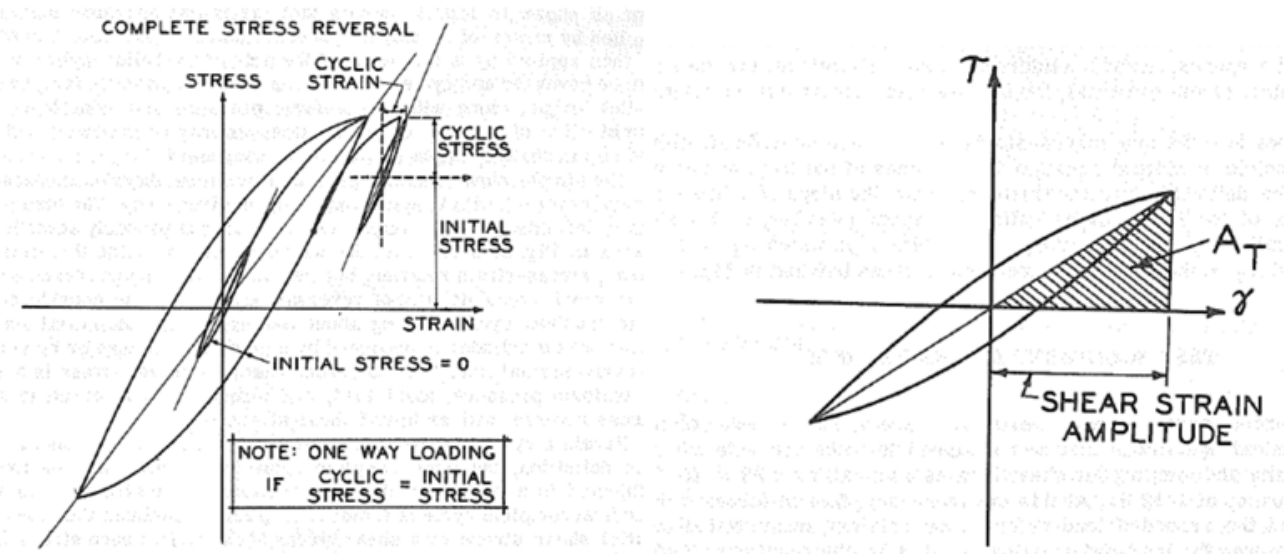

FIG. 3.-COMPLETE STRESS REVERSAL WITH AND WITHOUT INTTIAL SHEAR FIG. 4.-DEFINITION OF MODULUS, DAMPING, AND STRAIN AMPLITUDE STRESS

Fig. 3-60. (izda.) Ciclo de carga e histéresis del modelo de suelo. (dcha) Definición del módulo de cortante secante, y amortiguamiento equivalente. (Hardin \& Drnevich, 1972).

De manera más o menos contemporánea, y partir de los resultados de Hardin y Drnevich y de otros autores, Seed e Idriss (Seed \& Idriss, 1972) proponen una forma más general para evaluar la rigidez secante de arenas, arcillas, y gravas, para un amplio rango de deformaciones. Establecen así una expresión para el valor de la rigidez secante en arenas (Ec. 3-74) dependiente de un parámetro $K_{2}$ de reducción de la rigidez, y de la tensión media efectiva $\sigma_{m}^{\prime}$ expresada en unidades imperiales [psf] libras por pie cuadrado.

$$
G=100 \cdot K_{2} \cdot \sigma_{m}^{\prime 1 / 2}
$$

Seed e Idriss indican que el parámetro $K_{2}$ depende, para pequeñas deformaciones $\left(\mathcal{1} 1 \cdot 10^{-5}\right)$ tan sólo del índice de huecos $e$ (o densidad relativa); para deformaciones intermedias $\left(1 \cdot 10^{-5}<\gamma<1 \cdot 10^{-3}\right)$ depende del índice de huecos $e$ y de la deformación tangencial $\gamma$, y para grandes deformaciones $\left(\gamma>1 \cdot 10^{-3}\right)$ es prácticamente independiente del índice de huecos y alcanza un valor asintótico, dependiendo tan sólo de $\gamma$. Seed e Idriss proporcionan la expresión hiperbólica (Ec. 3-75) para obtener la curva de reducción (Fig. 3-61, izda.). En esta expresión $G_{\max }$ es el módulo de cortante incial para pequeñas deformaciones, $\gamma_{r}$ una deformación de referencia, y $\tau_{\max }$ la máxima tensión de cortante que viene dada por la expresión (Ec. 3-77). En esta expresión $K_{0}$ es el coeficiente de empuje al reposo, $\phi$ ' el ángulo de rozamiento interno, y $\sigma_{v}^{\prime}$ la tensión vertical efectiva medida en unidades imperiales [psf] libras por pie cuadrado. 


$$
\begin{gathered}
G=\frac{G_{\max }}{1+\frac{\gamma}{\gamma_{r}}} \\
\gamma_{r}=\frac{\tau_{\max }}{G_{\max }} \\
\tau_{\max }=\left(\left(\frac{1+K_{0}}{2} \sigma_{v}^{\prime} \cdot \sin \phi^{\prime}+c^{\prime} \cdot \cos \phi^{\prime}\right)^{2}-\left(\frac{1-K_{0}}{2} \sigma_{v}^{\prime}\right)^{2}\right)^{\frac{1}{2}}
\end{gathered}
$$

Para el caso de las arcillas, argumentan que es muy difícil obtener muestras inalteradas sobre las que realizar ensayos en laboratorio. No obstante, señalan que las variaciones en las características de las arcillas pueden ser evaluadas razonablemente bien mediante la relación $\mathrm{G} / \mathrm{su}$, siendo $s u$ la resistencia a cortante no drenada. De esta manera presentan una curva de reducción del módulo de cortante secante representativa (Fig. 3-62, izda.).
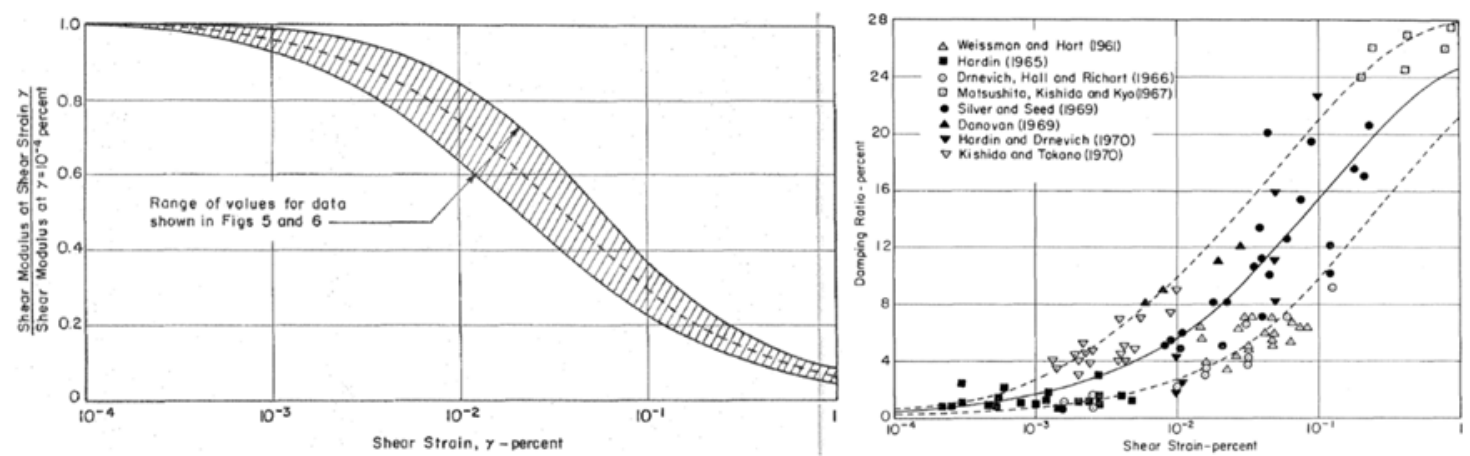

Fig. 3-61. (izda.) Curvas de reducción del módulo de cortante $G / G_{\max }$ para arenas. (dcha.) Curvas de amortiguamiento para arenas. (Seed \& Idriss, 1972).
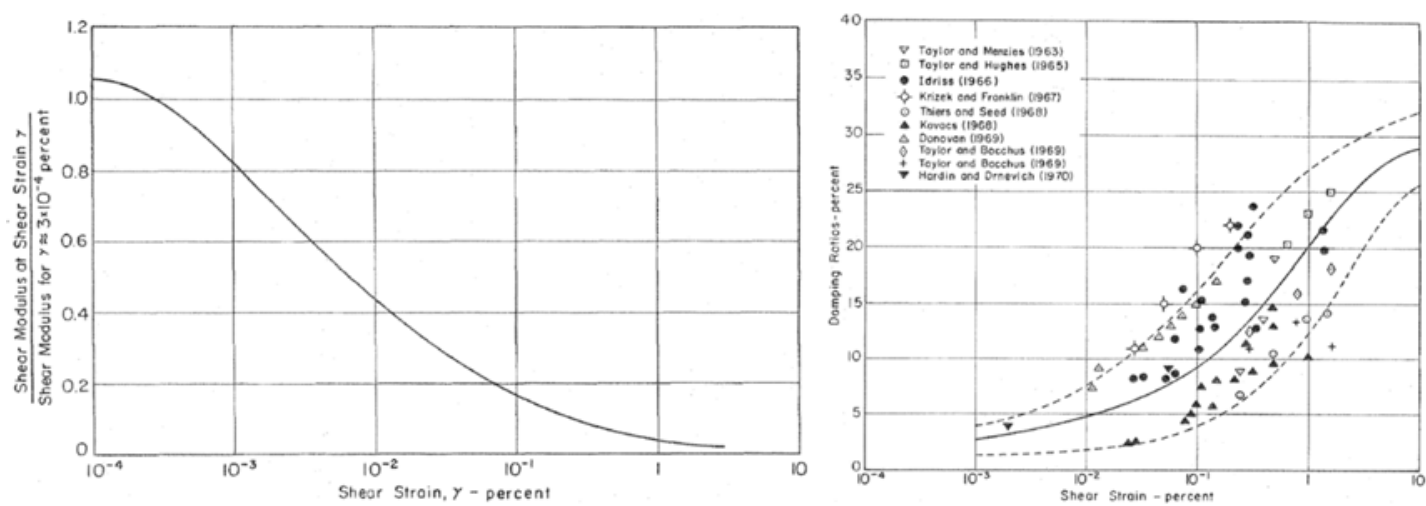

Fig. 3-62. (izda.) Curva típica de reducción del módulo de cortante $G / G_{\max }$ para arcilla. (dcha.) Curvas típicas de amortiguamiento para arcillas. (Seed \& Idriss, 1972). 
Por su parte, Hardin y Drnevich proponen una expresión hiperbólica idéntica a (Ec. 3-75) para el caso de las arcillas, pero evaluando la rigidez inicial máxima mediante la fórmula (Ec. 3-78), en la que e es el índice de huecos, OCR el índice de sobreconsolidación, $\sigma_{m}^{\prime}$ la tensión efectiva octaédrica en unidades imperiales [psf], y un exponente $a$ que depende del índice de plasticidad IP resumido en la Tabla 3-3.

$$
G_{\max }=14760 \frac{(2,973-e)^{2}}{1+e} \cdot O C R^{a} \cdot\left(\sigma_{m}^{\prime}\right)^{\frac{1}{2}}
$$

\begin{tabular}{|c|c|c|c|c|c|}
\hline \multirow{3}{*}{$\begin{array}{c}\text { Exponente } \\
\boldsymbol{a}\end{array}$} & \multicolumn{5}{|c|}{ Índice de Plasticidad IP } \\
\cline { 2 - 6 } & $\mathbf{2 0}$ & $\mathbf{4 0}$ & $\mathbf{6 0}$ & $\mathbf{8 0}$ & $>\mathbf{1 0 0}$ \\
\cline { 2 - 6 } & 0,18 & 0,30 & 0,41 & 0,48 & 0,50 \\
\hline
\end{tabular}

Tabla 3-3. Valor del exponente a dependiente del índice de plasticidad IP. (Seed \& Idriss, 1972).

Adicionalmente, Seed e Idriss (Seed \& Idriss, 1972) proporcionan curvas de amortiguamiento equivalente en función de la deformación para arenas y arcillas (Fig. 3-61, dcha., Fig. 3-62, dcha.). La expresión para evaluarlas es (Ec. 3-79), en la que el término de amortiguamiento máximo $\xi_{\max }$ está expresado en función del número de ciclos de histéresis $N$, la frecuencia de la oscilación $f$, y tensión media principal $\sigma_{m}$ en unidades imperiales [psf]. Para arenas se evalúa mediante (Ec. 3-80) y para arcillas mediante (Ec. $3-81)$.

$$
\begin{gathered}
\xi=\frac{\xi_{\max } \cdot \frac{\gamma}{\gamma_{r}}}{1+\frac{\gamma}{\gamma_{r}}} \\
\xi_{\text {max }}=30-1,5 \cdot \log _{10} \cdot N \\
\xi_{\text {max }}=31-(3+0,3 f)\left(\sigma_{m}\right)^{\frac{1}{2}}-1,5 \cdot \log _{10} \cdot N
\end{gathered}
$$

\subsubsection{Relaciones tensión-deformación tangencial y reglas de Masing}

A partir de los años 60 del s. XX se desarrollan numerosos modelos de comportamiento no lineal con aplicación en diversas ramas de la mecánica (plasticidad de metales, materiales geotécnicos, etc.). Estos modelos sirven como aproximación más o menos sencilla para la modelización de un fenómeno complejo determinado por multitud de variables. 
Uno de los más destacables y sencillos es el denominado bilineal desarrollado para arcillas por Thiers y Seed (Thiers \& Seed, 1968), correspondiente a una pendiente de carga $G_{1}$ denominada elástica, que tras rebasar la deformación de plastificación $\gamma_{y}$ continúa por una rama denominada postelástica con una pendiente $G_{2}$. Si ocurre una descarga, esta se produce a lo largo de una rama con pendiente $G_{1}$, hasta que se alcanza una deformación de $-2 \cdot \gamma_{y}$ medida desde el punto de retorno. A partir de este punto se continua con una pendiente $G_{2}$. La (Fig. 3-63, izda.) muestra las dos ramas, elástica y postelástica, y un proceso de carga y descarga con plastificación en ambos sentidos.

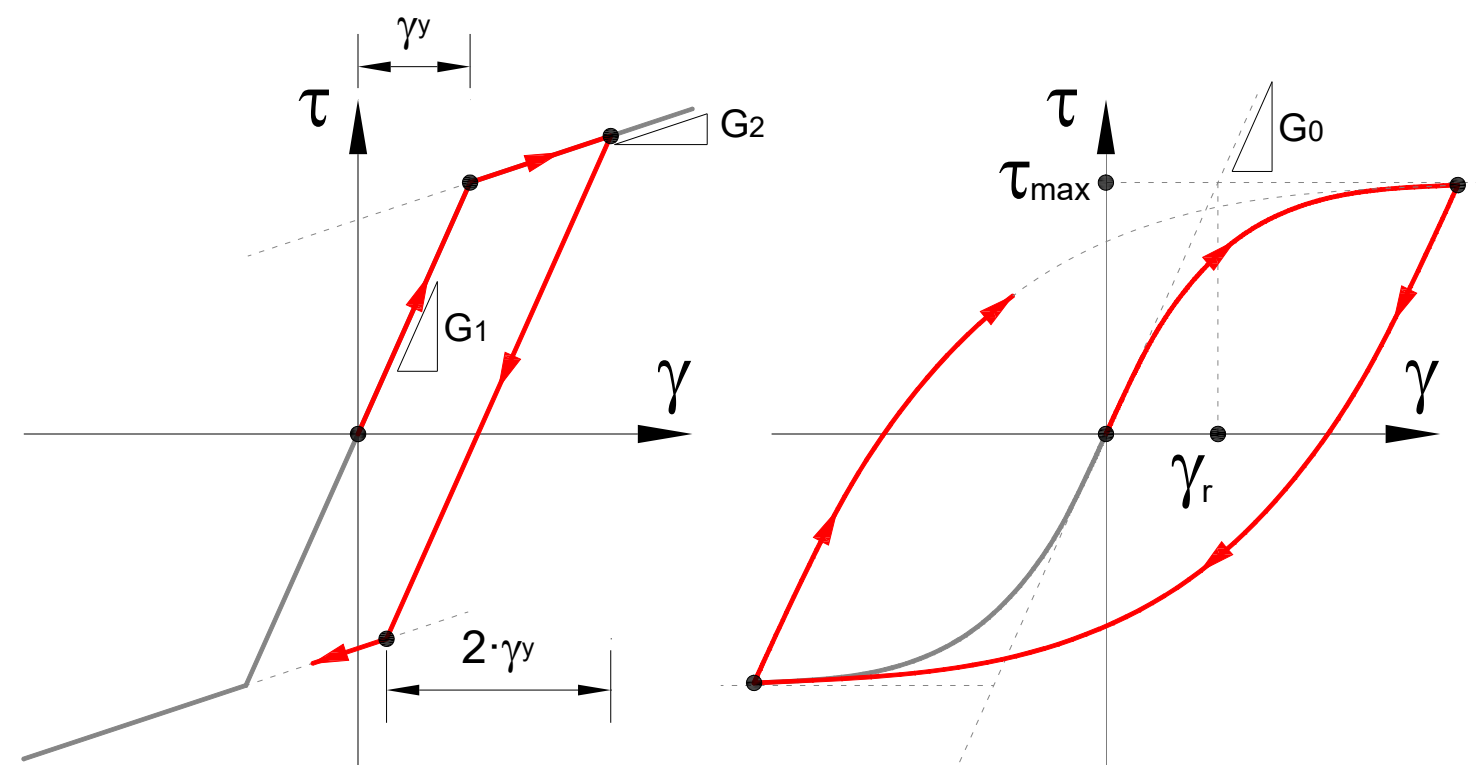

Fig. 3-63. (izda.) Modelo de comportamiento bilineal (Thiers \& Seed, 1968). (dcha.) Modelo de comportamiento hiperbólico (Kondner \& Zelasko, 1963) con reglas de descarga de Masing (Masing, 1926).

Otro modelo ampliamente empleado en el ámbito geotécnico es la relación hiperbólica propuesta por Kodner y Zelasko (Kodner \& Zelasko, 1963), cuya rama de carga noval (backbone curve en la literatura anglosajona) sigue la expresión (Ec. 3-82).

$$
\begin{gathered}
\tau=\frac{\gamma}{\frac{1}{G_{0}}+\frac{\gamma}{\tau_{\max }}}=G_{0} \frac{\gamma}{1+\frac{\gamma}{\gamma_{r}}} \\
\gamma_{r}=\frac{\tau_{\max }}{G_{0}}
\end{gathered}
$$

Para los procesos de descarga y recarga, conjuntamente con este modelo hiperbólico se emplean habitualmente las denominadas reglas de Masing (Masing, 1926), y reglas de Masing ampliadas desarrolladas por Pyke (Pyke, 1979). Estas consisten en: 
- El módulo de cortante $G$ para cada instante en el que comienza una carga, descarga, o recarga es igual al módulo de cortante inicial máximo $G_{0}$.

- La forma y expresión para la curva de descarga o de recarga es igual a la de carga noval (Ec. 3-82), pero ampliando la escala en horizontal y vertical un factor $x 2$. Es decir, $\tau_{\max \text {,escarga }}=2 \cdot \tau_{\max }$ en la expresión (Ec. 3-83).

- Las curvas de descarga y recarga retornan a la curva de carga noval cuando se supera la última deformación máxima en ese sentido.

- Si la curva de carga, que se está siguiendo en un momento dado, intersecta con alguna curva previa, se vuelve sobre dicha curva de carga previa.

\subsubsection{Modelos empíricos contemporáneos}

Vucetic y Dobry (Vucetic \& Dobry, 1990), estudiando el comportamiento de las arcillas del valle de México durante el terremoto de 1985, identifican como parámetro más determinante del mismo la influencia del índice de plasticidad IP, tanto para arcillas normalmente consolidadas como sobreconsolidadas. En este sentido, indican que, para una deformación de cortante $\gamma$ dada, para índices de plasticidad IP mayores la curva de reducción $G / G_{\max }$ aumenta y el amortiguamiento se reduce (Fig. 3-64). De esta manera, los suelos muy plásticos tienden a comportarse linealmente para deformaciones pequeñas $\left(\gamma<1 \cdot 10^{-3}\right)$, y se degradan menos para deformaciones mayores que los suelos con un IP menor. Vucetic y Dobry indican que se trata de un papel similar al que juega el índice de huecos $e$ en arenas, donde, a mayor índice de huecos, las curvas tienden a aumentar.
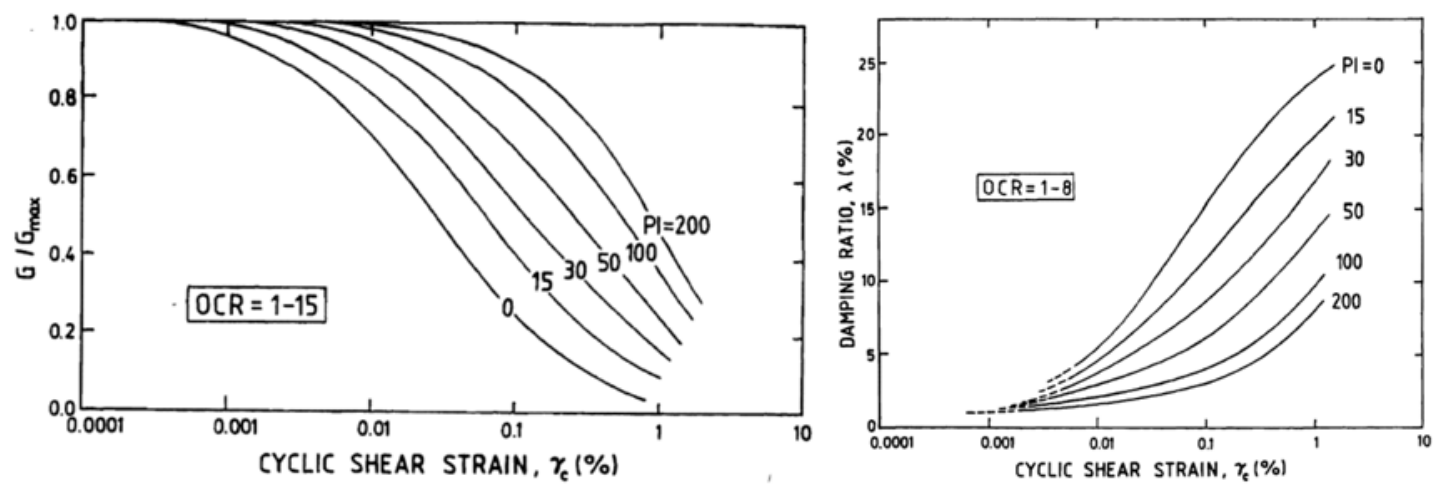

Fig. 3-64. (izda.) Curvas de reducción del módulo de cortante $G / G_{\max }$ para arcillas en función del índice de plasticidad PI. (dcha.) Curvas de amortiguamiento para arcillas en función del índice de plasticidad PI. (Vucetic \& Dobry, 1990).

Por otra parte, Vucetic y Dobry observan que el módulo de cortante incial para sucesivas etapas de carga y descarga no permanece constante, si no que depende del 
número de ciclos acumulado. De esta manera introducen un índice de degradación del módulo de cortante $\delta$ definido en la (Ec. 3-84), donde $G$ es el módulo de cortante inicial, $G_{N}$ el módulo de cortante inicial para el número de ciclo $N$, y $t$ un exponente que se obtiene empíricamente y resumido en la Tabla 3-4.

$$
\delta=\frac{G}{G_{N}}=N^{-t}
$$

\begin{tabular}{|c|c|c|}
\hline $\begin{array}{c}\text { Índice de Plasticidad } \\
\boldsymbol{I P}\end{array}$ & $\begin{array}{c}\text { Deformación cíclica } \\
\text { constante } \boldsymbol{\gamma}_{\boldsymbol{c}}\end{array}$ & $\begin{array}{c}\text { Exponente de degradación } \\
\boldsymbol{t}\end{array}$ \\
\hline $\begin{array}{c}I P \approx 15 \\
(\mathrm{Bajo})\end{array}$ & $0.1 \%$ & 0.035 \\
\hline$I P \approx 50$ & $1.0 \%$ & 0.24 \\
$(\mathrm{Alto})$ & $0.1 \%$ & 0.015 \\
\cline { 2 - 3 } & $1.0 \%$ & 0.06 \\
\hline
\end{tabular}

Tabla 3-4. Exponente del parámetro de degradación del módulo de cortante por carga cíclica. (Vucetic \& Dobry, 1990).

En su tesis doctoral, Darendeli (Darendeli, 2001), basándose en ensayos dinámicos realizados en la década de 1990 en la University of Texas, Austin, desarrolla un marco para generar ecuaciones simples de reducción del módulo de cortante, en base a la deformación angular, para suelos con componente arcillosa. Basándose en la idea ya propuesta por Hardin y Drnevich (Hardin \& Drnevich, 1972) de una relación hiperbólica con un parámetro de ajuste de la curvatura a (Ec. 3-85), propone también una ley de amortiguamiento del tipo de la (Ec. 3-86), en la que se asume que hay una parte del amortiguamiento debido al comportamiento histerético obtenido con las reglas de Masing (descritas en el apartado §3.6.1.2 de esta tesis), y otra parte inherente y que corresponde a la fase de comportamiento esencialmente lineal del suelo.

$$
\begin{gathered}
\frac{G}{G_{\max }}=\frac{1}{1+\left(\frac{\gamma}{\gamma_{r}}\right)^{a}} \\
\xi=b\left(\frac{G}{G_{\max }}\right)^{0,1} \xi_{\text {Masing }}+\xi_{\text {min }}
\end{gathered}
$$

La importancia del trabajo de Darendeli no es tanto la forma particular de estas expresiones, si no el estudio estadístico con el que se caracterizan los 4 parámetros $\gamma_{r}, a$, $b, \mathrm{y} \xi_{\min }$, para la gran muestra de suelos analizada. 

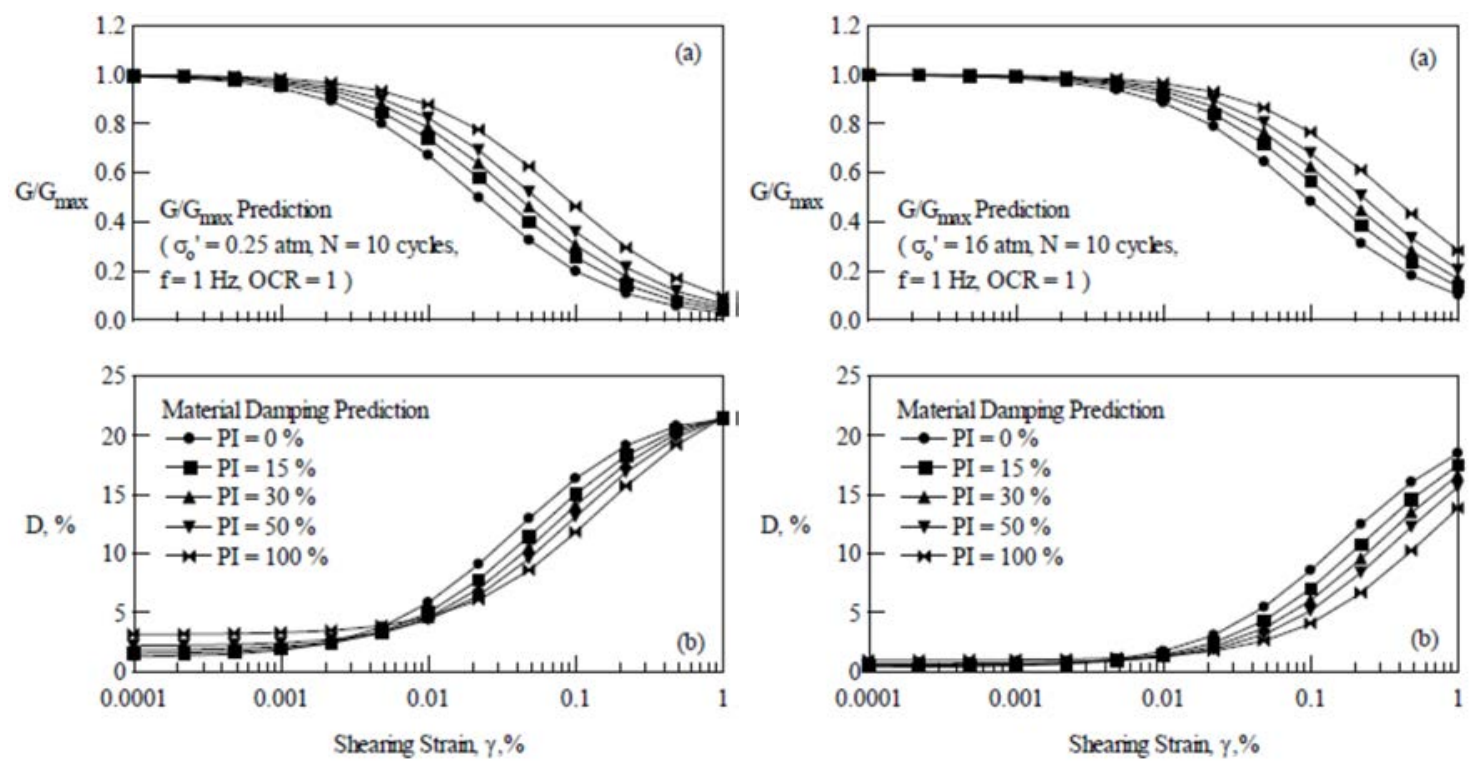

Fig. 3-65. Curvas de reducción del módulo de cortante $G / G_{\max }$ y de amortiguamiento equivalente en función del índice de plasticidad para diferentes presiones efectivas de confinamiento $\sigma \sigma^{\prime}$. (izda.) $\sigma_{0}^{\prime}=0.25 \mathrm{~atm}$. (dcha.) $\sigma_{0}^{\prime}=16 \mathrm{~atm}$. (Darendeli, 2001).

De manera contemporánea al estudio anterior, Menq, en su tesis doctoral (Menq, 2003) desarrollada también en la University of Texas, Austin, elabora un estudio similar para suelos granulares de arenas no plásticas y gravas. Partiendo de una expresión hiperbólica con exponente $a$ de ajuste de la curvatura (Ec. 3-85), propone las expresiones para determinar la curvatura de referencia $\gamma_{r}$, y para el exponente $a$. En estas exprisiones $C_{u}$ es un coeficiente de uniformidad, $\sigma_{0}{ }_{0}$ la tensión efectiva de confinamiento, y $P_{a}$ la presión atmosférica.

$$
\begin{gathered}
\gamma_{r}=0,12 \cdot C_{u}{ }^{-0,6} \cdot\left(\frac{\sigma_{0}^{\prime}}{P a}\right)^{0,5 \cdot C_{u}}{ }^{-0,15} \\
a=0,86+0,1 \cdot \operatorname{Ln}\left(\frac{\sigma_{0}^{\prime}}{P a}\right)
\end{gathered}
$$
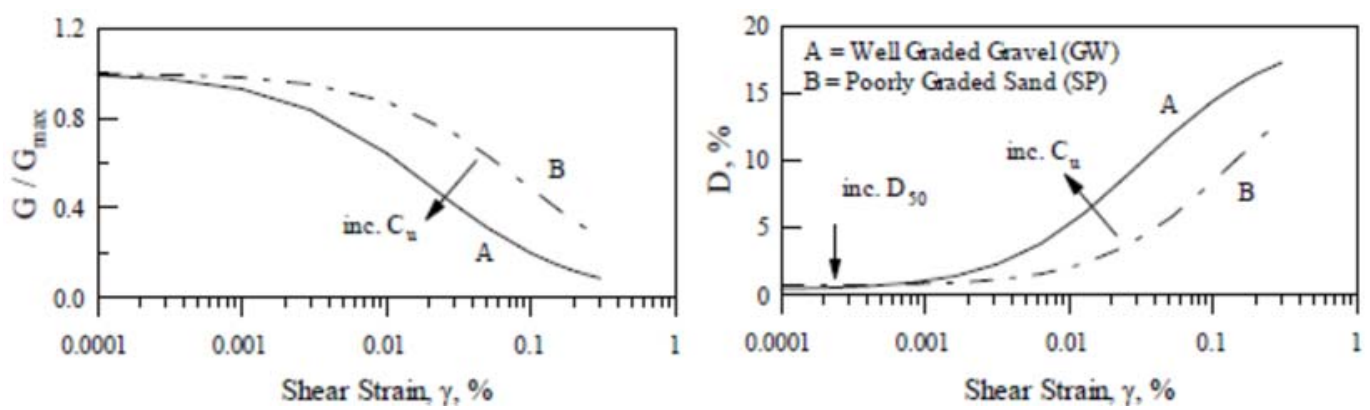

Fig. 3-66. Curvas de reducción del módulo de cortante $G / G_{\max }$ y de amortiguamiento. (Menq, 2003). 
El trabajo conjunto de Darendeli y Menq representa uno de los modelos más recientes de comportamiento de terrenos cohesivos y granulares. Un buen resumen de ambos modelos puede encontrarse en (Stokoe, Darendeli, Menq, \& Choi, 2004), que proporciona una tabla resumen de los parámetros de ambos modelos para suelos típicos de cada categoría.

\begin{tabular}{|c|c|c|c|c|c|c|c|c|c|c|c|c|}
\hline $\begin{array}{c}\text { Tipo } \\
\text { Suelo }\end{array}$ & $\begin{array}{c}\sigma_{0} 0 \\
{[\mathbf{a t m}]}\end{array}$ & $\begin{array}{c}\boldsymbol{D}_{50} \\
{[\mathbf{m m}]}\end{array}$ & $\boldsymbol{C}_{\boldsymbol{u}}$ & $\boldsymbol{e}$ & $\begin{array}{c}\boldsymbol{S}_{\boldsymbol{r}} \\
{[\mathbf{\%}]}\end{array}$ & $\begin{array}{c}\boldsymbol{P I} \\
{[\mathbf{\%}]}\end{array}$ & OCR & $\boldsymbol{a}$ & $\begin{array}{c}\gamma_{\boldsymbol{r}} \\
{[\mathbf{\%}]}\end{array}$ & $\begin{array}{c}\boldsymbol{G}_{\max } \\
{[\mathbf{M P a}]}\end{array}$ & $\boldsymbol{b}$ & $\begin{array}{c}\boldsymbol{D}_{\min } \\
{[\mathbf{\%}]}\end{array}$ \\
\hline GW & 1 & 10 & 50 & 0,30 & 90 & $\mathrm{NP}$ & 1,0 & 0,86 & 0,011 & 306 & 0,62 & 0,50 \\
\hline SW & 1 & 1 & 10 & 0,35 & 80 & $\mathrm{NP}$ & 1,0 & 0,86 & 0,030 & 183 & 0,62 & 0,80 \\
\hline CL & 1 & NA & NA & 0,64 & 100 & 20 & 1,5 & 0,97 & 0,058 & 81 & 0,62 & 1,05 \\
\hline CH & 1 & NA & NA & 1,12 & 100 & 60 & 1,5 & 1,26 & 0,104 & 58 & 0,62 & 1,54 \\
\hline
\end{tabular}

Tabla 3-5. Parámetros típicos de los modelos de Darendeli y Menq para diferentes tipos de suelos. (Stokoe et al., 2004).

\subsubsection{Modelos matemáticos de plasticidad}

La aplicación de los modelos empíricos descritos en el apartado §3.6.1 es esencialmente el estudio de la respuesta del terreno bajo solicitación sísmica en las denominadas condiciones de campo libre; es decir, cual es el comportamiento del suelo durante un sismo en el que las ondas de cortante se propagan verticalmente hacia la superficie, solicitando cíclicamente el terreno, y para permitir conocer cual será la respuesta de la superficie del terreno frente a un sismo.

No obstante, le campo de la ingeniería geotécnica necesita de otras descripciones más generales del comportamiento del suelo, frente a acciones dinámicas y cíclicas, que permitan modelizar fenómenos más complejos de interacción suelo estructura. Estas descripciones del comportamiento son modelos matemáticos de plasticidad que se emplean en programas de análisis numérico del tipo elementos finitos o diferencias finitas.

\subsubsection{Aspectos generales de la formualción de la plasticidad tridimensional}

En la teoría de la elasticidad generalizada, la proporcionalidad entre tensiones y deformaciones viene dada por una relación constitutiva del tipo de las (Ec. 3-89) y (Ec. 3-90), donde el tensor de cuarto orden $C_{i j k l}$, denominado tensor de constantes elásticas, relaciona el tensor de tensiones $\sigma_{i j} \mathrm{y}$ el de deformaciones $\varepsilon k l$, y tiene el mismo papel que el módulo de Young E en la elasticidad unidimensional (Olivella \& Agelet de SaracíbarBosch, 2000). En estas ecuaciones $\lambda$ y $\mu$ son las constantes de Lamé, definidas en la (Ec. 
3-91) y en la (Ec. 3-92) en función de los parámetros de módulo de Young E, módulo de cortante $G$, y coeficiente de Poisson $v$ del material.

$$
\begin{gathered}
\sigma_{i j}=C_{i j k l} \cdot \varepsilon_{k l} \\
\sigma_{i j}=\lambda \delta_{i j} \varepsilon_{l l}+2 \mu \varepsilon_{i j} \\
\lambda=\frac{v E}{(1+v)(1-2 v)} \\
\mu=\frac{E}{2(1+v)}=G
\end{gathered}
$$

Estas ecuaciones de la elasticidad están asociadas a un determinado sistema de referencia espacial (p.ej. una determinada orientación de los ejes cartesianos x, y, z), y los valores de tensiones y deformaciones para un determinado punto del cuerpo lógicamente variarán si se cambia el sistema de referencia. Sin embargo, existen una serie de valores denominados invariantes tensoriales $J_{i}$ que permanecen constantes independientemente de cual sea la orientación de los ejes de referencia. Esta propiedad los hace muy útiles a la hora de formular modelos matemáticos de plasticidad. Los invariantes $J_{i}$ tienen por expresión la (Ec. 3-93), donde $\sigma$ representa el tensor de tensiones, y $\operatorname{Tr}(\cdot)$ el operador traza. Por su relevancia, destacamos en la (Ec. 3-94) la particularización de la expresión anterior para el invarante $J_{2}$.

$$
\begin{aligned}
& J_{i}=\frac{1}{i} \operatorname{Tr}\left(\boldsymbol{\sigma}^{i}\right) \\
& J_{2}=\frac{1}{2} \sigma_{i j} \cdot \sigma_{j i}
\end{aligned}
$$

En el contexto del espacio de tensiones principales que se desarrollan en cualquier punto del cuerpo $\left(\sigma_{1}, \sigma_{2}, \sigma_{3}\right)$, la trisectriz del triedro trirectángulo formado por los ejes de tensiones principales representa el eje de tensiones hidrostáticas, en el sentido de que un aumento de tensión hidrostática del cuerpo (de igual valor en los tres ejes, $\sigma_{1}=\sigma_{2}=\sigma_{3}$ ) supondría un movimiento del punto de tensiones a lo largo de este eje (Fig. 3-67, izda.). En este espacio de tensiones principales, los planos $\Pi$ perpendiculares al eje de tensiones hidrostáticas se denominan planos octaédricos de tensiones (Fig. 3-67, izda.). De esta manera un punto $P$ en el espacio de tensiones principales queda determinado por la 
posición del plano $\Pi$ de tensiones octaédricas que lo contiene, y la distancia que lo separa del eje hidrostático de tenisones (Fig. 3-67, izda.).
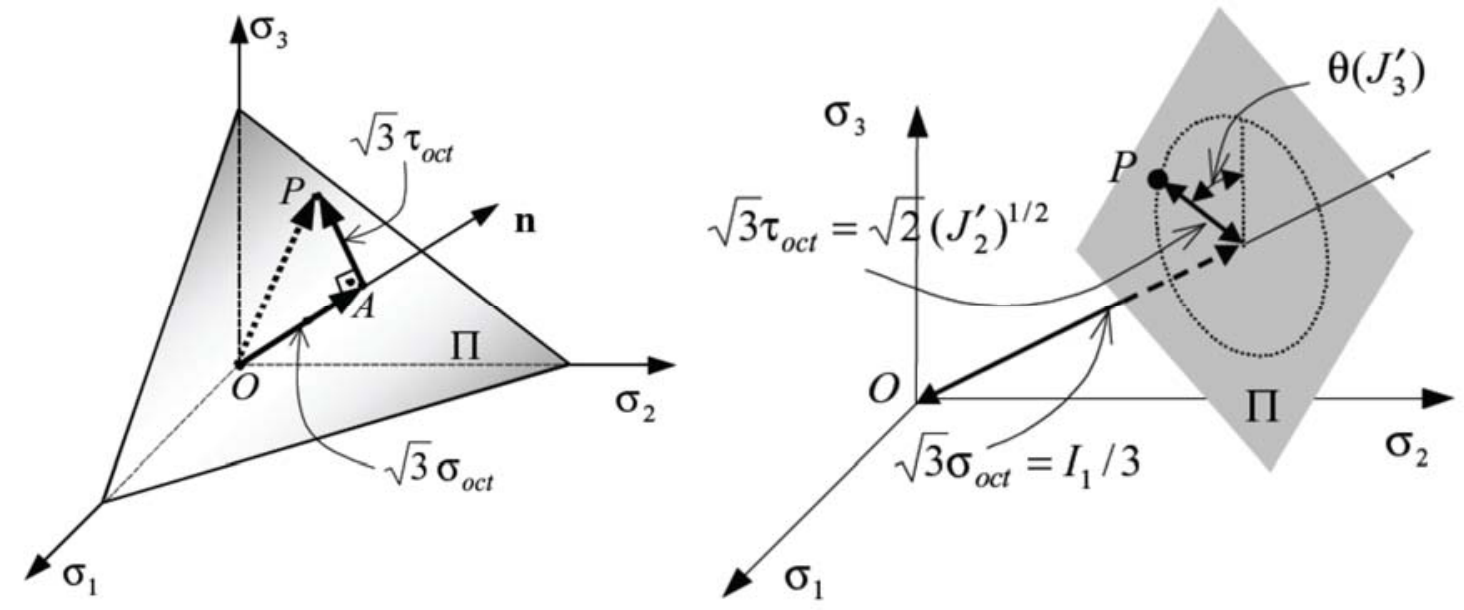

Fig. 3-67. (izda.) Espacio de tensiones principales y plano de tensiones octaédricas. (dcha.) Punto de tensiones principales $P$ expresado como función de sus invariantes tensoriales. (Olivella $\&$ Agelet de Saracíbar-Bosch, 2000).

A la distancia $|O A|$ que separa el plano $\Pi$ del punto de tensiones 0 se le denomina tensión sigma octaédrica $\sigma_{o c t}$ y a la distancia $|A P|$ que se para al punto $P$ del eje hidrostático de tensiones, tensión tau octaédrica $\tau_{\text {oct. }}$ Sus valores quedan determinados en las expresiones (Ec. 3-95) y (Ec. 3-96), en esta última se muestra también a través del invariante $J_{2}$.

$$
\begin{gathered}
|\overline{O A}|=\sqrt{3} \sigma_{o c t} \\
|\overline{A P}|=\sqrt{3} \tau_{\text {oct }}=\sqrt{2}\left(J_{2}\right)^{\frac{1}{2}}
\end{gathered}
$$

Cuando se sobrepasan ciertos valores de tensiones o deformaciones, la formulación elástica deja de ser válida, y se entra en el campo de la plasticidad. Al igual que en la plasticidad unidimensional se restringen los valores de tensiones que pueden darse en un elemento (p.ej. no es posible que el acero tenga tensiones superiores a la de plastificación $f_{y}$ ), en plasticidad tridimensional se establecen funciones de plastificación que determinan superficies en el espacio de tensiones principales, tales que restringen el campo de tensiones que puede darse en cada punto. Estas funciones de plastificación reciben el nombre superficies o criterios de fluencia, y determinan aquellos estados tensoniales que son admisibles y elásticos (en el interior de la superficie de fluencia), 
estados tensionales inadmisibles (en el exterior de la superficie de fluencia), y estados tensoniales plásticos (sobre la superficie de fluencia).

Dos de los criterios de plastificación más comunes son el criterio de von Mises (von Mises, 1913) empleado fundamentalmente en materiales arcillosos (Fig. 3-68, izda.), y el criterio de Drucker-Prager (Drucker \& Prager, 1952) empleado fundamentalmente en materiales granulares (Fig. 3-68, dcha.). El criterio de plastifiación de von Mises corresponde a una superficie cilíndrica con eje el eje de tensiones hidrostáticas. Como puede observarse en este modelo un aumento hidrostático de las tensiones (a lo largo de rectas paralelas al eje hidrostático) nunca llega a intersectar con la superficie de fluencia, y por lo tanto nunca llega a plastificar. El criterio de plastifiación de Drucker-Prager, sin embargo, corresponde a una superficie cónica cuyo eje es el eje de tensiones hidrostáticas.
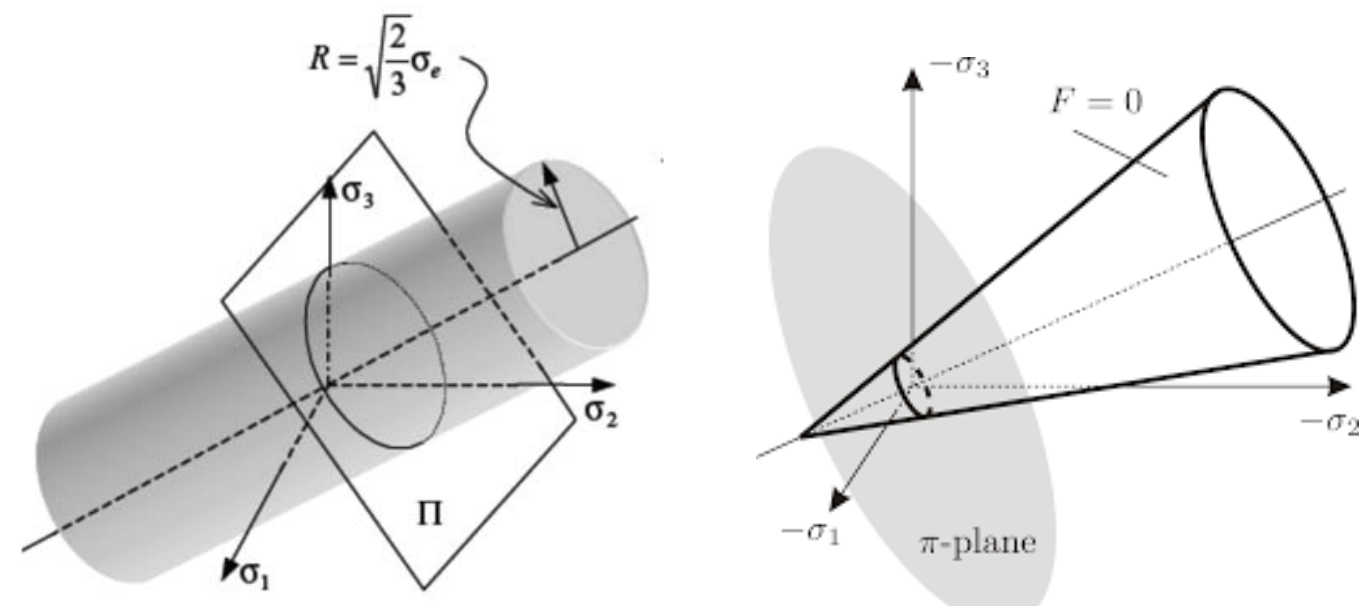

Fig. 3-68. Criterios de plastificación (izda.) de von Mises. (dcha.) de Drucker-Prager. (Olivella \& Agelet de Saracíbar-Bosch, 2000).

Estos criterios de fluencia se expresan analíticamente a través de las expresiones (Ec. 3-97) y (Ec. 3-98) para el criterio de von Mises y Drucker-Prager respectivamente, donde $J_{2}$ es el invariante tensorial indicado anteriormente, $\sigma_{y}$ la tensión de plastificación uniaxial, $\sigma_{m}$ la tensión media o hidrostática, y $\alpha$ y $\beta$ parámetros dados en las expresiones (Ec. 3-99) y (Ec. 3-100).

$$
\begin{gathered}
F(\boldsymbol{\sigma}) \equiv \sqrt{3 \cdot J_{2}}-\sigma_{y}=0 \\
F(\boldsymbol{\sigma}) \equiv 3 \cdot \alpha \cdot \sigma_{m}+\sqrt{J_{2}}-\beta=0
\end{gathered}
$$




$$
\begin{aligned}
& \alpha=\frac{2 \cdot \sin \phi}{\sqrt{3}(3-\sin \phi)} \\
& \beta=\frac{6 \cdot c \cdot \cos \phi}{\sqrt{3}(3-\sin \phi)}
\end{aligned}
$$

\subsubsection{Modelos de superficies anidadas}

Estos modelos de plasticidad sencillos descritos en el apartado §3.6.2.1 no pueden tener en cuenta el complejo mecanismo de plastificación pregresiva, descarga y recarga observado empíricamente y descrito en el apartado §3.6.1 de esta tesis.

De manera conjunta a los criterios anteriores, estos se asocian con modelos de endurecimiento, de tal manera que se definen sucesivas superficies de flujo.

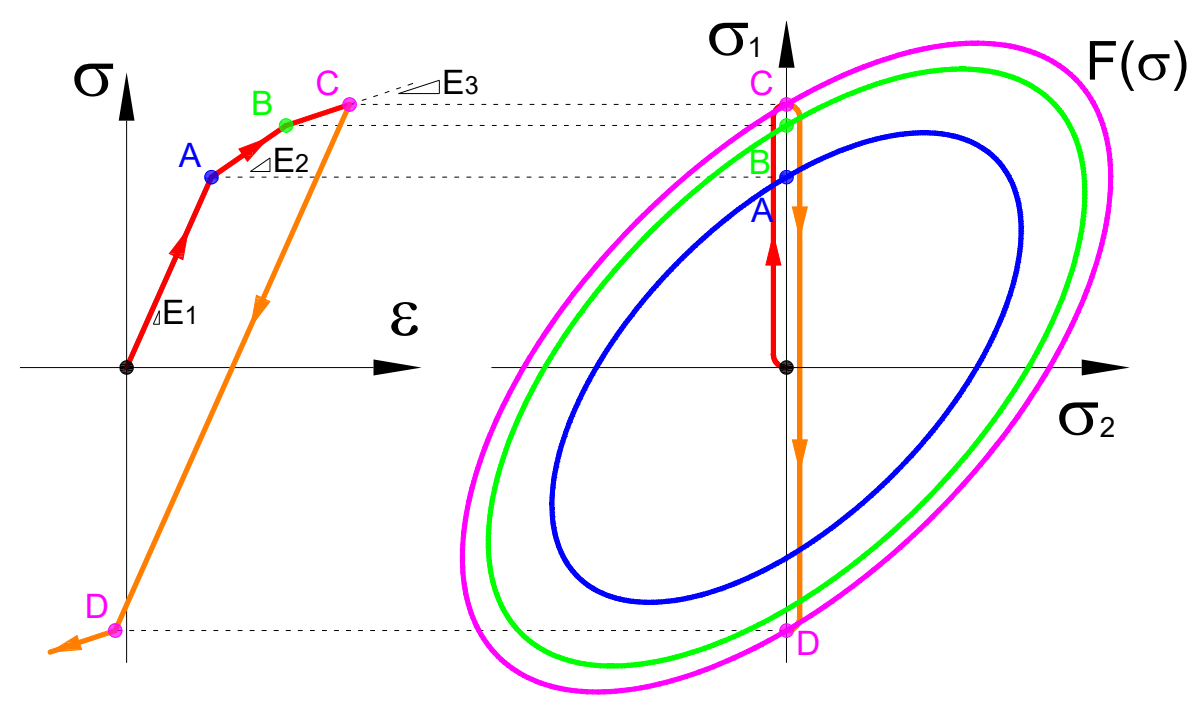

Fig. 3-69. Criterio de endurecimiento isotrópico para carga y descarga uniaxial.

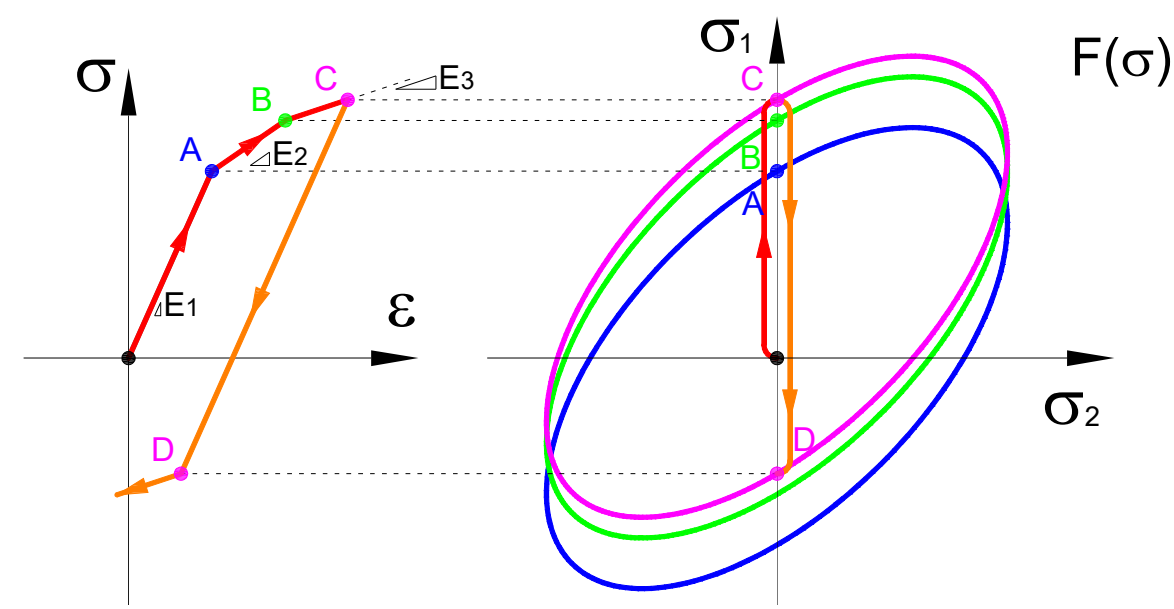

Fig. 3-70. Criterio de endurecimiento cinemático para carga y descarga uniaxial. 
Según sea el modo en el que se representa el endurecimiento se habla de un endurecimiento isotrópico, o cinemático (Zienkiewicz et al. 1999). Si al rebasar una superficie de fluencia, la siguiente superficie de fluencia es homotética de la primera, se dice que el endurecimiento es isotrópico (Fig. 3-69). Si, por el contrario, al rebasar una superficie de fluencia la siguiente superficie de fluencia es igual que la anterior pero trasladada, se dice que el endurecimiento es cinemático (Fig. 3-70).

Mróz (Mróz, 1967) fue el primero en formular con éxito un modelo de plasticidad con endurecimiento, y desde entonces el planteamiento del problema ha evolucinado hasta formar una familia de modelos matemáticos que se conocen hoy en día bajo el nombre de "de superficies anidadas" (nested surfaces en la literatura anglosajona). En ellos, se considera un conjunto de superficies de fluencia $f_{i}$ concéntricas que se van moviendo y haciendo tangentes entre sí según va evolucionando el punto $P$ en el espacio de tensiones principales (Fig. 3-71). A la región del espacio de tensiones principales delimitada por dos superficies anidadas consecutivas $f_{i}$ y $f_{i+1}$ le corresponde un módulo plástico $E^{p_{i}}$. Cuando se alcanza la superficie i+1, se cambia el módulo plástico a $E^{p_{i+1}, \mathrm{y}}$ así sucesivamente.
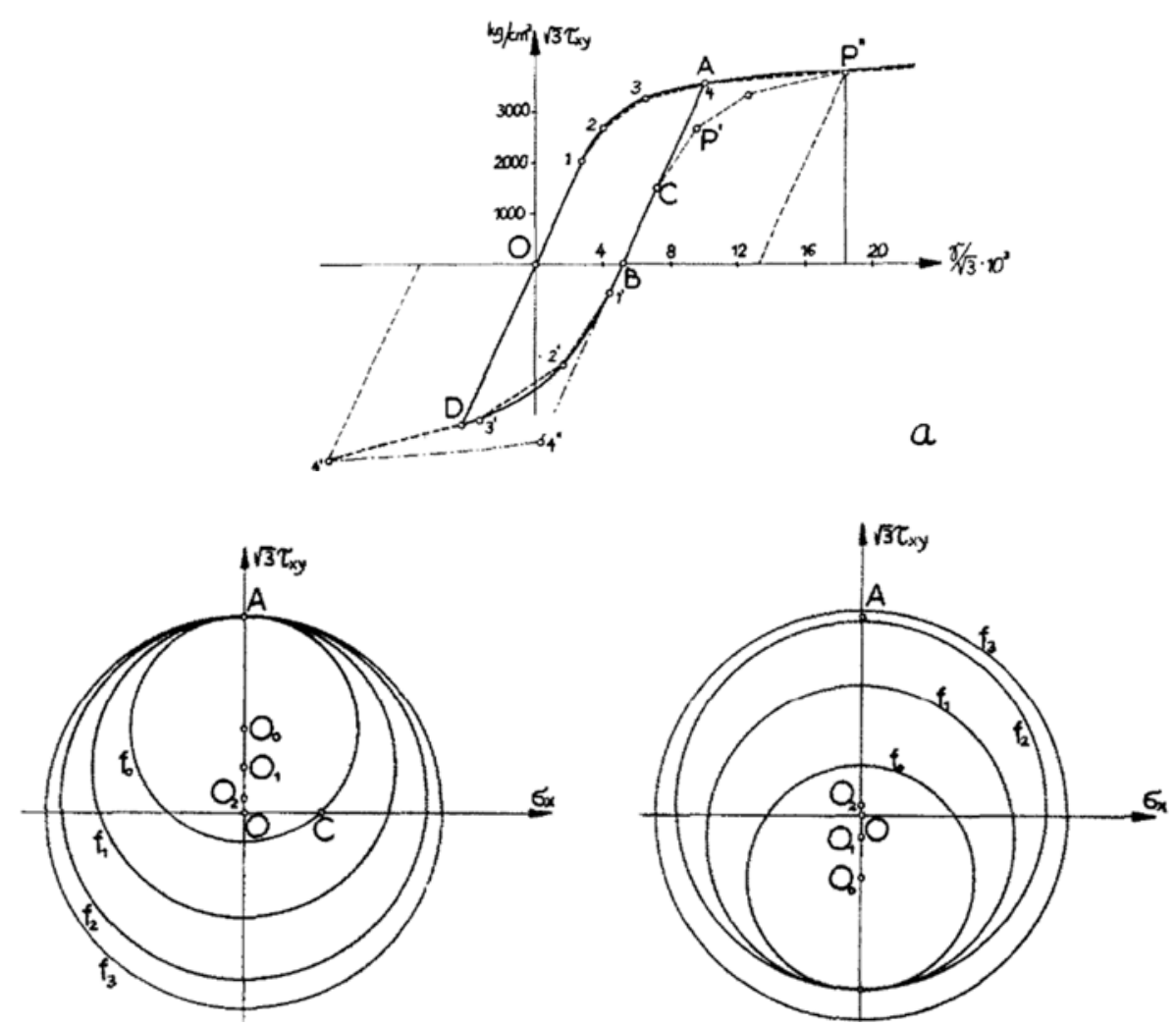

Fig. 3-71. Criterio de endurecimiento planteado por Mróz (Mróz, 1967). (sup.) Trayectoria uniaxial tensión-deformación. (inf. izda.) Evolución de las superficies de fluencia durante la carga. (if. Dcha.) Evolución de las superficies de fluencia durante la descarga. 
De manera conjunta con los modelos de superficies anidadas, se emplea la denominada ley de normalidad o de flujo asociativo, que asume de antemano que la dirección de la trayectoria del incremento de deformaciones plásticas, en el espacio de tensiones, es perpendicular a la superficie de fluencia. Esto implica que la dirección de la deformación se puede determinar de antemano mediante la derivada local de la superficie de fluencia.

\subsubsection{Respuesta dinámica de un suelo frente a la acción sísmica}

Como se ha indicado en el apartado §3.5.2, con el propósito de obtener información más precisa acerca de cual será el movimiento sísmico esperable en superficie para unas condiciones geotécnicas locales y específicas, es habitual realizar lo que se denomina un estudio de respuesta del terreno GRA (Ground Response Analysis).

La meta de este tipo de análisis es obtener una representación lo más certera posible del sismo en su propagación a través de un terreno, despreciando los proxies habituales de amplificación del terreno tipo $V_{S, 30}$ (despreciando la hipótesis de ergodicidad), y estudiando como los distintos estratos geotécnicos filtran el movimiento sísmico que llega al basamento rocoso, amplificando ciertos contenidos espectrales, y reduciendo otros (Stewart et al., 2014).

Habitualmente, en un análisis de respuesta del terreno GRA se realizan las siguientes hipótesis simplificadoras (Matasovic \& Hashash, 2012):

- Las ondas sísmicas, que llegan desde la zona de ruptura de la falla al basamento rocoso, se refractan en su camino hacia la superficie, debido a la menor rigidez y menor densidad del terreno cuanto más cerca está este de la superficie (Fig. 3-72). A efectos prácticos, las odas adquieren una dirección de propagación vertical en la zona de interés para las obras de ingeniería.

- Las ondas más relevantes, a efectos de la acción sísmica a emplear en el diseño de obras, son las ondas de cortante de polarización horizontal $\left(S_{H}\right)$.

- Debido a lo anterior, se puede asumir que el comportamiento del terreno se puede estudiar mediante un modelo de propagación unidimensional vertical, de ondas de cortante, en el que se representen los diferentes estratos del terreno con sus propiedades mecánicas correspondientes. 


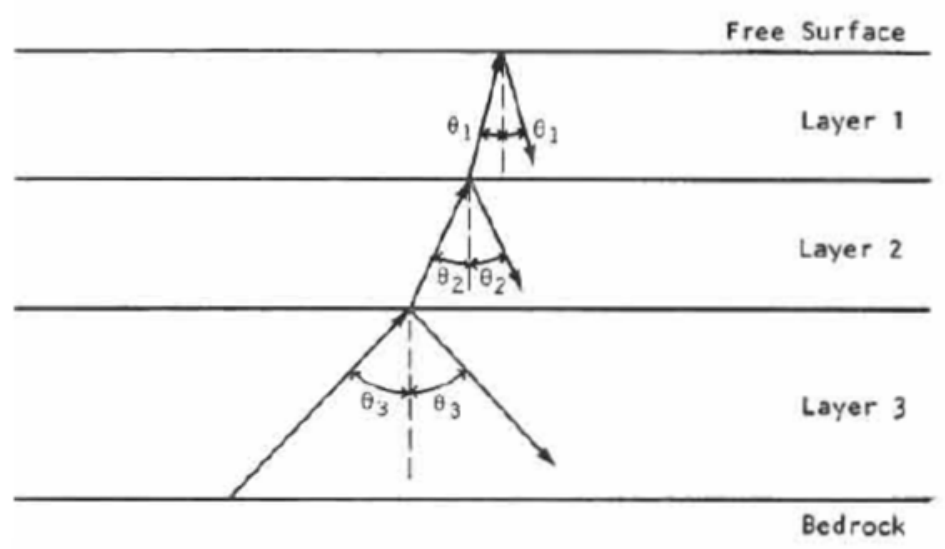

Fig. 3-72. Refracción y reflexión de las ondas de cortante desde el sustrato rocoso hasta la superficie del terreno. (Owen \& Scholl, 1981)

Desde los años 70 del s. XX se han seguido dos enfoques para realizar estos estudios de respuesta del terreno, ambos muy ligados a las capacidades de análisis por ordenador, y a la disponibilidad y difusión de programas adecuados para llevarlos a cabo. Una primera aproximación es la denominada de respuesta lineal equivalente (Schnabel, Lysmer, \& Seed, 1972), otra, los métodos no lineales completos (Stewart et al., 2008). En los apartados siguientes se revisan en detalle estos dos enfoques.

\subsubsection{Respuesta lineal equivalente tipo SHAKE}

Como se ha visto en el apartado §3.5.3, la propagación de las ondas de cortante a través de un medio elástico se puede representar analíticamente mediante dos ondas armónicas que viajan en direcciones opuestas. Esta representación armónica resulta muy cómoda, ya que presenta la ventaja de poder tratar el problema en el dominio de la frecuencia. En la práctica, el problema de determinar la respuesta en superficie, frente a un acelerograma dado en el basamento rocoso cuando atraviesa diferentes estratos elásticos, se puede determinar discretizando el paquete de terreno en diferentes capas viscoelásticas $i$, con rigidez a cortante $G_{i}$, densidad $\rho_{i}$, y amortiguamiento $\beta_{i}$ cada una. Puesto que el problema es lineal, admite la solución consistente en estudiar la respuesta a un input transitorio (acelerograma), mediante descomposición en series de Fourier del mismo, y obtener la respuesta del sistema en forma de suma de modos propios solicitados por el espectro de Fourier.

Para tratar el problema del comportamiento no lineal del terreno (el método anterior es únicamente válido para medios elásticos), Schnabel, Lysmer e Idriss (Schnabel et al., 1972) propusieron emplear una linealización equivalente en el programa SHAKE. 


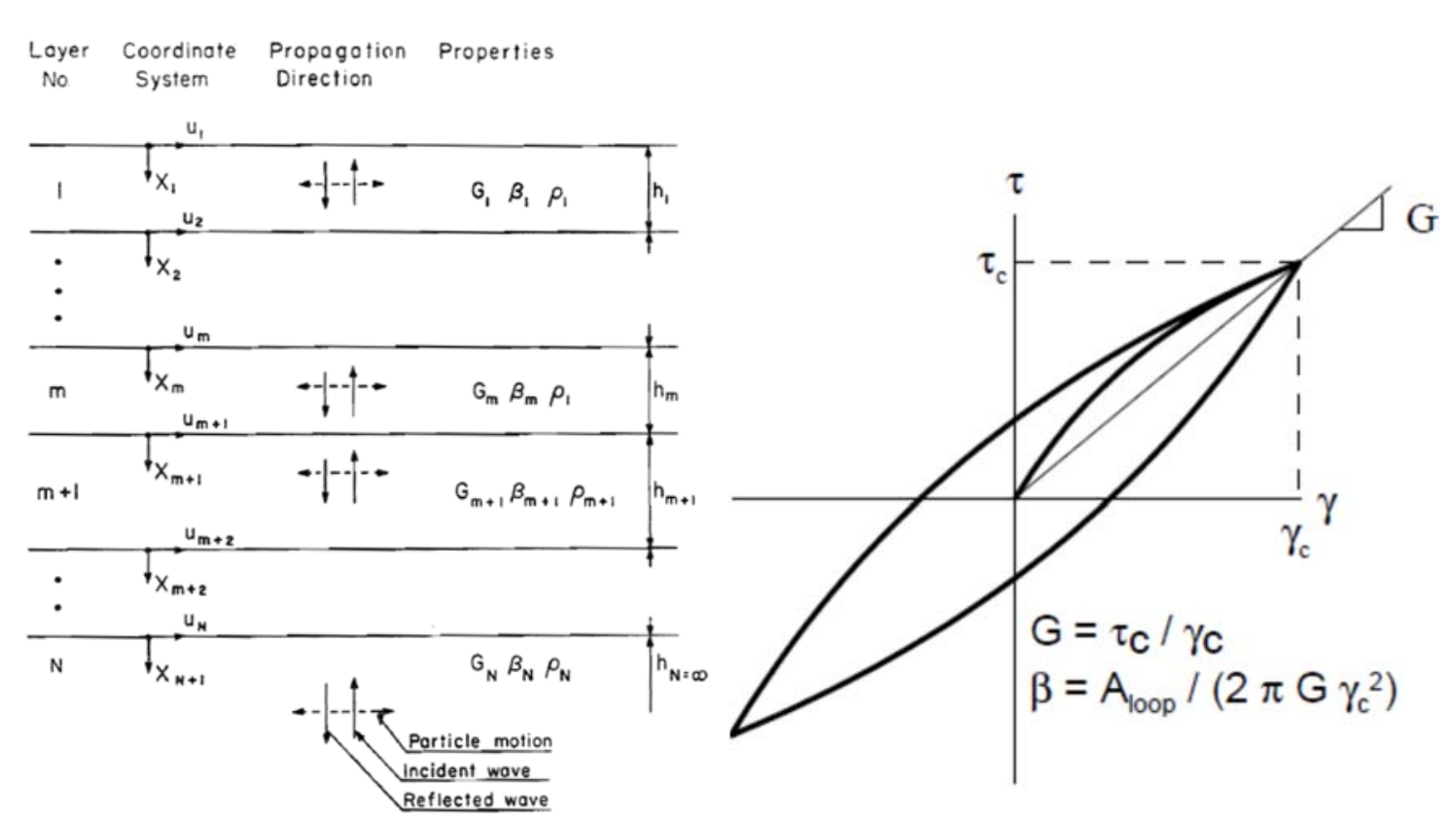

Fig. 3-73. (izda.) Modelo de capas de SHAKE con ondas ascendentes y descendentes. (Schnabel et al., 1972). (dcha.) Parámetros de rigidez $G$ y amortiguamiento $\beta$ de la linealización equivalente. (Stewart et al., 2008).

En dicha linealización se procede de manera iterativa mediante el siguiente esquema (Fig. 3-73):

1) Se realiza un primer análisis suponiendo el terreno elástico con propiedades mecánicas de rigidez y amortiguamiento correspondientes a pequeñas deformaciones.

2) Se obtienen las deformaciones tangenciales máximas $\gamma_{i}$ en cada capa modelizada.

3) Se entra con dicha deformación tangencial $\gamma_{i}$ en las curvas de reducción de la rigidez $G / G_{\max }$, y de amortiguamiento $\beta$ de cada material, y se obtiene la rigidez secante equivalente $G_{\text {sec }}$ y amortiguamiento desarrollado para esa deformación (Fig. 3-73, dcha.).

4) Se repite el análisis elástico suponiendo las propiedades actualizadas de las capas de terreno. Se repite el proceso hasta que la variación de las deformaciones sea menor que un límite prefijado.

Este esquema de análisis se emplea ampliamente en la práctica actualmente (Matasovic \& Hashash, 2012), con el programa SHAKE, u otras implementaciones más actuales. Una de las ventajas de este método frente a otros más avanzados es la sencillez 
de los datos que necesita, y que todos los parámetros de análisis tienen un significado físico concreto y bien conocido (Stewart et al., 2008).

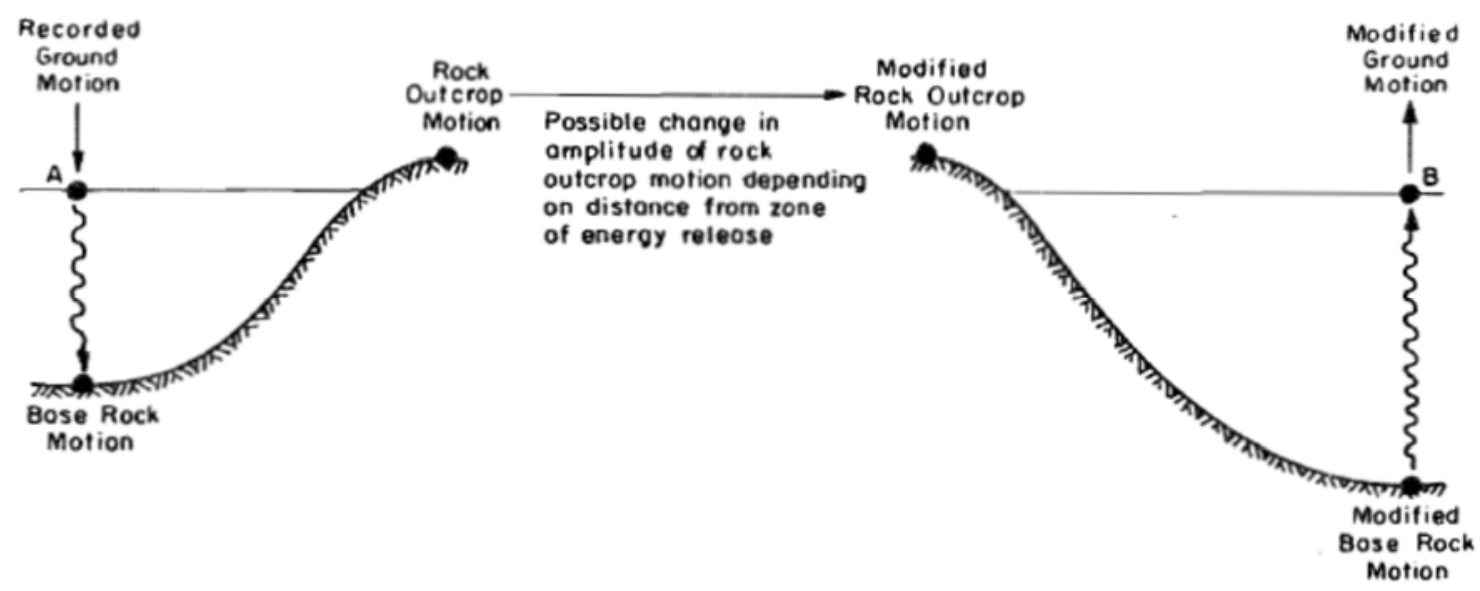

Fig. 3-74. (izda.) Análisis de deconvolución para obtener un acelerograma en superficie rocosa de un sismo registrado en suelo blando. (dcha.) Análisis de convolución para obtener un acelerograma en superficie de un suelo blando conocido el sismo en superficie rocosa. (Schnabel et al., 1972).

\subsubsection{Respuesta no lineal completa tipo Deepsoil}

El análisis de la respuesta del terreno mediante métodos numéricos realmente no lineales es menos frecuente que los métodos lineales equivalentes. La causa de la limitación práctica de esta metodología se puede achacar a protocolos de selección de parámetros pobremente documentados, así como a instrucciones poco claras para su implementación (Stewart et al., 2008). Sin embargo, estos métodos son capaces de proporcionar resultados más precisos, especialmente en lo que respecta al comportamiento del suelo (Hashash, Phillips, \& Groholski, 2010).

Los métodos de respuesta no-lineal se basan en la discretización del problema de propagación vertical de ondas de cortante, mediante una serie de nudos con masa concentrada, y modelización de la rigidez a cortante y amortiguamiento del terreno entre nudos mediante resortes con comportamiento no lineal. 

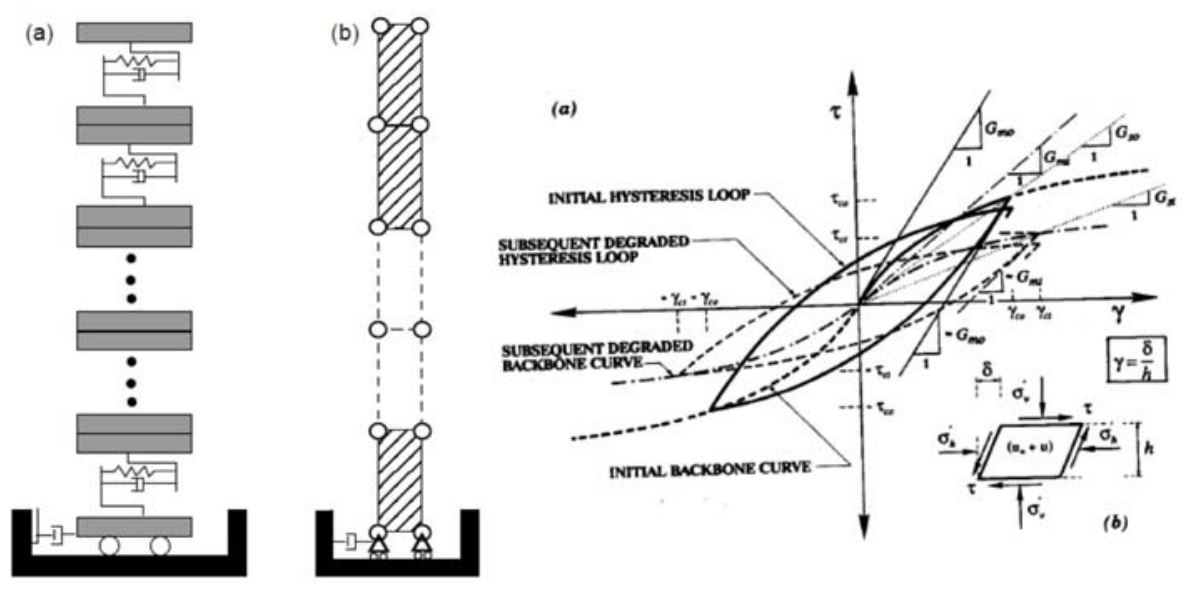

Fig. 3-75. (izda.) Modelo discretizado en nudos con masa, y elementos con rigidez a cortante y amortiguamiento. (dcha.) Parámetros de rigidez $G$ y amortiguamiento $\beta$ de la linealización equivalente. (Stewart et al., 2008).

Estos modelos (en esencia no lineales) no pueden calcularse en el dominio de la frecuencia, si no que demen analizarse en el dominio del tiempo para cargas transitorias (análisis time-history). De esta manera, se someten a acelerogramas en su base, que respresenta el contacto con el sustrato rocoso, o con alguna otra capa dura con un contraste de impedancia adecuado con respecto al suelo que reposa encima. Los resultados que proporcionan estos modelos son, tanto las historias de aceleraciones en superficie, como las historias de deformaciones y tensiones para cada capa modelizada de terreno.

A la hora de modelizar las condiciones de contorno, tanto en lo que se refiere a las vinculaciones de los nudos como a la acción solictante, es necesario prestar atención a la compatibilidad del tipo de acelerograma que se introduce como acción solicitante, y al tipo de condición de contorno de la parte inferior del modelo, ya que una elección inadecuada de ambos puede producir resultados que sean del orden del doble, o de la mitad, del valor esperable. Un buen resumen de este fenómeno puede encontrarse en los trabajos de Stewart et al. (Stewart et al., 2014, 2008; Stewart \& Kwok, 2008), y cuyas conclusiones se resumen a continuación.

Por regla general los acelerogramas que el ingeniero puede encontrar a su disposición corresponden a registros en superficie, es decir, de movimientos registrados con acelerómetros en la superficie del terreno (registros de tipo outcrop en la literatura anglosajona). Sin embargo, y como se ha comentado en el apartado §3.5.3.2.3 de esta tesis al describir la condición de borde libre, en las proximidades de la superficie del terreno la amplitud del movimiento sísmico esencialmente se duplica con respecto a la 
amplitud del movimiento a mayor profundidad. De esta manera, si en el modelo de análisis se introduce como solicitación un acelerograma tipo outcrop, el movimiento en superficie será del orden del doble del esperado, y por lo tanto producirá resultados erróneos. Adicionalmente, si la condición de contorno del borde inferior es de tipo rígido, la onda descendente procedente de la reflexión en superficie, se verá completamente reflejada de nuevo en el borde rígido inferior, transmitiéndose de nuevo al medio, y acumulándose sin posibilidad de que su energía se pierda por el borde inferior.

Una solución a ambos problemas consiste en solicitar el modelo con un acelerograma tipo outcrop y emplear como condición de borde inferior una del tipo Lysmer-Kuhlemeyer (O. Lysmer \& Kuhlemeyer, 1969) como la descrita en el apartado §3.5.3.3 de esta tesis. Con este tipo de condición de borde, aproximadamente la mitad de la acción introducida se transmite al medio del terreno, mientras que la otra mitad queda disipada en los amortiguadores; de esta manera tan sólo llega a superficie la mitad de la acción, que al duplicarse por efecto borde libre proporciona exactamente el orden de magnitud del movimiento esperado. Adicionalmente, al tratarse de una condición de borde absorbente, la onda que se refleja en la superficie y avanza hacia abajo se pierde al alcanzar el límite inferior del modelo.

Otra opción para solucionar satisfactoriamente el problema consiste en emplear una condición de borde rígido, pero introduciendo como acelerograma solicitante uno que se haya registrado a gran profundidad (conocido como un acelerograma within en la literatura anglosajona). Sin embargo, los registros sísmicos a gran profundidad son mucho más escasos, y se limitan a algunas pocas localizaciones en California y Japón. Por otra parte, el emplear un registro solicitante de tipo within junto con una condición de borde de tipo Lysmer-Kuhlemeyer también proporcionaría resultados erróneos, ya que estos amortiguadores absorberían la mitad de la energía inyectada en el sistema, y por lo tanto la aceleración registrada en superficie sería tan sólo la mitad de la esperable.

Las conclusiones de la discusión precedente pueden resumirse en la Tabla 3-6.

\begin{tabular}{|c|c|c|c|}
\hline \multicolumn{2}{|c|}{$\begin{array}{c}\text { Condiciones de contorno y } \\
\text { acelerograma de entrada }\end{array}$} & \multicolumn{2}{c|}{ Condición de contorno } \\
\cline { 3 - 4 } & Outcrop & Lysmer-Kuhlemeyer & Borde rígido \\
\hline \multirow{2}{*}{ Acelerograma } & Within & Inapropiado (x1/2) & Inapropiado (x2) \\
\cline { 2 - 4 } & & Apropiado \\
\hline
\end{tabular}

Tabla 3-6. Combinaciones de condiciones de contorno y acelerograma solicitante 


\subsection{La acción dinámica del terreno sobre la estructura}

De manera similar a como ocurriera con la acción estática del empuje del terreno sobre una estructura de contención descrita en el apartado §3.4, el problema de determinar cuál es el empuje de tierras debida a la acción del sismo, sobre estructuras de contención u obras subterráneas, ha sido objeto de diversos desarrollos a lo largo de la reciente historia de la ingeniería sísmica.

En particular se distinguen varios grupos de métodos, que se describen a continuación, según el orden histórico de su aparición, y que consisten en los métodos pseudo-estáticos de empuje dinámico (apartado §3.7.1), los métodos elásticos de empuje dinámico (§3.7.2), métodos de deformaciones de campo libre (§3.7.3), y finalmente los métodos de interacción cinemática suelo-estructura (\$3.7.4).

\subsubsection{Métodos pseudo-estáticos de empuje dinámico}

Los métodos pseudo-estáticos de empuje dinámico, en un estado de equilibrio límite, encuentran su paralelo estático en las teorías clásicas de empuje sobre muros rígidos de Coulomb (Coulomb, 1776) y Rankine (Rankine, 1856), descritas en los apartados $\S 3.4 .1 .1$ y $\S 3.4 .1 .2$ respectivamente.

En particular, estos métodos se ocupan de determinar cuál es el empuje total que ejerce el terreno contenido por la estructura cuando el conjunto se ve sometido a la acción de un sismo, y el punto de aplicación de este empuje, con el propósito de poder determinar las condiciones de equilibrio general de la estructura, así como los esfuerzos (momento flector y esfuerzo cortante) en el propio muro.

\subsubsection{Método de Mononobe Okabe}

El método de Monobe-Okabe (Mononobe \& Matsuo, 1929; Okabe, 1924) fue desarrollado en Japón como respuesta a los problemas de estabilidad que mostraron gran número de obras de contención de tierras en el puerto de Yokohama durante del terremoto de Kanto, en 1923. La esencia de este método de cálculo de la presión de tierras durante un evento sísmico radica en la aplicación de la teoría estática de Coulomb, extendida a condiciones pseudoestáticas. En el análisis propuesto originalmente por Mononobe y Matsuo (Mononobe \& Matsuo, 1929) las aceleraciones pseudoestáticas máximas horizontal $k_{h}$ y vertical $k_{v}$, que experimenta el terreno en superficie durante un sismo, se 
aplican a una cuña activa o pasiva de terreno de Coulomb, de manera conjunta con la acción de la gravedad (Fig. 3-76). El empuje pseudoestático $P_{A E}$ del terreno sobre la estructura de contención se obtiene de la formulación del equilibrio de esta cuña de terreno, de manera análoga a como hiciera Coulomb (Kramer, 1996). Puesto que la aceleración vertical $k_{v}$ actúa alternativamente en sentido ascendente y descendente, el método desarrollado establece que deben realizarse dos análisis, uno en cada sentido de la componente vertical, y adoptar como solicitación el más desfavorable de ellos. Adicionalmente, Mononobe propone que la resultante del empuje de tierras se ubica a $1 / 3$ de la altura del muro sobre su base.

Puesto que el equilibrio de la cuña activa de terreno se plantea de manera conjunta para las dos acciones actuantes, gravedad y aceleración sísmica, la resultante de fuerza horizontal $P_{A E}$ que se obtiene corresponde a la suma de la acción habitual estática, más la componente debida a la acción del sismo. Mononobe plantea el equilibrio del conjunto muro-cuña para una geometría de muro como la de la (Fig. 3-78), algo más compleja que la representada en la Fig. 3-76. A continuación, sin embargo, planteamos las ecuaciones de equilibrio correspondientes a la figura más sencilla (Fig. 3-76) para mostrar de manera más clara el razonamiento subyacente. Si se establece el equilibrio de la cuña de terreno indicada en la (Fig. 3-76), en el que el sentido ascendente o descendente de la componente vertical se tiene en cuenta con el término $\pm k_{v}$, se obtienen los siguientes resultados:

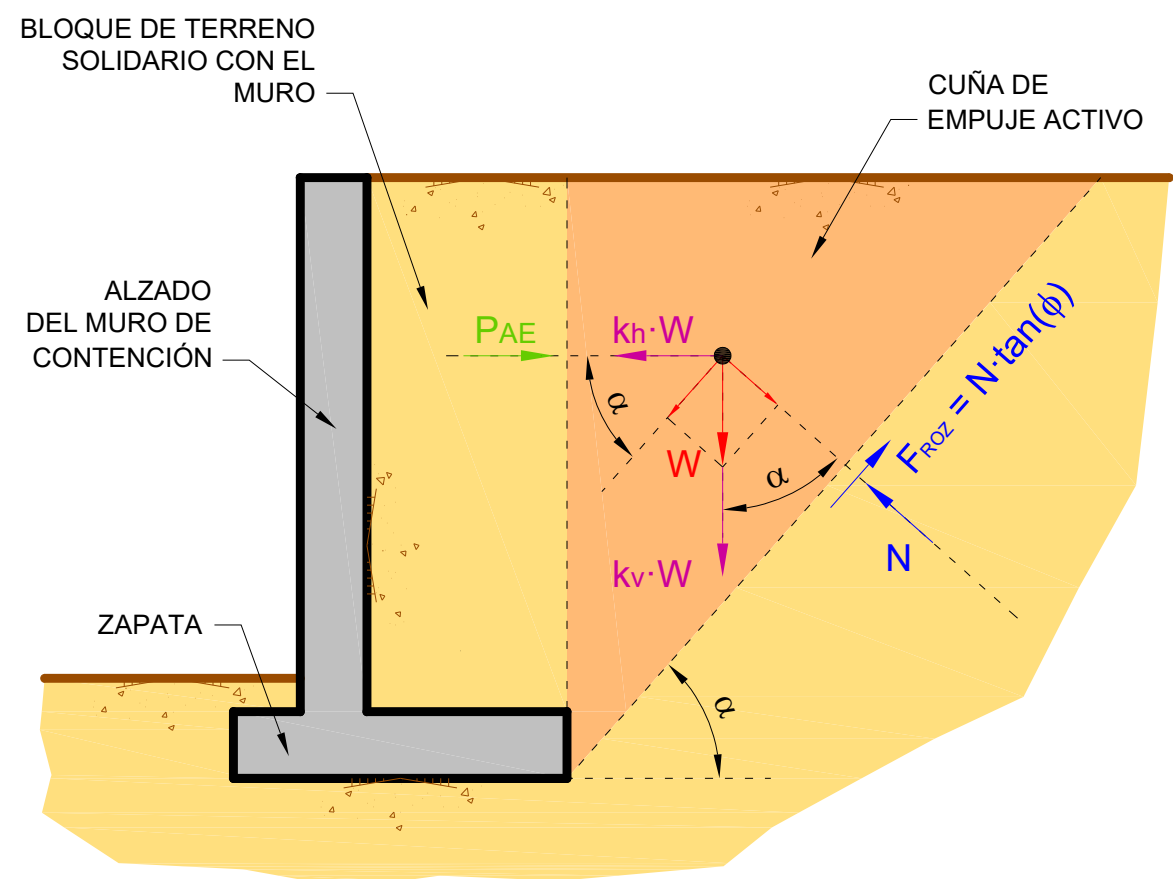

Fig. 3-76. Esquema de cuña de empuje activo de Mononobe (Mononobe \& Matsuo, 1929). 
- Equilibrio de fuerzas vertical:

$$
\begin{gathered}
W \cdot\left(1 \pm k_{v}\right)=N \cdot \cos (\alpha)+N \cdot \tan (\varphi) \cdot \sin (\alpha) \therefore \\
N=\frac{W \cdot\left(1 \pm k_{v}\right)}{\cos (\alpha)+\tan (\varphi) \cdot \sin (\alpha)}
\end{gathered}
$$

- Equilibrio de fuerzas horizontal:

$$
\begin{gathered}
N \cdot \sin (\alpha)+W \cdot k_{h}=P_{A E}+N \cdot \tan (\varphi) \cdot \cos (\alpha) \therefore \\
P_{A E}=N \cdot(\sin (\alpha)-\tan (\varphi) \cdot \cos (\alpha))+W \cdot k_{h} \therefore \\
P_{A E}=\frac{W \cdot\left(1 \pm k_{v}\right) \cdot(\sin (\alpha)-\tan (\varphi) \cdot \cos (\alpha))}{\cos (\alpha)+\tan (\varphi) \cdot \sin (\alpha)}+W \cdot k_{h}
\end{gathered}
$$

Al igual que ocurriera en el caso estático de Coulomb, la resolución del equilibrio de fuerzas horizontal y vertical depende del ángulo $\alpha$ de la cuña activa, que es un dato que no se conoce a priori. Para poder determinar este ángulo, Mononobe propone que, del lado de la seguridad en el dimensionamiento de muros, se emplee aquel que proporcione un empuje horizontal mayor.

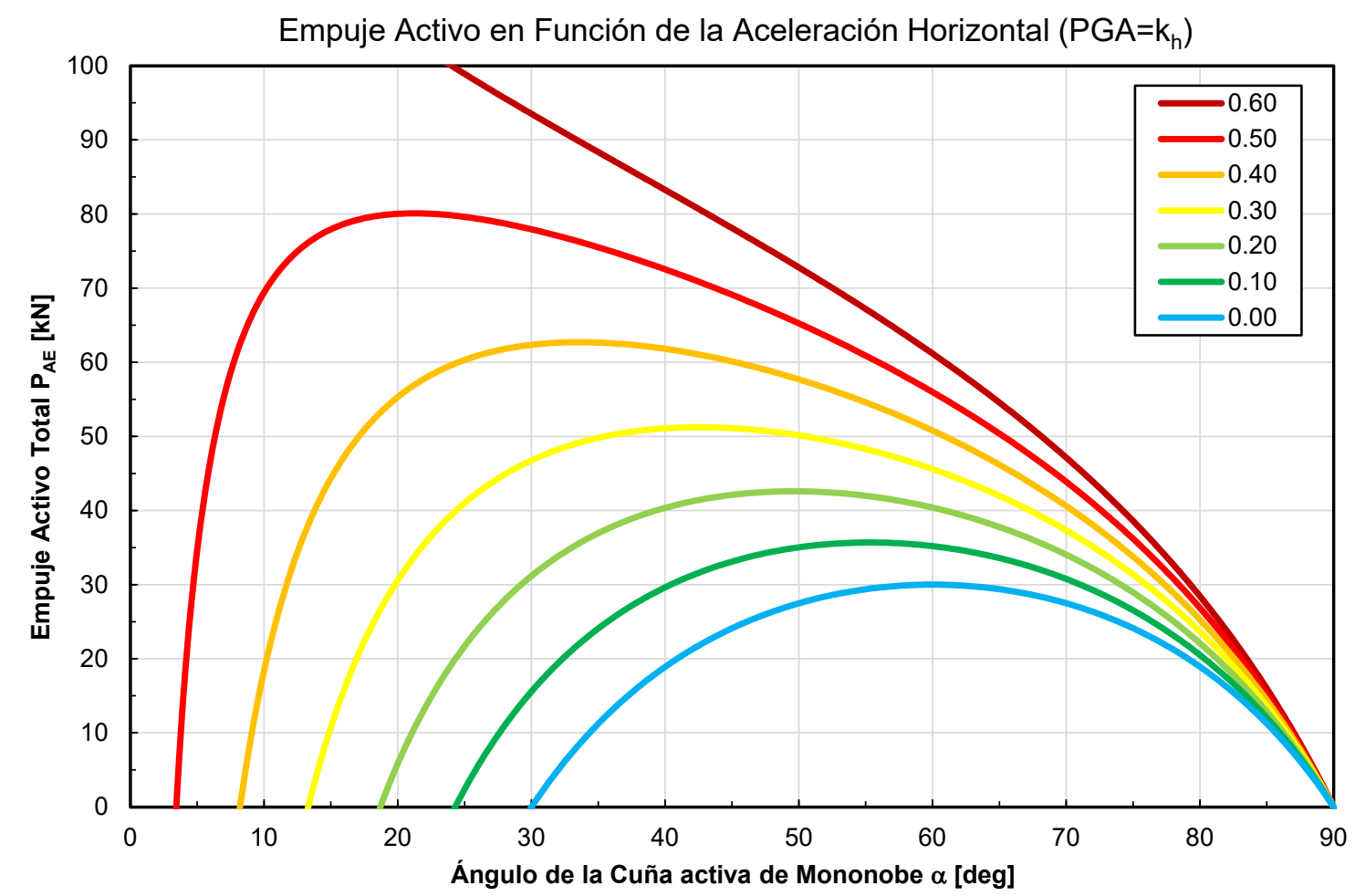

Fig. 3-77. Empuje activo total de Mononobe para un muro de $10 \mathrm{~m}$ de altura, relleno del trasdós con densidad $\rho=18 \mathrm{kN} / \mathrm{m}^{3}$ ángulo de rozamiento interno $\phi=30^{\circ}$, aceleración vertical $k_{v}$ nula, $y$ aceleración máxima horizontal del terreno $k_{h}$ variable entre $0 \cdot g$ y $0.6 \cdot g$. 
Derivando la expresión del empuje horizontal una vez con respecto al ángulo $\alpha$, e igualando esta derivada a 0 , Mononobe establece que el empuje máximo posible responde a la ecuación (Ec. 3-103), donde $\phi$ es el ángulo de rozamiento interno del terreno, $\psi$ el ángulo de inclinación del trasdós del muro respecto a la vertical, $\beta$ el ángulo de la superficie del terreno en el trasdós con respecto a la horizontal, $\delta$ el ángulo de rozamiento entre el trasdós del muro y el terreno, $\theta$ la relación entre aceleración máxima horizontal y vertical $k_{h} / k_{v}$, como se muestra en la Fig. 3-78.

$$
K_{A E}=\frac{\sin ^{2}(\psi+\phi-\theta)}{\cos \theta \cdot \sin ^{2} \psi \cdot \sin (\psi-\theta-\delta) \cdot\left[1+\sqrt{\frac{\sin (\phi+\delta) \cdot \sin (\phi-\beta-\theta)}{\sin (\psi-\theta-\delta) \cdot \sin (\psi+\beta)}}\right]^{2}}
$$

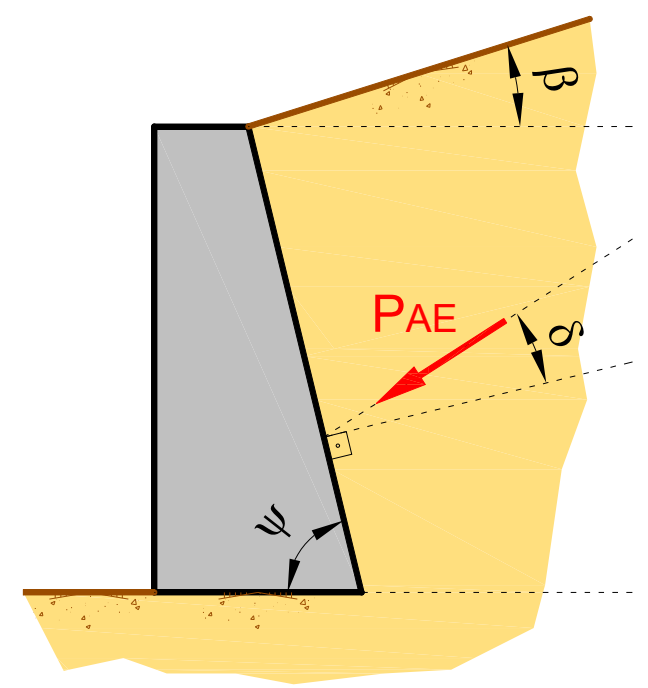

Fig. 3-78. Geometría del trasdós del muro de gravedad planteada originalmente por Mononobe.

La hipótesis subyacente en el método de Mononobe, y que debe comprobarse que se cumple en cada caso concreto para que el método sea de aplicación, es que la estructura de contención y el terreno contenido tenga una configuración geométrica tal que permita que se forme una cuña activa de terreno en el trasdós de la estructura de contención. La verificación de esta hipótesis resulta especialmente relevante en aquellos casos en los que el conjunto de la estructura de contención y su cimentación sean tan rígidos que no permitan una deformación suficiente del terreno ni de la estructura como para que se forme la cuña de empuje activo. Este puede ser el caso por ejemplo de estructuras muy rígidas cimentadas en roca, o de muros de contención de gravedad cuya cimentación se encuentra hormigonada en un cajeado de roca que no permita el desplazamiento. 
Puesto que el equilibrio de cuña del terreno del tipo Coulomb propuesto por Mononobe tan sólo proporciona resultados del empuje horizontal total $P_{A E}$, correspondientes a la acción total sobre la estructura de contención (gravedad y aceleración sísmica), Okabe (Okabe, 1924) propone asignar un estado de presiones de empuje activo del tipo de Rankine, y separar esta presión en dos componentes, una estática correspondiente a un coeficiente de empuje activo $K_{a}$ habitual, y otra dinámica $\Delta K_{a}$ (Fig. 3-79), obtenida como diferencia de la presión total y la estática (Ec. 3-101).

$$
\Delta K_{a}=K_{A E}-K_{a}
$$
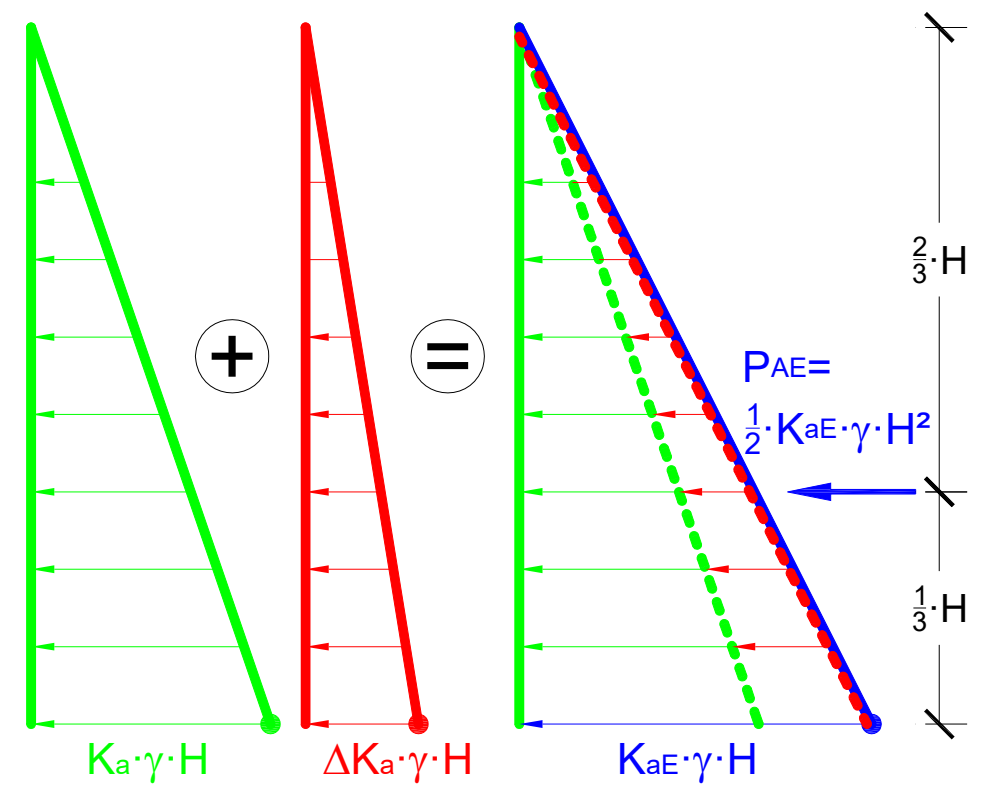

Fig. 3-79. Interpretación conceptual de la distribución de presiones de Okabe.

Puesto que la propuesta conjunta de Mononobe y Okabe se basa en los métodos de Coulomb y Rankine, es significativo señalar que la parte de la presión del terreno correspondiente a la acción del sismo tiene su resultante aplicada a 1/3 de la altura del muro respecto a su base (Fig. 3-79).

\subsubsection{Método de Seed y Whitman}

El método desarrollado por Mononobe y Okabe, junto con sus hipótesis de partida, permanece como el estándar de diseño de las estructuras de contención durante la primera mitad del s. XX hasta que Seed y Whitman (Seed \& Whitman, 1970) retoman el análisis del problema, motivados por los fallos de varios muros en estructuras portuarias ocurridos durante los terremotos de Valdivia (Chile, 1960) de Mw 9.5, y Niigata (Japón, 1964) de $\mathrm{Mw}_{\mathrm{w}}$ 7.5. 
Basándose en los resultados de los ensayos realizados por Murphy (Murphy, 1960), Seed y Whitman concluyen que el mecanismo de fallo geotécnico se describe correctamente con el que se asume en el método de Mononobe y Okabe. Adicionalmente, a través de un estudio paramétrico de sensibilidad, también concluyen que la componente vertical $k_{v}$ del método de Mononobe-Okabe puede despreciarse.
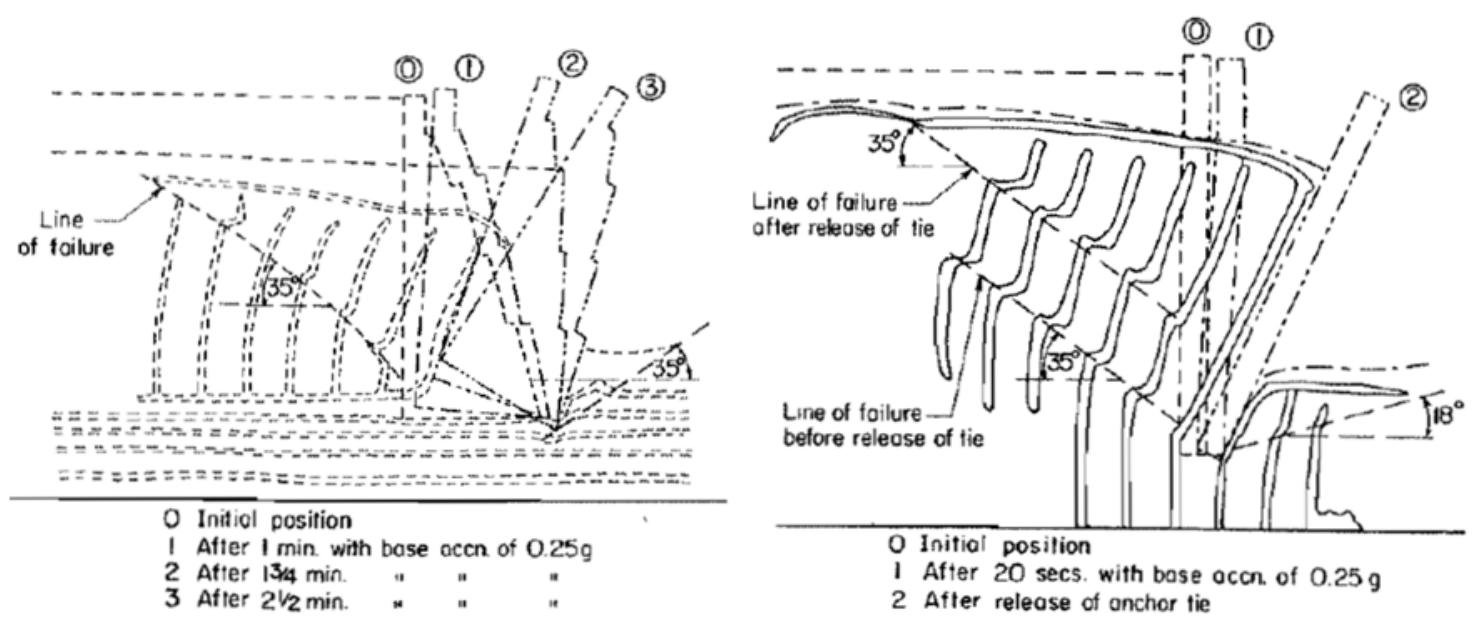

Fig. 3-80. (izda.) Mecanismo de fallo de un muro de gravedad durante un sismo. (dcha.) Mecanismo de fallo de una tablestaca durante un sismo (Murphy, 1960).

Refiriéndose a diversos estudios experimentales, entre los cuales destacan los de Kurata (Kurata, Arai, \& Yokoi, 1965) para pantallas de tablestacas ancladas en cabeza, y Jacobsen (Jacobsen, 1939), en los que los resultados parecen mostrar que la resultante de las presiones actúa en un punto más elevado del trasdós del muro, Seed y Whitman (Seed \& Whitman, 1970) proponen separar la acción del terreno en dos componentes, estática y dinámica al igual que propone Okabe, pero aplicar las resultantes de ambas en puntos diferentes. Así proponen que la componente estática se aplique a una altura de $1 / 3 \cdot H$ con respecto a la base del muro (como corresponde a una ley triangular de presiones que aumentan con la profundidad), pero que la componente debida a la acción del sismo se aplique a una altura de $2 / 3 \cdot H$ con respecto a la base. 

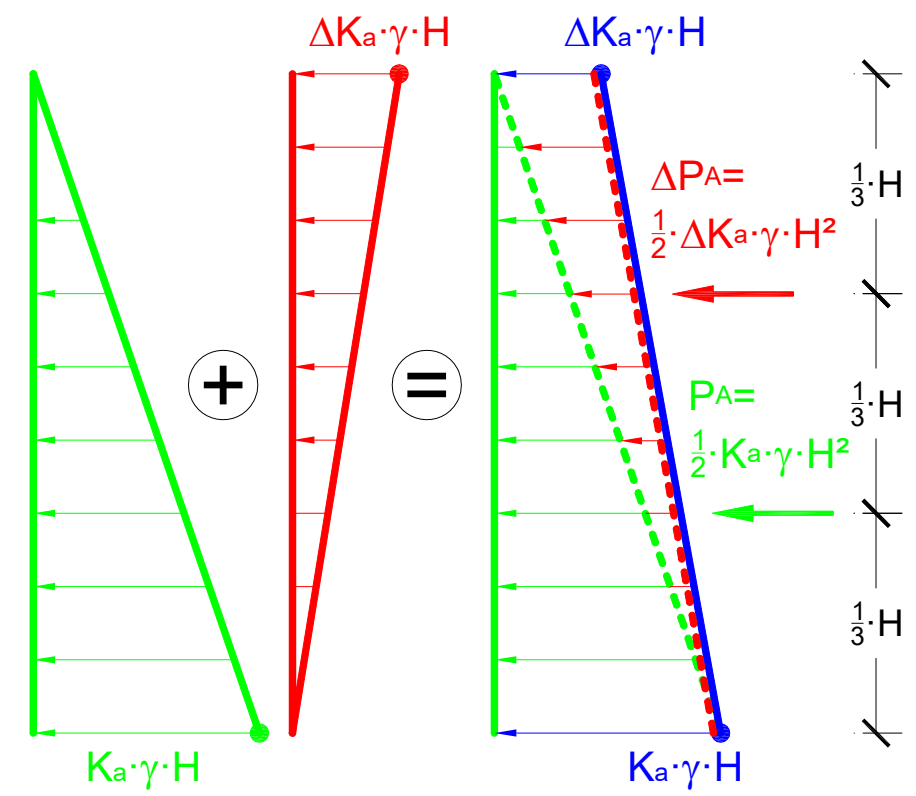

Fig. 3-81. Distribución de presiones de propuesta por Seed y Whitman (Seed \& Whitman, 1970).

\subsubsection{Método de EIms y Richards}

Elms y Richards (Elms \& Richards, 1979), en sus recomendaciones para la elaboración de la normativa sismorresistente de Nueva Zelanda, realizan una revisión de las metodologías de cálculo desarrolladas por Mononobe y Okabe (Mononobe \& Matsuo, 1929; Okabe, 1924), así como de la modificación de la posición del centro de presiones resultante propuesta por Seed y Whitman (Seed \& Whitman, 1970), y realizan dos precisiones para modificar el método precedente: la consideración de la propia inercia del muro de gravedad, y la posibilidad de admitir que el muro pueda deslizar.

Hasta este momento, los procedimientos desarrollados despreciaban las fuerzas de inercia que pueden desarrollarse en el propio cuerpo del muro de contención por efecto de la aceleración horizontal del terreno debida al sismo. Como señalan Elms y Richards (Elms \& Richards, 1979), se trata de una hipótesis que está claramente del lado de la inseguridad, y que no resulta razonable, ya que es precisamente la masa del muro de gravedad la que proporciona la mayor parte de, si no toda, la resistencia al movimiento del conjunto muro-terreno. Con esta consideración, recomiendan que la masa del muro multiplicada por la aceleración máxima del terreno $k_{h}$ sea considerada en el término desestabilizador de la fuerza horizontal (Ec. 3-102) que debe ser resistida.

Por otra parte, recogiendo el concepto desarrollado por Newmark (Newmark, 1965) para analizar la estabilidad frente al sismo de terraplenes y presas de materiales 
sueltos, proponen incorporar al análisis de muros de contención la posibilidad de que la obra deslice siempre que esto no provoque la ruina de la misma.

En efecto, partiendo de la idea de un sólido rígido, apoyado sobre un plano horizontal con rozamiento, y sometido a un pulso finito de aceleración horizontal, Newmark demostró que, si la aceleración del pulso es menor que el rozamiento capaz de desarrollar el bloque, el desplazamiento relativo suelo-bloque será nulo. Si por el contrario la aceleración del pulso es mayor que el rozamiento, existirá desplazamiento relativo suelo-bloque, pero dado que el pulso es finito (duración acotada en el tiempo), el deslizamiento relativo cesará en algún instante Fig. 3-82.
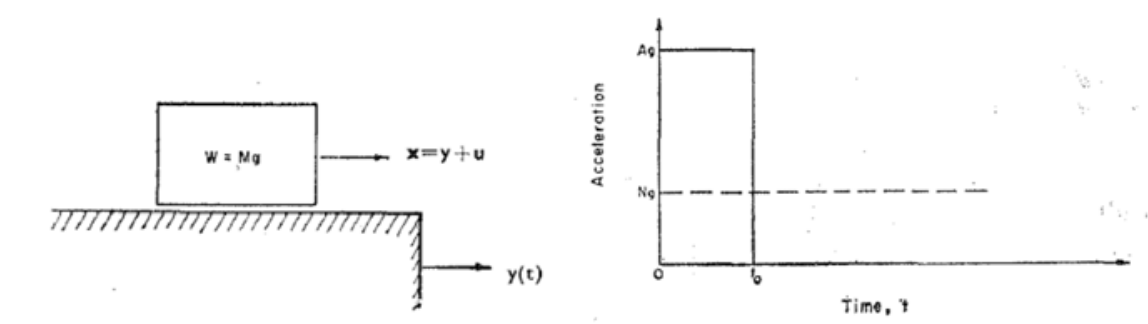

Fig. 16. Rigid block on a moving support Fig. 17. Rectangular block acceleration pulse

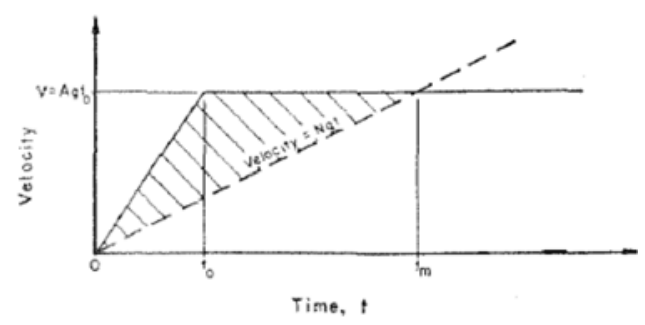

Fig. 18. Velocity response to rectangular block acceleration

Fig. 3-82. Respuesta conceptual al desplazamiento de un bloque rígido sometido a un pulso finito de aceleración constante (Newmark, 1965).

Interpretando un sismo como un acelerograma consistente en una sucesión de pulsos de duración finita, Newmark propone un algoritmo para calcular el desplazamiento total acumulado por el bloque a lo largo de todo el terremoto (Fig. 3-83, izda.). Este consiste en comparar la aceleración del suelo, en cada instante del acelerograma, con el rozamiento $\mu$ del bloque. Cuando esta aceleración sobrepase el coeficiente de rozamiento $\mu$ bloque-suelo, el suelo deslizará por debajo del bloque y se producirá desplazamiento relativo. Mientras el suelo deslice bajo el bloque, el bloque estará sometido a una aceleración constante de valor igual al coeficiente de rozamiento $\mu$, de tal manera que en algún momento el bloque adquirirá una velocidad que igualará a la del suelo. Cuando ambas velocidades se igualen, el deslizamiento relativo cesará, y bloque y suelo pueden 
considerarse de nuevo imbricados, hasta que un nuevo pulso de aceleración superior a $\mu$ haga deslizar de nuevo al bloque. Para poder calcular el desplazamiento relativo acumulado durante el tiempo en el que el suelo ha estado deslizando bajo el bloque, basta con calcular la diferencia de las integrales de velocidades del suelo y del bloque (Fig. 3-83, izda.).

Newmark (Newmark, 1965) analizó con este método varios acelerogramas disponibles en la época, y estableció una relación entre la ratio $\mu / P G A$, de coeficiente de rozamiento y aceleración máxima del registro, y el desplazamiento que es esperable que alcance el bloque (Fig. 3-83, dcha.).

Más adelante, Franklin y Chang, y Hynes y Franklin (Franklin \& Chang, 1977; Hynes-Griffin \& Franklin, 1984) repitieron varios análisis del tipo Newmark con un catálogo mayor de acelerogramas, confirmando que las líneas generales del estudio de Newmark eran válidas.
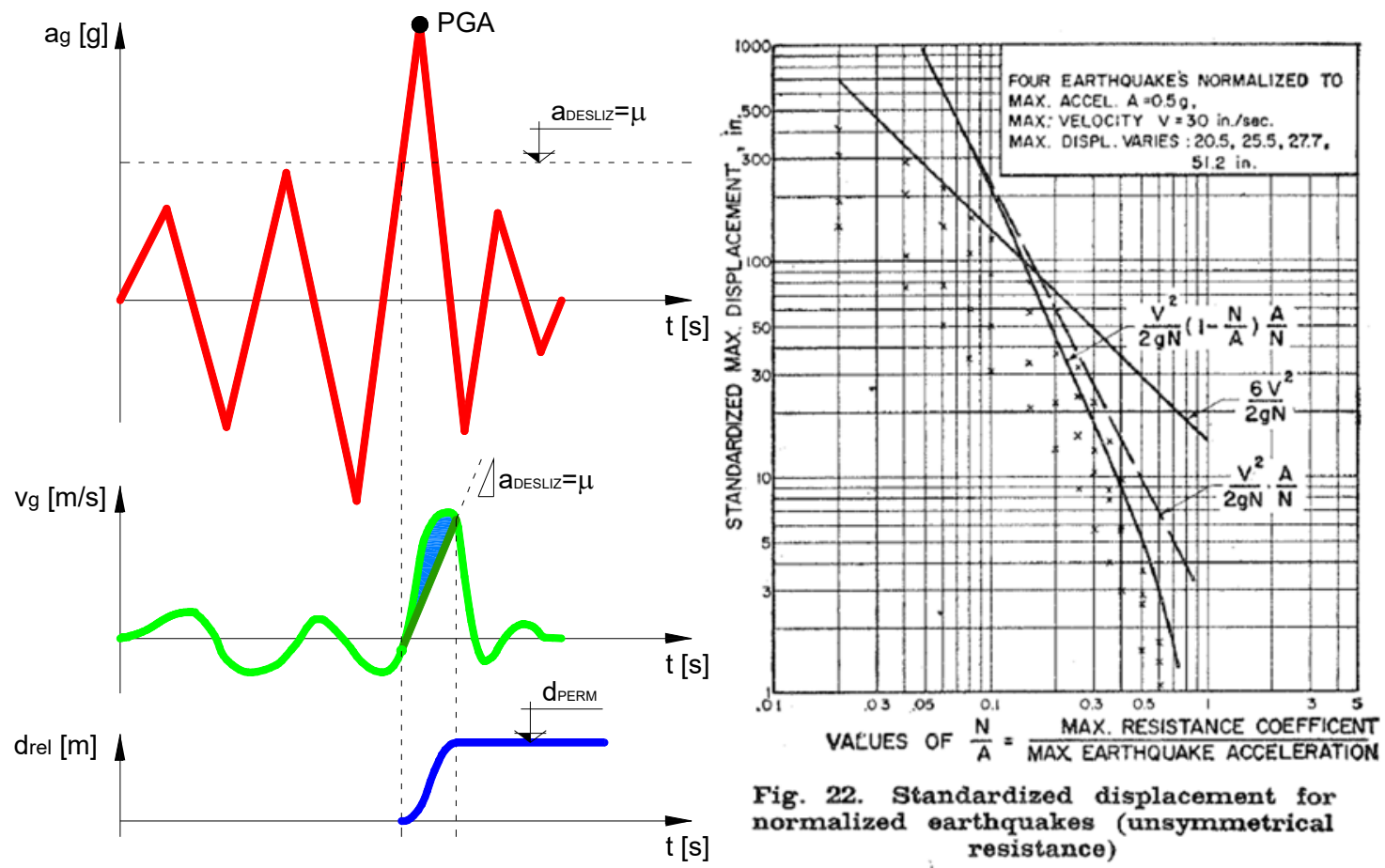

Fig. 3-83. (izda.) Método de Newmark para calcular el desplazamiento de un bloque, apoyado en un plano horizontal con rozamiento, sometido a un acelerograma. (dcha.) Ábaco de desplazamiento calculado por Newmark para diferentes ratios de coeficiente de rozamiento frente a la aceleración horizontal máxima $\mu / P G A$ (Newmark, 1965).

Elms y Richards aplican este método de bloque deslizante al análisis de muros rígidos de gravedad que, según las teorías desarrolladas desde Coulomb hasta MononobeOkabe, no se apartan significativamente del concepto de un bloque rígido formado por el 
cuerpo del muro y las tierras del trasdós contenidas por este. Proponen así que se emplee el concepto de deslizamiento como un fusible que limite la acción del sismo en otras partes del muro de contención (Fig. 3-84).

En efecto, en caso de que se produzca deslizamiento, la máxima aceleración a la que se ve sometida el muro es la correspondiente a la que motiva el propio deslizamiento. Si se permite el deslizamiento del muro, las fuerzas desarrolladas en el cuerpo del mismo serán menores a las correspondientes a la aceleración máxima del terreno PGA, y el dimensionamiento del mismo resultará más económico.

La premisa obvia en las que debe fundamentarse esta estrategia de diseño es que el deslizamiento del muro debe ser físicamente factible, es decir el muro no debe estar cimentado en un cajeado de roca que impida el deslizamiento, el muro no debe estar pilotado, no debe topar con otras estructuras durante su movimiento progresivo de reptación, etc. Por otra parte, el deslizamiento del muro debe ser funcionalmente compatible con la contención de las tierras, y el deslizamiento no debería ser causante de daños mayores en la dirección del deslizamiento, tales como interferencia con canalizaciones de gas o electricidad, etc.

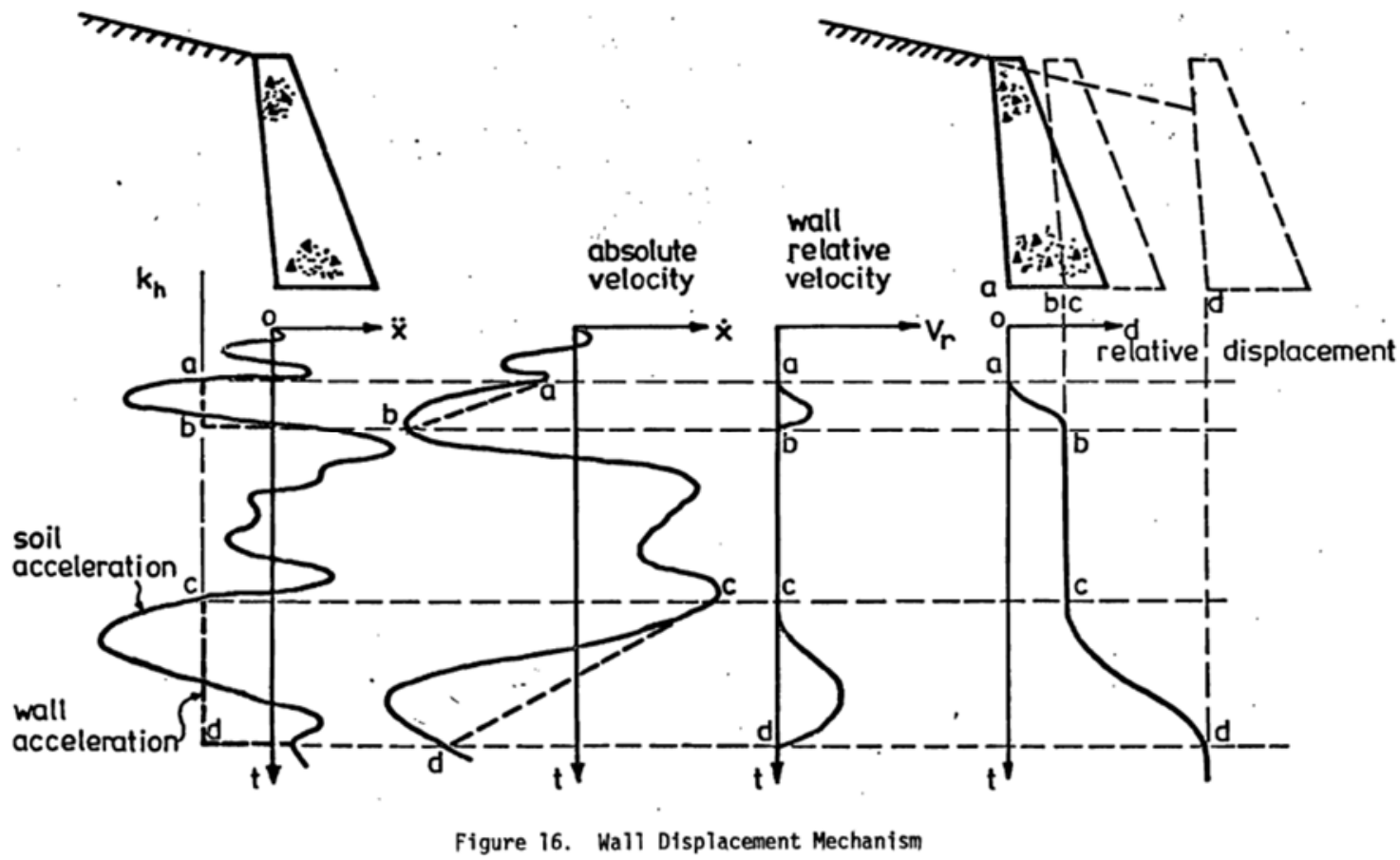

Fig. 3-84. Aplicación del método de Newmark al cálculo del desplazamiento de un muro de gravedad (EIms \& Richards, 1979). 


\subsubsection{Métodos elásticos de empuje dinámico}

Los métodos descritos en el apartado §3.7.1 están basados en una hipótesis de equilibrio límite, en el sentido de que estudian el comportamiento del conjunto murosuelo contenido en el instante previo al fallo de la obra. En los siguientes apartados se resumen las principales teorías que se basan en el comportamiento del conjunto murosuelo desde un punto de vista dinámico con comportamiento elástico.

\subsubsection{Método de Matsuo y Ohara}

Matuso y Ohara (Matsuo \& Ohara, 1960) reconocen que el método de MononobeOkabe entra en contradicción con los resultados experimentales de las presiones en un muro debidas al sismo, que tienden a ser mayores en la cabeza del mismo, mientras que el método de Mononobe-Okabe prevé que el máximo resulte en la base del mismo.

En base a un estudio teórico y medidas experimentales independientes, proponen el primer método de cálculo de presiones laterales en un muro de contención basado en el comportamiento elástico del terreno del trasdós y del propio muro. Para ello asumen que el terreno del trasdós se comporta como un sólido elástico bidimensional sin desplazamiento vertical, con densidad $\rho$, y constantes de Lamé $\lambda$ y $\mu$, y estudian dos casos de muro infinitamente rígido, y muro rígido pero cimentado sobre una base infinitamente flexible Fig. 3-85.
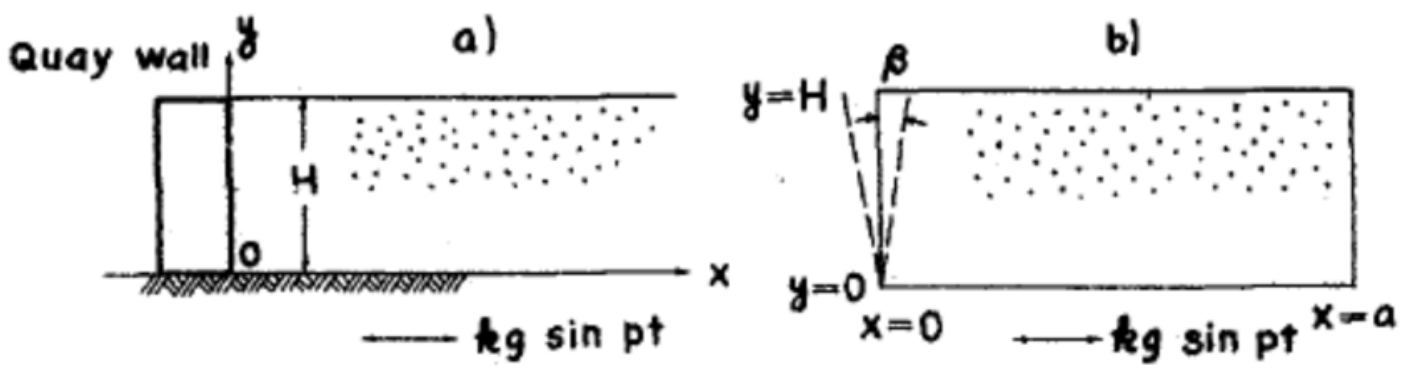

Fig. 3-85. Esquema de los dos modelos de muro estudiados (Matsuo \& Ohara, 1960). (izda.) Muro infinitamente rígido. (dcha.) Muro con base infinitamente flexible.

Planteando el estudio como un problema de elasticidad dinámica, proponen que la solución en términos de presión sobre el muro, para cotas normalizadas a la altura del muro $\eta=y / H$, y excitación armónica de aceleraciones de amplitud $K \cdot g$ y de frecuencia circular $p$, responde a la serie (Ec. 3-105), donde los términos $C_{1}^{2}$ y $C_{2}^{2}$ para el caso de muro rígido están dados por la (Ec. 3-106), y para el caso de muro flexible por la (Ec. 3-107). 


$$
\begin{array}{ccc}
\sigma_{x}(\eta)=-\rho \sum_{m=1}^{\infty} \frac{4 \cdot K \cdot g \cdot \sin (p t)}{\pi(2 m+1)} \frac{C_{\frac{1}{C_{2}{ }^{2}}\left(\frac{(2 m+1) \pi}{2}\right)^{2}-\left(\frac{p H}{C_{1}}\right)^{2}}}{s i n}\left(\frac{(2 m+1) \pi}{2} \eta\right) \\
C_{1}{ }^{2}=\frac{\lambda+2 \mu}{\rho} & C_{2}{ }^{2}=\frac{\mu}{\rho} \\
C_{1}{ }^{2}=\frac{E}{\rho\left(1-v^{2}\right)} & C_{2}{ }^{2}=\frac{\mu}{p}
\end{array}
$$

La representación gráfica de las presiones correspondientes a estas soluciones proporcionada por los propios autores en su estudio puede comprobarse en la (Fig. 3-86).
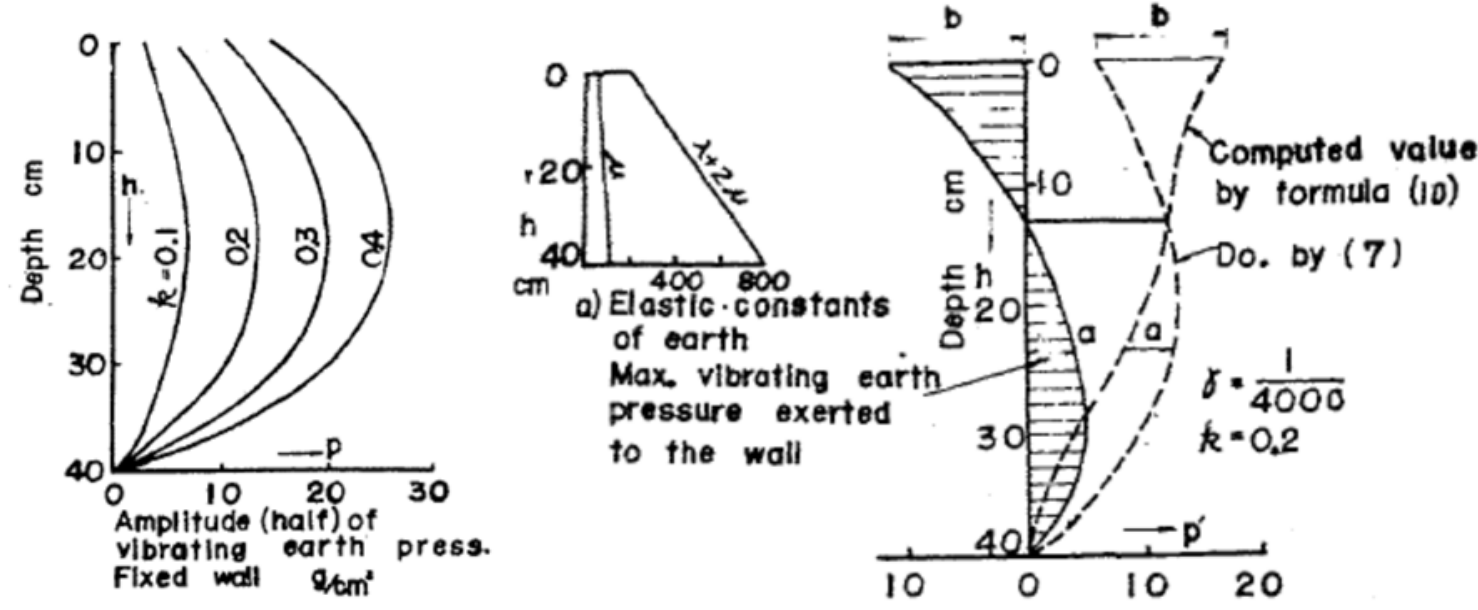

Fig. 3-86. Distribución de presiones ejercidas por el terreno sobre un muro. (Matsuo \& Ohara, 1960). (izda.) Caso de un muro infinitamente rígido. (dcha.) Caso de un muro con base infinitamente flexible.

\subsubsection{Método de Wood}

Consciente de las hipótesis subyacentes en la mayor parte de las metodologías desarrolladas hasta el momento para el cálculo del empuje de tierras durante un sismo, que esencialmente asumen que el movimiento de la estructura de contención es suficiente como para desarrollar el empuje límite activo, Wood (Wood, 1973) analiza en su tesis doctoral cual es el empuje dinámico del terreno en una estructura extraordinariamente rígida y cimentada en roca que no es capaz de ningún movimiento (caso conocido en la literatura anglosajona como "nonyielding walls").

Wood se enfrenta al problema de determinar el empuje sísmico de tierras que puede desarrollarse sobre la estación hidroeléctrica de Castaic (Los Ángeles, California), 
una estructura masiva cimentada en roca en la que el deslizamiento o rotación de la cimentación es improbable, y cuyo trasdós cuenta con un relleno de tierras (Fig. 3-87).

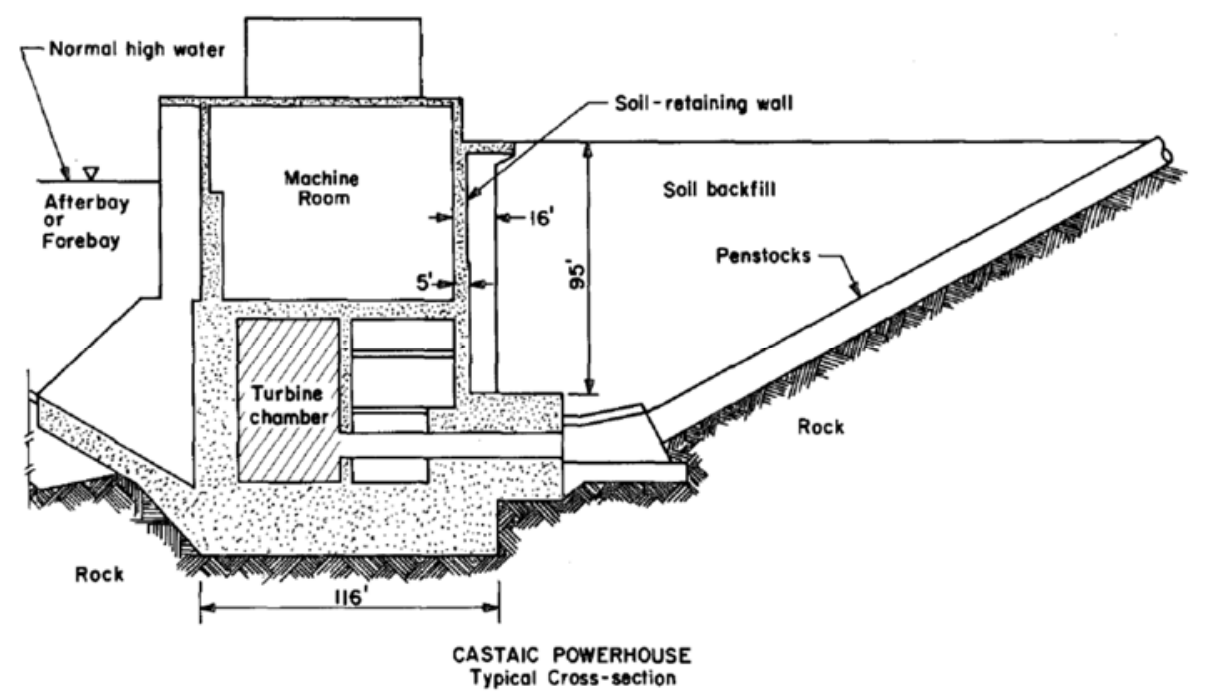

Fig. 3-87. Esquema de estructura de la estación hidroeléctrica de Castaic (Wood, 1973).

Para realizar su propuesta Wood estudia, analíticamente y mediante métodos numéricos (Fig. 3-88 y Fig. 3-91, izda.), un contenedor bidimensional con paredes y fondo infinitamente rígidos, el cual considera relleno de un material elástico en régimen de deformación plana. En este trabajo, Wood considera como variables fundamentales por un lado el coeficiente de Poisson $v$ del suelo, y por otro la separación horizontal $L$ entre muros del contenedor normalizada a la altura del contenedor $H$ (Fig. 3-88), y realiza un estudio paramétrico de la máxima presión resultante sobre los muros cuando se somete al terreno tanto a una aceleración horizontal de valor constante, como a una aceleración sinusoidal.

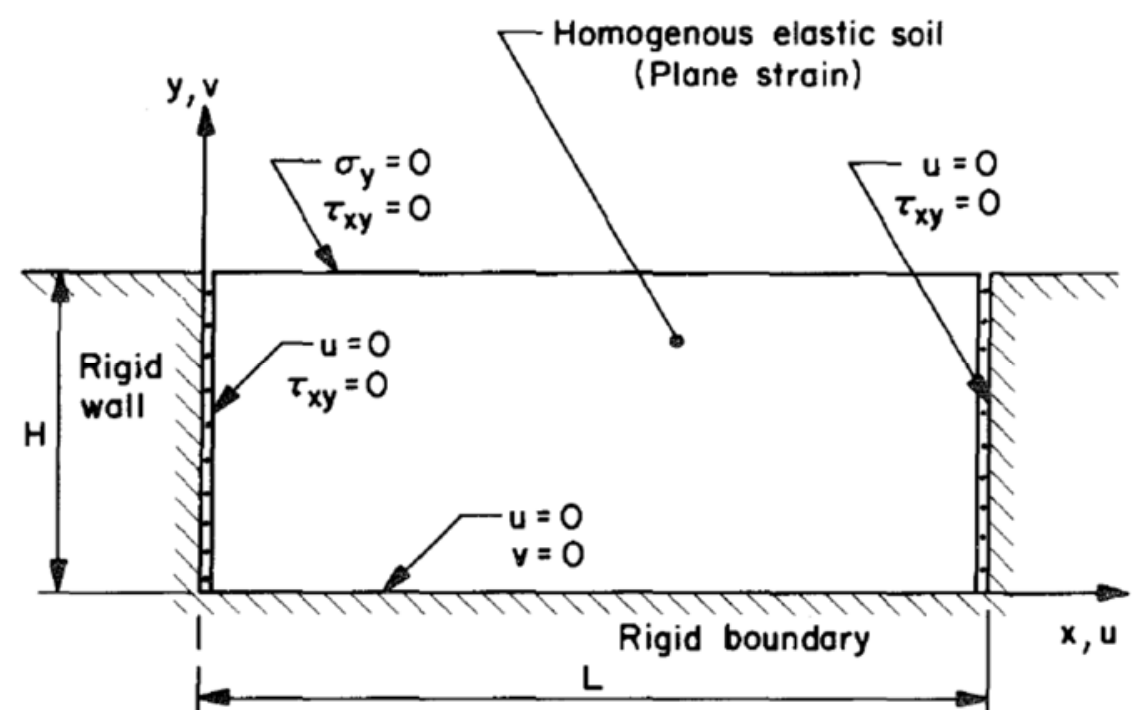

Fig. 3-88. Esquema de muro rígido apoyado sobre fondo rígido estudiado por Wood (Wood, 1973). 
Observando los resultados de distribución de presiones obtenidos por Wood (Fig. 3-89), estos se asemejan en cierto sentido a las hipótesis establecida por Seed y Whitman (Seed \& Whitman, 1970), descrita en el apartado \$3.7.1.2, en la que se indicaba que las presiones debidas al sismo son mayores en la parte superior del muro, corrigiendo la hipótesis anterior de Mononobe-Okabe que situaba el máximo cerca de la base, pero presentan diferencias notables con las mencionadas. La más significativa es que la ley de presiones obtenida no es lineal, si no curva, y que una zona considerable de la parte superior del muro se encuentra sometida a presiones que en la práctica pueden considerarse de valor constante (Fig. 3-89).

LENGTH/HEIGHT $=2.0$

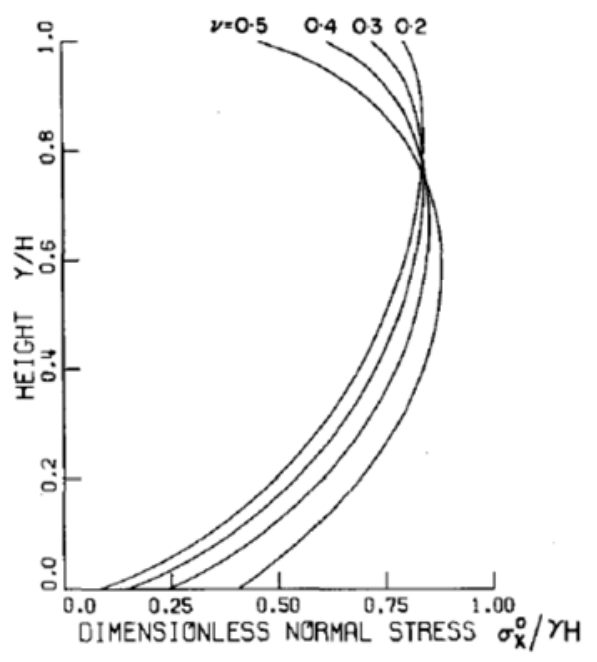

LENGTH/HEIGHT $=10.0$

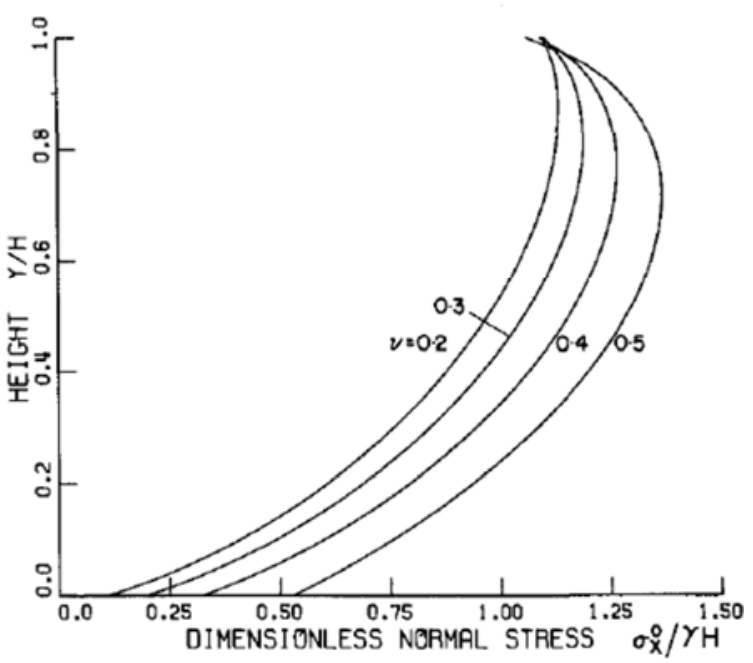

Fig. 3-89. Distribución de presiones dinámicas estudiadas por Wood (Wood, 1973) para diferentes ratios longitud/altura del contenedor de suelo, y coeficientes de Poisson $v$.

Como corolario de su estudio, Wood plantea dos curvas que resumen de manera sintética las leyes de presiones encontradas, una $F_{p}$ que corresponde a la resultante total de fuerza horizontal (Fig. 3-90, izda.), y otra $F_{m}$ de momento flector en la base del muro (Fig. 3-90, dcha.), para diferentes valores de la ratio $L / H$ y del coeficiente de Poisson $v$. Las curvas de Wood de fuerza horizontal se presentan normalizadas al valor $a_{g} /\left(g \cdot H^{2}\right)$, mientras que las correspondientes al momento se normalizan al valor $a_{g} /\left(g \cdot H^{3}\right)$. 

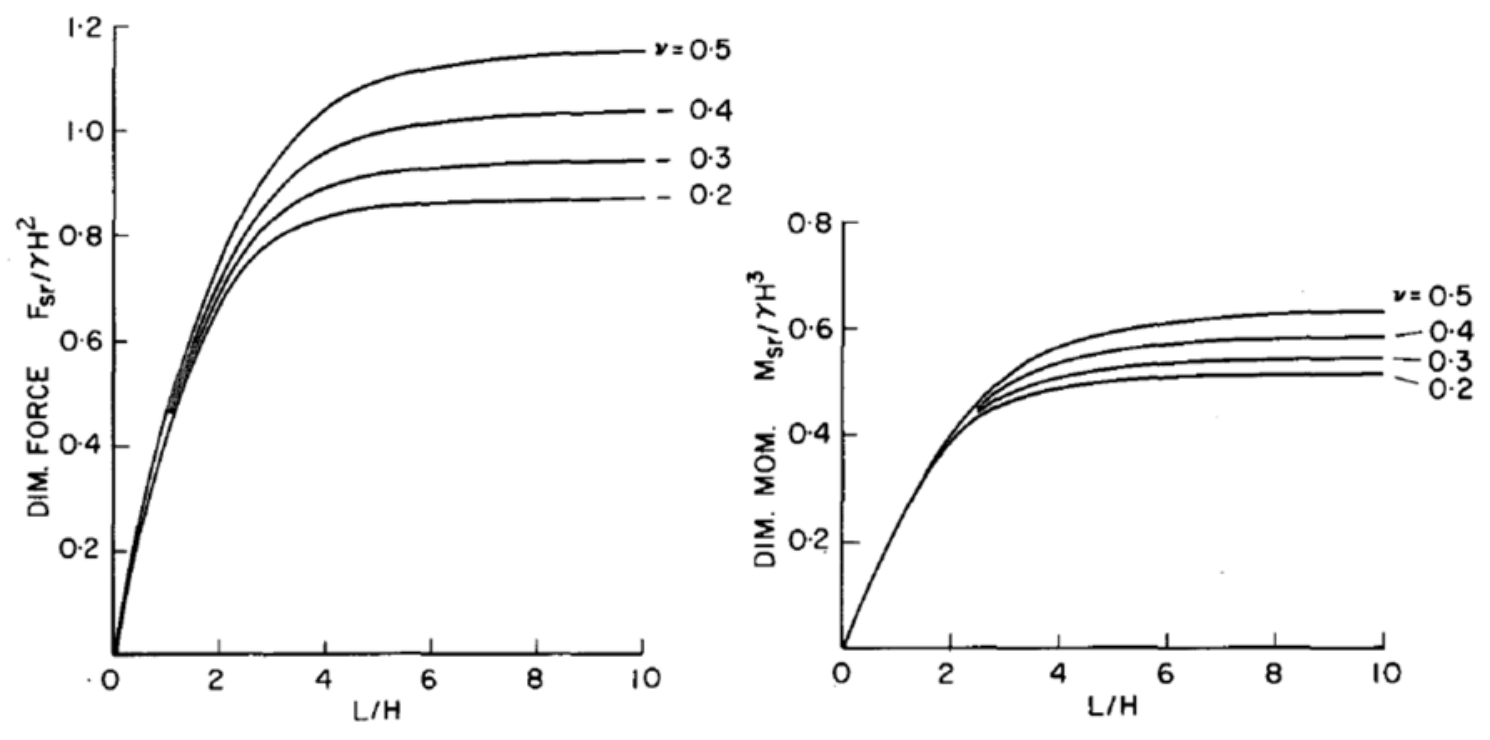

Fig. 3-90. (izda.) Resultante total de fuerzas horizontales, (dcha.) y de momentos en la base del muro obtenidas por Wood (Wood, 1973) para diferentes ratios longitud/altura del contenedor de suelo, y coeficientes de Poisson $v$.

De esta manera Wood propone calcular el empuje total mediante la ecuación (Ec. 3-108), y el momento total mediante la ecuación (Ec. 3-109), donde los factores $F_{p}$ y $F_{m}$ se obtienen de sus curvas (Fig. 3-90) en función de la geometría y coeficiente de Poisson $v$ que correspondan al problema en estudio.

$$
\begin{aligned}
\Delta P_{e q} & =\gamma H^{2} \frac{a_{g}}{g} \cdot F_{p} \\
\Delta M_{e q} & =\gamma H^{3} \frac{a_{g}}{g} \cdot F_{m}
\end{aligned}
$$

Si se analiza con detenimiento el caso de geometría que puede considerarse más frecuente, esto es una relación $L / H$ grande, en el que no hay efecto silo, y que corresponde a un único muro de contención con los contornos muy alejados, se observa que el factor correspondiente a la fuerza horizontal es aproximadamente $F_{p} \approx 1,20$, y el factor correspondiente al momento volcador es aproximadamente $F_{m} \approx 0,60$. Con estos dos valores, el diagrama de presiones resultante puede asimilarse a una ley de presiones constante a lo largo de toda la altura de valor $1,20 \cdot \gamma \cdot H \cdot P G A$. 

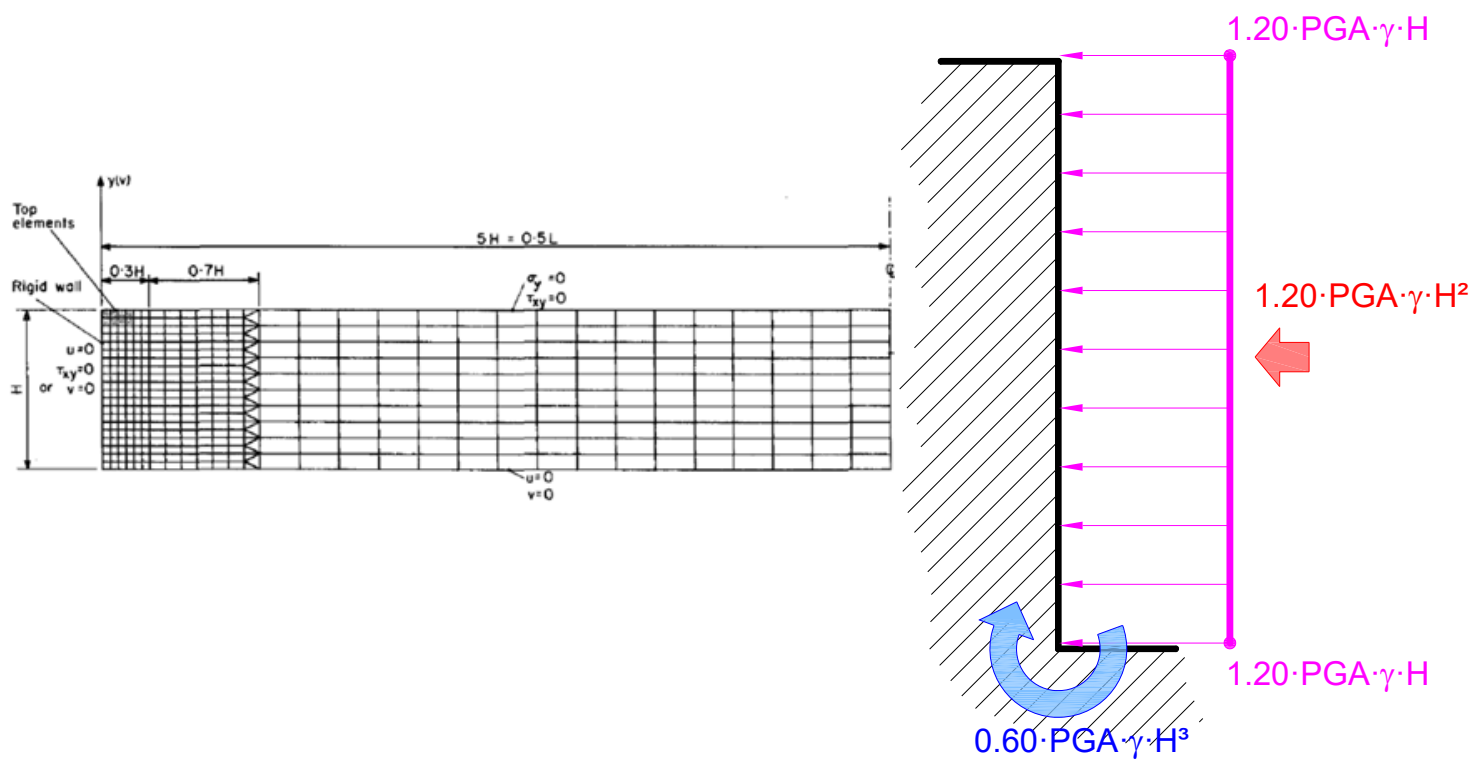

Fig. 3-91. (izda.) Modelo de elementos finitos empleado por Wood (Wood, 1973) para su estudio.

(dcha.) Distribución equivalente de presiones dinámicas de acuerdo a la formulación de Wood.

Resulta interesante comparar desde el punto de vista cuantitativo los resultados de empujes obtenidos por Wood frente a los obtenidos por Mononobe-Okabe, y Seed y Whitman. Los gráficos de la Fig. 3-92 muestra los resultados de empujes, y momentos en base del muro obtenidos mediante cada una de estas formulaciones, para un muro tipo de altura $h=10 \mathrm{~m}$, con un relleno de tierras en trasdós con un ángulo de rozamiento interno $\phi=30^{\circ}$, y diversos valores de máxima aceleración del terreno (PGA, Peak Ground Acceleration) entre $0 \cdot \mathrm{g} \mathrm{y} 0.5 \cdot \mathrm{g}$.

En particular, en la figura (Fig. 3-92 izda.) se muestran los resultados correspondientes a los empujes horizontales totales $P_{A E}$, es decir debidos a la acción estática del terreno $P_{A}$ más la acción sísmica $\triangle P_{A E}$, normalizados a la acción estática del terreno $P_{A}$. Para obtener la curva correspondiente al empuje de Wood, puesto que la formulación de Wood proporciona tan sólo la componente dinámica, se ha asumido que la componente estática corresponde al empuje estático activo de la misma manera que en la formulación de Mononobe-Okabe, de manera que se pueda hacer una comparación entre los tres métodos en términos análogos. Como se puede observar y cabría esperar, en lo que se refiere a la resultante de fuerzas horizontales, las hipótesis de MononobeOkabe (Mononobe \& Matsuo, 1929; Okabe, 1924) y de Seed y Whitman (Seed \& Whitman, 1970) proporcionan resultados idénticos (las curvas se superponen), ya que la posición en cota de la resultante de presiones no afecta al empuje total. 

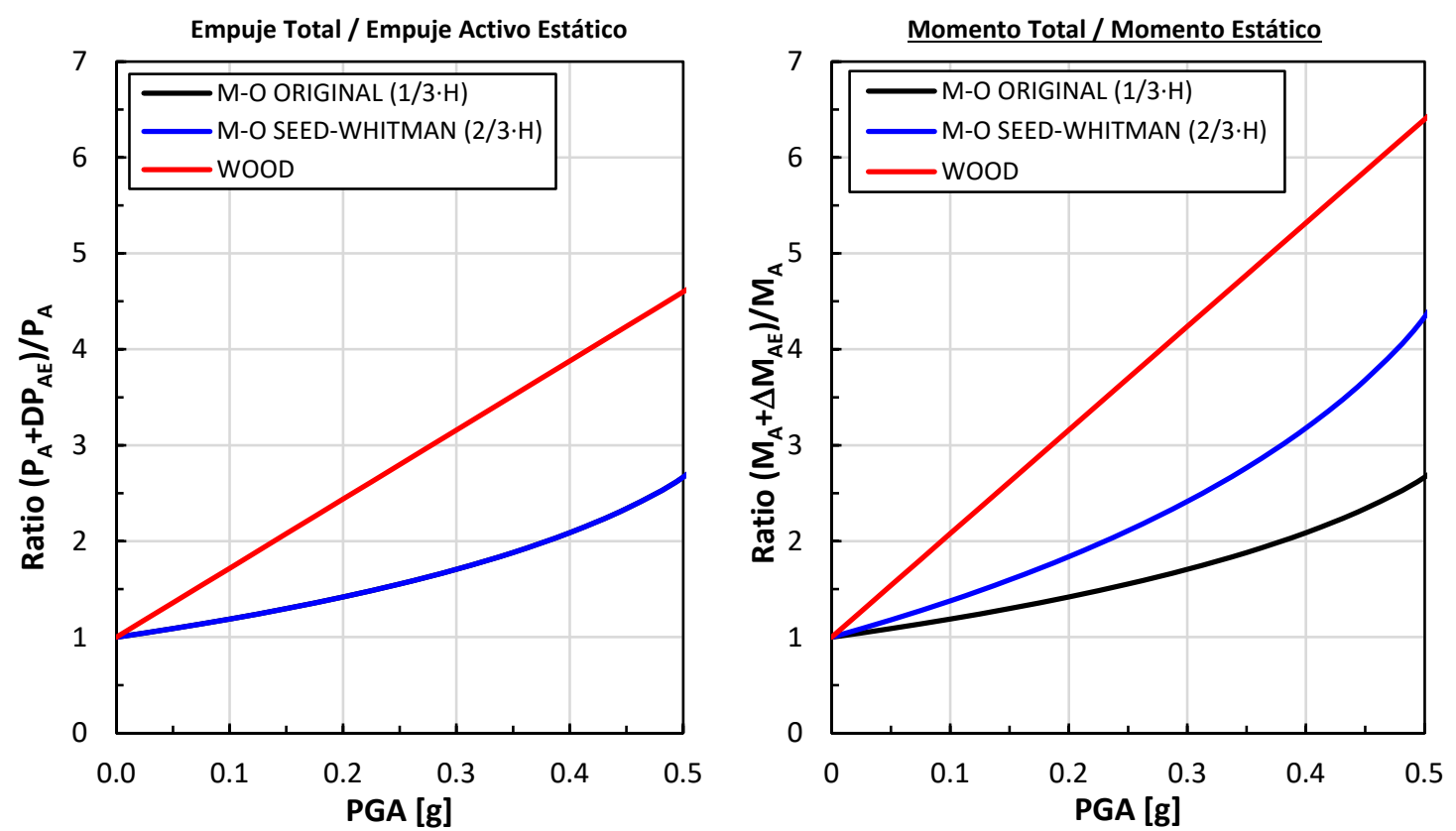

Fig. 3-92. Resultantes totales de empuje sísmico y estático sobre un muro de altura $h=10 \mathrm{~m}$, relleno del trasdós $\phi=30^{\circ}$ sin cohesión, y diferentes valores de aceleración máxima horizontal PGA, normalizadas a las resultantes de empuje activo estático. (izda.) Ratio de empuje horizontal total $\boldsymbol{P}_{T O T A L}=\boldsymbol{P}_{A}+\Delta \boldsymbol{P}_{A E}$ entre empuje activo estático $\boldsymbol{P}_{A}$. (dcha.) Momento volcador total $M_{\text {TотAL }}=\mathbf{M}_{A}+\Delta M_{A E}$ entre momento activo estático $M_{A}$.

Por otra parte, el gráfico de la (Fig. 3-92 dcha.), de manera similar muestra los resultados correspondientes al momento en base del muro debido los empujes horizontales totales $P_{A E}$, es decir debidos a la acción estática del terreno $P_{A}$ más la acción sísmica $\triangle P_{A E}$, normalizados a la acción estática del terreno $P_{A}$.

Como puede apreciarse, la resultante de empuje horizontal del método de Wood es del orden de 2 a 4 veces mayor que la correspondiente a la metodología de MononobeOkabe. En lo que se refiere al momento volcador, el correspondiente al método de Wood es del orden de 3 a 6 veces mayor que el correspondiente a la metodología de MononobeOkabe (descrito en el apartado \$3.7.1.1), con el punto de aplicación de la resultante modificado según la propuesta de Seed y Whitman (descrito en el apartado 3.7.1.2). Estos resultados se pueden apreciar gráficamente en la (Fig. 3-93), en la que se ha obtenido la ratio entre empujes y momentos correspondientes a ambos métodos.

Esta comparación, para un caso concreto de muro, muestra claramente la dispersión de resultados que se obtienen con ambos métodos, y lo significativo de la diferencia entre ellos. 


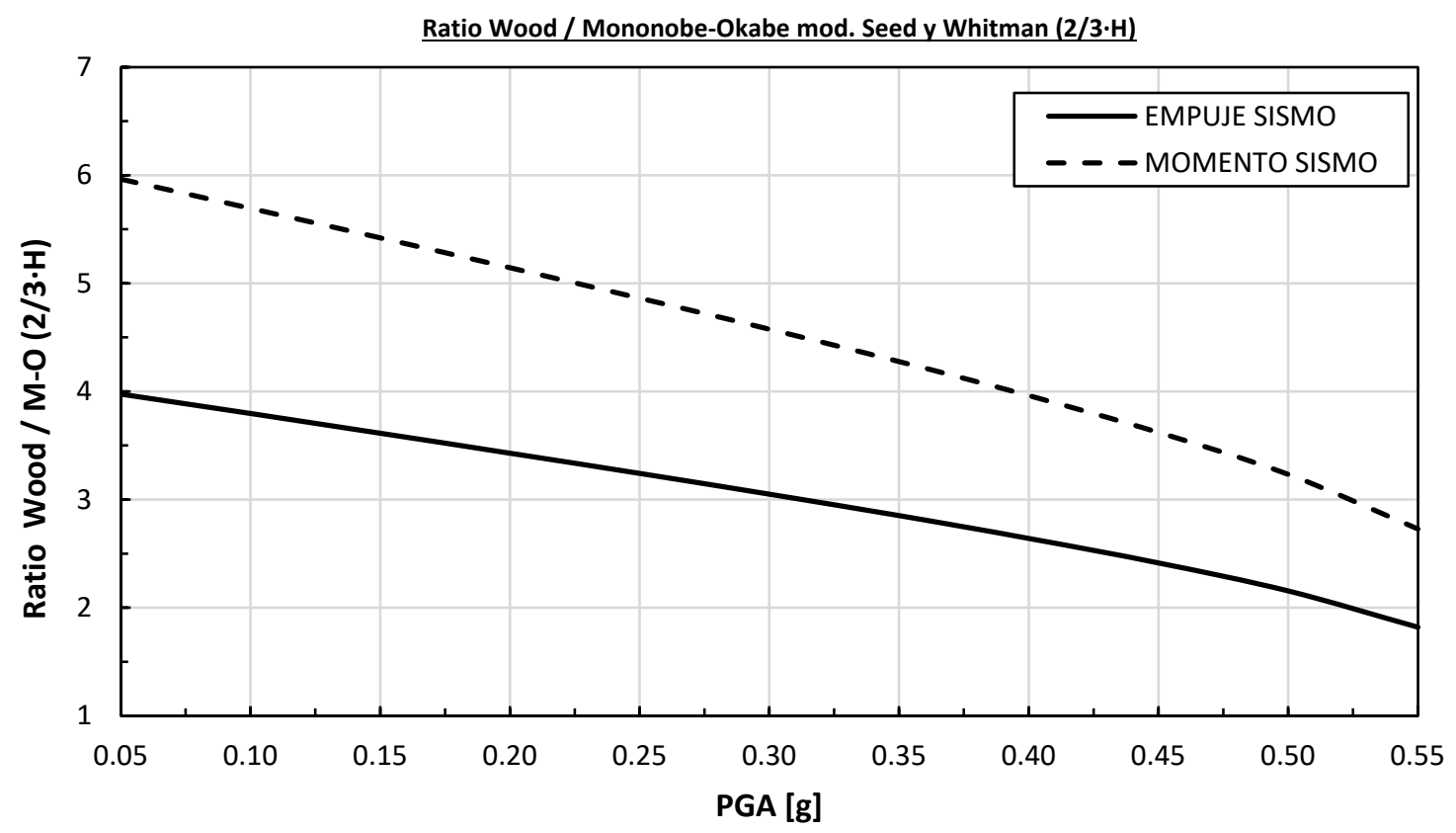

Fig. 3-93. Ratio de resultantes de componentes sísmicas de las resultantes de empujes (resultante horizontal, y momento volcador), entre la hipótesis de Wood (Wood, 1973), y la hipótesis de Mononobe-Okabe modificada según Seed y Whitman (Seed \& Whitman, 1970).

\subsubsection{Método de Scott}

Scott (Scott, 1974) propone un método complementario al de Wood (Wood, 1973) para analizar el comportamiento de un muro rígido, que contiene un terreno de comportamiento elástico, bajo la acción del sismo. El método desarrollado por Scott propone considerar el terreno del trasdós como una viga unidimensional, deformable a cortante caracterizada por su densidad $\rho$ y rigidez a cortante $G$, vinculada al muro frente a desplazamientos horizontales $u$ mediante muelles de interacción suelo-estructura de rigidez $k$ (Fig. 3-94).

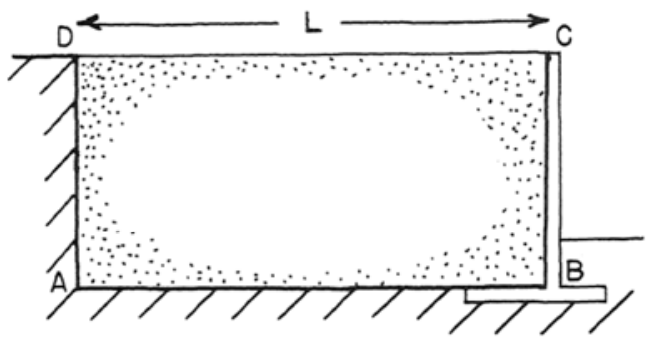

FIG.I REGION OF PROBLEM

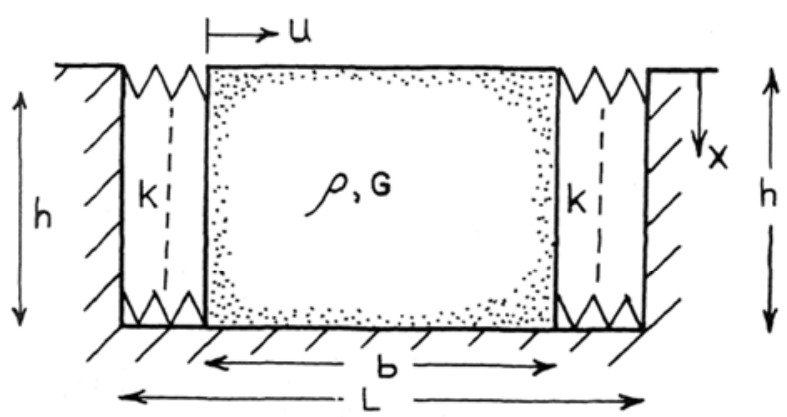

FIG.3 CONTINUOUS SHEAR BEAM

Fig. 3-94. Modelo de Scott para el análisis dinámico conjunto de muro deformable y suelo del trasdós elástico. 
En su hipótesis de partida, Scott asume que la presión ejercida por el terreno sobre el muro para cada cota $x$ del muro, es proporcional al desplazamiento horizontal $u$ de la capa de terreno que corresponde a la cota $x$. Para el valor de la rigidez de los muelles $k$, Scott considera adecuado tomar el valor correspondiente a una barra de sección transversal con área unitaria, y longitud 2,5· $H$ que no puede deformarse por efecto Poisson a lo largo de sus bordes, es decir, una rigidez dada por la fórmula (Ec. 3-110).

$$
k=\frac{0.8(1-v)}{1-2 v} \frac{G}{H}
$$

Basándose en la ecuación diferencial de propagación de ondas de cortante en una viga de cortante, modificada adecuadamente para tener en cuenta las condiciones de contorno tipo muelle (Ec. 3-111), Scott propone que la solución a esta ecuación es una suma de modos propios de vibración del tipo mostrado en la ecuación (Ec. 3-112), con la condición de contorno de desplazamiento $u$ nulo en la base del muro (Ec. 3-113).

$$
\begin{gathered}
\frac{\partial^{2} u}{\partial t^{2}}=\frac{G}{\rho} \cdot \frac{\partial^{2} u}{\partial x^{2}}-\frac{2 k u}{\rho b} \\
u=D \cdot \cos (\lambda x) \cdot \sin (\omega t) \\
u(x=h)=D \cdot \cos (\lambda h)=0
\end{gathered}
$$

Para los diferentes modos de vibración correspondientes a las longitudes de onda $\lambda_{n}$ (Ec. 3-114), Scott calcula que las frecuencias circulares de oscilación $\omega_{n}$ correspondientes responden a la fórmula (Ec. 3-115), en la que el primer sumando del lado derecho corresponde a la frecuencia de una viga de cortante sin coacción elástica de muelles, y el segundo sumando al efecto de los muelles de coacción.

$$
\begin{gathered}
\lambda_{n}=(2 n-1) \frac{\pi}{2 h} \\
\omega_{n}=\left(\frac{(2 n-1)^{2} \pi^{2} G}{4 h^{2} \rho}+\frac{2 k}{\rho b}\right)^{\frac{1}{2}}
\end{gathered}
$$

Si el terreno y los muelles de coacción son homogéneos a lo largo de la altura, los coeficientes de participación de cada modo $n$ vienen dados por la ecuación (Ec. 3-116), y en consecuencia, el desplazamiento modal correspondiente a un modo determinado se 
podrá expresar como en la (Ec. 3-117), en la que el término $S_{a, n}$ es la aceleración espectral correspondiente al modo $n$.

$$
\begin{gathered}
\alpha_{n}=\frac{\int_{0}^{h} \rho(x) \cdot X_{n}(x) \cdot d x}{\int_{0}^{h} \rho(x) \cdot X_{n}^{2}(x) \cdot d x}=\frac{\int_{0}^{h} \cos \left(\lambda_{n} x\right) \cdot d x}{\int_{0}^{h} \cos ^{2}\left(\lambda_{n} x\right) \cdot d x} \\
=\frac{4 \cdot \sin \left(\lambda_{n} h\right)}{2 \lambda_{n} h+\sin \left(2 \lambda_{n} h\right)} \\
u_{n}=\frac{S_{a, n} \cdot \alpha_{n} \cdot \cos \left(\lambda_{n} x\right)}{\omega_{n}{ }^{2}}
\end{gathered}
$$

Scott analiza mediante este método varios casos prácticos correspondientes a dimensiones típicas de muros y propiedades mecánicas de suelos, y concluye que el primer modo es el responsable de la mayor parte de la distribución de presiones, siendo marginal la contribución del resto de modos. De esta manera concluye que el máximo desplazamiento $u$ del muro se produce en cabeza del mismo y corresponderá al proporcionado por la ecuación (Ec. 3-118) con $x=0$, y la máxima presión a la de la ecuación (Ec. 3-119) con $x=0$, es decir a la ecuación .

$$
\begin{gathered}
u_{1}(x)=\frac{4 \cdot S_{a, 1}}{\pi \cdot \omega_{1}{ }^{2}} \cdot \cos \left(\frac{\pi x}{2 h}\right) \\
p_{1}(x)=\frac{4 \cdot k \cdot S_{a, 1}}{\pi \cdot \omega_{1}^{2}} \cdot \cos \left(\frac{\pi x}{2 h}\right) \\
p_{0}=\frac{4 \cdot k \cdot S_{a, 1}}{\pi \cdot \omega_{1}^{2}}
\end{gathered}
$$

Las resultantes de empuje horizontal y momento son las correspondientes a la integral de la (Ec. 3-119), y proporcionada por las fórmulas (Ec. 3-121) y (Ec. 3-122).

$$
\begin{gathered}
P_{1}=\frac{2}{\pi} \cdot p_{0} \cdot h \\
M_{1}=\frac{4}{\pi^{2}} \cdot p_{0} \cdot h^{2}
\end{gathered}
$$


La relación entre $M_{1}$ y $P_{1}$ proporciona el punto de aplicación de la resultante de empuje sísmico, que resulta de $2 / \pi \cdot h=0,63$, un valor similar al indicado por Seed y Whitman de $2 / 3 \cdot h=0,66$.

Scott (Scott, 1974) también analiza el caso en el que el muro rígido cuente con una cimentación elástica en su base, simulada en su estudio mediante un muelle rotacional $M=T \cdot \theta$ de constante de rigidez $T$, y despreciando la masa propia del muro por simplicidad. Con este estudio, Scott argumenta que, puesto que el muro es rígido, los desplazamientos del muro se incrementan linealmente con la cota medida desde la base, y que para el primer modo de vibración los desplazamientos del suelo considerado como viga de cortante también crecen linealmente con la cota. De esta manera, Scott concluye que las presiones sobre el muro se incrementan linealmente con la cota medida desde la base, y que estas son proporcionales a la diferencia de desplazamientos multiplicadas por la constante $k$ del muelle de interacción suelo-estructura.

Como corolario de esta fase de su estudio, Scott concluye que la formulación que propone para un muro rígido sigue siendo válida para el caso de un muro con cimentación flexible, si se modifica la constante del muelle de interacción suelo-estructura $k$ por una de valor $k^{\prime}$ proporcionada por la fórmula (Ec. 3-123).

$$
k^{\prime}=\frac{1}{1+\frac{k h^{3}}{3 T}} \cdot k
$$

\subsubsection{Método de Arias el al.}

Arias, Sánchez-Sesma, y Ovando-Shelley (Arias, Sanchez-Sesma, \& OvandoShelley, 1981), reconocen algunas deficiencias en los dos modelos elásticos desarrollados hasta el momento en el que desarrollan su propia propuesta. En particular, señalan que el modelo de Matsuo y Ohara (Matsuo \& Ohara, 1960) se desvía ampliamente de las hipótesis habituales de los problemas de elasticidad, así como que proporciona un empuje de valor infinito para coeficientes de Poisson $v=0.5$. Adicionalmente, sobre el modelo de Wood (Wood, 1973) señalan que es necesario hacer la hipótesis artificial de una condición de contorno suficientemente alejada del muro. De la metodología de Scott (Scott, 1974) arguyen que, para obtener resultados compatibles con la teoría de la elasticidad, la rigidez de los muelles que vinculan muro y suelo deben seguir una variación lineal con la altura, y que la obtención del valor de esta rigidez no es inmediato. 


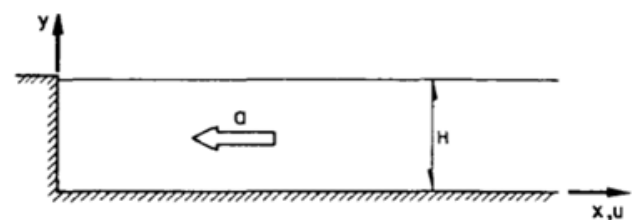

(a)
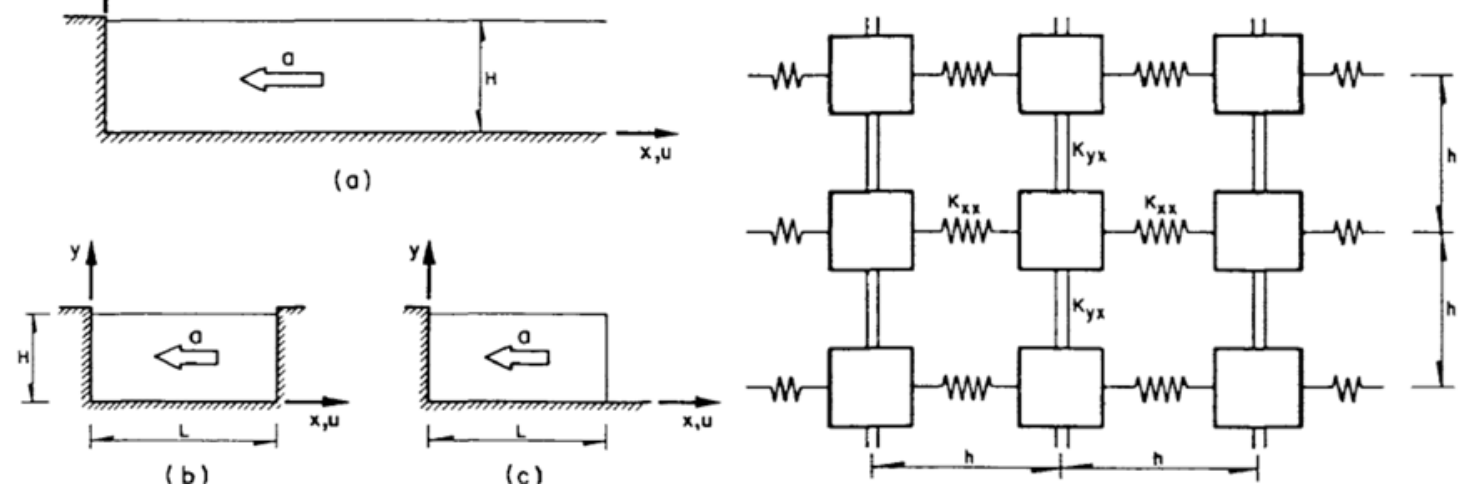

Fig. 3-95. (izda.) Geometría de los casos analizados. (dcha.) modelo simplificado (Arias et al., 1981).

Por estas razones, Arias et al. proponen un método alternativo partiendo de tres hipótesis fundamentales: 1) El suelo del trasdós se comporta como un sólido deformable en el que no existen términos de momentos flectores (Fig. 3-95, dcha.). 2) Las tensiones verticales en el relleno del trasdós son nulas. 3) Las tensiones y deformaciones en el trasdós están relacionadas mediante las fórmulas (Ec. 3-124) de tensiones y deformaciones horizontales, y (Ec. 3-125) de tensiones y deformaciones tangenciales.

$$
\begin{aligned}
\sigma_{x}=K_{x x} \frac{\partial u}{\partial x} & K_{x x}=\frac{E}{1-v^{2}} \\
\tau_{y x}=K_{y x} \frac{\partial u}{\partial y} & K_{y x}=G
\end{aligned}
$$

Bajo estas hipótesis establecen el equilibrio dinámico correspondiente a la ecuación, en la que $X$ es la componente horizontal de las cargas volumétricas, y $\rho$ la densidad del terreno.

$$
\rho \frac{\partial^{2}}{\partial t^{2}}=\frac{\partial}{\partial x}\left(K_{x x} \frac{\partial u}{\partial x}\right)+\frac{\partial}{\partial y}\left(K_{y x} \frac{\partial x}{\partial y}\right)+\rho X
$$

El modelo de la figura (Fig. 3-95, dcha.), cuyo comportamiento queda descrito por la ecuación diferencial (Ec. 3-126), es capaz de transmitir verticalmente ondas de cortante mediante el comportamiento de viga de cortante, representado por el término $K_{x y}$ que vincula elementos de masa situados en la misma vertical. De esta manera, los autores señalan que si el término de rigidez horizontal $K_{x x}$ se hace suficientemente grande, el comportamiento del sistema propuesto se asemeja al de viga de cortante de Scott (Scott, 1974). 
Mediante este modelo, Arias et al. estudian los casos de un muro infinitamente rígido que contiene un terreno elástico de longitud infinita, de longitud finita $L$ confinado entre dos muros rígidos, y de longitud finita $L$ sin contener en el borde opuesto ningún muro (Fig. 3-95).

Obteniendo soluciones a la ecuación diferencial (Ec. 3-126) mediante una suma en serie de armónicos, Arias et al. proporcionan expresiones para la distribución de presiones en función de la cota (Ec. 3-127), y para la resultante de empujes horizontales (Ec. 3-128), y momentos volcadores (Ec. 3-129).

$$
\begin{gathered}
p(y)=\frac{8 \gamma H}{\pi^{2}} \cdot \frac{a}{g} \cdot \frac{\alpha}{\beta} \sum_{n=1}^{\infty} \frac{\phi_{n}(y)}{(2 n-1)^{2}} \\
P=\frac{16 \gamma H^{2}}{\pi^{3}} \cdot \frac{a}{g} \cdot \frac{\alpha}{\beta} \sum_{n=1}^{\infty} \frac{1}{(2 n-1)^{3}} \approx 0,543 \frac{\gamma H^{2} a \alpha}{g \beta} \\
M=\frac{32 \gamma H^{3}}{\pi^{4}} \cdot \frac{a}{g} \cdot \frac{\alpha}{\beta} \sum_{n=1}^{\infty} \frac{(-1)^{n+1}}{(2 n-1)^{4}} \approx 0,325 \frac{\gamma H^{3} a \alpha}{g \beta} \\
\alpha=\beta \sqrt{\frac{2}{1-v}}
\end{gathered}
$$
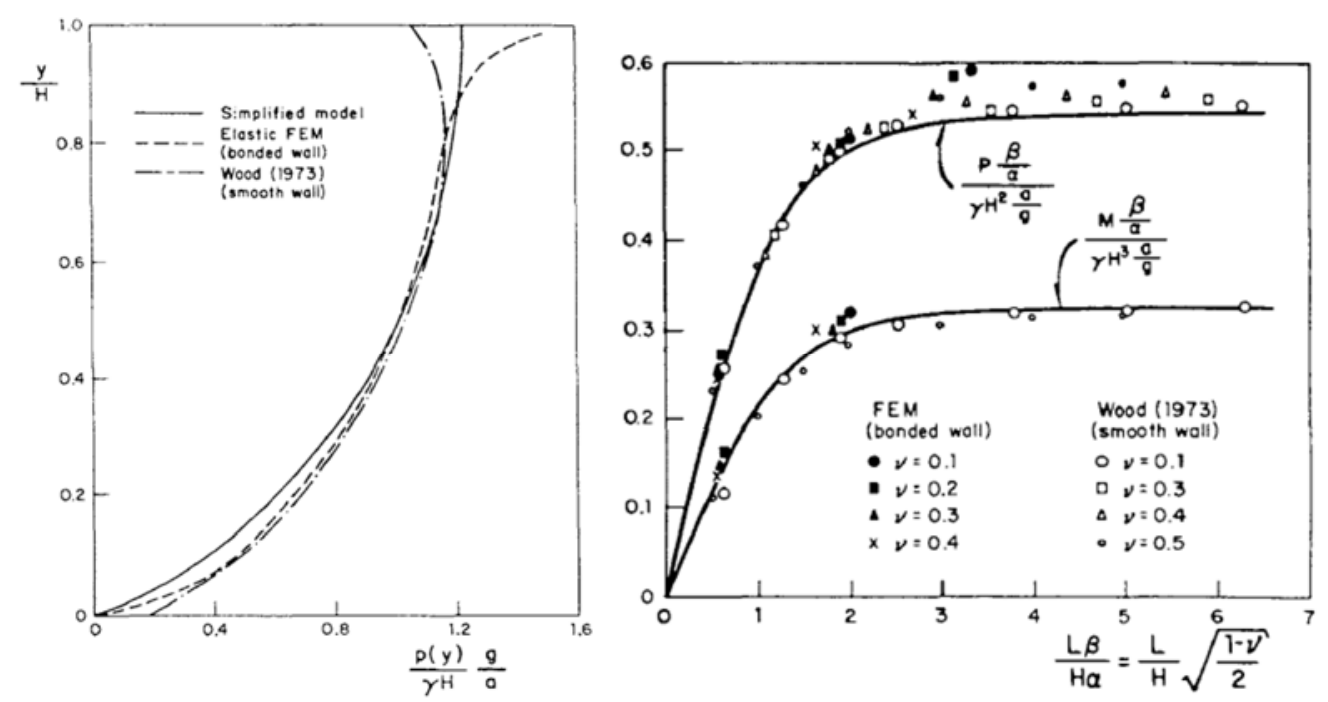

Fig. 3-96. (izda.) Distribución de presiones normalizada a la altura del muro y a la tensión vertical. (dcha.) Resultante de empuje horizontal y de momento volcador. (Arias et al., 1981). 
Arias et al. proporcionan resultados gráficos de sus análisis, que comparan con las soluciones obtenidas por Wood (Wood, 1973), y con resultados obtenidos mediante modelos de elementos finitos. Como se aprecia en la (Fig. 3-96, izda.), los resultados en términos de presión sobre el muro son muy similares en los tres métodos. De manera similar, los resultados de resultantes de empujes horizontales, y momentos volcadores obtenidos por los tres métodos resultan muy similares (Fig. 3-96, dcha.).

\subsubsection{Método de Veletsos y Younan}

Veletsos y Younan, motivados por lo que indican como deficiencias de las soluciones propuestas con anterioridad, analizan en dos estudios casos similares a los estudiados por Wood (Wood, 1973), cuya solución califican de excesivamente compleja, y Scott (Scott, 1974), cuya solución creen ajustada en el compromiso de precisiónsimplicidad. Un primer estudio (Veletsos \& Younan, 1994) analiza la respuesta de un muro infinitamente rígido, cimentado en un terreno infinitamente rígido, frente a la solicitación del terreno del trasdós con una acción sísmica (Fig. 3-97). Un segundo estudio (Veletsos \& Younan, 1993, 1997) analiza la respuesta de un muro igualmente rígido, pero con un resorte rotacional flexible en su base, sometido a la acción sísmica en el terreno (Fig. 3-98).

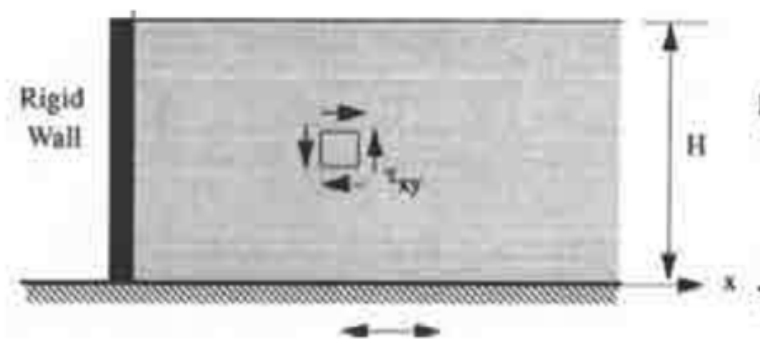

(a) Ground-Excited

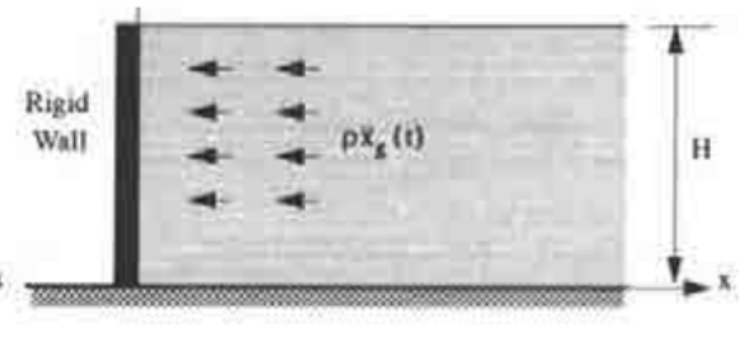

(b) Force-Excited

Fig. 3-97. Modelo de muro rígido con cimentación rígida (Veletsos \& Younan, 1994).

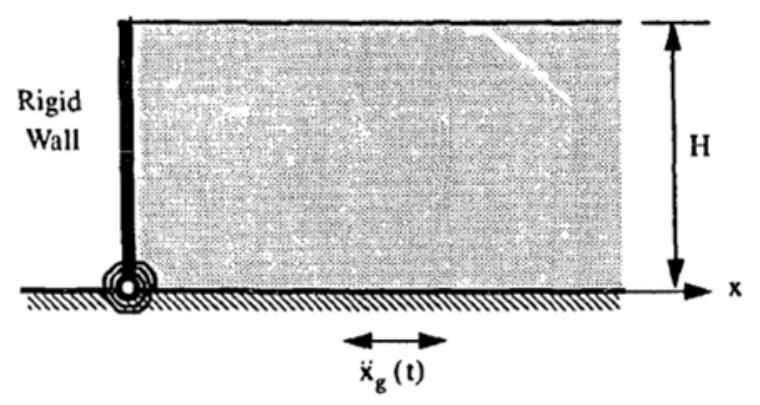

(a) Ground-Excited

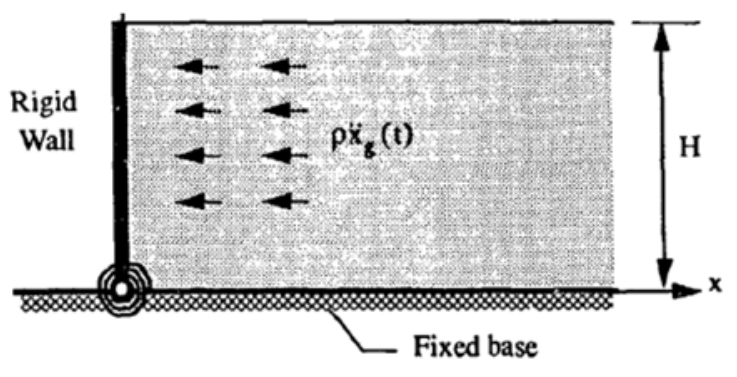

(b) Force-Excited

Fig. 3-98. Modelo de muro rígido con cimentación flexible (Veletsos \& Younan, 1993). 
El objetivo del primer estudio de Veletsos y Younan (Veletsos \& Younan, 1994) es proponer una solución analítica similar a la desarrollada por Wood (Wood, 1973) pero de menor complejidad, (en particular, que no necesite de una serie doble de términos armónicos), y que esta solución sirva para evaluar la idoneidad el modelo de análisis propuesto por Scott (Scott, 1974).

Para ello parten de las ecuaciones de equilibrio horizontal (Ec. 3-131), y vertical (Ec. 3-132), de la elastodinámica, en las que las variables $\eta=x / H$ y $\xi=y / H$ son la longitud y cota de cada punto normalizadas a la altura del muro, y $G^{*}$ y $\lambda^{*}$ las constantes de Lamé de valor complejo indicadas en las fórmulas (Ec. 3-136) y (Ec. 3-137).

$$
\begin{gathered}
\frac{\partial \sigma_{x}}{\partial \xi}+\frac{\partial \tau_{x y}}{\partial \eta}=\rho H \frac{\partial^{2} u}{\partial t^{2}}+\rho H \ddot{x}_{g}(t) \\
\frac{\partial \sigma_{y}}{\partial \eta}+\frac{\partial \tau_{x y}}{\partial \xi}=\rho H \frac{\partial^{2} v}{\partial t^{2}} \\
\sigma_{x}=\left(\lambda^{*}+2 G^{*}\right) \frac{1}{H} \frac{\partial u}{\partial \xi}+\lambda^{*} \frac{1}{H} \frac{\partial v}{\partial \eta} \\
\tau_{x y}=G^{*} \frac{1}{H}\left(\frac{\partial u}{\partial \eta}+\frac{\partial v}{\partial \xi}\right) \\
\sigma_{y}=\left(\lambda^{*}+2 G^{*}\right) \frac{1}{H} \frac{\partial v}{\partial \eta}+\lambda^{*} \frac{1}{H} \frac{\partial u}{\partial \xi} \\
G^{*}=G(1+i \delta) \\
\lambda^{*}=\frac{2 v}{1-2 v} G^{*}
\end{gathered}
$$

Haciendo las hipótesis adicionales de que: 1) no se desarrollan tensiones verticales $\sigma_{y}$ en ningún punto del medio, 2) que no es necesario satisfacer la condición de equilibrio vertical proporcionada por la ecuación (Ec. 3-132), y 3) que no es necesario satisfacer la condición de cortante nulo $\tau_{x y}=0$ en superficie, Veletsos y Younan proponen que la solución en términos de desplazamientos debe corresponder a una serie de armónicos del tipo indicado en la ecuación (Ec. 3-138), en la que $n$ es un entero impar. 


$$
U(\xi, \eta)=\sum_{n=1,3}^{\infty} U_{n}(\xi) \cdot \sin \left(\frac{n \pi}{2} \eta\right)
$$

Tras diversas manipulaciones matemáticas, y tras aplicar las condiciones de contorno, Veletsos y Younan llegan a determinar el campo de desplazamientos horizontal $U$ y vertical $V$ del problema, proporcionado por las ecuaciones (Ec. 3-138) y (Ec. 3-139) respectivamente.

$$
\begin{gathered}
U(\xi, \eta)=-\frac{16}{\pi^{3}} \frac{\rho \ddot{X}_{g} H^{2}}{G} \sum_{n=1,3}^{\infty} \frac{1}{n^{3}} \frac{1-e^{-\left(c_{n}+i d_{n}\right) \xi}}{1-\phi_{n}{ }^{2}+i \delta} \cdot \sin \left(\frac{n \pi}{2} \eta\right) \\
V(\xi, \eta)=-\frac{16 \psi_{v}}{\pi^{3}} \frac{\rho \ddot{X}_{g} H^{2}}{G} \sum_{n=1,3}^{\infty} \frac{1}{n^{3}} \frac{\left(a_{n}+i b_{n}\right) e^{-\left(c_{n}+i d_{n}\right) \xi}}{1-\phi_{n}{ }^{2}+i \delta} \\
\cdot\left(1-\cos \left(\frac{n \pi}{2} \eta\right)\right) \\
\psi_{v}=\frac{v}{\sqrt{(1-v)(2-v)}}
\end{gathered}
$$

De manera similar, proporcionan expresiones para las tensiones normales $\sigma$ (Ec. 3-142), y tensiones tangenciales $\tau$ (Ec. 3-143).

$$
\begin{gathered}
\sigma(\xi, \eta)=-\frac{8 \psi_{\sigma}}{\pi^{2}} \rho \ddot{X}_{g} H(1+i \delta) \sum_{n=1,3}^{\infty} \frac{1}{n^{2}} \frac{\left(a_{n}+i b_{n}\right) e^{-\left(c_{n}+i d_{n}\right) \xi}}{1-\phi_{n}{ }^{2}+i \delta} \\
\cdot \sin \left(\frac{n \pi}{2} \eta\right) \\
\tau(\xi, \eta)=-\frac{8}{\pi^{2}} \rho \ddot{X}_{g} H \sum_{n=1,3}^{\infty} \frac{1}{n^{2}}\left[\frac{(1+i \delta)\left(1-e^{-\left(c_{n}+i d_{n}\right) \xi}\right)}{1-\phi_{n}{ }^{2}+i \delta} \cos \left(\frac{n \pi}{2} \eta\right)\right. \\
\left.+\frac{v}{2-v} e^{-\left(c_{n}+i d_{n}\right) \xi}\left(1-\cos \left(\frac{n \pi}{2} \eta\right)\right)\right]
\end{gathered}
$$

Particularizando la expresión de tensiones normales para la abscisa $\eta=0$, se obtienen las presiones en el muro $\sigma_{w}$, que resultan ser las proporcionadas por la fórmula (Ec. 3-144). Integrando esta distribución de presiones se obtiene el empuje total $P$ sobre el muro (Ec. 3-145), y el momento volcador $M$ en la base (Ec. 3-146). 


$$
\begin{gathered}
\sigma_{w}(\eta)=-\frac{8 \psi_{\sigma}}{\pi^{2}} \rho \ddot{X}_{g} H \sqrt{1+i \delta} \sum_{n=1,3}^{\infty} \frac{1}{n^{2}} \frac{1}{\sqrt{1-\phi_{n}{ }^{2}+i \delta}} \cdot \sin \left(\frac{n \pi}{2} \eta\right) \\
P=\int_{0}^{1} \sigma_{w}(\eta) \cdot H \cdot d \eta=-\frac{16 \psi_{\sigma}}{\pi^{3}} \rho \ddot{X}_{g} H^{2} \sqrt{1+i \delta} \sum_{n=1,3}^{\infty} \frac{1}{n^{3}} \frac{1}{\sqrt{1-\phi_{n}{ }^{2}+i \delta}} \\
M=\int_{0}^{1} \sigma_{w}(\eta) \cdot H^{2} \cdot \eta \cdot d \eta \\
=-\frac{32 \psi_{\sigma}}{\pi^{4}} \rho \ddot{X}_{g} H^{3} \sqrt{1+i \delta} \sum_{n=1,3}^{\infty} \frac{(-1)^{\frac{n-1}{2}}}{n^{4}} \frac{1}{\sqrt{1-\phi_{n}{ }^{2}+i \delta}}
\end{gathered}
$$

Para acciones del terreno suficientemente lentas, las aceleraciones horizontales pueden considerarse estáticas a efectos dinámicos, y las expresiones anteriores se reducen a los siguientes valores de presión máxima en el muro $\sigma^{s t}{ }_{w, \max }$, empuje total $P^{s t}, \mathrm{y}$ momento en base $M^{\text {st }}$.

$$
\begin{gathered}
\left(\sigma_{w}^{s t}\right)_{\max }=-0.742 \psi_{\sigma} \rho \ddot{X}_{g} H \\
P^{s t}=-0.543 \psi_{\sigma} \rho \ddot{X}_{g} H^{2} \\
M^{s t}=-0.325 \psi_{\sigma} \rho \ddot{X}_{g} H^{3}
\end{gathered}
$$

En su segundo estudio, Veletsos y Younan (Veletsos \& Younan, 1993, 1997) extienden el concepto y soluciones planteadas para el caso de un muro empotrado rígidamente en su base, al caso de muro con base flexible (Fig. 3-98), y estudian la importancia relativa de cada uno de los factores involucrados en la distribución de presiones sobre el muro.

En particular, estudian la influencia de la flexibilidad del muro y del terreno contenido $d_{w}$, definida como la expresión (Ec. 3-150). También estudian la flexibilidad relativa entre en el muelle rotacional de la base del muro y del terreno contenido $d_{\theta}$, definida como la expresión (Ec. 3-151). En estas expresiones, $G$ es el módulo de cortante del suelo, $H$ la altura del muro, $R_{\theta}$ la rigidez rotacional de la base del muro, $E_{w}$ el módulo de Young del muro, y $t_{w}$ el espesor del mismo. 


$$
\begin{gathered}
d_{w}=\frac{G \cdot H^{3}}{D_{w}} \\
d_{\theta}=\frac{G \cdot H^{2}}{R_{\theta}} \\
D_{w}=\frac{E_{w} \cdot t_{w}{ }^{2}}{12\left(1-v_{w}{ }^{2}\right)}
\end{gathered}
$$

La (Fig. 3-99) muestra la distribución de presiones obtenida por Veletsos y Younan para una solicitación estática de aceleraciones laterales. La (Fig. 3-99, izda.) para el caso de un muro con base infinitamente rígida $d_{\theta}=0$ y alzado flexible, mientras que la (Fig. 3-99, dcha.) para el caso de un muro con alzado infinitamente rígido $d_{w}=0$ y base flexible.

En ambos casos puede observarse como una condición tanto de muro, como de base, infinitamente rígidos concuerda con la solución obtenida en su estudio anterior. De manera similar, puede observarse como una relajación de cualquiera de las condiciones de rigidez resulta en una disminución de las presiones ejercidas sobre el muro, llegando a aparecer en el 10\% superior del mismo incluso tensiones de tracción.

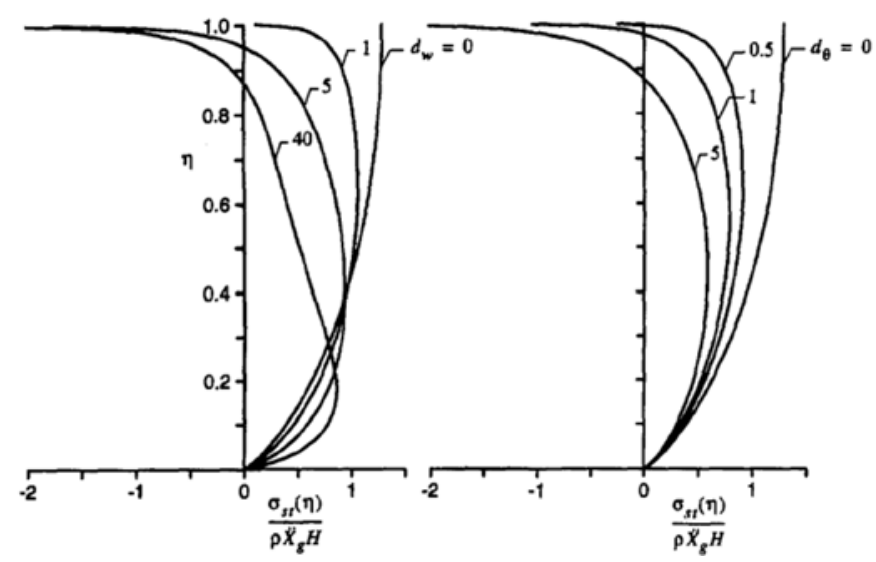

Fig. 3-99. Distribución de presiones sobre el muro para sistemas solicitados estáticamente, con diferentes flexibilidades de muro y base. (izda.) Caso con base infinitamente rígida $d_{\theta}=0$ y alzado flexible. (dcha.) Caso con alzado del muro infinitamente rígido $\mathrm{dw}=0 \mathrm{y}$ base flexible. (Veletsos \& Younan, 1997).

Veletsos y Younan finalizan su estudio concluyendo que, tanto la magnitud de las presiones ejercidas sobre el muro, como la propia distribución de las mismas, son bastante sensibles a las flexibilidades tanto del alzado del muro como de la cimentación. Adicionalmente, indican que siempre que se desprecien los efectos de amplificación 
dinámica, y considerando rigideces realistas de los muros y sus bases, el empuje total es similar al obtenido mediante el método de Mononobe-Okabe, y que la resultante de las presiones parece estar más cercana del $1 / 3 \cdot \mathrm{H}$ indicado por estos autores, que del $2 / 3 \cdot \mathrm{H}$ propuesto por Seed y Whitman (Seed \& Whitman, 1970).
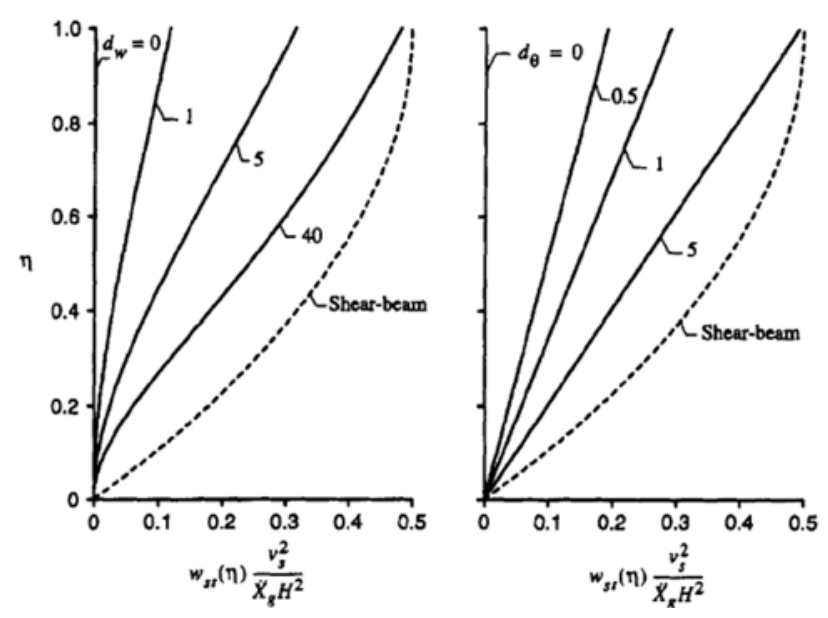

Fig. 3-100. Deformaciones en el muro relativas a la base para sistemas solicitados estáticamente, diferentes flexibilidades de muro y base. (izda.) Caso con base infinitamente rígida $d_{\theta}=0$ y alzado flexible. (dcha.) Caso con alzado del muro infinitamente rígido $d_{w}=0$ y base flexible. (Veletsos \& Younan, 1997).

\subsubsection{Método de Ostadan}

Ostadan (Ostadan, 2004; Ostadan \& White, 1998), en su estudio de acciones del terreno ejercidas sobre muros de sótano bajo la acción del sismo, argumenta que los métodos basados en las hipótesis de Mononobe y Okabe (Elms \& Richards, 1979; Mononobe \& Matsuo, 1929; Okabe, 1924; Seed \& Whitman, 1970) son sólo aplicables en aquellos casos en los que, bajo la acción del sismo, el muro es capaz de desplazarse lo suficiente como para movilizar el deslizamiento de la cuña activa del trasdós, e inducir de esta manera el estado límite de empuje activo. Sin embargo, considera que en el caso de un muro de sótano esta condición es difícilmente alcanzable, y es necesario desarrollar un método alternativo.

Con respecto a la solución propuesta por Wood (Wood, 1973), Ostadan parece obviar el estudio que este autor hace para las acciones dinámicas, y se centra tan sólo en la parte del método correspondiente a las acciones pseudo-estáticas, que es la recogida en la normativa americana del momento ASCE 4-98 de análisis sísmico de estructuras relacionadas con la seguridad nuclear. 
Con respecto a las soluciones propuestas por Veletsos y Younan (Veletsos \& Younan, 1993, 1994, 1997), Ostadan argumenta que se trata de desarrollos complejos, y que el método carece de pasos sencillos para aplicar en el diseño de estructuras de contención.

Con estas consideraciones, Ostadan (Ostadan, 2004; Ostadan \& White, 1998) propone un marco conceptual de estudio similar al desarrollado por Veletsos y Younan, e implementa una serie de modelos numéricos (Fig. 3-101) en el programa SASSI (J. Lysmer, Tabatabaie-Raissi, Tajirian, Vahdani, \& Ostadan, 1981), para estudiar los efectos de interacción cinemática entre suelo y estructura, y la distribución de presiones que esta genera.

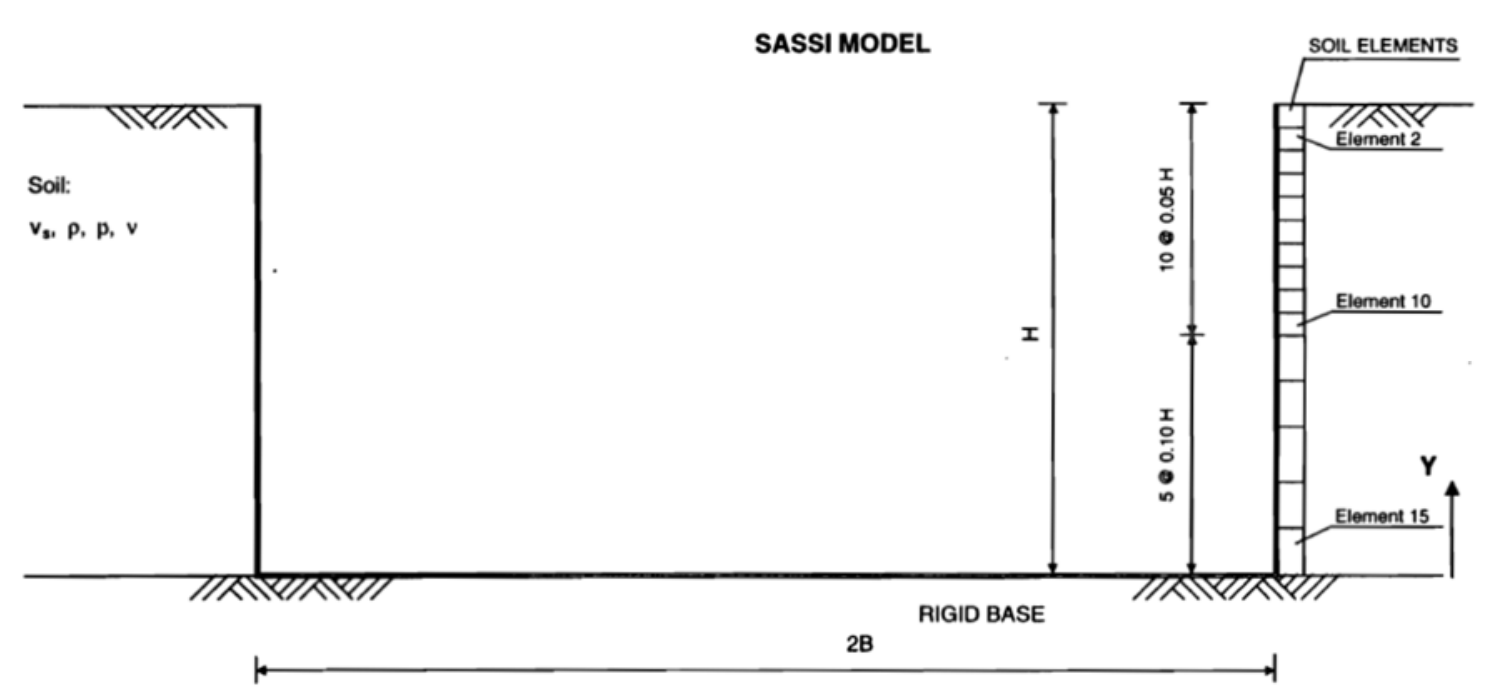

Fig. 3-101. Modelo de interacción suelo-estructura desarrollado por Ostadan en el programa SASSI. (Ostadan \& White, 1998).

El modelo de Ostadan incluye un muro de altura $H$, que contiene un terreno en su trasdós caracterizado por su densidad $\rho$, velocidad de ondas de cortante $V_{s}$, coeficiente de Poisson $v$, y amortiguamiento $\beta$. Ostadan supone el muro infinitamente rígido, en virtud de las condiciones de contorno que asume, y que considera características de un muro de sótano, es decir, la vinculación del muro a los forjados y diafragmas de los diversos niveles del sótano. De manera similar, Ostadan asume que el muro se encuentra cimentado sobre roca o suelo competente para despreciar cualquier rotación de su base. El modelo numérico es sometido a una aceleración armónica en su base, y estudia la respuesta en términos de presiones para diferentes propiedades del suelo y frecuencias de excitación. 


$$
f_{1}=\frac{V_{s}}{4 \cdot H}
$$

En particular, Ostadan obtiene lo que denomina funciones de transferencia de la presión máxima, que son, para unas propiedades de terreno dato, representaciones de la máxima presión solicitante en el muro en función de la frecuencia $f$ de la excitación en la base (Fig. 3-102. izda.). Observando el resultado y el máximo de la función de transferencia, propone normalizar dichas funciones de transferencia a la frecuencia fundamental $f_{1}$ del terreno del trasdós (Ec. 3-150), obteniendo una curva de transferencia independiente de las características del terreno (Fig. 3-102. dcha.).
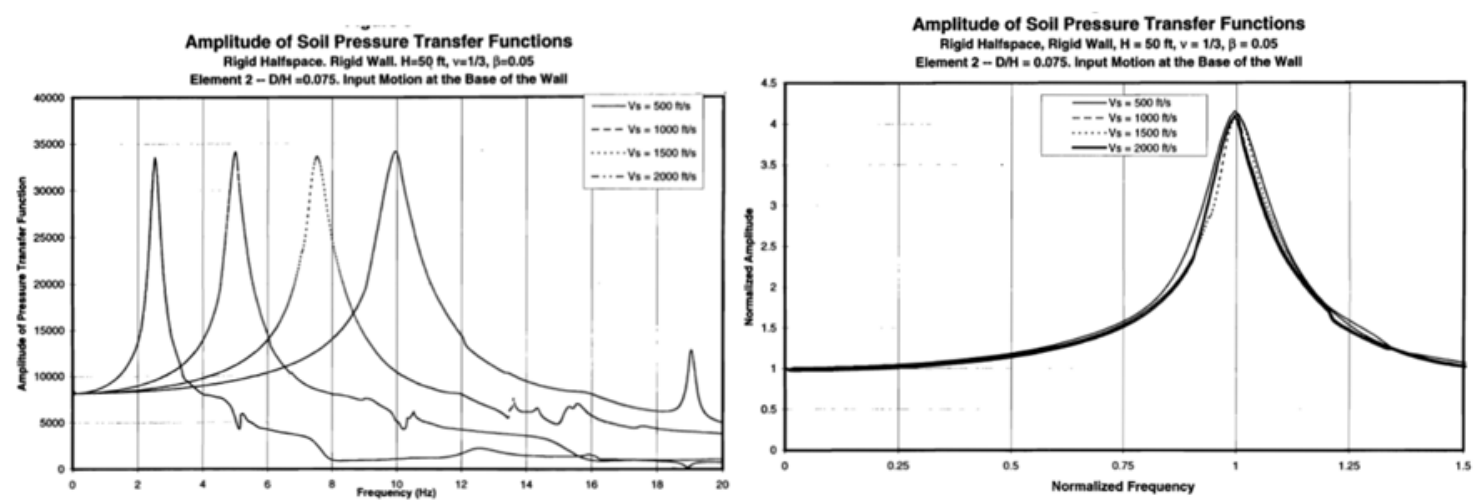

Fig. 3-102. Función de transferencia de presión máxima ejercida por el suelo. (izda.) En función de diferentes velocidades de propagación de ondas de cortante del suelo contenido. (dcha.) En función de la frecuencia normalizada del primer modo de cortante del suelo contenido. (Ostadan \& White, 1998).

De estos resultados, en los que las curvas de transferencia tienen un máximo tan pronunciado, Ostadan colige que el comportamiento del terreno puede asimilarse al comportamiento de un sistema de un único grado de libertad (SDOF, Single Degree of Freedom en la literatura anglosajona). En este sentido, Ostadan indica que la masa de suelo participante en el modelo de un único grado de libertad responderá a la expresión (Ec. 3-154), en la que $\rho$ es la densidad del suelo, $H$ la altura del muro, y $\Psi_{v}$ un factor para tener en cuenta el coeficiente de Poisson v, y que define con la ecuación (Ec. 3-156).

$$
\begin{aligned}
& m=0,50 \cdot \rho \cdot H^{2} \cdot \Psi_{v} \\
& \Psi_{v}=\frac{2}{\sqrt{(1-v)(2-v)}}
\end{aligned}
$$


Adicionalmente, y puesto que su estudio se basa tan sólo en resultados numéricos, propone una ley normalizada de presiones, que resulta de ajustar un polinomio de $5^{\circ}$ grado (Ec. 3-156) a la distribución obtenida con el programa SASSI, para el que la coordenada $y$ es la cota $Y$ normalizada a la altura total del muro $y=Y / H$, y que resulta contener un área de valor $0,744 \cdot H$.

$$
\begin{gathered}
p(z)=-0,0015+5,05 y-15,84 y^{2}+28,25 y^{3}-24,59 y^{4} \\
+8,14 y^{5}
\end{gathered}
$$

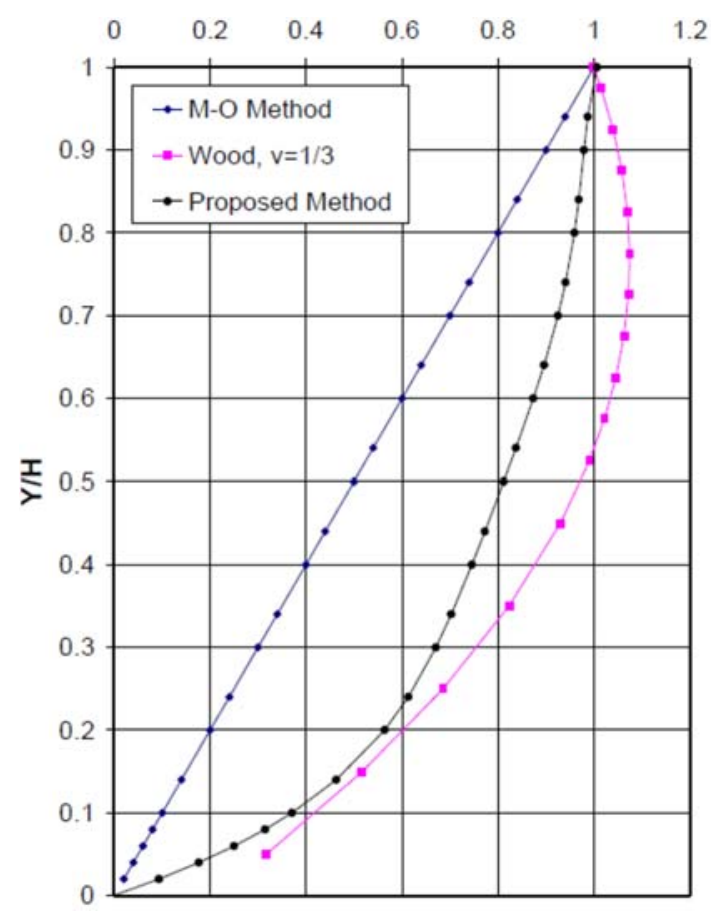

Fig. 3-103. Distribución de presiones propuesta por Ostadan (Ostadan, 2004), y comparación con las distribuciones de Mononobe-Okabe modificada según Seed y Whitman (Seed \& Whitman, 1970), y la distribución de Wood (Wood, 1973).

De esta manera, el método propuesto por Ostadan consistiría en los siguientes pasos:

- Realizar un estudio unidimensional de respuesta del suelo, y obtener las aceleraciones del terreno a la cota de la base del muro.

- Emplear la ecuación (Ec. 3-154) para obtener la masa de suelo participante en ejercer presión sobre el muro.

- Obtener la fuerza lateral sísmica equivalente, como el producto de la masa participante del paso 2), por la aceleración del terreno a la cota de la base del muro. 
- Obtener la presión máxima del terreno, dividiendo la fuerza obtenida en el paso 3) por el área contenida en la distribución de presiones normalizada $(0,744 \cdot H)$.

- Obtener el perfil de presiones multiplicando la presión máxima del paso 4) por la fórmula (Ec. 3-155).

\subsubsection{Métodos de deformaciones de campo libre impuestas}

Los métodos descritos en los apartados $\$ 3.7 .1$ y $\$ 3.7 .2$, están orientados a determinar la distribución de presiones que ejerce el terreno sobre una estructura de contención tipo muro. Sin embargo, aunque estos métodos están relacionados con las obras subterráneas, dado el carácter intrínseco del problema de interacción sueloestructura, y a pesar de que pueden resultar de aplicación durante la ejecución de las mismas, no abordan el problema con la perspectiva más general de una obra subterránea tipo túnel.

Los métodos de análisis sísmico de deformaciones de campo libre impuestas, que se describen en este apartado, sí se han elaborado para dar respuesta esencialmente a la determinación de acciones de estructuras subterráneas completamente enterradas, tales como túneles, estaciones de metro, cavernas de centrales eléctricas, etc.

Estos métodos toman como hipótesis fundamental que los efectos dinámicos inerciales de la propia estructura, durante el evento sísmico, son poco significativos con respecto a los efectos inerciales de la masa del terreno que rodea la obra subterránea, ya que la masa del terreno es mucho mayor que la de la propia estructura (J. N. Wang, 1993), (Penzien, 2000). De esta manera, se puede considerar que la estructura enterrada, durante la acción de un sismo, se adaptará a la deformación del terreno circundante cuando este se vea sometido al paso de las ondas de deformación originadas por el terremoto.

Es relevante destacar e incidir de manera un poco más detallada en este último aspecto. Pese a que existe un consenso generalizado en que los efectos dinámicos debidos a la propia masa de la estructura son poco relevantes, hay otros efectos cinemáticos que, como se verá más adelante, pueden modificar la respuesta deformacional de la estructura con respecto a la del terreno circundante. Este el hecho fundamental que diferencia los métodos denominados de deformaciones de campo libre impuestas (descritos en el apartado §3.7.3) frente a los métodos denominados de interacción cinemática (descritos en el apartado §3.7.3.3). En los métodos de deformaciones de campo libre impuestas se 
considera que la estructura enterrada se deforma igual que el terreno. En los métodos de interacción cinemática se considera que la estructura enterrada no se deforma igual que el terreno debido a la interacción terreno-estructura (J. N. Wang, 1993).

En general, tal y como se ha indicado en $§ 3.5 .3$, los sismos generan en las zonas de deslizamiento de la falla, tanto ondas de deformación volumétrica del tipo $P$ (compresión-tracción) como del tipo $S$ (cortante). Estas ondas reflejan y refractan tanto en las capas más profundas del sustrato rocoso como en la superficie libre del terreno, siguiendo caminos más o menos indirectos cuanto más alejada se encuentre la zona de interés de la zona de ruptura de falla (Fig. 3-104). En general, cuando estas ondas de deformación alcanzan la zona de interés, producirán deformaciones correspondientes a varios trenes de ondas de tipo $P$, y a varios trenes de ondas tipo $S$, cada uno de ellos procedente de, y propagándose hacia, una dirección diferente.

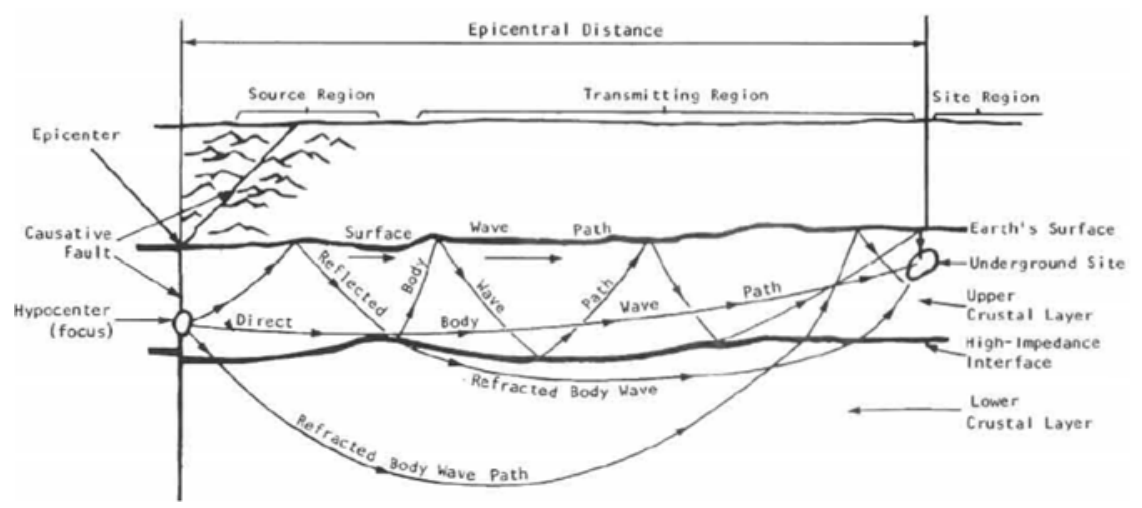

Fig. 3-104. Algunos caminos seguidos por las ondas desde la zona de fractura de la falla hasta la obra subterránea (Owen \& Scholl, 1981).

Con respecto a los trenes de ondas de tipo $P$, las dos direcciones más significativas serán o bien paralelos al eje del túnel, o bien perpendiculares al eje del túnel (Fig. 3-105). Con respecto a la deformación debida a las ondas $P$ que se propagan en dirección paralela al eje, es de esperar que estas induzcan incrementos o decrementos de la parte hidrostática del empuje de tierras, análogas a un aumento de la presión radial en un túnel circular (St John \& Zahrah, 1987). Esta componente de la deformación es generalmente considerada como muy poco relevante en la literatura, ya que los esfuerzos producidos en la estructura del túnel son menores que los producidos en el caso de propagación perpendicular. 

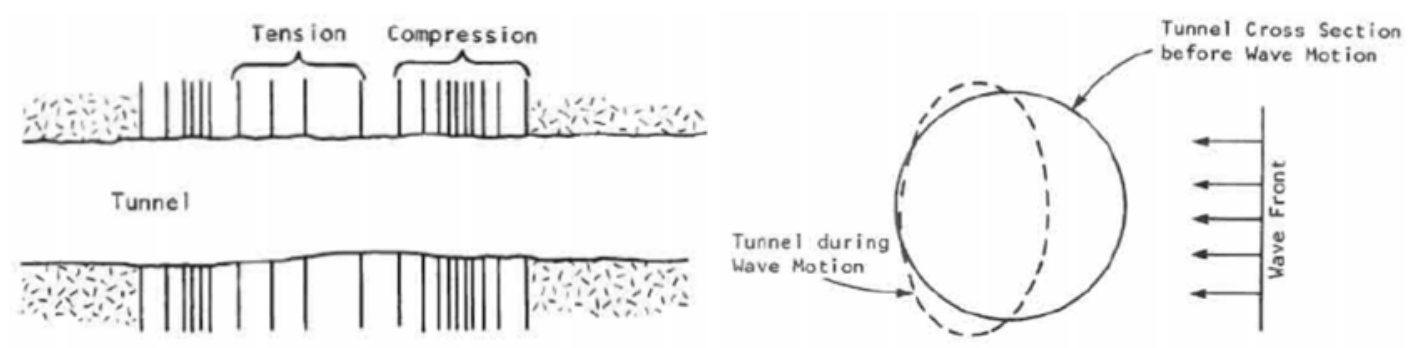

Fig. 3-105. (Izda.) Vista en planta de la deformación longitudinal del túnel durante el paso de ondas P de compresión-tracción propagándose en la dirección longitudinal del túnel. (Dcha.) Vista en sección de la deformación anular del túnel durante el paso de ondas $P$ de compresión tracción propagándose en la dirección perpendicular del túnel (Owen \& Scholl, 1981).

Con respecto a los trenes de ondas de tipo $\mathrm{S}$, las direcciones más significativas serán, de manera análoga al caso anterior, o bien paralelos al eje del túnel, o bien perpendiculares al eje del túnel (Fig. 3-107).

En el caso de las ondas de tipo $S$, caben dos tipos de movimientos en función de cómo se encuentren polarizadas: o bien ondas polarizadas verticalmente que producen movimientos verticales $\left(S_{V}\right)$, o bien polarizadas horizontalmente que producen movimientos oscilatorios horizontales $\left(S_{H}\right)$. En general, las ondas $S_{V}$ en la superficie del terreno tienen una amplitud considerablemente menor que las $S_{H}$ (Stein \& Wysession, 2003) y resultan poco relevantes para la ingeniería civil; esto se debe a que la mayor parte de las ondas $S$ radiadas desde la zona hipocentral tienden a adquirir una dirección de propagación vertical (y por lo tanto polarización horizontal) debido a la refracción en sucesivas capas de materiales geológicos, cada vez menos rígidos cuanto más cercanos a la superficie (Tsai \& Housner, 1970) (Fig. 3-72).

De manera similar, las ondas $S_{H}$ que se propagan en dirección horizontal, ya sea en dirección paralela al eje del túnel, o en dirección horizontal perpendicular al mismo, son poco relevantes. Como se ha comentado la refracción sucesiva de ondas $S$ en materiales cada vez menos rígidos, verticaliza la dirección de propagación. Sin embargo la propagación en una dirección sub-vertical, es decir no completamente vertical, inducirá un desfase de movimientos horizontales para diferentes puntos de la superficie, que puede a su vez inducir movimientos diferenciales en planta en el túnel (Kuesel, 1969) (Fig. 3-106). 

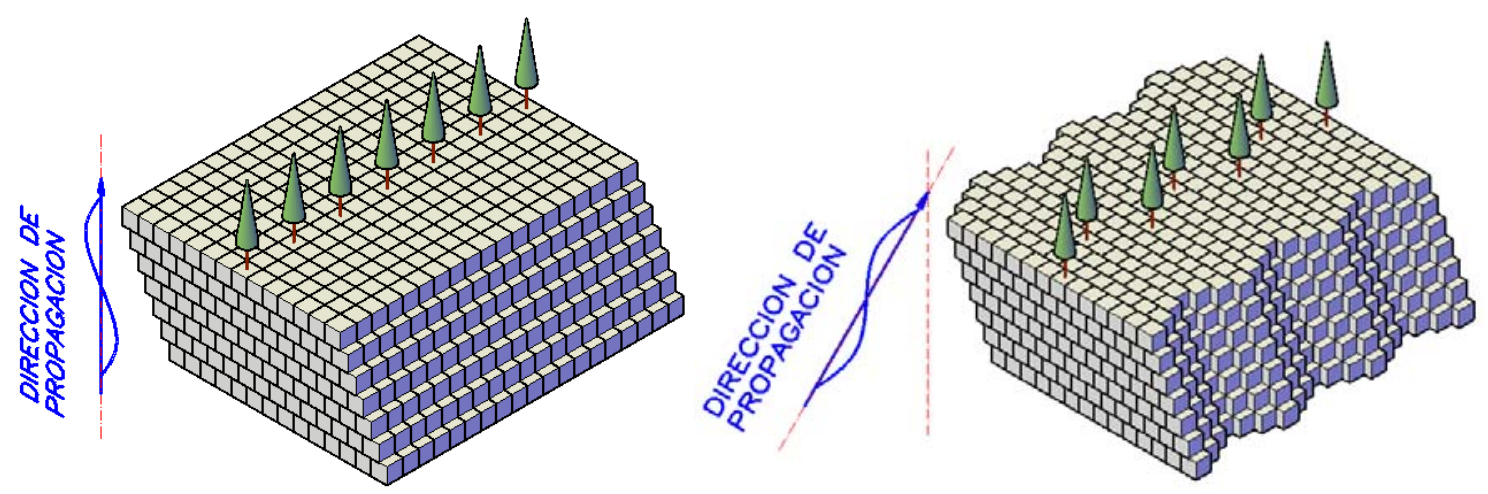

Fig. 3-106. (Izda.) Esquema de deformación del terreno bajo una onda $S_{H}$ que se propaga verticalmente. (Dcha.) Esquema de deformación del terreno bajo una onda $S_{H}$ que se propaga sub-verticalmente.

Las ondas $S_{H}$ de dirección de propagación vertical son reconocidas en la literatura como las más relevantes, y como las que inducen deformaciones de mayor amplitud en el terreno (Kuesel, 1969), (St John \& Zahrah, 1987), (Monsees, 1991), (J. N. Wang, 1993), (Penzien, 2000), (Kramer, 1996), (Anderson, Martin, Lam, \& Wang, 2008). En general la mayor parte de la literatura técnica se ha ceñido casi exclusivamente al estudio de las deformaciones en la estructura subterránea solicitada por estas ondas (Fig. 3-107)

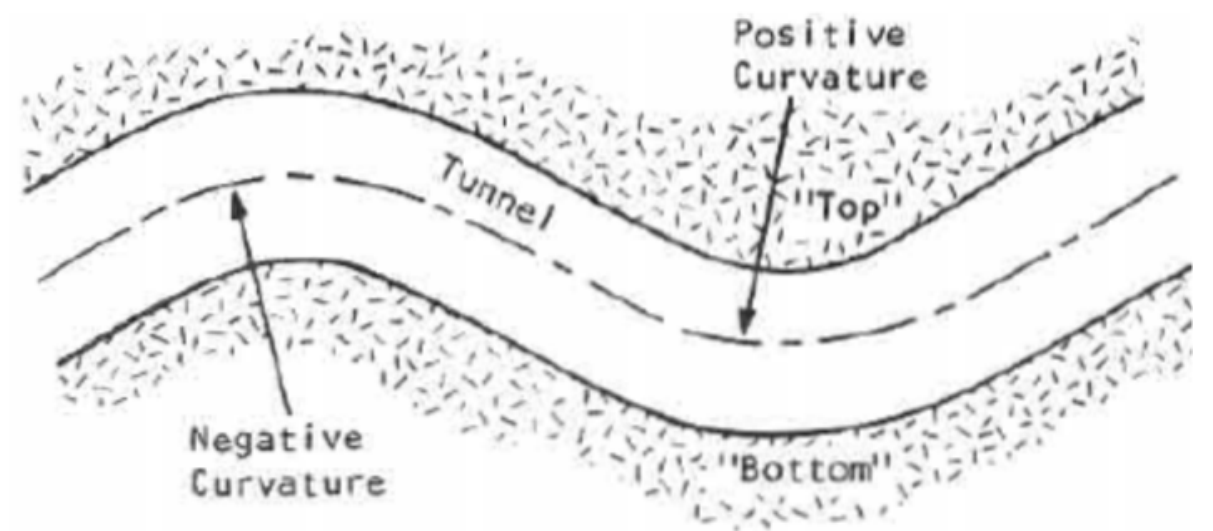

Fig. 3-107. Vista en planta de la deformación transversal en planta del túnel y efectos sobre la curvatura de la estructura por el desfase espacial de ondas $S_{H}$ de cortante propagándose en dirección vertical (Owen \& Scholl, 1981).

\subsubsection{Método de Kuesel}

El primer planteamiento de análisis de una estructura subterránea basado en deformaciones impuestas fue establecido por Kuesel (Kuesel, 1969) con la ocasión del proyecto y construcción de los túneles de ferrocarril suburbano del área metropolitana de San Francisco, EE.UU. (BART, Bay Area Rapid Transit System). A partir de esta idea original de tratar el problema como un problema de deformaciones impuestas se han 
elaborado las metodologías más sofisticadas actuales de interacción cinemática, también denominadas de racking.

Kuesel es el primero en establecer que, durante un evento sísmico, la estructura del túnel debe adaptarse a las deformaciones impuestas por el terreno circundante, y que resulta poco factible, $\mathrm{y}$ en cualquier caso muy oneroso, intentar oponerse a estas deformaciones. De igual manera, Kuesel se anticipa con acierto a los paradigmas de la ingeniería sismorresistente actual con conceptos muy modernos, al asumir que, puesto que la deformación es inevitable, una estrategia de diseño efectiva consistirá en adaptarse lo mejor posible a estas deformaciones impuestas; y en el caso de que estas involucren daño, proyectar la estructura de tal manera que este daño se concentre en zonas accesibles para facilitar la reparación tras el evento sísmico. En particular, Kuesel indica:

"It is important for the designer to recognize that the effect of the earthquake on underground structures is the imposition of an arbitrary deformation which cannot be changed by strengthening the structure. The structural design criterion is therefore a provision of sufficient ductility to absorb the imposed deformation without losing the capacity to carry static loads, rather than a criterion for resisting inertial loads at a specified unit stress."(Kuesel, 1969, p.1215).

Adicionalmente, Kuesel anticipa cuales son los daños más relevantes que pueden producirse en una estructura subterránea sometida a la acción del sismo:

"The principal effects of earthquake distortion are likely to be starting leaks in corner joints and cracking brittle finish materials. Structural and architectural details should be approached with this in mind. Areas of sharp discontinuity of structural form, such as the connection of a station entrance passageway to the main structural shell of the station, are particularly vulnerable.” (Kuesel, 1969, p.1215-1216).

De igual manera, indica que, si la estructura no puede adaptarse elásticamente a la deformación impuesta por el terreno circundante, es decir, sin producir deformación plástica en sus elementos, la ductilidad inelástica de dichos elementos debe estudiarse para asegurar que sean capaces de adaptarse a las deformaciones impuestas por el terreno:

"If certain joints are strained into the plastic range, the ductility of such joints should be investigated. Plastic straining of corner joints in conformance with shearing distortion of the ground may affect the elastic properties of the structural frame. If continuity of the structural frame has been assumed in the design for static loads, the 
effects of plastic joint straining may require special consideration.” (Kuesel, 1969, p.1216).

Como se ha indicado con anterioridad, las deformaciones de mayor amplitud en la obra subterránea son las correspondientes al paso de ondas $S_{H}$ que se propagan verticalmente o sub-verticalmente. Kuesel propone que las deformaciones correspondientes a las ondas $S_{H}$ que se propagan sub-verticalmente se consideren como una deformación de curvatura impuesta en planta, mientras que las ondas $S_{H}$ que se propagan verticalmente se consideren como una deformación de distorsión o racking en alzado de la sección transversal (Fig. 3-108).

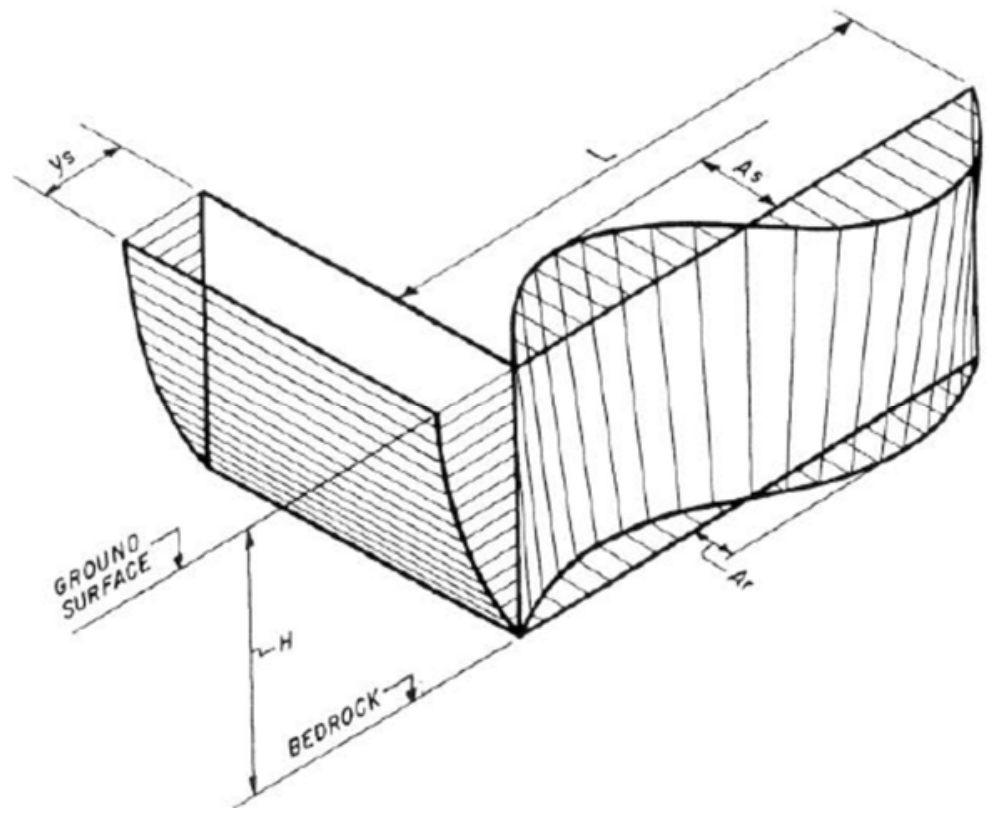

Fig. 3-108. Deformaciones de distorsión $\left(y_{s}\right)$, y de curvatura en planta $\left(A_{r}\right.$ y $\left.A_{s}\right)$ de una sección rectangular enterrada de túnel de metro sometida a la acción del sismo (Kuesel, 1969).

Para el análisis de las amplitudes de cada una de las deformaciones en planta y en alzado, Kuesel asume que las deformaciones de la estructura serán idénticas a las deformaciones del terreno circundante; es decir, iguales a la deformación en campo libre.

Se describen a continuación la metodología empleada por Kuesel para obtener cada una de estas deformaciones.

\subsection{Deformación de curvatura en planta}

Para evaluar la máxima deformación longitudinal en planta de la estructura subterránea, Kuesel asume que el tren de ondas sísmico tendrá una forma sinusoidal de amplitud $A$ y longitud de onda $L$, del tipo mostrado en la (Fig. 3-109, izda.). 


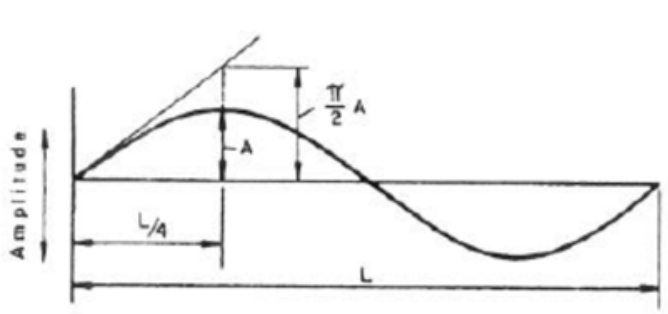

FIG. 6.-GEOMETRY OF A SINUSOIDAL WAVE

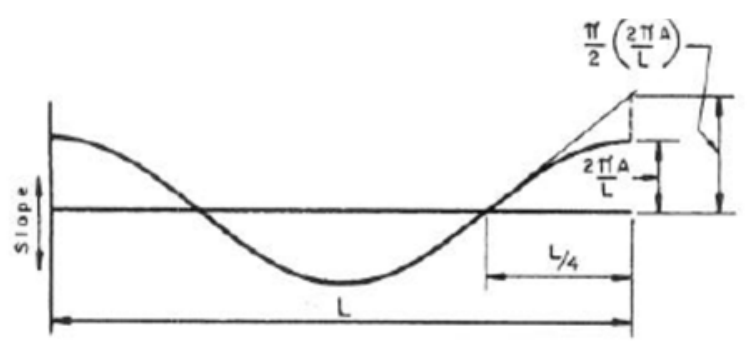

FIG. 7.-DISTRIBUTION OF SLOPE OF SINUSOIDAL WAVE

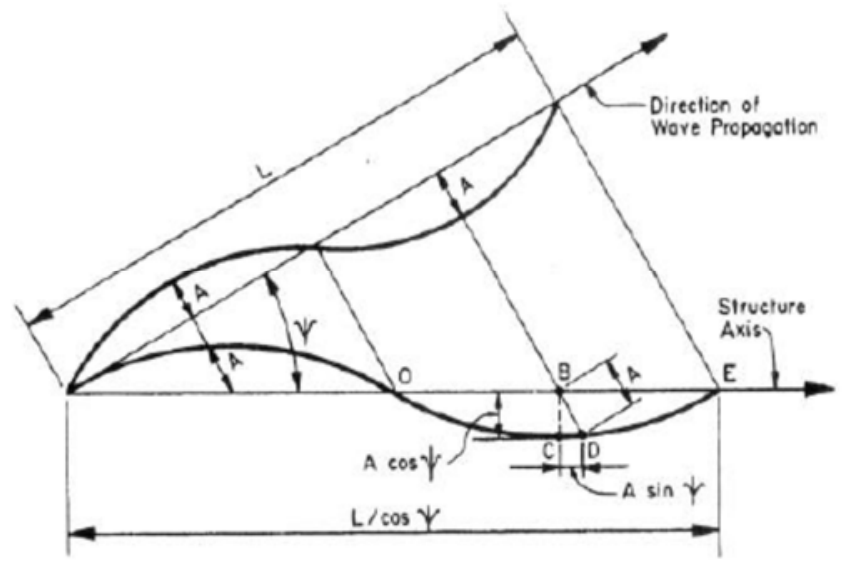

FIG. 8.-WAVE OBLIQUE TO STRUCTURE AXIS

Fig. 3-109. (izda.) Esquema de deformaciones transversales de un túnel bajo el paso de una onda en dirección longitudinal. (dcha.) Esquema de la pendiente de la deformada longitudinal. (cent.) Composición de deformaciones en la estructura para el paso de un tren de ondas que se propaga oblicuamente al eje. (Kuesel, 1969).

Para este perfil de deformación del terreno, la máxima pendiente de la deformada en planta de una sección de túnel viene dada por la primera derivada de la deformada como en la expresión (Ec. 3-157), mientras que la máxima curvatura viene dada por la segunda derivada como en la expresión (Ec. 3-158).

$$
\begin{gathered}
A_{\text {max }}^{\prime}=\varepsilon_{s}=\frac{\frac{\pi}{2} A}{\frac{L}{4}}=\frac{2 \pi A}{L} \\
A_{\text {max }}^{\prime \prime}=\varepsilon_{b}=\frac{\frac{\pi}{2} \frac{2 \pi A}{L}}{\frac{L}{4}}=\frac{4 \pi^{2} A}{L^{2}}
\end{gathered}
$$

Kuesel establece que la máxima tasa de deformación de cortante $\varepsilon_{s}$ en planta será proporcional a esta primera derivada, mientras que la tasa de deformación a flexión $\varepsilon b$ será proporcional a la segunda derivada. 
Para el paso de ondas que se propagan oblicuamente al eje de la estructura con un ángulo $\psi$ (Fig. 3-109, cent.), las expresiones anteriores se transforman en las ecuaciones (Ec. 3-159) y (Ec. 3-160), al proyectar el ángulo $\psi$.

$$
\begin{gathered}
\varepsilon_{s}=\frac{2 \pi A}{L} \cdot \sin (\psi) \cdot \cos (\psi) \\
\varepsilon_{b}=\frac{4 \pi^{2} A}{L^{2}} \cdot \cos ^{3}(\psi)
\end{gathered}
$$

Por una parte, Kuesel indica que la ecuación (Ec. 3-159) tiene un máximo para $\psi=45^{\circ}$, para el cual el producto $\sin (\psi) \cdot \cos (\psi)=1 / 2$. Por otro lado, para establecer la longitud de onda $L$ del tren de ondas incidente, Kuesel indica que se considere como crítica el valor de $L=6 \cdot W$, siendo $W$ el ancho de la estructura en planta. Para justificar este valor de longitud de onda, indica que es una estimación de la longitud de túnel mínima para la cual se puede considerar como dominante el comportamiento a flexión, ya que para longitudes menores los efectos de deformación a cortante del túnel serán más significativos. El efecto combinado de ambas deformaciones de cortante $\varepsilon_{s} \mathrm{y}$ de flexión $\varepsilon b$, queda expresado por la suma de ambas (Ec. 3-161), que como indica Kuesel tiene un máximo para un ángulo $\psi=32^{\circ},($ Ec. $3-162)$.

$$
\begin{gathered}
\varepsilon=\varepsilon_{s}+\varepsilon_{b}=\frac{2 \pi A}{L} \cdot \sin (\psi) \cdot \cos (\psi)+\frac{\pi^{2} A}{3 L} \cdot \cos ^{2}(\psi) \\
\varepsilon_{\max }=1.67 \cdot \frac{\pi A}{L} \cong \frac{5.2 \cdot A}{L}
\end{gathered}
$$

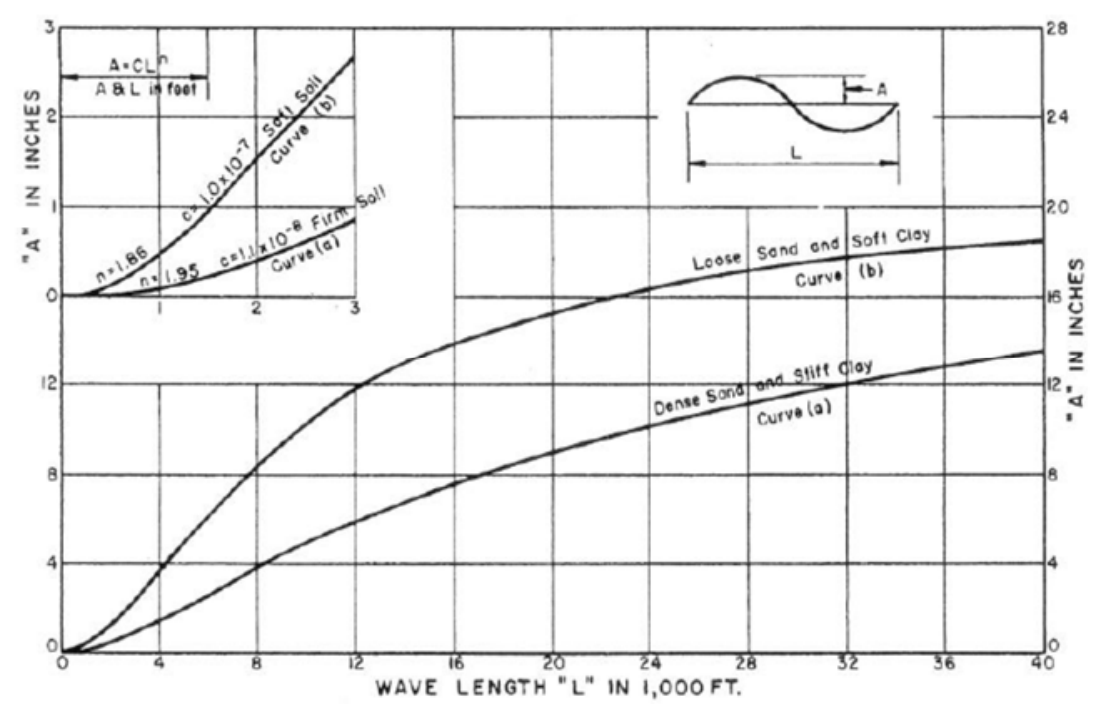

Fig. 3-110. Deformaciones de curvatura en planta (A) de una sección rectangular enterrada de túnel de metro sometida a la acción del sismo (Kuesel, 1969). 
Para el análisis de la deformación en planta, Kuesel establece un espectro de deformaciones transversales $A$ en función de la longitud de onda $L$ incidente (Fig. 3-110).

Adicionalmente, indica que excepto en suelos especialmente problemáticos, esta curvatura impuesta en planta arrojará valores de deformación, a nivel de la fibra longitudinal de la estructura, muy por debajo de un valor de $\varepsilon \leq 0.1 \%$, considerando que este valor queda completamente dentro del rango elástico de los materiales, concluyendo que, por lo tanto, este efecto de curvatura en planta tiene consecuencias efectivas muy poco relevantes sobre la estructura.

\subsection{Deformación de distorsión en alzado}

Para el análisis de las deformaciones distorsión en alzado de la sección transversal, es decir de deformación transversal o de racking, Kuesel establece que la máxima distorsión angular $\gamma=y_{s} / h$, de la faja de terreno comprendida entre la cara inferior del túnel y la cara superior del mismo(Fig. 3-111), responde a la expresión (Ec. 3-163). En esta expresión $y_{s}$ es la deformación horizontal máxima del terreno, relativa entre el nivel de la cara superior de la estructura, y la cara inferior de la misma, $h$ es la altura entre estas dos caras, $H$ es la altura total de suelo comprendida entre la roca subyacente y la superficie, y $V$ la velocidad de propagación de las ondas de cortante en el suelo.

$$
\frac{y_{s}}{h}=\frac{5}{2} \cdot\left(\frac{H}{V^{2}}\right)
$$

Kuesel es el primero en denominar a esta deformación como "racking”, que es la denominación que mantendrá hasta la actualidad.

Para la obtención de la expresión (Ec. 3-163), Kuesel realizó un estudio con un modelo numérico de una columna de terreno, simulada mediante una viga vertical a cortante, con constantes estáticas variables linealmente con la profundidad. Este modelo se solicitó en la base con una historia de aceleraciones obtenida a partir de la modificación del registro del terremoto de El Centro (1940). El registro original se amplificó para alcanzar un $P G A=0.33 \cdot g$ en la base del modelo, y una aceleración máxima en superficie de $0.5 \cdot g$.

De la historia de deformaciones angulares máximas obtenidas en el terreno, Kuesel reporta las correspondientes a algunos de los terrenos más habituales encontrados 
en la bahía de San Francisco, como son los suelos granulares compactos, arenas limosas, arcillas medias, blandas, y las habituales en la zona de estudio (Fig. 3-111).

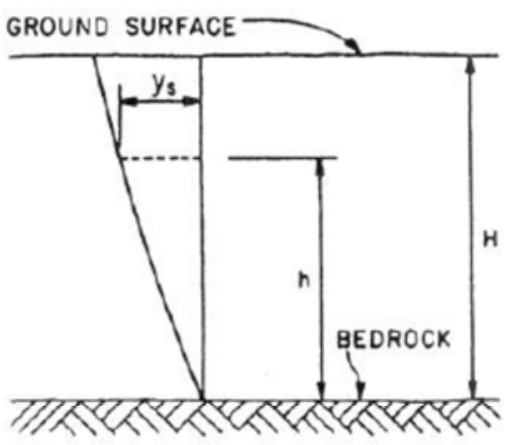

$$
\frac{y_{s}}{h}=\frac{5}{2}\left(\frac{H}{v^{2}}\right)
$$

$H=$ DEPTH OF SOIL ABOVE BEDROCK - FT

$V$ = VELOCITY OF PROPAGATION OF SHEAR WAVE IN SOIL - FT.ISEC.

NOTE: $V \cong 1 / 2$ TO $\frac{1}{3}$ SEISMIC VELOCITY FOR SMALL AMPLITUDES

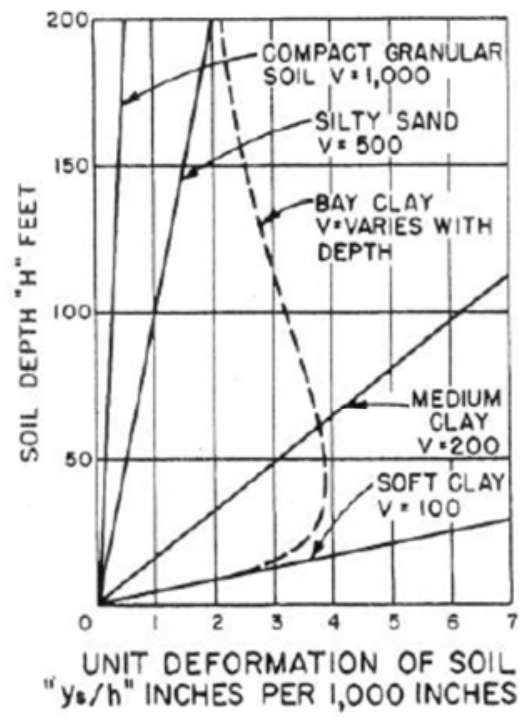

FIG. 3.-SHEARING DISTORTION OF GROUND

Fig. 3-111. Deformación de distorsión en alzado del terreno sometido al sismo (Kuesel, 1969).

Para las condiciones de terreno analizadas, en las que hace un estudio paramétrico variando tanto la densidad del terreno $\rho$, como la velocidad de propagación $V_{s}$, Kuesel ajusta empíricamente la fórmula anterior (Ec. 3-163) a los resultados obtenidos.

Adicionalmente, Kuesel estudia cual será la distribución de deformaciones, en la propia estructura tipo marco, correspondiente a la deformación angular impuesta tanto en fase elástica, como en fase plástica cuando alguna de las secciones próxima a las esquinas del marco haya experimentado la formación de una rótula plástica (Fig. 3-112).

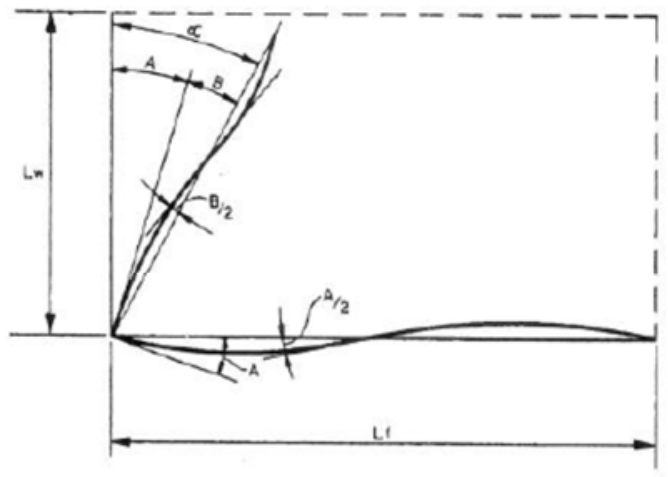

FIG. 11.-ELASTIC DEFORMATION

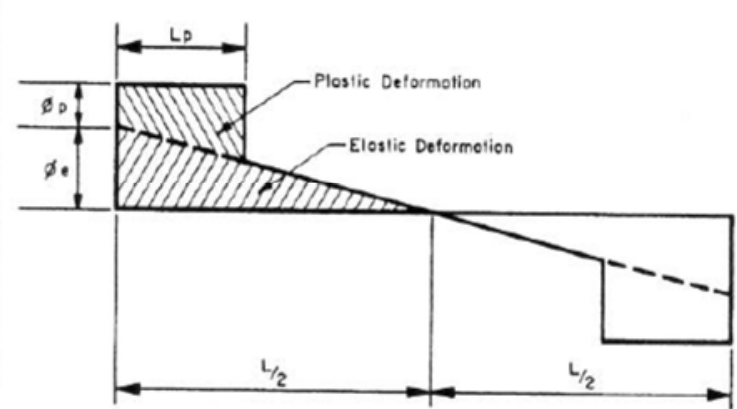

FIG. 14.-PLASTIC DEFORMATION

Fig. 3-112. (izda.) Deformación elástica de $1 / 4$ de marco. (dcha.) Distribución de deformaciones elásticas y plásticas en un elemento tipo losa o muro del túnel. (Kuesel, 1969). 


\subsubsection{Método de St. John y Zahrah}

En el extenso artículo de St. John y Zahrah (St John \& Zahrah, 1987), en el que describen con detalle el estado del arte del diseño sismorresistente de túneles en el momento, estos dos autores plantean una metodología de análisis muy similar a la ya desarrollada por Kuesel (Kuesel, 1969). Aunque no citan explícitamente el trabajo realizado por este autor, sí lo hacen con respecto a los criterios de diseño empleados en el metro de San Francisco, y por lo tanto parece que parte del método propuesto por estos dos autores se basa en el trabajo de Kuesel.

\subsection{Deformación de curvatura en planta}

Tras realizar un resumen de cómo afectan los diferentes trenes de ondas a la deformación en campo libre, St. John y Zahrah exponen que la obra subterránea deberá ser capaz de adaptarse a las deformaciones impuestas por los 3 trenes de ondas que pueden solicitarla, ondas volumétricas $P$, ondas volumétricas $S$, y ondas superficiales de Rayleigh. Puesto que las deformaciones del túnel dependen de la orientación del mismo con respecto a la dirección de propagación del tren de ondas (Fig. 3-113), St. John y Zahrah proporcionan un resumen de las deformaciones correspondientes para cada tipo de onda (Tabla 3-7).

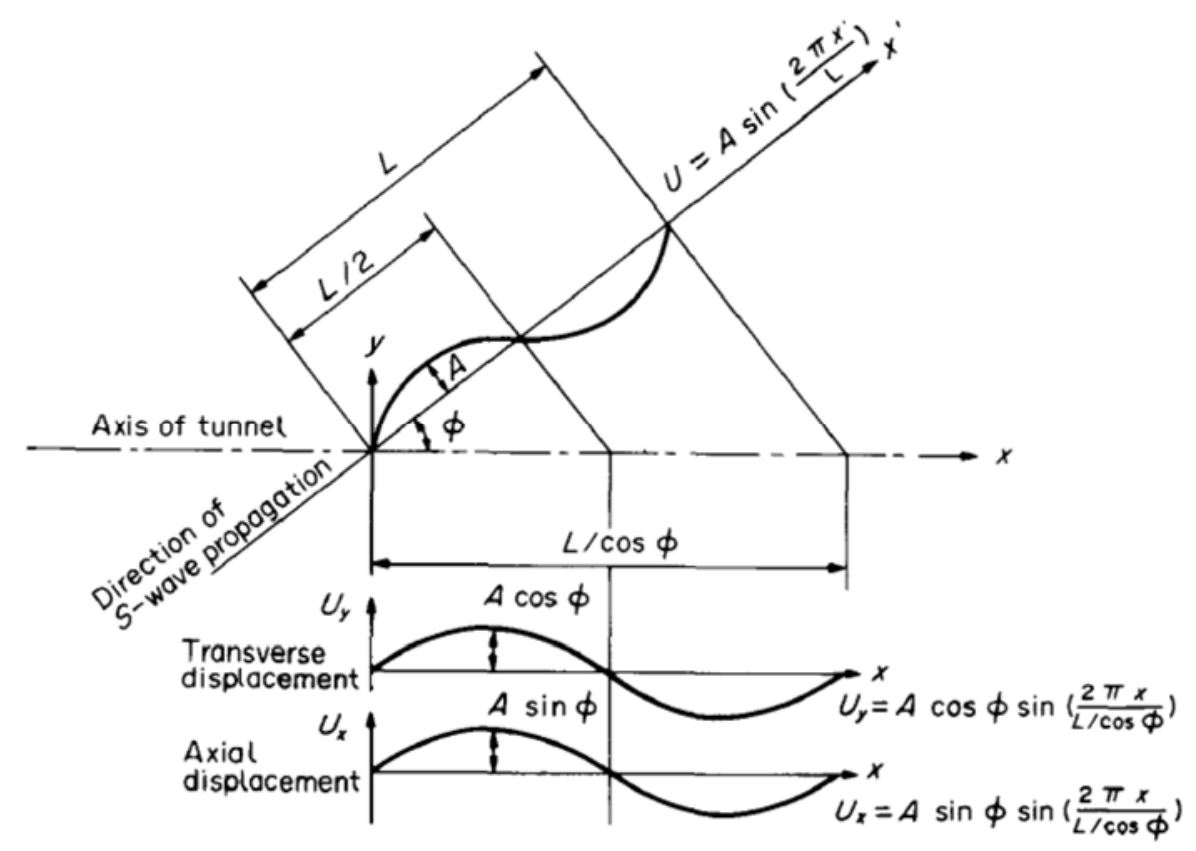

Fig. 3-113. Deformación en planta de un túnel frente al paso de un tren de ondas oblícuo (St John \& Zahrah, 1987). 


\begin{tabular}{|c|c|c|c|c|c|}
\hline \multicolumn{2}{|c|}{ Tipo de Onda } & $\begin{array}{l}\text { Deformación } \\
\text { Longitudinal }\end{array}$ & $\begin{array}{l}\text { Deformación } \\
\text { Normal }\end{array}$ & $\begin{array}{l}\text { Deformación de } \\
\text { Cortante }\end{array}$ & Curvatura \\
\hline \multicolumn{2}{|c|}{ Onda $P$} & $\varepsilon_{l}=\frac{V_{p}}{c_{p}} \cdot \cos ^{2} \phi$ & $\varepsilon_{n}=\frac{V_{p}}{c_{p}} \cdot \sin ^{2} \phi$ & $\gamma=\frac{V_{p}}{c_{p}} \cdot \sin \phi \cdot \cos \phi$ & $\frac{1}{\rho}=\frac{a_{p}}{c_{p}^{2}} \sin \phi \cdot \cos ^{2} \phi$ \\
\hline \multicolumn{2}{|c|}{ Onda S } & $\varepsilon_{l}=\frac{V_{s}}{c_{s}} \sin \phi \cdot \cos \phi$ & $\varepsilon_{n}=\frac{V_{s}}{c_{s}} \sin \phi \cdot \cos \phi$ & $\gamma=\frac{V_{s}}{c_{S}} \cdot \cos ^{2} \phi$ & $K=\frac{a_{s}}{c_{s}^{2}} \cdot \cos ^{3} \phi$ \\
\hline \multirow{2}{*}{$\begin{array}{l}\text { Onda de } \\
\text { Rayleigh }\end{array}$} & $\begin{array}{c}\text { Componente } \\
\text { de } \\
\text { Compresión }\end{array}$ & $\varepsilon_{l}=\frac{V_{R P}}{c_{R}} \cdot \cos ^{2} \phi$ & $\varepsilon_{n}=\frac{V_{R P}}{c_{R}} \cdot \sin ^{2} \phi$ & $\gamma=\frac{V_{R P}}{c_{R}} \cdot \sin \phi \cdot \cos \phi$ & $K=\frac{a_{R P}}{c_{R}{ }^{2}} \sin \phi \cdot \cos ^{2} \phi$ \\
\hline & $\begin{array}{l}\text { Componente } \\
\text { de Cortante }\end{array}$ & & $\varepsilon_{n}=\frac{V_{R S}}{c_{R}} \sin \phi$ & $\gamma=\frac{V_{R S}}{c_{R}} \cdot \cos \phi$ & $K=\frac{a_{R S}}{c_{R}{ }^{2}} \cdot \cos ^{2} \phi$ \\
\hline
\end{tabular}

Tabla 3-7. Deformaciones y curvaturas correspondientes a paso de ondas volumétricas y superficiales. (St John \& Zahrah, 1987).

Asumiendo que el túnel se comporta longitudinalmente como una viga a flexión, St. John y Zahrah recomiendan que se aplique la curvatura máxima (Ec. 3-165) producida por la deformación del tren de ondas a la estructura (Ec. 3-164), que se calculen los momentos flectores (Ec. 3-166) y esfuerzos cortantes (Ec. 3-167) correspondientes, y que se dote a la estructura de resistencia en consecuencia con estos esfuerzos.

$$
\begin{gathered}
u_{x}=A \cdot \sin (\phi) \cdot \sin \left(\frac{2 \pi x}{\frac{L}{\cos (\phi)}}\right) \\
\frac{1}{\rho}=\frac{\partial^{2} u_{y}}{\partial x^{2}}=-\left(\frac{2 \pi}{L}\right)^{2} \cdot \cos ^{3}(\phi) \cdot A \cdot \sin \left(\frac{2 \pi x}{\frac{L}{\cos (\phi)}}\right) \\
M=\frac{E I}{\rho}=-\left(\frac{2 \pi}{L}\right)^{2} \cdot \cos ^{3}(\phi) \cdot E I A \cdot \sin \left(\frac{\frac{2 \pi x}{\frac{L}{\cos (\phi)}}}{\partial x}\right) \\
V=\frac{\partial M}{\partial x}=\left(\frac{2 \pi}{L}\right)^{2} \cdot \cos ^{4}(\phi) \cdot E I A \cdot \cos \left(\frac{2 \pi x}{\frac{L}{\cos (\phi)}}\right)
\end{gathered}
$$

\subsection{Deformación de distorsión en alzado}

En lo que se refiere a la deformación en alzado, es decir, a la distorsión del túnel, St. John y Zahrah se centran en estudiar la respuesta de un túnel circular, ya que esta 
geometría cuenta con numerosas soluciones analíticas, y proponen un estudio que, en líneas generales, es similar al desarrollado por Kuesel (Kuesel, 1969).

Sin embargo, a diferencia de lo indicado por Kuesel, y como primera contribución histórica hacia los métodos de interacción cinemática, hacen una distinción de comportamiento del túnel en función de cual sea la rigidez del mismo comparada con la del terreno. En base a los trabajos previos de Peck (Peck, 1969), y Hendron y Fernández (Hendron \& Fernández, 1983), centrados en el comportamiento de túneles bajo acciones estáticas en función de su rigidez, St. John y Zahrah emplean la ratio de flexibilidad $F$ (Ec. 3-168) para caracterizar la deformación de distorsión de un túnel bajo acción del sismo. Esta ratio de flexibilidad $F$ es una medida de la flexibilidad relativa entre túnel y suelo en la que $E$ es el módulo de Young, y $v$ el coeficiente de Poisson del suelo, $R$ el radio del túnel, $t$ el espesor de su pared, $E_{l}$ el módulo de Young, y $n$ el coeficiente de Poisson del túnel. Una interpretación más precisa de esta ratio de flexibilidad se proporciona en el apartado §3.7.4.1.1 de esta tesis.

$$
F=\frac{2 E\left(1-v_{l}^{2}\right) R^{3}}{E_{l}(1+v) t^{3}}
$$

En particular St. John y Zahrah afirman:

"Whether a liner will significantly interact with the medium depends upon the compressibility ratio and the flexibility ratio. Of these, the flexibility ratio $F$ is the more important because it is related to the ability of the liner to resist distortion." (St John \& Zahrah, 1987, p.173).

Sin embargo, consideran que la flexibilidad del túnel afectará a las deformaciones tan sólo en aquellos casos en los que el túnel sea muy rígido, considerando que para los caos flexibles la deformación del túnel será idéntica a la del terreno. En particular afirman:

"In that case, the liner conforms to the distortions imposed on it by the medium. If, on the other hand, the flexibility ratio is low, then the liner will resist the distortion of the medium. Whether there is a concentration of stress in the liner depends mainly on the relative elastic modulus of the liner and the medium.". "In general, it would be conservative to check that the liner is capable of withstanding the unrestrained distortion of the medium". (St John \& Zahrah, 1987, p.173).

"Most importantly, we expect the response to earthquake loading to be near enough pseudostatic and we expect ground/structure interaction effects to be relatively 
unimportant providing the ground support system is relatively flexible. In practice, the ground support is generally flexible and the conservative approach of assuming that the liner experiences the unrestrained deformation of the medium can be adopted.”. (St John \& Zahrah, 1987, p.174).

"If the flexibility ratio of a liner, as defined above, is low, then the liner is stiff compared to the medium and will resist the distortions imposed on it by the medium. Of course, it will be conservative to design the liner to withstand the unrestrained distortions of the medium. However, this approach may be unduly conservative for stiff liners, and the liner may become very difficult to design. In such cases, the ground/structure interaction is important and should be considered in the design.”. (St John \& Zahrah, 1987, p.175).

Por lo tanto, aunque parecen reconocer la importancia de la flexibilidad o rigidez de la estructura enterrada, St. John y Zahrah no aplican el concepto a todo el rango de flexibilidades, y por lo tanto su método puede clasificarse a caballo entre los de deformaciones de campo libre impuestas, y los de interacción cinemática. De esta manera hacen una distinción entre estructuras flexibles que se adaptan a la deformación (Structures that conform to ground motion) y estructuras rígidas (Structures that resist ground motion).

Para las estructuras flexibles, St. John y Zahrah proponen una metodología de análisis idéntica a la de Kuesel, consistente en determinar el perfil de deformaciones de cortante del terreno frente a ondas de cortante que se propagan verticalmente (Fig. 3-114), mediante un análisis con un programa tipo SHAKE (Schnabel et al., 1972), e imponer a la estructura la diferencia de deformaciones horizontales entre las losas superior e inferior (Fig. 3-115).
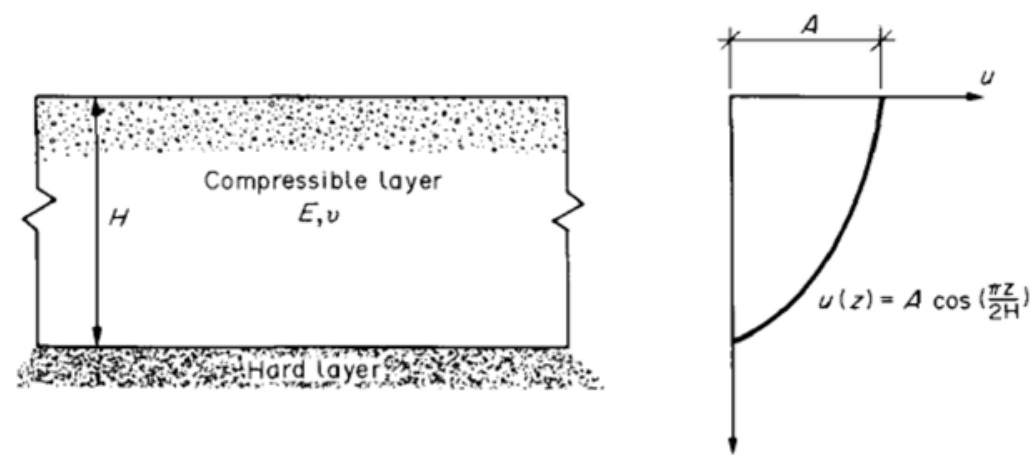

Fig. 3-114. Perfil de deformación transversal del terreno en campo libre frente a ondas que se propagan verticalmente (St John \& Zahrah, 1987). 


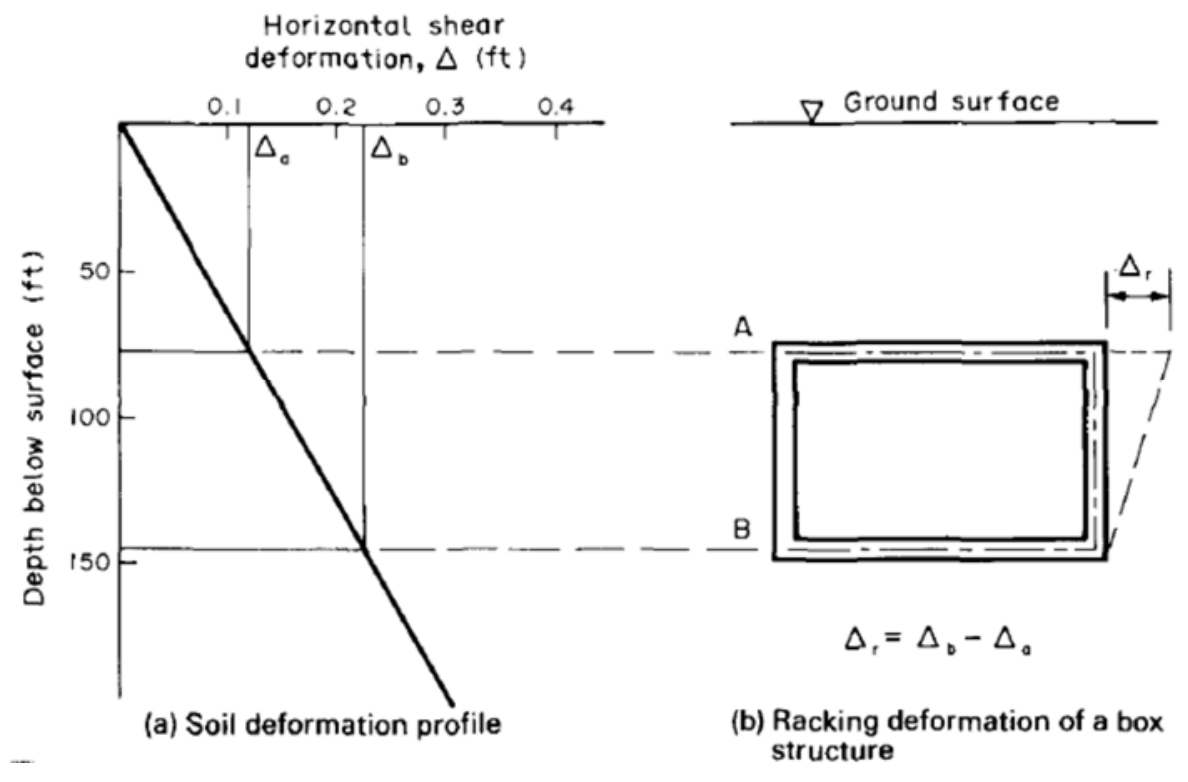

Fig. 3-115. Vista en Sección de la deformación transversal de distorsión durante el paso de ondas $\boldsymbol{S}_{\boldsymbol{H}}$ propagándose en dirección vertical (St John \& Zahrah, 1987).

Conscientes de que esta deformación impuesta puede ser excesivamente conservadora para el caso de estructuras muy rígidas (p.ej. estructuras con muros de cortante), para estos casos proponen realizar un análisis tipo marco, en el que se estime la rigidez de la cimentación, para la cual proponen la expresión del módulo de balasto (Ec. 3-169), donde el término B viene dado por la expresión (Ec. 3-170).

$$
\begin{gathered}
K_{v}=\frac{2 \pi B}{L} \\
B=\frac{G}{(1-v)}
\end{gathered}
$$

\subsubsection{Método de Ortigosa y Musante}

Ortigosa y Musante (Ortigosa \& Musante, 1991), proponen un método empleado en el proyecto del Metro de Santiago de Chile, basado parcialmente en el de deformaciones en campo libre desarrollado por Kuesel (Kuesel, 1969), y en el de empuje dinámico de Wood (Wood, 1973). 


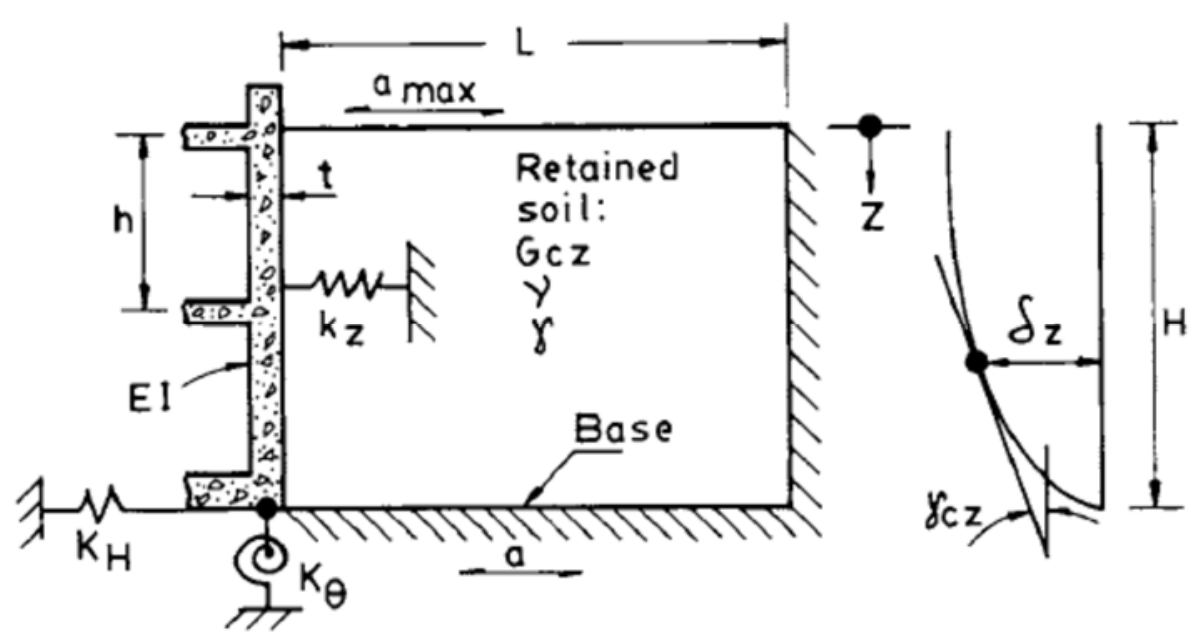

Fig. 3-116. Modelo de análisis de interacción cinemática.(Ortigosa \& Musante, 1991).

En base al esquema presentado en la (Fig. 3-116), que representa una estructura de contención flexible con rigidez EI con base flexible de rigidez $K_{\theta}$, Ortigosa y Musante indican que la solicitación, en forma de presiones ejercidas por el terreno, sobre el muro de contención de la obra subterránea puede asimilarse a la acción que ejercen unos muelles tipo Winkler de contacto con el terreno que en su extremo no vinculado a la estructura se desplazan una magnitud igual al desplazamiento en campo libre $\delta_{\mathrm{z}}$.

De manera alternativa, la acción del terreno puede considerarse directamente como la fuerza que ejercen estos muelles, que se habrán deformado cada uno de ellos una magnitud $\delta_{z}-\delta_{s z}$, dónde $\delta_{z}$ es el desplazamiento de campo libre a la cota $z$, y $\delta_{s z}$ el desplazamiento de la estructura a cota $z$, tal y como se indica en la (Ec. 3-171). Si la estructura es muy rígida ( $E I$ y $K_{\theta}$, muy grandes), el desplazamiento de la estructura $\delta_{s z}$ será nulo.

$$
\sigma_{s}=k_{z}\left(\delta_{z}-\delta_{s z}\right)
$$

Por otra parte, deben satisfacerse las condiciones (Ec. 3-172) y (Ec. 3-173), que corresponden a que la fuerza horizontal ejercida por cada muelle no puede ser mayor que el empuje pasivo del terreno, y a que el desplazamiento del terreno no puede atravesar al propio muro.

$$
\begin{gathered}
\sigma_{s}+\sigma_{h} \leq \sigma_{p} \\
\delta_{s z} \leq \delta_{z}
\end{gathered}
$$


Para el cálculo de la rigidez de los muelles, Ortigosa y Musante proponen una expresión (Ec. 3-174) que tiene en cuenta la plastificación a cortante del terreno (Fig. 3-117).

$$
\begin{gathered}
k_{z}=\frac{2 G_{c z}}{1-v} \frac{1}{\sqrt{H^{2}-z^{2}}} \\
G_{c z}=70 \cdot K_{2} \sqrt{\sigma_{c}}
\end{gathered}
$$

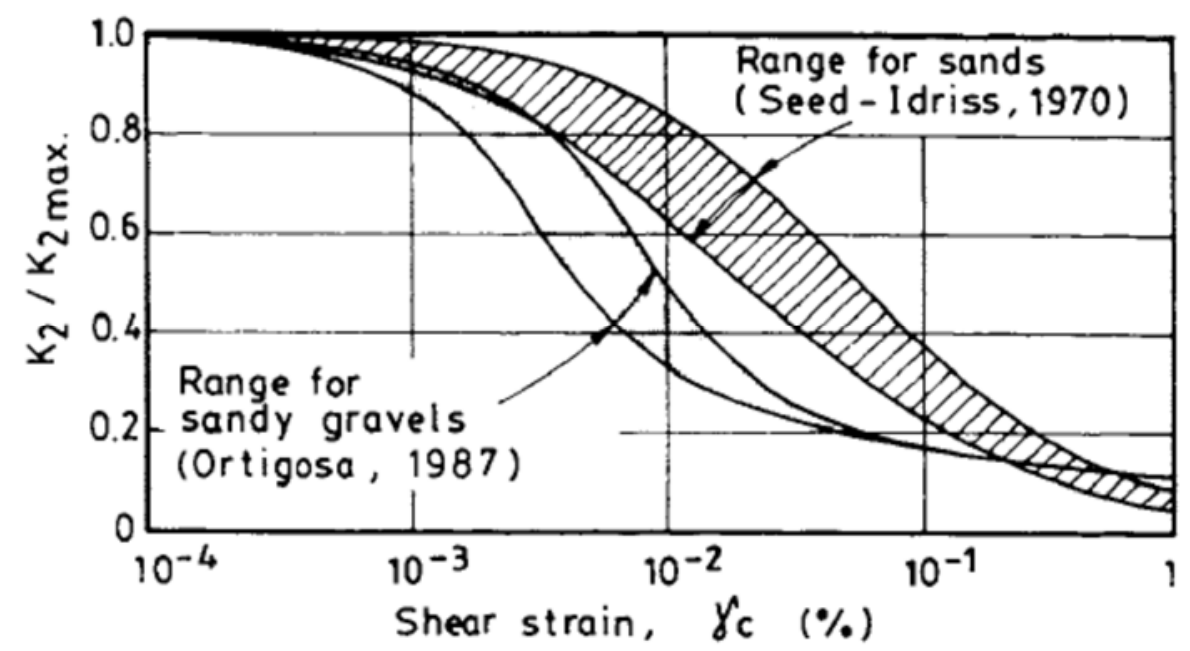

Fig. 3-117. Curva de reducción del módulo de cortante para gravas arenosas. (Ortigosa \& Musante, 1991).
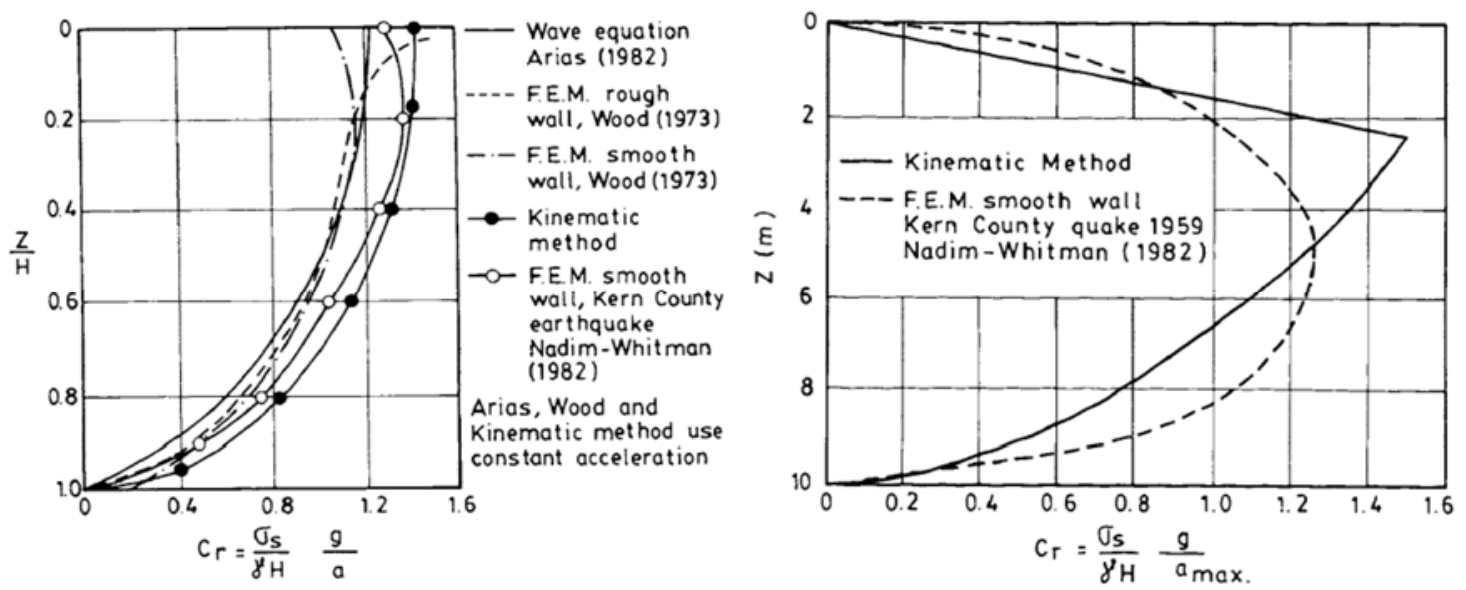

Fig. 3-118. Resultados del modelo de interacción. (izda.) Comportamiento lineal. (dcha.) Comportamiento no lineal. (Ortigosa \& Musante, 1991).

\subsubsection{Métodos de interacción cinemática}

Los métodos de análisis de interacción cinemática, aplicados a la deformación de racking (también denominada de deformación transversal, o de distorsión), son los métodos que se recoge en la normativa actual de EE.UU. para el análisis de 
deformaciones y de esfuerzos en estructuras enterradas, ya sean estas rectangulares o circulares, sometidas a la acción del sismo.

En particular, los documentos con carácter normativo, o recomendaciones con carácter cuasi-normativo que refieren esta metodología, y que se analizan en detalle en el apartado \$3.8.2 de esta tesis, son el Technical Manual for Design and Construction of Road Tunnels - Civil Elements de la FHWA (Hung, Monsees, Munfah, \& Wisniewski, 2009), el Seismic Retrofitting Manual for Highway Structures de la FHWA (Buckle et al., 2006; Power et al., 2004), los criterios Metro Rail Design Criteria del Metro de Los Angeles (LA Metro Authority, 2012), y los criterios The Alaskan Way Viaduct \& Seawall Replacement Program Seismic Design Criteria de Seattle (WSDOT, 2010). La metodología de interacción cinemática para la deformación de racking recogida en estos documentos presenta, esencialmente, la formulación del método según ha sido planteada por Wang (J. N. Wang, 1993), y que se describe en detalle en el apartado §3.7.4.1 de esta tesis.

El método de análisis de interacción cinemática asume, de manera similar a los métodos de deformaciones de campo libre impuestas discutidos en el apartado §3.7.3, que los efectos dinámicos inerciales de la propia estructura durante el evento sísmico, son poco significativos con respecto a los efectos inerciales de la masa del terreno que rodea a la estructura subterránea, ya que la masa del terreno es mucho mayor que la de la propia estructura (J. N. Wang, 1993), (Penzien, 2000). De esta manera, se puede considerar que la estructura enterrada, durante la acción de un sismo, se adaptará a la deformación del terreno circundante cuando este se vea sometido al paso de las ondas de deformación originadas por el terremoto.

Sin embargo, a diferencia de los métodos de deformaciones de campo libre impuestas, el método de interacción cinemática para la deformación de racking no asume a priori que las deformaciones de distorsión de la estructura son iguales a las de distorsión del terreno en campo libre. Este método, por el contrario, considera que las deformaciones de la estructura pueden verse amplificadas o reducidas con respecto a las del campo libre en función de la interacción cinemática que existe entre la estructura y el terreno circundante. En particular en función de la relación entre la rigidez a la distorsión de la estructura subterránea y de la rigidez a la distorsión del terreno al que sustituye la estructura. 
A continuación se enuncian los fundamentos teóricos que subyacen en el método de interacción cinemática, según las formulaciones presentadas por los diversos autores que han contribuido a establecerlo (J. N. Wang, 1993), (Penzien, 2000), (Anderson et al., 2008).

\subsubsection{Método de Wang}

El método propuesto por Wang (J. N. Wang, 1993), toma como base las consideraciones realizadas por Kuesel (Kuesel, 1969) al plantear su metodología, esto es, el terreno se deforma ante el paso de las ondas sísmicas de deformación y la estructura enterrada debe adaptarse a ellas. Tras hacer un resumen del estado del arte en lo que se refiere a las deformaciones longitudinales del túnel, Wang se centra en el estudio de la deformación transversal de la sección del túnel (Fig. 3-119) frente al paso de ondas de cortante que se propagan verticalmente, en las deformaciones que denomina de ovalización (ovaling) para geometrías circulares, y distorsión (racking) para geometrías rectangulares.
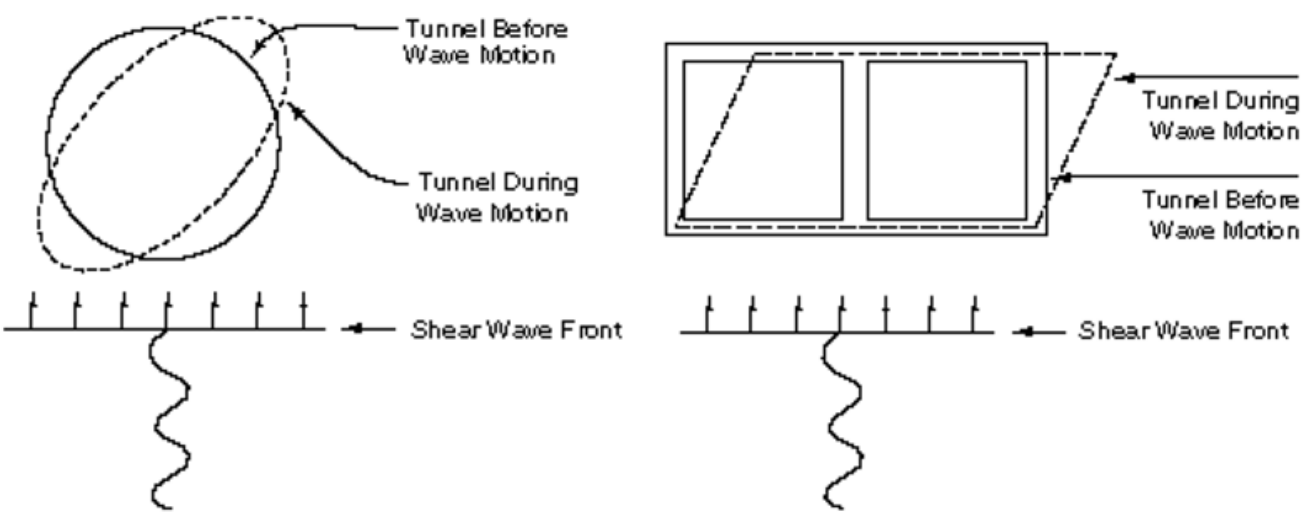

Fig. 3-119. (Izda.) Deformación de distorsión (ovaling) en forma de óvalo de una sección circular.

(Dcha.) Deformación de distorsión (racking) de una sección rectangular (J. N. Wang, 1993).

\subsection{Formulación para túneles circulares}

En su tesis doctoral, Wang planeta la incoherencia en la que parece incurrirse cuando se considera que un túnel de sección circular debe deformarse de igual manera que el terreno en campo libre, cuando se somete al mismo a un estado tensional de cortante puro.

Partiendo de las soluciones analíticas existentes (Jaeger et al., 2007), (Pollard \& Fletcher, 2005) para obtener la deformación diametral que correspondería a una porción circular en una rebanada de suelo en régimen de deformación plana, considerando por un 
lado que esta porción circular tiene suelo (Ec. 3-176), y por otro lado que está hueca (Ec. 3-177), Wang realiza la siguiente comparación, en la que $D$ es el diámetro del túnel circular, $\Delta D$ es la variación del diámetro del túnel, $\gamma_{\max }$ la máxima deformación angular del medio circundante en campo libre sometido a un estado de cortante puro en una zona suficientemente alejada de la oquedad circular, y $v$ el coeficiente de Poisson del suelo:

$$
\begin{gathered}
\frac{\Delta D}{D}= \pm \frac{\gamma_{\max }}{2} \\
\frac{\Delta D}{D}= \pm 2 \cdot \gamma_{\max } \cdot(1-v)
\end{gathered}
$$
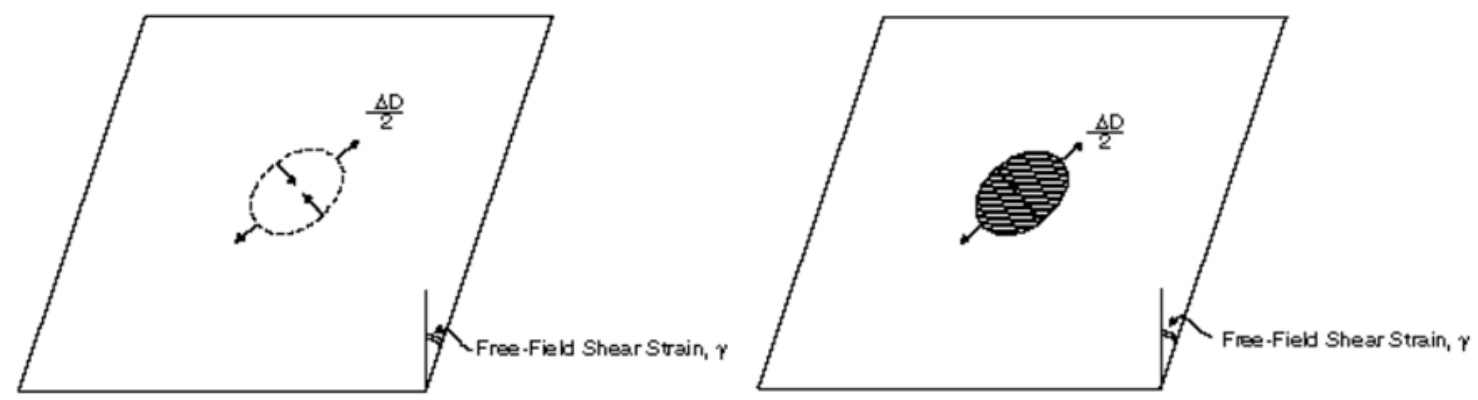

Fig. 3-120. Esquema de deformación diametral $\Delta D$ para un suelo sometido a cortante puro. (Izda.) Si no se considera el suelo perforado por el túnel circular. (Dcha.) Considerando la perforación del túnel circular. (J. N. Wang, 1993).

Wang constata que la diferencia de deformaciones es muy notable, siendo la deformación al considerar la oquedad del túnel entre 2 y 2.8 veces mayor que la deformación correspondiente a no considerar la oquedad, en función del valor del coeficiente de Poisson, y postula las siguientes hipótesis:

- La expresión (Ec. 3-176) es una buena aproximación en el caso en el que la rigidez de la estructura del túnel sea similar a la del terreno que sustituye.

- La expresión (Ec. 3-177) es una buena aproximación en el caso en el que la rigidez de la estructura sea mucho más pequeña que la del terreno que sustituye.

- Para otros casos de rigidez intermedios entre los dos anteriores, o para casos en los que la rigidez de la estructura del túnel sea mucho mayor que la rigidez del terreno que sustituye, las expresiones (Ec. 3-176) y (Ec. 3-177) pueden no ser adecuadas. 
A partir de estas hipótesis, y basándose en el coeficiente de flexibilidad $F$ definido por Peck (Ec. 3-178) (Peck, 1969), Wang establece el coeficiente $K_{1}$ (Ec. 3-179) de respuesta de la estructura del túnel circular, a partir del cual se determina la deformación diametral de la estructura (Ec. 3-180). En estas expresiones, $F$ es el coeficiente de flexibilidad suelo-estructura, comparación de la flexibilidad a la distorsión de la estructura y del medio al que sustituye; $E_{m}$ y $v_{m}$ el módulo de Young y coeficiente de Poisson del medio, $E_{l}$ y $\eta_{l}$ el módulo de Young de la estructura circular, $I$ la inercia a flexión de la sección de la pared de la estructura circular, $R$ el radio del túnel, $K_{1}$ el coeficiente de respuesta de la estructura, $D$ el diámetro del túnel, $\Delta D$ la variación del mismo, y $\gamma_{\max }$ la máxima deformación angular del medio en campo libre.

$$
\begin{aligned}
& F=\frac{E_{m} \cdot\left(1-v_{l}^{2}\right) \cdot R^{3}}{6 \cdot E_{l} \cdot I \cdot\left(1+v_{m}\right)} \\
& K_{1}=\frac{12 \cdot\left(1-v_{m}\right)}{2 \cdot F+5-6 \cdot v_{m}} \\
& \frac{\Delta D}{D}= \pm \frac{1}{3} \cdot K_{1} \cdot F \cdot \gamma_{\max }
\end{aligned}
$$

Las siguientes figuras (Fig. 3-121) muestran el valor del coeficiente de respuesta $K_{1}$ obtenido por Wang para valores del coeficiente de flexibilidad $F$ entre 0 y 100 , y para diferentes valores del coeficiente de Poisson $v$.
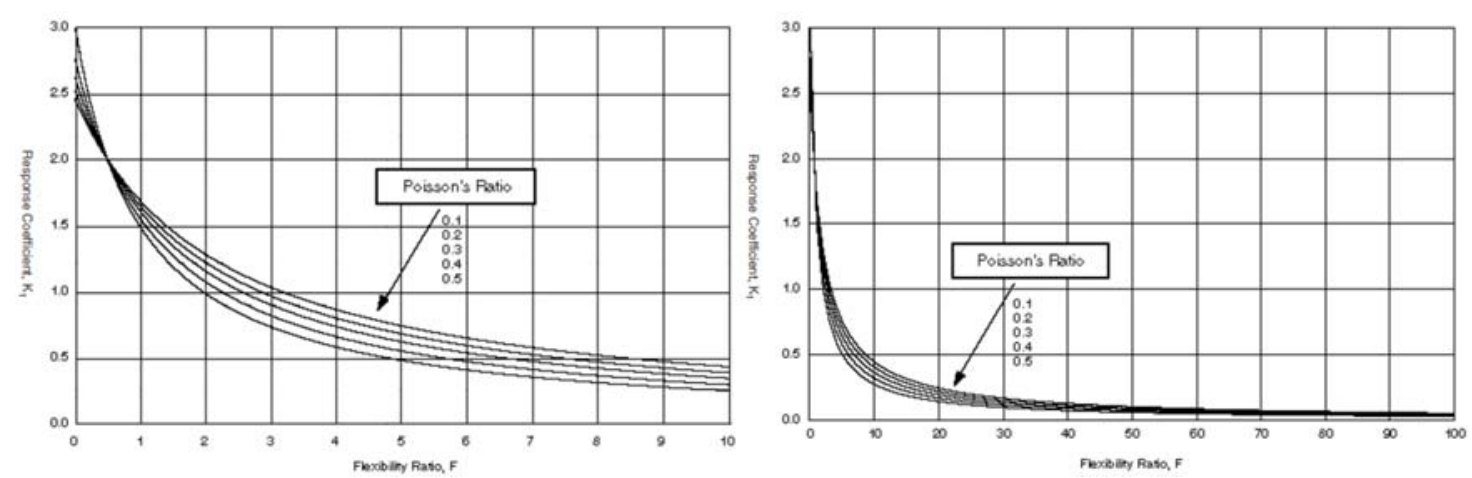

Fig. 3-121. Coeficiente de respuesta $K_{1}$ en función del coeficiente de flexibilidad F. (Izda.) Valores de $K_{1}$ para valores $0 \leq F \leq 10$. (Dcha.) Valores de $K_{1}$ para valores $0 \leq F \leq 100$ (Wang 1993).

Para hacer el resultado más intuitivo y fácilmente interpretable, dividiendo la expresión (Ec. 3-180) entre la expresión (Ec. 3-176), se obtiene el coeficiente $R$ (Ec. 
3-181) de amplificación de la deformación de distorsión en la estructura $n$ con respecto a la deformación de distorsión de campo libre Yff, es decir:

$$
R=\frac{\gamma_{l}}{\gamma_{f f}}=\frac{2}{3} \cdot K_{1} \cdot F
$$

La siguiente figura (Fig. 3-122) es el resumen de la expresión (Ec. 3-181) en la que se expresa la amplificación de la deformación diametral de la estructura del túnel circular como fracción de la que le correspondería si este se deformara con la deformación angular de campo libre $\left(\Delta D / D / \gamma_{\max }\right)$, en función del coeficiente de flexibilidad $F$, es decir, en función de la flexibilidad relativa de distorsión entre la estructura del túnel y la del terreno al que sustituye, o de manera recíproca, en función de la rigidez relativa de distorsión entre el suelo sustituido y la rigidez de la estructura del túnel.

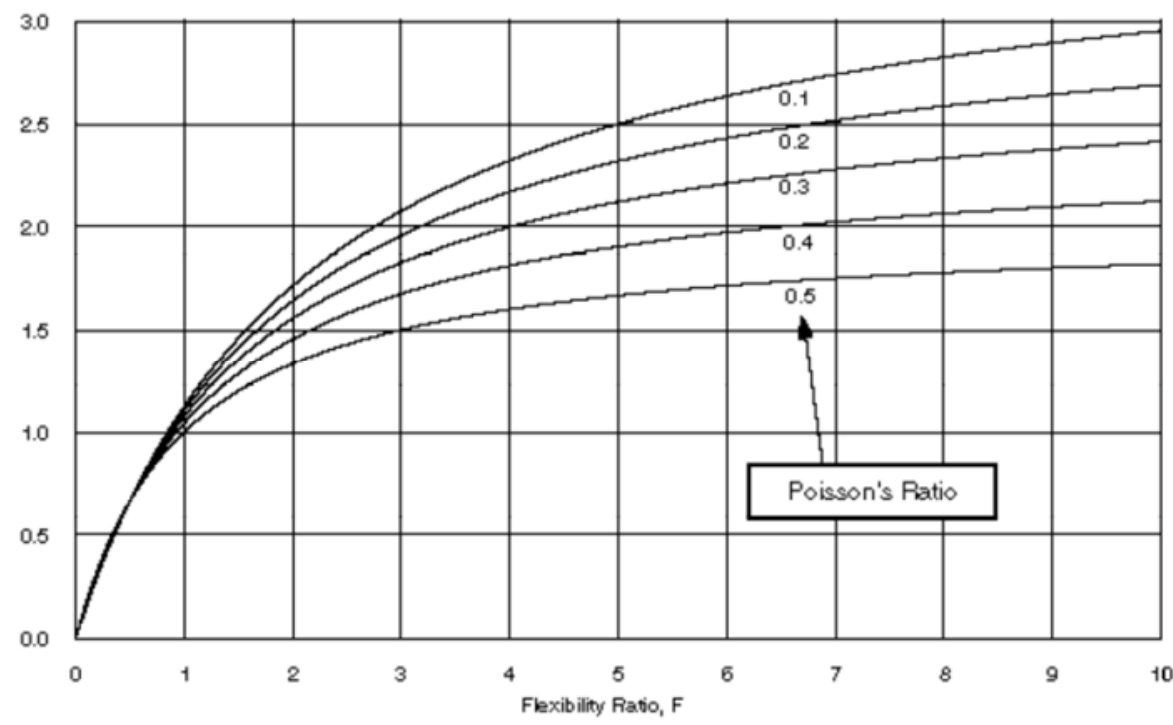

Fig. 3-122. Amplificación de la deformación de distorsión $\eta / \gamma_{f f}$ de una sección circular en función del coeficiente de flexibilidad $F$ y del coeficiente de Poisson del suelo. (Wang 1993).

Como puede apreciarse en la figura anterior, la formulación propuesta por Wang responde adecuadamente a las hipótesis iniciales en las que fundamentó su estudio:

- Para estructuras con una rigidez a la distorsión similar a la del suelo al que sustituyen $(F \approx 1)$, el túnel se deforma de manera muy similar a como se deformaría si la misma porción de oquedad circular estuviera ocupada por suelo $\left(R=n / \gamma_{f f} \approx 1\right)$.

- Para estructuras con una rigidez a la distorsión muy pequeña en comparación a la del suelo al que sustituyen $(F>10)$, el túnel se deforma 
de manera muy similar a como se deformaría si no existiera ningún tipo de estructura, y tan sólo existiera el hueco vacío del terreno $\left(2 \leq n / \gamma_{f f} \leq 3\right)$. Este resultado es coherente con los valores proporcionados por las expresión (Ec. 3-177), correspondiente a una cavidad hueca sin estructura, para diferentes valores del coeficiente de Poisson, a los que se acercan de manera asintótica las curvas de la (Fig. 3-122).

- Para estructuras con una rigidez a la distorsión intermedia en comparación a la del suelo al que sustituyen $(1 \leq F \leq 10)$, las curvas de la (Fig. 3-122) proporcionan valores intermedios de la deformación entre el caso de estructura con misma rigidez que el suelo, y rigidez nula.

- Para estructuras con una rigidez a la distorsión mucho mayor que la del terreno al que sustituyen $(F<1)$, las curvas de la (Fig. 3-122) proporcionan valores de la deformación inferiores a los del terreno. En particular, para el caso de $F=0$ (estructura infinitamente rígida), la deformación de la estructura resulta ser también $\gamma_{/} / f=0$.

\subsection{Formulación para túneles rectangulares}

De manera análoga al caso de secciones circulares, Wang conjetura que no hay motivo para pensar que la deformación de distorsión de la estructura será igual a la deformación de distorsión de campo libre cuando las rigideces de la estructura y del suelo al que sustituye sean diferentes.

En particular, Wang postula que la metodología basada en el desplazamiento de campo libre es manifiestamente errónea, ya que, si se asume que una estructura mucho más rígida que el terreno se deforma igual que el campo libre, se estará incurriendo en un diseño excesivamente conservador, ya que análogamente al caso de túneles circulares, resulta esperable que esta estructura se deforme menos que el terreno circundante.

Puesto que no existe una solución analítica para el problema de una sección rectangular en un medio elástico sometido a cortante puro con el que verificar su hipótesis, Wang recurre a un estudio paramétrico de modelos numéricos de elementos finitos elásticos.

De manera similar al caso de secciones circulares, Wang evalúa los resultados de deformaciones angulares de distorsión de la estructura $\gamma_{s}$ con respecto a los resultados de 
deformaciones angulares del suelo en campo libre $\gamma_{f f}$, siendo la relación entre estas dos deformaciones el denominado coeficiente de racking $R$ (Ec. 3-182).

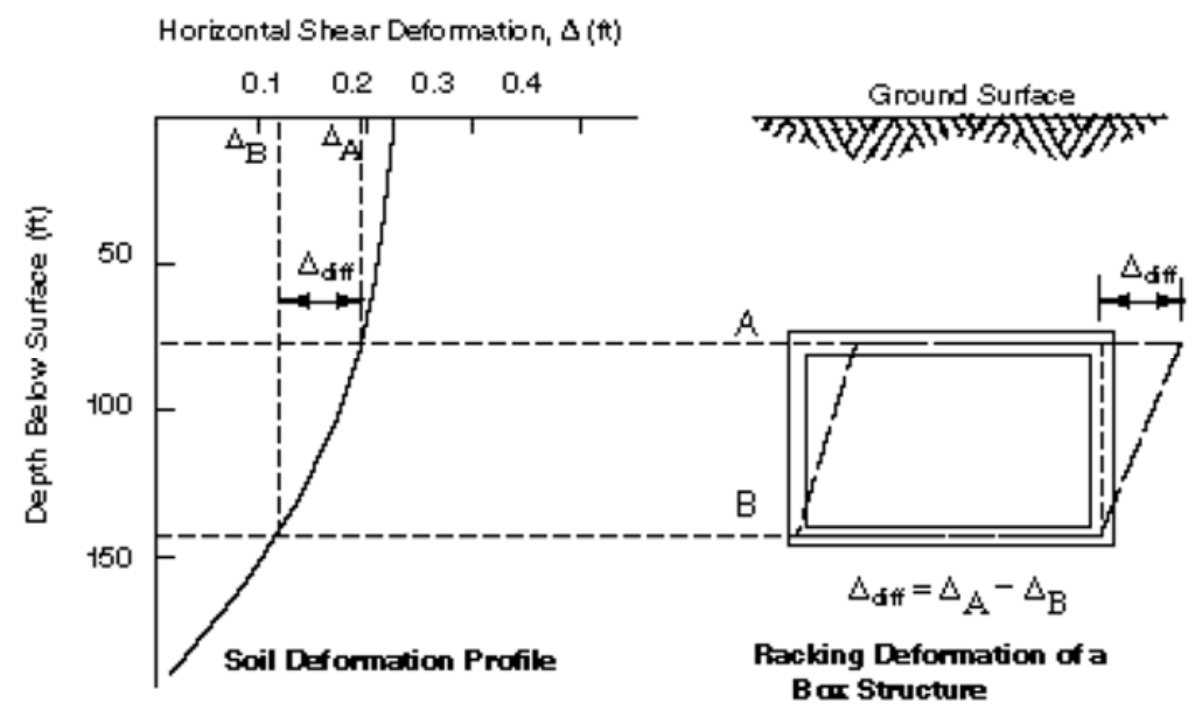

Fig. 3-123. (Ida.) Perfil de deformación del terreno en campo libre. (Dcha.) Deformación de distorsión o de la estructura asumiendo que la deformación es la misma que la del campo libre (J. N. Wang, 1993).

$$
R=\frac{\gamma_{s}}{\gamma_{f f}}
$$
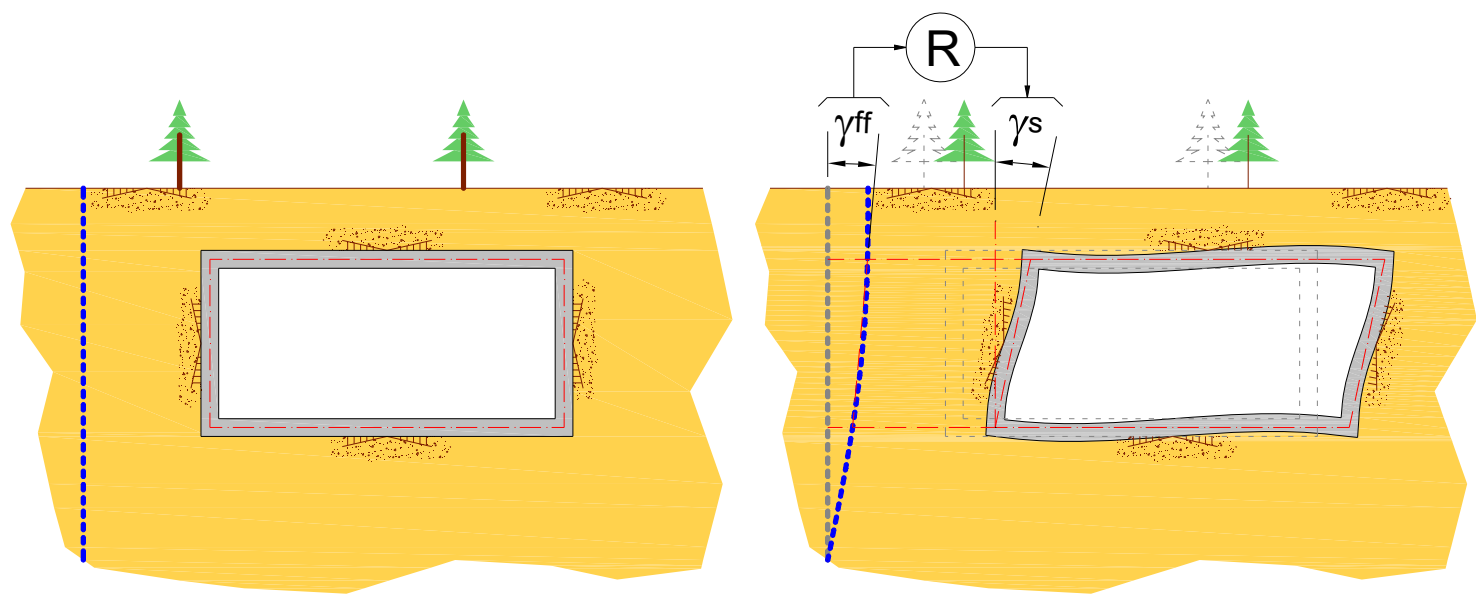

Fig. 3-124. Concepto de deformación de coeficiente de racking o distorsión $R$. (izda.) La estructura y el terreno no deformados en ausencia de acción sísmica. (dcha.) La estructura y el terreno bajo la acción sísmica en el instante de máxima deformación. भff es la máxima deformación angular del terreno en campo libre, $\gamma_{s}$ es la máxima deformación angular o de racking de la estructura.

Para obtener $R$, de manera similar al caso de secciones de túnel circulares, Wang establece como parámetro fundamental el coeficiente de flexibilidad $F$. El coeficiente de 
flexibilidad F (Ec. 3-183) se define como la relación entre rigideces a la deformación angular o distorsión del suelo al que sustituye el túnel $\left(K_{\text {suelo }}\right)$, y la rigidez de la estructura del túnel (Kestructura) (Fig. 3-125).
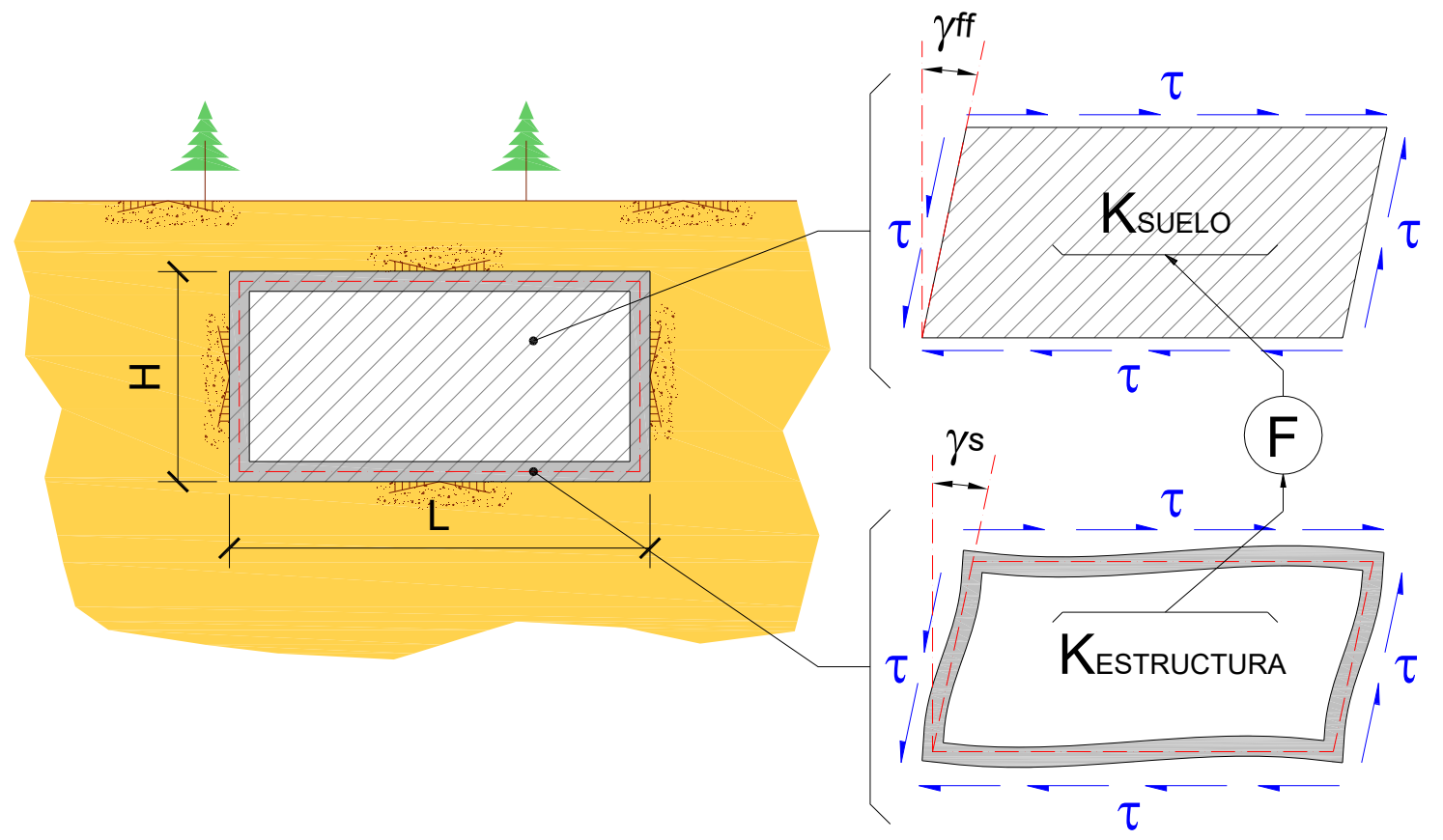

Fig. 3-125. Rigidez a la distorsión del suelo que sustituye la estructura $\left(K_{\text {suelo }}\right)$, y rigidez de la propia estructura ( $\left.K_{\text {estructura }}\right)$ frente a un estado de cortante puro.

$$
F=\frac{K_{\text {suelo }}}{K_{\text {estructura }}}
$$

La rigidez del suelo $K_{\text {suelo }}$ es la rigidez de un bloque elástico sometido a un estado de cortante puro (Ec. 3-184), donde $G$ es el módulo de cortante del suelo, y $L$ y $H$ las dimensiones horizontal y vertical del bloque de suelo sustituido túnel Fig. 3-125.

$$
K_{\text {suelo }}=\frac{G \cdot L}{H}
$$

La rigidez de la estructura $K_{\text {estructura }}$ es la rigidez del marco rectangular sometido a un estado de cortante puro. La configuración geométrica de la estructura subterránea puede presentar múltiples variantes, con columna intermedia, con pared intermedia, con losa intermedia, etc. La rigidez de cada una de estas configuraciones tendrá una expresión distinta, y Wang presenta tan sólo la correspondiente a un marco simple, es decir, un marco compuesto tan sólo por dos muros laterales y dos losas superior e inferior (Ec. 3-185). En esta expresión E corresponde al módulo de Young del material de la estructura, 
mientras que $I_{B}$ e $I_{W}$ corresponden a las inercias a flexión de las losas y muros respectivamente.

$$
K_{\text {estructura }}=\frac{1}{\frac{H^{2} \cdot L^{2}}{24 \cdot E \cdot I_{B}}+\frac{H}{4 \cdot E \cdot I_{W}} \cdot\left(\frac{H^{2}}{12}+\frac{L \cdot H}{8}\right)}
$$

Para configuraciones geométricas diferentes al marco simple, Wang indica que se puede obtener la rigidez a la distorsión realizando un modelo sencillo de barras con el desplazamiento restringido en la losa inferior, y estudiando la rigidez al desplazamiento lateral frente a una fuerza unitaria aplicada en la losa superior (Fig. 3-126).

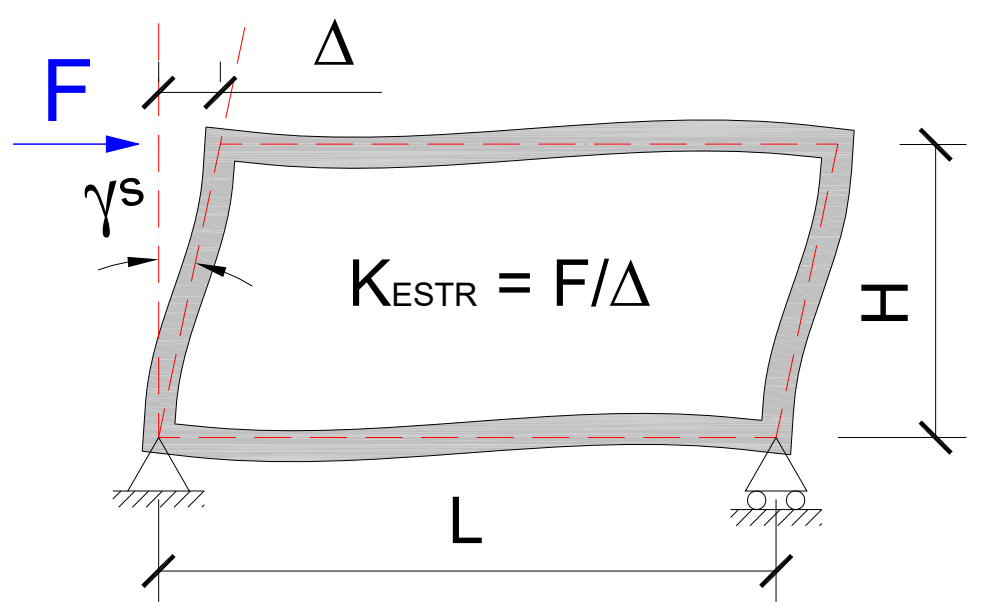

Fig. 3-126. Rigidez a la distorsión de la propia estructura (Kestructura) frente a una fuerza aplicada en la losa superior.

El estudio paramétrico desarrollado por Wang comprende modelos de elementos finitos (Fig. 3-128) con varias configuraciones geométricas (Fig. 3-127), varias propiedades mecánicas del suelo, y varias profundidades del túnel con respecto a la superficie; estos modelos se ordenan en función de su coeficiente de flexibilidad F. La Tabla 3-8 resume los principales parámetros tenidos en cuenta en el estudio de Wang, y los resultados del coeficiente de racking $R$ obtenidos. Cabe destacar que en sus análisis, Wang emplea valores del coeficiente de Poisson ventre 0.4 y 0.48 , pero no indica el valor que corresponde a cada modelo. 

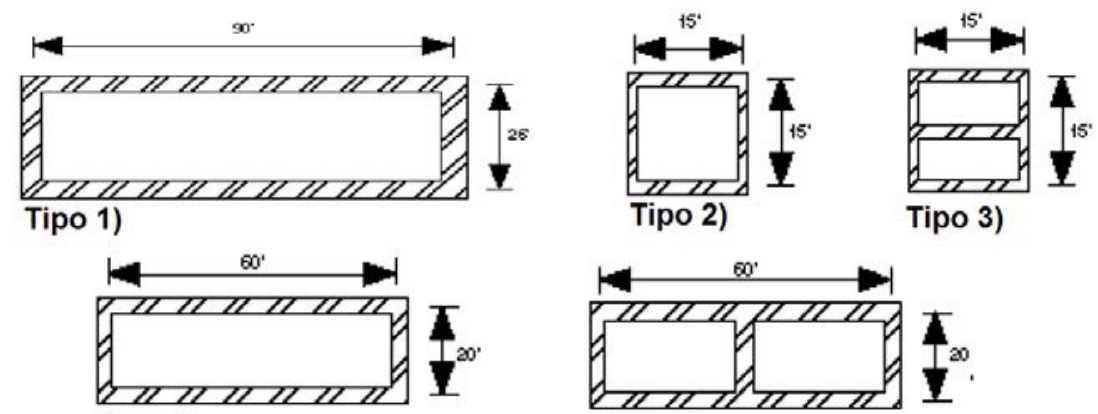

Tipo 4)

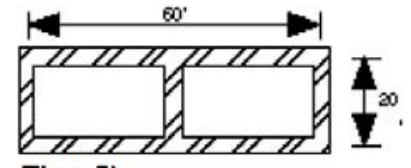

Tipo 5)

Fig. 3-127. Geometrías analizadas en el estudio numérico de elementos finitos (J. N. Wang, 1993).

\begin{tabular}{|c|c|c|c|c|}
\hline Modelo & $\begin{array}{c}\text { Tipo de } \\
\text { Estructura }\end{array}$ & Espesor de Tierras [m] & Coeficiente F & Coeficiente R \\
\hline 1 & 1 & 6.10 & 0.101 & 0.133 \\
\hline 2 & 1 & 6.10 & 0.271 & 0.323 \\
\hline 3 & 1 & 6.10 & 0.661 & 0.733 \\
\hline 4 & 1 & 6.10 & 1.313 & 0.957 \\
\hline 5 & 1 & 6.10 & 1.000 & 2.420 \\
\hline 6 & 1 & 6.10 & 3107.000 & 0.549 \\
\hline 7 & 2 & 4.57 & 0.463 & 0.565 \\
\hline 8 & 2 & 6.86 & 0.463 & 0.537 \\
\hline 9 & 2 & 4.57 & 0.463 & 0.562 \\
\hline 10 & 2 & 4.57 & 0.468 & 0.000 \\
\hline 11 & 2 & 4.57 & 0.000 & 1.550 \\
\hline 12 & 2 & 4.57 & 3.000 & 2.800 \\
\hline 13 & 2 & 4.57 & 3100.000 & 0.271 \\
\hline 14 & 2 & 4.57 & 0.187 & 0.789 \\
\hline 15 & 2 & 4.57 & 0.766 & 1.260 \\
\hline 16 & 2 & 4.57 & 1.840 & 0.900 \\
\hline 17 & 2 & 4.57 & 1.000 & 1.930 \\
\hline 18 & 2 & 4.57 & 6.600 & 0.930 \\
\hline 19 & 2 & 4.57 & 1.000 & 0.287 \\
\hline 20 & 3 & 4.57 & 0.215 & 0.280 \\
\hline 21 & 3 & 4.57 & 0.215 & 0.445 \\
\hline 22 & 4 & 6.10 & 0.309 & 0.448 \\
\hline 23 & 4 & 6.10 & 0.309 & 0.351 \\
\hline 24 & 5 & 6.10 & 0.142 & \\
\hline 25 & 5 & 6.10 & & \\
\hline
\end{tabular}

Tabla 3-8. Parámetros del estudio numérico para secciones rectangulares (J. N. Wang, 1993). 


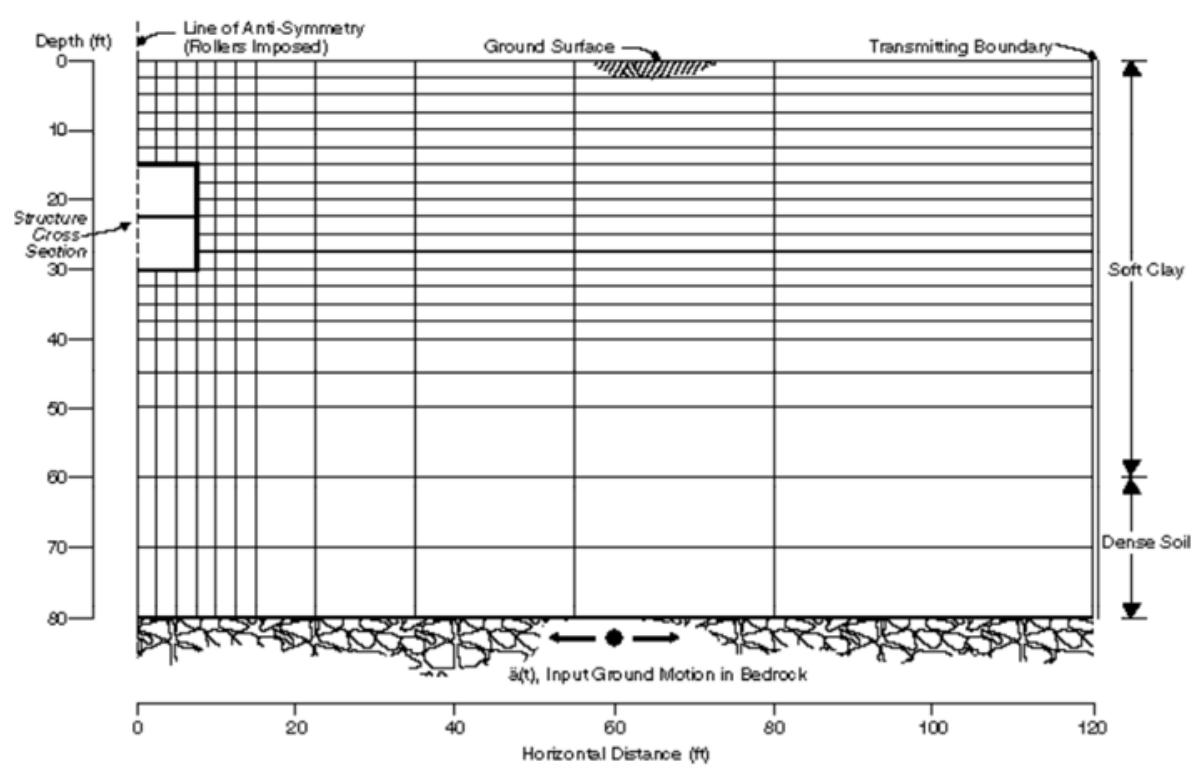

Fig. 3-128. Modelo de elementos finitos para el estudio del coeficiente de racking $\boldsymbol{R}$ de una sección rectangular (J. N. Wang, 1993).

En base a los resultados de los modelos numéricos, Wang elabora una gráfica de resultados comparando los coeficientes de flexibilidad $F$ y de racking $R$ de cada modelo (Fig. 3-129), de manera similar al caso de secciones circulares (Fig. 3-122).
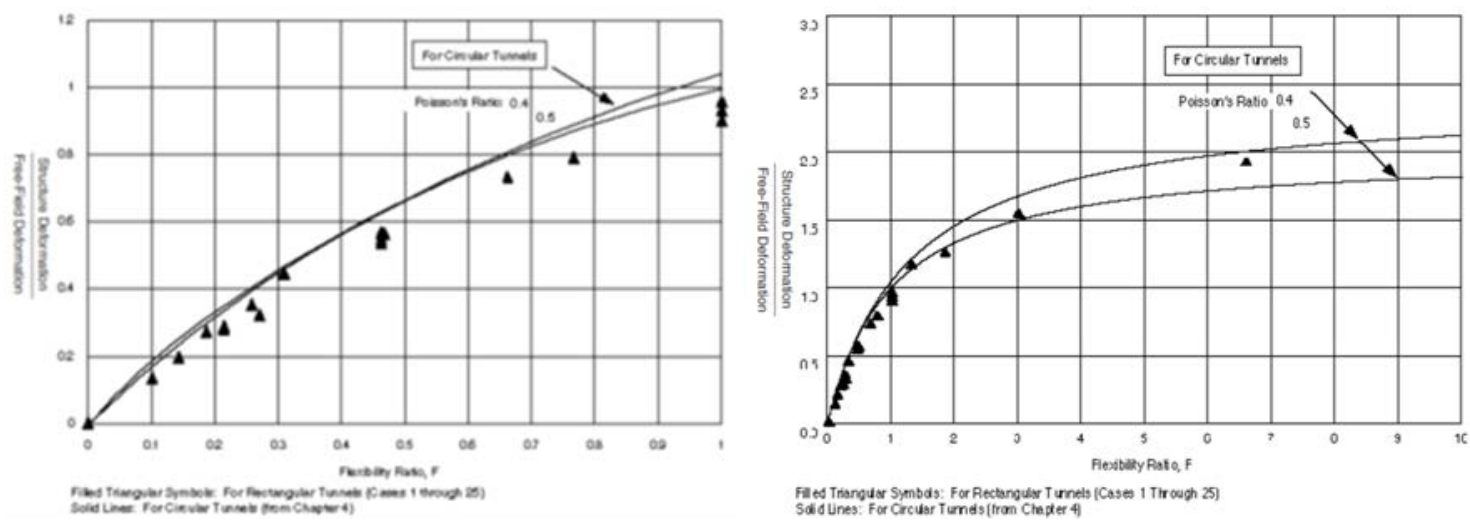

Fig. 3-129. Valores de los coeficientes de racking $R$ para diferentes valores del coeficiente de flexibilidad $F$. (Izda.) Para valores entre $0 \leq F \leq 1$. (Dcha.) Para valores entre $0 \leq F \leq 10$. Los triángulos representan las soluciones obtenidas con los modelos MEF, las curvas sólidas representan la solución analítica obtenida para secciones circulares. (J. N. Wang, 1993).

Wang indica que los resultados del análisis numérico para secciones rectangulares muestran una excelente consistencia con los obtenidos para túneles circulares, siendo aproximadamente un $10 \%$ más rígida la sección rectangular para el mismo coeficiente $F$, y por lo tanto plantea emplear la formulación analítica del coeficiente de racking de túneles circulares para el caso rectangular, que empleando las ecuaciones (Ec. 3-179) y (Ec. 3-181), queda en la forma de la expresión analítica (Ec. 3-186). 


$$
R=\frac{4 \cdot\left(1-v_{m}\right) \cdot F}{\frac{5}{2}-3 \cdot v_{m}+F}
$$

Un caso de particular interés, mencionado por Wang, es el correspondiente a estructuras de gran rigidez $(F \approx 0)$, tales como las pantallas de testeros de una estación de metro rectangular construída por el método de cut-and-cover. En efecto, para este caso, que se puede considerar como una estructura con rigidez a la distorsión virtualmente infinita, el coeficiente de flexibilidad adquiere valor nulo, y por lo tanto el coeficiente de racking toma valor nulo $R=0$. Esto significa que la deformación a la distorsión es nula, $y$ por lo tanto el problema de determinar los esfuerzos transmitidos a la pantalla de testeros, mediante el método del coeficiente de racking, queda indeterminado.

Para este caso específico, Wang recomienda amplicar el método de Wood (Wood, 1973) descrito en el apartado §3.7.2.2 de esta tesis, que corresponde al análisis de empuje dinámico del terreno para una estructura infinitamente rígida, y cimentada sobre una roca infinitamente rígida. En particular, Wang indica textualmente:

“Another theoretical form of dynamic earth pressure was derived by Wood (1973). [...] A posible application of this method in a cut-and-cover tunnel construction is at the end walls of subway station, where the ed walls act as rigid shear Wall diaphragms and prevent the structure from making sideways movements during earthquakes.” (J. N. Wang, 1993, p.87-88).

\subsubsection{Método de Penzien}

La interacción cinemática suelo-estructura fue inicialmente postulada por Penzien (Penzien, Chen, Lee, \& Jean, 1992), (Clough \& Penzien, 1993). Este autor indica que, para analizar las deformaciones de una estructura enterrada sometida a la acción del sismo se puede proceder abordando el problema desde un punto de vista cuasi-estático, es decir despreciando los efectos dinámicos producidos por la masa de la estructura. Según se indica en el documento citado, conocido el campo de deformaciones del terreno en campo libre, y aplicando este campo de deformaciones a un modelo de elementos finitos que represente suelo y estructura (Fig. 3-130), se pueden obtener las deformaciones y esfuerzos en la propia estructura.

En este estudio original, Penzien realiza un análisis con elementos finitos de un caso base de geometría de túnel y propiedades del suelo, y a partir de este caso base realiza 
una variación paramétrica similar a la del estudio realizado por Wang. Para un terreno modelizado por capas y una geometría de túnel rectangular, varía proporcionalmente el módulo de cortante de cada capa, y varía el espesor de las losas y muros de túnel.

Los resultados se resumen en la (Fig. 3-130). El eje de ordenadas de esta figura muestra la relación $\gamma / \gamma_{s}$, es decir la relación entre la deformación de distorsión de la estructura y la deformación de distorsión del campo libre, y que en el estudio de Wang se denomina coeficiente de racking $R$. El eje de abscisas se representa el cociente $\left(S \cdot G_{0}\right) /\left(S_{0} \cdot G\right)$, siendo $S$ la rigidez a la distorsión de la estructura y $S_{0}$ la rigidez a la distorsión del caso base de la estructura; mientras que $G$ es la rigidez del suelo a cortante y $G_{0}$ la rigidez del caso base de suelo.
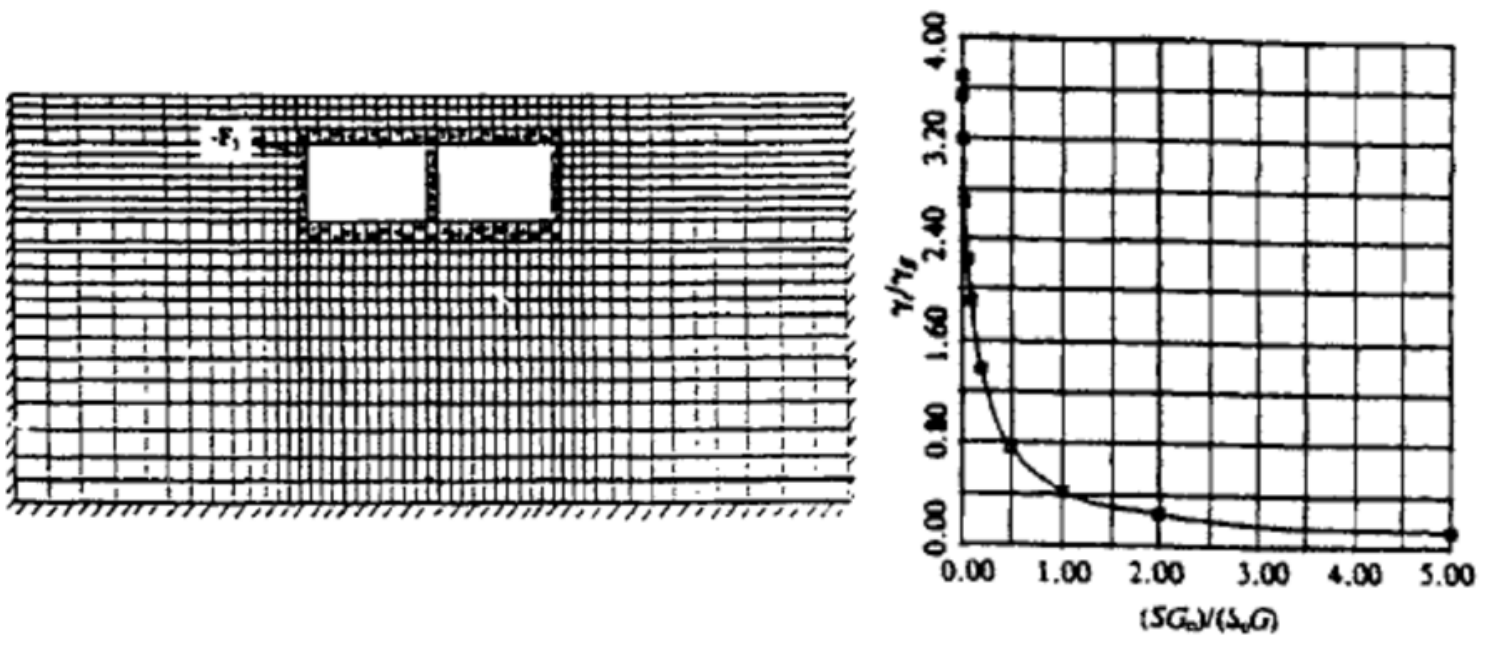

Fig. 3-130. (izda.) Modelo de elementos finitos para el estudio de la interacción cinemática sueloestructura de estructuras enterradas. (dcha.) Amplificación de la deformación de distorsión del túnel en función de la relación de rigideces. (Penzien, 2000).

Aunque los resultados obtenidos por Penzien no están expresados con el mismo formato que los indicados por Wang, y la comparación resulta por lo tanto menos evidente, se puede observar que las tendencias indicadas por ambos autores son muy similares. Partiendo del caso base de Penzien, que corresponde a la abscisa $\left(S \cdot G_{0}\right) /\left(S_{0} \cdot G\right)=1$ y para el cual en el caso arroja un valor de $\gamma / \gamma_{s}=0.42$ se puede observar como:

- Para estructuras con la misma rigidez que el terreno, la estructura se deforma lo mismo que el terreno que la rodea. 
- Al aumentar la rigidez de la estructura, es decir al aumentar $S$ manteniendo $G$ constante y desplazarnos hacia la derecha en el eje de abscisas, disminuye la deformación angular de la estructura.

- Al disminuir la rigidez de la estructura, es decir al disminuir $S$ manteniendo $G$ constante y desplazarnos hacia la izquierda en el eje de abscisas, aumenta la deformación angular de la estructura.

- Al aumentar la rigidez del suelo, es decir al aumentar $G$ manteniendo $S$ constante y desplazarnos hacia la izquierda en el eje de abscisas, aumenta la deformación angular de la estructura.

- Al disminuir la rigidez del suelo, es decir al disminuir $G$ manteniendo $S$ constante y desplazarnos hacia la derecha en el eje de abscisas, disminuye la deformación angular de la estructura.

En dos artículos posteriores (Penzien \& Wu, 1998), (Penzien, 2000), este autor realiza un análisis en términos similares al desarrollado por Wang, y propone una fórmula analítica para el coeficiente de racking que denomina $\beta$ en lugar de $R$. En estos trabajos Penzien parte de dos hipótesis fundamentales:

- Los campos de deformaciones y de tensiones de una oquedad rectangular serán similares a los de una oquedad circular.

- La única vinculación que existe entre suelo y estructura es el esfuerzo rasante que se produce en las caras de contacto.

Partiendo de la primera hipótesis, Penzien indica que el coeficiente $\beta$ de amplificación de la deformación de distorsión de una cavidad hueca con respecto a la deformación del campo libre es (Ec. 3-187), donde $v_{s}$ es el coeficiente de Poisson del suelo. Puede comprobarse que esta expresión responde al mismo concepto que el coeficiente de racking $R$ definido por Wang, y cuya expresión para el caso de una oquedad circular resulta de combinar las expresiones (Ec. 3-176) y (Ec. 3-177), proporcionando un resultado idéntico.

$$
\beta=4 \cdot\left(1-v_{s}\right)
$$

Adicionalmente, y atendiendo al esquema de la (Fig. 3-131), Penzien formula la rigidez $k_{s o}$ como el valor de la tensión de rasante que es necesario aplicar en el perímetro del suelo para obtener un desplazamiento de distorsión unitario en la cavidad (Ec. 3-188). 

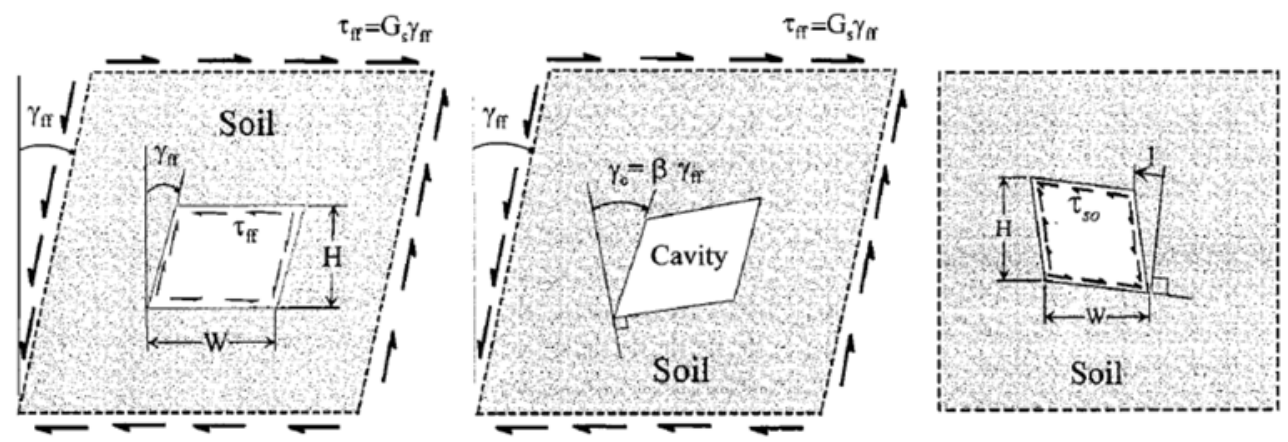

Fig. 3-131. Deformación de una cavidad rectangular sometida a un estado de cortante puro. (izda.)

Con una distribución de tensiones de cortante igual a la del campo libre aplicada en la superficie interior de la cavidad. (cent.) Sin la distribución de tensiones en la superficie de la cavidad interior. (dcha.) Con una distribución de tensiones de cortante en el interior de la cavidad (Penzien, 2000).

En esta expresión $k_{s o}$ es el coeficiente de rigidez que indica el valor de la tensión de rasante que es necesario aplicar en el contorno exterior del suelo para obtener un desplazamiento de distorsión unitario en la oquedad, $\tau_{f f}$ es la tensión perimetral aplicada en el contorno del terreno en un estado de cortante puro, $\gamma_{c}$ es la deformación angular de la estructura, $\gamma_{f f}$ la deformación angular del suelo en campo libre, y $G_{s}$ y $v_{s}$ el módulo de cortante y coeficiente de Poisson del suelo.

$$
k_{s o}=\frac{\tau_{f f}}{\left(\gamma_{c}-\gamma_{f f}\right) \cdot H}=\frac{G_{s}}{\left(3-4 \cdot v_{s}\right) \cdot H}
$$

Para obtener la rigidez de distorsión $k_{l}$ de la estructura, entendida como la tensión que es necesario aplicar en los bordes de la estructura para obtener un desplazamiento de distorsión unitario en la misma, Penzien indica que basta con calcularla mediante un modelo simple de barras (Fig. 3-132).
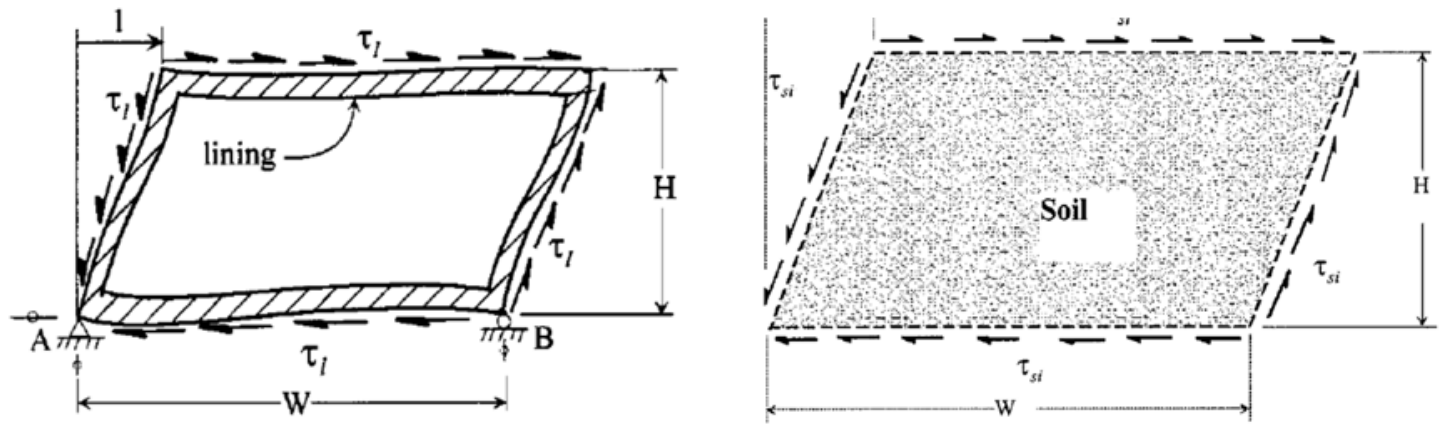

Fig. 3-132. (izda.) Rigidez de la estructura. (dcha.) Rigidez del suelo que es sustituido por el túnel. (Penzien, 2000). 
Adicionalmente, Penzien define el coeficiente de rigidez $k_{s i}$, equivalente a la rigidez a la distorsión del bloque de suelo sustituido por el túnel (Ec. 3-189), (Fig. 3-132).

$$
k_{s i}=\frac{G_{s}}{H}
$$

Para evaluar la interacción entre suelo y estructura, Penzien hace uso de las expresiones (Ec. 3-190) y (Ec. 3-191) en las que se considera que:

- El campo de deformaciones del suelo para el caso de un marco de geometría rectangular es asimilable al caso de un túnel circular.

- La única vinculación entre suelo y estructura se produce a través del esfuerzo rasante de las caras en contacto, y se desprecia la influencia que puedan tener las tensiones normales de compresión-tracción entre estructura y suelo.

$$
\begin{gathered}
\Delta_{i l}+\Delta_{i s} \cong 4 \cdot\left(1-v_{s}\right) \cdot \gamma_{f f} \cdot H \\
k_{s o} \cdot \Delta_{i s} \cong k_{l} \cdot \Delta_{i l}
\end{gathered}
$$

En estas expresiones, $\Delta_{i l}$ es el desplazamiento de distorsión de la estructura producido por la interacción con el suelo, y $\Delta_{i s}$ es la reducción en el desplazamiento de distorsión de la cavidad producida por su interacción con la estructura.

Comparando las expresiones (Ec. 3-188), (Ec. 3-189), (Ec. 3-190), y (Ec. 3-191), se obtiene la siguiente ecuación (Ec. 3-192).

$$
k_{s o}=\frac{k_{s i}}{\left(3-4 \cdot v_{s}\right)}
$$

Finalmente, haciendo uso de las expresiones (Ec. 3-188), (Ec. 3-189), (Ec. 3-190), y (Ec. 3-191), Penzien llega a la fórmula siguiente (Ec. 3-193) que expresa el coeficiente de Racking $R$ en términos idénticos a los de Wang, como relación entre la deformación de distorsión de la estructura del túnel y la de campo libre.

$$
R=\frac{\gamma_{i l}}{\gamma_{f f}}=\frac{4 \cdot\left(1-v_{s}\right)}{1+\left(3-4 \cdot v_{s}\right) \cdot \frac{k_{l}}{k_{s i}}}=\frac{4 \cdot\left(1-v_{s}\right)}{1+\left(3-4 \cdot v_{s}\right) \cdot \frac{1}{F}}
$$




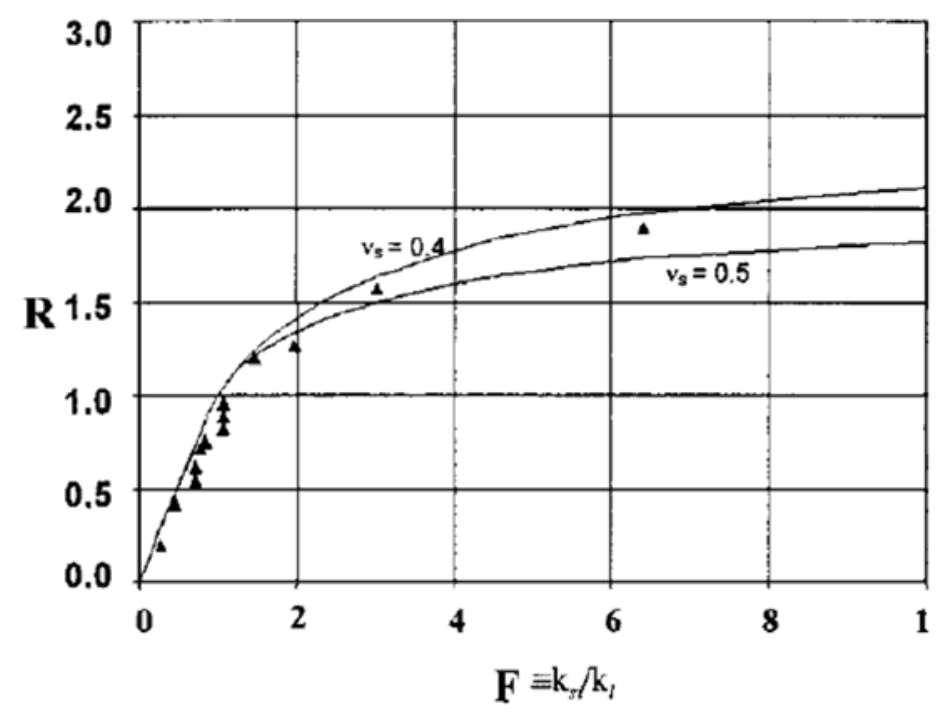

Fig. 3-133. Coeficiente de racking $R$ en función del coeficiente de flexibilidad $F$. Las líneas continuas representan la expresión (Ec. 3-193) para valores del coeficiente de Poisson $v=0.4$ y $v=0.5$. Los puntos triangulares representan los valores de los análisis numéricos referidos por Wang (Penzien, 2000).

\subsubsection{Método de Anderson et al.}

Anderson (Anderson et al., 2008) realiza para el NCHRP (National Cooperative Highway Research Program) una revisión del estado del arte acerca el diseño sismorresistente de estructuras de contención de tierras, entre ellas de las estructuras enterradas asimilables a túneles. En el capítulo dedicado al análisis de túneles, Anderson explica la metodología y resultados desarrollada por Wang (J. N. Wang, 1993) y resumida en el apartado 3 3.7.4.1 de esta tesis.

Sin embargo, al proporcionar la expresión del coeficiente de racking $R$, Anderson obvia la dependencia del mismo con respecto al módulo de Poisson del suelo $v_{s}$, y refiere una expresión (Ec. 3-194) similar a la de Wang, pero en la que implícitamente se asume un valor del coeficiente de Poisson de $v_{s}=0.5$, es decir, un suelo incompresible.

$$
R=\frac{2 \cdot F}{1+F}
$$

En la formulación propuesta por Anderson, tanto el coeficiente $R$ de racking como el coeficiente $F$ de flexibilidad tienen el mismo significado que el indicado en el apartado §3.7.4.1 de esta tesis. La justificación para proponer esta versión simplificada del 
coeficiente $R$ de racking, es que se ajusta mejor a los resultados obtenidos de un estudio numérico mediante el programa de diferencias finitas FLAC.

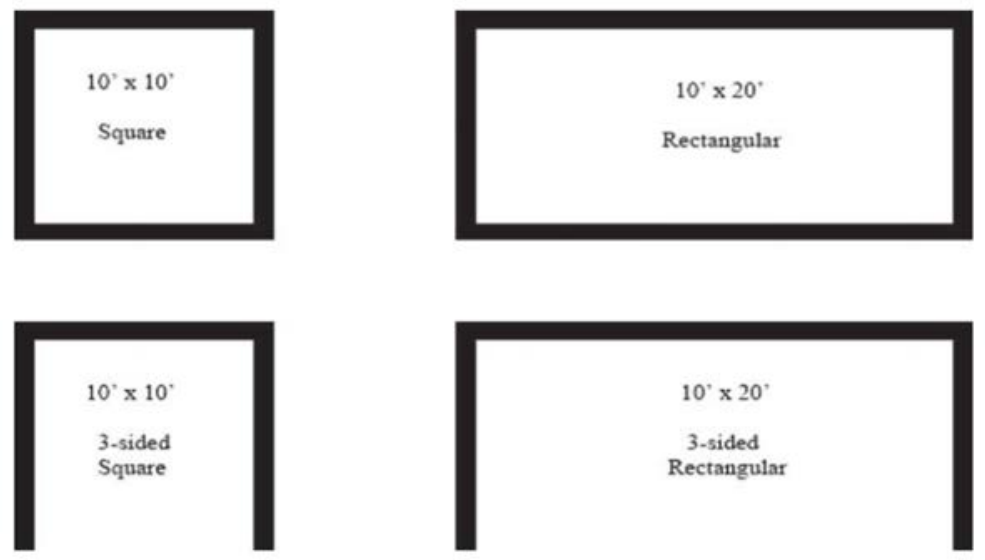

Fig. 3-134. Estructuras analizadas por Anderson en su estudio paramétrico. (Anderson et al., 2008).

En su estudio numérico, Anderson et al. (Anderson et al., 2008), analizan 4 tipos diferentes de estructuras (Fig. 3-134), con diferentes configuraciones estructurales (marco de 4 elementos, y pórtico de 3 elementos), dimensiones, rigideces, y propiedades del terreno adyacente. En particular estudia los 5 casos que se resumen en la Tabla 3-10. Para todos estos casos considera que las losas y muros de la estructura tienen las propiedades resumidas en la Tabla 3-9. En todos los casos, Anderson indica que la solicitación sísmica se modeliza como una aceleración horizontal constante a lo largo de toda la profundidad de valor $a_{g}=0,3 \cdot \mathrm{g}$.

\begin{tabular}{|c|c|}
\hline Propiedad & Valor \\
\hline Módulo de Young del Hormigón & $E_{c}=4000 \mathrm{ksi}$ \\
\hline Coeficiente de Poisson del Hormigón & $\nu_{c}=0,3$ \\
\hline Espesor de Losas y Muros & $t=0,67 \mathrm{ft}$ \\
\hline Momento de Inercia de Losas y muros & $I=0,025 \mathrm{ft}^{4}$ \\
\hline
\end{tabular}

Tabla 3-9. Propiedades mecánicas de las estructuras de los casos estudiados por Anderson en su análisis numérico. (Anderson et al., 2008).

Adicionalmente, para cada caso, Anderson estudia varias configuraciones de profundidades de la estructura enterrada. Las diferentes profundidades estudiadas corresponden a relaciones de profundidad $z$ de la losa superior, frente al canto $H$ de la estructura resumidas en la Tabla 3-11.

Los resultados numéricos obtenidos por Anderson muestran claramente que el coeficiente de racking $R$ es esencialmente independiente de la profundidad a la que se encuentre enterrada la estructura (Fig. 3-135). 


\begin{tabular}{|c|c|c|c|}
\hline Caso & $\begin{array}{c}\text { Configuración } \\
\text { Estructural y } \\
\text { Parámetros del Suelo }\end{array}$ & $\begin{array}{c}\text { Rigidez Estructural a } \\
\text { la Distorsión } \\
K_{s}[\text { kips/ft] }\end{array}$ & $\begin{array}{l}\text { Ratio de Flexibilidad } \\
\qquad F_{R E C}\end{array}$ \\
\hline Caso 1 & $\begin{array}{c}\text { Marco } 10 \times 10 \\
E_{m}=3 \mathrm{ksi} \\
v_{m}=0.3 \\
\end{array}$ & 172 & 0,97 \\
\hline Caso 2 & $\begin{array}{c}\text { Marco } 10 ’ \times 10 \\
E_{m}=7,5 \mathrm{ksi} \\
v_{m}=0.3\end{array}$ & 172 & 2,40 \\
\hline Caso 3 & $\begin{array}{c}\text { Marco } 100^{\prime} \times 20 \\
E_{m}=3 \mathrm{ksi} \\
\nu_{m}=0.3\end{array}$ & 115 & 2,90 \\
\hline Caso 4 & $\begin{array}{c}\text { Pórtico } 10 ’ x 10^{\prime} \\
E_{m}=7,5 \mathrm{ksi} \\
v_{m}=0.3 \\
\end{array}$ & 57 & 7,30 \\
\hline Caso 5 & $\begin{array}{c}\text { Pórtico } 10 ` \times 20^{\prime} \\
E_{m}=7,5 \mathrm{ksi} \\
V_{m}=0.3\end{array}$ & 43 & 19,30 \\
\hline
\end{tabular}

Tabla 3-10. Casos estudiados por Anderson en su análisis numérico. (Anderson et al., 2008).

\begin{tabular}{|c|c|}
\hline Configuración de Profundidad & $\mathbf{z} / \mathbf{H}$ \\
\hline Configuración 1 & 0,5 \\
\hline Configuración 2 & 1 \\
\hline Configuración 3 & 2 \\
\hline Configuración 4 & 3 \\
\hline Configuración 5 & 5 \\
\hline
\end{tabular}

Tabla 3-11. Configuraciones de profundidad de la estructura de los casos estudiados por Anderson en su análisis numérico. (Anderson et al., 2008).
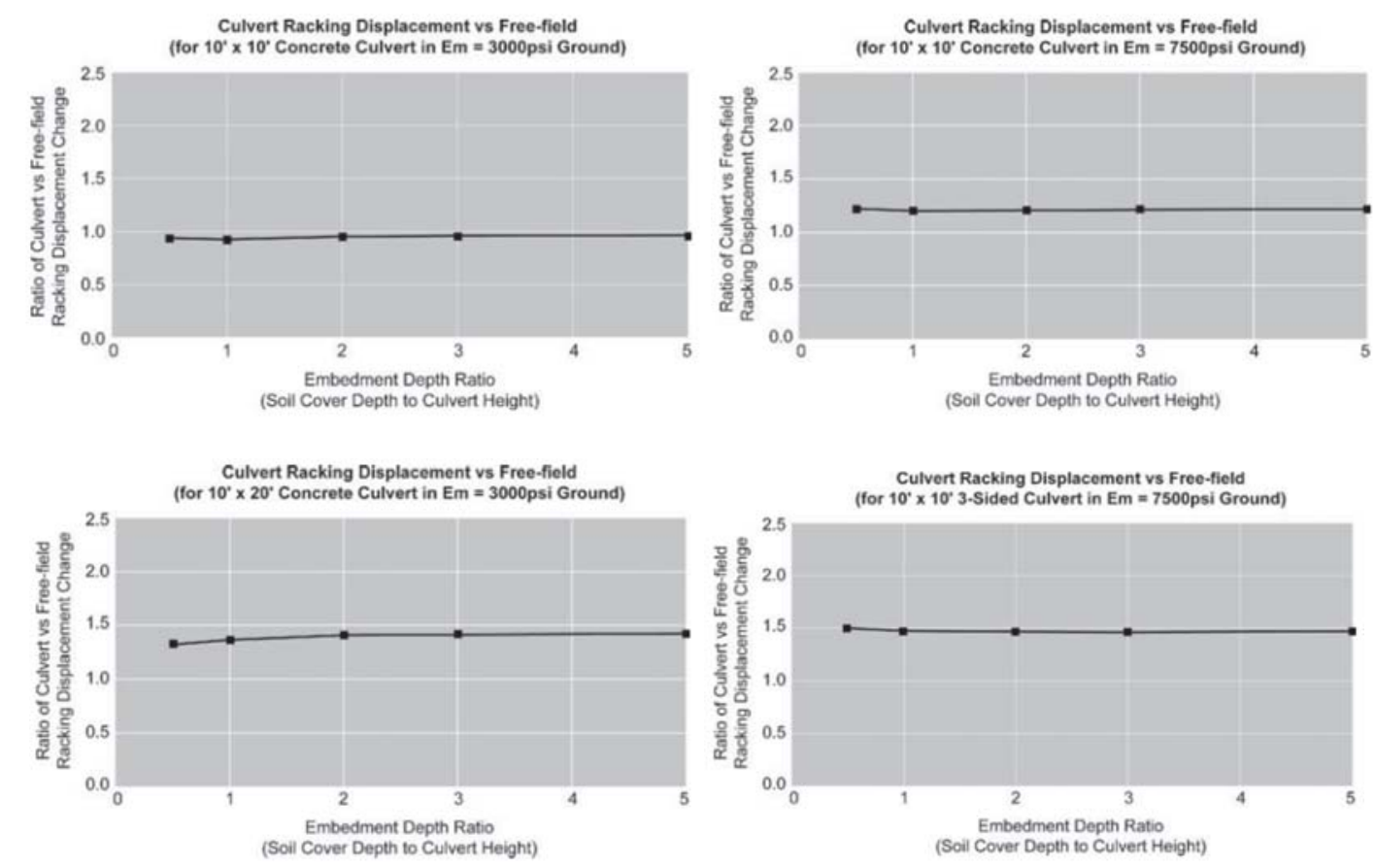

Fig. 3-135. Coeficientes de racking $R$ obtenidos por Anderson en su estudio numérico (Anderson et al., 2008). (sup. izda.) Caso 1. (sup. dcha.) Caso 2. (inf. izda) Caso 3. (inf. dcha.) Caso 4. 
Finalmente, y en base a un ajuste de las diferentes curvas propuestas por Wang ( $\mathrm{J}$. N. Wang, 1993) y Penzien (Penzien, 2000) en sus estudios, Anderson escoge la que mejor se adapta a los resultados numéricos de su estudio. Dicha expresión y los resultados numéricos se presentan en la (Fig. 3-136).

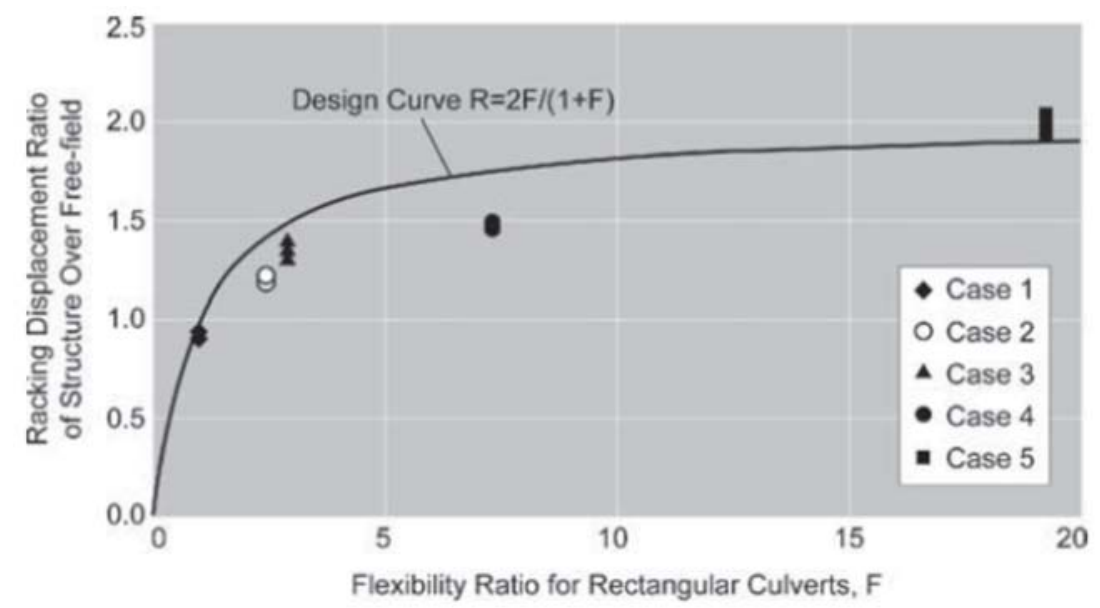

Fig. 3-136. Expresión del coeficiente de racking $R$ y resultados numéricos obtenidos por Anderson (Anderson et al., 2008).

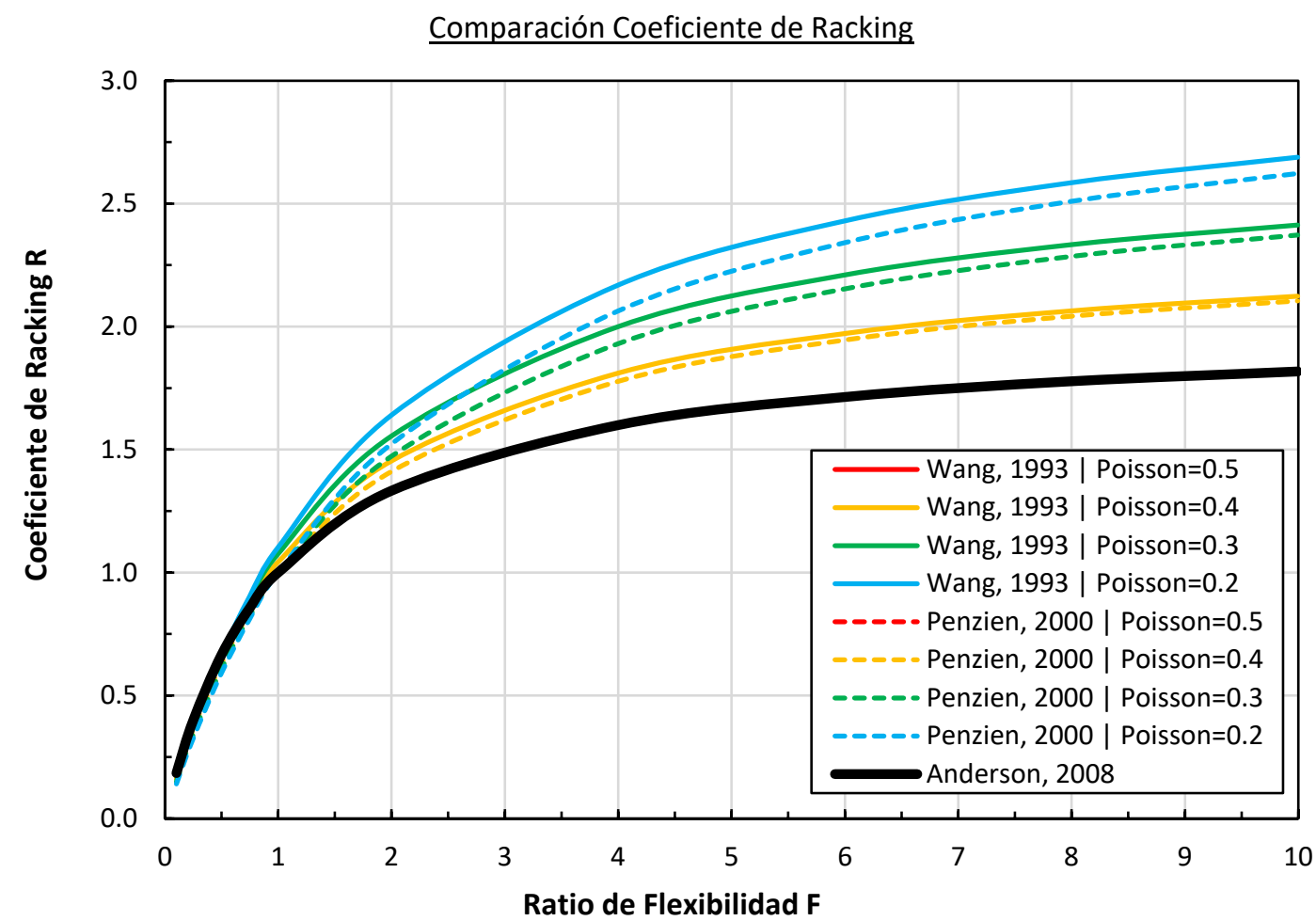

Fig. 3-137. Coeficiente de racking $R$ propuesto por Anderson (Anderson et al., 2008), comparado al obtenido por Wang (J. N. Wang, 1993), y Penzien (Penzien, 2000), para diferentes valores del coeficiente de Poisson. 
La figura Fig. 3-137 muestra la representación de la fórmula escogida por Anderson (Ec. 3-194), junto a las propuestas por Wang y Penzien. Si bien la curva presenta características similares a las obtenidas por Wang y Penzien, la independencia de la misma con respecto al coeficiente de Poisson, hace que los valores obtenidos sean hasta del orden del $50 \%$ menores para estructuras flexibles $F \approx 10$ que las predichas por estos autores.

\subsubsection{Método de Huo}

En su tesis doctoral Huo (Hongbin Huo, 2005), analiza las metodologías previas de interacción cinemática propuestas por Wang (J. N. Wang, 1993) y Penzien (Penzien, 2000), y conjetura que, aunque aproximadas, estas soluciones pueden mejorarse si se incluyen los efectos de interacción suelo-estructura correspondientes a las tensiones normales que se producen en la interfaz de suelo y marco del túnel.

En efecto, tanto Wang como Penzien asumen que la única interacción que se desarrolla en los planos de contacto entre la estructura y el medio elástico que los rodea es la debida a la compatibilidad de deformaciones tangenciales, y que, por lo tanto, las únicas acciones que solicitan a la estructura, y que recíprocamente reaccionan contra el suelo, son las tensiones tangenciales actuantes en el contorno de la interfaz. Sin embargo, si atendemos a la deformación local fuera de su plano que tendrán tanto los muros laterales como las losas de la estructura, parece razonable pensar que o bien empujarán contra el suelo circundante, o que tirarán de él. La aportación fundamental de Huo es estudiar la influencia de este término extra de rigidez.

El trabajo de Huo se basa en las siguientes hipótesis de partida:

- La estructura rectangular se encuentra embebida en un medio elástico infinito.

- Las condiciones de deformación plana pueden asumirse como válidas en cualquier sección perpendicular al eje longitudinal de la estructura.

- El comportamiento del suelo y de la estructura son elásticos lineales.

- Las deformaciones sísmicas del suelo y de la estructura pueden ser aproximadas por un campo lejano de deformaciones o tensiones tangenciales de cortante puro. Asume por lo tanto como válido un enfoque pseudo-estático del problema. 

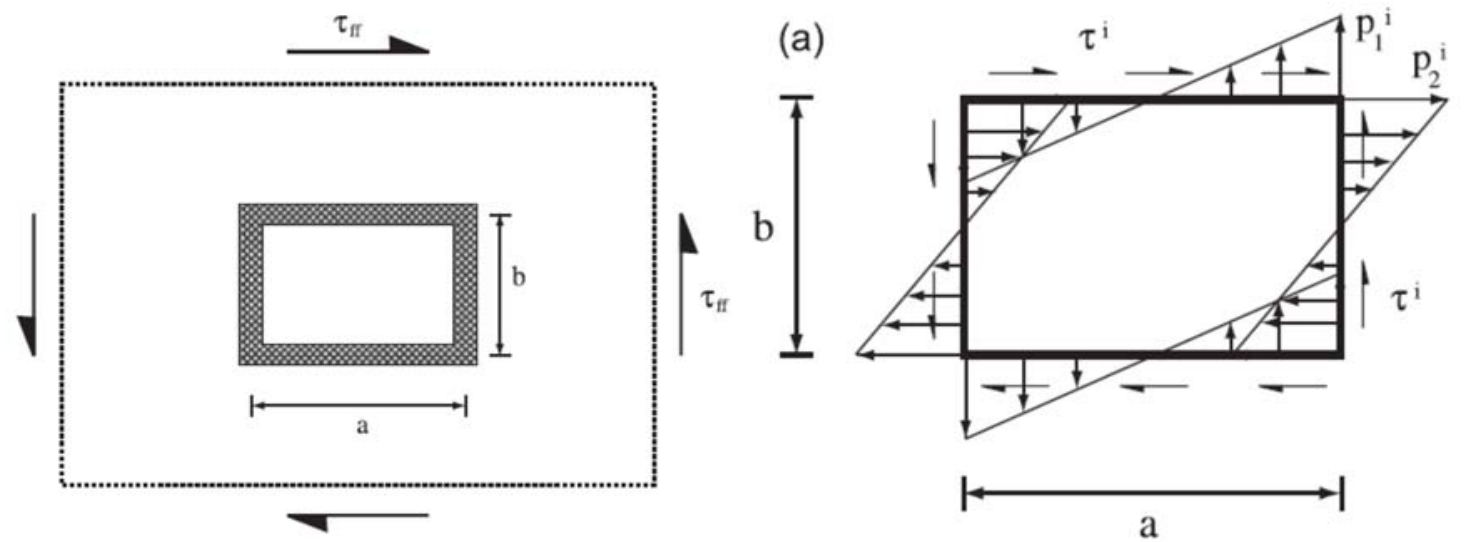

Fig. 3-138. (Izda.) Esquema de la configuración de bloque de suelo sometido a cortante puro y estructura rectangular embebida. (Dcha.) Distribución de tensiones tangenciales y normales sobre la estructura asumido en el estudio (Bobet, Fernandez, Huo, \& Ramirez, 2008).

Para establecer la formulación matemática del problema, Huo parte de los postulados básicos de la elasticidad y propone la búsqueda de una función de tensiones de Airy $\Phi$ que cumplan la igualdad (Ec. 3-195), donde $\nabla^{2}$ es el operador laplaciano.

$$
\nabla^{2}\left(\nabla^{2} \Phi\right)=0
$$

La función de Airy $\Phi$ se relaciona con el campo de tensiones y de deformaciones a través de las siguientes expresiones, donde $E$ y $v$ son el módulo de Young y coeficiente de Poisson del material.

$$
\begin{gathered}
\sigma_{x}=\frac{\partial^{2} \Phi}{\partial y^{2}} \\
\sigma_{y}=\frac{\partial^{2} \Phi}{\partial x^{2}} \\
\tau_{x y}=\frac{\partial^{2} \Phi}{\partial x \partial y} \\
\varepsilon_{x}=\frac{\partial u_{x}}{\partial x}=\frac{1}{E}\left[\left(1-v^{2}\right) \cdot \sigma_{x}-v \cdot(1+v) \cdot \sigma_{y}\right] \\
\varepsilon_{x}=\frac{\partial u_{y}}{\partial y}=\frac{1}{E}\left[\left(1-v^{2}\right) \cdot \sigma_{y}-v \cdot(1+v) \cdot \sigma_{x}\right]
\end{gathered}
$$

Para abordar el problema de hallar la distribución de tensiones en un medio elástico con una perforación rectangular, Huo se apoya en el problema similar de 
perforación circular, que cuenta con una solución clásica, y mediante técnicas de variable compleja y mapeo conformal establece una correspondencia entre ambos. De esta manera, convierte la geometría y la solución del caso rectangular al caso de una perforación de forma polinómica y similar geometría que la del túnel rectangular (Savin, 1970), para después transformar esta geometría polinómica mediante variable compleja $(i=\sqrt{ }-1)$ al caso de un problema de túnel circular, para el que existen soluciones analíticas.
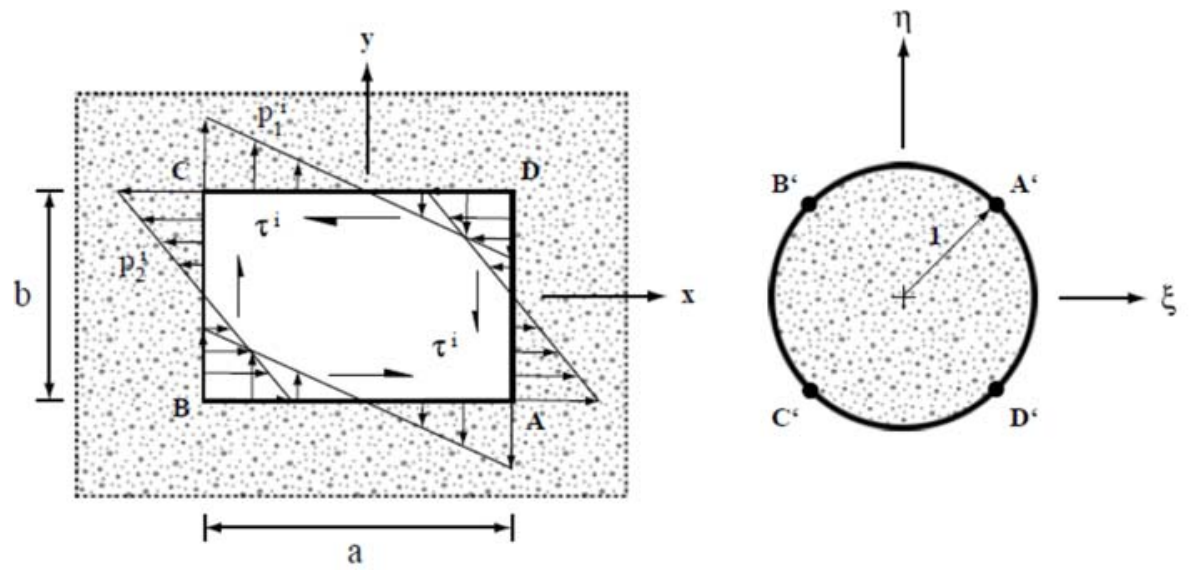

Fig. 3-139. Transformación de mapeo conformal entre el problema. (Izda.) En el plano real. (Dcha.)

En el plano imaginario. (H. Huo, Bobet, Fernández, \& Ramírez, 2006).

La complejidad matemática del desarrollo planteado por Huo es muy notable, y proporciona resultados con variables intermedias que son tan sólo entidades matemáticas, sin un correlato con sentido físico. Para una descripción más detallada del método propuesto por Huo, se refiere al lector a los artículos en los que desarrolla esta metodología (Bobet et al., 2008; H. Huo et al., 2006; Hongbin Huo, 2005; Hongbin Huo, Bobet, Fernández, \& Ramírez, 2004, 2005).

Finalmente, Huo llega a la expresión (Ec. 3-201) que proporciona el coeficiente de racking $R$, que como en casos anteriores relaciona la deformación de distorsión del túnel frente a la de campo libre.

$$
R=\frac{\Delta_{s t r u}}{\Delta_{f f}}=\left(1-v_{s}^{2}\right) \cdot\left[N \cdot \Delta_{p_{2}^{i}}+\left(M \cdot \Delta_{p_{2}^{i}}+\Delta_{\tau^{i}}\right) \cdot L\right] \cdot \frac{G}{b}
$$

Las expresiones (Ec. 3-202), (Ec. 3-203), y (Ec. 3-204) indican los parámetros intermedios que emplea Huo en su formulación, donde $R$ es el coeficiente de racking, amplificación de la deformación angular de la estructura con respecto a la deformación angular en campo libre, $\Delta_{\text {stru }}$ es la deformación de la estructura medida como diferencia de desplazamientos horizontales entre la losa superior y la losa inferior, $\Delta_{f f}$ es la 
deformación de distorsión de campo libre medida entre los mismos puntos, $G$ y $v_{s}$ son el módulo de cortante y el coeficiente de Poisson del suelo, $\Delta_{\tau i}$ es la deformación de la estructura aislada debida a un estado tensional en sus bordes de cortante puro de valor $\tau_{i}$, $\Delta_{p 2}{ }^{i}$ es la deformación de la estructura aislada debida a una distribución triangular de tensiones normales a las caras de la estructura con valor $p_{2}{ }^{i}=1$ y $p_{1}{ }^{i}=(b / a)^{2}$.

$$
\begin{gathered}
L=\frac{\left(1-v_{s}^{2}\right) \cdot N \cdot \Delta_{p_{2}^{i}}-\frac{a}{G} \cdot F_{1}}{\left(1-v_{s}^{2}\right) \cdot\left(M \cdot \Delta_{p_{2}^{i}}+\Delta_{\tau^{i}}\right)-\frac{a}{G} \cdot F_{2}} \\
\Delta_{\tau^{i}}=\frac{1}{24} \lambda b^{4}\left[\frac{\lambda}{(E I)_{S}}+\frac{1}{(E I)_{W}}\right] \\
\Delta_{p_{2}^{i}}=\frac{1}{60} b^{4}\left[\frac{\lambda}{(E I)_{S}}+\frac{1}{(E I)_{W}}\right]
\end{gathered}
$$

Huo (H. Huo et al., 2006) compara los resultados obtenidos con su método, con las expresiones propuestas por Penzien (Penzien, 2000), y los resultados numéricos desarrollados por Wang (J. N. Wang, 1993). La Fig. 3-140 muestra esta comparación, en la que se puede apreciar como para estructuras flexibles $(F>1)$, la formulación que propone Huo proporciona deformaciones del orden del 40\% mayores que las de Wang y Penzien (Penzien, 2000; J. N. Wang, 1993).

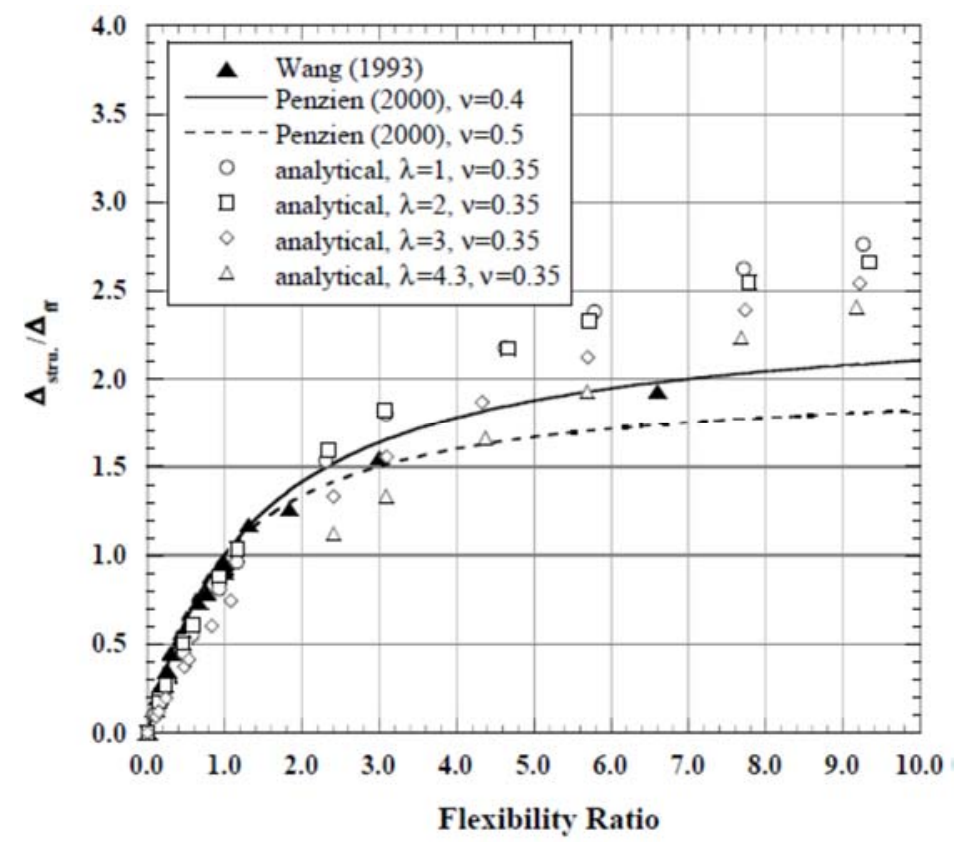

Fig. 3-140. Coeficiente de racking $R$ propuesto por Huo, junto con. la solución analítica de Penzien, y los resultados numéricos de Wang (H. Huo et al., 2006). 


\subsection{Revisión de la normativa internacional de proyecto sismorresistente de obras subterráneas}

En este apartado se realiza un análisis crítico de las metodologías vigentes en las diferentes normativas internacionales, o documentos de uso habitual en la práctica de proyectos que pueden asimilarse a normativas de facto, para el análisis de los efectos de la acción sísmica en obras subterráneas, comparando cualitativamente las formulaciones propuestas en estas normativas frente a las descritas por las teorías enunciadas en el apartado $§ 3.7$ de esta tesis.

Como normativas a revisar y analizar, se han elegido las de aquellos países que, por su nivel de desarrollo técnico, y exposición a la peligrosidad sísmica, se han considerado más relevantes. En particular, se ha revisado la normativa europea de Eurocódigos, la normativa francesa, la normativa federal estadounidense, las normativas estatales para dos proyectos muy significativos de California (línea ferroviaria de Alta Velocidad) y Washington (Túnel SR99 en Seattle), la normativa japonesa, y la normativa chilena.

Como aspectos a revisar, se ha analizado lo que estas normativas proponen respecto a:

- Niveles de demanda y desempeño sísmicos.

- Métodos de análisis de la acción del sismo.

\subsubsection{Normativa Europea}

En la actualidad, no existe una normativa de ámbito europeo con disposiciones específicas para las obras subterráneas. En este sentido, un reciente documento de la Comisión Europea titulado "Standardisation needs for the design of underground structures" (Athanasopoulou et al., 2019), señala la necesidad de abordar este aspecto para dotar a las obras subterráneas de un cuerpo común de reglas de construcción. Entre otros aspectos, remarca la necesidad de incluir reglas de diseño sismorresistente para las obras subterráneas, especialmente en zonas de suelos blandos.

Los únicos aspectos sísmicos, relativos a obras subterráneas o de contención de tierras, que se incluyen en las normativas europeas y que se revisan a continuación son los recogidos en los Eurocódigos (apartados §3.8.1.1 de esta tesis), y en el documento de 
recomendaciones de la Association Française du Génie Parasismique (apartado §3.8.1.2 de esta tesis).

3.8.1.1 Eurocódigo 8. EN 1998-2:2005 Diseño sismorresistente de puentes y EN 19985:2004 Diseño sismorresistente de cimentaciones, obras de contención, y aspectos geotécnicos

\subsection{Niveles de demanda y desempeño}

El eurocódigo EC8-2 (EN 1998-2:2005) de diseño sismorresistente de puentes, establece un único nivel de demanda sísmica, correspondiente a un periodo de retorno de $T_{R}=475$ años, correspondiente a una probabilidad de excedencia de $10 \%$ en una vida útil de $T_{L}=50$ años.

Por otra parte, establece clases de importancia para los puentes tanto de carretera como de ferrocarril, en función de su relación con los planes de emergencia post-sismo. La clasificación de un puente dado en una u otra categpría se deja a elección de la autoridad competente en cada país de la UE, pero las líneas generales que recomienda para realizar la clasificación son las de la Tabla 3-12.

\begin{tabular}{|c|c|c|}
\hline Importancia & \multicolumn{1}{c|}{ Descripción } & $\begin{array}{c}\text { Factor de } \\
\text { Mayoración } \gamma_{\text {I }}\end{array}$ \\
\hline Clase I & $\begin{array}{l}\text { - Aquellos puentes que no son críticos para las } \\
\text { comunicaciones, y resulta injustificacada la } \\
\text { probabilidad de no excedencia de 10\% en 50 } \\
\text { años. }\end{array}$ & 0,85 \\
\hline Clase II & $\begin{array}{l}- \text { Todos los puentes, por defecto, son de categoría } \\
\text { II a menos de que puedan clasificarse como I ó } \\
\text { III. }\end{array}$ & 1,00 \\
\hline Clase III & $\begin{array}{l}\text { - Puentes de importancia crítica para el } \\
\text { manteniminento de las comunicaciones, } \\
\text { especialmente en el periodo post-sismo. } \\
- \text { Puentes cullo fallo estaría asociado a un gran } \\
\text { número probable de víctimas. } \\
\text { - Grandes puentes para los que la vida útil es } \\
\text { mayor que la habitual. }\end{array}$ & 1,30 \\
\hline
\end{tabular}

Tabla 3-12. Clases de importancia sísmica para puentes del Eurocódigo. (EN 1998-2:2005).

La clasificación de importancia sísmica anterior está basada en la clasificación de clases de consecuencia definidas en el Eurocódigo 0 (EN 1990:2002) referentes a los criterios de fiabilidad de las obras públicas (Tabla 3-13). Estos términos de clases de 
consecuencias operan para el proyecto de todas las estructuras diseñadas de acuerdo a los eurocódigos, para todas las acciones, además de la acción sísmica.

\begin{tabular}{|c|c|c|}
\hline $\begin{array}{l}\text { Clasificación } \\
\text { de } \\
\text { Consecuencia }\end{array}$ & Descripción & $\begin{array}{l}\text { Ejemplos de edificios } \\
\text { y obras públicas }\end{array}$ \\
\hline Clase CC1 & $\begin{array}{l}\text { - Consecuencias bajas para la pérdida de vidas } \\
\text { humanas. } \\
\text { - Consecuencias pequeñas o despreciables en } \\
\text { términos económicos, sociales, o } \\
\text { medioambientales. }\end{array}$ & $\begin{array}{l}\text { - Edificios destinados a la } \\
\text { agricultura donde la } \\
\text { gente normalmente no } \\
\text { entra. } \\
\text { - Almacenes. } \\
\text { - Invernaderos. }\end{array}$ \\
\hline Clase CC2 & $\begin{array}{l}\text { - Consecuencias medias para la pérdida de vidas } \\
\text { humanas. } \\
\text { - Consecuencias considerables en términos } \\
\text { económicos, sociales, o medioambientales. }\end{array}$ & $\begin{array}{l}\text { - Edificios residenciales y } \\
\text { de oficinas. }\end{array}$ \\
\hline Clase CC3 & $\begin{array}{l}\text { - Consecuencias altas para la pérdida de vidas } \\
\text { humanas. } \\
\text { - Consecuencias muy grandes en términos } \\
\text { económicos, sociales, o medioambientales. }\end{array}$ & $\begin{array}{l}\text { - Estadios. } \\
\text { - Auditorios de Conciertos. } \\
\text { - Edificios públicos. }\end{array}$ \\
\hline
\end{tabular}

Tabla 3-13. Clases de consecuencias del Eurocódigo. (EN 1990:2002).

En lo que se refiere a los niveles de demanda sísmicos, el EC8-2 (EN 19982:2004) establece dos niveles, Estado Límite Último (ELU) y Estado Límite de Servicio (ELS), cuyos criterios se resumen en la Tabla 3-14.

\begin{tabular}{|c|c|}
\hline $\begin{array}{c}\text { Nivel de } \\
\text { Desempeño }\end{array}$ & \multicolumn{1}{c|}{ Descripción } \\
\hline ELU & $\begin{array}{l}\text { - El puente mantiene su integridad estructural, y resistencia residual adecuada, } \\
\text { aunque en algunas partes del puente puede ocurrir daño considerable. } \\
\text { - Se permite la plastificación a flexión de ciertas secciones en las pilas (formación de } \\
\text { rótulas plásticas). } \\
\text { - El tablero del puente debe diseñarse para que no tenga daño más allá de elementos } \\
\text { secundarios como juntas de dilatación, losas de transición, o parapetos. } \\
\text { - El puente debe permitir el tráfico de emergencia inmediatamente después del sismo. }\end{array}$ \\
\hline ELS & $\begin{array}{l}\text { - El daño causado en el puente será menor. } \\
\text { - Todas las zonas fuera de las rótulas plásticas estará libre de daño. }\end{array}$ \\
\hline
\end{tabular}

Tabla 3-14. Niveles de Desempeño del Eurocódigo. (EN 1990:2002).

De manera sorprendente, el Eurocódigo no fija de manera explícita cual es el nivel de demanda correspondiente al nivel de desempeño ELS, indicando tan sólo que será un sismo con mayor probabilidad de ocurrencia que el correspondiente al nivel ELU.

\begin{tabular}{|c|c|}
\hline Nivel de Demanda & Nivel de Desempeño \\
\hline $\begin{array}{c}\text { Terremoto Infrecuente } \\
\left(T_{R}=475 \text { años }\right)\end{array}$ & ELU \\
\hline $\begin{array}{c}\text { Terremoto Frecuente } \\
\text { (Periodo de retorno sin definir })\end{array}$ & ELS \\
\hline
\end{tabular}

Tabla 3-15. Niveles de Demanda y Desempeño del Eurocódigo. (EN 1998-1-1:2004). 


\subsection{Métodos de análisis en EN 1998-2:2005 de puentes}

El Eurocódigo 8 parte 2 de diseño sismorresistente de puentes (EN-1998-2:2005, en adelante EC8-2) establece en el apartado §6.7 una metodología para el análisis de la acción sísmica en estribos de hormigón armado de puentes y de muros de contención, que en cierto modo pueden considerarse similares a una obra subterránea ya que la acción principal que los solicita es el empuje de tierras.

De manera general, el EC8-2 separa en dos términos la acción total del terreno sobre un muro:

- Un primer término $E_{0}$ correspondiente al empuje estático del terreno sobre el muro, es decir, el empuje que las tierras ejercerían sobre el muro si este no estuviera sometido a la acción sísmica.

- Un segundo término $\Delta E_{d}$ correspondiente al incremento de empuje, sobre el Eo estático, que ejercen las tierras por estar sometido a la acción sísmica. Este incremento de empuje dinámico $\Delta E_{d}$ se calcula a partir del empuje dinámico total $E_{d}$ de acuerdo a la fórmula (Ec. 3-205).

$$
\Delta E_{d}=E_{d}-E_{0}
$$

El EC8-2 remite al Eurocódigo 8 parte 5 de diseño de cimentaciones y aspectos geotécnicos (EN-1998-5:2004, en adelante EC8-5) para la obtención del empuje dinámico total del terreno $E_{d}$. En el apartado $§ 3.8 .1 .1 .3$ de esta tesis se profundiza las particularidades de la obtención de este empuje, sin embargo adelantamos que la hipótesis subyacente es la de comportamiento activo del tipo Mononobe-Okabe (§3.7.1.1), o de empuje sobre estructuras rígidas del tipo Wood (§3.7.2.2).

Por otra parte, EC8-2 establece una formulación diferente para estructuras enterradas en las que la profundidad de la losa superior es mayor que el $50 \%$ de la longitud del vano de la estructura. Como se indica en esta normativa, bajo estas condiciones se asume que la estructura está suficientemente enterrada en el terreno circundante, y que los efectos inerciales del terreno y de la estructura ya no pueden analizarse a través de una hipótesis de comportamiento basada en estados límite (hipótesis de formación de una cuña de empuje de Coulomb como plantea la metodología de Mononobe-Okabe). 


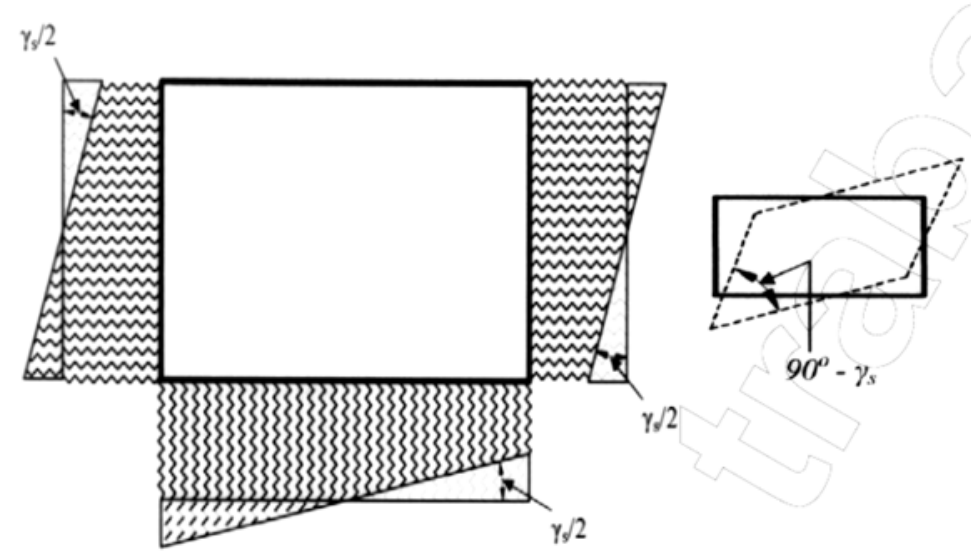

Fig. 3-141. Esquema de EC8-2 representado la deformación del terreno que rodea la estructura enterrada $\gamma_{s}$ y la acción que esta ejerce sobre la propia estructura a través de una malla de muelles elásticos tipo Winkler que simulan la interacción suelo-estructura.

La formulación establecida por EC8-2 se basa en una simplificación de la interacción cinemática suelo-estructura descrita en los apartados $§ 3.7 .3$ y $§ 3.7 .3 .3$, y se articula en los siguientes pasos, ilustrados en la (Fig. 3-141):

- Se calcula la deformación tangencial máxima del terreno circundante $\gamma_{s}$ como si la estructura no estuviera presente, es decir, la deformación del suelo en condiciones de campo-libre entre las cotas correspondientes a la losa superior e inferior.

- Se caracteriza el terreno circundante a la estructura en términos de una fundación elástica de Winkler, es decir, mediante una malla de muelles de rigidez $k$. EC8-2 no proporciona una fórmula o guía para caracterizar la rigidez de estos muelles.

- Se aplica la deformación tangencial $\gamma_{s}$ calculada anteriormente a los extremos de la fundación elástica que no están vinculados a la estructura.

- La reacción de los muelles sobre la estructura para este estado de cargas de deformación impuesta proporciona la acción distorsora del terreno sobre la estructura enterrada.

Según la formulación del EC8-2, la deformación angular del suelo circundante $\gamma_{s}$ puede calcularse mediante la relación entre la velocidad máxima del suelo $v_{g}$ (ground velocity) y la velocidad de propagación de las ondas de cortante ascendentes $v_{s}$ (shear velocity) en el terreno circundante a través de la fórmula (Ec. 3-206): 


$$
\gamma_{s}=\frac{v_{g}}{v_{s}}
$$

La máxima velocidad del terreno puede calcularse si se conoce el periodo fundamental de oscilación del mismo, y la máxima aceleración del terreno PGA. Habitualmente y a falta de análisis más precisos suele considerarse que el periodo fundamental del terreno corresponde al periodo mayor en el que acaba la meseta de aceleraciones de un espectro de diseño, es decir, en términos del EC8-1 el periodo de esquina $T_{C}$. Esta hipótesis se refleja en la formulación de EC8-2 al establecer la fórmula (Ec. 3-207) para definir la velocidad máxima de la superficie del suelo $v_{g}$, en la que $S$ es el coeficiente de amplificación de la aceleración en función de las características del terreno de cimentación, y $a_{g}$ es la aceleración máxima del terreno PGA, en unidades dimensionales (p.ej. $\left.\left[\mathrm{m} / \mathrm{s}^{2}\right]\right)$.

$$
v_{g}=\frac{S \cdot T_{C} \cdot a_{g}}{2 \pi}
$$

Esta formulación de la (Fig. 3-141) para el análisis simplificado, es en apariencia similar a la propuesta por los métodos simplificados de interacción suelo-estructura para estructuras enterradas descritos anteriormente, en especial parece similar al método de Wang descrito en el apartado \$3.7.4.1 de esta tesis. Sin embargo, un análisis más detallado revela una diferencia fundamental: la metodología de EC8-2 parece no tener en cuenta la amplificación o reducción diferencial de la deformación de la estructura con respecto al terreno circundante.

Para argumentar esta reflexión, recurriremos a un caso límite de aplicación del método de EC8-2, que, a pesar de ser poco representativo de una situación real, puede arrojar luz sobre esta aparente discordancia.

Imaginemos de acuerdo a la (Fig. 3-141) una estructura enterrada infinitamente flexible, y que por lo tanto es incapaz de oponer ninguna resistencia a la acción que los muelles de la fundación de Winkler intentan ejercer sobre ella. Si se procede a aplicar una deformación tangencial de campo libre $\gamma_{s}$ a los extremos libres de los muelles de Winkler, estos deformarán la estructura un valor exactamente igual a $\gamma_{s}$, ya que estos muelles no pueden contraerse ni alargarse dado que la reacción en el extremo vinculado con la estructura es nula. Se tiene por lo tanto que, según la metodología de EC8-2 para 
estructuras enterradas, una estructura infinitamente flexible se deformará hasta alcanzar una distorsión $\gamma$ igual a la deformación tangencial de campo libre $\gamma_{s}$.

Sin embargo, como se ha comentado en el apartado §3.7.4 de esta tesis, tanto el planteamiento de Wang (J. N. Wang, 1993), como el de Penzien (Penzien, 2000), y Anderson (Anderson et al., 2008) rechazan el criterio de que la máxima deformación posible en una estructura subterránea es la de campo libre, y consideran que las estructuras más flexibles que el terreno $(F>1)$ se deforman más.

En consecuencia, se puede concluir que el planteamiento de EC8-2 para estructuras enterradas tipo marco responde más bien al descrito como método de deformaciones de campo libre, descrito en el apartado $§ 3.7 .3$ de esta tesis.

\subsection{Métodos de análisis en EN 1998-5:2004 de aspectos qeotécnicos}

El EC8-2 remite al Eurocódigo 8 parte 5 de diseño de cimentaciones y aspectos geotécnicos (EN-1998-5:2004, en adelante EC8-5) para la obtención del empuje dinámico total del terreno $E_{d}$. En general, esta formulación responde a la metodología de Mononobe-Okabe (Mononobe \& Matsuo, 1929; Okabe, 1924), modificada según los resultados obtenidos por Seed y Whitman (Seed \& Whitman, 1970), y que como se ha comentado en el apartado $\$ 3.7 .1$ consisten esencialmente en situar la resultante total debida a la parte estática y dinámica del empuje de tierras a $1 / 2$ de la altura del muro (apartado §7.3.2.3(4) de EC8-2).

El empuje total que actúa en el trasdós del muro se calcula mediante la fórmula (Ec. 3-208), recogida en el apéndice E de EC8-5, en la que $\gamma^{*}$ es el peso específico del suelo del trasdós, $k_{v}$ es la aceleración vertical del terreno, $K$ es el coeficiente de empuje del terreno (empuje total de las partes estática más dinámica), $H$ es la altura del muro, y $E_{w s}$ y $E_{w d}$ son el empuje estático y dinámico del agua en el trasdós si la hubiera.

$$
E_{d}=\frac{1}{2} \gamma^{*}\left(1 \pm k_{v}\right) K \cdot H^{2}+E_{w s}+E_{w d}
$$

Como puede comprobarse, el empuje dinámico total, prescindiendo del empuje del agua, corresponde a una distribución lineal de presiones. El coeficiente $K$ de presión del terreno responde a la ya mencionada formulación de Mononobe-Okabe. Para el caso más común en el que el terreno en el trasdós del muro tenga una pendiente horizontal, y se considere que la flexibilidad del muro es suficiente como para que el terreno del trasdós 
desarrolle un estado de empuje activo, el coeficiente de empuje $K$ se calcula mediante la fórmula (Ec. 3-209). En esta fórmula $\psi$ es el ángulo geométrico del trasdós del muro con la horizontal $\left(90^{\circ}\right.$ si el trasdós del muro es vertical), $\phi^{\prime} d$ es el ángulo de rozamiento interno del suelo del trasdós, $\theta$ es el ángulo que forma la componente horizontal de la aceleración sísmica $k_{h}$ con la componente total de aceleración vertical $1+k_{v}$, es decir el ángulo tal que $\theta=\operatorname{atan}\left[k_{h} /\left(1 \pm k_{v}\right)\right]$, y $\delta_{d}$ es el ángulo de rozamiento entre el terreno y el trasdós del muro.

$$
=\frac{\sin ^{2}\left(\psi+\phi_{d}^{\prime}-\theta\right)}{\cos (\theta) \cdot \sin \left(\psi-\theta-\delta_{d}\right) \cdot\left[1+\sqrt{\frac{\sin \left(\phi_{d}^{\prime}+\delta_{d}\right) \cdot \sin \left(\phi_{d}^{\prime}-\theta\right)}{\sin \left(\psi-\theta-\delta_{d}\right) \cdot \sin (\psi)}}\right]^{2}}
$$

Sin embargo, para estructuras rígidas en las que no se puede suponer que se puede desarrollar un estado de empuje activo, porque la estructura de contención no es lo suficientemente flexible como para que se desarrolle una cuña de empuje de Coulomb, el EC8-5 establece en el apartado §E.9 una metodología basada en la teoría de Wood, descrita en el apartado $§ 3.7 .2 .2$, para calcular el empuje total del terreno $\Delta P_{d}$ sobre el trasdós de la estructura de contención, y que responde a la fórmula (Ec. 3-210). Para aplicar el método de Wood, EC8-5 ha elegido un coeficiente 1 en la curva de la Fig. 3-90, correspondiente a un coeficiente de Poisson $v=0,4$.

En esta fórmula (Ec. 3-210), $\alpha$ es la aceleración horizontal del terreno en roca, PGA, en unidades de $[g], S$ es el coeficiente de amplificación de la aceleración en función de las características del terreno de cimentación, $\gamma$ es el peso específico del suelo del trasdós, y $H$ la altura del muro.

$$
\Delta P_{d}=\alpha \cdot S \cdot \gamma \cdot H^{2}
$$

EC8-5 indica adicionalmente que, el incremento de empuje debido al sismo, puede considerarse aplicado a media altura del muro. Como puede observarse, la formulación propuesta por EC8-5 para estructuras rígidas, corresponde a una ley de presiones uniforme, siendo el valor de esta presión $p=\alpha \cdot S \cdot \gamma$. 


\subsubsection{Recomendaciones francesas AFPS}

De manera previa a la publicación de los Eurocódigos, la AFPS (Association Française du Génie Parasismique) publicó una guía de concepción y protección sismorresistente de obras subterráneas (Wojtkowiak et al., 2001), que recoge la experiencia francesa en este tipo de obras.

En su preámbulo, esta guía hace hincapié en la práctica inexistencia de normativa internacional de referencia para aspectos sísmicos en obras subterráneas, y conmina a tomar con cautela los escasos documentos de otros países, tales como Japón o California, ya que la sismicidad de estas regiones es notablemente mayor que en Francia.

\subsection{Niveles de demanda y desempeño}

La guía AFPS no hace una consideración explícita de diferentes niveles de demanda sísmica, y refiere uno único correspondiente al definido en la normativa sismorresistente en vigor en el momento (Règles PS 92, 1995).

En dicha normativa (Règles PS 92, 1995), aplicable esencialmente al ámbito de la edificación, se especifica un periodo de retorno de referencia de $T_{R}=475$ años, correspondiente a una probabilidad de excedencia de $P=10 \%$ en una vida útil de $T_{L}=50$ años. De manera similar, se establecen 4 clases de importancia de edificios, y coeficientes de amplificación o reducción de la acción de referencia, resumidas en la Tabla 3-16.

\begin{tabular}{|c|c|c|c|c|}
\hline $\begin{array}{c}\text { Clase de } \\
\text { Importancia }\end{array}$ & Edificios que Engloba & $\begin{array}{l}\text { Coeficiente de } \\
\text { Importancia }\end{array}$ & $\begin{array}{c}\text { Probabilidad } \\
\text { de Excedencia }\end{array}$ & $\begin{array}{c}\text { Periodo de } \\
\text { Retorno } T_{R} \text { [años] }\end{array}$ \\
\hline Clase A & $\begin{array}{l}\text { - Construcciones agrícolas } \\
\text {-Edificios de una planta para } \\
\text { garajes o talleres privados }\end{array}$ & $\gamma=0,8$ & $\begin{array}{c}20 \% \text { en } 50 \\
\text { años }\end{array}$ & 225 \\
\hline Clase B & $\begin{array}{l}\text { - Construcciones } \\
\text { residenciales. } \\
\text { - Oficinas y locales } \\
\text { comerciales. } \\
\text { - Talleres y fábricas. } \\
\text { - Garajes públicos }\end{array}$ & $\gamma=1,0$ & $\begin{array}{c}10 \% \text { en } 50 \\
\text { años }\end{array}$ & 475 \\
\hline Clase C & $\begin{array}{l}\text { - Escuelas y universidades. } \\
\text { - Estadios y salas de } \\
\text { espectáculos. } \\
\text { - Halls de viajeros. } \\
\text { - Museos. } \\
\text { - Centrales eléctricas. }\end{array}$ & $\gamma=1,2$ & $6 \%$ en 50 años & 820 \\
\hline Clase D & $\begin{array}{l}\text { - Hospitales. } \\
\text { - Estaciones de bomberos y } \\
\text { ambulancias. } \\
\text { - Museos y bibliotecas. }\end{array}$ & $\gamma=1,4$ & $4 \%$ en 50 años & 1300 \\
\hline
\end{tabular}

Tabla 3-16. Clases de importancia. (Règles PS 92, 1995). 
De esta manera, aunque la guía AFPS no indica explícitamente el nivel de demanda para el diseño de las obras subterráneas, es razonable suponer que las estaciones de Metro deberían englobarse en una clase C (Hall de viajeros), a la que correspondería un periodo de retorno de $T_{R}=820$ años y probabilidad de excedencia de $6 \%$ en 50 años.

En lo que se refiere al nivel de desempeño esperable durante el evento sísmico correspondiente a dicho nivel de demanda, la única referencia consiste en una descripción poco detallada de la ductilidad seccional en obras de hormigón armado, y cómo esta ductilidad es una característica que debe buscarse en las obras subterráneas.

Sin embargo es destacable que esta normativa prevé el recurso a la ductilidad de los elementos estructurales para acomodar las deformaciones impuestas por el sismo. En particular indica:

“La ductilité n’est indispensable que si la conception prévoit un comportement post-elastique sous l'action des déplacements imposés par le seisme. Elle n'est donc pas a obtenir systematiquement. L'augmentation de la ductilité accroît la capacité de la structure à emmagasiner de l'énergie potentielle ou bien à supporter de grandes déformations. Dans le cas des tunnels, c'est cette seconde caractéristique qui est recherchée”. (Wojtkowiak et al., 2001, p.15-16).

Asímismo, indica lo siguiente con respecto a la formación de rótulas plásticas, y añade un croquis de la ley momento-curvatura de una rótula plástica Fig. 3-142.

"L'apparition et la localisation de rotules plastiques au cours du séisme améliorent la ductilité de la construction. L'importance de cette ductilité variera suivant les conditions de frettage de ces rotules plastiques”. (Wojtkowiak et al., 2001, p.16).
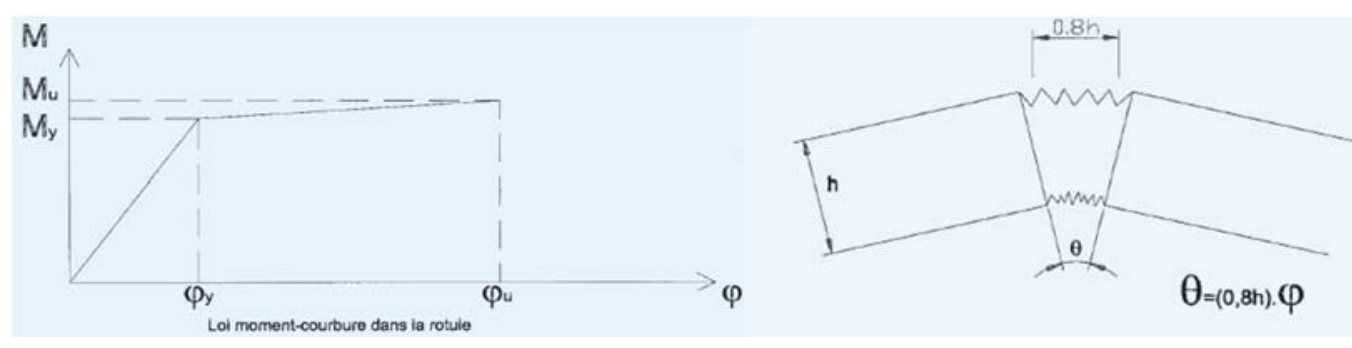

Fig. 3-142. Diagrama momento curvatura de una rótula plástica de la guía AFPS (Wojtkowiak et al., 2001). 


\subsection{Métodos de análisis}

Una primera parte del documento está dedicado al estudio de las solicitaciones longitudinales sobre la estructura, y que recoge esencialmente las conclusiones del trabajo de St. John y Zahrah (St John \& Zahrah, 1987) y Hashash (Hashash, Hook, Schmidt, \& I-Chiang Yao, 2001) descritos en el apartado §3.7.3.2 de esta tesis.

En lo que se refiere a la acción distorsora de la sección de un túnel, la guía propone un método simplificado, que aunque guarda relación aparente con los descritos en los apartados $§ 3.7 .3$ y $§ 3.7 .3 .3$ de esta tesis, tiene diferencias notables. A continuación, se describe este método.

En primer lugar, se propone una fórmula simplificada (Ec. 3-211) para la obtención de la máxima deformación de distorsión en campo libre. Esta fórmula es idéntica a la fórmula expuesta (Ec. 3-206) en el EC8-2, y los términos $V_{0}$ y $V_{s}$ corresponden a la velocidad máxima del terreno y velocidad de propagación de las ondas de cortante respectivamente.

$$
\gamma_{\max }=\frac{V_{0}}{V_{s}}
$$

Para caracterizar como esta deformación de distorsión afecta a la estructura enterrada, la guía AFPS propone un modelo de interacción suelo-estructura como el representado en la Fig. 3-143. Este modelo está constituido por el marco de la estructura subterránea, y una serie de muelles tipo Winkler de rigidez $k$. La solicitación del sismo sobre la estructura se ejerce de dos maneras a considerar de manera conjunta:

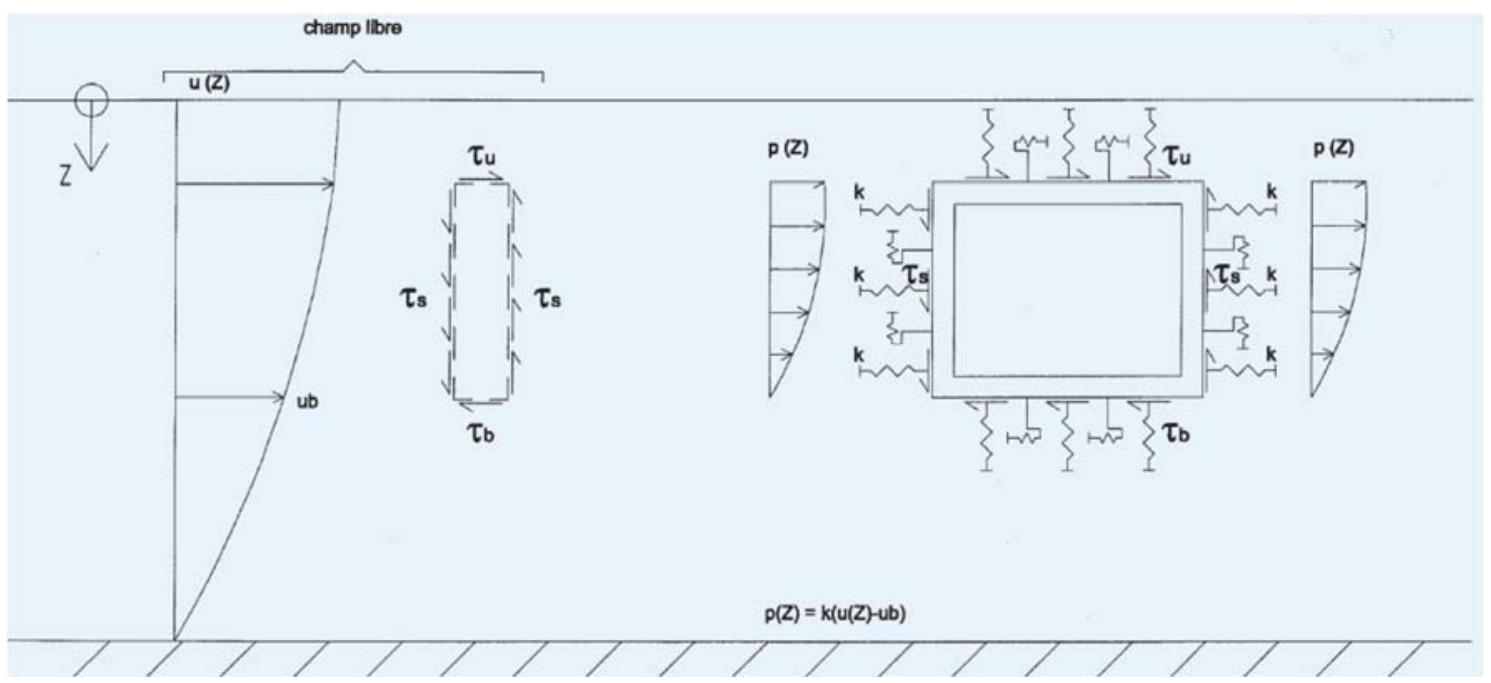

Fig. 3-143. Esquema de acción sísmica transversal de la guía AFPS (Wojtkowiak et al., 2001). 
- Aplicando sobre el extremo no ligado a la estructura de los muelles de Winkler un campo de desplazamientos dependiente de la cota $u(z)$. Alternativamente se puede aplicar sobre la estructura una fuerza de valor $p(z)=k \cdot u(z), y$ fijar los extremos de los muelles no ligados a la estructura.

- Aplicando sobre la estructura unas tensiones tangenciales $\tau_{u}, \tau_{s}$, y $\tau_{b}$ de valor igual a las tensiones tangenciales desarrolladas en sobre el bloque de terreno al que sustituye el túnel en condiciones de campo libre.

- Adicionalmente, se indica que se puede añadir el efecto inercial de la propia estructura del túnel, multiplicando su masa por la aceleración máxima del terreno $A_{0}$, aunque se puntualiza que este efecto es poco significativo.

Para obtener la rigidez $k$ de los muelles, la guía AFPS en su anejo $\S 5$ propone tres expresiones diferentes, basadas en los estudios de Scott (Scott, 1974) (Ec. 3-212), Veletsos (Veletsos \& Younan, 1994) (Ec. 3-213), y una expresión original de esta guía (Ec. 3-214).

$$
\begin{gathered}
k=\frac{8 G(1-v)}{10 H(1-2 v)} \\
k=1,086 \frac{x^{2}}{4} \frac{G}{\sqrt{(1-v)(2-v)}} \\
k=0.5 \frac{G}{H}
\end{gathered}
$$

Es destacable la similitud de esta metodología con la que presenta el EC8-2, descrita en el apartado §3.8.1.1 de esta tesis, siendo probablemente este método de la AFPS la base sobre la que se asienta la formulación del Eurocódigo 8.

De manera similar a como se ha hecho al analizar la formulación de EC8-2, el planteamiento de este método resulta criticable desde el punto de vista del fenómeno de amplificación cinemática de la distorsión. En efecto, para casos flexibles en los que la rigidez a la distorsión de la estructura sea despreciable $(F>>1)$, la formulación de la AFPS lleva a asumir una deformación de la estructura igual a la del campo libre $\gamma_{\max }$. Como se ha indicado en el apartado §3.8.1.1, este planteamiento entra en contradicción con los resultados obtenidos con los métodos de interacción cinemática de Wang (J. N. 
Wang, 1993) y Penzien (Penzien, 2000) descritos en el apartado §3.7.3.3 y, como se verá más adelante, con la normativa de EE.UU.

Por otra parte, resulta interesante destacar una diferencia importante con respecto al método propuesto por EC8-2 y que puede pasar desapercibida en una primera lectura de ambos documentos. Refiriéndonos a las figuras Fig. 3-141 y Fig. 3-143, puede observarse que el EC8-2 impone una deformación de distorsión $\gamma / 2$ a los muelles de las paredes laterales, y otra deformación $\gamma / 2$ a la losa de fondo, mientras que la guía AFPS sólo impone una deformación horizontal $p(\mathrm{z})$ en los muelles de las paredes laterales. La relevancia de este hecho se pondrá de manifiesto en el capítulo $\S 4$ de esta tesis.

\subsubsection{Normativa Estadounidense}

Al contrario de lo que ocurre en el ámbito europeo, en EE.UU. existe una normativa, desarrollada por primera vez en fechas tan recientes como 2017, para el campo de los túneles carreteros subterráneos. Por otra parte, las competencias de los propios estados en materia de obras públicas, lleva a que los diferentes estados puedan tener normativas de proyecto diferentes. En este apartado revisamos las normas existentes, y documentos normativos de facto, para el diseño sismorresistente de obras subterráneas o relacionadas con aspectos geotécnicos, tanto a nivel federal, como de los dos estados que históricamente tienen un mayor desarrollo en temas sísmicos (California y Washington en la costa oeste del Pacífico).

\subsubsection{AASHTO LRFD Road Tunnel Design and Construction Guide Specifications 2017}

Recientemente, la American Association of State Highway and Transportation Officials (AASHTO) ha desarrollado una normativa específica para túneles de carretera en la que se recogen aspectos de diseño sísmico. Esta normativa está fuertemente influenciada por los documentos estadounidenses previos FHWA Technical Design Manual for Road Tunnels 2009, y Metro of Los Angeles Design Criteria, descritos respectivamente en los apartados $§ 3.8 .2 .3$ y $§ 3.8 .2 .8$ de esta tesis que, hasta la fecha de publicación de la norma AASHTO, formaban la normativa de-facto en este país para las obras subterráneas sometidas a la acción del sismo. 


\subsection{Niveles de demanda y desempeño}

La normativa AASHTO LRFD de túneles (AASHTO Tunnels, 2017) adopta en su articulado el paradigma más reciente de diseño basado en el desempeño. En este sentido, establece dos niveles de demanda sísmica y dos objetivos de desempeño para estos escenarios. Por un lado establece un nivel de seguridad elevado para la vida de las personas durante el denominado Sismo de Evaluación de la Seguridad (Safety Evaluation Earthquake, SEE), mientras que establece un nivel de seguridad elevado para la continuidad de las operaciones durante y después del sismo denominado Sismo de Evaluación de la Funcionalidad (Functionality Evaluation Earthquake, FEE). Estos niveles de demanda se describen en dicha norma de la siguiente manera, muy relacionada con los objetivos de desempeño:

- SEE (Safety Evaluation Earthquake): Este evento tiene una pequeña probabilidad de ser excedido durante la vida útil de la infraestructura. Después del sismo SEE, se permite cierta interrupción del servicio. Cuando la estructura se ve sometida al sismo de nivel SEE, es aceptable que las estructuras se comporten de manera inelástica. No debe producirse el colapso ni la inundación catastrófica que suponga un peligro para la vida. Cualquier daño estructural debe ser controladp y limitado a aquellos elementos que son reparables. La estructura debe ser diseñada con una resistencia y ductilidad adecuadas para sobrevivir a las cargas y deformaciones impuestas en la estructura durante el evento SEE, y evitando de esta manera el colapso y manteniendo la seguridad de la vida de las personas.

- FEE (Functionality Evaluation Earthquake): Este evento tiene un periodo de retorno inferior al del sismo SEE. Debe haber una interrupción mínima al servicio durante o después de un sismo FEE. Cuando la estructura se someta a un sismo de nivel FEE, esta debe diseñarse para que responda de una manera elástica. No debe producirse el colapso, y tan sólo se permite un daño mínimo a los elementos estructurales. Este daño debe ser menor y reparable. La estructura debe permanecer completamente operacional tras el sismo, tras unas cuantas horas de inspección.

La norma AASHTO LRFD Tunnels 2017 no establece de manera taxativa cuales deben ser los periodos de retorno que corresponden a estos dos escenarios SEE y FEE, si 
no que los deja a elección de la autoridad reguladora competente o Propiedad de la infraestructura (Departamento de transportes del estado correspondiente, ayuntamiento, etc). Sin embargo, proporciona algunos valores de referencia que se han empleado en proyectos de túneles de carretera. Estos valores se resumen en la Tabla 3-17.

\begin{tabular}{|c|c|}
\hline Nivel de demanda & Periodo de retorno \\
\hline & - Entre $T_{R}=1000$ años y $T_{R}=2500$ años. \\
SEE & - En la mayor parte de las ocasiones se ha optado \\
(Safety Evaluation Earthquake) & por $T_{R}=2500$ años. \\
& $-T_{R}=2500$ años corresponde a una probabilidad de \\
& ser excedido del $4 \%$ en un horizonte de 100 años. \\
\hline & - Generalmente $T_{R}=100$ años. \\
& $-T_{R}=100$ años corresponde a una probabilidad de \\
& ser excedido de $65 \%$ en un horizonte de 100 años. \\
& En zonas con una sismicidad menor (Este de \\
FEE & EE.UU.), o en aquellos casos en los que las \\
(Functionality Evaluation Earthquake) & consecuencias de la interrupción del servicio del \\
& sistema son graves, se ha optado por un periodo \\
& de retorno de $T_{R}=500$ años. \\
& $-T_{R}=500$ años corresponde a una probabilidad de \\
& ser excedido de $20 \%$ en un horizonte de 100 años. \\
\hline
\end{tabular}

Tabla 3-17. Niveles de demanda sísmica y periodos de retorno correspondientes en la normativa AASHTO de Túneles. (AASHTO Tunnels 2017).

En lo que respecta a los criterios de desempeño, la norma AASHTO de túneles (AASHTO Tunnels, 2017) establece que las deformaciones en los materiales deben ser inferiores a los límites que se resumen en la Tabla 3-18.

\begin{tabular}{|c|c|c|c|c|}
\hline \multirow{2}{*}{$\begin{array}{c}\text { Nivel de } \\
\text { demanda }\end{array}$} & \multicolumn{4}{|c|}{ Límite de deformación } \\
\cline { 2 - 5 } & Tunel en mina o con tuneladora & \multicolumn{2}{|c|}{ Tunel cut-and-cover } \\
\cline { 2 - 5 } & Hormigón & Acero & Hormigón & Acero \\
\hline $\begin{array}{c}\text { SEE } \\
\text { (Safety Evaluation } \\
\text { Earthquake) }\end{array}$ & $\varepsilon_{c} \leq 0,33 \%$ & $\varepsilon_{s} \leq 2 \%$ & $\varepsilon_{c} \leq 0,6 \%$ & $\varepsilon_{s} \leq 2 \%$ \\
\hline $\begin{array}{c}\text { FEE } \\
\text { (Functionality } \\
\text { Evaluation } \\
\text { Earthquake) }\end{array}$ & $\varepsilon_{c} \leq 0,2 \%$ & $\varepsilon_{s} \leq 0,2 \%$ & $\varepsilon_{c} \leq 0,3 \%$ & $\varepsilon_{s} \leq 0,2 \%$ \\
\hline
\end{tabular}

Tabla 3-18. Límites de deformación en los materiales correspondientes en la normativa AASHTO de Túneles. (AASHTO Tunnels 2017).

Como puede apreciarse en los valores resumidos en la Tabla 3-18, en general los límites correspondientes a las obras construídas mediante cut-and-cover son ligeramente mayores que los correspondientes a las obras ejecutadas en mina o mediante tuneladora. Este hecho es debido, probablemente, a que el mecanismo resistente fundamental es diferente en ambos tipos de obras: en un túnel cut-and-cover la flexión es el mecanismo 
que proporciona la resistencia a la estructura, mientras que en una estructura en mina o con tuneladora es la propia forma de la estructura, en tanto que antifunicular de cargas, la que proporciona el mecanismo resistente con esfuerzos axiles.

Por otra parte, en las estructuras en mina o con tuneladora, las deformaciones máximas permitidas para el nivel de demanda menor (FEE) corresponden a los límites convencionales habituales en los que se asume que tanto el hormigón como el acero inician el comportamiento plástico $\left(\varepsilon_{c, \text { Plast }} \approx 0,2 \%, y \varepsilon_{s, y}=f_{y} / E_{s}=0,2 \%\right)$. De esta manera y en vista de los comentado en la descripción cualitativa de los objetivos de desempeño, puede observarse que AASHTO considera que para las estructuras subterráneas en mina o con tuneladora, la funcionalidad inmediata de la infraestructura tras un sismo sólo se consigue con un comportamiento perfectamente elástico.

También para estructuras en mina o con tuneladora, las deformaciones máximas permitidas para el nivel de demanda superior (SEE) corresponden al límite convencional en el que se asume que se incia el fenómeno de spalling en el hormigón $\left(\varepsilon_{c, S p a l l i n g} \approx\right.$ 0,35\%), y una deformación plástica en el acero muy limitada dentro de la capacidad plástica de este $\left(\varepsilon_{s, u} \approx 9 \%\right)$. Estos límites restrictivos en la deformación de los materiales tienen sentido en el contexto de la resistencia por forma de antifunicular indicada anteriormente. En efecto, unos límites superiores corresponderían a una deformación plástica considerable en el caso del acero, o a una pérdida de, con lo que se perdería la forma de antifunicular para resistir los empujes de tierras estáticos convencionales.

Sin embargo, para estructuras de tipo cut-and-cover que resisten por flexión, para el nivel de demanda menor (FEE), el límite de deformación en el hormigón corresponde esencialmente a la deformación en la que se produce el spalling, y al límite elástico del acero $\left(\varepsilon_{c, \text { Spalling }} \approx 0,35 \%, y \varepsilon_{s, y}=f_{y} / E_{s}=0,2 \%\right.$ ). Interpretando los límites impuestos por la AASHTO se puede llegar la conclusión de que la funcionalidad inmediata de la infraestructura tras un sismo se consigue con un comportamiento esencialmente elástico de los materiales, o ligeramente plástico pero sin producir daño apreciable.

Para el nivel mayor de demanda (SEE) la norma AASHTO permite un comportamiento plástico mayor en las estructuras cut-and-cover que en el caso de los túneles en mina, pero aún así muy contenido. Los límites que propone corresponden a una situación en la que claramente se ha producido el spalling en el hormigón, pero la deformación es todavía contenida, al igual que el acero, que ha plastificado pero aún está 
lejos de agotar su rango máximo de deformación. Interpretando los límites impuestos por la AASHTO se puede llegar la conclusión de que estas deformaciones en hormigón y acero corresponden a estados que pueden ser facilmente reparables.

\subsection{Métodos de análisis}

En lo que respecta al análisis de esfuerzos y deformaciones en las estructuras subterráneas rectangulares, la norma AASHTO indica que se deberán evaluar los esfuerzos engendrados por la deformación lateral de racking, imponiendo en un modelo de estructura las deformaciones diferenciales entre losa superior e inferior. Para el cálculo preciso de cuales son estas deformaciones, la norma AASHTO remite al FHWA Technical Manual for Design and Construction of Road Tunnels (Hung et al., 2009), el cual a su vez asume el método de análisis de Wang (J. N. Wang, 1993), tal y como se expone en el apartado §3.8.2.3 de esta tesis que describe dicho manual.

\subsubsection{AASHTO LRFD 2012 y AASHTO Guide Specifications for LRFD Seismic Bridge Design 2011}

\subsection{Niveles de demanda y desempeño}

La norma AASHTO LRFD 2012 (American Association of State Highway and Transportation Officials. Load Resistance Factor Design. Bridge Design Specifications 2012) proporciona un único nivel de demanda sísmica para el cual deben ser diseñadas las estructuras, que corresponde a un escenario con probabilidad de excedencia del 7\% durante una vida útil de 75 años, y a un periodo de retorno de $T_{R}=1000$ años. Para este nivel de demanda la norma indica, de manera imprecisa, que resulta un desempeño admisible el que las estructuras sufran daño significativo, e incluso que requieran su sustitución parcial o total, pero que no deben colapsar.

De manera indirecta, AASHTO LRFD 2012 indica que, en términos generales, las estructuras diseñadas de acuerdo a esta norma se comportarán de manera elástica sin daño significativo para terremotos de pequeños a moderados.

En particular, en lo que resepecta a las acciones sísmicas para estructuras enterradas, AASHTO LRFD 2012 indica textualmente en el apartado §3.10.1:

"Seismic effects for box culverts and buried structures need not to be considered, except where they cross active faults”. (AASHTO LRFD 2012, p.3.53). 
Por otra parte, la guía de diseño sísmico AASHTO 2011 (American Association of State Highway and Transportation Officials. Guide Specifications for LRFD. Bridge Design 2011), más centrada en los aspectos sismorresistentes y de desempeño sísmico, proporciona unos términos idénticos para establecer un único nivel de demanda sísmica.

Para este nivel de demanda, la guía de diseño sísmico AASHTO 2011 proporciona en el apartado §3.2 una descripción cualitativa de los criterios de desempeño esperables para este único nivel de demanda, en forma de daños esperables y que se resumen en la Tabla 3-17.

\begin{tabular}{|c|l|}
\hline Nivel de Demanda & \multicolumn{1}{c|}{ Nivel de Desempeño } \\
\hline Diseño ELU & $\begin{array}{l}\text { - Fisuración. } \\
\text { - Plastificación de las armaduras. } \\
\text { - Spalling del hormigón de recubrimiento. }\end{array}$ \\
\hline
\end{tabular}

Tabla 3-19. Matriz de Demanda-Desempeño de la normativa AASHTO. (AASHTO Guide Specifications for LRFD Seismic Bridge Design, 2011).

\subsection{Métodos de análisis}

Para el análisis de muros de gravedad de contención de tierras, AASHTO 2012 plantea la formulación de Mononobe-Okabe descrita en el apartado §3.7.1.1 de esta tesis.

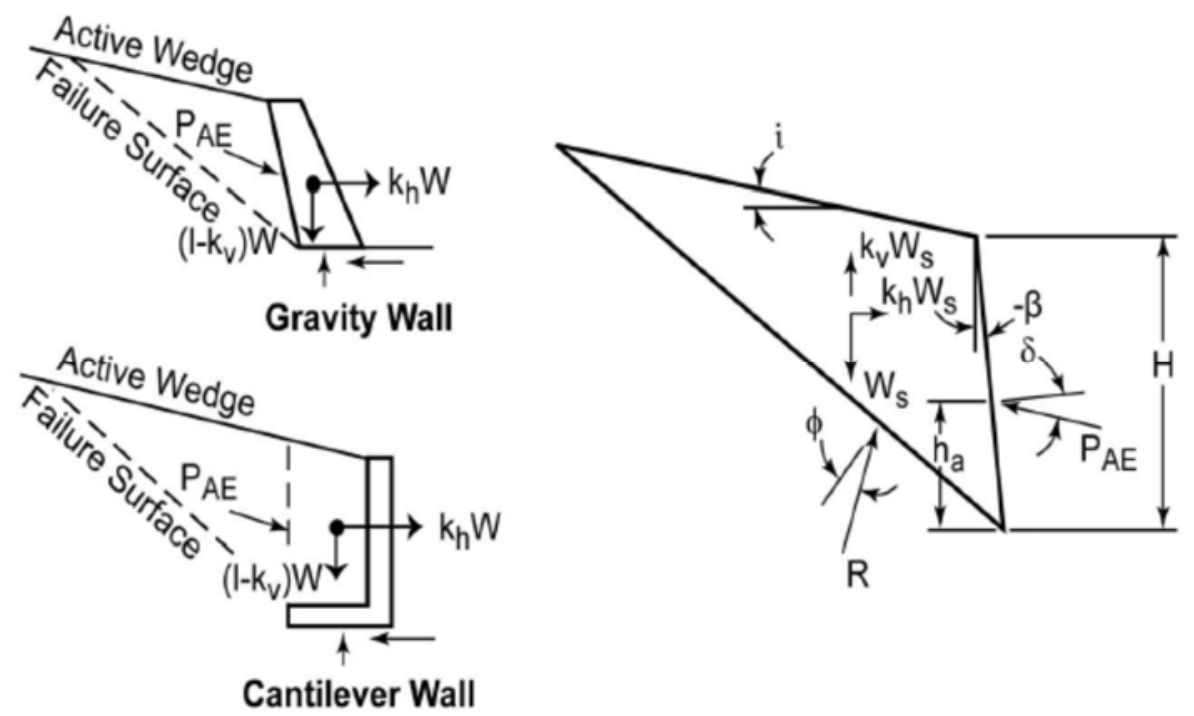

Fig. 3-144. Esquemas de cuña activa de empuje en situación sísmica. (AASHTO, 2012).

El empuje total debido a las partes estática y dinámicas viene dado por la expresión (Ec. 3-215), en la que $K_{A E}$ es coeficiente de empuje total, g la densidad del terreno, $H$ la altura del muro, h la altura del muro en el extremo del talón, $\phi_{f}$ el ángulo de rozamiento interno del suelo, $\theta_{\mathrm{MO}}$ el $\operatorname{atan}\left(k_{h} /\left(1-k_{v}\right)\right), \delta$ el ángulo de rozamiento del trasdós 
del muro, $k_{h}$ la aceleración horizontal máxima, $k_{v}$ la aceleración vertical máxima, $i$ el ángulo de las tierras en el trasdós, y $\beta$ el ángulo del trasdós del muro.

$$
\begin{aligned}
K_{A E}=\frac{\cos ^{2}\left(\phi-\theta_{M O}-B\right)}{\cos \left(\theta_{M O}\right) \cdot \cos ^{2}(\beta) \cdot \cos \left(\delta+\beta+\theta_{M O}\right)} \\
\cdot\left[1-\sqrt{\frac{\sin (\phi+\delta) \cdot \sin \left(\phi-\theta_{M O}-i\right)}{\cos \left(\delta+\beta+\theta_{M O}\right) \cdot \cos (i-\beta)}}\right]^{-2}
\end{aligned}
$$

Con respecto al punto de aplicación de la resultante, AASHTO 2012 comenta las diversas posiciones que se han asumido históricamente, desde la $H / 3$ original de Mononobe (Mononobe \& Matsuo, 1929), a la 2/3·H de la parte dinámica de Seed y Whitman (Seed \& Whitman, 1970), a la tradición de aplicarla a $0.5 \cdot H$ en versiones anteriores de la AASHTO. En base a los resultados experimentales de Al Atik y Sitar (A1 Atik \& Sitar, 2010), AASHTO 2012 termina recomendando la aplicación a una altura de $H / 3$ para muros convencionales, y entre $0,4 \cdot H$ y $0,5 \cdot H$ para muros cuyo fallo puede tenr consecuencias relevantes.

En lo que se refiere a muros de contención muy rígidos, en los que no se puede considerar factible la formación de la cuña de empuje activo (nonyielding walls), AASHTO 2012 asume las conclusiones del método de Wood (Wood, 1973) descrito en el apartado §3.7.2.2, y exige que se considere una presión uniforme de valor $P G A \cdot g \cdot H$ a lo largo de toda la altura del muro.

En lo que se refiere al análisis de estructuras subterráneas propiamente dichas, la AASHTO LFRD 2012 no exige ningún tipo de análisis si la estructura no cruza una falla activa. Así lo indica en su apartado §12.6.1 de cargas (Loading) del capítulo 12 dedicado a obras subterráneas y túneles (Underground Structures and Tunnel Liners):

"Earthquake loads should be considered only where buried structures cross active faults." (AASHTO, 2012, p. 12-13).

\subsubsection{FHWA Technical Manual for Design and Construction of Road Tunnels 2009}

\subsection{Niveles de demanda y desempeño}

El manual de diseño de túneles de la FHWA (Hung et al., 2009), no establece de manera taxativa niveles de demanda para los cuales debe diseñarse la obra subterránea. Aduciendo los efectos catastróficos que el colapso de un túnel tendría para el transporte, 
especialmente los que forman parte de una red de transporte de masas como el metro, y los profundos efectos sociales y económicos, indica en el apartado §13.2.2 que es habitual que los túneles modernos se diseñen para resistir terremotos con un periodo de retorno de $T_{R}=2500$ años (probabilidad de excedencia del 2\% en 50 años). Asimismo, indica que para evitar largos periodos en los que el túnel pueda quedar fuera de servicio durante las reparaciones, los túneles deberían diseñarse para que para que puedan ser puestos de nuevo en servicio tras un terremoto de menor intensidad. El manual FHWA de diseño de túneles indica que este nivel menor se define generalmente con un periodo de retorno de $T_{R}=108$ años (probabilidad de excedencia del 50\% en 50 años) para zonas sísmicamente activas, y con un periodo de retorno de $T_{R}=500$ años para zonas donde los terremotos son menos frecuentes. Estos escenarios se resumen en la Tabla 3-20.

\begin{tabular}{|c|l|}
\hline Nivel de Demanda & \multicolumn{1}{c|}{ Definición } \\
\hline Nivel L1 & $\begin{array}{l}\text { - Periodo de retorno } T_{R}=108 \text { años para zonas activas. } \\
\text { - Periodo de retorno } T_{R}=500 \text { años para zonas poco activas. }\end{array}$ \\
\hline Nivel L2 & - Periodo de retorno $T_{R}=2500$ años. \\
\hline
\end{tabular}

Tabla 3-20. Niveles de demanda sísmica del manual de túneles FHWA. (Hung et al., 2009).

En lo que se refiere a los criterios de desempeño que las estructuras subterráneas deben satisfacer para cada uno de estos escenarios, el manual FHWA de diseño de túneles no proporciona ninguna guía a la que referirse, más allá de los criterios proco precisos indicados anteriormente.

\subsection{Métodos de análisis}

El manual FHWA de diseño de túneles (Hung et al., 2009) se refiere a los métodos de interacción cinemática desarrollados por Wang (J. N. Wang, 1993), Penzien (Penzien, 2000), y Owen y Scholl (Owen \& Scholl, 1981), para el análisis transversal y longitudinal simplificado de túneles bajo solicitación sísmica. El manual resalta que el objetivo del diseño de la estructura es asegurar que la misma puede absorber la deformación de distorsión impuesta, más que resistir un determinado nivel de fuerzas. Por otra parte, indica que en aquellos casos en los que los métodos simplificados anteriores son de aplicación más incierta, poco concluyentes, o para el caso de estructuras muy importantes en entornos sísmicamente muy activos, puede ser aconsejable el empleo de métodos numéricos del tipo elementos finitos.

Con respecto a las estructuras rectangulares construídas por el método de cut-andcover, el manual indica que suelen ser más vulnerables, ya que se encuentran 
habitualmente en suelos blandos que tienden a deformarse más bajo la acción del sismo que los suelos más rígidos. De manera similar, comenta que este tipo de estructuras suele estar a poca profundidad, donde los efectos de la deformación son mayores.

Para los métodos simplificados de estructuras rectangulares, el manual establece una primera aproximación grosera consistente en diseñar la estructura para que sea capaz de adaptarse a las deformaciones impuestas de campo libre, con un análisis similar al de Kuesel (Kuesel, 1969) (Fig. 3-145), descrito en el apartado §3.7.3.1 de esta tesis.

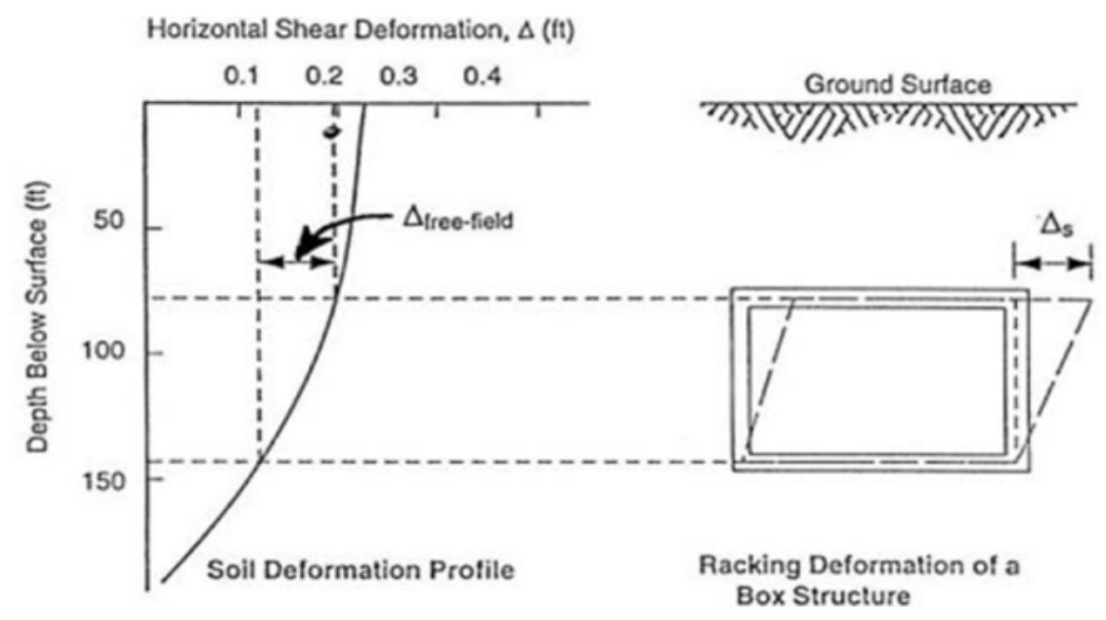

Fig. 3-145. Esquemas de diseño grosero con deformación de campo libre. (Hung et al., 2009).

Sin embargo, este manual, a diferencia de las normas revisadas en los apartados anteriores, recoge las consideraciones de Wang (J. N. Wang, 1993) respecto a la influencia de la rigidez de la propia estructura en la demanda de los desplazamientos impuestos. En efecto, indica que el procedimiento de la (Fig. 3-145) puede dar lugar a diseños excesivamente conservadores cuando las estructuras son muy rígidas, o del lado de la inseguridad cuando las estructuras son muy flexibles.

Para tener en cuenta la influencia de la rigidez, el manual FHWA de diseño de túneles reproduce la metodología de Wang descrita en el apartado §3.7.4.1 de esta tesis. En particular, propone la fórmula (Ec. 3-216) para determinar el coeficiente de flexibilidad estructura-suelo, y establece las fórmulas (Ec. 3-217) y (Ec. 3-218) para calcular el coeficiente de racking para condiciones de no deslizamiento y deslizamiento completo de la interfaz túnel-suelo. La representación gráfica de estos coeficientes de racking es la de la (Fig. 3-146).

$$
F_{r}=\frac{G_{m}}{K_{s}} \cdot \frac{W}{H}
$$




$$
\begin{gathered}
R_{r, \text { no slip }}=\frac{4\left(1-v_{m}\right) F_{r}}{3-4 v_{m}+F_{r}} \\
R_{r, \text { full slip }}=\frac{4\left(1-v_{m}\right) F_{r}}{2.5-3 v_{m}+F_{r}}
\end{gathered}
$$
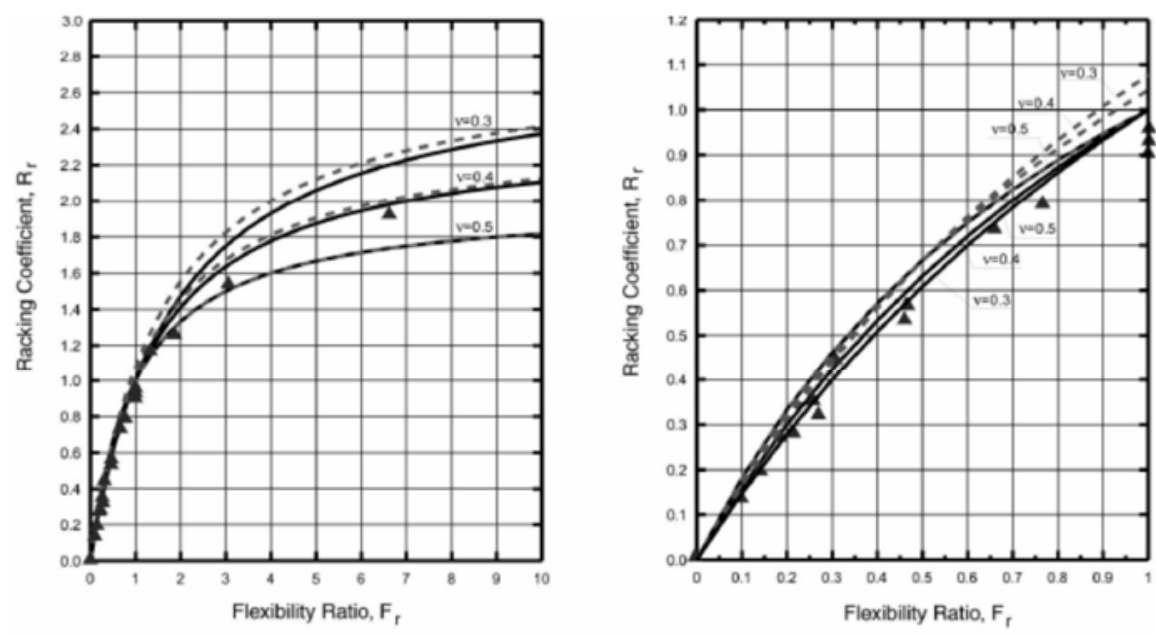

Dashed Lines: Full Slip, $R_{\mathrm{r}}=4(1-\mathrm{v}) \mathrm{F}_{\mathrm{r}} /\left(\mathrm{F}_{\mathrm{r}}+2.5-3 \mathrm{v}\right)($ Wang, 1993, Penzien, 2000)

Solid Lines: $\quad$ No Slip, $R_{r}=4(1-v) F_{r} /\left(F_{r}+3-4 v\right)$ (Penzien, 2000)

Fig. 3-146. Coeficiente de racking. (izda) Flexibilidades $0<F<10$. (dcha) Flexibilidades $0<F<1$. (Hung et al., 2009).

Tras obtener el coeficiente de racking $R_{r}$, se obtiene el desplazamiento horizontal relativo $\Delta_{s}$ entre losa superior e inferior del túnel mediante la fórmula (Ec. 3-219). El manual propone entonces aplicar una fuerza concentrada en la losa superior tal que produzca este desplazamiento si la estructura está enterrada a gran profundidad (Fig. $3-147$, izda.), o una ley triangular de presiones en los muros laterales tal que produzca este desplazamiento si la estructura es más superficial (Fig. 3-147, dcha.).

$$
\Delta_{s}=R_{r} \cdot \Delta_{\text {free-field }}
$$

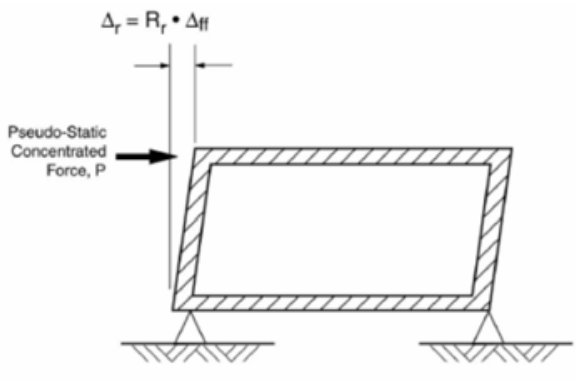

a. Pseudo-Concentrated Force for Deep Tunnels

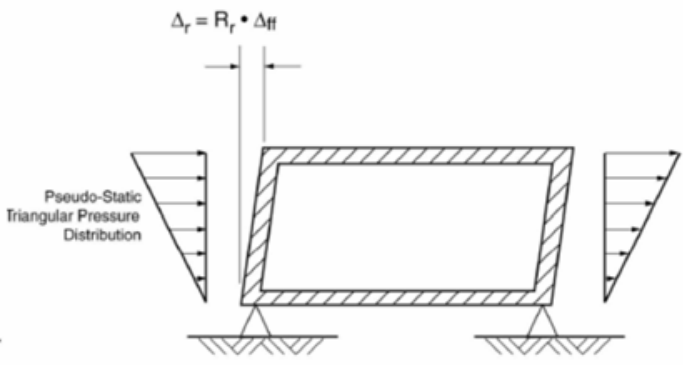

b. Pseudo-Triangular Pressure Distribution for Shallow Tunnels

Fig. 3-147. Esquemas de cargas equivalentes que producen el desplazamiento de racking. (Hung et al., 2009). 
En el manual se hacen varias apreciaciones cualitativas interesantes con respecto al comportamiento para diferentes rigideces:

- En primer lugar señala que las estructuras más flexibles $\left(F_{R}>1\right)$ se deformarán más que el suelo circundante, y que para el caso límite de una estructura infinitamente flexible $\left(F_{R} \rightarrow \infty\right)$ esta tiende a deformarse tanto como una cavidad sin estructura, a la que le corresponde una deformación de 4(1- $\left.v_{m}\right)$ veces la deformación en campo libre (Penzien, 2000; Penzien $\& \mathrm{Wu}, 1998)$.

- Por otra parte, las estructuras con una rigidez similar a la del terreno $\left(F_{R} \approx 1\right)$ se deformarán de manera similar al terreno, y por lo tanto el uso del método de las deformaciones de campo libre resulta lícito.

- Por último, las estructuras más rígidas se deformarán menos que el suelo circundante, y que para el caso límite de una estructura infinitamente rígida $\left(F_{R} \rightarrow 0\right)$ no se produce ninguna deformación en la estructura.

El primer punto es muy interesante, ya que incide sobre la crítica que se hace en esta tesis (apartado §3.8.1.1.2) a los métodos del Eurocódigo EC8-2, de la guía AFPS, de la normativa japonesa, y de la normativa chilena.

El análisis del último punto también es muy interesante, ya que el método parece dejar sin respuesta como deben analizarse las estructuras extremadamente rígidas. En efecto, no parece realista asumir que puesto que la deformación de racking es nula, la acción del sismo sobre la estructura es nula, ya que entraría en contradicción con lo expuesto por los métodos elásticos de enpuje dinámico (descritos en el apartado §3.7.2 de esta tesis), y que predicen acciones muy notables sobre las estructuras rígidas.

Podemos concluir que esta formulación del método de racking no está definida de manera apropiada para tratar el caso de estructuras muy rígidas.

\subsubsection{FHWA Seismic Retrofitting Manual for Highway Structures 2004}

\subsection{Niveles de demanda y desempeño}

A pesar de no tratar específicamente la demanda y desempeño de las obras subterráneas, el manual de reacondicionamiento de la FHWA (Buckle et al., 2006; Yen, Fallon, \& Connor, 2005) trata de manera muy interesante los aspectos relacionados con la demanda y desempeño sísmicos esperables en puentes en función de cual sea la vida 
remanente de la obra. De esta manera establece un marco conceptual para abordar la planificación presupuestaria de las reparaciones en obras públicas.

En cuanto al nivel de demanda, el manual establece dos niveles de peligrosidad sísmica, uno frecuente con un periodo de retorno $T_{R}=100$ años ( $63 \%$ de probabilidad de excedencia en una vida útil de $T_{L}=100$ años), y otro infrecuente con un periodo de retorno $T_{R}=1000$ años ( $10 \%$ de probabilidad de excedencia en una vida útil de $T_{L}=100$ años). Estos niveles de demanda se resumen en la Tabla 3-21.

\begin{tabular}{|c|c|c|}
\hline Nivel de Demanda & $\begin{array}{c}\text { Periodo de Retorno } \\
T_{R}[\mathrm{años}]\end{array}$ & $\begin{array}{c}\text { Probabilidad de } \\
\text { Excedencia }\end{array}$ \\
\hline Nivel L1 & 100 años & $63 \%$ en $T_{L}=100$ años \\
\hline Nivel L2 & 1000 años & $10 \%$ en $T_{L}=100$ años \\
\hline
\end{tabular}

Tabla 3-21. Niveles de demanda sísmica para reacondicionamiento de puentes. (Buckle et al., 2006).

Con respecto a los niveles de daño esperable, el manual de reacondicionamiento indica de manera poco precisa un primer nivel de daño inexistente, para el cual la estructura puede ser usada inmediatamente después de la inspección pertinente, y un nivel de daño mayor para el cual la obra no debe colapsar, pero puede se dañada severamente y quedar inutilizable tras el sismo.

Por otra parte, clasifica los puentes en dos categorías, importancia Esencial e importancia Normal. Todos los puentes que no satisfacen algún criterio para clasificarse como esenciales entran en la categoría de normales. La Tabla 3-22 resume los criterios de clasificación de cada categoría.

\begin{tabular}{|c|c|}
\hline Importancia & Criterios de Calsificación \\
\hline & - Puente necesario para garantizar la seguridad de la vida en \\
aspectos secundarios. (p.ej. proporciona acceso a servicios \\
locales de emergencia tales como hospitales, o cruza vías que \\
proporcionan acceso a dichos servicios, o soporta servicios \\
básicos como electricidad, conducciones de gas o de agua, etc.). \\
- La pérdida del puente conleva un impacto económico severo \\
(p.ej. es un elemento principal en la red de transporte, o es vital \\
para la recuperación económica de la región, o proporciona \\
servicio a un área que tiene un impacto principal en la economía \\
local). \\
- El puente se incluye en un plan de emergencia local (p.ej. forma \\
parte de una evacuación, proporciona acceso a servicios de \\
emergencias tales como bomberos, agencias de salud, etc.). \\
& - El puente es un vínculo crítico en la red nacional de defensa, o \\
& necesario para la seguridad de la nación. (p.ej. en carreteras que \\
& dan acceso a instalaciones militares, industrias estratégicas, etc.) \\
\hline Normal & - Todos aquellos que no son esenciales. \\
\hline
\end{tabular}

Tabla 3-22. Categorías sísmicas para reacondicionamiento de puentes. (Buckle et al., 2006). 
Además de lo anterior, el manual de rehabilitación FHWA, establece un criterio de clasificación en función de la vida de servicio remanente (Anticipated Service Life), un concepto relacionado con la edad y condición de la estructura. Indica que los puentes que todavía son nuevos permanecerán en servicio más tiempo, y que por lo tanto estarán expuestos durante un mayor tiempo a la amenaza de un sismo, y consecuentemente deberán reacondicionarse para hacerlos más resistentes. Por otro lado, el reacondicionamiento de un puente con una vida remanente escasa es menos justificable desde la perspectiva de la probabilidad de que ocurra un terremoto en el periodo de vida remanente que afronta. La Tabla 3-23 resume los criterios del manual de rehabilitación de la FHWA para clasificar los puentes en función de su vida remanente.

\begin{tabular}{|c|c|}
\hline Categoría de Vida Remanente & Vida Remanente en Servicio Aproximada \\
\hline ASL1 & $0-15$ años \\
\hline ASL2 & $16-50$ años \\
\hline ASL3 & $\geq 50$ años \\
\hline
\end{tabular}

Tabla 3-23. Categorías de clasificación de vida remanente para reacondicionamiento de puentes. (Buckle et al., 2006).

Finalmente, el manual FHWA establece cuatro niveles de desempeño que se resumen en la Tabla 3-24.

\begin{tabular}{|c|c|}
\hline $\begin{array}{c}\text { Nivel de } \\
\text { Desempeño }\end{array}$ & \multicolumn{1}{c|}{ Descripción } \\
\hline PL0 & \multicolumn{1}{c|}{ Sin objetivos } \\
\hline PL1 & $\begin{array}{l}\text { Seguridad de la vida } \\
\text { - No hay colapso de la estructura. } \\
\text { - Se asegura que no habrá pérdidas de vidas. } \\
\text { y el servicio puede verse afectado. }\end{array}$ \\
\hline PL2 & $\begin{array}{l}\text { - El daño significativo es mínimo. } \\
\text { - El servicio para vehículos de emergencias está disponible inmediatamente tras el } \\
\text { sismo e inspección correspondiente. } \\
\text {-El puente es reparable, pero puede haber restricciones al tráfico. }\end{array}$ \\
\hline PL3 & $\begin{array}{l}\text { Completamente Operativo } \\
\text { - El puente se comporta elásticamente y no presenta daños significativos. } \\
\text { - El servicio puede restaurarse inmediatamente tras el sismo para todos los vehículos. }\end{array}$ \\
\hline
\end{tabular}

Tabla 3-24. Niveles de desempeño sísmico para reacondicionamiento de puentes. (Buckle et al., 2006).

La asignación de los niveles de desempeño en función del nivel de demanda sísmica, la importancia del puente, y vida remanente quedan resumidos en la Tabla 3-25. 


\begin{tabular}{|c|c|c|c|c|c|c|}
\hline \multirow{2}{*}{$\begin{array}{c}\text { Nivel de } \\
\text { Demanda }\end{array}$} & \multicolumn{4}{|c|}{ Importancia de la Obra y Categoría de Vida Remanente } \\
\cline { 2 - 7 } & ASL1 & ASL2 & ASL3 & ASL1 & ASL2 & ASL3 \\
\hline $\begin{array}{c}\text { L1 } \\
T_{R}=100 a n ̃ o s\end{array}$ & PL0 & PL3 & PL3 & PL0 & PL3 & PL3 \\
\hline $\begin{array}{c}\text { L2 } \\
T_{R}=1000 \text { años }\end{array}$ & PL0 & PL1 & PL1 & PL0 & PL1 & PL2 \\
\hline
\end{tabular}

Tabla 3-25. Asignación de objetivos de desempeño para reacondicionamiento de puentes. (Buckle et al., 2006).

\subsection{Métodos de análisis}

El manual de rehabilitación FHWA (Power et al., 2004) propone un doble análisis en lo que respecta al comportamiento transversal del las secciones de túneles rectangulares: Un análisis de las deformaciones de distorsión racking, y un análisis de las presiones dinámicas para los muros y losas.

En lo que respecta al análisis de la distorsión racking, los métodos descritos en el manual de rehabilitación FHWA son idénticos a los que figuran en el manual FHWA de túneles (Hung et al., 2009), que se han descrito en el apartado §3.8.2.3 de esta tesis, y que se basan en los métodos de Wang y Penzien (Penzien, 2000; J. N. Wang, 1993) para el análisis de la interacción cinemática suelo-estructura.

En lo que respecta al análisis de presiones dinámicas, se indica que los túneles rígidos (aquellos con $F_{r} \leq 1$ ), es necesario calcular la resistencia de los elementos frente a una distribución de presión dinámica $\Delta p_{E}$ como la mostrada en la Fig. 3-148.

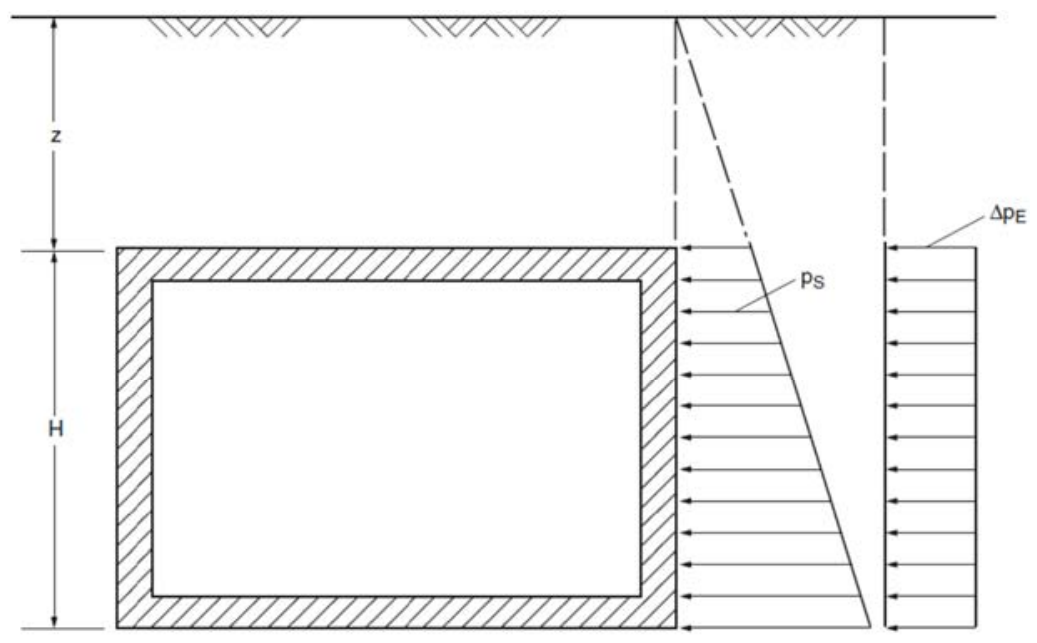

$\mathrm{p}_{\mathrm{s}}=$ Static, at rest lateral earth pressure

$\Delta p_{e}=$ Seismic increment of lateral earth pressure

Fig. 3-148. Esquema de distribución de presiones dinámicas ejercidas por el terreno. (Power et al., 2004). 
Para el cálculo del valor del incremento de presión dinámico $\Delta p_{E}$, siempre que el túnel sea superficial (es decir, que la relación $Z / H \leq 0.5$ ), se emplea la fórmula (Ec. 3-220). En esta fórmula $C_{V}$ es el coeficiente de presión de empuje del terreno (que puede tomar valores $C_{V}=1.0$ para estructuras cimentadas en roca, y $C_{V}=0.4$ para las cimentadas en suelo), $k_{h}$ la aceleración horizontal del terreno, $\gamma_{t}$ la densidad del terreno, y $Z$ y $H$ las cotas indicadas en la Fig. 3-148.

$$
\Delta \mathrm{p}_{E}=C_{V} \cdot k_{h} \cdot \gamma_{t} \cdot(H+Z)
$$

Como puede observarse, esta formulación es idéntica a la planteada por Wood (Wood, 1973) para el caso de estructuras infinitamente rígidas, y descrita en el apartado $\S 3.7 .2 .2$ de esta tesis.

\subsubsection{FHWA Manual for the Seismic Analysis and Design of Transportation} Geotechnical Features and Structural Foundations 2011

\subsection{Niveles de demanda y desempeño}

El manual FHWA para el diseño de obras geotécnicas (Kavazanjian et al., 2011) establece dos niveles de demanda sísmica. Un primer nivel de peligrosidad que se define como frecuente y de manera probabilista con un periodo de retorno $T_{R}=108$ años $(50 \%$ de probabilidad de excedencia en una vida útil de $T_{L}=75$ años). Un segundo nivel de peligrosidad que se define como raro, y se determina como el mayor de un estudio probabilista con un periodo de retorno $T_{R}=2500$ años ( $3 \%$ de probabilidad de excedencia en una vida útil de $T_{L}=75$ años), y 1,5 veces el terremoto medio resultante de un escenario determinista que se juzque como representativo. Estos niveles de demanda se resumen en la tabla Tabla 3-26.

\begin{tabular}{|c|c|c|}
\hline Nivel de Demanda & $\begin{array}{c}\text { Periodo de Retorno } \\
T_{R}[\mathrm{años}]\end{array}$ & $\begin{array}{c}\text { Probabilidad de } \\
\text { Excedencia }\end{array}$ \\
\hline Nivel L1 & 108 años & $50 \%$ en $T_{L}=75$ años \\
\hline \multirow{2}{*}{ Nivel L2 } & 2500 años & $3 \%$ en $T_{L}=75$ años \\
\cline { 2 - 3 } & $1,5 \times$ Terremoto Medio de Escenario Determinista \\
\hline
\end{tabular}

Tabla 3-26. Niveles de demanda sísmica para obras geotécnicas. (Kavazanjian et al., 2011).

Los niveles de daño que admite este manual son poco precisos, y se resumen junto a la asignación a cada nivel de demanda en la Tabla 3-27. 


\begin{tabular}{|c|c|c|c|}
\hline \multirow{2}{*}{ Nivel de Demanda } & \multirow{2}{*}{ Affección al } & \multicolumn{2}{|c|}{ Nivel de Desempeño } \\
\cline { 2 - 4 } & Seguridad de Vida & Operacional \\
\hline Terremoto Raro & Tráfico & Significativa & Inmediato \\
$\boldsymbol{T}_{\boldsymbol{R}}=\mathbf{2 5 0 0}$ años & Daño Estructural & Significativo & Mínimo \\
\hline $\begin{array}{c}\text { Terremoto Esperable } \\
\boldsymbol{T}_{\boldsymbol{R}}=\mathbf{1 0 8} \text { años }\end{array}$ & Tráfico & Inmediato & Inmediato \\
\cline { 2 - 4 } & Daño Estructural & Mínimo & Mínimo a ninguno \\
\hline
\end{tabular}

Tabla 3-27. Asignación de objetivos de desempeño para obras geotécnicas. (Kavazanjian et al., 2011).

\subsection{Métodos de análisis}

En lo que respecta al análisis de la distorsión racking, los métodos descritos en el manual de rehabilitación FHWA son idénticos a los que figuran en el manual FHWA de túneles (Hung et al., 2009), que se han descrito en el apartado §3.8.2.3 de esta tesis, y que se basan en los métodos de Wang y Penzien (Penzien, 2000; J. N. Wang, 1993) para el análisis de la interacción cinemática suelo-estructura.

\subsubsection{NCHRP 611 Seismic Analysis and design of retaining walls, buried structures, slopes, and embankments}

\subsection{Niveles de demanda y desempeño}

El documento NCHRP 611 (Anderson et al., 2008) presenta un esquema de niveles de demanda y desempeño idéntico al propuesto por AASHTO LRFD 2012. Es decir, presenta un único nivel de demanda correspondiente a un periodo de retorno de $T_{R}=1000$ años, correspondiente a una probabilidad de excedencia del $7 \%$ en una vida útil de $T_{L}=75$ años.

\subsection{Métodos de análisis}

La guía NCHRP 611 (Anderson et al., 2008) establece explícitamente como metodología para el análisis frente a la distorsión racking de estructuras rectangulares enterradas la desarrollada por Wang (J. N. Wang, 1993). Asume por completo los planteamientos e hipótesis de Wang descritos en el apartado §3.7.4.1 de esta tesis, y la única modificación sustancial que propone es un cambio en la expresión matemática del coeficiente de racking $R$. La expresión que propone esta norma y su justificación teórica se han descrito en el apartado $\$ 3.7 .4 .3$ de esta tesis.

Por otra parte, al describir la metodología propuesta y justificar el empleo del coeficiente de racking $R$ para amplificar las deformaciones, esta guía NCHRP 611 (Anderson et al., 2008) indica que este fenómeno no está causado por un efecto de 
amplificación dinámica, si no más bien por el hecho de que el suelo cuenta con una cavidad, por oposición al caso de campo libre en el que todo el suelo está relleno.

\subsubsection{California High-Speed Train Project}

El departamento de transporte de California (CALTRANS) cuenta con una detallada normativa relacionada con el diseño sismorresistente de estructuras de transporte. Sin embargo, en esta no se hace referencia a los criterios específicos que deben cumplir las obras subterráneas.

Sin embargo, recientemente se ha acometido el proyecto y construcción de dos grandes infraestructuras, como son la línea de Alta Velocidad de California y la ampliación del Metro de Los Angeles, para las cuales se han redactado criterios específicos de diseño, y que tratan de manera concreta los aspectos sismorresistentes de los túneles. En los siguientes apartado se revisan dichos criterios.

\subsection{Niveles de demanda y desempeño}

La normativa de diseño de la línea ferroviaria de Alta Velocidad de California (Waggoner, Jacob, Jong, \& Winkle, 2011) establece tres niveles de demanda sísmica, un sismo máximo (MCE, Maximum Considered Earthquake), un sismo funcional (FBE, Functional Basis Earthquake), y un sismo de operación (OBE, Operating Basis Earthquake). La Tabla 3-28 resume la definición probabilista de estos niveles de demanda.

\begin{tabular}{|c|c|c|}
\hline Nivel de Demanda & $\begin{array}{c}\text { Periodo de } \\
\text { Retorno }\end{array}$ & $\begin{array}{c}\text { Probabilidad de } \\
\text { Excedencia }\end{array}$ \\
\hline $\begin{array}{c}\text { Terremoto Máximo Considerado } \\
(\mathrm{MCE}-\text { Maximum Considered Earthquake })\end{array}$ & $T_{R}=950$ años & $10 \%$ en $T_{L}=100$ años \\
\hline $\begin{array}{c}\text { Terremoto Funcional } \\
(\mathrm{FBE}-\text { Functional Basis Earthquake })\end{array}$ & $T_{R}=500$ años & $18 \%$ en $T_{L}=100$ años \\
\hline $\begin{array}{c}\text { Terremoto Operativo } \\
(\mathrm{OBE}-\text { Operating Basis Earthquake })\end{array}$ & $T_{R}=50$ años & $86 \%$ en $T_{L}=100$ años \\
\hline
\end{tabular}

Tabla 3-28. Niveles de demanda sísmica para la línea ferroviaria de Alta Velocidad de California.

(Waggoner et al., 2011).

De manera similar, se establece la correspondencia entre niveles de demanda y de desempeño que se resumen en la Tabla 3-29. 


\begin{tabular}{|c|c|}
\hline Nivel de Demanda & Nivel de Desempeño \\
\hline $\begin{array}{c}\text { Terremoto Máximo Considerado } \\
\text { (MCE - Maximum Considered Earthquake) }\end{array}$ & Nivel de No Colapso (NCL) \\
\hline $\begin{array}{c}\text { Terremoto Funcional } \\
(\mathrm{FBE}-\text { Functional Basis Earthquake) }\end{array}$ & Nivel Funcional (FPL) \\
\hline $\begin{array}{c}\text { Terremoto Operativo } \\
(\mathrm{OBE}-\text { Operating Basis Earthquake) }\end{array}$ & Nivel de Operatividad (OPL) \\
\hline
\end{tabular}

Tabla 3-29. Correspondencia entre demanda y desempeño sísmicos para la línea ferroviaria de Alta Velocidad de California. (Waggoner et al., 2011).

Finalmente, establece tres niveles de desempeño sísmico: No colapso, Funcional, y Operatividad. Los criterios de daño estructural admisibles para cada uno de estos niveles de desempeño, y los niveles de demanda correspondientes se resumen en la tabla Tabla 3-30.

Es interesante destacar que, de acuerdo a lo establecido en el apartado §3.3.3 de Filosofía del Diseño Sísmico de Túneles y Estructuras Enterradas de esta norma (Waggoner et al., 2011), se espera que el comportamiento de las mismas durante un sismo sea el de una estructura dúctil. En particular:

- El túnel o estructura subterránea debe tener un mecanismo claramente definido de respuesta a la acción sísmica.

- El comportamiento inelástico debe limitarse a regiones escogidas de la estructura, y las zonas restantes deben protegerse para evitar los mecanismos de frágiles de rotura.

- En general, el diseño puede permitir que ciertos componentes estructurales tengan un comportamiento inelástico bajo los niveles mayores de demanda, es decir, del Terremoto Máximo Considerado (MCE), y el Terremoto Funcional (FBE), mientras se protege al resto de la estructura.

- La estructura debe permanecer en el rango elástico bajo el nivel inferior de demanda del Terremoto Operativo (OBE).

- Se debe proveer un margen suficiente de seguridad entre los modos de rotura dúctiles y no-dúctiles, proporcionando una capacidad de sobrerresistencia de los no-dúctiles de al menos el 120\%, para asegurar que estos no se producen. 


\begin{tabular}{|c|c|c|}
\hline & Objetivos de Desempeño & Daño Aceptable \\
\hline 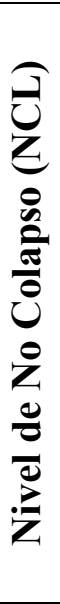 & $\begin{array}{l}\text { - El objetivo principal es limitar el daño estructural para evitar } \\
\text { el colapso durante y después de un terremoto. Los objetivos } \\
\text { concretos de desempeño son: } \\
\text { - No se produce el colapso. } \\
\text { - Los ocupantes que no se encuentran en los trenes son capaces } \\
\text { de evacuar la estructura con seguridad. } \\
\text { - El daño y colapso debido al descarrilamiento de trenes es } \\
\text { mitigado mediante el diseño de estructuras de contención. } \\
\text { - Si ocurre el descarrilamiento, los pasajeros de los trenes y los } \\
\text { operadores son capaces de evacuar los trenes descarrilados } \\
\text { con seguridad. } \\
\text { - Se pueden requerir reparaciones extensivas o reemplazo de } \\
\text { algunos elementos antes de que se pueda reanudar el tráfico. } \\
\text { - Para estructuras subterráneas no se producen inundaciones, ni } \\
\text { flujo de barro y tierras al interior. }\end{array}$ & $\begin{array}{l}\text { - Plastificación significativa } \\
\text { de la armadura principal. } \\
\text { - Fracturas menores en } \\
\text { armaduras redundantes } \\
\text { - No colapso. } \\
\text { - Fisuración y spalling del } \\
\text { recubrimiento extensivos. } \\
\text { - Mínima pérdida de la } \\
\text { capacidad portante vertical. } \\
\text { - Desplazamientos remanentes } \\
\text { grandes que pueden requerir } \\
\text { reparación extensiva o } \\
\text { sustitución completa antes } \\
\text { de que se pueda reanudar el } \\
\text { servicio. }\end{array}$ \\
\hline 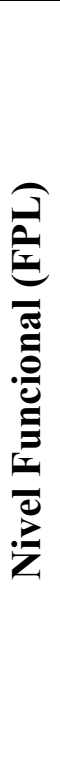 & $\begin{array}{l}\text { - El objetivo fundamental es limitar el daño estructural de tal } \\
\text { manera que sea reparable, y que el servicio normal del } \\
\text { tráfico pueda reanudarse tras un tiempo razonable tras el } \\
\text { terremoto. Los objetivos concretos de desempeño son: } \\
\text { - Daño estructural y a la vía limitados, que requieren de } \\
\text { reparaciones rápidas de realizar. } \\
\text { - Los ocupantes fuera de los trenes son capaces de evacuar la } \\
\text { estructura con seguridad. } \\
\text { - El daño y colapso debido al descarrilamiento de los trenes se } \\
\text { mitiga mediante el diseño de medidas de contención. } \\
\text { - El tráfico se reanuda tras un periodo razonable. } \\
\text { - Se restaura el servicio de todas las instalaciones en un tiempo } \\
\text { razonable. } \\
\text { - Desempeño seguro durante las réplicas. } \\
\text { - Los pilotes de las cimentaciones profundas de los puentes no } \\
\text { sufren daño significativo. El basculamiento de las } \\
\text { cimentaciones superficiales es limitado. } \\
\text { - Para estructuras subterráneas no se producen inundaciones, ni } \\
\text { flujo de barro y tierras al interior. }\end{array}$ & $\begin{array}{l}\text { - Plastificación del acero } \\
\text { longitudinal, aunque su } \\
\text { sustitución no es necesaria. } \\
\text { - La estructura se puede } \\
\text { mantener en servicio } \\
\text { durante las reparaciones. } \\
\text { - El spalling del recubrimiento } \\
\text { del hormigón en las zonas } \\
\text { accesibles para la reparación } \\
\text { está permitido. } \\
\text { - La plastificación de las } \\
\text { rótulas plásticas en } \\
\text { columnas está permitida } \\
\text { como mecanismo fusible en } \\
\text { aquellos casos en los que el } \\
\text { basculamiento no está } \\
\text { permitido o no es viable } \\
\text { economicamente. }\end{array}$ \\
\hline 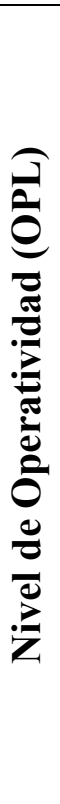 & $\begin{array}{l}\text { - El objetivo principal es que las estructuras se comporten } \\
\text { elásticamente, sin spalling en el hormigón, y con daños } \\
\text { mínimos a la vía para evitar tensiones en la misma y proteger } \\
\text { frente al eventual descarrilamiento. Los objetivos concretos } \\
\text { de desempeño son: } \\
\text { - No se produce descarrilamiento, los trenes son capaces de } \\
\text { frenar con seguridad desde la máxima velocidad de diseño } \\
\text { hasta una parada segura. } \\
\text { - Los ocupantes en el exterior de los trenes pueden evacuar la } \\
\text { estructura con seguridad. } \\
\text { Los pasajeros en los trenes y los operadores son capaces de } \\
\text { evacuar con seguridad los trenes parados. } \\
\text { - Disrupción mínima del servicio para todos los sistemas de } \\
\text { apoyo a la operación del tráfico de alta velocidad. } \\
\text { - Reanudación del tráfico en el plazo de algunas horas, y } \\
\text { posiblemente a velocidades reducidas. } \\
\text { - Desempeño seguro en las réplicas del terremoto. } \\
\text { - No hay basculamiento de las cimentaciones. } \\
\text { - Para estructuras subterráneas no se producen inundaciones, ni } \\
\text { flujo de barro y tierras al interior. }\end{array}$ & $\begin{array}{l}\text { - Respuesta estructural } \\
\text { elástica. } \\
\text { - Sin daño estructural. } \\
\text { - Sin spalling del } \\
\text { recubrimiento. } \\
\text { - No hay daño en las vías. } \\
\text { - Deformaciones remanentes } \\
\text { despreciables. }\end{array}$ \\
\hline
\end{tabular}

Tabla 3-30. Niveles de desempeño sísmico para la línea ferroviaria de Alta Velocidad de California.

(Waggoner et al., 2011). 


\subsection{Métodos de análisis}

De acuerdo a esta norma (Waggoner et al., 2011), la respuesta sísmica de los túneles está dominada por la respuesta del suelo circundante, y no por los efectos inerciales de la propia estructura. En consecuencia, la norma preconiza que el énfasis en el análisis debe ser en la deformación de campo libre del terreno circundante y en su interacción con el túnel.

De igual manera, indica que el procedimiento general para el diseño de estructuras subterráneas deberá basarse en el enfoque de la deformación del terreno. Subraya que durante los terremotos las estructuras subterráneas se mueven de manera conjunta con el medio geológico adyacente, y que en consecuencia las estructuras deben ser diseñadas para acomodar las deformaciones impuestas por el suelo, teniendo en cuenta la rigidez relativa de la estructura y del suelo, así como los efectos de interacción suelo-estructura.

En particular, los métodos de análisis de deformación de las estructuras enterradas que propone esta norma (Waggoner et al., 2011), son los desarrollados por Wang (J. N. Wang, 1993), Penzien (Penzien, 2000), y Anderson (Anderson et al., 2008), y los resumidos por Hashash (Hashash et al., 2001; Hashash, Karina, Koutsoftas, \& O’Riordan, 2010), a cuyos artículos refiere directamente sin implementar consideraciones específicas en el texto de la norma.

Como vemos, esta norma, a diferencia de la europea EC2-8, la guía AFPS, la norma japonesa, y la norma chilena, sí tiene en cuenta la interacción cinemática sueloestructura, que prevee defromaciones mayores que las correspondientes a la de campo libre para estructuras más flexibles que el terreno $(F>1)$.

\subsubsection{Los Angeles Metro Design Criteria, 2012}

\subsection{Niveles de demanda y desempeño}

Las bases de diseño de la ampliación del Metro de Los Angeles (LA Metro Authority, 2012), establecen dos niveles de demanda sísmica definidos de manera probabilista: un nivel de terremoto máximo de diseño (MDE, Maximum Design Earthquake) con un periodo de retorno $T_{R}=2500$ años y probabilidad de excedencia de $4 \%$ en una vida útil de $T_{L}=100$ años, y un nivel de terremoto operativo (ODE, Operating Design Earthquake) con un periodo de retorno de $T_{R}=150$ años y probabilidad de excedencia de $50 \%$ en una vida útil de $T_{L}=100$ años. La Tabla 3-31 resume estos niveles. 


\begin{tabular}{|c|c|c|}
\hline Nivel de Demanda & Periodo de Retorno & Probabilidad de Excedencia \\
\hline $\begin{array}{c}\text { Nivel MDE } \\
\text { (Maximum Design Earthquake) }\end{array}$ & $T_{R}=2500$ años & $4 \%$ en $T_{L}=100$ años \\
\hline $\begin{array}{c}\text { Nivel ODE } \\
\text { (Operative Design Earthquake) }\end{array}$ & $T_{R}=150$ años & $50 \%$ en $T_{L}=100$ años \\
\hline
\end{tabular}

Tabla 3-31. Niveles de demanda sísmica para obras subterráneas. (LA Metro Authority, 2012).

Por otra parte, también establece los niveles de desempeño correspondientes a los niveles de demanda, tanto en términos de servicio, como de daño estructural, y que fija de una manera precisa. Estos se resumen en la Tabla 3-32.

\begin{tabular}{|c|c|c|}
\hline Desemp & Descripción & Daños Admisibles y Criterios de Diseño \\
\hline 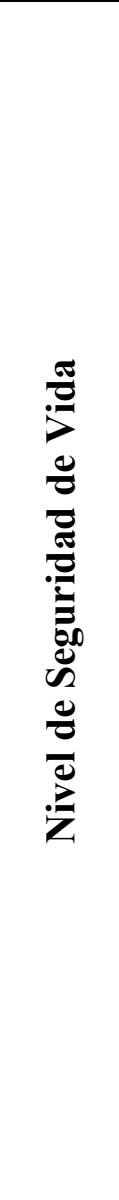 & $\begin{array}{l}\text { - No debe suponer un peligro para la } \\
\text { vida. } \\
\text { - La estructura puede sufrir daño } \\
\text { significativo y disrupción } \\
\text { significativa del tráfico. } \\
\text { - La estructura no debe colapsar. } \\
\text { - La estructura no debe inundarse. } \\
\text { - La estructura puede comportarse } \\
\text { inelásticamente. } \\
\text { - El daño estructural debe ser limitado } \\
\text { a aquellos elementos accesibles y } \\
\text { que puedan ser reparados }\end{array}$ & $\begin{array}{l}\text { - La capacidad de los elementos estructurales a cortante debe evaluarse } \\
\text { con coeficientes } \Phi \text { de minoración de la resistencia. La resistencia } \\
\text { minorada debe ser tal que la solicitación sea menor que la capacidad } \\
\text { resistente. } V_{u} \leq 0.9 \cdot \Phi \cdot V_{n} \text {. } \\
\text { - El momento de plastificación esperable puede estimarse como } \\
M_{e}=1,1 \cdot M_{n} \text {. En aquellos casos en los que el axil es menor que el } 10 \% \\
\text { de la capacidad bruta a axil. } N_{u}<0.1 \cdot A_{g} \cdot f_{c} \text { ' } \\
\text { - Para elementos con un axil mayor, el momento de plastificación } \\
\text { esperable debe evaluarse en base a análisis momento-curvatura, } \\
\text { teniendo en cuenta el comportamiento no lineal de los materiales con } \\
\text { endurecimiento. } \\
\text { - Para dimensionar elementos protegidos por capacidad/sobrerresistencia, } \\
\text { se empleará un coeficiente de sobrerresistencia de } 1,2 \text {. } \\
\text { - Las longitudes de rótulas plásticas } L_{p} \text { debe evaluarse teniendo en cuenta } \\
\text { un límite superior según las disposiciones al efecto de CALTRANS, y } \\
\text { un límite inferior que se tomará como Lp,min o h/2. Esta disposición } \\
\text { se justifica en el hecho de que la longitud analítica } L_{p} \text { de Caltrans está } \\
\text { basada en niveles grandes de plastificación, que normalmente no } \\
\text { ocurrirán en una estructura enterrada. } \\
\text { - Los elementos deben dimensionarse de tal manera que las rótulas } \\
\text { plásticas se produzcan en los muros laterales, mientras que las losas } \\
\text { de cubrición y contrabóveda queden protegidas por criterios de } \\
\text { capacidad/sobrerresistencia. } \\
\text { - Los elementos deben dimensionarse de tal manera que la demanda de } \\
\text { ductilidad sea menor que } \mu_{D} \leq 4 \text {. } \\
\text { - Las rótulas plásticas deben dimensionarse de tal manera que la } \\
\text { capacidad de ductilidad sea mayor que } \mu_{D} \geq 4 \text {. } \\
\text { - Las máximas deformaciones permitidas en aquellos elementos de rótula } \\
\text { plástica confinada con estribos, para que puedan considerarse como } \\
\text { reparables son: } \\
\text { - Acero: } \varepsilon_{s} \leq 2 \% \\
\text { - Hormigón: } \varepsilon_{c} \leq 0.33 \% \\
\text { - Las máximas deformaciones permitidas en aquellos elementos de rótula } \\
\text { plástica confinada con cercos, para que puedan considerarse como } \\
\text { reparables son: } \\
\bullet \quad \text { Acero: } \varepsilon_{s} \leq 2.5 \% \\
\text { - Hormigón: } \varepsilon_{c} \leq 0.4 \%\end{array}$ \\
\hline 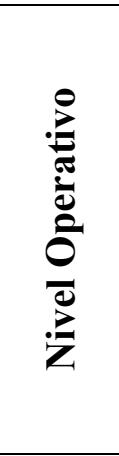 & $\begin{array}{l}\text { - No debe haber interrupción en el } \\
\text { tráfico ferroviario. } \\
\text { - Las estructuras deben responder } \\
\text { esencialmente de manera elástica. } \\
\text { - No se debe producir el colapso ni } \\
\text { daño a los elementos estructurale } \\
\text { primarios. } \\
\text { - Se permite daño mínimo en } \\
\text { elementos secundarios, que debe } \\
\text { ser facilmente reparable. } \\
\text { - La estructura debe ser operacional } \\
\text { inmediatamente tras el sismo, tras } \\
\text { pocas horas requeridas para la } \\
\text { inspección. }\end{array}$ & $\begin{array}{l}\text { - La capacidad de los elementos estructurales deben evaluarse con } \\
\text { coeficientes } \Phi \text { de minoración de la resistencia. La resistencia } \\
\text { minorada debe ser tal que la solicitación sea menor que la capacidad } \\
\text { resistente. } R_{u} \leq \Phi \cdot R_{n} \text {. } \\
\text { - El diseño debe basarse de tal manera que se produzcan mecanismos de } \\
\text { rotura dúctiles a flexión. } \\
\text { - La resistencia a cortante debe deterinarse mediante criterios de } \\
\text { capacidad y sobrerresistencia. } \\
\text { - La resistencia a cortante debe evaluarse sin el efecto del axil } \\
\text { concomitante, si esto resulta desfavorable. } \\
\text { - Los elementos deben dimensionarse de tal manera que la capacidad a } \\
\text { flexión de los muros se alcance antes que la capacidad de la losa de } \\
\text { cubrición, contrabóveda, o juntas. }\end{array}$ \\
\hline
\end{tabular}

Tabla 3-32. Niveles de desempeño sísmica para obras subterráneas. (LA Metro Authority, 2012). 
En cuanto los elementos estructurales susceptibles de sufrir daño por la formación de rótulas plásticas, las bases de diseño indica que estas se producirán en los muros laterales, mientras que la losa de cubrición y contrabóveda deben protegerse mediante criterios de capacidad y sobrerresistencia. La idea que subyace tras este criterio es que la formación de rótulas plásticas en la losa de cubrición puede crear preocupación indebida acerca de la estabilidad y posibilidad de colapso, y por lo tanto no debería permitirse el daño en esta sección.

Por último, se fija la correspondencia entre niveles de demanda y de desempeño esperable, que se resumen en la Tabla 3-33.

\begin{tabular}{|c|c|}
\hline Nivel de Demanda & Nivel de Desempeño \\
\hline Nivel MDE (Maximum Design Earthquake) & Nivel de Seguridad de Vida \\
\hline Nivel ODE (Operative Design Earthquake) & Nivel Operativo \\
\hline
\end{tabular}

Tabla 3-33. Niveles de demanda y desempeño sísmicos para obras subterráneas. (LA Metro Authority, 2012).

\subsection{Métodos de análisis}

Las bases de diseño del metro de Los Angeles (LA Metro Authority, 2012) establecen como métodos generales de análisis de la deformación de distorsión de las secciones, o bien los basado en expresiones semi-analíticas, o bien los basado en simulaciones numéricas.

El análisis con expresiones semi-analíticas se señala como apropiado para aquellos casos en los que la estructura es rectangular, el terreno es razonablemente uniforme, y no hay efectos de interacción con túneles adyacentes u otras estructuras. Las simulaciones numéricas se reservan para aquellos casos en los que el terreno circundante es heterogéneo, o las estructuras se apartan significativamente de la forma rectangular.

En lo que respecta a las expresiones semi-analíticas, las bases de diseño adoptan por completo la formulación de interacción cinemática propuesto por Wang (J. N. Wang, 1993) descrito en el apartado 33.7 .4 .1 de esta tesis.

Adicionalmente, las bases de diseño establece criterios generales para evaluar los mecanismos plásticos admisibles en la estructura para el nivel de desempeño de Seguridad de Vida, permitiendo la formación de hasta dos rótulas plásticas en cualquier elemento principal, y prohibiendo la formación de tres rótulas plásticas en cualquier elemento Fig. 3-149. 

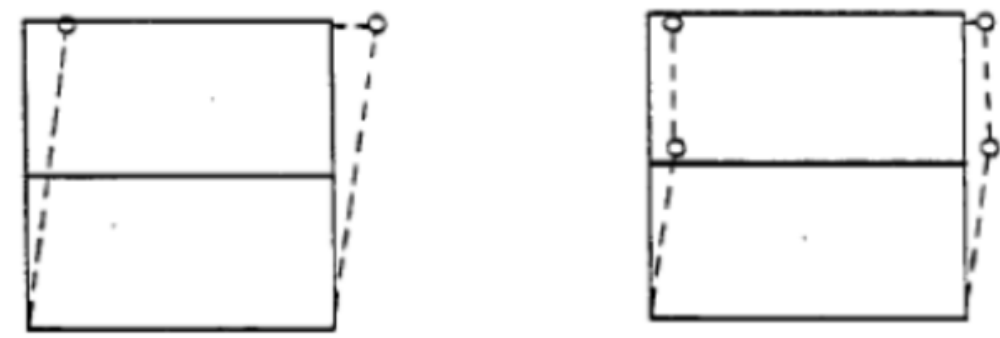

a. Acceptable Condition - Two Hinges b.
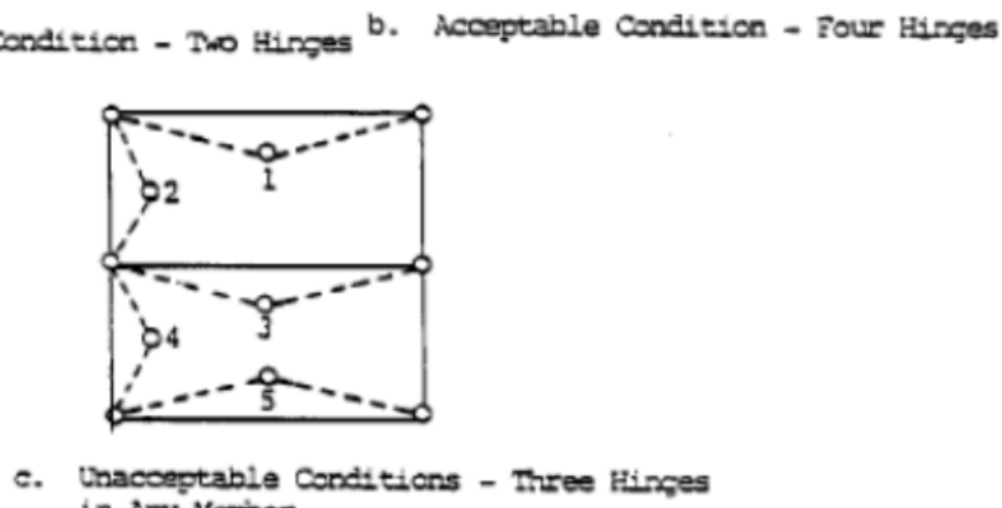

in Any Member

Fig. 3-149. Esquemas de formación de rótulas y mecanismos plásticos. (sup.) Mecanismos aceptables. (inf) Mecanismos inaceptables. (Hung et al., 2009).

\subsubsection{WSDOT Alaskan Way SR99 Tunnel Design Criteria 2010}

El departamento de transporte de Washington (WSDOT, Washington State Department of Trasnsportation) cuenta con una detallada normativa relacionada con el diseño sismorresistente de estructuras de transporte. Sin embargo, en esta no se hace referencia a los criterios específicos que deben cumplir las obras subterráneas.

Sin embargo, recientemente se ha acometido el proyecto y construcción de un túnel de autopista urbana en Seattle (Alaskan Way SR99 Tunnel), para el cual se han redactado criterios específicos de diseño (WSDOT, 2010), y que tratan de manera concreta los aspectos sismorresistentes de los túneles, y específicamente los correspondientes a estructuras construídas por el método de cut-and-cover que se encuentran en los accesos al túnel principal. En este apartado se revisan dichos criterios.

\subsection{Niveles de demanda y desempeño}

Los criterios de diseño del túnel SR99 establecen que la vida útil será de $T_{L}=100$ años, y establece dos niveles de demanda sísmica determinados de manera probabilista: Un terremoto de frecuencia rara (RE, Rare Earthquake) con un periodo de retorno de $T_{R}=2500$ años y una probabilidad de excedencia de $4 \%$ durante la vida útil de $T_{L}=100$ años. También establece un terremoto frecuente (EE, Expected Earthquake) con un 
periodo de retorno de $T_{R}=108$ años, y una probabilidad de excedencia de $60 \%$ durante la vida útil de $T_{L}=100$ años. La Tabla 3-34 resume estos niveles de demanda sísmica.

\begin{tabular}{|c|c|c|}
\hline Nivel de Demanda & Periodo de Retorno $\boldsymbol{T}_{\boldsymbol{R}}$ [años] & Probabilidad de Excedencia \\
\hline $\begin{array}{c}\text { Nivel RE } \\
\text { (Rare Earthquake) }\end{array}$ & 2500 años & $4 \%$ en $T_{L}=100$ años \\
\hline $\begin{array}{c}\text { Nivel EE } \\
\text { (Expected Earthquake) }\end{array}$ & 108 años & $60 \%$ en $T_{L}=100$ años \\
\hline
\end{tabular}

Tabla 3-34. Niveles de demanda sísmica para obras subterráneas. (WSDOT, 2010).

Por otra parte, también establece los niveles de desempeño correspondientes a los niveles de demanda, tanto en términos de servicio, como de daño estructural en forma de deformaciones máximas admisibles, y de estanqueidad frente al agua. Estos se resumen en la Tabla 3-35.

\begin{tabular}{|c|c|c|c|}
\hline $\begin{array}{c}\text { Nivel de } \\
\text { Desempeño }\end{array}$ & Descripción & $\begin{array}{c}\text { Daño Estructural } \\
\text { Admisible }\end{array}$ & $\begin{array}{c}\text { Objetivo de } \\
\text { Estanqueidad }\end{array}$ \\
\hline 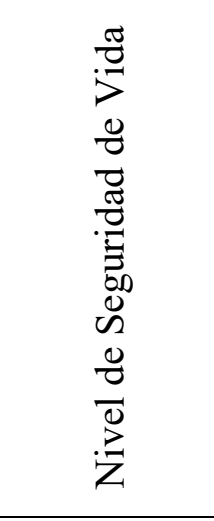 & $\begin{array}{l}\text { - Seguridad de Vida. } \\
\text { - Los ocupantes deben ser } \\
\text { capaces de evacuar el túnel } \\
\text { con seguridad. } \\
\text { - La estructura puede sufrir daño } \\
\text { significativo y disrupción } \\
\text { significativa del tráfico. } \\
\text { - La estructura puede ser } \\
\text { reemplazada parcial o } \\
\text { completamente. } \\
\text { - La estructura no debe colapsar. } \\
\text { - Se debe limitar la pérdida de } \\
\text { estanqueidad. }\end{array}$ & $\begin{array}{l}\text { - Deformación máxima } \\
\text { del acero } \varepsilon_{s} \leq 6 \% \text {. } \\
\text { - Deformación máxima } \\
\text { del hormigón } \varepsilon_{c} \leq 1 \% \text {. }\end{array}$ & $\begin{array}{l}\text { - La estructura debe } \\
\text { seguir siendo } \\
\text { esencialmente } \\
\text { estanca. } \\
\text { - Se permite un flujo de } \\
\text { agua hacia el interior } \\
\text { dos veces superior al } \\
\text { máximo establecido } \\
\text { para el uso normal } \\
\text { del túnel. }\end{array}$ \\
\hline 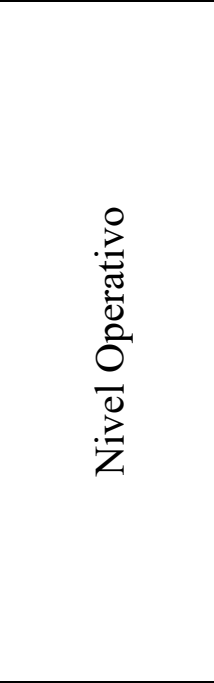 & $\begin{array}{l}\text { - Se debe poder restaurar el } \\
\text { tráfico general tras la } \\
\text { inspección correspondiente. } \\
\text { - Se permite la respuesta } \\
\text { inelástica siempre que sea } \\
\text { escasa y conlleve un nivel } \\
\text { menor de fisuración. } \\
\text { - No deben producirse } \\
\text { distoriones permanentes. } \\
\text { - Las reparaciones deben poder } \\
\text { llevarse a cabo sin que sean } \\
\text { consideradas de emergencia, } \\
\text { y mientras el túnel permanece } \\
\text { operativo, tal vez con algún } \\
\text { carril cortado. } \\
\text { - Se debe limitar la pérdida de } \\
\text { estanqueidad. }\end{array}$ & $\begin{array}{l}\text { - Deformación máxima } \\
\text { del acero } \varepsilon_{s} \leq 6 \% \text {. } \\
\text { - Deformación máxima } \\
\text { del hormigón } \\
\varepsilon_{c} \leq 0,5 \% \text {. }\end{array}$ & $\begin{array}{l}\text { - La estructura debe } \\
\text { seguir siendo } \\
\text { esencialmente } \\
\text { estanca. } \\
\text { - Se permite un flujo de } \\
\text { agua hacia el interior } \\
\text { igual al máximo } \\
\text { establecido para el } \\
\text { uso normal del túnel. }\end{array}$ \\
\hline
\end{tabular}

Tabla 3-35. Niveles de desempeño sísmica para obras subterráneas. (WSDOT, 2010).

Por último, se fija la correspondencia entre niveles de demanda y de desempeño esperable, que se resumen en la Tabla 3-36. 


\begin{tabular}{|c|c|}
\hline Nivel de Demanda & Nivel de Desempeño \\
\hline Nivel RE (Rare Earthquake) & Nivel de Seguridad de Vida \\
\hline Nivel EE (Expected Earthquake) & Nivel Operativo \\
\hline
\end{tabular}

Tabla 3-36. Niveles de demanda y desempeño sísmicos para obras subterráneas. (WSDOT, 2010).

\subsection{Métodos de análisis}

Las bases de diseño del túnel SR99 (WSDOT, 2010) establecen dos metodos de análisis para las estructuras cut-and-cover: método de deformación del terreno, y método de presiones dinámicas. Todas las estructuras deben analizarse mediante los dos métodos, y dimensionarse de acuerdo al resultado más desfavorable de ambos, pero los resultados de uno y otro método no deben superponerse.

Para el análisis de deformaciones del terreno, las bases de diseño SR99 dirigen a lo especificado en el manual de túneles FHWA (Hung et al., 2009) (descrito en el apartado §3.8.2.3 de esta tesis), y en particular a lo establecido con respecto a los análisis numéricos.

Con respecto al análisis de de las presiones dinámicas, las bases de diseño establecen que deben ser determinadas para cada caso particular por el proyectista, sin fijar ninguna guía ni procedimiento preferido.

\subsubsection{Normativa Japonesa}

\subsubsection{RTRI Railway Structures, Cut and Cover Tunnel, Seismic Design, 2007}

La normativa del RTRI (Railway Technical Research Institute) (Design Standards for Railway Structures and Commentary (Cut and Cover Tunnel), 2008; Design Standards for Railway Structures and Commentary (Seismic Design), 2007), trata específicamente el diseño sismorresistente de obras construídas por el método de cut-andcover. A este respecto, define niveles de demanda específicos a tener en cuenta, y objetivos de desempeño de las estructuras para cada uno de los niveles.

\subsection{Niveles de demanda y desempeño sísmicos}

La normativa prescribe dos niveles de demanda, que se obtienen mediante metodologías diferentes. El nivel de demanda menor L1 se obtiene mediante un análisis probabilístico de la peligrosidad para un periodo de retorno $T_{R}=50$ años. El nivel de demanda mayor L2 cubre dos escenarios diferentes, un escenario L2-I que corresponde a 
un terremoto de magnitud M 8 a una distancia de 30 a 40 km y cuya acción se obtiene de manera determinista, y un terremoto L2-II que corresponde a un terremoto producido en una falla local y que se determina mediante un análisis probabilistico de la peligrosidad para una probabilidad de excedencia del 10\% durante la vida útil de la obra. La Tabla 3-37 resume estas definiciones de la demanda sísmica.

\begin{tabular}{|c|c|}
\hline Nivel de Demanda & \multicolumn{1}{c|}{ Definición } \\
\hline \multirow{2}{*}{ Nivel L1 } & - Periodo de retorno $T_{R}=50$ años \\
& - Aceleración espectral máxima $0,25 \cdot \mathrm{g}$ en roca. \\
\hline & - Correspondientes a dos escenarios: \\
& - Subducción (Espectro tipo L2-I). Determinista, M8 $30 \mathrm{~km}$. \\
Nivel L2 & - Falla local (Espectro tipo L2-II). Probabilista con prob. de \\
& de excedencia del $10 \%$ en la vida útil de la obra. Para una \\
& vida útil de $T_{L}=100$ años, corresponde a un periodo de \\
& retorno de $T_{R}=950$ años. \\
\hline
\end{tabular}

Tabla 3-37. Niveles de demanda sísmica de la normativa japonesa. (Design Standards for Railway Structures and Commentary (Seismic Design), 2007).
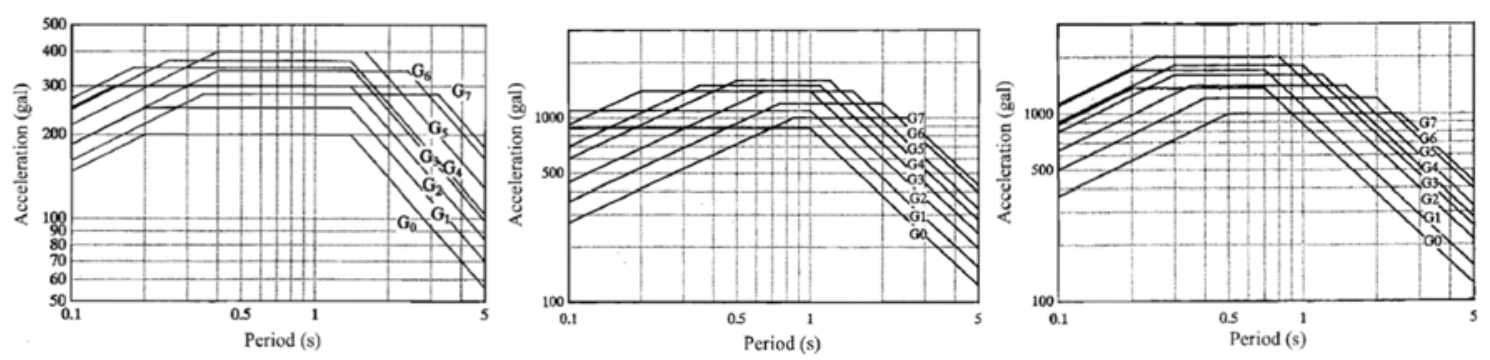

Fig. 3-150. Espectros de diseño de la norma japonesa. (izda.) Nivel L1. (cent.) Nivel L2-I Subducción. (dcha.) Nivel L2-II Falla local. (Design Standards for Railway Structures and Commentary (Seismic Design), 2007).

Adicionalmente, la normativa japonesa RTRI 2007 establece tres niveles de desempeño sísmico para los elementos de una estructura.

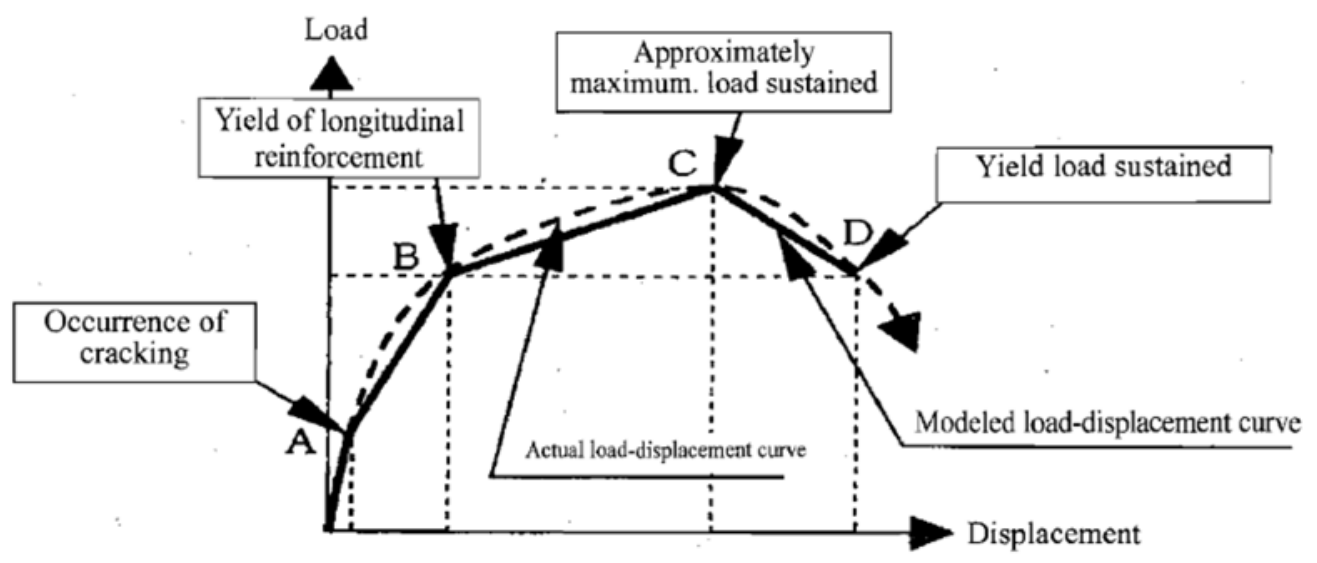

Fig. 3-151. Niveles de daño en estructuras de hormigón según la normativa japonesa. (Design Standards for Railway Structures and Commentary (Seismic Design), 2007). 


\begin{tabular}{|c|c|c|}
\hline $\begin{array}{l}\text { Nivel de } \\
\text { Daño }\end{array}$ & Descripción & Reparación Esperable \\
\hline 1 & $\begin{array}{l}\text { - Sin daño. } \\
\text { - Deformación máxima esperable en el } \\
\text { acero longitudinal correspondiente a la } \\
\text { deformación de plastificación } \varepsilon_{y}=f_{y} / E \text {. } \\
\text { - Punto B en la Fig. } 3 \text {-151. }\end{array}$ & - Sin reparación. \\
\hline 2 & $\begin{array}{l}\text { - Daño que puede requerir reparación } \\
\text { dependiendo de la situación. } \\
\text { - Deformación máxima esperable en el } \\
\text { acero longitudinal correspondiente a la } \\
\text { deformación para la que se alcanza la } \\
\text { tensión última del acero } \varepsilon_{S}=f_{u} \text {. } \\
\text { - Punto C en la Fig. } 3 \text { - } 151 \text {. }\end{array}$ & $\begin{array}{l}\text {-Inyección de las fisuras. } \\
\text {-Parcheo si resultara necesario. }\end{array}$ \\
\hline 3 & $\begin{array}{l}\text { - Daño que requiere reparación. } \\
\text { - Punto D en la Fig. 3-151, } \\
\text { correspondiente a un nivel total de } \\
\text { fuerza igual al correspondiente a la } \\
\text { primera plastificación del punto B. }\end{array}$ & $\begin{array}{l}\text {-Inyección de las fisuras. } \\
\text {-Parcheo si resultara necesario. } \\
\text {-Restitución de los cercos si resultara } \\
\text { necesario. }\end{array}$ \\
\hline 4 & $\begin{array}{l}\text { - Daño que requiere reparación, y } \\
\text { posiblemente la sustitución dependiendo } \\
\text { de la situación. } \\
\text { - Punto correspondiente a un } \\
\text { desplazamiento mayor que el del punto } \\
\text { D. }\end{array}$ & $\begin{array}{l}\text {-Inyección de las fisuras. } \\
\text {-Parcheo si resultara necesario. } \\
\text {-Restitución de los cercos si resultara } \\
\text { necesario. } \\
\text {-Restitución de la armadura longitudinal si } \\
\text { hubiera pandeado. }\end{array}$ \\
\hline
\end{tabular}

Tabla 3-38. Niveles de daño en estructuras de hormigón según la normativa japonesa RTRI. (Design

Standards for Railway Structures and Commentary (Seismic Design), 2007).

En lo que respecta a la verificación del desepeño de los diferentes elementos de la estructura, y en base al esquema de niveles de demanda y niveles de daño indicados anteriormente, la resume los requerimientos de cada elemento.

\begin{tabular}{|c|c|c|}
\hline \multirow{2}{*}{ Nivel de Demanda } & \multicolumn{2}{|c|}{ Nivel de Desempeño } \\
\cline { 2 - 3 } Demanda L1 & $\begin{array}{c}\text { Desempeño I } \\
\text { - Nivel de Daño 1 en } \\
\text { todos los elementos. }\end{array}$ & Desempeño II \\
\hline \multirow{2}{*}{ Demanda L2 } & - No necesario. & $\begin{array}{c}\text { - Nivel de Daño 2 en elementos sobre los que } \\
\text { circule tráfico. } \\
\text { - Nivel de Daño 2 en elementos de difícil } \\
\text { reparación por estar en contacto con el terreno } \\
\text { (muros laterales y losas). }\end{array}$ \\
& & - Nivel de Daño 3 en el resto de elementos. \\
\hline
\end{tabular}

Tabla 3-39. Matriz de Demanda-Desempeño de la normativa japonesa RTRI. (Design Standards for Railway Structures and Commentary (Seismic Design), 2007).

\subsection{Métodos de análisis}

La normativa japonesa (Design Standards for Railway Structures and Commentary (Seismic Design), 2007) indica que, históricamente, las estructuras subterráneas se han considerado seguras con respecto a los efectos de los terremotos, y que por ello no se han desarrollado disposiciones específicas claras en lo que respecta al 
diseño sismorresistente de las mismas. Sin embargo, a raíz del daño sufrido por varias estructuras del tipo cut-and-cover durante el terremoto de Kobe de 1995, incluído el colapso de la estación de Daikai, se han prescrito normas al respecto.

Como conceptos básicos señala que el comportamiento de estructuras subterráneas del tipo cut-and-cover está fuertemente influenciado por el comportamiento del suelo que las rodea, y que por lo tanto es necesario comprenderlo con precisión, así como los efectos de interacción suelo-estructura. En particular, señala como aspectos importantes el comportamiento no lineal del suelo y de la propia estructura durante los sismos más severos.

Para el análisis práctico de las magnitudes de respuesta (deformaciones, esfuerzos, etc.) señala el método de la deformación sísmica (seismic deformation method), que resume en los siguientes pasos referidos a la Fig. 3-152, en la que aparece modelizada la estructura rodeada de unos muelles tipo Winkler.

- Calcular las deformaciones del suelo que rodea la estructura como si esta no existiera (deformación en campo libre).

- Aplicar la deformación obtenida al extremo de los muelles no fijado a la estructura, y obtener los esfuerzos resultantes (momentos flectores y cortantes).

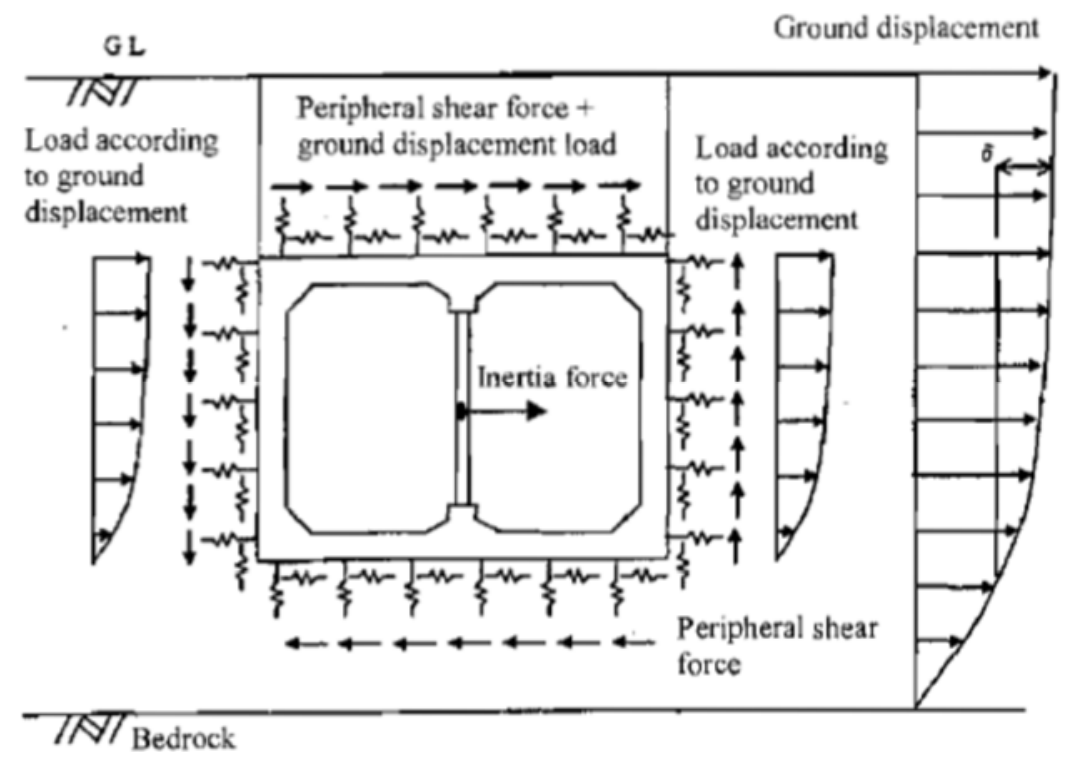

Fig. 3-152. Esquema de acción sísmica transversal de la normativa Japonesa RTRI. (Design Standards for Railway Structures and Commentary (Seismic Design), 2007).

Como se puede apreciar, se trata de un método idéntico al propuesto por la guía AFPS y el Eurocódigo EC8-2. En este sentido, se pueden verter sobre este método las 
mismas críticas que se hicieron en el apartado $\$ 3.8 .1 .1$ en lo que respecta al comportamiento de estructuras flexibles.

\subsubsection{JSCE Standard Specification for Tunneling-2016: Cut-and-Cover Tunnels}

\subsection{Niveles de demanda y desempeño sísmicos}

Las recientes especificaciones de la JSCE (Japan Society of Civil Engineers) (Takemura et al., 2018) respecto al diseño de túneles construídos por el método de cutand-cover establecen un interesante marco conceptual en lo que se refiere a los estados límite de demanda y desempeño. A este respecto, destaca que el desempeño debe fijarse considerando tanto la seguridad como el servicio de la estructura durante y tras el sismo de manera similar a lo que indican otras de las normativas analizadas en esta tesis, pero también incluye una mención a la reparabilidad de la misma. La especificación de la JSCE indica que la reparabilidad no depende tan sólo de la dificultad de reparar un daño, si no también de como de fácil resulta realizar las inspecciones correspondientes tras el sismo, y la facilidad de obtención de los materiales para rehabilitar la obra.

Con respecto al daño símico, las especificaciones de la JSCE remiten a la normativa de estructuras de hormigón (Hiroyuki et al., 2007) para establecer los tres niveles de desempeño: i) La estructura es capaz de mantener su funcionamiento tras un sismo sin reparación, ii) La estructura puede volver al normal funcionamiento tras la reparación en un breve lapso de tiempo, iii) La estructura no colapsa tras el sismo.

Las especificaciones de la JSCE remiten a la norma de estructuras de hormigón (Hiroyuki et al., 2007) para establecer dos niveles de demanda. . Estos dos niveles L1 y L2 de intensidad creciente se resumen en la Tabla 3-40.

\begin{tabular}{|c|c|}
\hline Nivel de Demanda & Definición \\
\hline Nivel L1 & - Periodo de retorno tal que este nivel de sismo ocurre varias \\
& veces a lo largo de la vida útil de la estructura. \\
\hline & - Correspondientes a dos escenarios: \\
& - Sismo causado por una falla activa continental \\
Nirectamente bajo, o en las cercanías, del emplazamiento \\
\\
& de la obra. \\
& - Gran sismo que ocurre en el contacto entre la placa \\
& continental y oceánica. \\
\hline
\end{tabular}

Tabla 3-40. Niveles de demanda sísmica de la normativa japonesa JSCE Concrete Structures. (Hiroyuki et al., 2007). 
De manera similar a los niveles de demanda, las normativas JSCE de túneles cutand-cover (Takemura et al., 2018), así como la de estructuras de hormigón (Hiroyuki et al., 2007) establece descripciones cualitativas a partir de los cuales fundamentar objetivamente que una estructura cumple con cada uno de estos objetivos de desempeño. Estas descripciones se resumen en la Tabla 3-41.

\begin{tabular}{|c|l|}
\hline Nivel de Daño & \multicolumn{1}{c|}{ Descripción } \\
\hline \multirow{3}{*}{ Grado 1 } & $\begin{array}{l}\text { - La estructura mantiene su función durante un sismo, y puede ser } \\
\text { usada sin reparaciones tras el mismo. } \\
\text { - La estructura no alcanza la plastificación, en forma de } \\
\text { desplazamiento o rotación, de ninguno de sus elementos. }\end{array}$ \\
\hline & $\begin{array}{l}\text { - La estructura mantiene la capacidad necesaria para ser usada tras } \\
\text { un terremoto, y puede recuperar su función tras un breve periodo de } \\
\text { tiempo. } \\
\text { - La estructura puede plastificar, pero no se alcanza la capacidad } \\
\text { última de desplazamiento o rotación de ninguno de sus elementos. } \\
\text { Se mantiene la capacidad a cortante y a torsión de los elementos de } \\
\text { la estructura. } \\
\text { - Los elementos que presentan dificultad de reparación y refuerzo } \\
\text { pueden observar límites más estrictos. }\end{array}$ \\
\hline Grado 3 & $\begin{array}{l}\text { - Se mantiene tan sólo la capacidad de a cortante de los elementos } \\
\text { verticales, y la capacidad de resistir el peso propio de la estructura. } \\
\text { - La estructura no debe colapsar por completo, a pesar de que puede } \\
\text { no resultar reparable tras el terremoto. }\end{array}$ \\
\hline
\end{tabular}

Tabla 3-41. Niveles de daño sísmico de la normativas japonesas JSCE Cut-and-Cover Tunnels (Takemura et al., 2018), y JSCE Concrete Structures. (Hiroyuki et al., 2007).

Finalmente, la norma JSCE de túneles Cut-and-Cover indica que, puesto que las estructuras subterráneas son mucho más difíciles de reparar que las estructuras en superficie, los objetivos de desempeño deben establecerse con el máximo de los cuidados, y propone la siguiente matriz de desempeño.

\begin{tabular}{|c|c|}
\hline Nivel de Demanda & Nivel de Daño \\
\hline Demanda L1 & Grado 1 \\
\hline Demanda L2 & Grado 2 o Grado 3 \\
\hline
\end{tabular}

Tabla 3-42. Matriz de Demanda-Desempeño de la normativa japonesa JSCE Standard Specifications for Tunnelling 2016. Cut-and-Cover Tunnels (Takemura et al., 2018).

\subsection{Métodos de análisis}

En lo que respecta a los métodos de análisis de la acción sísmica, la norma JSCE de túneles Cut-and-Cover (Takemura et al., 2018) indica que la interacción entre la estructura y el suelo circundante debe ser analizada de manera apropiada. También indica 
que las acciones a considerar serán tanto los efectos inerciales de la masa de la propia estructura y la acción inducida por el movimiento del suelo.

Para considerar estas acciones propone dos métodos de análisis:

- Un análisis dinámico del conjunto suelo-estructura en el que la acción sísmica se considera como la resultante de un cálculo del tipo time-history en el que se solicita con un registro de aceleraciones a la base del modelo.

- Un análisis estático denominado de "deformación sísmica”, en el que se considera al suelo y a la estructura como sistemas separados. En el análisis del terreno se obtienen los desplazamientos y tensiones tangenciales del mismo en la zona sustituída por el túnel, y más tarde se aplican dichos desplazamientos y tensiones tangenciales a un modelo separado de la estructura del tunel. Este método simplificado se resume gráficamente en la (Fig. 3-153).

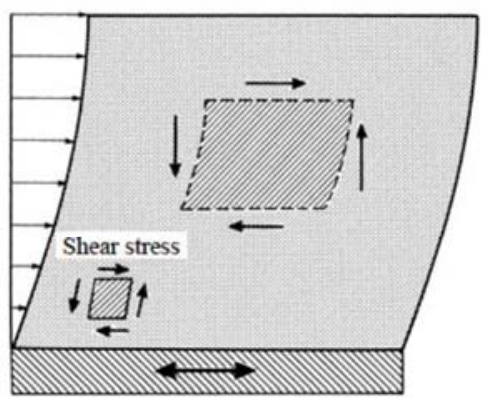

Fig. C2.9.2 Generation mechanism of peripheral surface shear force

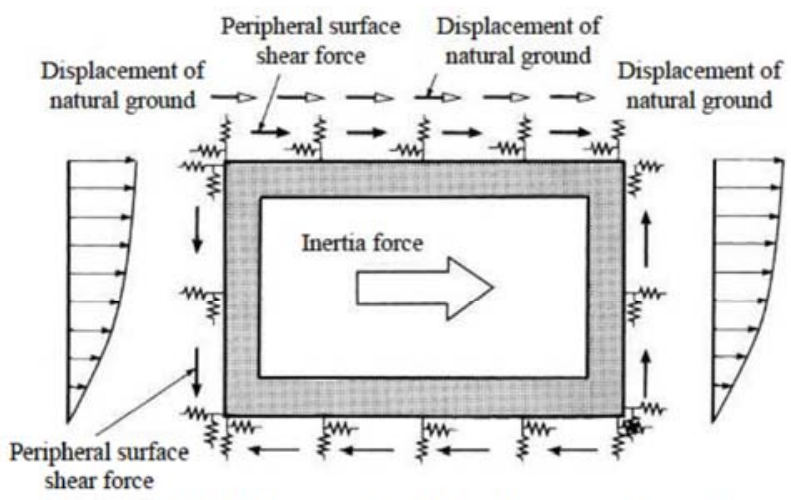

Fig. C2.9.3 Effects of earthquake considered by seismic deformation method

Fig. 3-153. Esquema de acción sísmica transversal de la normativa Japonesa JSCE Standard Specifications for Tunnelling 2016. Cut-and-Cover Tunnels (Takemura et al., 2018).

Tal y como se puede apreciar, la metodología de análisis simplificado propuesta por esta normativa es idéntica a la de la norma japonesa del RTRI descrita en el apartado \$3.8.3.1.2 de esta tesis, e idéntico al propuesto por la guía AFPS y el Eurocódigo EC8-2. En este sentido, se pueden verter sobre este método las mismas críticas que se hicieron en el apartado §3.8.1.1 en lo que respecta al comportamiento de estructuras flexibles. 


\subsubsection{Normativa Chilena}

\subsubsection{Niveles de demanda y desempeño}

La normativa chilena (Manual de Carreteras. Instrucciones y Criterios de Diseño, 2016) establece en el apartado $\$ 3.1004 .1$ un único nivel de demanda basado en criterios probabilistas, correspondiente a un periodo de retorno $T_{R}=475$ años, que corresponde a una probabilidad de excedencia del $10 \%$ en 50 años.

Sin embargo, también establece coeficientes de importancia para dos categorías de obras denominadas I (esenciales) y II (normales), que se resumen en la Tabla 3-43. Como puede apreciarse, la demanda correspondiente a las estructuras esenciales es efectivamente la que corresponde a un periodo de retorno $T_{R}=475$ años. Sin embargo las estructuras de importancia normal se calculan para una demanda menor.

\begin{tabular}{|c|c|}
\hline Importancia & Coeficiente de Importancia CI \\
\hline I (Esencial) & 1,0 \\
\hline II (Normal) & 0,8 \\
\hline
\end{tabular}

Tabla 3-43. Coeficientes de importancia según la clasificación de la obra de la normativa chilena.

(Manual de Carreteras. Instrucciones y Criterios de Diseño, 2015) .

Este criterio contrasta con las demandas establecidas en el resto de normativas consideradas, en las que el terremoto de diseño que corresponde al nivel mayor se establece para un periodo de retorno mayor a $T_{R}=475$ años.

\subsubsection{Métodos de análisis}

La norma chilena (Manual de Carreteras. Instrucciones y Criterios de Diseño, 2016) establece en el apartado §3.1003.501 los modelos de análisis sísmico mediante los cuales deben evaluarse las estructuras enterradas tipo marco o cajón. El modelo propuesto por esta norma sigue parcialmente la formulación propuesta por Kuesel (Kuesel, 1969) para el Metro de San Francisco, y la desarrollada por Ortigosa y Musante (Ortigosa \& Musante, 1991), descrita en el apartado §3.7.3.3 de esta tesis, y que ha sido empleada para el proyecto del Metro de Santiago de Chile a partir de 1971.

En la Fig. 3-154 se plantea la esencia del método, consistente en modelizar el marco estructural que se conecta al suelo circundante mediante unos muelles tipo Winkler de rigidez $K_{h}$ que representan la interacción suelo-estructura. En los extremos no vinculados a la estructura de estos muelles, se imponen los desplazamientos sísmicos $\delta$ s 
calculados para el campo libre, relativos a la base de la estructura. La imposición de estos desplazamientos tendrá como resultado los esfuerzos (momento flector, cortante, etc.), y los desplazamientos de la propia estructura.

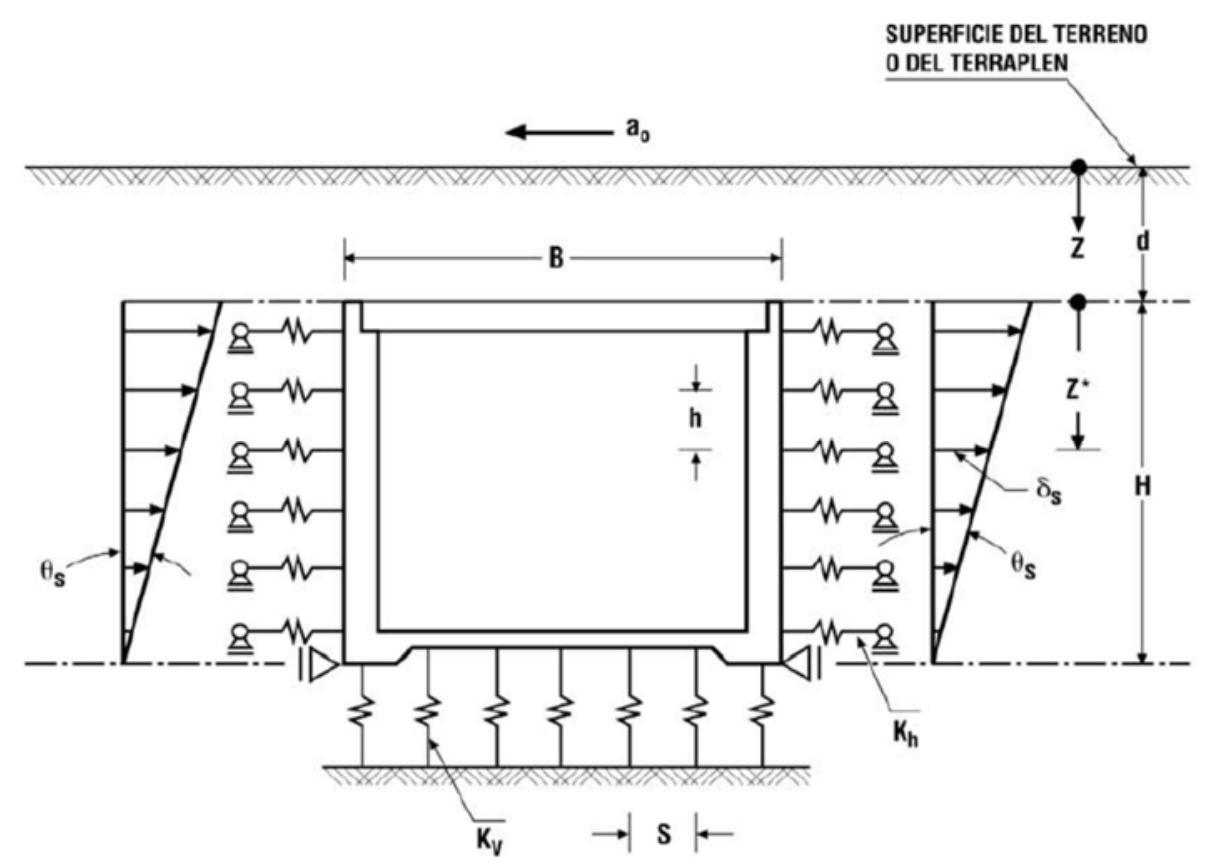

Fig. 3-154. Esquema de acción sísmica transversal de la normativa Chilena. (Manual de Carreteras. Instrucciones y Criterios de Diseño, 2015).

La deformación $\delta_{\text {si }}$ de campo libre se analiza para cada cota $i$ del túnel mediante la expresión (Ec. 3-221), donde $\theta_{i}$ es ángulo de distorisón (desangulamiento en términos de la norma chilena) y se calcula a través de la expresión (Ec. 3-222). En esta expresión, zi es la cota de cada punto, $a_{0}$ la aceleración máxima en superficie $[\mathrm{g}], \gamma$ la densidad del suelo $\left[\mathrm{t} / \mathrm{m}^{3}\right], G_{c i}$ el módulo de cortante del suelo a la cota correspondiente (Ec. 3-223), $K_{2 i}$ el coeficiente adimensional de reducción del módulo de cortante, y $\sigma_{v i}$ la tensión vertical efectiva en el centro de la capa.

$$
\begin{gathered}
\delta_{s i}=\sum_{i}^{n} \theta_{s i} \cdot h \\
\theta_{s i}=\frac{\left(1-0,0167 \cdot z_{i}\right) \cdot a_{0} \cdot \gamma \cdot z_{i}}{G_{c i}} \\
G_{c i}=53 \cdot K_{2 i} \cdot \sqrt{\overline{\sigma_{v l}}}
\end{gathered}
$$

Para evaluar el coeficiente $K_{2 i}$, se recurre al gráfico de la Fig. 3-155. 


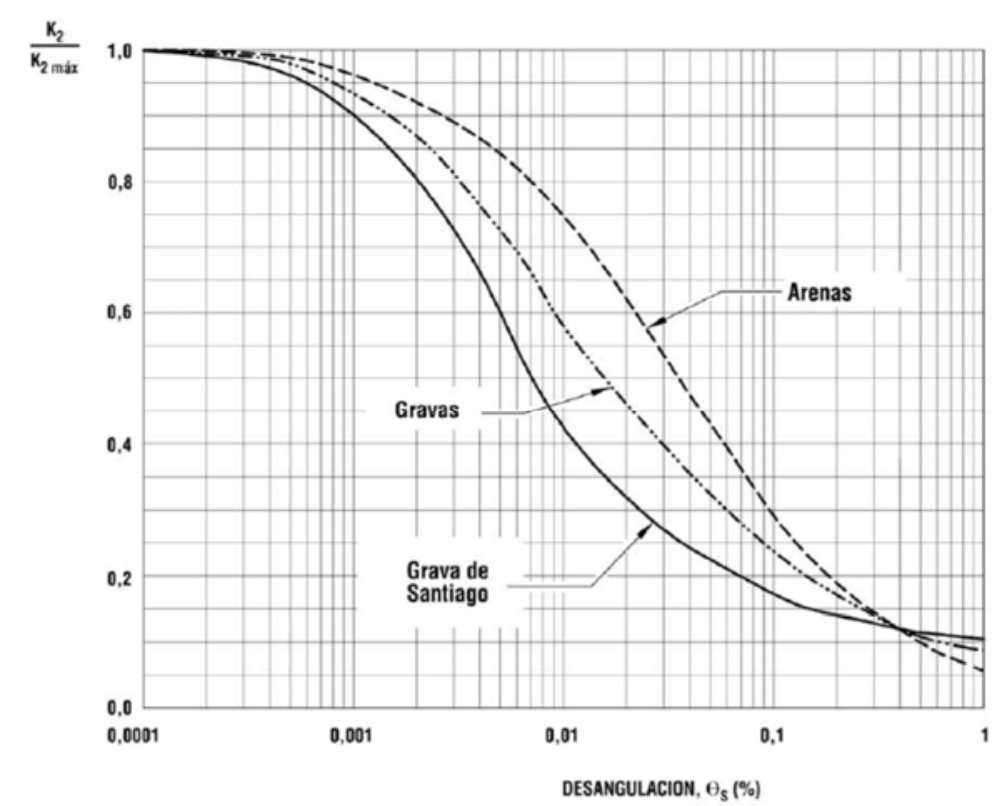

Fig. 3-155. Reducción del módulo de cortante de la normativa Chilena. (Manual de Carreteras. Instrucciones y Criterios de Diseño, 2015).

$$
\begin{gathered}
K_{h i}=k_{h i} \cdot h \\
k_{h i}=\frac{2,7 \cdot G_{c}}{H} \frac{1}{\sqrt{1-\left(\frac{Z_{i}^{*}}{H}\right)^{2}}}
\end{gathered}
$$

Para determinar el valor de la rigidez de los muelles de Winkler, los horizontales dependen de la profundidad y se calculan a través de las (Ec. 3-224) y (Ec. 3-225).

Como se puede apreciar, se trata de un método muy similar al propuesto por la guía francesa de la AFPS, el Eurocódigo EC8-2, y la normativa japonesa. En este sentido, se pueden verter sobre este método las mismas críticas que se hicieron en el apartado §3.8.1.1 en lo que respecta al comportamiento de estructuras flexibles. La única diferencia relevante con respecto a las anteriores, es la inclusión explícita del comportamiento no lineal de los muelles de Winkler.

\subsubsection{Normativa internacional ISO 23469:2005 (R2014)}

La organización de normalización internacional ISO (International Organization for Standardization) ha desarrollado una normativa referente a las acciones diseño sísmico a considerar en el proyecto de obras geotécnicas: ISO-23469. Bases for design of structures - Seismic actions for designing geotechnical works. En particular, este texto 
está orientado a aquellas obras relacionadas con suelo o roca, e incluye estructuras subterráneas (p.ej. túneles enterrados, pasos inferiores, canalizaciones subterráneas, instalaciones de almacenamiento), cimentaciones (p.ej. cimentaciones superficiales y profundas, muros pantalla), muros de contención de muelles y otros, muelles de atraque y diques, estructuras de tierras (p.ej. presas y ataguías de tierra y escollera), presas de gravedad, rellenos y vertederos.

Esta norma, publicada en el año 2005, ha sido objeto de una revisión en 2014 (R2014), es esta última versión la que se describe en este apartado.

\subsubsection{Niveles de demanda y desempeño}

La norma ISO-23469 establece dos niveles de demanda diferentes, con sus correspondientes objetivos de desempeño, aunque la descripción cuantitativa de ambos es vaga, y poco concreta. En este sentido, la norma ISO-23469 se trata más bien de una recomendación para adoptar un enfoque basado en el control de dos escenarios sísmicos diferentes, y deja libertad a cada autoridad competente de fijar la intensidad de dichos escenarios y los requisitos de desempeño correspondientes.

En lo que respecta a los niveles de demanda, en el apartado $§ 5.1 .3$ establece dos niveles: un nivel de "servicio" correspondiente a sismos que tengan una probabilidad "razonable" de ocurrencia durante la vida útil de la obra. Adicionalmente, establece un nivel de "seguridad" que está asociado a eventos sísmicos infrecuentes que pueden involucrar movimientos severos en el emplazamiento de la obra.

En lo que se refiere a los objetivos de desempeño, en los apartados $§ 5.1 .2$ y $§ 5.1 .4$ por un lado establece un objetivo de desempeño de "servicio" durante y tras el sismo, para el cual el impacto a las actividades industriales y sociales debe ser "menor". Para este objetivo, las obras geotécnicas pueden experimentar desplazamientos residuales que se consideren aceptables, sin que por ello se impida la funcionalidad de la obra, de tal manera que se mantenga en operativa, o que esta operatividad se recupere tras una interrupción temporal.

Por otro lado, establece un objetivo de desempeño de "seguridad" durante y tras el sismo, para el cual las víctimas personales y daños a la propiedad deben ser minimizadas. Las obras geotécnicas que sean parte fundamental de una instalación que albergue o emplee materiales peligrosos, o que sean parte de una instalación de 
emergencia post-sísmica, deben mantener íntegra su capacidad operacional, y las obras geotécnicas no deben colapsar.

\subsubsection{Métodos de análisis}

En el Anexo §H.4 de la norma ISO-23469 se establecen tres procedimientos para analizar la acción del sismo en las secciones transversales de estructuras enterradas, un método de análisis estático simplificado equivalente, un método de análisis estático detallado equivalente, y un método de análisis dinámico detallado.

El método estático simplificado equivalente es muy similar al desarrollado en la normativa japonesa (Iai, 2005), descrito en el apartado §3.8.3.1.2. Consiste en el desarrollo de un modelo estructural simple del tipo viga con fundación elástica (Fig. 3-156). La acción correspondiente al sismo debe introducirse como una deformación de campo libre. De manera textual, la norma ISO-23469 indica:

“[...] peak displacement distribution of the free field response or the displacement distribution at the instant when the maximum relative displacement or deformation occurs between the top and bottom of the buried portion of the structure." (ISO-23469, pp. 62).

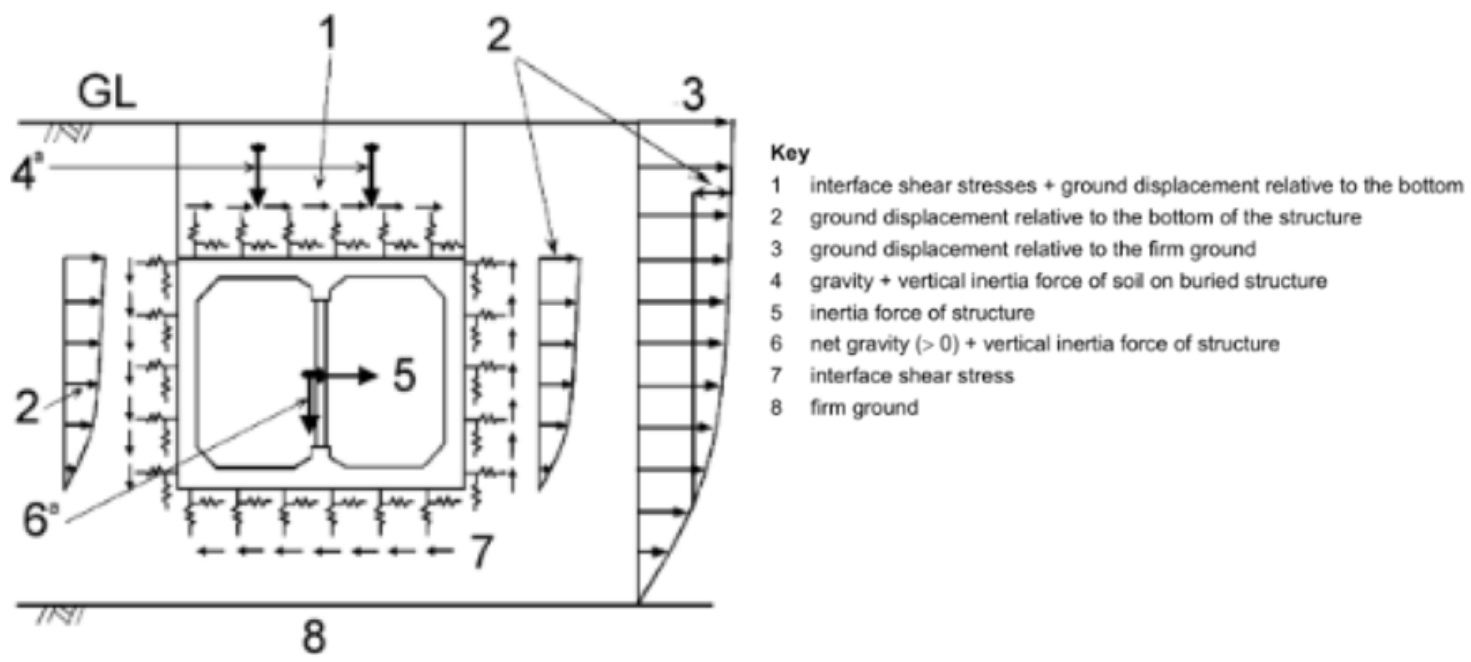

Fig. 3-156. Método de análisis estático simplificado equivalente. (ISO-23469).

De manera similar a como se indicó en las normativas anteriormente descritas que aplican este método de análisis, queda claro que, con la aplicación de este método, las estructuras muy flexibles se verán sometidas a unas deformaciones que, como mucho, podrán ser del orden de magnitud de la deformación de campo libre $\gamma_{F F}$, y no del orden de $R \cdot \gamma_{F F}$. Este método es por lo tanto un método de campo libre, y entra en contradicción 
con los métodos de interacción cinemática postulados por Wang (J. N. Wang, 1993), Penzien (Penzien, 2000), Anderson (Anderson et al., 2008), y Huo (H. Huo et al., 2006; Hongbin Huo, 2005; Hongbin Huo et al., 2005), y recogidos en la normativa de Estados Unidos descrita en el apartado 33.8 .2 .3 .

Adicionalmente, la norma ISO-23469 establece un método estático detallado equivalente, consitente en desarrollar un modelo numérico de elementos finitos del conjunto suelo-estructura (Fig. 3-157), el cual se solicita con un un patrón de aceleraciones inerciales correspondiente al instante en el que se produce el desplazamiento relativo máximo entre la parte superior e inferior de la estructura. De manera textual, la norma ISO-23469 indica:

"In detailed equivalent static analysis of buried structure in horizontally layered ground, a FE model is used based on the seismic coefficient approach as shown in figure H.4. As shown in this figure, acceleration of free field is at first computed through site response analysis such as site-specific dynamic analysis, and then the distributed inertia force in ground is applied for each node of FE analysis domain of soil-structure system.

Relevant parameters and actions are as follows:

a) parameters of reference earthquake motions: the acceleration distribution at the instant when the maximum relative displacement deformation occurs between the top and bottom of the buried portion of the structure;

b) actions: distributed inertia force on soil mass of soil-structure system." (ISO23469, pp. 63).

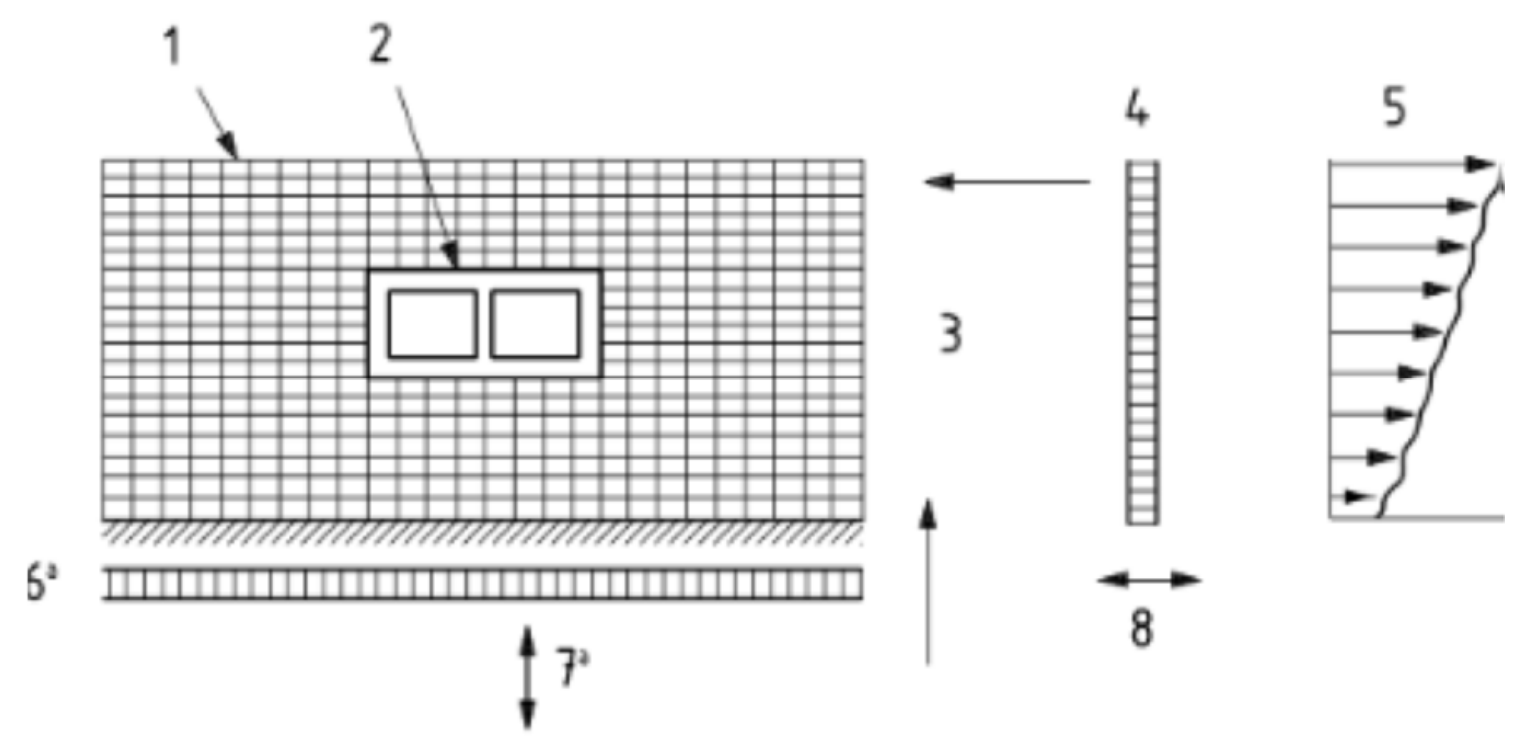

Fig. 3-157. Método de análisis estático simplificado equivalente. (ISO-23469). 
Por último, la norma ISO-23469 establece un procedimiento de análisis dinámico detallado, consistente en el desarrollo de un modelo numérico de elementos finitos similar al del procemiento simplificado anterior (Fig. 3-157), solicitado por una acción sísmica en forma de acelerograma, y análisis time-history o modal espectral del conjunto sueloestructura. De manera textual, la norma ISO-23469 indica:

"The model for detailed analysis is typically based on a FE model. Relevant parameters and actions are the same as described in H.2.3.

Response mode, peak values of the stress resultants, stresses and strains in a structure, and peak deformation of structure can be computed if an equivalent linear model is used. Failure mode, peak and residual values of the stress resultants, stresses and strains in the structure, peak and residual deformation of the structure can be computed if a non-linear model is used.” (ISO-23469, pp. 64). 


\section{ESTUDIO DE LA DISTORSIÓN EN SISTEMAS SUELO- ESTRUCTURA LINEALES EN DEFORMACIÓN PLANA}

\subsection{Introducción}

El comportamiento de las estructuras subterráneas sometidas a la acción del sismo difiere notablemente del caso de estructuras en superficie. En la mayor parte de los casos de estructuras subterráneas, la componente inercial de la masa de la estructura es despreciable, y no condiciona el comportamiento dinámico durante un evento sísmico (Bobet, 2010; H. Huo, Bobet, Fernández, \& Ramírez, 2006; Penzien, 2000; Pitilakis, Anastasiadis, Raptakis, Boussolas, \& Papageorgiou, 2007; Grigorios Tsinidis, Rovithis, Pitilakis, \& Chazelas, 2015; J. N. Wang, 1993), mientras que para las estructuras en superficie es el aspecto más significativo. Adicionalmente, las estructuras enterradas ven su movimiento restringido por el suelo circundante, y por lo tanto se encuentran sometidas, a grandes rasgos, a un rango de desplazamientos similar al que se ve sometido el suelo (Bobet, Fernandez, Huo, \& Ramirez, 2008; Hashash, Karina, Koutsoftas, \& O’Riordan, 2010; Hongbin Huo, Bobet, Fernández, \& Ramírez, 2005).

Para evaluar los desplazamientos, y posteriormente los esfuerzos internos tales como momentos flectores y cortantes, durante un evento sísmico, en la actualidad se siguen tres enfoques (Bobet et al., 2008; Hung, Monsees, Munfah, \& Wisniewski, 2009; LA Metro Authority, 2012; WSDOT, 2010), a saber: enfoques pseudo-estáticos basados en la deformación de campo libre, enfoques pseudo-estáticos con intervención de la interacción cinemática suelo-estructura, y enfoques basados en la implementación numérica de modelos de interacción suelo-estructura.

Los enfoques pseudo-estáticos basados en la deformación de campo libre (Hendron and Fernandez, 1983, Merrit, 1985, Monsees, 1991) constituyen los primeros intentos de estudiar el comportamiento interrelacionado del suelo y de la estructura enterrada durante un terremoto. El primer método propuesto, desarrollado para el 
proyecto del túnel de la bahía de San Francisco (EE.UU.) (Kuesel, 1969), describe con precisión las principales características del problema: en lo que respecta al terreno, el terremoto consiste en una sucesión de ondas de deformación que atraviesan el subsuelo, y a las que debe acomodarse la estructura subterránea sufriendo un daño limitado. Este enfoque consiste, en una primera etapa, en determinar el perfil de desplazamiento del suelo, a una distancia suficientemente alejada de la estructura (deformación de campo libre, free-field displacement en la literatura anglosajona), y en la profundidad comprendida por la estructura subterránea (p.ej. profundidad entre la losa superior de cubrición, e inferior de contrabóveda). Una segunda etapa consiste en imponer esta deformación de campo libre a la estructura, analizar los esfuerzos resultantes de estas deformaciones impuestas, y diseñar los elementos estructurales para que sean capaces de resistir estos esfuerzos. Dado que este enfoque propone imponer los desplazamientos de campo libre a la estructura, no considera que la propia interacción suelo-estructura puede modificar localmente el perfil de deformaciones en la región de suelo cercana a la estructura subterránea.

Tras constatar que la estructura subterránea embebida en el suelo puede alterar el patrón de deformaciones del terreno en su región más cercana, diversos autores desarrollaron durante la década de los 90 del s. XX un enfoque más detallado denominado método pseudo-estático de interacción suelo-estructura, para el cual Hashash (Hashash, Hook, Schmidt, \& I-Chiang Yao, 2001) proporciona una descripción amplia y detallada. Partiendo de un concepto similar al enfoque de deformación en campo libre, una vez que se determina el perfil de desplazamiento del suelo a una distancia suficientemente alejada de la estructura, se aplica a esta deformación de campo libre un factor de amplificación o de reducción, denominado coeficiente de distorsión $R$ (racking coefficient en la literatura anglosajona) para obtener la deformación de la estructura a la que esta debe acomodarse sufriendo un daño limitado. Este coeficiente $R$ de racking, que encapsula el efecto de interacción suelo-estructura, se ha obtenido en estudios anteriores de los otros autores a través de métodos basados en la teoría de la elasticidad, y se ha verificado con posterioridad mediante análisis numéricos.

El método se ha sustanciado en diferentes expresiones analíticas del coeficiente $R$ de racking, cada una desarrollada bajo hipótesis ligeramente diferentes. Wang (J. N. Wang, 1993) propone que un único parámetro denominado ratio de flexibilidad $F_{R}$ (que mide la rigidez relativa a cortante del terreno sustituido por la estructura subterránea, 
comparada a la rigidez a cortante de la propia estructura subterránea) condiciona el efecto de interacción suelo-estructura, de tal manera que cuanto más flexible es la estructura respecto al suelo más se deforma la estructura, y viceversa. Wang propone una expresión analítica basada en el trabajo anterior desarrollado por Peck (Peck, 1969) para estructuras circulares, y que adapta al caso de estructuras rectangulares.

Penzien (Penzien, 2000; Penzien \& Wu, 1998) desarrolló una base teórica para el coeficiente de racking $R$ basándose en la teoría de la elasticidad, y propuso una expresión analítica para el coeficiente de racking similar a la de Wang, que resulta exacta para el caso de una estructura circular, y a la que asimila el caso de una estructura rectangular.

Anderson (Anderson, Martin, Lam, \& Wang, 2008) desprecia la influencia que el coeficiente de Poisson pudiera tener en el fenómeno de interacción suelo-estructura, y propone una expresión similar a la Wang y Penzien correspondiente a un coeficiente de Poisson de $v=0.5$.

Más recientemente Huo (H. Huo et al., 2006; Hongbin Huo, 2005; Hongbin Huo, Bobet, Fernández, \& Ramírez, 2004), notando que las expresiones anteriores, al aplicarse al caso de estructuras rectangulares, desprecian el efecto que tiene el desplazamiento fuera de su plano de las losas y pantallas cuando reaccionan contra el terreno, desarrolla una expresión analítica para el coeficiente de racking de estructuras rectangulares mediante una transformación en el plano complejo entre una estructura circular y una estructura rectangular.

Por último, los enfoques basados en el análisis numérico de la interacción sueloestructura constituyen la metodología más detallada para estudiar el efecto de una estructura subterránea sometida a la acción sísmica. Estos consisten en el análisis numérico del problema mediante el desarrollo de un modelo de elementos finitos (MEF) o de diferencias finitas del sistema enterrado suelo-estructura, y realizar o bien un análisis dinámico completo o un análisis pseudo-estático, ambos lineales o no lineales, en función de la característica de interés que se pretende estudiar (Abate \& Massimino, 2017; Debiasi, Gajo, \& Zonta, 2013; Fabozzi et al., 2017; Guoxing et al., 2015; Hashash et al., 2001; Hung et al., 2009; LA Metro Authority, 2012; H. F. Wang, Lou, Chen, \& Zhai, 2013; WSDOT, 2010). Aunque este enfoque pudiera parecer el más general y preciso, dado que puede considerar de manera apropiada diferentes efectos mecánicos, en la práctica apenas se emplea durante las primeras fases del proyecto de una estructura 
subterránea (LA Metro Authority, 2012). En primer lugar, el proceso de diseño contempla fases de diseño conceptual, preliminar, y detallado, durante las cuales la planificación funcional y de la arquitectura (p.ej. esquemas de circulación de los pasajeros en estaciones de metro) pueden modificar ampliamente, y con frecuencia, las configuraciones estructurales y geotécnicas previas. Esto convierte a los modelos de elementos finitos en muy poco prácticos hasta que se alcanzan las fases finales del proyecto, cuando muchas de las decisiones referentes a la ingeniería del proyecto ya se han tomado, y apenas queda margen para realizar cambios, si no únicamente para la verificación. En segundo lugar, el confiar únicamente en modelos numéricos complejos para obtener resultados estructurales relevantes (p.ej. momentos flectores, esfuerzos cortantes, desplazamientos, etc.) puede dejar al ingeniero sin herramientas más prácticas e inmediatas para que pueda guiar sus decisiones hacia un diseño seguro y económico.

\subsection{Propósito de la solución propuesta}

Tal y como se expone en los apartados previos, de las expresiones analíticas existentes hasta la fecha para analizar el efecto de interacción suelo-estructura, y por lo tanto la deformación de distorsión ó racking de la estructura rectangular enterrada, 3 de ellas (Anderson et al., 2008; Penzien, 2000; J. N. Wang, 1993) están basadas en la hipótesis de que el campo de tensiones y deformaciones del suelo que rodea la estructura es similar al que se desarrolla en el caso de un túnel circular. La expresión desarrollada por Huo (H. Huo et al., 2006) corresponde al caso de geometría rectangular, sin embargo el desarrollo matemático subyacente es intrincado y puede entorpecer la comprensión de los fenómenos mecánicos subyacentes al ingeniero proyectista que diseñe la estructura.

En lo que sigue, proponemos una expresión analítica desarrollada para en caso de geometría rectangular que, intentando ser lo más precisa posible, proporcione al ingeniero proyectista un medio efectivo para entender intuitivamente la auténtica naturaleza del efecto de la distorsión o racking diferencial (es decir, una deformación mayor de la estructura que la correspondiente al campo libre si esta estructura es más flexible que el suelo, y viceversa). Esta comprensión intuitiva es un aspecto que no debería pasarse por alto: tal y como se ha comentado con anterioridad, los métodos basados en la deformación de campo libre (Kuesel, 1969; Monsees, 1991) se basan en la hipótesis de que el suelo cercano a la estructura se deforma de manera similar a como lo hace en la parte alejada 
de la misma, y que no existe interacción suelo-estructura, probablemente guiados por una idea intuitiva que fue corregida con estudios posteriores.

\subsection{Solución propuesta para el coeficiente de distorsión de Racking}

Consideremos una estructura subterránea rectangular (de ancho $b$, canto $d, \mathrm{y}$ proporción ancho/canto $\lambda=b / d$ ), y una porción de suelo que rodea la estructura de tamaño arbitrario (de ancho $L$ y canto $H$ ) concéntrica a la estructura subterránea, tal y como se refleja en la (Fig. 4-1). Consideremos que el perímetro exterior del suelo está sometido a un campo de tensiones de cortante puro, y consideremos que pretendemos determinar el campo de deformaciones en el suelo y en la estructura.

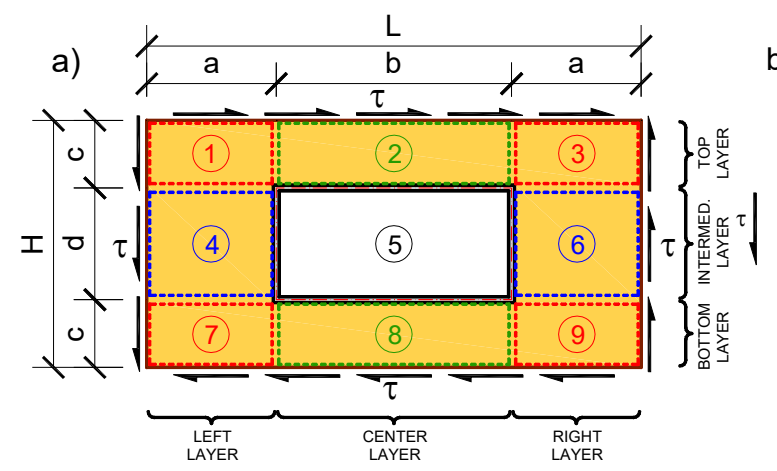

b)
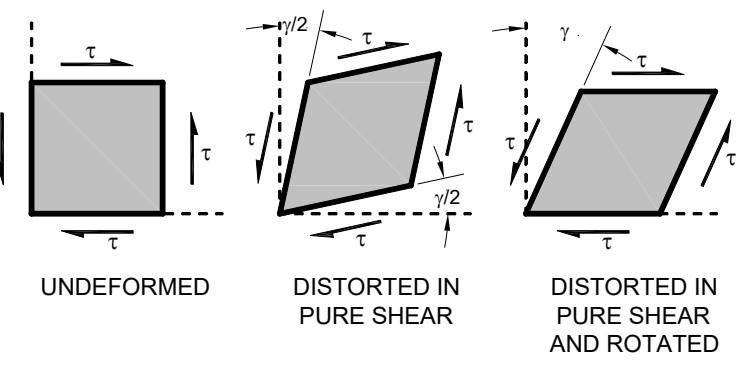

Fig. 4-1. (a) Diagrama de bloques de una porción arbitraria del sistema suelo-estructura. (b)

Distorsión a cortante puro de un bloque individual.

Para determinar el campo de deformaciones haremos las tres hipótesis siguientes:

- El sistema suelo-estructura se puede dividir en bloques rectangulares, numerados del 1 al 9 en la (Fig. 4-1, a).

- Cada bloque se puede deformar tan sólo con un patrón de deformación de cortante puro, tal y como se representa en la (Fig. 4-1, b), con la rigidez de un medio elástico, homogéneo, e isotrópico, definido por su módulo de cortante G, y la ecuación de la elasticidad $\gamma=\tau / G$. En esta ecuación, $\gamma$ mide el ángulo total de la distorsión producida entre dos de los bordes ortogonales, pero el ángulo distorsionado por cada borde, respecto a las rectas horizontal y vertical, es $\gamma / 2$ cada uno (Hudson \& Harrison, 2000).

- Existe compatibilidad de movimiento entre las esquinas de los bloques adyacentes, es decir, las esquinas compartidas por diferentes bloques se desplazan horizontal y verticalmente la misma magnitud. Esto se 
traduciría en una condición de no-deslizamiento en la terminología de otros autores (Penzien, 2000; J. N. Wang, 1993).

Como consecuencia de estas hipótesis, se deriva que en cada bloque las deformaciones y tensiones son constantes a lo largo de todo su ancho y de su canto, y en particular en sus bordes. Esta hipótesis significa que no se producirá ninguna concentración de tensiones en las esquinas de del suelo-estructura, y que solamente se considerará una "tensión media" y "deformación media" para cada bloque. Por otra parte, se llama la atención sobre el hecho de que el ángulo total $\gamma$ distorsionado por cada bloque será la suma del ángulo que produce desplazamiento horizontal $\gamma_{H}$, más el ángulo que produce desplazamiento vertical $\mathcal{W}$.

Si se sigue la transferencia de, digamos, la fuerza de rasante horizontal desde el borde superior hasta el inferior a través del canto del sistema, en base a consideraciones de equilibrio, es fácil darse cuenta de que la fuerza resultante total en cualquier sección horizontal debe ser constante (Fig. 4-2, a), incluso si la tensión de cortante horizontal en cada bloque puede ser diferente. De manera similar, y en base a las hipótesis anteriores, y a consideraciones de compatibilidad entre bloques contiguos, se puede apreciar que para cada bloque contiguo (es decir, perteneciente a la misma capa: capa superior de bloques 1-3, la capa intermedia de bloques 4-6, y la capa inferior de bloques 7-9) la deformación de distorsión horizontal $\gamma_{H}$ debe ser de igual valor.

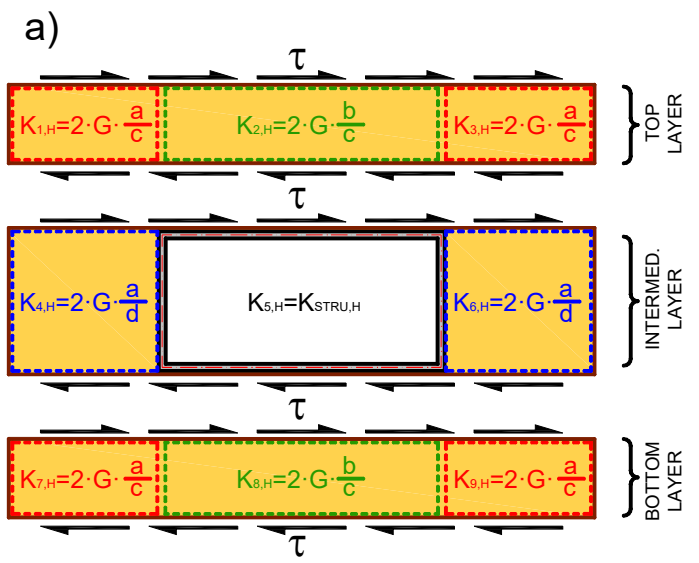

b)
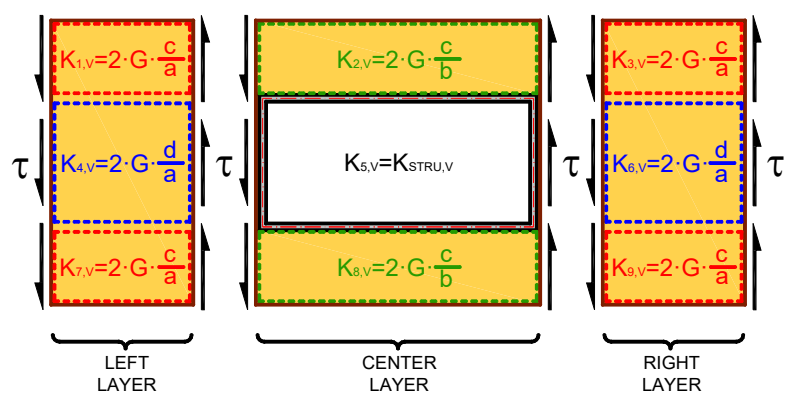

Fig. 4-2. Diagrama de bloques, transferencia de rasante entre capas, $y$ rigidez horizontal a cortante de cada bloque. (a) Horizontales. (b) Verticales.

Por lo tanto, la rigidez al desplazamiento horizontal de cada capa de bloques debe ser la suma en paralelo de las rigideces de cada uno de los tres bloques dentro de la misma capa. En particular, y considerando que el desplazamiento horizontal corresponde 
únicamente al ángulo distorsionado horizontalmente $\gamma / 2$, la rigidez $K_{n, H}$ de cada bloque $n$ para una fuerza horizontal será la que se muestra en las ecuaciones (Ec. 4-1), (Ec. 4-2), (Ec. 4-3) y (Ec. 4-4).

$$
\begin{gathered}
K_{1, H}=K_{3, H}=K_{7, H}=K_{9, H}=2 \cdot G \cdot \frac{a}{c} \\
K_{2, H}=K_{8, H}=2 \cdot G \cdot \frac{b}{c} \\
K_{4, H}=K_{6, H}=2 \cdot G \cdot \frac{a}{d} \\
K_{5, H}=K_{S T R U, H}=2 \cdot \frac{G \cdot \frac{b}{d}}{F_{R}}
\end{gathered}
$$

En la que el término $F_{R}$ en la (Ec. 4-4) corresponde a la ratio de flexibilidad clásica definida por Wang (J. N. Wang, 1993), que en el caso de una estructura lineal elástica constituida por un único marco sin pilares o losas intermedias, de ancho $b$ y canto $d, \mathrm{y}$ con inercias a flexión de muros y losa $I_{w}$ e $I_{b}$ respectivamente, queda determinada por la expresión .

$$
F_{R}=\frac{K_{\text {SOIL }}}{K_{S T R U}}=\frac{G \cdot \frac{b}{d}}{\frac{1}{\frac{d^{2} \cdot b}{24 \cdot E \cdot I_{b}}+\frac{d^{3}}{24 \cdot E \cdot I_{w}}}}
$$

Hay que subrayar que esta expresión concreta de $F_{R}$ no es determinante para el procedimiento descrito en este apartado, y que puede cambiarse con facilidad por cualquier otra rigidez a la distorsión de una aplicación concreta (p.ej. rigidez con columnas interiores, losas intermedias, etc.).

Un razonamiento similar sería válido para la fuerza vertical que se transfiere desde la derecha hacia la izquierda (Fig. 4-2, b). Empleando las dimensiones geométricas apropiadas, la rigidez de cada bloque $K_{n, V}$ de cada bloque $n$ frente a una fuerza vertical sería la que se muestra en las ecuaciones (Ec. 4-6), (Ec. 4-7), (Ec. 4-8), y (Ec. 4-9).

$$
\begin{gathered}
K_{1, V}=K_{3, V}=K_{7, V}=K_{9, V}=2 \cdot G \cdot \frac{c}{a} \\
K_{2, V}=K_{8, V}=2 \cdot G \cdot \frac{c}{b} \\
K_{4, V}=K_{6, V}=2 \cdot G \cdot \frac{d}{a} \\
K_{5, V}=K_{S T R U, V}=2 \cdot \frac{G \cdot \frac{d}{b}}{F_{R}}
\end{gathered}
$$


A partir de las expresiones anteriores (Ec. 4-1), (Ec. 4-2), (Ec. 4-3) y (Ec. 4-4), y debido a la compatibilidad de deformaciones de cortante horizontales entre bloques horizontales adyacentes, la rigidez a cortante para cada capa horizontal ( $K_{T O P}$ para la capa

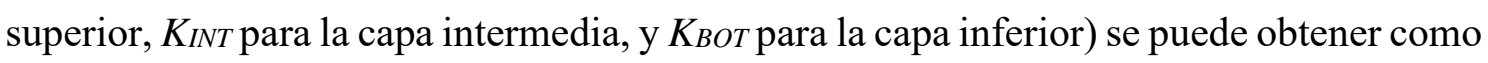
una suma en paralelo de rigideces, como se muestra en las (Ec. 4-10) y (Ec. 4-11).

$$
\begin{gathered}
K_{T O P, H}=K_{B O T, H}=K_{1, H}+K_{2, H}+K_{3, H}=K_{7, H}+K_{8, H}+K_{9, H} \\
=2 \cdot G \cdot \frac{a+b+a}{c}=2 \cdot G \cdot \frac{L}{c} \\
K_{I N T, H}=K_{4, H}+K_{5, H}+K_{6, H}=2 \cdot G \cdot \frac{2 a}{d}+K_{S T R U, H}
\end{gathered}
$$

La rigidez vertical de cada capa vertical (KLEFT para la capa izquierda, $K_{C E N T}$ para la capa central, y $K_{R I G H T}$ para la capa derecha) se obtendría de manera similar mediante las expresiones (Ec. 4-12) y (Ec. 4-13).

$$
\begin{gathered}
K_{L E F T, V}=K_{R I G H T, V}=K_{1, V}+K_{4, V}+K_{7, V}=K_{3, V}+K_{5, V}+K_{9, V} \\
=2 \cdot G \cdot \frac{c+d+c}{a}=2 \cdot G \cdot \frac{H}{a} \\
K_{C E N T, V}=K_{2, V}+K_{5, V}+K_{8, H}=2 \cdot G \cdot \frac{2 c}{b}+K_{S T R U, V}
\end{gathered}
$$

Si se fuera a estimar la rigidez media horizontal $K_{A V G, H}$ del conjunto sueloestructura, (esto es, de los 9 bloques), midiendo la fuerza requerida en la cara superior para producir un desplazamiento horizontal unitario, un método consistente con las hipótesis enunciadas anteriormente sería sumar la rigidez en serie de cada capa (Ec. 4-14).

$$
K_{A V G, H}=\frac{1}{\frac{1}{K_{T O P, H}}+\frac{1}{K_{I N T, H}}+\frac{1}{K_{B O T, H}}}=\frac{1}{2 \cdot \frac{1}{2 \cdot G \cdot \frac{L}{c}}+\frac{1}{2 \cdot G \cdot \frac{2 a}{d}+K_{S T R U, H}}}
$$
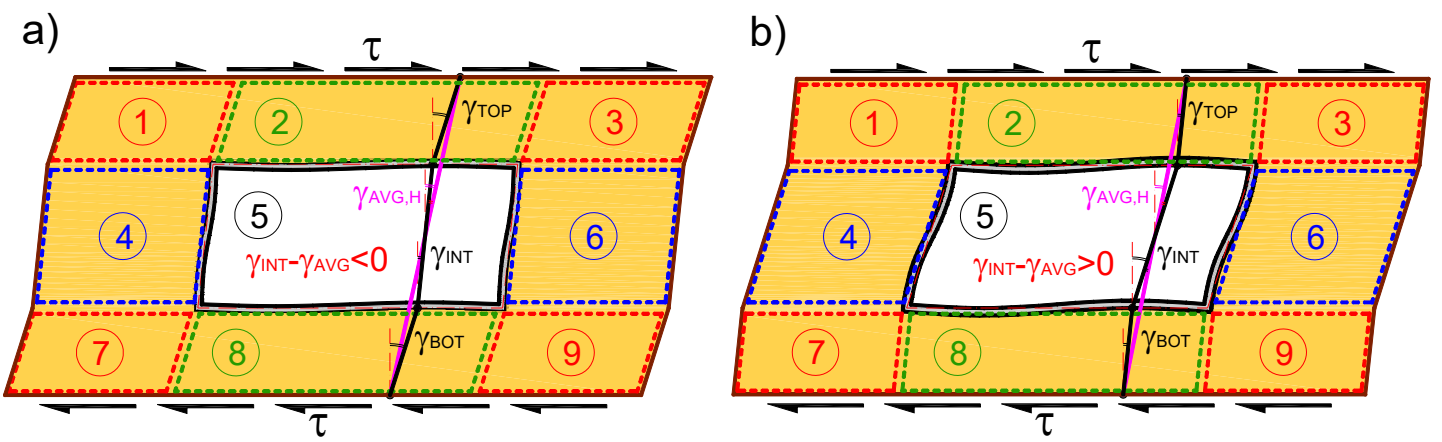

Fig. 4-3. Perfil de deformación a cortante horizontal para: (a) Una estructura más rígida que el suelo sustituido $\left(F_{R}<1\right)$, con una deformación de la capa intermedia $\gamma_{I N T, H}$ menor que la deformación media $\gamma_{A V G, H}$ (b) Una estructura más flexible que el suelo sustituido $\left(F_{R}>1\right)$, con una deformación de la capa intermedia $\gamma_{I N T, H}$ mayor que la deformación media $\gamma_{A V G, H}$. 
De manera similar, para obtener la rigidez media vertical $K_{A V G, V}$ del conjunto suelo-estructura se podría sumar la rigidez en serie de cada capa vertical como en la expresión.

$$
K_{A V G, V}=\frac{1}{\frac{1}{K_{L E F T, V}}+\frac{1}{K_{C E N T, V}}+\frac{1}{K_{R I G H T, V}}}=\frac{1}{2 \cdot \frac{1}{2 \cdot G \cdot \frac{H}{a}}+\frac{1}{2 \cdot G \cdot \frac{2 c}{b}+K_{S T R U, V}}}
$$

En base a los resultados anteriores, se puede proceder a calcular un coeficiente de racking aproximado, para la distorsión de la estructura embebida y la distorsión media del conjunto suelo-estructura; es decir, la relación de deformaciones a la distorsión entre la estructura interior $\gamma_{I N N}=\gamma_{I N T, H}+\gamma_{C E N T, V}$, y el perímetro exterior $\gamma_{A V G}=\gamma_{A V G, H}+\gamma_{A V G, V}$, cuando este perímetro exterior está sujeto a un estado de cortante puro de valor $\tau$. Este coeficiente de racking sería la relación entre la suma de deformaciones tal y como se muestra en la (Ec. 4-16), en la que el sombrero de $\widetilde{R}$ denota que esta expresión de racking es aproximada y condicional al comportamiento de los bloques indicado anteriormente.

$$
\begin{gathered}
\tilde{R}=\frac{\gamma_{I N T, H}+\gamma_{C E N T, V}}{\gamma_{A V G, H}+\gamma_{A V G, V}}=\frac{\frac{\tau \cdot L / K_{I N T, H}}{d}+\frac{\tau \cdot H}{\tau \cdot L / K_{C E N T, V}}}{\frac{\partial}{\tau \cdot H} / K_{A V G, H}}+\frac{H}{L} \\
=\frac{\frac{L}{d \cdot K_{I N T, H}}+\frac{H}{b \cdot K_{C E N T, V}}}{\frac{L}{H \cdot K_{A V G, H}}+\frac{H}{L \cdot K_{A V G, V}}}
\end{gathered}
$$
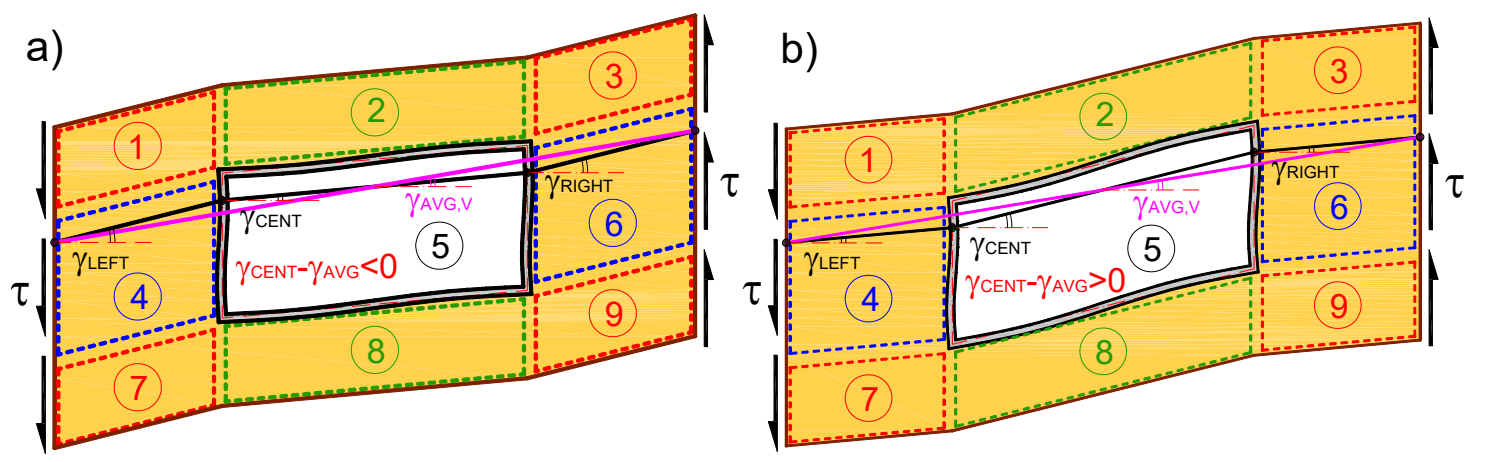

Fig. 4-4. Perfil de deformación a cortante vertical para: (a) Una estructura más rígida que el suelo sustituido $\left(F_{R}<1\right)$, con una deformación de la capa central $\gamma_{C E N T, H}$ menor que la deformación media $\gamma_{A V G, H .}$ (b) Una estructura más flexible que el suelo sustituido $\left(F_{R}>1\right)$, con una deformación de la capa central $\gamma_{C E N T, H}$ mayor que la deformación media $\gamma_{A V G, H}$.

A partir de las expresiones anteriores, por simplicidad de interpretación y sin pérdida de generalidad, si se considera sólo la contribución del cortante horizontal (Ec. 4-10), (Ec. 4-11), (Ec. 4-14), y (Ec. 4-16), se puede obtener información importante 
respecto al comportamiento del conjunto suelo-estructura. Como cabría esperar, si la capa intermedia fuera más rígida que el conjunto suelo-estructura, la capa intermedia se deformaría menos que el conjunto (Fig. 4-3, a). Por el contrario, si la capa intermedia fuera más flexible, la capa intermedia se deformaría más que el conjunto sueloestructura(Fig. 4-3, b).

Como puede comprobarse, la rigidez a la distorsión de la capa intermedia está determinada por la rigidez a la distorsión de la estructura embebida: una rigidez pequeña de esta estructura comparada con la del suelo sustituido $\left(F_{R}>1\right)$ resultaría en una capa intermedia más flexible que el conjunto, y viceversa. Se puede desarrollar un razonamiento similar con respecto a la componente vertical de la deformación a cortante, para el cual se muestran dos casos en las figuras (Fig. 4-4, a) y (Fig. 4-4, b), que corresponden a dos casos, uno con una estructura más rígida que el suelo $\left(F_{R}<1\right)$, y otro con una estructura más flexible que el suelo $\left(F_{R}>1\right)$, respectivamente.

Hasta este punto en el desarrollo, las dimensiones $L$ y $H$ del perímetro del suelo se han elegido de tamaño arbitrario. Si reflexionamos acerca de cuáles serían unas dimensiones apropiadas para las que las hipótesis de comportamiento de los bloques pudieran considerarse como aproximadamente válidas, podemos considerar que, para un perímetro suficientemente cercano a la estructura, la distorsión media se puede suponer constante en cada capa. Por lo tanto, podemos pensar que podemos calcular aproximadamente un coeficiente de racking entre un perímetro de suelo suficientemente cerca de la estructura y la estructura en sí misma mediante la ecuación (Ec. 4-16).

Más aún, podemos asumir que si consideramos perímetros de suelo sucesivos (Fig. 4-5), suficientemente cercanos uno de otro (p.ej. perímetros $i-1$ e $i$ ), podemos calcular un coeficiente aproximado individual $\tilde{R}_{i}$, que relacione la distorsión de dichos perímetros sucesivos empleando las ecuaciones (Ec. 4-14), (Ec. 4-15), y (Ec. 4-16). 


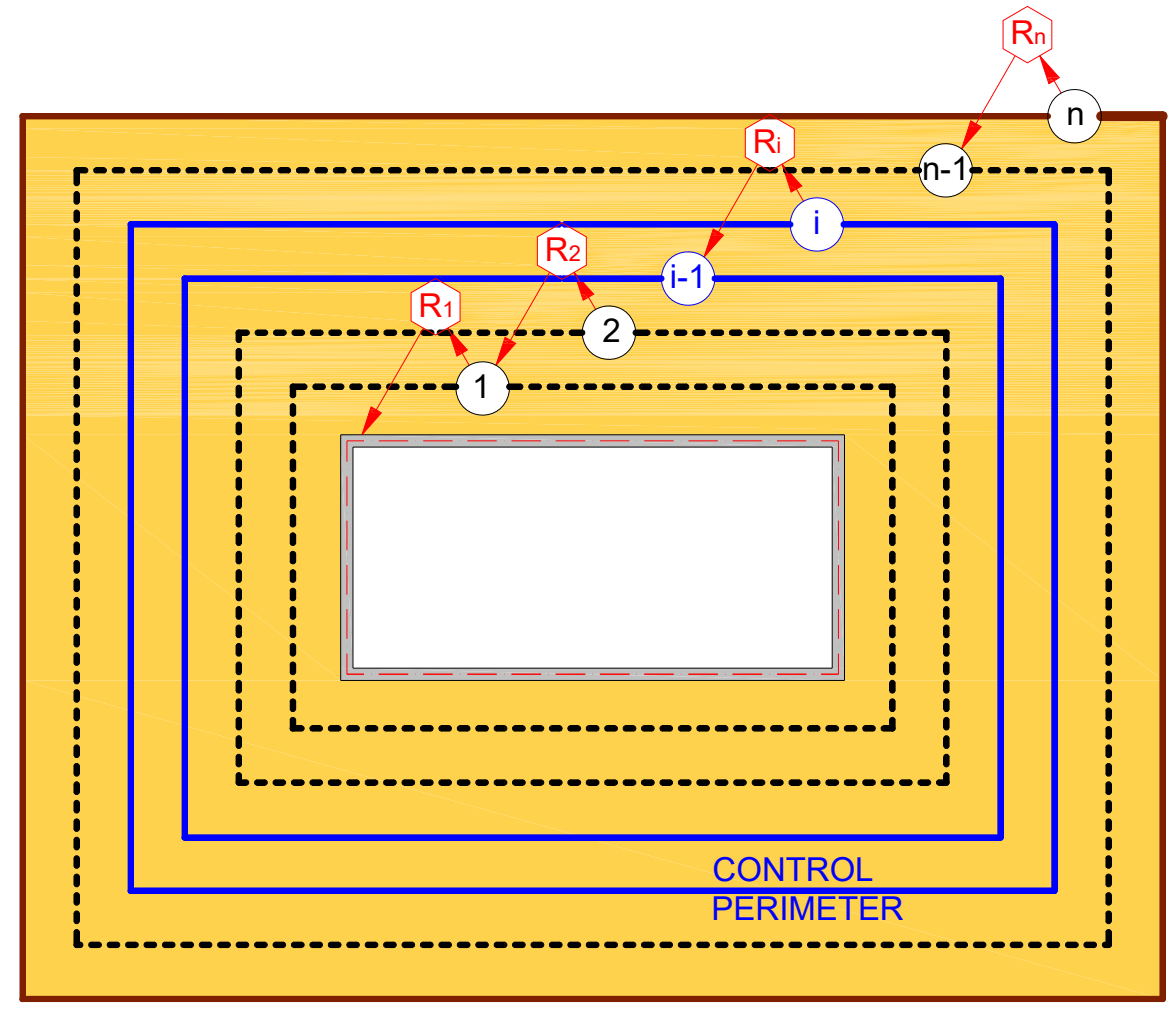

Fig. 4-5. Serie de perímetros de control sucesivos de 1 a $n$. Cada coeficiente individual de racking $\widetilde{R}_{i}$ mide la relación de distorsión entre los perímetros de control $i-1$ e $i$, siendo $\widetilde{R}_{i}=\frac{\gamma_{A V G, i-1}}{\gamma_{A V G, i}}$.

Para hacer esto en cualquier perímetro de control $i$, bastará sustituir la rigidez de la estructura y en las ecuaciones (Ec. 4-14) y (Ec. 4-15), por la rigidez horizontal y vertical del perímetro más interno, y elegir las dimensiones geométricas $a_{i}, b_{i}, c_{i}, d_{i}, L_{i}$, y $H_{i}$ que correspondan al perímetro de control dado i, tal y como se muestra en la ecuación (Ec. 4-17).

$$
\tilde{R}_{i}=\frac{\gamma_{A V G, H, i-1}+\gamma_{A V G, V, i-1}}{\gamma_{A V G, H, i}+\gamma_{A V G, V, i}}=\frac{\frac{L_{i}}{d_{i} \cdot K_{I N T, H, i-1}}+\frac{H_{i}}{b_{i} \cdot K_{C E N T, V, i-1}}}{\frac{L_{i}}{H_{i} \cdot K_{A V G, H, i}}+\frac{H_{i}}{L_{i} \cdot K_{A V G, V, i}}}
$$

Si continuamos con el razonamiento, podemos pensar que el coeficiente de racking total que relaciona la deformación de distorsión de la estructura $\gamma_{S T R U}$, y la distorsión de campo libre $\gamma_{F F}$, se puede aproximar mediante una porción suficientemente grande de suelo que rodee la estructura, por una discretización fina de la misma en sucesivos perímetros de control, y por el producto de cada coeficiente de racking como en la ecuación multiplicativa (Ec. 4-18). 


$$
R=\frac{\gamma_{S T R U}}{\gamma_{F F}} \cong \prod_{i=1}^{i=n} \frac{\gamma_{i-1}}{\gamma_{i}}=\prod_{i=1}^{i=n} \tilde{R}_{i}
$$

En la ecuación (Ec. 4-18), la expresión de $\widetilde{R}_{i}$ está dada por la ecuación (Ec. 4-17), y en esta, para $i=1$ que corresponde al perímetro de control más interno, los valores de $K_{A V G, H, i-1=0}$ y $K_{A V G, V, i-1=0}$ son las rigideces de la estructura dadas por las ecuaciones (Ec. 4-4) у (Ec. 4-9) respectivamente.

De la exposición anterior, debemos notar que el modelo de bloques a cortante propuesto no puede considerar de manera apropiada la dependencia de la solución con respecto al coeficiente de Poisson $v$ que han demostrado varios autores (H. Huo et al., 2006; Penzien, 2000; J. N. Wang, 1993). Esto es debido a que, puesto que cada bloque se encuentra sometido tan sólo a un estado de cortante puro, la deformación de cortante no depende de manera directa del coeficiente de Poisson $v$, una vez que se ha definido el módulo de cortante G. Dado que en un estado de cortante puro no existe cambio de volumen, cabría esperar que la expresión analítica propuesta para el coeficiente de racking (Ec. 4-18) reprodujese con mayor precisión el comportamiento de aquellos casos en los que el coeficiente de Poisson es cercano a $v=0,5$. Esta falta de dependencia del modelo propuesto con respecto al coeficiente de Poisson puede ser ajustada introduciendo un factor de modificación que se presenta más adelante en el apartado §4.6.

Para verificar la precisión de la solución analítica propuesta para el coeficiente de racking, se ha desarrollado una serie de modelos de elementos finitos (MEF) en el programa OpenSEES (McKenna, Scott, \& Fenves, 2010). Los análisis MEF desarrollados representan el problema de un medio suficientemente grande, isótropo y homogéneo, que cuenta con una estructura rectangular embebida en su centro. Se suelo se ha mallado con elementos cuadriláteros de 4 nodos y comportamiento en deformaciones planas, mientras que la discretización de la estructura se ha realizado con elementos viga de 2 nudos, los cuales se han vinculado frente a desplazamientos horizontales y verticales a los nudos de suelo adyacentes, con el propósito de representar un comportamiento completamente vinculado de la interfaz hormigón-suelo.

Los bordes exteriores del suelo no presentan ningún tipo de restricción al movimiento, y están sujetos a un estado de cortante puro de valor de tensiones tangenciales $\tau$. Únicamente el nudo inferior izquierdo tiene los desplazamientos $u_{x}$ y $u_{y}$ 
restringidos, y el nudo inferior derecho el desplazamiento $u_{y}$ restringido, de tal manera que se pueda alcanzar el equilibrio numérico al calcular (Fig. 4-6).

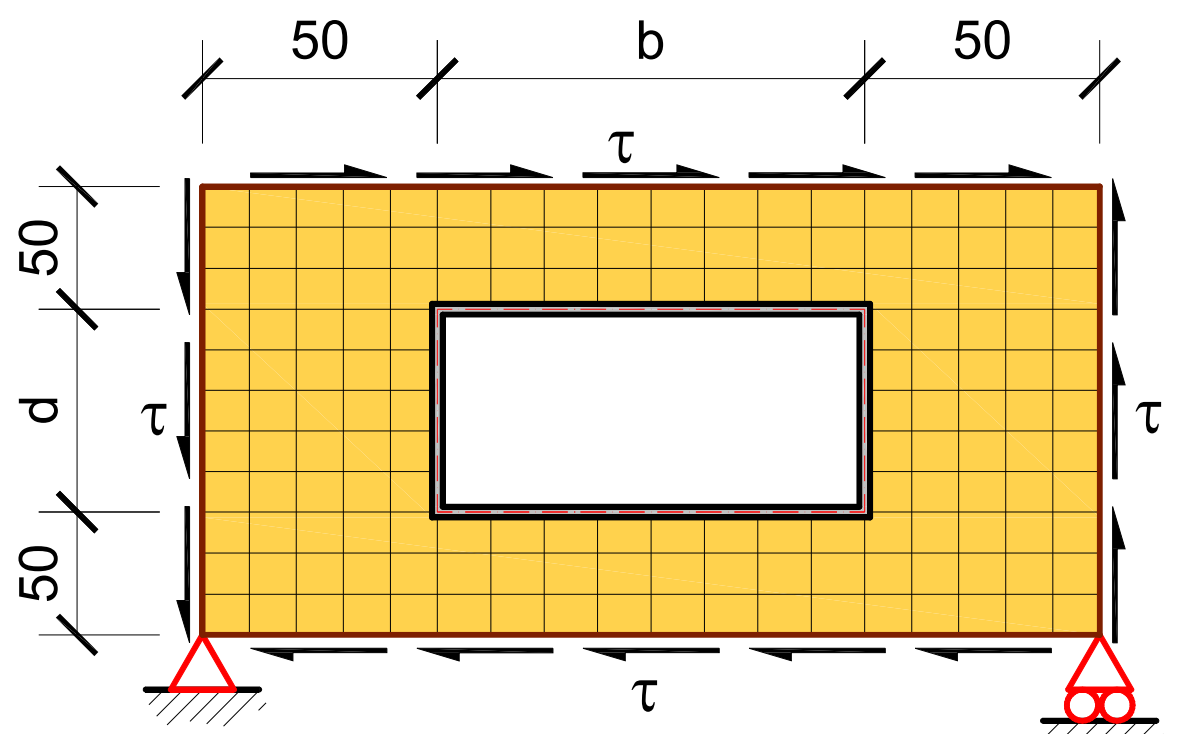

Fig. 4-6. Croquis conceptual del modelo de elementos finitos con las dimensiones más relevantes, las condiciones de contorno, y el estado tensional de cortante. El mallado y dimensiones no se muestran a escala.

El suelo está caracterizado por una velocidad de las ondas de cortante de $V_{S}=360$ $\mathrm{m} / \mathrm{s}$, y un peso específico de $\rho=20 \mathrm{kN} / \mathrm{m}^{3}$, lo cual proporciona un módulo de cortante de $G=259,20 \mathrm{MPa}$. En lo que respecta al túnel, se ha considerado una estructura de hormigón con un módulo de Young $E_{c}=30 \mathrm{GPa}$, y unos espesores constantes de muros y losas de $h_{w}=h_{b}=1,50 \mathrm{~m}$ que proporcionan la inercia bruta con la que se ha analizado el sistema.

Se ha estudiado un rango de ratios de flexibilidad $F_{R}$, para los cuales se han variado las dimensiones de ancho $b$ y canto $d$ de la estructura entre $1 \mathrm{~m}$ y $20 \mathrm{~m}$. En particular, se han analizado casos correspondientes a diferentes proporciones $\lambda=b / d$ que abarcan un rango de $\lambda=1$ a $\lambda=3$, para estudiar su influencia en la solución propuesta.

Los límites del perímetro exterior del suelo, tanto para los análisis MEF como para la solución analítica propuesta en esta tesis se han tomado alejados de la estructura $50 \mathrm{~m}$ en horizontal y en vertical (Fig. 4-6). Para evaluar la solución analítica propuesta en esta tesis, se han empleado 1000 perímetros de control, es decir, se ha empleado $n=1000$ en la ecuación (Ec. 4-18). 

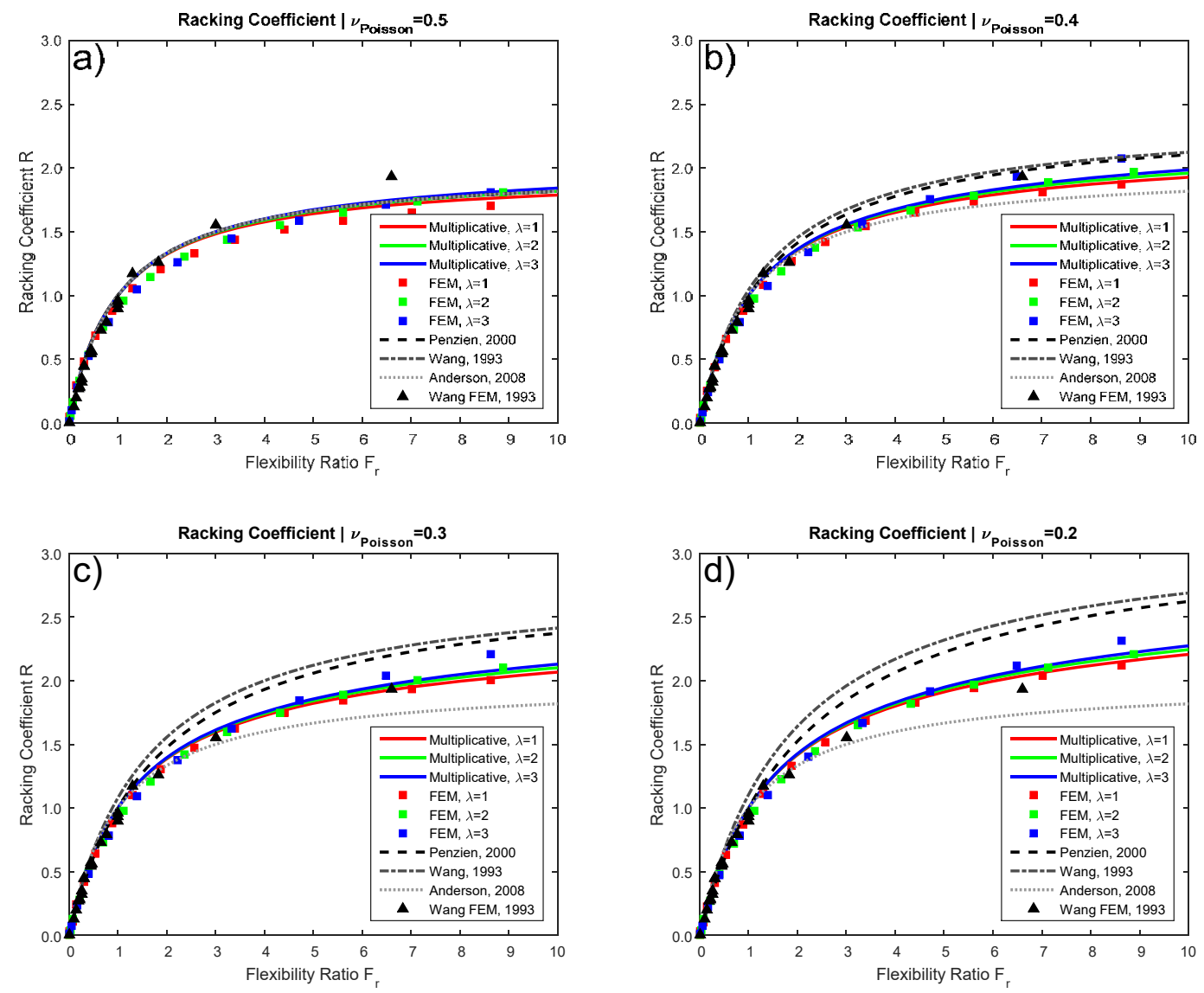

Fig. 4-7. Comparación de las soluciones analíticas propuestas por Wang (J. N. Wang, 1993), Penzien (Penzien, 2000), y Anderson (Anderson et al., 2008), y las propuestas en esta tesis, superpuestas a los resultados de análisis MEF desarrollados en este estudio, y los descritos por Wang (J. N. Wang, 1993). Para coeficientes de Poisson (a) $v=0,5$, (b) $v=0,4$, (c) $v=0,3, \mathrm{y}$ para (d) $v=0,2$.

La figura (Fig. 4-7, a) muestra una correspondencia muy buena de la solución multiplicativa (Ec. 4-18) propuesta en esta tesis con los resultados de análisis MEF para todas las proporciones $\lambda$, y para el caso en el que $v=0,5$ tal y como se esperaba. Para otros valores del coeficiente de Poisson $v$, y cuando se introduce el factor de modificación que se presenta más adelante en el apartado $§ 4.6$, se obtienen concordancias similares con los resultados $\mathrm{MEF}$, y se pueden apreciar tendencias similares a las presentadas en las soluciones analíticas de otros autores.

\subsection{Solución propuesta para el perfil de distorsión de Racking}

Se puede analizar y comparar el perfil del coeficiente de racking a diferentes distancias (cerca y lejos de la estructura), a lo largo de una sección como la que se muestra en la (Fig. 4-8, b). Es decir, cuanto se deforma a distorsión un perímetro intermedio con 
respecto a la distorsión de campo libre. En lo que respecta a la expresión multiplicativa presentada en el apartado anterior §4.3, una expresión similar a la (Ec. 4-18) para calcular dicho perfil para un perímetro dado $j$ sería la ecuación (Ec. 4-19), en la que se hace uso de las mismas hipótesis descritas anteriormente, pero se extiende el productorio sólo desde el perímetro más exterior $n$ hasta el perímetro de interés $j$.

$$
R_{\text {PERIM } j}=\frac{\gamma_{\text {PERIM } j}}{\gamma_{F F}} \cong \prod_{i=j+1}^{i=n} \frac{\gamma_{i-1}}{\gamma_{i}}=\prod_{i=j+1}^{i=n} \tilde{R}_{i}
$$

Al igual que en el caso del coeficiente de racking, se ha empleado el mismo conjunto de análisis FEM para obtener los resultados numéricos del perfil de racking frente a los que comparar la solución analítica (Ec. 4-19). La distorsión media $\gamma_{F E M, P E R I M, j}$ de cada perímetro de control $j$ en los análisis MEF se ha calculado como la diferencia de desplazamientos horizontales y verticales entre la esquina superior derecha y la esquina inferior izquierda de cada perímetro mediante la ecuación (Ec. 4-20), tal y como se muestra en la (Fig. 4-8, a), y posteriormente se ha normalizado con respecto a la distorsión de campo libre $\gamma_{F F}$ para obtener el perfil de racking en cada perímetro $j$.

$$
\gamma_{F E M, P E R I M} j=\frac{\Delta_{H O R I Z, T O P, j}-\Delta_{H O R I Z, B O T T O M, j}}{H_{j}}+\frac{\Delta_{V E R T, R I G H T, j}-\Delta_{V E R T, L E F T, j}}{L_{j}}
$$

a)

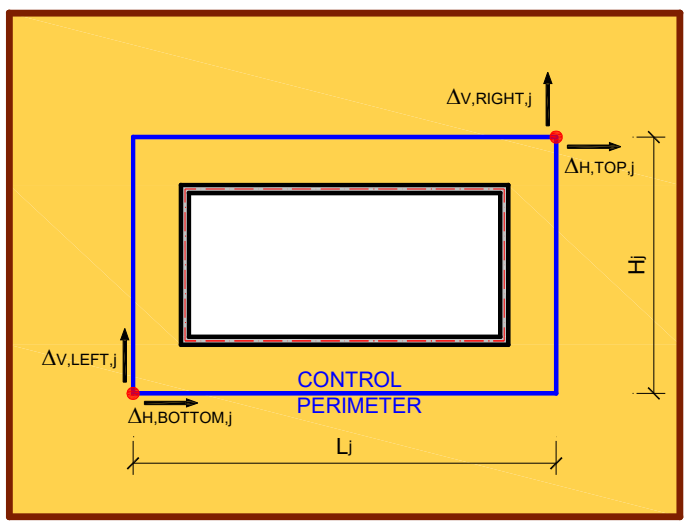

b)

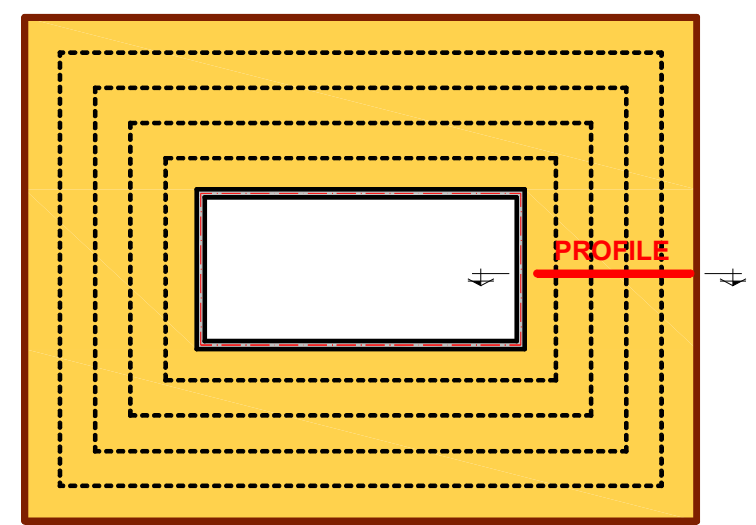

Fig. 4-8. (a) Puntos de control del desplazamiento para un perímetro de control intermedio $j$ de ancho $L_{j}$, y canto $H_{j}$, para calcular el coeficiente de racking intermedio. (b) Perfil de racking. 

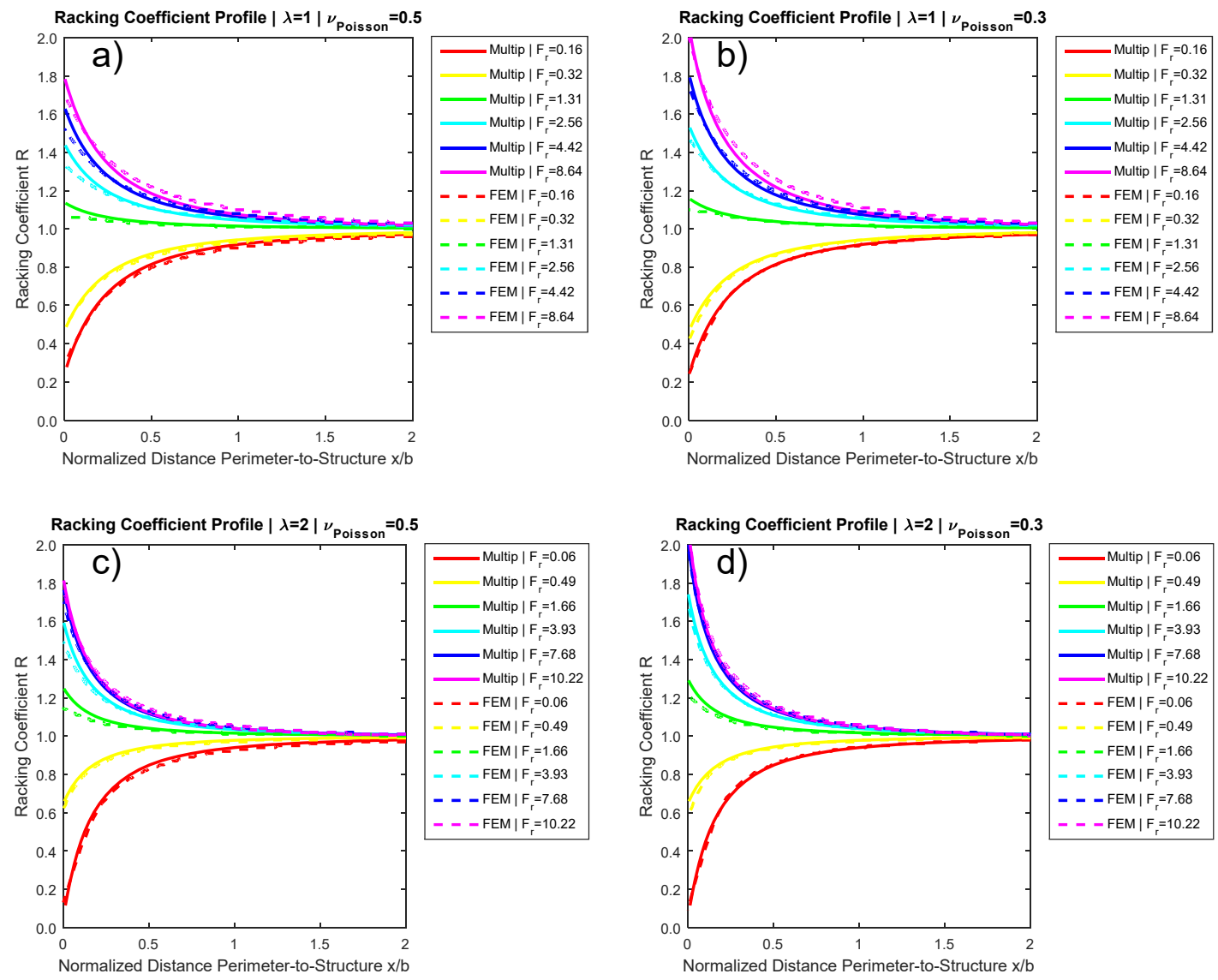

Fig. 4-9. Perfiles de coeficiente de racking calculados con la expresión analítica (líneas macizas), y mediante modelos MEF (líneas a trazos), para diferentes proporciones $\lambda$, valores del coeficiente de flexibilidad $F_{R}$, y coeficientes de Poisson $v$. Las distancias horizontales abarcan desde adyacentes a la estructura $\left(X_{P E R I M} / b_{S T R U}=0\right)$ hasta una distancia de 2 anchos de la estructura $\left(X_{P E R I M} / b_{S T R U}=2\right)$.

Los resultados se muestran en la Fig. 4-9, en los que la abscisa horizontal se ha normalizado entre modelos como la ratio de distancia del perímetro de control a la estructura $X$, dividida por el ancho de la estructura $b\left(X_{\text {PERIMETER }} / b_{S T R U C T U R E}=0\right.$ indica un perímetro adyacente a la estructura, y $X_{\text {PERIMETER }} / b_{\text {STRUCTURE }}=2$ indica un perímetro alejado 2 anchos de la estructura).

En la Fig. 4-9, se muestra como la expresión (Ec. 4-19) concuerda muy bien con los resultados obtenidos mediante los modelos de elementos finitos, e indica que a una distancia en el torno de a 1,5 a 2 anchos de la estructura, la distorsión del conjunto es similar a la distorsión de campo libre $(R \approx 1)$. Es decir, a distancias mayores que 2 anchos, la influencia de la estructura embebida se vuelve prácticamente despreciable. 


\subsection{Solución propuesta para el coeficiente de rotación de Rocking}

Varios autores (Cilingir \& Madabhushi, 2011; Debiasi et al., 2013; Iwatate, Kobayashi, Kusu, \& Rin, 2000; Pitilakis \& Tsinidis, 2016; Grigorios Tsinidis, 2017; Grigorios Tsinidis \& Pitilakis, 2018; Grigorios Tsinidis, Pitilakis, \& Heron, 2015; Ulgen, Saglam, \& Ozkan, 2015) han señalado que existe un interesante comportamiento de rotación (denominado rocking), y que presentan aquellas estructuras enterradas con una rigidez relativa diferente a la del suelo al que sustituyen $\left(F_{R} \neq 1\right)$. Las estructuras rígidas $\left(F_{R}<1\right)$ tienden a presentar un patrón de desplazamiento de rotación de sólido rígido, en el sentido de que la estructura tiende a rotar rígidamente en la misma dirección que la distorsión global (Fig. 4-10). Por el contrario, las estructuras más flexibles $\left(F_{R}>1\right)$ tienden a presentar un patrón de rotación de rocking en dirección opuesta a la de la distorsión global. Tsinidis (Grigorios Tsinidis, 2017) define el coeficiente de rocking como el ángulo $\theta$ rotado por la losa inferior o superior, y normalizado al ángulo de distorsión de campo libre $\theta / \gamma_{F F}$.

En la figura (Fig. 4-10) se muestran imágenes de la zona cercana a la estructura embebida, y los patrones de desplazamientos verticales, similares a los obtenidos por Tsinidis y Pitilakis (Pitilakis \& Tsinidis, 2016; G Tsinidis, Pitilakis, \& Mantikas, 2016; Grigorios Tsinidis, 2017; Grigorios Tsinidis \& Pitilakis, 2018), en los que los tonos de color representan los desplazamientos verticales normalizados al máximo en cada figura (no entre figuras), para resaltar el patrón de desplazamiento vertical en cada figura.

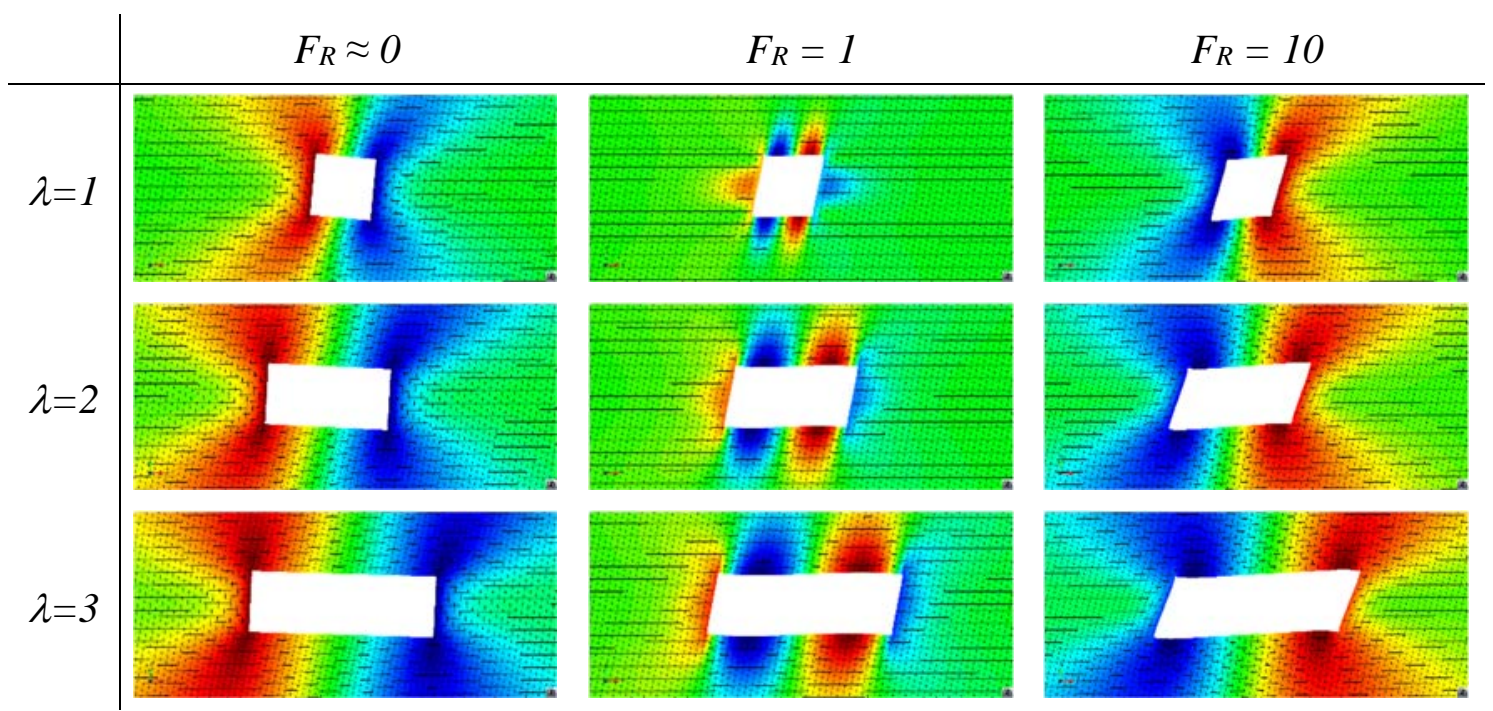

Fig. 4-10. Patrones de desplazamiento resultantes de los análisis FEM, en función de la relación de flexibilidad $F_{R}$ y de la proporción geométrica $\lambda=b / d$. 
Si se considera el patrón de desplazamientos del mecanismo de bloques presentado en apartados anteriores de este capítulo (\$4.3), se obtiene una explicación sencilla de este comportamiento de rocking.

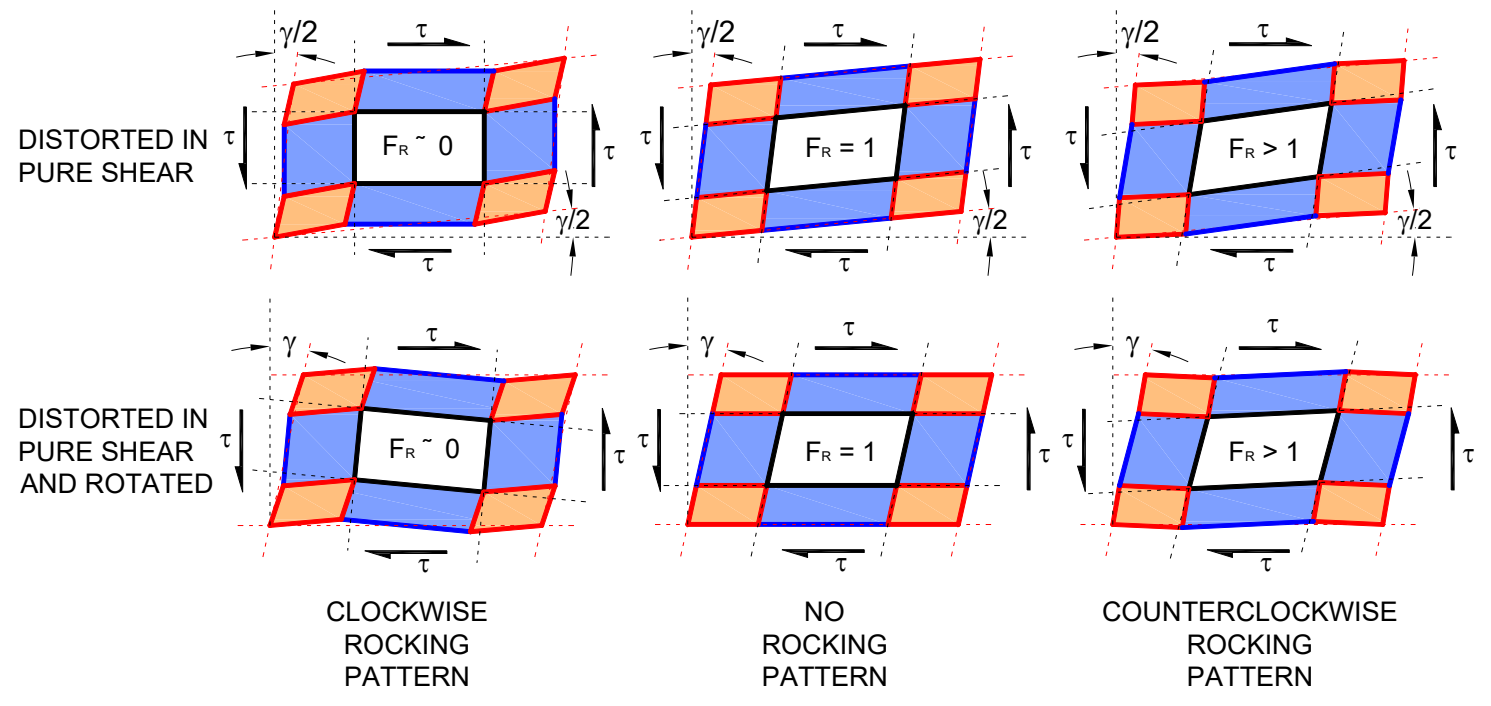

Fig. 4-11. Patrones conceptuales de rocking en función de la rigidez de la estructura.

Refiriéndonos a la (Fig. 4-11), y considerando, por ejemplo, el caso de una estructura muy rígida $\left(F_{R} \approx 0\right)$, la deformación de distorsión de racking de la estructura será de menor valor que el correspondiente a los bordes exteriores de un perímetro de control dado. Por lo tanto, cuando consideremos las condiciones de contorno del campo de desplazamiento (p.ej. el borde inferior del perímetro más exterior del suelo debe ser horizontal, debido al contacto con la roca de fondo), se debe aplicar un movimiento de rotación de sólido rígido al conjunto de bloques para compatibilizar los desplazamientos prescritos. Para el caso particular comentado de $F_{R} \approx 0$, esto proporciona una rotación de sólido rígido de la estructura embebida, en sentido horario si la distorsión de campo libre es hacia la derecha.

Si la estructura es tan rígida como el suelo sustituido $\left(F_{R}=1\right)$, la distorsión de racking de la estructura será del mismo orden de magnitud que el perímetro exterior de suelo, y cuando se aplique la rotación de sólido rígido al conjunto para que los desplazamientos sean compatibles con las condiciones de contorno, la estructura no presentará ninguna rotación. Finalmente, si la estructura es más flexible que el suelo circundante $\left(F_{R}>1\right)$, puesto que la distorsión de racking de la estructura será mayor que la distorsión de los bordes exteriores del bloque de suelo, la rotación de sólido rígido aplicada al conjunto para compatibilizar las condiciones de contorno no será suficiente 
para cancelar, por ejemplo, la rotación de las losas horizontales. De esta manera aparecerá una rotación antihoraria si la distorsión de campo libre es hacia la derecha.

Considerando el modelo conceptual de sucesivos perímetros de control propuesto en esta tesis, la rotación acumulada, de cada perímetro interior relativa al perímetro adyacente exterior, proporcionará la rotación total de la estructura en función del valor de la flexibilidad relativa $F_{R}$. Conceptualmente, podemos pensar en este comportamiento de rocking como un efecto de perspectiva, que depende del borde que estemos eligiendo como referencia, y en qué dirección con respecto a este se deforma la estructura.

Cuantitativamente, considerando el modelo de bloques presentado en apartados anteriores (§4.3), y siguiendo la notación de Tsinidis (Grigorios Tsinidis, 2017), podemos pensar que la rotación relativa de los bordes horizontales de dos perímetros consecutivos $i-1$ (interior) e $i$ (exterior), normalizada a la deformación de distorsión del perímetro $i$ exterior, es la que proporciona la ecuación .

$$
\tilde{\theta}_{i-1, i}=\frac{\gamma_{V, i-1}-\gamma_{V, i}}{\gamma_{H, i}+\gamma_{V, i}}
$$

Dado que, cuando el suelo a gran distancia (en campo libre) se deforma a cortante puro una magnitud $\gamma_{F F}$, el perímetro $i$ se deformará el coeficiente de racking correspondiente $\widetilde{R}_{\text {PERIM } i}$ veces la deformación de campo libre $\gamma_{F F}$, el ángulo total rotado por la losa de la estructura se puede calcular sumando todos los ángulos relativos entre perímetros consecutivos (i-1 e i), normalizado cada uno a la distorsión del perímetro exterior i, y ponderando cada ángulo relativo por el coeficiente de racking del perímetro exterior i, como se muestra en la (Ec. 4-22).

$$
\frac{\theta}{\gamma_{F F}} \cong \sum_{i=1}^{i=n} \tilde{\theta}_{i-1, i} \cdot \tilde{R}_{\text {PERIM } i}=\sum_{i=1}^{n}\left(\frac{\gamma_{V, i-1}-\gamma_{V, i}}{\gamma_{H, i}+\gamma_{V, i}} \cdot \prod_{j=i+1}^{j=n} \frac{\gamma_{j-1}}{\gamma_{j}}\right)
$$

Para evaluar la precisión de la expresión analítica (Ec. 4-22) propuesta para el coeficiente de rocking, los resultados que proporciona esta se han comparado a una serie de análisis de elementos finitos $\mathrm{MEF}$, en los que la rotación de la losa inferior se han

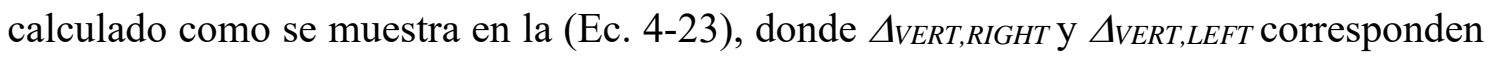
a los desplazamientos verticales del extremo superior-derecho e inferior-izquierdo de la estructura embebida, y $b$ corresponde al ancho de la estructura.

$$
\theta_{F E M}=\frac{\Delta_{V E R T, R I G H T}-\Delta_{V E R T, L E F T}}{b}
$$



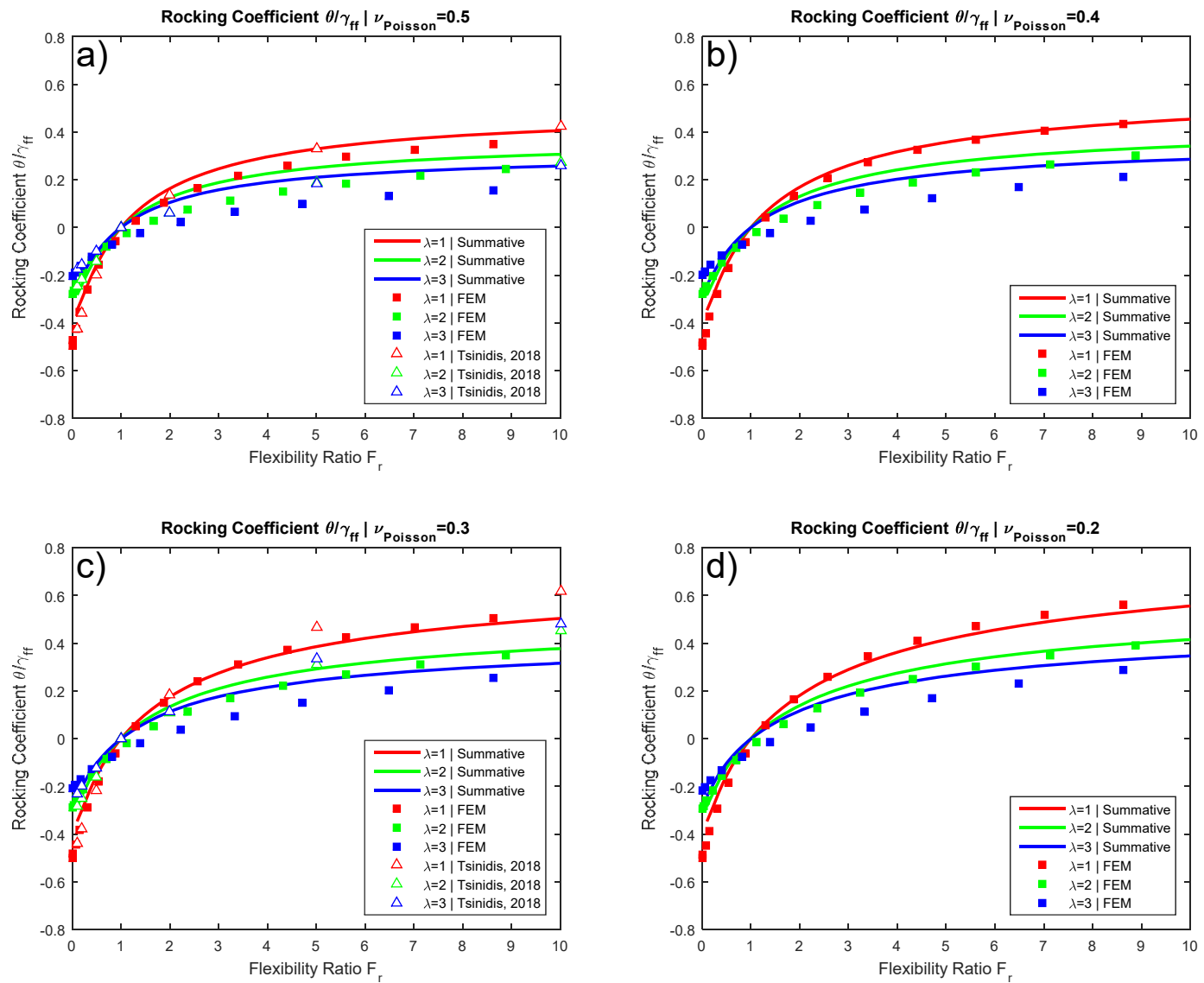

Fig. 4-12. Comparación de la solución analítica del coeficiente de rocking para tres proporciones geométricas $\lambda=1,2,3, \mathrm{y}$ resultados de análisis MEF desarrollados para este estudio, junto con los publicados por Tsinidis y Pitilakis (Grigorios Tsinidis \& Pitilakis, 2018) en los casos en los que están disponibles. Para coeficientes de Poisson (a) $v=0,5$, (b) $v=0,4$, (c) $v=0,3$, (d) $v=0,2$.

Los resultados de la expresión analítica propuesta, y los resultados numéricos de los análisis FEM muestran una coincidencia muy razonable, tal y como se muestra en la (Fig. 4-12).

\subsection{Modificación de las soluciones propuestas para considerar la influencia del coeficiente de Poisson}

Tal y como se ha indicado en el apartado $\S 4.3$ de esta tesis, el modelo mecánico subyacente para las expresiones analíticas propuestas, es decir, la hipótesis del comportamiento de los bloques, es incapaz de considerar la dependencia del coeficiente de Poisson. Para tratar este efecto, se puede introducir un simple factor de ajuste $\alpha$ para la expresión multiplicativa de racking de la (Ec. 4-18), para la expresión multiplicativa del perfil de racking de la (Ec. 4-19), y para la expresión del coeficiente de rocking dado 
en la (Ec. 4-22). Este factor de modificación debe ser capaz de ajustar la solución analítica a los resultados del modelo de elementos finitos.

La forma funcional del factor de modificación $\alpha$ es la mostrada en la ecuación (Ec. 4-24), y es una expresión logarítmica que depende tanto del coeficiente de Poisson $\nu$ como de la flexibilidad relativa $F_{R}$. Los coeficientes correspondientes $\alpha_{1}, \alpha_{2}$, y $\alpha_{3}$ se resumen en la tabla Tabla 4-1, y se han calculado para obtener un ajuste óptimo.

$$
\alpha=\left\{\begin{aligned}
1, & F_{R}<1 \\
\left(\alpha_{1} \cdot v+\alpha_{2}\right) \cdot \operatorname{Ln}\left(F_{R}\right)+\alpha_{3}, & F_{R} \geq 1
\end{aligned}\right.
$$

\begin{tabular}{|c|c|c|}
\hline$\alpha_{1}$ & $\alpha_{2}$ & $\alpha_{3}$ \\
\hline$-0,342$ & 0,176 & 1,0 \\
\hline
\end{tabular}

Tabla 4-1. Coeficientes del factor de modificación $\alpha$

Para realizar el ajuste de los valores de $\alpha_{1}, \alpha_{2}$, y $\alpha_{3}$ se procedió a ajustar los parámetros $a$ y $b$ de las curvas de la forma $\alpha=a \cdot \operatorname{Ln}\left(F_{R}\right)+b$ mediante un procedimiento de mínimos cuadrados para los resultados MEF de 0,2<v<0,5, como se ve en la (Fig. 4-13).
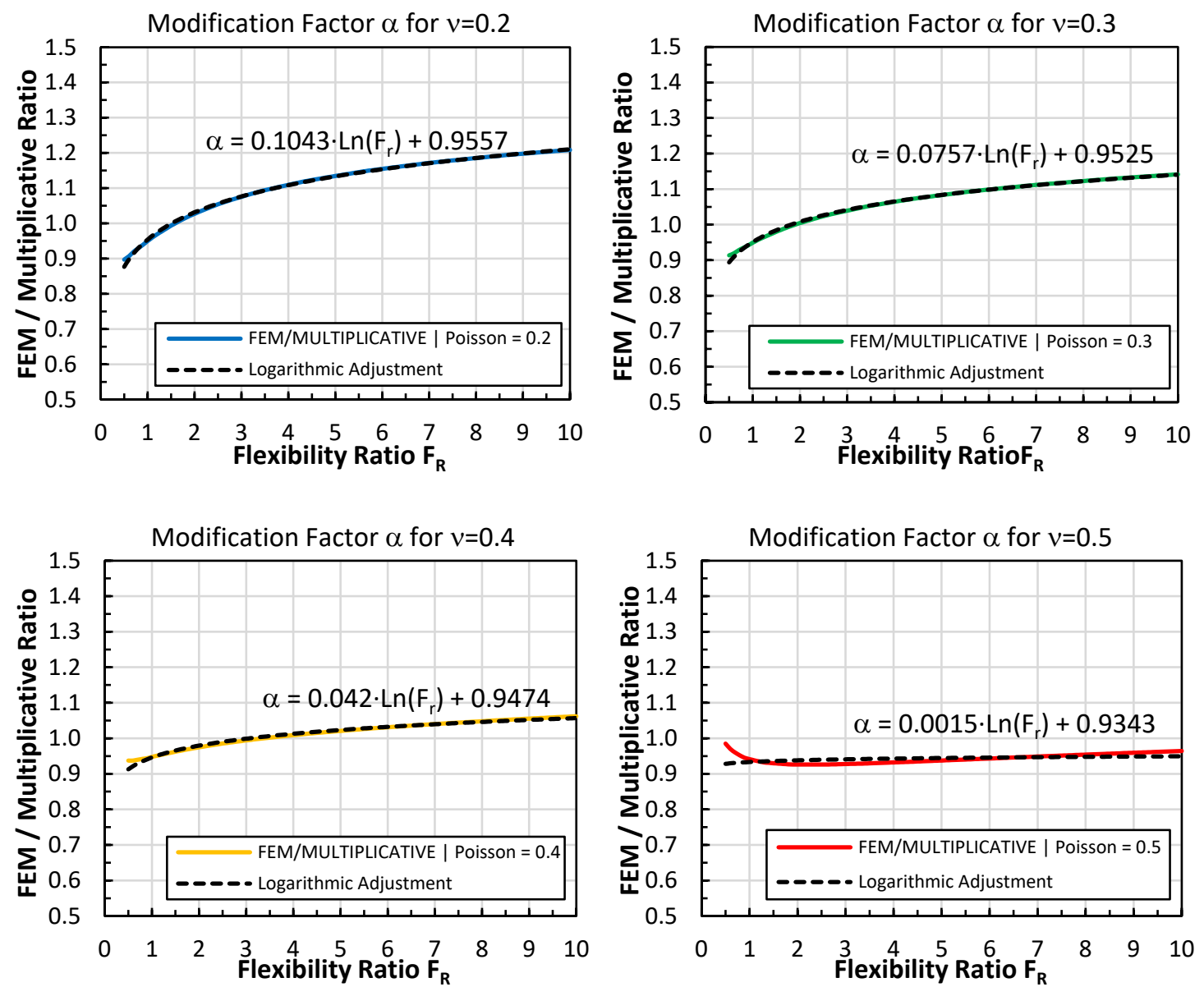

Fig. 4-13. Expresiones para el factor de modificación $\alpha$ para diferentes coeficientes de Poisson $v$. 


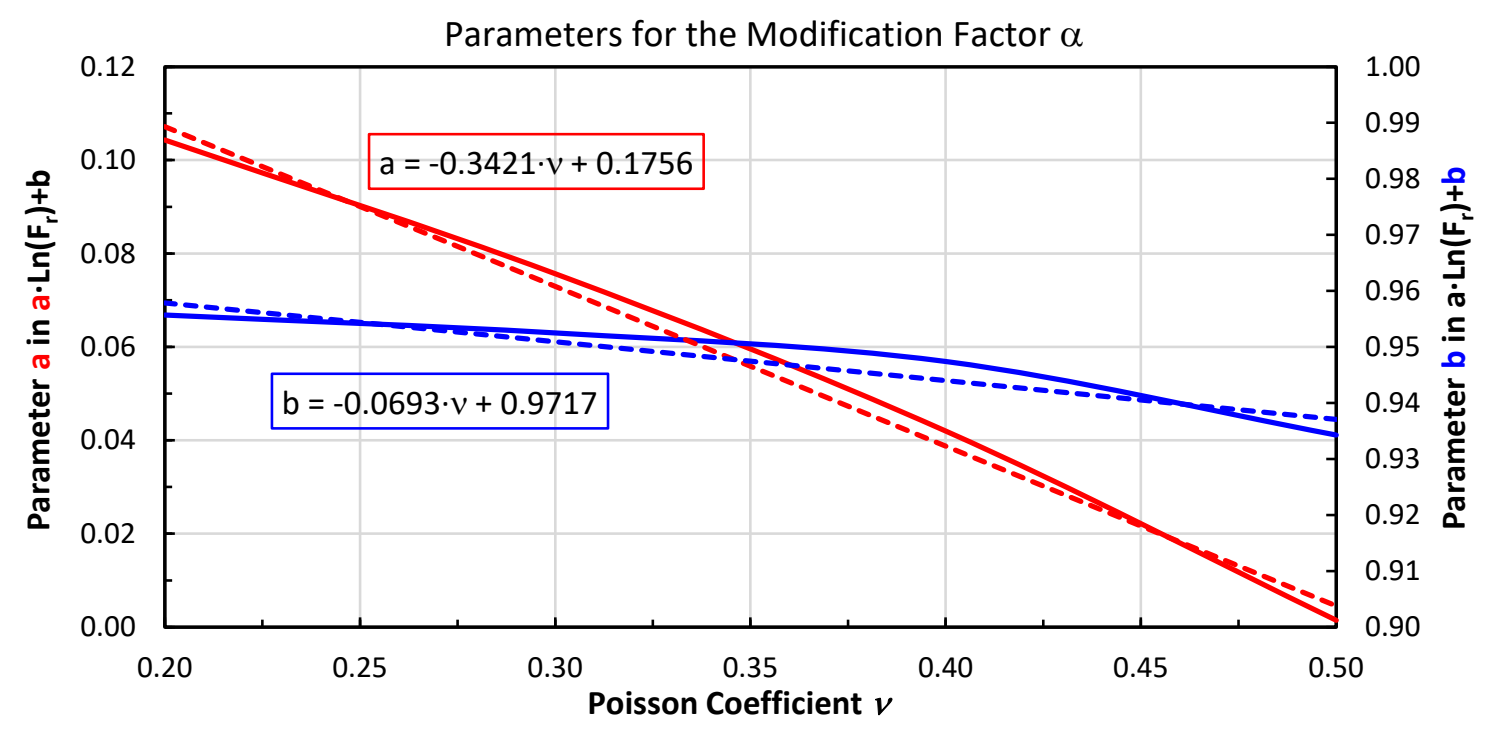

Fig. 4-14. Expresiones para el factor de modificación $\alpha$.

A partir de estas regresiones se planteó la dependencia lineal de los parámetros $a$ y $b$ en función del coeficiente de Poisson $n$, como se muestra en la (Fig. 4-14). Puesto que el valor de $b$ es a todos los efectos prácticos igual a la unidad, como muestra la curva azul de la Fig. 4-14, se ha determinado $\alpha_{3}=1$ tal y como se resume en la Tabla 4-1. El valor de $a$ se ha hecho linealmente dependiente de los valores $\alpha_{1}$ y $\alpha_{2}$, como muestra la curva roja de la Fig. 4-14.

Tras la aplicación del factor de modificación $\alpha$, la expresión analítica del coeficiente de racking queda como la (Ec. 4-25), en la que el término $\widetilde{R}_{i}$ viene dado por la (Ec. 4-17).

$$
R=\frac{\gamma_{S T R U}}{\gamma_{F F}} \cong \alpha \cdot \prod_{i=1}^{i=n} \tilde{R}_{i}
$$

De manera similar, tras la aplicación del factor de modificación $\alpha$, la expresión analítica del perfil del coeficiente de racking, para el perímetro $j$, queda como en la ecuación (Ec. 4-26). Para el cálculo del factor $\alpha_{j}$, el valor de la flexibilidad relativa $F_{R}$ debe ser la del perímetro $j$ que está siendo analizado.

$$
R_{\text {PERIM } j}=\frac{\gamma_{\text {PERIM } j}}{\gamma_{F F}} \cong \alpha_{j} \cdot \prod_{i=j+1}^{i=n} \tilde{R}_{i}
$$

Por último, tras la aplicación del factor de modificación $a$, la expresión analítica del coeficiente de rocking queda como en la (Ec. 4-27). Al igual que en el caso previo, en 
el cálculo del factor $\alpha_{i}$, el valor de la flexibilidad relativa $F_{R}$ debe ser el del perímetro $i$ que está siendo evaluado.

$$
\begin{aligned}
\frac{\theta}{\gamma_{F F}} \cong \sum_{i=1}^{n}\left(\alpha_{i} \cdot \tilde{\theta}_{i-1, i}\right) \cdot\left(\alpha_{i} \cdot \tilde{R}_{\text {PERIM } i}\right) \\
=\sum_{i=1}^{n}\left(\left(\alpha_{i} \cdot \frac{\gamma_{V, i-1}-\gamma_{V, i}}{\gamma_{H, i}+\gamma_{V, i}}\right) \cdot\left(\alpha_{i} \cdot \prod_{j=i+1}^{j=n} \frac{\gamma_{j-1}}{\gamma_{j}}\right)\right)
\end{aligned}
$$

\subsection{Evaluación de las soluciones propuestas}

Podemos examinar cómo se comportan las soluciones analíticas propuestas, tanto en términos de eficiencia con respecto a la finura de la discretización (p.ej. número de perímetros de control involucrados en la expresión analítica), y precisión relativa a los resultados obtenidos mediante los análisis de elementos finitos FEM.

Se puede calcular una ratio de convergencia, que dependa del número de perímetros de control involucrados en la expresión analítica propuesta del coeficiente de racking, como la relación entre el coeficiente de racking obtenido con la solución analítica (Ec. 4-25), y mediante el análisis MEF para el caso $v=0,5$ y $\lambda=1$. Los resultados correspondientes a esta ratio de convergencia, para un rango de flexibilidades relativas $0<F_{R}<10$ se muestran en la figura (Fig. $4-15$, a), en los que se puede apreciar que para aproximadamente 200 perímetros se alcanza una precisión del 10\%. Un incremento del número de perímetros proporciona estabilidad al valor obtenido del coeficiente de racking.
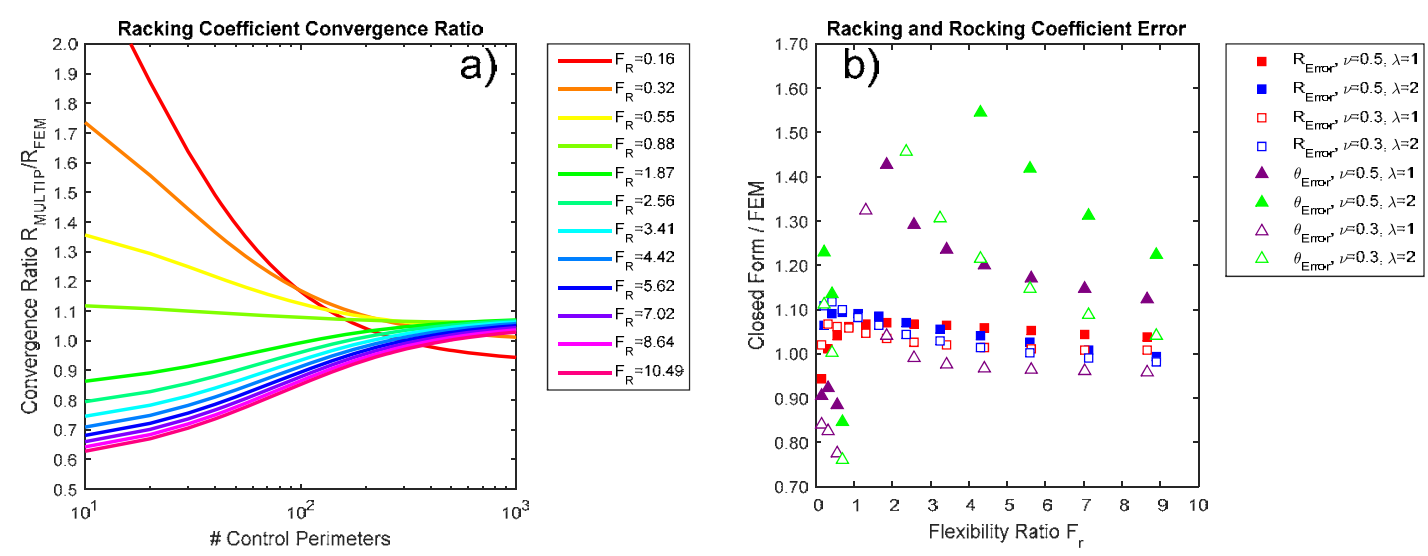

Fig. 4-15. (a) Ratio de convergencia del coeficiente de racking en función del número de perímetros empleado en la discretización. (b) Error en el valor de los coeficientes de racking y rocking 
calculados con las expresiones analíticas propuestas en esta tesis y con los análisis de elementos finitos MEF.

Se ha evaluado la precisión de las expresiones de los coeficientes de racking y rocking, calculada como la relación entre los valores obtenidos con las soluciones analíticas y las de los análisis MEF, los resultados se muestran en la figura (Fig. 4-15, b) para un rango de flexibilidades relativas $F_{R}$, proporciones geométricas $\lambda$, y coeficientes de Poisson $v$. Como se puede apreciar, el coeficiente de racking $R$ proporciona una precisión pésima del orden del $\pm 10 \%$, y que mejora al orden de $\pm 5 \%$ para estructuras más flexibles, mientras que el coeficiente de rocking $\theta / \gamma_{F F}$ presenta una dispersión mayor.

\subsection{Aplicación del método al caso de estructuras infinitamente rígidas}

Como se comentó en el apartado §3.7.4.1 al describir el método propuesto por Wang, a la hora de evaluar los esfuerzos transmitidos a las estructuras infinitamente rígidas $\left(F_{R}=0\right)$, el método del coeficiente de racking según las expresiones analíticas de Wang (J. N. Wang, 1993) o Penzien (Penzien, 2000) no resulta el más adecuado.

En efecto, estos métodos basan el análisis de esfuerzos en la imposición de unos desplazamientos a la estructura de valor $\gamma_{S T R U}=R \cdot \gamma_{F F}$. Si la flexibilidad relativa es nula $\left(F_{R}=0\right)$ porque la estructura es infinitamente rígida, el coeficiente de racking toma valor nulo $(R=0)$, y por lo tanto el problema de obtener esfuerzos queda indeterminado.

Sin embargo, en base a la formulación propuesta en este capítulo, el problema de determinar los esfuerzos transmitidos a una estructura infinitamente rígida $\left(F_{R}=0\right)$ tiene un planteamiento y solución sencillos.

Partiendo del esquema de bloques de la (Fig. 4-1, a), de la transmisión de tensiones tangenciales horizontales entre capas superior, intermedia, e inferior de la (Fig. 4-16, a), y de la aplicación recursiva de estos conceptos a los sucesivos perímetros de control, podemos plantear el reparto de tensiones tangenciales entre dos perímetros consecutivos de la siguiente manera. 
a)

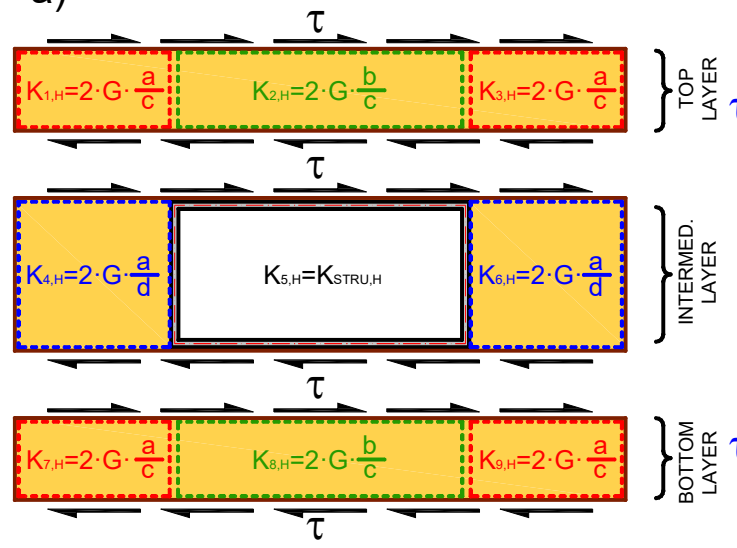

b)

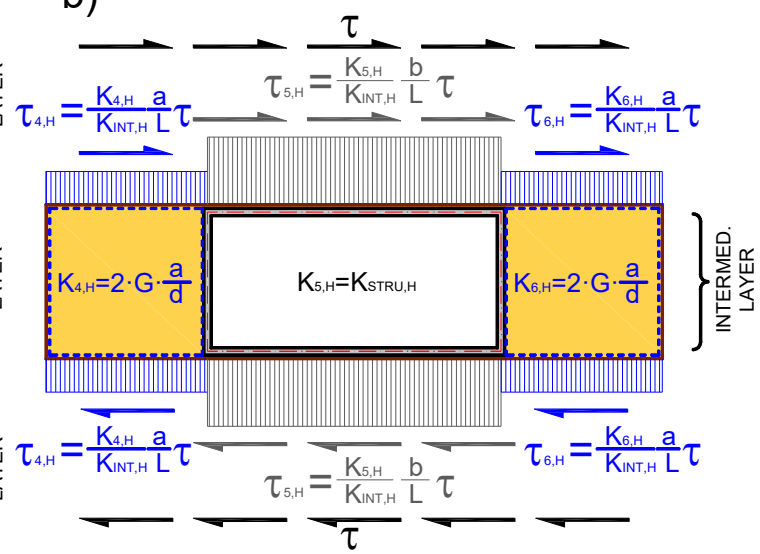

Fig. 4-16. (a) Diagrama de bloques con capas horizontales, y transferencia de rasante entre capas, y rigidez horizontal a cortante de cada bloque. (b) Reparto de rasante entre bloques de la capa intermedia, en el que se ha supuesto que el bloque 5 es más rígido que el suelo.

En general, entre dos perímetros de control consecutivos, el perímetro más exterior está solicitado por un estado de cortante puro de valor $\tau$. Por simplicidad, fijándonos tan sólo en la transmisión de tensiones horizontales, y en particular en el reparto de tensiones entre bloques adyacentes de la capa intermedia (bloques 4, 5, y 6), puesto que se trata de 3 elementos elásticos en paralelo, se puede afirmar que el perímetro de control del bloque interno (5) estará solicitado por una tensión horizontal proporcional a la relación de rigideces del bloque interno $K_{5, H}$, frente a la de la capa intermedia $K_{I N T, H}$ (Fig. 4-16, b). Este reparto de tensiones responde a la ecuación (Ec. 4-28).

$$
\tau_{5, H}=\frac{K_{5, H}}{K_{I N T, H}} \cdot \frac{L}{b} \cdot \tau
$$

En general, podremos plantear la transferencia de rasante de la (Ec. 4-28) entre dos perímetros adyacentes cualesquiera como en la (Ec. 4-29), en la que el coeficiente $\alpha_{\tau, i}$,al que llamaremos coeficiente de transferencia de rasante, representa la fracción de rasante del perímetro exterior $i+1$ que se transmite al perímetro interior $i$.

$$
\tau_{5, H, i}=\frac{K_{5, H, i}}{K_{I N T, H, i}} \cdot \frac{L_{i}}{b_{i}} \cdot \tau_{H, i+1}=\alpha_{\tau, i} \cdot \tau_{H, i+1}
$$

Si pretendemos obtener la transferencia de rasante entre el perímetro más exterior del suelo y el más interior de la estructura, podremos proceder de manera similar al caso del coeficiente de racking, y multiplicar todos los coeficientes de transferencia de rasante entre perímetros consecutivos mediante la ecuación (Ec. 4-30), obteniendo el coeficiente de transferencia de rasante total $\alpha_{\tau}$, que permite conocer cuanta tensión de rasante $\tau_{\text {STRU }}$ se transmite a la estructura conocida la tensión de cortante puro de campo libre $\tau_{F F}$. 


$$
\alpha_{\tau}=\frac{\tau_{S T R U}}{\tau_{F F}} \cong \prod_{i=1}^{i=n} \frac{K_{5, H, i}}{K_{I N T, H, i}} \cdot \frac{L_{i}}{b_{i}}=\prod_{i=1}^{i=n} \alpha_{\tau, i}
$$

Para el caso de una estructura interior infinitamente rígida $\left(F_{R}=0\right)$, este procedimiento produce, como cabría esperar, una indeterminación, ya que tanto el numerador $K_{5, H, i}$ como el denominador $K_{I N T, H, i}$ del perímetro más interior toman valor infinito. Sin embargo, esta singularidad es fácilmente resoluble analizando en detalle la transmisión de rasante en ese caso particular. Analizando la figura (Fig. 4-16, b), queda claro que en el caso de una estructura interior infinitamente rígida toda la fuerza correspondiente a la tensión de rasante del perímetro exterior $(\tau \cdot L)$ se transmitirá a la estructura, ya que los bloques adyacentes 4 y 6 (de rigidez finita) no aportarán rigidez frente a la del bloque 5 (de rigidez infinita). Por lo tanto el coeficiente de transferencia de rasante parcial del perímetro más interior $\alpha_{\tau, 1}$ tendrá el valor (Ec. 4-31).

$$
\alpha_{\tau, 1}=\left\{\text { si } F_{R}=0\right\}=\frac{L_{1}}{b_{1}}
$$

Esta expresión analítica (Ec. 4-30), para el caso de estructuras enterradas infinitamente rígidas $\left(F_{R}=0\right)$, arroja un valor $\alpha_{\tau}$ diferente en función del valor de proporción geométrica $\lambda$. Empleando esta formulación se obtienen los valores resumidos en la Tabla 4-2 (Fig. 4-17).

\begin{tabular}{|c|c|c|}
\hline$\lambda=1$ & $\lambda=2$ & $\lambda=3$ \\
\hline$\alpha_{\tau}=2,0$ & $\alpha_{\tau}=1,75$ & $\alpha_{\tau}=1,60$ \\
\hline
\end{tabular}

Tabla 4-2. Valores del coeficiente de transferencia de rasante para estructuras rígidas $F_{R}=0$.

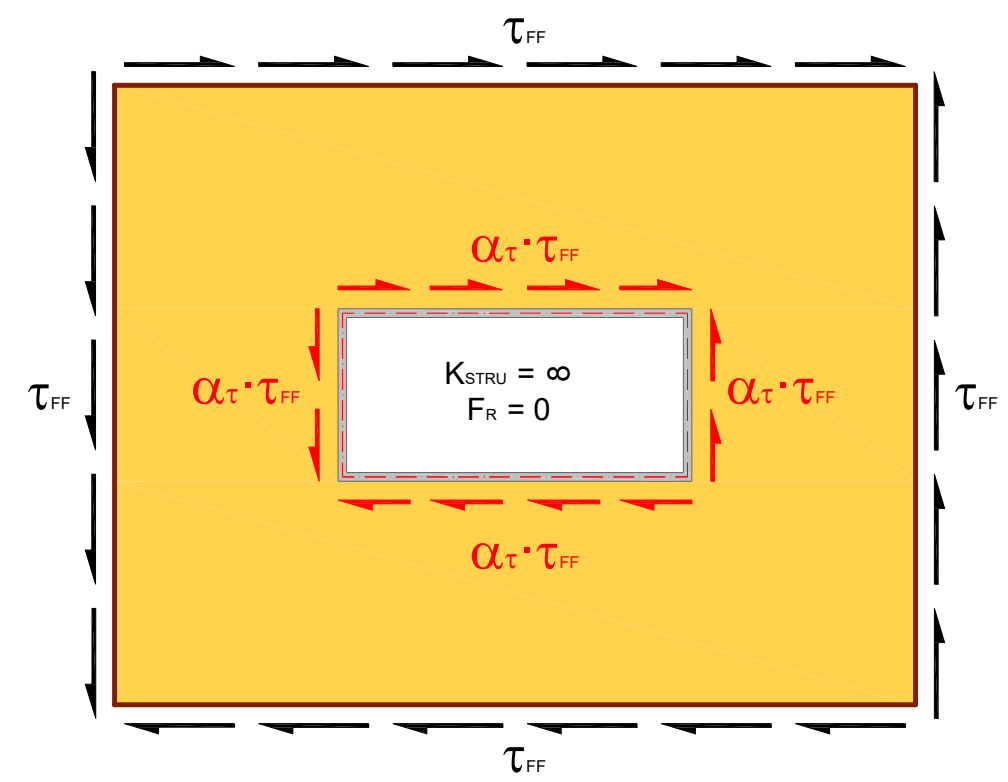


Fig. 4-17. Estado de cortante puro para una estructura infinitamente rígida.

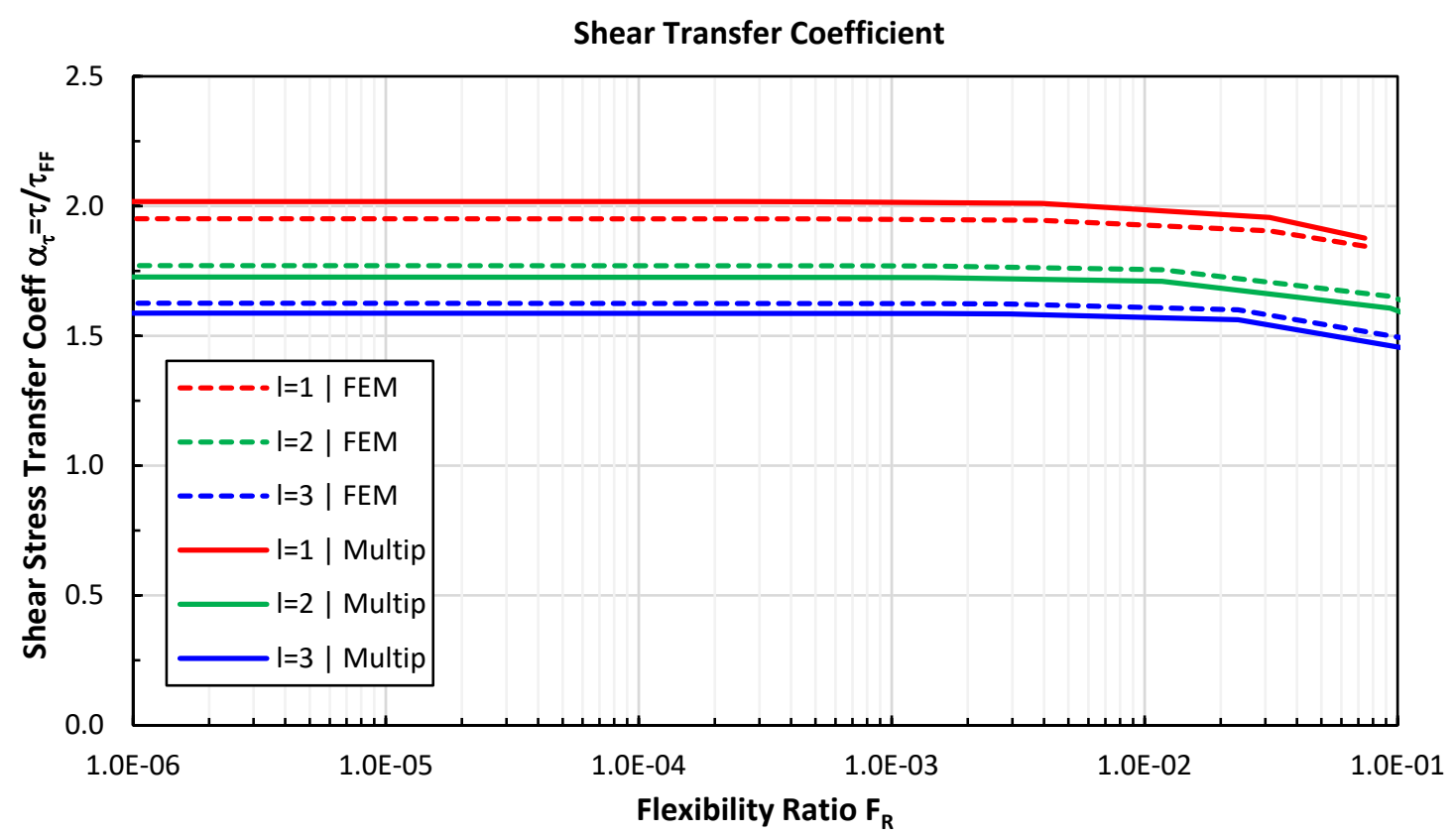

Fig. 4-18. Comparación de coeficientes de transferencia de rasante.

Para validar estos resultados, se ha realizado una comparación con los resultados obtenidos mediante análisis numéricos de elementos finitos. En estos análisis, basados en el modelo descrito en el apartado $\S 4.3$, se han realizado para estructuras rectangulares de tamaños $b \cdot a=5.5 \mathrm{~m}, 10.5 \mathrm{~m}$, y $15.5 \mathrm{~m}$, con rigideces tales que las ratios de flexibilidad relativa estuvieran comprendidos entre $1 \cdot 10^{-6}<F_{R}<1 \cdot 10^{-1}$. Los resultados del coeficiente de transferencia calculado mediante la formulación (Ec. 4-30) y los modelos de elementos finitos se muestran en la figura (Fig. 4-18), y presentan un ajuste muy bueno.

Este resultado, presenta tres ventajas importantes:

1) Proporcionar una solución sencilla para un caso extremo de interés teórico.

2) Demuestra que el enfoque del análisis basado en la deformación de distorsión es también válido para estructuras muy rígidas.

3) Es de utilidad inmediata en una aplicación práctica muy concreta: el análisis de las pantallas de testeros de estaciones de metro construidas por el método de cut-and-cover.

Tal y como se comentó en el apartado \$3.7.4.1.2, los muros testeros son estructuras con una rigidez virtualmente infinita. La propuesta recomendada por Wang (J. N. Wang, 1993) para tratar este caso consiste en abandonar el método de racking, y emplear el método de Wood (Wood, 1973) de análisis de empujes sobre estructuras 
infinitamente rígidas, con una rigidez de cimentación también infinita. Sin embargo, queda claro tras lo expuesto en el apartado $§ 4.5$, que en el caso de una estructura infinitamente rígida embebida en un medio elástico no es correcto asumir que se encuentra cimentada rígidamente. Efectivamente, para este caso se produce una rotación de rocking, lo cual invalida una de las dos hipótesis subyacentes en el método de Wood (estructura rígida sobre cimentación rígida), y resta base racional para la aplicación de dicho método.

De manera alternativa, para el caso de estructuras infinitamente rígidas, en esta tesis se propone emplear el método descrito en este apartado, que corresponde a un caso extremo del método del coeficiente de racking, y que proporciona resultados más fiables y precisos en términos de esfuerzos, tal y como se describe en el siguiente capítulo §5. 


\section{ESTUDIO DE LOS ESFUERZOS DE DISTORSIÓN EN SISTEMAS LINEALES EN DEFORMACIÓN PLANA}

\subsection{Introducción}

Es bien sabido que el factor que condiciona sísmicamente de una manera más notable el diseño sismorresistente de estructuras subterráneas (p.ej. los revestimientos de los túneles) es la deformación a cortante del suelo circundante debida a las ondas de cortante propagándose verticalmente en el terreno (Bobet, 2010; Youssef M. A. Hashash et al., 2001; Hongbin Huo et al., 2005; Kuesel, 1969; Monsees, 1991; St John \& Zahrah, 1987). El análisis de la estructuras subterráneas sometidas a la acción del sismo se lleva a cabo frecuentemente mediante métodos simplificados pseudo-estáticos de la interacción suelo-estructura. Estos métodos consisten esencialmente de tres etapas (Anderson et al., 2008; Youssef M. A. Hashash et al., 2010; Hung et al., 2009):

1) Evaluación de la deformación de distorsión del terreno en campo libre $\gamma_{F F}$ cuando este se somete la acción del sismo.

2) Evaluación de la deformación de distorsión de la estructura ySTRU, denominada deformación de racking, a través del denominado coeficiente de racking $R$.

3) Análisis de los esfuerzos en la estructura, en función de la deformación de racking de la estructura $\gamma_{S T R U}$.

El cálculo de la deformación del terreno en campo libre habitualmente se lleva a cabo mediante estudios específicos de respuesta del terreno (GRA, Ground Response Analysis) (Youssef M. A. Hashash et al., 2010), ya sean estos análisis lineales equivalentes (Schnabel et al., 1972), o análisis no lineales completos (Youssef M. A. Hashash \& Park, 2001). Con estos análisis, se evalúa la deformación horizontal diferencial entre las profundidades de suelo que corresponden al nivel superior e inferior de la estructura, a la cual se denomina deformación de campo libre $\gamma_{F F}$. 
Tras esto, la deformación de la estructura $\gamma_{S T R U}$ (desplazamiento relativo entre los niveles superior e inferior de la estructura enterrada) se evalúa multiplicando la deformación de campo libre $\gamma_{F F}$ por el coeficiente de racking $R$ (J. N. Wang, 1993), un término que comprende todos los efectos de interacción suelo-estructura (SSI, SoilStructure Interaction), y que amplifica o reduce la deformación de campo libre $\gamma_{F F}$. El parámetro fundamental que determina el efecto de interacción suelo-estructura es la rigidez relativa de distorsión entre el suelo sustituido por la estructura, y la rigidez de distorsión de la propia estructura, denominada ratio de flexibilidad $F_{R}$ (J. N. Wang, 1993). Diferentes autores han propuesto varias expresiones analíticas para este coeficiente de racking $R$ basadas en la ratio de flexibilidad $F_{R}$ y en el coeficiente de Poisson $v$. Entre estas, las de Wang (J. N. Wang, 1993), Penzien (Penzien, 2000), y Anderson (Anderson et al., 2008) se basan en la hipótesis de que el campo de deformaciones que se desarrolla en la región próxima a la estructura rectangular subterránea es similar a la que corresponde a una geometría circular. Huo (H. Huo et al., 2006) obtuvo una solución analítica para una estructura rectangular subterránea mediante técnicas de mapeo conformal en el plano complejo, y asumiendo un distribución predefinida de tensiones normales entre la estructura y el suelo circundante. Tsinidis (Grigorios Tsinidis \& Pitilakis, 2018) ha proporcionado valores numéricos para el coeficiente de racking para valores discretos de $F_{R}$, coeficiente de Poisson $v$, proporciones geométricas $\lambda, \mathrm{y}$ profundidades de la estructura. Más recientemente, Gordo Monsó et al. (Gordo-Monsó, González-Galindo, \& Olalla-Marañón, 2019) ha propuesto una expresión analítica para estructuras de geometría rectangular basándose en el concepto simple de un bloque sometido a un estado de cortante puro, y su aplicación recursiva a perímetros de control sucesivos.

Una vez que se ha obtenido la deformación de distorsión de la estructura $\gamma_{S T R U}$, el análisis de los esfuerzos de la estructura (p.ej. momentos flectores y esfuerzos cortantes) se realiza a menudo mediante un sencillo modelo estructural tipo marco, al que se imponen los desplazamientos relativos entre las losas superior e inferior (Hung et al., 2009; Ostadan \& Penzien, 2001; Penzien, 2000; J. N. Wang, 1993).

Sin embargo, varios estudios (Debiasi et al., 2013; Pitilakis \& Tsinidis, 2014, 2016; Grigorios Tsinidis, 2017; Grigorios Tsinidis, Pitilakis, Anagnostopoulos, \& Madabhushi, 2015) han demostrado que los esfuerzos predichos por el método descrito presentan diferencias significativas frente a los obtenidos mediante métodos numéricos 
(p.ej. modelos de elementos finitos, MEF), y con los medidos en ensayos en laboratorio (Abuhajar, Naggar, \& Newson, 2015; Cilingir \& Madabhushi, 2011, 2012; Grigorios Tsinidis, Pitilakis, \& Heron, 2015), tanto en valor absoluto como en la forma de la ley de esfuerzos.

\subsection{Modelo propuesto para la obtención de esfuerzos en la estructura}

A pesar de que son aproximadas por naturaleza, algunas de las soluciones analíticas propuestas hasta la fecha para obtener el coeficiente de racking $R$ son capaces de predecir con una precisión del $\pm 10 \%$ ó $\pm 5 \%$ la deformación de cortante de las estructuras subterráneas cuando se comparan a resultados con elementos finitos (GordoMonsó et al., 2019). Por lo tanto, es lícito preguntarse por cuales son los efectos mecánicos que intervienen para evitar que se puedan predecir con precisión los momentos flectores y esfuerzos cortantes, pero que no influyen en el comportamiento deformacional global de la estructura.

El mecanismo que se propone en esta tesis para explicar este comportamiento es el de la reacción local del suelo. Al deformarse a distorsión la estructura, la flexión local de los elementos (p.ej. losas y muros) produce deformaciones fuera de los planos geométricos definidos por las esquinas de la estructura. Estas deformaciones inducen un conjunto de reacciones locales mutuas entre el suelo circundante y la estructura, que a su vez modifican la deformación de los elementos, y en consecuencia los esfuerzos en los mismos.

Para predecir este comportamiento local, y para mejorar la evaluación de los esfuerzos en la estructura, en esta tesis se propone un modelo simple como el de la (Fig. 5-1). Conceptualmente, podemos pensar que, una vez que la distorsión global se ha impuesto al marco de la estructura, la reacciones locales mutuas autoequilibradas entre el suelo y la estructura se pueden modelizar mediante una fundación elástica tipo Winkler (Winkler, 1867). 


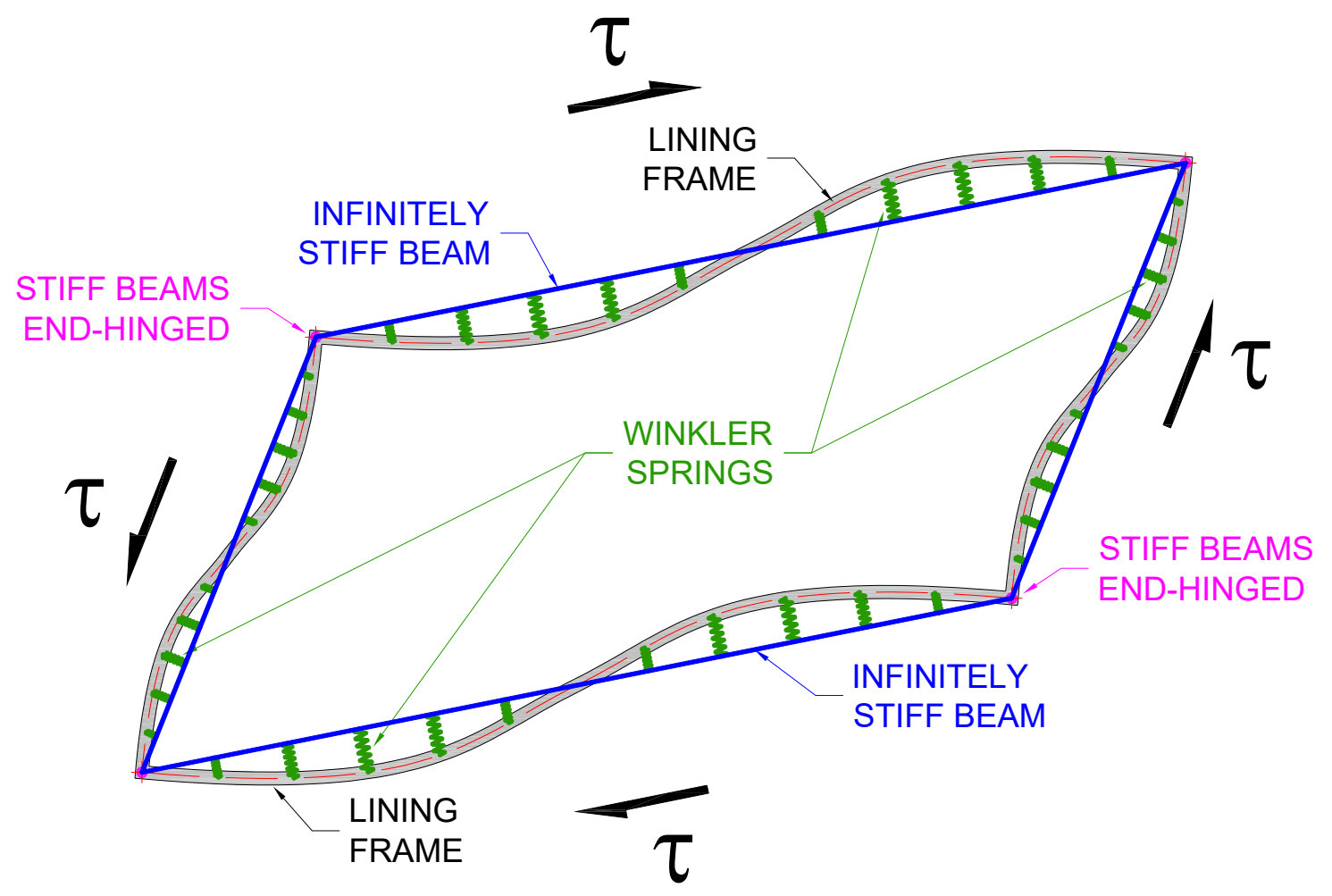

Fig. 5-1. Vista esquemática del modelo mejorado con el marco estructural, vigas rígidas rotuladas, y muelles de vinculación de Winkler.

Puesto que la estructura y suelo circundante ya se encuentran distorsionados por el desplazamiento impuesto, la fundación elástica de Winkler no debe vincular los elementos de la estructura a un borde indefinido, si no a un marco de referencia que sea capaz de moverse sin esfuerzo acompañando a la estructura en su movimiento distorsor. Este marco de referencia representa la línea media de contacto entre el suelo y la estructura, y puede representarse de manera apropiada en un modelo sencillo en un programa de estructuras mediante un conjunto de vigas infinitamente rígidas (p.ej. mucho más rígidas que la losa y muros de la estructura), que se vinculan a las esquinas del marco estructural, y a las que se les dota de rótulas a flexión en estas esquinas. Este marco de referencia de vigas rígidas se vincula al marco estructural por una fundación de muelles de Winkler, que representa la interacción local suelo-estructura.

Respecto al valor de rigidez $k$ de los muelles de Winkler, en esta tesis se demuestra que la expresión (Ec. 4-1) propuesta por Vesic (Vesic, 1963) proporciona resultados suficientemente precisos a la hora de comparar los resultados con los obtenidos con análisis de elementos finitos. 

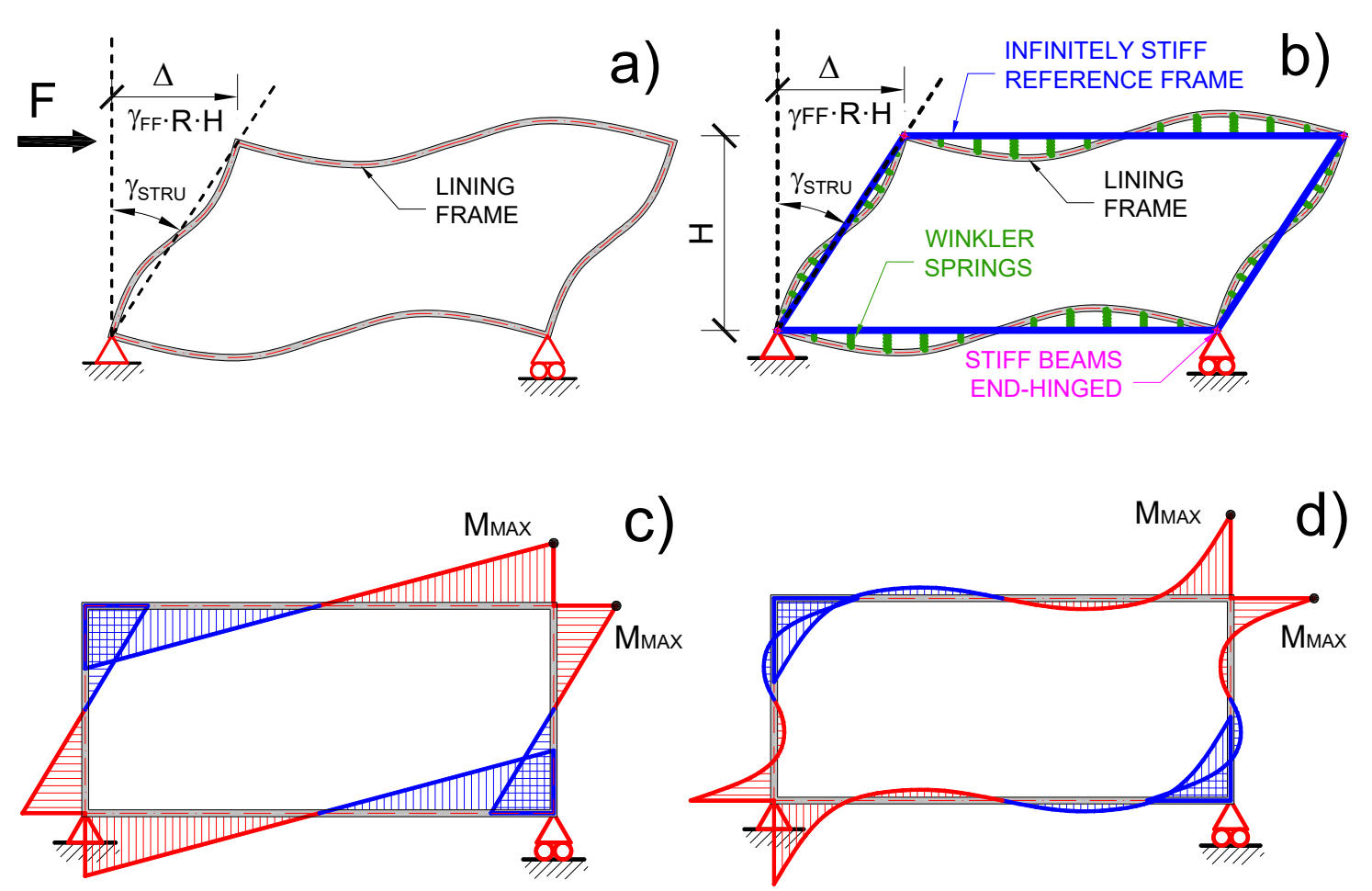

Fig. 5-2. (a) Modelo marco propuesto por Wang (J. N. Wang, 1993) para obtener esfuerzos. (b) Modelo marco mejorado propuesto en esta tesis. (c) Diagrama de momentos flectores consecuente con la hipótesis de comportamiento de Wang (J. N. Wang, 1993). (d) Diagrama de momentos flectores consecuente con la hipótesis de comportamiento mejorado propuesta en esta tesis.

En esta expresión $E_{s}$ y $v$ son el módulo de Young y coeficiente de Poisson del suelo, y $E$ el módulo de Young de la estructura, e $I$ la inercia a flexión del elemento para el cual se están obteniendo los muelles (p.ej. se obtendrá la rigidez de los muelles de la losa $k_{b}$ empleando la inercia de la losa $I b$, y la rigidez de los muelles de los muros $k_{w}$ cuando empleando la inercia del muro $I_{w}$ ). Para obtener el módulo de Young del suelo $E_{s}$ conocido su módulo de cortante $G$, basta con emplear la relación elástica entre ambos (Ec. 5-2). Sin embargo, esto no es óbice para excluir otros valores de la rigidez de Winkler que se puedan determinar a partir de ensayos in-situ.

$$
\begin{gathered}
k=0.65 \cdot \sqrt[12]{\frac{E_{S}}{E I}} \cdot \frac{E_{s}}{1-v^{2}} \\
E_{S}=G \cdot 2(1+v)
\end{gathered}
$$




\subsection{Verificación de momentos flectores}

Para evaluar la precisión del método mejorado propuesto en esta tesis, y descrito en el apartado anterior §5.2, para obtener esfuerzos en la estructura, se han desarrollado una serie de modelos de elementos finitos (MEF) en el programa OpenSEES (McKenna et al., 2010). Los análisis MEF desarrollados representan el problema de un medio suficientemente grande, isótropo y homogéneo, que cuenta con una estructura rectangular embebida en su centro. El suelo se ha mallado con elementos cuadriláteros de 4 nodos y comportamiento en deformaciones planas, mientras que la discretización de la estructura se ha realizado con elementos viga de 2 nudos, los cuales se han vinculado frente a desplazamientos horizontales y verticales a los nudos de suelo adyacentes, con el propósito de representar un comportamiento completamente vinculado de la interfaz hormigón-suelo.

Los bordes exteriores del suelo no presentan ningún tipo de restricción al movimiento, y están sujetos a un estado de cortante puro de valor de tensiones tangenciales $\tau$. Únicamente el nudo inferior izquierdo tiene los desplazamientos $u_{x} \mathrm{y} u_{y}$ restringidos, y el nudo inferior derecho el desplazamiento $u_{y}$ restringido, de tal manera que se pueda alcanzar el equilibrio numérico al calcular.

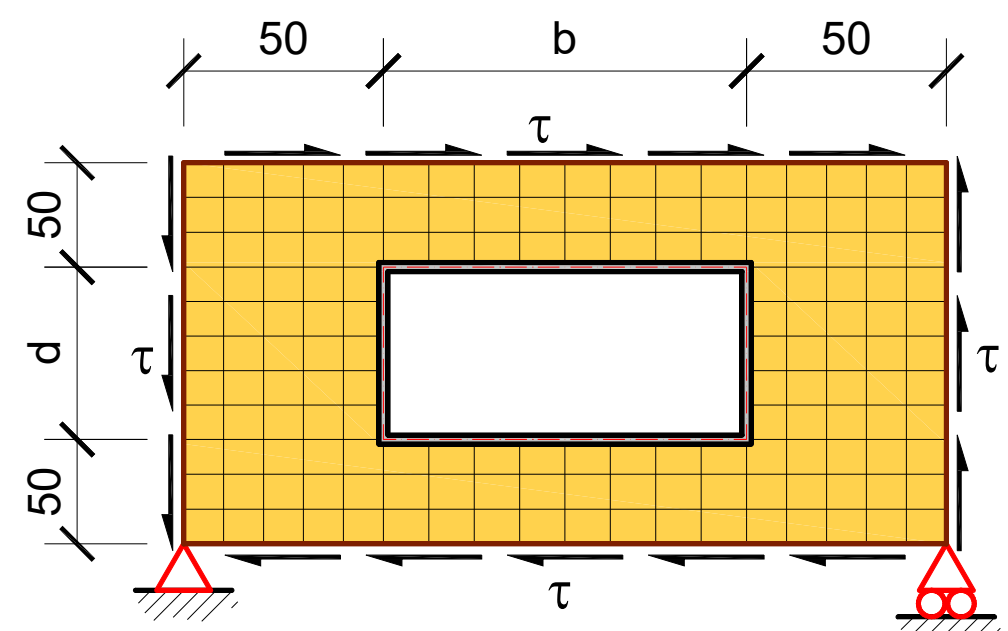

Fig. 5-3. Croquis conceptual del modelo de elementos finitos con las dimensiones más relevantes, las condiciones de contorno, y el estado tensional de cortante. El mallado y dimensiones no se muestran a escala.

El suelo está caracterizado por una velocidad de las ondas de cortante de $V_{s}=360$ $\mathrm{m} / \mathrm{s}$, y un peso específico de $\rho=20 \mathrm{kN} / \mathrm{m}^{3}$, lo cual proporciona un módulo de cortante de $G=259,20 \mathrm{MPa}$. En lo que respecta al túnel, se ha considerado una estructura de hormigón 
con un módulo de Young $E_{c}=30 \mathrm{GPa}$, y unos espesores constantes de muros y losas de $h_{w}=h_{b}=1,50 \mathrm{~m}$ que proporcionan la inercia bruta con la que se ha analizado el sistema.

Se ha estudiado un rango de ratios de flexibilidad $F_{R}$, para los cuales se han variado las dimensiones de ancho $b$ y canto $d$ de la estructura entre $1 \mathrm{~m}$ y $20 \mathrm{~m}$. En particular, se han analizado casos correspondientes a diferentes proporciones $\lambda=b / d$ que abarcan un rango de $\lambda=1$ a $\lambda=3$, para estudiar su influencia en la solución propuesta. Los bordes del modelo MEF se han ubicado a $50 \mathrm{~m}$ de la estructura tanto en dirección horizontal como en dirección vertical (Fig. 5-3).

Con respecto al método de análisis simplificado, se ha elegido la expresión analítica del coeficiente de racking $R$ propuesta por Gordo Monsó (Gordo-Monsó et al., 2019) y descrita en el capítulo $\S 4$ de esta tesis, con un suelo circundante discretizado en 1000 perímetros de control, e idénticas propiedades mecánicas que las empleadas en los análisis MEF. Para poder llevar a cabo el análisis paramétrico de una manera más eficiente, los esfuerzos del modelo simplificado mejorado propuesto en esta tesis se han calculado mediante expresiones analíticas (derivadas en el apéndice $\S \mathrm{A}$ de esta tesis) de un marco restringido por una fundación de Winkler como la mostrada en la figura (Fig. $5-2$, b). Cabe señalar que estas expresiones analíticas de esfuerzos son incidentales a la metodología propuesta en esta tesis, y que pueden ser reemplazadas por un modelo estructural simple de ordenador del tipo mostrado en la figura (Fig. 5-2, b).

La Fig. 5-4 muestra los resultados en términos de momentos flectores de la losa superior, para una deformación de campo libre $\gamma_{F F}$, tal y como predice el método simplificado (Hung et al., 2009; Ostadan \& Penzien, 2001; J. N. Wang, 1993), y calculando el coeficiente de racking $R$ con la solución analítica de Wang (J. N. Wang, 1993), y considerando la losa superior a flexión doble (viga cuyos extremos están sometidos a un valor igual de momento pero de signo contrario, y sin más cargas aplicadas en secciones intermedias) como en la (Fig. 5-2, c). Para comparar más fácilmente y resaltar las diferencias en la forma de la ley de momentos flectores de cada modelo (diferentes valores de $F_{R}$ corresponden a longitudes diferentes de losa superior), la abscisa en los gráficos se ha normalizado a 1.

Tal y como se puede apreciar en la (Fig. 5-4), las leyes de momentos flectores obtenidas mediante la formulación simplificada de Wang (J. N. Wang, 1993) se apartan de las obtenidas con el análisis mediante elementos finitos. En particular, el método de 
Wang falla al predecir tanto la forma de las leyes de momentos flectores (que para el análisis de Wang corresponde a una línea recta), como el valor máximo en los extremos de la losa, especialmente para los casos más flexibles $\left(F_{R}>1\right)$. Además, los análisis MEF muestran como para las estructuras más flexibles y con vanos más largos, entre la sección de centro de vano y el extremo, aparece una zona con una inversión del signo del momento flector, y más tarde un incremento brusco hasta que se alcanza el valor máximo, mientras que el análisis de Wang tan sólo muestra un incremento lineal uniforme a lo largo de toda la longitud.
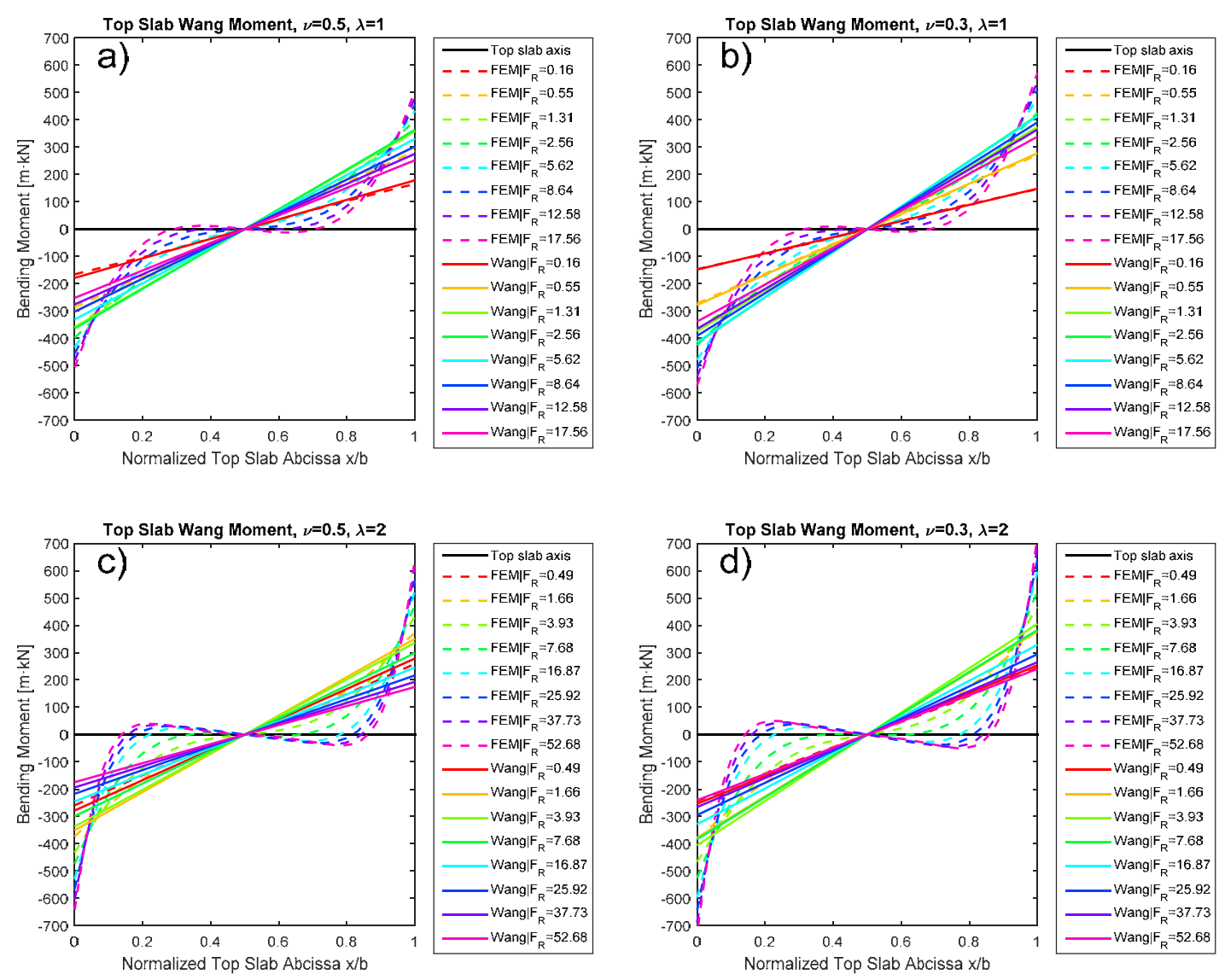

Fig. 5-4. Diagramas de momentos flectores en la losa superior, resultantes de un análisis de elementos finitos, y del método de Wang (J. N. Wang, 1993), para un amplio rango de flexibilidades relativas $F_{R}, y$ con (a) Coeficiente de Poisson $v=0,5$ y proporción geométrica $\lambda=1$. (b) Coeficiente de Poisson $v=0,3$ y proporción geométrica $\lambda=1$. (c) Coeficiente de Poisson $v=0,5$ y proporción geométrica $\lambda=2$. (d) Coeficiente de Poisson $v=0,3$ y proporción geométrica $\lambda=2$.

Esto no debería sorprendernos, ya que el método propuesto por Wang está enfocado especialmente al estudio del comportamiento de estructuras subterráneas rígidas: de los 25 análisis numéricos que realizó en su estudio para evaluar la precisión de la solución analítica del coeficiente de racking $R$, tan sólo 6 casos corresponden a 
$F_{R}>1$, y 3 casos a $F_{R}>4$. Por otra parte, de los 5 casos que Wang emplea para evaluar la precisión de su método de obtención de esfuerzos (aplicar los desplazamientos impuestos mediante una fuerza localizada en la losa superior), tan sólo 1 caso corresponde a $F_{R}>1$, y además es un caso que se aparta muy poco de una estructura con rigidez similar a la del suelo, ya que ese único caso corresponde a $F_{R}=1,313$ (Wang, 1993, pp.113 y 129).

Tal y como se aprecia en la (Fig. 5-4), para las estructuras más rígidas $\left(F_{R}<1\right)$ el modelo simplificado de Wang proporciona resultados que están en concordancia con los obtenidos mediante los modelos de elementos finitos.

La (Fig. 5-5) muestra resultados similares pero para el caso del método mejorado propuesto en este capítulo de la tesis, calculando el coeficiente de racking $R$ tal y como propone Gordo-Monsó (Gordo-Monsó et al., 2019), y considerando el marco restringido por una fundación de Winkler vinculada a un marco de referencia rígido y articulado como el de la (Fig. 5-2, b). Tal y como se puede apreciar, los resultados de este modelo en términos de momentos flectores se ajustan con precisión a los obtenidos con los análisis MEF. En particular, el método mejorado propuesto en este estudio es capaz de replicar el acusado incremento en la ley de momentos según nos acercamos a la sección de extremo de la losa.

También es capaz de predecir, para los casos de marcos más flexibles, la inversión local del signo de los momentos en las zonas a cada lado de la sección de centro de vano. Adicionalmente, se puede apreciar como los marcos más rígidos $\left(F_{R}<1\right)$ presentan leyes de momentos que no se apartan significativamente del caso de una viga en flexión doble: tal y como se podría esperar intuitivamente, los marcos más rígidos se deforman localmente menos fuera de su plano, y por lo tanto las fuerzas de reacción de los muelles de Winkler se tornan menos significativas, y proporcionan un comportamiento a flexión similar al obtenido mediante un análisis del tipo de Wang (J. N. Wang, 1993). Por el contrario, las vigas más flexibles presentan deformaciones locales mayores, y por lo tanto movilizan en mayor medida la reacción local del suelo circundante, modificando significativamente el diagrama de momentos flectores. La forma de la ley de momentos flectores obtenida tanto mediante los análisis FEM como con el método mejorado propuesto en esta tesis se encuentran en buena concordancia con los presentados por Tsinidis (Grigorios Tsinidis, Pitilakis, \& Heron, 2015), tanto para marcos rígidos $\left(F_{R}<1\right)$, como flexibles $\left(F_{R}>1\right)$. 

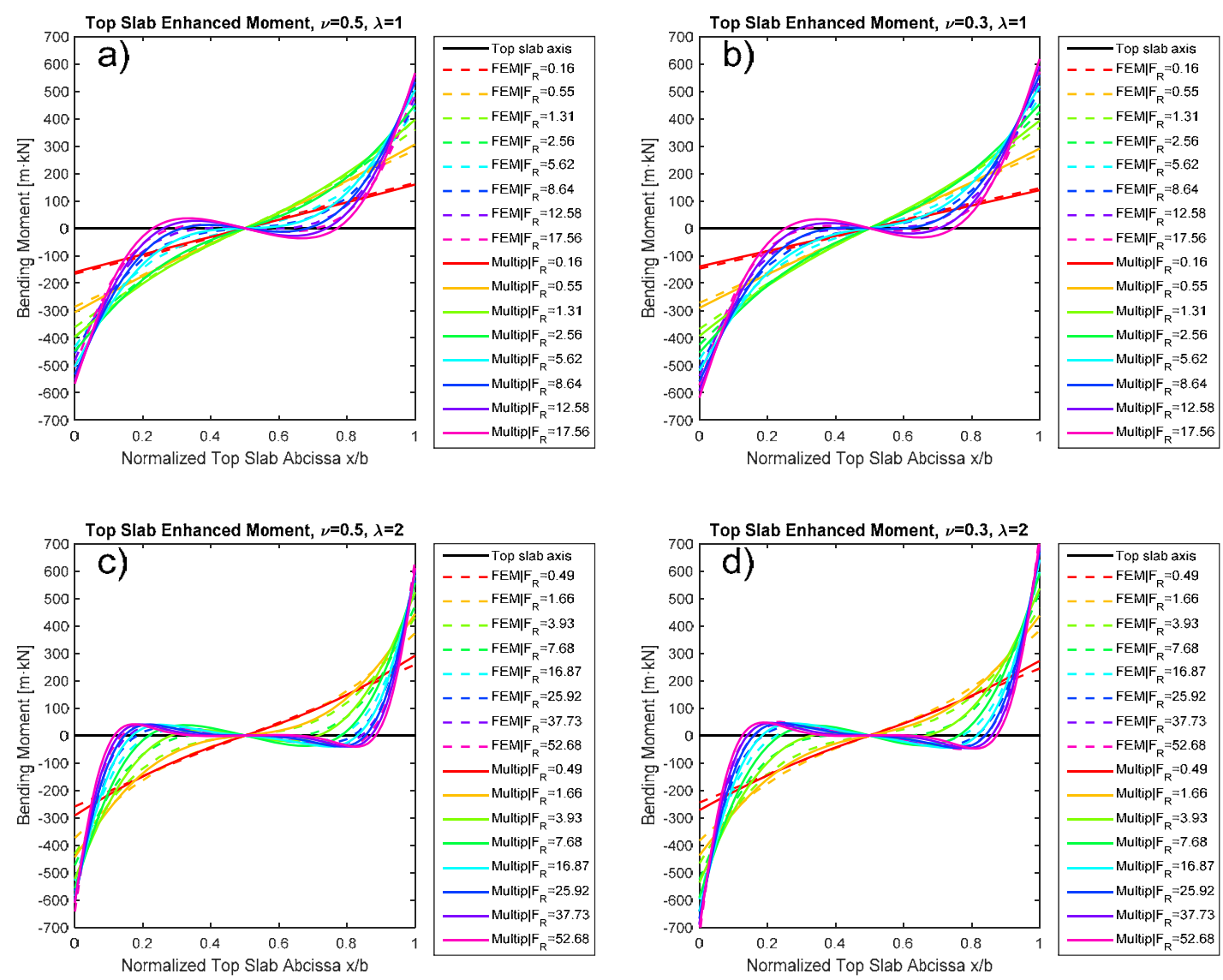

Fig. 5-5. Diagramas de momentos flectores en la losa superior, resultantes de un análisis de elementos finitos, y del método mejorado propuesto en esta tesis, para un amplio rango de flexibilidades relativas $F_{R}, y$ con (a) Coeficiente de Poisson $v=0,5$ y proporción geométrica $\lambda=1$. (b) Coeficiente de Poisson $v=0,3$ y proporción geométrica $\lambda=1$. (c) Coeficiente de Poisson $v=0,5$ y proporción geométrica $\lambda=2$. (d) Coeficiente de Poisson $v=0,3$ y proporción geométrica $\lambda=2$.

Se puede realizar una comparación similar con los momentos flectores que se producen en el muro izquierdo, que para el caso del método de Wang se muestran en la (Fig. 5-6), mientras que la (Fig. 5-7) muestra los momentos flectores tal y como se predicen con el método mejorado presentado en este capítulo de la tesis. 

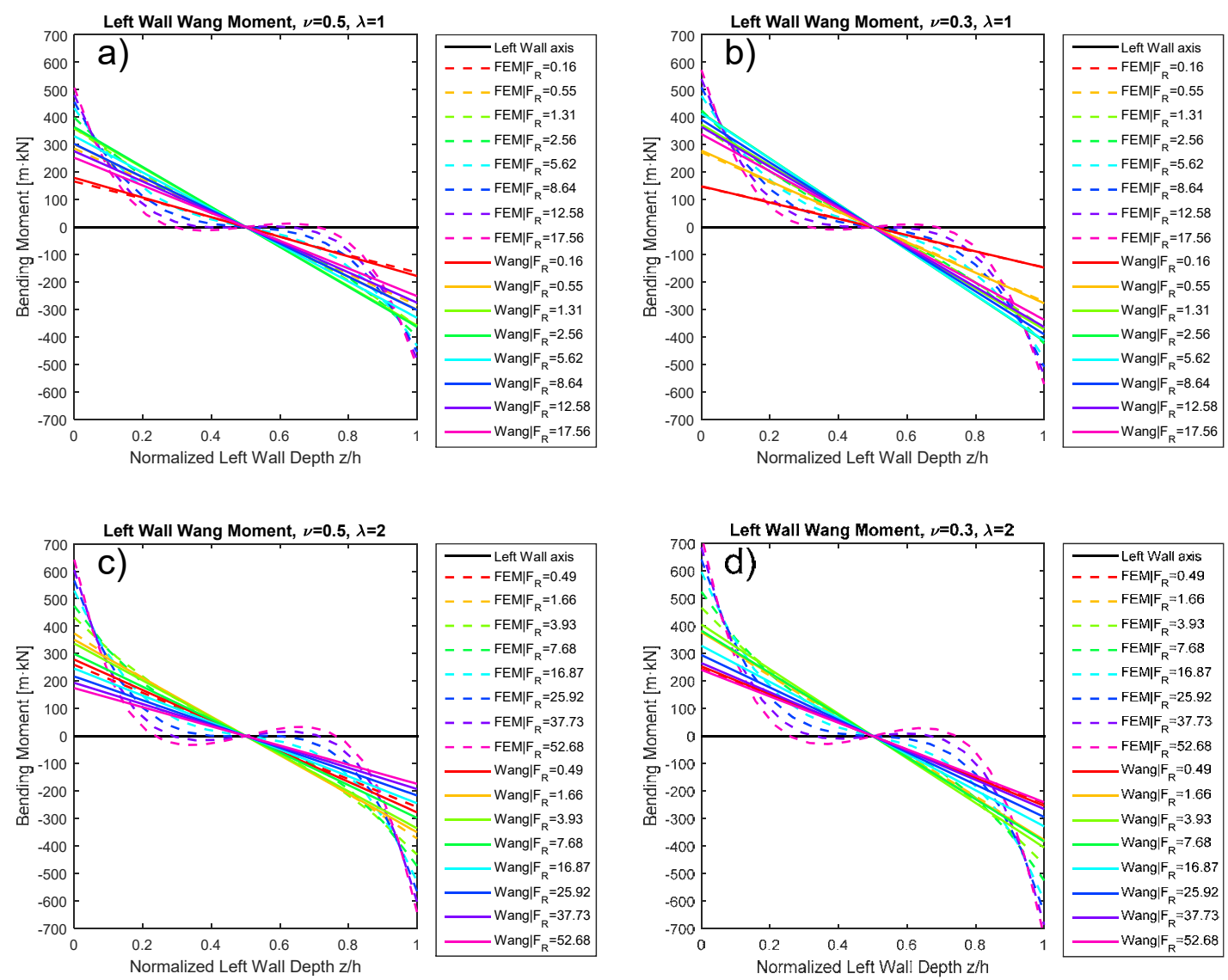

Fig. 5-6. Diagramas de momentos flectores en el muro izquierdo, resultantes de un análisis de elementos finitos, y del método de Wang (J. N. Wang, 1993), para un amplio rango de flexibilidades relativas $F_{R}, y$ con (a) Coeficiente de Poisson $v=0,5$ y proporción geométrica $\lambda=1$. (b) Coeficiente de Poisson $v=0,3$ y proporción geométrica $\lambda=1$. (c) Coeficiente de Poisson $v=0,5$ y proporción geométrica $\lambda=2$. (d) Coeficiente de Poisson $v=0,3$ y proporción geométrica $\lambda=2$.

Cuantitativamente, podemos medir la precisión de la metodología mejorada propuesta en esta tesis, así como la mejora que esta representa respecto a los métodos simplificados previos, comparando los valores del momento flector máximo en la estructura predicho por cada metodología, frente a los obtenidos mediante los análisis numéricos de elementos finitos. La (Fig. 5-8) muestra la ratio del momento flector obtenido mediante cada método simplificado entre el obtenido mediante análisis MEF $\left(M_{M E T H O D} / M_{F E M}\right)$ para un amplio rango de flexibilidades relativas $F_{R}$, coeficientes de Poisson entre $v=0,2$ y 0,5 , y rango de proporciones geométricas entre $\lambda=1$ y 3 . 

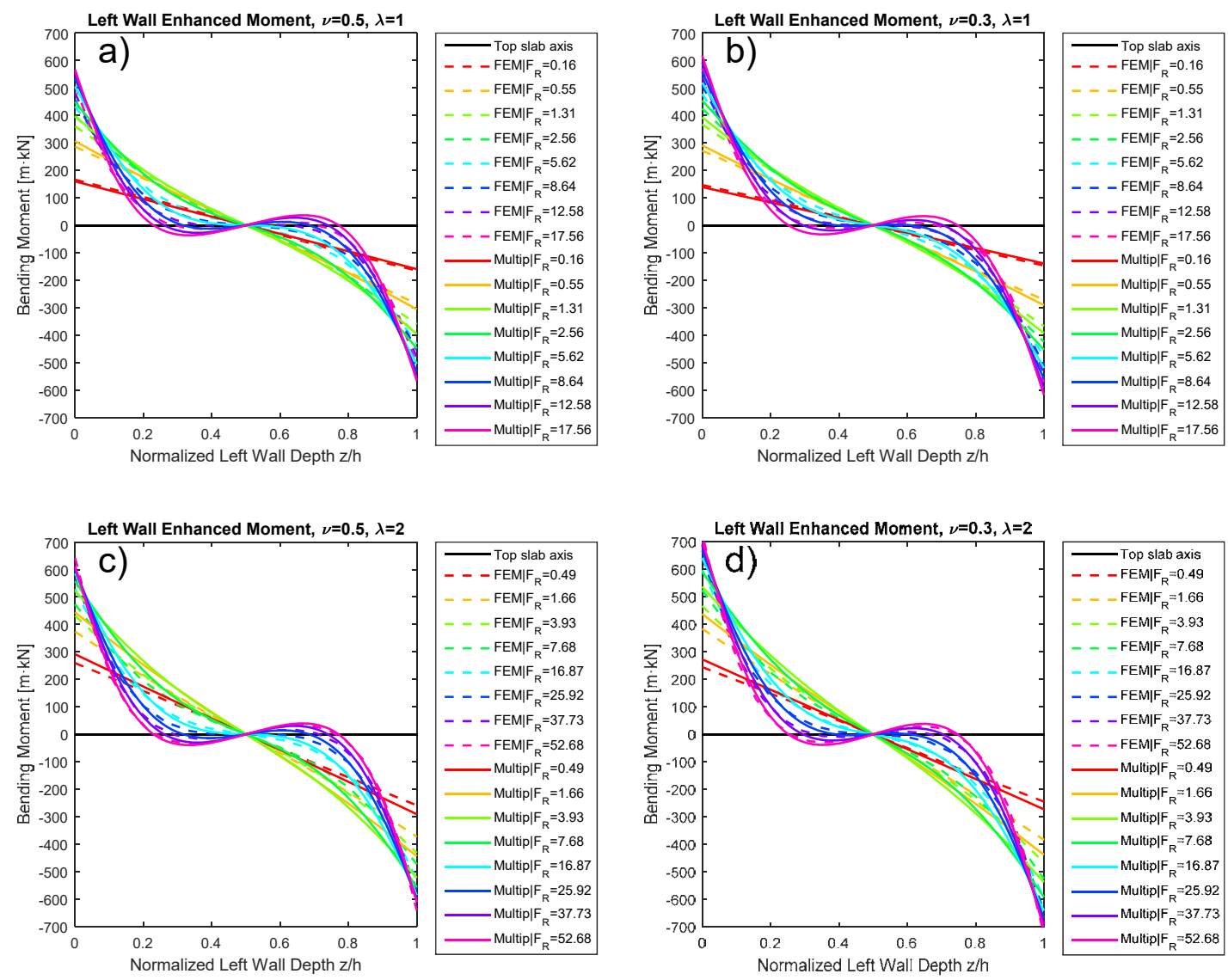

Fig. 5-7. Diagramas de momentos flectores en el muro izquierdo, resultantes de un análisis de elementos finitos, y del método mejorado propuesto en esta tesis, para un amplio rango de flexibilidades relativas $F_{R}$, y con (a) Coeficiente de Poisson $v=0,5$ y proporción geométrica $\lambda=1$. (b) Coeficiente de Poisson $v=0,3$ y proporción geométrica $\lambda=1$. (c) Coeficiente de Poisson $v=0,5$ y proporción geométrica $\lambda=2$. (d) Coeficiente de Poisson $v=0,3$ y proporción geométrica $\lambda=2$.

La figura (Fig. 5-8) muestra también la ratio de momentos obtenidos con el modelo mejorado propuesto en esta tesis (Fig. 5-2, b) calculados a partir de las deformaciones resultantes de aplicar el coeficiente de racking $R$ mediante la expresión analítica de Gordo-Monsó (Gordo-Monsó et al., 2019), frente a los momentos obtenidos con los análisis MEF. De manera similar, la (Fig. 5-8) muestra las ratios de momentos flectores obtenidos con el modelo de marco simple (Fig. 5-2, a), y coeficientes de racking $R$ calculados a partir de las expresiones de Wang (J. N. Wang, 1993), Penzien (Penzien, 2000), y Anderson (Anderson et al., 2008), frente a los resultados MEF. 

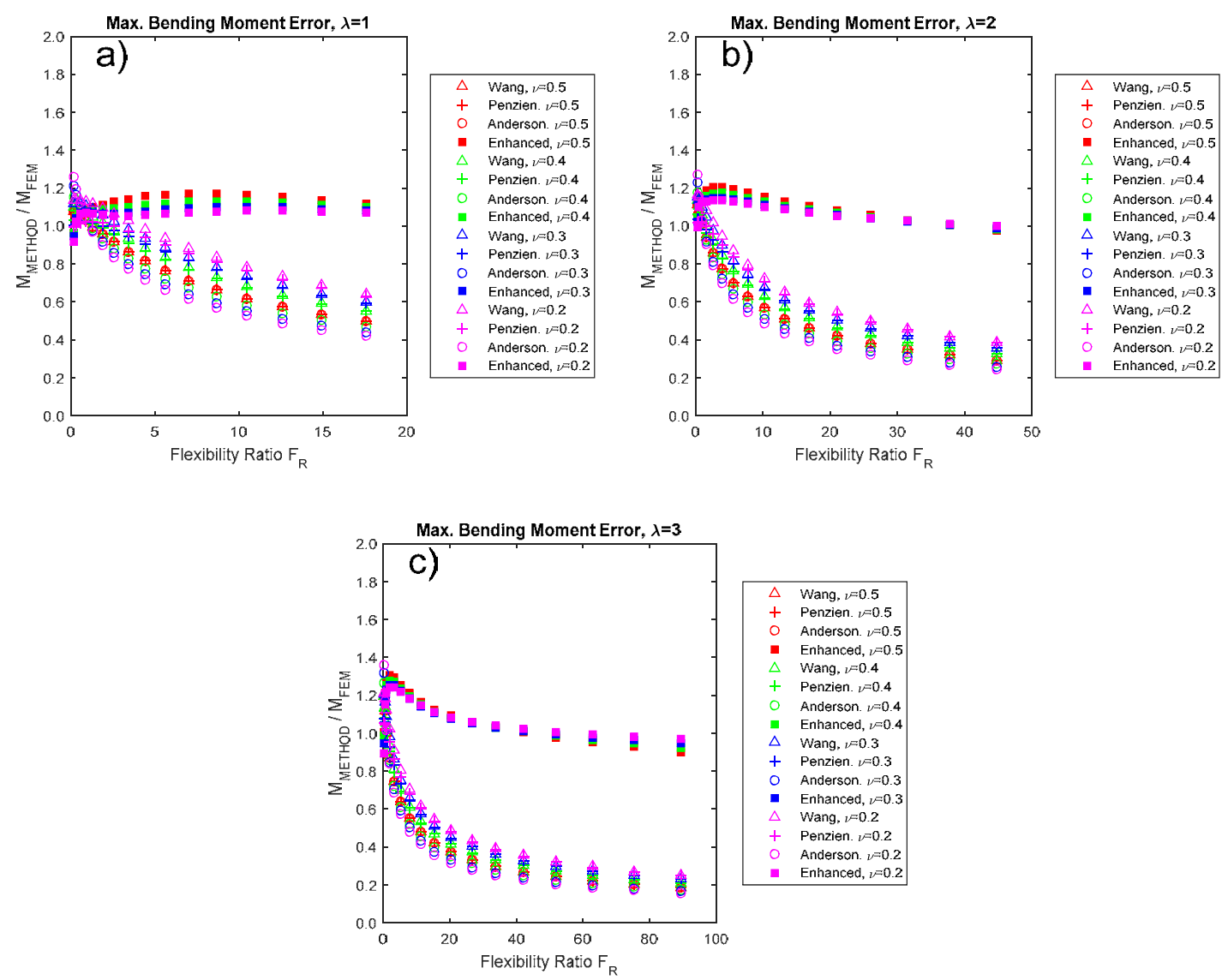

Fig. 5-8. Máximo error de valor del momento flector en la losa superior, para un amplio rango de

flexibilidades relativas $F_{R}$, coeficientes de Poisson $v, y$ proporciones (a) $\lambda=1$. (b) $\lambda=2$. (c) $\lambda=3$.

Como se puede apreciar, los resultados del método mejorado propuesto en esta tesis tienen un rango de precisión del $\pm 10 \%$ - $20 \%$, que mejoran hasta el $\pm 5 \%$ - $10 \%$ para las flexibilidades relativas $F_{R}$ mayores. De manera similar, se puede apreciar que las otras metodologías simplificadas analizadas proporcionan resultados mucho menos precisos, especialmente para las flexibilidades relativas $F_{R}$ mayores, infravalorando los momentos flectores en el rango del -90\%-80\%. Es interesante destacar que el aspecto fundamental que mejora la predicción del valor del momento flector no es el valor particular del coeficiente de racking $R$ correspondiente a una u otra expresión analítica, si no la elección de un modelo de marco que sea capaz de considerar la reacción local del suelo.

\subsection{Verificación de esfuerzos cortantes}

Se puede realizar una comparación similar en términos de esfuerzos cortantes, para evaluar la precisión del método simplificado mejorado propuesto en esta tesis con respecto a los análisis de elementos finitos. A este respecto, la (Fig. 5-9) muestra los esfuerzos cortantes de la losa superior que resultan del método simplificado con el 
coeficiente de racking $R$ calculado según la expresión de Wang (J. N. Wang, 1993), y con los elementos estructurales en flexión doble como se muestra en la (Fig. 5-2, c).
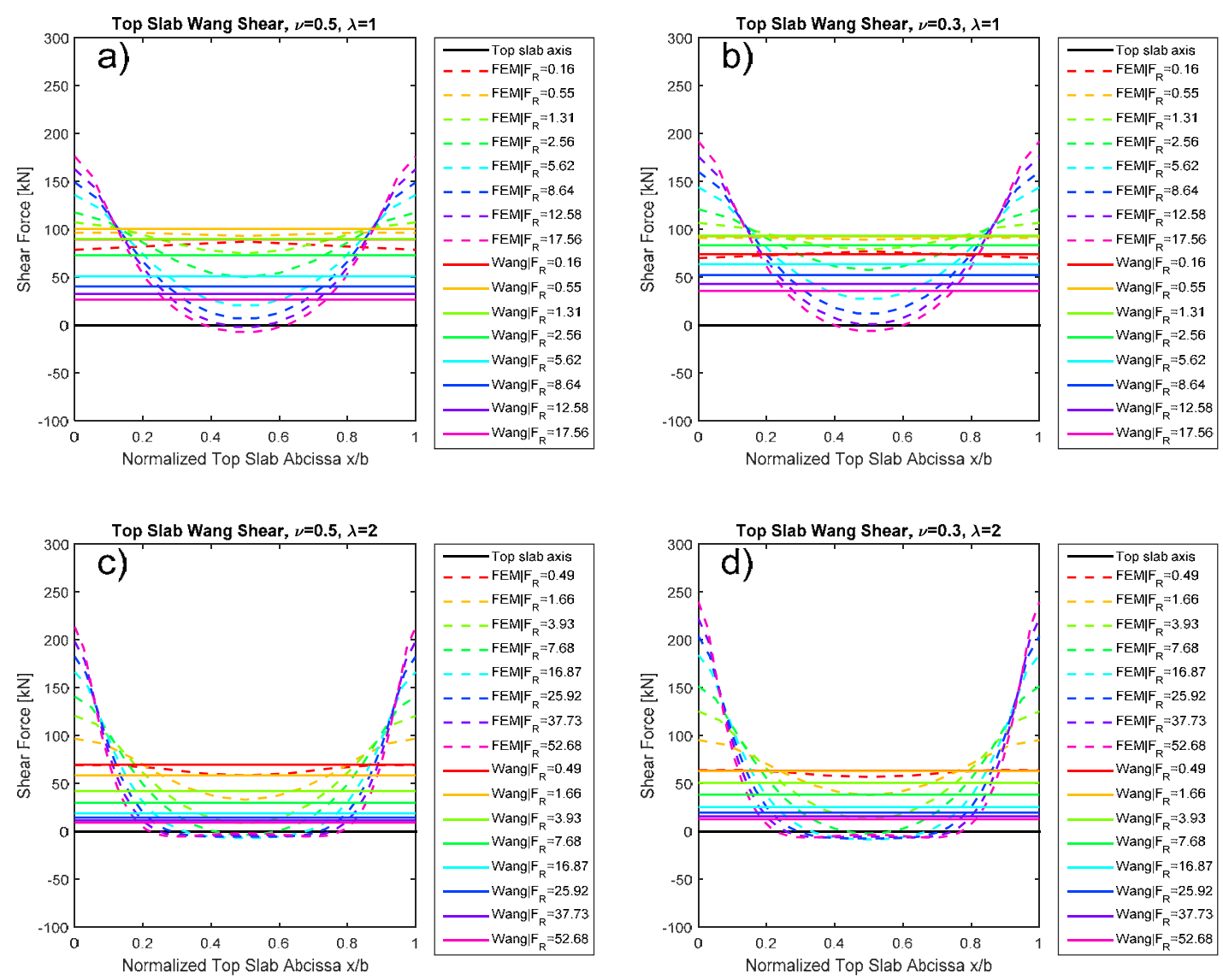

Fig. 5-9. Diagramas de esfuerzos cortantes en la losa superior, resultantes de un análisis de elementos finitos, y del método de Wang (J. N. Wang, 1993), para un amplio rango de flexibilidades relativas $F_{R}, y$ con (a) Coeficiente de Poisson $v=0,5$ y proporción geométrica $\lambda=1$. (b) Coeficiente de Poisson $v=0,3$ y proporción geométrica $\lambda=1$. (c) Coeficiente de Poisson $v=0,5$ y proporción geométrica $\lambda=2$. (d) Coeficiente de Poisson $v=0,3$ y proporción geométrica $\lambda=2$.

Como puede apreciarse, las leyes de momentos obtenidas mediante ambos métodos presentan diferencias notables. Las leyes obtenidas mediante el análisis simplificado corresponden a líneas rectas de valor constante, tal y como cabría esperar en un elemento sujeto a flexión doble, con una variación uniforme de la ley de flectores. Sin embargo, el análisis MEF muestra un patrón de esfuerzos cortantes más complejo, con un marcado incremento en la zona cercana a los extremos de la losa, y con una región cercana a la sección de centro de vano que en algunos casos presenta un valor cercano a un cortante nulo. 

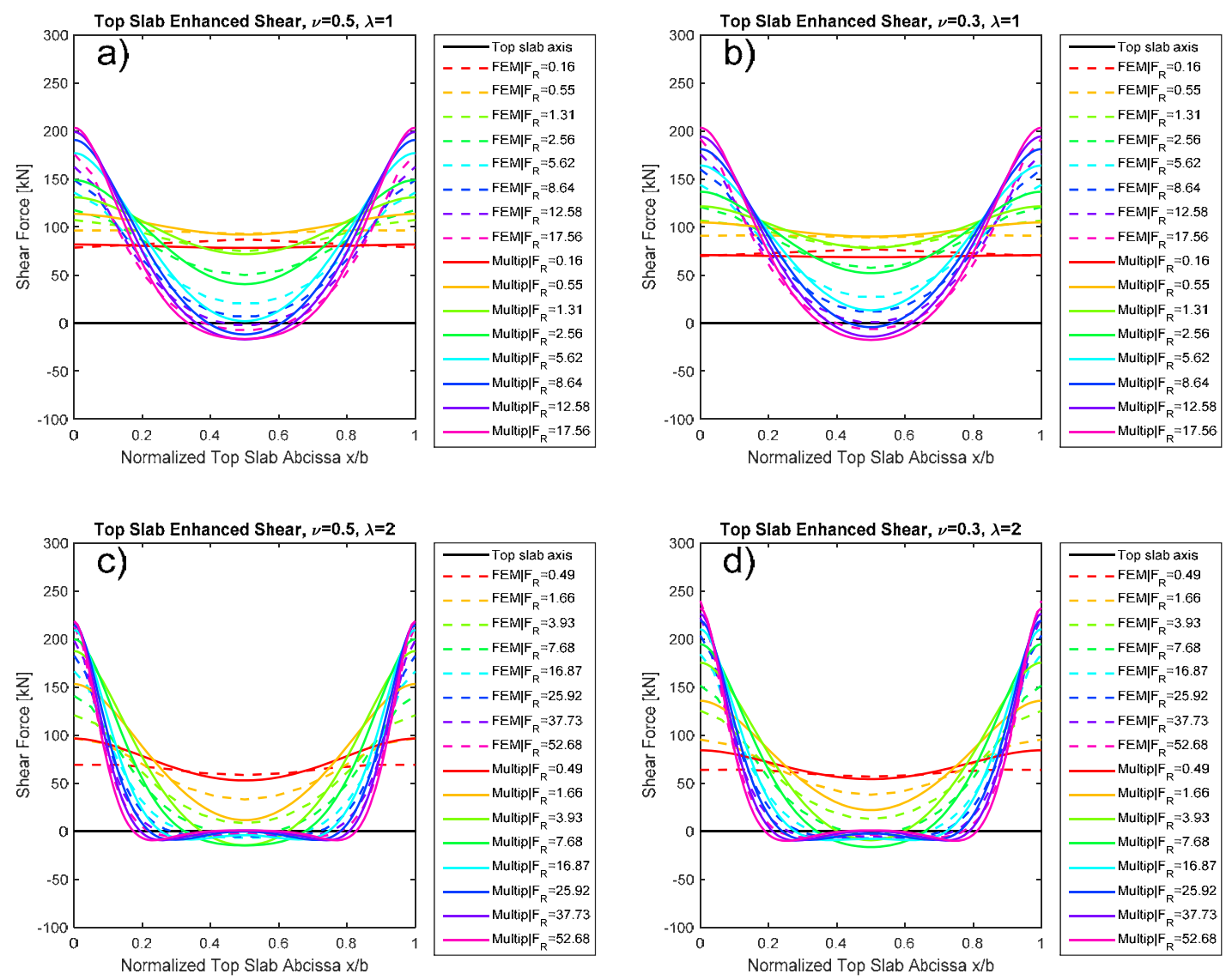

Fig. 5-10. Diagramas de esfuerzos cortantes en la losa superior, resultantes de un análisis de elementos finitos, y del método mejorado propuesto en esta tesis, para un amplio rango de flexibilidades relativas $F_{R}$, y con (a) Coeficiente de Poisson $v=0,5$ y proporción geométrica $\lambda=1$. (b) Coeficiente de Poisson $v=0,3$ y proporción geométrica $\lambda=1$. (c) Coeficiente de Poisson $v=0,5$ y proporción geométrica $\lambda=2$. (d) Coeficiente de Poisson $v=0,3$ y proporción geométrica $\lambda=2$.

Por otro lado, la (Fig. 5-10) muestra resultados de análisis similares, pero para el caso de la metodología mejorada propuesta en esta tesis, calculando el coeficiente de racking $R$ con la expresión analítica de Gordo-Monsó (Gordo-Monsó et al., 2019), y considerando la estructura coaccionada por una condición de Winkler vinculada a un marco de elementos infinitamente rígidos como el de la (Fig. 5-2, b). Como se puede apreciar, los resultados en términos de esfuerzos cortantes de este modelo se ajustan mucho mejor a los obtenidos mediante los modelos MEF. 

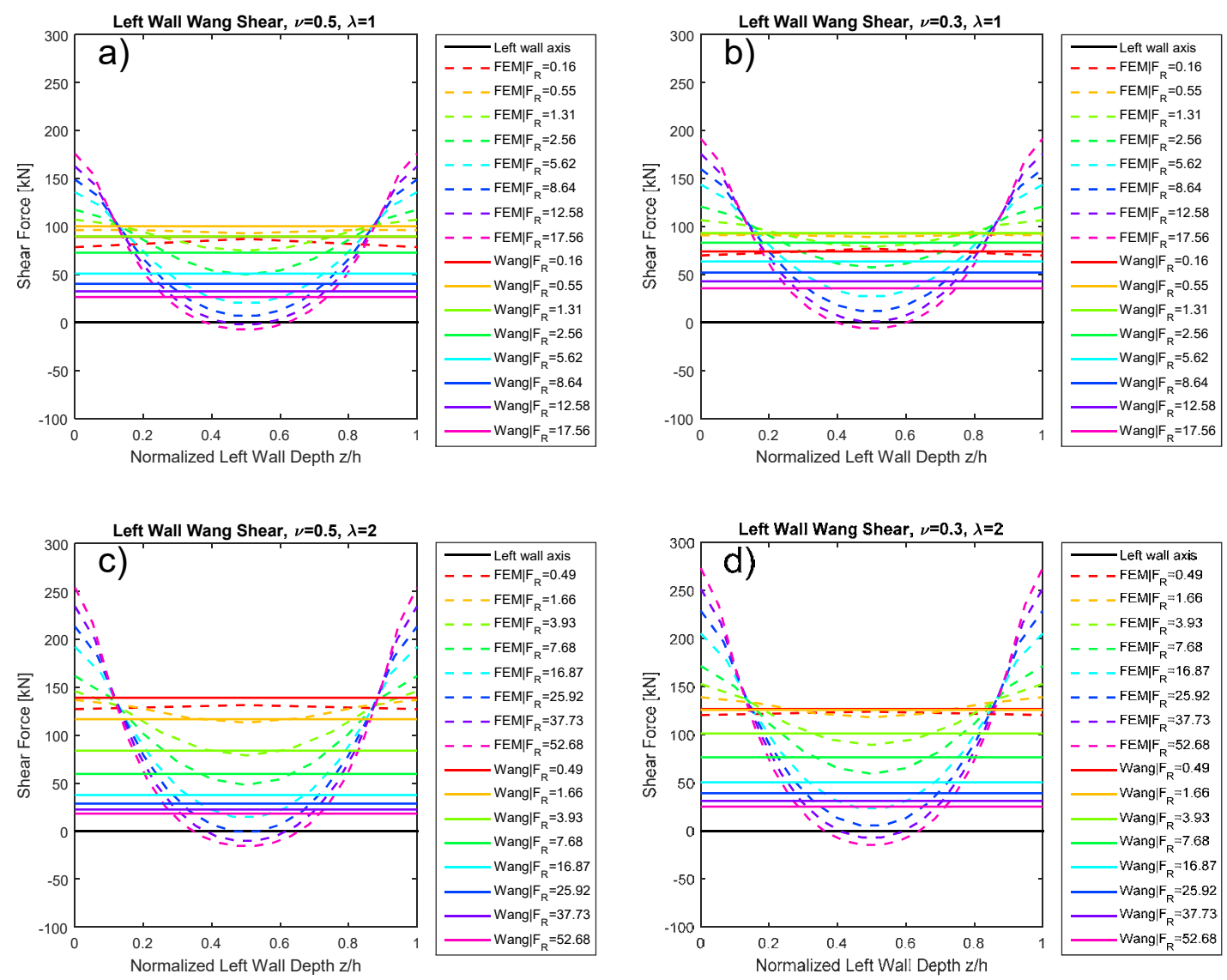

Fig. 5-11. Diagramas de esfuerzos cortantes en el muro izquierdo, resultantes de un análisis de elementos finitos, y del método de Wang (J. N. Wang, 1993), para un amplio rango de flexibilidades relativas $F_{R}, y$ con (a) Coeficiente de Poisson $v=0,5$ y proporción geométrica $\lambda=1$. (b) Coeficiente de Poisson $v=0,3$ y proporción geométrica $\lambda=1$. (c) Coeficiente de Poisson $v=0,5$ y proporción geométrica $\lambda=2$. (d) Coeficiente de Poisson $v=0,3$ y proporción geométrica $\lambda=2$.

Con respecto a los esfuerzos cortantes correspondientes al muro izquierdo, que para el caso del modelo de Wang (J. N. Wang, 1993) se muestran en la (Fig. 5-11), y para el modelo mejorado que se propone en esta tesis se muestran en la (Fig. 5-12), se pueden apreciar diferencias similares entre los resultados MEF y el modelo de Wang (Fig. 5-2, a), y concordancias similares entre los resultados MEF y el modelo mejorado (Fig. 5-2, b). 

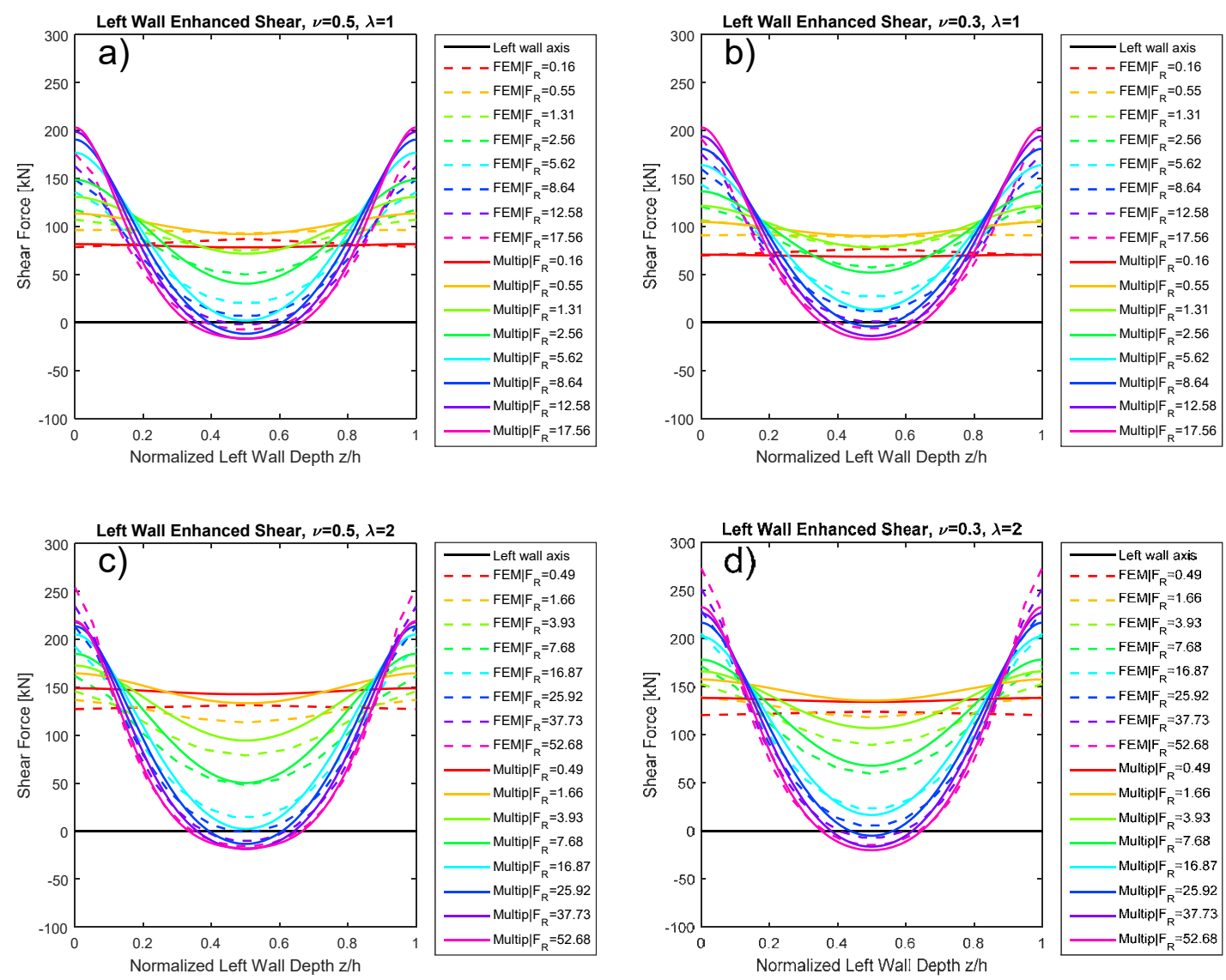

Fig. 5-12. Diagramas de esfuerzos cortantes en el muro izquierdo, resultantes de un análisis de elementos finitos, y del método mejorado propuesto en esta tesis, para un amplio rango de flexibilidades relativas $F_{R}$, y con (a) Coeficiente de Poisson $v=0,5$ y proporción geométrica $\lambda=1$. (b) Coeficiente de Poisson $v=0,3$ y proporción geométrica $\lambda=1$. (c) Coeficiente de Poisson $v=0,5$ y proporción geométrica $\lambda=2$. (d) Coeficiente de Poisson $v=0,3$ y proporción geométrica $\lambda=2$.

Cuantitativamente, podemos medir la precisión de la metodología mejorada propuesta en esta tesis, así como la mejora que esta representa respecto a los métodos simplificados previos, comparando los valores del esfuerzo cortante máximo en el marco predicho por cada metodología frente a los obtenidos mediante los análisis numéricos de elementos finitos. La (Fig. 5-13) muestra la ratio del momento flector obtenido mediante cada método simplificado entre el obtenido mediante análisis MEF ( $\left.M_{M E T H O D} / M_{F E M}\right)$ para un amplio rango de flexibilidades relativas $F_{R}$, coeficientes de Poisson entre $v=0,2$ y 0,5 , y rango de proporciones geométricas entre $\lambda=1$ y 3 . 

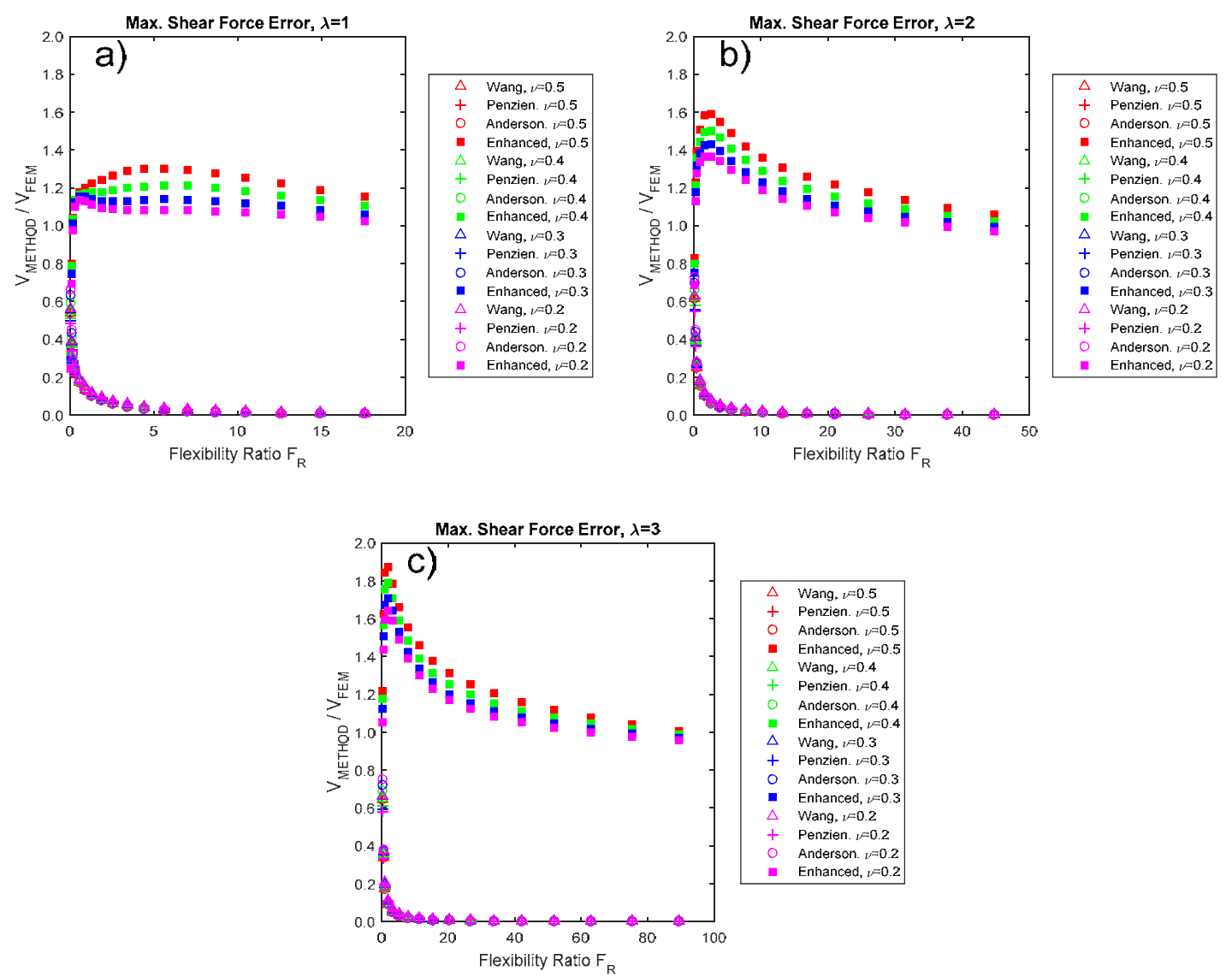

Fig. 5-13. Máximo error de valor del esfuerzo cortante en la losa superior, para un amplio rango de flexibilidades relativas $F_{R}$, coeficientes de Poisson $v, y$ proporciones (a) $\lambda=1$. (b) $\lambda=2$. (c) $\lambda=3$.

Es destacable señalar que, aunque los estudios previos han incidido en las diferencias en términos de momentos flectores entre los métodos simplificados y los análisis de elementos finitos, las referencias en la literatura técnica relevante relacionadas con las diferencias de esfuerzos cortantes son mucho más escasas. Este hecho resulta sorprendente dado que, por oposición al comportamiento a flexión de las estructuras de hormigón, en las que pueden llegar a desarrollarse rótulas plásticas que actúen de fusible y limiten el incremento de la flexión al valor del momento de plastificación, el hormigón a cortante presenta un comportamiento eminentemente frágil, y es difícil que pueda producirse ninguna redistribución de esfuerzos una vez que se alcanza la resistencia a cortante de la pieza.

\subsection{Método propuesto para la obtención de esfuerzos en la estructura}

En base a los resultados descritos en los apartado $§ 5.3$ y $§ 5.4$, se propone en esta tesis la siguiente metodología mejorada de análisis, para obtener una representación más precisa de los esfuerzos en una estructura enterrada tipo marco: 
1) Evaluar la distorsión de campo libre $\gamma_{F F}$ entre las profundidades comprendidas entre los elementos superior e inferior de la estructura. Este paso no difiere conceptualmente de las metodologías previas.

2) Calcular la rigidez de la estructura KSTRU en base a un modelo simple sin muelles de Winkler. Calcular la rigidez lateral del suelo KsoIL como $K_{S O I L}=G \cdot b / d$. Comparar ambas rigideces y obtener la flexibilidad relativa $F_{R}=K_{\text {SOIL }} / K_{\text {STRU. }}$. Este paso no difiere conceptualmente de las metodologías previas.

3) Calcular la deformación de distorsión o racking de la estructura $\gamma_{S T R U}$, con el coeficiente de racking $R$ correspondiente, como $\gamma_{S T R U}=R \cdot \gamma_{F F}$. Para hacer esto, emplear el valor de $R$ propuesto por Gordo-Monsó (Gordo-Monsó et al., 2019), ya que proporciona valores más precisos para estructuras enterradas rectangulares. Este paso no difiere conceptualmente de las metodologías previas.

4) Desarrollar un modelo sencillo de la estructura, con un marco de referencia formado por vigas rígidas articuladas en sus extremos, y una fundación de Winkler que vincule la estructura al marco de referencia (Fig. 5-1). En ausencia de estudios más detallados para determinar la rigidez de los muelles tipo Winkler, emplear el valor propuesto por Vesic (Vesic, 1963).

5) Imponer la distorsión $\gamma_{S T R U}$ al modelo de la estructura y marco de referencia para obtener los esfuerzos (Fig. 5-2, b). 


\section{ESTUDIO DE LA DISTORSIÓN EN SISTEMAS SUELO- ESTRUCTURA CON COMPORTAMIENTO NO LINEAL EN DEFORMACIÓN PLANA}

\subsection{Introducción}

Los procedimientos simplificados desarrollados hasta la fecha para evaluar el comportamiento de las estructuras subterráneas sometidas a la acción del sismo se basan en la obtención de la deformación de distorsión de la estructura $\gamma_{S T R U}$, a partir de la deformación de campo libre del terreno circundante $\gamma_{F F}$, mediante la multiplicación de esta última $\gamma_{F F}$ por el denominado coeficiente de racking $R$ (Wang, 1993), un factor que comprende todo el fenómeno de interacción suelo-estructura.

La obtención de este factor de racking $R$ suele estar basado en diversas expresiones analíticas desarrolladas por varios autores bajo hipótesis ligeramente diferentes. Entre ellas destacan las de Wang (Wang, 1993), Penzien (Penzien, 2000), Anderson (Anderson, Martin, Lam, \& Wang, 2008), y Huo (H. Huo, Bobet, Fernández, \& Ramírez, 2006). Todas estas soluciones analíticas, cuya obtención se basa en la resolución de un problema de elasticidad bidimensional, tienen obviamente como hipótesis subyacente el comportamiento lineal del terreno circundante.

Sin embargo, este no suele ser el caso de los suelos blandos en los que suelen ejecutarse las estructuras subterráneas construidas por el método de cut-and-cover. Para solicitaciones sísmicas de relativa intensidad, en muchas ocasiones los suelos blandos responderán con deformaciones angulares importantes, que se traducirán en el comportamiento no lineal de los mismos. Por lo tanto, si se pretende conseguir una metodología precisa para evaluar las deformaciones y esfuerzos producidos por la acción sísmica en estructuras subterráneas, resulta necesario elaborar un marco de análisis que tenga en cuenta el comportamiento no lineal del suelo. 
Hung (Hung, Monsees, Munfah, \& Wisniewski, 2009) y Anderson (Anderson et al., 2008) han propuesto una adaptación de los métodos de Wang (Wang, 1993) y Penzien (Penzien, 2000) para tener en cuenta este comportamiento no lineal, basándose en lo que se denomina elección de la rigidez a cortante compatible con las deformaciones (straincompatible shear modulus en inglés). En esta adaptación, en el momento de evaluar la ratio de flexibilidad relativa $F_{R}=K_{\text {suelo }} / K_{\text {estructura }}$ con el que se obtiene el coeficiente de racking $R$, se elige el módulo de cortante del suelo $G$ de tal manera que sea compatible con el nivel de deformaciones desarrollado en el campo libre $\gamma_{F F}$. Es decir, el método se fundamenta en la caracterización del suelo mediante una curva de reducción del módulo de cortante $\left(G / G_{\max }\right.$ en su forma normalizada), y en elegir como rigidez del suelo la correspondiente a la deformación de campo libre $\gamma_{F F}$.

Por otra parte Bobet (Bobet, Fernandez, Huo, \& Ramirez, 2008), partiendo de la solución analítica desarrollada por Huo (Hongbin Huo, 2005), propone un método iterativo que es conceptualmente similar al anterior, pero que en el momento de evaluar la ratio de flexibilidad relativa $F_{R}=K_{\text {suelo }} / K_{\text {estructura }}$ emplea el módulo de cortante del suelo $G$ compatible con la deformación de racking de la estructura $\gamma_{S T R U}=R \cdot \gamma_{F F}$. El razonamiento que aduce para esta variación, es que el terreno próximo a la estructura se habrá deformado tanto como esta, y que por lo tanto tiene más sentido elegir como deformación de referencia para evaluar la rigidez del terreno la deformación de la propia estructura. En este método, puesto que para conocer la rigidez del suelo es necesario conocer la deformación de racking de la estructura, y puesto que esta depende de la flexibilidad relativa $F_{R}$, que a su vez depende de la rigidez del suelo que se buscaba en primera instancia, Bobet propone un esquema iterativo que se resume en los pasos siguientes:

1) Se hace un primer análisis del coeficiente de racking $R$ basado en el módulo de cortante del suelo para pequeñas deformaciones $G_{0}=G_{\max }$, obteniéndose un coeficiente de racking $R_{0}$.

2) Se evalúa la deformación del terreno próximo a la estructura como $\gamma_{S T R U}=R \cdot \gamma_{F F}$ y se escoge la nueva rigidez del suelo $G_{1}$ basada en esta deformación.

3) Se calcula de nuevo el coeficiente de racking con esta nueva rigidez del suelo $G_{1}$, obteniéndose un coeficiente de racking $R_{1}$. 
4) Se repite el proceso iterativamente hasta que la variación del coeficiente de racking sea pequeña (menor del 1\%).

\subsection{Propósito de la solución propuesta}

El propósito de este capítulo es proponer un método, basado en la solución analítica del coeficiente de racking $R$ presentada en el capítulo $\S 4$ de esta tesis, para tener en cuenta el comportamiento no lineal del suelo que rodea la estructura.

Una vez desarrollado el método, se comparan los resultados predichos por este con los obtenidos mediante una colección de cálculos numéricos mediante elementos finitos, así como con los métodos desarrollados por Hung y Anderson (Anderson et al., 2008; Hung et al., 2009), y por Bobet (Bobet et al., 2008).

\subsection{Solución propuesta para considerar el comportamiento no lineal del suelo}

Partiendo del modelo conceptual de bloques propuesto en el capítulo $\S 4$ de esta tesis, y en particular del concepto de su aplicación recursiva en diferentes perímetros de control, se puede plantear una solución semi-analítica para tratar el comportamiento no lineal del terreno, y valorar como afecta la plastificación del suelo circundante a las deformaciones de la estructura.

Tal y como se ha indicado anteriormente, una metodología habitual para describir el comportamiento no lineal del terreno consiste en caracterizarlo mediante la curva de reducción del módulo de cortante $G / G_{\max }$ del mismo, es decir, obtener el módulo de cortante secante $G_{\text {sec }}$ para diferentes valores de la deformación de cortante $\gamma$. De hecho, muchos de los programas de cálculo empleados en los análisis de respuesta del suelo bajo solicitación sísmica (GRA, Ground Response Análisis), tales como SHAKE (Schnabel, Lysmer, \& Seed, 1972) y Deepsoil (Hashash et al., 2016), emplean estas curvas como elemento fundamental para describir el comportamiento del suelo.

Por otra parte, en base a los perfiles de racking que se obtuvieron en el apartado $\S 4.4$, sabemos que la deformación del terreno se ve modificada por la estructura, y que esta modificación se produce de manera gradual, tal y como se muestra en la (Fig. 6-1) para un caso particular. A grandes distancias de la estructura, el terreno se distorsiona 
tanto como en campo libre $\gamma_{F F}(R \approx 1)$, mientras que según nos acercamos a una distancia $x_{j} / b$ de la estructura el terreno se distorsiona una cantidad $\gamma_{j}=R j \cdot \gamma_{F F}(R \neq 1)$.

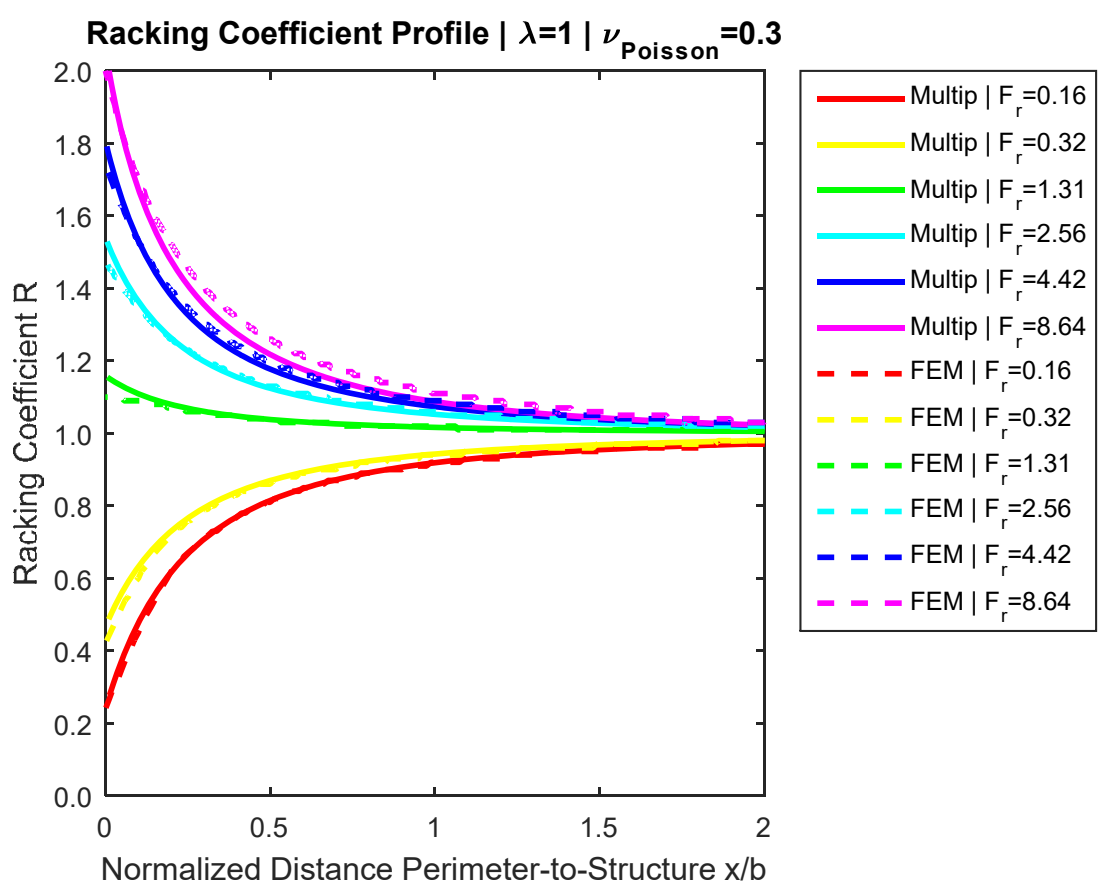

Fig. 6-1. Perfil de coeficiente de racking.

Por lo tanto, un método racional para incorporar el comportamiento no lineal del suelo en el método propuesto en el capítulo $\S 4$ podría ser el realizar el mismo cálculo con unas propiedades secantes del suelo $G_{s e c}$ que tuvieran en cuenta cual es el nivel de deformación que se ha alcanzado en cada punto del terreno.

Puesto que sabemos cuál es la deformación de distorsión de cada perímetro de control gracias al perfil del coeficiente de racking, se podría proceder en base al siguiente procedimiento iterativo para deformaciones incrementales, similar a un procedimiento de tipo pushover (Krawinkler, 1996), partiendo de un estado de deformación muy pequeño $\gamma_{F F, 0}$, e incrementándolo progresivamente $\left(\gamma_{F F, 1}, \gamma_{F F, 2}, \ldots \gamma_{F F, n,}\right)$, hasta alcanzar la deformación de campo libre solicitante $\gamma_{F F}$ (Fig. 6-2):

1) Obtener en un primer análisis el coeficiente de racking $R_{0}$, y el perfil del coeficiente de racking $R_{j, 0}$, para deformaciones muy pequeñas de campo libre $\gamma_{F F, 0}$, es decir, con un módulo de cortante del suelo $G_{\max }$ constante en todos los perímetros de control. 
2) Obtener la deformación de cada perímetro de control en términos absolutos $\gamma \jmath, 0$, como el producto de ese primer perfil del coeficiente de racking y la deformación de campo libre como $\gamma_{j, 0}=R j, 0 \cdot \gamma_{F F, 0}$.

3) Evaluar el módulo de cortante $G_{j}$ que le corresponde a cada perímetro de control para esa deformación $\gamma_{j}, 0$, es decir, entrar para cada perímetro $j$ en la curva de reducción del módulo de cortante $G_{j, 0}=G / G_{\max }\left(\gamma_{j, 0}\right)$.

4) Repetir el cálculo del coeficiente de racking y del perfil de racking con el módulo de cortante $G_{j}$ actualizado del paso anterior para cada perímetro $j$.

5) Incrementar el valor de deformación del suelo hasta $\gamma_{F F, 1}$, y repetir los pasos anteriores sucesivamente hasta que se alcance la deformación de campo libre solicitante $\gamma_{F F}$ deseada.

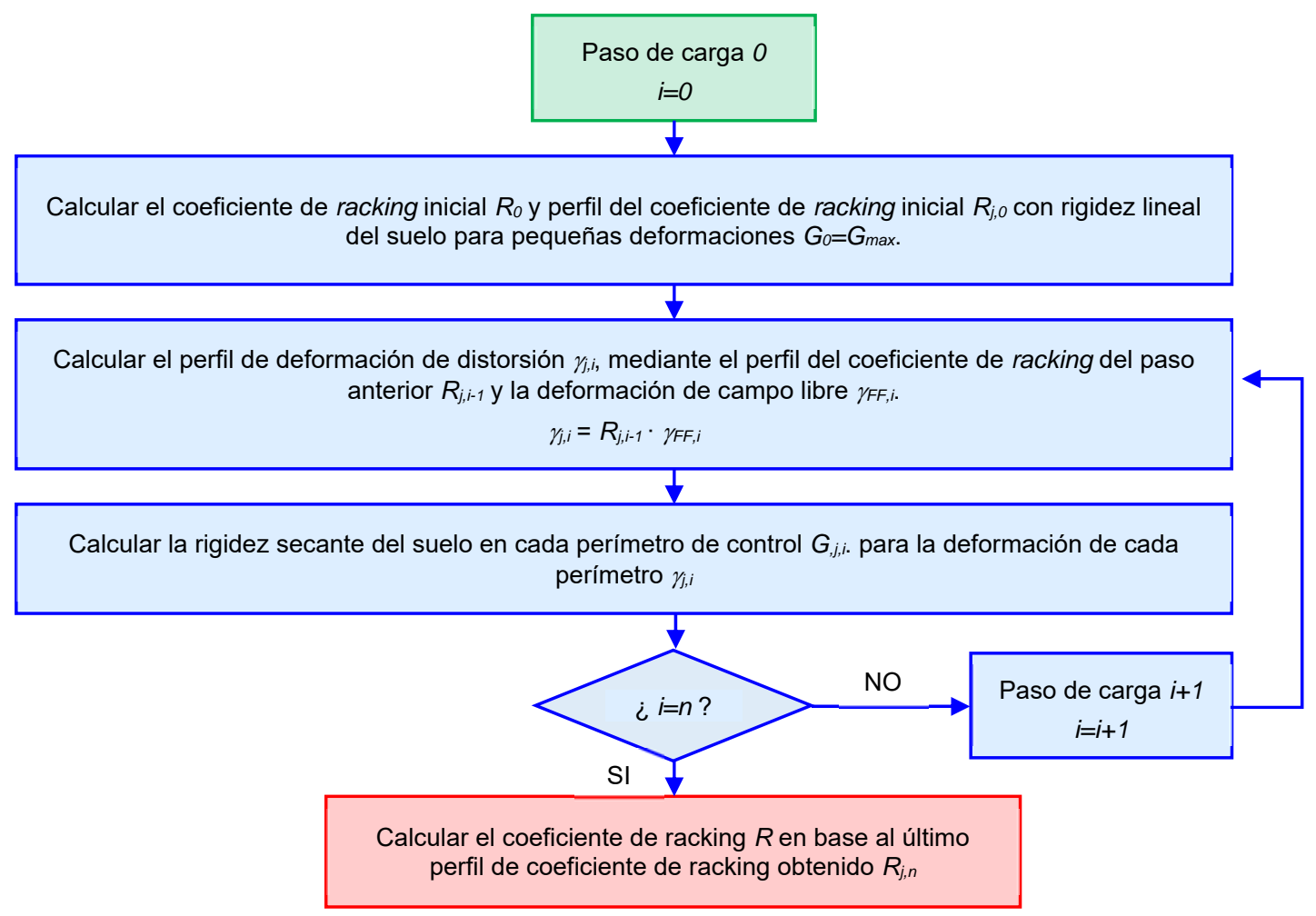

Fig. 6-2. Diagrama de flujo del procedimiento propuesto para considerar el comportamiento no lineal del terreno. 

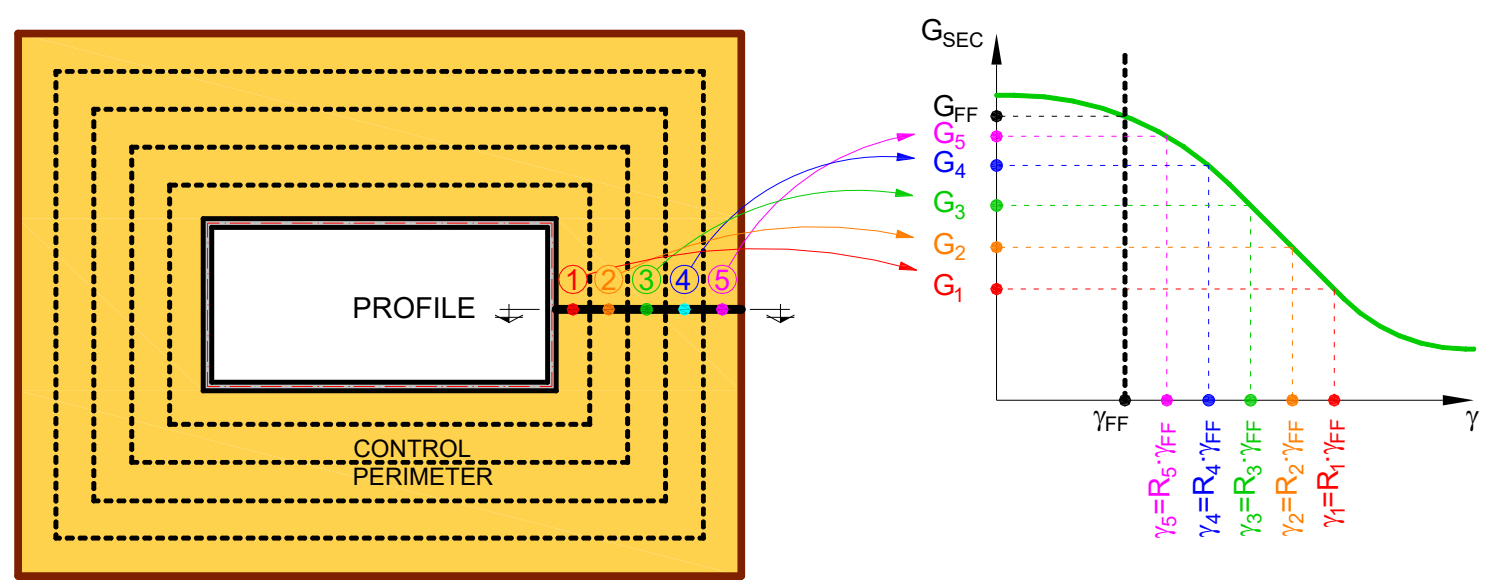

Fig. 6-3. Concepto de perfil de racking no lineal.

Conceptualmente, el procedimiento propuesto se encuentra a medio camino entre el planteado por Hung y Anderson (que considera para a todo el suelo la rigidez correspondiente a zonas lejanas a la estructura), y planteado por Bobet (que considera para todo el terreno la rigidez correspondiente a zonas cercanas a la estructura).

\subsection{Verificación de la solución propuesta}

\subsubsection{Parámetros del modelo de elementos finitos no lineal}

Para evaluar la adecuación y precisión de la solución propuesta en el apartado $\S 6.3$, se han comparado los resultados de esta solución frente a los obtenidos con una serie de modelos de elementos finitos (MEF). En particular, se ha desarrollado una colección de análisis del tipo pushover (empuje incremental) en el que se ha sometido a un conjunto suelo-estructura, similar al empleado en los capítulos $\S 4$ y $§ 5$ de esta tesis, a un estado tensional de cortante puro. Es decir, se ha analizado una estructura tipo marco rectangular rodeada por un bloque de suelo concéntrico, y se ha sometido el perímetro exterior de suelo a tensiones $\tau$ incrementales hasta alcanzar una deformación de campo libre $\gamma_{F F}=3 \cdot 10^{-3}=0,3 \%$.

Los sistemas analizados, corresponden a un rango de estructuras caracterizadas por flexibilidades relativas $F_{R}$ entre 0 y 10 , proporciones geométricas $\lambda=b / d$ (ancho/canto) entre 1 y 3, y nueve tipos de suelo, correspondientes a las combinaciones de rigideces baja, media, y alta, y coeficientes de Poisson $v$ entre 0,2 y 0,4. Para obtener unos resultados ordenados en una base de clasificación común entre todos los métodos (Hung y Anderson, Bobet, y el método propuesto en esta tesis), se han caracterizado las 
estructuras en base a su flexibilidad inicial que se ha denominado $F_{R, 0}$, es decir, en base a la rigidez relativa del suelo para deformaciones pequeñas $G_{0}=G_{\max }$.

Los modelos de elementos finitos se han implementado en el programa OpenSEES (McKenna, Scott, \& Fenves, 2010), y representan el problema de un medio suficientemente grande, isótropo, y homogéneo y comportamiento inelástico, que cuenta con una estructura rectangular embebida en su centro. El suelo se ha mallado con elementos cuadriláteros de 4 nodos y comportamiento en deformaciones planas, mientras que la discretización de la estructura se ha realizado con elementos viga de 2 nudos, los cuales se han vinculado frente a desplazamientos horizontales y verticales a los nudos de suelo adyacentes, con el propósito de representar un comportamiento completamente vinculado de la interfaz hormigón-suelo. Los bordes exteriores del suelo no presentan ningún tipo de restricción al movimiento, y están sujetos a un estado de cortante puro de valor de tensiones tangenciales $\tau$. Únicamente el nudo inferior izquierdo tiene los desplazamientos $u_{x}$ y $u_{y}$ restringidos, y el nudo inferior derecho el desplazamiento $u_{y}$ restringido, de tal manera que se pueda alcanzar el equilibrio numérico al calcular (Fig. $6-4)$.
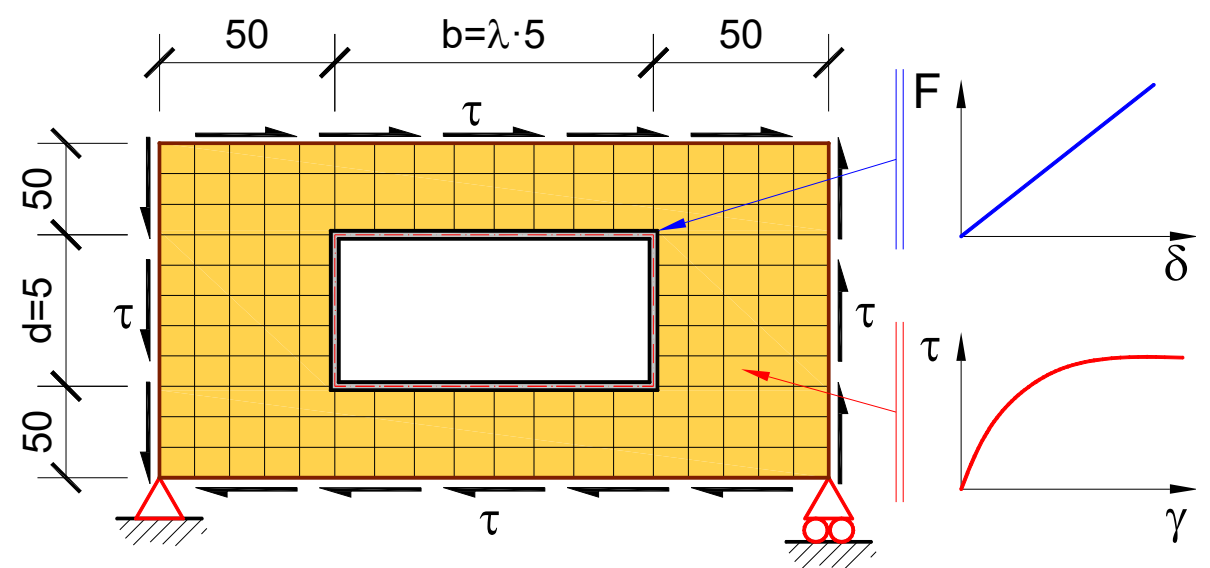

Fig. 6-4. Esquema del modelo de elementos finitos no lineal implementado.

El comportamiento no lineal del suelo se ha caracterizado mediante un modelo de plasticidad del tipo de superficies anidadas con invariante $J_{2}$ (Mróz, 1967), como el descrito en el apartado §3.6.2.2 de esta tesis. En particular, se ha empleado el modelo independiente de la presión de confinamiento PressureIndependMultiYield de OpenSEES desarrollado por Yang (Q. Gu, Conte, Yang, \& Elgamal, 2011; Quan Gu, Conte, Elgamal, \& Yang, 2009). 

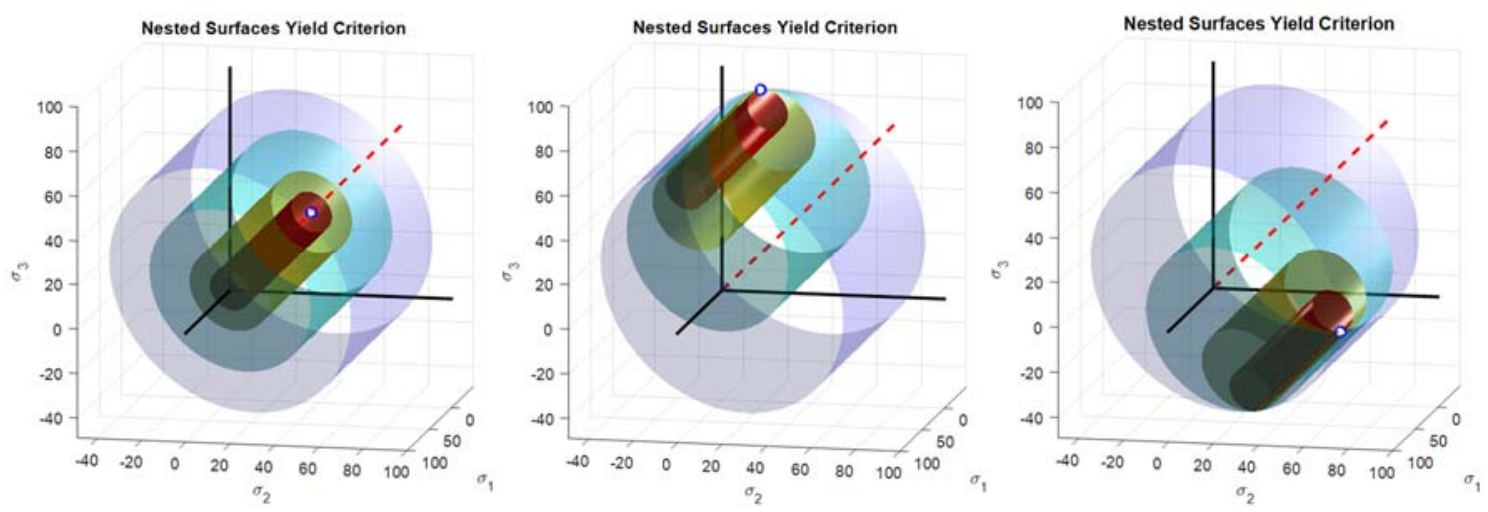

Fig. 6-5. Modelo de plastificación con endurecimiento de superficies anidadas (Mróz, 1967). (izda.)

Antes de empezar la carga. (cent.) Tras la plastificación total en una dirección. (dcha.) Tras la plastificación total en la dirección opuesta.

Este modelo, desarrollado para representar el comportamiento de suelos cohesivos, cuenta con un número finito de superficies de plastificación cilíndricas, sobre las que aplica sucesivamente el modelo de plastificación de von Mises (von Mises, 1913), para obtener un comportamiento discretizado de la plastificación en forma de sucesivos tramos elastoplásticos (Fig. 6-5).

Los sucesivos módulos de endurecimiento cuentan con valores de tal manera que la relación tensión-deformación de cortante $\tau-\gamma$ siga una ley hiperbólica como la de la ecuación (Ec. 6-1) discretizada por tramos. En esta ecuación $G_{r}$ es el módulo de cortante de referencia para pequeñas deformaciones (tangente en el origen), $\gamma$ la deformación de cortante, y $\gamma_{\max }$ la deformación de cortante para la que se alcanza el valor máximo de la tensión de cortante $\tau_{f}$, mientras que la deformación de referencia $\gamma_{r}$ viene dada por la ecuación (Ec. 6-2).

$$
\begin{gathered}
\tau=\frac{G_{r} \cdot \gamma}{1+\frac{\gamma}{\gamma_{r}}} \\
\gamma_{r}=\frac{\gamma_{\max }}{G_{r} \frac{\gamma_{\max }}{\tau_{f}}-1}
\end{gathered}
$$

El valor de la tensión de cortante de plastificación total $\tau_{f}$ (sin más endurecimiento para deformaciones mayores), viene dado por el valor de la cohesión c según la (Ec. 6-3).

$$
\tau_{f}=\frac{2 \sqrt{2}}{3} c=\frac{G_{r} \cdot \gamma_{\max }}{1+\frac{\gamma_{\max }}{\gamma_{r}}}
$$


En estas ecuaciones, y para cada uno de los casos de suelo, blando, medio, y rígido, se han empleado los parámetros resumidos en la Tabla 4-1.
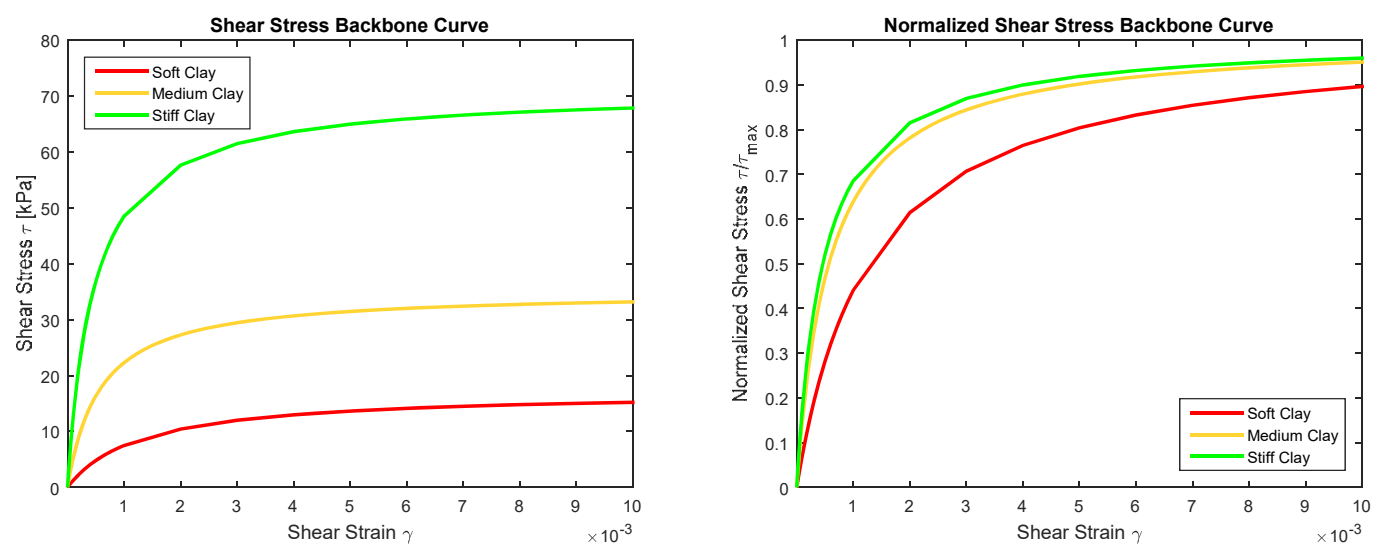

Fig. 6-6. Leyes tensión-deformación tangencial del suelo con comportamiento plástico. (izda.) Leyes $\tau-\gamma \sin$ normalizar. (dcha.) Leyes $\tau-\gamma$ normalizadas.
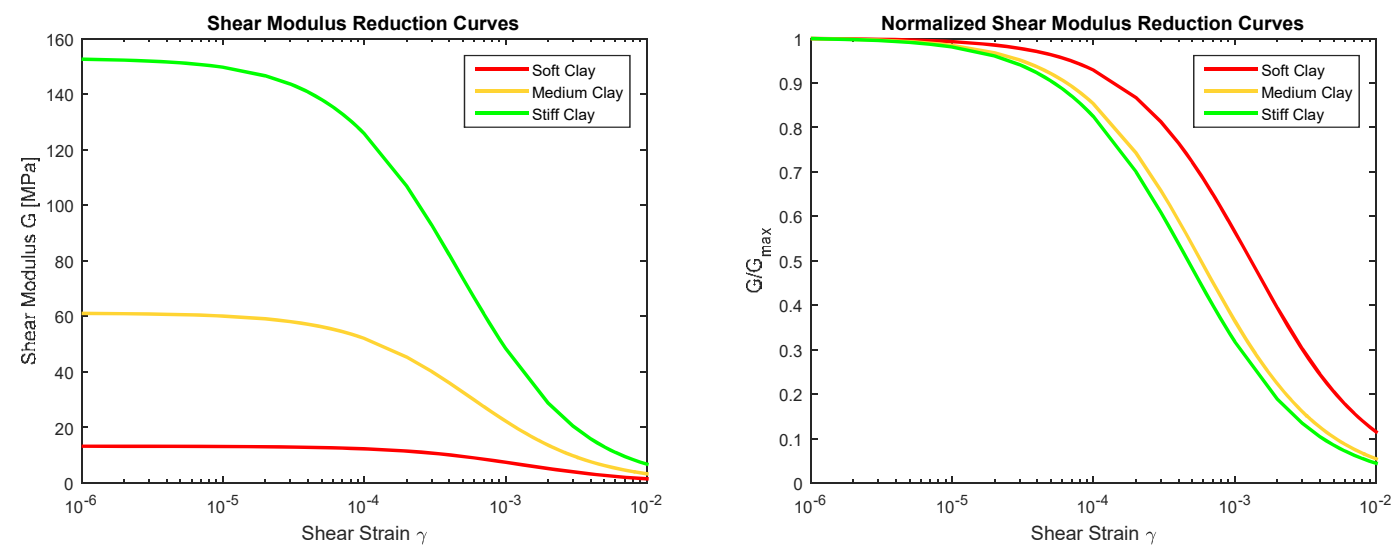

Fig. 6-7. Leyes de reducción del módulo de cortante del suelo. (izda.) Leyes $G-\gamma$ sin normalizar. (dcha.) Leyes normalizadas $G / G_{\max }$.

Las curvas tensión-deformación correspondientes a estas expresiones, son las que se presentan en escala absoluta en la (Fig. 6-5, izda.), y normalizadas a la tensión máxima (que corresponde esencialmente a la cohesión $c$ de cada material) en la (Fig. 6-5, dcha.).

\begin{tabular}{|c|c|c|c|}
\hline Parámetro & Arcilla Blanda & Arcilla Media & Arcilla Rígida \\
\hline$\rho$ Densidad & $13 \mathrm{kN} / \mathrm{m}^{3}$ & $15 \mathrm{kN} / \mathrm{m}^{3}$ & $18 \mathrm{kN} / \mathrm{m}^{3}$ \\
\hline$G_{r}$, Módulo de Cortante de Ref. & $13 \mathrm{MPa}$ & $60 \mathrm{MPa}$ & $150 \mathrm{MPa}$ \\
\hline$K_{r}$, Módulo Volumétrico de Ref. & $65 \mathrm{MPa}$ & $300 \mathrm{MPa}$ & $750 \mathrm{MPa}$ \\
\hline$c$, Cohesión & $18 \mathrm{kPa}$ & $37 \mathrm{kPa}$ & $75 \mathrm{kPa}$ \\
\hline$\gamma_{\max }$, Deformación Máxima & 0,1 & 0,1 & 0,1 \\
\hline
\end{tabular}

Tabla 6-1. Parámetros de definición de los materiales.

De manera similar, la figura (Fig. 6-7, izda.) muestra las curvas de reducción del módulo de cortante de cada suelo en escala absoluta, y la figura (Fig. 6-7, dcha.) las curvas 
de reducción normalizadas al valor del módulo de cortante máximo en el origen Gmax para cada una de ellas.

En lo que respecta a la estructura enterrada, y con el propósito de realizar una comparación ordenada, los marcos analizados para cada caso de terreno tienen tamaños constantes, y las diferentes flexibilidades relativas $F_{R}$ se han obtenido variando el espesor de las losas y de los muros, que se han supuesto de hormigón con módulo de Young $E_{c}=30 \mathrm{GPa}$. La Tabla 6-2 indica los espesores adoptados correspondientes a cada caso.

En total, se han realizado un total de 270 análisis pushover no lineales (3 geometrías $\lambda, 3$ comportamientos del suelo $G / G_{\max }, 3$ coeficientes de Poisson $v$, y 10 flexibilidades relativas $F_{R}$ ), con deformaciones en campo libre entre $1 \cdot 10^{-6} \leq \gamma_{F F} \leq 3 \cdot 10^{-3}$.

\begin{tabular}{|c|c|c|c|c|c|c|c|c|c|c|c|}
\hline \multicolumn{12}{|c|}{ Espesores de losas $t_{b}$ y muros $t_{w}$ de los modelos [m] } \\
\hline \multirow{2}{*}{ Geometría } & \multirow{2}{*}{ Suelo } & \multicolumn{10}{|c|}{ Ratio de Flexibilidad Relativa $F_{R}$} \\
\hline & & $\mathbf{0 , 1}$ & $\mathbf{0 , 2 5}$ & 0,5 & $\mathbf{0 , 7 5}$ & 1 & 2 & 4 & 6 & 8 & 10 \\
\hline \multirow{3}{*}{$\begin{array}{c}\lambda=1 \\
b=5 \mathrm{~m} \\
d=5 \mathrm{~m}\end{array}$} & Blando & 0,81 & 0,60 & 0,48 & 0,42 & 0,38 & 0,30 & 0,24 & 0,21 & 0,19 & 0,18 \\
\hline & Medio & 1,35 & 1,00 & 0,79 & 0,69 & 0,63 & 0,50 & 0,40 & 0,35 & 0,31 & 0,29 \\
\hline & Rígido & 1,84 & 136 & 1,08 & 0,94 & 0,85 & 0,68 & 0,54 & 0,47 & 0,43 & 0,40 \\
\hline \multirow{3}{*}{$\begin{array}{c}\lambda=2 \\
b=10 \mathrm{~m} \\
d=5 \mathrm{~m}\end{array}$} & Blando & 1,17 & 0,87 & 0,69 & 0,60 & 0,55 & 0,43 & 0,34 & 0,30 & 0,27 & 0,25 \\
\hline & Medio & 1,96 & 1,44 & 1,14 & 1,00 & 0,91 & 0,72 & 0,57 & 0,50 & 0,45 & 0,42 \\
\hline & Rígido & 2,65 & 0,96 & 1,55 & 1,36 & 1,23 & 0,98 & 0,78 & 0,68 & 0,62 & 0,57 \\
\hline \multirow{3}{*}{$\begin{array}{c}\lambda=3 \\
b=15 \mathrm{~m} \\
d=5 \mathrm{~m}\end{array}$} & Blando & 1,48 & 1,09 & 0,87 & 0,76 & 0,69 & 0,55 & 0,43 & 0,38 & 0,34 & 0,32 \\
\hline & Medio & 2,46 & 1,81 & 1,44 & 1,26 & 1,14 & 0,91 & 0,72 & 0,63 & 0,57 & 0,53 \\
\hline & Rígido & 3,34 & 2,46 & 1,96 & 1,71 & 1,55 & 1,23 & 0,98 & 0,85 & 0,78 & 0,72 \\
\hline
\end{tabular}

Tabla 6-2. Espesores de losa y muro de los modelos estudiados.

\subsubsection{Análisis de resultados}

La comparación detallada del método propuesto en el apartado $§ 6.3$ de esta tesis, y de los modelos de elementos finitos para cada uno de los 27 casos analizados, puede resultar excesivamente largo. Puesto que los resultados obtenidos en cada uno de los 27 casos de terreno y geometría presentan tendencias muy similares, se analiza a continuación en detalle tan sólo uno de ellos, y se refiere al lector al anexo §B de esta tesis, donde se presentan los gráficos correspondientes a los resultados de todos los casos analizados.

El caso que se estudia a continuación corresponde a unos parámetros de suelo blando según lo indicado en la Tabla $6-1$, con proporciones geométricas $\lambda=b / d=1$, y coeficiente de Poisson del terreno $v=0$,3. Para este caso, se estudia primero la correspondencia entre el método de análisis propuesto en el apartado $§ 6.3$ y los resultados de los análisis por elementos finitos MEF. Posteriormente, se estudia la correspondencia 
de estos dos resultados con el método propuesto por Hung y Anderson (Anderson et al., 2008; Hung et al., 2009), y el método propuesto por Bobet (Bobet et al., 2008).

\subsubsection{Comparación del método propuesto frente a los resultados de modelos numéricos}

Para presentar los resultados de los cálculos realizados se han elegido tres formatos. En primer lugar, y para cada paso de carga del análisis pushover, se comparan las deformaciones de distorsión absolutas obtenidas en la estructura subterránea $\gamma_{\text {Tunnel }}$ frente a las deformaciones de distorsión correspondientes de campo libre $\gamma_{F F}$, tomadas como las del perímetro exterior de suelo. La comparación entre los resultados de ambos métodos de análisis puede verse en la figura (Fig. 6-8), en la que las líneas macizas representan los resultados del método propuesto en esta tesis, y las líneas discontínuas los resultados de los modelos de elementos finitos.

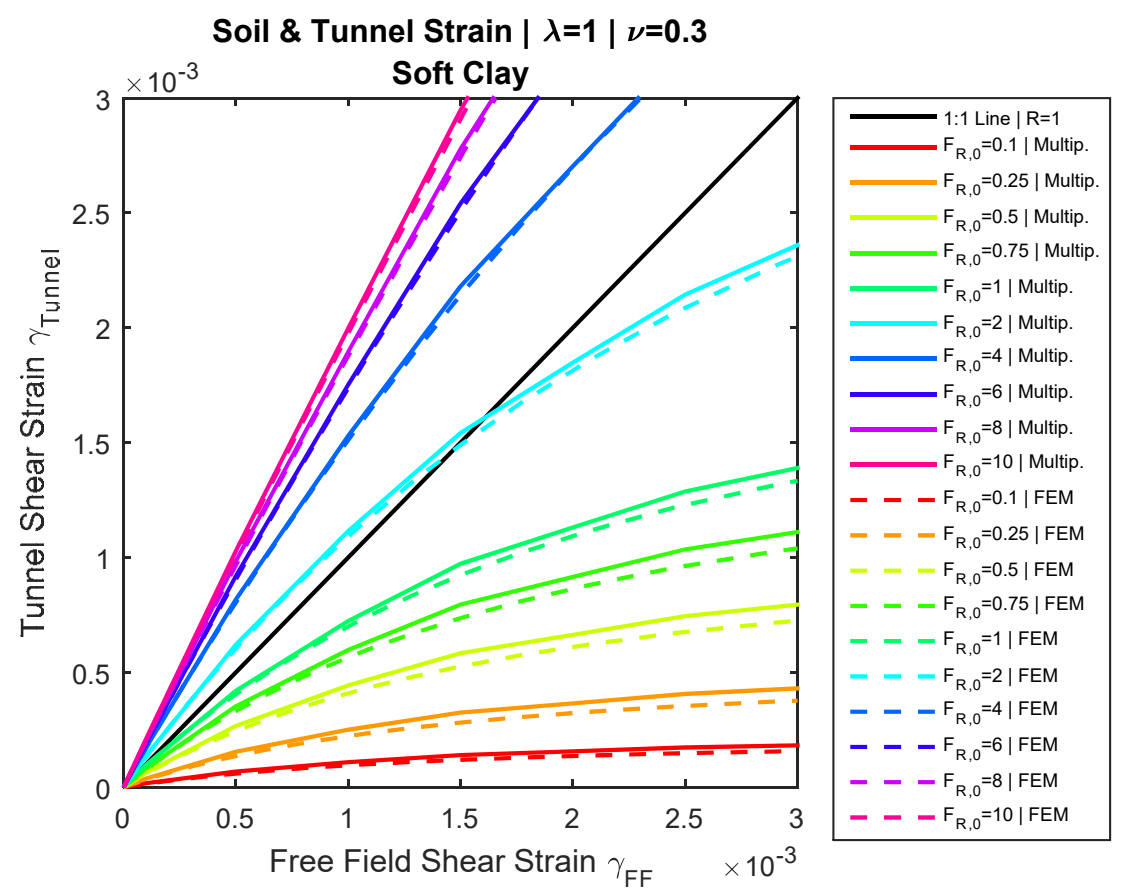

Fig. 6-8. Relación de deformaciones de la estructura enterrada $\gamma_{T u n n e l}$ y de campo libre $\gamma_{F F}$.

Esta figura (Fig. 6-8), que muestra gráficamente cuanto más se deforma la estructura enterrada $\gamma_{\text {Tunnel }}$ que el campo libre $\gamma_{F F}$, es una forma alternativa a la habitual de representar el coeficiente de racking. Si el comportamiento del suelo fuera lineal, en esta figura las curvas representadas serían rectas que pasan por el origen $\left(\gamma_{\text {Tunnel }}=0\right.$ para $\gamma_{F F}=0$ ), y la pendiente de las mismas correspondería precisamente al coeficiente de racking $R$. De hecho, se ha dibujado una recta negra de pendiente 1:1 que representa el coeficiente de racking unitario, y que para el caso de terreno lineal correspondería una 
flexibilidad relativa $F_{R}=1$ (rigidez de la estructura igual a la rigidez del terreno). Coeficientes de racking $R>1$ corresponderían a la región por encima de la recta $1: 1, y$ coeficientes de racking menores $R<1$ a la región por debajo de la recta 1:1.

Como puede apreciarse, según evoluciona la deformación de distorsión de campo libre $\gamma_{F F}$ que solicita al sistema, la pendiente que van adoptando todas las curvas tiende a hacerse más horizontal, con respecto a la pendiente inicial con la que se partía en origen.

Como caso particular, cabe resaltar la trayectoria de la curva correspondiente a una ratio de flexibilidad $F_{R, 0}=2$. Puesto que $F_{R, 0}>1$, a este caso le corresponde un coeficiente de racking $R>1$, que se manifiesta en dicha curva por estar por encima de la recta negra 1:1 para deformaciones pequeñas. Sin embargo, se aprecia como a partir de una deformación de campo libre de aproximadamente $\gamma_{F F}=1,5 \cdot 10^{-3}$, la curva $F_{R, 0}=2$ cruza la recta $1: 1$, y pasa a estar por debajo de la línea $1: 1$, es decir se ha convertido en una estructura a la que le corresponde un coeficiente de racking $R<1$.

Esta curvatura y cambio de pendiente de las trayectorias $\gamma_{\text {Tunnel- } \gamma_{F F} \text { pone de }}$ manifiesto la plastificación progresiva que se produce en el terreno del sistema sueloestructura. En efecto, puesto que el terreno se comporta no linealmente, y va progresando en su estado de plastificación según evolucionan las deformaciones de campo libre $\gamma_{F F}$, mientras que la rigidez de la estructura permanece constante, se produce una "rigidización relativa" de la estructura, en el sentido de que en la flexibilidad relativa $F_{R}=K_{\text {Suelo }} / K_{\text {Tunel }}$ el numerador disminuye.

Finalmente, y como puede apreciarse en la (Fig. 6-8), el ajuste entre los resultados obtenidos por el método propuesto en esta tesis, y los correspondientes a los modelos de elementos finitos es notable.

En segundo lugar, también se pueden analizar los resultados estudiando cómo evoluciona el coeficiente de racking no lineal $R_{N L}$ según se incrementa la deformación de campo libre $\gamma_{F F}$ que solicita al sistema suelo-estructura. Esta evolución se puede observar en la figura (Fig. 6-9), en la que se representa en abscisas la deformación angular $\gamma_{F F}, y$ en ordenadas el coeficiente de racking no lineal $R_{N L}$ que resulta de dividir la deformación en la estructura enterrada $\gamma_{\text {Tunnel }}$ entre la deformación de campo libre $\gamma_{F F}$. En esta figura cada curva corresponde a la trayectoria del coeficiente de racking no lineal $R_{N L}$ para diferentes valores de la ratio de flexibilidad relativa inicial $F_{R, 0}$, es decir flexibilidades de la estructura relativas a la rigidez del suelo para pequeñas deformaciones $G_{\max }=G_{0}$. 


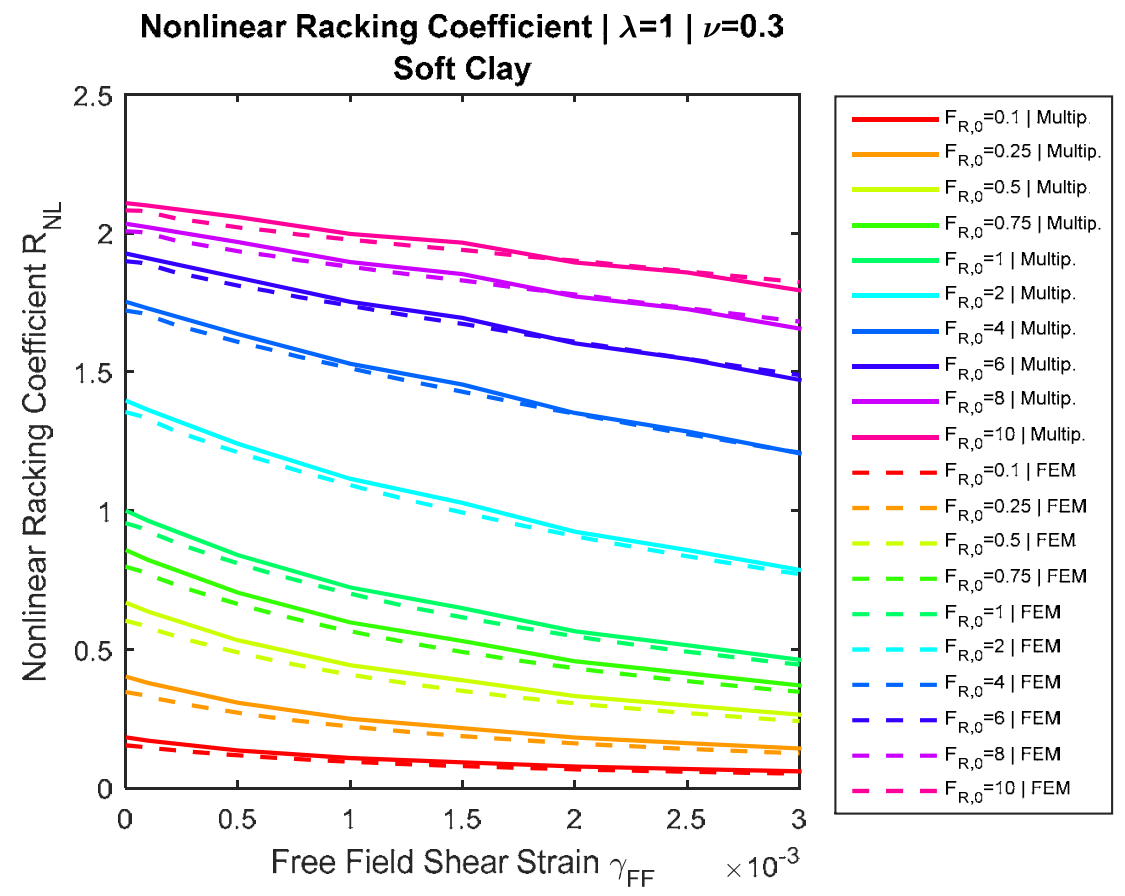

Fig. 6-9. Evolución del coeficiente de racking no lineal $\boldsymbol{R}_{N L}$ frente al incremento de deformaciones de campo libre $\gamma_{F F}$.

Al igual que en el gráfico anterior (Fig. 6-8), en la figura (Fig. 6-9) puede observarse como la rigidización relativa de la estructura, a medida que aumenta la deformación del suelo circundante, y a medida que este progresa en su estado de plastificación, proporciona coeficientes de racking siempre menores que el inicial. Si, en particular, se observa la evolución de la curva correspondiente a $F_{R, 0}=2$ puede verse como a partir de $\gamma_{F F}=1,5 \cdot 10^{-3}$ se pasa de un coeficiente de racking no lineal $R_{N L}>1$ (la estructura se deforma más que el suelo) a uno $R_{N L}<1$ (la estructura se deforma menos que el suelo).

La correspondencia entre los valores obtenidos mediante el método propuesto en esta tesis (líneas macizas), y los valores obtenidos mediante los análisis de elementos finitos (líneas punteadas) es notable.

Por último, podemos analizar los resultados obtenidos en forma de una curva tradicional del coeficiente de racking, en la que, como en la (Fig. 6-10), se representan en abscisas las ratios de flexibilidad relativa $F_{R, 0}$ (calculadas con propiedades del suelo para pequeñas deformaciones), y en ordenadas el valor del coeficiente de racking no lineal obtenido $R_{N L}$. En la figura se han representado varias curvas que corresponden a diferentes valores de la deformación de campo libre $\gamma_{F F}$. 


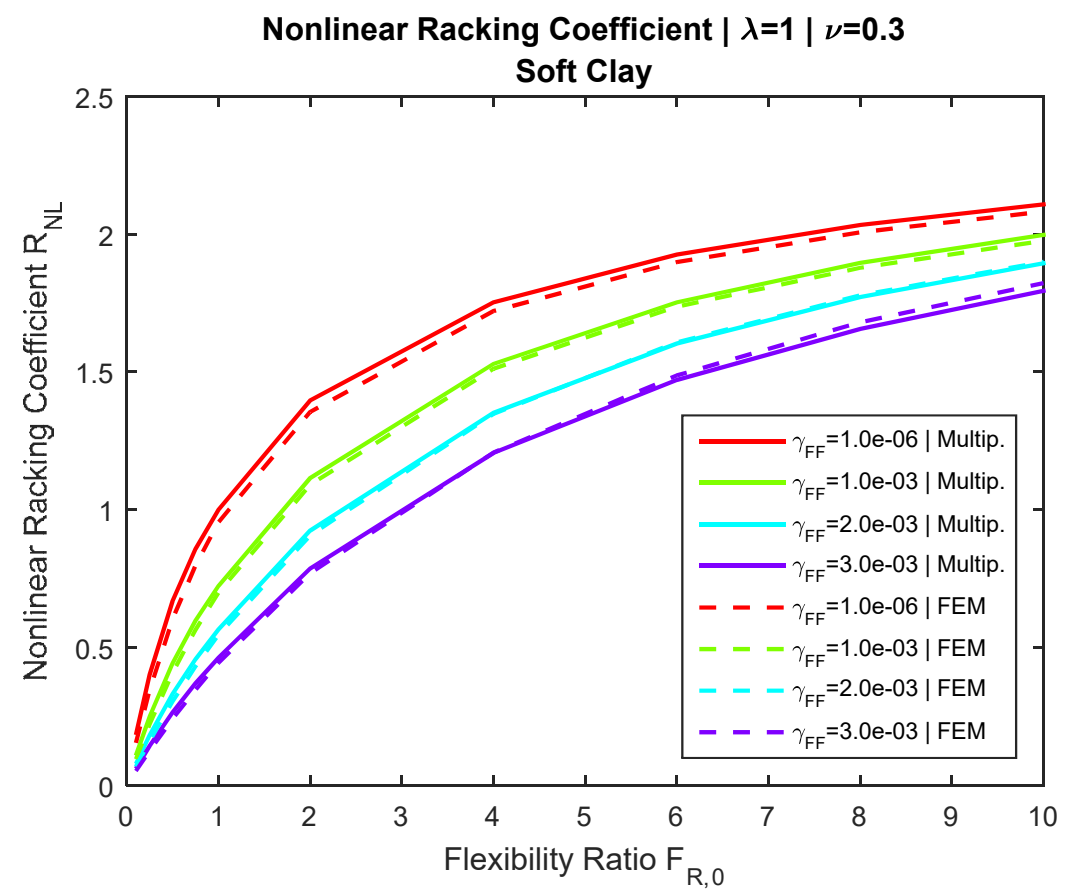

Fig. 6-10. Coeficiente de racking no lineal $\boldsymbol{R}_{N L}$ en función de la ratio de flexibilidad relativa inicial

$F_{R, 0}$ para diferentes deformaciones de campo libre $\gamma_{F F}$.

Como puede apreciarse en la (Fig. 6-10), los coeficientes de racking no lineales $R_{N L}$ reducen su valor con respecto al inicial que corresponde a deformaciones muy pequeñas. Este fenómeno se produce para todos los valores de la ratio de flexibilidad relativa $F_{R, 0}$ (basada en la rigidez del terreno para pequeñas deformaciones $G_{\max }$ ).

La correspondencia entre los valores obtenidos mediante el método propuesto en esta tesis (líneas macizas), y los valores obtenidos mediante los análisis de elementos finitos (líneas punteadas) es notable.

Cuantitativamente, podemos medir la precisión de la metodología propuesta en esta tesis comparando los valores del coeficiente de racking no lineal $R_{N L}$ obtenidos por la formulación descrita en el apartado §6.3, y los resultados obtenidos mediante los análisis numéricos de elementos finitos. La (Fig. 6-11) muestra esta relación de valores obtenidos con el método propuesto e esta tesis y los análisis MEF.

Como se puede apreciar, los resultados se ajustan con gran precisión, la cual está en el orden del \pm 15 - $20 \%$, y mejora al orden del $\pm 5 \%$ - $10 \%$ para las estructuras más flexibles. 


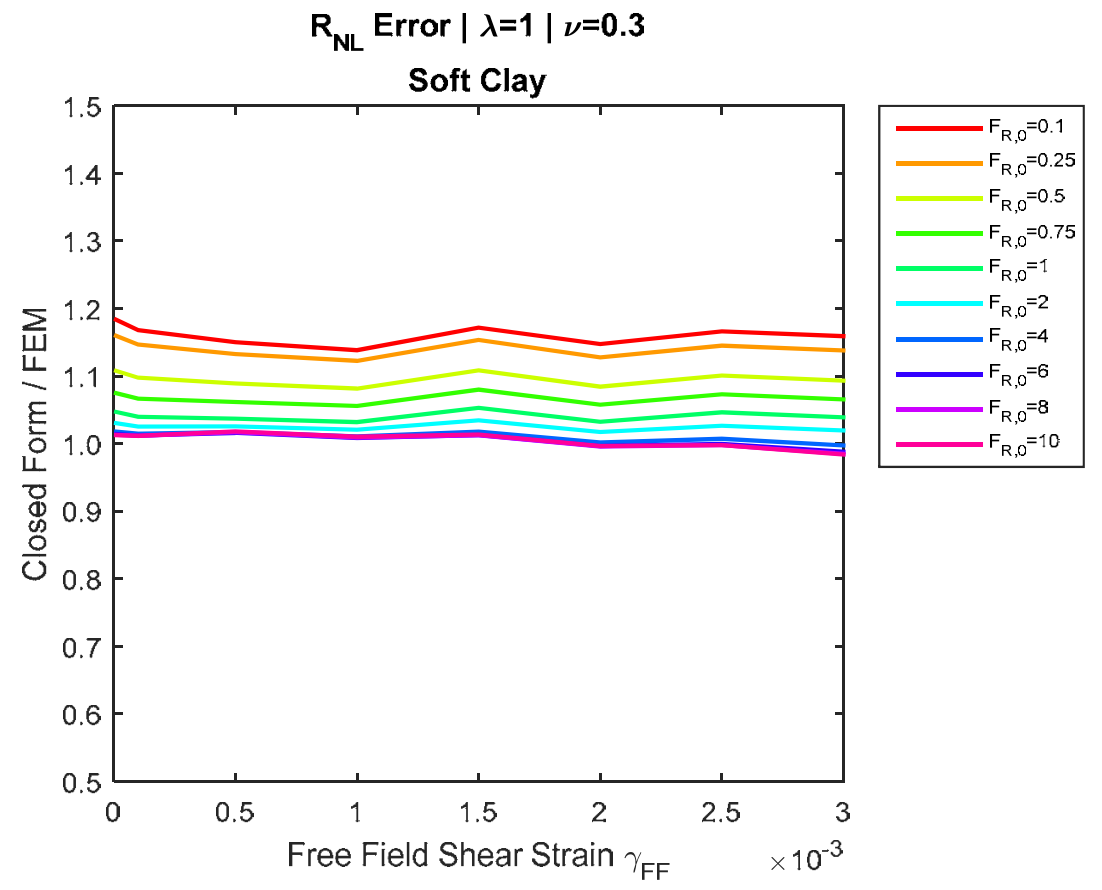

Fig. 6-11. Máximo error del valor del coeficiente de racking no lineal $\boldsymbol{R}_{N L}$ medido como relación entre el obtenido con el método propuesto en esta tesis y con análisis numérico MEF.

\subsubsection{Comparación del método propuesto frente a los métodos de otros autores}

Tal y como se ha comentado en el apartado $§ 6.1$, hasta el momento existen dos enfoques diferentes para tratar de manera simplificada el fenómeno de la plastificación del terreno. Anderson y Hung (Anderson et al., 2008; Hung et al., 2009) proponen evaluar el coeficiente de flexibilidad $F_{R}$ en función del módulo de cortante $G$ del suelo compatible con la deformación de campo libre $\gamma_{F F}$. Por el contrario, Bobet (Bobet et al., 2008) propone evaluar el coeficiente de flexibilidad $F_{R}$ en función del módulo de cortante $G$ del suelo compatible con la deformación del terreno cercano a la estructura, es decir $R \cdot \gamma_{F F}$.

Puesto que, para una misma estructura, y dado un nivel de deformación de campo libre $\gamma_{F F}$, el módulo de cortante $G$ calculado según cada autor es diferente, y en consecuencia la caracterización de la flexibilidad relativa de esa estructura $F_{R}$ será diferente, para poder comparar los resultados obtenidos con los métodos de cada uno de estos autores, con el método propuesto en esta tesis, y con los modelos de elementos finitos, se ha optado por establecer el siguiente un criterio común:

- Para todos los casos, la flexibilidad relativa $F_{R}$ de una estructura se caracteriza refiriéndose a las propiedades elásticas del suelo, es decir $F_{R}=K_{S U E L O} / K_{S T R U}$ se evalúa con un módulo de cortante para deformaciones 
pequeñas $G=G_{\max }$. Esta ratio de flexibilidad relativa se denomina en este estudio $F_{R, 0}$, y es el valor en base al cual se ordenan los gráficos.

- Para calcular el coeficiente de racking mediante el método de Hung y Anderson (Anderson et al., 2008; Hung et al., 2009), se entra en la expresión analítica de Wang (Wang, 1993) con una flexibilidad que

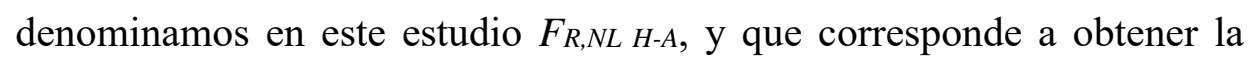
rigidez del suelo con un módulo de cortante compatible con la deformación de campo libre, es decir $G_{N L H-A}=G\left(\gamma_{F F}\right)$.

- Para calcular el coeficiente de racking mediante el método de Bobet (Bobet et al., 2008) se entra en la expresión analítica de Wang (Wang, 1993) con una flexibilidad que denominamos en este estudio $F_{R, N L}$ Bobet, y que corresponde a obtener la rigidez del suelo con un módulo de cortante compatible con la deformación de la estructura, es decir el módulo de cortante $G_{N L}$ Bobet $=G\left(R \cdot \gamma_{F F}\right)$. Para evaluar el coeficiente de racking $R$ de acuerdo con el método propuesto por Bobet se han realizado 3 iteraciones de acuerdo al esquema descrito en el apartado $§ 6.1$.

La figura (Fig. 6-12) muestra los resultados, obtenidos por los 4 métodos (Hung y Anderson, Bobet, el propuesto en esta tesis, y los modelos MEF), en términos de deformaciones de distorsión obtenidas en la estructura $\gamma_{\text {Tunnel }}$ para diferentes valores de deformación de campo libre $\gamma_{F F}$. Como se puede comprobar, el método de evaluar la no linealidad del terreno propuesto por Hung y Anderson (líneas con triángulos) se ajusta razonablemente bien a los resultados numéricos MEF para estructuras rígidas $\left(F_{R, 0}<1\right)$ mientras que arroja resultados algo más discordantes para las estructuras flexibles $\left(F_{R, 0}>1\right)$. Justo al contrario, el método propuesto por Bobet (líneas con cuadrados) se separa notablemente de los resultados numéricos MEF para el caso de estructuras rígidas $\left(F_{R, 0}<1\right)$, mientras que proporciona un buen ajuste para las estructuras más flexibles $\left(F_{R, 0}>1\right)$. Finalmente, como ya se había notado en el apartado $\$ 6.4 .2 .1$, el método propuesto en esta tesis se ajusta muy bien a los resultados numéricos MEF para todo el rango de flexibilidades relativas $F_{R, 0}$. 


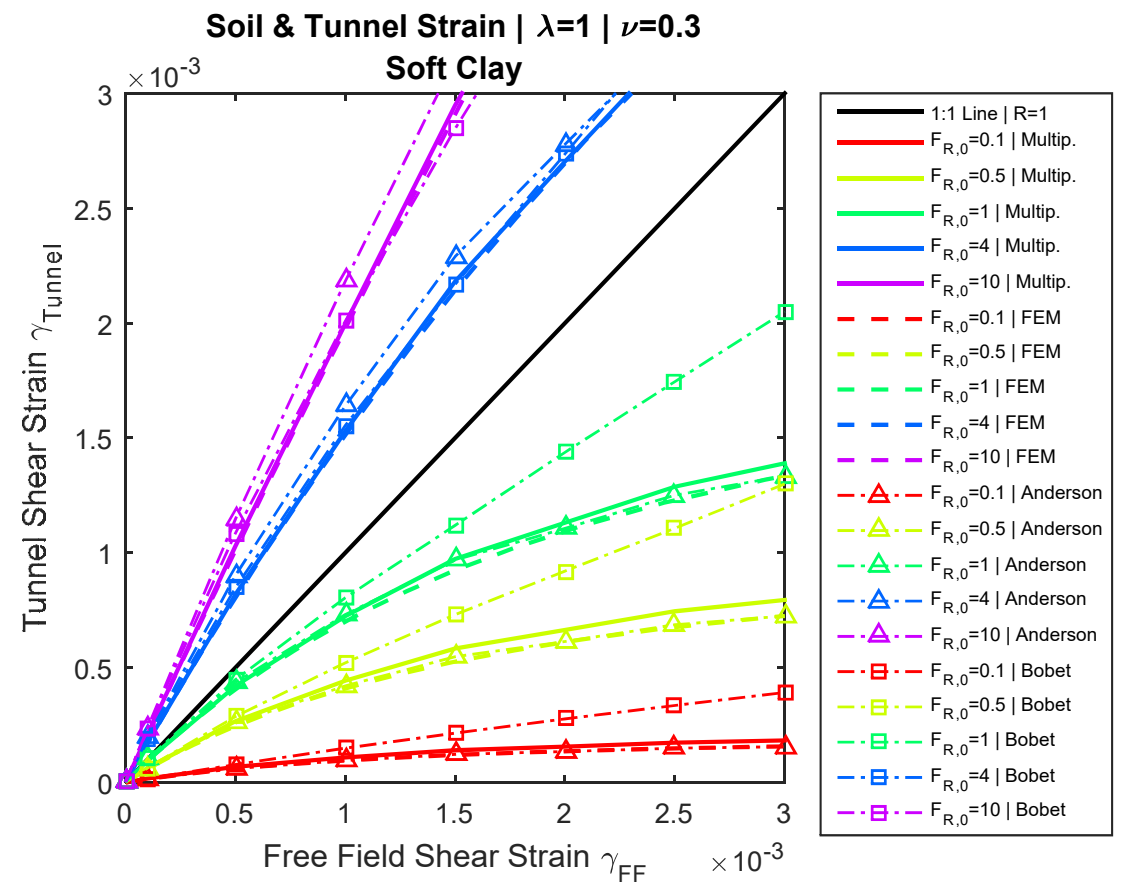

Fig. 6-12. Relación de deformaciones de la estructura enterrada $\gamma_{\text {Tunnel }}$ y de campo libre $\gamma_{F F}$ para el método propuesto en esta tesis, los resultados MEF, el método de Hung y Anderson (Anderson et al., 2008; Hung et al., 2009), y el método de Bobet (Bobet et al., 2008).

Si comparamos, como se hizo en el apartado §6.4.2.1, las predicciones de los 4 métodos acerca de cómo evoluciona el coeficiente de racking no lineal $R_{N L}$ según evoluciona la deformación de campo libre $\gamma_{F F}$ que solicita al sistema suelo-estructura, se obtiene lo representado en la figura (Fig. 6-13). En este gráfico se representa en abscisas la deformación angular $\gamma_{F F}$, y en ordenadas el coeficiente de racking que resulta de dividir la deformación en la estructura enterrada $\gamma_{T u n n e l}$ entre la deformación de campo libre $\gamma_{F F}$. Las tendencias que sigue cada método son las mismas que se han indicado en la figura anterior (Fig. 6-12), es decir, el método de Hung y Anderson proporciona resultados ajustados para estructuras rígidas $\left(F_{R, 0}<1\right)$, mientras que el método de Bobet se aproxima mejor para las estructuras flexibles $\left(F_{R, 0}>1\right)$. Sin embargo, el método propuesto en esta tesis se ajusta de manera fidedigna a los resultados de los modelos de elementos finitos para todo el rango estudiado de flexibilidades relativas $F_{R, 0}$ y deformaciones de campo libre $\gamma_{F F}$. 


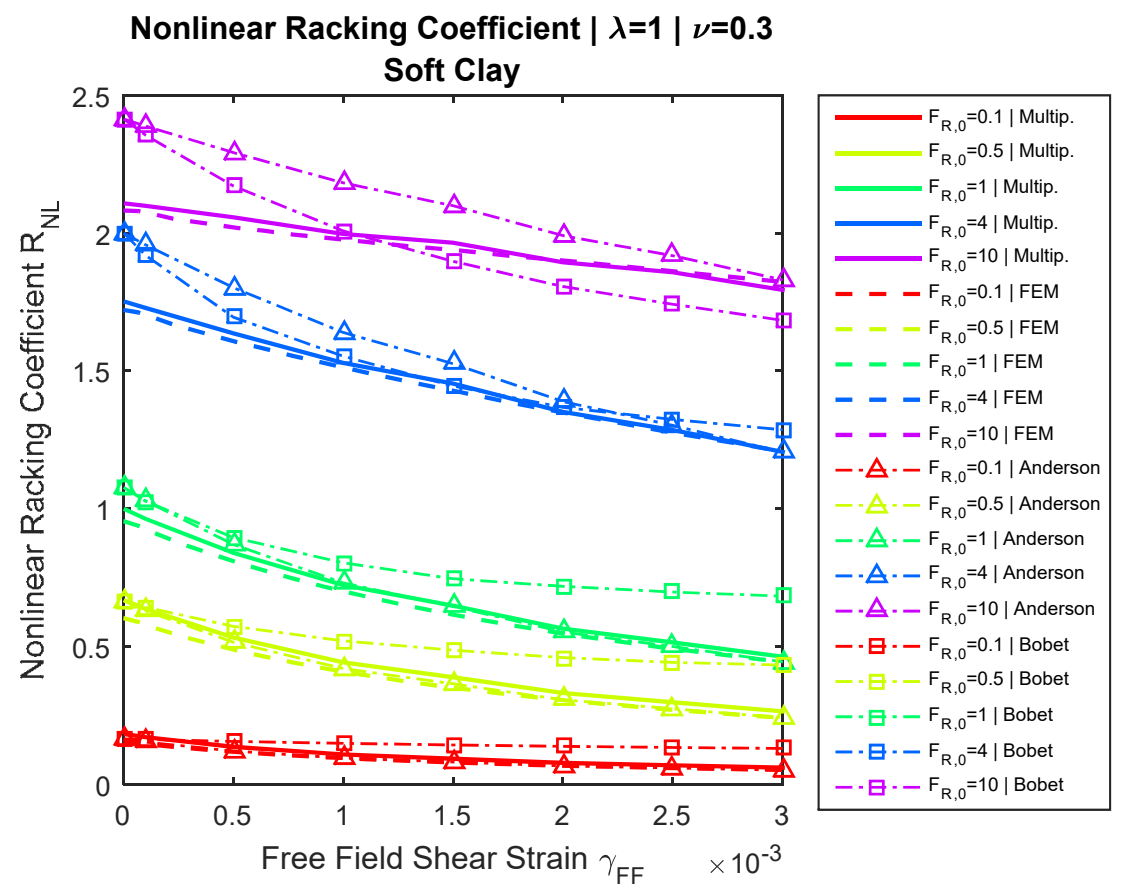

Fig. 6-13. Coeficiente de racking no lineal $\boldsymbol{R}_{N L}$ en función de la ratio de flexibilidad relativa inicial $F_{R, 0}$ para diferentes deformaciones de campo libre $\gamma_{F F}$ para el método propuesto en esta tesis, los resultados MEF, el método de Hung y Anderson (Anderson et al., 2008; Hung et al., 2009), y el método de Bobet (Bobet et al., 2008).

Las mismas tendencias de encaje comentadas se observan representando de manera tradicional las curvas del coeficiente de racking no lineal $R_{N L}$ ( Fig. 6-14).

Por último, se puede evaluar cuantitativamente la precisión del ajuste de cada uno de los 3 métodos simplificados calculando el error de cada método como la ratio del valor obtenido en cada método frente al valor del coeficiente de racking no lineal $R_{N L}$ obtenido mediante el análisis numérico mediante elementos finitos MEF (Fig. 6-15). Esta figura pone de manifiesto de manera numérica la precisión de cada método, y se aprecia claramente como el método propuesto por Bobet presenta un error muy elevado para las estructuras rígidas cuyo terreno circundante se somete a grandes deformaciones de distorsión.

Como conclusión, y para los casos analizados, el método propuesto en esta tesis alcanza una precisión del $20 \%$ en la hipótesis más desfavorable, que mejora hacia una precisión virtualmente exacta para las estructuras más flexibles. 


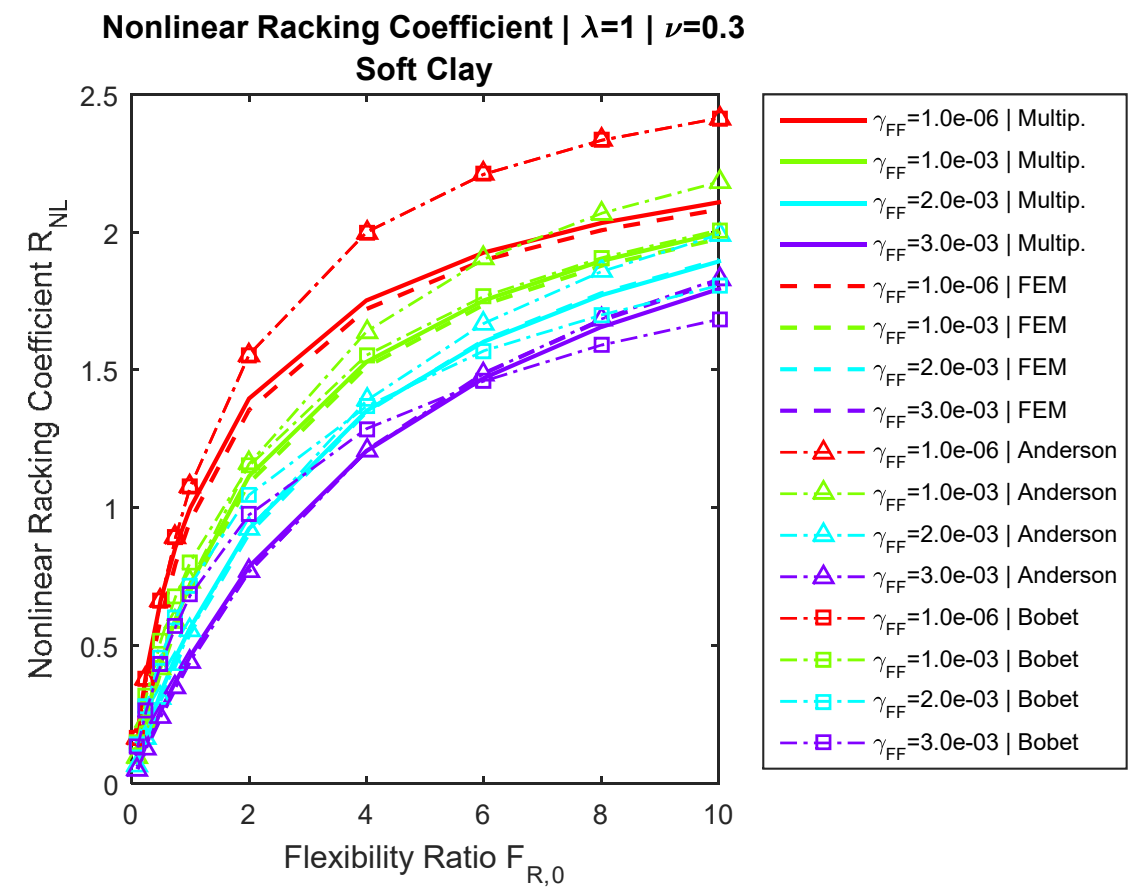

Fig. 6-14. Evolución del coeficiente de racking no lineal $\boldsymbol{R}_{N L}$ frente al incremento de deformaciones de campo libre $\gamma_{F F}$ para el método propuesto en esta tesis, los resultados MEF, el método de Hung y Anderson (Anderson et al., 2008; Hung et al., 2009), y el método de Bobet (Bobet et al., 2008).

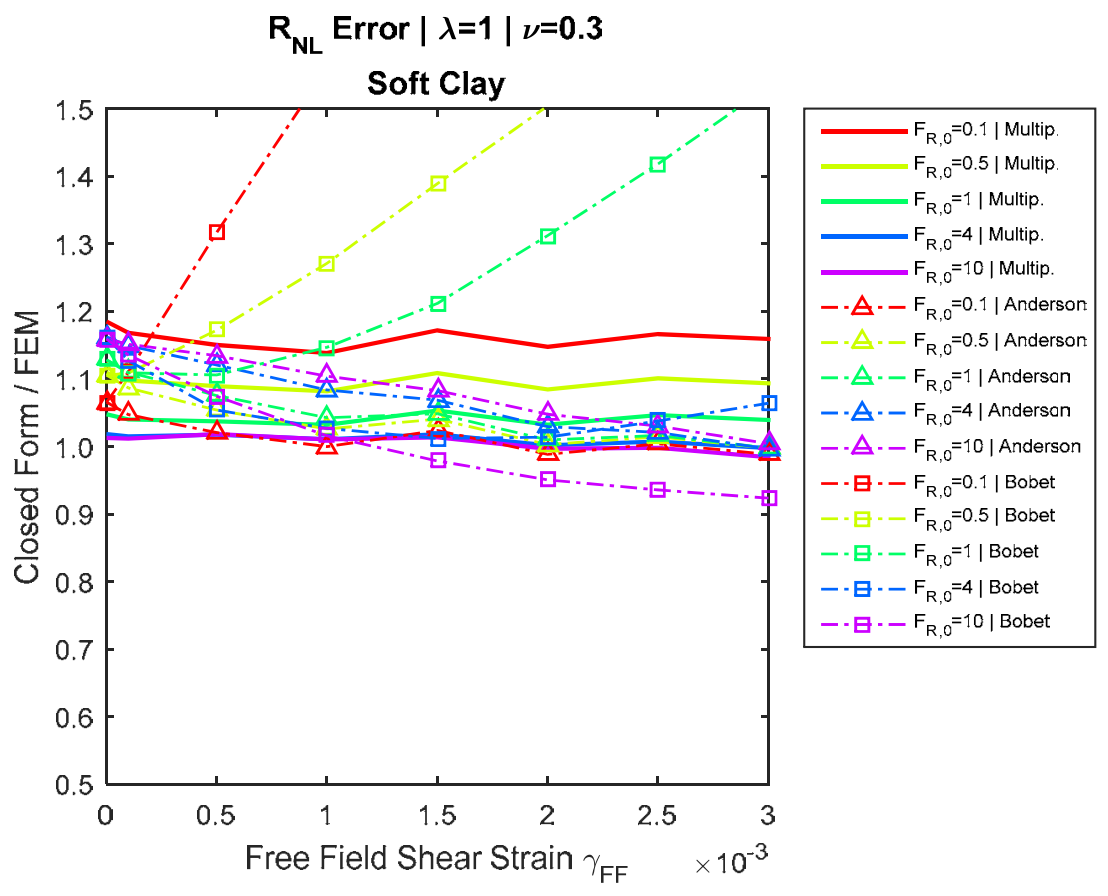

Fig. 6-15. Máximo error del valor del coeficiente de racking no lineal $\boldsymbol{R}_{N L}$ medido como relación entre el obtenido con el método propuesto en esta tesis, el método de Hung y Anderson (Anderson et al., 2008; Hung et al., 2009), el método de Bobet (Bobet et al., 2008), con respecto al MEF. 


\section{ESTUDIO DE LA INFLUENCIA DE LA PROFUNDIDAD}

\subsection{Introducción}

En los métodos propuestos en capítulos anteriores de esta tesis se ha asumido implícitamente que la estructura subterránea se encuentra enterrada a gran profundidad, de tal manera que la solicitación sísmica del conjunto suelo-estructura pueda asimilarse a un estado de cortante puro en el perímetro más exterior.

Esta hipótesis no se cumple, claramente, para el caso de estructuras enterradas a poca profundidad. Efectivamente, la superficie del terreno, debido a su condición de borde libre no puede estar sometida a ningún tipo de solicitación tangencial, y por lo tanto la solicitación de cortante puro no puede aplicarse para aquellos casos en los que la superficie del terreno esté lo suficientemente cerca de la estructura subterráneas.

En este capítulo se revisan las metodologías propuestas por otros autores para estudiar la influencia de la profundidad de la estructura subterránea, centrándose en dos aspectos:

- Qué influencia tiene la profundidad de la estructura en el comportamiento deformacional global de la misma, es decir, cómo varía el coeficiente de racking $R$ a diferentes profundidades. Este aspecto se estudia en el apartado $\S 7.2$, y se propone una expresión para un coeficiente de ajuste que denominamos $R_{乙} / R_{\text {Deep, }}$ y que multiplica al coeficiente de racking $R$ para obtener la distorsión en los casos superficiales.

- Qué influencia tiene la profundidad de la estructura en la deformación local de la misma, y cual es su repercusión en la distribución de esfuerzos en los elementos de losas superior e inferior, y muros. Este aspecto se estudia en el apartado $§ 7.3$, mientras que se propone un método alternativo al descrito en la literatura técnica pertinente para tratar esta condición. En particular, el método propuesto se describe en el apartado §7.3.2, y en los 
apartados $§ 7.3 .3$ y $§ 7.3 .4$ se comparan los resultados obtenidos con este método frente a los resultados obtenidos mediante modelos numéricos de elementos finitos (MEF).

\subsection{Variación del coeficiente de racking a diferentes profundidades}

\subsubsection{Estudios previos}

El efecto que puede tener la proximidad a la superficie de la estructura subterránea en el comportamiento sísmico se ha analizado en varias ocasiones en la literatura técnica más relevante. Wang (Wang, 1993) estudió mediante análisis de elementos finitos varios casos de estructuras rectangulares con una ratio de flexibilidad relativa moderadamente rígida $F_{R}=0,463$, enterradas a diferentes profundidades entre $0 \mathrm{~m}$ y $12 \mathrm{~m}$. Para estos casos, Wang encontró que el coeficiente de racking no es muy dependiente de la profundidad, presentando una ligera reducción para los casos de estructuras más superficiales, pero con valores esencialmente constantes para una ratio profundidad de la losa superior de la estructura $h$, frente al canto total de la misma $H$, de $h / H=1$,5. (Fig. 7-1). A partir de esta profundidad Wang estima que la estructura puede considerarse como profundamente enterrada, mientras que, para estructuras más superficiales, puesto que el coeficiente de racking $R$ obtenido numéricamente resulta inferior al obtenido con su formulación analítica, asume que está del lado de la seguridad considerar la estructura como profunda.

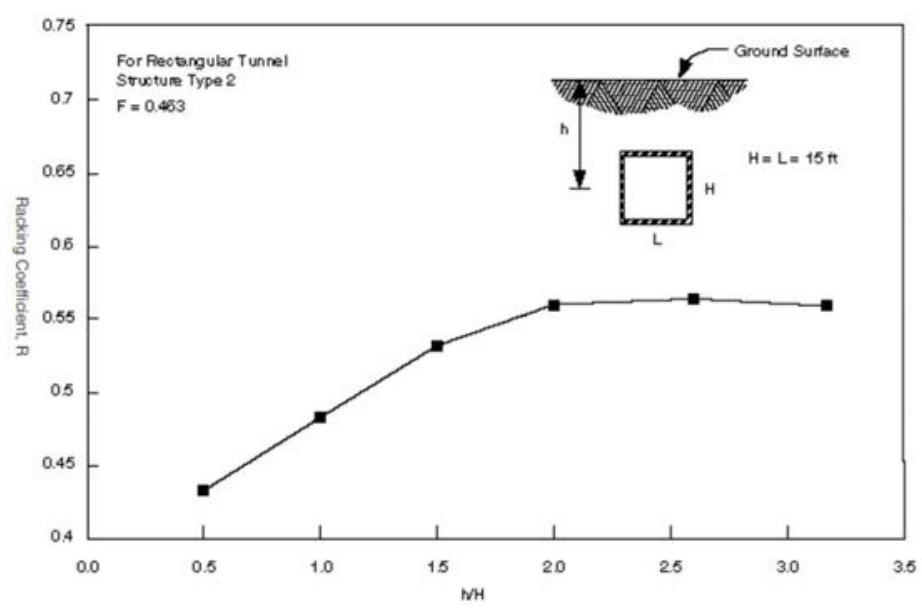

Fig. 7-1. Resultados de Wang (Wang, 1993) de la influencia de la profundidad en el coeficiente de racking $R$ para estructuras moderadamente rígidas $\left(0,45<F_{R}<0,60\right)$.

Bobet (Bobet, 2011) realizó unos análisis similares, mediante elementos finitos, de un rango de estructuras rectangulares con proporciones geométricas $(\lambda=$ ancho/alto $=a / b)$ comprendidas entre $1<\lambda<3$, y diferentes profundidades de 
enterramiento $d$ (Fig. 7-2). Sin embargo, Bobet no indica cual es el rango de flexibilidades relativas de la estructura $F_{R}$ que considera en su análisis, aunque de acuerdo al resto de resultados expuesto en su estudio se puede inferir que se trata de estructuras moderadamente rígidas. Para los casos analizados (Fig. 7-2), Bobet concluye que, a pesar de que hay cierta dependencia del coeficiente de racking $R$ con respecto a la geometría de la sección $\lambda$, las estructuras más superficiales presentan una distorsión menor que el caso de estructuras profundas. De manera similar a Wang, Bobet indica que para estructuras enterradas una profundidad mayor que $d / b=1,5$, la estructura puede considerarse como profunda, y no se ve afectada por la proximidad de la superficie.

Como se puede apreciar, los dos estudios citados incumben tan sólo a estructuras moderadamente rígidas.

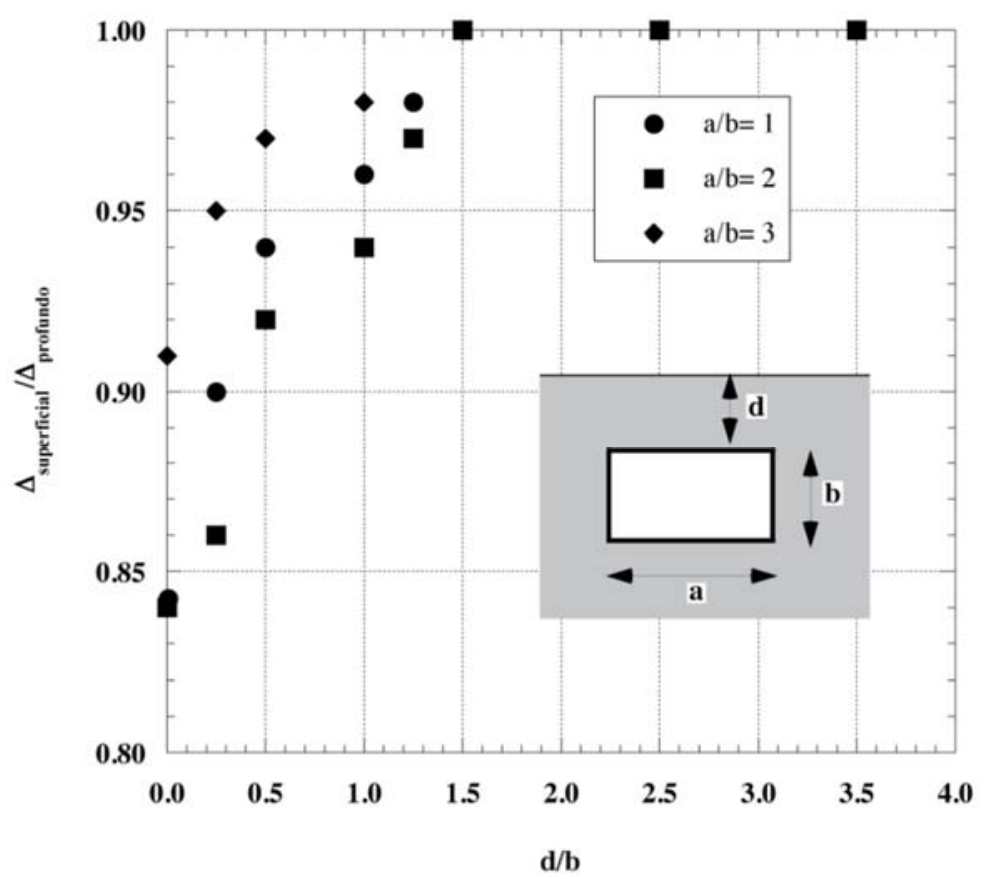

Fig. 7-2. Resultados de Bobet (Bobet, 2011) de la influencia de la profundidad en el coeficiente de racking $R$, sin indicar la rigidez relativa de la estructura.

Anderson et al. (Anderson, Martin, Lam, \& Wang, 2008), tal y como se ha indicado en el apartado \$3.7.4.3 de esta tesis, estudian mediante elementos finitos y un cálculo pseudo-estático, un rango más amplio de estructuras con ratios de flexibilidad relativa comprendidos entre $0,97<F_{R}<19,30$, es decir, desde estructuras con esencialmente la misma rigidez que el suelo, a estructuras muy flexibles. Por otra parte, y para cada uno de estos casos, considera profundidades $z$ variables, que normalizadas al canto de la estructura $H$ están comprendidas entre $0,5<z / H<5$. En este estudio 
paramétrico, Anderson estudia como varía la deformación de distorsión de la estructura en función de la profundidad, en particular, calculando el coeficiente de racking $R$ para cada caso y estudiando su variación.

A partir de sus resultados (Fig. 7-3), Anderson afirma que la profundidad a la que se encuentra enterrada la estructura no tiene una influencia significativa en el coeficiente de racking $R$, y que, por lo tanto, la expresión analítica que propone para el mismo es válida para cualquier profundidad.
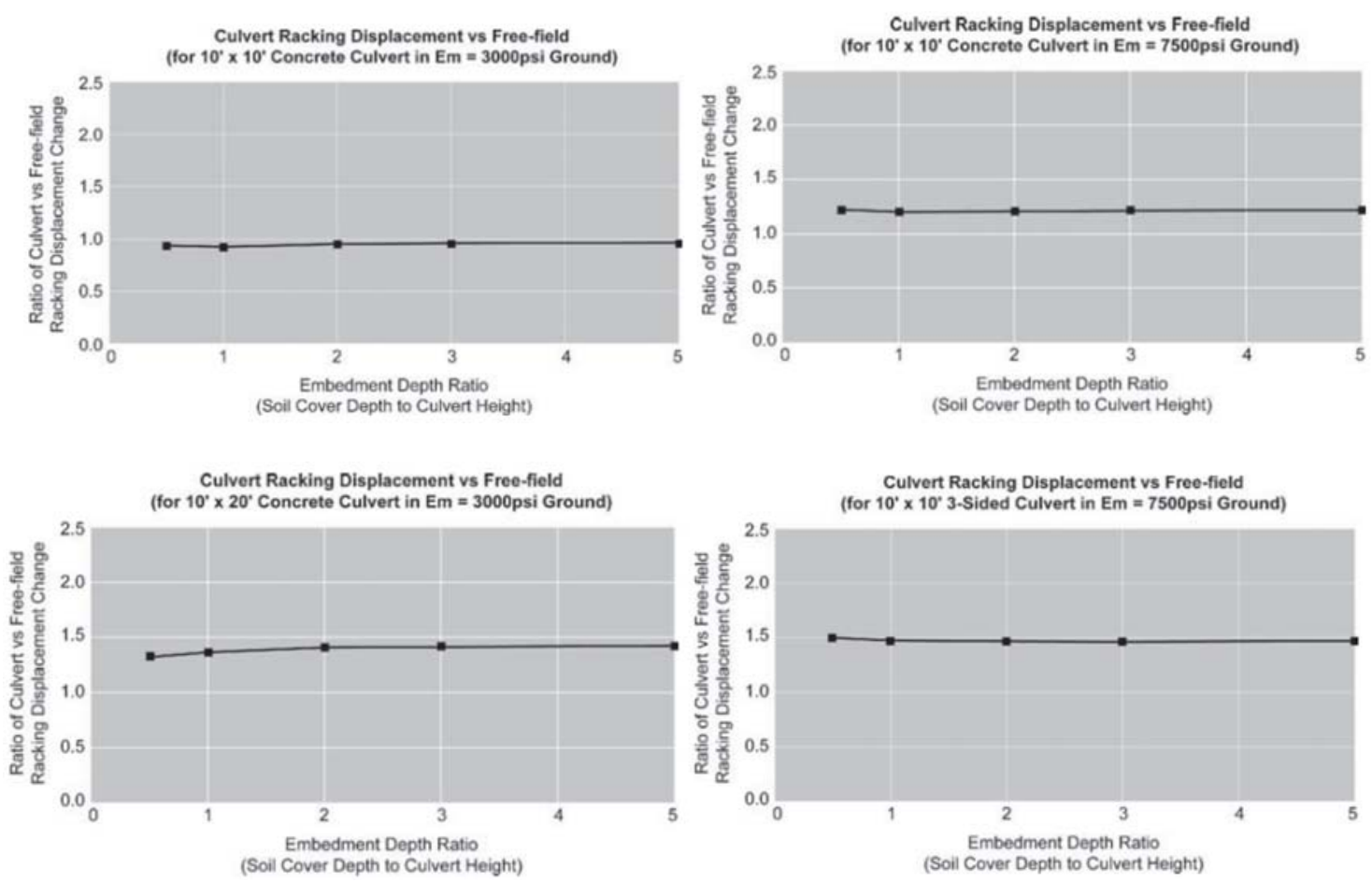

Fig. 7-3. Resultados de Anderson et al. (Anderson et al., 2008) de la influencia de la profundidad en el coeficiente de racking $R$. (sup. izda.) $F_{R}=0,97$. (sup. dcha.) $F_{R}=2,40$. (inf. izda.) $F_{R}=2,90$. (inf. dcha.) $F_{R}=7,30$.

Más recientemente, Tsinidis y Pitilakis (G Tsinidis, Pitilakis, \& Mantikas, 2016; Grigorios Tsinidis, 2017; Grigorios Tsinidis \& Pitilakis, 2018) han estudiado, entre otros parámetros, la influencia de la profundidad de la estructura. Basándose en análisis numéricos, han propuesto valores del coeficiente de racking $R$ para valores discretos de la ratio de flexibilidad relativa $F_{R}$, proporciones geométricas $\lambda=$ ancho/canto, coeficientes de Poisson $v$, y valores absolutos de profundidad $z$ (Fig. 7-4). 

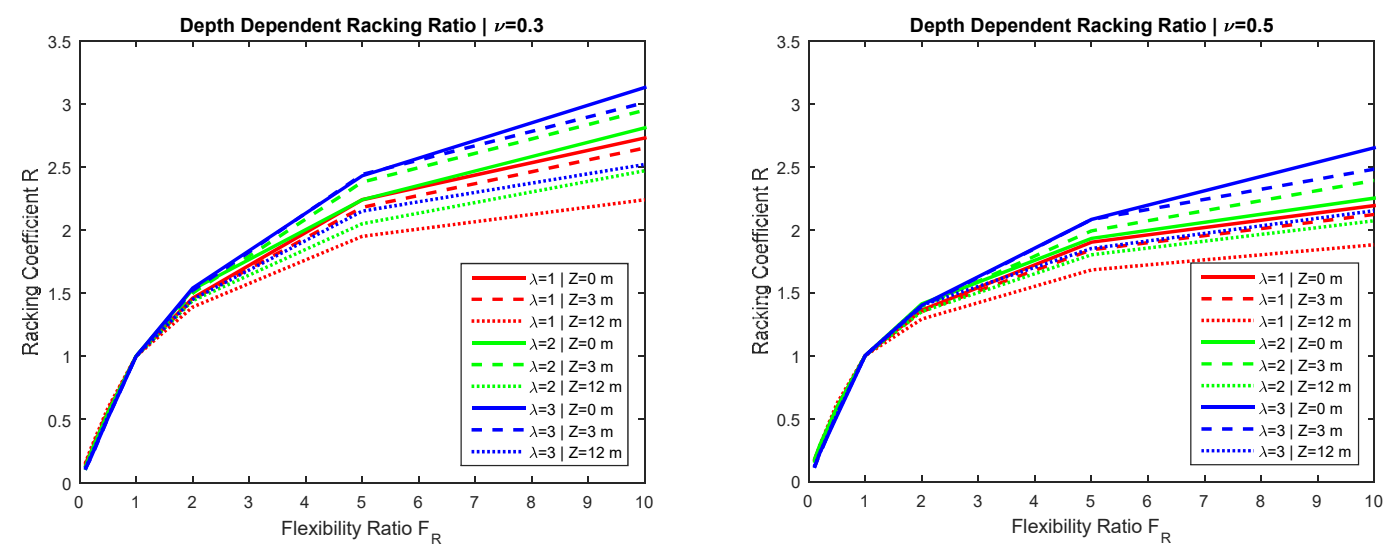

Fig. 7-4. Resultados de Tsinidis y Pitilakis (Grigorios Tsinidis \& Pitilakis, 2018) de la influencia de la profundidad en el coeficiente de racking $R$.

En los valores publicados por Tsinidis et al. se puede apreciar una cierta dependencia del coeficiente de racking $R$ con respecto a la profundidad. Tal y como se muestra el los gráficos de la (Fig. 7-4), las estructuras más superficiales presentan valores de distorsión mayores que los correspondientes a estructuras profundas, especialmente para las estructuras más flexibles.

Estos resultados están en contradicción con los presentados por Wang (Wang, 1993) y Bobet (Bobet, 2011), que indicaban que el coeficiente de racking $R$ disminuye para estructuras más superficiales, y con los presentados por Anderson, que indica que el coeficiente de racking $R$ permanece esencialmente constante independientemente de la profundidad.

\subsubsection{Análisis de la variación del coeficiente de racking con la profundidad}

A la vista de disparidad de resultados presentados por los autores mencionados, en lo que se refiere a la variación del coeficiente de racking $R$ en función de la profundidad $Z$, se ha realizado un estudio paramétrico mediante modelos numéricos de elementos finitos. El estudio paramétrico contempla análisis similares a los desarrollados por los autores indicados anteriormente, pero para un rango mayor de profundidades y coeficientes de flexibilidad, de tal manera que permita comparar todos los resultados y establecer patrones de comportamiento de manera más precisa.

En los modelos implementados en el programa OpenSEES (McKenna, Scott, \& Fenves, 2010) se ha representado un conjunto suelo-estructura, similar al estudiado en los capítulos $\S 4, \S 5$, y $\S 6$ de esta tesis. Es decir, se ha analizado una estructura tipo marco rectangular rodeada por un bloque de suelo concéntrico con comportamiento lineal 
isótropo. La estructura se modeliza mediante elementos viga de 2 nudos, y el suelo mediante elementos cuadriláteros de 4 nudos en deformaciones planas. En particular se han estudiado 432 casos, todos aquellos correspondientes a las combinaciones de ratios de flexibilidad relativa $F_{R}=\{0,10,250,51246810\}$, profundidades $Z=\{0 \mathrm{~m} 2 \mathrm{~m} 4 \mathrm{~m} 6 \mathrm{~m}$ $8 \mathrm{~mm} 10 \mathrm{~m} 15 \mathrm{~m} 20 \mathrm{~m}\}$, coeficientes de Poisson $v=\{0,30,5\}$, y proporción geométrica $\lambda=$ ancho/canto $=\left\{\begin{array}{lll}1 & 2 & 3\end{array}\right\}$.

Sin embargo, el modelo de elementos finitos empleado en este análisis difiere del de capítulos anteriores en las condiciones de contorno y de carga. Puesto que se pretende representar el comportamiento superficial, el borde superior del modelo debe estar libre de tensiones tangenciales, y por lo tanto no se puede someter al conjunto a un estado de cortante puro. Para simular las condiciones de carga máxima durante un sismo, se ha asumido una aceleración horizontal constante en todo el suelo $\ddot{u}_{x}=1 \cdot g$, que se ha equilibrado horizontalmente con una tensión tangencial horizontal $\tau_{x}$ de valor $\tau_{x, I n f}=1 \cdot g \cdot H$ en el borde inferior, y con dos distribuciones triangulares de tensiones tangenciales verticales en los bordes laterales de valor $\tau_{y, \text { Inf }}=1 \cdot g \cdot H$ y $\tau_{y}$,Sup $=0$. Estas condiciones de carga y de distribuciones de tensiones de reacción están en equilibrio. Adicionalmente, el nudo inferior izquierdo tiene los desplazamientos $u_{x}$ y $u_{y}$ restringidos, y el nudo inferior derecho el desplazamiento $u_{y}$ restringido, de tal manera que se pueda alcanzar el equilibrio numérico al calcular. El resto de nudos no tiene restricción de desplazamientos, excepto los nudos del borde izquierdo y derecho que se han vinculado mutuamente frente a desplazamientos horizontales $u_{x, \text { Left }}=u_{x, \text { Right }}$ para simular las condiciones periódicas de simetría.

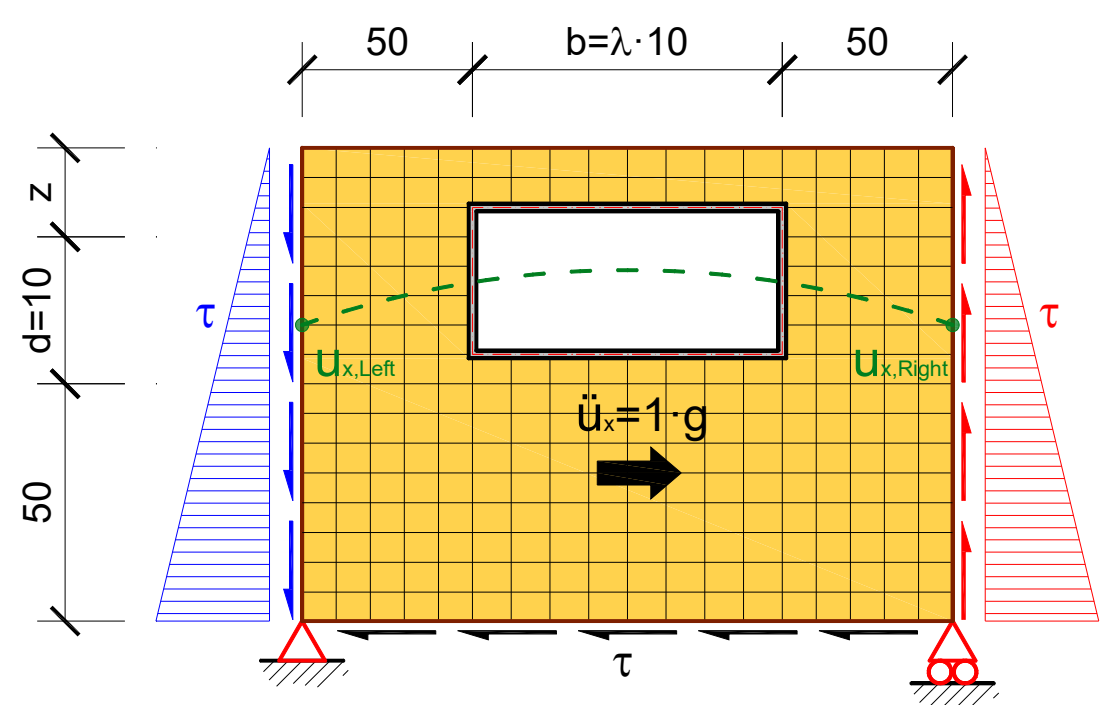

Fig. 7-5. Esquema del modelo de elementos finitos implementado. 
La figura (Fig. 7-6, a) muestra el coeficiente de racking $R$ para el caso de coeficiente de Poisson $v=0,5$, y proporción geométrica $\lambda=1$, para las diferentes profundidades $z$ analizadas, y en ella se puede observar una ligera dependencia de los resultados en función de la profundidad. Si tomamos como referencia el coeficiente de racking $R_{\text {Deep }}$ obtenido para las estructuras más profundas $\left(R_{D e e p}=R Z=20 \mathrm{~m}\right)$, y analizamos como varía el coeficiente de racking $R z$ para las diferentes profundidades mediante la ratio $R z / R_{\text {Deep }}$, obtenemos lo representado en la figura (Fig. 7-6, b), es decir, cuanto más o cuanto menos se distorsiona un estructura dada por el hecho de encontrarse cerca de la superficie.
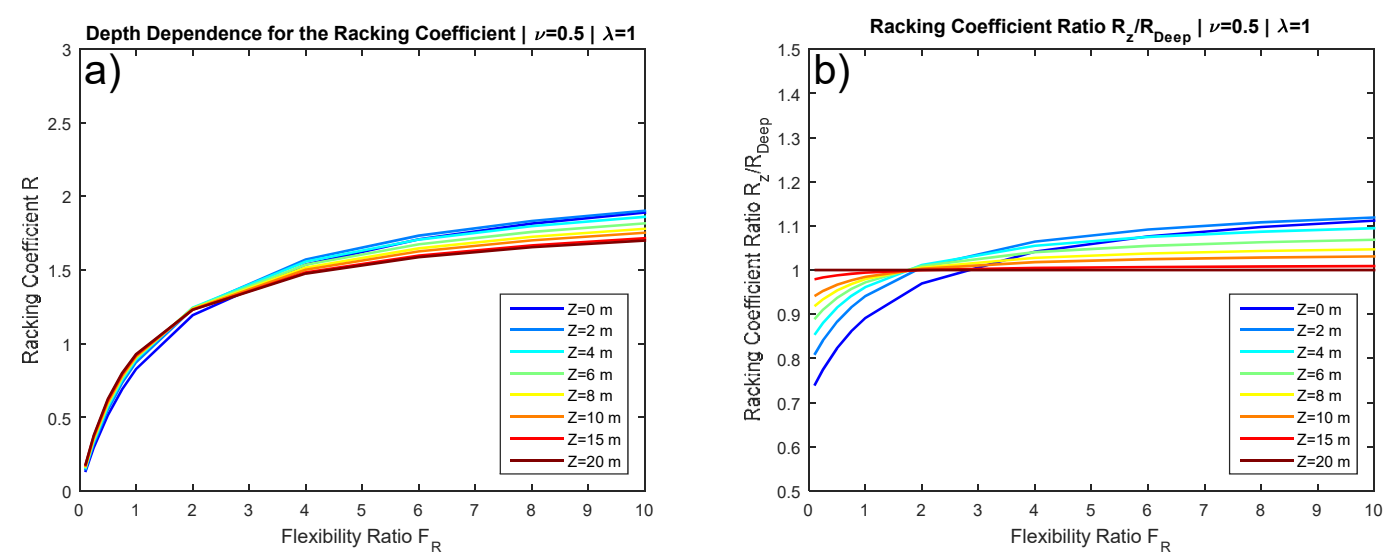

Fig. 7-6. Influencia de la profundidad en el coeficiente de racking para $v=0,5$ y $\lambda=b / d=1$. (a) Coeficiente de racking $R$. (b) Ratio entre el coeficiente de racking $R_{z}$ a la profundidad $z$, y el coeficiente de racking a gran profundidad $R_{\text {Deep. }}$.

En la figura (Fig. 7-6, b) se puede apreciar con mayor claridad el patrón de dependencia del coeficiente de racking: las estructuras rígidas tienden a distorsionarse menos según se aproximan a la superficie $\left(R z / R_{D e e p}<1\right)$, mientras que las estructuras flexibles tienden a deformarse más al acercarse a la superficie $\left(R_{z} / R_{\text {Deep }}>1\right)$. La flexibilidad relativa $F_{R}$ para la cual se produce esta transición no corresponde a un valor claramente definido, si no que según el caso analizado oscila entre $1<F_{R}<3$.

Estos resultados son coherentes con los presentados tanto por Wang (Wang, 1993), y Bobet (Bobet, 2011). En efecto, Wang obtiene sus resultados de reducción del coeficiente de racking $R$ cuanto más superficial es la estructura basándose en el análisis de moderadamente rígidas $\left(0,45<F_{R}<0,6\right)$, lo que claramente se observa en la figura (Fig. 7-6, b). Por otra parte, si se comparan los valores de la (Fig. 7-6, b) con los de la (Fig. 7-1) de Wang, puede apreciarse que el orden de magnitud de la reducción del coeficiente de racking es similar. Algo análogo ocurre con los resultados obtenidos por Bobet, de los 
cuales, a pesar de no referir la rigidez relativa de la estructura que analiza, se puede inferir que corresponden a una estructura rígida, ya que los resultados mostrados en la figura (Fig. 7-2) concuerdan con bastante precisión con los presentados en la (Fig. 7-6, b).

Por otra parte, también son resultados coherentes con los obtenidos por Anderson (Anderson et al., 2008), quien muestra que prácticamente el coeficiente de racking es independiente de la profundidad para estructuras flexibles $\left(1<F_{R}<7\right)$. Efectivamente, observando las figuras (Fig. 7-7, a y b), similares a la (Fig. 7-6) pero con resultados correspondientes al coeficiente de Poisson $v=0,3$ que emplea Anderson en su análisis, se puede apreciar que la diferencia entre los coeficientes de racking a gran profundidad $R_{\text {Deep }}$ y los más superficiales $R_{z}$ son a lo sumo del $10 \%$ para las estructuras más flexibles y superficiales.

La mínima profundidad que Anderson analiza en su estudio corresponde a $\mathrm{z} / \mathrm{H}=0,5, \mathrm{y}$ los resultados homólogos de esta tesis presentados en la figura (Fig. 7-7) serían los correspondientes a un valor intermedio entre las curvas $z=4 \mathrm{~m}$ y $z=6 \mathrm{~m}$, para las cuales la máxima diferencia entre los coeficientes de racking a gran profundidad $R_{\text {Deep }} \mathrm{y}$ los más superficiales $R_{z}$ son todavía menores, del orden del 5\%.
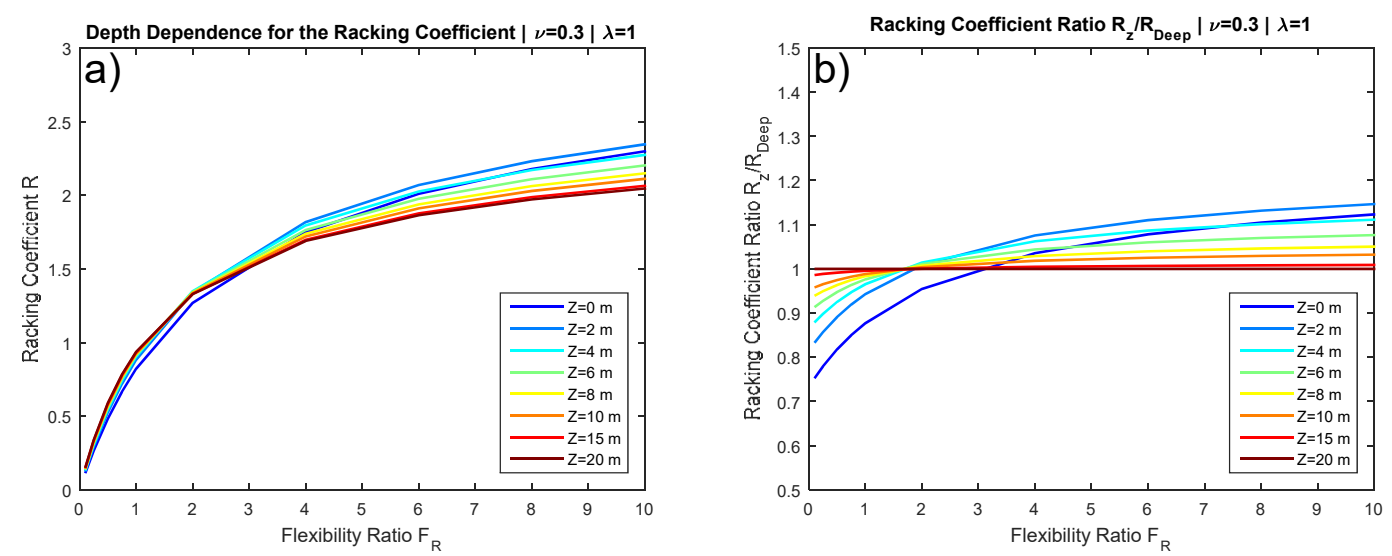

Fig. 7-7. Influencia de la profundidad en el coeficiente de racking para $v=0,3$ y $\lambda=b / d=1$. (a) Coeficiente de racking $R$. (b) Ratio entre el coeficiente de racking $R_{z}$ a la profundidad z, y el coeficiente de racking a gran profundidad $R_{D e e p}$.

Por último, los resultados obtenidos también son coherentes con los presentados por Tsinidis et al. (Grigorios Tsinidis \& Pitilakis, 2018), en el sentido de que, tal y como se ha comentado, las estructuras más flexibles y superficiales muestran incremento de deformación de distorsión de hasta el $10 \%$ con respecto a los valores más profundos, aunque algo inferiores a los mostrados por Tsinidis et al. que indica incrementos de hasta el 25\%. Un aspecto a destacar de los resultados presentados por Tsinidis et al., que entra 
en cierta contradicción con los resultados de Wang, Bobet, y los del estudio realizado en esta tesis, es el correspondiente a la variación del coeficiente de racking $R$ para estructuras rígidas superficiales. En efecto, Tsinidis indica valores esencialmente constantes para estructuras rígidas $\left(R_{z} / R_{D e e p} \approx 1\right.$ para $\left.F_{R}<1\right)$, mientras que, como puede apreciarse en las figuras de este estudio (Fig. 7-6) y (Fig. 7-7), así como en las de Wang (Fig. 7-1) y Bobet (Fig. 7-2), las reducciones de la distorsión pueden llegar a ser de hasta el 25\% $\left(R_{z} / R_{D e e p} \approx 0,75\right)$.

Los resultados presentados en las figuras (Fig. 7-6) y (Fig. 7-7) son los correspondientes a coeficientes de Poisson $v=0,5$ y $v=0,3$ para una proporción geométrica $\lambda=$ ancho/canto $=1$. El resto de resultados analizados, correspondientes a $\lambda=2$ y $\lambda=3$, presentan tendencias similares a las anteriores, y se detallan en el anexo $\S \mathrm{C}$ de esta tesis.

\subsubsection{Coeficiente de corrección en función de la profundidad.}

En base a los resultados de los análisis descritos en el punto anterior $§ 7.2 .2$, se propone a continuación una expresión del coeficiente de corrección $R_{z} / R_{D e e p}$ para tener en cuenta el incremento o decremento del coeficiente de racking $R$ para estructuras superficiales, en función de la profundidad de la losa superior normalizada al canto de la estructura $z / d$. Para obtener la expresión de este coeficiente de corrección se ha realizado un ajuste de curvas en dos etapas. En una primera etapa se ha elegido, para representar el coeficiente de corrección, una función logarítmica del tipo (Ec. 7-1) dependiente de la ratio de flexibilidad relativa $F_{R}$, y se han obtenido los coeficientes $\alpha$ y $\beta$ que mejor ajustan

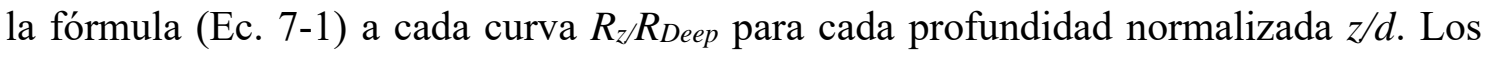
resultados de este ajuste se muestran en la figura (Fig. 7-8). Como se puede observar en esta figura, las curvas logarítmicas se adaptan muy bien a los resultados obtenidos mediante los análisis numéricos de elementos finitos.

$$
\frac{R_{z}}{R_{\text {Deep }}}=\left\{\begin{array}{cc}
\alpha \cdot \operatorname{Ln}\left(F_{R}\right)+\beta & \text { si } \frac{z}{d}<2 \\
1 & \text { si } \frac{z}{d} \geq 2
\end{array}\right.
$$

En una segunda etapa, se ha procedido a ajustar los parámetros $\alpha$ y $\beta$ de (Ec. 7-1) mediante funciones lineales de los tipos (Ec. 7-2) y (Ec. 7-3) dependientes tan sólo de la profundidad normalizada $z / d$. Se ha elegido una función lineal como una solución de compromiso entre un buen ajuste numérico y la sencillez de su expresión. 

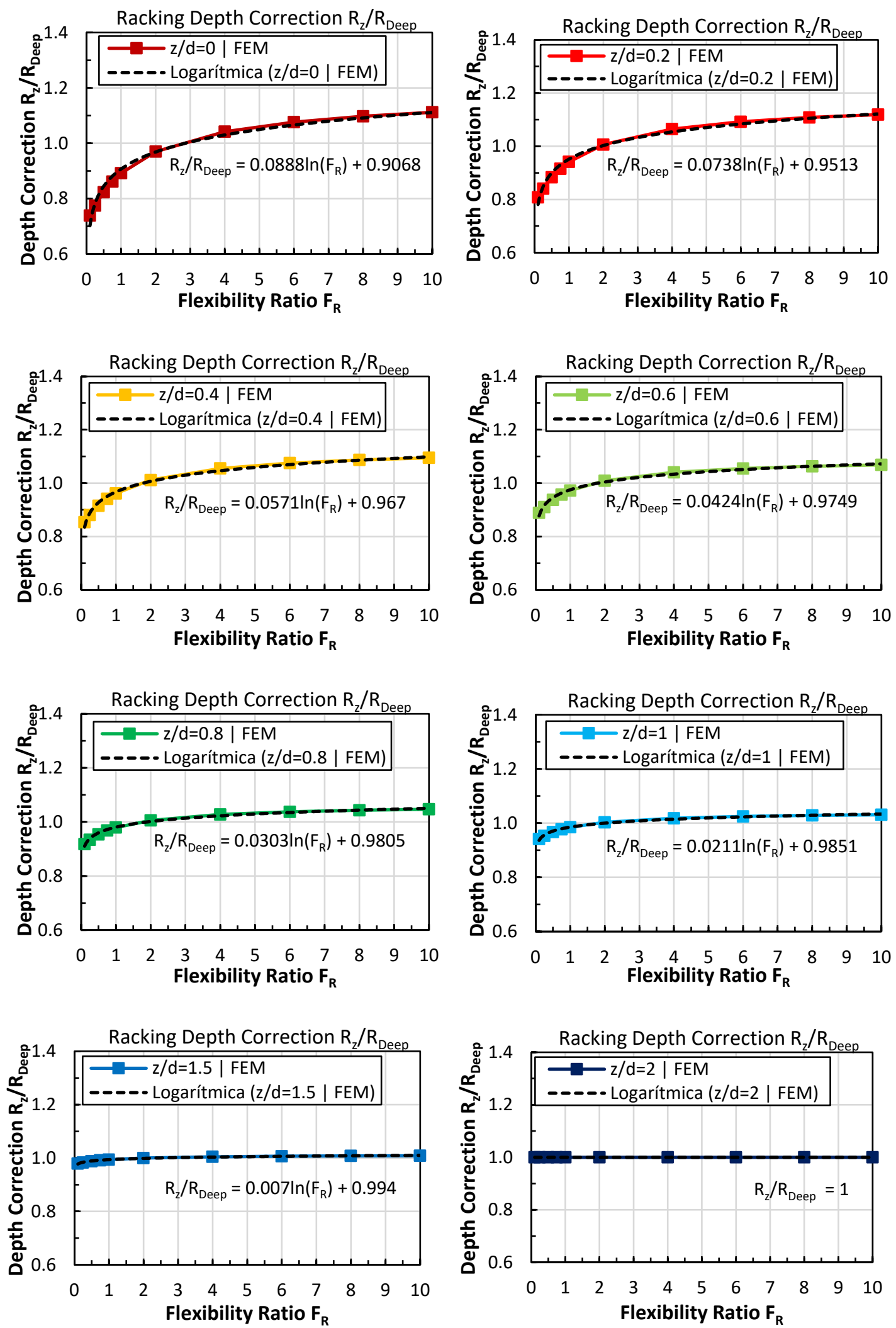

Fig. 7-8. Primera etapa de ajuste de curvas del factor de corrección $\boldsymbol{R}_{\boldsymbol{Z}} / \boldsymbol{R}_{\text {Deep }}$ en función de la ratio de flexibilidad $F_{R}$ y la profundidad normalizada $z / d$. 


$$
\begin{aligned}
& \alpha=\alpha_{1} \cdot\left(\frac{z}{d}\right)+\alpha_{2} \\
& \beta=\beta_{1} \cdot\left(\frac{z}{d}\right)+\beta_{2}
\end{aligned}
$$

Los parámetros $\alpha_{1}, \alpha_{2}, \beta_{1}, \mathrm{y} \beta_{2}$, de estas ecuaciones se resumen en la (Tabla 4-1).

\begin{tabular}{|c|c|c|c|}
\hline$\alpha_{1}$ & $\alpha_{2}$ & $\beta_{1}$ & $\beta_{2}$ \\
\hline$-0,04$ & 0,08 & 0,035 & 0,93 \\
\hline
\end{tabular}

Tabla 7-1. Parámetros de los coeficientes $\alpha$ y $\beta$

Los parámetros $\alpha_{1}, \alpha_{2}, \beta_{1}, \mathrm{y} \beta_{2}$, de estas ecuaciones se han determinado mediante ajuste de mínimos cuadrados a los resultados de las expresiones logarítmicas de la etapa anterior (Fig. 7-8), pero teniendo en cuenta que se debe satisfacer un coeficiente $R_{z} / R_{\text {Deep }}=1$ para profundidades normalizadas $\mathrm{z} / \mathrm{d}=2$. Este ajuste se muestra en la (Fig. 7-9).

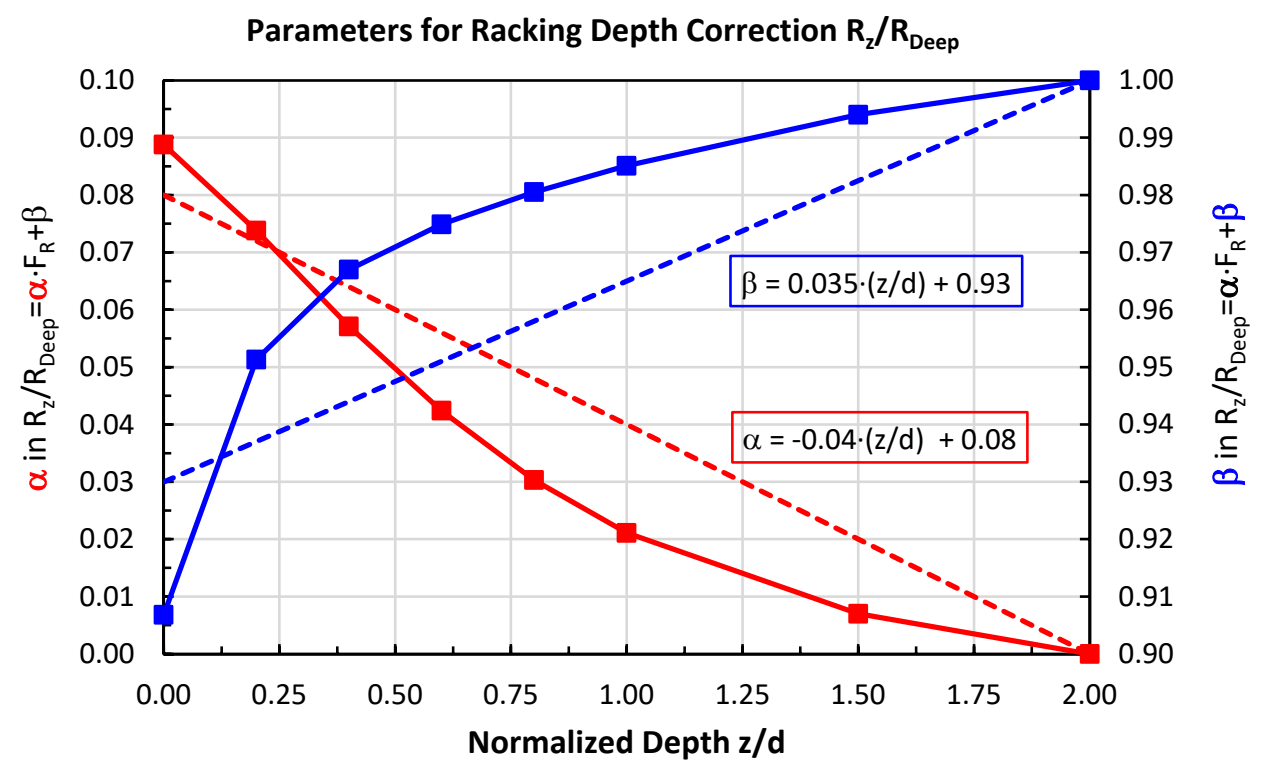

Fig. 7-9. Segunda etapa de obtención de los parámetros $\alpha_{1}, \alpha_{2}, \beta_{1}$, y $\beta_{2}$, de la expresión de corrección $R_{z} / R_{D e e p}$ en función de la profundidad normalizada $z / d$.

Finalmente, en la (Fig. 7-10) se muestran los resultados obtenidos mediante la expresión propuesta (Ec. 4-1), y mediante los análisis numéricos de elementos finitos. Como se puede comprobar, el ajuste es notable. 


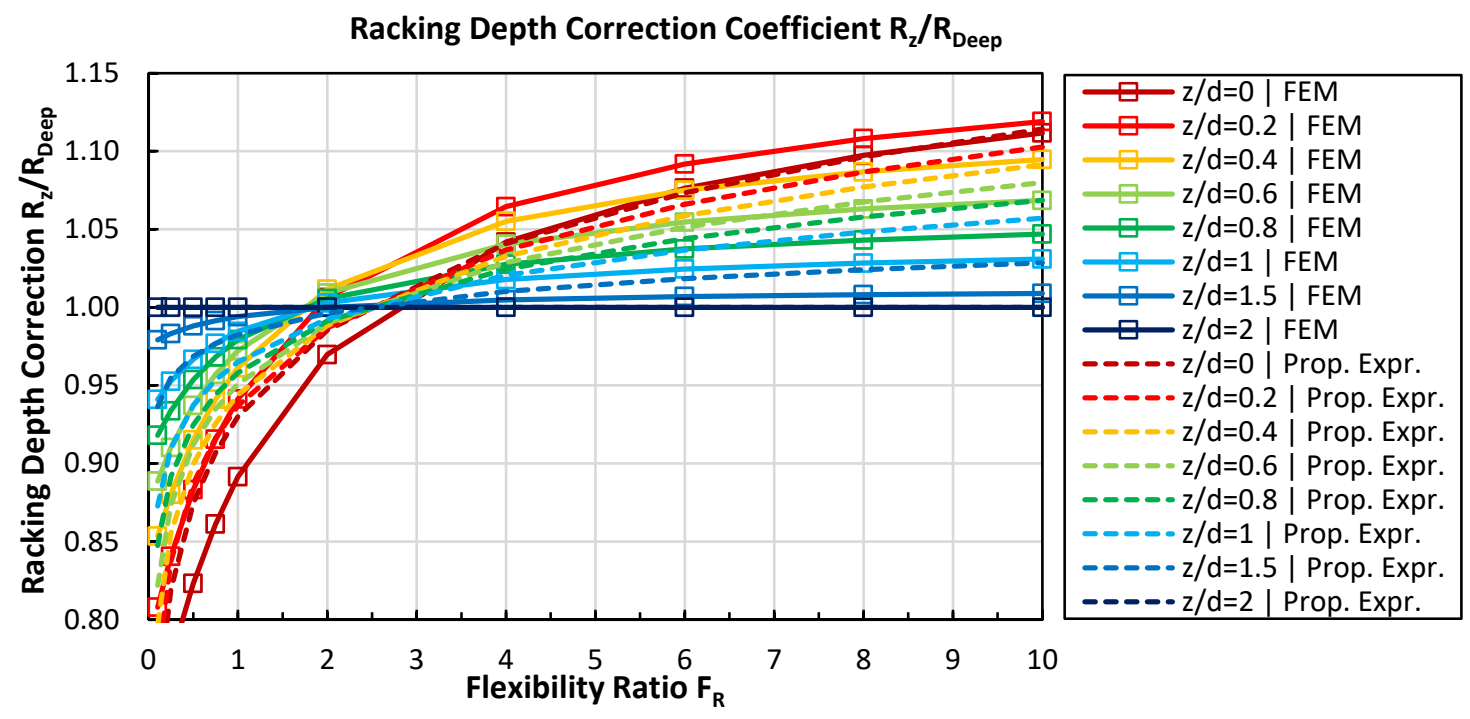

Fig. 7-10. Expresión del coeficiente de corrección $R_{z} / R_{D e e p}$ dependiente de la profundidad frente a los resultados obtenidos mediante análisis numéricos de elementos finitos.

\subsection{Modelo propuesto para la obtención de esfuerzos en la estructura a diferentes profundidades}

\subsubsection{Estudios previos}

Varios autores (Al Atik \& Sitar, 2010; Arias, Sanchez-Sesma, \& Ovando-Shelley, 1981; Matsuo \& Ohara, 1960; Mikola \& Sitar, 2013; Ostadan, 2004; Scott, 1974; Veletsos \& Younan, 1994; Wagner \& Sitar, 2016) se han interesado por el estudio elástico de la distribución lateral de presiones debidas a la acción del sismo, con el propósito de obtener esfuerzos en los muros y losas de la estructura. Los métodos propuestos por estos autores se describen en el apartado $\$ 3.7 .2$ de esta tesis.

Otros autores (Kuesel, 1969; Ortigosa \& Musante, 1991; St John \& Zahrah, 1987) han abordado el análisis de esfuerzos en los elementos de la estructura en términos de compatibilización de deformaciones de la misma y de deformación de campo libre del suelo circundante. Los métodos propuestos por estos autores se describen en el apartado $\S 3.7 .3$ de esta tesis.

Wang (Wang, 1993) es el primer autor en tratar de manera conjunta el fenómeno de la amplificación o reducción de distorsión por racking en función de la flexibilidad relativa $F_{R}$, y la distribución de presiones laterales en los muros debidas al sismo. Wang propone que los esfuerzos en las estructuras profundas son atribuibles a la fuerza de rasante que se desarrolla en la interfaz suelo-estructura de la losa superior, y que, por lo 
tanto, se pueden analizar los esfuerzos en la estructura mediante un cálculo convencional tipo marco con una fuerza concentrada en la losa superior, de tal manera que esta arroje una deformación $\Delta$ Stru igual a la de campo libre $\Delta_{F F}=d \cdot \gamma_{F F}$, multiplicada por el coeficiente de racking $R$, es decir $\Delta$ stru $=d \cdot \gamma_{F F} \cdot R$ (Fig. 7-11, izda).

Por otra parte, indica que, para el caso de las estructuras superficiales, la fuerza de rasante desarrollada en la interfaz suelo-estructura de la losa superior serán inferiores a las del caso profundo, ya que el espesor de tierras sobre esta losa será escaso. Argumenta, por lo tanto, que en el caso superficial la fuerza dominante que causa la distorsión de la estructura son las presiones laterales desarrolladas en los muros laterales. De esta manera, recomienda aplicar sendas distribuciones triangulares de presiones en los muros tales que estas arrojen una deformación $\Delta$ stru igual a la de campo libre $\Delta_{F F}=d \cdot \gamma_{F F}$, multiplicada por el coeficiente de racking $R$, es decir $\Delta S_{t r u}=d \cdot \gamma_{F F} \cdot R$ (Fig. 7-11, dcha).
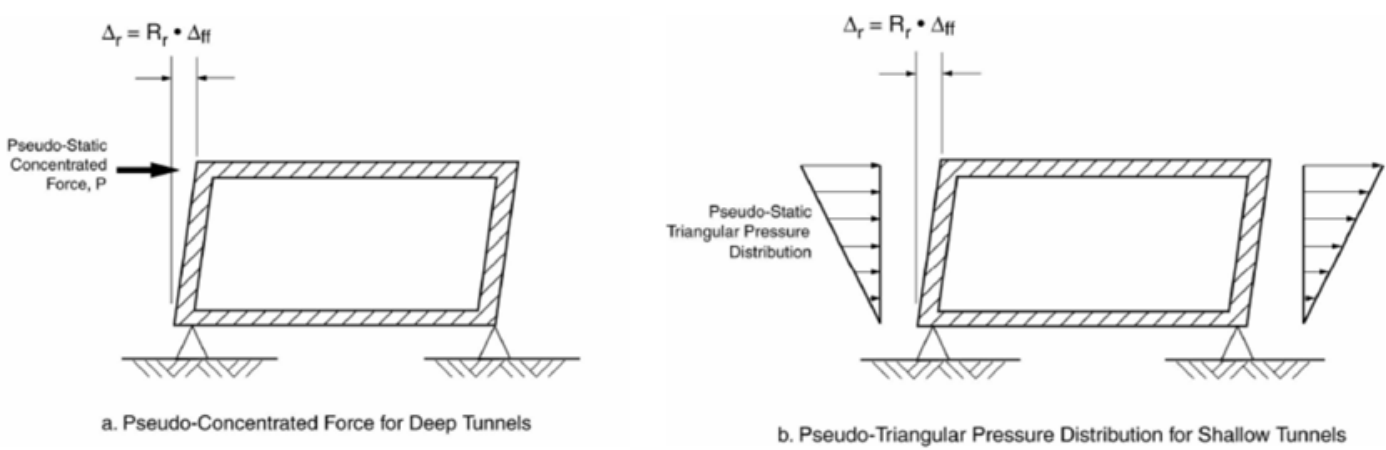

Fig. 7-11. Patrones de carga propuestos por Wang (Wang, 1993). (izda.) Para túneles profundos. (dcha.) Para túneles superficiales.

Wang indica que la distribución triangular de presiones generalmente proporciona momentos solicitantes mayores en el encuentro de los muros y la losa inferior, mientras que la fuerza concentrada aumenta las solicitaciones en los encuentros de los muros con la losa superior. Por otro lado, argumenta que el cambio entre ambos modos de solicitación es gradual, e indica como criterio de aplicación que se analicen esfuerzos mediante ambos, y que se emplee el más desfavorable para el dimensionamiento de los elementos estructurales.

Para validar su método, Wang compara los resultados obtenidos mediante modelos de elementos finitos (MEF) y los predichos por su procedimiento. Para ello analiza 5 casos, que corresponden a estructuras esencialmente rígidas, cuyas ratios de flexibilidad relativa $F_{R}$ y coeficientes de racking $R$ se resumen en la (Tabla 7-2). Wang 
no indica en su estudio para que rango de profundidades de la estructura realiza sus análisis.

\begin{tabular}{|c|c|c|}
\hline Caso & Ratio Flexibilidad $\boldsymbol{F}_{\boldsymbol{R}}$ & Coeficiente de Racking $\boldsymbol{R}$ \\
\hline 1 & 0,101 & 0,133 \\
\hline 2 & 0,271 & 0,323 \\
\hline 3 & 0,661 & 0,733 \\
\hline 4 & 1,313 & 1,170 \\
\hline 5 & 1,000 & 0,957 \\
\hline
\end{tabular}

Tabla 7-2. Casos estudiados por Wang (Wang, 1993) para validar el método de fuerza concentrada en cabeza y distribución triangular de presiones laterales.

Los resultados obtenidos por Wang se presentan en forma de momentos flectores en el encuentro muro-losa en la figura (Fig. 7-12) para el caso de fuerza concentrada, y en la figura (Fig. 7-13) para la distribución triangular.
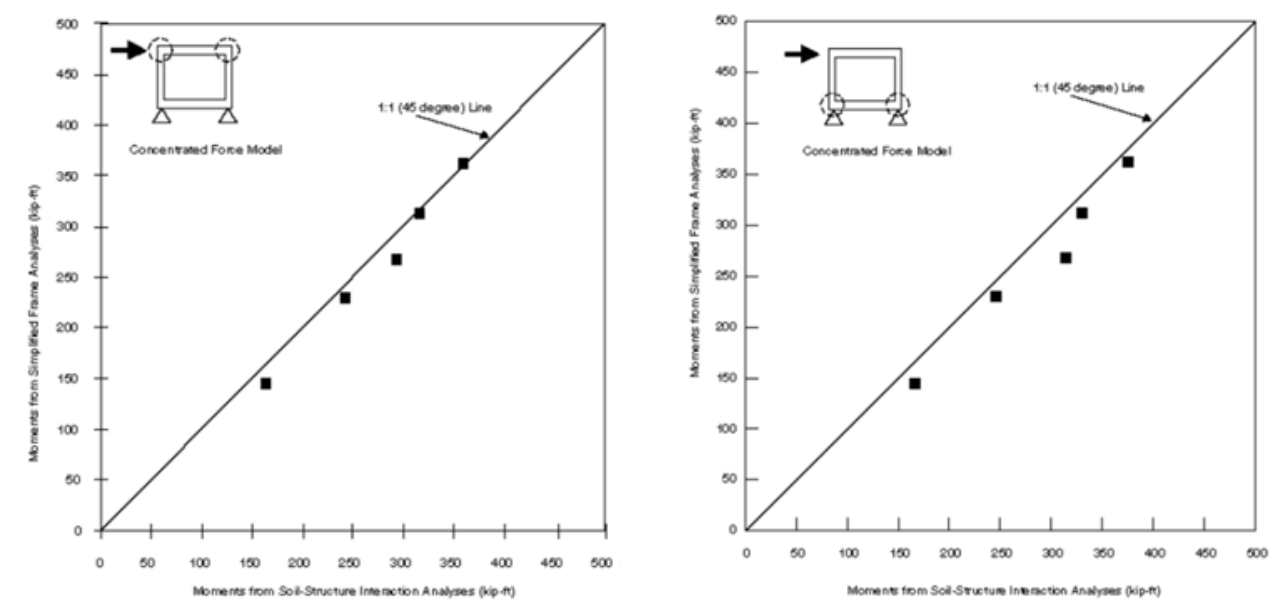

Fig. 7-12. Comparación de esfuerzos MEF-método simplificado(Wang, 1993) para túneles profundos con fuerza concentrada. Momentos en losa: (izda.) Superior. (dcha.) Inferior.
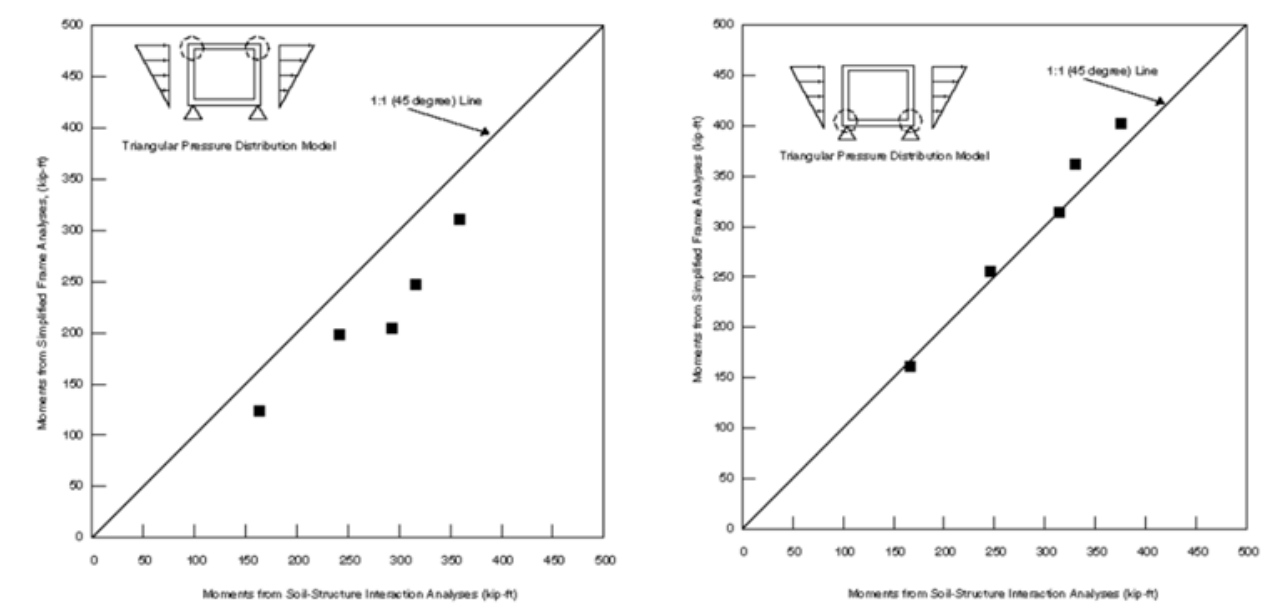

Fig. 7-13. Comparación de esfuerzos MEF-método simplificado (Wang, 1993) para túneles superficiales con fuerza concentrada. Momentos en losa: (izda.) Superior. (dcha.) Inferior. 
Como puede apreciarse, y según el propio autor indica, el ajuste del método de Wang es razonablemente bueno. Sin embargo, es muy relevante destacar que los casos para los cuales Wang valida su método corresponden a estructuras esencialmente rígidas, tal y como se muestra en la Tabla 7-2, y que su extrapolación a casos flexibles no tiene por qué ser apropiada.

Este método propuesto por Wang es también el que se recoge en la normativa FHWA Technical Manual for Design of Road Tunnels (Hung, Monsees, Munfah, \& Wisniewski, 2009) analizada en el apartado §3.9.2.2 de esta tesis.

Tanto Penzien (Penzien, 2000) como Anderson (Anderson et al., 2008) no establecen procedimientos específicos para analizar de manera diferente los esfuerzos de estructuras superficiales o profundas. En efecto, estos autores asumen que los únicos esfuerzos que se desarrollan en la estructura son los debidos a la acción de las tensiones tangenciales en la interfaz suelo-estructura, y que por lo tanto los momentos flectores y cortantes se pueden analizar de acuerdo a un modelo similar al de Wang para estructuras profundas (Fig. 7-11, izda.).

Por su parte, Huo et al. (Huo, Bobet, Fernández, \& Ramírez, 2006), en el desarrollo de su compleja formulación del coeficiente de racking $R$, asume que la distribución de presiones normales en los elementos sigue una ley lineal, y que los esfuerzos resultantes son producto de la actuación concomitante de estas presiones normales y tangenciales en la interfaz suelo-estructura.

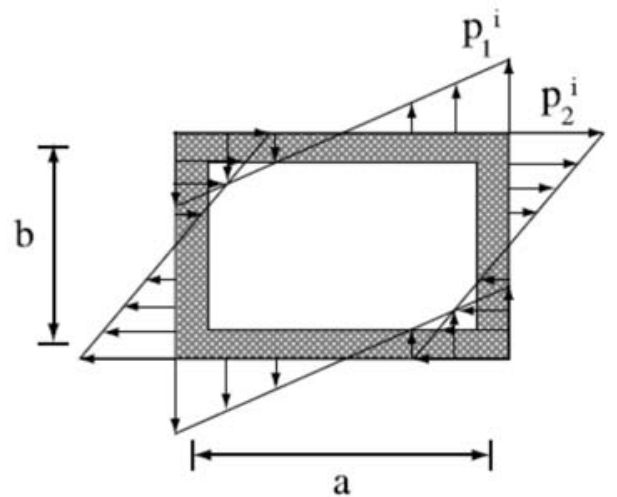

(a) Normal stress

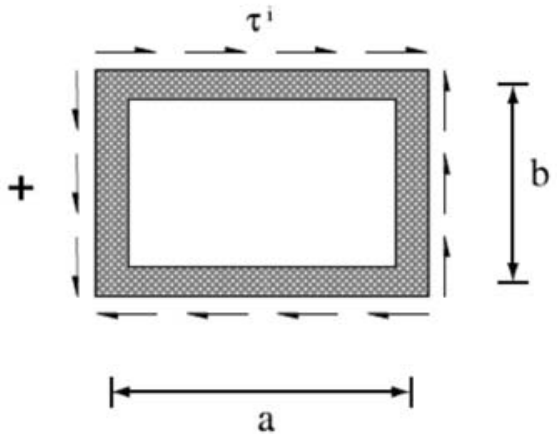

(b) Shear stress

Fig. 7-14. Esquema de tensiones normales y tangenciales subyacente en la propuesta de Huo (Huo et al., 2006) para obtener su expresión del coeficiente de racking $R$.

Sin embargo, tal y como se ha indicado en el apartado $\$ 5.1$ de esta tesis, varios autores han puesto de manifiesto que los esfuerzos predichos por los métodos 
simplificados descritos no son capaces de reproducir con precisión los resultados obtenidos mediante análisis de elementos finitos (Debiasi, Gajo, \& Zonta, 2013; Pitilakis \& Tsinidis, 2014; Grigorios Tsinidis, 2017; Grigorios Tsinidis, Pitilakis, Anagnostopoulos, \& Madabhushi, 2015), ni con los medidos experimentalmente en laboratorio (Abuhajar, El Naggar, \& Newson, 2015; Cilingir \& Madabhushi, 2011; Grigorios Tsinidis, Pitilakis, \& Heron, 2015). Estas malas experiencias han motivado que en la literatura técnica tienda a favorecerse el análisis mediante elementos finitos, en detrimento de los métodos simplificados.

\subsubsection{Modelo propuesto para la obtención de esfuerzos en la estructura a diferentes profundidades}

En este apartado se propone una modificación racional del método descrito en el apartado $§ 5.2$ de esta tesis, para adaptarlo al caso de estructuras superficiales, y que como se verá, proporciona resultados muy ajustados a los análisis numéricos más complejos.

Partiendo del esquema conceptual descrito en el apartado $§ 5.2$ de esta tesis, en el que se ha estudiado el caso en el que la estructura se encuentra enterrada a suficiente profundidad y se puede considerar la solicitación sísmica como un estado de cortante puro, se puede razonar que:

- La deformación global a distorsión de la estructura enterrada se produce debido, esencialmente, a la transferencia de esfuerzos tangenciales y rasantes, motivados por la solicitación y por la diferencia de rigideces entre el suelo circundante y la estructura. La estructura debe adaptarse al perfil de deformación del suelo circundante, y al hacerlo engendra esfuerzos (momentos flectores y cortantes) en sus elementos.

- Adicionalmente, la estructura se deforma localmente para poder adaptarse a la deformación global. Esta deformación local induce reacciones locales mutuas entre la estructura y el suelo circundante, las cuales a su vez modifican las leyes de esfuerzos correspondientes tan sólo a la transferencia de tensiones tangenciales.

Analizando conceptualmente cuáles pueden ser las diferencias que podrían apartar el caso anteriormente estudiado de estructura profunda frente a los casos superficiales, se puede argumentar que la variación más relevante consiste en la diferencia de perfiles de deformación que presenta el suelo circundante, incluso en condiciones de campo libre, en 
las proximidades a la superficie. Para hacer más claro el razonamiento que sigue, y sin pérdida de generalidad, asumiremos que el terreno, desde la superficie hasta una profundidad $z$ considerable, se encuentra sometido a una aceleración de valor constante, por ejemplo, como en la figura (Fig. 7-15, a).
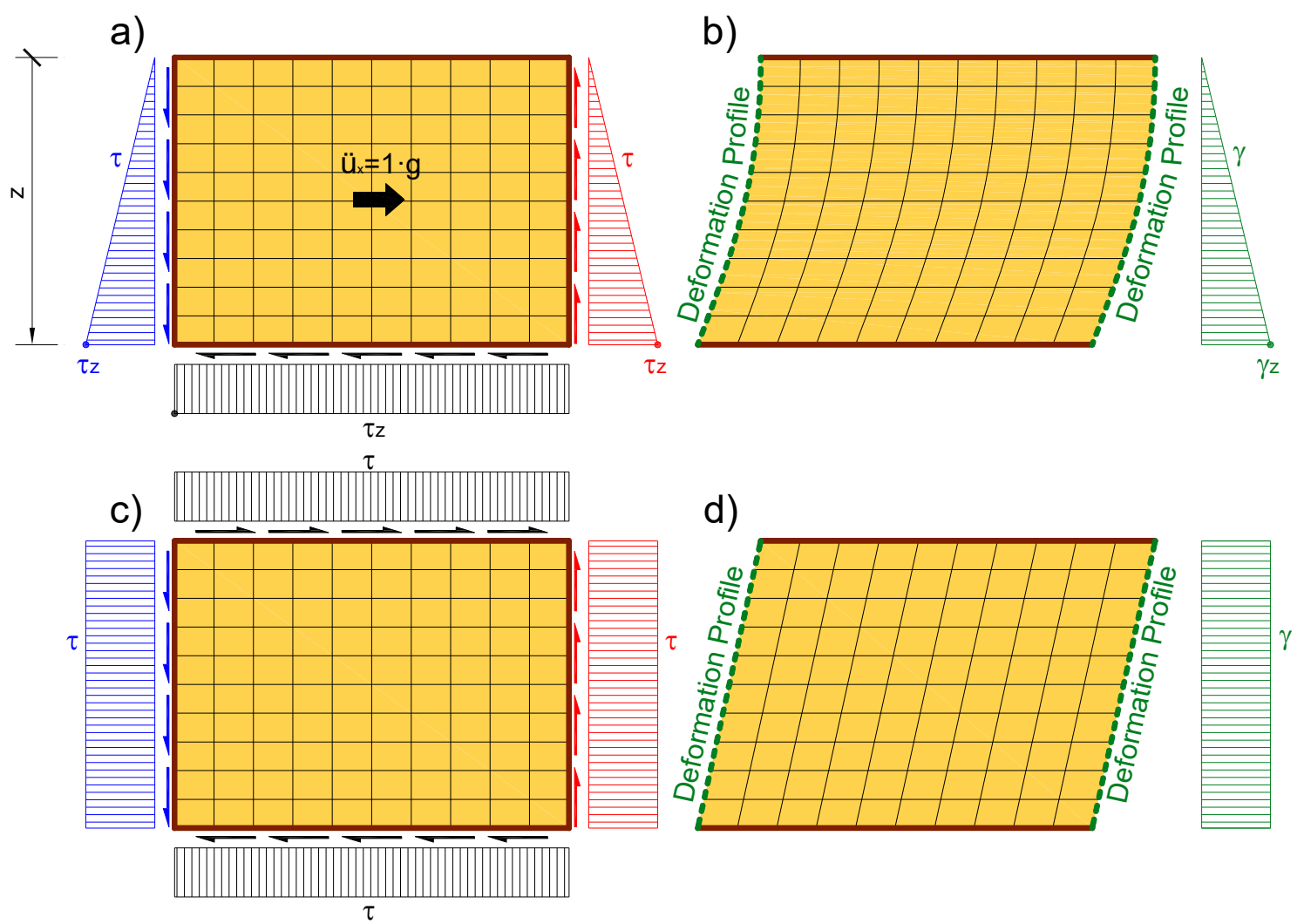

Fig. 7-15. (a) Estado tensional de cortante a una profundidad $z$ en equilibrio con una aceleración horizontal de valor constante. (b) Perfil parabólico de deformación del suelo compatible con una solicitación de aceleración uniforme. (c) Estado tensional de cortante puro, (d) Perfil lineal de deformación del suelo compatible con un estado de cortante puro.

Si se plantea el equilibrio de tensiones horizontales a cualquier profundidad $z$, parece claro que las tensiones horizontales deben incrementarse linealmente a mayores profundidades, ya que deben equilibrar una fuerza horizontal mayor, correspondiente al volumen de terreno que hay por encima. Si el terreno se considera lineal y homogéneo, el perfil de deformaciones tangenciales $\gamma$ será proporcional al de tensiones $\tau$, ya que $\tau=G \cdot \gamma$ (Fig. 7-15, b). En consecuencia, el perfil de deformaciones del terreno tendrá forma parabólica, ya que corresponde a la integral, a lo largo de la profundidad z, de las deformaciones tangenciales $\gamma$, que siguen una ley lineal.

Si la profundidad $z$ es muy grande, el incremento de deformación entre dos profundidades consecutivas $\mathrm{z}_{1}$ y $\mathrm{z}_{2}$ no será muy significativo con respecto a los valores 
totales de deformación $\gamma_{1} \approx \gamma_{2}$, ya que la deformación total estará claramente dominada por las grandes tensiones acumuladas desde la superficie, y el incremento de tensión entre profundidades $Z_{1}$ y $Z_{2}$ será pequeño en proporción a la tensión total acumulada. Por lo tanto, en este caso de gran profundidad, resulta lícito asumir que el estado tensional de tensiones tangenciales es aproximadamente constante. Este caso corresponde a un estado de cortante puro, para el cual el perfil de deformación del terreno resulta lineal, ya que corresponde a la integral, a lo largo de la profundidad $z$, de las deformaciones tangenciales $\gamma$, que siguen una ley constante.

Esta última es la hipótesis que se ha asumido implícitamente en los capítulos $\S 4$, $\S 5, y \S 6$, en los que se ha partido de una definición de la solicitación sísmica como un estado de cortante puro. Sin embargo, esta hipótesis deja de ser válida en el caso de las regiones próximas a la superficie: cerca de la misma, las tensiones tangenciales horizontales acumuladas hasta una profundidad $z$ no son tan grandes comparadas con el incremento que se produce entre dos profundidades consecutivas $z_{1} y_{2} z_{2}$, y no se puede asumir que la acción sísmica corresponde a un estado de cortante puro.

Sin embargo, sí se puede razonar de manera análoga a como se hizo en el capítulo $\S 5$ de esta tesis, y se puede asumir que, además de la deformación global de racking de la estructura y los esfuerzos que esta engendra, las reacciones mutuas autoequilibradas entre el suelo circundante y la estructura modifican la deformación de los elementos, y en consecuencia los esfuerzos en los mismos.

Por lo tanto, de manera similar a como se planteó en el capítulo $§ 5$ de esta tesis, se puede pensar que la estructura se ve solicitada, no por un patrón de cargas, sino por un perfil de deformaciones impuestas, que corresponde a la línea media de contacto entre el suelo y la estructura. Los esfuerzos de interacción suelo-estructura, que modifican a los de distorsión global, surgen debido a la diferencia de desplazamientos entre esta línea media de contacto y la deformación de la propia estructura.

Al igual que en el modelo conceptual planteado en el capítulo $§ 5$ de esta tesis, la interacción local suelo-estructura se puede plantear mediante una fundación elástica tipo Winkler (Winkler, 1867). Para la rigidez $k$ de estos muelles, se puede considerar que la expresión propuesta por Vesic (Vesic, 1963) proporciona resultados suficientemente precisos. 


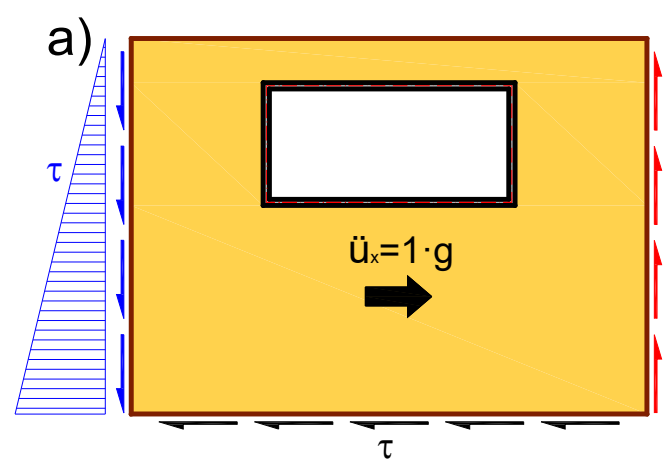

b)

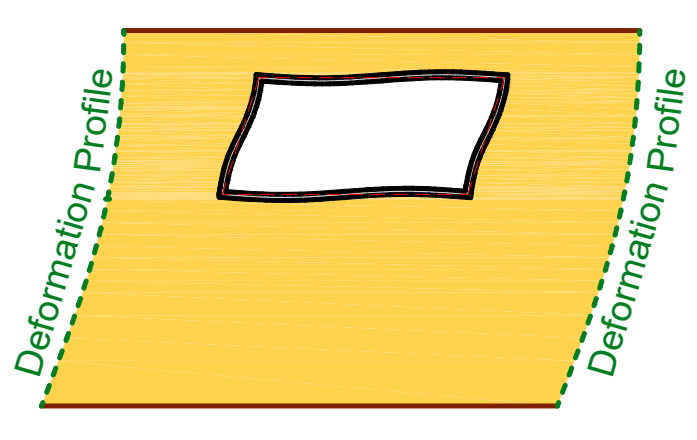

c)

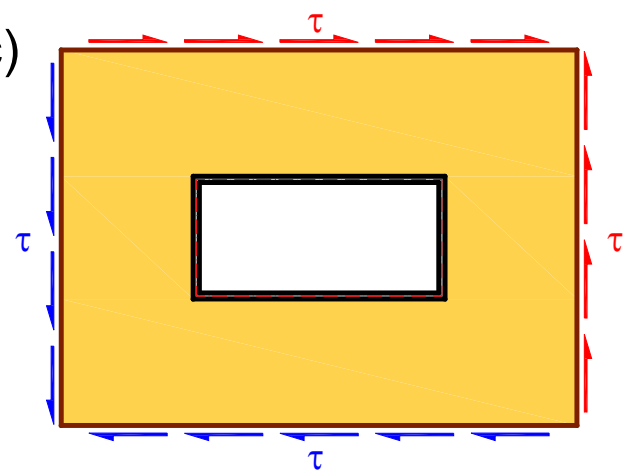

d)

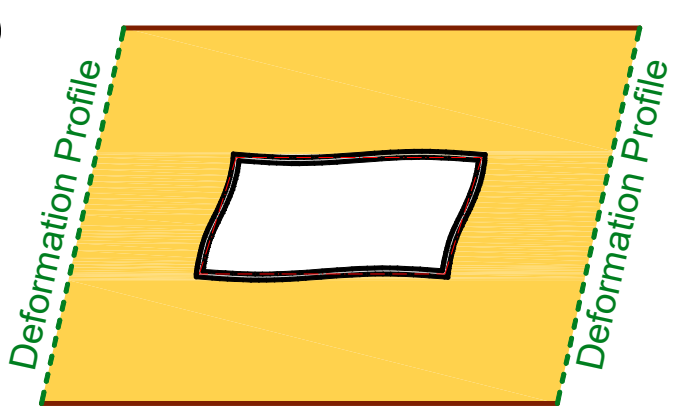

Fig. 7-16. (a) Estado tensional de cortante a una profundidad $z$ en equilibrio con una aceleración horizontal de valor constante y estructura embebida. (b) Perfil parabólico de deformación del suelo compatible a una solicitación aceleración uniforme y estructura embebida. (c) Estado tensional de cortante puro y estructura embebida. (d) Perfil lineal de deformación del suelo compatible con un estado de cortante puro y estructura embebida.

Sin embargo, y a diferencia de lo planteado en el capítulo §5, el perfil de desplazamiento lateral solicitante ya no puede considerarse como un perfil lineal correspondiente a un estado de cortante puro, sino que debe asumirse un perfil mixto en parte lineal y en parte parabólico, como se ha indicado anteriormente que corresponde a un estado de aceleración uniforme del terreno. Este modelo conceptual de patrón de deformaciones e interacción local suelo-estructura se muestra en la (Fig. 7-17). 


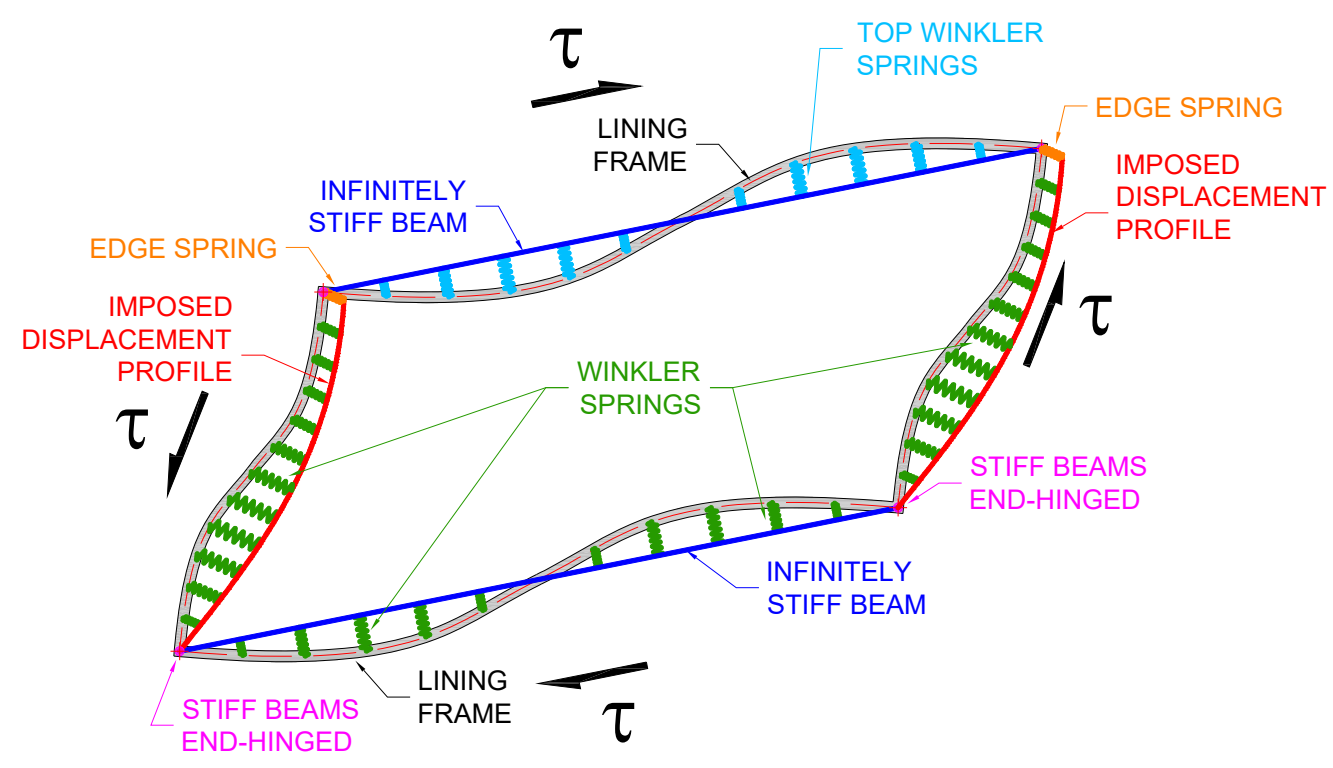

Fig. 7-17. Vista esquemática del modelo mejorado con perfil de deformaciones curvas impuestas en los muros laterales, y vinculaciones de Winkler.

Este modelo presenta ciertas diferencias con respecto al análogo del capítulo $§ 5$ para estructuras profundas:

- En primer lugar, como se ha indicado, el patrón de deformación lateral no corresponde a un perfil lineal, sino a una combinación de perfil lineal y parabólico, que representa mejor la línea media de deformación del terreno, en función de cual sea la profundidad de la estructura.

- Por otra parte, la fundación de Winkler de la losa superior cuenta con un valor de rigidez $k_{T o p}$ diferente del resto de bordes. Este valor diferente representa la eficacia de la capa superior de terreno para oponerse a las deformaciones locales del marco. Para una estructura muy superficial con una losa superior a profundidad $z=0$ claramente no existe terreno por encima de ella, y por lo tanto en este caso la rigidez de estos muelles será nula $k_{T o p}=0$. Para estructuras profundas los muelles serán igual de eficaces que el resto de fundaciones de Winkler de losa inferior y muros laterales.

- Por último, la vinculación del perfil de deformaciones impuestas con la losa superior no es una restricción de compatibilidad total como en el caso

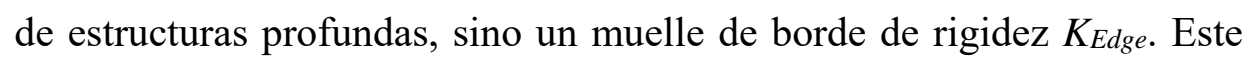
muelle, de manera similar al caso de los muelles $k_{\text {Top }}$ de la losa superior, representa la eficacia del terreno por encima de la losa superior para transmitir tensiones tangenciales y compatibilizar movimientos. Para una 
estructura muy superficial con una losa superior a profundidad $z=0$ claramente no existe terreno por encima de ella, y por lo tanto en este caso la rigidez de este muelle será nula $k_{E d g e}=0$. Para estructuras profundas este muelle tendrá una rigidez virtualmente infinita $k_{E d g e}=\infty$.

Partiendo de estas consideraciones cualitativas de valores para los casos extremos, y considerando como suficientemente profunda una estructura a $z / d=2$, se ha establecido una variación lineal de dichas rigideces de muelles en función de la profundidad normalizada al canto de la estructura $z / d$, tal y como se resume en la tabla. Donde $k_{w}$ es la rigidez habitual de los muelles de Winkler obtenida mediante la formulación de Vesic (Vesic, 1963), tal y como se describe en el apartado §5.2.

\begin{tabular}{|c|c|}
\hline Parámetro del modelo & Expresión \\
\hline$k_{T o p}$ & $\frac{z / d}{2} \cdot k_{W}$ \\
\hline$K_{\text {Edge }}$ & $\frac{z / d}{2} \cdot 10 \cdot k_{W}$ \\
\hline$\Delta_{\text {Imposed }}(y / d)$ & $\alpha_{\text {Shape }} \cdot \Delta_{\text {Linear }}\left(\frac{y}{d}\right)+\left(1-\alpha_{\text {Shape }}\right) \cdot \Delta_{\text {Parabolic }}\left(\frac{y}{d}\right)$ \\
\hline QShape & $\left\{\begin{array}{cc}0,5+\frac{z}{d} & \text { si } \frac{z}{d}<0,5 \\
1 & \text { si } \frac{z}{d} \geq 0,5\end{array}\right.$ \\
\hline
\end{tabular}

Tabla 7-3. Expresiones para los parámetros del modelo dependientes de la profundidad.

Los patrones de deformación lineal $\Delta_{\text {Linear }}(y / d)$ y parabólica $\Delta$ Parabolic $(y / d)$ en función de la ordenada, descendente desde la losa superior, y normalizada al canto total de la estructura $y / d$, quedan descritos por las ecuaciones (Ec. 7-4) y (Ec. 7-5) respectivamente.

$$
\begin{aligned}
\Delta_{\text {Linear }}\left(\frac{y}{d}\right) & =\Delta_{\text {Top }} \cdot\left(1-\frac{y}{d}\right) \\
\Delta_{\text {Parabolic }}\left(\frac{y}{d}\right) & =\Delta_{\text {Top }} \cdot\left(1-\left(\frac{y}{d}\right)^{2}\right)
\end{aligned}
$$

Con este modelo mejorado (Fig. 7-17), que considera explícitamente los efectos debidos a la proximidad de la superficie, se puede proceder de forma análoga a como se indica en el capítulo $\S 5$, aplicando el patrón de desplazamientos impuestos laterales hasta un valor tal que el desplazamiento relativo $\Delta$ stru entre losas superior e inferior de la estructura sea igual al de la ecuación (Ec. 7-6), en la que $\gamma_{F F}$ es la deformación tangencial 
en campo libre, $d$ es el canto de la estructura, $R$ el coeficiente de racking a gran profundidad, y $R_{Z} / R_{\text {Deep }}$ el coeficiente de ajuste por proximidad a la superficie obtenido en el apartado §7.2.3 de esta tesis. Un resumen gráfico del procedimiento es el que se presenta en la (Fig. 7-18, b).

$$
\Delta_{S t r u}=\gamma_{F F} \cdot d \cdot R \cdot\left(\frac{R_{z}}{R_{\text {Deep }}}\right)
$$
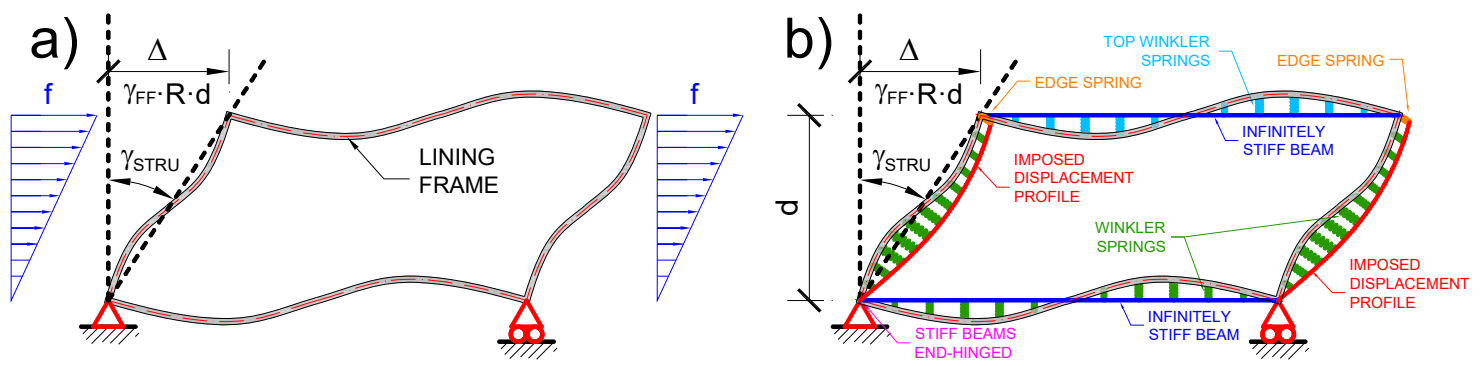

C)

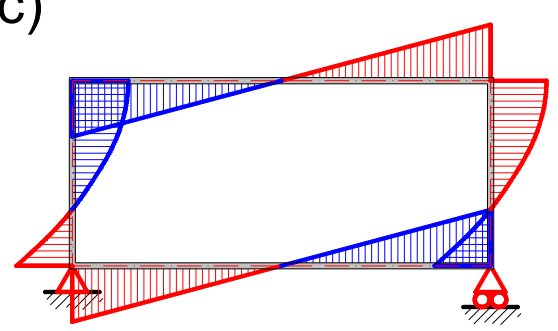

d)

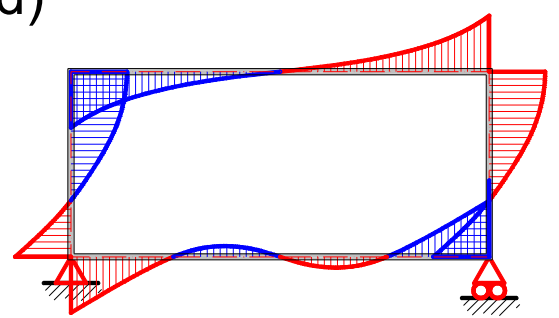

Fig. 7-18. (a) Modelo marco propuesto por Wang (Wang, 1993) para obtener esfuerzos. (b) Modelo marco mejorado propuesto en esta tesis. (c) Diagrama de momentos flectores consecuente con la hipótesis de comportamiento de Wang (Wang, 1993). (d) Diagrama de momentos flectores consecuente con la hipótesis de comportamiento mejorado propuesta en esta tesis.

\subsubsection{Verificación de momentos flectores}

A continuación, se presentan resultados de los análisis de momentos flectores tanto en la losa superior, como losa inferior, y muros laterales, resultantes de los modelos de elementos finitos descritos en el apartado §7.2.2, del procedimientos simplificado de Wang de ley de presiones laterales triangular (Fig. 7-18, a), y del procedimiento simplificado propuesto en esta tesis.

De manera similar a casos anteriores, dada la gran similitud encontrada entre los diferentes casos analizados, tan sólo se presentan y discuten los correspondientes a proporción geométrica $\lambda=$ ancho/canto $=1$ y $\lambda=2$ y profundidades $z / d=0$ y $z / d=0,4$. El resto de resultados puede encontrarse en el anexo $\S \mathrm{C}$ de esta tesis. 


\subsubsection{Resultados obtenidos mediante el método de Wang}

\subsection{Caso de $\lambda=1$ y $\mathrm{z} / \mathrm{d}=0$}

La figura (Fig. 5-1) muestra los resultados de elementos finitos y del procedimiento de Wang (Wang, 1993) para el caso $\lambda=1 \mathrm{y} z / d=0$. Tal y como se puede apreciar, el método proporciona resultados de precisión dispar.
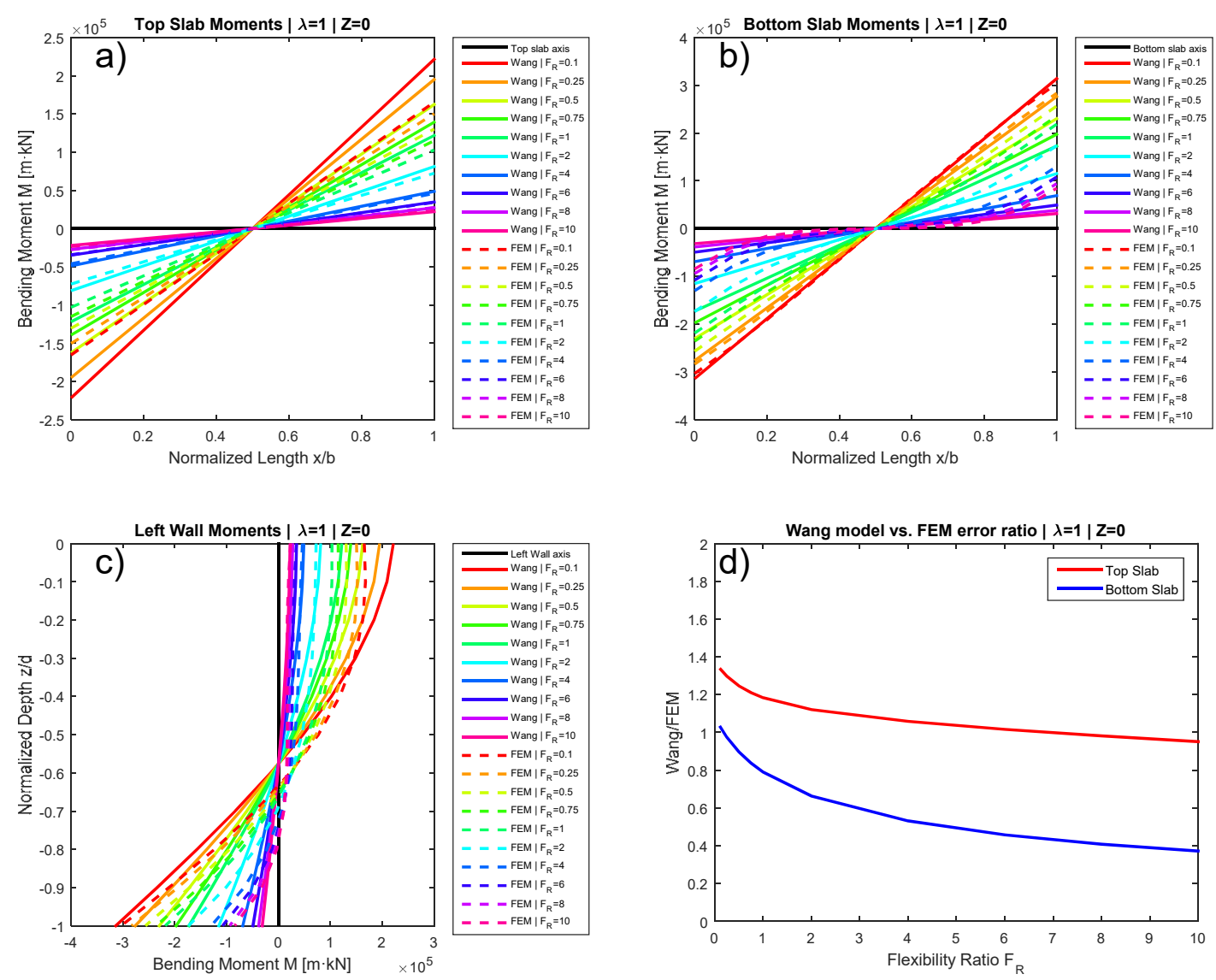

Fig. 7-19. Método de Wang. Momentos flectores para profundidad $\mathrm{z} / \mathrm{d}=0 \mathrm{y}$ proporción geométrica $\lambda=b / d=1$. (a) En losa superior. (b) En losa inferior, (c) En muro lateral izquierdo. (d) Ratio de resultados obtenidos mediante el método y los modelos numéricos MEF.

En lo que se refiere a los momentos en la losa superior (Fig. 5-1, a) los casos de estructuras más flexibles $\left(F_{R} \approx 10\right)$ son muy precisos, mientras que los correspondientes a los casos más rígidos $\left(F_{R} \approx 0,1\right)$ proporcionan resultados excesivamente conservadores de hasta del orden de hasta el 40\%. La figura (Fig. 5-1, d) muestra las ratios de error entre los valores predichos por Wang y los obtenidos mediante los análisis de elementos finitos.

Por el contrario, los momentos de la losa inferior (Fig. 5-1, b) proporcionan resultados relativamente ajustados para las estructuras más rígidas $\left(F_{R} \approx 0,1\right)$, mientras que 
las más flexibles resultan en esfuerzos hasta un $40 \%$ inferiores a los obtenidos mediante elementos finitos.

Atendiendo a la forma de las leyes de momentos en la losa superior, como cabría esperar para una estructura tan superficial $(z / d=0)$, los elementos finitos muestran una distribución de momentos de tipo biempotrada. El método de Wang también presenta esta ley lineal entre puntos de momento máximo a ambos lados de la losa.

En lo que se refiere a la losa inferior, se puede apreciar como los elementos finitos proporcionan, para los casos más flexibles, unas zonas hacia los extremos con un rápido incremento, que apartan la ley de momentos flectores de una línea recta, Mientras que las estructuras más rígidas sí presentan una distribución similar a la biempotrada. La explicación de este cambio en la forma de la ley de momentos ya se indicó en el apartado $\S 5.3$ de esta tesis, y responde al efecto mayor que tiene la vinculación elástica del terreno sobre las estructuras flexibles. Por el contrario, el método de Wang no es capaz de reflejar esta característica, y presenta para todos los casos una ley de viga biempotrada.

Con respecto a la distribución de momentos en el muro, podemos apreciar que, en líneas generales, la distribución de Wang se parece a la obtenida mediante los elementos finitos, pero con errores significativos en valor absoluto de hasta el 40\%, tanto por exceso o defecto dependiendo del caso, en los encuentros con las losas.

\subsection{Caso de $\lambda=2$ y $\mathrm{z} / \mathrm{d}=0$}

Los resultados correspondientes al caso $\lambda=2$ y $z / d=0$ se presentan en la figura (Fig. 7-20) y muestran tendencias similares al caso anterior, si acaso con errores más acentuados. En lo que respecta a la losa superior, los resultados del método de Wang muestran un ajuste bueno con errores del orden del 20\% inferiores a los elementos finitos $\left(M_{\text {Wang }}=0,8 \cdot M_{F E M}\right)$. La losa inferior, sin embargo, presenta errores mucho más significativos especialmente para las estructuras más flexibles, en los que los errores llegan a ser del orden del 70\% (MWang $\left.=0,3 \cdot M_{F E M}\right)$. 

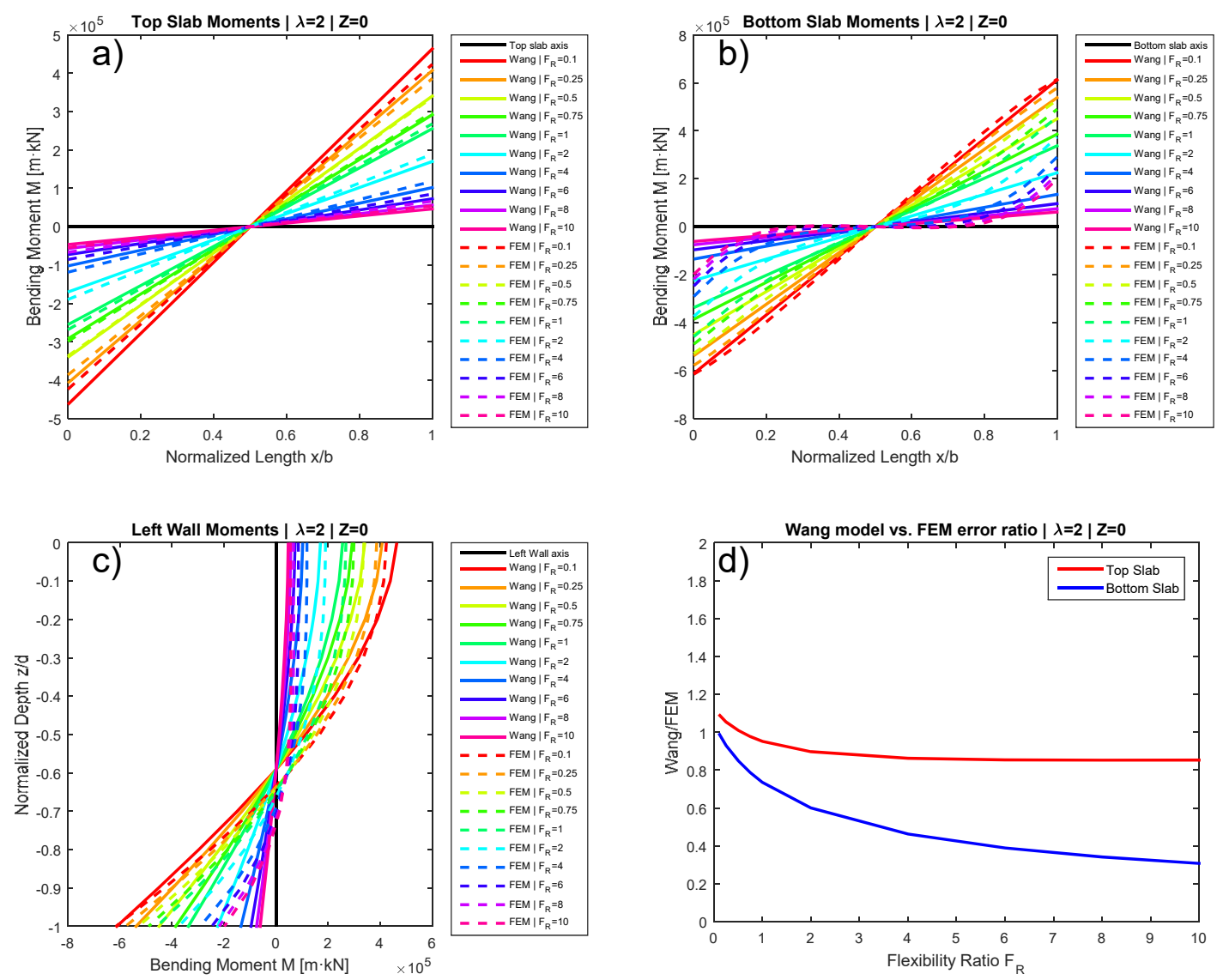

Fig. 7-20. Método de Wang. Momentos flectores para profundidad $z / d=0$ y proporción geométrica $\lambda=b / d=2$. (a) En losa superior. (b) En losa inferior, (c) En muro lateral izquierdo. (d) Ratio de resultados obtenidos mediante el método y los modelos numéricos MEF.

\subsection{Caso de $\lambda=1$ y $\mathrm{z} / \mathrm{d}=0,4$}

Los resultados correspondientes al caso $\lambda=1 \mathrm{y} z / d=0,4$ se presentan en la figura (Fig. 7-21) y muestran tendencias similares a los casos anteriores. En lo que respecta a la losa superior, los resultados del método de Wang muestran un mal ajuste con errores máximos del orden del $40 \%$ inferiores a los elementos finitos tanto para la losa superior como para la inferior $\left(M_{\text {Wang }}=0,6 \cdot M_{F E M}\right)$. Al igual que en casos anteriores, los errores se incrementan según aumenta la flexibilidad de la estructura. 

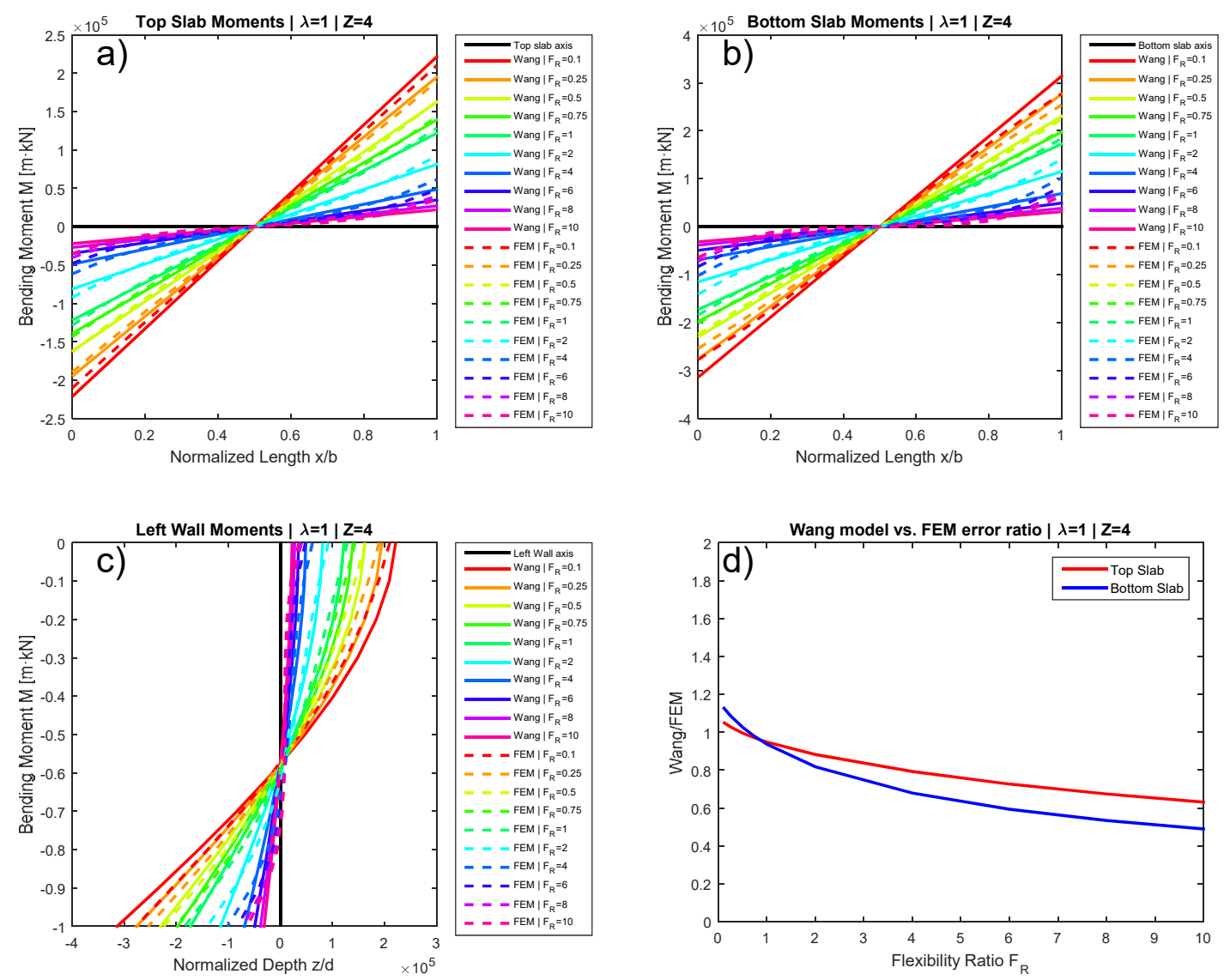

Fig. 7-21. Método de Wang. Momentos flectores para profundidad $z / d=0,4 \mathrm{y}$ proporción geométrica $\lambda=b / d=1$. (a) En losa superior. (b) En losa inferior, (c) En muro lateral izquierdo. (d) Ratio de resultados obtenidos mediante el método y los modelos numéricos MEF.

\subsection{Caso de $\lambda=2$ y $\mathrm{z} / \mathrm{d}=0,4$}

Los resultados correspondientes al caso $\lambda=2$ y $z / d=0,4$ se presentan en la figura (Fig. 7-22) y muestran tendencias similares a los casos anteriores. En lo que respecta a la losa superior, los resultados del método de Wang muestran un mal ajuste con errores máximos del orden del $40 \%$ inferiores a los elementos finitos $\left(M_{W a n g}=0,6 \cdot M_{F E M}\right)$ para la losa superior. La losa inferior tiene errores aún mayores del orden del $60 \%$ $\left(M_{W a n g}=0,4 \cdot M_{F E M}\right)$. Al igual que en casos anteriores, los errores se incrementan según aumenta la flexibilidad de la estructura. 

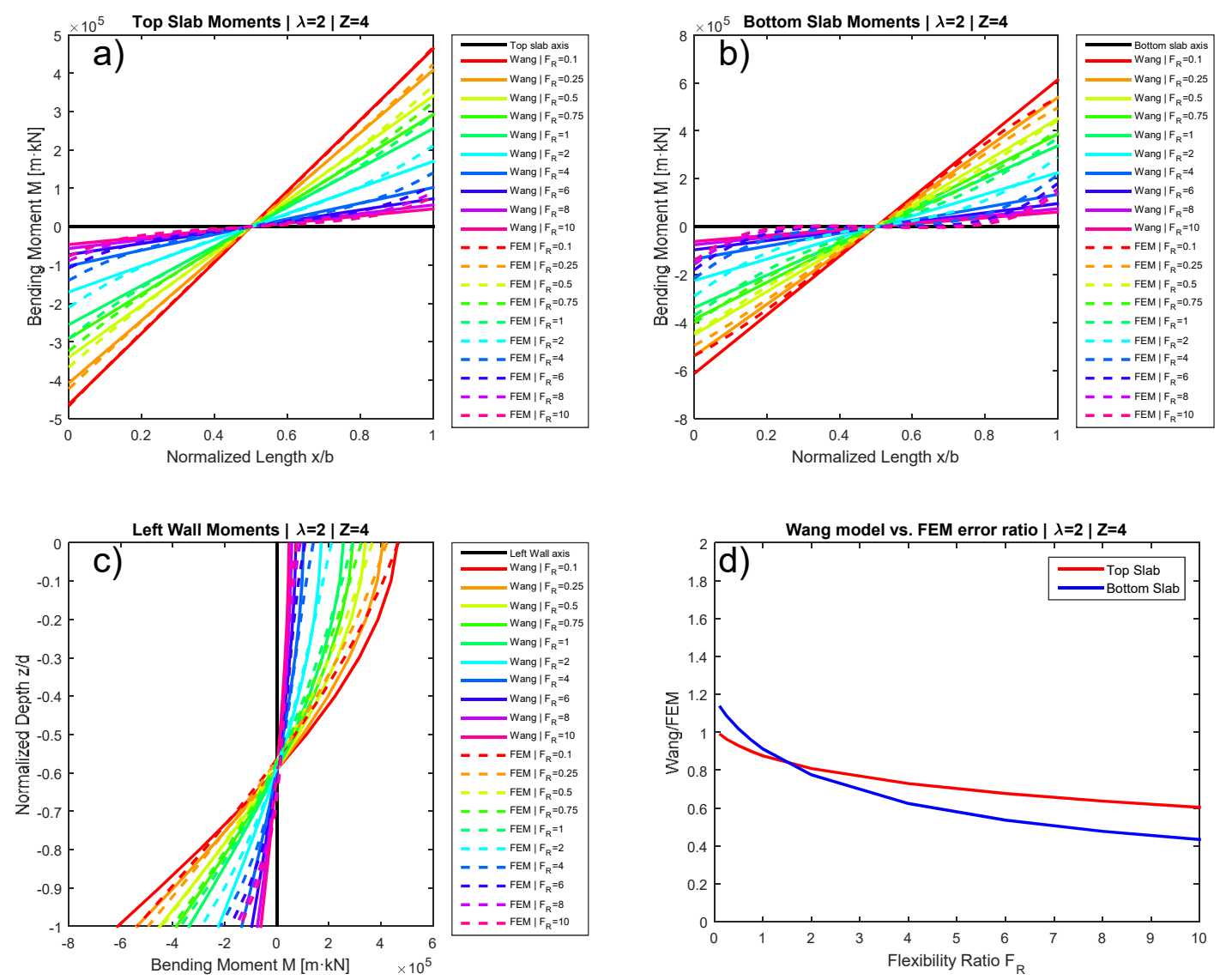

Fig. 7-22. Método de Wang. Momentos flectores para profundidad $z / d=0,4 \mathrm{y}$ proporción geométrica $\lambda=b / d=2$. (a) En losa superior. (b) En losa inferior, (c) En muro lateral izquierdo. (d) Ratio de resultados obtenidos mediante el método y los modelos numéricos MEF.

\subsubsection{Resultados obtenidos mediante el método propuesto}

\subsection{Caso de $\lambda=1$ y $\mathrm{z} / \mathrm{d}=0$}

La figura (Fig. 7-23) muestra los resultados de elementos finitos y del procedimiento propuesto en esta tesis, y descrito en el apartado $§ 7.3 .2$, para el caso $\lambda=1$ y $z / d=0$. Tal y como se puede apreciar, el método proporciona resultados de gran precisión.

En lo que se refiere a los momentos en la losa superior (Fig. 7-23, a) la precisión alcanzada es del orden de un $10 \%$ de error máximo para todo el rango de ratios de flexibilidad relativa $F_{R}$ estudiado, como se precisa en la figura (Fig. 7-23, d).

De manera similar, los momentos de la losa inferior (Fig. 7-23, b) proporcionan resultados incluso más ajustados, con errores máximos que oscilan entre virtualmente nulos y hasta del $5 \%$. 
Atendiendo a la forma de las leyes de momentos en la losa superior, el método propuesto muestra una ley lineal entre puntos de momento máximo a ambos lados de la losa. Como cabría esperar, esta forma de la ley de flectores se corresponde a un valor de la rigidez de fundación de Winkler de la losa superior $k_{T o p}=0$.

En lo que se refiere a la losa inferior, se puede apreciar como el método propuesto es capaz de reflejar de manera fidedigna el incremento localizado de momentos en las zonas próximas a los extremos para los casos más flexibles $\left(F_{R} \approx 10\right)$, mientras que, para los casos rígidos, presenta una ley propia de una viga biempotrada, tal y como resulta de los análisis de elementos finitos.
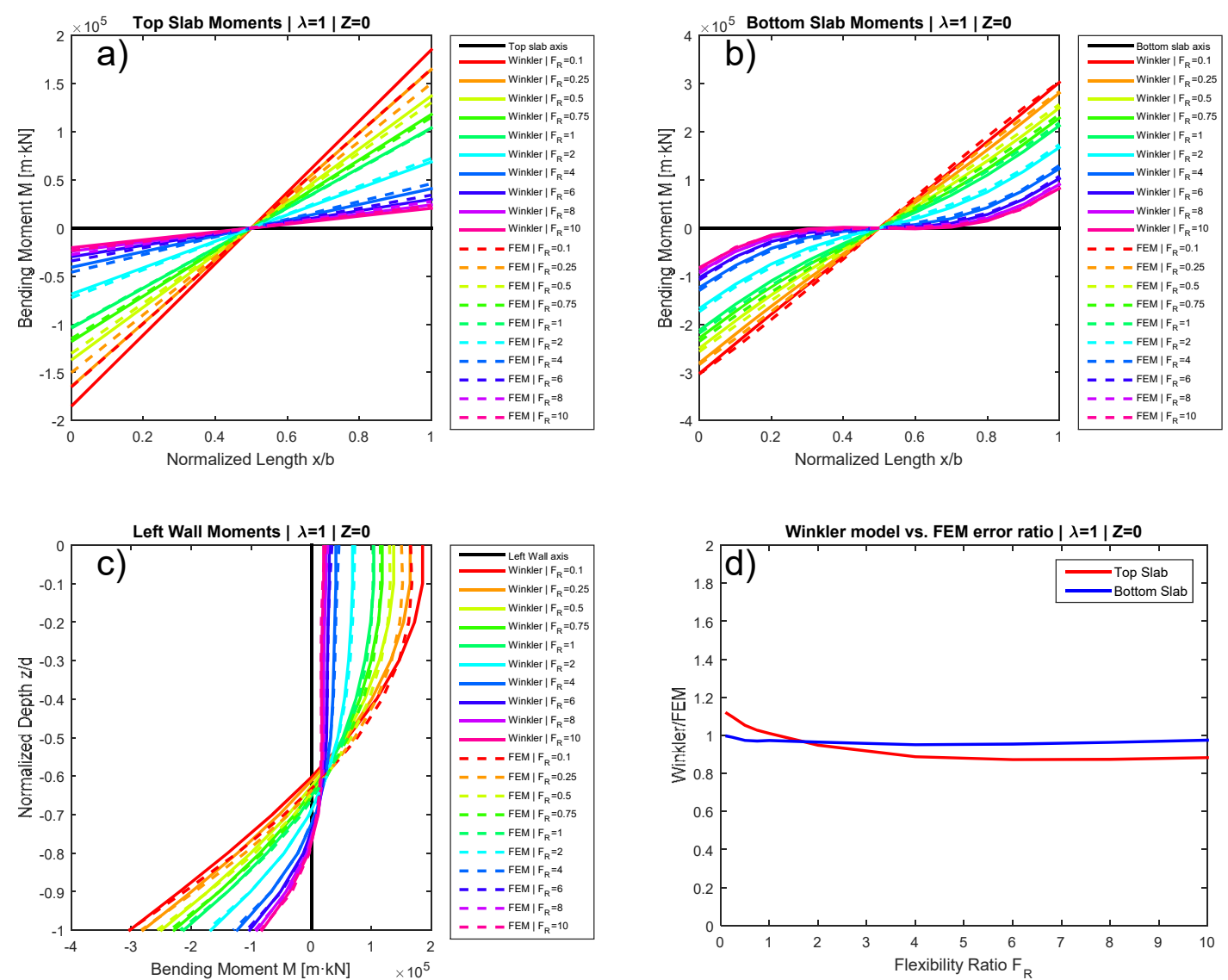

Fig. 7-23. Método propuesto. Momentos flectores para profundidad $\mathrm{z} / \mathrm{d}=0 \mathrm{y}$ proporción geométrica $\lambda=b / d=1$. (a) En losa superior. (b) En losa inferior, (c) En muro lateral izquierdo. (d) Ratio de resultados obtenidos mediante el método y los modelos numéricos MEF.

Con respecto a la distribución de momentos en el muro, podemos apreciar que las leyes de momentos obtenidas mediante el método simplificado propuesto se ajustan de manera excepcional a lo largo de toda la altura. En particular, se llama la atención sobre el cambio en la forma de la ley de momentos que se observa entre estructuras más rígidas y flexibles. En efecto, las estructuras flexibles presentan una zona, que corresponde 
esencialmente a la mitad superior del muro, para la cual los momentos son esencialmente constantes. El método propuesto es capaz de reproducir esta característica de la ley de momentos obtenida mediante los análisis de elementos finitos.

\subsection{Caso de $\lambda=2$ y $\mathrm{z} / \mathrm{d}=0$}
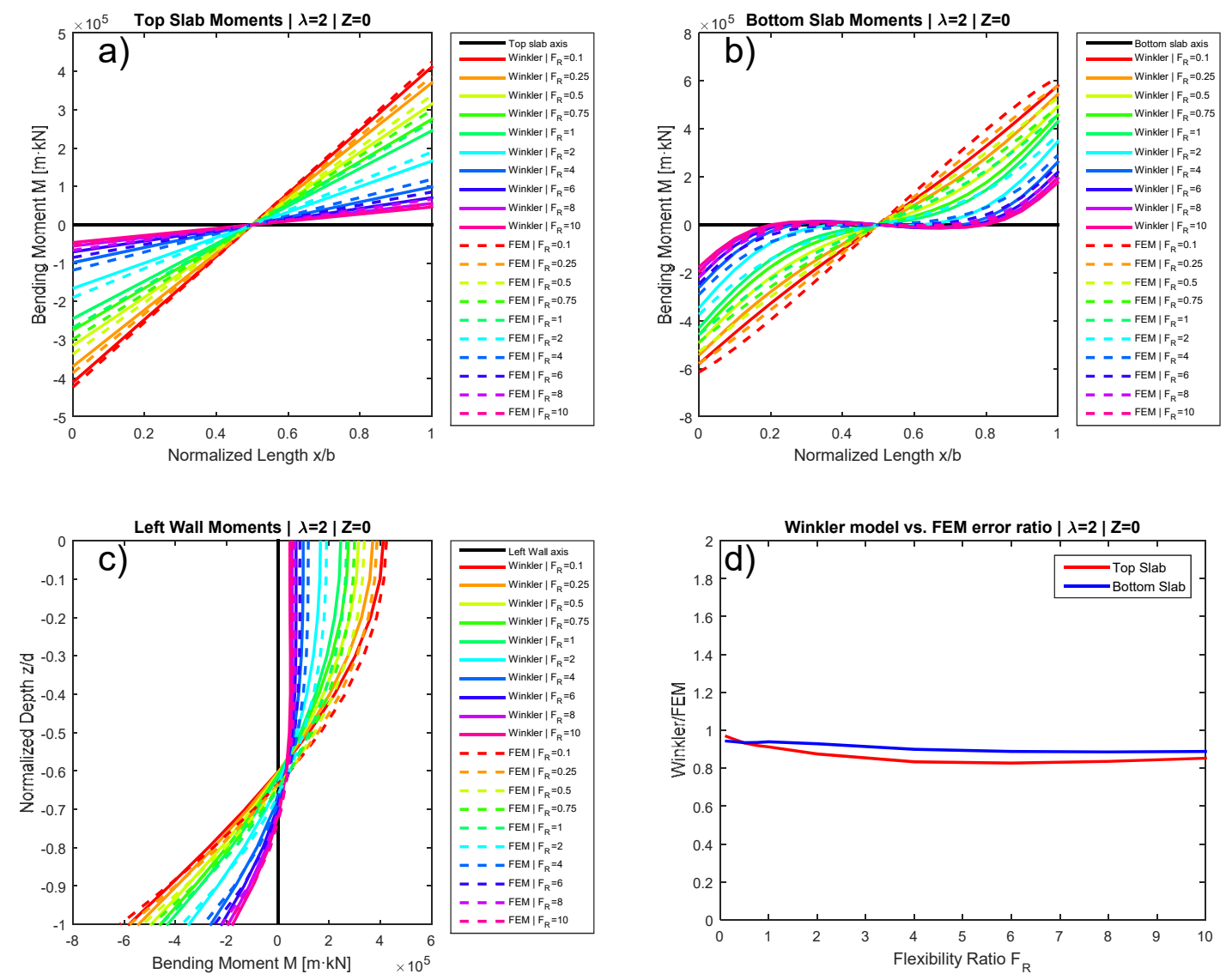

Fig. 7-24. Método propuesto. Momentos flectores para profundidad $z / d=0$ y proporción geométrica $\lambda=b / d=2$. (a) En losa superior. (b) En losa inferior, (c) En muro lateral izquierdo. (d) Ratio de resultados obtenidos mediante el método y los modelos numéricos MEF.

Los resultados correspondientes al caso $\lambda=2$ y $z / d=0$ se presentan en la figura (Fig. 7-24) y muestran tendencias similares al caso anterior. En lo que respecta a los momentos flectores en las losas, los resultados del método propuesto muestran un ajuste bueno con errores máximos que oscilan entre el 20\% para la losa superior y el $15 \%$ de la losa inferior.

\subsection{Caso de $\lambda=1$ y $\mathrm{z} / \mathrm{d}=0,4$}

Los resultados correspondientes al caso $\lambda=1 \mathrm{y} z / d=0,4$ se presentan en la figura (Fig. 7-25) y muestran aspectos similares al caso anterior. En lo que respecta a la losa 
superior, los resultados del método propuesto muestran un ajuste bueno con errores máximos que oscilan entre el 15\% para la losa superior y virtualmente nulos en la losa inferior.
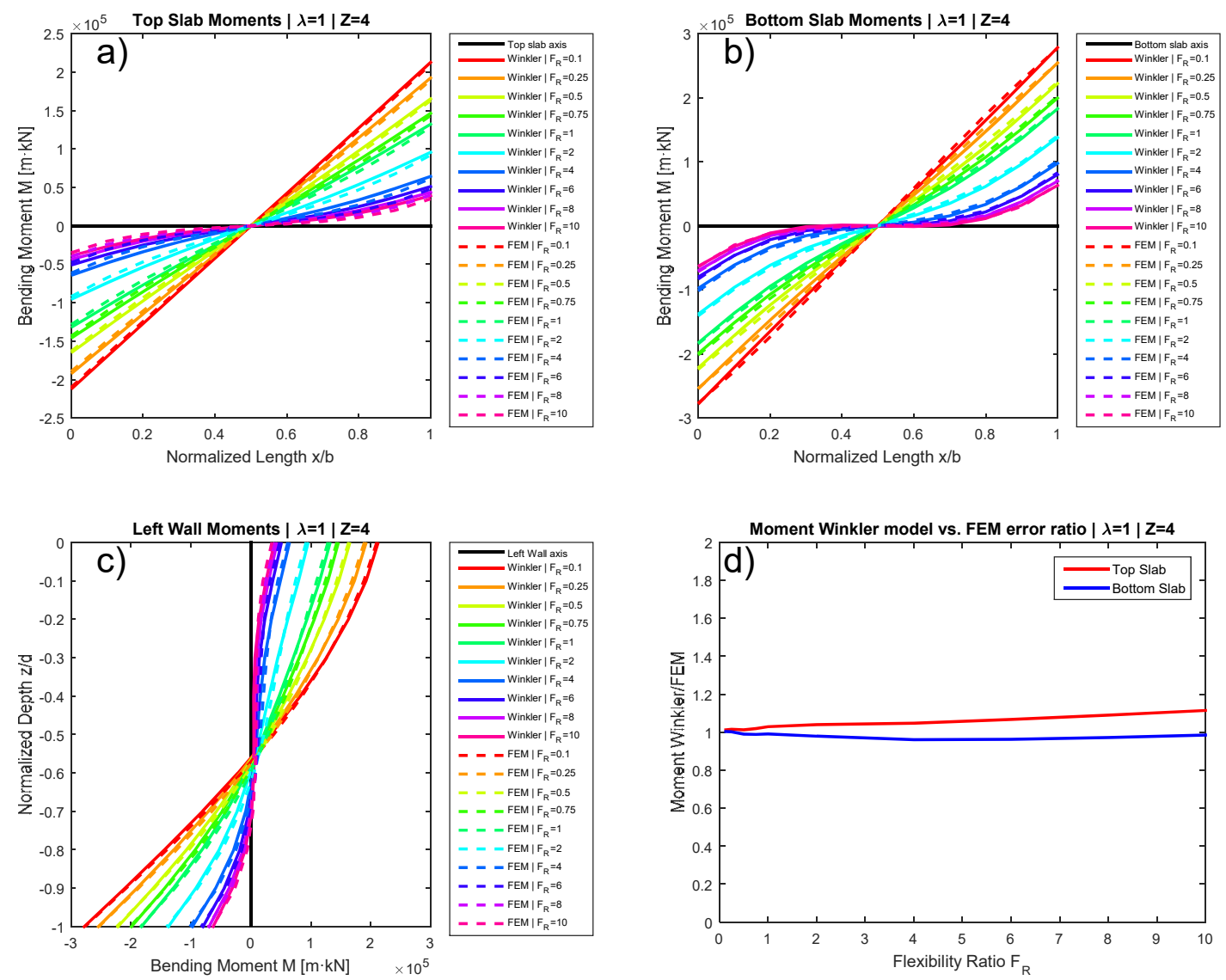

Fig. 7-25. Método propuesto. Momentos flectores para profundidad $\mathrm{z} / \mathrm{d}=0,4 \mathrm{y}$ proporción geométrica $\lambda=b / d=1$. (a) En losa superior. (b) En losa inferior, (c) En muro lateral izquierdo. (d) Ratio de resultados obtenidos mediante el método y los modelos numéricos MEF.

Respecto a las formas de las leyes de momentos, se aprecia como la rigidez del terreno por encima de la losa superior es capaz de curvar ligeramente la ley de momentos de la losa superior para los casos de estructuras más flexibles, aspecto que recoge con gran precisión el método propuesto. De manera análoga, la ley de momentos en el muro presenta para los casos más flexibles una ligera curvatura al acercarse a la losa superior; este fenómeno queda reproducido fielmente por el método propuesto en esta tesis.

\subsection{Caso de $\lambda=2$ y $\mathrm{z} / \mathrm{d}=0,4$}

Los resultados correspondientes al caso $\lambda=2$ y $z / d=0,4$ se presentan en la figura (Fig. 7-26) y muestran ajustes similares al caso anterior. En lo que respecta a las losas, los resultados del método propuesto muestran un ajuste bueno con errores máximos que 
oscilan entre el $5 \%$ y virtualmente nulos tanto para la losa superior como para la losa inferior.
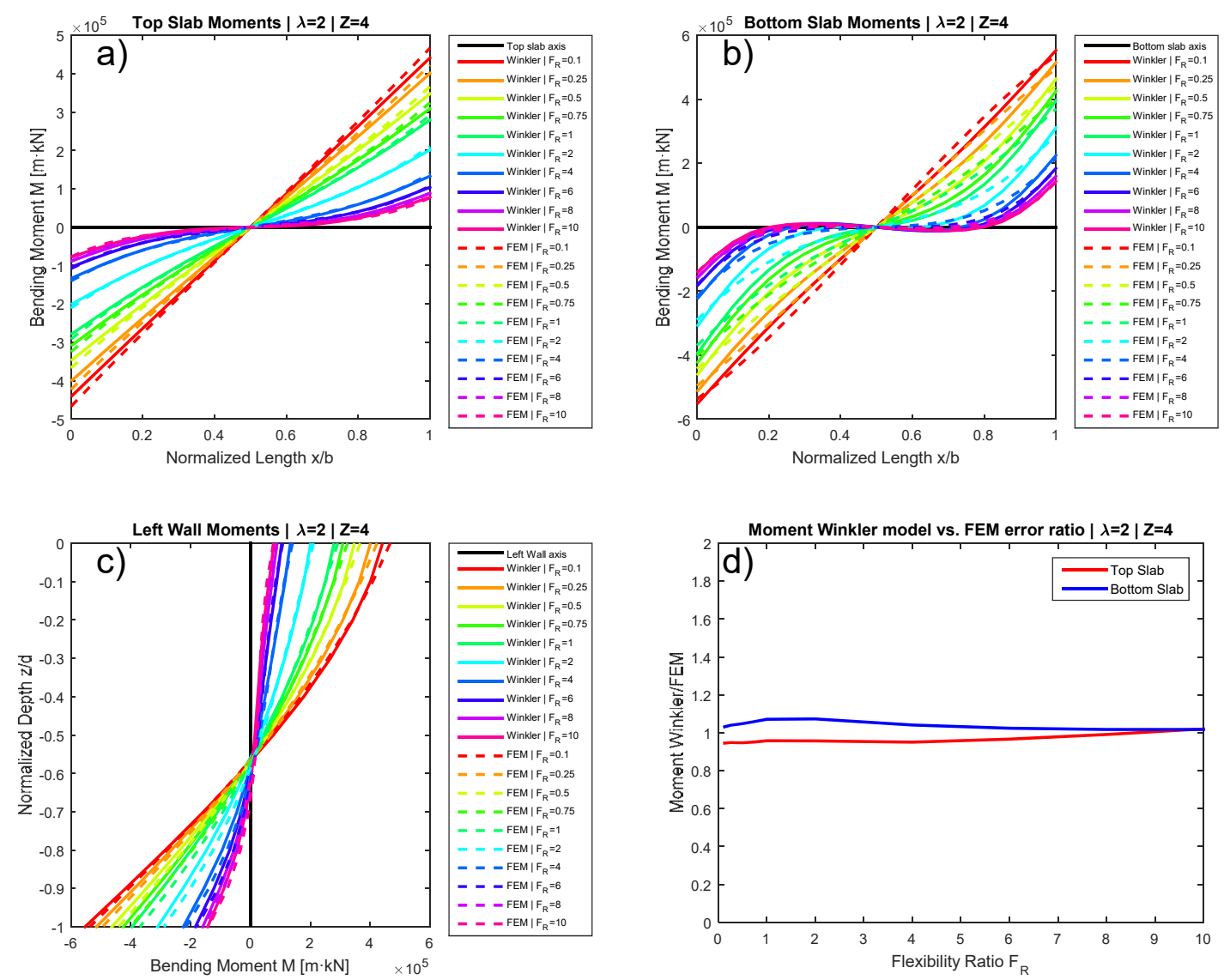

Fig. 7-26. Método propuesto. Momentos flectores para profundidad $\mathrm{z} / \mathrm{d}=0,4 \mathrm{y}$ proporción geométrica $\lambda=b / d=2$. (a) En losa superior. (b) En losa inferior, (c) En muro lateral izquierdo. (d) Ratio de resultados obtenidos mediante el método y los modelos numéricos MEF.

\subsubsection{Verificación de esfuerzos cortantes}

A continuación, se presentan resultados de los análisis de esfuerzos cortantes tanto en la losa superior, como losa inferior, y muros laterales, resultantes de los modelos de elementos finitos descritos en el apartado §7.2.2, del procedimientos simplificado de Wang con ley de presiones laterales triangular (Fig. 7-18, a), y del procedimiento simplificado propuesto en esta tesis. De manera similar a casos anteriores, dada la gran similitud encontrada entre los diferentes casos analizados, tan sólo se presentan y discuten los correspondientes a proporción geométrica $\lambda=a$ ancho/canto $=1$ y $\lambda=2$ y profundidades $\mathrm{z} / \mathrm{d}=0 \mathrm{y} \mathrm{z} / \mathrm{d}=0,4$. El resto de resultados puede encontrarse en el anexo $\S \mathrm{C}$ de esta tesis. 


\subsubsection{Resultados obtenidos mediante el método de Wang}

\subsection{Caso de $\lambda=1$ y $\mathrm{z} / \mathrm{d}=0$}

La figura (Fig. 7-27) muestra los resultados de elementos finitos y del procedimiento de Wang (Wang, 1993) para el caso $\lambda=1 \mathrm{y} z / d=0$. Tal y como se puede apreciar, el método proporciona resultados de precisión dispar.
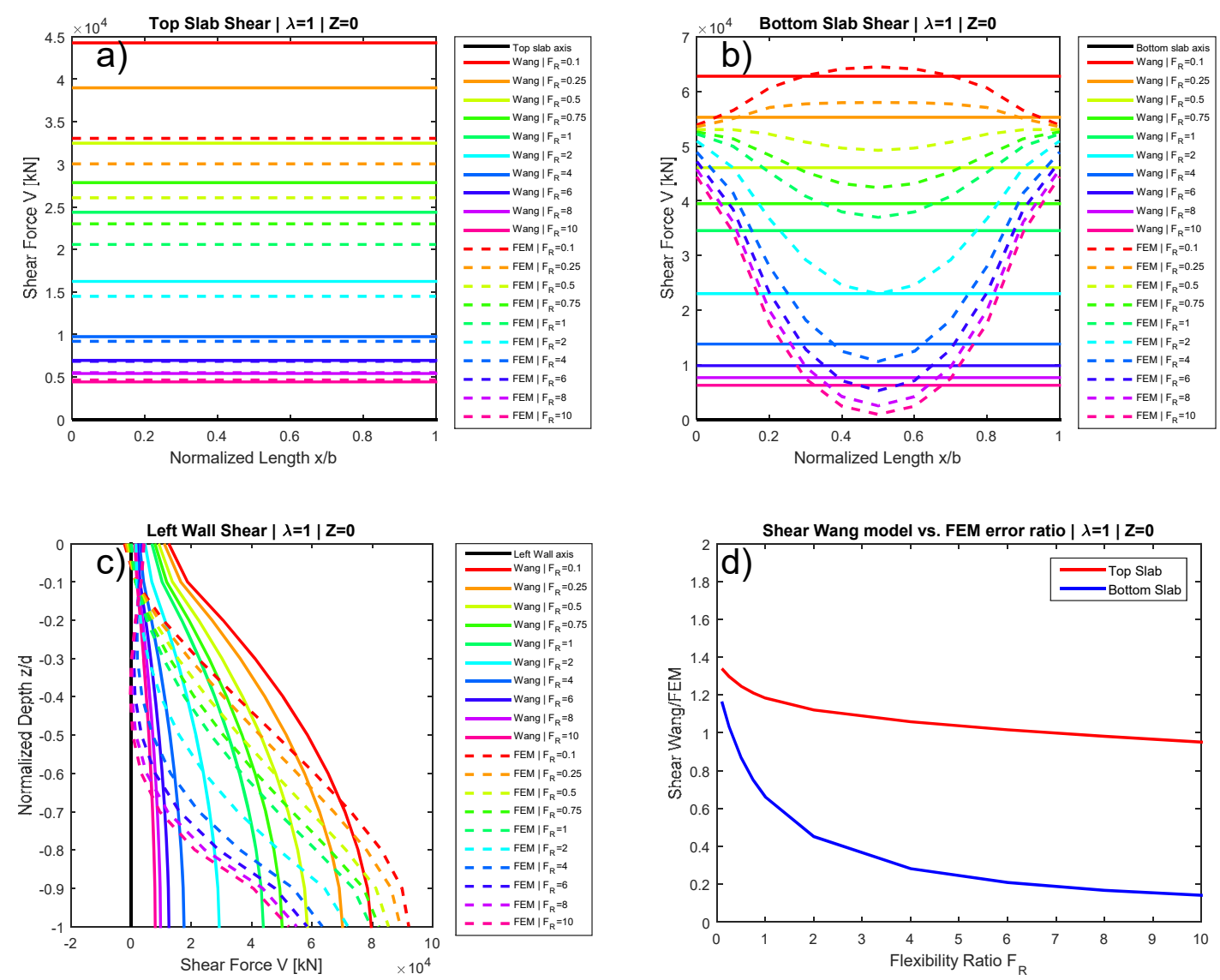

Fig. 7-27. Método de Wang. Esfuerzos cortantes para profundidad $z / d=0$ y proporción geométrica $\lambda=b / d=1$. (a) En losa superior. (b) En losa inferior, (c) En muro lateral izquierdo. (d) Ratio de resultados obtenidos mediante el método y los modelos numéricos MEF.

En lo que se refiere a los cortantes en la losa superior (Fig. 7-27, a) los casos de estructuras más flexibles $\left(F_{R} \approx 10\right)$ son muy precisos, mientras que los correspondientes a los casos más rígidos $\left(F_{R} \approx 0,1\right)$ proporcionan resultados excesivamente conservadores del orden de hasta el 40\%. La figura (Fig. 7-27, d) muestra las ratios de error entre los valores predichos por Wang y los obtenidos mediante los análisis de elementos finitos.

Por el contrario, los momentos de la losa inferior (Fig. 7-27, b) proporcionan con un ajuste muy pobre a la ley obtenida mediante elementos finitos, con errores de hasta el $80 \%$ para las estructuras más flexibles $\left(V_{\text {Wang }}=0,2 \cdot V_{F E M}\right)$. 
Atendiendo a la forma de las leyes de cortantes en la losa superior, como cabría esperar para una estructura tan superficial $(z / d=0)$, los elementos finitos muestran una distribución de cortantes constante. El método de Wang también presenta esta ley lineal entre puntos de a ambos lados de la losa.

En lo que se refiere a la losa inferior, se puede apreciar como los elementos finitos proporcionan, para los casos más flexibles, unas zonas hacia los extremos con un rápido incremento, que apartan la ley de cortantes de una línea recta, mientras que las estructuras más rígidas si presentan una distribución de cortantes constante. Por el contrario, el método de Wang no es capaz de reflejar esta característica, y presenta para todos los casos una ley de cortantes constante.

Con respecto a la distribución de cortantes en el muro, podemos apreciar que, en líneas generales, la distribución de Wang es notablemente diferente de la obtenida mediante elementos finitos.

\subsection{Caso de $\lambda=2$ y $\mathrm{z} / \mathrm{d}=0$}

Los resultados correspondientes al caso $\lambda=2 \mathrm{y} z / d=0$ se presentan en la figura (Fig. 7-28) y muestran tendencias similares al caso anterior, si acaso con errores más acentuados.

En lo que respecta a la losa superior, los resultados del método de Wang muestran un ajuste bueno con errores del orden del $20 \%$ inferiores a los elementos finitos $\left(\mathrm{V}_{\text {Wang }}=0,8 \cdot V_{\text {FEM }}\right)$.

La losa inferior, sin embargo, presenta errores mucho más significativos especialmente para las estructuras más flexibles, en los que los errores llegan a ser del orden del $90 \%\left(M_{\text {Wang }}=0,1 \cdot M_{F E M}\right)$. 

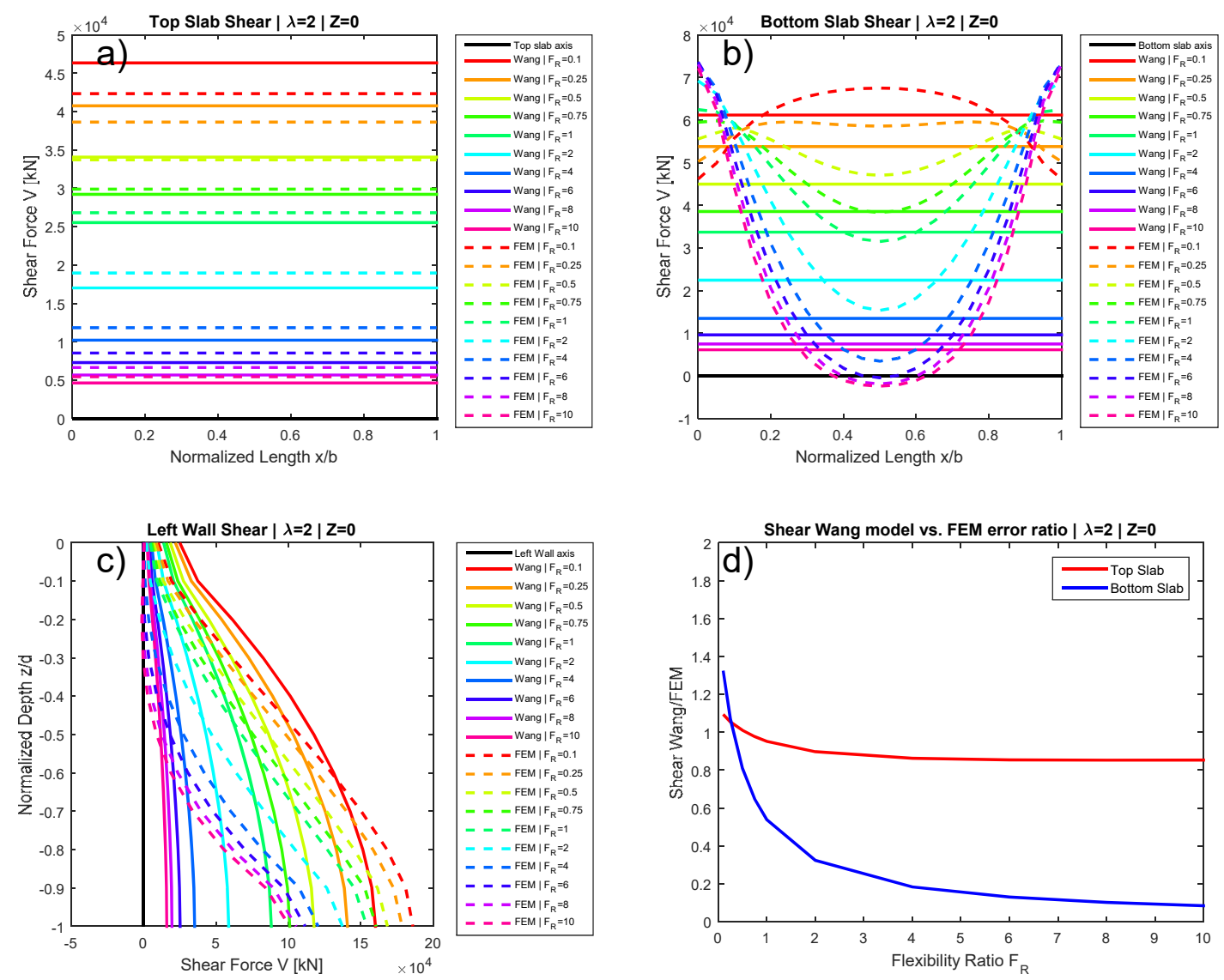

Fig. 7-28. Método de Wang. Esfuerzos cortantes para profundidad $z / d=0$ y proporción geométrica $\lambda=b / d=2$. (a) En losa superior. (b) En losa inferior, (c) En muro lateral izquierdo. (d) Ratio de resultados obtenidos mediante el método y los modelos numéricos MEF.

\subsection{Caso de $\lambda=1$ y $\mathrm{z} / \mathrm{d}=0,4$}

Los resultados correspondientes al caso $\lambda=1 \mathrm{y} z / d=0,4$ se presentan en la figura (Fig. 7-29) y muestran tendencias similares a los casos anteriores. En lo que respecta a la losa superior, los resultados del método de Wang muestran un mal ajuste con errores máximos del orden del $80-70 \%$ inferiores a los elementos finitos tanto para la losa superior como para la inferior $\left(V_{\text {Wang }}=0,2 \cdot V_{F E M}\right)$. Al igual que en casos anteriores, los errores se incrementan según aumenta la flexibilidad de la estructura. 

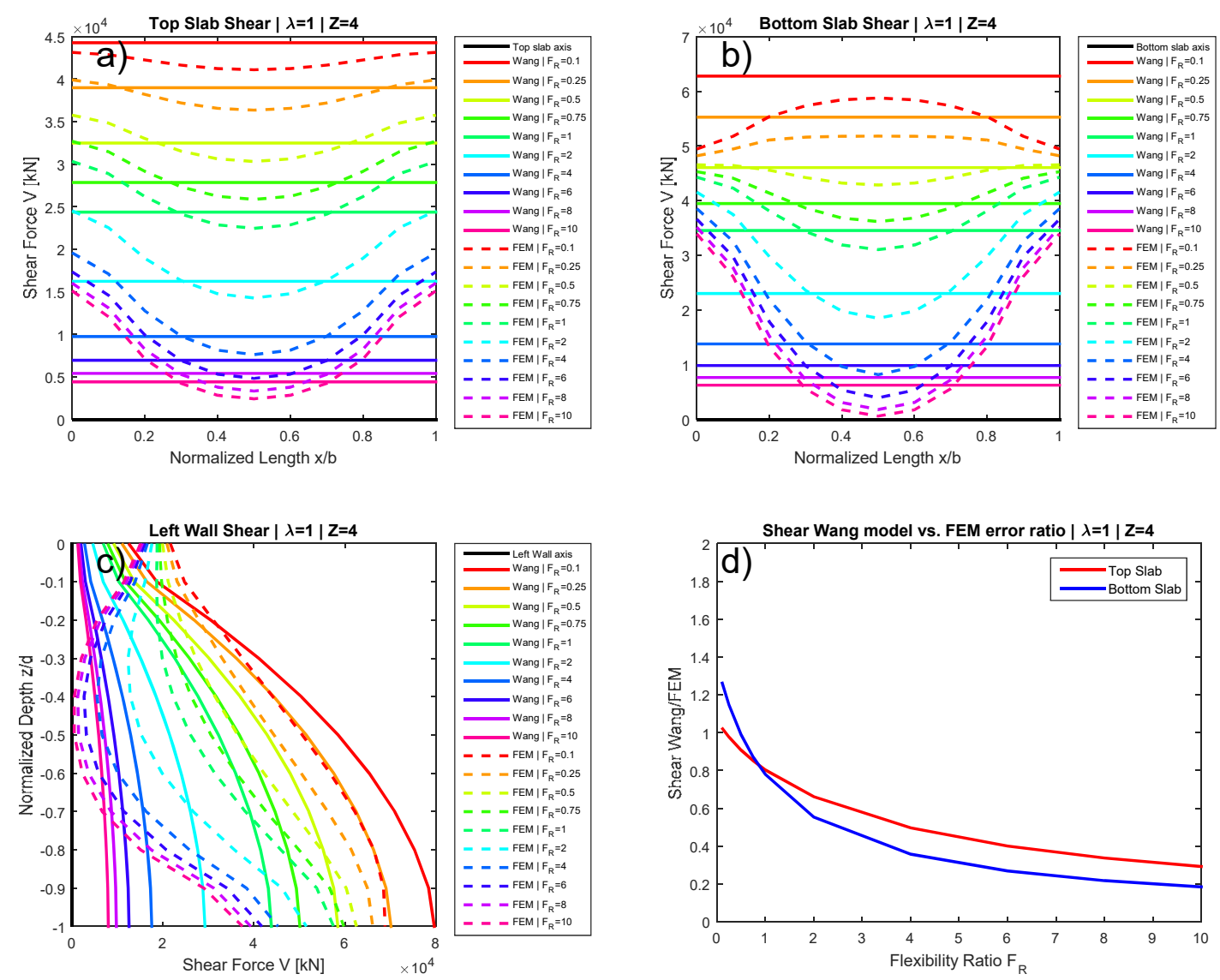

Fig. 7-29. Método de Wang. Momentos flectores para profundidad $z / d=0,4 \mathrm{y}$ proporción geométrica $\lambda=b / d=1$. (a) En losa superior. (b) En losa inferior, (c) En muro lateral izquierdo. (d) Ratio de resultados obtenidos mediante el método y los modelos numéricos MEF.

\subsection{Caso de $\lambda=2$ y $\mathrm{z} / \mathrm{d}=0,4$}

Los resultados correspondientes al caso $\lambda=2$ y $z / d=0,4$ se presentan en la figura (Fig. 7-30) y muestran tendencias similares a los casos anteriores. En lo que respecta a la losa superior, los resultados del método de Wang muestran un mal ajuste con errores máximos del orden del $80 \%$ inferiores a los elementos finitos $\left(V_{\text {Wang }}=0,2 \cdot V_{F E M}\right)$ para la losa superior. La losa inferior tiene errores aún mayores del orden del $90 \%$ $\left(V_{\text {Wang }}=0,1 \cdot V_{F E M}\right)$. Al igual que en casos anteriores, los errores se incrementan según aumenta la flexibilidad de la estructura. 

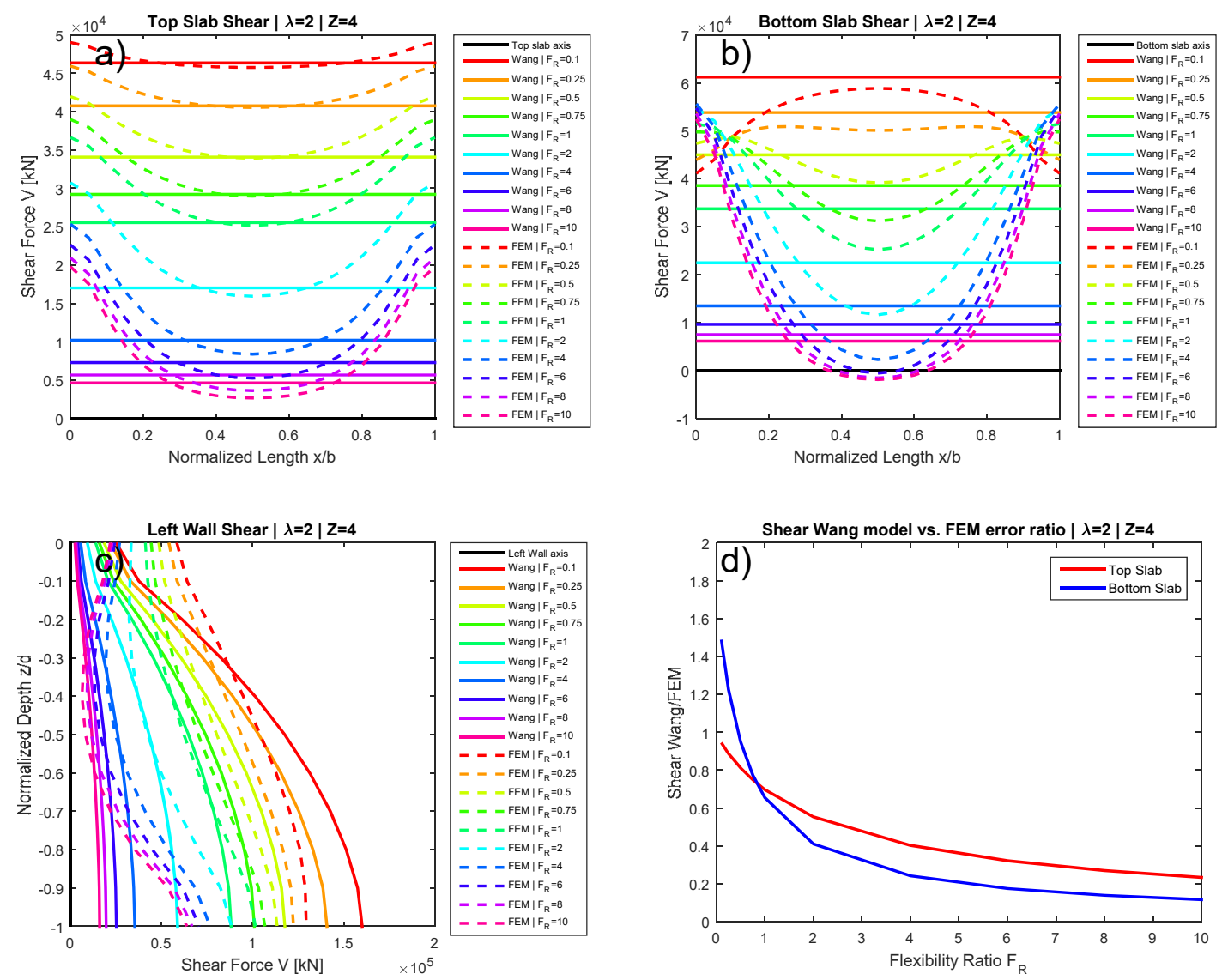

Fig. 7-30. Método de Wang. Esfuerzos cortantes para profundidad $z / d=0,4$ y proporción geométrica $\lambda=b / d=2$. (a) En losa superior. (b) En losa inferior, (c) En muro lateral izquierdo. (d) Ratio de resultados obtenidos mediante el método y los modelos numéricos MEF.

\subsubsection{Resultados obtenidos mediante el método propuesto}

\subsection{Caso de $\lambda=1$ y $\mathrm{z} / \mathrm{d}=0$}

La figura (Fig. 7-31) muestra los resultados de elementos finitos y del procedimiento propuesto en esta tesis, y descrito en el apartado $§ 7.3 .2$, para el caso $\lambda=1$ y $z / d=0$. Tal y como se puede apreciar, el método proporciona resultados de notable precisión.

En lo que se refiere a los cortantes en la losa superior e inferior (Fig. 7-31, a y b) la precisión alcanzada es del orden de un $15 \%$ de error máximo para todo el rango de ratios de flexibilidad relativa $F_{R}$ estudiado, como se precisa en la figura (Fig. 7-31, d).

Atendiendo a la forma de las leyes de cortantes en la losa superior, el método propuesto muestra una ley lineal entre puntos de a ambos lados de la losa. Como cabría 
esperar, esta forma de la ley de cortantes se corresponde a un valor de la rigidez de fundación de Winkler de la losa superior $k_{T o p}=0$.

En lo que se refiere a la losa inferior, se puede apreciar como el método propuesto es capaz de reflejar de manera fidedigna el incremento localizado de momentos en las zonas próximas a los extremos para los casos más flexibles $\left(F_{R} \approx 10\right)$, mientras que, para los casos rígidos, presenta una ley propia de una viga biempotrada, tal y como resulta de los análisis de elementos finitos.
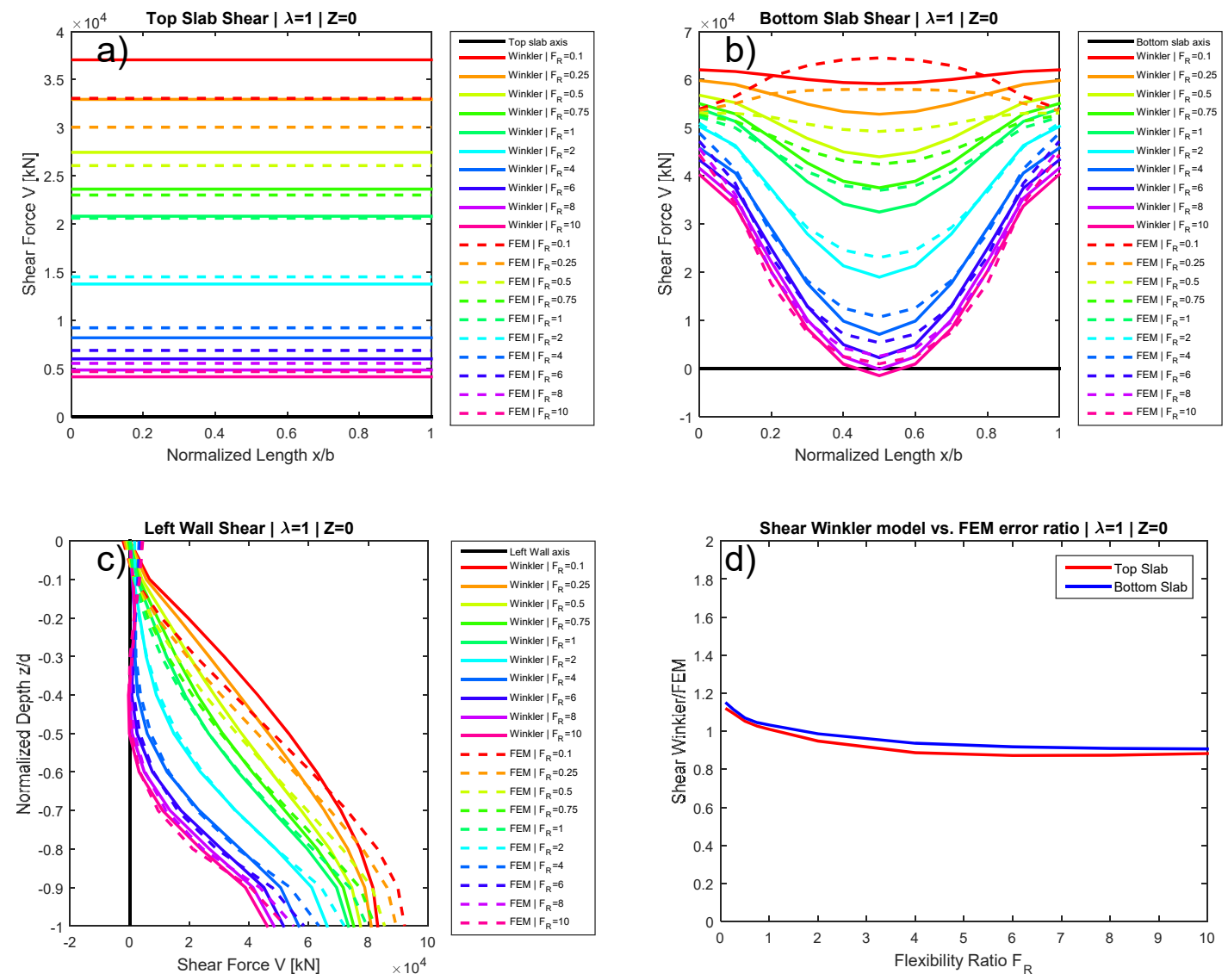

Fig. 7-31. Método propuesto. Esfuerzos cortantes para profundidad $z / d=0$ y proporción geométrica $\lambda=b / d=1$. (a) En losa superior. (b) En losa inferior, (c) En muro lateral izquierdo. (d) Ratio de resultados obtenidos mediante el método y los modelos numéricos MEF.

Con respecto a la distribución de cortantes en el muro, podemos apreciar que las leyes de cortante obtenidas mediante el método simplificado propuesto se ajustan de manera notable a lo largo de toda la altura. En particular, se llama la atención sobre el cambio en la forma de la ley de cortantes que se observa entre estructuras más rígidas y flexibles. En efecto, las estructuras flexibles presentan una zona que corresponde esencialmente a la mitad superior del muro para la cual los cortantes son esencialmente 
constantes. El método propuesto es capaz de reproducir esta característica de la ley de cortantes que se observa en los análisis de elementos finitos.

\subsection{Caso de $\lambda=2$ y $\mathrm{z} / \mathrm{d}=0$}

Los resultados correspondientes al caso $\lambda=2$ y $z / d=0$ se presentan en la figura (Fig. 7-32) y muestran tendencias similares al caso anterior. En lo que respecta a los momentos flectores en las losas, los resultados del método propuesto muestran un ajuste bueno con errores máximos que oscilan entre el $40 \%$ para estructuras rígidas en la losa superior, y que mejora hasta el 15\% para estructuras flexibles, y del $20-15 \%$ en la losa inferior para todo el rango de flexibilidades.
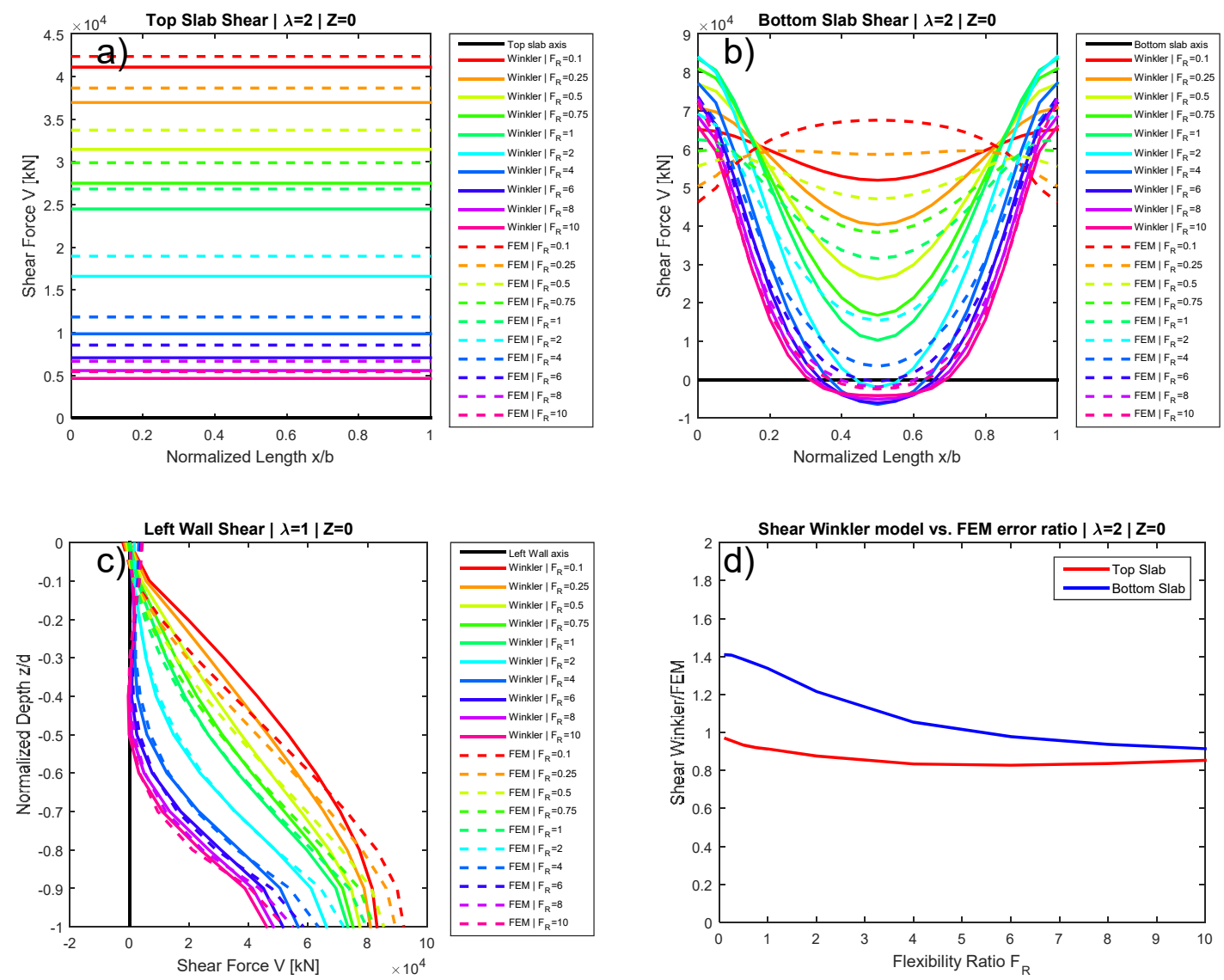

Fig. 7-32. Método propuesto. Esfuerzos cortantes para profundidad $z / d=0$ y proporción geométrica $\lambda=b / d=2$. (a) En losa superior. (b) En losa inferior, (c) En muro lateral izquierdo. (d) Ratio de resultados obtenidos mediante el método y los modelos numéricos MEF. 


\subsection{Caso de $\lambda=1$ y $\mathrm{z} / \mathrm{d}=0,4$}

Los resultados correspondientes al caso $\lambda=1$ y $z / d=0,4$ se presentan en la figura (Fig. 7-33) y muestran aspectos similares al caso anterior. En lo que respecta a la losa superior, los resultados del método propuesto muestran un ajuste bueno con errores máximos que oscilan entre el $20 \%$ para la losa superior y el $15 \%$ en la losa inferior.

Respecto a las formas de las leyes de momentos, se aprecia como la rigidez del terreno por encima de la losa superior es capaz de curvar la ley de cortantes de la losa superior para los casos de estructuras más flexibles, aspecto que recoge con precisión el método propuesto. De manera análoga, la forma de la ley de cortantes en el muro presenta gran similitud con la obtenida mediante elementos finitos.
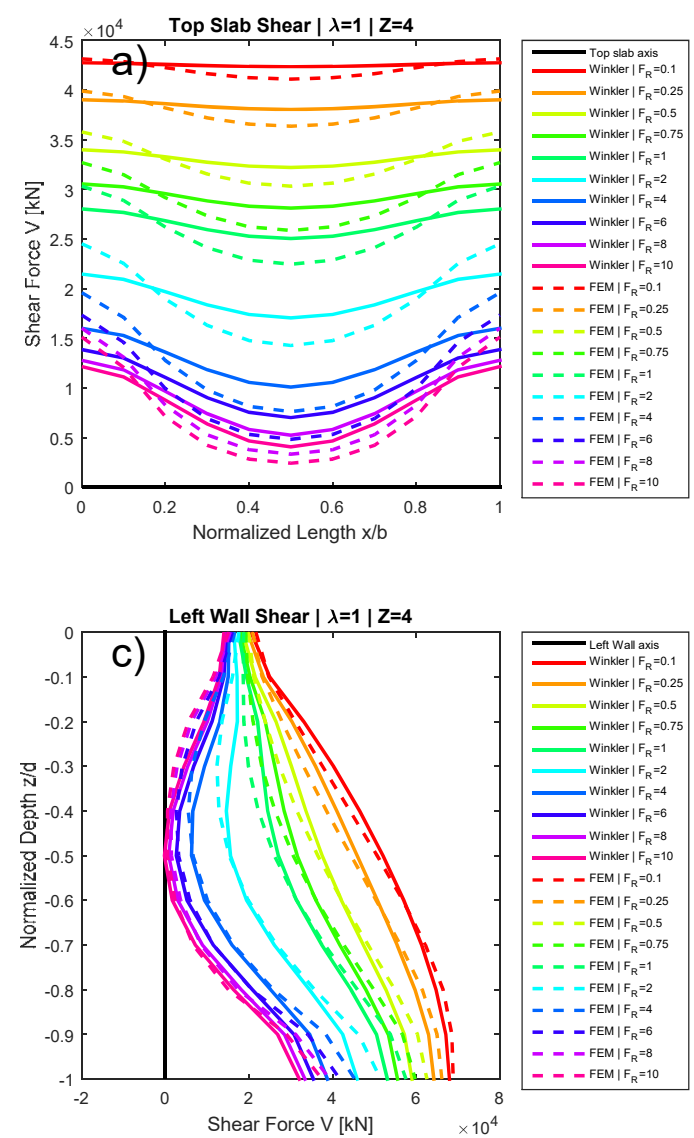
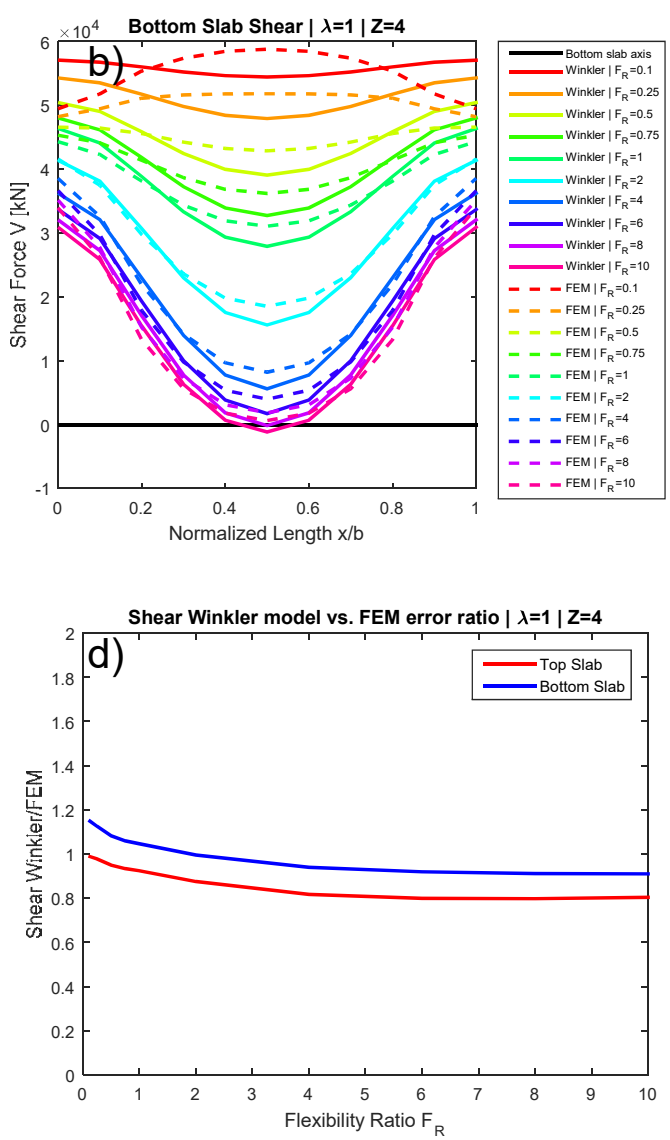

Fig. 7-33. Método propuesto. Esfuerzos cortantes para profundidad $\mathrm{z} / \mathrm{d}=0,4 \mathrm{y}$ proporción geométrica $\lambda=b / d=1$. (a) En losa superior. (b) En losa inferior, (c) En muro lateral izquierdo. (d) Ratio de resultados obtenidos mediante el método y los modelos numéricos MEF. 


\subsection{Caso de $\lambda=2$ y $\mathrm{z} / \mathrm{d}=0,4$}

Los resultados correspondientes al caso $\lambda=2$ y $z / d=0,4$ se presentan en la figura (Fig. 7-34) y muestran ajustes similares al caso anterior.
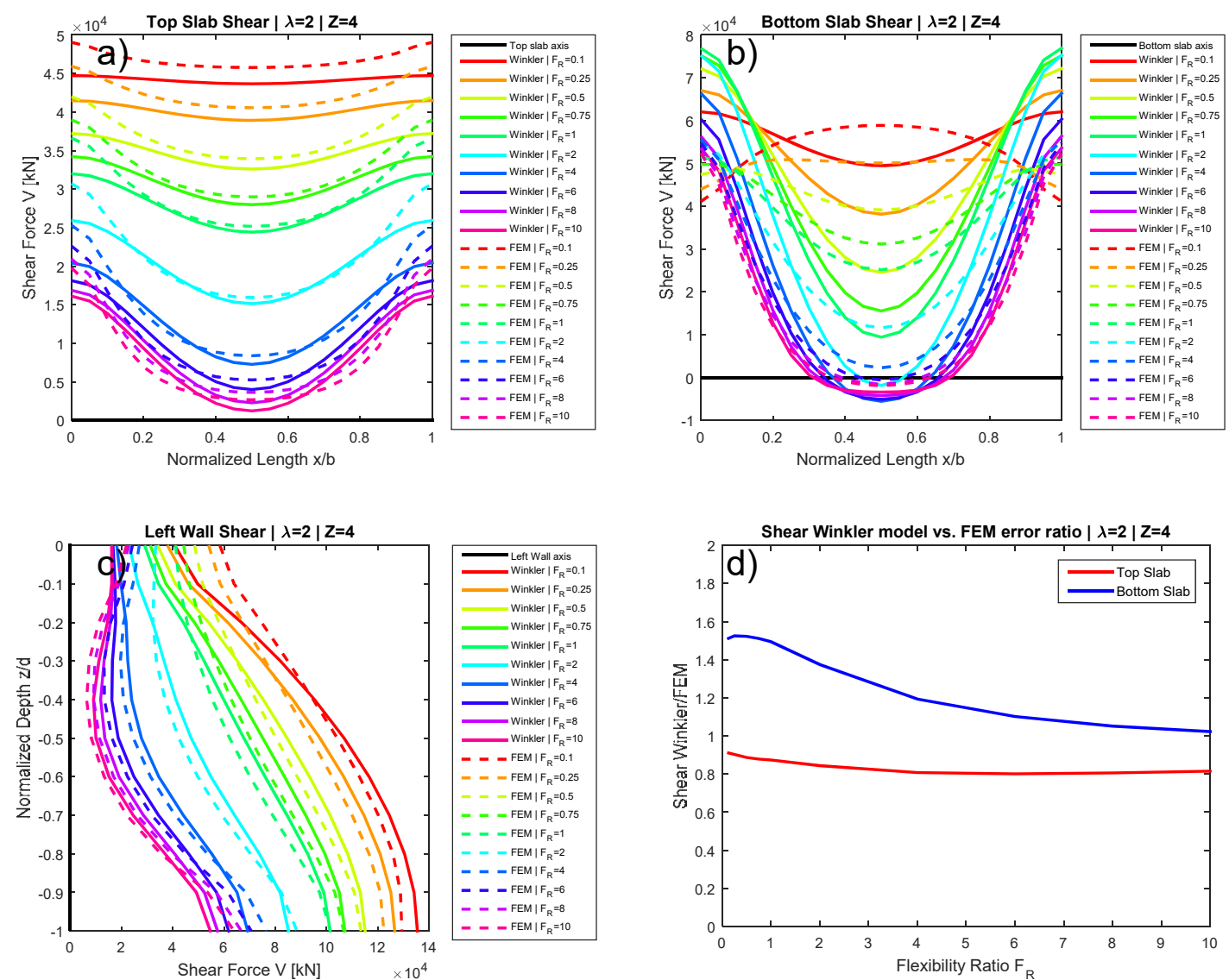

Fig. 7-34. Método propuesto. Esfuerzos cortantes para profundidad z/d=0,4 y proporción geométrica $\lambda=b / d=2$. (a) En losa superior. (b) En losa inferior. (c) En muro lateral izquierdo. (d) Ratio de resultados obtenidos mediante el método y los modelos numéricos MEF. 


\section{CRITERIOS DE DEMANDA Y DESEMPEÑO PARA EL PROYECTO DE ESTACIONES SUBTERRÁNEAS DE METRO}

Como se ha expuesto en el capítulo $\S 3$ de esta tesis, especialmente en el apartado $\S 3.8$ que revisa diversas normativas internacionales, la falta de consenso entre ellas tanto en lo que respecta a los niveles de demanda sísmica, como a los objetivos de desempeño estructural, es significativa.

A pesar de que cada autoridad competente es libre de establecer tanto las acciones como las limitaciones estructurales que crea conveniente, resulta razonable pensar que estructuras similares, con similar función y características, en diferentes regiones sometidas a amenazas sísmicas similares, debieran tener criterios homólogos en lo que se refiere a su diseño y comportamiento esperable. Resulta por lo tanto razonable preguntarse por la razón de esta falta de homogeneidad en dichos criterios.

La situación actual de falta de consenso puede deberse a varios factores:

1) Por una parte, la metodología de diseño basado en el desempeño, aún en su vertiente más elemental, es relativamente nueva y, en consecuencia, su uso en la práctica no se ha extendido los suficiente como para alcanza un grado de madurez satisfactorio.

Efectivamente, de manera comparativa con otros requisitos (p.ej. definición de acciones de tráfico, resistencia a flexión de secciones), son pocas las normativas que tienen una descripción explícita de diferentes niveles de demanda, y objetivos de desempeño consecuentes con estas, con parámetros precisos y objetivos a los que puede atenerse el proyectista. Sin suficientes normativas que implementen estos métodos, y escasas autoridades públicas o entes privados que los potencien, resulta lógico pensar que la tendencia natural de la profesión sea mantener las 
metodologías tradicionales de acción-resistencia, y prestar tan sólo una atención marginal a estas nuevas metodologías.

Sin una atención suficiente, resulta natural que no se suscite el debate necesario para poder alcanzar un consenso respecto a, por ejemplo, cuáles deben ser los límites de deformación admisibles para cada objetivo de desempeño (p.ej. a partir de que deformación en el acero puede considerarse reparable o no reparable una sección de hormigón armado).

2) Por otra parte, la naturaleza esencialmente incierta, tanto de la acción sísmica, como de la respuesta estructural, como de la propia definición del daño, suponen una importante dificultad en lo que se refiere a la definición de demandas y objetivos de desempeño.

Con respecto a la acción sísmica, esta incertidumbre se refleja, por ejemplo, en el mayor o menor grado de subjetividad involucrado en la definición del periodo de retorno del sismo. Siguiendo la evolución reciente de los criterios de AASHTO respecto al diseño de puentes (Marsh \& Stringer, 2013), se puede ver como en el año 1990 se fijaba un único nivel de demanda con periodo de retorno $T_{R}=500$ años. Más adelante, el proyecto MCEER/ATC-49 propuso para AASHTO dos niveles, uno inferior con $T_{R}=108$ años y otro superior con $T_{R}=2500$ años, pero que en la redacción final se quedó en un único nivel con $T_{R}=2500$ años. A finales de la década de 2000, AASHTO convino un único nivel con un periodo de retorno de $T_{R}=1000$ años, que se mantiene hasta la actualidad.

Con respecto a la definición del daño, la incertidumbre se refleja, por ejemplo, en la dificultad experimental de establecer el nivel de deformación en el hormigón en el que comienza a producirse el spalling o el pandeo de las armaduras longitudinales.

3) Por último, el hecho de que, conceptualmente, no pueda haber un único conjunto demanda-desempeño que se pueda aplicar a todos los proyectos. Resulta razonable que se espere que infraestructuras de mayor envergadura, importancia económica o social, etc, deban satisfacer criterios más exigentes que los de menor entidad. Muchas veces, las agencias competentes que establecen los criterios lo hacen analizando caso 
por caso las circunstancias particulares del proyecto (peligrosidad sísmica, disponibilidad de rutas alternativas en caso de daño, tipo y uso de la obra, etc.). Esta multiplicidad de criterios, conlleva una lógica falta de homogeneidad entre ellos.

En este capítulo se plantea una discusión crítica acerca de la aplicabilidad de los criterios de demanda y desempeño de las diferentes normativas analizadas en el capítulo $\S 3.8$ al caso específico de estaciones subterráneas de metro construidas por el método de cut-and-cover. De manera conjunta, se propone un marco conceptual para establecer una matriz de demanda/desempeño, teniendo en cuenta especialmente la reparabilidad del daño sísmico que, en opinión del autor, resulta el aspecto más crítico para este tipo de estructuras.

\subsection{Niveles de relevancia urbana de la estación}

\subsubsection{Discusión crítica del estado actual de la normativa}

En la escasa normativa específica que hay referente al diseño sismorresistente de infraestructuras de metro, que esencialmente se restringe a los criterios de diseño para el metro de Los Ángeles (LA Metro Authority, 2012), todas las estructuras, tanto de túnel como de estaciones, se consideran de la misma importancia. Es decir, todas las estaciones deben cumplir el mismo nivel de seguridad frente al sismo, así como cumplir con los mismos requisitos de desempeño, independientemente de su ubicación, del tipo de estructuras adyacentes que haya en superficie, del número de viajeros que circulen por ellas, etc.

En lo que respecta a otros tipos de obra pública de transporte, tales como puentes, algunas de las normativas actuales plantean cierta diferenciación entre obras que pueden considerarse como normales, y obras especiales. Los criterios para adscribir cada puente en particular a una u otra categoría no aparecen reflejados de manera explícita en las normativas, y en algunas ocasiones, estos suelen fijarse caso por caso por la administración pertinente en función del proyecto concreto que se trate.

Por ejemplo, el Eurocódigo 8 EN 1998-2, indica que los puentes se clasificarán en clases de importancia I (menor), II (normal), y III (especial), dependiendo de las consecuencias de su fallo para la vida de las personas, de su importancia para mantener las comunicaciones especialmente en el periodo post-sísmico, y en las consecuencias 
económicas del colapso. Aunque defiere la clasificación precisa de la importancia de cada tipo de puente a lo que disponga cada autoridad nacional en el Documento de Aplicación Nacional pertinente, sin embargo, proporciona las siguientes guías para proceder a la clasificación:

- En general, todos los puentes de carretera y ferrocarril se clasificarán como de importancia normal (clase II).

- Los puentes de importancia especial (clase III) comprenden puentes de importancia crítica para el mantenimiento de las comunicaciones, especialmente en el periodo post-sísmico, puentes cuyo fallo está asociado con un probable gran número de víctimas, y grandes puentes para los cuales se requiere una vida útil mayor que la normal.

- Los puentes se clasificarán como de importancia menor (clase I), si se cumplen las dos condiciones siguientes:

o El puente no es crítico para las comunicaciones.

o La adopción de la probabilidad de referencia de no excedencia $P_{N C R}$, en 50 años para la acción sísmica de diseño, o de la vida útil estándar de 50 años, no está justificada económicamente.
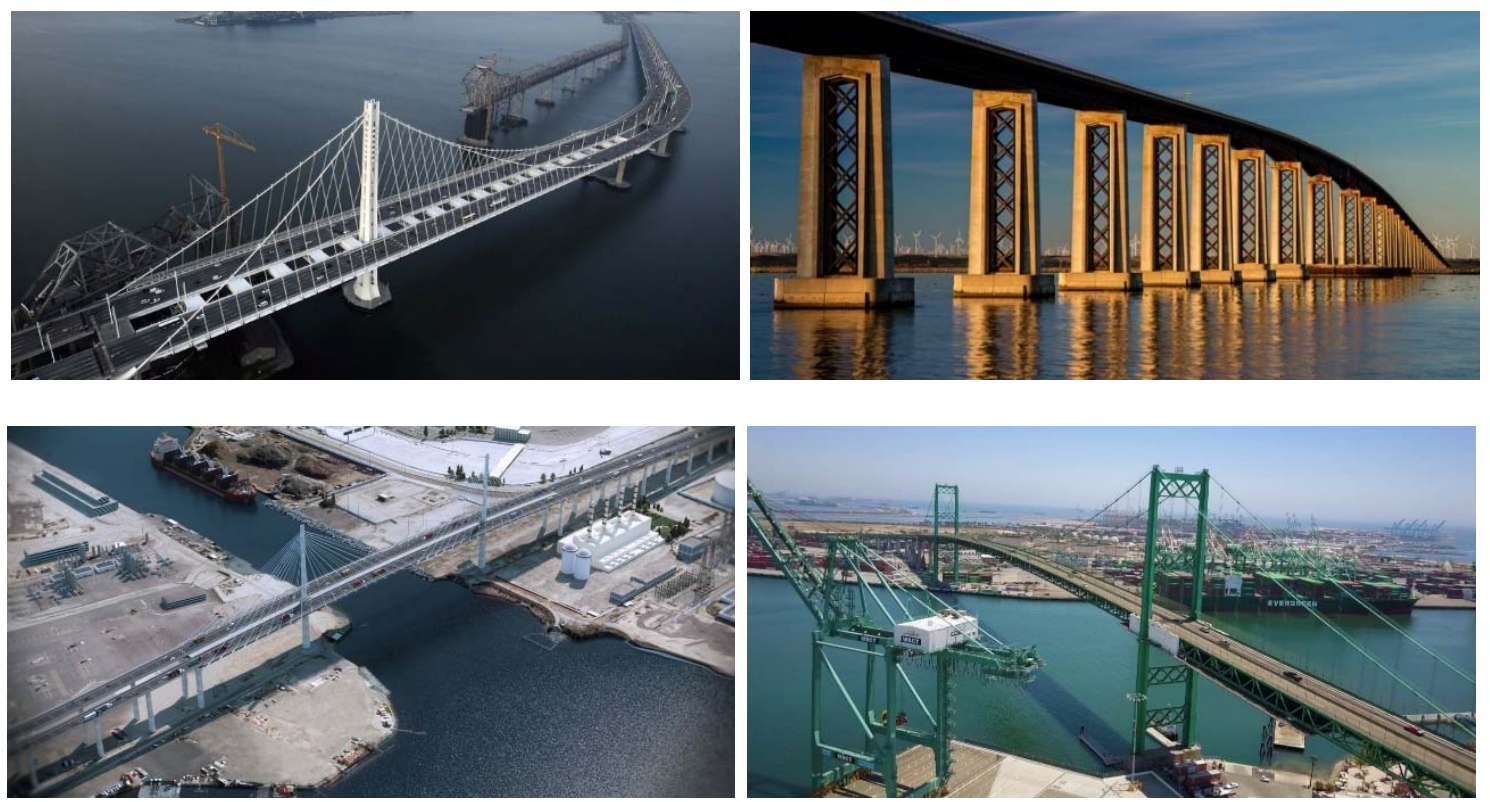

Fig. 8-1 (sup. izda.) Tramo Este del puente de la bahía de San Francisco-Oakland. (sup. dcha.) Puente de Antioch, Sacramento. (inf. izda.) Puente Gerald-Desmond, Long Beach. (inf. dcha.) Puente Vincent Thomas, Los Ángeles.

Por otra parte, los criterios específicos de CALTRANS (Departamento de Transportes de California) para establecer la importancia de un puente, suelen tener en 
cuenta varios aspectos complementarios, tales como la peligrosidad sísmica a la que se encuentra sometido el puente, la tipología del mismo, el uso del puente, el volumen de tráfico esperable, las necesidades dentro del plan de emergencias local, la disponibilidad de rutas alternativas, y la economía local y regional (Marsh \& Stringer, 2013).

Algunos puentes recientemente construidos o reacondicionados sísmicamente, considerados importantes por CALTRANS, y para los cuales ha desarrollado criterios específicos, son el tramo este del puente de la Bahía de San Francisco-Oakland, el puente de Antioch, el puente Gerald-Desmond, y el puente Vincent Thomas (Fig. 8-1).

\subsubsection{Propuesta de clasificación de la relevancia urbana de la estación}

Dentro del marco del transporte suburbano, resulta razonable argumentar que toda la red de metro tiene una importancia similar, en el sentido de que todas las líneas y estaciones forman parte de un conjunto igualmente relevante para el transporte de pasajeros, y que el fallo de uno de sus elementos repercutirá en el funcionamiento del conjunto.

Sin embargo, a juicio del autor, en el contexto del escenario posterior al sismo, cuando deban acometerse las posibles reparaciones, pueden darse circunstancias que hagan que algunas situaciones sean especialmente relevantes. Fundamentalmente debido a la entidad de los medios auxiliares, o disposiciones específicas, a los que se deba recurrir para acometer dichas reparaciones. De esta manera, se considera interesante clasificar en dos categorías, relevancia urbana normal y relevancia urbana especial, cada una de las estaciones de metro, y establecer criterios de desempeño sísmico ligeramente diferentes para estas categorías.

Estas categorías de relevancia urbana pueden admitir diversos criterios de clasificación, en función de cuales sean las prioridades de la Propiedad de la infraestructura, así como de la autoridad que gestione su explotación. En esta tesis se proponen tres criterios de clasificación, sin que esto signifique que sean los únicos posibles. Los tres criterios propuestos son:

1) En función del patrimonio histórico de las construcciones en superficie que pueden verse afectadas por la reparación de la estación. 
2) En función de las cargas transmitidas al terreno circundante por las construcciones en superficie que pueden verse afectadas por la reparación de la estación.

3) En función de la relevancia funcional de la estación dentro del sistema global de transporte de la ciudad, y como este puede verse afectado por la reparación de la estación.

En lo que respecta al patrimonio histórico, un ejemplo de esta relevancia especial puede consistir en la existencia en las inmediaciones de la estación de edificaciones de gran importancia, con características únicas e irrepetibles. Parece razonable pensar que, si se deben acometer reparaciones en la estación, debido al daño producido por el sismo, la preservación del patrimonio en superficie deba requerir de medidas especiales. Por ejemplo, medidas más restrictivas de apuntalamiento provisional entre pantallas de la estación, medidas más onerosas para el acceso a la zona de la estación próxima a la superficie, etc. Sin embargo, otras estaciones pueden encontrarse en zonas de accesibilidad más sencilla, o que no requieran de medidas especiales a fin de preservar las construcciones en superficie.

Una posible metodología objetiva para establecer la adscripción de una estación de metro de acuerdo a este criterio relevancia urbana especial podría ser comprobar si la estación se encuentra en una zona que pueda afectar a un edificio catalogado como patrimonio a preservar (UNESCO, Catálogo municipal de patrimonio arquitectónico, etc.).

Como ejemplos de este criterio de adscripción a la categoría de relevancia urbana especial o normal en base al patrimonio cultural en superficie, se proponen los casos de las estaciones del metro de Quito, San Francisco y Fondo de Saco.

- La estación de San Francisco (Fig. 8-2, izda.), bajo la plaza de mismo nombre, cuenta con un conjunto arquitectónico en superficie declarado Patrimonio de la Humanidad por la UNESCO. El acceso a la losa superior de la estación obliga a retirar el pavimento original del s. XVI, que se encuentra protegido, y que requiere de medidas especiales para su preservación (numeración individual de los adoquines, almacenamiento especial, etc.). Según el criterio de afección al patrimonio, esta estación se clasificaría como de relevancia urbana especial. 
- La estación de Fondo de Saco (Fig. 8-2, dcha.) se encuentra en una zona libre de construcciones aledañas. Según el criterio de afección al patrimonio, esta estación se clasificaría como de relevancia urbana normal.
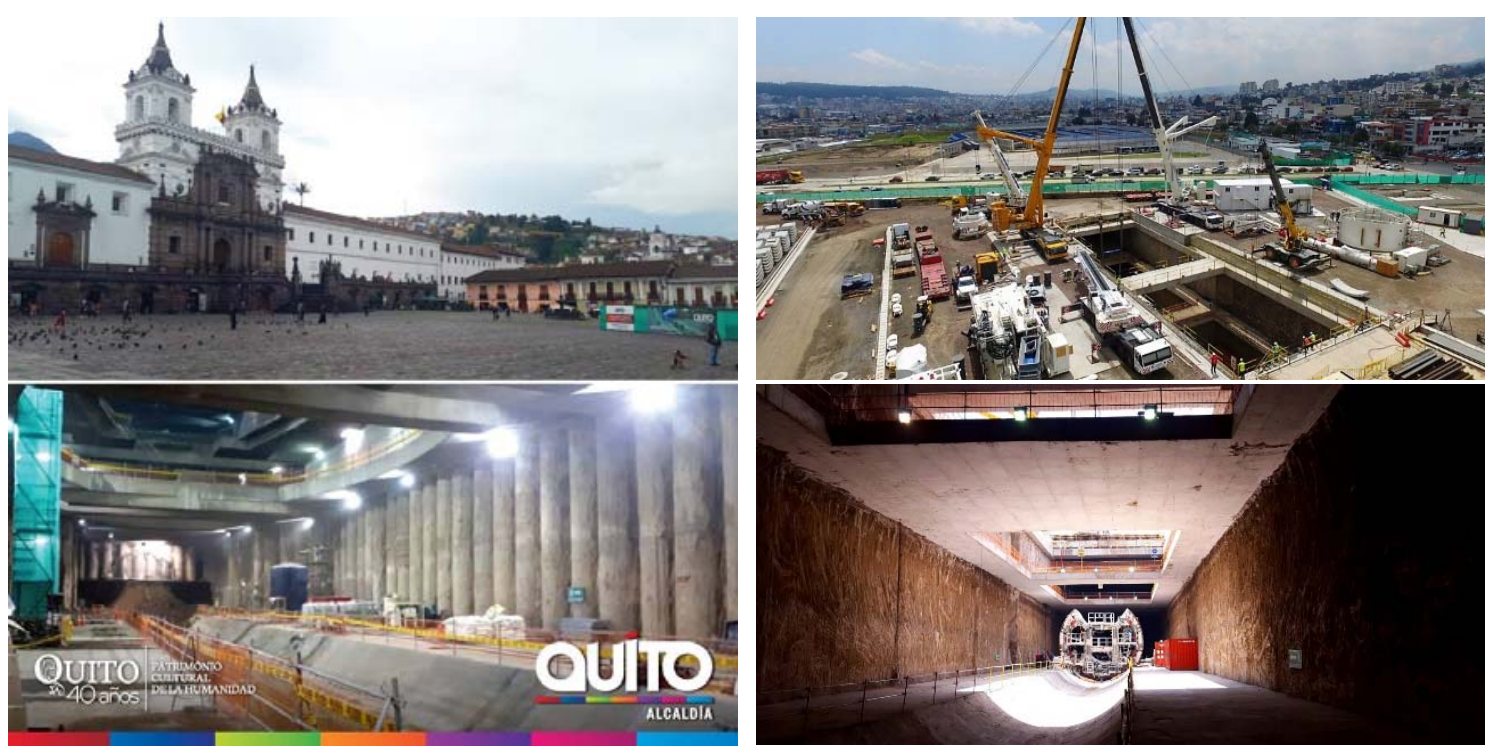

Fig. 8-2 (izda.) Vista de la Iglesia de San Francisco del s. XVI en Quito, Patrimonio Cultural de la Humanidad, y estación de metro bajo la plaza durante su construcción. (dcha.) Vista de la superficie de la zona de la estación de Fondo de Saco del metro de Quito y de la propia estación en construcción.

En lo que atañe a las cargas transmitidas al terreno por las construcciones adyacentes en superficie, parece razonable pensar que una estación que debe soportar empujes laterales estáticos mayores, debidos a cargas mayores en superficie, necesitará de medidas especiales para poder acometer su reparación. Estas medidas pueden consistir en niveles de apuntalamiento provisional entre pantallas, etc. Sin embargo, otras estaciones pueden encontrarse en zonas con construcciones adyacentes que no supongan un nivel de carga excepcional, o que simplemente no cuenten en las inmediaciones con edificaciones en superficie. Una posible metodología objetiva para establecer si una estación es de relevancia urbana especial podría ser comprobar si la estación cuenta con edificación de gran altura, o con estructuras masivas, en su zona de afección.

Como ejemplo de este criterio de adscripción a la categoría de relevancia urbana especial o normal en base a las cargas transmitidas en superficie, se proponen los casos de las estaciones de metro de Ciudad de México, Insurgentes, y Coyoacán.

- La estación de Insurgentes (Fig. 8-3, izda.) se encuentra en las inmediaciones del Paseo de la Reforma, una avenida que cuenta a ambos lados con torres de gran altura, y que transmiten al subsuelo cargas 
elevadas. Según el criterio de cargas transmitidas al terreno adyacente por las construcciones en superficie, esta estación se clasificaría como de relevancia urbana especial.

- La estación de Coyoacán (Fig. 8-3, dcha.) se encuentra en las inmediaciones de la avenida Universidad, una calle que en esta zona cuenta con edificaciones de 2 a 3 alturas e incluso con un parque en los alrededores. Según el criterio de cargas transmitidas al terreno adyacente por las construcciones en superficie, esta estación se clasificaría como de relevancia urbana normal.
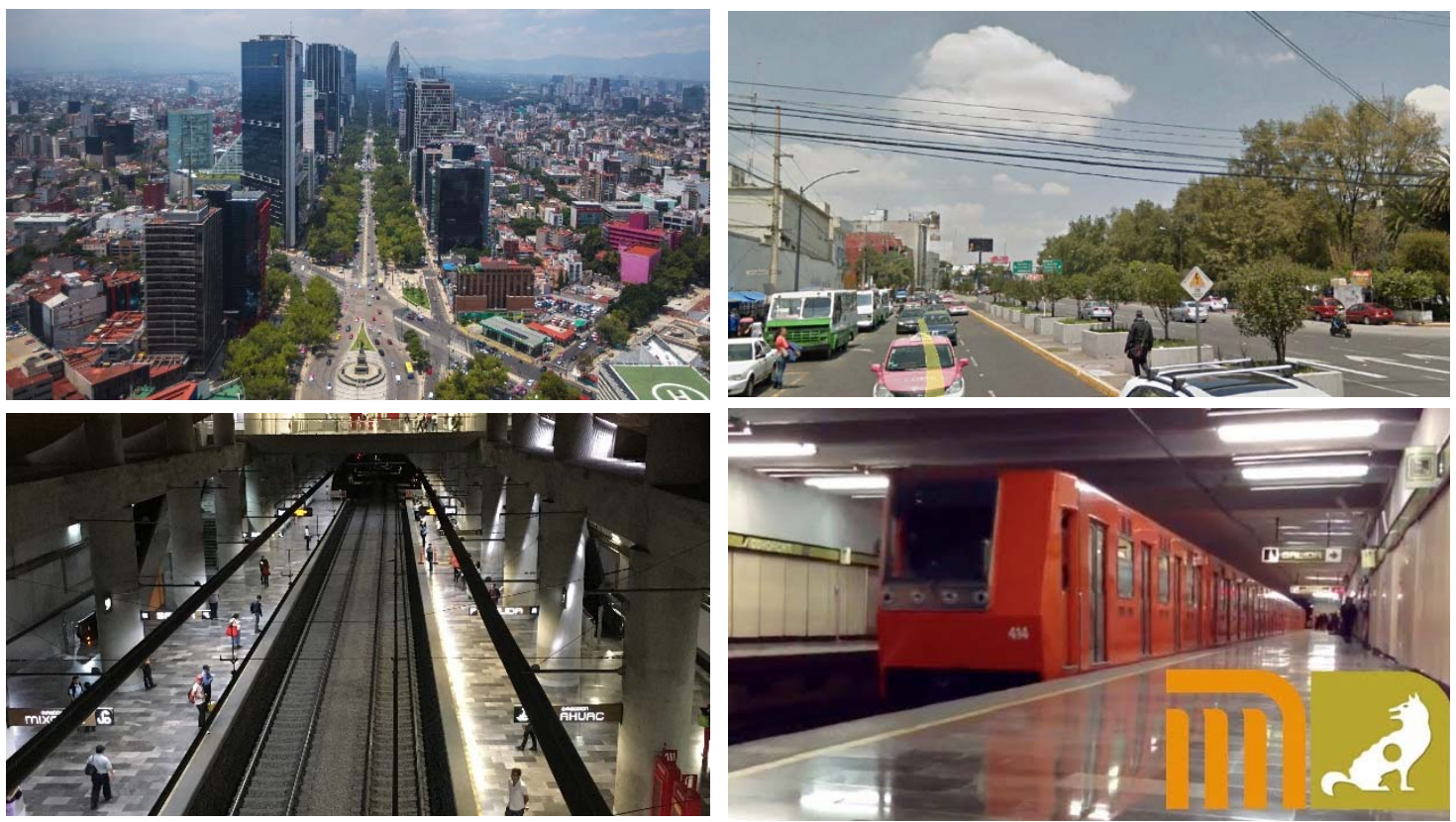

Fig. 8-3 (izda.) Paseo de la Reforma, y estación de Insurgentes en las inmediaciones de este en Ciudad de México. (dcha.) Av. Universidad y de la estación de metro de Coyoacán en Ciudad de México.

En lo que atañe a la relevancia de una única estación con respecto a la red global de transporte de la ciudad, parece razonable pensar que una estación que sea un punto de conexión con otros sistemas de transporte (intercambiadores intermodales), o que conecte varias líneas de metro entre sí, puede suponer un punto más crítico dentro del sistema que una estación periférica que tan sólo recibe pasajeros del área tributaria de ciudad a la que presta servicio. En este sentido, el restringir o limitar el servicio durante un periodo de tiempo prolongado de una estación de relevancia especial, debido a las reparaciones que haya que llevar a cabo en ella, puede resultar más crítico que en una estación de relevancia normal. Una posible metodología objetiva para establecer si una estación es de relevancia 
urbana especial podría ser a través el volumen diario de pasajeros que soporta cada estación.

Como ejemplo de este criterio de adscripción a la categoría de relevancia urbana especial o normal en base al volumen de pasajeros, se proponen los casos de las estaciones de metro de Tokio, Shibuya y Takebashi.

- La estación de Shibuya (Fig. 8-4, izda.) constituye el centro neurálgico de la red de trasporte suburbano de Tokio, con un volumen de alrededor de un millón de pasajeros al día. Esta estación se clasificaría como de relevancia urbana especial.

- La estación de Takebashi (Fig. 8-4, dcha.) es una estación a la que accede una única línea de metro, y que cuenta con un volumen diario de 49000 pasajeros al día. En el contexto del sistema global de transporte de esta ciudad, esta estación se clasificaría como de relevancia urbana normal.
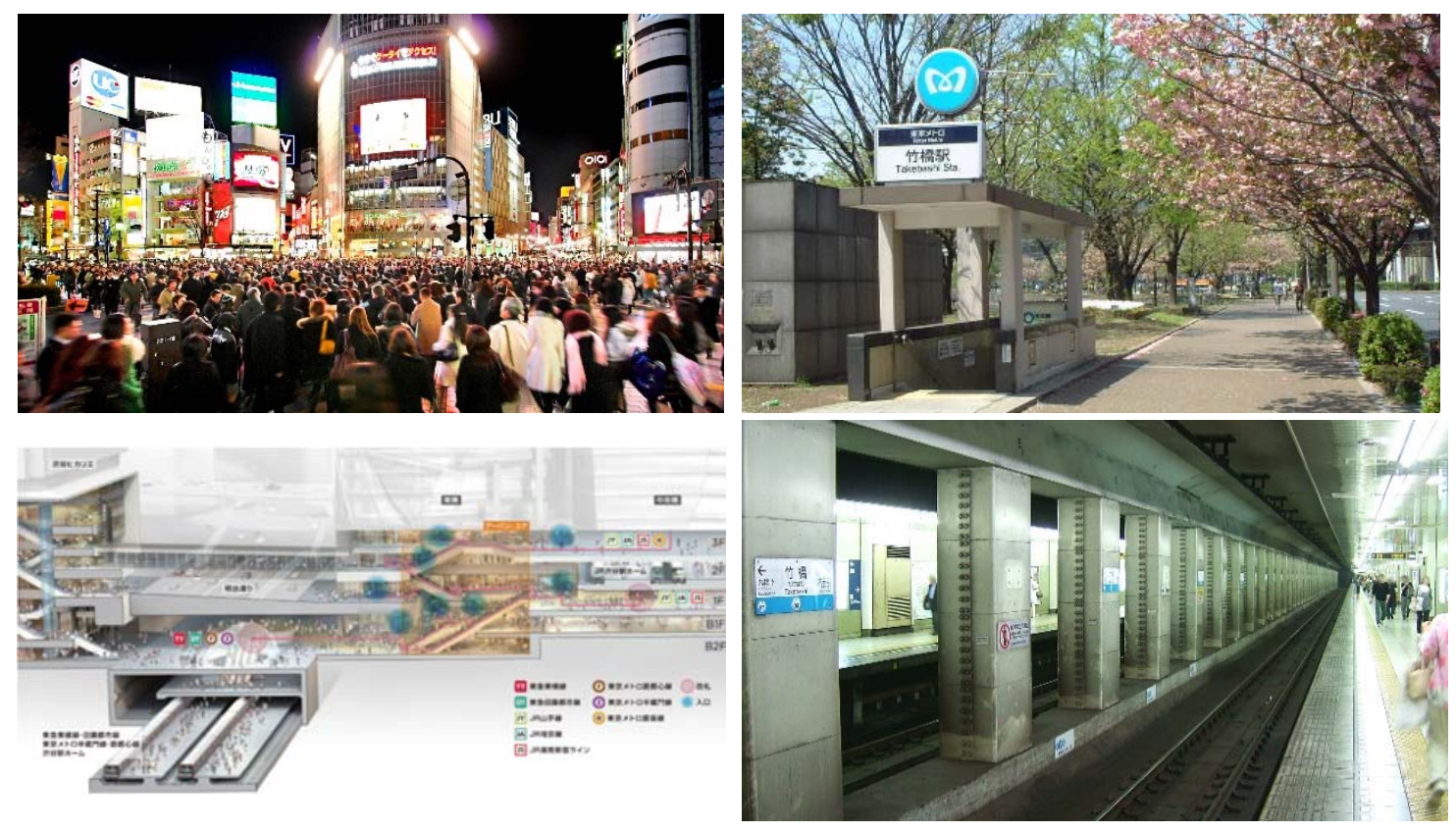

Fig. 8-4 (izda.) Vista del cruce de Shibuya y estación-intercambiador de metro bajo este en Tokio. (dcha.) Vista en superficie y subterránea de la estación de metro de Takebashi en Tokio.

De acuerdo a lo indicado anteriormente, se propone el cuadro esbozado en la Tabla 8-1, en el que se resumen los criterios para adscribir una determinada estación dentro de las categorías de relevancia urbana especial o normal.

En este sentido, se propone que una estación de metro debiera considerarse como de relevancia urbana especial si satisface al menos uno o más de los criterios expuestos 
en la Tabla 8-1. Para el resto de casos, la relevancia urbana de la estación puede considerarse normal.

\begin{tabular}{|c|c|c|}
\hline \multirow{2}{*}{ Criterio } & \multicolumn{2}{|c|}{ Categoría de Relevancia Urbana } \\
\hline & Especial & Normal \\
\hline Patrimonio Cultural & $\begin{array}{l}\text { - Construcciones Históricas o } \\
\text { patrimonio cultural en superficie. }\end{array}$ & $\begin{array}{l}\text { - Construcciones normales en } \\
\text { superficie. }\end{array}$ \\
\hline Carga Vertical & $\begin{array}{l}\text { - Edificaciones adyacentes de gran } \\
\text { altura (torres, rascacielos, etc.). } \\
\text { - Construcciones adyacentes que } \\
\text { transmiten carga elevada al } \\
\text { subsuelo. }\end{array}$ & $\begin{array}{l}\text { - Edificaciones adyacentes } \\
\text { residenciales de altura normal. } \\
\text { - Aledaños de parques y zonas } \\
\text { verdes. }\end{array}$ \\
\hline $\begin{array}{l}\text { Relevancia dentro } \\
\text { de la red de } \\
\text { transporte }\end{array}$ & $\begin{array}{l}\text { - Centros neurálgicos de } \\
\text { comunicaciones. } \\
\text { - Intercambiadores intermodales. } \\
\text { - Estaciones con conexiones con } \\
\text { múltiples líneas de metro. } \\
\text { - Estaciones con volumen de tráfico } \\
\text { rodado crítico en superficie }\end{array}$ & $\begin{array}{l}\text { - Estaciones sin conexión con otras } \\
\text { líneas de metro. } \\
\text { - Estaciones con volumen de tráfico } \\
\text { rodado normal o nulo en superficie. }\end{array}$ \\
\hline
\end{tabular}

Tabla 8-1. Propuesta de criterios de clasificación de la relevancia urbana de las estaciones de metro, y ejemplos de adscripción a cada categoría.

\subsection{Niveles de demanda sísmica}

Uno de los factores fundamentales, a la hora de establecer la demanda sísmica, es determinar la vida útil de la estructura. En efecto, la definición habitual de la acción sísmica en términos probabilistas suele basarse en la probabilidad de ocurrencia de un determinado escenario durante la vida útil de la obra. En los casos más frecuentes de edificación, es habitual establecer que la vida útil de un edificio es de $T_{L}=50$ años, sobreentendiéndose que a partir de este momento el edificio puede necesitar una revisión general de su estado y eventuales readecuaciones o reparaciones, o que tal vez el destino original del edificio haya cambiado debido a la evolución del contexto urbano, existiendo la posibilidad de que sea demolido para construir otro diferente (p.ej. transformación de un entorno residencial en uno comercial, con construcción de bloques de oficinas donde anteriormente existían viviendas).

En el marco de las obras públicas de transporte, y en el caso más frecuente de los puentes, es habitual establecer que la vida útil de una obra es de $T_{L}=100$ años, sobreentendiéndose que a partir de este momento la obra puede necesitar una readecuación para ajustarse a las nuevas necesidades, o que simplemente las nuevas, y difícilmente previsibles a tan largo plazo, necesidades de transporte necesiten de 
infraestructuras de distinta capacidad que motiven la demolición de la obra previa y sustitución por una nueva de mayor capacidad.

En el caso de infraestructuras de transporte suburbano es, en opinión del autor, incluso más complicado establecer cuál es la vida útil de una obra. Las ciudades han experimentado un crecimiento acelerado desde mediados del s. XX, en una tendencia que se prevé que se mantendrá en el futuro cercano (UN, 2018), y que previsiblemente conducirá a una mayor demanda de las infraestructuras de transporte suburbano actualmente existentes. En este contexto, resulta difícil de justificar que una línea de metro o estación pueda quedar obsoleta y pueda ser demolida o sustituida. Un claro ejemplo puede ser el metro de Madrid, que en 2019 cumple 100 años desde su inauguración en 1919 (Fig. 8-5), y que ha visto incrementado su uso exponencialmente desde 14 millones de viajeros en 1919 a 657 millones de viajeros en 2018 (Metro de Madrid, 2018).
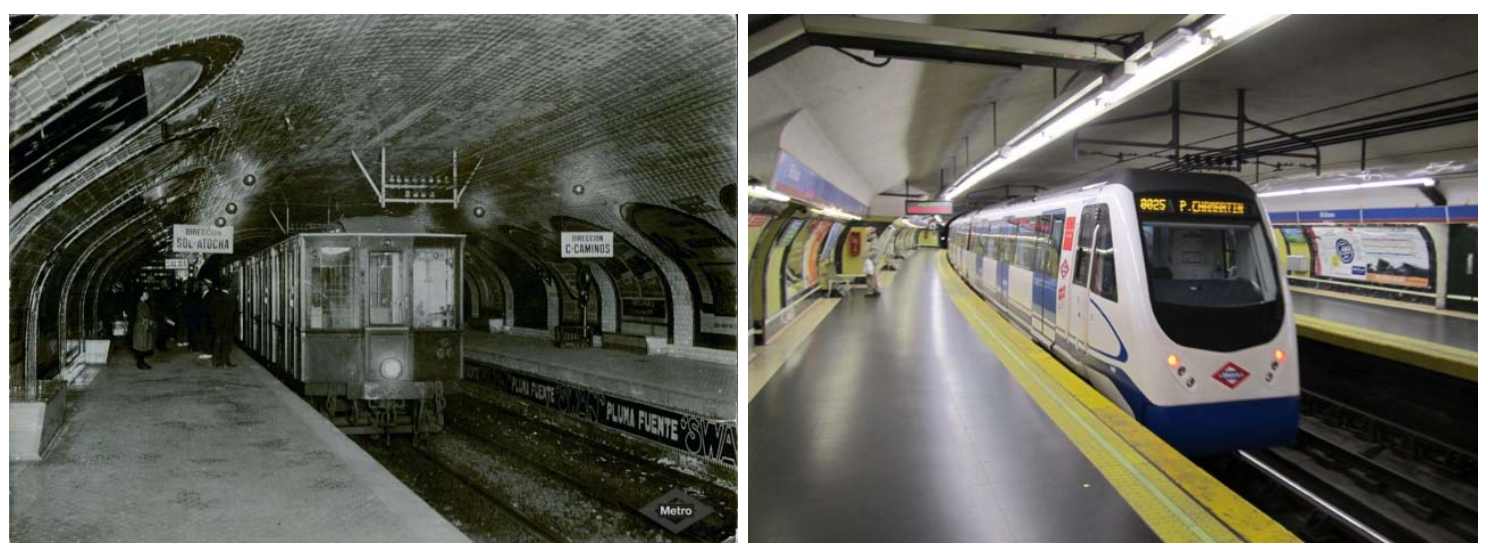

Fig. 8-5 (izda.) Metro de Madrid en 1919. (dcha.) Metro de Madrid en 2019.

En este sentido, la justificación de la vida útil de una estación de Metro sólo puede entenderse desde la perspectiva de que probablemente, a partir de le finalización de la misma, serán necesarias obras de readecuación y mejora.

\subsubsection{Discusión crítica del estado actual de la normativa}

En la escasa normativa específica que hay referente al diseño sismorresistente de infraestructuras de metro que, como se ha indicado anteriormente en el apartado $§ 3.8$ de esta tesis, esencialmente se restringe a los criterios de diseño adoptados para el metro de Los Ángeles (LA Metro Authority, 2012), se asume una vida útil de 100 años, y se especifican dos niveles de demanda sísmica (MDE Maximum Design Earthquake, y ODE 
Operating Design Earthaquake). En particular, en el apéndice de diseño sísmico de esta norma se indica:

"Current Metro design criteria assume a design life of 100 years. To establish probabilistic seismic ground motion criteria, design earthquake motions are defined as follows [...]” (LA Metro Authority, 2012, p. 5A-22).

"Since Metro Rail is a very important transit facility that requires substantial financial investment and has significant economic consequences if it fails, a two-level ground motion approach to seismic design similar to that outlined in Applied Technology Council/Multidisciplinary Center for Earthquake Engineering Research, 2003, Recommended LRFD Guidelines for the Seismic Design of Highway Bridges (ATC-49) is appropriate. The Maximum Design earthquake (MDE) and the Operating Design Earthquake (ODE) discussed below form the basis of the two-level ground motion approach adopted for the Metro Rail project.”. (LA Metro Authority, 2012, p. 5-19).

Para estos niveles de demanda MDE y ODE, se fijan periodos de retorno de 2500 años y 144 años, que corresponden con probabilidades de excedencia del 4\% y 50\% durante la vida útil de la estructura ( $T_{L}=100$ años $)$.

Los criterios adoptados por el resto de normativas analizadas en el apartado 33.8 de esta tesis se resumen en la Tabla 8-2.

\begin{tabular}{|c|c|c|c|c|c|c|c|c|}
\hline \multirow{2}{*}{$\begin{array}{l}\text { Nivel de } \\
\text { Demanda }\end{array}$} & \multicolumn{2}{|c|}{ EN 1998-2:2005 } & \multirow{2}{*}{$\begin{array}{c}\text { AASHTO } \\
2017 \\
\text { Túneles }\end{array}$} & \multirow{2}{*}{$\begin{array}{c}\text { AASHTO } \\
2011 \\
\text { Puentes }\end{array}$} & \multirow{2}{*}{$\begin{array}{c}\text { ASCE } \\
61-14 \\
\text { Puertos } \\
\end{array}$} & \multicolumn{3}{|c|}{$\begin{array}{c}\text { CALTRANS } \\
\text { Específicos de puentes importantes }\end{array}$} \\
\hline & $\begin{array}{c}\text { Puentes } \\
\text { Normales }\end{array}$ & $\begin{array}{c}\text { Puentes } \\
\text { Importantes }\end{array}$ & & & & SFOBB & GD. MS & VTB \\
\hline Sin Daño & $\mathrm{N} / \mathrm{E}$ & $\mathrm{N} / \mathrm{E}$ & 100 años & $\mathrm{N} / \mathrm{E}$ & 72 años & 300 años & 100 años & $\mathrm{N} / \mathrm{E}$ \\
\hline $\begin{array}{c}\text { Daño } \\
\text { Reparable }\end{array}$ & $\mathrm{N} / \mathrm{E}$ & $\mathrm{N} / \mathrm{E}$ & 2500 años & $\mathrm{N} / \mathrm{E}$ & 475 años & $\begin{array}{l}1500 \\
\text { años }\end{array}$ & $\begin{array}{l}1000 \\
\text { años }\end{array}$ & 285 años \\
\hline $\begin{array}{c}\text { Daño } \\
\text { Extensivo }\end{array}$ & 475 años & $\begin{array}{c}1000 \text { años } \\
(*)\end{array}$ & $\mathrm{N} / \mathrm{E}$ & 1000 años & $\begin{array}{c}1000 \text { años } \\
(* *)\end{array}$ & $\mathrm{N} / \mathrm{E}$ & $\mathrm{N} / \mathrm{E}$ & 950 años \\
\hline \multicolumn{9}{|c|}{$\begin{array}{l}\text { N/E : No especificado } \\
(*) \text { Extrapolado desde un periodo de retorno de } 475 \text { años y con un coeficiente de importancia } \gamma=1,3 . \\
(* *) \text { Extrapolado desde un periodo de retorno de } 2500 \text { años y un coeficiente reductor de valor } 2 / 3 . \\
\text { SFOBB : San Francisco - Oakland Bay Bridge. } \\
\text { GD.MS : Gerald Desmond Bridge. Main Span. } \\
\text { VTB : Vincent Thomas Bridge }\end{array}$} \\
\hline
\end{tabular}

Tabla 8-2. Periodos de retorno de diferentes niveles de demanda sísmica adoptados por las normativas sismorresistentes analizadas.

\subsubsection{Propuesta de niveles de demanda}

A tenor de lo indicado anteriormente, y teniendo en cuenta el aspecto esencial de los sistemas de transporte suburbano en lo que se refiere a la resiliencia de las ciudades 
frente al escenario tras el terremoto, es decir, la capacidad de las ciudades para recuperarse de los efectos del terremoto y volver a un estado que permita a su población retomar un estado de actividad normal, se proponen tres niveles de demanda, de intensidad creciente. Estos niveles se resumen en la Tabla 8-3.

\begin{tabular}{|c|c|c|}
\hline Nivel de Demanda & Periodo de Retorno $\boldsymbol{T}_{\boldsymbol{R}}$ [años] & Probabilidad de Excedencia \\
\hline $\begin{array}{c}\text { Nivel L1 } \\
\text { (Sismo Esperable) }\end{array}$ & 144 años & $50 \%$ en $T_{L}=100$ años \\
\hline $\begin{array}{c}\text { Nivel L2 } \\
\text { (Sismo de Contingencia) }\end{array}$ & 950 años & $10 \%$ en $T_{L}=100$ años \\
\hline $\begin{array}{c}\text { Nivel L3 } \\
\text { (Sismo Excepcional) }\end{array}$ & 2500 años & $4 \%$ en $T_{L}=100$ años \\
\hline
\end{tabular}

Tabla 8-3. Niveles de demanda sísmica propuestos para el diseño de estaciones subterráneas de metro construidas por el método de cut-and-cover.

En estos niveles de demanda, para los cuales se propondrán más adelante criterios de desempeño, se ha considerado:

- Todos los niveles llevan implícito un nivel de seguridad máximo frente a fallo catastrófico (colapso de toda o parte de la estación).

- Un escenario (Nivel L1) que se puede considerar como probable, en el sentido de que es esperable que ocurra alrededor de una vez durante la vida útil de la obra. Cuando se aborde el desempeño de la obra, para este nivel de demanda se fijarán los niveles de daño más conservadores.

- Un escenario (Nivel L2) que se puede considerar como poco probable, en el sentido de que haya un $90 \%$ de probabilidad de que este no ocurra durante la vida útil de la obra. Cuando se aborde el desempeño de la estructura, para este nivel de demanda se fijará que los daños que se puedan producir sean fácilmente reparables. $\mathrm{Y}$ en principio, con una previsión de medios para su reparación que no serán mayores que los empleados para la construcción de la propia estación.

- Un escenario (Nivel L3) que se puede considerar como improbable, en el sentido de que haya más de un $95 \%$ de probabilidad de que este no ocurra durante la vida útil de la obra. Cuando se aborde el desempeño de la estructura, para este nivel de demanda se fijará que los daños que se puedan producir sean reparables. Los medios previstos para abordar la 
reparación pueden ser similares a los empleados para la propia construcción de la estación.

\subsection{Niveles de daño estructural}

Un aspecto fundamental de la metodología de diseño basado en el desempeño es la necesidad de determinar el tipo de daño, y la probabilidad de que dicho daño ocurra, en los componentes individuales del sistema estructural. Este concepto resulta de la máxima importancia, ya que el daño sufrido por la estructura, y por los componentes no estructurales, puede relacionarse directamente con la funcionalidad o pérdidas económicas tras un sismo.

Diversas agencias, como por ejemplo CALTRANS (Departamento de transporte de California), han desarrollado correlaciones entre niveles de daño y niveles de funcionalidad esperables tras alcanzar dicho nivel de daño (Tabla 8-4). La definición de estos niveles de daño puede venir acompañada de una descripción gráfica en forma de catálogo visual para orientar a los inspectores que revisan la infraestructura tras el sismo (Fig. 8-6).

\begin{tabular}{|c|c|l|c|}
\hline $\begin{array}{c}\text { Nivel de } \\
\text { Daño }\end{array}$ & $\begin{array}{c}\text { Clasificación } \\
\text { del Daño }\end{array}$ & \multicolumn{1}{|c|}{ Descripción del Daño } & $\begin{array}{c}\text { Nivel de } \\
\text { Desempeño }\end{array}$ \\
\hline I & Ninguno & - Fisuras mínimas. & $\begin{array}{c}\text { Completamente } \\
\text { Operativo }\end{array}$ \\
\hline II & Menor & $\begin{array}{l}\text { - Ensanchamiento de las fisuras. } \\
\text { - Inicio de la plastificación de la armadura } \\
\text { longitudinal }\end{array}$ & Operativo \\
\hline III & Moderado & $\begin{array}{l}\text { - Inicio de la deformación inelástica. } \\
\text { - Inicio del spalling del recubrimiento. } \\
\text { - Desarrollo de fisuras diagonales }\end{array}$ & Daño Limitado \\
\hline IV & Mayor & $\begin{array}{l}\text { - Formación de fisuras muy anchas } \\
\text { - Propagación del spalling del hormigón. }\end{array}$ & $\begin{array}{c}\text { Seguridad de } \\
\text { Vida }\end{array}$ \\
\hline V & Colapso & $\begin{array}{l}\text { - Pandeo de la armadura longitudinal } \\
\text { - Fractura de los cercos de zunchado. } \\
\text { - Aplastamiento del hormigón confinado. }\end{array}$ & Colapso \\
\hline
\end{tabular}

Tabla 8-4. Niveles de daño en rótulas plásticas. (Caltrans, 2008).

Estas correlaciones entre daño y niveles de desempeño estructural son algo subjetivas, y están basadas en el riesgo percibido, y en el comportamiento real observado en estructuras que han sufrido terremotos en el pasado (Marsh \& Stringer, 2013). En este sentido, hay cierta variación en las correlaciones entre daño y desempeño dependiendo de la agencia o institución que la desarrolle. 
En la actualidad, la manera más habitual de correlacionar el daño es a través de niveles discretos de deformación de los materiales: En el momento en el que se rebasa un nivel de deformación determinado en un material, se asume que se ha producido algún nivel de daño de manera determinista. Sin embargo, la aparición del daño raramente sigue un patrón tan claro, y muestra más bien un carácter probabilista (para una deformación dada, a veces ocurre el daño y a veces no), con una densidad de probabilidad de deformaciones para las cuales puede producirse el daño.
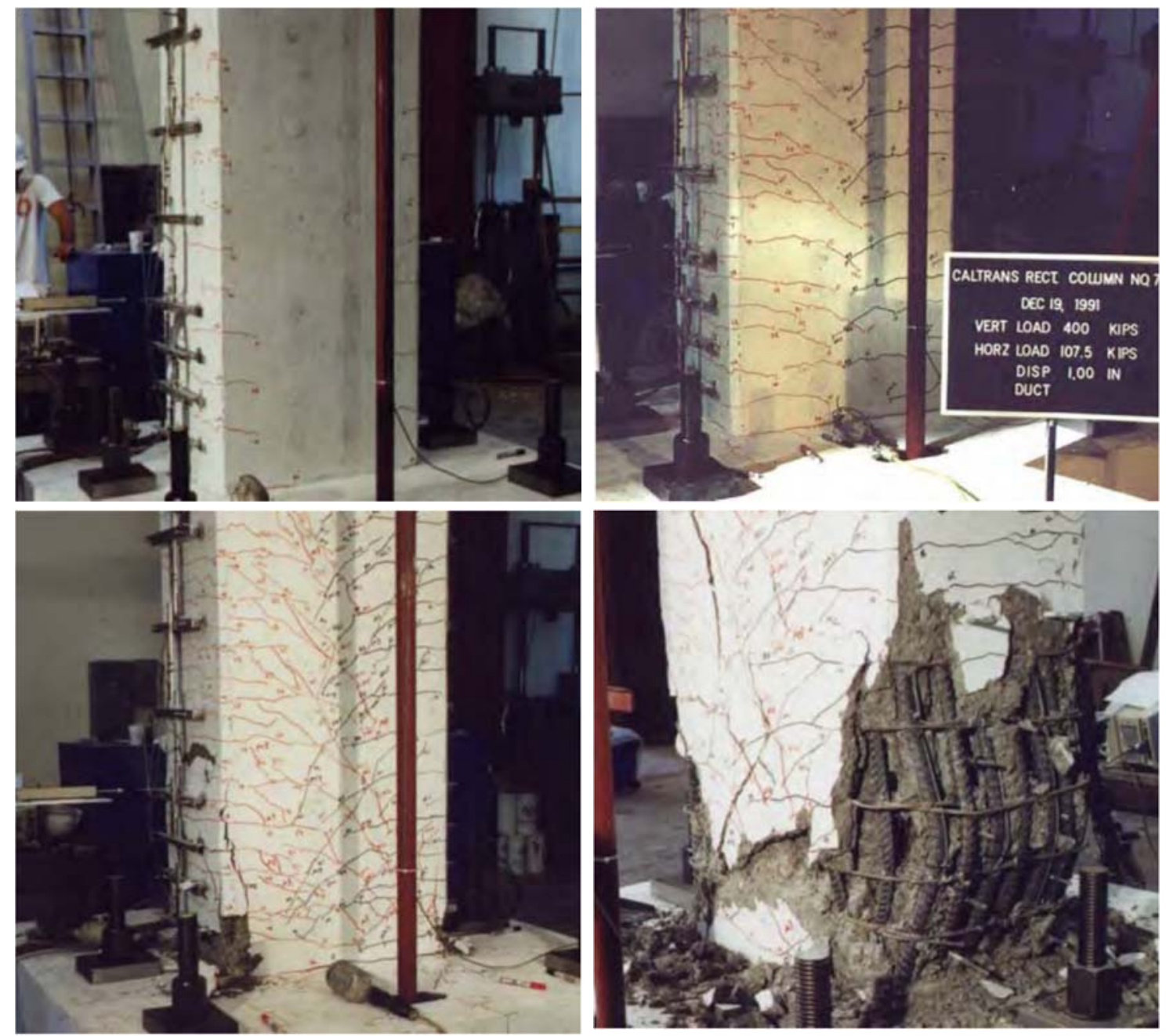

Fig. 8-6 Niveles de daño en rótulas plásticas. (sup. izda.) Nivel I, aparición de fisuras. (sup. dcha.) Nivel II, ensanchamiento de fisuras. (inf. izda.) Nivel IV, propagación del spalling. (Inf. Dcha.) Nivel V, pandeo de barras longitudinales y rotura de zunchos de confinamiento. (Caltrans, 2008).

Un claro ejemplo de esta incertidumbre a la hora de correlacionar deformación y daño es la correspondiente a determinar la deformación para la cual se produce el spalling del hormigón. La deformación en el hormigón no se puede medir directamente en un ensayo de laboratorio, y por lo tanto debe calcularse basándose en la curvatura medida 
experimentalmente y la deformación en el acero considerando la hipótesis de secciones planas. Aunque en teoría este enfoque es sencillo, el cálculo puede introducir errores significativos con respecto a la curvatura y los registros de deformaciones debido a la fisuración y al deterioro de la adherencia de las barras de armadura. La curvatura medida durante un ensayo es una curvatura media a lo largo de la longitud de la galga extensométrica, y la deformación del acero se ve afectada por su proximidad a una fisura. Esto, junto a los efectos térmicos debidos al calor generado durante la plastificación del acero, introduce errores que hacen que el análisis de la deformación que corresponde al spalling del hormigón sea compleja. Otra alternativa a la medida "directa" consiste en relacionar flechas medidas en ménsulas ensayadas en laboratorio: mediante un análisis momento-curvatura en el que se integran deformaciones en alguna longitud de rótula plástica fijada a priori, se infiere la deformación en el hormigón (Berry \& Eberhard, 2003). Sin embargo, este método también está sujeto a incertidumbre, con un rango de valores de la deformación de spalling que está en la horquilla de $0.2 \%<\varepsilon_{c \text {,spall }}<1.8 \%$ para elementos circulares, y $0.2 \%<\varepsilon_{c, \text { spall }}<1 \%$ para elementos rectangulares (Marsh \& Stringer, 2013).
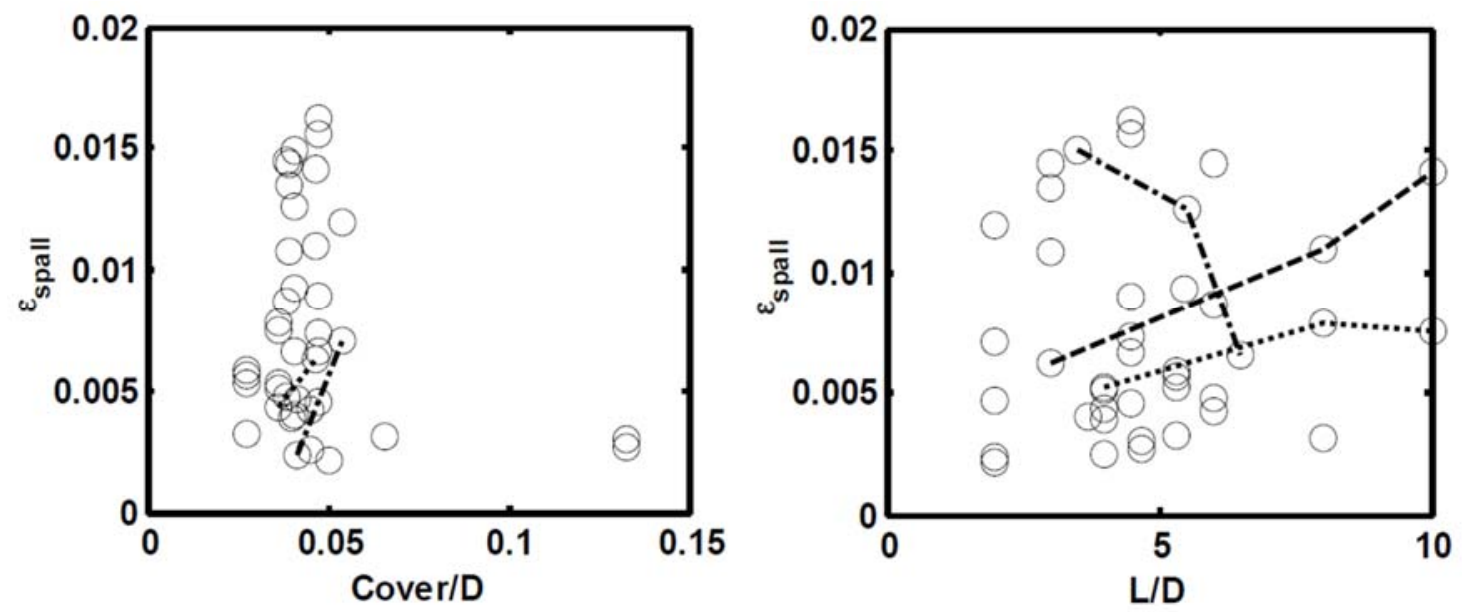

Fig. 8-7 Dispersión de la deformación en el hormigón $\varepsilon_{s p a l l}$ a la que se produce el spalling del recubrimiento. (izda.) Dispersión respecto al recubrimiento normalizado al diámetro de la columna. (dcha.) Dispersión respecto a la esbeltez de la columna. (Berry \& Eberhard, 2003).

Los gráficos de la (Fig. 8-7) muestran que los valores de deformación del hormigón $\varepsilon_{c}$ de la fibra más comprimida empleados frecuentemente para establecer el inicio del spalling (entre $0,4 \%$ y $0,5 \%$ ) son simplificaciones más o menos conservadoras de una magnitud presenta gran variabilidad (Marsh \& Stringer, 2013). 
El problema es todavía más complicado cuando se trata de establecer el inicio del daño de la armadura pasiva de acero, ya que este depende de la historia completa de deformación inelástica, y el proceso de acumulación de daño. Durante la acción del sismo, el número y magnitud de las excursiones plásticas depende de la historia del movimiento sísmico, para la que es necesaria tener en cuenta la degradación de la resistencia, y la posibilidad de varios modos de fallo de la armadura, tales como la fatiga oligocíclica, pandeo de las barras comprimidas, etc. Adicionalmente, la interacción entre el pandeo de las barras, fractura de las mismas como resultado de la fatiga oligocíclica, y la cuantía de acero en forma de zunchos de confinamiento es muy compleja, y todavía está lejos de entenderse completamente (Fig. 8-8) (Marsh \& Stringer, 2013).
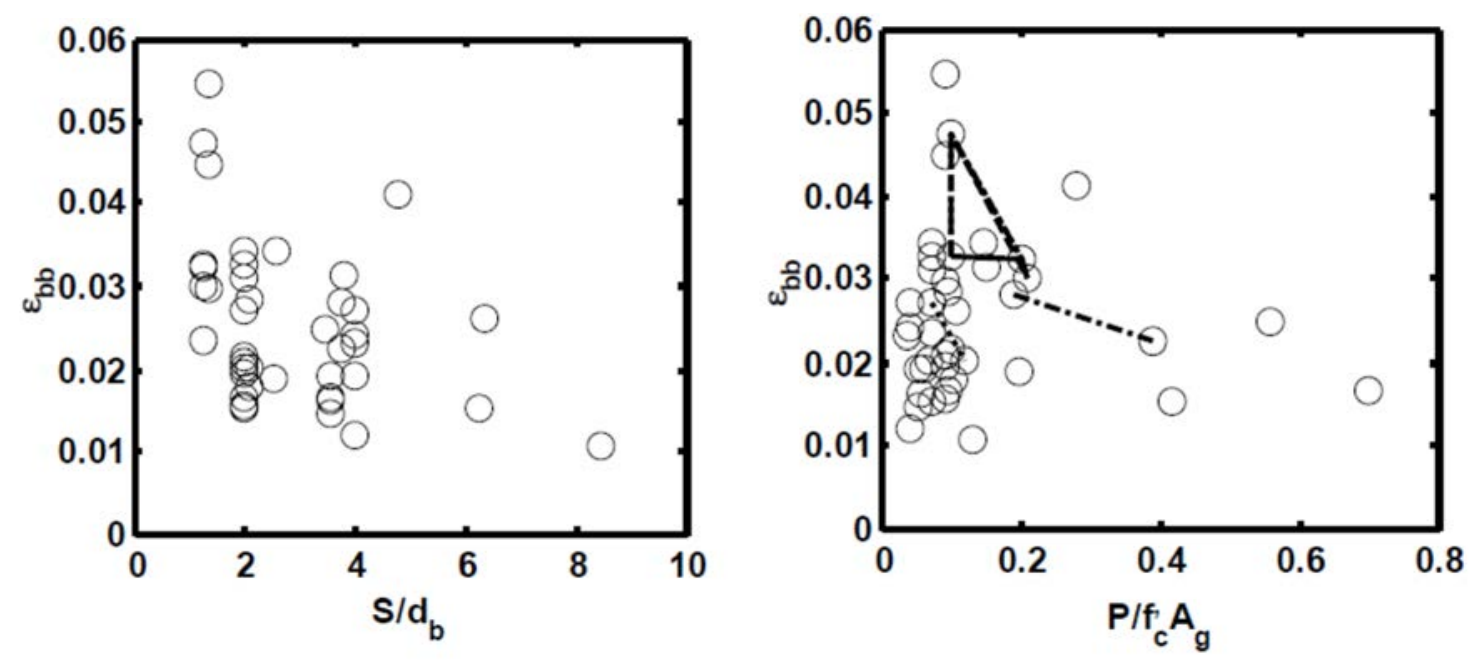

Fig. 8-8 Dispersión de la deformación en el hormigón $\varepsilon_{b}$ a la que se produce el pandeo de la armadura comprimida. (izda.) Dispersión respecto a la separación entre cercos normalizada al diámetro de la barra. (dcha.) Dispersión respecto al axil en la columna normalizado a la capacidad bruta a compresión. (Berry \& Eberhard, 2003).

De acuerdo a Marsh y Stringer (Marsh \& Stringer, 2013), los límites de deformación del acero seleccionados actualmente no tienen una justificación o base consistente, de tal manera que un límite de deformación dado no corresponde de manera inequívoca a un desplazamiento específico de la estructura, debido a la acumulación irregular de deformación de tensión y compresión durante el proceso de carga cíclica.

Debido a esta incertidumbre o variabilidad en la aparición del daño, habitualmente se emplea una estimación conservadora como un límite determinista. Esta estimación conservadora proporciona seguridad a la estructura y reduce la probabilidad de que ocurra daño para niveles de deformación reducida. 


\subsubsection{Discusión crítica del estado actual de la normativa}

Tal y como se ha expuesto en el capítulo $\S 3$ de esta tesis, especialmente en el apartado $\S 3.8$ que revisa las diversas normativas internacionales, los criterios de límites de deformación admisible en los materiales no son homogéneos entre diferentes documentos. La falta de coherencia respecto a los límites de deformación es especialmente heterogénea en aquellos aspectos que tratan con la reparabilidad de la estructura tras el posible evento sísmico, tanto para el caso de obras subterráneas como en superficie.

Sin embargo, parece existir un consenso entre las diversas normativas acerca de cuáles deben ser los objetivos generales de desempeño:

- Debe establecerse un objetivo de desempeño muy restrictivo para escenarios sísmicos que puedan ocurrir con gran probabilidad durante la vida útil de la estructura. Para estos escenarios, la funcionalidad de la estructura debe quedar asegurada tras el sismo, y los daños, en caso de haberlos, deben ser mínimos y fácilmente reparables

- Debe establecerse un objetivo de desempeño más laxo que permita asegurar la vida para escenarios sísmicos que tengan una probabilidad reducida de ocurrir durante la vida útil de la estructura.

- Para las estructuras de importancia especial, los escenarios de probabilidad reducida, además de asegurar la vida, deben causar tan sólo daños controlados, para los cuales se pueda asegurar, con cierta garantía, que serán reparables en un plazo moderado de tiempo.

\begin{tabular}{|c|c|c|c|c|c|c|c|c|c|}
\hline \multicolumn{10}{|c|}{ Deformaciones máximas en el hormigón } \\
\hline \multirow{2}{*}{$\begin{array}{l}\text { Nivel de } \\
\text { Demanda }\end{array}$} & \multicolumn{2}{|c|}{ EN 1998-2:2005 } & \multirow{2}{*}{\begin{tabular}{|c|}
$\begin{array}{c}\text { AASHTO } \\
2017\end{array}$ \\
Túneles \\
\end{tabular}} & \multirow{2}{*}{$\begin{array}{c}\begin{array}{c}\text { AASHTO } \\
2011\end{array} \\
\text { Puentes }\end{array}$} & \multirow{2}{*}{$\begin{array}{c}\begin{array}{c}\text { L.A. } \\
\text { Metro }\end{array} \\
\text { Túneles }\end{array}$} & \multirow{2}{*}{$\begin{array}{c}\text { ASCE } \\
61-14 \\
\text { Puertos }\end{array}$} & \multicolumn{3}{|c|}{$\begin{array}{c}\text { CALTRANS } \\
\text { Específicos de puentes importantes } \\
\end{array}$} \\
\hline & $\begin{array}{l}\text { Puentes } \\
\text { Normales }\end{array}$ & $\begin{array}{c}\text { Puentes } \\
\text { Importantes }\end{array}$ & & & & & SFOBB & GD. AB & VTB \\
\hline Sin Daño & $\mathrm{N} / \mathrm{E}$ & $\mathrm{N} / \mathrm{E}$ & $0,3 \%$ & $\mathrm{~N} / \mathrm{E}$ & $0,3 \%$ & $0,5 \%$ & $0,4 \%$ & $0,4 \%$ & $0,4 \%$ \\
\hline $\begin{array}{c}\text { Daño } \\
\text { Reparable }\end{array}$ & $\mathrm{N} / \mathrm{E}$ & $\mathrm{N} / \mathrm{E}$ & $0,6 \%$ & $\mathrm{~N} / \mathrm{E}$ & $0,4 \%$ & $\varepsilon_{c u}$ & $0,66 \cdot \varepsilon_{c u}$ & $0,75 \cdot \varepsilon_{c u}$ & $0,66 \cdot \varepsilon_{c u}$ \\
\hline $\begin{array}{c}\text { Daño } \\
\text { Extensivo }\end{array}$ & $\mu_{\Delta \leq 3}$ & $\mu_{\Delta \leq 3}$ & $\mathrm{~N} / \mathrm{E}$ & $\varepsilon_{c u}$ & $\mathrm{~N} / \mathrm{E}$ & $\begin{array}{c}\text { Sin } \\
\text { Límite }\end{array}$ & $\mathrm{N} / \mathrm{E}$ & $\mathrm{N} / \mathrm{E}$ & $\mathrm{N} / \mathrm{E}$ \\
\hline \multicolumn{10}{|c|}{$\begin{array}{l}\text { N/E : No especificado } \\
\mu_{\Delta}: \text { Ductilidad de desplazamiento. La formulación del Eurocódigo no está basada en límites precisos de deformación en los } \\
\quad \text { materiales, si no en niveles globales de ductilidad. } \\
\varepsilon_{c u}: \text { Deformación correspondiente al aplastamiento del hormigón confinado / fractura del zuncho. } \\
\text { SFOBB : San Francisco - Oakland Bay Bridge. } \\
\text { GD.AB : Gerald Desmond Bridge. Approach Bridge. } \\
\text { VTB : Vincent Thomas Bridge }\end{array}$} \\
\hline
\end{tabular}

Tabla 8-5. Valores de deformación máxima permitida en el hormigón adoptados por las normativas sismorresistentes analizadas. 
Algunas de las normativas más avanzadas proporcionan, para estos escenarios, niveles de deformación admisibles en los materiales, basados en el contexto comentado en el apartado anterior. Estos niveles se han descrito con más detalle en el apartado $§ 8.3$ de esta tesis, y por claridad se resumen en la Tabla 8-5 y en la Tabla 8-6, correspondientes a la deformación en el hormigón y en el acero respectivamente.

\begin{tabular}{|c|c|c|c|c|c|c|c|c|c|}
\hline \multicolumn{10}{|c|}{ Deformaciones máximas en el acero pasivo } \\
\hline \multirow{2}{*}{$\begin{array}{l}\text { Nivel de } \\
\text { Demanda }\end{array}$} & \multicolumn{2}{|c|}{ EN 1998-2:2005 } & \multirow{2}{*}{$\begin{array}{l}\begin{array}{c}\text { AASHTO } \\
2017\end{array} \\
\text { Túneles }\end{array}$} & \multirow{2}{*}{$\begin{array}{c}\text { AASHTO } \\
2011 \\
\text { Puentes }\end{array}$} & \multirow{2}{*}{$\begin{array}{c}\begin{array}{c}\text { L.A. } \\
\text { Metro }\end{array} \\
\text { Túneles }\end{array}$} & \multirow{2}{*}{$\begin{array}{c}\text { ASCE 61-14 } \\
\text { Puertos }\end{array}$} & \multicolumn{3}{|c|}{$\begin{array}{c}\text { CALTRANS } \\
\text { Específicos de puentes importantes }\end{array}$} \\
\hline & $\begin{array}{l}\text { Puentes } \\
\text { Normales }\end{array}$ & $\begin{array}{c}\text { Puentes } \\
\text { Importantes }\end{array}$ & & & & & SFOBB & GD. AB & VTB \\
\hline Sin Daño & $\mathrm{N} / \mathrm{E}$ & $\mathrm{N} / \mathrm{E}$ & $0,2 \%$ & $\mathrm{~N} / \mathrm{E}$ & $0,2 \%$ & $1,5 \%$ & $1,5 \%$ & $1,5 \%$ & $1,5 \%$ \\
\hline $\begin{array}{c}\text { Daño } \\
\text { Reparable }\end{array}$ & $\mathrm{N} / \mathrm{E}$ & $\mathrm{N} / \mathrm{E}$ & $2 \%$ & $\mathrm{~N} / \mathrm{E}$ & $2,5 \%$ & $0,6 \cdot \varepsilon_{s u}$ & $0,5 \cdot \varepsilon_{s u}$ & $6 \%$ & $0,5 \cdot \varepsilon_{s u}$ \\
\hline $\begin{array}{c}\text { Daño } \\
\text { Extensivo }\end{array}$ & $\mu_{\Delta \leq 3}$ & $\mu_{\Delta} \leq 3$ & $\mathrm{~N} / \mathrm{E}$ & $0,75 \cdot \varepsilon_{\text {su }}$ & $\mathrm{N} / \mathrm{E}$ & $0,8 \cdot \varepsilon_{s u}$ & $\mathrm{~N} / \mathrm{E}$ & $\mathrm{N} / \mathrm{E}$ & $\mathrm{N} / \mathrm{E}$ \\
\hline \multicolumn{10}{|c|}{$\begin{array}{l}\text { N/E : No especificado } \\
\mu_{\Delta}: \text { Ductilidad de desplazamiento. La formulación del Eurocódigo no está basada en límites precisos de deformación en los } \\
\quad \text { materiales, si no en niveles globales de ductilidad. } \\
\varepsilon_{s u}: \text { Deformación correspondiente a la tensión de fractura del acero } f_{u} . \\
\text { SFOBB : San Francisco - Oakland Bay Bridge. } \\
\text { GD.AB : Gerald Desmond Bridge. Approach Bridge. } \\
\text { VTB : Vincent Thomas Bridge }\end{array}$} \\
\hline
\end{tabular}

Tabla 8-6. Valores de deformación máxima permitida en la armadura de acero pasivo adoptados por las normativas sismorresistentes analizadas.

\subsubsection{Propuesta de niveles de daño admisibles en función de la reparabilidad}

En base a todo lo indicado anteriormente, en esta tesis se proponen los siguientes límites de deformaciones de los materiales para determinar la reparabilidad de una estructura de hormigón armado de una estación de metro construida por el método de cutand-cover.

\begin{tabular}{|c|c|c|c|}
\hline \multirow{2}{*}{ Nivel de Daño } & \multicolumn{3}{|c|}{ Límites de Deformación en los Materiales } \\
\hline & \multicolumn{2}{|c|}{ Hormigón } & Acero \\
\hline \multirow{2}{*}{$\begin{array}{c}\text { SD - Sin Daño } \\
\text { (Reparaciones Marginales) }\end{array}$} & $\begin{array}{l}\text { Fibras no } \\
\text { confinadas }\end{array}$ & $\begin{array}{c}\varepsilon_{c} \leq 0,3 \% \\
\text { (Sin spalling) }\end{array}$ & \multirow[b]{2}{*}{$\begin{array}{c}\varepsilon_{s} \leq f_{y} / E_{s} \\
\text { (límite elástico) }\end{array}$} \\
\hline & $\begin{array}{l}\text { Fibras } \\
\text { confinadas }\end{array}$ & $\begin{array}{c}\text { Limitada } \\
\text { indirectamente por las } \\
\text { fibras no confinadas } \\
\end{array}$ & \\
\hline \multirow{2}{*}{$\begin{array}{c}\text { DM - Daño Moderado } \\
\text { (Reparable) }\end{array}$} & $\begin{array}{l}\text { Fibras no } \\
\text { confinadas }\end{array}$ & $\begin{array}{c}\text { Sin Límite } \\
\text { (Spalling permitido) }\end{array}$ & \multirow{2}{*}{$\begin{array}{c}\varepsilon_{\mathrm{s}} \leq 1 \% \\
\quad \text { (inicio del } \\
\text { endurecimiento) }\end{array}$} \\
\hline & $\begin{array}{c}\text { Fibras } \\
\text { confinadas }\end{array}$ & $\varepsilon_{C} \leq 0,6 \%(*)$ & \\
\hline \multirow{2}{*}{$\begin{array}{l}\text { DE - Daño Extensivo } \\
\text { (Reparaciones tecnológicamente } \\
\text { factibles, posible sustitución) }\end{array}$} & $\begin{array}{l}\text { Fibras no } \\
\text { confinadas }\end{array}$ & $\begin{array}{c}\text { Sin Límite } \\
\text { (Spalling permitido) }\end{array}$ & \multirow{2}{*}{$\begin{array}{c}\varepsilon s \leq 0.66 \cdot \varepsilon s u \\
(66 \% \text { de la deformación } \\
\left.\text { a tensión máxima } f_{u k}\right)\end{array}$} \\
\hline & $\begin{array}{l}\text { Fibras } \\
\text { confinadas }\end{array}$ & $\varepsilon_{c} \leq 1 \%(*)$ & \\
\hline
\end{tabular}

Tabla 8-7. Límites de deformación en los materiales en función de la reparabilidad, propuestos para el diseño de estaciones subterráneas de metro construidas por el método de cut-and-cover. 


\subsection{Niveles de accesibilidad a elementos susceptibles de sufrir daño}

\subsubsection{Discusión crítica del estado actual de la normativa}

De manera general, las normativas de construcción sismorresistente admiten únicamente como zonas susceptibles de sufrir daño (p.ej. mediante la formación de rótulas plásticas), aquellas que cuentan con un acceso fácil y rápido, tanto para la inspección posterior a un sismo, como para la posible reparación de daños. En este sentido, se promueve la formación de rótulas en vigas en edificación, o en fustes de pilas en puentes, y se desaconseja o se excluye la posibilidad de formación de estos mecanismos en pilotes, $\mathrm{u}$ otros elementos de cimentación. En este contexto, la normativa entiende que una zona enterrada, como puede ser la cabeza de un pilote bajo un encepado, es complicada de inspeccionar, requiere numerosos medios materiales para hacerlo, y por lo tanto no es inmediata, y tal vez la reparación resulte inviable.

En particular, la guía AASHTO de diseño sísmico de puentes indica en los comentarios del apartado $\S 3.3$ :

"Bridges are seismically designed so that inelastic deformation (damage) intentionally occurs in columns so that the damage can be readily inspected and repaired after the earthquake. Capacity design procedures are used to prevent damage from occurring in foundations and beams of bents and in the connections of columns to foundations and columns to the superstructure." (AASHTO Guide Specifications for LRFD Seismic Bridge Design, 2011, p.3-4).

Por su parte, el Eurocódigo EN 1998-2:2005 indica en el apartado §2.3.2.2:

“(2)P Bridges of ductile behaviour shall be designed so that a dependably stable partial or full mechanism can develop in the structure through the formation of flexural plastic hinges. These hinges normally form in the piers and act as the primary energy dissipating components.

(3) As far as is reasonably practicable, the location of plastic hinges should be selected at points accessible for inspection and repair." (EN 1998-2:2005, p.26).

Sin embargo, dependiendo del tipo de estructura, no siempre es posible ubicar las rótulas plásticas fuera de una zona enterrada. Este resulta ser el caso, por ejemplo, de las pilas de puente con configuración de pila-pilote (drilled shafts en la literatura anglosajona), en los que inevitablemente el punto de momento máximo resulta estar por 
debajo del terreno superficial. Este caso, por ejemplo, queda recogido explícitamente en la guía AASHTO de diseño sísmico de puentes, que indica en los comentarios del apartado §3.3:

"[...] There are two exceptions to this design philosophy. For pile bents and drilled shafts, some limited inelastic deformation is permitted below the ground level. The amount of permissible deformation is restricted to ensure that no long-term serviceability problems occur from the amount of cracking that is permitted in the concrete pile or shaft”. (AASHTO Guide Specifications for LRFD Seismic Bridge Design, 2011, p.3-4).

Otro caso significativo es el de los muelles marginales portuarios cimentados sobre pilotes (pier wharves en la literatura anglosajona), en los que la configuración geométrica de los pilotes, y del talud de terreno bajo la losa, hace que los pilotes más cortos y rígidos tiendan a desarrollar rótulas plásticas tanto en su parte superior de encuentro con la losa, como en una zona inferior enterrada bajo el terreno (Fig. 8-9).

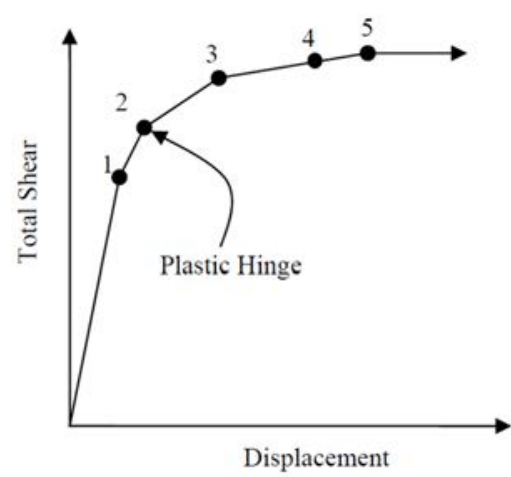

a) Pushover Curve

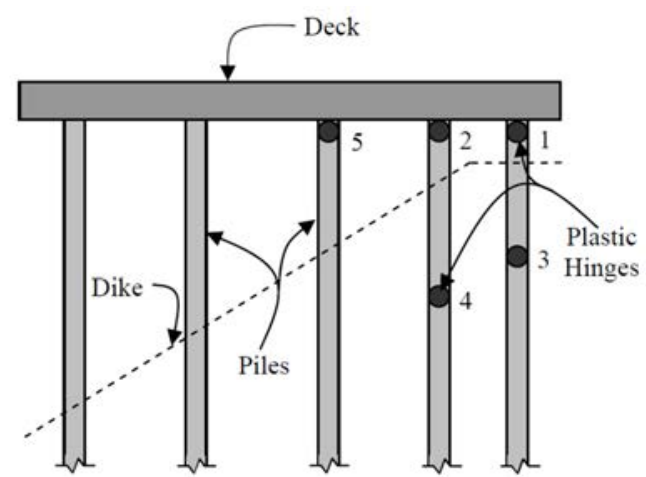

b) Plastic Hinge Sequence

Fig. 8-9 Muelle marginal cimentado sobre pilotes (izda.) Curva pushover. (dcha.) Esquema en sección transversal con la posible ubicación de las rótulas plásticas (POLB, 2012).

Para este tipo de estructuras, la normativa prevé que el elemento a proteger es la losa del muelle, y que los elementos susceptibles de rotular son los propios pilotes. Por ejemplo, la norma ASCE 61-14 indica en el apartado §3.8.1:

"Capacity Protection: The deck shall be designed as a capacity-protected element, such that all inelastic deformations occur in piles rather than in the deck elements. Yielding of the pile-to-deck connection is permitted." (ASCE 61-14. p.7).

De esta manera, la norma ASCE 61-14 proporciona criterios para calcular la longitud de rótula plástica tanto en el encuentro pilote-losa, como en la porción enterrada del pilote (apartado §6.6.4.1 In-ground plastic hinge length), e indica en croquis la 
posición de las posibles rótulas plásticas. Otras normativas sismorresistentes del ámbito de las obras portuarias (Port of Los Angeles 2010; Port of Long Beach, 2012), proporcionan consideraciones similares.
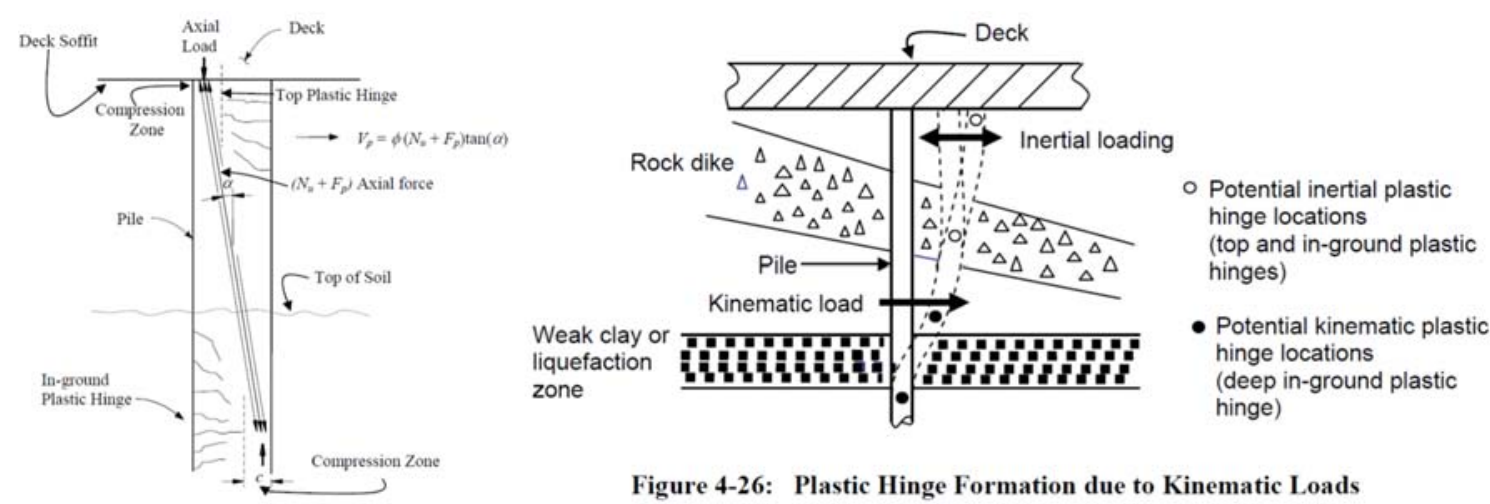

Figure 4-26: Plastic Hinge Formation due to Kinematic Loads

Fig. 8-10 (izda.) Ubicación admisible de rótulas plásticas en un pilote de muelle portuario (ASCE 6114). (dcha.) Ubicación admisible de rótulas plásticas (POLB, 2012).

Por otra parte, la norma ASCE 61-14, indica límites diferentes de deformaciones máximas en los materiales para ambas ubicaciones de rótulas (apartado §3.10, tablas 3-1, 3-2, y 3-3). Estos niveles se han comentado en el apartado $\$ 8.3 .1$ de esta tesis, y esencialmente corresponden a deformaciones admisibles menores para los elementos enterrados (de difícil acceso), que para los elementos superficiales de acceso más sencillo.

\subsubsection{Propuesta de clasificación de la accesibilidad para la reparación}

Como se ha visto en el apartado anterior, el posible daño estructural que admiten las normativas actuales depende en gran medida de la facilidad de acceso que tenga la zona dañada, y las consiguientes posibilidades de inspección y reparación.

De manera consecuente con este planteamiento, en esta tesis se propone una clasificación, en función de la accesibilidad, de las diferentes posibles ubicaciones de rótulas plásticas en las que pueda concentrarse el daño. De esta manera, se podrán precisar de manera más coherente los objetivos de desempeño de acuerdo a los objetivos de reparabilidad subyacentes. La clasificación propuesta, y razonamiento que la motiva son:

1) Elementos de accesibilidad fácil: Comprende aquellos elementos que se pueden inspeccionar visualmente, de manera completa e inmediata desde el interior de la estación. Es decir, aquellos en los que tanto el estado del hormigón, como de las barras de armadura longitudinales, y como los cercos de zunchado y cortante de ambas caras, pueden verse $\mathrm{y}$ 
fotografiarse de manera sencilla. Para acceder a estos elementos se podrán retirar revestimientos de chapa, fábrica, u otros elementos arquitectónicos, funcionales, o señaléticos que oculten los elementos estructurales, pero no se podrá ejecutar obras de envergadura mayor como movimientos de tierras, demolición parcial de otros elementos estructurales, etc. En esta categoría se incluyen los elementos que puedan revisarse completamente en el transcurso de algunas horas. De manera análoga, la reparación de estos elementos debe poder realizarse completamente desde el interior de la estación.

2) Elementos de accesibilidad moderada: Comprende aquellos elementos que se pueden inspeccionar visualmente de manera inmediata tan sólo por uno de los dos lados. Sin embargo, la inspección/reparación del lado opuesto requiere la ejecución de obras de cierta envergadura, tales como el movimiento de tierras de pocos metros de profundidad, o la demolición parcial del elemento. El razonamiento que se sigue para establecer esta categoría es

- Puesto que el elemento es visible desde un lado, se puede realizar una valoración general de su estado, infiriendo que el lado opuesto no accesible presentará un estado de daños similar al del lado accesible. Por lo tanto, es parcialmente inspeccionable.

- Sin embargo, la conclusión de la revisión es incierta, porque tan sólo se ha podido inspeccionar el 50\% del elemento, y el resto permanece oculto.

- De cualquier manera, la reparación completa del elemento requiere el acceso a ambos lados, y por lo tanto ejecutar las obras de cierta envergadura que se han mencionado anteriormente.

3) Elementos inaccesibles: Comprende aquellos elementos a los cuales no se puede acceder de manera inmediata para su inspección desde ningún lado, y que por lo tanto no se puede determinar en que estado se encuentran tras el sismo. En esta categoría también se incluyen aquellos elementos que se pueden inspeccionar de manera inmediata tan sólo por uno de los lados, pero que, sin embargo, para acceder al otro lado para su inspección/reparación se requieren obras de envergadura desproporcionada, o que resultan poco verosímiles en la práctica. 
Esta clasificación es la que se resume en la Tabla 8-8 y en la figura (Fig. 8-11).

\begin{tabular}{|c|c|}
\hline Accesibilidad & Descripción \\
\hline Fácil & $\begin{array}{l}\text { - Elementos de la estructura a los que tiene acceso inmediato, desde el interior } \\
\text { de la estación, a ambos lados del elemento. }\end{array}$ \\
\hline Moderada & $\begin{array}{l}\text { - Elementos con acceso inmediato sólo por un lado desde el interior de la } \\
\text { estación. } \\
\text { - El acceso al otro lado del elemento puede requerir cierto movimiento de } \\
\text { tierras. } \\
\text { - El acceso al otro lado del elemento puede requerir la demolición parcial de } \\
\text { elementos intermedios. }\end{array}$ \\
\hline Inaccesible & $\begin{array}{l}\text { - Elementos que no tienen acceso inmediato a ninguno de ambos lados desde el } \\
\text { interior de la estación. } \\
\text { - Elementos con acceso inmediato sólo por un lado desde el interior de la } \\
\text { estación, pero para los que: } \\
\text { - El acceso al otro lado del elemento requiere movimiento de tierras } \\
\text { excesivo. } \\
\text { - El acceso al otro lado elemento puede desestabilizar las pantallas, o } \\
\text { requerir niveles extraordinarios de apuntalamiento intermedio. }\end{array}$ \\
\hline
\end{tabular}

Tabla 8-8. Propuesta de caracterización de la accesibilidad a las zonas de rótula plástica susceptibles de sufrir daño durante un sismo.

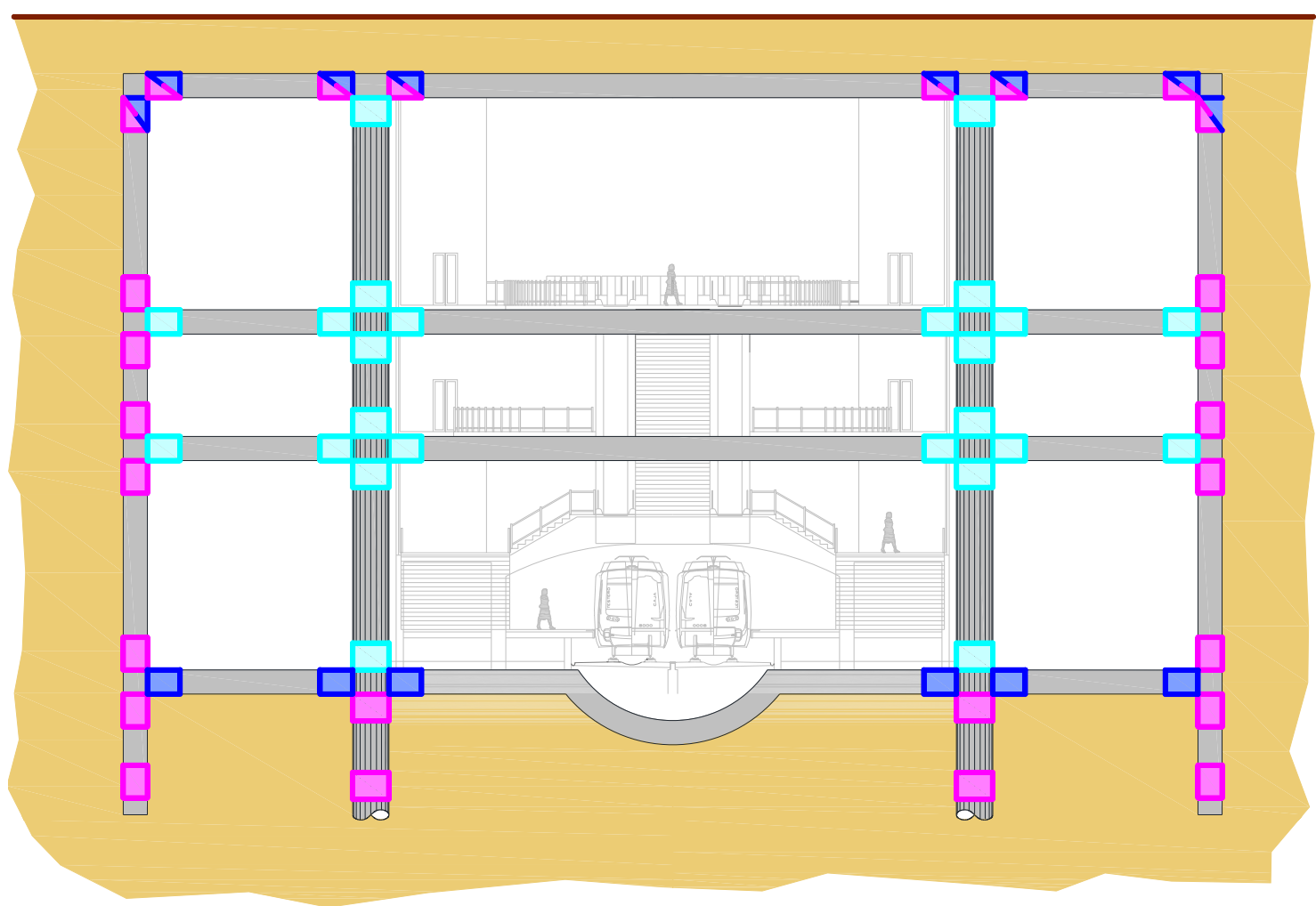

\section{Accesibilidad Fácil.}

Accesibilidad Moderada.

Accesibilidad Moderada / Inaccesible en función de la profundidad. Inaccesible.

Fig. 8-11 Mapa propuesto de accesibilidad de las diferentes ubicaciones potenciales de rótulas plásticas para una estación subterránea de metro construida mediante el método de cut-andcover. 


\subsection{Propuesta de matrices demanda-desempeño en función de la relevancia urbana, accesibilidad, y reparabilidad}

De acuerdo a los consideraciones expuestas los apartados anteriores, en los que se han propuesto dos niveles de relevancia urbana para estaciones de metro en función de tres criterios (apartado §8.1.2), tres niveles de demanda sísmica de intensidad creciente y probabilidad de ocurrencia decreciente (apartado §8.2.2), tres niveles de daño estructural caracterizados por la deformación en los materiales (apartado §8.3.2), y tres niveles de accesibilidad a las distintas zonas susceptibles de sufrir daño durante un sismo (apartado $\S 8.4 .2$ ), se propone a continuación una asignación de niveles desempeño para las diferentes demandas consideradas.

\begin{tabular}{|c|c|c|c|}
\hline \multicolumn{4}{|c|}{ Relevancia Urbana Normal } \\
\hline \multirow{2}{*}{ Nivel de Demanda } & Fácil Accesibilidad del Elemento \\
\cline { 2 - 4 } & SD & Moderada & Inaccesible \\
\hline $\begin{array}{c}\text { Nivel L1 } \\
\text { (Sismo Esperable, } T_{R}=144 \text { años) }\end{array}$ & DM & DM & SD \\
\hline $\begin{array}{c}\text { Nivel L2 } \\
\text { (Sismo de Contingencia, } T_{R}=950 \text { años) }\end{array}$ & DE & DE & DM \\
\hline $\begin{array}{c}\text { Nivel L3 } \\
\text { (Sismo Excepcional, } T_{R}=2500 \text { años) }\end{array}$ & \multicolumn{4}{|}{} \\
\hline $\begin{array}{l}\text { SD: Sin Daño } \\
\text { DM: Daño Moderado | Reparable } \\
\text { DE: Daño Extensivo | Reparaciones tecnológicamente factibles, posible sustitución) }\end{array}$ \\
\hline
\end{tabular}

Tabla 8-9. Matriz de objetivos de desempeño y niveles de demanda sísmica, en función de la accesibilidad, propuestos para el diseño de estaciones subterráneas de metro construidas por el método de cut-and-cover, de relevancia urbana normal.

\begin{tabular}{|c|c|c|c|}
\hline \multicolumn{4}{|c|}{ Relevancia Urbana Especial } \\
\hline \multirow{2}{*}{ Nivel de Demanda } & Fácil Accesibilidad del Elemento \\
\cline { 2 - 4 } & SD & Moderada & Inaccesible \\
\hline $\begin{array}{c}\text { Nivel L1 } \\
\text { (Sismo Esperable, } T_{R}=144 \text { años) }\end{array}$ & SD & SD \\
\hline $\begin{array}{c}\text { Nivel L2 } \\
\text { (Sismo de Contingencia, } T_{R}=950 \text { años) }\end{array}$ & DE & SD & SD \\
\hline $\begin{array}{c}\text { Nivel L3 } \\
\text { (Sismo Excepcional, } T_{R}=2500 \text { años) }\end{array}$ & DM & SD \\
\hline $\begin{array}{l}\text { SD: Sin Daño } \\
\text { DM: Daño Moderado | Reparable } \\
\text { DE: Daño Extensivo | Reparaciones tecnológicamente factibles, posible sustitución) }\end{array}$ \\
\hline
\end{tabular}

Tabla 8-10. Matriz de objetivos de desempeño y niveles de demanda sísmica, en función de la accesibilidad, propuestos para el diseño de estaciones subterráneas de metro construidas por el método de cut-and-cover, de relevancia urbana especial. 
8. Criterios de Demanda y Desempeño para el Proyecto de Estaciones Subterráneas de Metro 


\section{CONCLUSIONES}

En este capítulo se resumen las principales conclusiones de esta tesis doctoral, se destacan las aportaciones originales al estado del arte, y se enumeran las publicaciones derivadas del trabajo desarrollado en esta tesis.

\subsection{Conclusiones de esta tesis}

Las conclusiones principales de esta tesis son las siguientes:

Se ha realizado un estudio pormenorizado de la evolución histórica de los métodos de análisis de la interacción suelo-estructura para estructuras subterráneas y de contención de tierras, tanto para acciones estáticas convencionales, como para la acción del sismo. Este estudio ha permitido entender los fundamentos, e hipótesis subyacentes, de las metodologías actuales de análisis sísmico de estructuras subterráneas.

Se ha realizado un análisis crítico exhaustivo de las diferentes metodologías simplificadas actuales de análisis de la acción sísmica sobre estructuras subterráneas y de contención, que conviven en la actualidad en diferentes normativas internacionales de proyecto. A este respecto se han identificado tres grupos diferentes metodologías.

1) Un primer grupo de métodos cuyo propósito es determinar la ley de presiones laterales máximas que solicitan la estructura subterránea durante un sismo. Estos métodos pueden estar basados en análisis de estados límite, cuyo exponente más claro son los trabajos de Mononobe y Okabe (Mononobe \& Matsuo, 1929; Okabe, 1924), o en análisis elásticos, cuyo exponente más claro es el trabajo de Wood (Wood, 1973). En esta tesis, este tipo de métodos se considera como poco apropiado para el análisis de estructuras de estaciones subterráneas de metro, ya que las hipótesis subyacentes en su formulación no se cumplen. El método de Mononobe-Okabe asume desplazamientos considerables en la estructura, y la formación de una cuña de deslizamiento en 
el trasdós de la estructura. Este escenario es altamente improbable en una estación de Metro. El método de Wood asume que la estructura de contención es infinitamente rígida, y que su cimentación es igualmente infinitamente rígida. Este escenario es altamente improbable en una estación de Metro construida por el método de cut-and-cover; independientemente de la rigidez de la estructura, la cimentación queda lejos de tener esa rigidez infinita. El hecho de estar construida mediante la técnica de cut-and-cover implica que la estación se encuentra en un terreno blando, y que sus pantallas reposan sobre un estrato igualmente blando. Por lo tanto, tampoco se verifican las hipótesis necesarias para la aplicación de este método.

2) Un segundo grupo de métodos cuyo propósito es determinar el fenómeno de interacción suelo-estructura en forma de deformaciones globales de la estructura mediante el denominado coeficiente de racking $R$. Este coeficiente determina cuanto se amplifica o se reduce la deformación de distorsión en la estructura subterránea $\gamma_{S T R U}$ con respecto a la deformación tangencial de campo libre $\gamma_{F F}$, en función de cual sea la flexibilidad relativa $F_{R}$ de la estructura, respecto a la del suelo que sustituye. Los exponentes más claros de este grupo de métodos son los desarrollados por Wang (Wang, 1993) y Penzien (Penzien, 2000), e incorporados en diversas normas estadounidenses (FHWA Technical Design Manual for Design and Construction of Road Tunnels, 2009), (NCHRP 611 - Seismic Analysis and design of Retaining Walls, Buried Structures, Slopes, and Embankments, 2008), (LA Metro Rail Design Criteria Section 5 Structural / Geotechnical, 2012), (WSDOT Appendix B8 Seismic Design Criteria SR 99 Bored Tunnel Alternative Design-Build Project, 2010).

3) Un tercer grupo de métodos cuyo propósito es determinar el fenómeno de interacción-suelo estructura de manera conjunta en forma de presiones laterales, de esfuerzos inducidos por estas, y de deformaciones. Estos métodos asumen que la transmisión de esfuerzos sísmicos a la estructura se produce por la presión lateral del terreno. Abordan el problema mediante la modelización de un marco estructural con fundación elástica de Winkler en todos sus elementos (losas y muros) y aplicación en los extremos libres de los muelles de un patrón de deformaciones igual a la deformación en campo libre. Los exponentes más claros de estos métodos son los propuestos en la normativa 
europea (EN 1998-2:2005), norma francesa (Guide AFPS Conception et Protection Parasismiques des Ouvrages Souterrains 2001), norma japonesa (Design Standards for Railway Structures and Commentary (Seismic Design), 2007, JSCE Standard Specifications for Tunneling-2016: Cut-and-Cover Tunnels), norma ISO-23469:2005(R2014), y norma chilena Manual de Carreteras, 2015. Los resultados de este grupo de métodos entran en contradicción directa con los métodos del segundo grupo, especialmente para las estructuras más flexibles como son las estaciones de metro construidas por el método de cut-and-cover. Estos métodos predicen que una estructura se deformará como máximo la deformación del campo libre, acercándose asintóticamente a este valor según aumente la flexibilidad de la estructura. Sin embargo los métodos del segundo grupo predicen que las estructuras se puede deformar más de lo que lo hace el campo libre, hasta del orden de 3 veces más, en función de la flexibilidad relativa de la estructura $F_{R}$ y su coeficiente de racking $R$.

Por otra parte, en esta tesis se ha propuesto un marco conceptual que permite abordar satisfactoriamente el problema de interacción suelo-estructura en dos etapas, y explicar así cuales son los mecanismos fundamentales que rigen el comportamiento de las estructuras subterráneas bajo la acción del sismo:

1) El problema de interacción suelo-estructura de estructuras subterráneas en condiciones sísmicas es esencialmente un problema de interacción cinemática: el terreno se deforma y la estructura se adapta a esta deformación. La deformación global de la estructura se produce debido la transferencia de esfuerzos tangenciales desde el medio circundante hacia la estructura, y la compatibilidad de deformaciones entre diferentes zonas del conjunto sueloestructura. La rigidez relativa entre suelo y estructura gobierna el flujo de estos esfuerzos: las estructuras rígidas concentran los esfuerzos tangenciales, mientras que las flexibles los alejan.

2) Los esfuerzos en la estructura (momentos flectores y cortantes) se producen por un doble mecanismo acumulativo de compatibilidad de deformaciones. Por una parte, los esfuerzos son debidos a la deformación global de distorsión de la estructura, que se produce por la transferencia de tensiones tangenciales; por otra parte, los esfuerzos son debidos a la compatibilidad de deformaciones 
locales (fuera de los planos de losas y muros) entre la estructura y el terreno circundante.

Con este esquema conceptual, la determinación precisa de las distribuciones de presiones dinámicas laterales del terreno sobre la estructura, que hasta ahora ha ocupado una posición fundamental a la hora de abordar el problema, pierde relevancia. El marco conceptual propuesto establece, esencialmente, que la estructura se deforma debido a las tensiones tangenciales y a la compatibilidad de deformaciones, y que las presiones laterales son un resultado de la deformación y de la compatibilidad. Expresado de manera concisa, las presiones laterales no son la causa de la deformación de la estructura, sino la consecuencia de esta.

Este esquema conceptual, concretado en los métodos de análisis simplificados propuestos en esta tesis y que se resumen en el siguiente apartado $§ 9.2$, ha sido verificado comparando los resultados que predice frente a un conjunto extensivo de análisis numéricos mediante elementos finitos. La coherencia entre ambos grupos de resultados es muy buena, lo cual aporta confianza acerca de la validez del esquema conceptual.

Por otra parte, en esta tesis se han analizado las consecuencias en términos de deformaciones que tiene el comportamiento no-lineal del suelo que rodea la estructura. En particular, se ha analizado el comportamiento de un conjunto extensivo de estructuras rectangulares, con diferentes características geométricas y mecánicas, embebido en un conjunto de terrenos con comportamiento no-lineal, y caracterizados por diferentes parámetros geotécnicos.

A este respecto, se puede concluir que, para un mismo nivel de deformación del terreno en campo libre $\gamma_{F F}$, en la profundidad comprendida por la obra, la plastificación del terreno redunda en una solicitación menor de la estructura. El mecanismo que explica este comportamiento es sencillo: la plastificación diferencial del terreno respecto a la estructura produce la flexibilización relativa del mismo, y por lo tanto una disminución de la ratio $F_{R}$. A un valor menor de $F_{R}$ le corresponde un coeficiente de racking $R$ menor, y por lo tanto la estructura se deformará menos, pero conservando su rigidez. Consecuentemente, los esfuerzos en la estructura resultarán menores.

Adicionalmente, se ha propuesto un método simplificado de análisis de la plastificación del terreno, que se resume en el siguiente apartado §9.2, y que encaja en el resto de métodos simplificados propuestos en esta tesis. 


\subsection{Aportaciones originales de esta tesis}

Las principales aportaciones originales realizadas en el marco de esta tesis doctoral son los modelos simplificados propuestos, y que permiten determinar de manera precisa el comportamiento sísmico de las estructuras enterradas. Estos modelos son los siguientes.

1) Un modelo simplificado e intuitivo para determinar la deformación de distorsión de un marco rectangular enterrado a gran profundidad, en un medio elástico, homogéneo, e isótropo, sometido a la acción sísmica, representada como un campo lejano de cortante puro. Este modelo se basa en el concepto simple de un bloque elástico sometido a un estado de cortante puro, y su aplicación recursiva a lo largo de diferentes perímetros de control.

El método es capaz de predecir de manera más precisa que los métodos existentes en la actualidad, tanto la deformación de distorsión de la estructura, como el perfil de distorsión de diferentes perímetros de control cercanos y lejanos a la estructura. Este último aspecto no había sido abordado en la literatura técnica, y se ha revelado como una pieza fundamental para describir las consecuencias del comportamiento no lineal del terreno.

Adicionalmente, este método permite explicar que el fenómeno de rotación de la estructura enterrada, denominado de rocking, es tan sólo una manifestación más de la deformación diferencial a la distorsión de la estructura y del medio que la rodea. Este fenómeno de rocking se ha señalado recientemente en la literatura técnica (Cilingir \& Madabhushi, 2011; Debiasi et al., 2013; Iwatate, Kobayashi, Kusu, \& Rin, 2000; Pitilakis \& Tsinidis, 2016; Grigorios Tsinidis, 2017; Grigorios Tsinidis \& Pitilakis, 2018; Grigorios Tsinidis, Pitilakis, \& Heron, 2015; Ulgen, Saglam, \& Ozkan, 2015) como un mecanismo complejo que limita la aplicación de los métodos de análisis simplificados.

Por otra parte, el método permite analizar satisfactoriamente los esfuerzos desarrollados en las estructuras infinitamente rígidas. Este es un aspecto que queda indeterminado en los métodos simplificados existentes en la actualidad.

Finalmente, el método permite ser implementado fácilmente en una hoja de cálculo, y es la base del marco conceptual propuesto en esta tesis, que permite separar el análisis de la deformación, del cálculo preciso de las presiones 
laterales que ejerce el terreno. Este método se describe en detalle en el capítulo $\S 4$ de esta tesis.

2) Una modificación al método simplificado anterior para tratar el caso de terreno circundante con comportamiento no lineal. Este método, iterativo pero que converge satisfactoriamente en pocas iteraciones, se basa en la aplicación iterativa del método señalado en 1), modificando la rigidez del terreno en cada perímetro de control a la correspondiente a su nivel de deformación tangencial. El método permite predecir la interacción suelo-estructura no-lineal mediante una descripción sencilla del comportamiento del suelo en forma de curva de reducción del módulo de cortante $G / G_{\max }$.

El método es capaz de capturar con precisión el fenómeno de interacción suelo-estructura con suelo no lineal, tal y como se demuestra mediante con los resultados del análisis mediante elementos finitos Este método es especialmente adecuado para implementar análisis del tipo empuje incremental pushover, y poder determinar la sensibilidad de las solicitaciones en la estructura frente a la incertidumbre de la intensidad de la acción sísmica. Este método se describe en detalle en el capítulo §6 de esta tesis.

3) Un método simplificado para determinar los esfuerzos solicitantes (momentos flectores y cortantes) en un marco rectangular enterrado a gran profundidad, en un medio elástico, homogéneo, e isótropo, sometido a la acción sísmica, representada como un campo lejano de cortante puro. Este modelo se basa en el concepto simple de una condición tipo Winkler que vincula la estructura a la línea media de terreno circundante una vez que este se ha deformado a distorsión, junto con la estructura, por efecto de las tensiones tangenciales.

La fiabilidad de este método se ha contrastado con el análisis extensivo de un conjunto de modelos de elementos finitos, evaluados para diferentes características mecánicas y geométricas tanto de la estructura enterrada como del terreno circundante. La precisión obtenida es notable, y superior a la que proporcionan los métodos simplificados actuales.

El método puede ser implementado fácilmente en cualquier programa de estructuras, con muy poco esfuerzo extra respecto a lo propuesto en los 
métodos existentes actualmente. Este método se describe en detalle en el capítulo $§ 6$ de esta tesis.

4) Se han propuesto sendas modificaciones a los métodos simplificados indicados en 1) y 3) para tener en cuenta las particularidades que supone el que la estructura subterránea se encuentre a una profundidad somera, en lugar de enterrada a gran profundidad. En particular se ha propuesto un factor corrector de la deformación de la distorsión con la profundidad $R_{z} / R_{D e e p}$ para aplicar al método simplificado resumido en 1), y una variación de las propiedades mecánicas de las condiciones de Winkler, haciéndolas dependientes de la profundidad, para aplicar al método simplificado resumido en 3).

La fiabilidad de estas modificaciones se ha contrastado con el análisis extensivo de un conjunto de modelos de elementos finitos, evaluados para diferentes características mecánicas y geométricas tanto de la estructura enterrada como del terreno circundante. La precisión obtenida es notable, y superior a la que proporcionan los métodos simplificados actuales. Estas modificaciones se describen en detalle en el capítulo $§ 7$ de esta tesis.

Por último, en esta tesis se realiza una propuesta de criterios de proyecto para el diseño sismorresistente de estaciones de metro construidas por el método de cut-andcover, en términos de definición probabilista de los niveles de demanda sísmica a considerar, y de aspectos concretos de limitación de daño en los materiales para diferentes niveles de desempeño. Esta propuesta de criterios se describe en detalle en el capítulo $\S 8$ de esta tesis.

\subsection{Publicaciones derivadas de esta tesis}

Del trabajo desarrollado en esta tesis se han derivado las siguientes publicaciones en revistas científicas indexadas en el JCR Journal Citation Reports:

- Gordo-Monsó, C. González-Galindo, J. Olalla-Marañón, C. (2019). A closed-form solution for the seismic racking and rocking behavior of rectangular tunnels. Tunnelling and Underground Space Technology 88, 87-97. DOI: $10.1016 /$ j.tust.2019.03.002 
De igual modo, algunos de los métodos desarrollados en esta tesis se han sustanciado en las siguientes hojas de cálculo que complementan a las publicaciones referidas anteriormente. Estas son:

- Gordo-Monsó, C. González-Galindo, J. Olalla-Marañón, C. (2019). Data for: A closed-form solution for the seismic racking and rocking behavior of rectangular tunnels. Mendeley Data, v1. DOI: $\underline{10.17632 / \mathrm{jbry} 4 \mathrm{vt} 2 \mathrm{sf} .1}$

Asimismo, el trabajo desarrollado en esta tesis ha dado lugar a las siguientes comunicaciones en congresos:

- Gordo-Monsó, C. González-Galindo, J. Olalla-Marañón, C. (2020). A simplified method for the seismic analysis of cut-and-cover structures. Towards the unification of criteria. $17^{\text {th }}$ World Conference on Earthquake Engineering. 17WCEE. Sendai, Japan. September $13^{\text {th }}$ to $18^{\text {th }} 2020$. 


\section{FUTURAS LÍNEAS DE INVESTIGACIÓN}

Los métodos simplificados de análisis propuestos en esta tesis permiten posibles ampliaciones, así como notables aplicaciones que pueden ser exploradas. Planteamos a continuación las tres que a juicio del autor resultan más relevantes.

\subsection{Estudio de la acción del sismo sobre estructuras tridimensionales}

Tal y como se ha comentado en múltiples ocasiones a lo largo de esta tesis, tanto las metodologías descritas en la literatura técnica, como las presentadas en esta tesis, en lo que respecta al análisis de la acción que ejerce el sismo sobre las estructuras subterráneas, se basan en una premisa fundamental: la obra subterránea, por lo general un túnel, es lo suficientemente larga como para poder asumir como válida la hipótesis simplificadora de que el problema se reduce al estudio de un campo de deformación plano. Es decir, estudiando la respuesta y la interacción suelo-estructura de una única sección transversal de la obra, se puede asumir que el resto de secciones se comportará de manera similar. Esta asunción, que en principio es razonable para obras subterráneas lineales (p.ej. túneles, estaciones de metro largas, etc.), puede no serlo para obras en las que alguna de sus características geométricas o mecánicas invalide la hipótesis de campo de deformaciones plano. Este puede ser el caso de estaciones de metro, en el que las características que se enumeran a continuación presentan indicios razonables para pensar que secciones transversales diferentes tengan un comportamiento diferente:

- Se trata de estructuras de grandes dimensiones, del orden de 25,00 m de ancho entre pantallas laterales, 25,00 $\mathrm{m}$ de alto entre losa de cubrición y contrabóveda, y 120,00 m de largo entre paños testeros. 

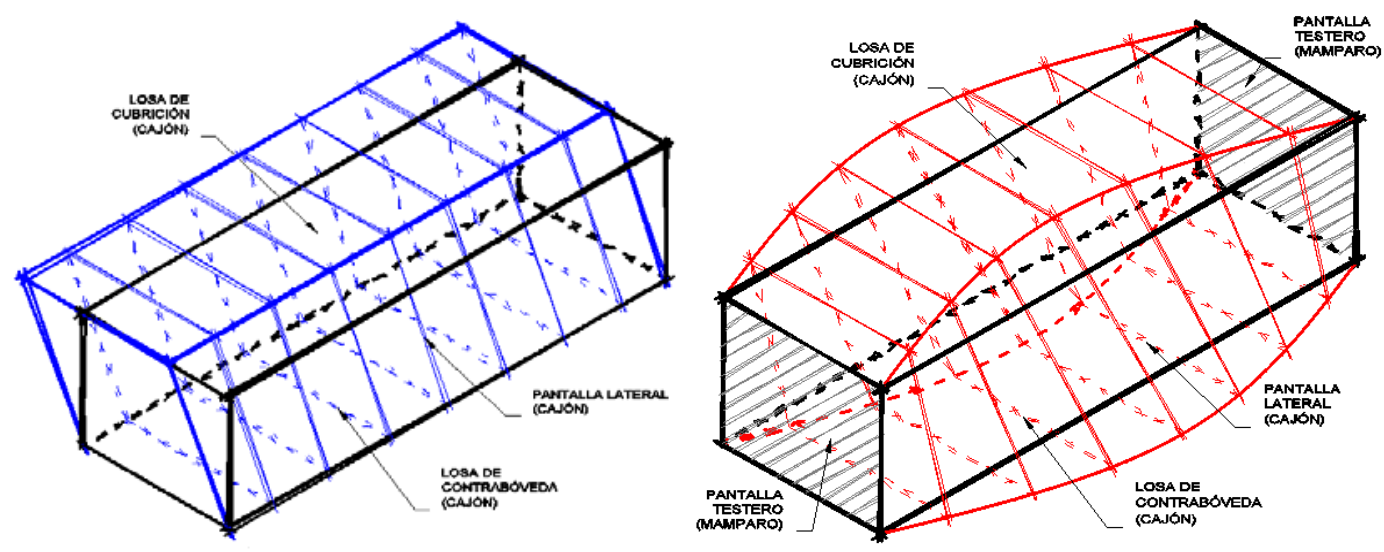

Fig. 10-1. Esquema tridimensional de la deformación de distorsión de un cajón. (izda) Sin mamparos. (dcha.) Con mamparos.

- Se trata de estructuras con elementos muy rígidos a flexión en su plano. Las grandes dimensiones mencionadas anteriormente hacen que la losa superior, intermedia de vestíbulo, e inferior de contrabóveda tengan una gran rigidez a la deformación en su propio plano. Si se asimilan a vigas rectangulares trabajando a flexión en su propio plano, en el ejemplo anterior corresponderían a vigas de $120 \mathrm{~m}$ de luz y $25 \mathrm{~m}$ de canto. De la misma manera, las pantallas laterales y de testeros, dependiendo de la técnica constructiva empleada en su ejecución, pueden ofrecer esta misma gran rigidez correspondiente a vigas de gran canto, que en el caso anterior corresponderían a vigas de $120 \mathrm{~m}$ de luz y $25 \mathrm{~m}$ de canto.

- Se trata de estructuras que, de cara a la deformación transversal, se encuentran rígidamente apoyadas en los paños testeros. En efecto, las losas de gran rigidez en su plano indicadas anteriormente se apoyan en sus extremos en las pantallas de testeros, que también son muy rígidas en su plano, configurando una estructura que puede considerarse como un cajón (losa superior, inferior y pantallas laterales), cerrado por mamparos frontales (pantallas de testeros) frente al cual el sismo intenta ejercer una acción distorsora (Fig. 10-1).

- Como es sabido, los cajones dotados de mamparos son estructuras que ofrecen una gran rigidez a la distorsión, y que se apartan de manera significativa del comportamiento de un marco simple, que sería el fenómeno estudiado mediante una metodología basada en deformaciones planas (Fig. 10-1). 
Por lo tanto, una interesante línea de investigación puede ser el estudio del comportamiento tridimensional de estructuras rectangulares enterradas bajo la acción del sismo, analizar cómo afecta la rigidez en su plano de las losas y muros a la acción distorsora, y tratar de derivar una metodología simplificada para el tratamiento del problema.

Una posible línea de acción para abordar este estudio, y proponer una metodología simplificada, puede ser a través de la analogía del problema de la distorsión de secciones cajón y el de la viga sobre fundación elástica tipo Winkler, dado que las ecuaciones diferenciales que gobiernan ambos fenómenos son homólogas.

Esta analogía, habitualmente empleada en el estudio del fenómeno de la distorsión en puentes de sección cajón, establece una correspondencia entre términos de uno y otro problema (Fig. 10-2). De esta manera, la distorsión angular de la sección cajón (denominada $\gamma_{S T R U}$ a lo largo de esta tesis) resulta análoga a la deformación vertical de la viga sobre fundación elástica. La rigidez a la distorsión de la sección cajón (denominada KSTRU a lo largo de esta tesis) resulta análoga a la rigidez de los muelles de la fundación elástica de Winkler. Las secciones muy rígidas, o infinitamente rígidas, a la distorsión (tales como los mamparos formados por las pantallas de testeros de la Fig. 10-1) resultan análogas a muelles concentrados de gran rigidez o incluso apoyos verticales fijos. Por último, el trabajo a flexión de las losas y pantallas que conforman el cajón resulta análogo al trabajo a flexión de la propia viga sobre fundación elástica.

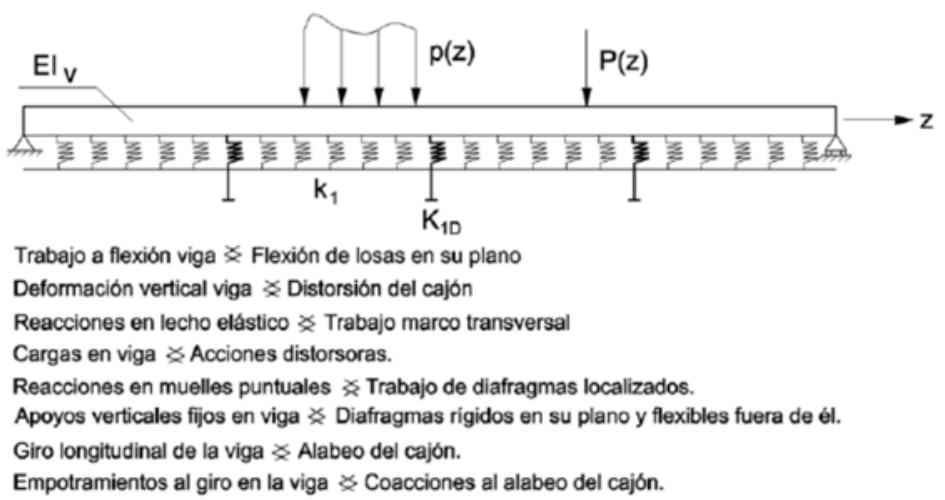

Fig. 10-2. Analogía de la viga sobre fundación elástica para el estudio de problemas de distorsión en secciones cerradas (Pascual Santos, 2004). 


\subsection{Ampliación de los métodos simplificados propuestos al caso de comportamiento no lineal de la estructura}

Los métodos simplificados de análisis propuestos en esta tesis consideran que la estructura tiene un comportamiento esencialmente lineal, mientras que permiten considerar el comportamiento del suelo tanto de manera lineal como no-lineal. Una ampliación interesante de estos métodos podría ser la consideración explícita del comportamiento no-lineal de la estructura, mediante la incorporación de plastificación concentrada en forma de rótulas plásticas en los elementos estructurales.

Una posible estrategia para abordar esta ampliación podría ser el establecer una curva de degradación de la rigidez de la estructura con las sucesivas plastificaciones (p.ej. en forma de curva pushover), e integrar dicha degradación de la rigidez en un esquema iterativo como el presentado en el capítulo $\S 6$ de esta tesis.

\subsection{Aplicación de los métodos presentados en la tesis al análisis probabilista de riesgo}

Los métodos simplificados de análisis propuestos en esta tesis, debido a su gran simplicidad y precisión, permiten ser integrados fácilmente dentro de un enfoque de análisis probabilista del riesgo sísmico, tal como el descrito en el apartado §3.2.2.2 de esta tesis.

En efecto, dentro del marco de la ingeniería sísmica basada en el desempeño (PBEE, Performance Based Engineering), uno de los pasos fundamentales consiste en establecer, en términos probabilistas, una correlación entre nivel de intensidad sísmica (p.ej. deformación en campo libre $\gamma_{F F}$ ) y el daño esperable en la estructura (p.ej. esfuerzos solicitantes, deformación en los materiales estructurales), con las denominadas curvas de fragilidad, para en un siguiente paso traducir este daño esperable en pérdidas económicas.

Una posible línea de investigación, que cuenta con recientes e interesantes aportaciones en la literatura técnica (Andreotti \& Lai, 2015; Argyroudis \& Pitilakis, 2012; Nguyen, Park, Shamsher, Nguyen, \& Lee, 2019; Pitilakis et al., 2013), consistiría en establecer un procedimiento para desarrollar, mediante estos métodos simplificados, curvas de fragilidad de obras subterráneas. 


\section{REFERENCIAS}

Abate, G., \& Massimino, M. R. (2017). Parametric analysis of the seismic response of coupled tunnel-soil-aboveground building systems by numerical modelling. Bulletin of Earthquake Engineering, 15(1), 443-467. https://doi.org/10.1007/s10518-016-9975-7

Abrahamson, N. A., Silva, W. J., \& Kamai, R. (2014). Summary of the ASK14 ground motion relation for active crustal regions. Earthquake Spectra, 30(3), 1025-1055. https://doi.org/10.1193/070913EQS198M

Abuhajar, O., El Naggar, H., \& Newson, T. (2015). Experimental and numerical investigations of the effect of buried box culverts on earthquake excitation. Soil Dynamics and Earthquake Engineering, 79, 130-148. https://doi.org/10.1016/j.soildyn.2015.07.015

Abuhajar, O., Naggar, H. El, \& Newson, T. (2015). Seismic soil - culvert interaction. Canadian Geotechnical Journal, 1667(April), 1649-1667.

Akkar, S. D., Sandikkaya, M. A., \& Bommer, J. J. (2014). Empirical ground-motion models for point- and extended-source crustal earthquake scenarios in Europe and the Middle East. Bulletin of Earthquake Engineering, 12(1), 359-387. https://doi.org/10.1007/s10518-013-9461-4

Al Atik, L., \& Sitar, N. (2010). Seismic Earth Pressures on Cantilever Retaining Structures. Journal of Geotechnical and Geoenvironmental Engineering, 136(10), 1324-1333. https://doi.org/10.1061/(ASCE)GT.1943-5606.0000351

An, X., Shaww, A. A., \& Maekawa, K. (1997). The Collapse Mechanism of a Subway Station during the Great Hanshin Earthquake. Cement and Concrete Composites, 19, $241-257$.

Anderson, D. G., Martin, G. R., Lam, I., \& Wang, J. N. (2008). NCHRP 611 - Seismic 
Analysis and design of Retaining Walls, Buried Structures, Slopes, and Embankments (Vol. 22). Washington, DC. https://doi.org/10.17226/13746

Arias, A., Sanchez-Sesma, F. J., \& Ovando-Shelley, E. (1981). A Simplified Elastic Model for Seismic Analysis of Earth-Retaining Structures with Limited Displacements. First International Conference on Recent Advances in Geotechnical Earthquake Engineering \& Soil Dynamics, 235-240.

Athanasopoulou, A., Bezuijen, A., Bogusz, W., Bournas, D., Brandtner, M., Breunese, A., ... Subrin, D. (2019). JRC Technical Reports: Standardisation needs for the design of underground structures. (A. Athanasopoulou, W. Bogusz, D. Bournas, S. Dimova, R. Frank, M. L. Sousa, \& A. Pinto, Eds.). Brussels, Belgium: JRC, European Commission. https://doi.org/10.2760/760968

Atik, L. Al, \& Sitar, N. (2009). Experimental and Analytical Study of the Seismic Performance of Retaining Structures. Richmond, CA.

Atkinson, G. M., \& Silva, W. J. (1997). An Empirical Study of Earthquake Source Spectra for California Earthquakes. Bulletin of the Seismological Society of America, 87(1), $97-113$.

Baker, J. W. (2013). Introduction to Probabilistic Seismic Hazard Analysis. Stanford, CA.

Benito-Oterino, B. Torres-Fernández, Y. (2009). La amenaza sísmica en América Central. pp. 371. Entimema. Madrid.

Biot, M. (1934). Theory of Vibration of Buildings During Earthquake. Zeitschrift Für Angewandte Matematik Und Mechanik, 19(2), 262-268.

Blum H. (1931). Einspannungsverhältnisse bei Bohlwerken, Berlin, W. Ernst \& Sohn.

Bobet, A. (2010). Drained and undrained response of deep tunnels subjected to far-field shear loading. Tunnelling and Underground Space Technology, 25(1), 21-31. https://doi.org/10.1016/j.tust.2009.08.001

Bobet, A., Fernandez, G., Huo, H., \& Ramirez, J. (2008). A practical iterative procedure to estimate seismic-induced deformations of shallow rectangular structures. Canadian Geotechnical Journal, 45(7), 923-938. https://doi.org/10.1139/T08-026

Boore, D. M., \& Atkinson, G. M. (2008). Ground-Motion Prediction Equations for the 
Average Horizontal Component of PGA, PGV, and 5\%-Damped PSA at Spectral Periods between $0.01 \mathrm{~s}$ and 10.0 s. Earthquake Spectra, 24(1), 99-138. https://doi.org/10.1193/1.2830434

Boore, D. M., Stewart, J. P., Atkinson, G. M., \& Eeri, M. (2014). NGA-West 2 Equations for Predicting PGA, PGV , and $5 \%$-Damped PSA for Shallow Crustal Earthquakes. Earthquake Spectra, (c), 1-38.

Boroschek, R. L., Contreras, V., Kwak, D. Y., \& Stewart, J. P. (2012). Strong Ground Motion Attributes of the $2010 \mathrm{M} \mathrm{w} 8.8$ Maule, Chile, Earthquake. Earthquake Spectra, 28(S1), S19-S38. https://doi.org/10.1193/1.4000045

Boussinesq, J. (1882). Note sur la détermination de l'épaisseur minimum que doit avoir un mur vertical, d'une hauteur et d'une densité données, pour contenir un massif terreux, sans cohésion, dont la surface est horizontale, Annales des Ponts et Chaussées, Tome 3, pp. 623-643

Brown, D. A., Turner, J. P., Castelli, R. J. (2010). Drilled Shafts: Construction Procedures and LRFD Design Methods. NHI Course No. 132014. Report FHWA NHI-10-016. pp 970. National Highway Institute. U.S. Department of Transportation. Federal Highway Administration. Washington, D.C. USA.

Brûlé, S. Cuira, F. (2018). Pratique de l'interaction sol-structure sous séisme. Application aux fondations et aux soutènements. AFNOR Éditions. La Plaine-Saint Dénis, Francia.

Bruneau M, Uang CM, Sabelli R. (2011.) Ductile Design of Steel Structures. pp 905. McGraw Hill. San Francisco, CA, USA.

Buckle, I. G., Friedland, I., Mander, J. B., Martin, G., Nutt, R., \& Power, M. (2006). Seismic Retrofitting Manual for Highway Structures: Part 1 - Bridges. McLean, VA.

Caquot, A. (1934). Equilibre des massifs a frottement interne. Stabilité des terres pulvérulentes ou cohérentes. Paris, France: Gauthier-Villars.

Caro-Perdigón, P. (2015). Análisis en la ejecución de cámaras mediante estructuras de contención flexible para estaciones de Metro. Universidad Politécnica de Madrid. Retrieved from http://oa.upm.es/42924/

Castillo Ron, E. (1973). Estudio de los movimientos originados por la excavación de 
túneles con escudos de presión de tierras en los suelos tosquizos de Madrid. Tesis Doctoral, Universidad Politécnica de Madrid, España.

Chopra, A. K. (2007). Dynamics of Structures. $3^{\text {rd }}$ edition. pp 876. Pearson Education. Upper Saddle River, NJ, USA.

Cilingir, U., \& Madabhushi, S. P. G. (2011). A model study on the effects of input motion on the seismic behaviour of tunnels. Soil Dynamics and Earthquake Engineering, 31(3), 452-462. https://doi.org/10.1016/j.soildyn.2010.10.004

Cilingir, U., \& Madabhushi, S. P. G. (2012). Effect of depth on the seismic response of square tunnels. Soils and Foundations, 51(3), 449-457.

Clough, R. W., \& Penzien, J. (1993). Dynamics of Structures. $2^{\text {nd }}$ edition. pp 738. McGraw Hill. New York, NY, USA.

Cornell, C. A. (1968). Engineering Seismic Risk Analysis. Bulletin of the Seismological Society of America, 58(5), 1583-1606.

Coulomb, C.A. (1776). Essai sur une application des regles de maximis et minimis quelques problemes de statique, relatits a l'architecture. Memoires de Mathematique de l'Academie Royale de Science 7, Paris.

Darendeli, M. B. (2001). Development of a New Family of Normalized Modulus Reduction and Material Damping Curves. University of Texas, Austin.

Debiasi, E., Gajo, A., \& Zonta, D. (2013). On the seismic response of shallow-buried rectangular structures. Tunnelling and Underground Space Technology, 38, 99-113.

Delattre, L. (2001). Un siècle de méthodes de calcul d'écrans de soutènement I. L'approche par le calcul - les méthodes classiques et la méthode au coefficient de réaction. Bulletin Des Laboratoires Des Ponts et Chaussées, 234(4308).

Delattre, L. (2004). Un siècle de méthodes de calcul d'écrans de soutènement III. La modélistaion des écrans de soutenement para la méthode des éléments finis. Bulletin Des Laboratoires Des Ponts et Chaussées, (252-253), 95-117.

Delattre, L., \& Marten, S. (2003). Un siècle de méthodes de calcul d'écrans de soutènement II. Les approches empiriques et semi-empiriques. Bulletin Des Laboratoires Des Ponts et Chaussées, (244-245), 31-51. Retrieved from http://cat.inist.fr/?aModele=afficheN\&amp;cpsidt=15462797 
Design Standards for Railway Structures and Commentary (Cut and Cover Tunnel). (2008). Tokyo, Japan.

Design Standards for Railway Structures and Commentary (Seismic Design). (2007). Tokyo, Japan.

Drucker, D. C., \& Prager, W. (1952). Soil mechanics and plastic analysis or limit design.

Quarterly of Applied Mathematics, 10(2), 157-165. https://doi.org/10.1090/qam/48291

Edward Kavazanjian, Wang, J.-N. J., Martin, G. R., Shamsabadi, A., Lam, I. (Po), Dickenson, S. E., \& Hung, J. (2011). LRFD Seismic Analysis and Design of Transportation Geotechnical Features and Structural Foundations - Reference Manual (Vol. 2011). Washington, D.C.

Elms, D. G., \& Richards, R. (1979). Seismic Design of Gravity Retaining Walls. Bulletin of the New Zealand Society for Earthquake Engineering, 1-19.

Fabozzi, S., Licata, V., Autuori, S., Bilotta, E., Russo, G., \& Silvestri, F. (2017). Prediction of the seismic behavior of an underground railway station and a tunnel in Napoli (Italy). Underground Space, 2(2), 88-105. https://doi.org/10.1016/j.undsp.2017.03.005

Fages, R., Bouyat, C. (1971a). Calcul de rideaux de parois moulees ou de palplanches. Modèle mathematique integrant le comportement irreversible du sol en état elastoplastique. Travaux, (439).

Fages, R., Bouyat, C. , (1971b). Calcul de rideaux de parois moulées ou de palplanches Modèle mathématique inté- grant le comportement irréversible du sol en état élastoplastique - Exemple d'application - Etude de l'influence de paramètres, Travaux, (441).

Galindo-Aires, R. Á. (2010). Análisis, Modelización e Implementación Numérica del Comportamiento de suelos Blandos Ante la Combinación de Tensiones Tangenciales Estáticas y Cíclicas. Univerisdad Politécnica de Madrid.

García-Jiménez, D. (2006). Estimación de Parámetros del Movimiento Fuerte del Suelo para Terremotos Interplaca e Intraslab en México Central. Universidad Complutense de Madrid.

Gioncu V, Mazzolani FM. (2002). Ductility of Seismic Resistant Steel Structures. pp 694. 
Spon Press. New York, NY, USA.

Gordo-Monsó, C., González-Galindo, J., \& Olalla-Marañón, C. (2019). A closed-form solution for the seismic racking and rocking behavior of rectangular tunnels. Tunnelling and Underground Space Technology, 88(February), 87-97. https://doi.org/10.1016/j.tust.2019.03.002

Gordo-Monsó, C., \& Miranda, E. (2018). Significance of directivity effects during the 2011 Lorca earthquake in Spain. Bulletin of Earthquake Engineering, 16(7), 27112728. https://doi.org/10.1007/s10518-017-0301-9

Gu, Q., Conte, J. P., Yang, Z., \& Elgamal, A. (2011). Consistent tangent moduli for multiyield-surface J2 plasticity model. Computational Mechanics, 48(1), 97-120. https://doi.org/10.1007/s00466-011-0576-7

Gu, Quan, Conte, J. P., Elgamal, A., \& Yang, Z. (2009). Finite element response sensitivity analysis of multi-yield-surface J2 plasticity model by direct differentiation method. Computer Methods in Applied Mechanics and Engineering, 198(30-32), 2272-2285. https://doi.org/10.1016/j.cma.2009.02.030

Guoxing, C., Su, C., Xi, Z., Xiuli, D., Chengzhi, Q. I., \& Zhihua, W. (2015). Shakingtable tests and numerical simulations on a subway structure in soft soil. Soil Dynamics and Earthquake Engineering, 76, 1-16. https://doi.org/10.1016/j.soildyn.2014.12.012

Gutenberg, B., \& Richter, C. F. (1944). Frequency of Earthquakes in California. Bulletin of the Seismological Society of America, 34(4), 185-188. https://doi.org/10.1038/156371a0

Haliburton, T. A. (1968). Numerical analysis of flexible retaining structures. Journal of Soil Mechanics \& Foundations Div. Hendron, A.J., Fernandez, G., 1983. Dynamic and static design considerations for underground chambers. In: Howard, T.R. (Ed.), Seismic Design of Embankments and Caverns. ASCE, New York, pp. 157-197.

Hanks, T. C., \& Kanamori, H. (1979). A moment magnitude scale. Journal of Geophysical Research, 84(B-5), 2348-2350.

Hardin, B. O., \& Black, W. L. (1966). Sand stiffness under various traxial stresses. Journal of the Soil Mechanics and Foundations Division, 92(2), 1966.

Hardin, B. O., \& Black, W. L. (1968). Vibration Modulus of normally consolidated Clay. 
Journal of the Soil Mechanics and Foundations Division, 94(2), 353-369.

Hardin, B. O., \& Drnevich, V. P. (1972). Shear Modulus and Damping in Soils: Measures and Parameter Effects. Journal of the Soil Mechanics and Foundations Division, 98(6), 603-624. Retrieved from https://nisee.berkeley.edu/elibrary/Text/201602043

Hashash, Y.M.A., Musgrove, M. I., Harmon, J. A., Groholski, D. R., Phillips, C. A., \& and Park, D. (2016). DEEPSOIL 6.1, User Manual. Urbana-Champaign.

Hashash, Youssef M. A., Hook, J. J., Schmidt, B., \& I-Chiang Yao, J. (2001). Seismic design and analysis of underground structures. Tunnelling and Underground Space Technology, 16(4), 247-293. https://doi.org/10.1016/S0886-7798(01)00051-7

Hashash, Youssef M. A., Karina, K., Koutsoftas, D., \& O’Riordan, N. (2010). Seismic Design Considerations for Underground Box Structures. In Proceedings of the 2010 Earth Retention Conference (pp. 620-637). Bellevue, WA. https://doi.org/10.1061/41128(384)64

Hashash, Youssef M. A., \& Park, D. (2001). Non-linear one-dimensional seismic ground motion propagation in the Mississippi embayment. Engineering Geology, 62(1-3), 185-206. https://doi.org/10.1016/S0013-7952(01)00061-8

Hudson, J. A., Harrison, J. P. (2000). Engineering rock mechanics: an introduction to the principles. Elsevier. Oxford, Reino Unido.

Humar, J. L. (2002). Dynamics of Structures. $2^{\text {nd }}$ edition. pp 966. Balkema Publishers. Lisse.

Hung, C. J., Monsees, J. E., Munfah, N., \& Wisniewski, J. (2009). Technical Manual for Design and Construction of Road Tunnels - Civil Elements. Washington, D.C.

Huo, H., Bobet, A., Fernández, G., \& Ramírez, J. (2006). Analytical solution for deep rectangular structures subjected to far-field shear stresses. Tunnelling and Underground Space Technology, 21(6), 613-625. https://doi.org/10.1016/j.tust.2005.12.135

Huo, Hongbin. (2005). Seismic Design and analysis of Rectangular Underground Structures. Purdue University.

Huo, Hongbin, Bobet, A., Fernández, G., \& Ramírez, J. (2004). Seismic Evaluation of the Failure of the Daikai Station During the Kobe Earthquake. In Proceedings of the 
11th International Conference on Soil Dynamics and Earthquake Engineering and 3rd International Conference on Earthquake Geotechnical Engineering (pp. 758765).

Huo, Hongbin, Bobet, A., Fernández, G., \& Ramírez, J. (2005). Load Transfer Mechanisms between Underground Structure and Surrounding Ground : Evaluation of the Failure of the Daikai Station. Journal of Geotechnical and Geoenvironmental Engineering, 131(12), 1522-1534.

Hushmand, A., Dashti, S., Davis, C., Hushmand, B., Zhang, M., Ghayoomi, M., ... Hu, J. (2016a). Seismic Performance of Underground Reservoir Structures: Insight from Centrifuge Modeling on the Influence of Backfill Soil Type and Geometry. Journal of Geotechnical and Geoenvironmental Engineering, 04016020. https://doi.org/10.1061/(ASCE)GT.1943-5606.0001477

Hushmand, A., Dashti, S., Davis, C., Hushmand, B., Zhang, M., Ghayoomi, M., ... Hu, J. (2016b). Seismic Performance of Underground Reservoir Structures: Insight from Centrifuge Modeling on the Influence of Structure Stiffness. Journal of Geotechnical and Geoenvironmental Engineering, 142(7), 04016020. https://doi.org/10.1061/(ASCE)GT.1943-5606.0001477

Hynes-Griffin, M. E., \& Franklin, A. G. (1984). Rationalizing the Seismic Coefficient Method. Vicksburg, MI.

Iwatate, T., Kobayashi, Y., Kusu, H., \& Rin, K. (2000). Investigation and Shaking Table Tests of Subway Structures of the Hyogoken-Nanbu Earthquake. In Proceedings 12th World Conference on Earthquake Engineering (pp. 1-8). Auckland, New Zealand.

Jacobsen, L. (1930). Steady Forced Vibrations as Influenced by Damping. Transactions of the American Society of Mechanical Engineers, 1(1), 169-181.

Jacobsen, L. S. (1939). Described in Appendix D of "The Kentucky project”. Technical Report No. 13, Tennessee Valley Authority, 1951.

Jaegger, J. C. Cook, N. G. W. Zimmerman, R. W. (2007). Fundamentals of Rock Mechanics. Blackwell Publishing. pp. 488.

Kanamori, H. (1977). The energy release in great earthquakes. Journal of Geophysical Research, 82(20), 2981-2987. 
Keykhosropour, L., \& Lemnitzer, A. (2019). Experimental studies of seismic soil pressures on vertical flexible, underground structures and analytical comparisons. Soil Dynamics and Earthquake Engineering, 118(January), 166-178. https://doi.org/10.1016/j.soildyn.2018.12.012

Kim, K., Giacalone, C., Elgamal, A., \& Shing, P. B. (2016). Racking Response of Reinforced Concrete Cut and Cover Tunnel. La Jolla, CA. Retrieved from http://www.umich.edu/ umtriswt

Kondner, R. L., \& Zelasko, J. S. (1963). Hyperbolic stress-strain formulation for sands. Proceedings of the $2^{\text {nd }}$ Pan American Conference on Soil Mechanics and Foundations Engineering.

Kramer S. L. (1996). Geotechnical Earthquake Engineering. pp 653. Prentice Hall. Upper Saddle River, NJ. USA.

Krawinkler, H., \& Miranda, E. (2004). Performance Based Earthquake Engineering. In Y. Bozorgnia \& V. V Bertero (Eds.), Earthquake Engineering (pp. 1-41). CRC Press.

Kuesel, T. B. (1969). Earthquake Design Criteria for Subways. Journal of the Structural Division, ASCE, 95(6), 6616-6626.

Kurata, S., Arai, H., \& Yokoi, T. (1965). On the Earthquake Resistance of Anchored Sheet Pile Bulkheads. In Proceedings of the 3rd World Conference on Earthquake Engineering (pp. 1-15). Christchurch, New Zealand. Retrieved from http://www.iitk.ac.in/nicee/wcee/article/vol2_II-369.pdf

LA Metro Authority. (2012). Metro Rail Design Criteria Section 5 Structural / Geotechnical. Los Angeles, CA.

Lanzano, G., Bilotta, E., \& Russo, G. (2008). Tunnels under seismic loading: a review of damage case histories and protection methods. In Workshop of Mitigation of the Earthquake ... (pp. 1-10). Naples, Italy. Retrieved from http://www.reluis.it/doc/pdf/Pubblicazioni/Lanzano-Bilotta-Russo.pdf

Lopez-Jimeno, C. (2003). Manual de Túneles y Obras Subterráneas. U.D. Proyectos E.T.S.I. Minas, Universidad Politécnica de Madrid. pp. 1082. Madrid, España.

Lysmer, J., Tabatabaie-Raissi, M., Tajirian, F., Vahdani, S., \& Ostadan, F. (1981). SASSI. A System for Analysis of Soil-Structure Interaction. Berkeley, CA. 
Magnan, J. P. (1999). Cours de Mécanique des Sols et des Roches. École Nationale des Ponts et Chaussées. Paris.

Martinez-Solares, J. M., \& Mezcua-Rodriguez, J. (2002). Catálogo sísmico de Península Ibérica. Madrid: Ministerio de Fomento.

Masing, G. (1926). Eigenspannungen und Verfestgung Beim Masing, Proceedings, Second International Congress of Applied Mechanics, pp.332-335.

Matasovic, N., \& Hashash, Y. M. A. (2012). SYNTHESIS 428 Practices and Procedures for Site-Specific Evaluations of Earthquake Ground Motions. Washington, DC.

Matsuo, H., \& Ohara, S. (1960). Lateral earth pressures and stability of quay walls during earthquakes. In Proceedings 2nd World Conference on Earthquake Engineering (pp. 165-183). Tokyo, Japan.

McGuire, R. K. (2004). Seismic Hazard and Risk Analysis. EERI, Earthquake Engineering Research Institute. Oakland, California.

McKenna, F., Scott, M. H., \& Fenves, G. L. (2010). Nonlinear Finite-Element Analysis Software Architecture Using Object Composition. Journal of Computing in Civil Engineering, 24(1), 95-107. https://doi.org/10.1061/(ASCE)CP.19435487.0000002

Menq, F. (2003). Dynamic Properties of Sandy and Gravelly Soils. University of Texas, Austin. Retrieved from https://repositories.lib.utexas.edu/handle/2152/779

Metro de Madrid. (2018). Datos Estadísticos. Resumen de demanda anual 2018. https://www.metromadrid.es/es/transparencia/informacion-economicapresupuestaria-y-estadistica/datos-estadisticos.

Miranda, E., \& Bertero, V. V. (1994). Evaluation of Strength Reduction Factors for Earthquake-Resistant Design. Earthquake Spectra, 10(665), 357-379. Retrieved from http://www.ce.berkeley.edu/ mahin/CE227/MirandaAndBertero1994.pdf

Mononobe, N., \& Matsuo, H. (1929). On the Determination of Earth Pressure during Earthquake. In Proceedings of the World Engineering Conference (pp. 177-185). Tokyo, Japan.

Monsees, J. E. (1991). Underground Seismic Design. In Fall Lecture Series of the Boston Society of Civil Engineers Section. Structural Group Lecture Series (pp. 1-41). 
Boston, MA.

Mróz, Z. (1967). On the description of anisotropic workhardening. Journal of the Mechanics and Physics of Solids, 15, 163-175.

Murphy, V. A. (1960). The effect of ground characteristics on the aseismic design of structures. In Proceedings of the 2nd World Conference on Earthquake Engineering (pp. 231-248). Tokyo, Japan. Retrieved from http://weekly.cnbnews.com/news/article.html?no=124000

Newmark, N. M. (1965). Effects of Earthquakes on Dams and Embankments. Geotechnique, 15(2), 109-129. Retrieved from http://geotip.igt.ethz.ch/img/8/files/Literatur/2012/Newmark_1965_erthquake_dam s.pdf

Newmark, N. M., \& Hall, W. J. (1982). Earthquake spectra and design. Earth System Dynamics. Oakland, CA. Retrieved from http://adsabs.harvard.edu/abs/1982esd..book......N

Ohde J., (1938). Zur Theorie des Erddruckes unter besonderer Berücksichtigung der Erddruckverteilung, Die Bautechnik, Heft 10/11, 13, 19, 25, 37, 42, 53/54.

Okabe, S. (1924). General Theory on Earth Pressure and Seismic Stability of Retaining Wall and Dam. Journal of Japan Society of Civil Engineers, 10(6), 1277-1323.

Olivella, X. O., \& Agelet de Saracíbar-Bosch, C. (2000). Mecánica de medios continuos para ingenieros. Barcelona: Edicions UPC. Universitat Politecnica de Catalunya.

Ortigosa, P., \& Musante, H. (1991). Seismic Earth Pressures Against Structures with Restrained Displacements. In Proceedings of the 2nd International Conference on Recent Advances in Geotechnical Earthquake Engineering and soil Dynamics (pp. 621-628). St. Louis, MI.

Ostadan, F. (2004). Seismic Soil Pressure for Building Walls. An Updated Approach. Soil Dynamics and Earthquake Engineering, 25(7), 785-793.

Ostadan, F., \& Penzien, J. (2001). Seismic Design of Cut-and-Cover Sections of the Bay Area Rapid Transit Extension to San Francisco Airport. In Proceedings of the 2nd UJNR Workshop on Soil Structure Interaction (pp. 1-16). Tsukuba, Japan.

Ostadan, F., \& White, W. H. (1998). Lateral Seismic Soil Pressure. An Updated 
Approach. In US-Japan SSI Workshop (pp. 1-36). Menlo Park, CA.

Oteo-Mazo, C., Moreno-Jiménez, J. de D., Arozamena-Cagigal, P., \& Díez-Fernández, J. (2009). Problemas geotécnicos en la Línea 1 del Metro de Sevilla. Revista de Obras Publicas, 3489(Abril), 43-64.

Owen, N. G., \& Scholl, R. E. (1981). Earthquake Engineering of Large Underground Structures. Washington, DC.

Parra, H., Benito, M., Gaspar, J., Fernández, A., Luna, M., \& Molina, X. (2018). Estimación de la peligrosidad sísmica en Ecuador continental. Sangolquí, Ecuador: Universidad de las Fuerzas Armadas ESPE.

Peck, R. B. (1969). Deep Excavations and Tunneling in Soft Ground. In 7th International Conference on Soil Mechanics and Foundation Engineering (Vol. 7, pp. 225-290). Retrieved from http://scholar.google.com/scholar?hl=en\&btnG=Search\&q=intitle:Deep+excavatio ns+and+tunneling+in+soft+ground\#0\%5Cnhttp://ci.nii.ac.jp/naid/10007809489/

Peck, R. B., Hendron, A. J., \& Mohraz, B. 1972. State of the art of soft-ground tunneling. Proceedings of the Norht American Rapid Excavation \& Tunneling Conference (Vol. 1).

Pecker, A. (1984). Dynamique des Sols. Presses de l'École Nationale des Ponts et Chaussées. Paris. Francia.

Penzien, J. (2000). Seismically induced racking of tunnel linings. Earthquake Engineering \& Structural Dynamics, 29(5), 683-691. https://doi.org/10.1002/(SICI)1096-9845(200005)29:5<683::AIDEQE932>3.0.CO;2-1

Penzien, J. (2001). EERI Distinguished Lecture 2000: Earthquake engineering for transportation structures. Past present and future. Earthquake Spectra, 17(1), 1-34.

Penzien, J., Chen, C. H., Lee, Y. J., \& Jean, W. Y. (1992). Seismic Analysis of Rectangular Tunnels in Soft Ground. In Proceedings 10th World Conference on Earthquake Engineering (pp. 1619-1624). Madrid, Spain.

Penzien, J., \& Wu, C. L. (1998). Stresses in linings of bored tunnels. Earthquake Engineering and Structural Dynamics, 27, 283-300. https://doi.org/10.1002/(SICI)1096-9845(199803)27:3<283::AID- 
EQE732>3.0.CO;2-T

Pitilakis, K., Anastasiadis, A., Raptakis, D., Boussolas, N., \& Papageorgiou, E. (2007). Seismic Design Loads for Metropolitan Subway Tunnels: The Case of the Thessaloniki Metro. In Proceedings of the 4th International Conference on Earthquake Geotechnical Engineering (pp. 1-15). Thessaloniki, Greece.

Pitilakis, K., \& Tsinidis, G. (2014). Performance and Seismic Design of Underground Structures. In M. Maugeri \& C. Soccodato (Eds.), Geotechnical, Geological and Earthquake Engineering(Vol. 28, pp. 279-340). https://doi.org/10.1007/978-3-31903182-8

Pitilakis, K., \& Tsinidis, G. (2016). Recent advances on the seismic behaviour and design of tunnels. In Conference in Honour of Michele Maugeri (pp. 1-46). Catania, Italy. Retrieved from http://www.didaktorika.gr/eadd/handle/10442/36086?locale=el

Poland, C., Hill, J., Sharpe, R., Bertero, V. V, Nicoletti, J., Hamburger, R., ... Phillips, R. (1995). SEAOC Vision 2000. Performance Based Seismic Engineering of Buildings. Sacramento, CA.

Pollard, D., \& Fletcher, R. C. (2005). Fundamentals of structural geology. Cambridge University Press.

Poncelet, J. V. (1840). Mémoire sur la stabilité des revêtements et de leurs fondations, Paris, Mém. de l'officier du génie, 13, 1840, pp. 7-226.

Power, M., Fishman, K. L., Makdisi, F., Musser, S., Richards, R., Youd, T. L., ... Youd, T. L. (2004). Seismic Retrofitting Manual for Highway Structures: Part 2 - Retaining Structures, Slopes, Tunnels, Culverts and Roadways. McLean, VA.

Priestley M. J. N., Calvi G. M., Kowalsky, M. J. (2007). Displacement-Based Seismic Design of Structures. pp 720. IUSS Press, Pavia, Italy.

Pyke, R. M. (1979). Nonlinear soil models for irregular cyclic loadings. Journal of geotechnical and geoenvironmental engineering, 105(ASCE 14642 Proceeding).

Rankine, M. W. J. (1856). On the Stability of Loose Earth. Philosophical Transactions of the Royal Society of London, 147, 1-19.

Règles PS 92. (1995) (Vol. 92). Paris, France.

Rosenblueth, E. (1951). A basis for aseismic design of structures. University of Illinois, 
Urbana-Champaign.

Rowe, P. W. (1952). Anchored sheet-pile walls, Proc. Instn Civ. Engrs, Pt I, Vol. 1, pp. $27-70$.

Rowe, P. W. (1955). A theoretical and experimental analysis of sheet-pile walls. Proceedings of the Institution of Civil Engineers, 4(1), 32-69.

Samartín-Quiroga, A. (2008). Curso de Ingeniería Sísmica (I). La Acción Sísmica. Colegio de Ingenieros de Caminos, Canales y Puertos. Madrid.

Sanhueza-Plaza, C. X. (2008). Criterios y parámetros de diseño para pantallas continuas en Madrid. Universidad Politécnica de Madrid. Retrieved from http://oa.upm.es/1167/

Schnabel, B., Lysmer, J., \& Seed, H. B. (1972). SHAKE A Computer Program for the Earthquake Response Analysis of Horizontally Layered Soils. Berkeley, CA.

Schwartz, D. P., \& Coppersmith, K. J. (1984). Fault behavior and characteristic earthquakes: examples from the Wasatch and San Andreas fault zones. Journal of Geophysical Research, 89(B7), 5681-5698. https://doi.org/10.1029/JB089iB07p05681

Scott, R. F. (1974). Earthquake-induced earth pressures on retaining walls. In Proceedings 5th World Conference on Earthquake Engineering (pp. 1611-1620). Rome, Italy. Retrieved from https://www.iitk.ac.in/nicee/wcee/fifth_conf_Rome/

Seed, H. B., \& Idriss, I. M. (1970). Soil moduli and damping factors for dynamic analyses. Berkeley, CA.

Seed, H. B., \& Whitman, R. V. (1970). Design of Earth Retainig Structures for Dynamic Loads. In ASCE Specialty Conference on Lateral Stresses in the Ground and Design of Earth-Retaining Structures (pp. 103-147). Ithaca, NY.

Seylabi, E. E., Zhang, W., Agapaki, E., Pitilakis, D., Brandenberg, S. J., Stewart, J. P., ... Ertugrul Taciroglu. (2018). Development of validated methods for soil-structure interaction analysis of buried structures. Los Angeles, CA.

St John, C. M., \& Zahrah, T. F. (1987). Aseismic design of underground structures. Tunnelling and Underground Space Technology, 2(2), 165-197. https://doi.org/10.1016/0886-7798(87)90011-3 
Stein, S. Wysession, M. (2003). An introduction to seismology, earthquakes, and earth structure. Blackwell Publishing. Malden, MA. USA.

Stewart, J. P., Afshari, K., \& Hashash, Y. M. A. (2014). Guidelines for Performing Hazard-Consistent One-Dimensional Ground Response Analysis for Ground Motion Prediction. Richmond, CA.

Stewart, J. P., Kwok, A. O.-L., Hashash, Y. M. A., Matasovic, N., Pyke, R., Wang, Z., \& Zhaouhi, Y. (2008). Benchmarking of Nonlinear Geotechnical Ground Response Analysis Procedures. Richmond, CA.

Stokoe, K. H., Darendeli, M. B., Menq, F., \& Choi, W. K. (2004). Comparison of the Linear and Nonlinear Dynamic Properties of Gravels, Sands, Silts and Clays. In Proceedings of the 11th International Conference on Soil Dynamics and Earthquake Engineering (pp. 8-11).

Terzaghi, K., Peck, R. B., \& Mesri, G. (1996). Soil Mechanics in Engineering Practice. Soil Science (3rd editio). New York, NY: John Wiley \& Sons. https://doi.org/10.1097/00010694-194911000-00029

Thiers, G. R., \& Seed, H. B. (1968). Cyclic stress-strain characteristics of clay. Journal of Soil Mechanics \& Foundations Div.

Trifunac, M. D. (2006). Biot response spectrum. Soil Dynamics and Earthquake Engineering, 26(6-7), 491-500. https://doi.org/10.1016/j.soildyn.2006.01.004

Tsai, N. C., \& Housner, G. W. (1970). Calculation of surface motions of a layered halfspace. Bulletin of the Seismological Society of America, 60(5), 1625-1651.

Tschebotarioff, G. P. (1948). Large scale model earth pressure tests on flexible bulkheads, Proc. ASCE, pp. 9-48.

Tsinidis, G, Pitilakis, K., \& Mantikas, G. (2016). Deformation patterns of rectangular tunnels in soft soils subjected to ground shaking. In Proceedings of the 1st ICONHIC International Conference on Natural Hazards \& Infrastructure (pp. 1-9). Chania, Greece.

Tsinidis, Grigorios. (2017). Response characteristics of rectangular tunnels in soft soil subjected to transversal ground shaking. Tunnelling and Underground Space Technology, 62, 1-22. https://doi.org/10.1016/j.tust.2016.11.003 
Tsinidis, Grigorios, \& Pitilakis, K. (2018). Improved R-F relations for the transversal seismic analysis of rectangular tunnels. Soil Dynamics and Earthquake Engineering, 107(January), 48-65. https://doi.org/10.1016/j.soildyn.2018.01.004

Tsinidis, Grigorios, Pitilakis, K., Anagnostopoulos, C., \& Madabhushi, G. (2015). Seismic response and Design of Rectangular Tunnels. In Proceedings of the SECED 2015 Conference: Earthquake Risk and Engineering towards a Resilient World (pp. 1-10). Cambridge, UK.

Tsinidis, Grigorios, Pitilakis, K., \& Heron, C. (2015). Dynamic response of flexible square tunnels : centrifuge testing and validation of existing design methodologies. Geotechnique, 65(5), 401-417. https://doi.org/10.1680/geot.SIP.15.P.004

Tsinidis, Grigorios, Pitilakis, K., Heron, C., \& Madabhushi, G. (2013). Experimental and Numerical Investigation of the Seismic Behavior of Rectangular Tunnels in Soft soils. In Proceedings of the Computational Methods in Structural Dynamics and Earthquake Engineering 2013 Conference COMPDYN 2013 (pp. 12-14). Kos Island, Greece.

Tsinidis, Grigorios, Rovithis, E., Pitilakis, K., \& Chazelas, J. (2015). Seismic Response of Rectangular Tunnels by Centrifuge Testing and Numerical Analysis. In Proceedings of the SECED 2015 Conference: Earthquake Risk and Engineering towards a Resilient World (pp. 1-10). Cambridge, UK.

Tsinidis, Grigorios, Rovithis, E., Pitilakis, K., \& Chazelas, J. L. (2016). Seismic response of box-type tunnels in soft soil: Experimental and numerical investigation. Tunnelling and Underground Space Technology, 59, 199-214. https://doi.org/10.1016/j.tust.2016.07.008

Turabi, D. A., \& Balla, A. (1968). Distribution of earth pressure on sheet-pile walls. Journal of Soil Mechanics \& Foundations Div.

UITP Observatory of Automated Metros. (2018). World Metro Figures 2018. Bruxelles, Belgique. Retrieved from https://www.uitp.org/sites/default/files/cck-focus-papersfiles/Statistics Brief - World metro figures 2018V4_WEB.pdf

Ulgen, D., Saglam, S., \& Ozkan, M. Y. (2015). Dynamic response of a flexible rectangular underground structure in sand: centrifuge modeling. Bulletin of Earthquake Engineering, 13(9), 2547-2566. https://doi.org/10.1007/s10518-015- 
9736-z

UN. (2018). Las ciudades seguirán creciendo, sobre todo en los países en desarrollo. Naciones Unidas. Departamento de Asuntos Económicos y Sociales. https://www.un.org/development/desa/es/news/population/2018-worldurbanization-prospects.html

Veletsos, A., \& Newmark, N. M. (1960). Effect of inelastic behavior on the response of simple systems to earthquake motions. In Proceedings of the 2nd World Conference on Earthquake Engineering (pp. 895-912). Tokyo, Japan. Retrieved from http://www.iitk.ac.in/nicee/wcee/article/vol.2_session2_895.pdf

Veletsos, A. S., \& Younan, A. H. (1994). Dynamic soil pressures on rigid vertical walls. Earthquake Engineering \& Structural Dynamics, 23(6), 645-669. https://doi.org/10.1002/eqe.4290230606

Veletsos, A. S., \& Younan, A. H. (1997). Dynamic response of cantilever retaining walls. Journal of Geotechnical and Geoenvironmental Engineering, 123(February), 161172.

Veletsos, A. S, Newmark, N. M., \& Chelapati, C. V. (1965). Deformation Spectra for Elastic and Elastoplastic Systems Subjected to Ground Shock and Earthquake Motions. In Proceedings of the 3rdWorld Conference on Earthquake Engineering (pp. 1-20). Tokyo, Japan.

Veletsos, Anestis S., \& Younan, A. H. (1993). Dynamic Modeling and Response of SoilWall Systems (Vol. 120). Washington, D.C. https://doi.org/10.1061/(asce)07339410(1994)120:12(2155)

Vesic, A. B. (1963). Beams on Elastic Subgrade and the Winkler's Hypothesis. Proceedings of 5th International Conference of Soil Mechanics, 845-850.

von Mises, R. (1913). Mechanik der festen Körper im plastisch-deformablen Zustand. Nachrichten von Der Gesellschaft Der Wissenschaften Zu Göttingen, MathematischPhysikalische Klasse, 4, 582-592.

Vucetic, M., \& Dobry, R. (1990). Effect of soil plasticity on cyclic response. Journal of Geotechnical Engineering, 117(1), 89-107.

Waggoner, F., Jacob, V., Jong, K., \& Winkle, H. Van. (2011). Seismic Design Criteria. Structures Supporting High-Speed Trains. Technical Memorandum. TM 2.10.4. 
Sacramento, CA.

Wang, H. F., Lou, M. L., Chen, X., \& Zhai, Y. M. (2013). Structure-soil-structure interaction between underground structure and ground structure. Soil Dynamics and Earthquake Engineering, 54, 31-38. https://doi.org/10.1016/j.soildyn.2013.07.015

Wang, H., \& Nishimura, A. (1999). Determination of Design Seismic Motion by Considering Inland and Interplate Earthquakes. Quarterly Report of RTRI, 40(3), $130-138$.

Wang, J. N. (1993). Seismic Design of Tunnels. A Simple State of the Art Approach. New York, NY.

Wells, D. L., \& Coppersmith, K. J. (1994). New Empirical Relationships among Magnitude , Rupture Length , Rupture Width , Rupture Area , and Surface Displacement. Bulletin of the Seismological Society of America, 84(4), 974-1002.

Wilson, E. L., Der Kiureghian, A., \& Bayo, E. P. (1981). A replacement for the SRSS method in seismic analysis. Earthquake Engineering and Structural Dynamics, 9, 18-194.

Winkler, E. (1867). Die Lehre von der Elasticitaet und Festigkeit. (H. Dominicus, Ed.). Prague, Chzec Republic.

Wojtkowiak, F., Betbeder Matibet, J., Dardard, B., Heitz, J.-F., Lejars, C., Pecker, A., ... Pre, M. (2001). Guide AFPS. Conception et Protection Parasismiques des Ouvrages Souterrains. Paris, France: Association Française du Génie Parasismique.

Wood, J. H. (1973). Earthquake Induced Soil Pressures on Structures. California Institute of Technology.

WSDOT. (2010). Appendix B8 Seismic Design Criteria SR 99 Bored Tunnel Alternative Design-Build Project. Seattle, WA.

Yen, P. W., Fallon, J. O., \& Connor, J. O. (2005). FHWA' S 2005 Seismic Retrofitting Manual, Part I: Bridges.

Zienkiewicz, O. C., Chan, A. H. C., Pastor, M., Schrefler, B. A., \& Shiomi, T. (1999). Computational Geomechanics. Chichester: Wiley. 


\section{A. RIGIDEZ DE UN MARCO CON VINCULACIÓN DE WINKLER}

\section{A.1 Introducción}

En este apéndice se obtiene una expresión analítica para la rigidez a la deformación de distorsión de un marco doblemente simétrico, con una condición de fundación elástica de Winkler como la de la (Fig. A-1), que vincula los elementos del marco a otro marco de referencia, infinitamente rígido pero con rótulas en sus extremos, superpuesto al primero. Las esquinas de ambos marcos, flexible y rígido, se encuentran vinculadas a desplazamientos horizontales y verticales.

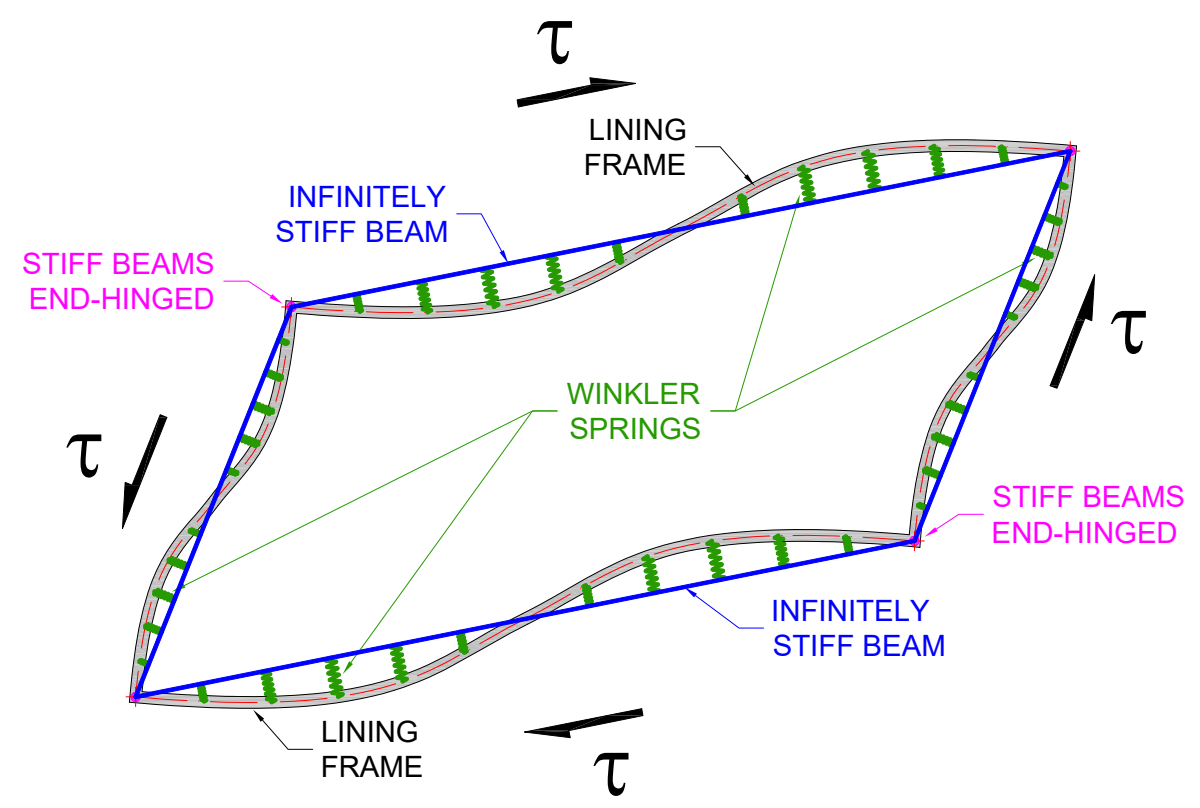

Fig. A-1. Vista esquemática del marco estructural, vigas rígidas rotuladas, y muelles de vinculación de Winkler.

La expresión que se propone está basada en las soluciones propuestas por Hetenyi (Hetenyi, 1979), y tiene en cuenta la doble antisimetría del problema elástico. 
Los símbolos en las ecuaciones indican: $b$ ancho del marco, $d$ canto del marco, $I_{b}$ inercia a flexión de los elementos horizontales, $I_{w}$ inercia a flexión de los elementos verticales, $k_{b}$ rigidez de la fundación de Winkler de los elementos horizontales, y $k_{w}$ rigidez de la fundación de Winkler de los elementos verticales, tal y como se muestra en la (Fig. A-2).

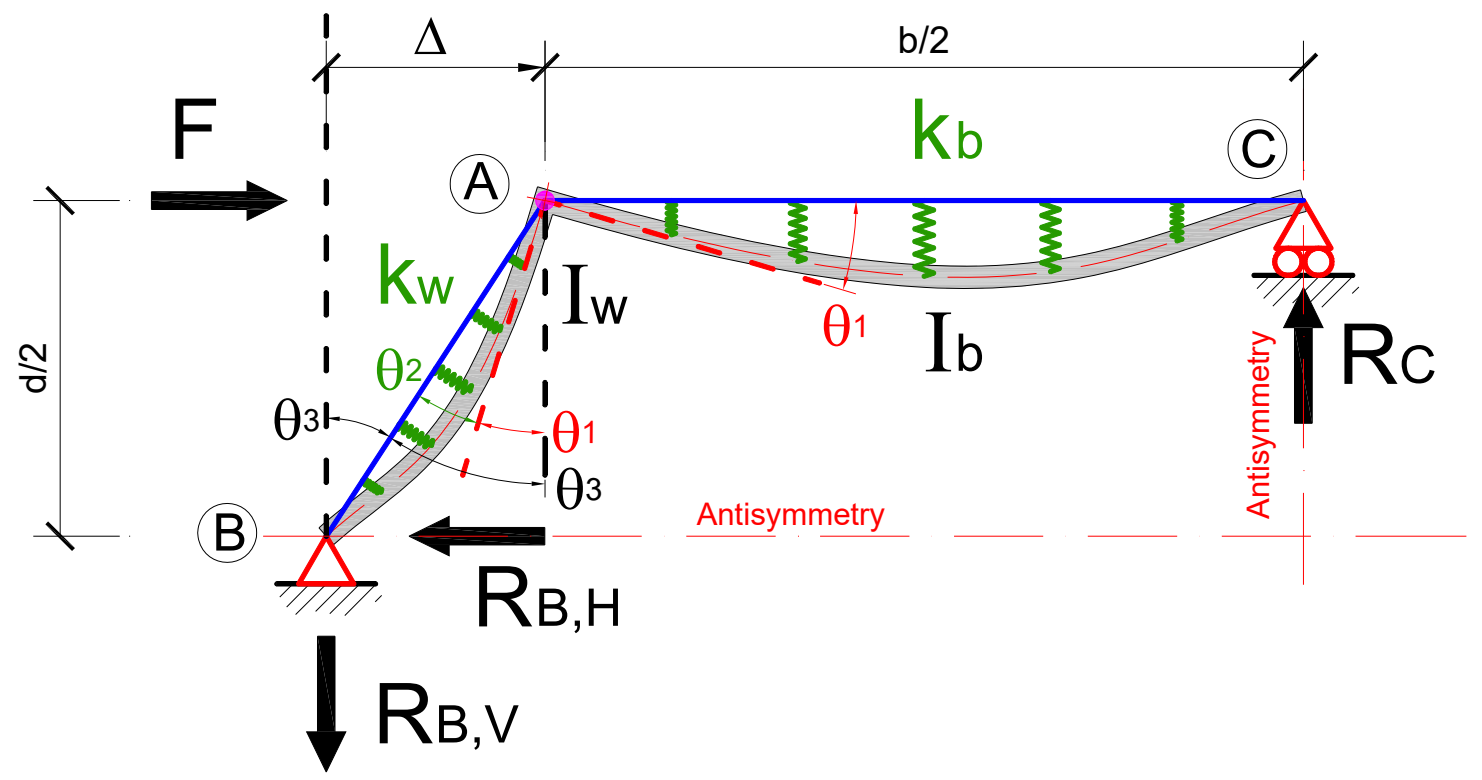

Fig. A-2. Un cuarto del marco rectangular con una fuerza horizontal actuante.

Partiendo de la hipótesis de equilibrio horizontal, la fuerza horizontal actuante $F$ debe estar equilibrada por la reacción horizontal $R_{B, H}$ del punto $B$. Considerando que $R_{B, H}$ es la única fuerza exterior actuante sobre el elemento de muro $A-B$ (nótese que las reacciones de Winkler son reacciones internas entre el marco flexible y el marco de referencia rígido), y puesto que el los elementos del marco rígido de referencia en los que se apoyan los muelles de Winkler están rotulados en sus extremos, el momento flector en el punto $A$ debe ser ¡Error! No se encuentra el origen de la referencia.:

$$
M_{A}=F \frac{d}{2}
$$

Conociendo el valor del momento flector $M_{A}$ en el punto $A$ del marco flexible, podemos calcular a continuación las rotaciones $\theta_{1}$ y $\theta_{2}$ producidas por dicho momento flector $M_{A}$, basándonos en las expresiones propuestas por Hetenyi (Hetenyi, 1979), tal y como se expone en las ecuaciones (Ec. A-2) y (Ec. A-3). 


$$
\begin{aligned}
\theta_{1}=M_{A} \cdot \alpha= & M_{A} \frac{2 \lambda_{b}{ }^{3}}{k_{b}} \\
& \cdot \frac{\operatorname{Cosh}\left(\lambda_{b} \frac{b}{2}\right) \cdot \operatorname{Sinh}\left(\lambda_{b} \frac{b}{2}\right)-\cos \left(\lambda_{b} \frac{b}{2}\right) \cdot \sin \left(\lambda_{b} \frac{b}{2}\right)}{\operatorname{Cosh}^{2}\left(\lambda_{b} \frac{b}{2}\right)-\cos ^{2}\left(\lambda_{b} \frac{b}{2}\right)} \\
\theta_{2}=M_{A} \cdot \beta= & M_{A} \frac{2 \lambda_{w}{ }^{3}}{k_{w}} \\
& \cdot \frac{\operatorname{Cosh}\left(\lambda_{w} \frac{d}{2}\right) \cdot \operatorname{Sinh}\left(\lambda_{w} \frac{d}{2}\right)-\cos \left(\lambda_{w} \frac{d}{2}\right) \cdot \sin \left(\lambda_{w} \frac{d}{2}\right)}{\operatorname{Cosh}^{2}\left(\lambda_{w} \frac{d}{2}\right)-\cos ^{2}\left(\lambda_{w} \frac{d}{2}\right)}
\end{aligned}
$$

En base a consideraciones geométricas, como se muestra en la (Fig. A-2), se puede notar que el desplazamiento horizontal del punto A es $\theta_{3}=\theta_{1}+\theta_{2}$ veces el brazo $d / 2$, y por lo tanto la rigidez a la distorsión de 1/4 del marco resulta la que se muestra en la (Ec. A-4), en la que por brevedad se emplean los símbolos $\alpha$ y $\beta$ definidos es las ecuaciones anteriores (Ec. A-2) y (Ec. A-3).

$$
K_{1 / 4}=\frac{F}{\Delta}=\frac{F}{\left(\theta_{1}+\theta_{2}\right) \cdot \frac{d}{2}}=\frac{F}{M_{A} \cdot(\alpha+\beta) \cdot\left(\frac{d}{2}\right)}=\frac{1}{(\alpha+\beta) \cdot\left(\frac{d}{2}\right)^{2}}
$$

Teniendo en cuenta que, para el marco completo, la mitad de la carga horizontal aplicada será repartida entre los dos muros, y que el desplazamiento, para un ángulo dado $\theta_{3}$, será el doble debido a que se multiplica por 2 el brazo $d$, la rigidez total puede expresarse mediante la ecuación (Ec. A-5).

$$
K_{\text {TOTAL }}=\frac{4}{(\alpha+\beta) \cdot d^{2}}
$$

En las ecuaciones anteriores, $\lambda_{b}$ y $\lambda_{w}$ son los parámetros de Winkler para la viga horizontal y muro vertical, tal y como se definen en las ecuaciones (Ec. A-6) y (Ec. A-7).

$$
\begin{gathered}
\lambda_{b}=\sqrt{\frac{k_{b}}{4 E I_{b}}} \\
\lambda_{w}=\sqrt{\frac{k_{w}}{4 E I_{w}}}
\end{gathered}
$$

Para la aplicación en el contexto de esta tesis, las rigideces de los muelles de Winkler pueden evaluarse mediante la formulación de Vesic (Vesic, 1963), que se muestra en la ecuación (Ec. A-8), reemplazando la inercia $I$ por $I_{b}$ ó $I_{w}$, y en la que $E$ y $E_{s}$ 
son respectivamente el módulo de Young de la estructura y del suelo, y $v$ el coeficiente de Poisson del suelo.

$$
k=0.65 \cdot \sqrt[12]{\frac{E_{S}}{E I}} \cdot \frac{E_{s}}{1-v^{2}}
$$

De acuerdo a Hetenyi (Hetenyi, 1979), la ley de momentos flectores $M(x)$ a lo largo de un elemento de longitud $l$, y parámetro de la fundación de Winkler $\lambda$, viene dada por la ecuación (Ec. A-9), mientras que la de esfuerzos cortantes $V(x)$ viene dada por la ecuación (Ec. A-10).

$$
\begin{aligned}
M(x)=M_{0} \frac{1}{\operatorname{Cosh}^{2}(\lambda l)-\cos ^{2}(\lambda l)}(\operatorname{Cosh}(\lambda l) \cdot \cos (\lambda x) \cdot \operatorname{Cosh}(\lambda \cdot(l-x)) \\
\quad-\cos (\lambda l) \cdot \operatorname{Cosh}(\lambda x) \cdot \cos (\lambda \cdot(l-x))) \\
\begin{aligned}
V(x)=-M_{0} \lambda & \frac{1}{\operatorname{Cosh}^{2}(\lambda l)-\cos ^{2}(\lambda l)}[\operatorname{Cosh}(\lambda l) \\
& \cdot(\cos (\lambda x) \cdot \operatorname{Sinh}(\lambda \cdot(l-x))+\sin (\lambda x) \cdot \operatorname{Cosh}(\lambda \cdot(l-x))) \\
& +\cos (\lambda l) \\
& \cdot(\operatorname{Sinh}(\lambda x) \cdot \cos (\lambda \cdot(l-x))+\operatorname{Cosh}(\lambda x) \cdot \sin (\lambda \cdot(l-x)))]
\end{aligned}
\end{aligned}
$$




\section{B. RESULTADOS DE DISTORSIÓN CON SUELO NO LINEAL}

En este apéndice se recopilan las figuras resumidas en el capítulo §6 de esta tesis.

\section{B.1 Resultados para terreno blando}

\section{B.1.1 Terreno blando y proporción $\lambda=1$, coeficiente de Poisson $v=0,20$}
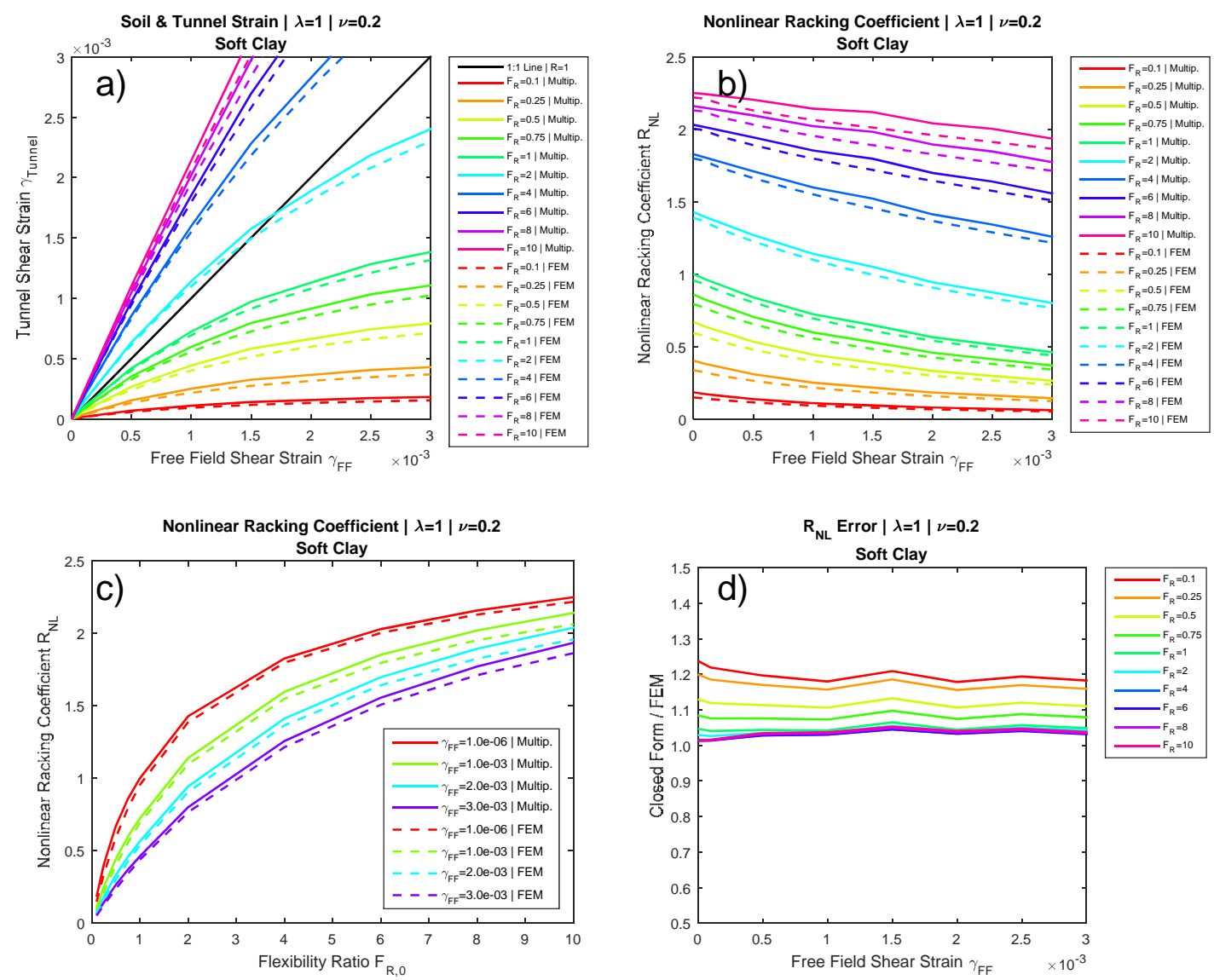

Fig. B-1. Distorsión no lineal para terreno blando, proporción geométrica $\lambda=b / d=1, y=0,2$. 


\section{B.1.2 Terreno blando y proporción $\lambda=1$, coeficiente de Poisson $v=0,30$}
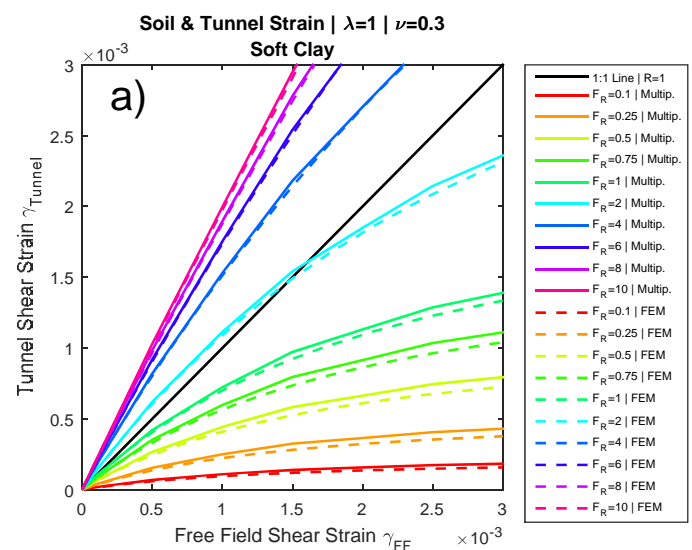

Nonlinear Racking Coefficient $|\lambda=1| \nu=0.3$

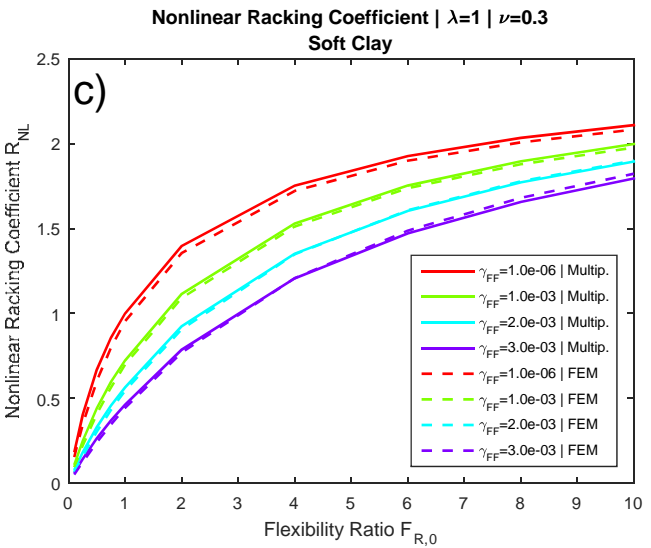

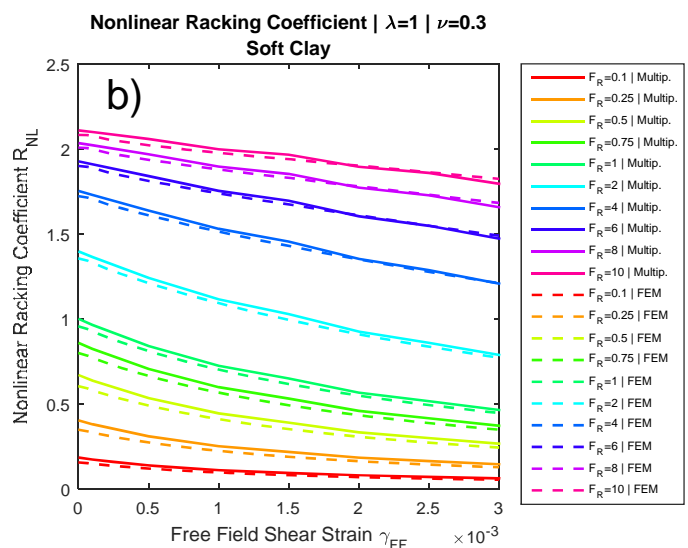

$\mathbf{R}_{\mathrm{NL}}$ Error $|\lambda=1| \nu=0.3$

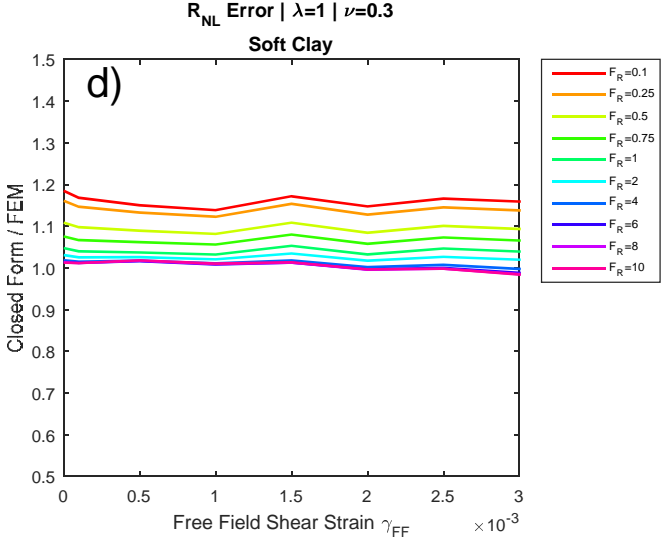

Fig. B-2. Distorsión no lineal para terreno blando, proporción geométrica $\lambda=b / d=1, y=0,3$. 


\section{B.1.3 Terreno blando y proporción $\lambda=1$, coeficiente de Poisson $v=0,40$}
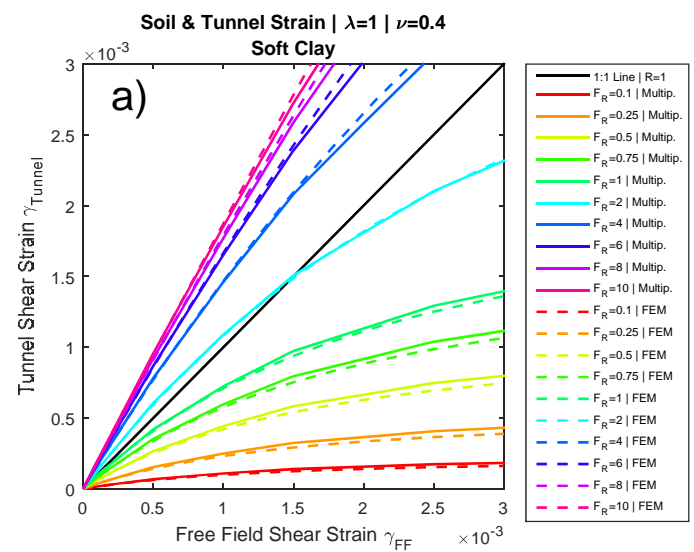

Nonlinear Racking Coefficient | $\lambda=1 \mid \nu=0.4$

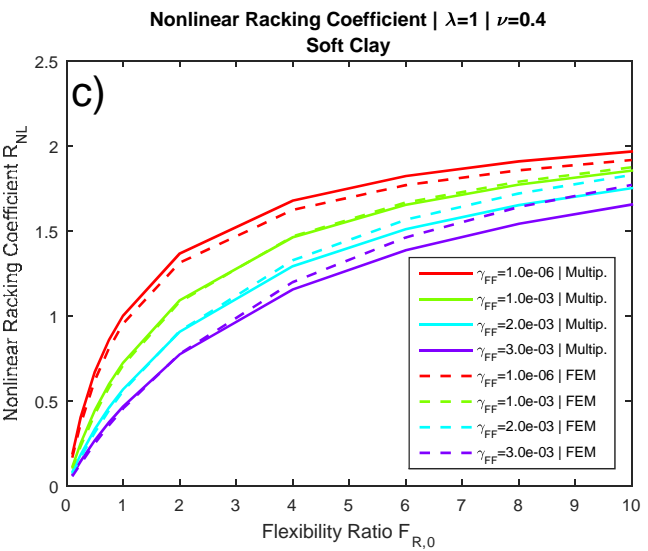

Nonlinear Racking Coefficient $|\lambda=1| \nu=0.4$

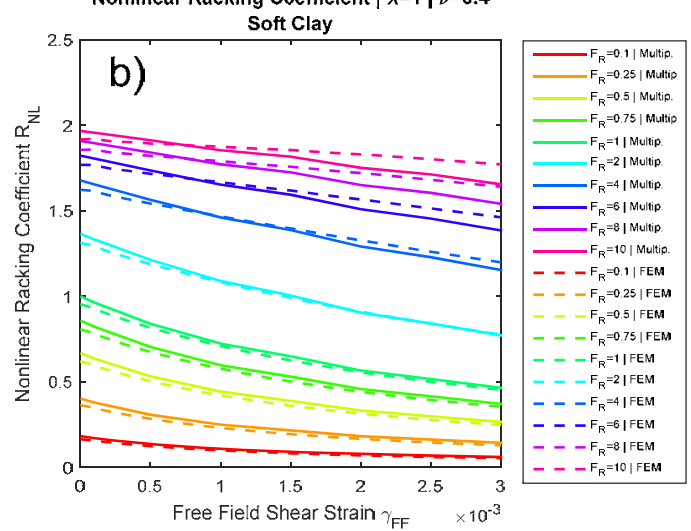

$\mathrm{R}_{\mathrm{NL}} \operatorname{Error}|\lambda=1| \nu=0.4$

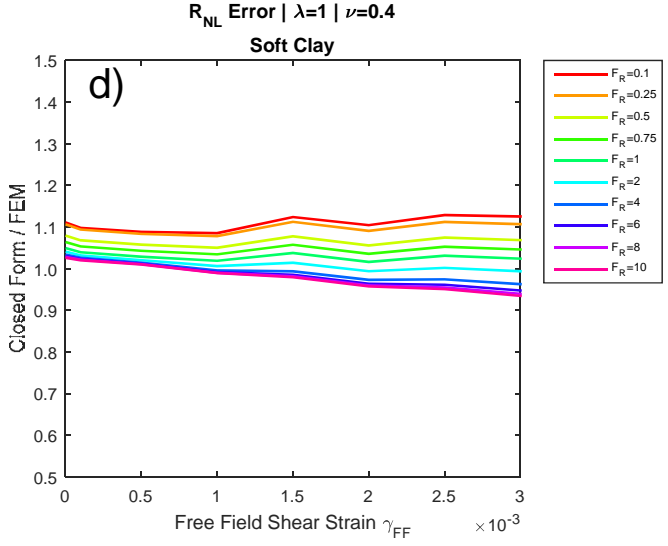

Fig. B-3. Distorsión no lineal para terreno blando, proporción geométrica $\lambda=b / d=1, y=0,4$. 


\section{B.1.4 Terreno blando y proporción $\lambda=2$, coeficiente de Poisson $v=0,20$}
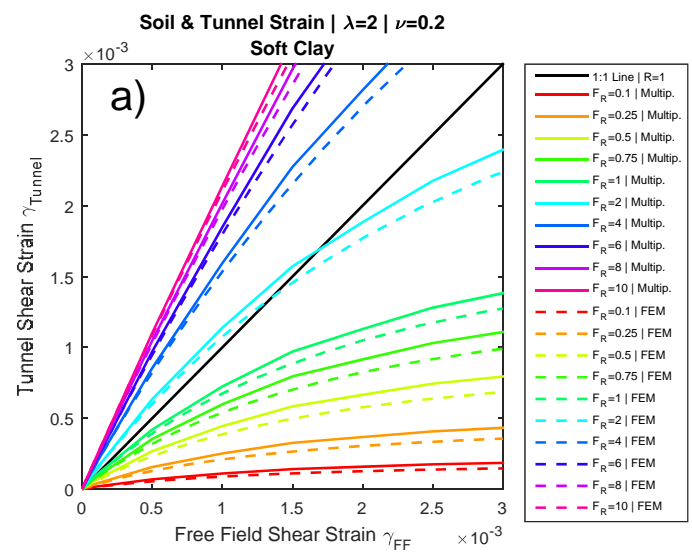

Nonlinear Racking Coefficient $|\lambda=2| \nu=0.2$

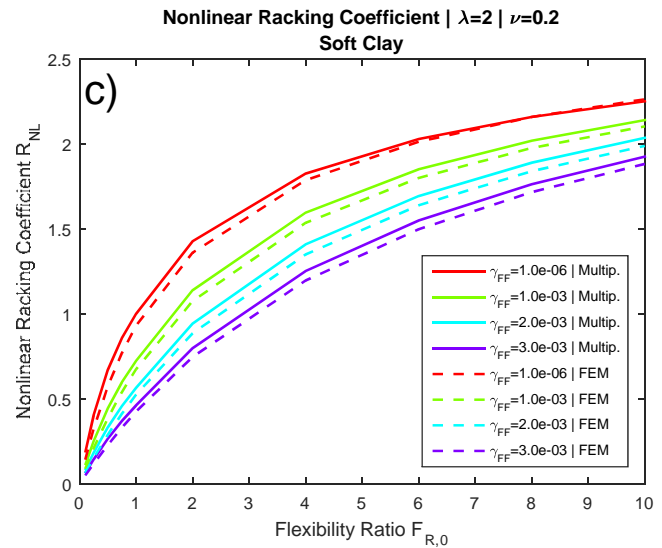

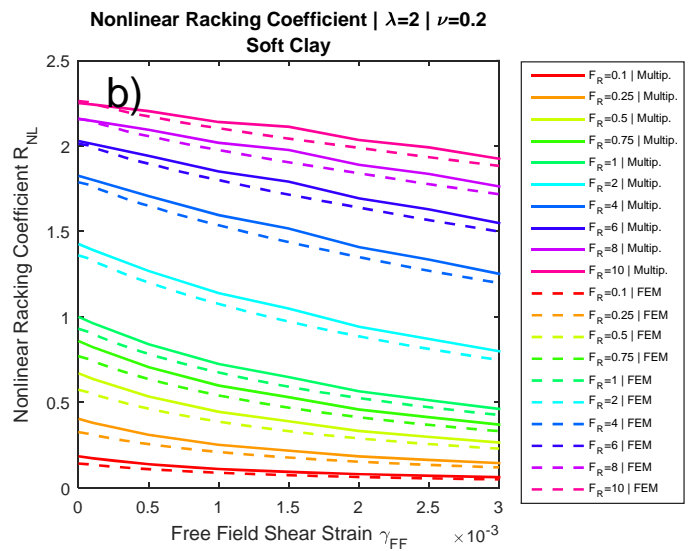

$\mathrm{R}_{\mathrm{NL}} \operatorname{Error}|\lambda=2| \nu=0.2$

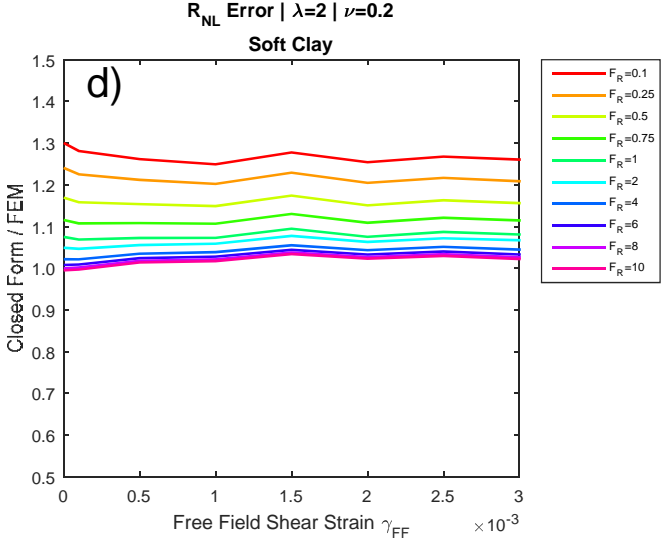

Fig. B-4. Distorsión no lineal para terreno blando, proporción geométrica $\lambda=b / d=2, y=0,2$. 


\section{B.1.5 Terreno blando y proporción $\lambda=2$, coeficiente de Poisson $v=0,30$}
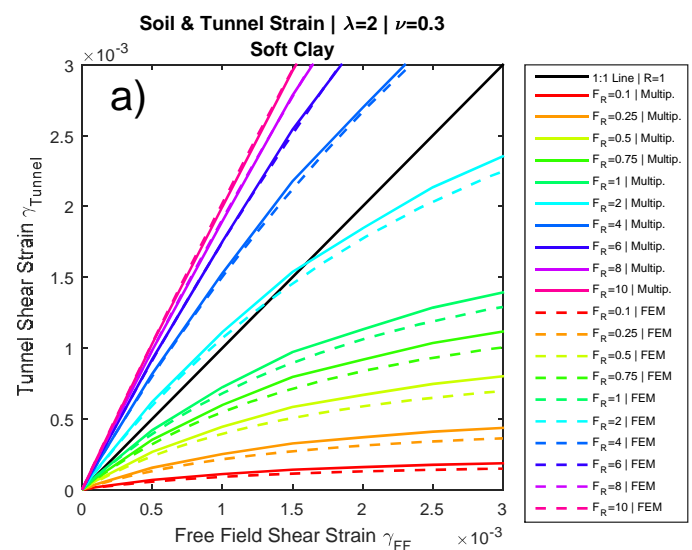

Nonlinear Racking Coefficient $|\lambda=2| \nu=0.3$

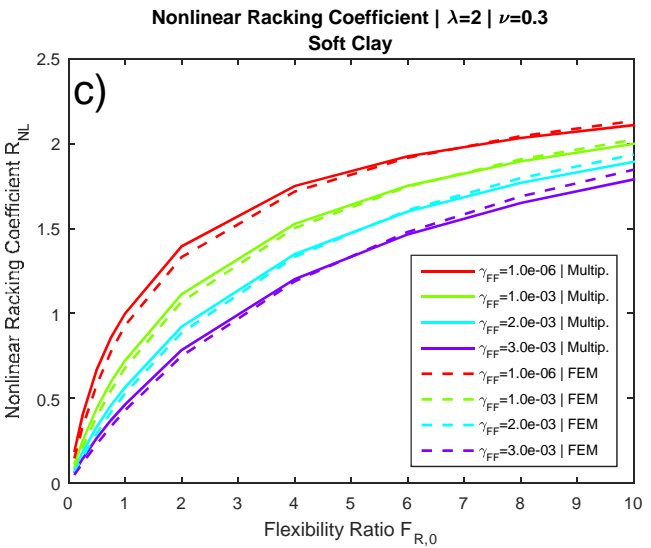

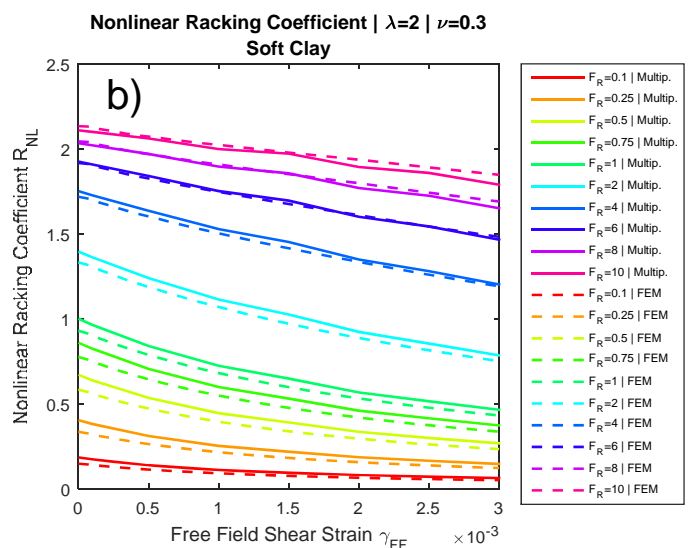

$\mathbf{R}_{\mathrm{NL}}$ Error $|\lambda=2| \nu=0.3$

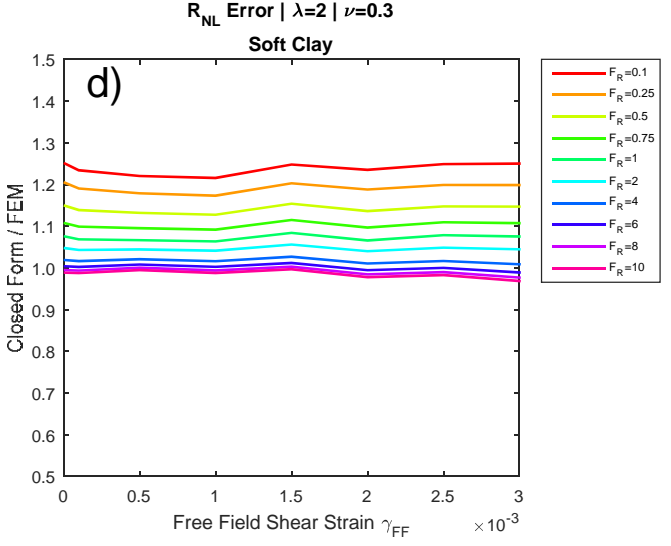

Fig. B-5. Distorsión no lineal para terreno blando, proporción geométrica $\lambda=b / d=2, y=0,3$. 


\section{B.1.6 Terreno blando y proporción $\lambda=2$, coeficiente de Poisson $v=0,40$}
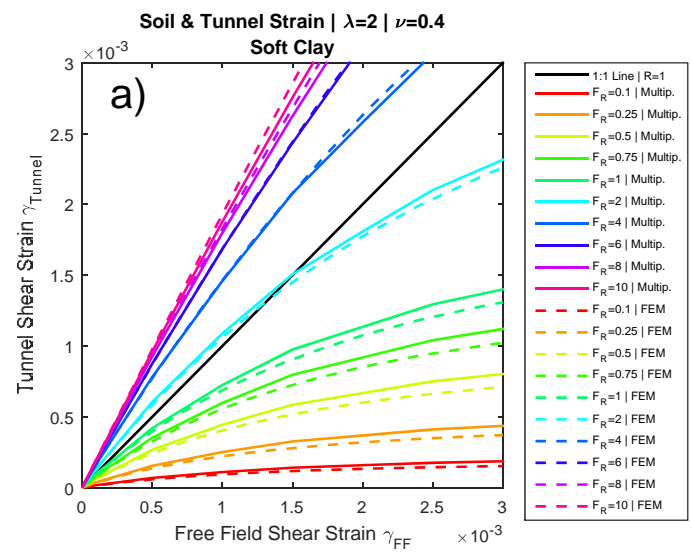

Nonlinear Racking Coefficient $|\lambda=2| \nu=0.4$

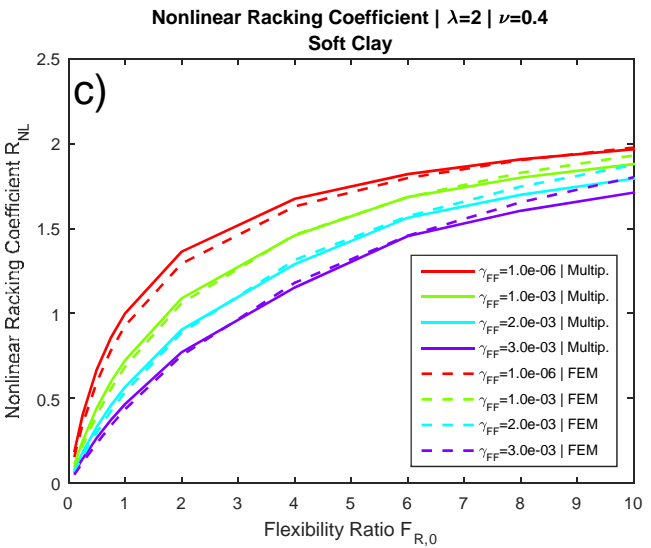

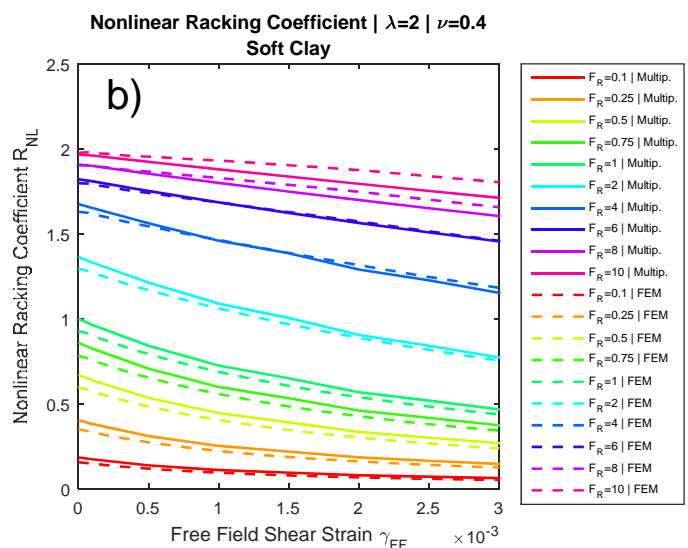

$\mathbf{R}_{\mathrm{NL}}$ Error $|\lambda=2| \nu=0.4$

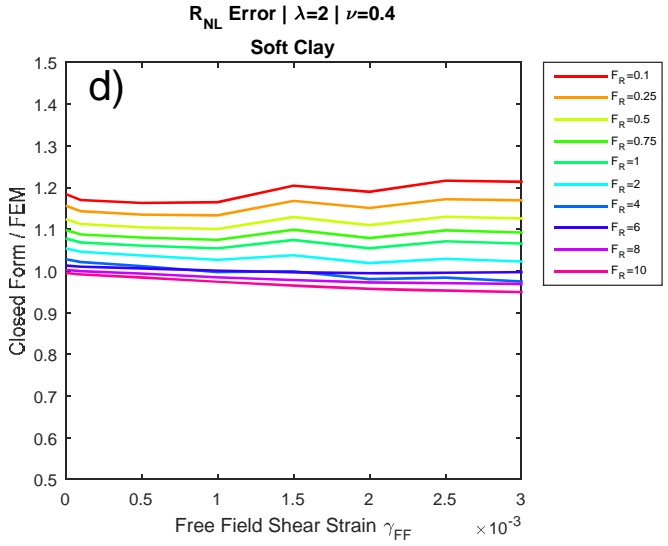

Fig. B-6. Distorsión no lineal para terreno blando, proporción geométrica $\lambda=b / d=2, y=0,4$. 


\section{B.1.7 Terreno blando y proporción $\lambda=3$, coeficiente de Poisson $v=0,20$}
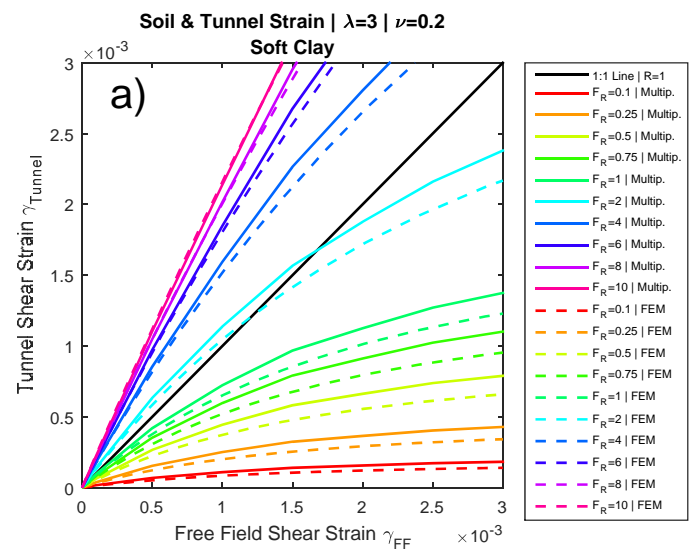

Nonlinear Racking Coefficient $|\lambda=3| \nu=0.2$

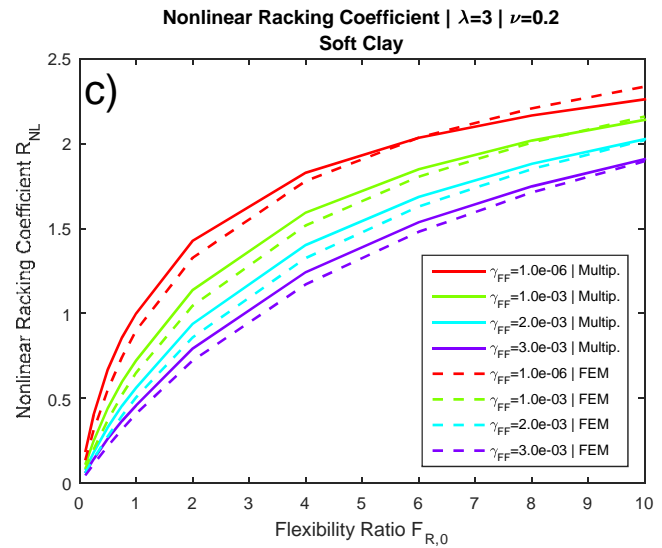

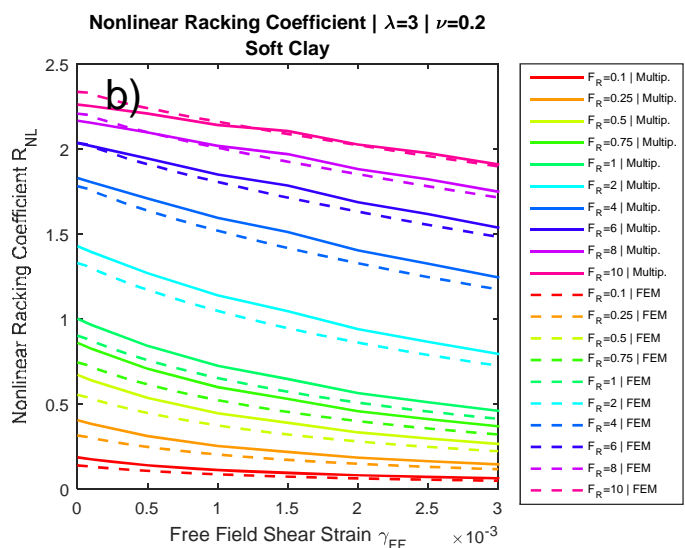

$\mathbf{R}_{\mathrm{NL}}$ Error $|\lambda=3| \nu=0.2$

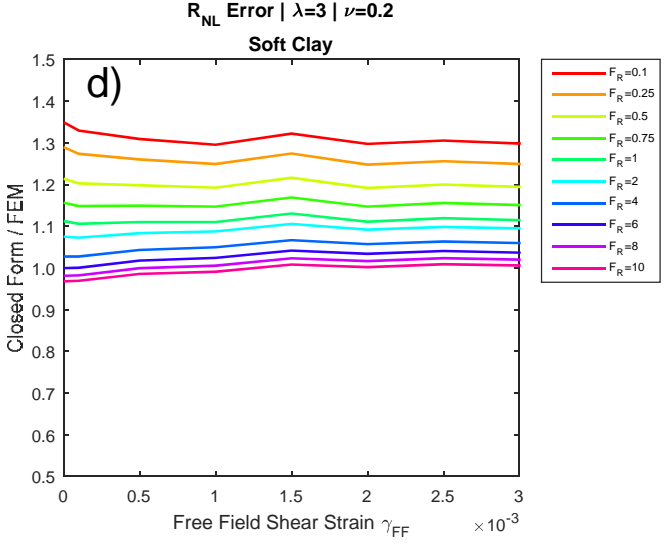

Fig. B-7. Distorsión no lineal para terreno blando, proporción geométrica $\lambda=b / d=3, y=0,2$. 


\section{B.1.8 Terreno blando y proporción $\lambda=3$, coeficiente de Poisson $v=0,30$}
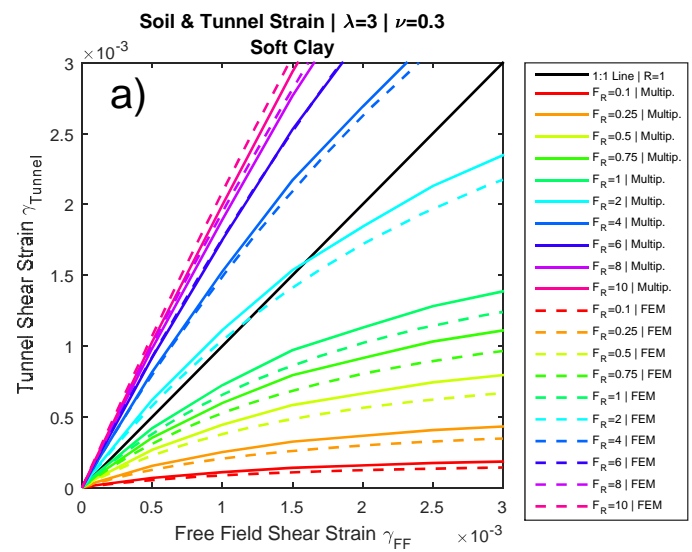

Nonlinear Racking Coefficient $|\lambda=3| \nu=0.3$

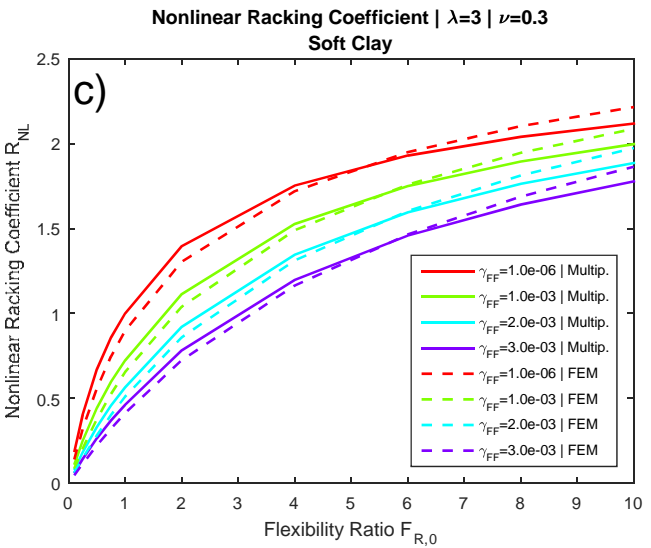

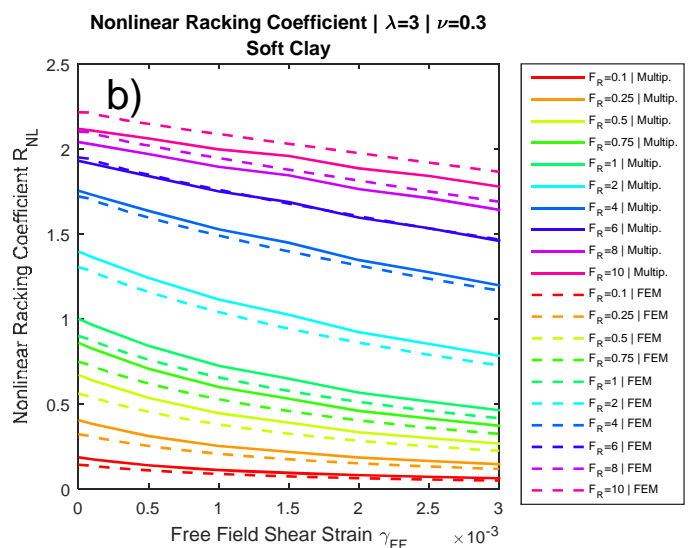

$\mathbf{R}_{\mathrm{NL}}$ Error $|\lambda=3| \nu=0.3$

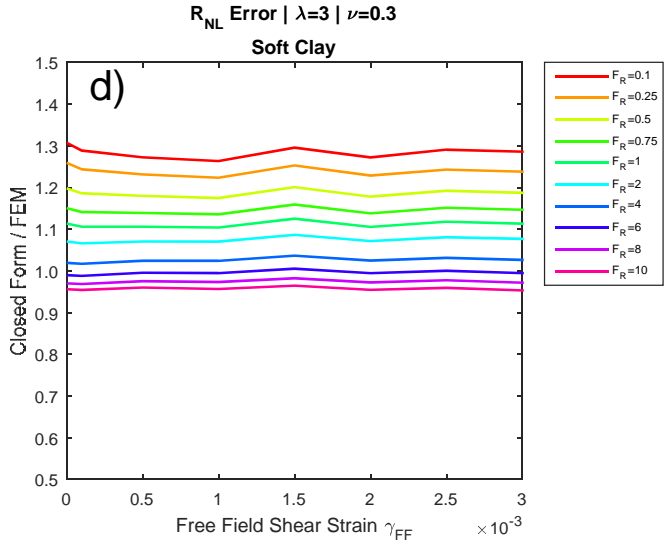

Fig. B-8. Distorsión no lineal para terreno blando, proporción geométrica $\lambda=b / d=3, y \quad v=0,23$ 


\section{B.1.9 Terreno blando y proporción $\lambda=3$, coeficiente de Poisson $v=0,40$}
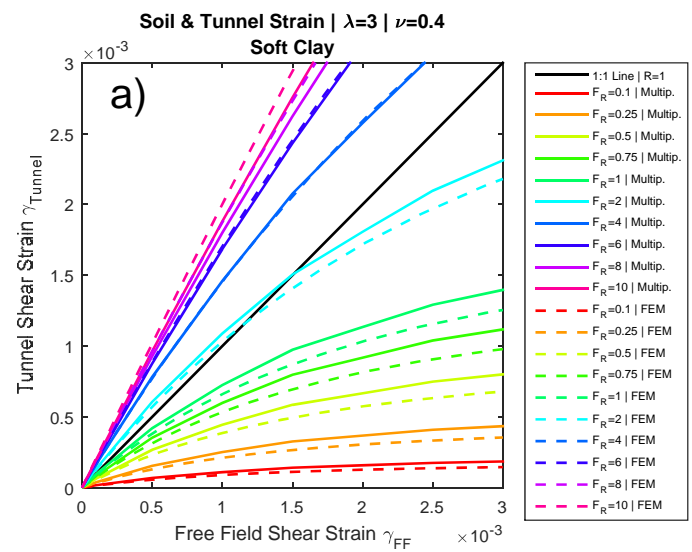

Nonlinear Racking Coefficient $|\lambda=3| \nu=0.4$

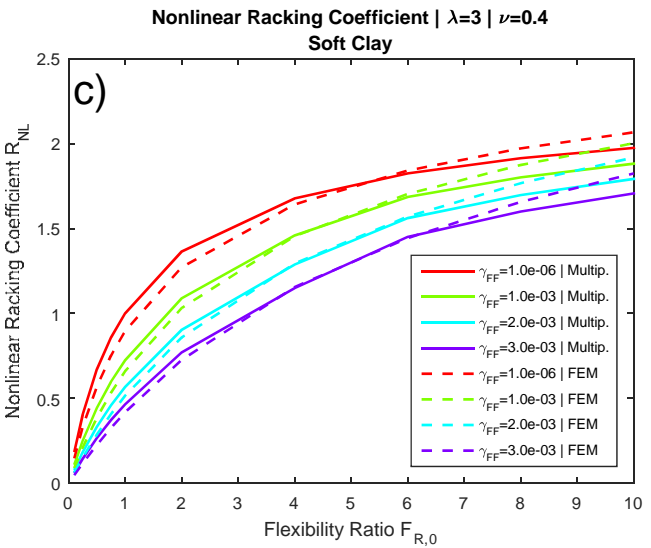

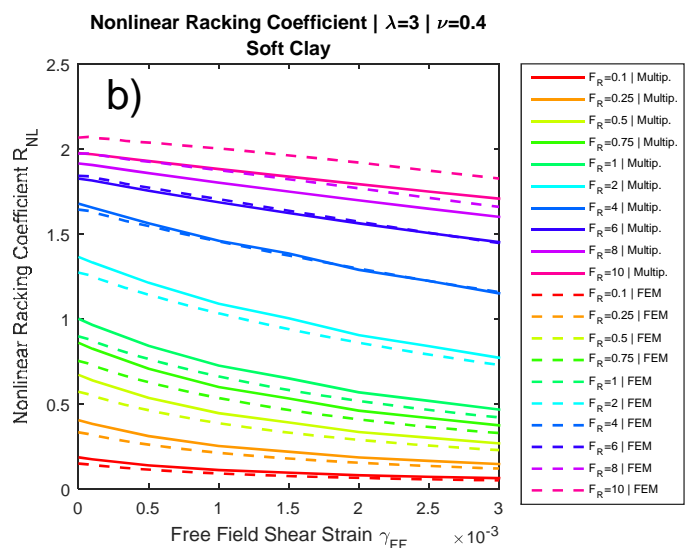

$\mathbf{R}_{\mathrm{NL}}$ Error $|\lambda=3| \nu=0.4$

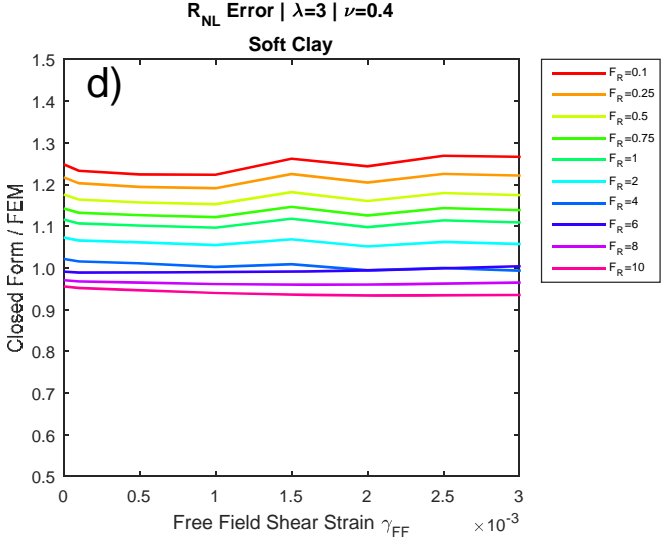

Fig. B-9. Distorsión no lineal para terreno blando, proporción geométrica $\lambda=b / d=3$, y $v=0,4$. 


\section{B.2 Resultados para terreno medio}

\section{B.2.1 Terreno medio y proporción $\lambda=1$, coeficiente de Poisson $v=0,20$}
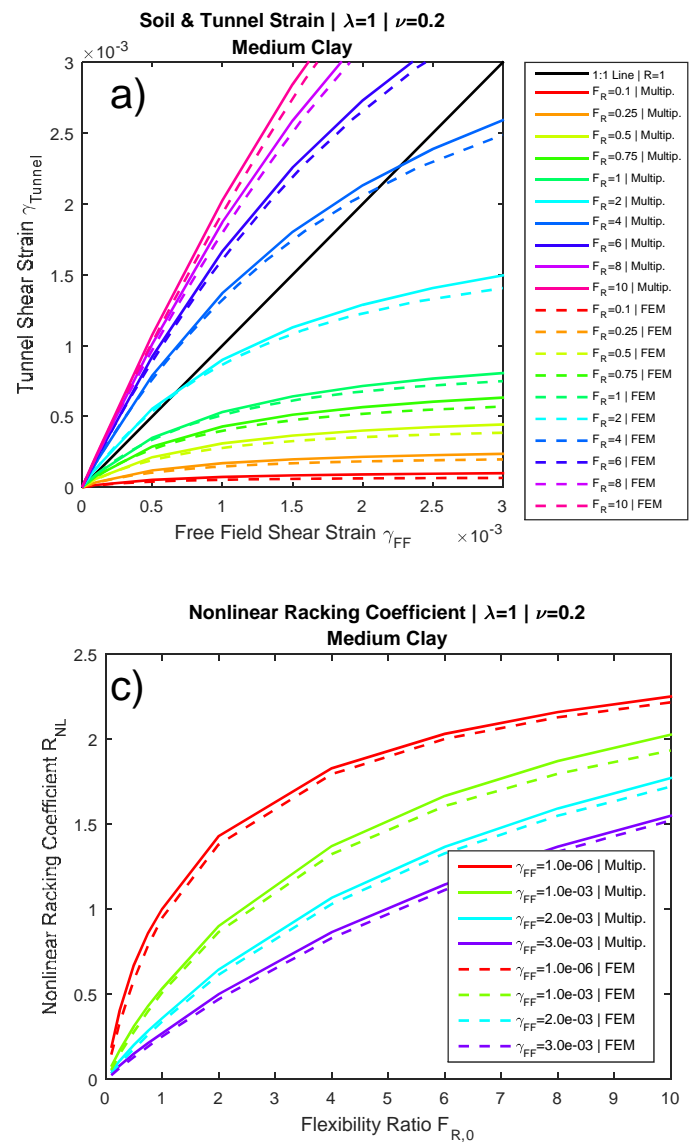

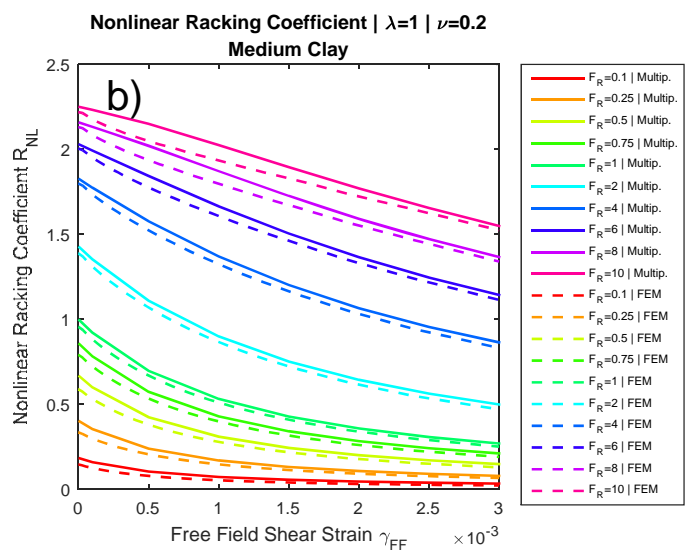

$\mathrm{R}_{\mathrm{NL}}$ Error $|\lambda=1| \nu=0.2$

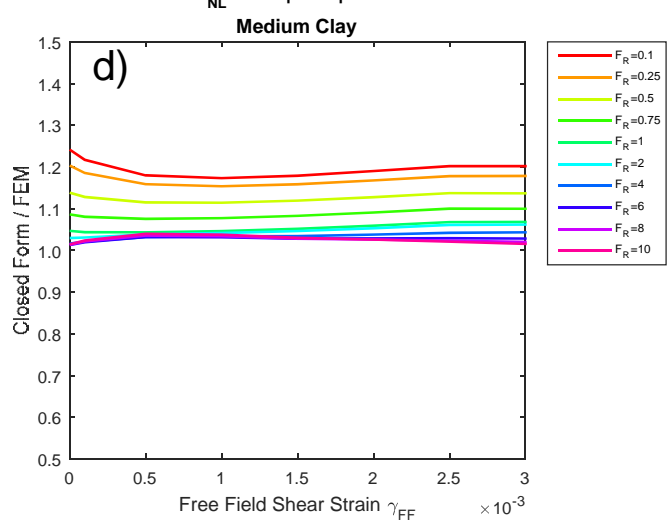

Fig. B-10. Distorsión no lineal para terreno medio, proporción geométrica $\lambda=b / d=1, y \quad v=0,2$. 


\section{B.2.2 Terreno medio y proporción $\lambda=1$, coeficiente de Poisson $v=0,30$}
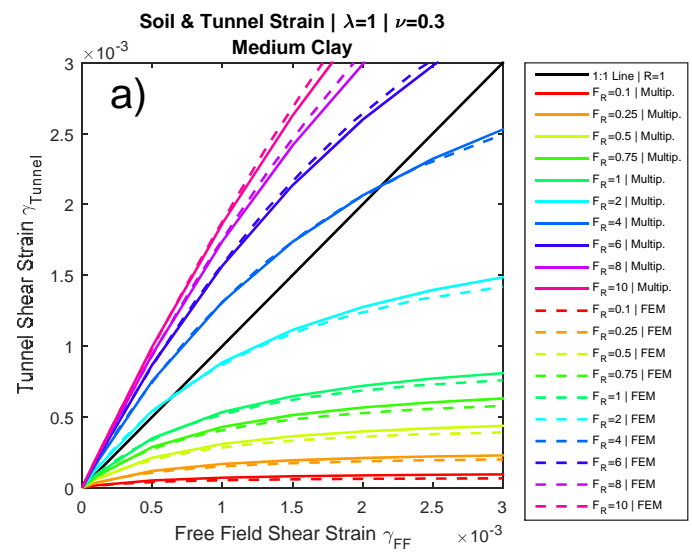

Nonlinear Racking Coefficient $|\lambda=1| \nu=0.3$

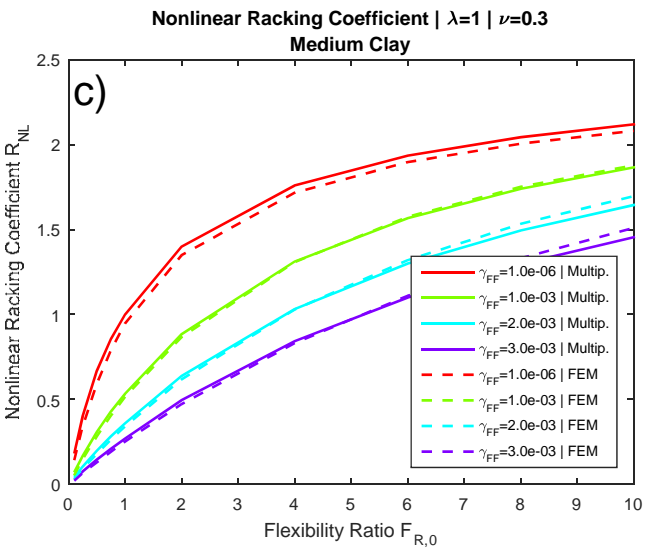

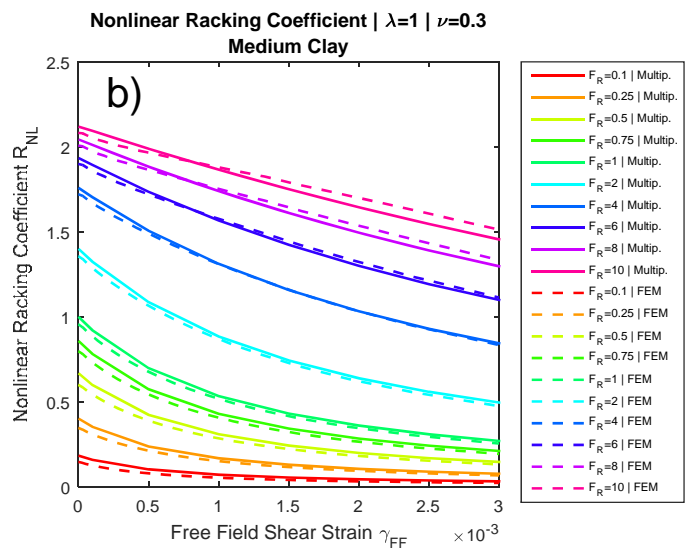

$\mathbf{R}_{\mathrm{NL}}$ Error $|\lambda=1| \nu=0.3$

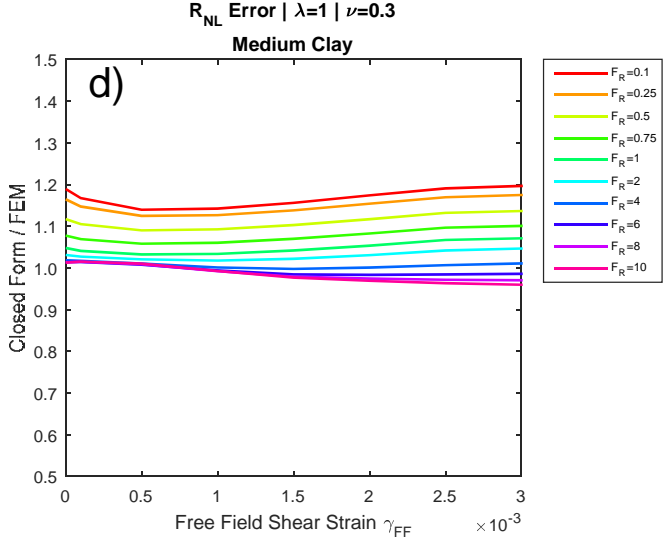

Fig. B-11. Distorsión no lineal para terreno medio, proporción geométrica $\lambda=b / d=1, y=0,3$. 


\section{B.2.3 Terreno medio y proporción $\lambda=1$, coeficiente de Poisson $v=0,40$}
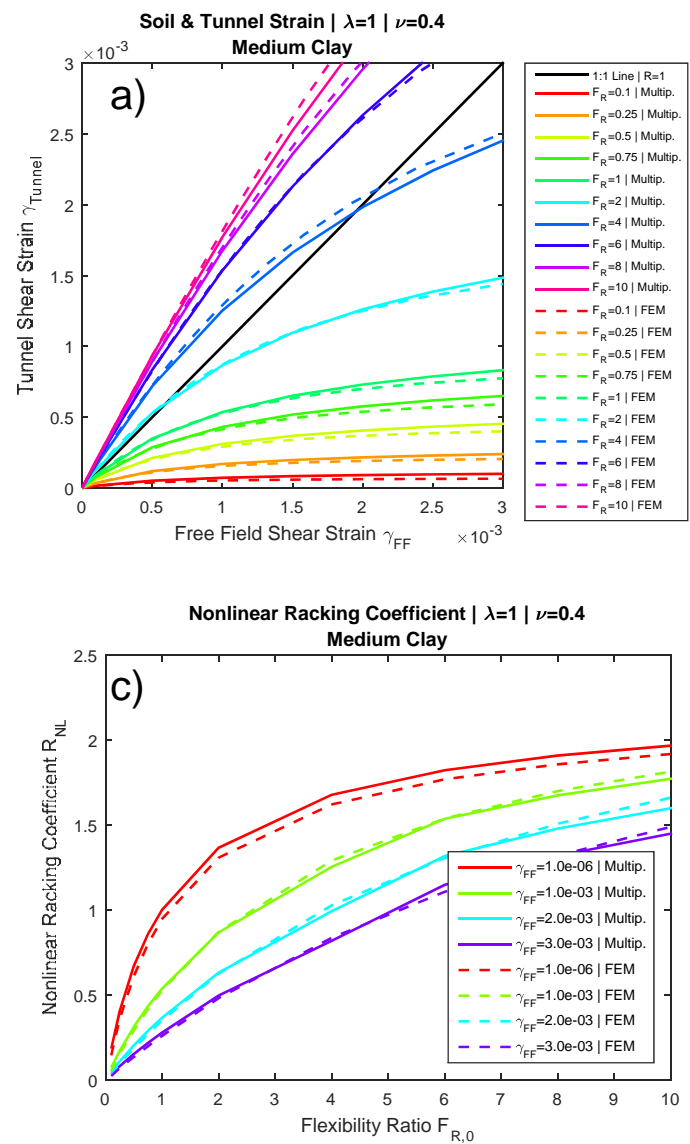
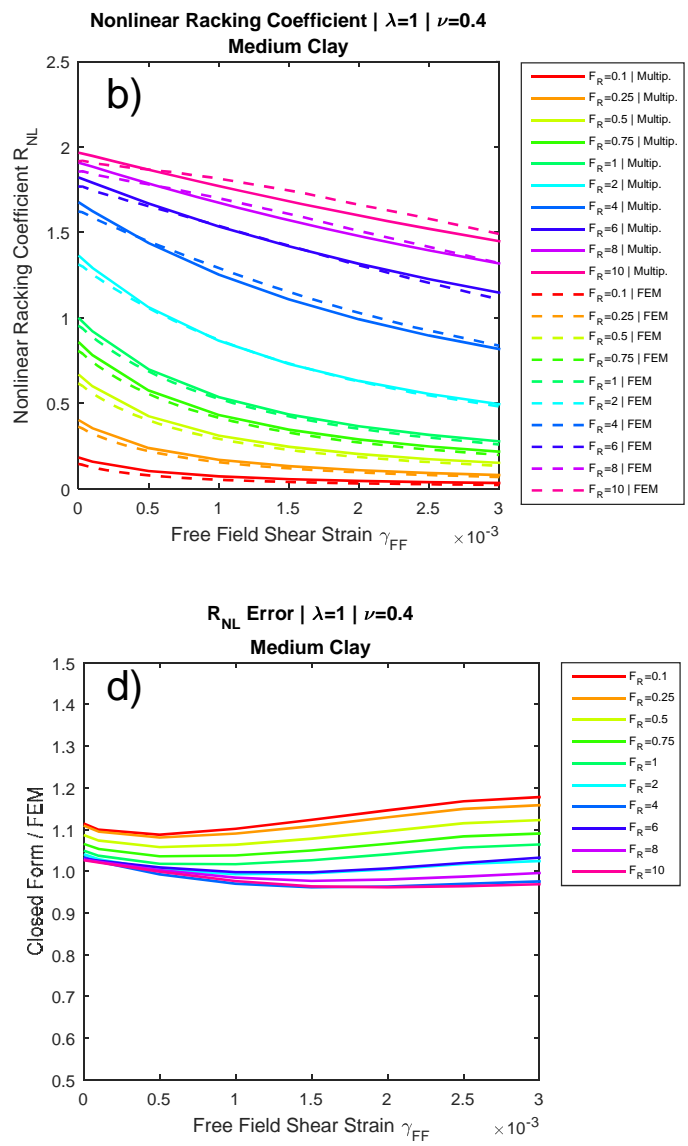

Fig. B-12. Distorsión no lineal para terreno medio, proporción geométrica $\lambda=b / d=1, y=0,4$. 


\section{B.2.4 Terreno medio y proporción $\lambda=2$, coeficiente de Poisson $v=0,20$}
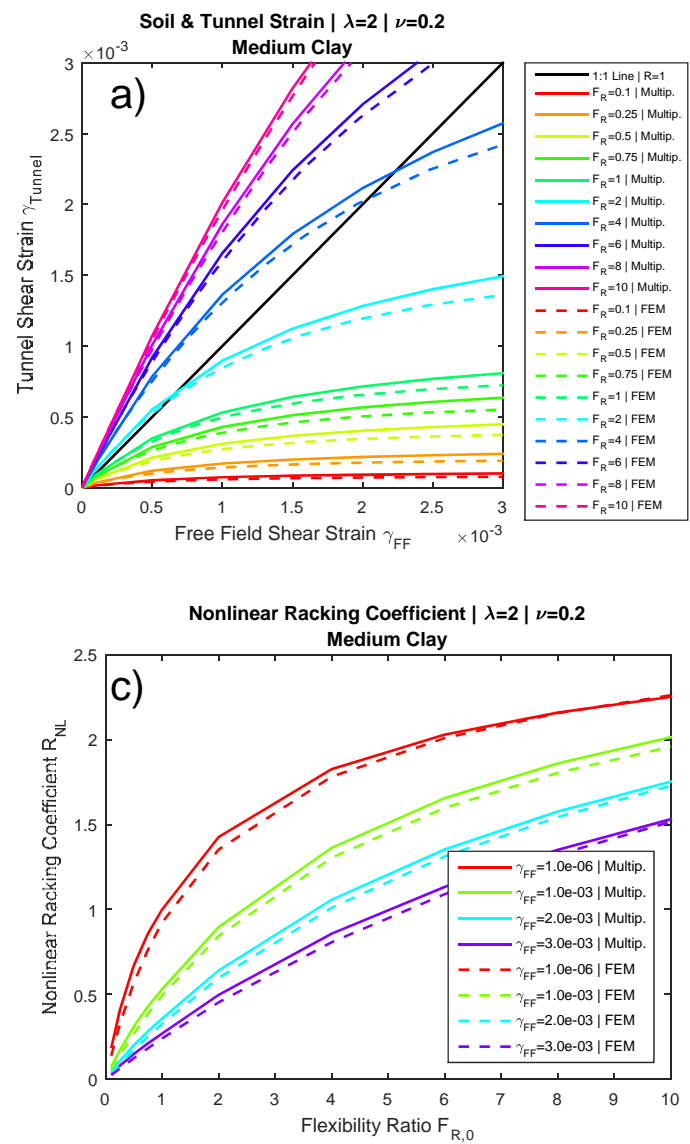

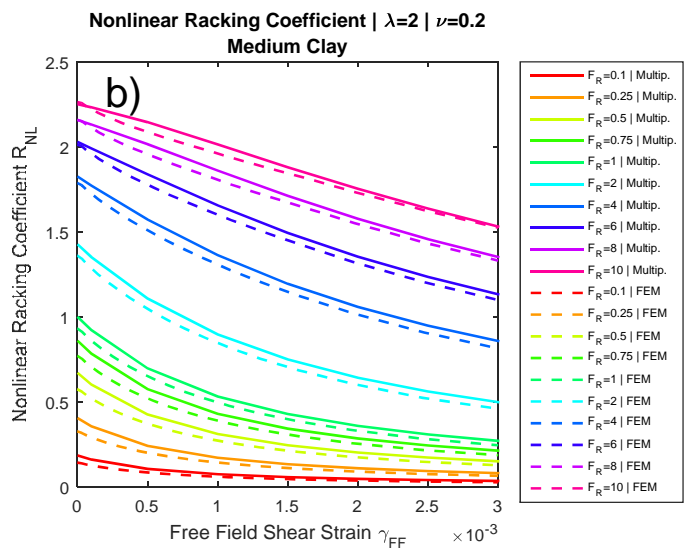

$\mathbf{R}_{\mathrm{NL}}$ Error $|\lambda=2| \nu=0.2$

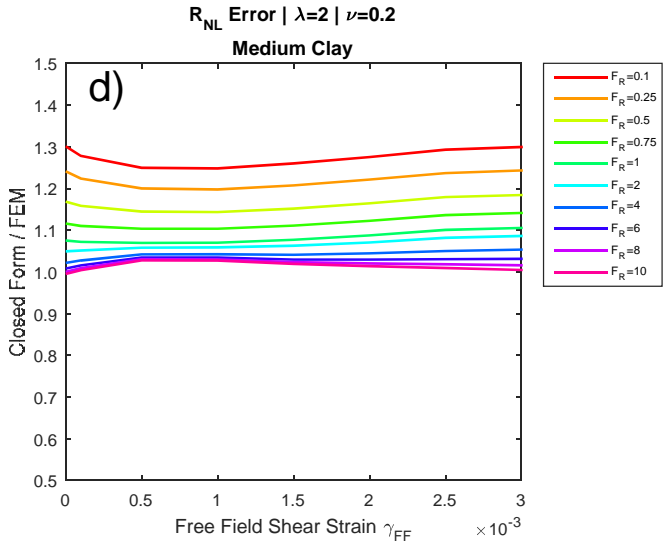

Fig. B-13. Distorsión no lineal para terreno medio, proporción geométrica $\lambda=b / d=2, y=0,2$. 


\section{B.2.5 Terreno medio y proporción $\lambda=2$, coeficiente de Poisson $v=0,30$}
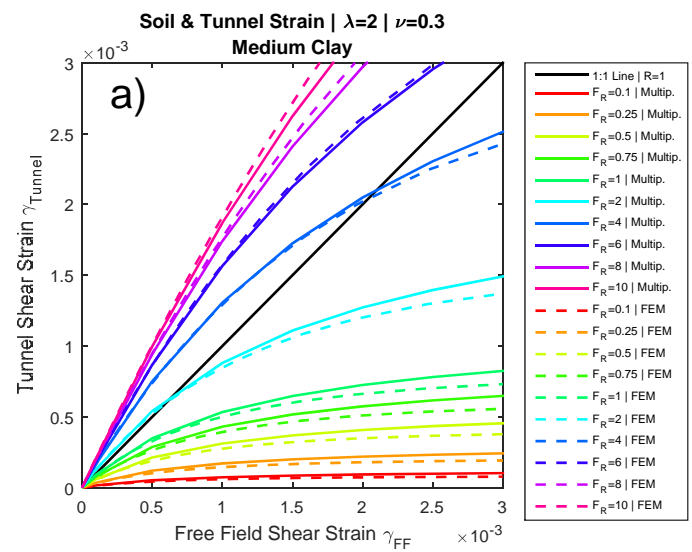

Nonlinear Racking Coefficient $|\lambda=2| \nu=0.3$

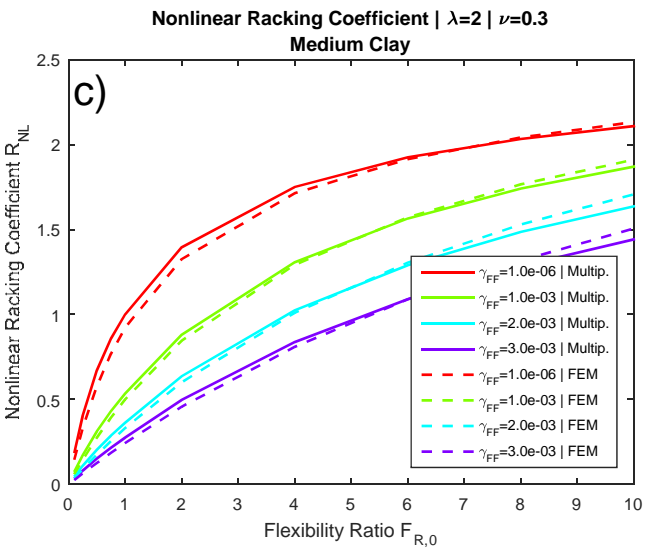

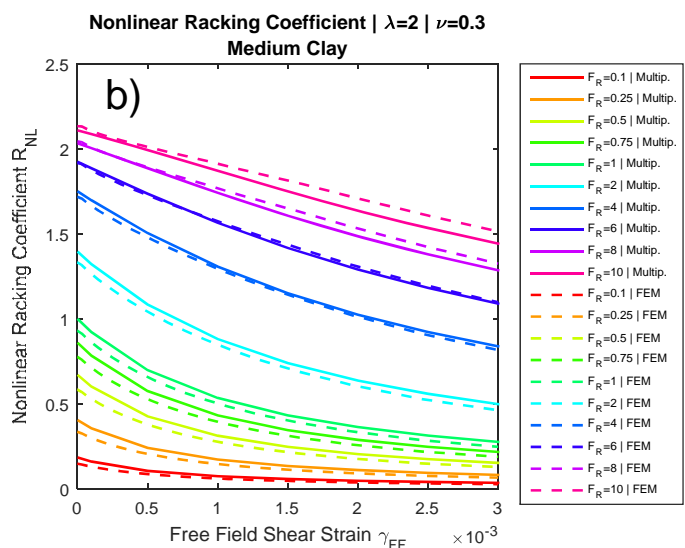

$\mathbf{R}_{\mathrm{NL}}$ Error $|\lambda=2| \nu=0.3$

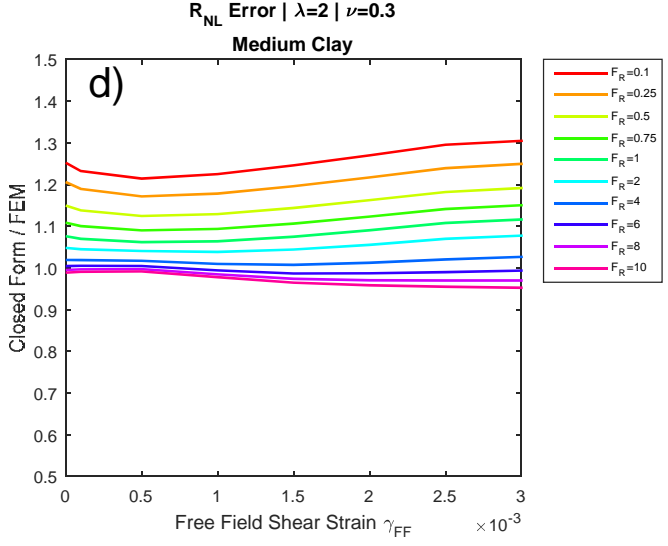

Fig. B-14. Distorsión no lineal para terreno medio, proporción geométrica $\lambda=b / d=2, y=0,3$. 


\section{B.2.6 Terreno medio y proporción $\lambda=2$, coeficiente de Poisson $v=0,40$}
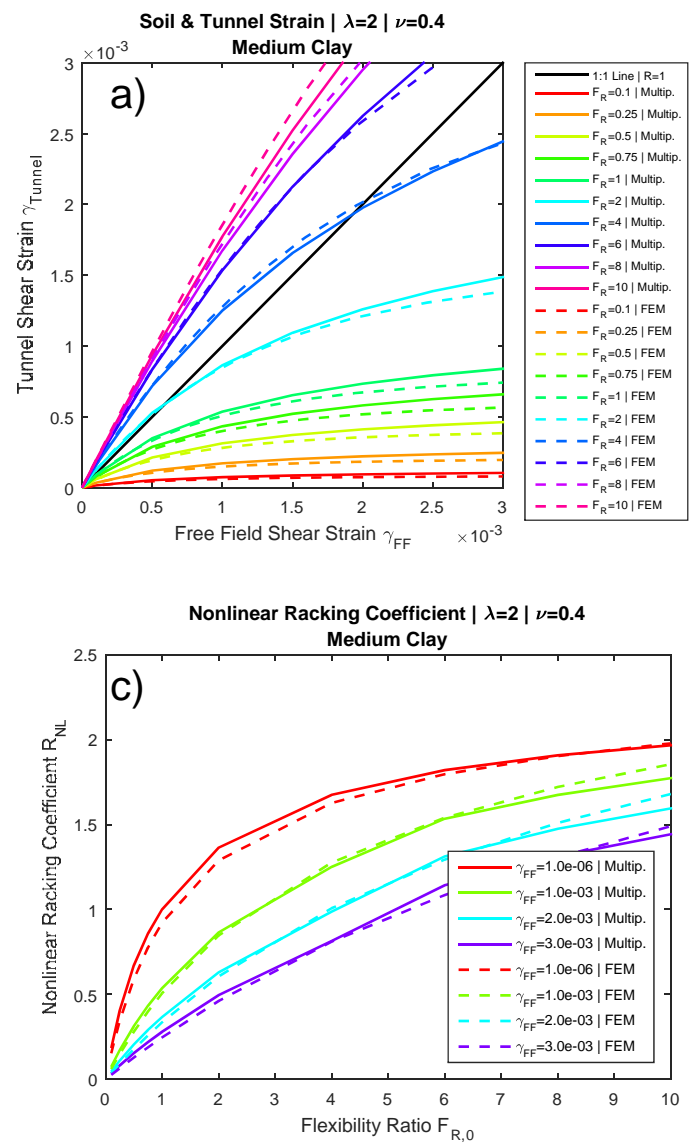
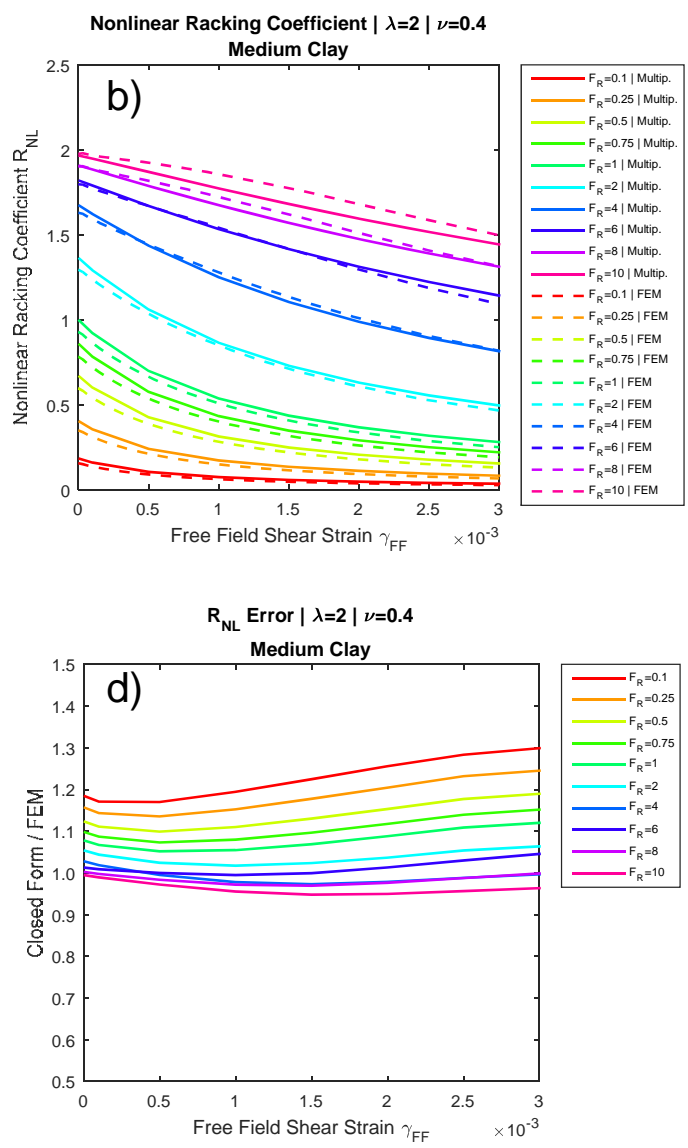

Fig. B-15. Distorsión no lineal para terreno medio, proporción geométrica $\lambda=b / d=2, y \quad v=0,4$. 


\section{B.2.7 Terreno medio y proporción $\lambda=3$, coeficiente de Poisson $v=0,20$}
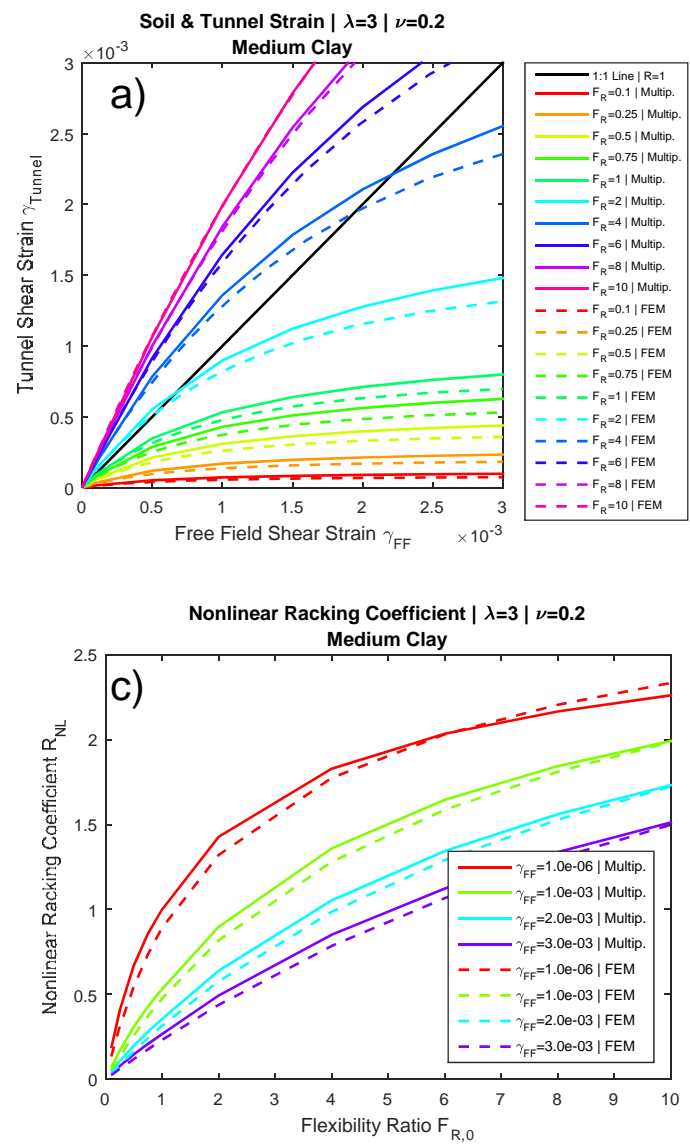

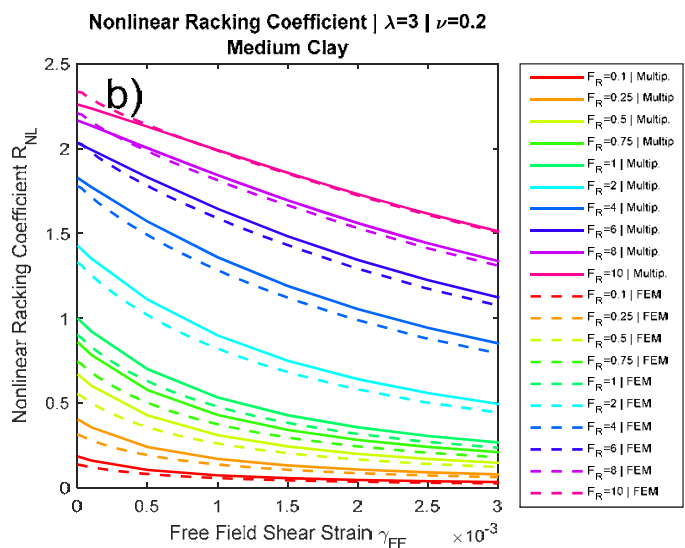

$\mathbf{R}_{\mathrm{NL}} \operatorname{Error}|\lambda=3| \nu=0.2$

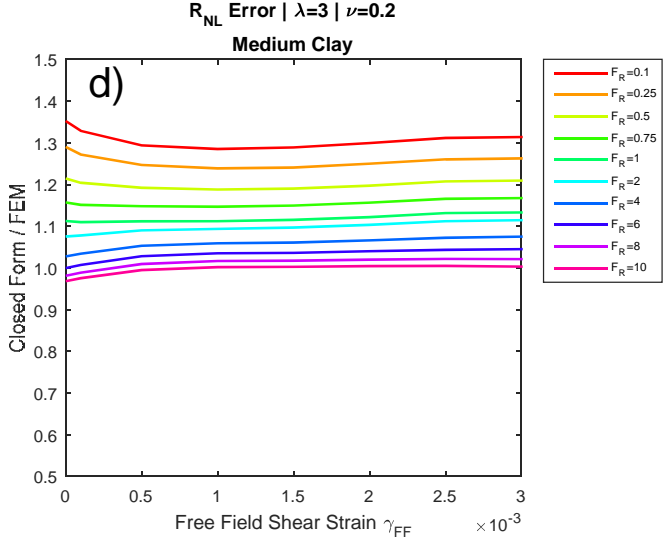

Fig. B-16. Distorsión no lineal para terreno medio, proporción geométrica $\lambda=b / d=3, y=0,2$. 


\section{B.2.8 Terreno medio y proporción $\lambda=3$, coeficiente de Poisson $v=0,30$}
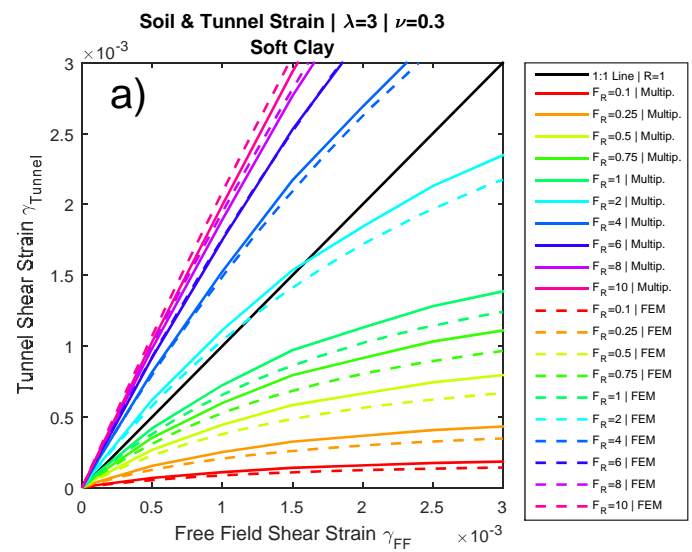

Nonlinear Racking Coefficient $|\lambda=3| \nu=0.3$

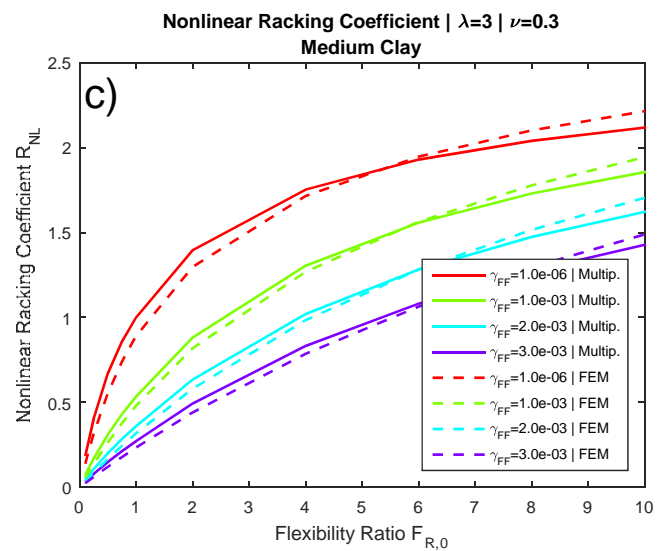

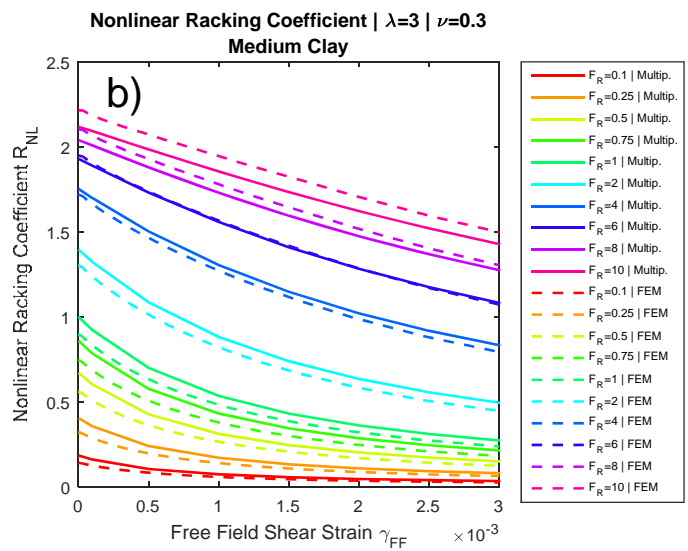

$\mathbf{R}_{\mathrm{NL}}$ Error $|\lambda=3| \nu=0.3$

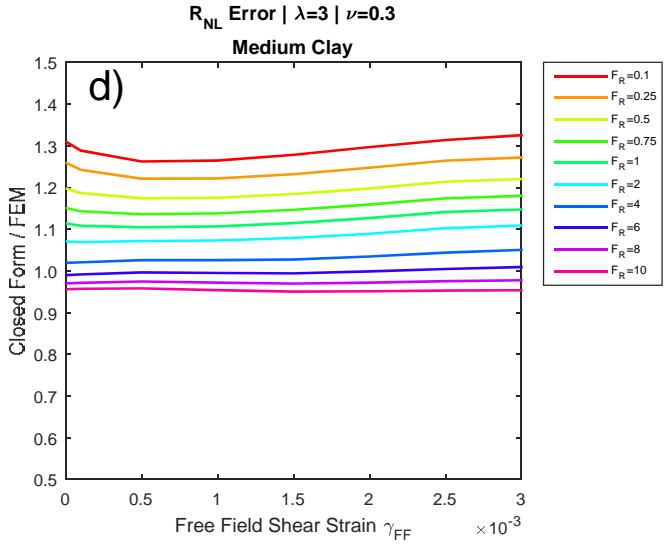

Fig. B-17. Distorsión no lineal para terreno medio, proporción geométrica $\lambda=b / d=3, y=0,3$. 


\section{B.2.9 Terreno medio y proporción $\lambda=3$, coeficiente de Poisson $v=0,40$}
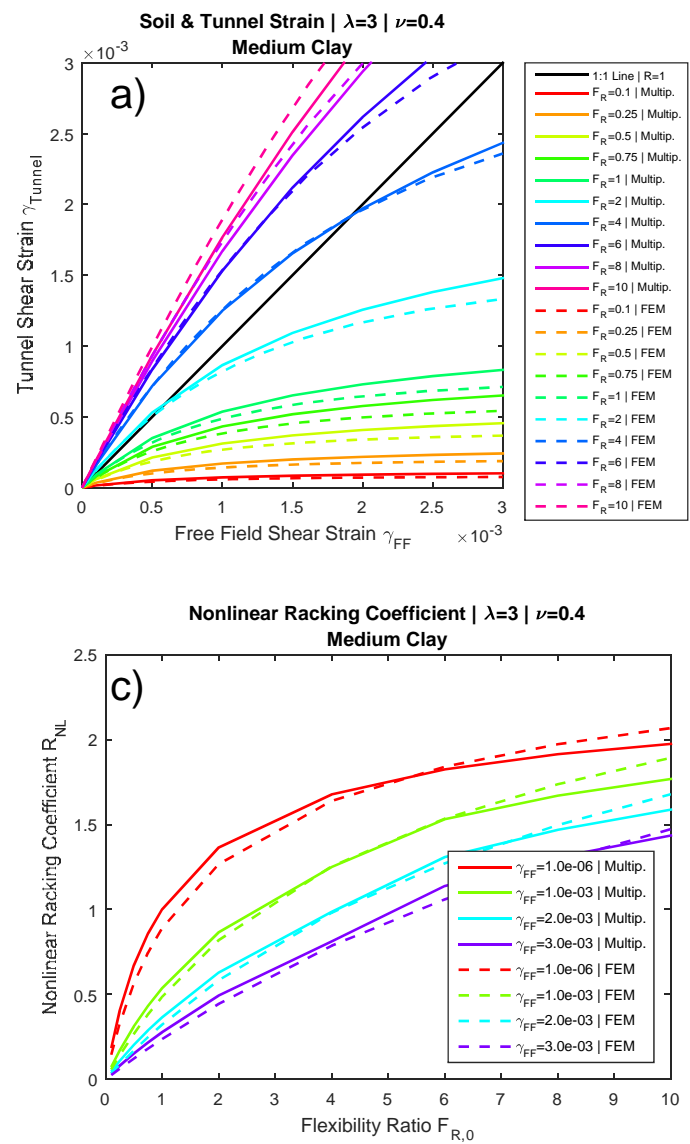

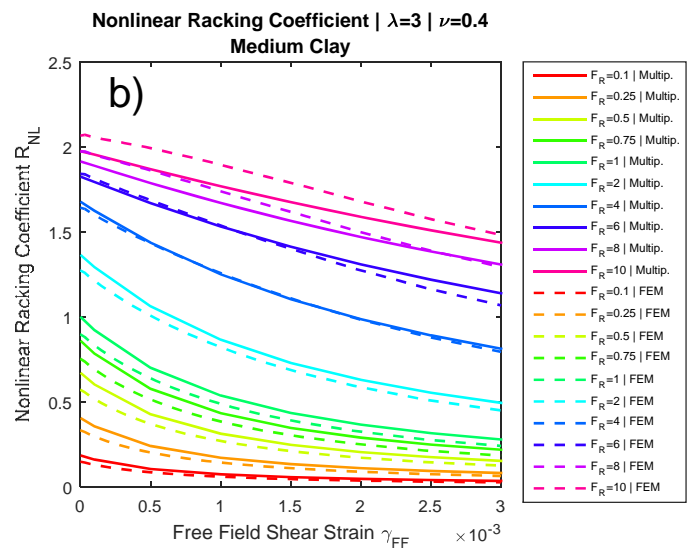

$\mathbf{R}_{\mathrm{NL}}$ Error $|\lambda=3| \nu=0.4$

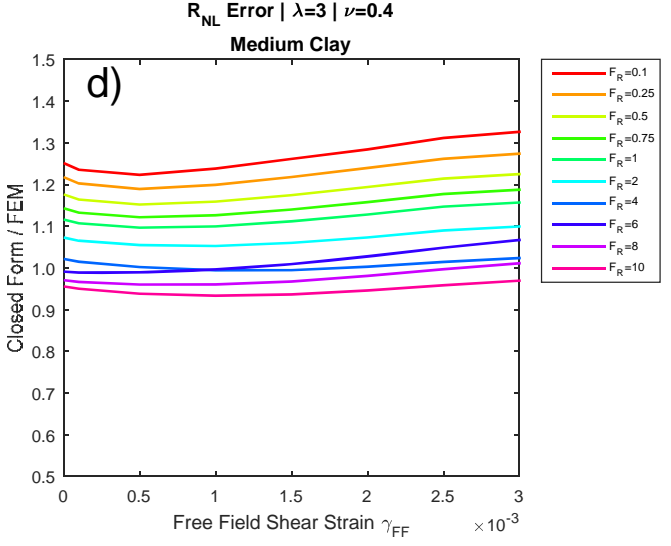

Fig. B-18. Distorsión no lineal para terreno medio, proporción geométrica $\lambda=b / d=3, y=0,4$. 


\section{B.3 Resultados para terreno rígido}

\section{B.3.1 Terreno rígido y proporción $\lambda=1$, coeficiente de Poisson $v=0,20$}
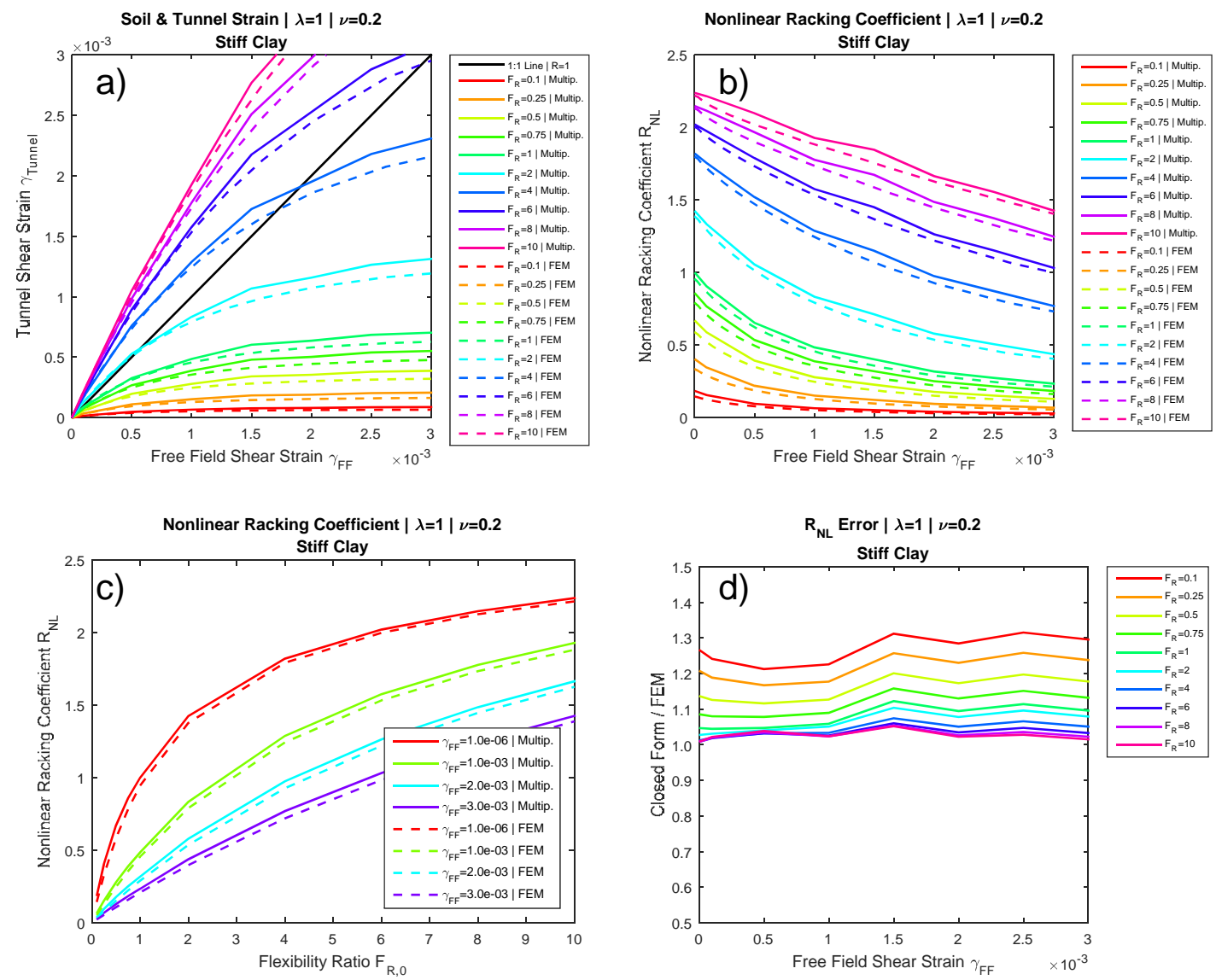

Fig. B-19. Distorsión no lineal para terreno rígido, proporción geométrica $\lambda=b / d=1$, y $v=0,2$. 


\section{B.3.2 Terreno rígido y proporción $\lambda=1$, coeficiente de Poisson $v=0,30$}
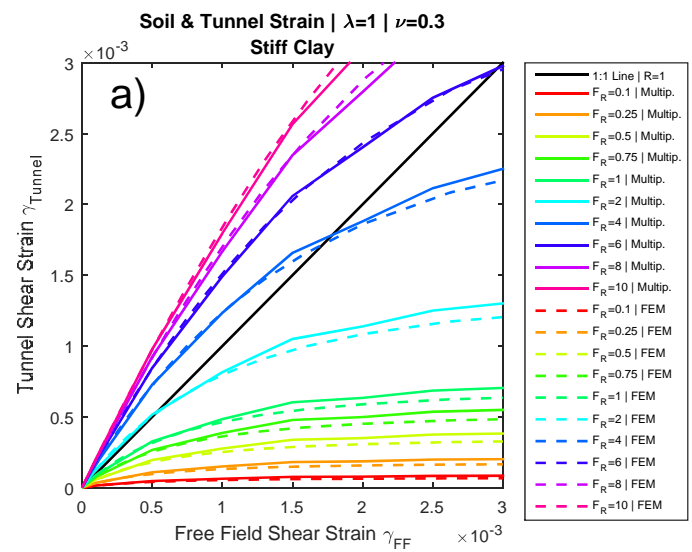

Nonlinear Racking Coefficient $|\lambda=1| \nu=0.3$

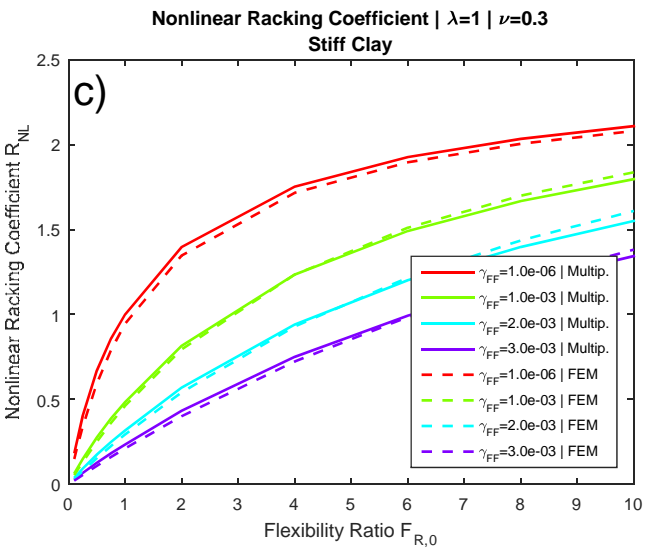

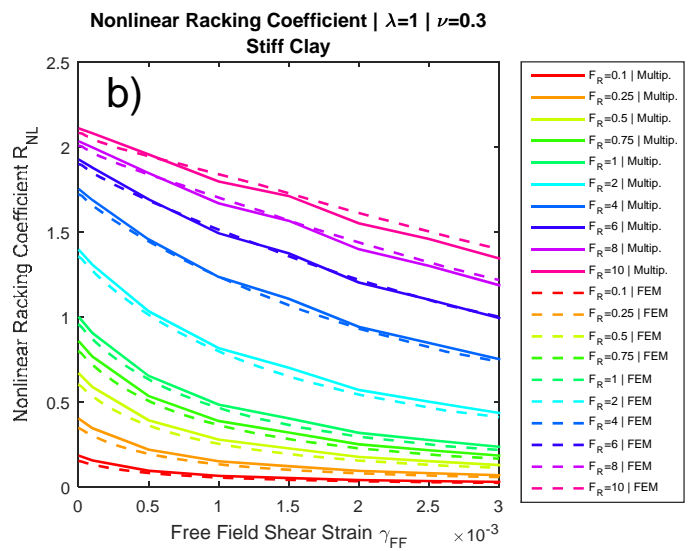

$\mathbf{R}_{\mathrm{NL}} \operatorname{Error}|\lambda=1| \nu=0.3$

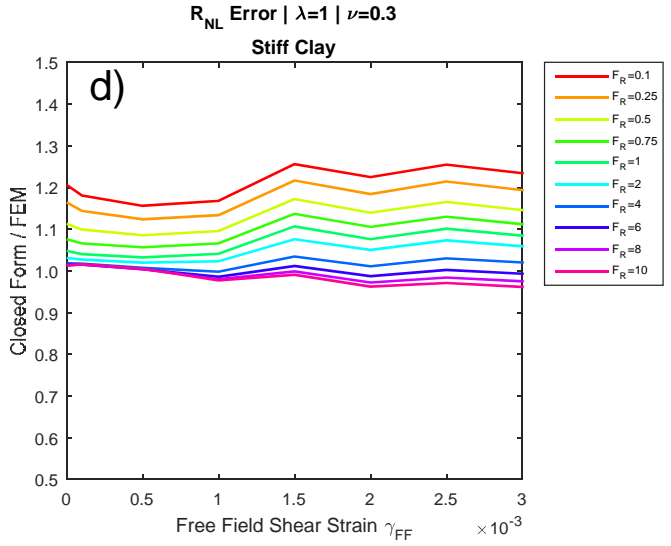

Fig. B-20. Distorsión no lineal para terreno rígido, proporción geométrica $\lambda=b / d=1, y=0,3$. 


\section{B.3.3 Terreno rígido y proporción $\lambda=1$, coeficiente de Poisson $v=0,40$}
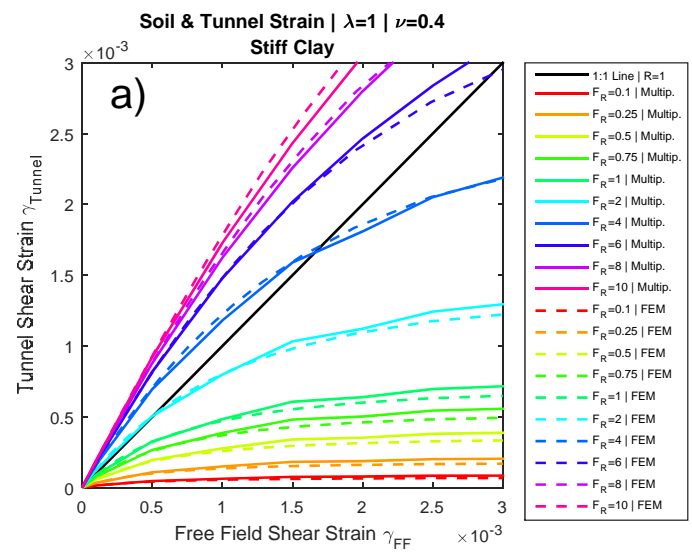

Nonlinear Racking Coefficient $|\lambda=1| \nu=0.4$

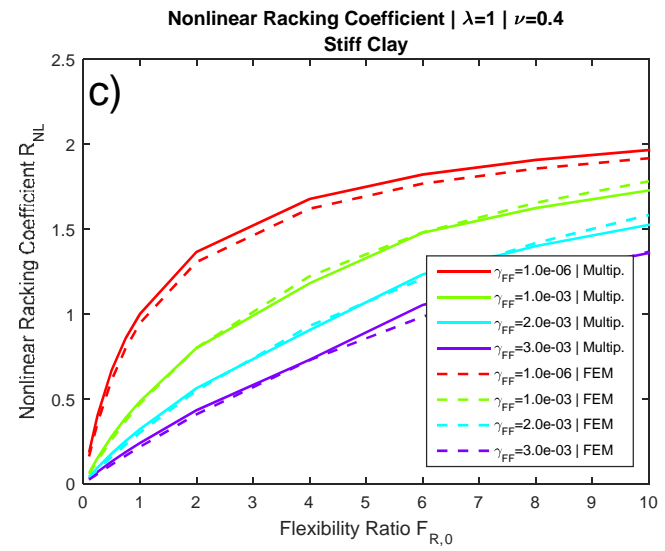

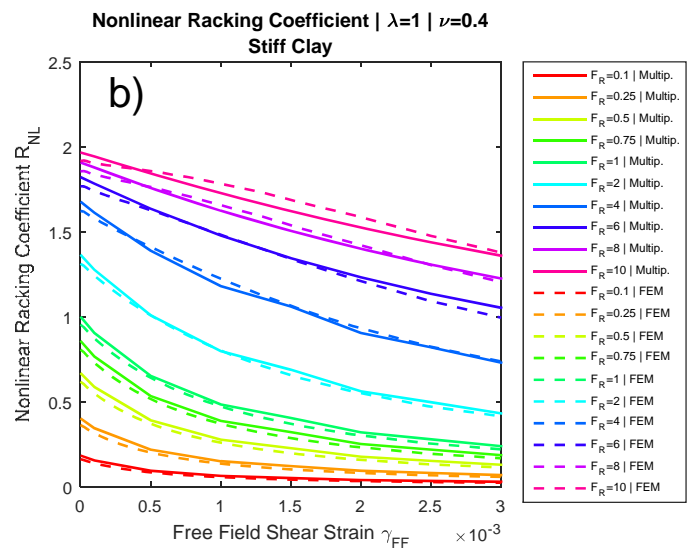

$\mathbf{R}_{\mathrm{NL}} \operatorname{Error}|\lambda=1| \nu=0.4$

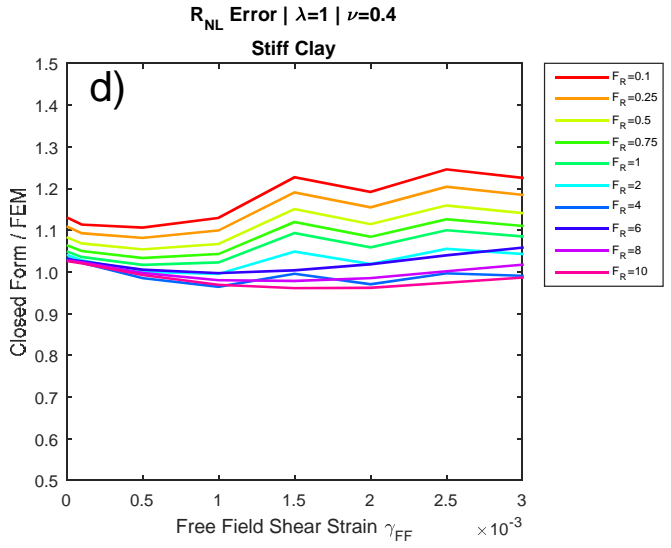

Fig. B-21. Distorsión no lineal para terreno rígido, proporción geométrica $\lambda=b / d=1, y=0,4$. 


\section{B.3.4 Terreno rígido y proporción $\lambda=2$, coeficiente de Poisson $v=0,20$}
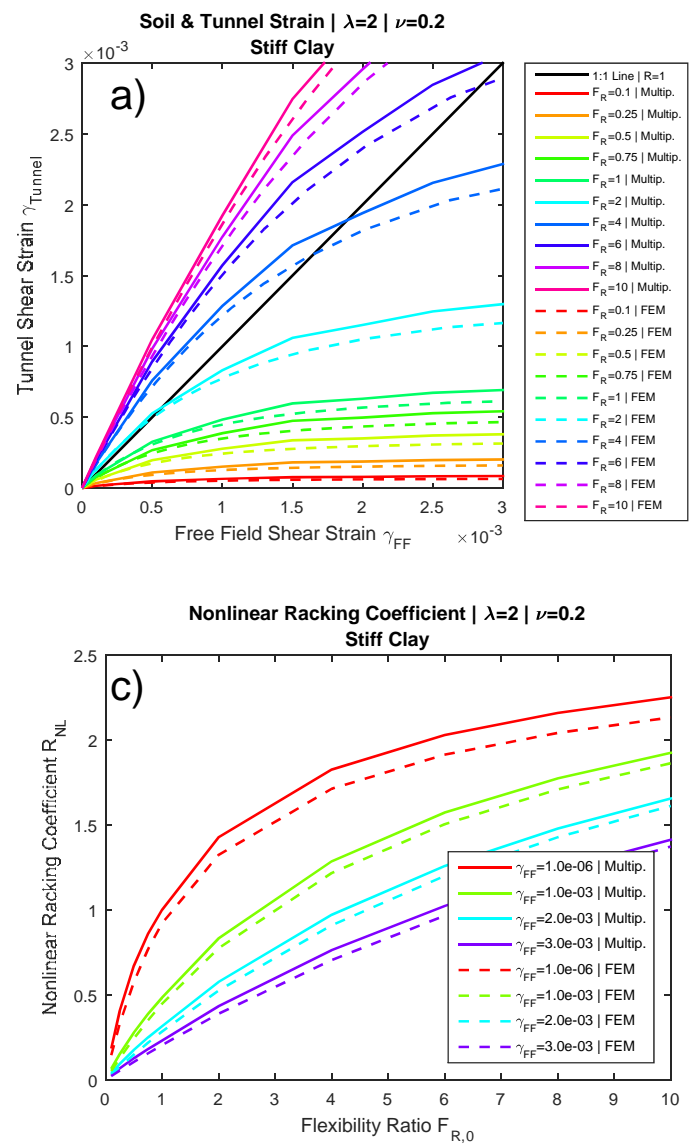

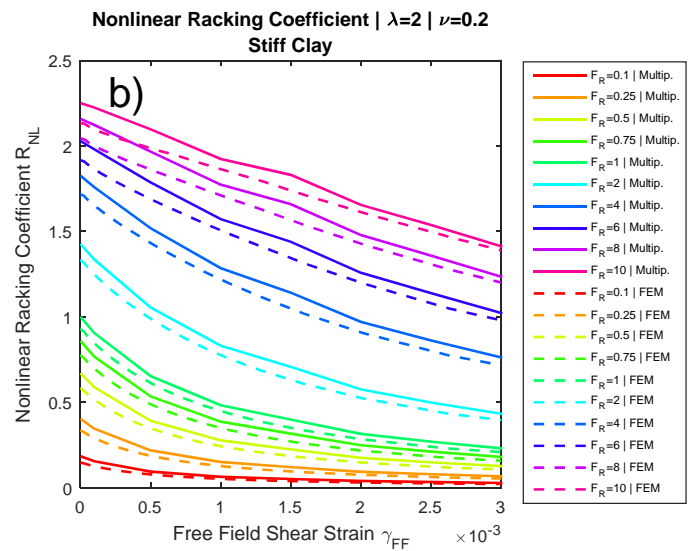

$\mathrm{R}_{\mathrm{NL}}$ Error $|\lambda=2| \nu=0.2$

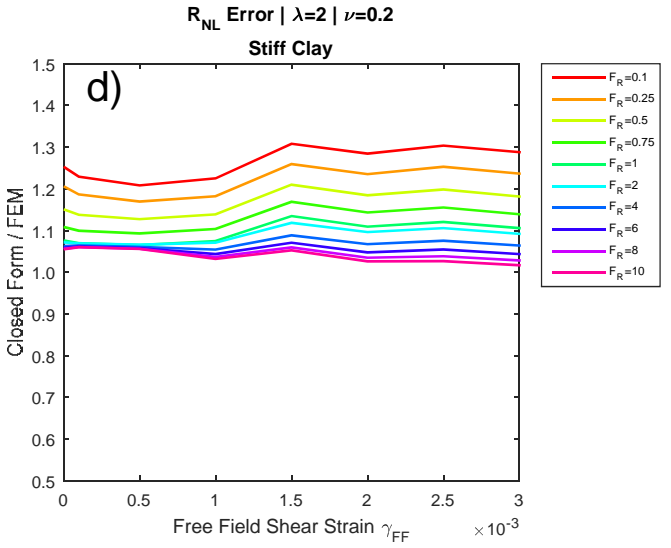

Fig. B-22. Distorsión no lineal para terreno rígido, proporción geométrica $\lambda=b / d=2, y=0,2$. 


\section{B.3.5 Terreno rígido y proporción $\lambda=2$, coeficiente de Poisson $v=0,30$}
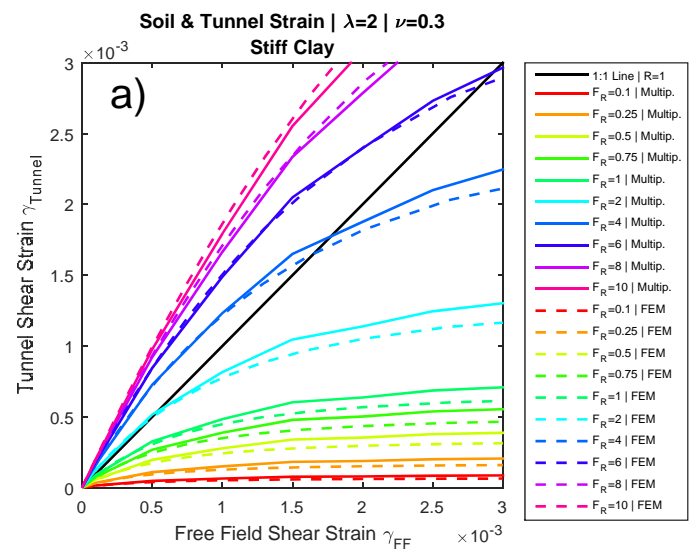

Nonlinear Racking Coefficient $|\lambda=2| \nu=0.3$

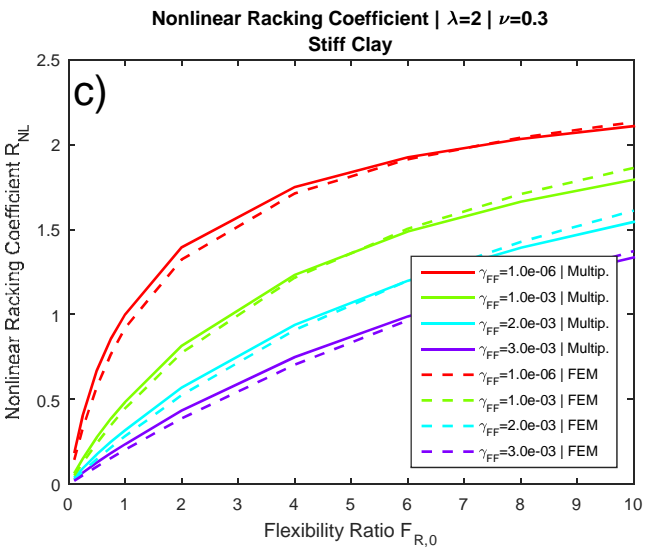

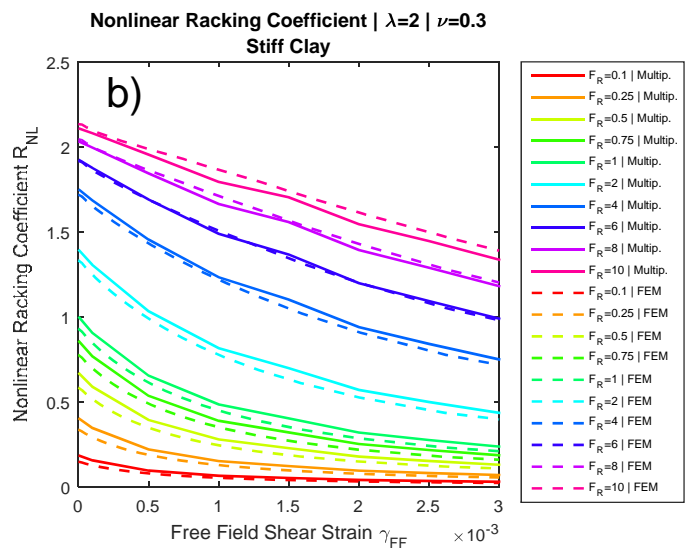

$\mathbf{R}_{\mathrm{NL}} \operatorname{Error}|\lambda=2| \nu=0.3$

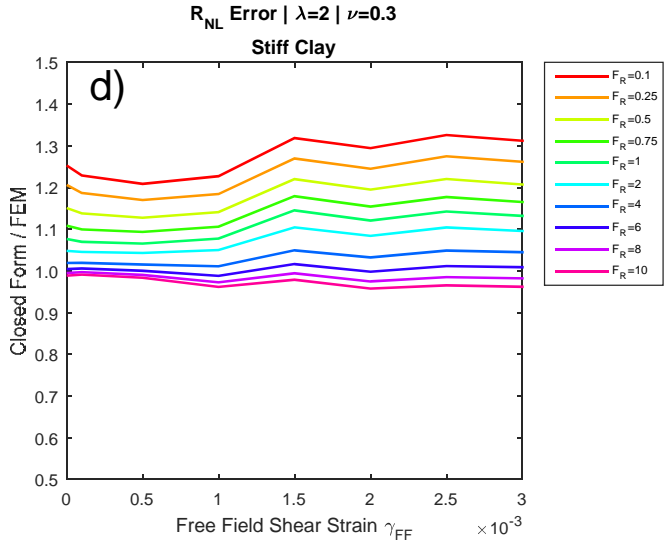

Fig. B-23. Distorsión no lineal para terreno rígido, proporción geométrica $\lambda=b / d=2, y=0,3$. 


\section{B.3.6 Terreno rígido y proporción $\lambda=2$, coeficiente de Poisson $v=0,40$}
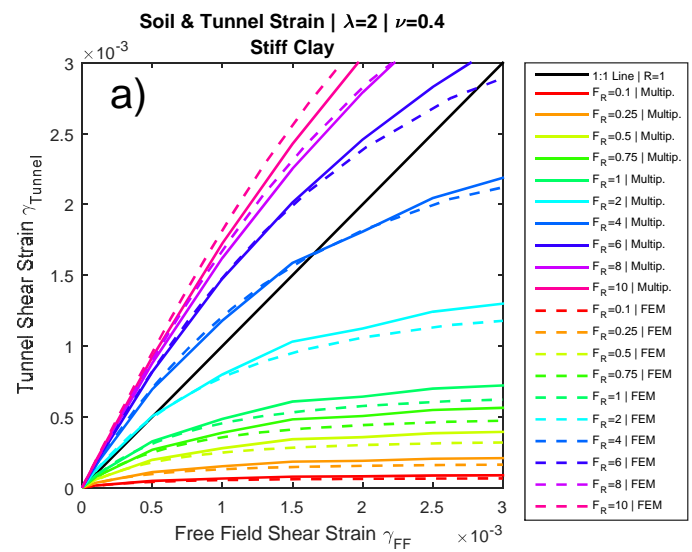

Nonlinear Racking Coefficient $|\lambda=2| \nu=0.4$

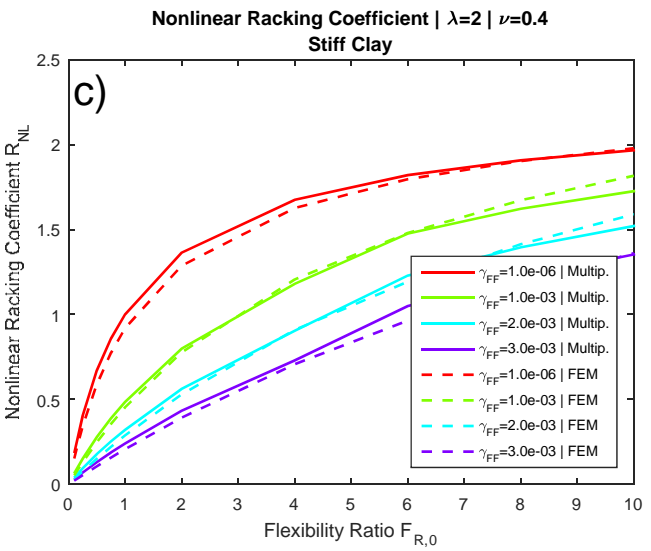

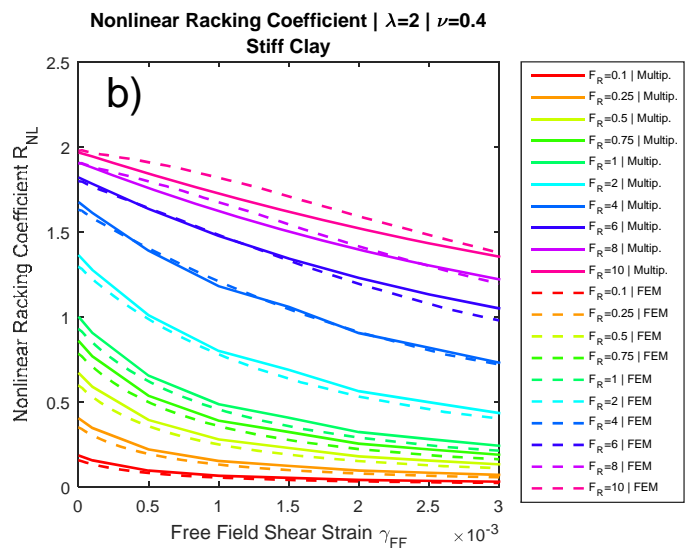

$\mathbf{R}_{\mathrm{NL}} \operatorname{Error}|\lambda=2| \nu=0.4$

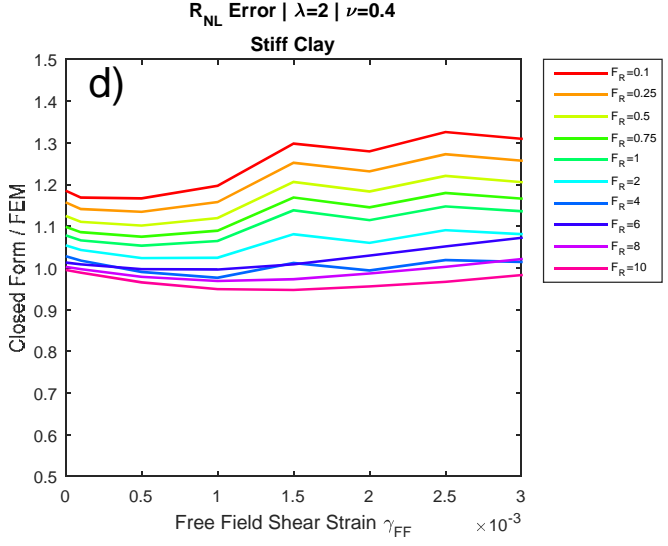

Fig. B-24. Distorsión no lineal para terreno rígido, proporción geométrica $\lambda=b / d=2, y=0,4$. 


\section{B.3.7 Terreno rígido y proporción $\lambda=3$, coeficiente de Poisson $v=0,20$}
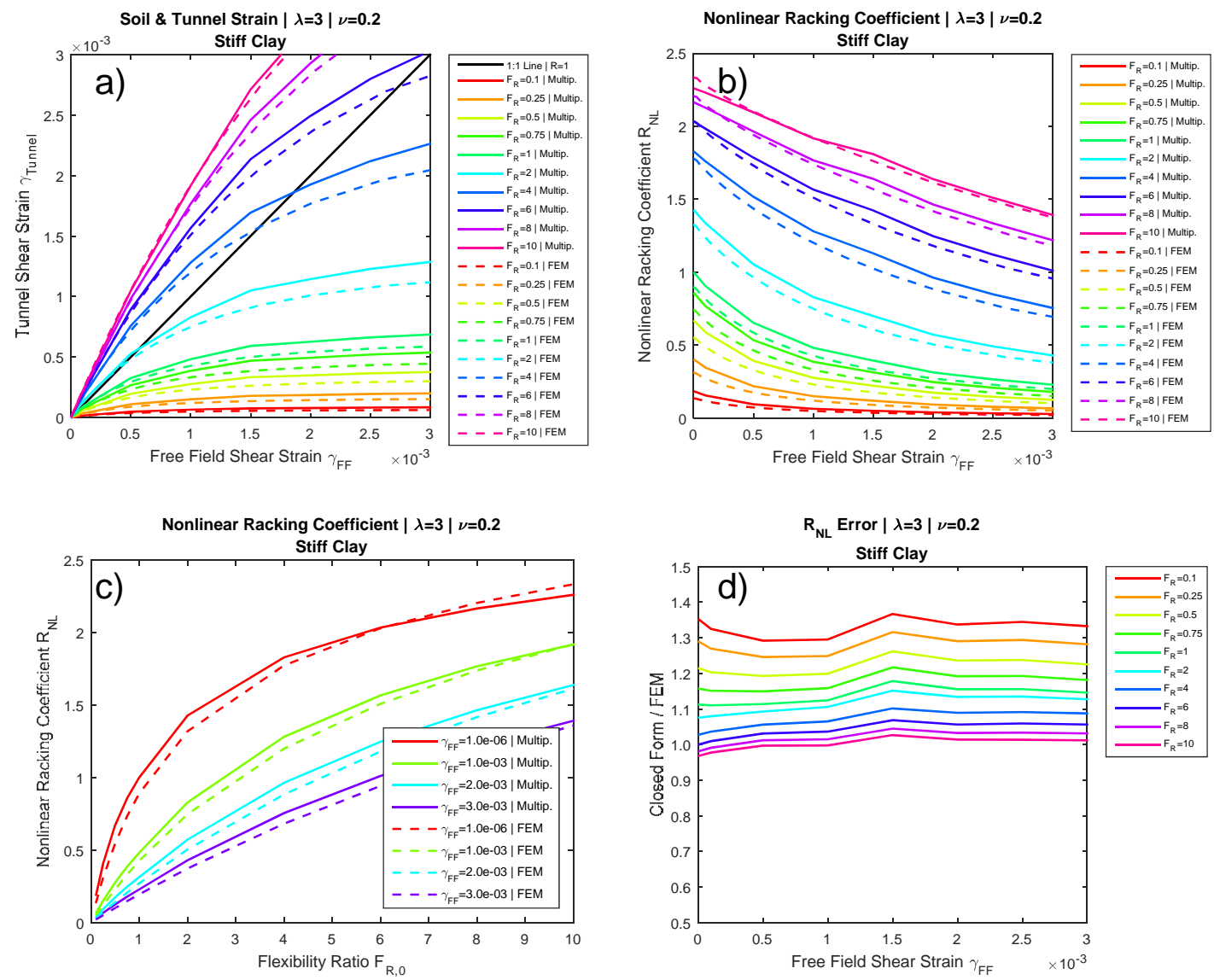

Fig. B-25. Distorsión no lineal para terreno rígido, proporción geométrica $\lambda=b / d=3, y=0,2$. 


\section{B.3.8 Terreno rígido y proporción $\lambda=3$, coeficiente de Poisson $v=0,30$}
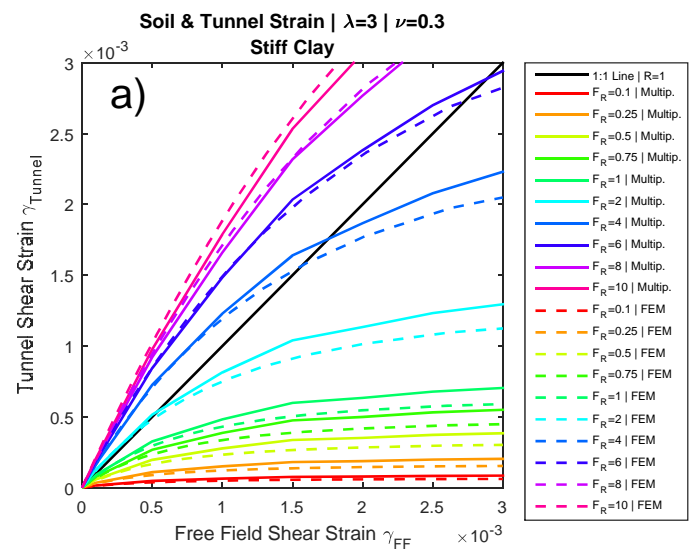

Nonlinear Racking Coefficient $|\lambda=3| \nu=0.3$

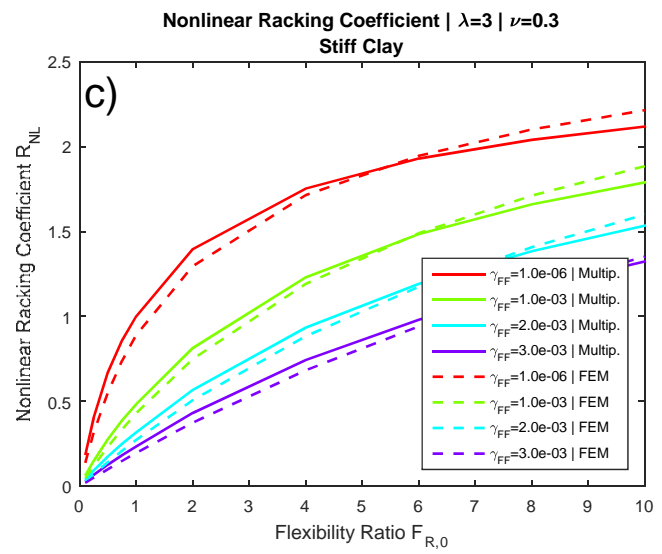

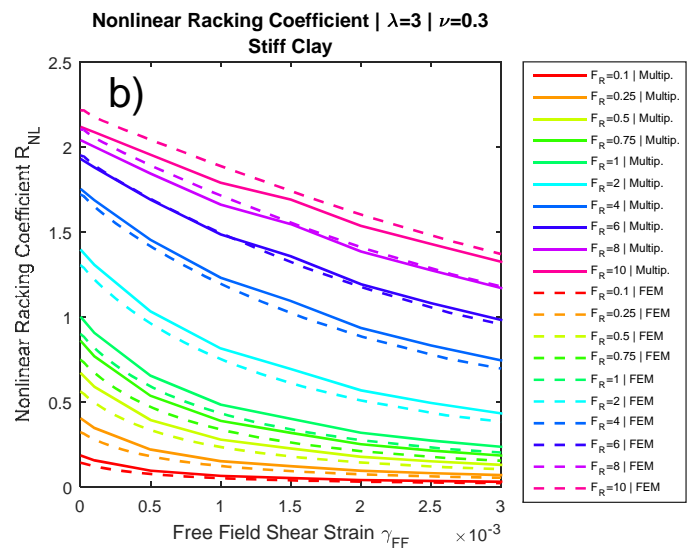

$\mathbf{R}_{\mathrm{NL}} \operatorname{Error}|\lambda=3| \nu=0.3$

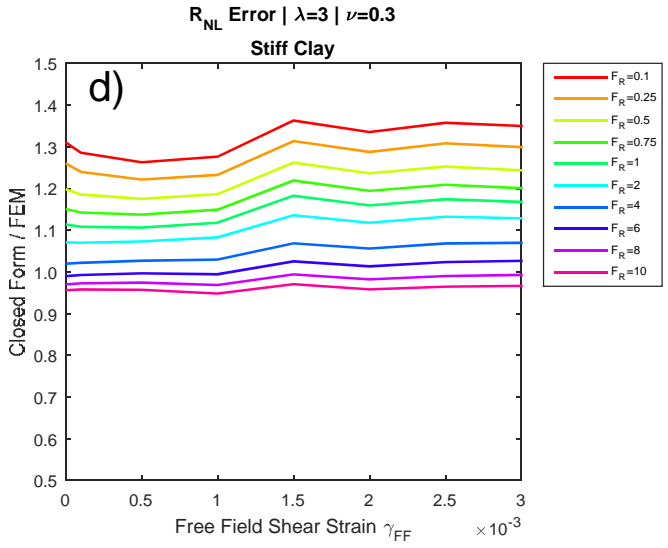

Fig. B-26. Distorsión no lineal para terreno rígido, proporción geométrica $\lambda=b / d=3, y=0,3$. 


\section{B.3.9 Terreno rígido y proporción $\lambda=3$, coeficiente de Poisson $v=0,40$}
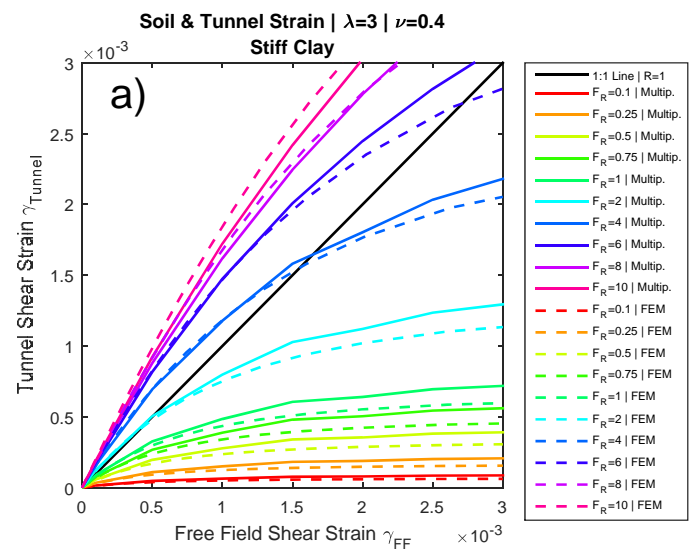

Nonlinear Racking Coefficient $|\lambda=3| \nu=0.4$

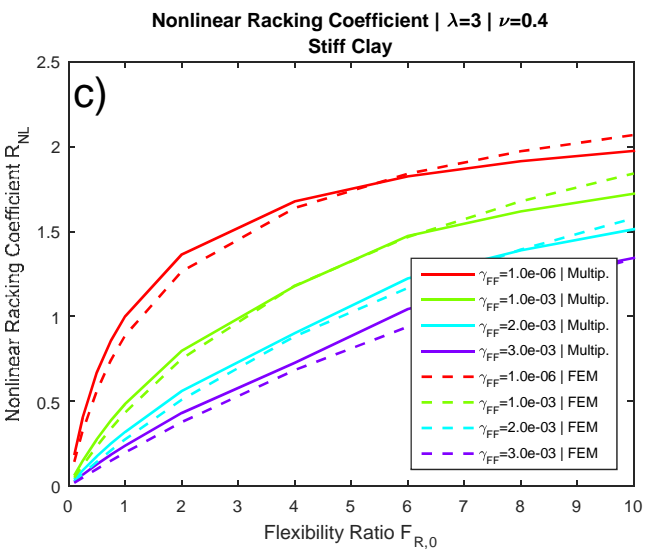

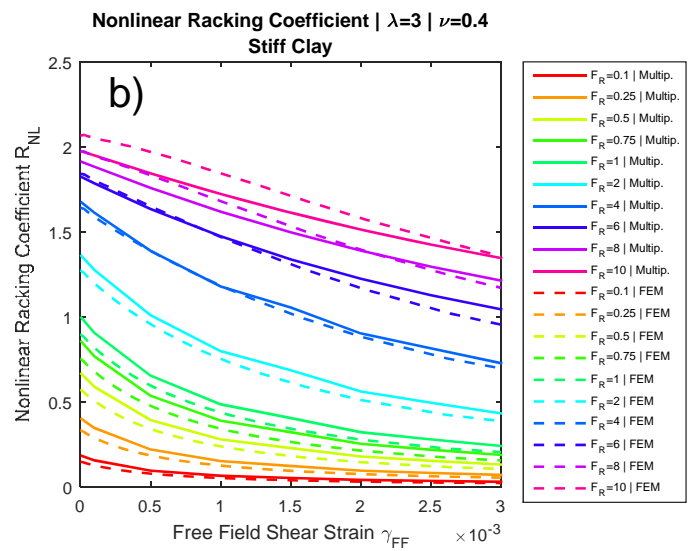

$\mathbf{R}_{\mathrm{NL}} \operatorname{Error}|\lambda=3| \nu=0.4$

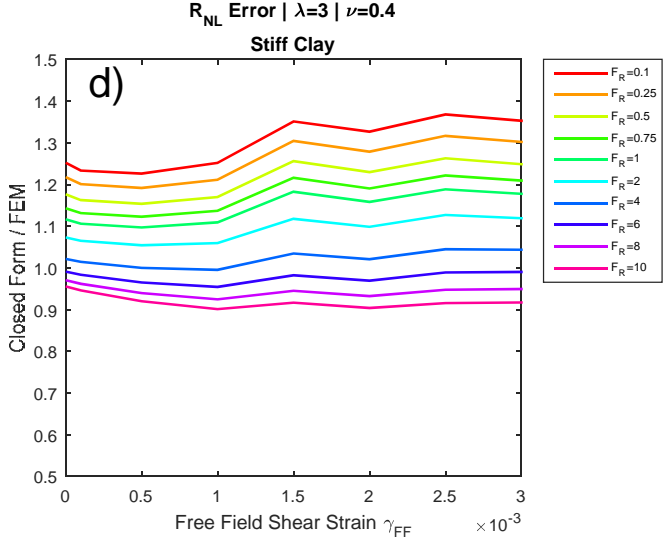

Fig. B-27. Distorsión no lineal para terreno rígido, proporción geométrica $\lambda=b / d=3$, y $v=0,4$. 


\section{RESULTADOS EN FUNCIÓN DE LA PROFUNDIDAD}

En este apéndice se recopilan las figuras resumidas en el capítulo §7 de esta tesis.

\section{C.1 Resultados del Coeficiente de Racking $R_{z}$ y de la relación $R_{z} / R_{\text {Deep }}$}
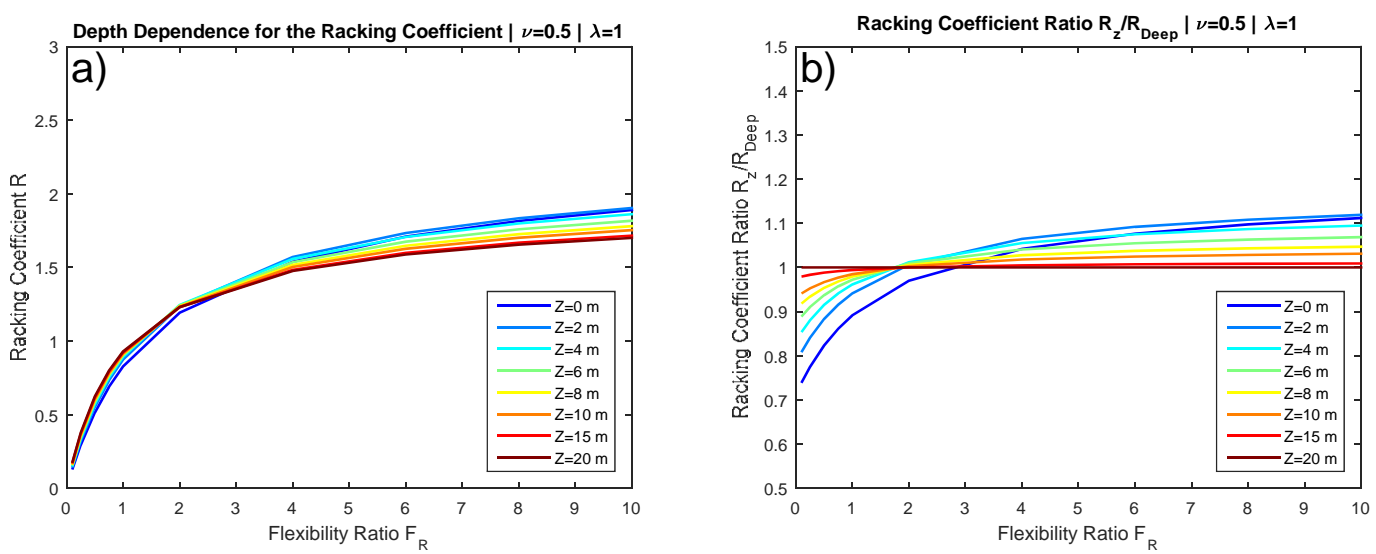

Fig. C-1. Influencia de la profundidad para $v=0,5$ y $\lambda=b / d=1$. (a) Coeficiente de racking $R$. (b) Ratio entre el coeficiente de racking $R_{\mathrm{z}}$ a la profundidad $\mathrm{z}, \mathrm{y}$ el coeficiente de racking profundo $\boldsymbol{R}_{\text {Deep }}$.
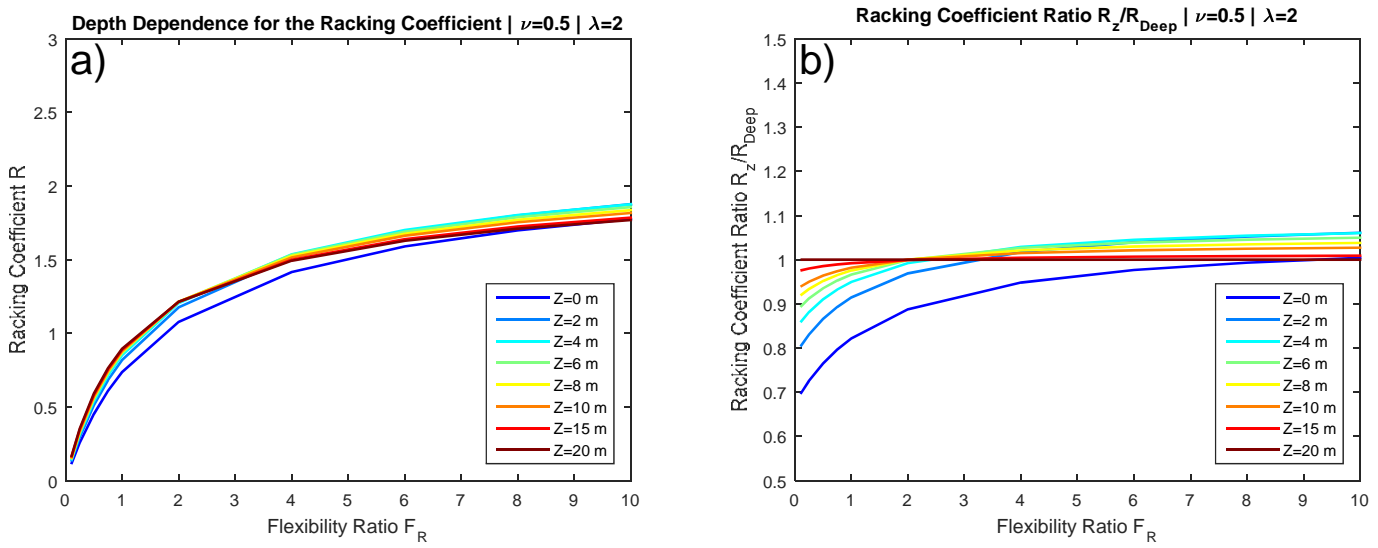

Fig. C-2. Influencia de la profundidad para $v=0,5$ y $\lambda=b / d=2$. (a) Coeficiente de racking $R$. (b) Ratio entre el coeficiente de racking $R_{\mathrm{z}}$ a la profundidad $\mathrm{z}, \mathrm{y}$ el coeficiente de racking profundo $\boldsymbol{R}_{\text {Deep }}$. 

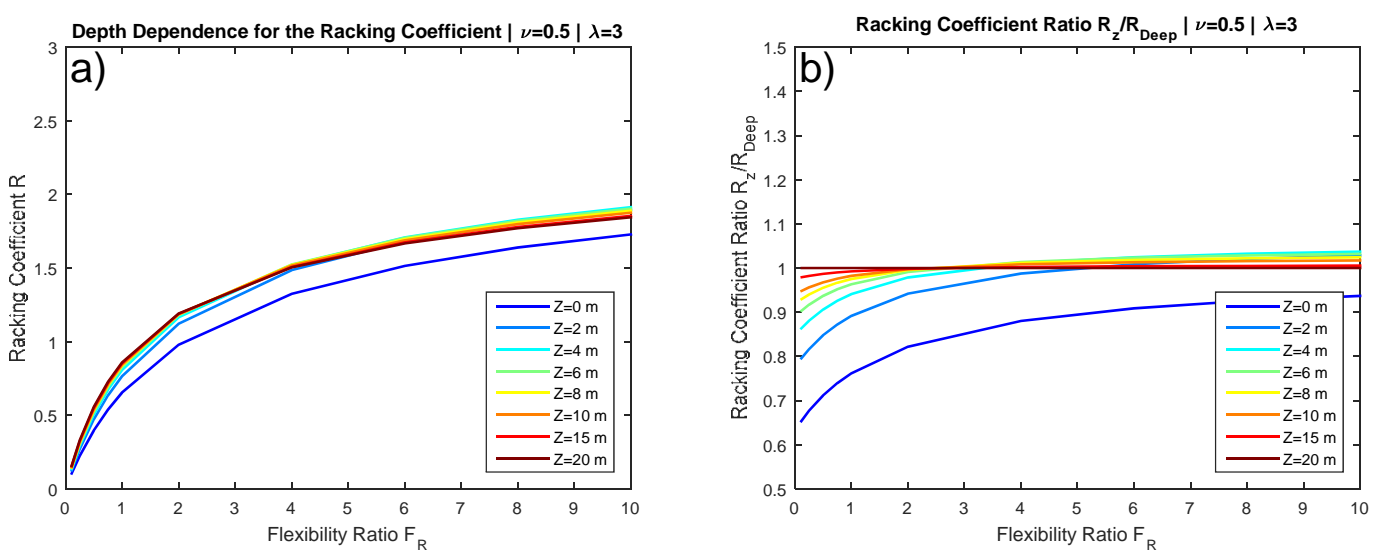

Fig. C-3. Influencia de la profundidad para $v=0,5$ y $\lambda=b / d=3$. (a) Coeficiente de racking $R$. (b) Ratio entre el coeficiente de racking $R_{z}$ a la profundidad $z, y$ el coeficiente de racking profundo $R_{\text {Deep }}$.
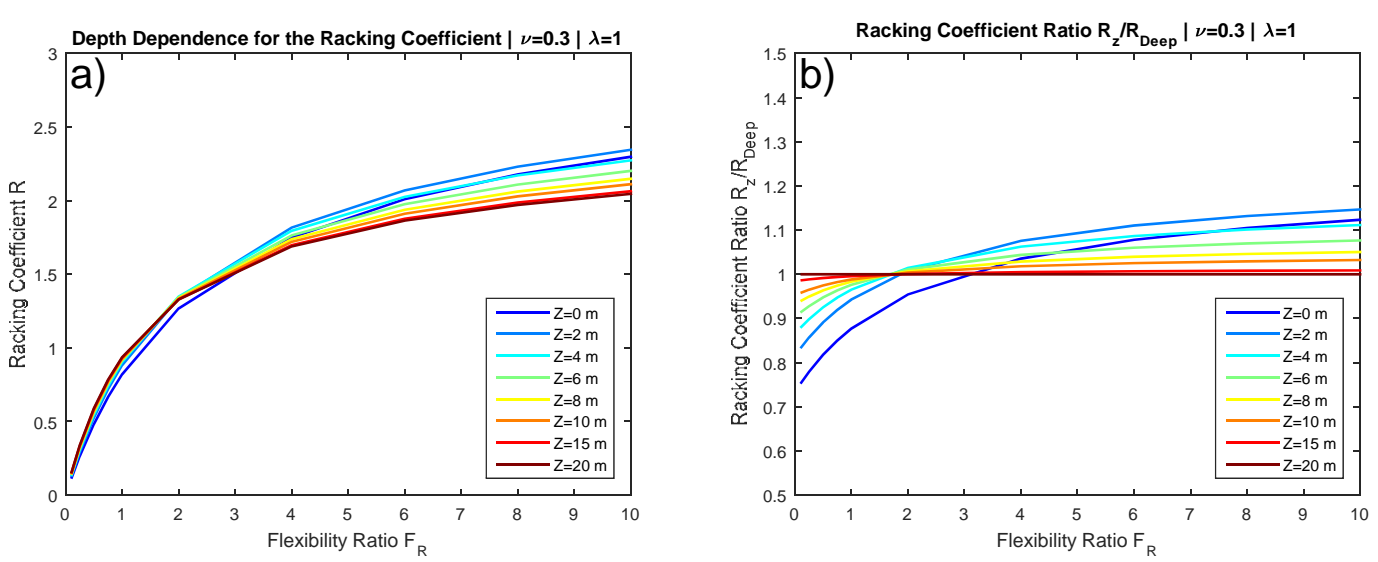

Fig. C-4. Influencia de la profundidad para $v=0,3$ y $\lambda=b / d=1$. (a) Coeficiente de racking $R$. (b) Ratio entre el coeficiente de racking $R_{z}$ a la profundidad $z$, y el coeficiente de racking profundo $R_{D e e p}$.
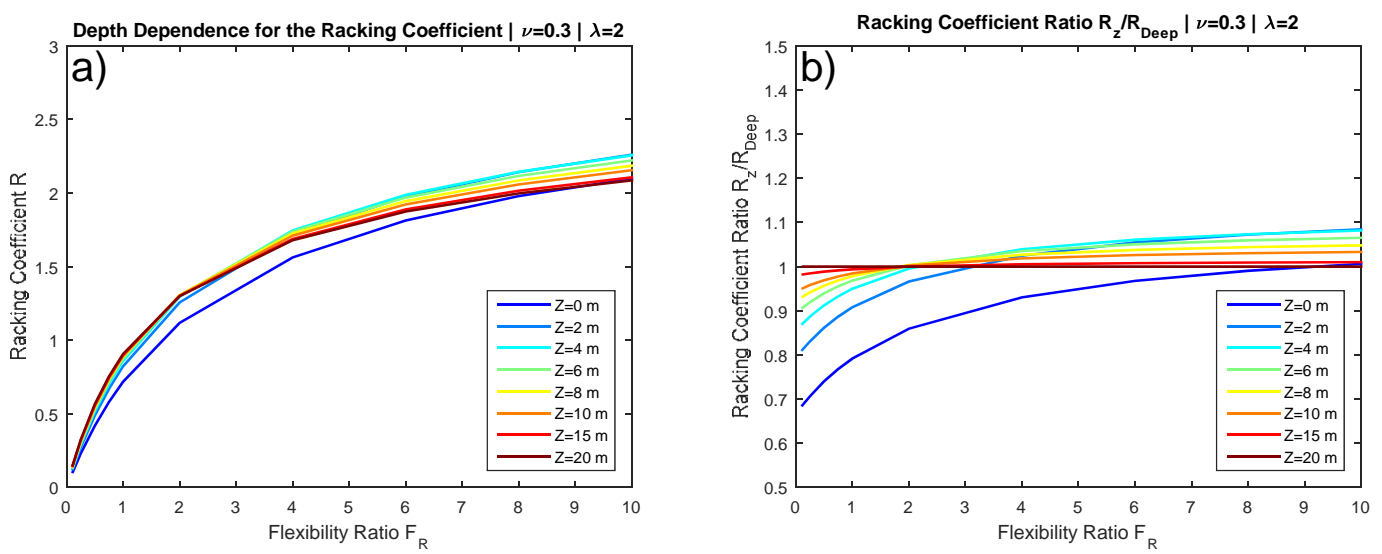

Fig. C-5. Influencia de la profundidad para $v=0,3$ y $\lambda=b / d=2$. (a) Coeficiente de racking $R$. (b) Ratio entre el coeficiente de racking $R_{z}$ a la profundidad $z$, y el coeficiente de racking profundo $R_{D e e p}$. 

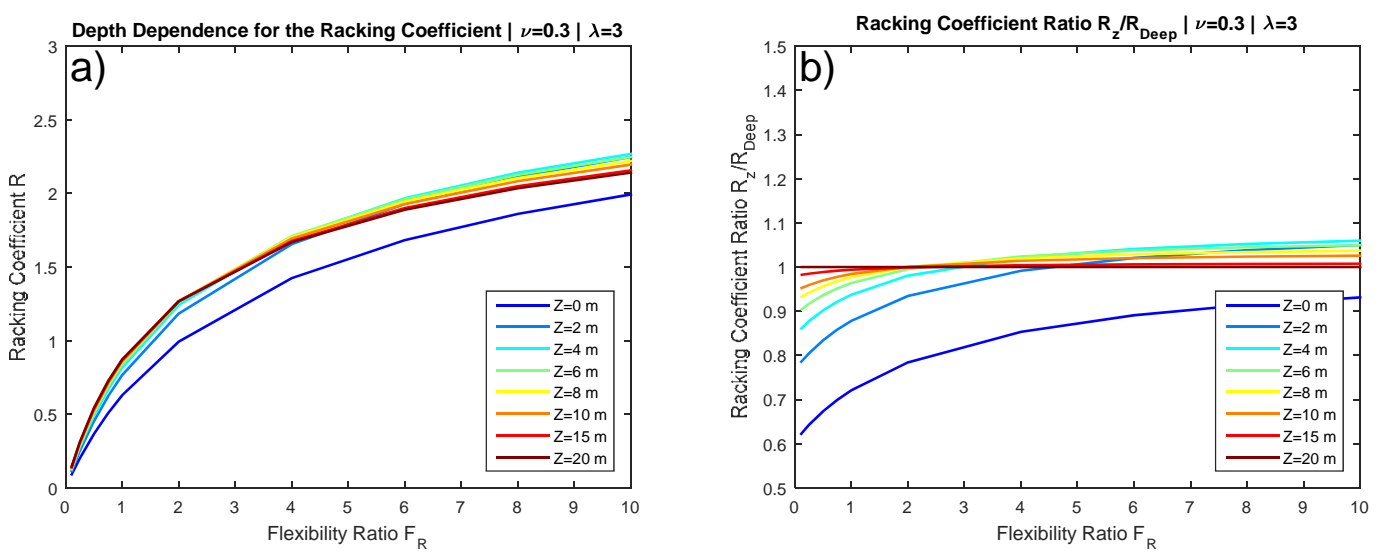

Fig. C-6. Influencia de la profundidad para $v=0,3$ y $\lambda=b / d=3$. (a) Coeficiente de racking $R$. (b) Ratio entre el coeficiente de racking $R_{z}$ a la profundidad z, y el coeficiente de racking profundo $R_{D e e p}$. 


\section{C.2 Resultados de Momentos Flectores}

\section{C.2.1 Profundidad $Z=0 \mathrm{~m}$}

\section{C.2.1.1 Profundidad $\mathrm{Z}=0 \mathrm{~m}$ y proporción geométrica $\lambda=1$}
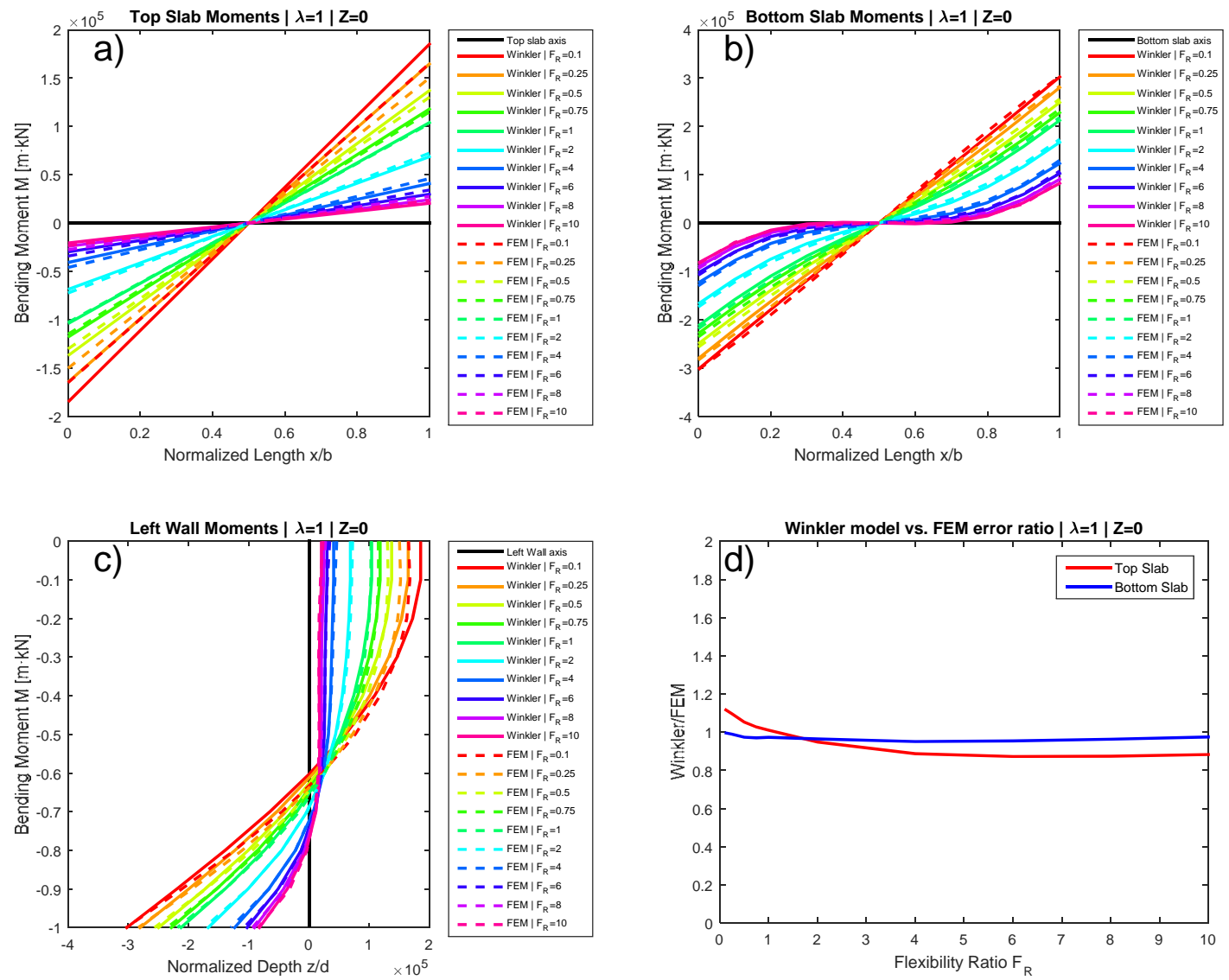

Fig. C-7. Momentos flectores para profundidad $Z=0 \mathrm{~m}$ y proporción geométrica $\lambda=b / d=1$. (a) En losa superior. (b) En muro lateral izquierdo, (c) En losa inferior. (d) Ratio Winkler/MEF. 


\section{C.2.1.2 Profundidad $Z=0 \mathrm{~m}$ y proporción geométrica $\lambda=2$}
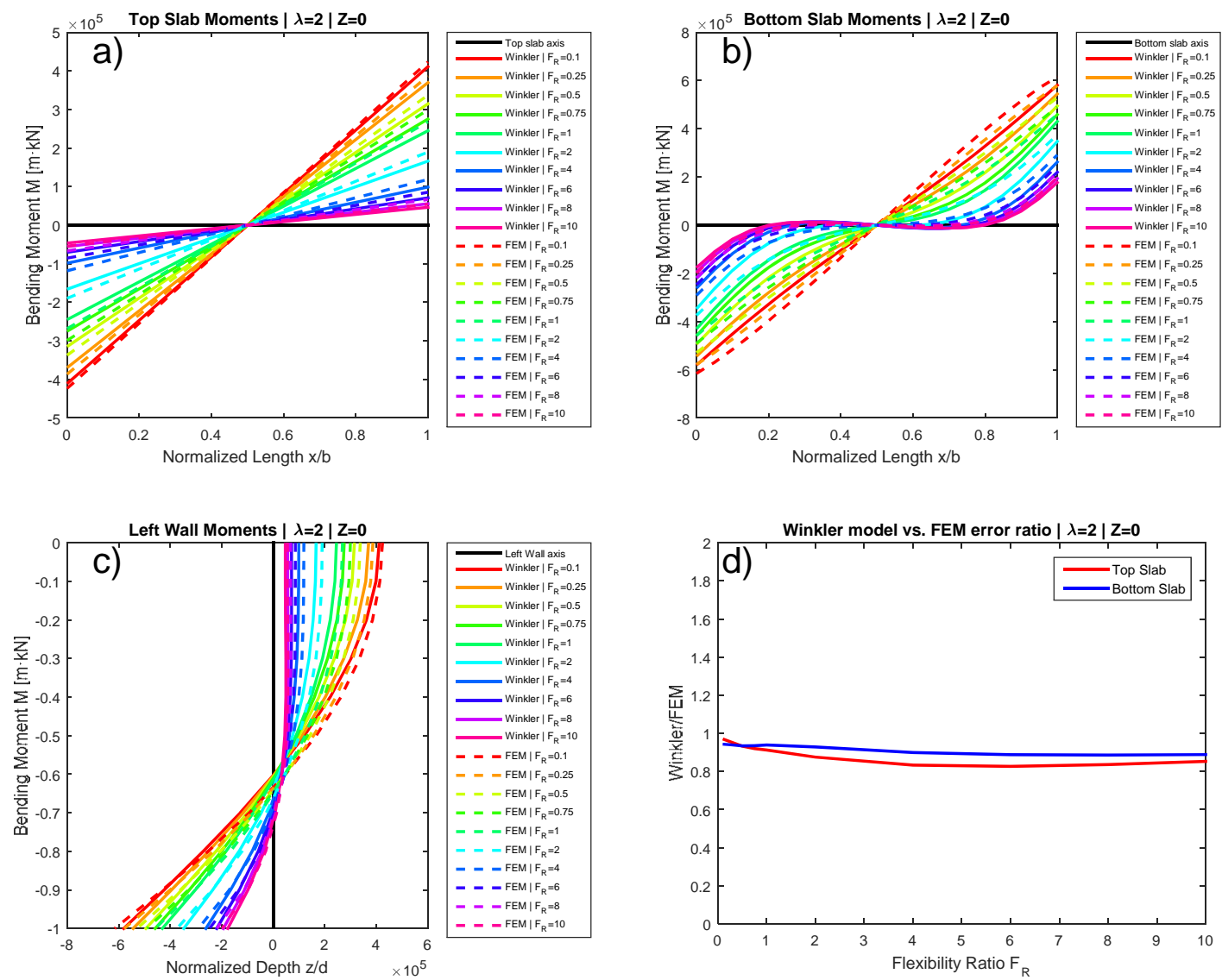

Fig. C-8. Momentos flectores para profundidad $Z=0 \mathrm{~m}$ y proporción geométrica $\lambda=b / d=2$. (a) En losa superior. (b) En muro lateral izquierdo, (c) En losa inferior. (d) Ratio Winkler/MEF. 


\section{C.2.1.3 Profundidad $Z=0 \mathrm{~m}$ y proporción geométrica $\lambda=3$}
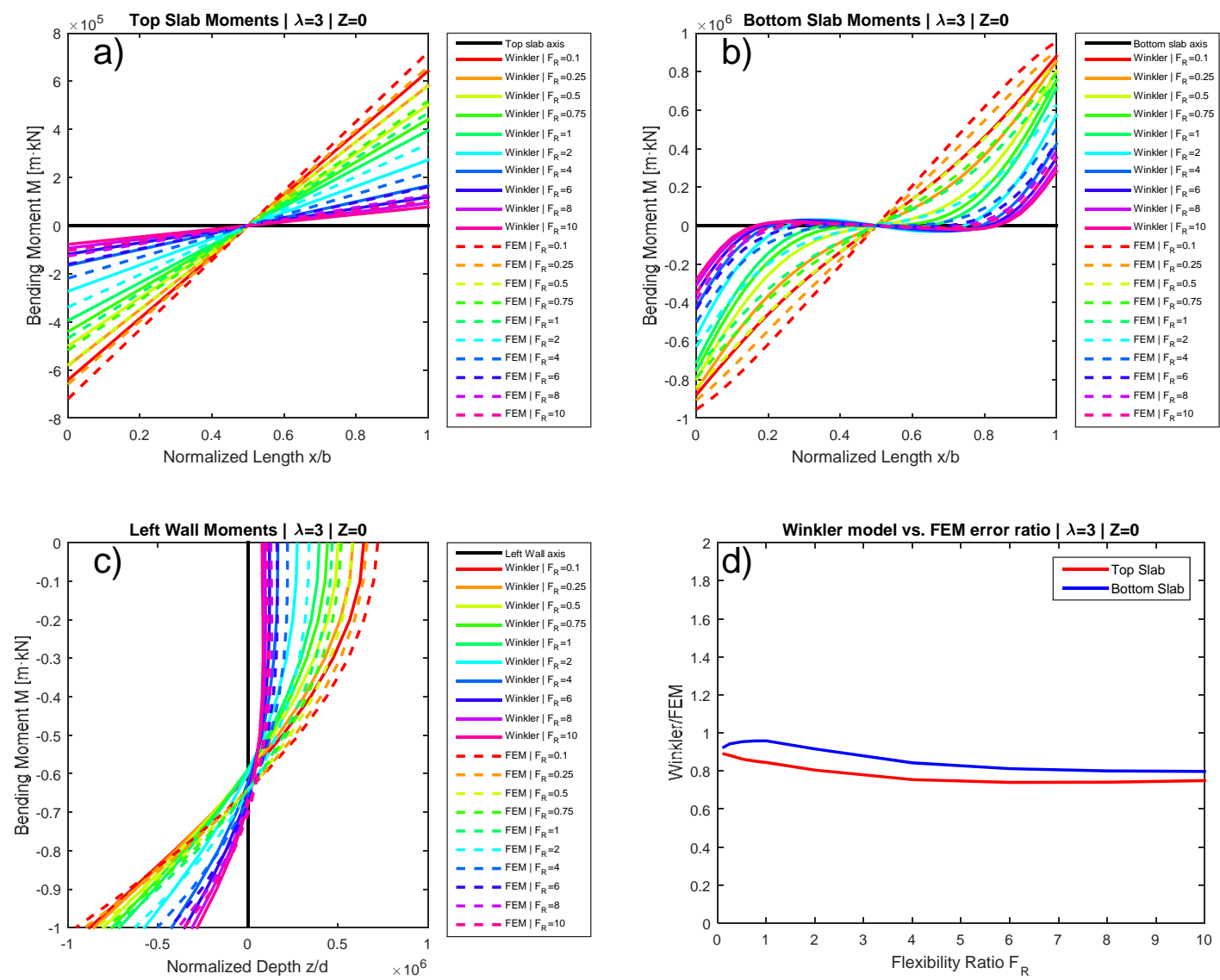

Fig. C-9. Momentos flectores para profundidad $Z=0 \mathrm{~m}$ y proporción geométrica $\lambda=b / d=3$. (a) En losa superior. (b) En muro lateral izquierdo, (c) En losa inferior. (d) Ratio Winkler/MEF. 


\section{C.2.2 Profundidad $Z=2 \mathrm{~m}$}

\section{C.2.2.1 Profundidad $Z=2 \mathrm{~m}$ y proporción geométrica $\lambda=1$}
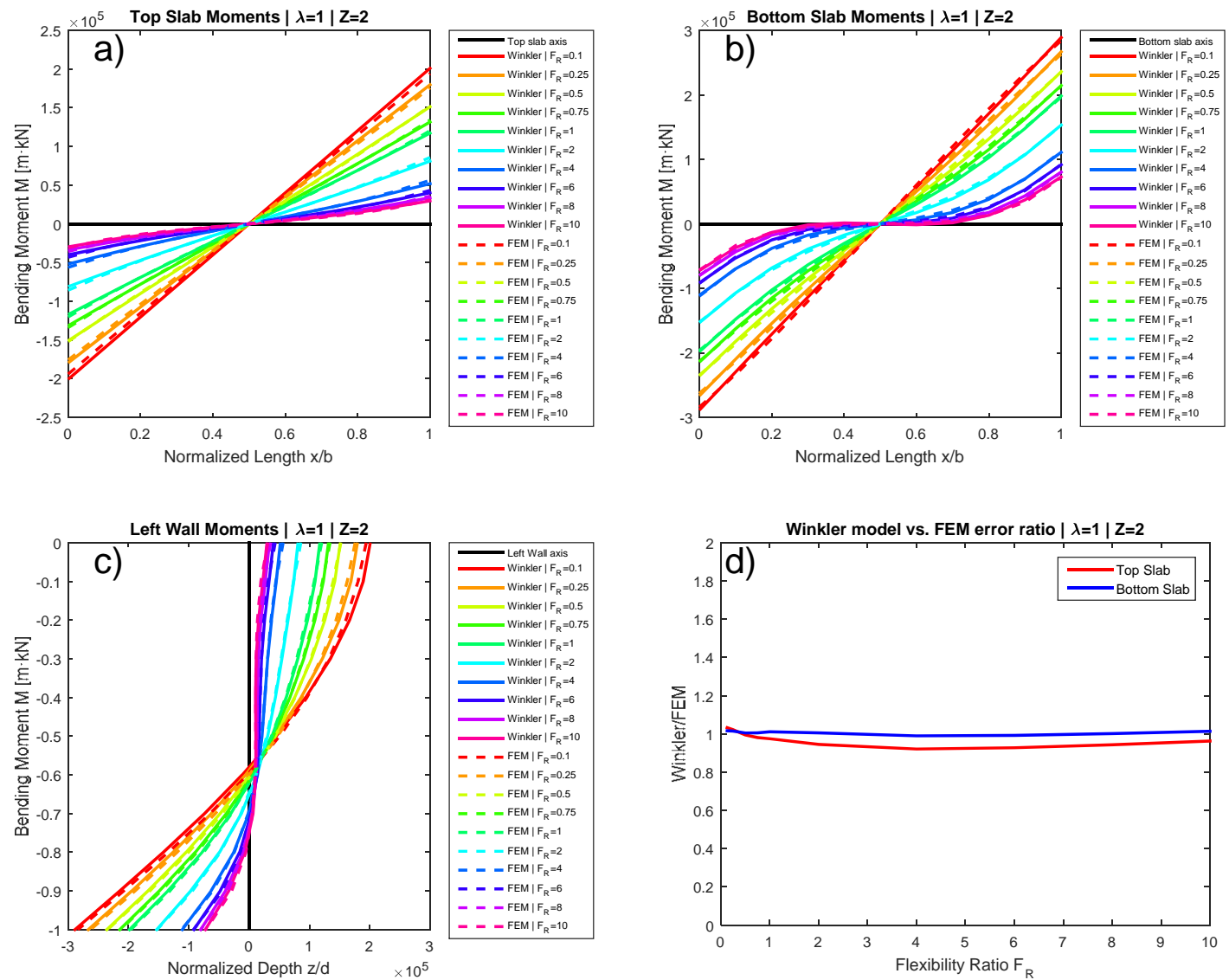

Fig. C-10. Momentos flectores para profundidad $Z=2 \mathrm{~m}$ y proporción geométrica $\lambda=b / d=1$. (a) En losa superior. (b) En muro lateral izquierdo, (c) En losa inferior. (d) Ratio Winkler/MEF. 


\section{C.2.2.2 Profundidad $Z=2 \mathrm{~m}$ y proporción geométrica $\lambda=2$}
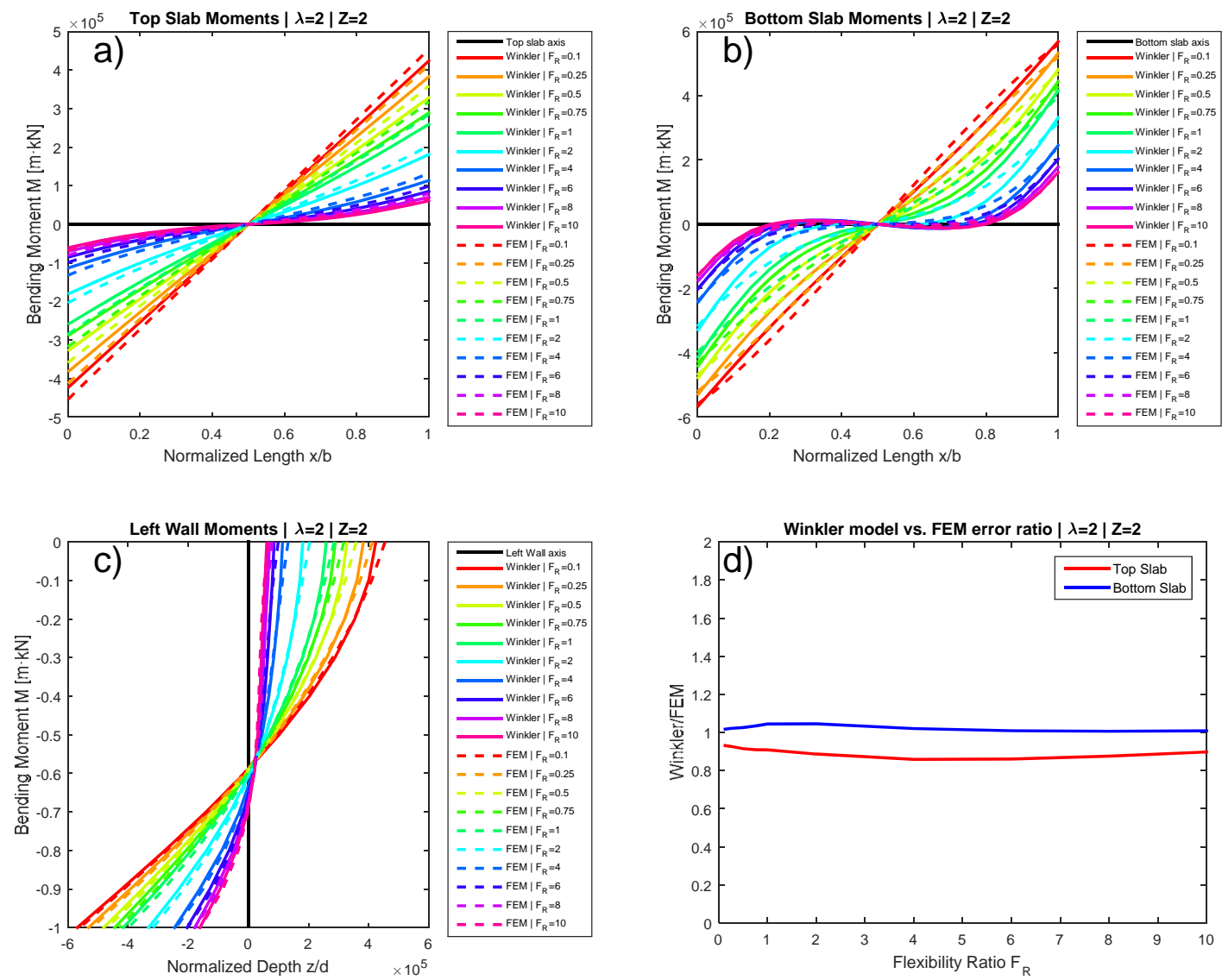

Fig. C-11. Momentos flectores para profundidad $Z=2 \mathrm{~m}$ y proporción geométrica $\lambda=b / d=2$. (a) En losa superior. (b) En muro lateral izquierdo, (c) En losa inferior. (d) Ratio Winkler/MEF. 


\section{C.2.2.3 Profundidad $Z=2 \mathrm{~m}$ y proporción geométrica $\lambda=3$}
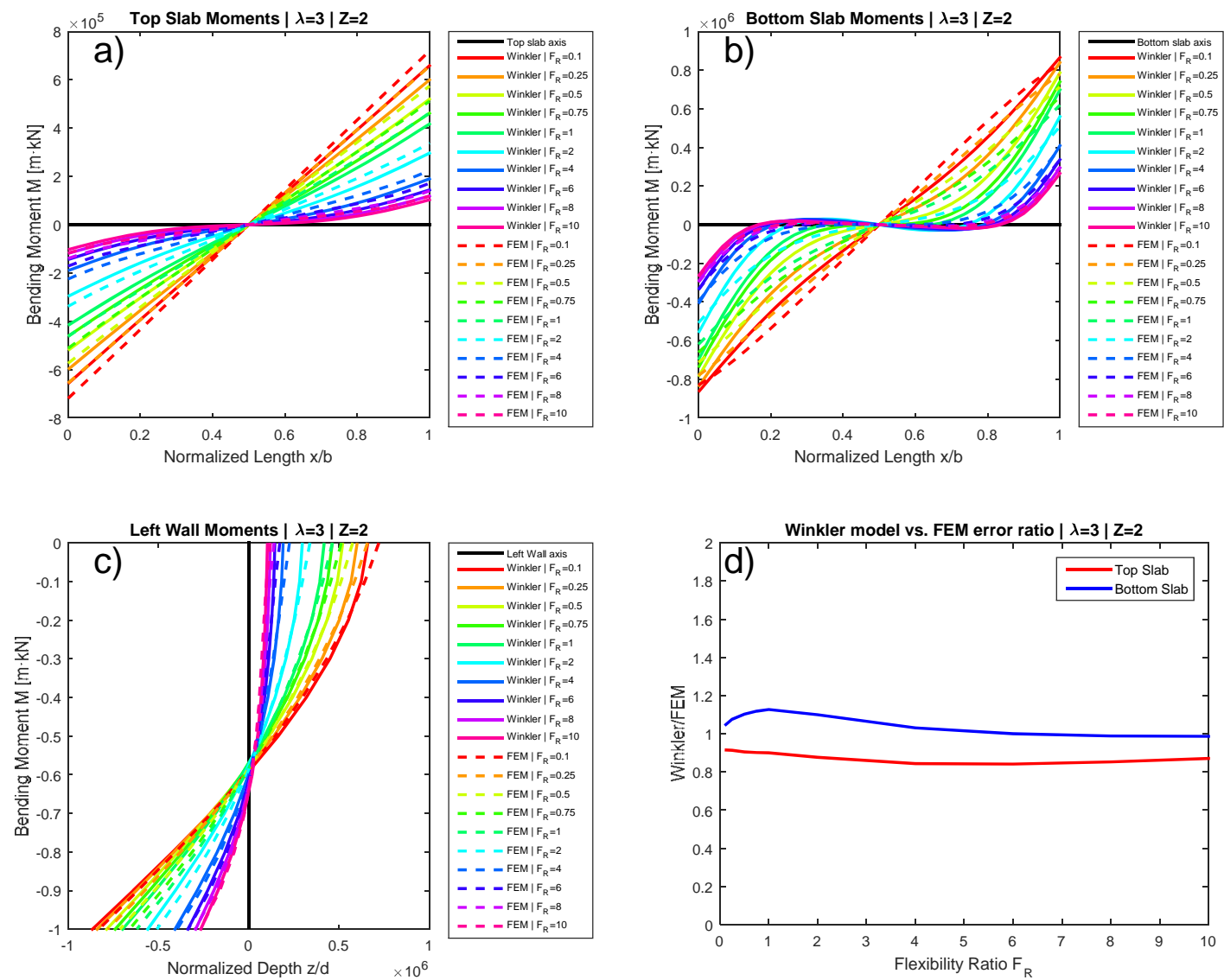

Fig. C-12. Momentos flectores para profundidad $Z=2 \mathrm{~m}$ y proporción geométrica $\lambda=b / d=3$. (a) En losa superior. (b) En muro lateral izquierdo, (c) En losa inferior. (d) Ratio Winkler/MEF. 


\section{C.2.3 Profundidad $Z=4 \mathrm{~m}$}

\section{C.2.3.1 Profundidad $Z=4 \mathrm{~m}$ y proporción geométrica $\lambda=1$}
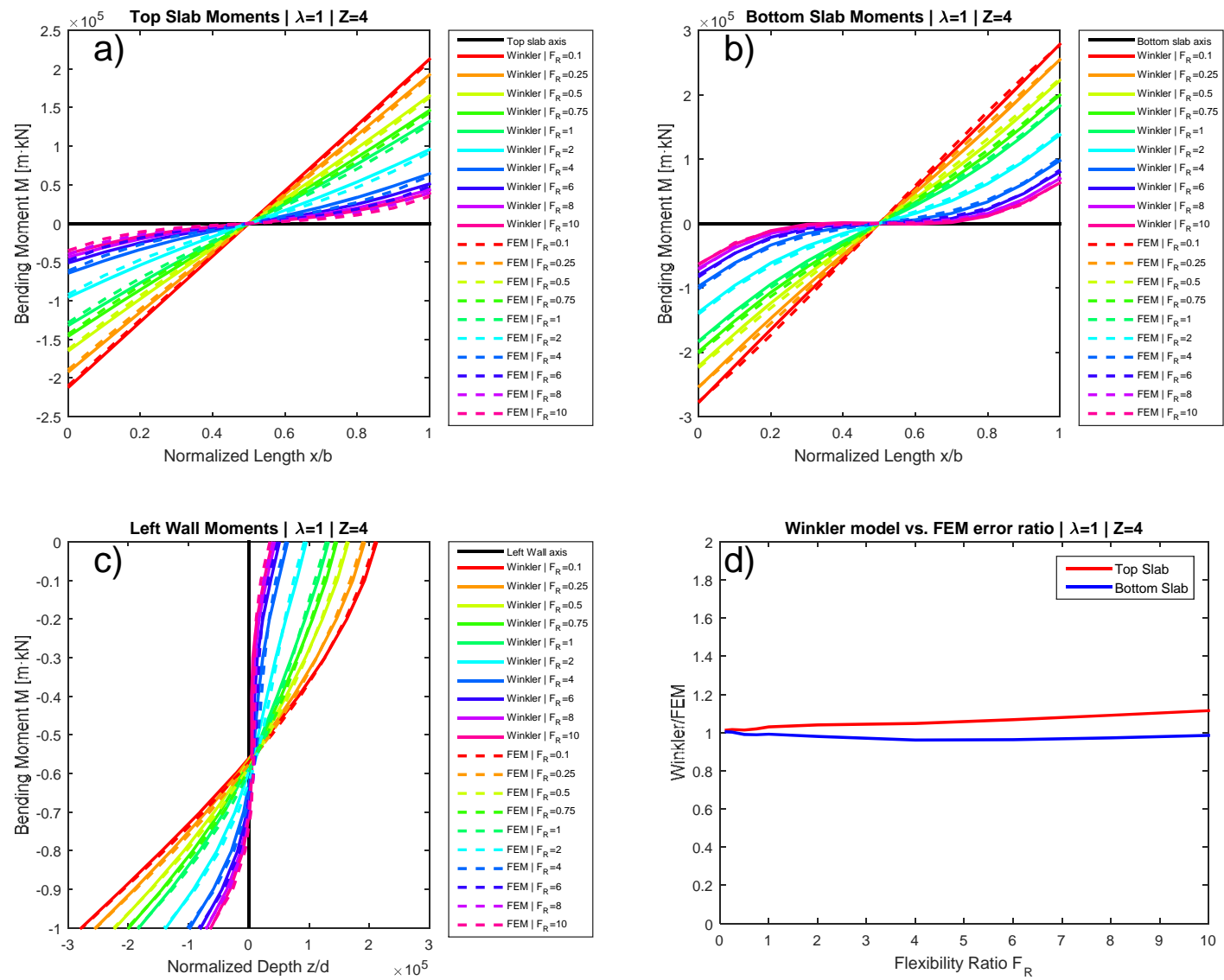

Fig. C-13. Momentos flectores para profundidad $Z=4 \mathrm{~m}$ y proporción geométrica $\lambda=b / d=1$. (a) En losa superior. (b) En muro lateral izquierdo, (c) En losa inferior. (d) Ratio Winkler/MEF. 


\section{C.2.3.2 Profundidad $Z=4 \mathrm{~m}$ y proporción geométrica $\lambda=2$}
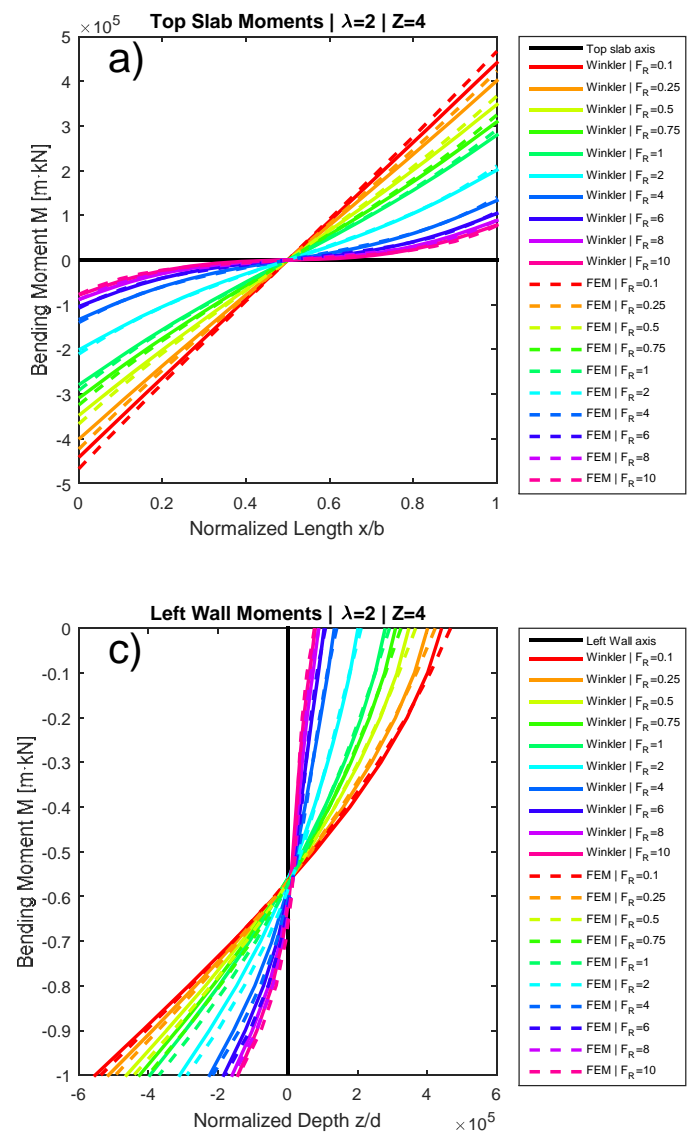
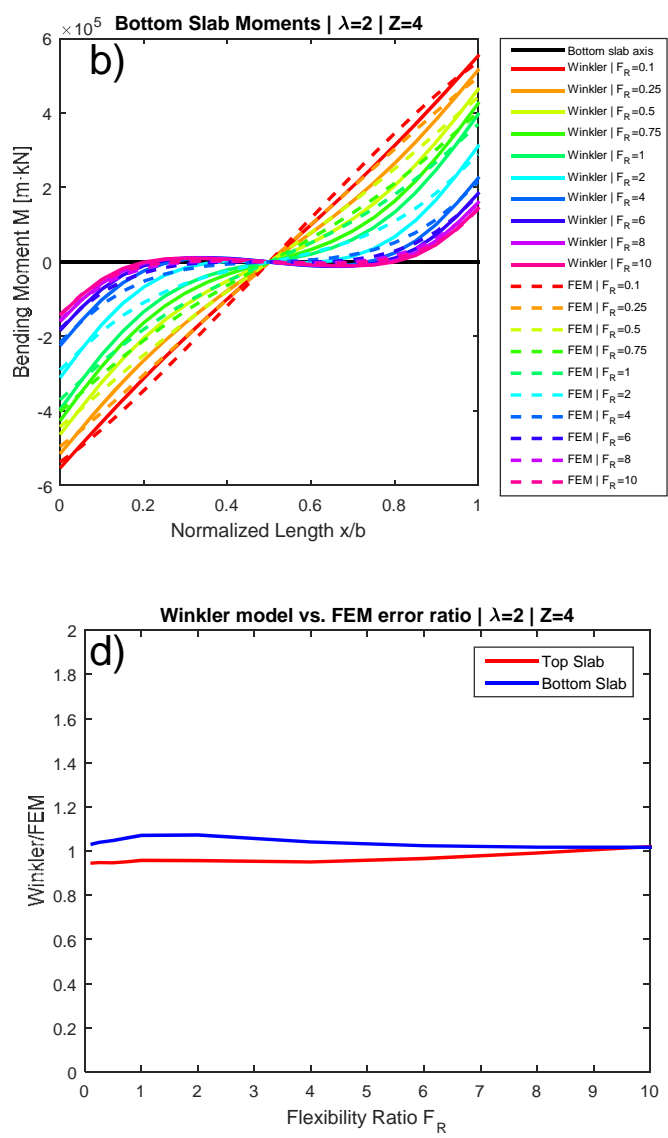

Fig. C-14. Momentos flectores para profundidad $Z=4 \mathrm{~m}$ y proporción geométrica $\lambda=b / d=2$. (a) En losa superior. (b) En muro lateral izquierdo, (c) En losa inferior. (d) Ratio Winkler/MEF. 


\section{C.2.3.3 Profundidad $\mathrm{Z}=4 \mathrm{~m}$ y proporción geométrica $\lambda=3$}
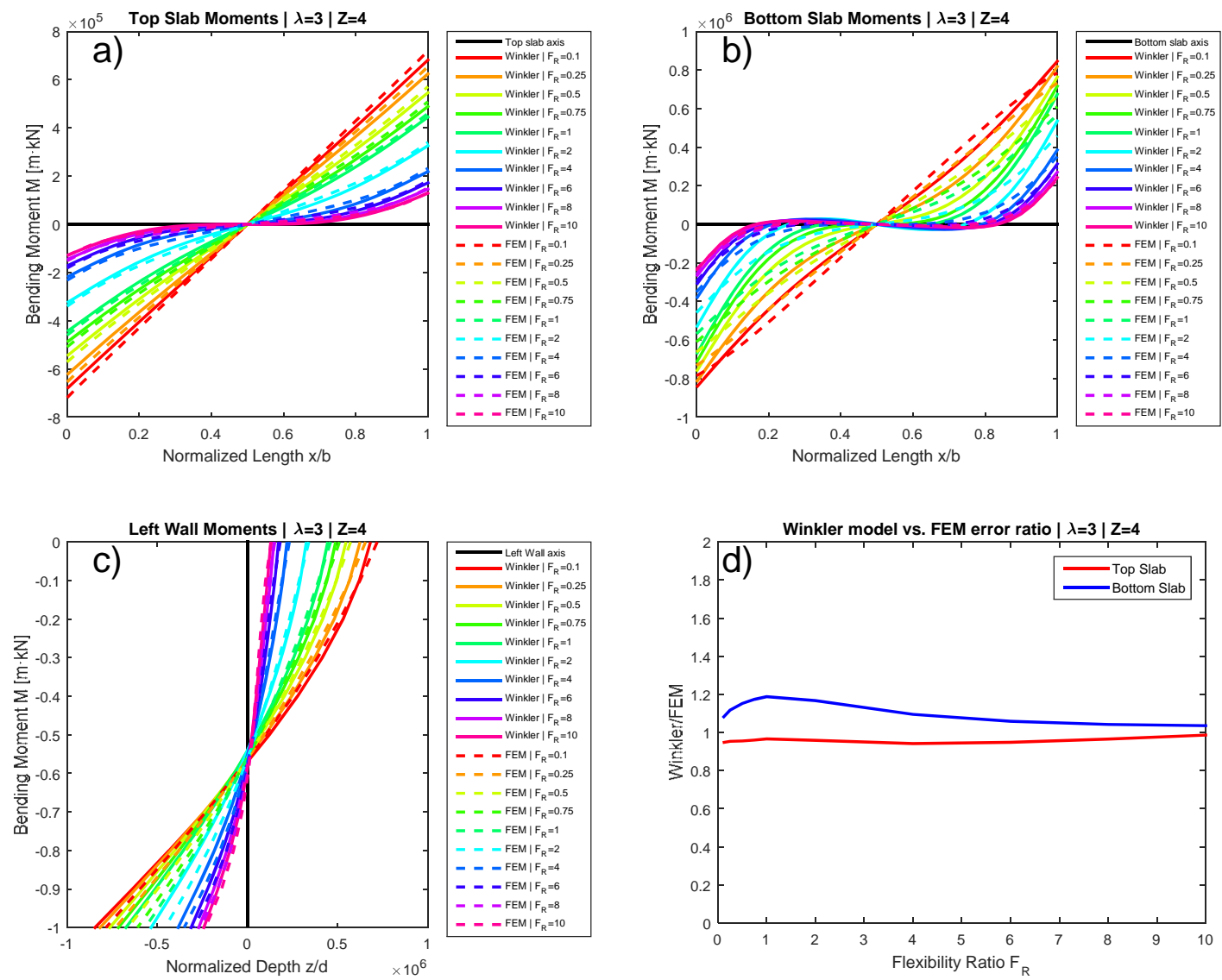

Fig. C-15. Momentos flectores para profundidad $Z=4 \mathrm{~m}$ y proporción geométrica $\lambda=b / d=3$. (a) En losa superior. (b) En muro lateral izquierdo, (c) En losa inferior. (d) Ratio Winkler/MEF. 


\section{C.2.4 Profundidad $Z=6 \mathrm{~m}$}

\section{C.2.4.1 Profundidad $Z=6 \mathrm{~m}$ y proporción geométrica $\lambda=1$}
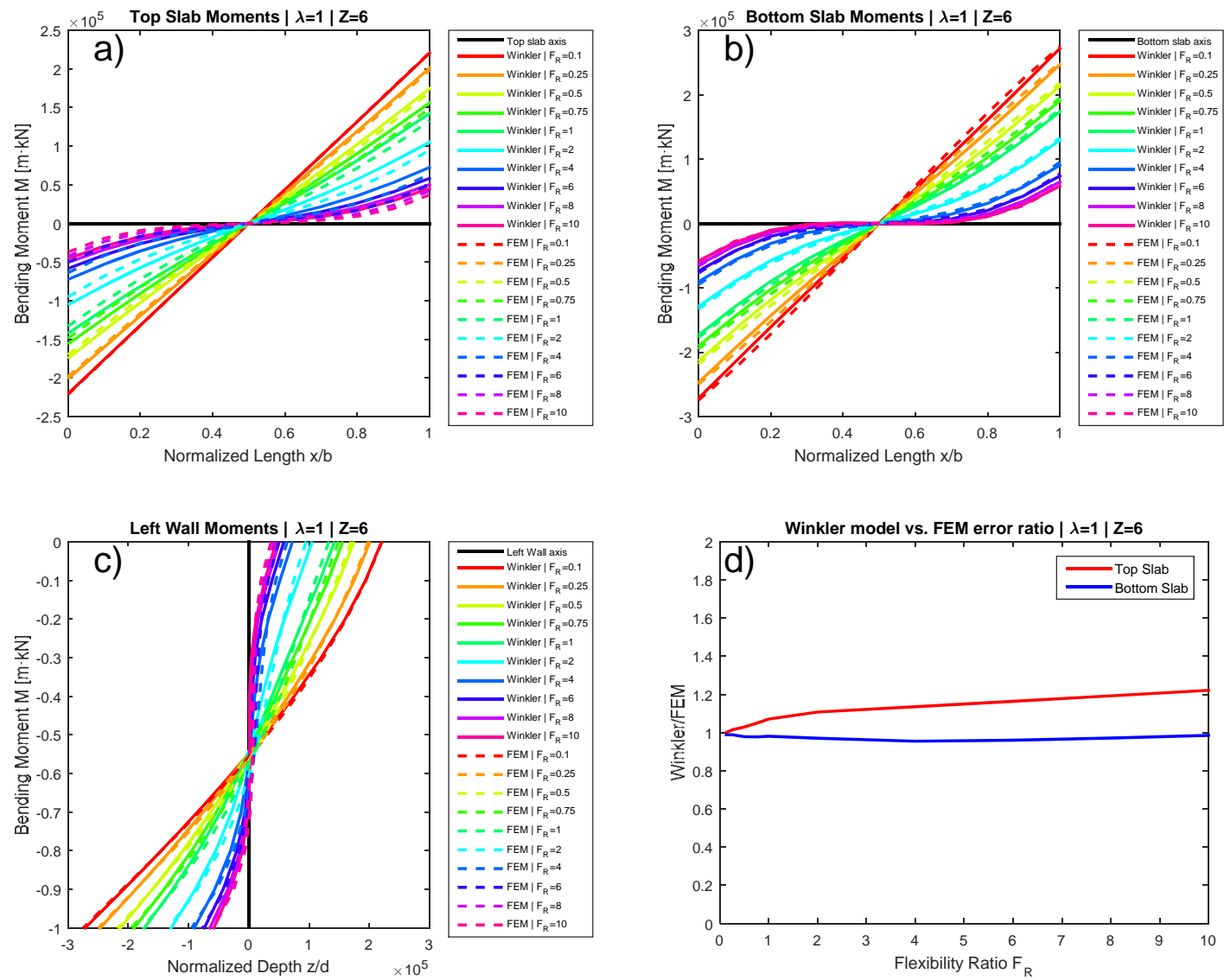

Fig. C-16. Momentos flectores para profundidad $Z=6 \mathrm{~m}$ y proporción geométrica $\lambda=b / d=1$. (a) En losa superior. (b) En muro lateral izquierdo, (c) En losa inferior. (d) Ratio Winkler/MEF. 


\section{C.2.4.2 Profundidad $Z=6 \mathrm{~m}$ y proporción geométrica $\lambda=2$}
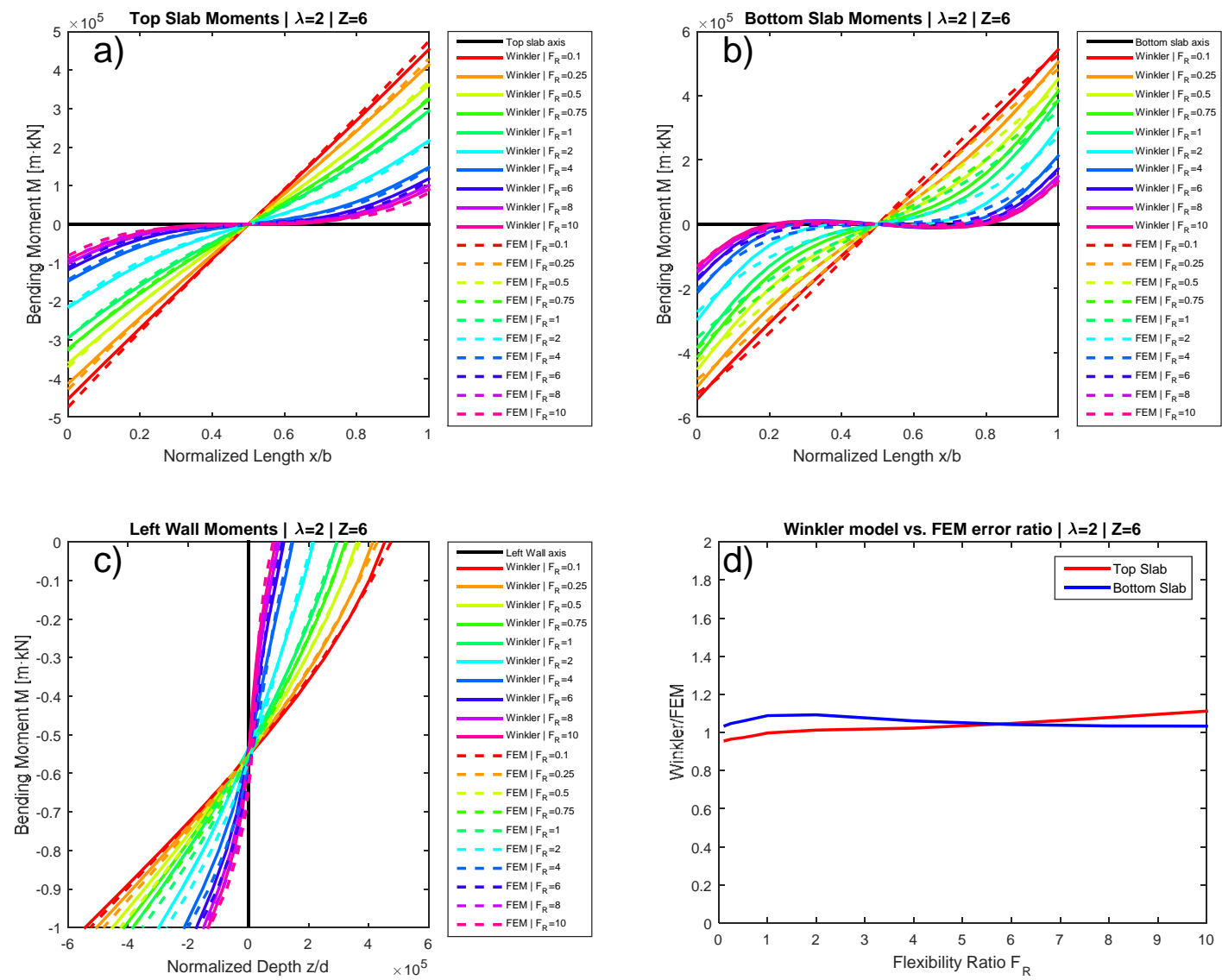

Fig. C-17. Momentos flectores para profundidad $Z=6 \mathrm{~m}$ y proporción geométrica $\lambda=b / d=2$. (a) En losa superior. (b) En muro lateral izquierdo, (c) En losa inferior. (d) Ratio Winkler/MEF. 


\section{C.2.4.3 Profundidad $Z=6 \mathrm{~m}$ y proporción geométrica $\lambda=3$}
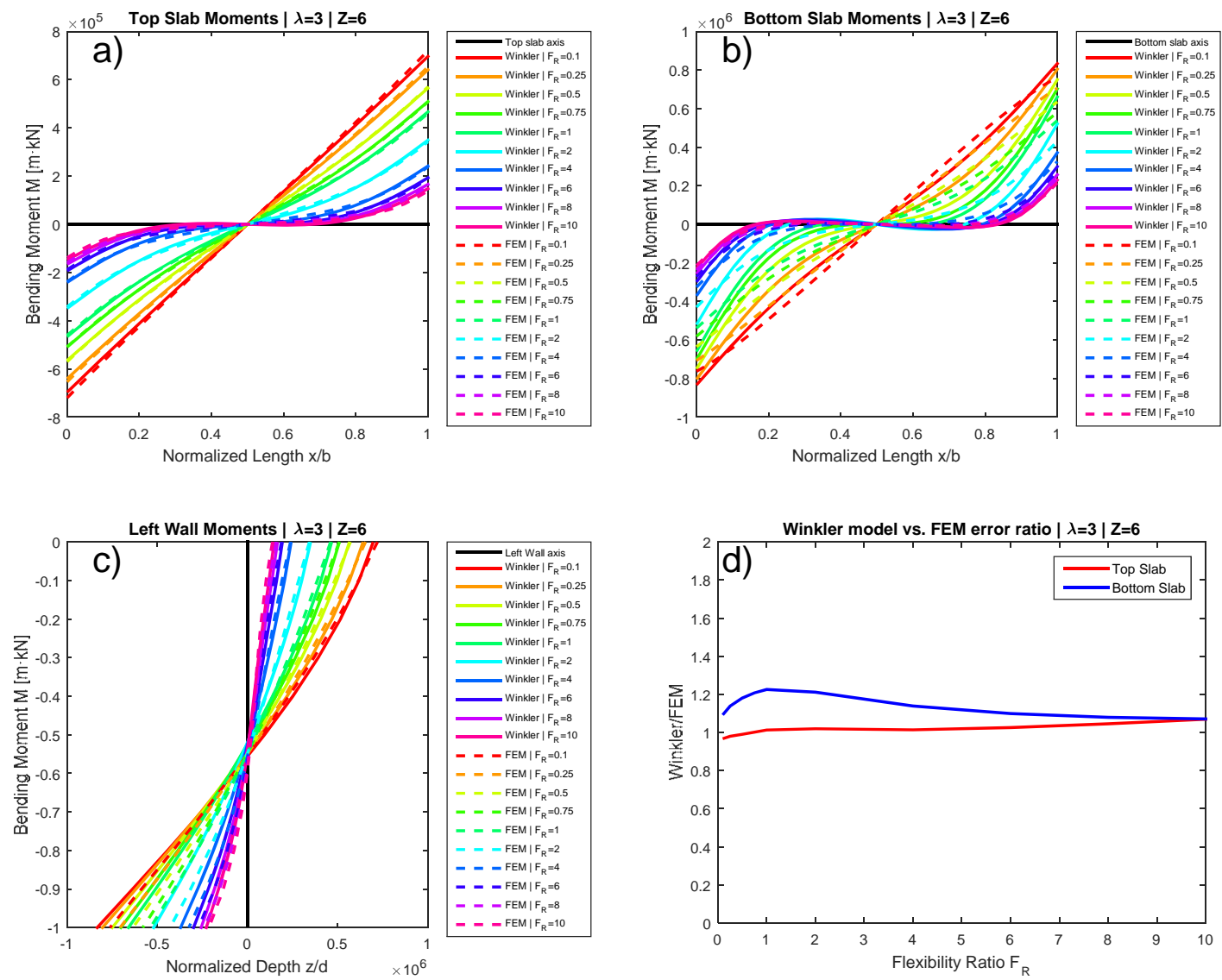

Fig. C-18. Momentos flectores para profundidad $Z=6 \mathrm{~m}$ y proporción geométrica $\lambda=b / d=3$. (a) En losa superior. (b) En muro lateral izquierdo, (c) En losa inferior. (d) Ratio Winkler/MEF. 


\section{C.2.5 Profundidad $Z=8 \mathrm{~m}$}

\section{C.2.5.1 Profundidad $Z=8 \mathrm{~m}$ y proporción geométrica $\lambda=1$}
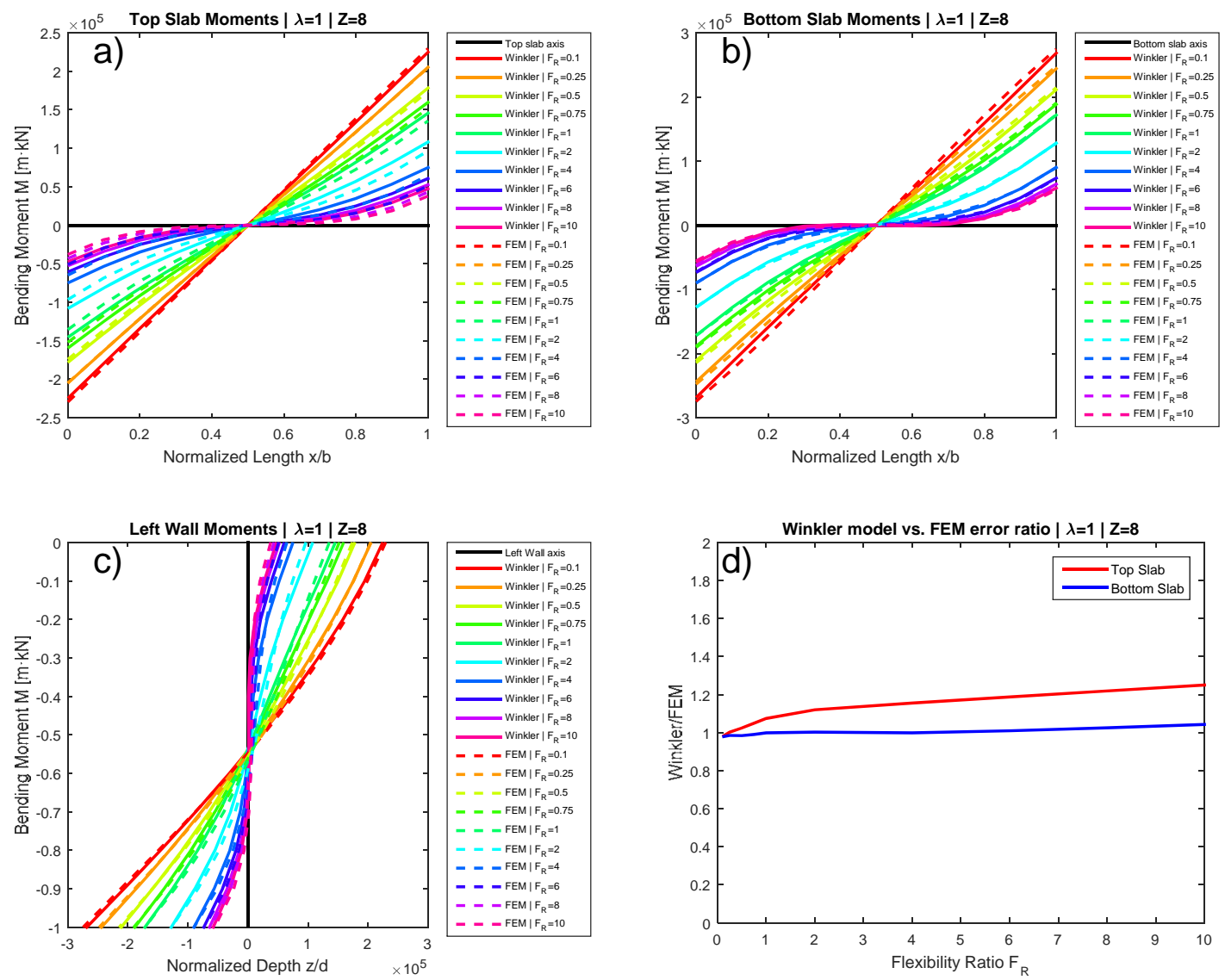

Fig. C-19. Momentos flectores para profundidad $Z=8 \mathrm{~m}$ y proporción geométrica $\lambda=b / d=1$. (a) En losa superior. (b) En muro lateral izquierdo, (c) En losa inferior. (d) Ratio entre momentos obtenidos con el método propuesto en esta tesis y los de análisis numérico MEF. 


\section{C.2.5.2 Profundidad $Z=8 \mathrm{~m}$ y proporción geométrica $\lambda=2$}
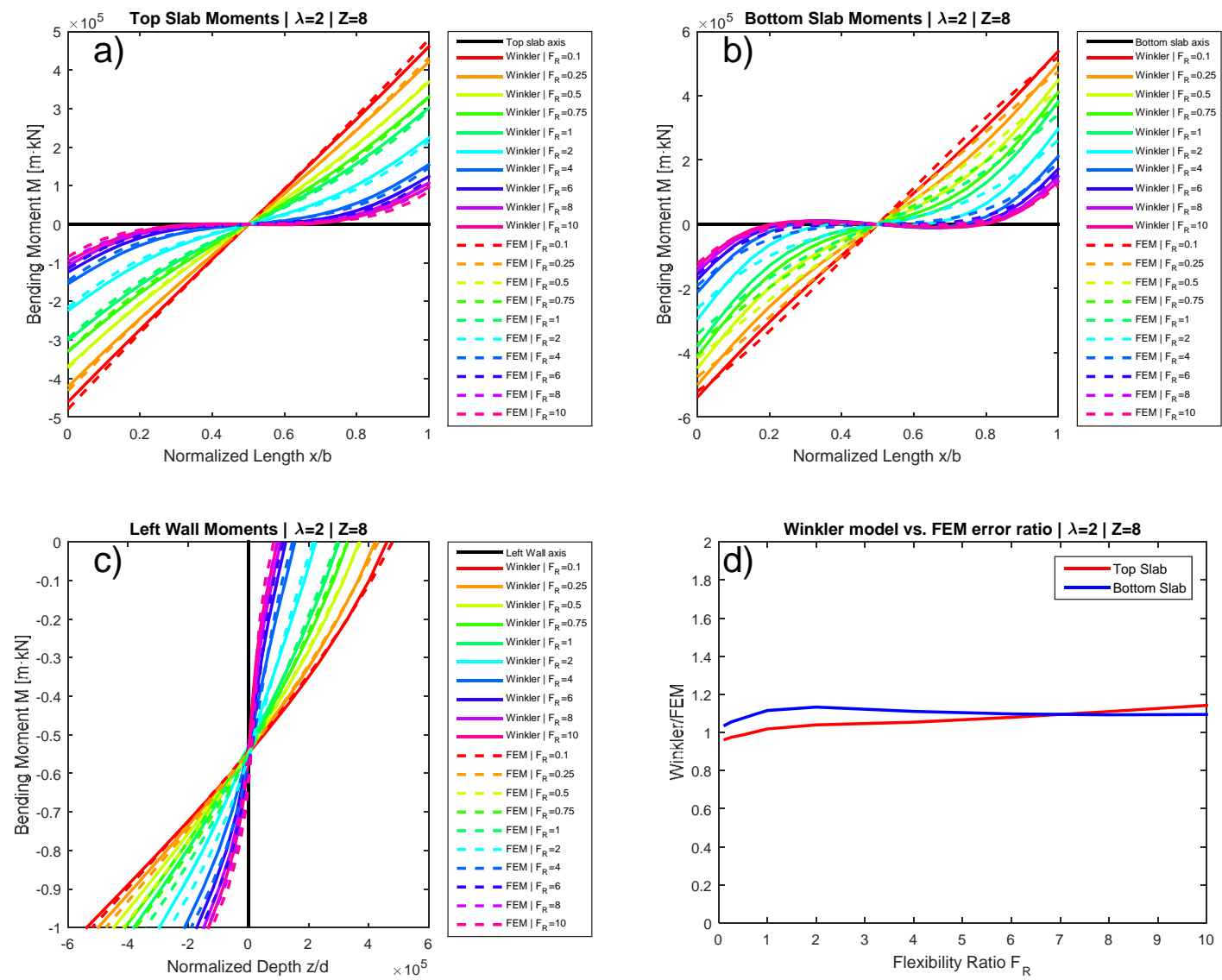

Fig. C-20. Momentos flectores para profundidad $Z=8 \mathrm{~m}$ y proporción geométrica $\lambda=b / d=2$. (a) En losa superior. (b) En muro lateral izquierdo, (c) En losa inferior. (d) Ratio Winkler/MEF. 


\section{C.2.5.3 Profundidad $Z=8 \mathrm{~m}$ y proporción geométrica $\lambda=3$}
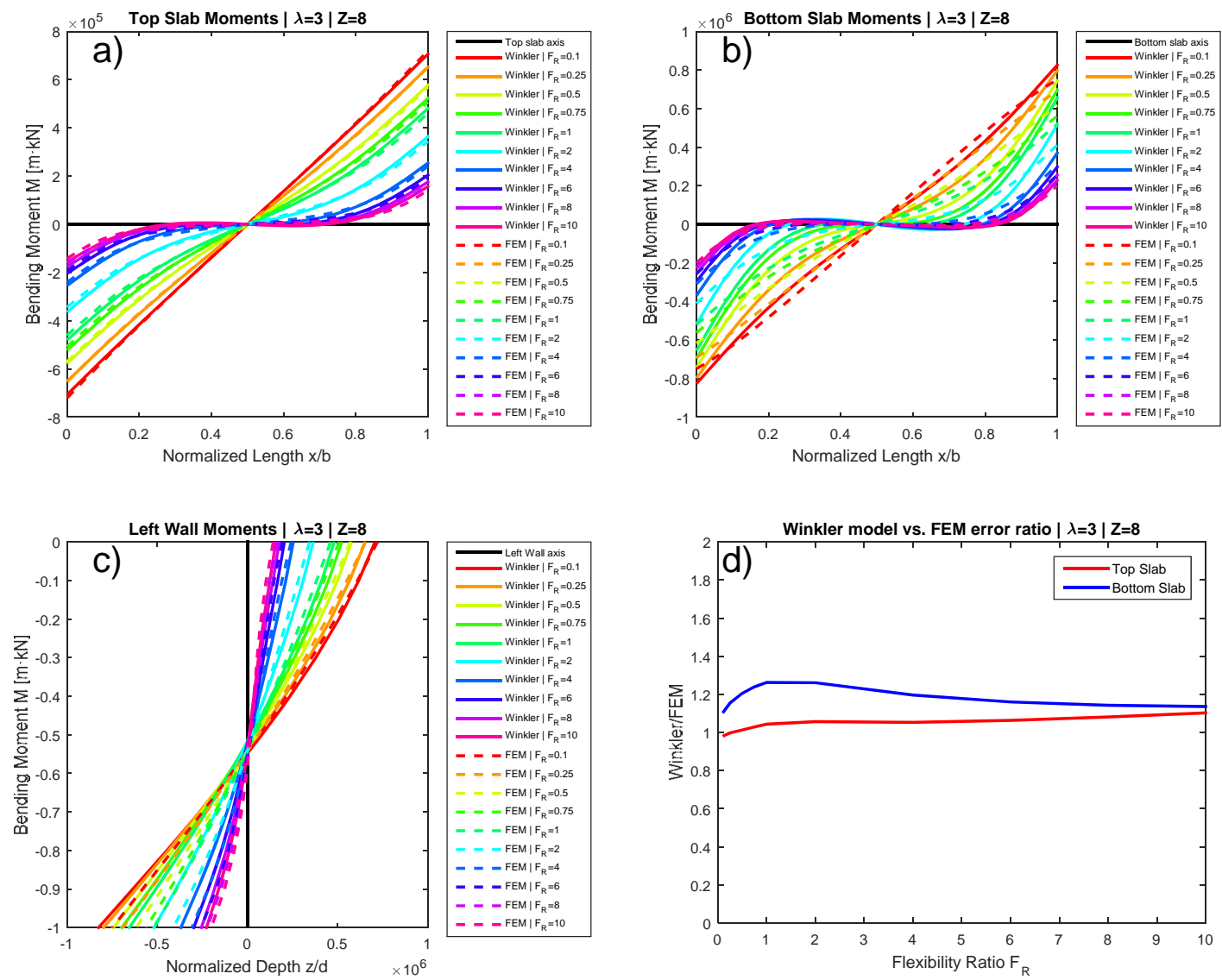

Fig. C-21. Momentos flectores para profundidad $Z=8 \mathrm{~m}$ y proporción geométrica $\lambda=b / d=3$. (a) En losa superior. (b) En muro lateral izquierdo, (c) En losa inferior. (d) Ratio Winkler/MEF. 


\section{C.2.6 Profundidad $Z=10 \mathrm{~m}$}

\section{C.2.6.1 Profundidad $Z=0 \mathrm{~m}$ y proporción geométrica $\lambda=1$}
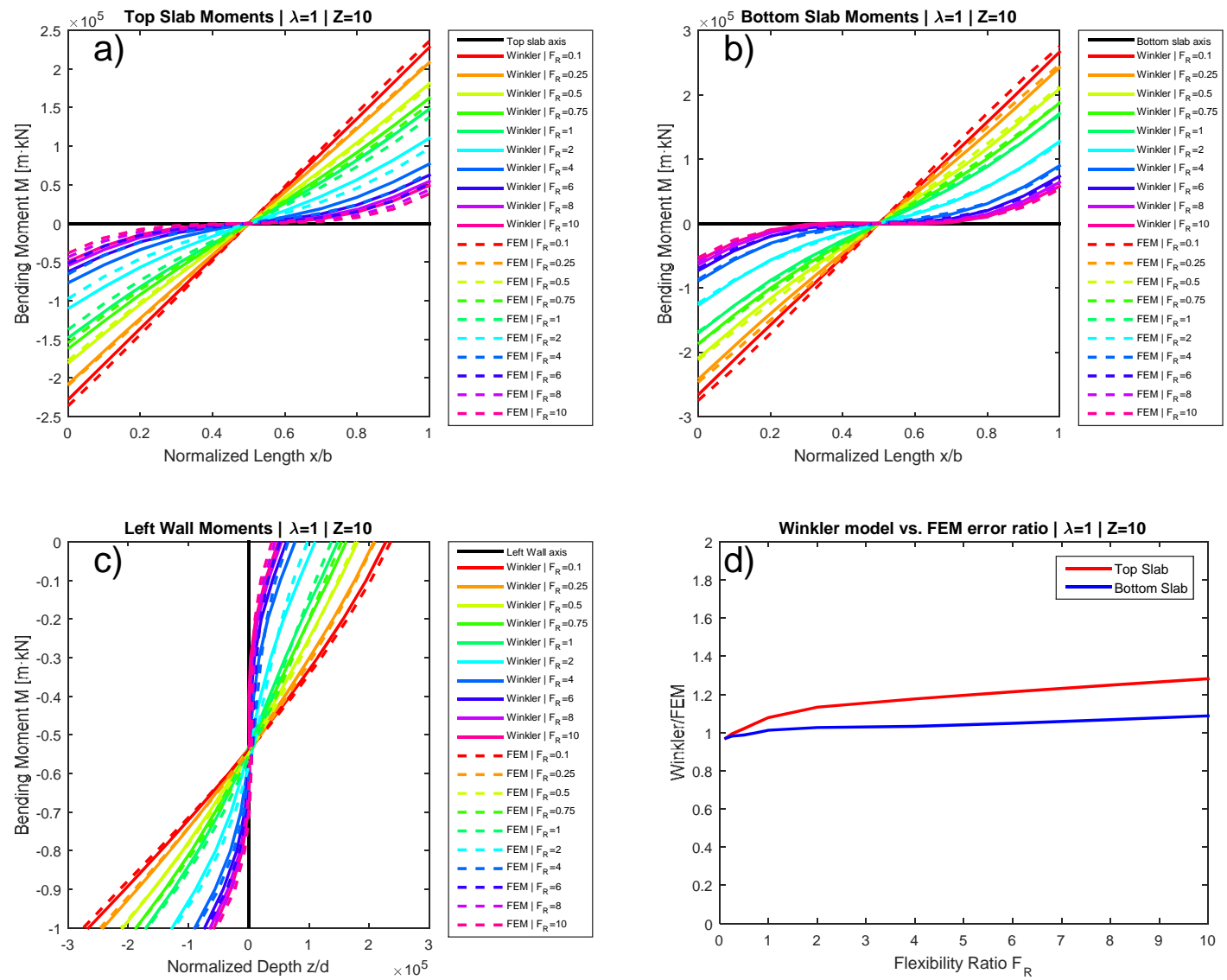

Fig. C-22. Momentos flectores para profundidad $Z=10 \mathrm{~m}$ y proporción geométrica $\lambda=b / d=1$. (a) En losa superior. (b) En muro lateral izquierdo, (c) En losa inferior. (d) Ratio Winkler/MEF. 


\section{C.2.6.2 Profundidad $Z=10 \mathrm{~m}$ y proporción geométrica $\lambda=2$}
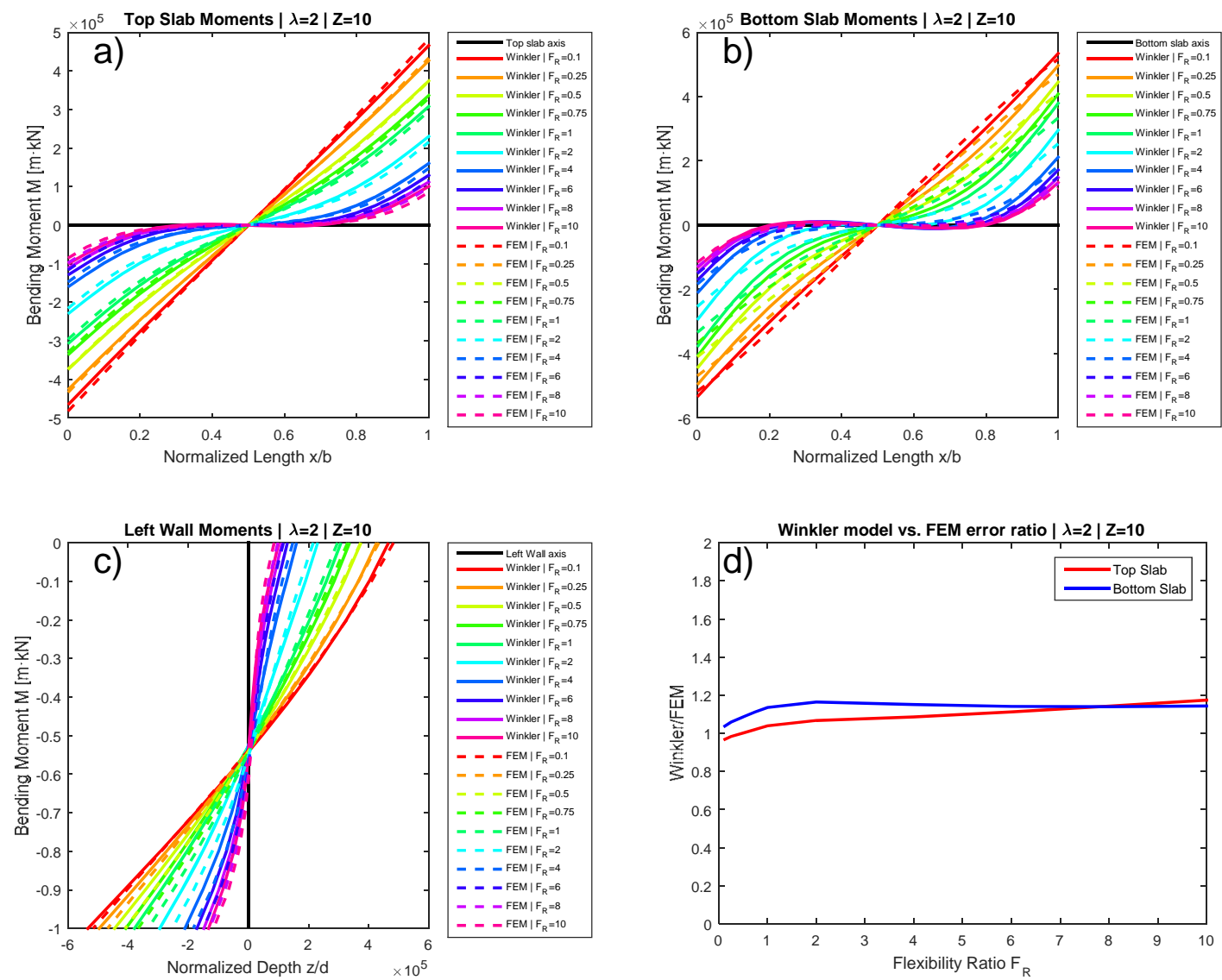

Fig. C-23. Momentos flectores para profundidad $Z=10 \mathrm{~m}$ y proporción geométrica $\lambda=b / d=2$. (a) En losa superior. (b) En muro lateral izquierdo, (c) En losa inferior. (d) Ratio Winkler/MEF. 


\section{C.2.6.3 Profundidad $Z=10 \mathrm{~m}$ y proporción geométrica $\lambda=3$}
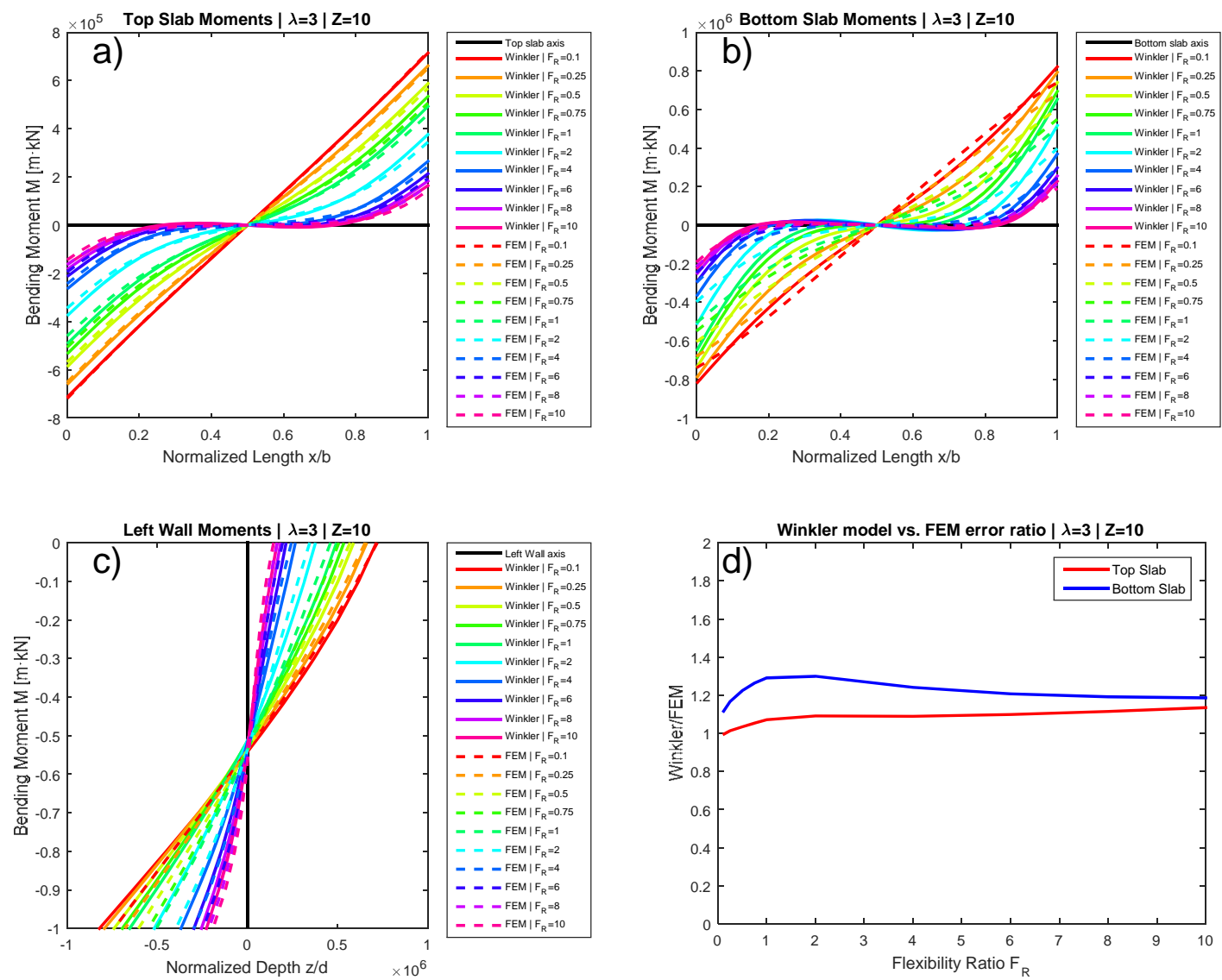

Fig. C-24. Momentos flectores para profundidad $Z=10 \mathrm{~m}$ y proporción geométrica $\lambda=b / d=3$. (a) En losa superior. (b) En muro lateral izquierdo, (c) En losa inferior. (d) Ratio Winkler/MEF. 


\section{C.2.7 Profundidad $Z=15 \mathrm{~m}$}

\section{C.2.7.1 Profundidad $Z=15 \mathrm{~m}$ y proporción geométrica $\lambda=1$}
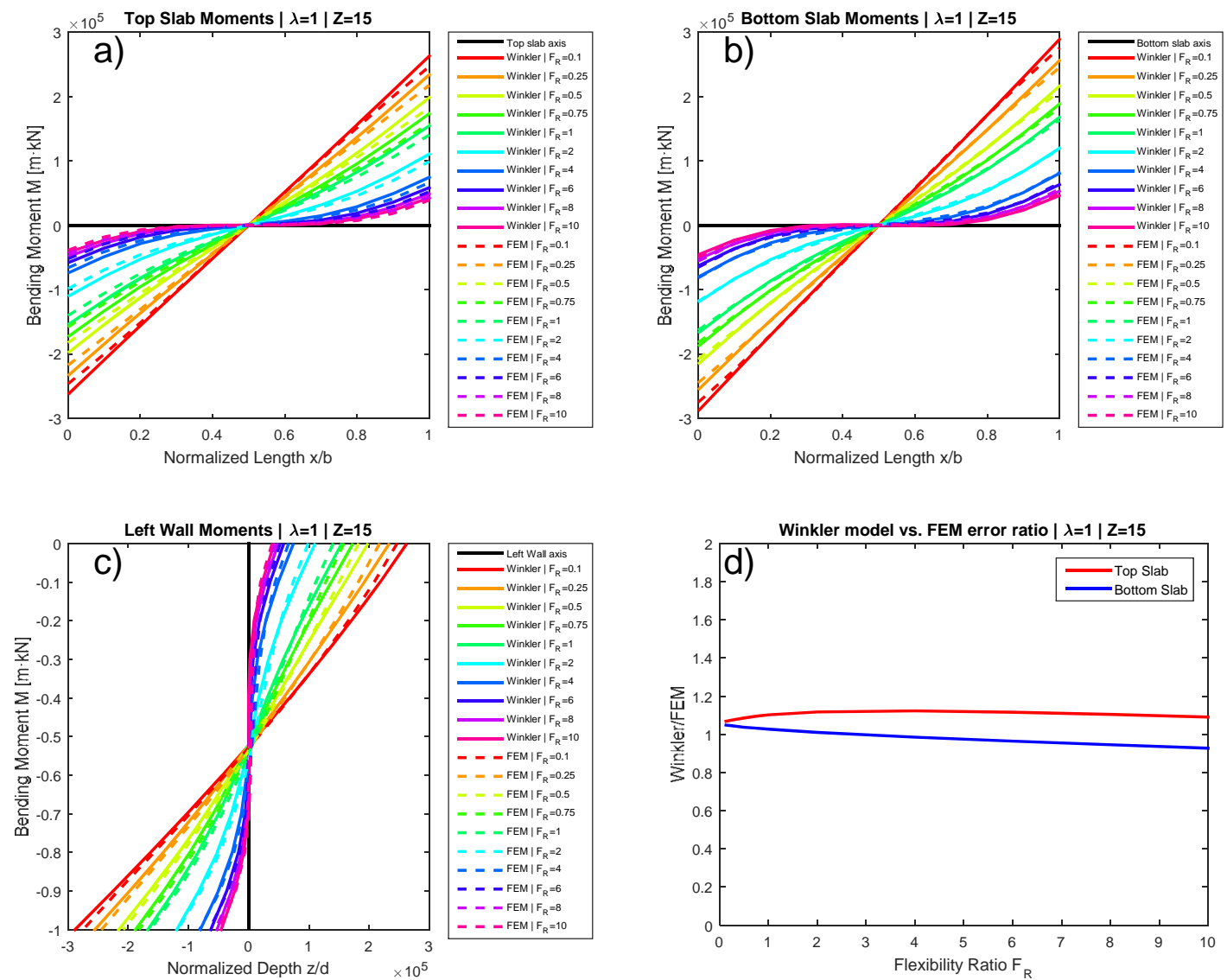

Fig. C-25. Momentos flectores para profundidad $Z=15 \mathrm{~m}$ y proporción geométrica $\lambda=b / d=1$. (a) En losa superior. (b) En muro lateral izquierdo, (c) En losa inferior. (d) Ratio Winkler/MEF. 


\section{C.2.7.2 Profundidad $Z=15 \mathrm{~m}$ y proporción geométrica $\lambda=2$}
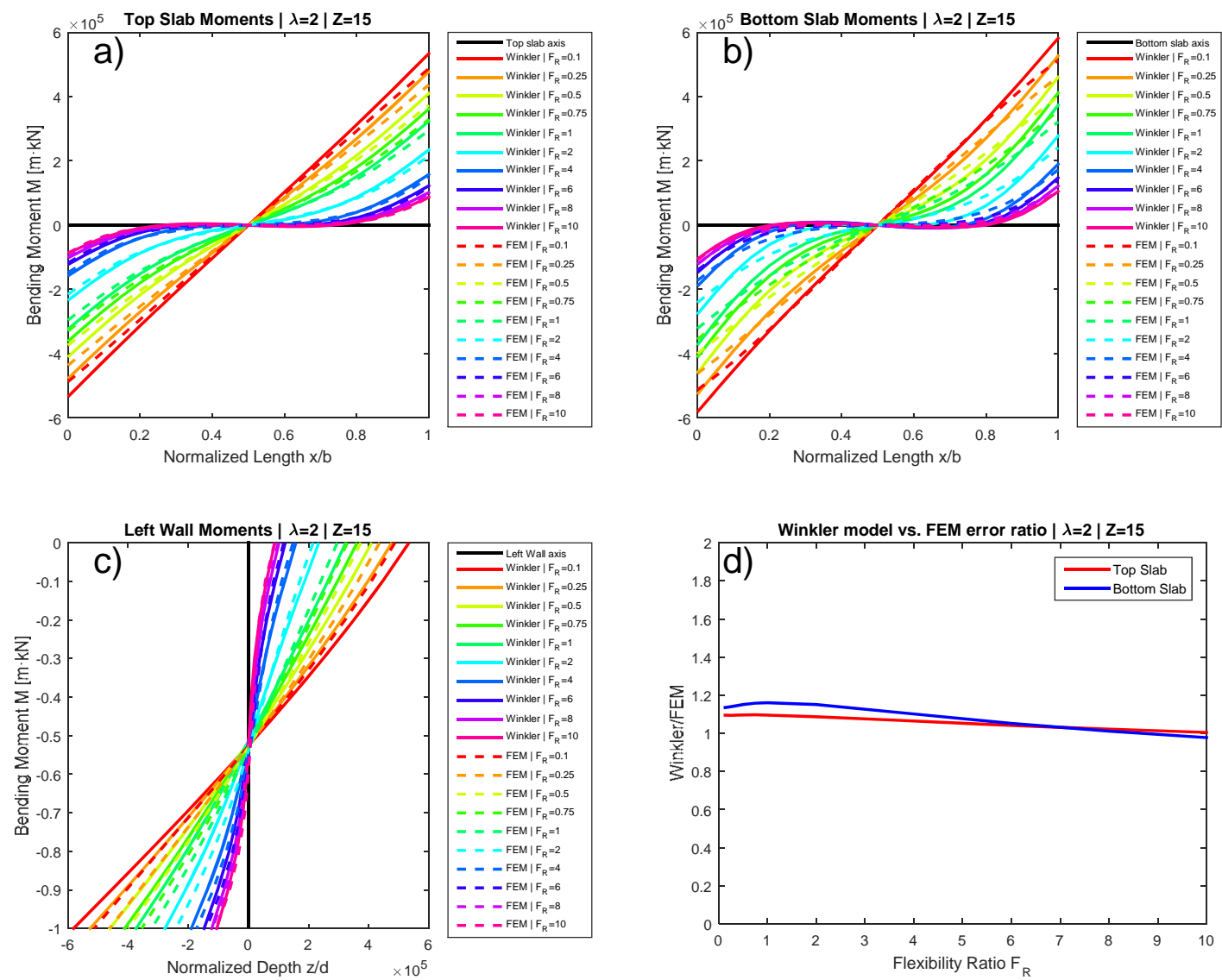

Fig. C-26. Momentos flectores para profundidad $Z=15 \mathrm{~m}$ y proporción geométrica $\lambda=b / d=2$. (a) En losa superior. (b) En muro lateral izquierdo, (c) En losa inferior. (d) Ratio Winkler/MEF. 


\section{C.2.7.3 Profundidad $Z=15 \mathrm{~m}$ y proporción geométrica $\lambda=3$}
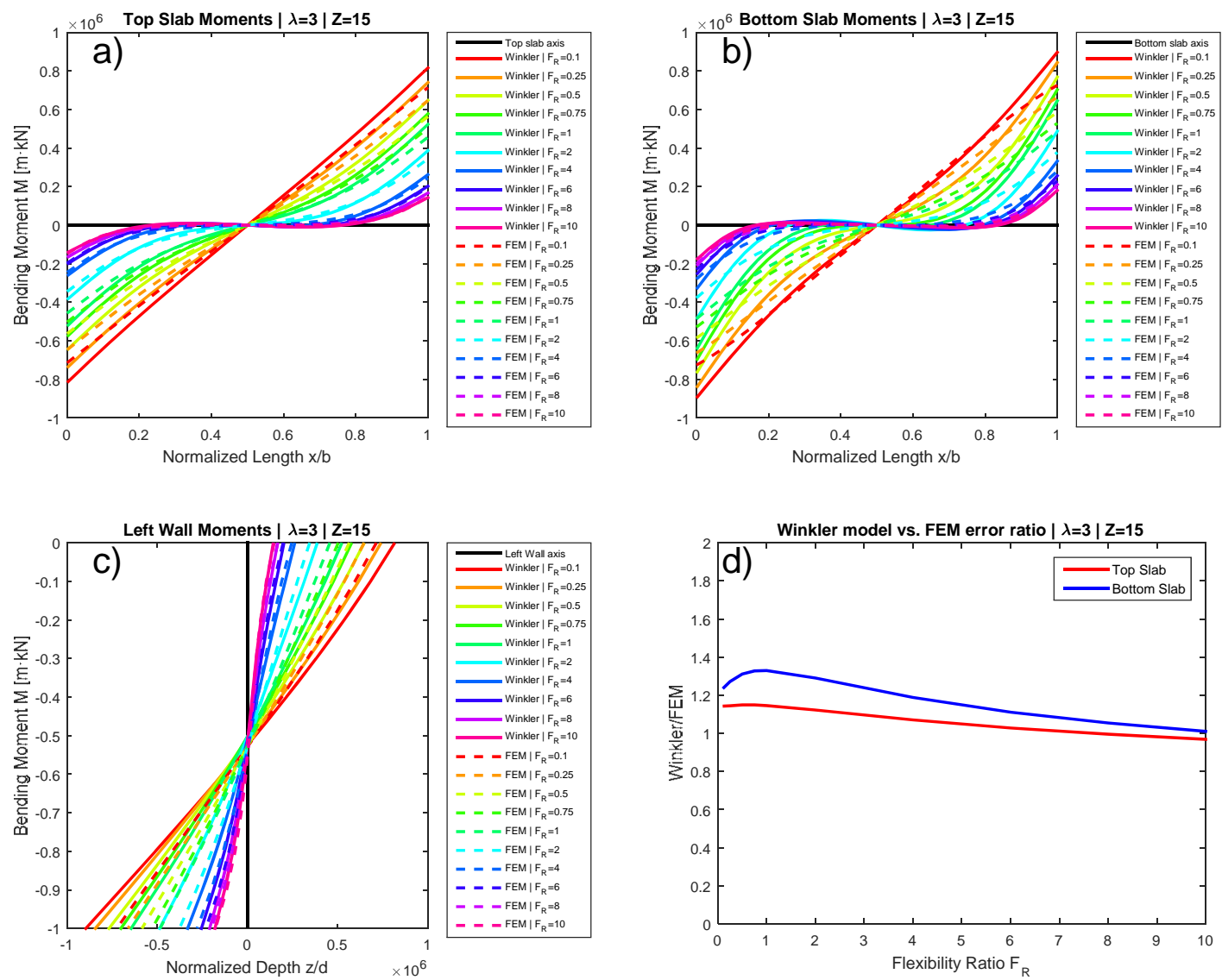

Fig. C-27. Momentos flectores para profundidad $Z=15 \mathrm{~m}$ y proporción geométrica $\lambda=b / d=3$. (a) En losa superior. (b) En muro lateral izquierdo, (c) En losa inferior. (d) Ratio Winkler/MEF. 


\section{C.2.8 Profundidad $Z=20 \mathrm{~m}$}

\section{C.2.8.1 Profundidad $Z=20 \mathrm{~m}$ y proporción geométrica $\lambda=1$}
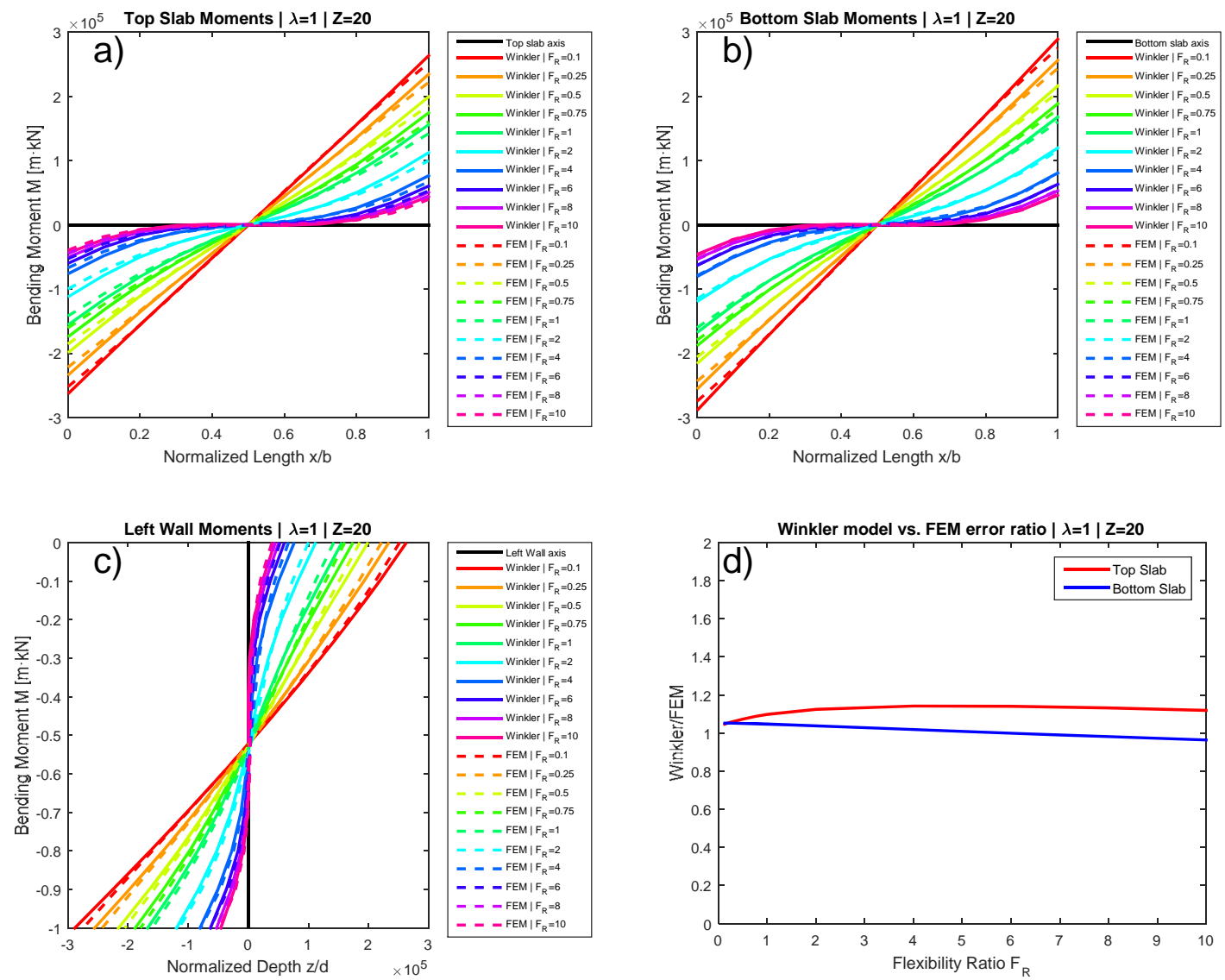

Fig. C-28. Momentos flectores para profundidad $Z=20 \mathrm{~m}$ y proporción geométrica $\lambda=b / d=1$. (a) En losa superior. (b) En muro lateral izquierdo, (c) En losa inferior. (d) Ratio Winkler/MEF. 


\section{C.2.8.2 Profundidad $\mathrm{Z}=20 \mathrm{~m}$ y proporción geométrica $\lambda=2$}
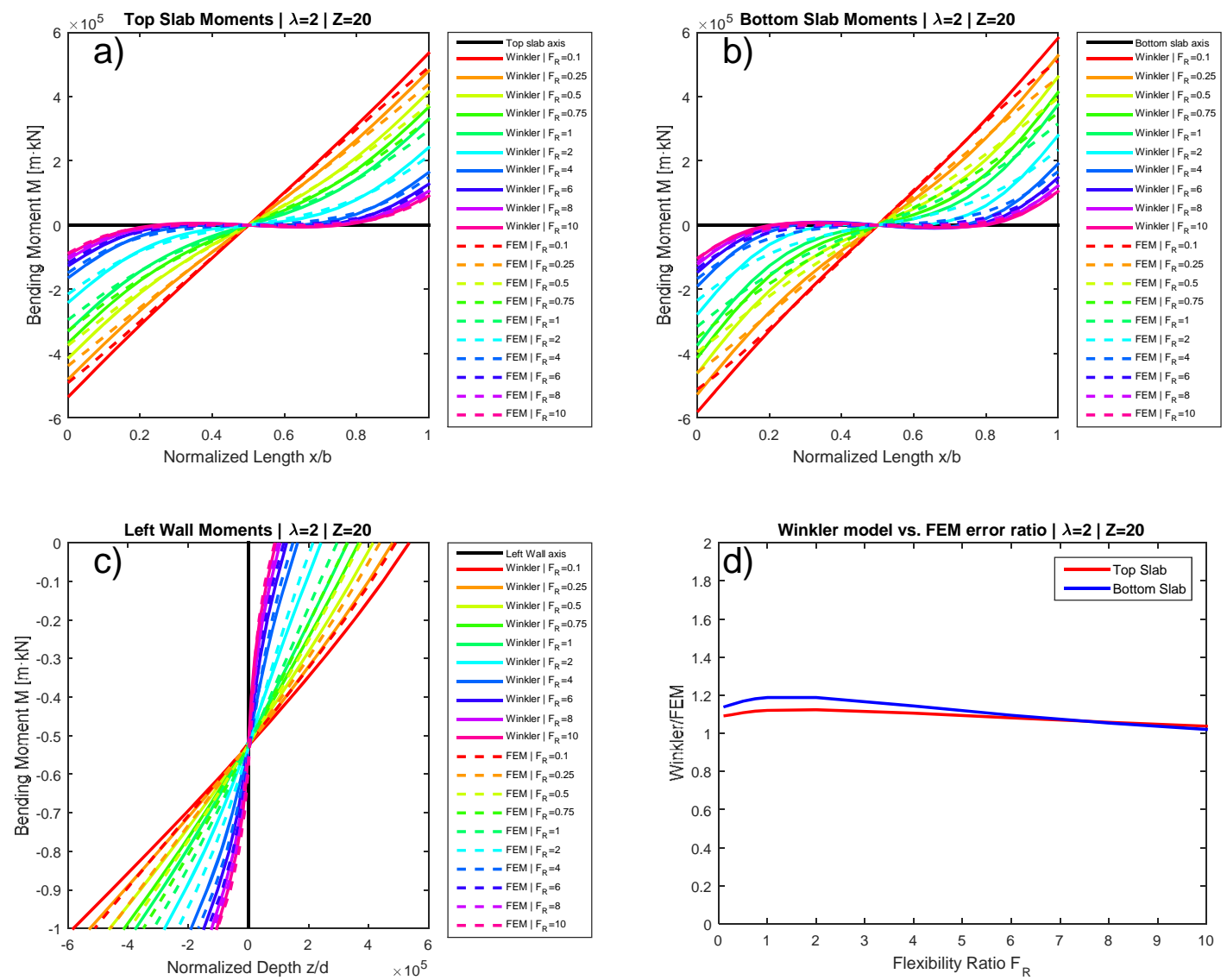

Fig. C-29. Momentos flectores para profundidad $Z=20 \mathrm{~m}$ y proporción geométrica $\lambda=b / d=2$. (a) En losa superior. (b) En muro lateral izquierdo, (c) En losa inferior. (d) Ratio Winkler/MEF. 


\section{C.2.8.3 Profundidad $Z=20 \mathrm{~m}$ y proporción geométrica $\lambda=3$}
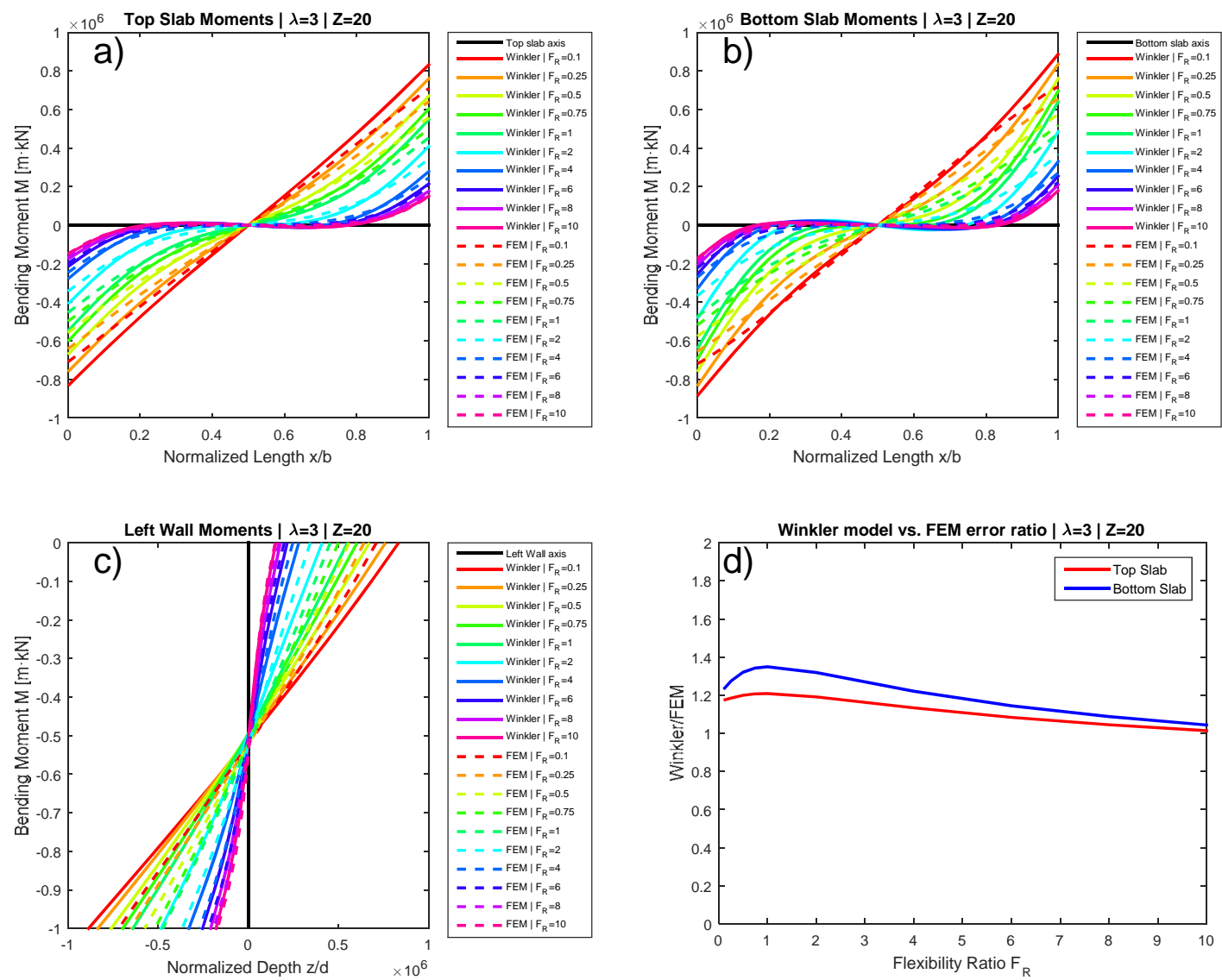

Fig. C-30. Momentos flectores para profundidad $Z=20 \mathrm{~m}$ y proporción geométrica $\lambda=b / d=3$. (a) En losa superior. (b) En muro lateral izquierdo, (c) En losa inferior. (d) Ratio Winkler/MEF. 


\section{C.3 Resultados de Esfuerzos Cortantes}

\section{C.3.1 Profundidad $Z=0 \mathrm{~m}$}

\section{C.3.1.1 Profundidad $Z=0 \mathrm{~m}$ y proporción geométrica $\lambda=1$}
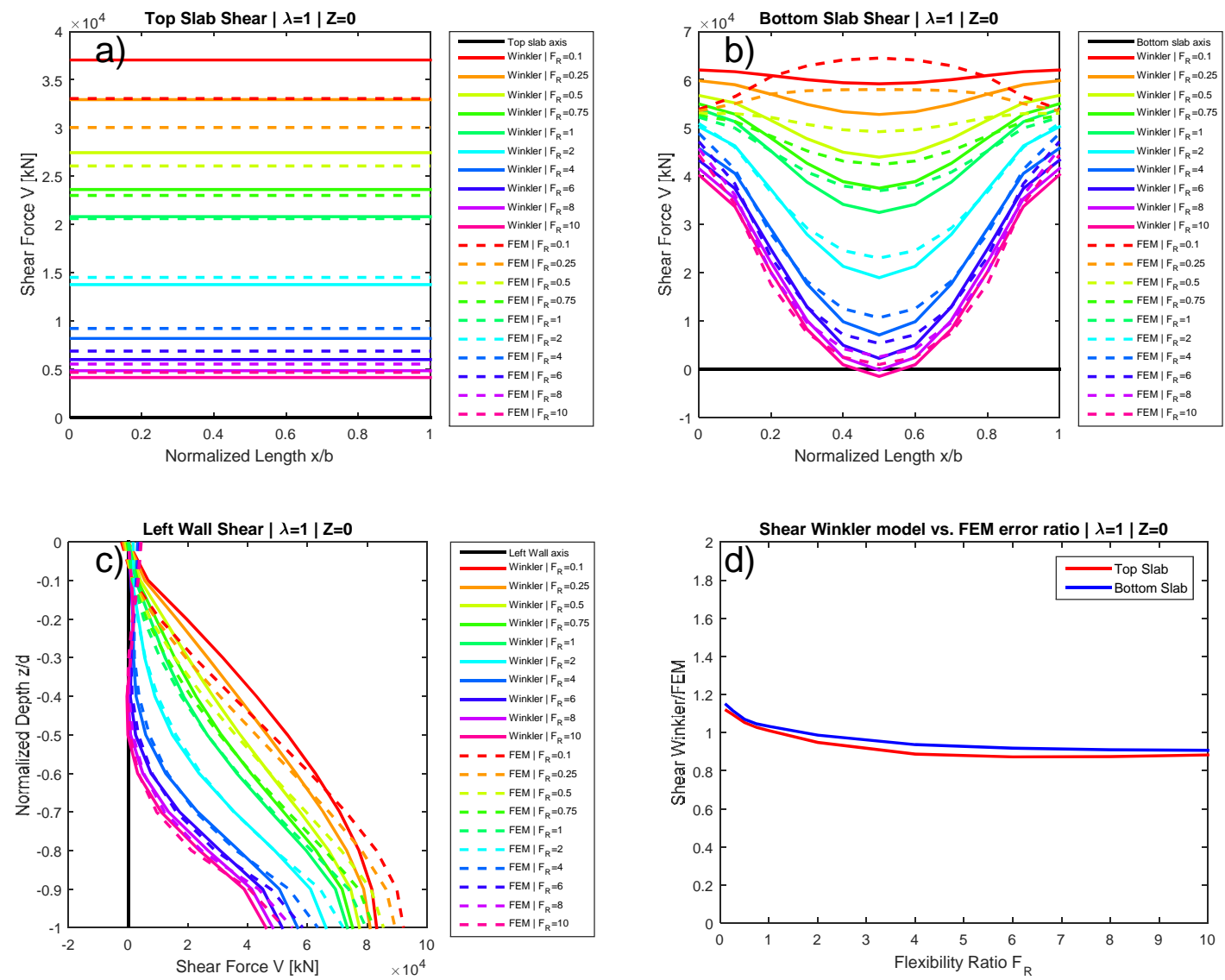

Fig. C-31. Esfuerzos cortantes para profundidad $Z=0 \mathrm{~m}$ y proporción geométrica $\lambda=b / d=1$. (a) En losa superior. (b) En muro lateral izquierdo, (c) En losa inferior. (d) Ratio Winkler/MEF. 


\section{C.3.1.2 Profundidad $Z=0 \mathrm{~m}$ y proporción geométrica $\lambda=2$}
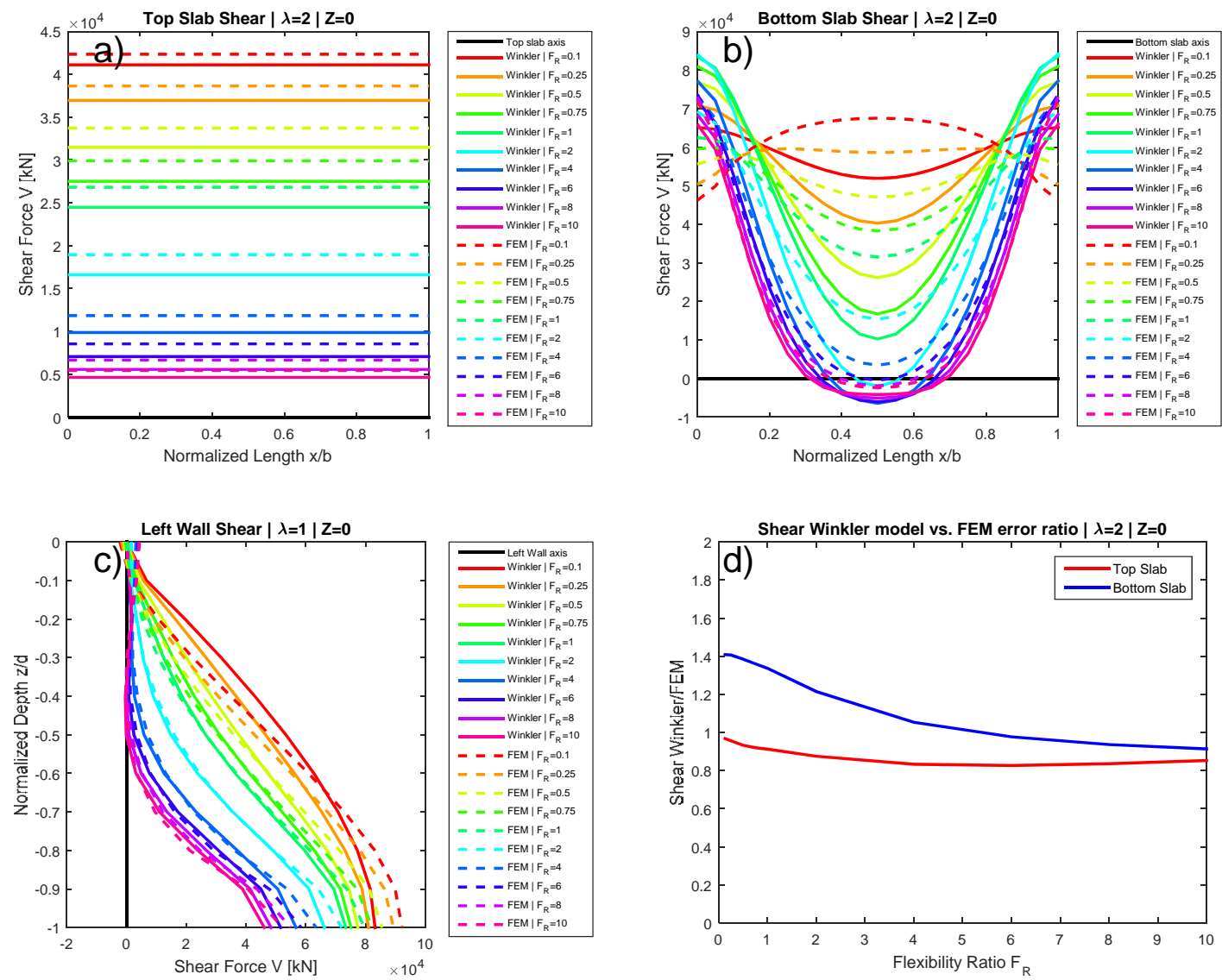

Fig. C-32. Esfuerzos cortantes para profundidad $Z=0 \mathrm{~m}$ y proporción geométrica $\lambda=b / d=2$. (a) En losa superior. (b) En muro lateral izquierdo, (c) En losa inferior. (d) Ratio Winkler/MEF. 


\section{C.3.1.3 Profundidad $Z=0 \mathrm{~m}$ y proporción geométrica $\lambda=3$}
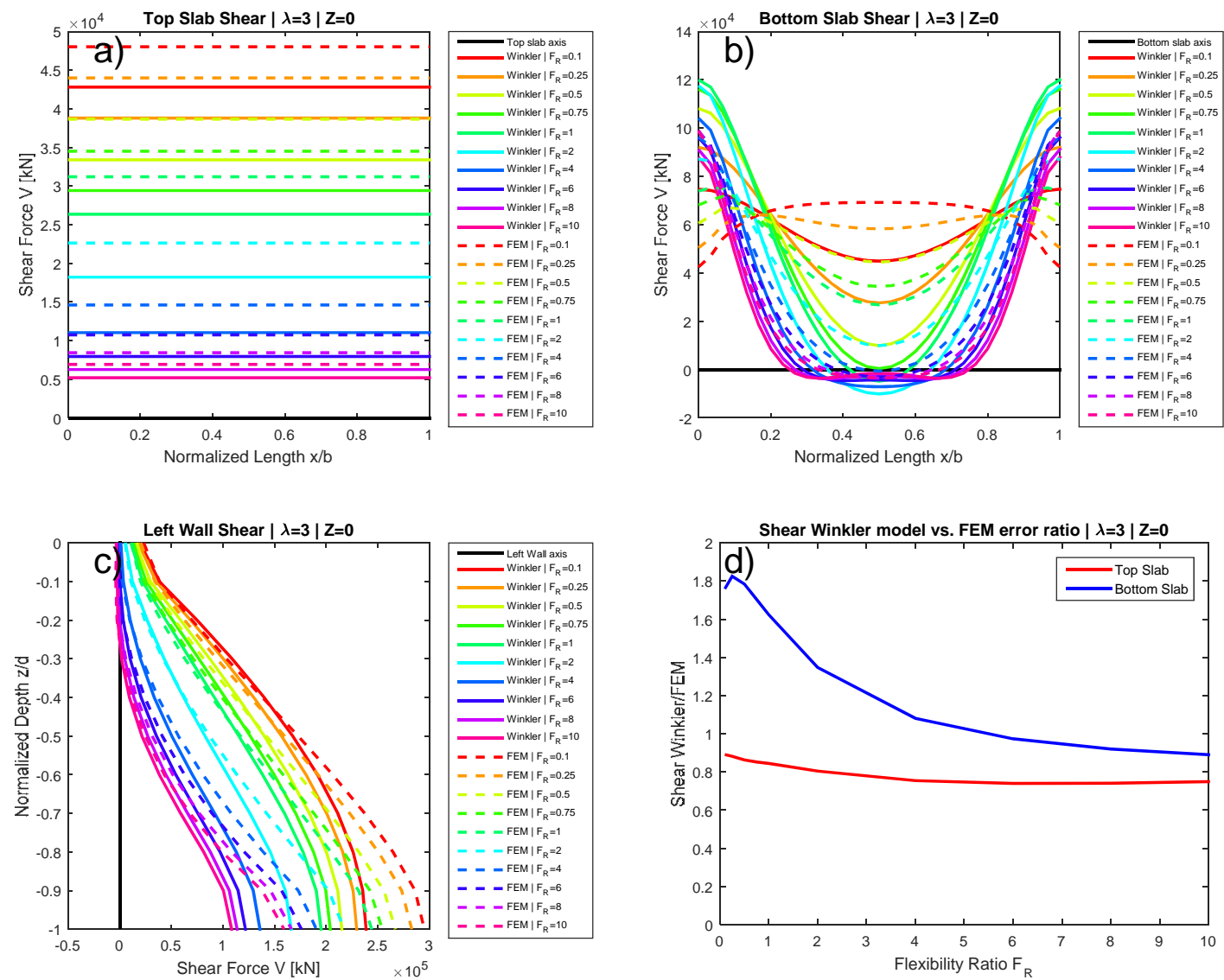

Fig. C-33. Esfuerzos cortantes para profundidad $Z=0 \mathrm{~m}$ y proporción geométrica $\lambda=b / d=3$. (a) En losa superior. (b) En muro lateral izquierdo, (c) En losa inferior. (d) Ratio Winkler/MEF. 


\section{C.3.2 Profundidad $Z=2 \mathrm{~m}$}

\section{C.3.2.1 Profundidad $Z=2 \mathrm{~m}$ y proporción geométrica $\lambda=1$}
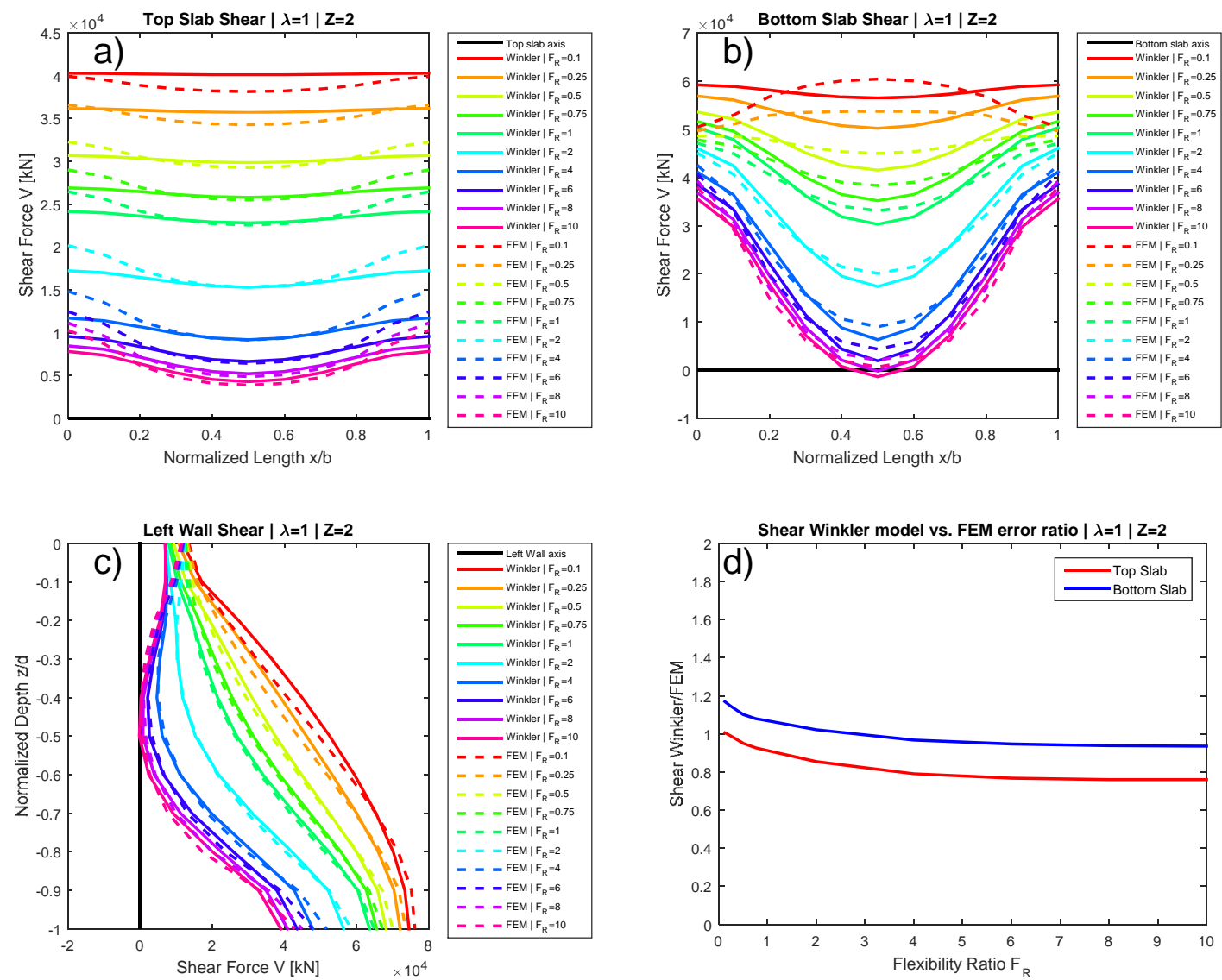

Fig. C-34. Esfuerzos cortantes para profundidad $Z=2 \mathrm{~m}$ y proporción geométrica $\lambda=b / d=1$. (a) En losa superior. (b) En muro lateral izquierdo, (c) En losa inferior. (d) Ratio Winkler/MEF. 


\section{C.3.2.2 Profundidad $Z=2 \mathrm{~m}$ y proporción geométrica $\lambda=2$}
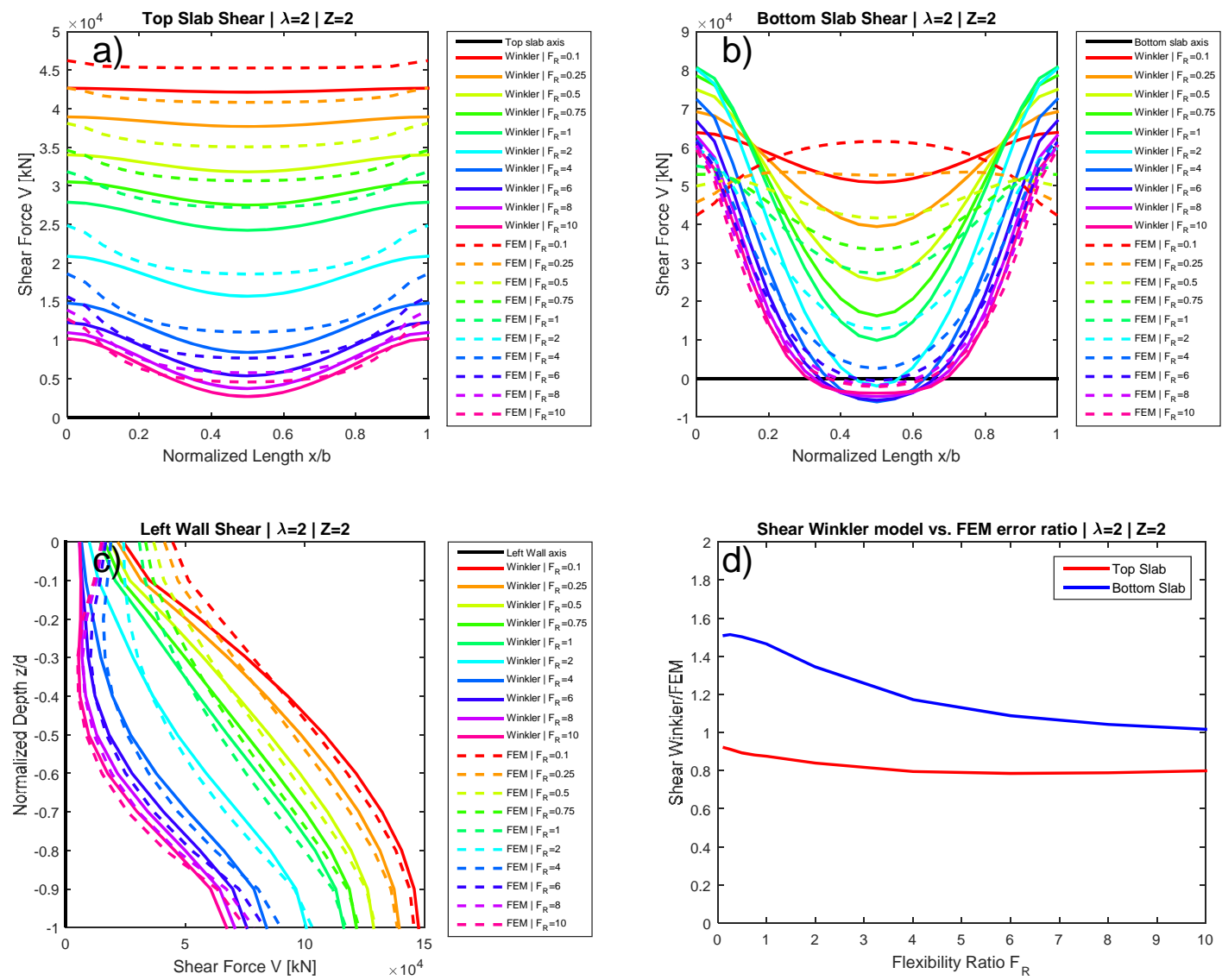

Fig. C-35. Esfuerzos cortantes para profundidad $Z=2 \mathrm{~m}$ y proporción geométrica $\lambda=b / d=2$. (a) En losa superior. (b) En muro lateral izquierdo, (c) En losa inferior. (d) Ratio Winkler/MEF. 


\section{C.3.2.3 Profundidad $Z=2 \mathrm{~m}$ y proporción geométrica $\lambda=3$}
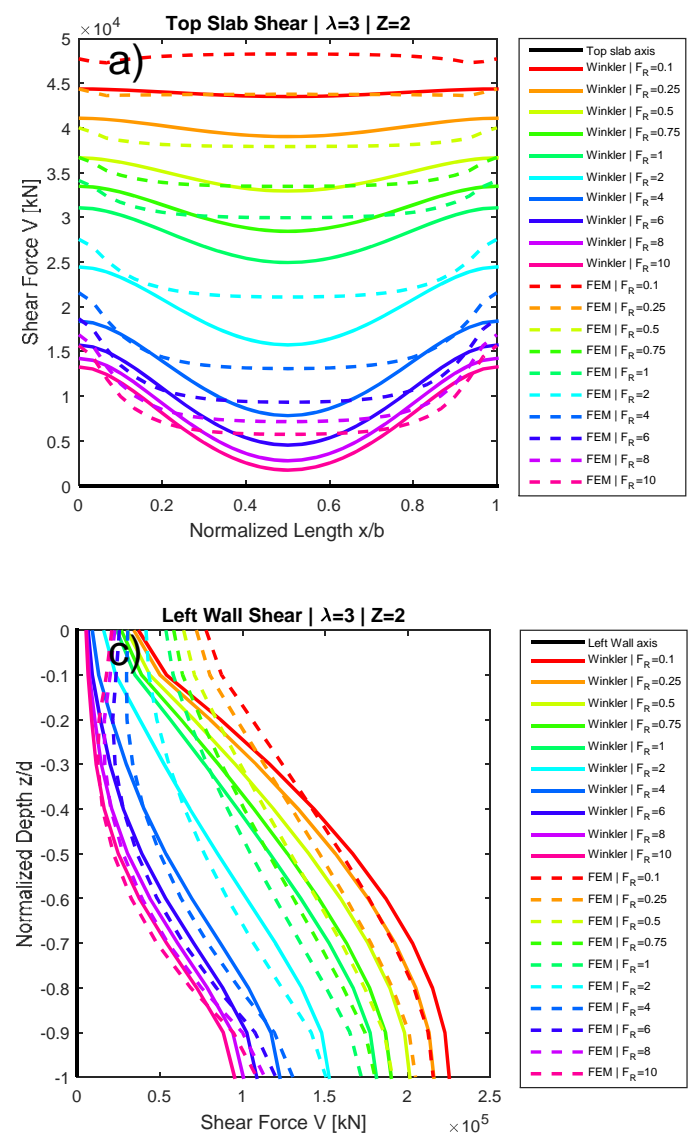
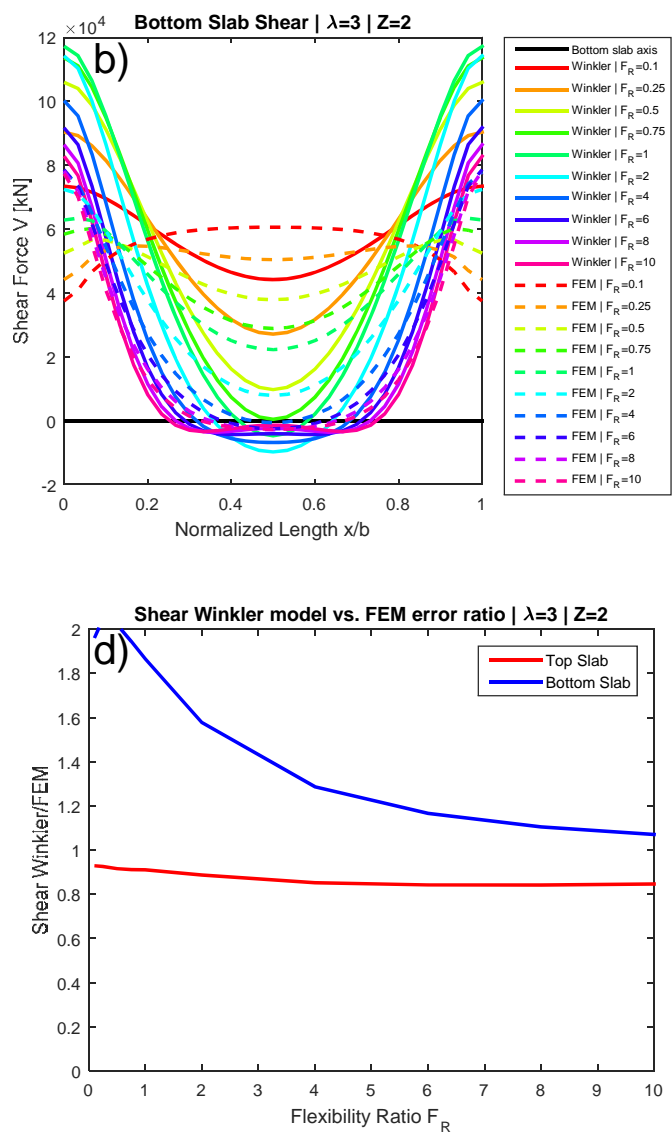

Fig. C-36. Esfuerzos cortantes para profundidad $Z=2 \mathrm{~m}$ y proporción geométrica $\lambda=b / d=3$. (a) En losa superior. (b) En muro lateral izquierdo, (c) En losa inferior. (d) Ratio Winkler/MEF. 


\section{C.3.3 Profundidad $Z=4 \mathrm{~m}$}

\section{C.3.3.1 Profundidad $Z=4 \mathrm{~m}$ y proporción geométrica $\lambda=1$}
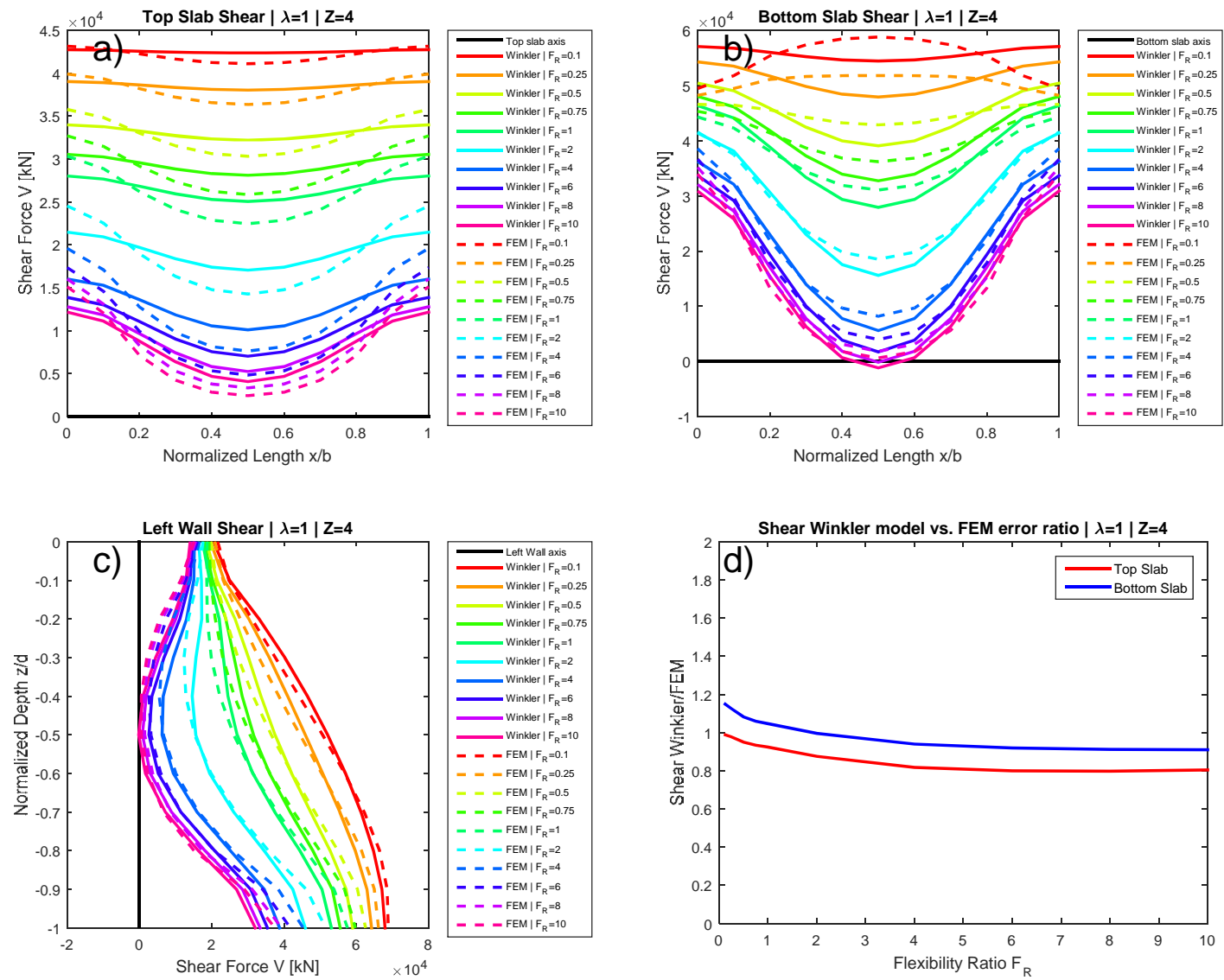

Fig. C-37. Esfuerzos cortantes para profundidad $Z=4 \mathrm{~m}$ y proporción geométrica $\lambda=b / d=1$. (a) En losa superior. (b) En muro lateral izquierdo, (c) En losa inferior. (d) Ratio Winkler/MEF. 


\section{C.3.3.2 Profundidad $Z=4 \mathrm{~m}$ y proporción geométrica $\lambda=2$}
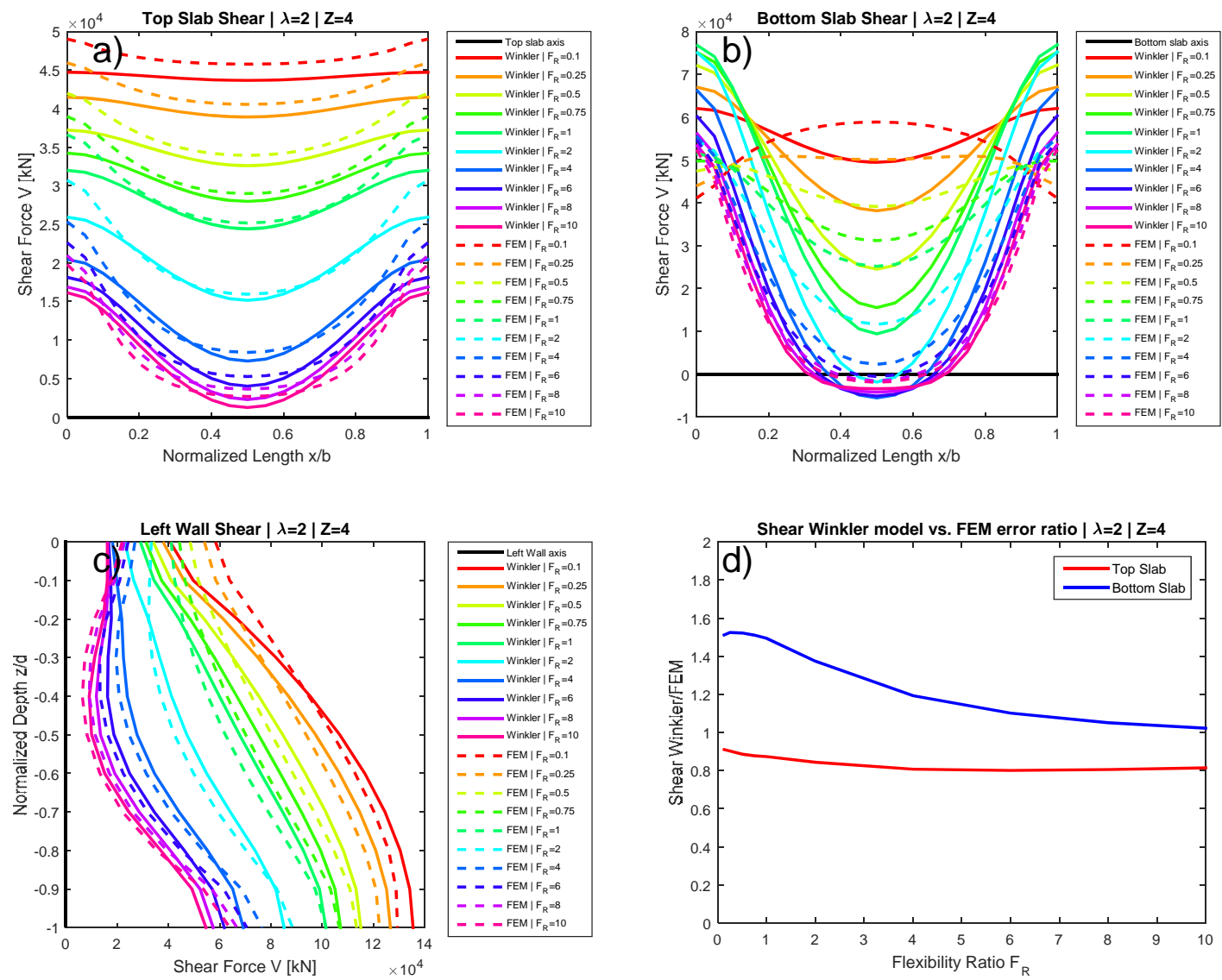

Fig. C-38. Esfuerzos cortantes para profundidad $Z=4 \mathrm{~m}$ y proporción geométrica $\lambda=b / d=2$. (a) En losa superior. (b) En muro lateral izquierdo, (c) En losa inferior. (d) Ratio Winkler/MEF. 


\section{C.3.3.3 Profundidad $Z=4 \mathrm{~m}$ y proporción geométrica $\lambda=3$}
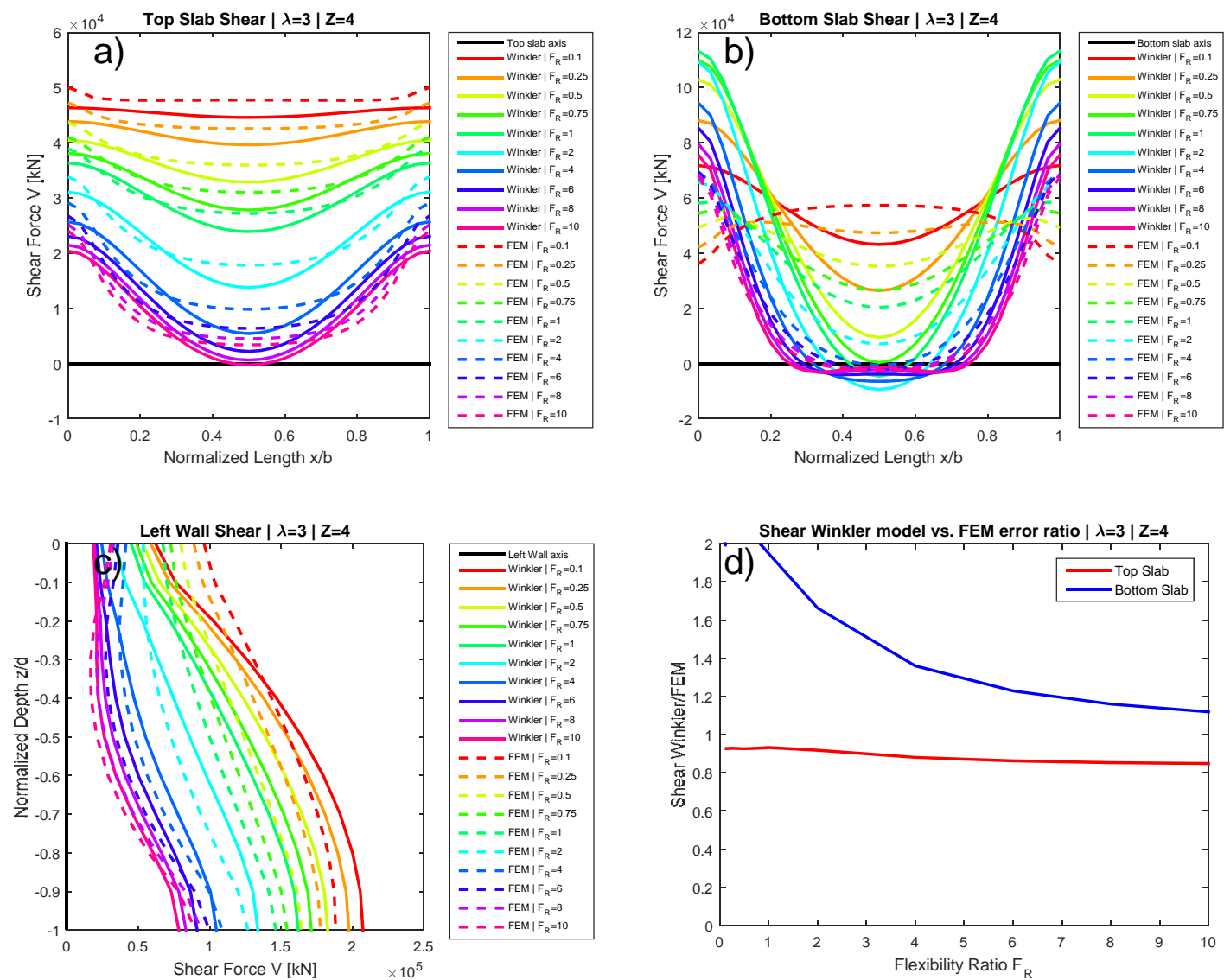

Fig. C-39. Esfuerzos cortantes para profundidad $Z=4 \mathrm{~m}$ y proporción geométrica $\lambda=b / d=3$. (a) En losa superior. (b) En muro lateral izquierdo, (c) En losa inferior. (d) Ratio Winkler/MEF. 


\section{C.3.4 Profundidad $Z=6 \mathrm{~m}$}

\section{C.3.4.1 Profundidad $Z=6 \mathrm{~m}$ y proporción geométrica $\lambda=1$}
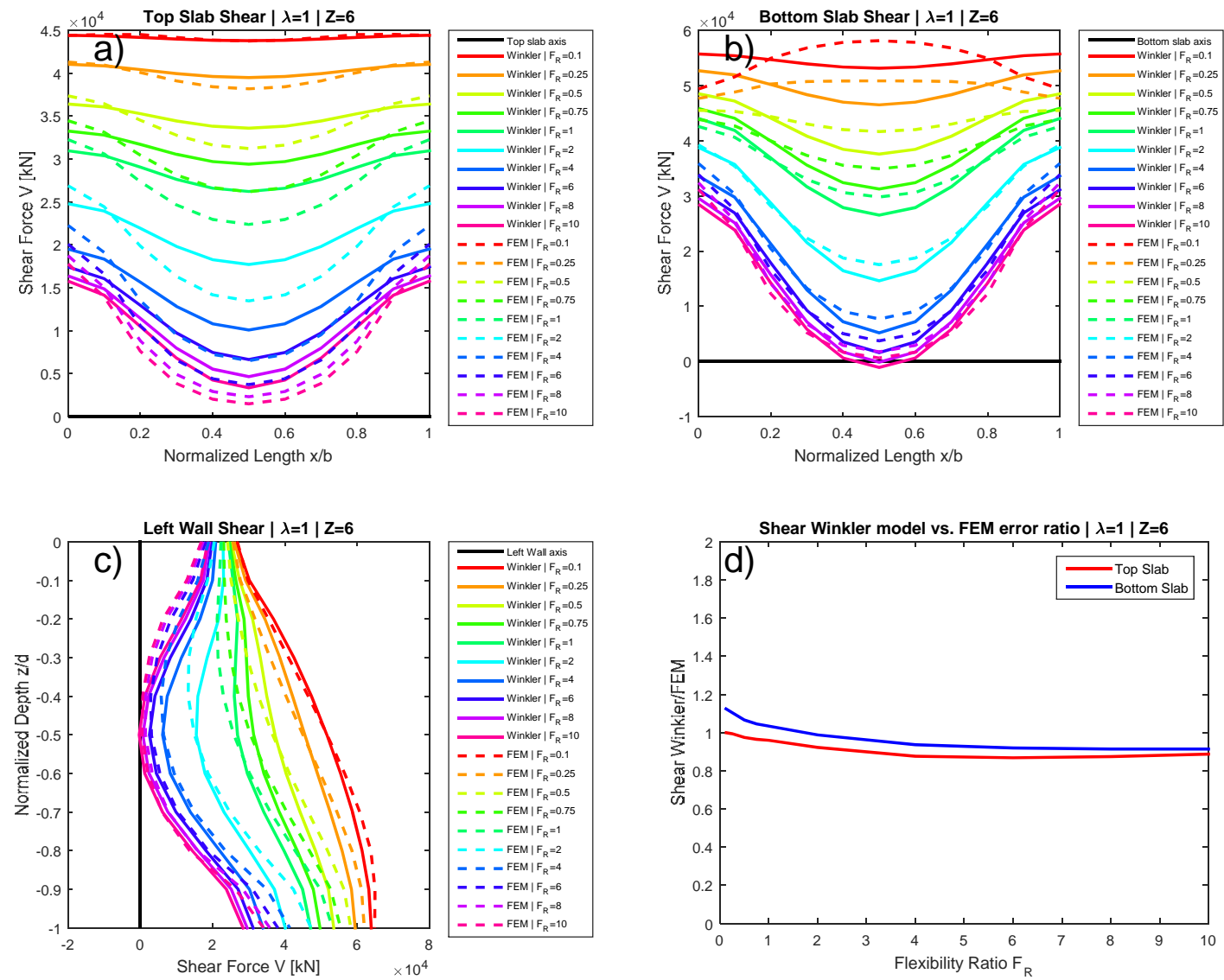

Fig. C-40. Esfuerzos cortantes para profundidad $Z=6 \mathrm{~m}$ y proporción geométrica $\lambda=b / d=1$. (a) En losa superior. (b) En muro lateral izquierdo, (c) En losa inferior. (d) Ratio Winkler/MEF. 


\section{C.3.4.2 Profundidad $Z=6 \mathrm{~m}$ y proporción geométrica $\lambda=2$}
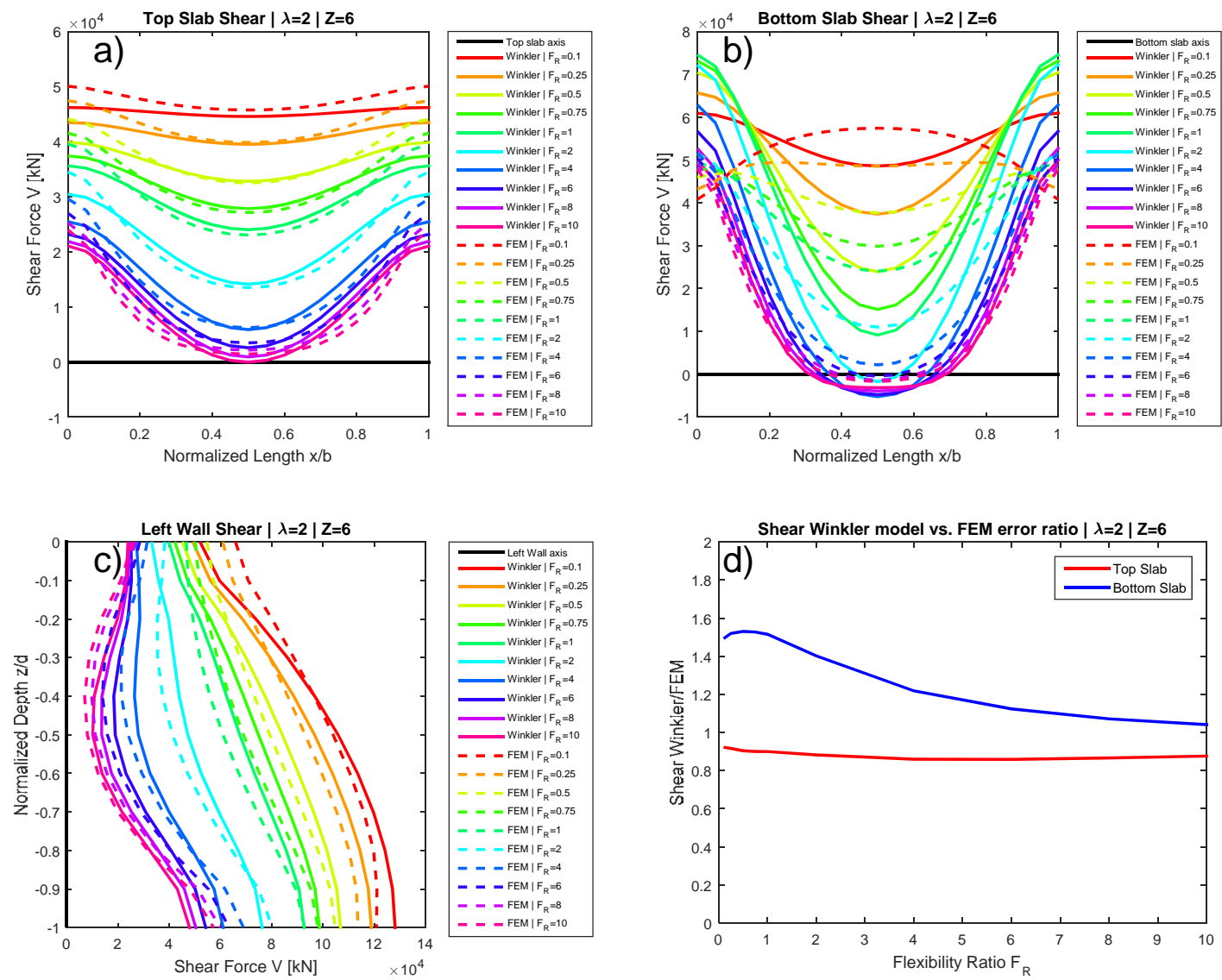

Fig. C-41. Esfuerzos cortantes para profundidad $Z=6 \mathrm{~m}$ y proporción geométrica $\lambda=b / d=2$. (a) En losa superior. (b) En muro lateral izquierdo, (c) En losa inferior. (d) Ratio Winkler/MEF. 


\section{C.3.4.3 Profundidad $Z=6 \mathrm{~m}$ y proporción geométrica $\lambda=3$}
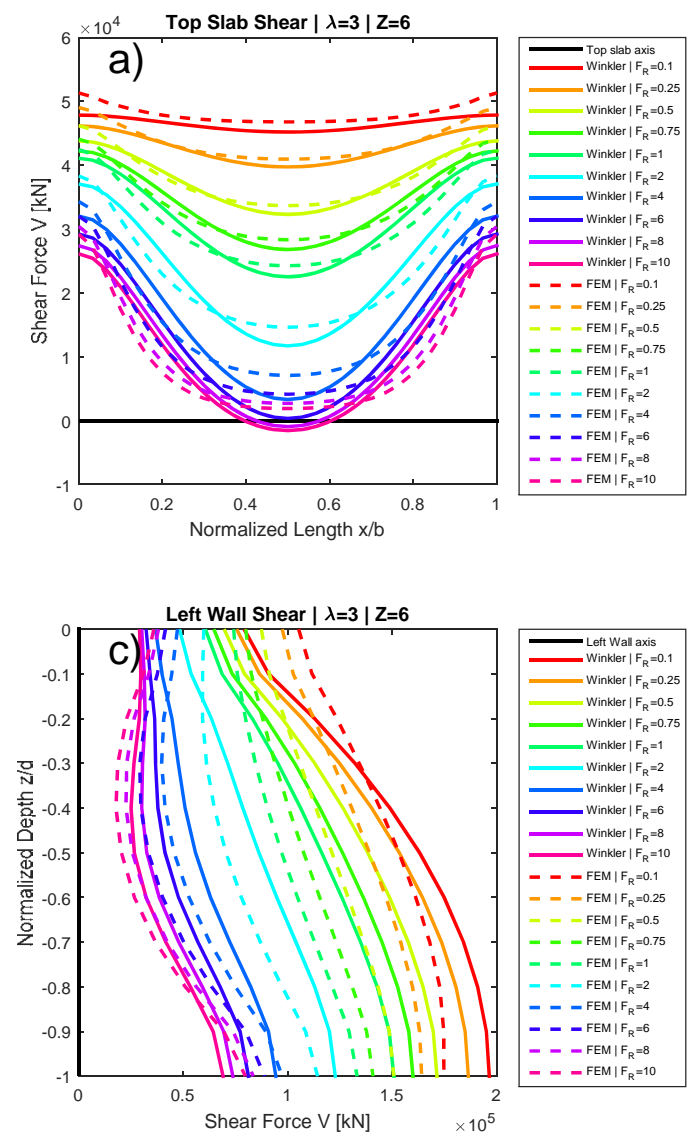
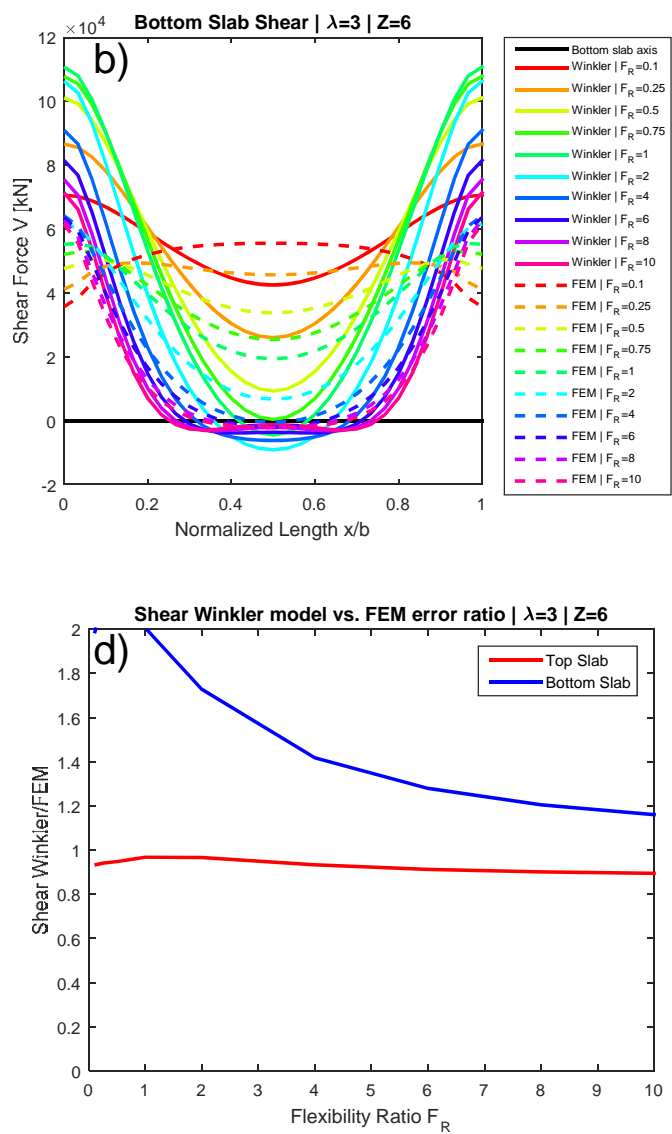

Fig. C-42. Esfuerzos cortantes para profundidad $Z=6 \mathrm{~m}$ y proporción geométrica $\lambda=b / d=3$. (a) En losa superior. (b) En muro lateral izquierdo, (c) En losa inferior. (d) Ratio Winkler/MEF. 


\section{C.3.5 Profundidad $Z=8 \mathrm{~m}$}

\section{C.3.5.1 Profundidad $Z=8 \mathrm{~m}$ y proporción geométrica $\lambda=1$}
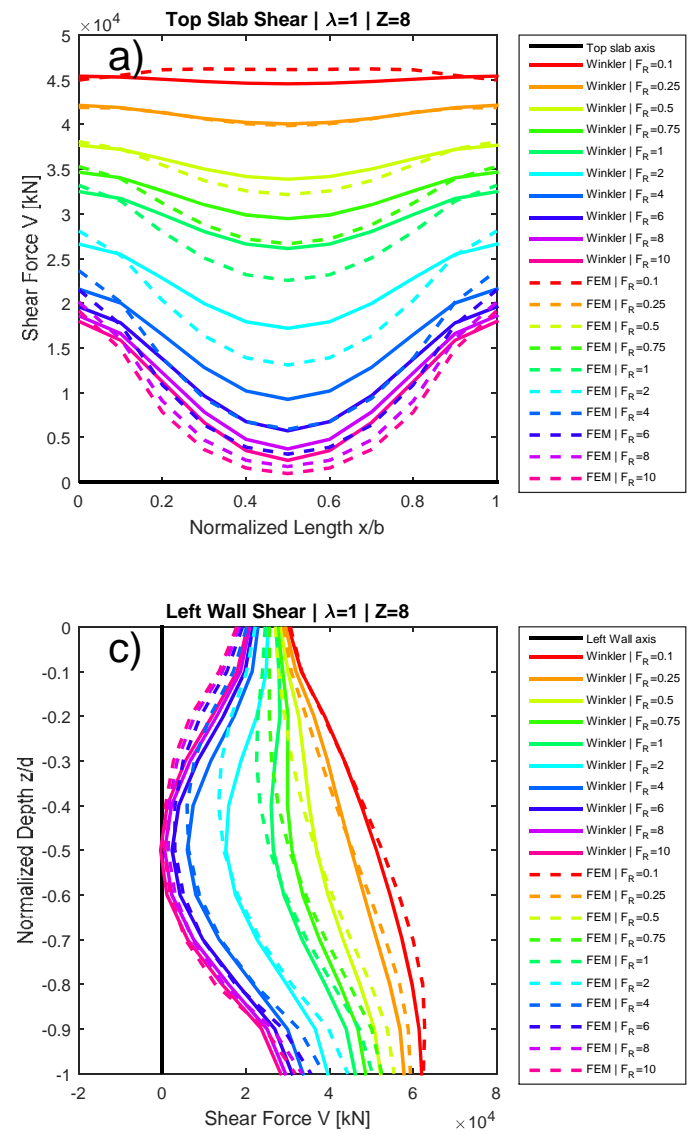
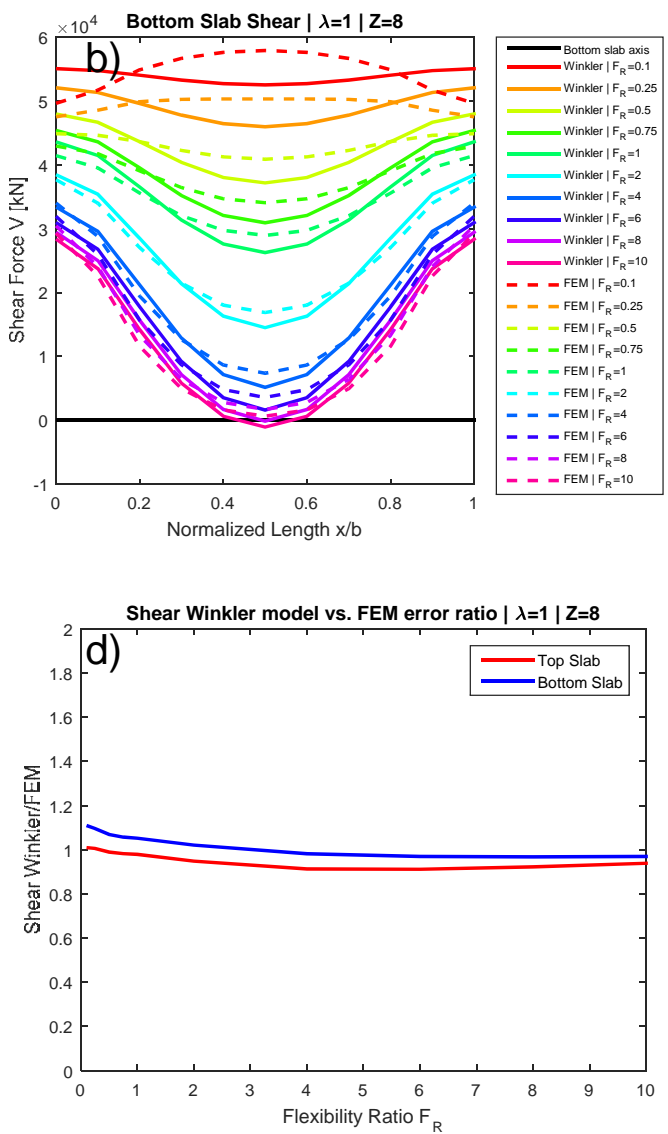

Fig. C-43. Esfuerzos cortantes para profundidad $Z=8 \mathrm{~m}$ y proporción geométrica $\lambda=b / d=1$. (a) En losa superior. (b) En muro lateral izquierdo, (c) En losa inferior. (d) Ratio entre momentos obtenidos con el método propuesto en esta tesis y los de análisis numérico MEF. 


\section{C.3.5.2 Profundidad $Z=8 \mathrm{~m}$ y proporción geométrica $\lambda=2$}
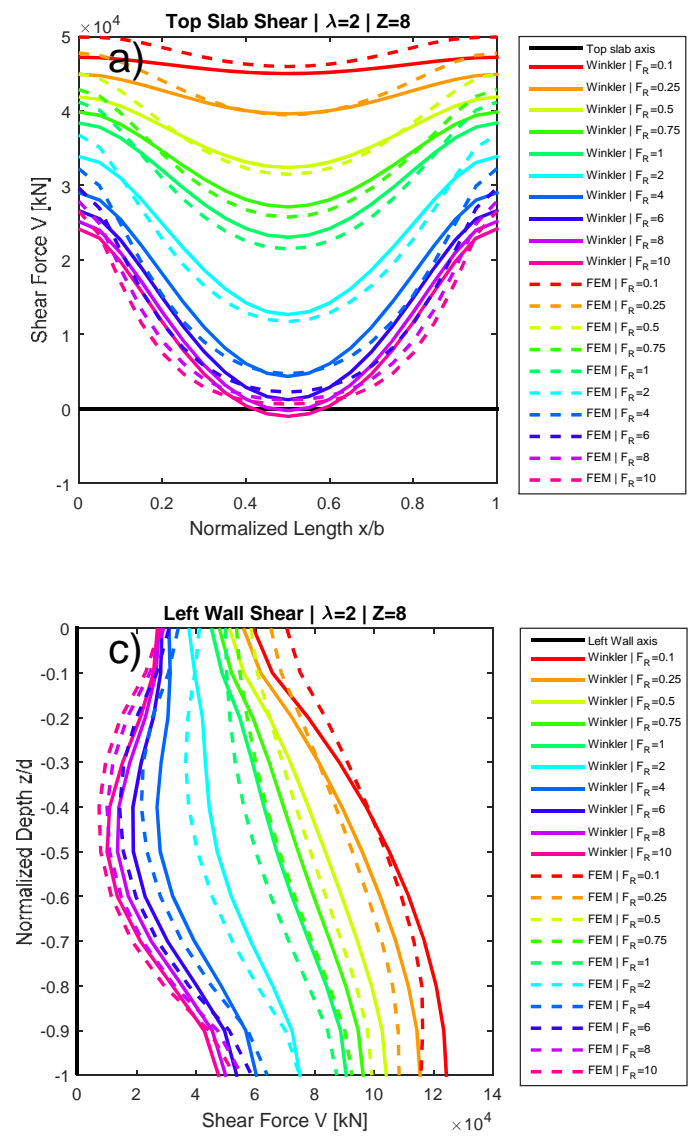
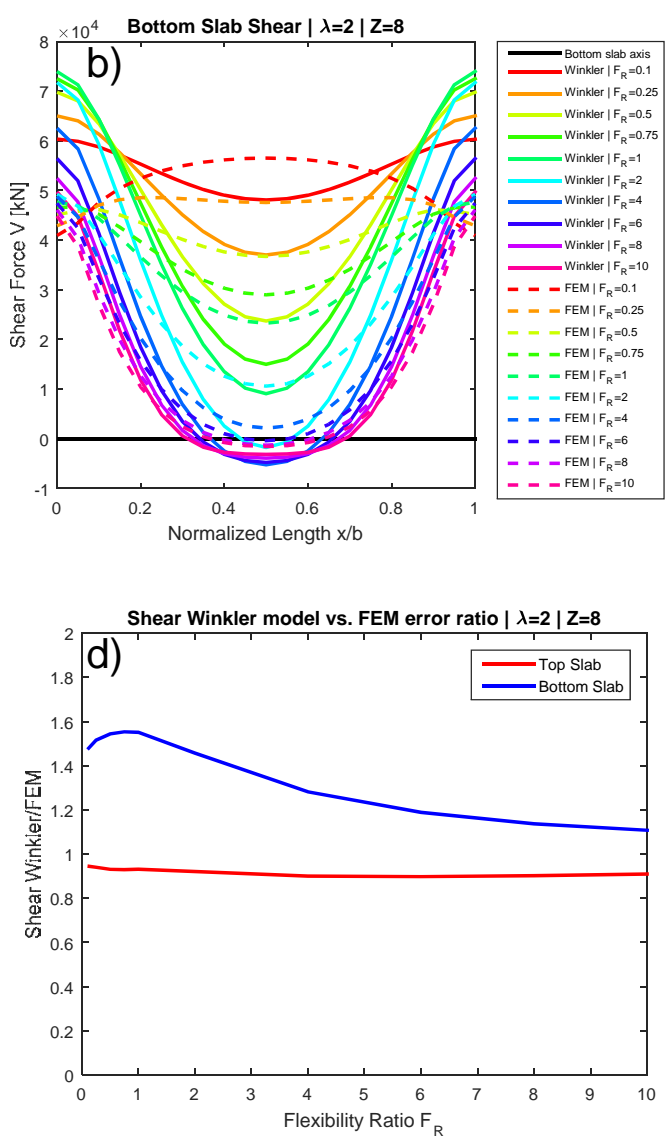

Fig. C-44. Esfuerzos cortantes para profundidad $Z=8 \mathrm{~m}$ y proporción geométrica $\lambda=b / d=2$. (a) En losa superior. (b) En muro lateral izquierdo, (c) En losa inferior. (d) Ratio Winkler/MEF. 


\section{C.3.5.3 Profundidad $Z=8 \mathrm{~m}$ y proporción geométrica $\lambda=3$}
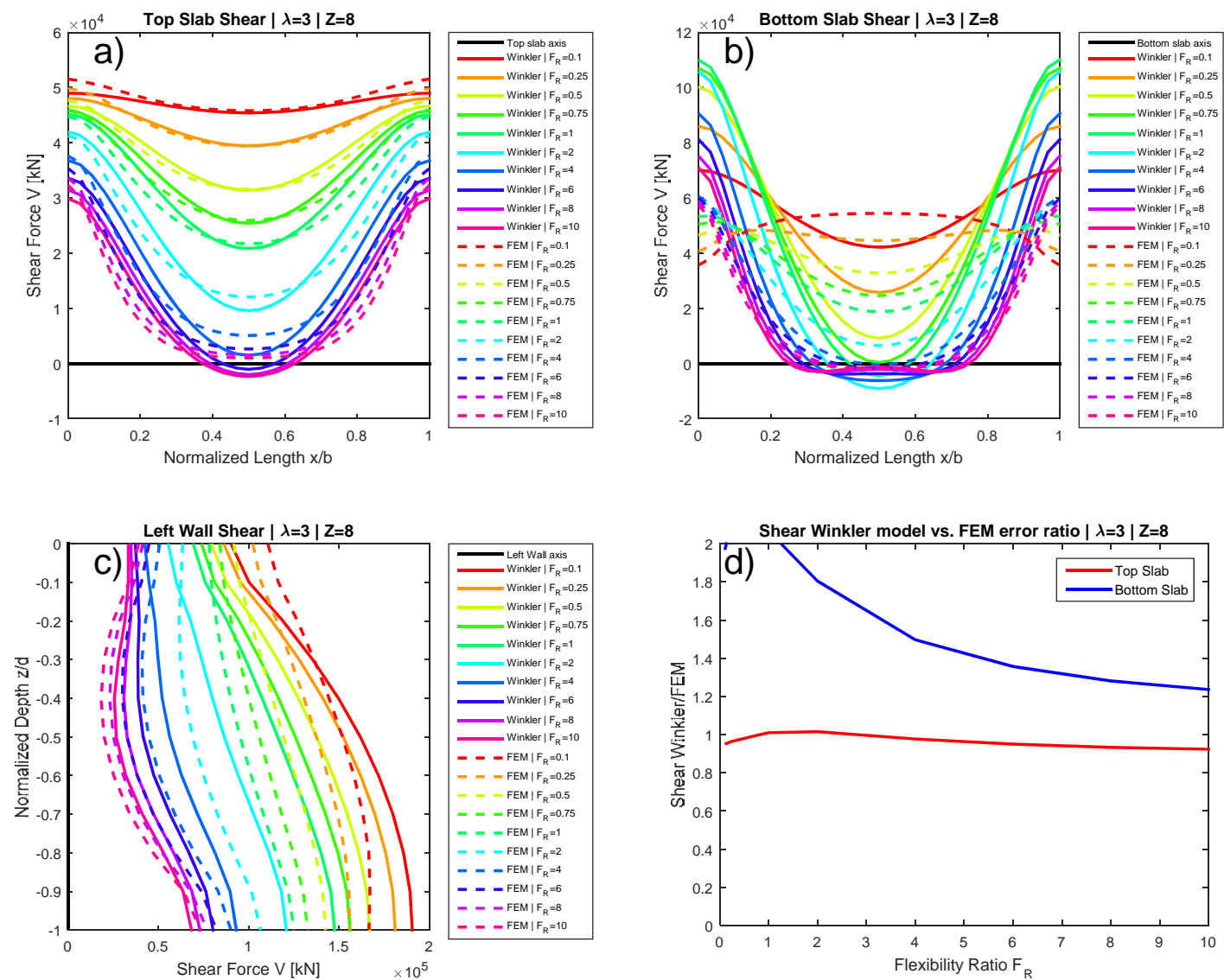

Fig. C-45. Esfuerzos cortantes para profundidad $Z=8 \mathrm{~m}$ y proporción geométrica $\lambda=b / d=3$. (a) En losa superior. (b) En muro lateral izquierdo, (c) En losa inferior. (d) Ratio Winkler/MEF. 


\section{C.3.6 Profundidad $Z=10 \mathrm{~m}$}

\section{C.3.6.1 Profundidad $Z=0 \mathrm{~m}$ y proporción geométrica $\lambda=1$}
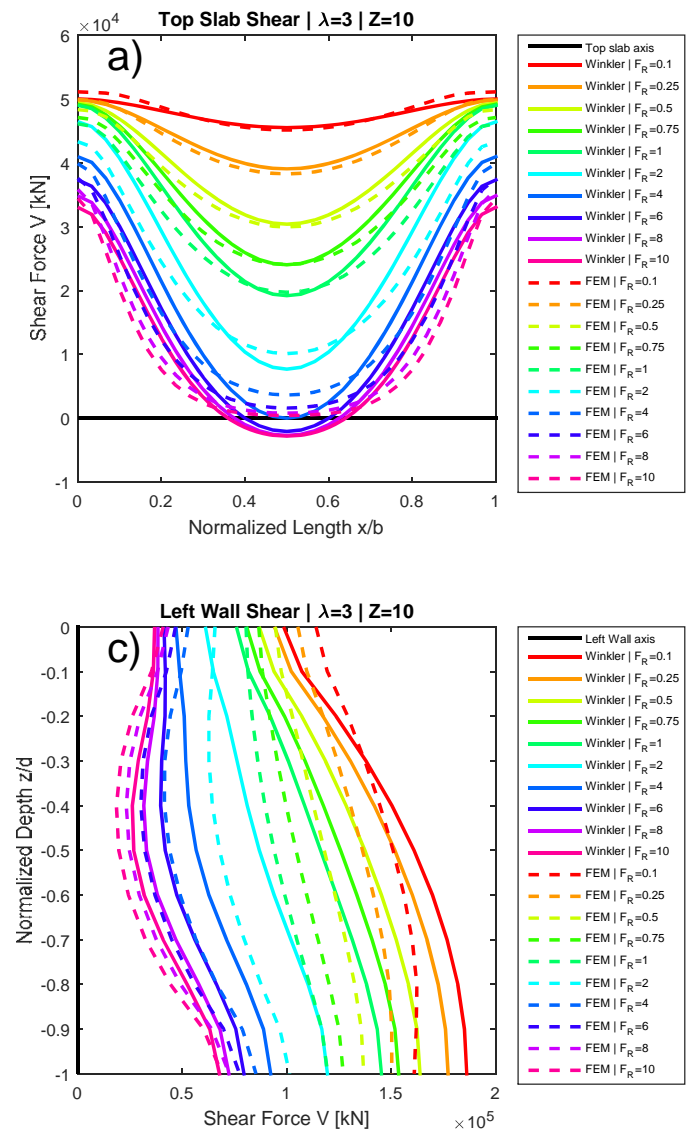
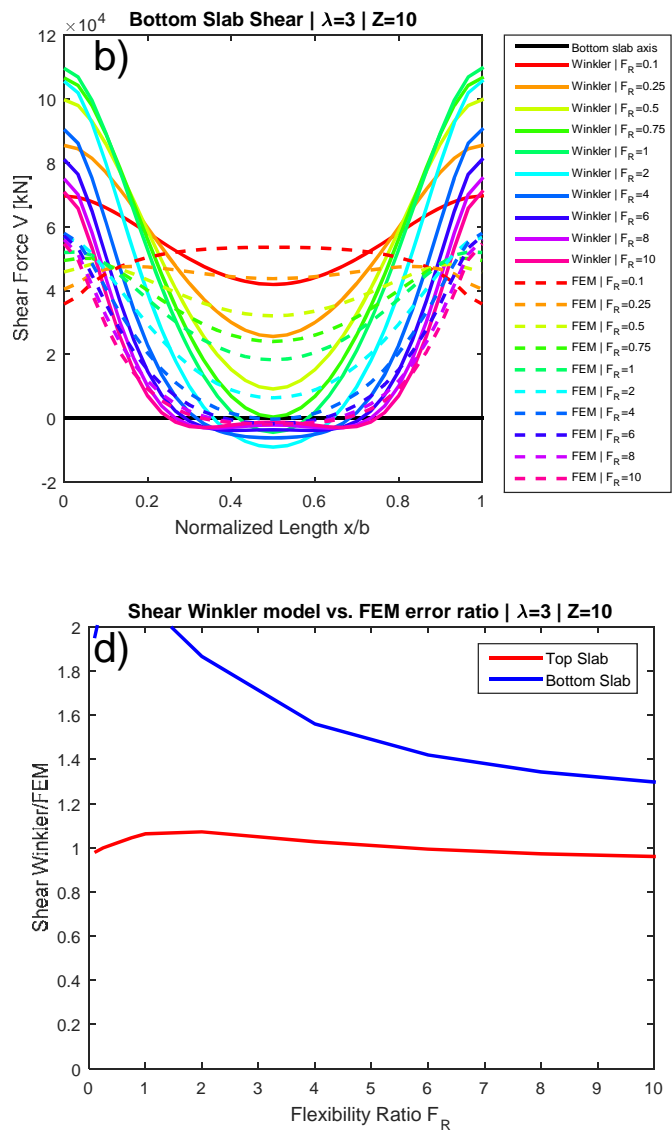

Fig. C-46. Esfuerzos cortantes para profundidad $Z=10 \mathrm{~m}$ y proporción geométrica $\lambda=b / d=1$. (a) En losa superior. (b) En muro lateral izquierdo, (c) En losa inferior. (d) Ratio Winkler/MEF. 


\section{C.3.6.2 Profundidad $Z=10 \mathrm{~m}$ y proporción geométrica $\lambda=2$}
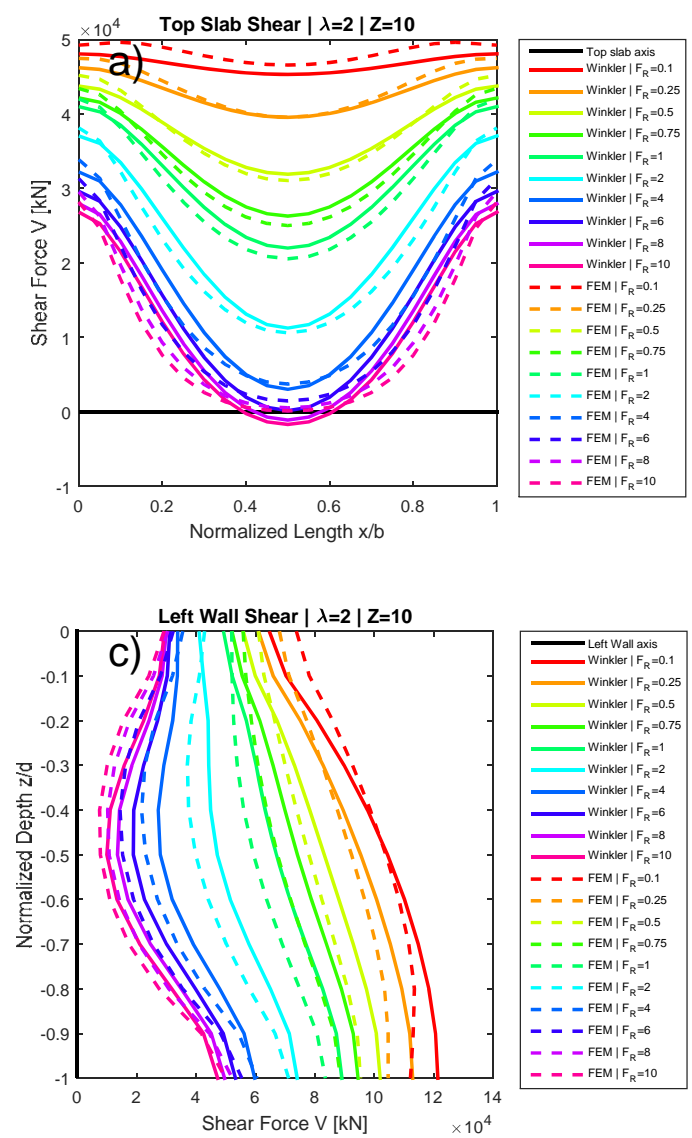
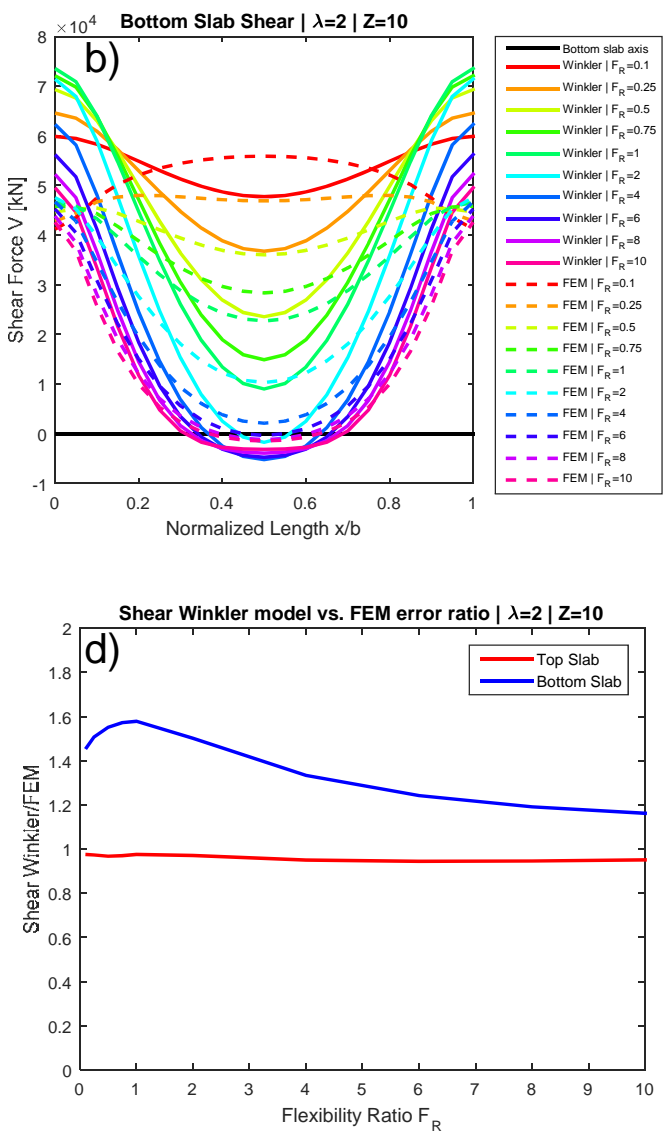

Fig. C-47. Esfuerzos cortantes para profundidad $Z=10 \mathrm{~m}$ y proporción geométrica $\lambda=b / d=2$. (a) En losa superior. (b) En muro lateral izquierdo, (c) En losa inferior. (d) Ratio Winkler/MEF. 


\section{C.3.6.3 Profundidad $Z=10 \mathrm{~m}$ y proporción geométrica $\lambda=3$}
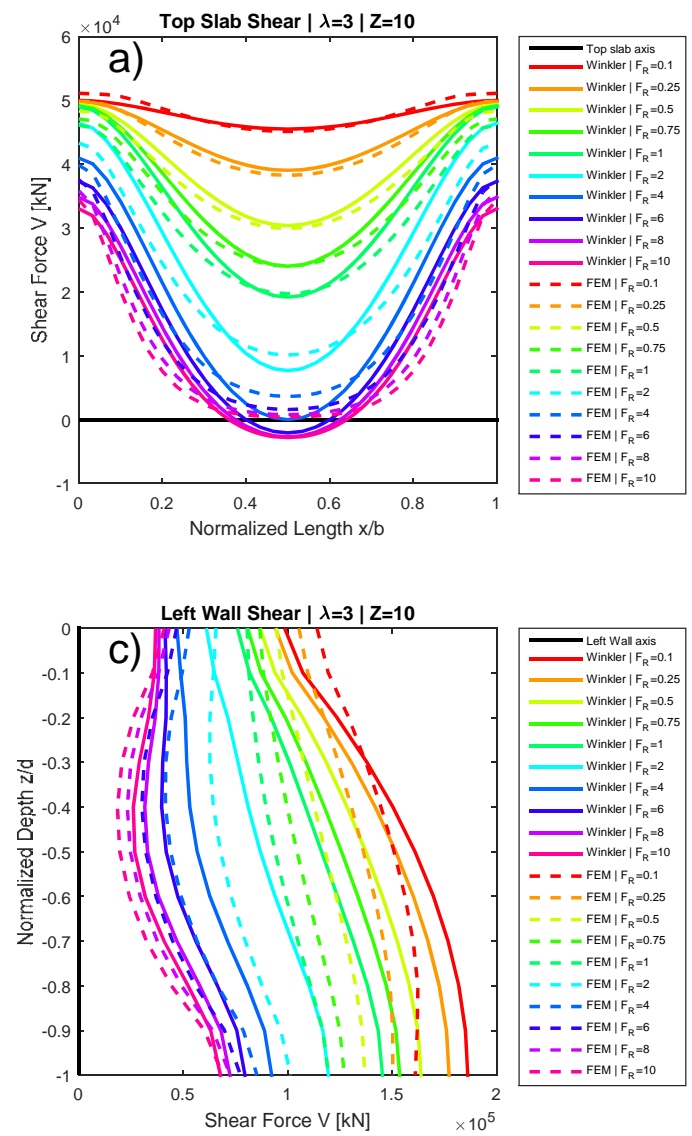
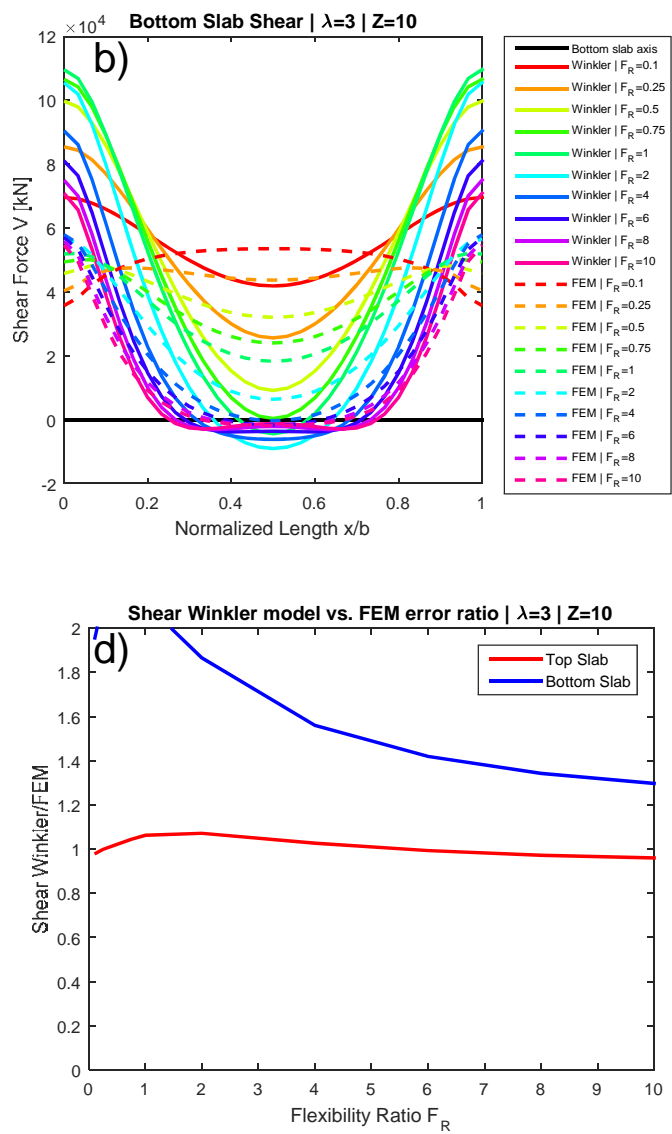

Fig. C-48. Esfuerzos cortantes para profundidad $Z=10 \mathrm{~m}$ y proporción geométrica $\lambda=b / d=3$. (a) En losa superior. (b) En muro lateral izquierdo, (c) En losa inferior. (d) Ratio Winkler/MEF. 


\section{C.3.7 Profundidad $Z=15 \mathrm{~m}$}

\section{C.3.7.1 Profundidad $Z=15 \mathrm{~m}$ y proporción geométrica $\lambda=1$}
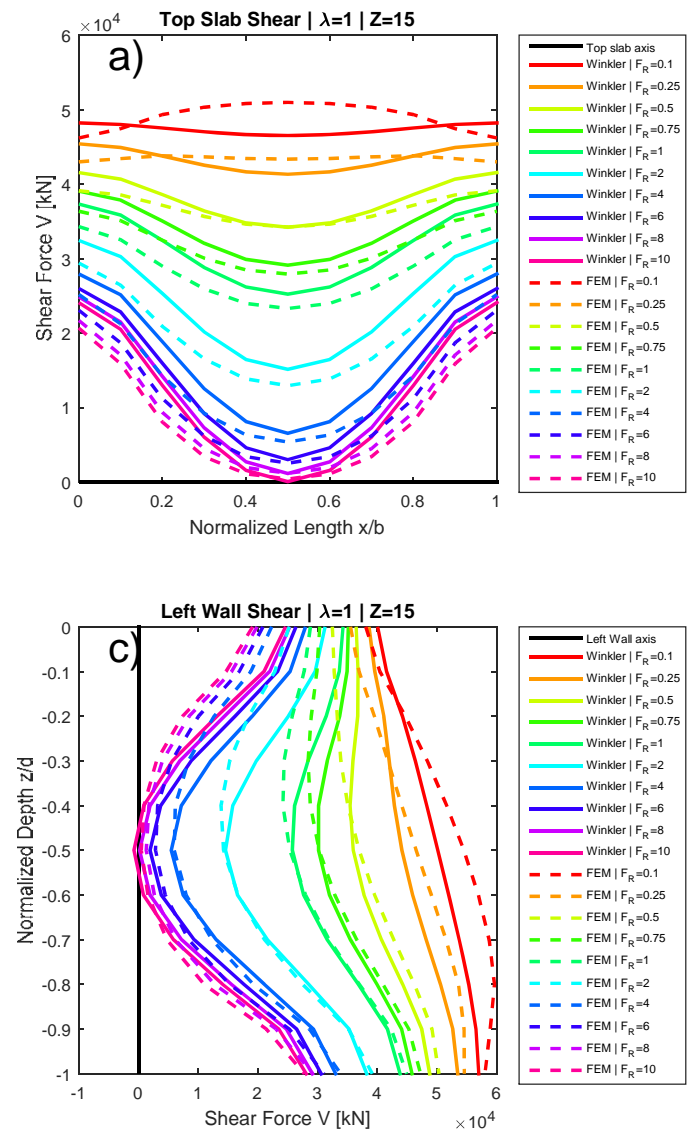
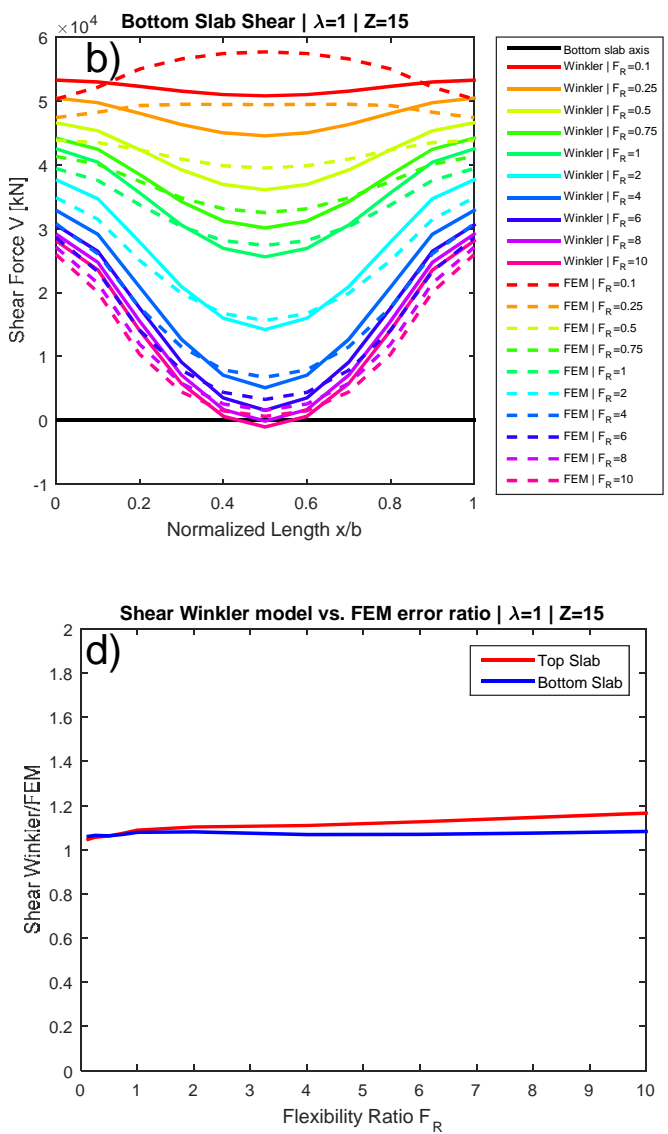

Fig. C-49. Esfuerzos cortantes para profundidad $Z=15 \mathrm{~m}$ y proporción geométrica $\lambda=b / d=1$. (a) En losa superior. (b) En muro lateral izquierdo, (c) En losa inferior. (d) Ratio Winkler/MEF. 


\section{C.3.7.2 Profundidad $Z=15 \mathrm{~m}$ y proporción geométrica $\lambda=2$}
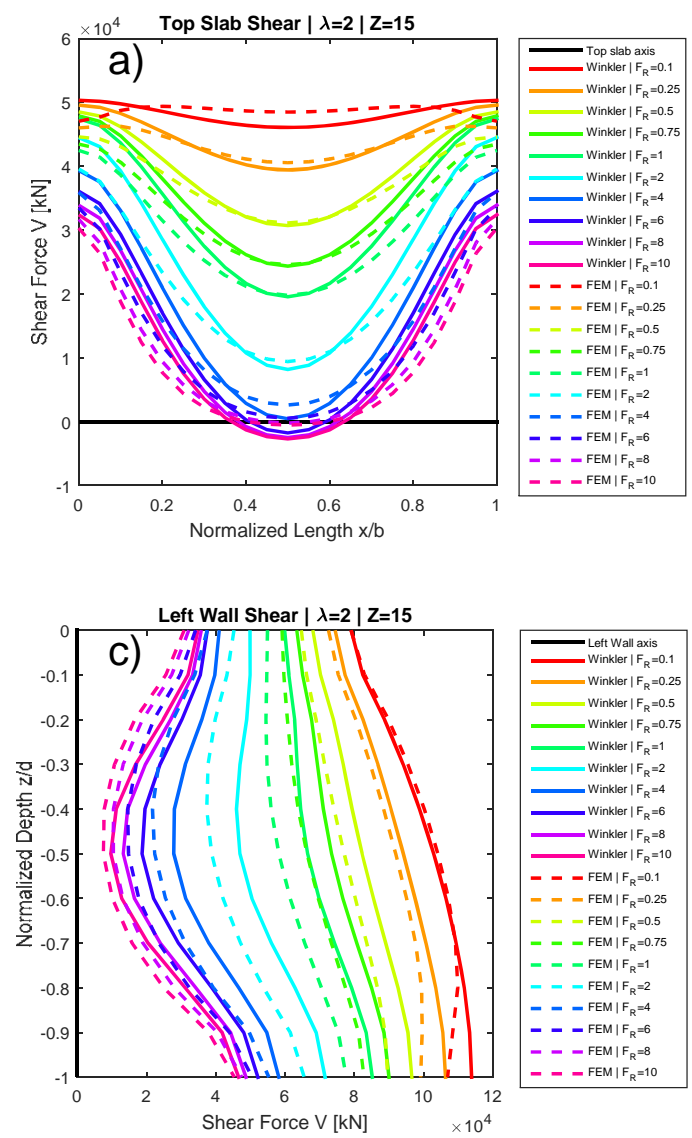
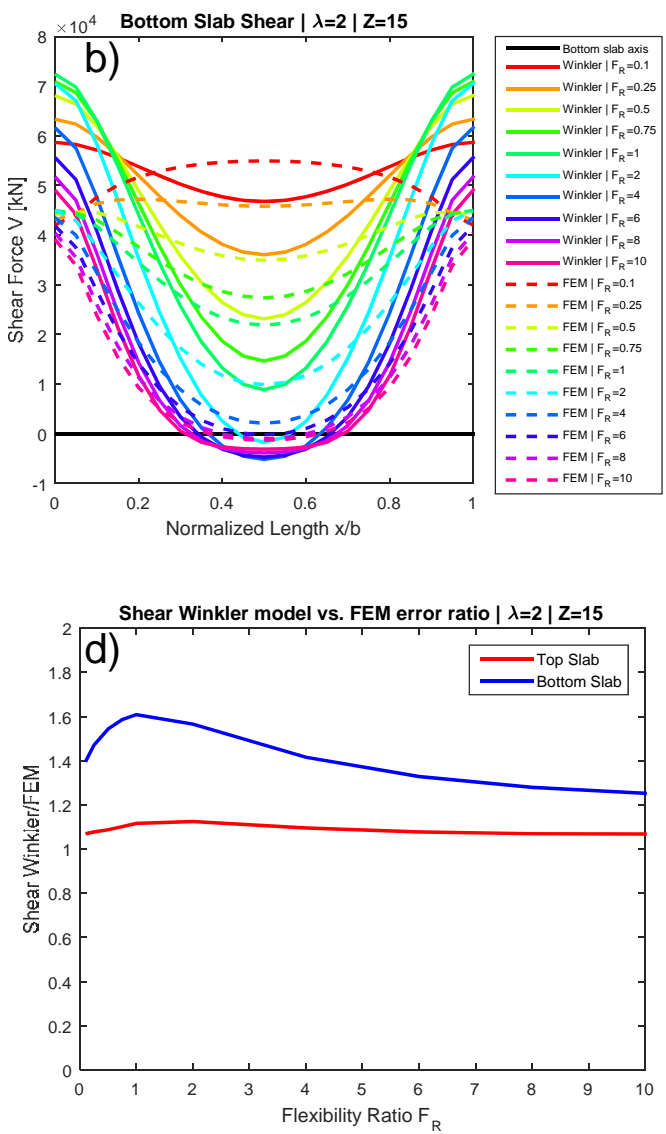

Fig. C-50. Esfuerzos cortantes para profundidad $Z=15 \mathrm{~m}$ y proporción geométrica $\lambda=b / d=2$. (a) En losa superior. (b) En muro lateral izquierdo, (c) En losa inferior. (d) Ratio Winkler/MEF. 


\section{C.3.7.3 Profundidad $Z=15 \mathrm{~m}$ y proporción geométrica $\lambda=3$}
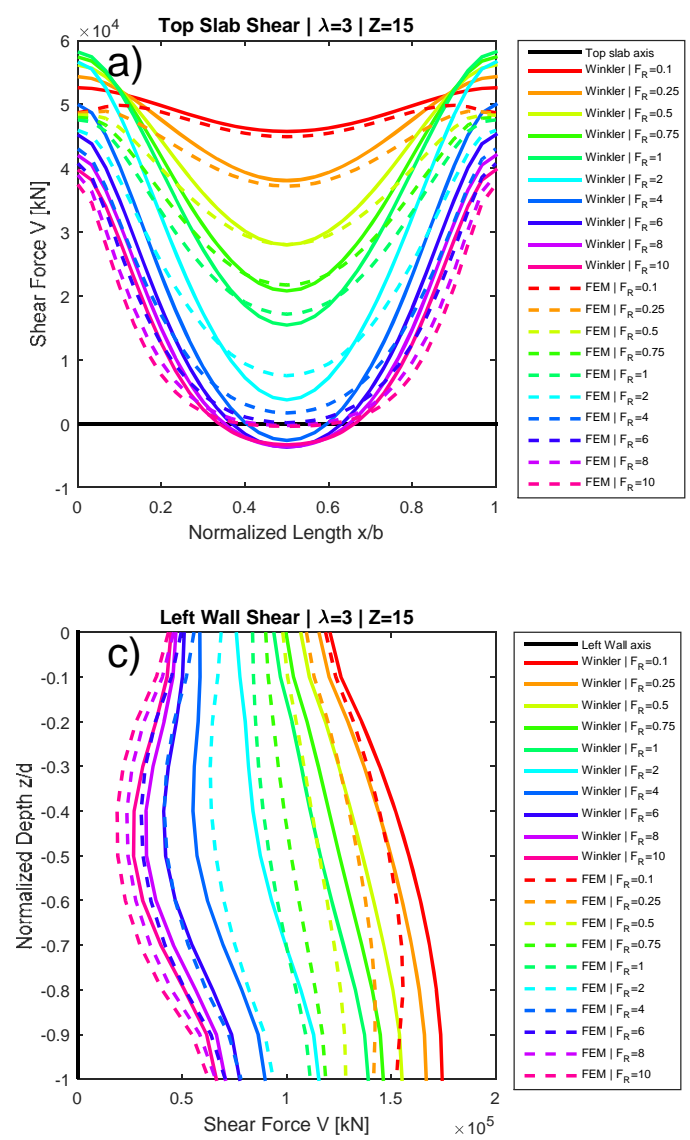
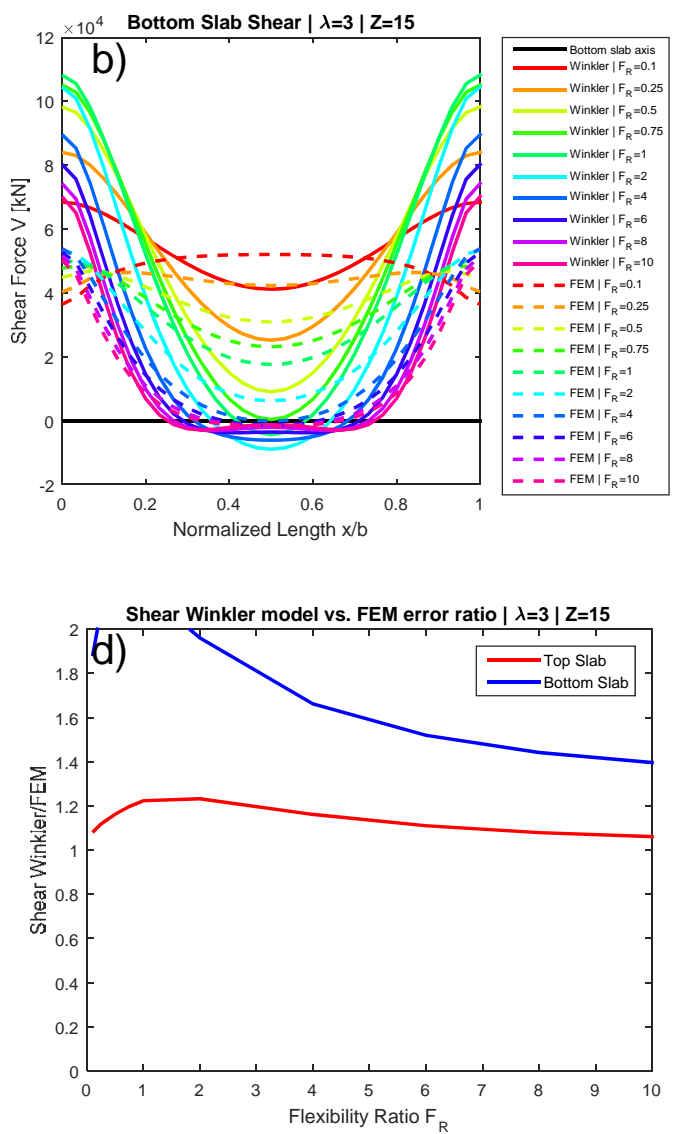

Fig. C-51. Esfuerzos cortantes para profundidad $Z=15 \mathrm{~m}$ y proporción geométrica $\lambda=b / d=3$. (a) En losa superior. (b) En muro lateral izquierdo, (c) En losa inferior. (d) Ratio Winkler/MEF. 


\section{C.3.8 Profundidad $Z=20 \mathrm{~m}$}

\section{C.3.8.1 Profundidad $Z=20 \mathrm{~m}$ y proporción geométrica $\lambda=1$}
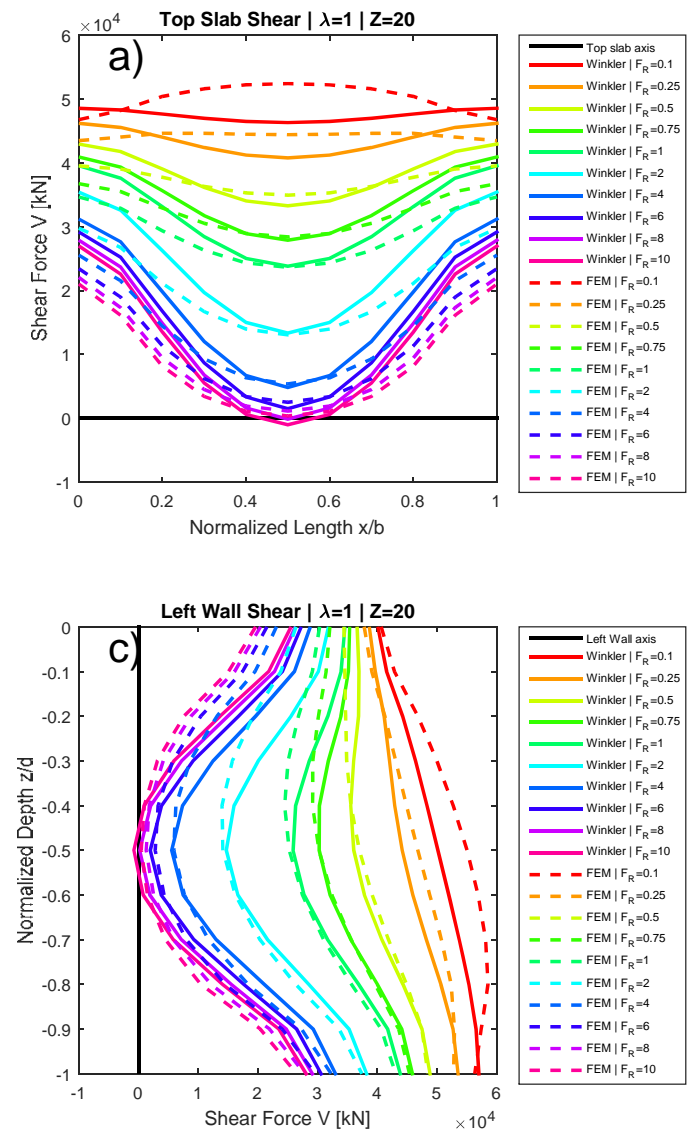
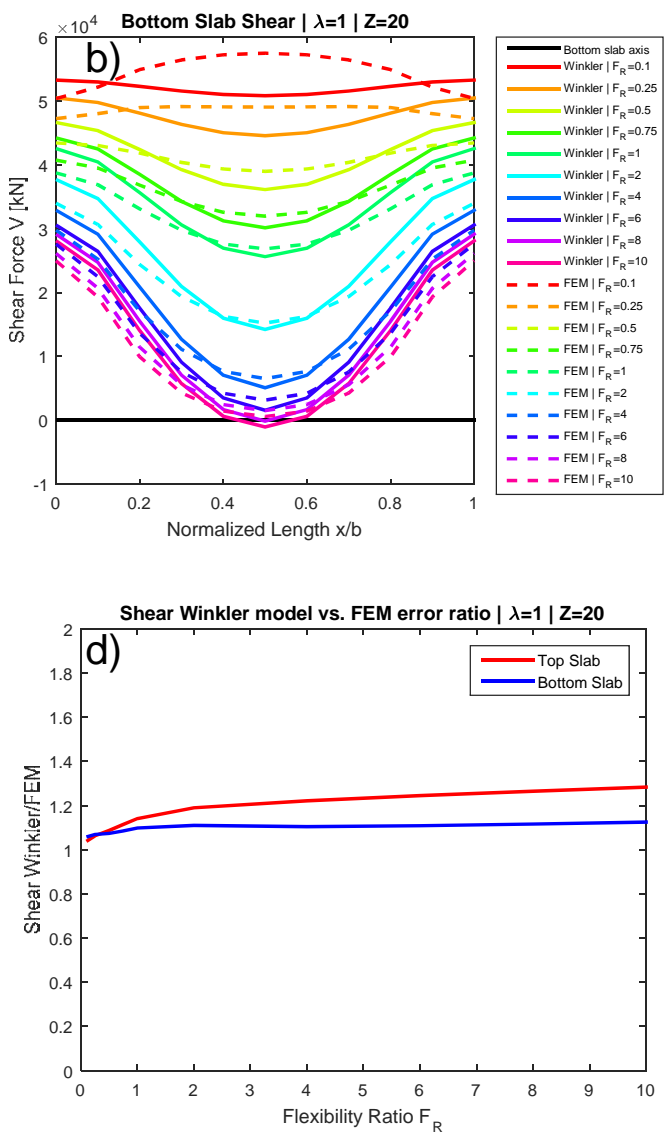

Fig. C-52. Esfuerzos cortantes para profundidad $Z=20 \mathrm{~m}$ y proporción geométrica $\lambda=b / d=1$. (a) En losa superior. (b) En muro lateral izquierdo, (c) En losa inferior. (d) Ratio Winkler/MEF. 


\section{C.3.8.2 Profundidad $\mathrm{Z}=20 \mathrm{~m}$ y proporción geométrica $\lambda=2$}
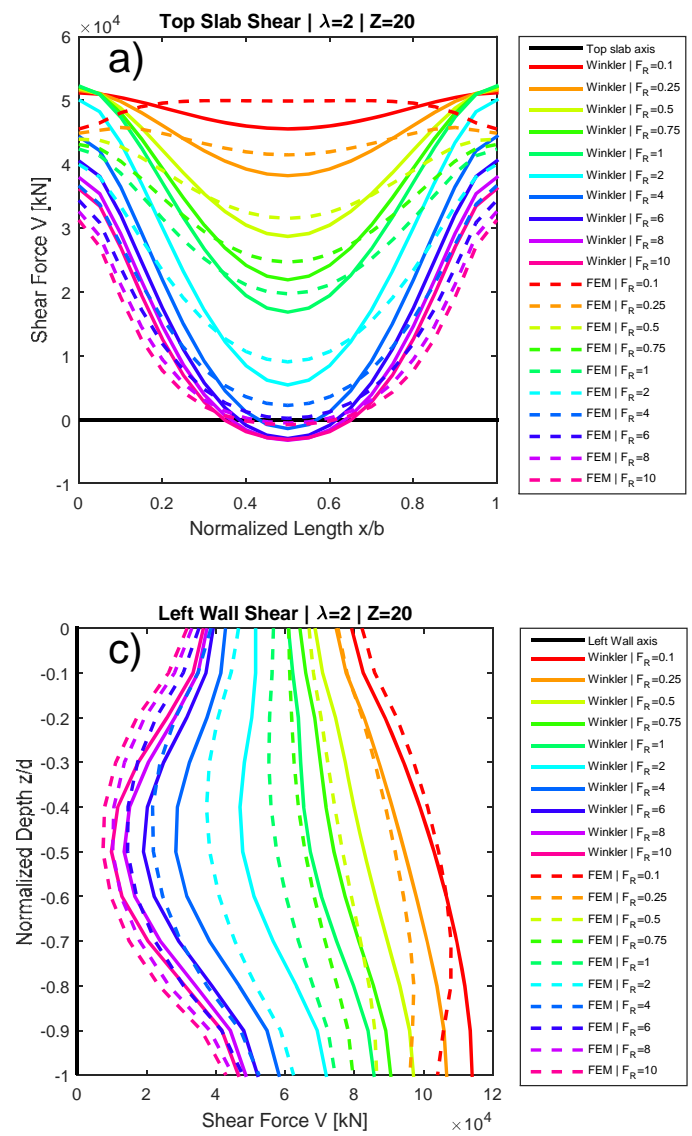
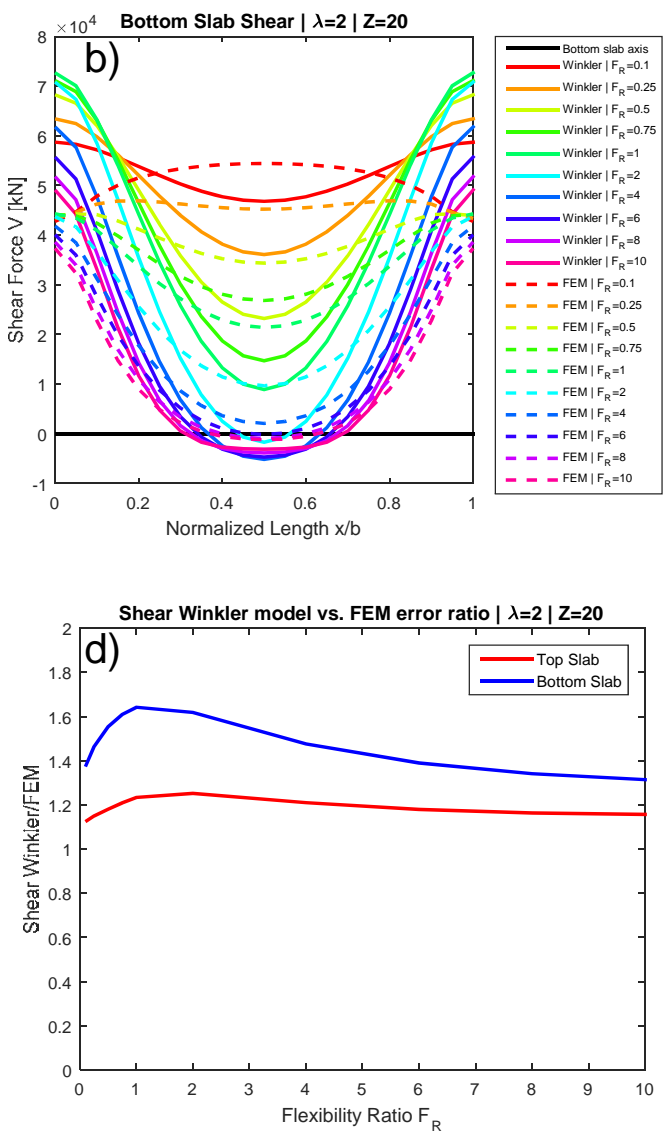

Fig. C-53. Esfuerzos cortantes para profundidad $Z=20 \mathrm{~m}$ y proporción geométrica $\lambda=b / d=2$. (a) En losa superior. (b) En muro lateral izquierdo, (c) En losa inferior. (d) Ratio Winkler/MEF. 


\section{C.3.8.3 Profundidad $Z=20 \mathrm{~m}$ y proporción geométrica $\lambda=3$}
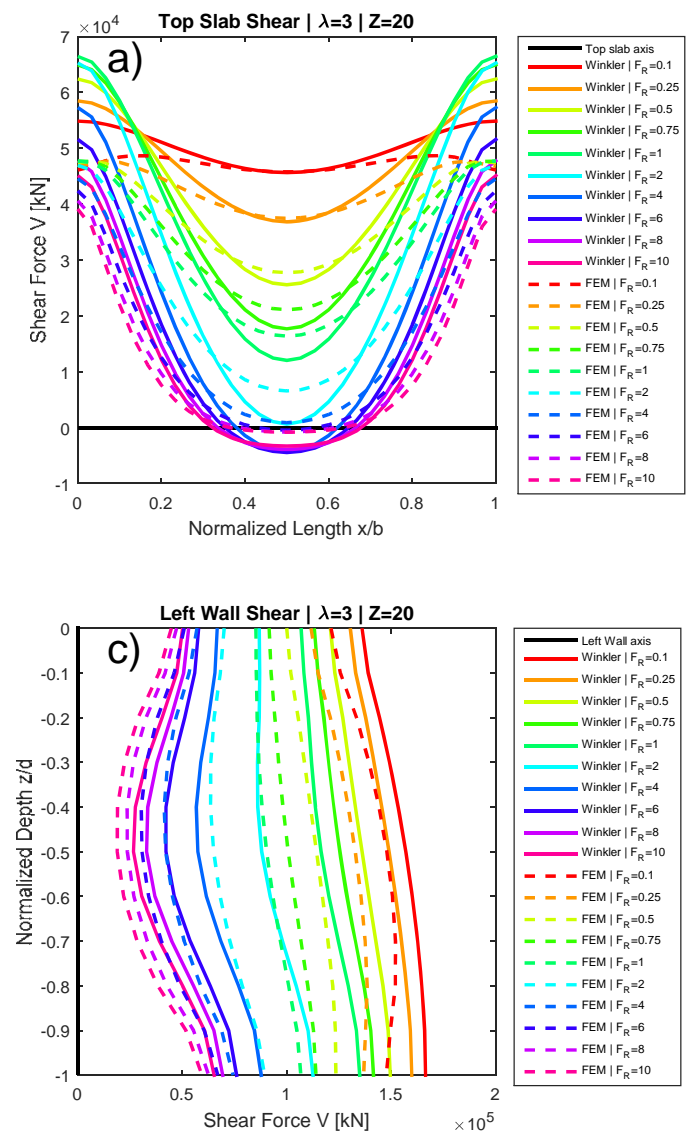
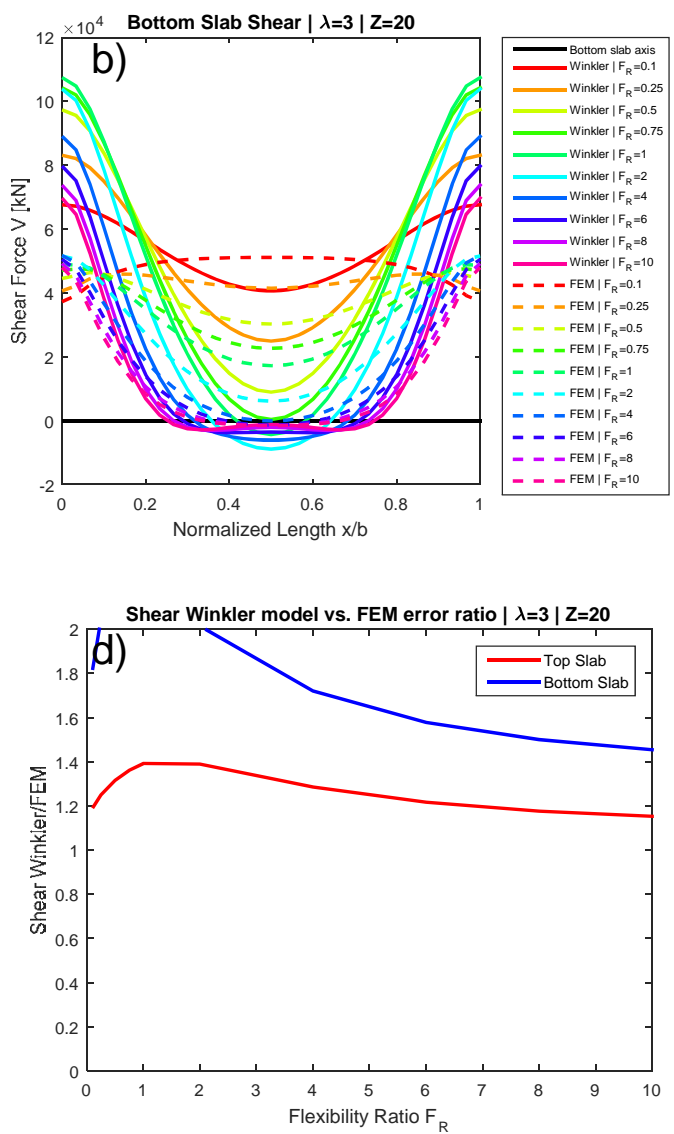

Fig. C-54. Esfuerzos cortantes para profundidad $Z=20 \mathrm{~m}$ y proporción geométrica $\lambda=b / d=3$. (a) En losa superior. (b) En muro lateral izquierdo, (c) En losa inferior. (d) Ratio Winkler/MEF. 
